\title{
Josef Vojvodík
}

\section{Symbolismus}

\section{im Spannungsfeld zwischen} ästhetischer und

eschatologischer Existenz

\section{Motivische Semantik im lyrischen Werk von Otokar Brezina}

Verlag Otto Sagner München · Berlin · Washington D.C.

Digitalisiert im Rahmen der Kooperation mit dem DFG-Projekt „Digi20“

der Bayerischen Staatsbibliothek, München. OCR-Bearbeitung und Erstellung des eBooks durch den Verlag Otto Sagner:

http://verlag.kubon-sagner.de

() bei Verlag Otto Sagner. Eine Verwertung oder Weitergabe der Texte und Abbildungen, insbesondere durch Vervielfältigung, ist ohne vorherige schriftliche Genehmigung des Verlages unzulässig. 


\title{
SLAVISTISCHE BEITRÄGE
}

\author{
Begründet von \\ Alois Schmaus \\ Herausgegeben von \\ Peter Rehder
}

\begin{abstract}
Beirat:
Tilman Berger · Walter Breu · Johanna Renate Döring-Smimov

Walter Koschmal · Ulrich Schweier · Miloš Sedmidubský · Klaus Steinke
\end{abstract}

BAND 371

\section{VERLAG OTTO SAGNER MÜNCHEN 1998}




\section{Josef Vojvodík Symbolismus im Spannungsfeld zwischen ästhetischer und eschatologischer Existenz}

Motivische Semantik im lyrischen Werk von Otokar Březina

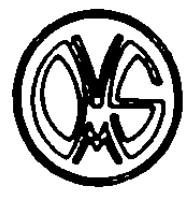

VERLAG OTTO SAGNER MÜNCHEN 1998 


\section{PVA}

98.

\section{0}

Gedruckt auf alterungsbeständigem Papier

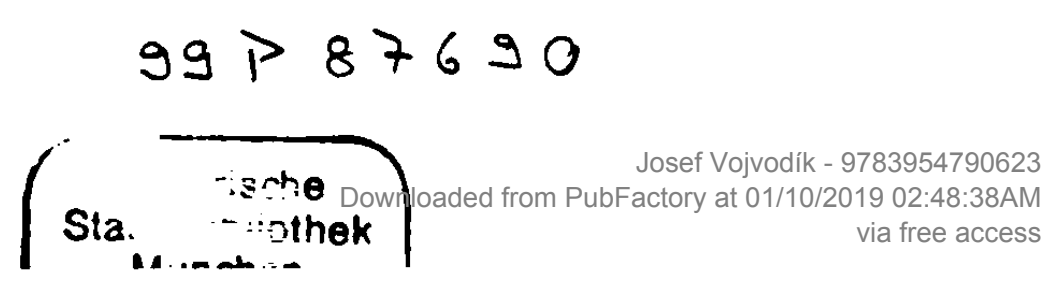

.

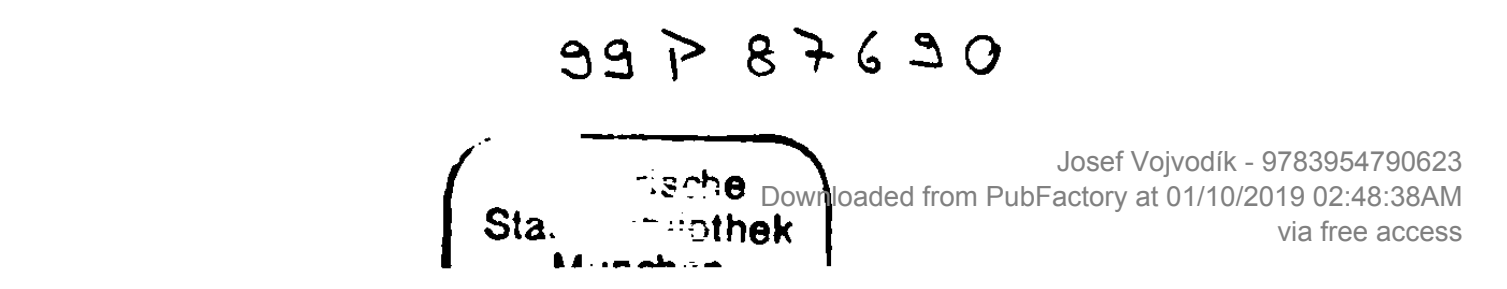

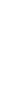

. 


\section{VORBEMERKUNG UND DANKSAGUNG}

Die vorliegende Arbeit entstand als Inaugural-Dissertation zur Erlangung des akademischen Grades eines Doktors der Philosophie am Institut für Slavische Philologie der Ludwig-Maximilians-Universität München und wurde dort im Frühjahr 1997 vorgelegt.

Meinem Doktorvater, Herrn Professor Dr. Miloš Sedmidubský, der die Arbeit wissenschaftlich betreut hat, statte ich aufrichtigen $D a n k$ ab für viele anregende Diskussionen und für die wirksame Förderung, die er mir hat zuteil werden lassen. Ohne seine konstruktive Kritik wäre diese Arbeit so nie entstanden. Danken möchte ich auch Frau Professor Dr. Johanna Renate Döring-Smimov und Herm Professor Dr. Hendrik Binus für die Unterstützung meines Stipendienantrags.

Für die Erteilung eines Druckkostenzuschusses danke ich dem Vorstand des Instituts für Slavische Philologie der Universität München und Herm Professor Dr. Peter Rehder für die Aufnahme des Textes in die Reihe "Slavistische Beiträge" und die damit gewährte großzügige Publikationsmöglichkeit.

Die Arbeit möchte ausdrücklich nicht nur Slavisten ansprechen, deshalb sind alle Zitate übersetzt. Die Übersetzungen aus dem Tschechischen, Kursivsetzungen oder Spernungen in den Zitaten stammen, soweit nicht anders gekennzeichnet, allesamt vom Verfasser.

Meiner Mutter, meiner Schwester Ivana und meinem Schwager Alex in Liebe und Dankbarkeit gewidmet. 


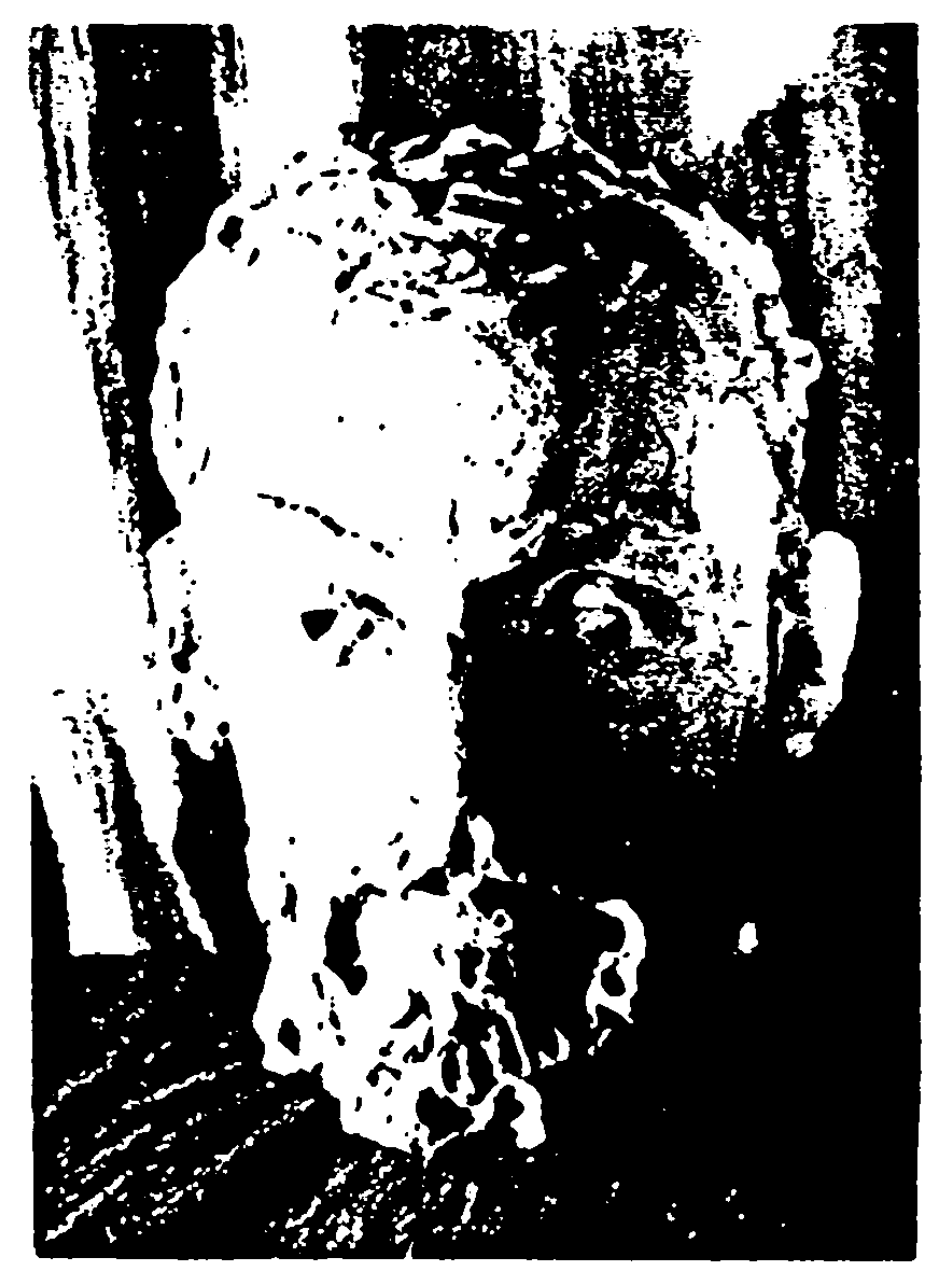

František Bilek Otokar Biezına (Gebrannter Ton, 1905)

Je sors au bras des ombres.

Je suis au bas des ombres.

seul".

"Ich erscheine in den Armen der Schatten. Ich bin auf dem Grund der Schatten.

$$
\text { allein". }
$$

Paul Eluard 


\section{INHALTSVERZEICHNIS}

1. EINLEITUNG

2. DEKADENTER SYMBOLISMUS

Gedichtzyklus Taje mn é dálky (Geheimnisvolle Fernen) 1895

ASTHETISCHE EXISTENZ - PRINZIP DER IRREALISIERUNG

2.1. Modi der Irrealisierung: Hypnos, Oneiros und Thanatos

Erinnerung als 'Initiatorin' des asthetischen Erlebnisses (der irrealisierten Welt)

2.1.1. Entgrenzung der absoluten Erkenntnis durch den Tod Modilita vecerni (Das Abendgebet)

2.1.2 Inszenierung der Apokalypse und der dekadenten 'Auferstehung'

(im Modus der Erinnerung): Sn a d po to m ... (Vielleicht dann...)

2.2 Irrealisierung und Denaturierung der Natur durch die Kunst

2.2.1 Die (Natur-)Welt als Produkt der eigenen Einbildungskraft

$V \grave{z} z$ en (Der Gefangene)

2.3 Kunst als sacrum

2.3.1 Leiden und (Selbst-)Opferung: Bedingungen der Initiation in das Kunst-Reich U ménl (Die Kunst)

2.3.2 Substitution der rationellen Argumentation durch Suggestion und Hypnose der 'Musik-Sprache': Intendierte Wirkung des (dekadenten) Gedichts?

Motiv Z Be thovena (Ein Motivaus Beethoven)

3. ESCHATOLOGISCHER SYMBOLISMUS I

Gnostisch-eschatologisches Modell

Gedichtzyklus S vítán l na zá pa dè (Tagen im Westen) 1896

ZWISCHEN ASTHETISCHER UND ESCHATOLOGISCHER EXISTENZ

3.1 Symbolik des (Lebens-)Weges

3.1.1 Die autistischen Künstlermenschen auf dem Irrweg

Pervertienung der dekadenten Kunst-Welt

und vergebliche Suche nach der (Er-)Losung:

Vla da ri s nù (Die Herrscher der Träume)

3.1.2 Der Weg zur (Selbst-)Erlösung durch die Gnosis (rvwّoı!c)

Ranní modlitba (Das Morgengeben)

3.2 Teleologie des Schmerzes

3.2.1 Der leidvolle Weg durch die Unterwelt der Dekadenz:

In-Frage-stellung der suggestiven Wirkung der 'Kunst-Sprache'?

Vitếzná pís eñ (Das siegreiche Lied)

3.2.2 Befreiung von den "Gesetzen der Erde" kraft des erlösenden Wissens

Gemeinde der gnostisierenden Pneumatiker:

Vino silnych (Der Wein der Starken)

\section{ESCHATOLOGISCHER SYMBOLISMUS II}

Theo-logisch - eschatologisches Modell

Gedichtzyklus Vétry od po lú (Polanwinde) 1897

Eschatologische Existenz im Glauben (ríotic)

THEO-LOGISIERUNG UND SPIRITUALISIERUNG DER POETISCHEN WELT

4.1 Symbolik des Lichtes: Die Rationalisierung des Mythischen

4.2 Vita contemplativa: Symbolik der 'Heiligkeit' 
4.3 Grundbestimmungen der eschatologischen Existenz: Hoffnung - Glaube - Liebe

4.3.1 Die Hoffnung auf die 'Enthüllung' der eschatologischen Zukunft:

Králo vna nadéj í (Die Königin der Hoffnungen)

4.3.2 Das 'Reifen' zur (Glaubens-)Stärke und zur Enfahrung des "heiligen Willens": Poledni zrání (Mittäglich Reifen)

4.3.3 Gnosis der Agape: Erkenntnis des soteriologischen Plans durch das Charisma der Liebe: Lá s ka (Liebe)

5. ESCHATOLOGISCHER SYMBOLISMUS III

Kosmogonisch-eschatologisches Modell

Gedichtzyklus Stavitelé chrámu (Baumeister am Tempen 1899

Eschatologische Existenz in Gnade (xápıs)

PLURALISIERUNG UND REMYTHISIERUNG DeR POETISCHEN WELT

5.1 Vita activa: Symbolik der schöpferischen Prozesse

5.1.1 'Risiken', 'Pflichten' und 'Privilegien' der Kunst-und der Lebensschöpfung Stavitelé chrám u (Baumeister am Tempen)

5.2 Symbolik der Endzeiterwartung

5.2.1 Erwartung des 'ewigen Morgen' - An der (Zeit-)Grenze

zwischen Vorahnung und Erfüllung: Vig il i e l-III (Vigilien I-III)

5.2.2 Katastrophische Eschatologie: endzeitliche Vollendung als 'Aufschub'

Proroci (Die Propheten)

6. ESCHATOLOGISCHER SYMBOLISMUS IV

Vitalistisch-eschatologisches Modell

Gedichtzyklus Ruce (Hände) 1901

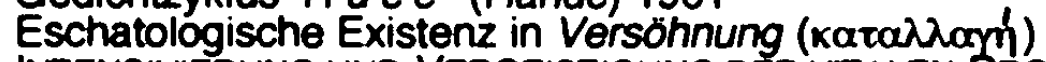

INTENSIVIERUNG UND VERGEISTIGUNG DER VITALEN PROZESSE

269

6.1 Symbolik der enttäuschten Erwartung:

'erstarrte' Zeit - 'verstummte' Erde - 'vereiste' Welt

6.1.1 Entropie des (Welt- und Existenz-)Sinns statt erwarteter Vollendung:

Vedra (Gluthitzen)

6.1.2 Scheitern des kosmischen Vereinigungs- und

Harmonisierungsversuchs durch die Liebe und das Licht des 'Herzens':

Hudba slep cú (Musik der Blinden)

6.2 Komplementarität des ('Dionysisch'-)Vitalen und ('Apollinisch'-)Geistigen

6.2.1 "Zusammenfließen des Erdhaft-Vitalen und des Geistigen

im kollektiven Chorgesang: D it h y ra m b s vêtú (Dithyrambus der Welten)

7. LETZTE GEDICHTE (1901-1907)

AUFLOSUNG DER POETISCHEN WELT: VON DER PLURALITAT ZUR

IN SICH GESCHLOSSENEN AUTO-INTERTEXTUALITAT

DAS VERSTUMMEN

7.1 Eine Heimkehr-ldylle als 'post-moderner' Auto-Zitat-Text?:

Návrat (Heimkehr)

8. AUSBLICK: PSYCHOLOGIK DER SCHOPFERISCHEN ENTWICKLUNG

VON OTOKAR BREZINA - VERSUCH EINER REINTERPRETATION

9. LITERATURVERZEICHNIS 


\section{EINLEITUNG}

Das gesamte lyrische Werk von Otokar B r e z i n a (eigentlich Václav Jebavy., 1868 . 1929) entstand in einem relativ kurzen Zeitabschnitt von lediglich fünfzehn Jahren zwischen 1892 und 1907. Vom literaturgeschichtlichen Standpunkt gesehen zählt Br̈ezina zu den Hauptrepräsentanten des tschechischen literarischen Symbolismus der Jahrhundertwende. Doch nicht der 'Klassiker' einer abgeschlossenen literarischen und kulturellen Epoche soll hier - sorgfältig mumifiziert - gezeigt werden, sondern ein Dichter, dessen Werk sich auch im Verlauf der Entwicklung der Sprache und der literarischen Struktur einer automatischen Erfassung seiner Bedeutung widersetzen und seine unverminderte ästhetische Wirksamkeit erhalten konnte.

Der Hauptgegenstand und das Ziel der vorliegenden Arbeit ist die Erforschung der motivischen Semantik des lyrischen Werkes von Otokar Bïezina in ihrer evolutionären Dynamik unter besonderer Berücksichtigung der $m$ y th o p o e t i s ch en Aspekte der ästhetischen Sinnkonstitution. Den in der bisherigen Biezina-Forschung tradierten, im Grunde noch positivistisch orientierten Erklärungsmodellen der schöpferischen Entwicklung Biezinas, die die aufgetretenen evolutionären Änderungen der poetischen Semantik seiner Texte als Resultat verschiedener äußerer Einflüsse erklären, setzte ich ein neues, mythopoetis ch orientiertes Erklärungskonzept entgegen. Den methodologischen Zugang meiner Untersuchung stellt die Kombination der Postulate der semiotischen Mythopoetik-Forschung der Tartuer und Moskauer Schule und der Postulate der hermeneutischen Mythos- und Mythologie-Forschung der Marburger Schule ( $R$. Bultmann, H. Jonas, P. Vielhauer, H. Schlier, E. Käsemann u. a.) dar. Von immenser Bedeutung war für mich auch die Rezeption der Arbeiten zur Mythopoetik des russischen Symbolismus von Aage A. Hansen-Löve. Die Entscheidung für die Kombination der Postulate der hermeneutischen und der struktural-semiotischen Mythologie- und Mythopoetik-Forschung resultiert aus meiner im Verlauf der Arbeit am analytischen Teil der Dissertation gemachten Erfahrung, daß die strukturale Interpretation allein nicht zur Ausschöpfung des semantischen Reichtums und zur Erfassung der über sich selbst hinausweisenden Sinnbewegung der Gedichttexte Bïezinas reicht, die nicht nur auf den hellenistischen bzw. (spät-)hellenistisch-gnostischen, sondern in hohem Maße auch auf den biblischen Mythos rekurrieren. In diesem Punkt hat sich die Heranziehung der Postulate der hermeneutischen Mythos-Forschung als sehr produktiv gezeigt, da diese sich speziell auf die Erforschung und Deutung des gnostischen und des biblischen Mythos und der immer neuen Wiederaufnahme seines 'Sinnangebots' in das kulturelle Gesamtsystem konzentriert. 1

Diese Arbeitsmethode ermöglicht nicht nur die mythopoetische Sinnkonstitution von Biezinas Werk, sondern auch seine Entwickungslogik systematisch zu beschreiben und das Bild der poetischen Semantik seiner imaginativen Wort-Kunst sowie inre literaturhistorische Verortung weiter zu spezifizieren, zu differenzieren und um neue Aspekte zu enweitern. Unter motivischer Semantik verstehe ich dabei im Anschluß an Ju. Lotman und die russische mythopoetische Schule (VI. N. Toporov, V. V. Ivanov, Z. G. Minc, E. Meletinskij, u. a.) das System von motivischen Konstanten, rekurrenten semantischen Merkmalen und Mythologemen, die in ihrer Gesamtheit das mythopoetische 'Weltbild' oder 'Weltmodell' eines Autors konstituieren.2 Die Betonung des systemhaften

1 Laut P. Ricoeur enthielte das hermeneutische Verstehen der biblischen Mythen deren strukturaie Analyse als Spezialfach in sich. Ricoeur nennt folgende "Niveauunterschiede" zwischen strukturalem und hermeneutischem Verstehen: "Die strukturale Erklărung bezieht sich 1. auf ein unbewußtes System, das sich 2. durch Differenzen und Gegensätze (durch signifikante Abstảnde) konstituiert, die 3. gewissermaßen vom Beobachter unabhängig sind. Die Interpretation eines übermittelten Sinnes jedoch vollzieht sich 1 . in der bewubten Wiederaufnahme 2. eines überdeterminierten Symbolgutes, 3. durch einen Interpreten, der sich unmittelbar in das semantische Feld des Gegenstandes, den er verstehen will, hineinbegibt". P. Ricoeur, Hermeneutik und Strukturalismus, München 1973, S. 72.

2 Als Einführung in die Problematik der Mythosforschung und in die des mythischen Denkens vgl. M.E. Meletinskij, Poetika Mifa. Moskva 1976. Vgl. auch: Ja.E. Golosovker, Logiga Mifa, Moskva 1987. Vgl. Ju.M. Lotmann, .O dvuch modeljach kommunikacii v sisteme kul'tury", in: Semeiotike. Trudy po znakoym sistemem, 6, Tartu, 227-243. Vgl. auch Aage. A. Hansen-Lóve, .Mythopoetik des russischen Symbolismus", in: Mythos in der slawischen Moderne. Wiener Slawistischer Almanach. Sonderband 20, hrsg. v. W. Schmid, Wien 1987, S. 61-103. In ihrer 
Charakters der Symbolparadigmatik bedeutet allerdings, daß sich die Untersuchung nicht in der Erstellung von Motivkatalogen erschöpfen darf. Es muß vielmehr darum gehen, die einzelnen bei Blezina vorkommenden Motive und Mythologeme auf ihre wechselseitige Substituierbarkeit hin zu untersuchen, sie zu motivischen Paradigmen zu bündeln, inre Korrespondenz- und Oppositionsrelationen zueinander zu untersuchen und die semantischen Dominanten bzw. Organisationsprinzipien der so rekonstruierten Bedeutungssysteme zu bestimmen. Dabei soll gezeigt werden, daß Biezinas Gesamtwerk in semantischer Hinsicht auf der stăndigen Rekurrenz eines relativ begrenzten Repertoires von Motiven. Symbolen und Topoi basiert, die aber in den einzelnen Entwicklungsphasen jeweils einem anderen semantischen Organisationsprinzip bzw. Kode unterliegen und entsprechend anders semantisiert, perspektiviert und konfiguriert werden.

Der hochrelevante Umstand, daß Br̈ezina sein lyrisches CEuvre, das fünf vollendete Gedichtzyklen umfaßt, als ein Ganzes, als ein 'einziges Buch' konzipierte, wurde in der bisherigen Bïezina-Forschung kaum berücksichtigt. 3 Gegenüber seinem Vertrauten und Mitherausgeber seines Werkes, Emanuel Chalupný, erwăhnte Bïezina, seine fünf Gedichtzyklen bildeten ein abgeschlossenes Ganzes, das den Weg markierte von dem Pessimismus des ersten Zyklus Tajemné dálky (Geheimnisvolle Fernen, 1895) bis zu dem letzten Zyklus Ruce (Hănde, 1901), in dem das Leben als ein kostbares Geschenk erscheine, für das wir dankbar zu sein hătten. Diese Ganzheit würde zerstört werden. würden dort noch spătere (nach 1901 abgefaßte) Gedichte hinzugefügt. ${ }^{4}$ In dieser "bemerkenswerten Konsequenz" (M. Cervenka), offenbart sich die Intention des Dichters, die Existenz des Kunst-Schöpfers mit ihren 'Existenz-Stadien' in den einzelnen Gedichtzyklen quasi zu rekonstruieren. Diese 'Existenz-Stadien' korrelieren mit den einzelnen 'Stadien' seiner künstlerischen Entwicklung, deren Gedichttexte jeweils zu einem Zyklus konfiguriert werden. Die 'Mythisierung' der Existenz des (symbolistischen) Kunst-Schöpfers fưhrt bei Bïezina von der individualistischen ästhetischen KünstlerExistenz in der Abgeschlossenheit der autonomen Kunst-Welt, die das 'reale' Leben gănzlich absorbieren soll, zum Postulat des kollektiven "Zusammenfließens" ("sliti") der "Ungezăhlten" ("nesčisiných") und der finalen "Versöhnung" ("smíleni") in der eschatologischen Existenz. In dieser letzten Schaffensphase soll die Kunst zum Lebens(Kunst-)Werk metamorphieren. Diese Entwicklung markiert Bïezina explizit in seiner Korrespondenz: Im Brief (vom 21. V. 1893; aus der Abfassungszeit des ersten Gedichtzyklus Tajemné dálky) an seinen Freund František Bauer postuliert Bł̌ezina die Absage an das 'reale' Leben als Bedingung für die Verwirklichung der ästhetischen

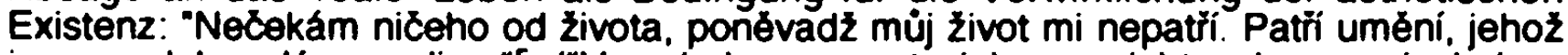
jsem nedokonalým mediem"5 ("Vom Leben erwarte ich gar nichts, denn mein Leben gehört mir nicht. Es gehört allein der Kunst, deren unvolikommenes Medium ich bin").

Studie "Ponjatie teksta i simvolistskaja estetika" (in: Meterialy vsesojuznogo simpoziuma po vtoričnym modelirujuścim sistemam 1. [5], Tartu 1974, S. 134-141) betont Z. G. Minc, daß im Symbolismus dem literarischen Text der Status der Realităt zuerkannt wird, wobei die Welt selbst in der Axiologie des Symbolismus einen Text-Korpus (die "Welt als Text") bildet, dem ein (archaischer) "universeller Text" übergeordnet ist, der mittels des symbolistischen dichterischen Wortes rekonstruiert wird. Dadurch wird auch seine Făhigkeit über die mythische Realitāt 'referieren' zu kơnnen, 'aktiviert'. Die künstlerischen Texte konvenieren nun im Symbolismus oft mit (individuellen) "Lebens-Texten", die schließlich einen Teil des "Welt-Textes" bilden, der dechiffriert werden soll; ein Modell, das gerade in Biezinas Texten in der Phase des eschatologischen Symbolismus eine wichtige Rolle spieft. Vgl. zum Beispiel den Prolog-Zweizeiler aus dem Gedicht Ruce (Hände) aus dem gleichnamigen Gedichtzyklus (1901): "V osinujici bèlosti svếtla ležela zemé, jako kniha pisni / otev̛̉ená płed našimi zraky. A takto jsme péli:" ("In blendender Weiße des Lichtes ruhte die Erde, gleich einem Buche von Liedern, I geóffnet vor unseren Augen. Und so sangen wir:").

3 Nur M. Cervenka (.Błezinovské úvahy", in: Symboly, pisné a mýty. Praha 1966, S. 51) erwăhnt Bǐezinas " $v$ devadesátých létech' zcela ojedinélou" ("in dén neunziger Jahren einzigartige") Vollkommenheit und Konsequenz der Realisierung seines dichterischen Werkes.

4 "Pét mých knih básni, vydaných soubornè, tvởi ukoncený celek, který obsahuje dráhu poćnajici pesimismem Tajemných dálek a konćcí Rukami, kde zivot se jevi jako cenny dar, za nějż máme by̆t vdếni. Celek ten by se porusil, kdyby k nému były pripojeny práce pozdéjsi". Vgi.

E. Chalupny, Dopisy a viroky Otokara Breziny. Praha 1931, S. 112.

5 Vgl. Otokar Blezina, Dopisy Frantisku Baverovi, Prana 1929, S. 191. 
Einige Wochen vor der Herausgabe des letzten vollendeten Gedichtzyklus Ruce (Hände, 1901) schreibt er an Bauer: "Vím, że největši a nejtẻžsí uměleckẻ dílo je żivot. A Że viny Żivota, námi mocnè pohnuté, mohou zazvoniti cistě jako stríbro o skály věcnosti". ("Ich weiß, daß das größte und schwerste Kunstwerk das Leben ist. Und daß die Wogen des Lebens, von uns mächtig zur Bewegung gebracht, an den Felsen der Ewigkeit rein wie das Silber erklingen können"). ${ }^{6}$

In seiner Schrift Stadier paa Livets Vei (1845) unterscheidet Søren Kierkegaard drei Existenz-Stadien des "Lebensweges": die ästhetische, ethische und religiöse Existenz. Auf die Bedeutung Kierkegaards existentiellen Denkens für den Entwurf der mytho- und theologischen Hermeneutik Rudolf Bultmanns und vor allem für seine existentiale (Bultmanns Orthographie) Interpretation, weist Bultmann selbst ausdrücklich hin. ${ }^{7}$ Im Mittelpunkt seiner Hermeneutik steht bekanntlich das Entmythologisierungskonzept, ${ }^{8}$ verstanden als existentiale Interpretation, das vor fünfzig Jahren einen heftigen Reflexionsprozeß in Gang setzte und seitdem nichts an Aktualität verloren hat. 9 Nach Bultmann will der Mythos in erster Linie anthropologische bzw. existentiale Aussagen machen: "Der eigentliche Sinn des Mythos ist nicht der, ein objektives Weltbild zu geben; vielmehr spricht sich in ihm aus, wie sich der Mensch selbst in seiner Welt versteht; der Mythos will nicht kosmologisch, sondern anthropologisch - besser: existential interpretiert werden". 10 Die existentiale Interpretation Bultmanns basiert auf zwei grundlegenden Schritten: Der Mensch versteht sich in seiner Existenz vor Gott, und dieses Daseinsverständnis formuliert er in primitiver Weise in der Objektivation des Mythos; es ist das Hauptanliegen des Entmythologisierungsprogramms der existentialen Interpretation, diese Objektivation durch Entmythologisierung (d. h. Entobjektivierung) in das ursprüngliche Daseinsverständnis zurückzuübersetzen. Anders gesagt geht es in Bultmanns Entmythologisierungskonzept um die Befreiung der 'existentialen' Inhatte der (gnostisch-)mythischen und biblischen Texte aus den formen, die ein archaisches Weltbild voraussetzten. Dadurch wird ebenfalls die explikative Funktion des Mythos quasi 'mit-entmythologisiert'.11 Erst im Prozeß der Entmythologisierung wird die tiefere

6 Vgl. a.a.O., S. 215. (Brief vom 26. VII. 1901).

7 In seinem Aufsatz .Zur Frage der Christologie* (1927; in: R. Bultmann, Glauben und Verstehen I. Tübingen 1933, S. 85-113) fordert Bultmann "die Theologie aus den Irrwegen des Idealismus und der Mystik herauszuführen und dabei die theologische Arbeit Kierkegaards fruchtbar zU machen". (Ibid. S. 85.) In seinem Brief (vom 31. XII. 1922) an Karl Barth betont Bultmann: "Ich meinerseits rechne Schleiermacher in die Ahnenreihe Jeremia-Kierkegaard. Ja wirklich". (Vgl. Karl Barth-Rudolf Bultmann, Brietwechsel 1922-1966, hrsg. v. B. Jaspert, Zürich 1971. S. 12). Bultmann versucht vor allem die vom spăten Kierkegaard entwickelte Identitätschristologie weiter zu denken.

$8 \mathrm{Vgl}$. R. Bultmann. Neues Testament und Mythologie. Das Problem der Entmythologisierung der neutestamentlichen Verkündung. Nachdruck der 1941 erschienenen Fassung. hrsg. $v$. $E$. Jüngel, Münctien 1988.

9 Dies scheinen sowohl die neuen Ausgaben der fundamentalen Werke R. Bultmanns als auch die Symposien zu beweisen; so 2. 8. der Wiener Kongreß Mythos und Rationalitat (1987), oder die Aufsatzsammlungen, die der Auseinandersetzung mit Bultmanns Denksystem gewidmet sind ( $z$. 8. Rudolf Bultmanns Werk und Wirkung, hrsg. v. Bemd Jaspert, Darmstadt 1984).

$10 \mathrm{Vgl}$. R. Bultmann, Neues Testament und Mythologie, München 1988, S. 22. Die Hermeneutik Bultunanns gründet allerdings nicht in der Hermeneutik Heideggers, obwohl Bultmann natürlich aufgrund seiner langen Freundschaft mit Heidegger, der sein Kollege an der Marburger Universitât war und aufgrund seines wissenschaftlichen Austausches mit dem Autor von Sein und Zeit sehr gut mit Heideggers Phänomenologie vertraut war. Als der wesentlichste Unterschied gilt. daß es Bultmann prinzipiell um das Verstehen schriftlich fixierter Äußenungen geht (und in diesem Punkt knüpft er an Diltheys Auffassung der Hermeneutik an), wogegen Heidegger die Hermeneutik als Hermeneutik des menschlichen Daseins versteht. Die Auslegung gründet für Heidegger existential im Verstehen, und die Auslegung von Texten korreliert bei inm mit der Austegung des Daseins: "Im Verstehen von Welt ist das In-Sein immer mitverstanden, Verstehen der Existenz als solche ist immer ein Verstehen von Welt". (M. Heidegger, Sein und Zeit, Tübingen 1977, S. 146f., § 31-32).

11 Paul Ricoeur versteht das hermeneutische Konzept der 'Entmythologisierung' als Streben nach der Emeverung des symbolischen Sinns. Als 'Symbol' bezeichnet Ricoeur jede semantische Struktur, in der der primăre, explizite Sinn (zusătzlich) auf einen anderen, indirekten oder übertragenen Sinn hindeutet, der nur durch den primăren Sinn erfaßt werden kann. Die Sphäre 
Bedeutung der mythischen bzw. biblischen Vorstellungen sichtbar. Dabei wird eine besondere Rolle der Metapher beigemessen, da in der Neuzeit der Mythos (ebenso wie die Metapher) nicht mehr als Mythos verstanden wird; Bultmann spricht von der Objektivierung mythologischer Aussagen. Indem der Mythos als bloße Aussage über das Funktionieren der Objekt-Welt verstanden wird, büßt er in der Neuzeit (die sich, laut Bultmann, durch die Eindimensionalität des Begrifflichen auszeichnet) seine Evidenz ein. ${ }^{12}$ Die metaphorische Prädikation (auf der Ebene der Sprache) erlaubt diese Eindimensionalităt der weltlichen Sprache zu sprengen, $d$. $h$. in der Metapher realisiert sich die Entmythologisierung der in sich abgeschlossenen Welt, indem die Metapher den univoken Sprachgebrauch sprengt. Insbesondere in Bultmanns hermeneutischen Interpretationen der mythischen Struktur der johanneischen Theologie manifestiert sich seine Tendenz, den Mythos durch die Metapher zu interpretieren. ${ }^{13}$

Ju. M. Lotman und Z. G. Minc, als Repräsentanten der Tartuer und Moskauer Mythopoetik-Forschung, begreifen Literatur und Mythologie als zwei spezifische Phänomene, zwischen denen eine Wechselbeziehung kultureller Informationen besteht. ${ }^{14}$ Innerhalb des kulturellen Systems fungieren sie als "dvukanal'naja model' obmena i chranenija informacii" 15 ("Zweikanalmodell des Austauschs und des Schutzes von Informationen"). In dem literarischen Kanal realisiert sich die Vermittlung von (mit Hilfe eines Kodes dechiffrierbaren) 'diskreten' Informationen, in dem mythologischen hingegen die Vermittlung von 'nichtdiskreten' (z. B. von reinen Sinnereignissen) Informationen, wobei in diesem Kanal das Prinzip des "Isomorphismus" ("izomorfizm") vorherrscht. Hinzu kommt (nach Ju.M.Lotman und Z.G.Minc) im gesamten Kultursystem noch eine dritte Funktion von grundlegender Bedeutung: die Hervorbringung von "neuen Botschaften" ("novye soobsccenija"), 16 worunter vor ailem die Zugangsmodi zur Wissenssubstanz des kulturellen Gesamtsystems zu verstehen sind. In den Arbeiten anderer Forscher der Tartuer und Moskauer Schule wird die Mythopoetik u. a. als ein zyklisches System von archaischen, mythologischen Prototypen definiert, die sich in mannigfachen Formen wiederholen (Meletinskij). ${ }^{17}$ Der Mythos hat die Struktur einer Spirale, in dem Sinne, daß die Mythen als 'Resultate' der Transformation von anderen Mythen erscheinen (Mythos als eine Art Meta-Mythos). In den Studien von Z. G. Minc, Ju. M. Lotman oder B.

des 'Doppelsinns' betrachtet er als die eigentliche Sphäre der Hermeneutik. Vgl. P. Ricoeur, .Existence et herméneutique", in: Interpretation der Welt, Festschrift für Romano Guardini, Würzburg 1965, S. 32-51. Vgl. auch Ricoeurs Dartegung zum Problem des 'Doppelsinns' in seiner Monographie Die Interpretation. Ein Versuch über Freud. Frankfurt am Main, 1969, S. 60ff. In seiner Arbeit Hermeneutik und Strukturalismus (München 1973, S. 22) liefert Ricoeur folgende Definition des Symbolbegriffes: "Mit dem Symbolbegriff bezeichne ich jede Sinnstruktur, in der ein unmittelbarer, erster, wortlicher Sinn überdies einen Mittelbaren, zweiten, übertragenen Sinn anzielt, der nur durch den ersten erfaBt werden kann". (Kursiv von P. R.). Dementsprechend definiert Ricoeur die Interpretation als "eine rationale Arbeit, die im offenbaren Sinn den verborgenen entschlüsselt; sie entfaltet die Bedeutungsschichten, die in der wortlichen Bedeutung impliziert sind".

12 Vgl. R. Bultmann, Neues Testament und Mythologie, München 1988 (Nachdruck der Ausgabe von 1941). S. 22, 34. Auch in seiner Theologie des Neuen Testaments (Tübingen 1984) betont Bultmann an mehreren Stellen die Bedeutung der metaphorischen Sprache. Im Zusammenhang mit den "phantastischen mythischen Vorstellungen" von der wunderbaren Speise im Johannes-Evangelium (6. 31) und vom Lebenswasser schreibt er: "Alle Bilder vom Brot und vom Licht, von der Tür und vom Weg, vom Hirten und vom Weinstock meinen doch das, was unbildlich das Leben und die Wahrheit heißt, also das, was der Mensch haben muB und was zu haben er ersehnt, um eigentlich existieren zu können" (ibid. S. 418). Vgl. auch P. Ricoeur (.Stellung und Funktion der Metapher in der biblischen Sprache*, in: P. Ricoeur, E. Jüngel, Metapher. Zur Hermeneutik religióser Sprache, München 1974): "So existiert die Metapher nicht in ihr selbst, sondern innerhalb einer Auslegung; die metaphorische Auslegung setzt die wörtliche Auslegung, die sich selbst zerstort, voraus; die metaphorische Auslegung besteht darin, einen sinnwidrigen Widerspruch in einen sinnvollen Widerspruch zu verwandeln" (ibid. S. 47).

13 Vgl. R. Bultmann, Das Evangetium des Johannes, Goutigen 1941.

14 Vgl. Ju. M. Lotman - Z, G. Minc, .Literatura i mifologia", in: Trudy po znakovym sistemam, Bd.13, 1981, S. 35-55.

15 Ibid., S. 37.

$16 \mathrm{lbid}$.

17 Vgl. E. M. Meletinskij, Poetika mifa, Moskva 1976, S. 87. 
Uspenskij übernimmt das Mythologem die Funktion einer Metapher, die fähig ist, ein autonomes Paradigma zu bilden, in dem sich ganze 'Texte' konzentrieren. Das Symbol (im Unterschied zum Mythologem) hingegen integriert eine Reihe von semantischen Merkmalen ('Bildern'). Daraus resultiert ein anderer wichtiger Unterschied zwischen Symbol und Mythologem: Die Voraussetzung für die 'Dechiffrierung' von Mythologemen ist die Kenntnis von Mythen, während die 'Dechiffrierung' eines Symbols im Prinzip die Kenntnis der Metaphorik eine(s)r bestimmten Kultur(kodes) erfordert. ${ }^{18}$

Wie die meisten Symbolisten der Jahrhundertwende verfügte auch Br̈ezina über profunde und nachprüfbare Kenntnisse auf dem Gebiet der Mythologie, der Religionsgeschichte ${ }^{19}$ und Philosophie, der Symbolsysteme oder sogar der Naturwissenschaft, die er dann in seinem Werk, auf der Grundlage der aktuellen literarischen Tradition, innovativ aktualisierte. Doch die Bedeutung der hellenistischgnostischen und der biblischen Mythen für seine Mythopoetik wurde in der älteren Brezina-Forschung entweder verkannt oder - U. a. aus ideologischen Gründen - für "unwesentlich" erklärt. 20 Dabei wurden die hochrelevanten Referenzsignale, die in Brezinas Gedichttexten sowohl die biblischen (insbesondere neutestamentlichen) SubTexte als auch verschiedene gnostische Quellen indizieren, völlig ignoriert oder pauschalisierend als 'philosophische Dichtung' etikettiert. Solche 'philosophische' und 'philosophisierende' Interpretation der Gedichte von Bïezina, der imaginativen Wort-Kunst kat exochēn, führt jedoch unvermeidlich zu deren Rationalisierung und Vereindeutigung: es ist offensichtlich, daß zwei derartig unterschiedlich geistige Leistungen, die eines Dichters und die eines professionellen Philosophen, auch unterschiedliche methodologische Zugänge erfordern. Als ein geradezu paradigmatisches Beispiel dieser Interpretationsstrategie kann die in vieler Hinsicht bemerkenswerte Brezina-Monographie von Urs Heftrich gelten: Otokar Brezina. Zur Rezeption Schopenhavers und Nietzsches im tschechischen Symbolismus.21 Die Arbeit ist als "philosophische Analyse von Briezinas geistigem Werdegang im Spannungsfeld zwischen Pessimismus und evolutionärem Optimismus, zwischen Décadence und Neuromantik“ konzipiert. Seit Anbeginn der Brezina-Forschung wird die Rezeption Schopenhauers und Nietzsches in Brezinas Werk vielfach erwähnt. Eine kritische, wissenschaftlich fundierte und systematische Untersuchung zu diesem Thema fehite jedoch bisher. Die Arbeit gliedert sich in zwei Teile: im ersten Teil wird die geistige Verwandschaft des im Bïezinas Werk modellierten poetischen Weltbildes mit dem Schopenhauerschen Weltbild untersucht, 22 im zweiten Teil wird die Bedeutung Nietzsches für Bïezina analysiert. Innerhalb dieser beiden Teile gliedert sich die Arbeit schematisch weiter in philosophische Themenbereiche nach dem analogen Schema: Erkenntnistheorie, Ontologie, Ästhetik und Ethik 1) in der Philosophie Schopenhauers und Nietzsches und 2) deren Rezeption im dichterischen und essayistischen Werk von Bíezina. Das Hauptproblem der "philosophischen" Lesart und Analyse von Biezinas Werk besteht darin, daß sie das Weltmodell eines Dichters als das eines $\mathrm{P} h \mathrm{i}$ l o s o p he $\mathrm{n} z \mathrm{u}$ rezipieren und $\mathrm{zu}$ interpretieren versuchen. Eine andere Crux

$18 \mathrm{Vgl.} \mathrm{Aage} \mathrm{A.} \mathrm{Hansen-Löve,} \mathrm{.Zur} \mathrm{Mythopoetik} \mathrm{des} \mathrm{russischen} \mathrm{Symbolismus,} \mathrm{in:} \mathrm{Wiener}$ Slawistischer Almanach. Sonderband 20, Mythos in der slawischen Modeme, hrsg. v. Wolf Schmid. Wien 1987, S. 63f. Vgl. auch: Zara G. Minc, Simvol u A. Bloka", in: Russian Literature, 7. 1979, S. 193-248. Vgl. auch: Zara G. Minc, Jurij M. Lotman, „Literatura i mifologija”, in: Trudy po znakovym sistemam, 13, Tartu 1981, S. 35-55.

19 In seinem ersten Wirkungsort Nová Řỉse (Neureisch) in Westmähren, wo Blezina die Jahre 1888-1901 verbrachte und wo alle seine fünf Gedichtzyklen entstanden, konnte er in der reichen Klosterbibliothek studieren, was Bỉezina in seiner Korrespondenz mehrfach erwähnt.

20 Vgl. z. B. das Nachwort von J. Hrabák - aus der Zeit der sog. "Normalisierung" (1968-1989) - zu der Gesamtausgabe des dichterischen Werkes von Otokar Blezina, in: O. Bíezina, Básnické spisy, Praha 1975, S. 237-245.

21 U. Heftrich, Otokar Bïezina. Zur Rezeption Schopenhauers und Nietzsches im tschechischen Symbolismus, Heidelberg 1993.

22 Es erhebt sich zum Beispiel die Frage, ob sich das pessimistische Weltbild, das - laut Heftrich - Březinas Gedichte von etwa 1892-1896 kennzeichnet, hauptsăchlich auf die Wirkung der Lehre Schopenhauers auf Błezina zurückłühren lăßt. Waren es nicht primăr die (konstitutions- und tiefen-) psychologischen Faktoren, von denen der Pessimismus Bỉezinas (Kap. B.II.2, S. 81ff. und vor allem B.IV.2., S. 138tf.) gesteuert wurde und der durch die Schopenhauer-Lektüre nur noch markanter in den Vordergrund trat? 
der "philosophischen" Interpretation von Bïezinas Werk resultiert daraus, daß sie ihr Deutungskonzept auf aus ihrem systematischen Textzusammenhang herausgerissenen Zitaten oder sehr oberflăchlichen Interpretationsskizzen aufbaut. Wie es scheint, stehen sich in der bisherigen Br̈ezina-Forschung de facto zwei konventionelle dichotome Deutungskonzepte Brezinas dichterischen Schaffens gegenüber: das INHALT sästhetische und das FORMästhetische Konzept. Ein inhalstästhetisches Deutungskonzept versuchen vor allem die Arbeiten von Králík und Heftrich zu etwickeln. Doch beide Autoren lesen Bïezinas Gedichttexte als philosophische Texte, ihre (ästhetischen) ${ }^{23}$ Inhalte rezipieren sie reduktionistisch als philosophische inhalte und versuchen sie als solche zu deuten. Unter dem Inhalt verstehen Heftrich, Králík $u$. a. in erster Linie das Kozentrat des (philosophischen) Gedankens; es ist daher kein Zufall, wenn Urs Heftrich in der Einleitung zu seiner Brezina-Arbeit betont: "Besondere Beachtung verdient, daß Biezina ausdrücklich auch seiner Lyrik die Intention beilegt, durch die Kraft des Gedankens zu wirken I...r.24 Auf eine Rekonstruktion des ästhetischen Inhaltsauftbaus wird jedoch verzichtet und statt dessen (vor allem bei Heftrich, Kabes und Janácek) ${ }^{25}$ nach der "Verwandschaft" des Brezinaschen "Weltbildes" mit dem von Schopenhauer oder Nietzsche gesucht. Die lyrischen Gedichte werden als Philosopheme (bzw. Psychologeme; s. u.) rezipiert. Auch Oldřich Králík versucht in seiner Monographie Otokar Bïezina. Logika jeho dila 1892-1907 (Praha 1948), 26 an die Urs Heftrich kritisch anknüpft, ein möglichst komplexes Bild von Bfezinas lyrischem Cuvre zu rekonstruieren. Obgleich Králík das Hauptanliegen seiner Arbeit im Vorwort als "Streben, zur Wirklichkeit des Werkes von Błezina zu gelangen" ("snažím se dospęt k realitě Bỉezinova díla") und "den wahren Rhythmus seines Schaffens zu erneuern" ("obnovit pravý rytmus Bíezinovy tvorby) formuliert, ist seine Arbeit im Grunde genommen keine inhaltsästhetische Analyse, sondern vielmehr eine unglückliche Sonderform der psychologisierenden Hermeneutik. In seinem Versuch einer komplexen Interpretation des Werkes von Bíezina erklärt Králik das gesamte Werk des Dichters als eine "scheinbar unübersichtliche Mannigfaltigkeit, die letzten Endes auf den ewigen Wechsel von Aufschunng und Zusammenbruch, Extase und Depression reduziert wird". ("Zdánlivè nepiehledná

23 Diese Arbeiten und Deutungsversuche beschrånken sich ausschließlich auf Themafundierte Funktionen der Gedichte, $d . h$. sie sehen den Inhalt rein auf der thematischen Ebene des literarischen Werkes.

24 Heftrich, a.a.O., S. 18. Der Autor beruft sich auch auf die Feststellung Jan Patockas ("Blezina ist nicht ursprünglich und hauptsachlich ein Dichter [...], er ist ein Meditierender, dessen Enthusiasmus sich in Poesie artikuliert"; J. Patocka, .Die tschechische Bildung in Europa", in: ders., Kunst und Zeit. Kulturphilosophische Schriften. Stuttgart 1897, S. 378) und fügt hinzu: "Patocka, immerhin ein Philosoph von Rang, nimmt Blezinas denkeriscthes Anliegen ernst, auch wenn er ihm einen "Mangel an dialektischer Schårfe" bescheinigt (ebd.)". Ibid., S. 345.

25 A. Janálek; J. Kabes, s. Literaturverzeichnis.

26 Die Monografie von Oldrich Králik galt in der tschechischen Bohemistik jahrzenntelang als ein Standardwerk der Blezina-Forschung. In seiner Arbeit versucht Králik das gesamte Schaffen des Dichters am Leitfaden der Chronologie zu rekonstruieren, die er als die zuverlássigste Quelle zur Erfassung der .inneren Biographie“ Biezinas betrachtet. Die postulierte Komplexităt soll die Darstellung der verschiedenen symbolistischen "Autostilisienungen" des dichterischen Ich in allen Gedichtzyklen ermoglichen. Doch im Endeffekt führt dieses Konzept, das von der Biographie Błezinas kaum abstrahiert, zur Erklărung der Entwicklungslogik seines Werkes als ein Resultat verschiedener externer Einflüsse. Die Entwicklungslogik von Bł́ezinas Werk interpretiert Králík als eine fortwăhrende "Überwindung" ("piekonáváni") der früheren "pessimistischen" Schaffensphasen und des für sie charakteristischen "Weltbildes" zugunsten einer neuen "optimistischen" Schaffensphase. Die Ursache dafür liegt einerseits in der methodologisch áußerst unsystematischen Arbeitsweise und in der Labilităt des Argumentationsstils von Králík - da die "innere Chronologie" der einzelnen Schaffenphasen, auf die sich sein ganzes Erklărungsmodell stützt, sehr relativ ist -, andererseits in der starken Vereindeutigung der Semantik der einzelnen Gedichttexte. Ein weiteres Problem ist der 'Intuitivismus'. der derm Dilettantismus Tür und Tor öffnet. Králík verwendet mit Vorliebe gerade solche 'bildlictie Vergleiche', die der gefühlsmāBigen Sphăre entstammen, und er verwendet diese, als ob in innen objektiv güttige Urteile vorlăgen. Daraus erklăren sich weitere Irrwege, wie 2.B. die seltsame Naivităt zahlreicher Gedichtinterpretationen. Aber es muB auch gesagt werden, daß Králík sich manchmal in erstaunlicher Weise der intendierten Bedeutung des interpretierten Textes năhert (um gleich darauf ins Abstruse umzukippen). 
mnohotvárnost se nakonec redukuje na věćnou stridu rozletu a pádu, extase a deprese", S. 450). ${ }^{27}$ Wie seine Vorgänger (Marten, Janácek, Dvorák u. a.) ${ }^{28}$ konzentriert sich auch Králík ausschließlich auf die thematische Ebene, nicht (oder nur sehr oberflächlich) auf den semantischen Aufbau der Gedichttexte. Dabei wird lediglich die Gesamtheit der dargestellten Gegenstände, Gedanken, Situationen und Ereignisse, d.h. die Substanz der Denotatenebene, reflektiert. Králíks Verfahren gründet darin, daß er thematische Einheiten isoliert, miteinander - wenn auch unsystematisch - konfrontiert, vergleicht und klassifiziert. Aus der Identität oder Ähnlichkeit der thematischen Einheiten versucht Králík am Leitfaden der Chronologie 29 genetische Beziehungen zu erschließen, um neue Inhaltsmomente zu gewinnen, die dann als Ausdruck und E r g e b $\mathrm{n}$ is der stets wechselnden persönlichen Situation des Dichters oder seiner momentanen seelischen Verfassung gedeutet werden. Geradezu symptomatisch für Králíks psychologisierendes Deutungskonzept scheint die Tatsache zu sein, daß er die in den einzelnen Gedichtzyklen auftretenden mythoge ne n Gestalten ("Vladar̆i snü" / "Herrscher der Träume"; "Silni" / "Die Starken": "Svati" / "Die Heiligen"; "Stavitelé chrámu" / "Baumeister am Tempel" usw.) als Projektionen des dichterischen Subjektes, des authentischen Dichters, betrachtet. Das Resultat stellt de facto eine fiktive 'Biographie' des in Biezinas Gedichten in verschiedenen 'Gestalten' und 'Verkleidungen' agierenden dichterischen Ich dar. Es ist kein Zufall, daß das erste Kapitel "Zrozeni básnika" ("Die Geburt des Dichters") heißt. Dabei reflektiert Králik ausschließlich Thema-fundierte Funktionen der Gedichttexte, und seine Analyse zielt lediglich auf Thematisches ab. Die signifikanten poetischen Strukturierungen, die sich im Inhalt selbst niederschlagen ( $\mathrm{sO}$ z. B. Klangäquivalenz, syntaktischer Parallelismus usw., ja die Kompositionsformen selbst) bleiben bei Králík (genauso wie bei Heftrich) einfach als etwas - für den Gedanken - Nebensächliches und Unwichtiges unberücksichtigt.

In den sechziger Jahren wandte sich Miroslav Cervenka, der sich um eine strukturalund formästhetisch orientierte Brezina-Forschung große Verdienste erwarb, gegen die These, Br̈ezinas Gedichte seien "Chiffren", die es 'auszulegen", d. h. in die Sprache

27 In diesem Sinne stellt Králik das gesamte Schaffen Biezinas bereits im ersten Kapitel dar, wenn er schreibt: " $/ . . /$ płes neustále vinèni od extase $k$ depresi, od únavy $k$ nadśeni, nezapomeneme na jediné dno niterné, z nẻhoż roste Bł̉ezinova tvorba". (ibid., S. 41; \% .../ und trotz des stetigen Schwingens von der Extase zur Depression, von der Ermüdung zur Begeisterung vergessen wir nicht den einzigen innerlichen Grund, aus dem Błezinas Schaffen erwächst'). Signifikant ist bereits Králiks Terminologie: "psychologický typ Bł̌ezinưv" ("Błezinas psychologischer Typus", S. 451), "depresivni basne" (depressive Gedichte", S. 67), "psychologischer Dualismus" (S. 121) etc. SchlieBlich betrachtet auch Urs Heftrich Biezinas schöpferische Entwicklung als "geistigen Werdegang im Spannungsfeld zwischen Pessimismus und evolutionärem Optimismus, zwischen Décadence und Neoromantik" (Heftrich, a.a.O., S. 5). Als einen im Prinzip (biographisch-)psychologisierenden Deutungsversuch wertet die BíezinaMonographie von Králik auch M. Cervenka: "Oldfich Králík, autor prúkopnického, i kdyż po mnoha stránkách sporného pokusu o sémantickou interpretaci Błezinova díla, ukázal na ladé autostylizaci. typú a gest jednottivých period i sezón Błezinova vivoje, jak radikálné se ménily básnikovy postoje $v$ souvislosti s okamżitymi výkyvy jeho osobni situace". ( $M$. Cervenka, .Błezinovské úvahy", in: Ders., Symboly, pisnẻ a myty. Praha 1966, S. 32; "Oidtich Králík, der Autor eines bahnbrechenden, wenn auch in vieler Hinsicht umstrittenen Versuches der semantischen Interpretation von Błezinas Werk, zeigte an einer ganzen Reihe von Autostilisierungen, Typen und Gesten aus den einzelnen Perioden und Abschnitten der Entwicklung Biezinas, wie radikal sich die Haltungen des Dichters im Zusammenhang mit den augenblicklichen Ausschlägen seiner persönlichen Situation ảnderten"). Vgl. auch Cervenkas Nactiwort (unter dem Namen Jan Adam) in der Błezina-Anthologie Neviastni déti zemé. Praha 1988. S. 198.

28 M. Marten, A. Janácek, M. Dvơák, s. Literaturverzeichnis.

29 Doch diese Methode versagt in dem Moment, wo zwei thematische Einheiten als auseinander hevorgegangen angesehen werden, die genetisch miteinander nichts zu tun haben; dann werden auch deren Verānderungen bzw. Umsemantisierung falsch beurteitt, und man wird auch zu einer falschen Vorstellung von der schöpferischen Entwicklung Błezinas kommen. Selbst die .innere Chronologie*, auf der Králik seinen Versuch einer komplexen Interpretation von Błezinas Werk aufbaut, muß als äußerst problematisch betrachtet werden, weil sie sich nur sehr ungenau rekonstruieren läßt. Auf die daraus resultierenden Irrtümer hat bereits $M$. Cervenka hingewiesen. 
philosophischer und ideologischer Urteile und Standpunkte zu übertragen gelte.30 In seinem Aufsatz Bïezinovské úvahy betont Cervenka mit allem Nachdruck, Biezinas Gedichttexte seien keineswegs "bloße Mittel zum "wanschaulichen« Dolmetschen der abstrakten Idee" ("prostredky k »názornému * tlumocení abstraktni ideje"); er lehnt die auf den Inhalt orientiete Rezeption und Interpretation Biezinas Gedichte ab und postuliert eine "materialistisch orientierte Lektüre" ("materialisticky orientované piečteni Br̈eziny"), die hinter der Vielfalt von spirituell konnotierten Bildern das potentielle Designat aufdecken würde, nămlich "den Reichtum und die Hehre des Lebens". 31 Die so formulierte neue Aufgabe der Brezina-Forschung wurde seitens der auf den thematischen oder vielmehr sogar 'gedanklichen' Inhalt orientietren Biezina-Interpreten vollkommen mißverstanden. Krảík kritisiert scharf Cervenkas vermeintliche "mörderische Dialektik", die nur dazu gut sei, zur Abwertung Biezinas als Denker beizutragen. 32 Das Wort "MATERIAListisch" 33 verwendet Cervenka nicht im ideologischen Sinne; es geht ihm keineswegs darum. Bíezina zum dialektischen Materialisten zu stilisieren. Er fordert eine 'MATERIAL'/FORMbezogene Lektüre. Im Anschluß an Mukarovský versteht Cervenka das literarische Kunstwerk als "materielles Artefakt", materielles Substrat, dem der Status eines Signifikants erst durch die Assoziation mit dem "kollektiven Normensystem" ("kolektivni

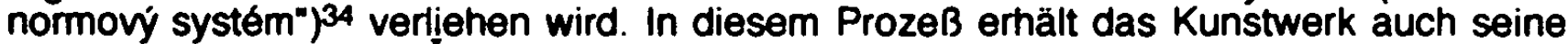
Bedeutung (Signifikat). Cervenka greift den von Bíezina verwendeten "Form"-Begriff (im Sinne des rhythmischen Aufbaus der Gedichte) auf und und fügt hinzu: "V tomto prípade bezzi nepochybnè o formu, jeż je zároveñ normou 1...l: o soubor neosobnich, nadindividuálních, obecnè platmých požadavkủ a předpisú, jež nejsou dílem dány, ale dílu zvnéjška zadány". ("In diesem Fall handelt es sich zweifelsohne um eine Form, die gleichzeitig eine Norm ist /.../: um einen Komplex von unpersönlichen, überindividuellen, allgemein gettenden Forderungen und Vorschriften, die nicht durch das Werk gegeben, sondern dem Werk von außen her aufgegeben werden“). ${ }^{35}$ Auf die Spezifika des

30 M. Cervenka, .Dostov", in: O. Błezina, Modlitba za neprátele (Anthologie), Praha 1966, S. 207. Noch in seinem Nachwort für die bisher letzte Anthologie aus dem Jahre 1988 (O. B., Neviastni déti zemé, Praha 1988, S. 207) betont Cervenka (unter dem Namen Jan Adam): $\%$...' Bł̌ezina nebyl nikdy pưvodnim myslitelem, tím méné filosofickým systematikem: Bł́ezina mluvi préedevšim svou poezii, jeji básnickou intenzitou /... . ( $\%$ /.../ Błezina ist nie ein origineller Denker und noch weniger ein philosophischer Systematiker gewesen: Bfezina spricht vor allem durch seine Poesie, durch ihre dichterische Intensität /... $/$ ).

31 M. Cervenka, „Bł̌ezinovské úvahy, in, ders., Symboly, pisnè a mýty. Praha 1966, S. 30-64, hier S. 31.

32 O. Králík, .Platnost básnického obrazu”, in: Stavba ve výsi. Sbornik vénovaný památce Otokara Bieziny, Brno 1970, S. 243.

33 Die Bezeichnung .materialistische Lektüre* ist zugleich auch als taktisches Manơver zu verstehen. Um 1966 galt Błezina für die marxistischen Zensoren immer noch als Hauptventreter des 'anrüchigen' "subjektiven Idealismus" und "Mystizismus" in der tschechischen Lyrik. Die Bezeichnung formásthetische Lektüre bzw. Analyse kơnnte damals wiederum verdacht auf den verpónten "bourgeoisen Formalismus" in der Literaturwissenschaft erregen.

34 Den Begriff der ásthetischen Norm (estetická norma) behandelt Mukałơvský eingehend in seiner grundlegenden semantischen Studie der dreiBiger Jahre Estetická funkce, norma a hodnota jako sociálni fakty (Ästhetische Funktion, Norm und ảsthetischer Wert als soziale Fakten, 19351936, in: ders., Studie 2 estetiky, Praha 1971, S. 7-65; dt. in: ders., Kapitel aus Ästhetik, Frankturt am M. 1970, S. 7-112). Mukafovský unterscheidet das System der künstierischen Normen, das sich bereits vor dem Entstehen der jeweiligen Kunstwerke konstituiert und in der kollektiven Normenstruktur der sog. "lebendigen Tradition" enthalten ist. Seinen allgemeinen, zeitlosen ästhetischen Wert erlangt das Kunstwerk erst im wechselnden Kontakt mit dem kollektiven Normensystem. In diesem konkreten Fall meint Cervenka mit "Norm" in erster Linie die für Błezina (in der Schaffensphase von TD) vertindliche hythmische Norm, doch in seinen Aufsătzen aus den sechziger Jahren betont Cervenka mit allem Nachdruck die Notwendigkeit, in Brezinas Werk den autonomen und lebendigen (ästhetischen) Wert zu entdecken (Bł̌ezinovské úvahy, a.a.O., S. 30).

35 M. Cervenka, „Błezinovské úvahy, a.a.O, S. 40. Es lăßt sich sagen, daß die Frage nach der Funktion des poetischen Rhythmus im Mittelpunkt des poetologischen Denkens von Mukarovovský steht, insbesondere in seinen formästhetischen Studien (Máchủv Máj, 1928; Úvod do estetiky, 1931-1932; Intonace jako cinitel básnického rytmu, 1933 u.a.). Den Rhythmus betrachtet Mukałovský prinzipiell als eine der fundamentalen anthropologischen Konstanten, die an allen 
rhythmischen Aufbaus und der Verssemantik konzentriert sich Červenka in seiner versologischen Studie Br̈ezinúv verš (Bïezinas Vers, 1965), 36 wo er auf formalistische Ansätze Mukařovskýs zurückgreift . Wie schon die russischen Formalisten hatte auch Mukariovský dem Reim neben seiner euphonischen und rhythmischen Aufgabe auch eine semantische zugeschrieben. 37 Die Aufgabe seiner versologischen Untersuchung in Bỉezinưv vers sieht Cervenka in der "Markierung jener grundlegenden Bedeutungsqualitäten und Zusammenhänge in Biezinas Werk, die mit dem dichterischen Rhythmus, mit dem Versaufbau verbunden sind". (" $/ . . /$ úkolem je naznačit ty základni významové kvality a souvislosti v Br̈ezinově díle, jež jsou spjaty s básnickým rytmem, s organizaci verse"). 38 In dieser Arbeit, die als Analyse der rhythmischen Struktur und als semantische Interpretation der Versvarianten in Bïezinas Gedichten konzipiert ist, geht es um die Erfassung der spezifischen semantischen Funktion des gereimten Verses, vor allem des jambischen Alexandriners, im Vergleich mit dem freien (vers libre) und dem sogenannten 'gelockerten' Vers ('vers libéré'). Bereits in diesem Aufsatz keimt jene Auffassung des Form-Begriffes und der formasthetischen Analyse, die im Aufsatz Bïezinovské úvahy (1966) deutlich zur Geltung kommmt. Nach dieser Auffassung, die bereits in den Konzepten von Mukařovský (vor allem in seinem Konzept von der semantischen Geste ${ }^{39}$ ) begründet liegt, werden die formästhetischen Problemstellungen

Kunstarten wirksam ist. (vgl. Estetická funkce, norma a hodnota jako sociálni fakty). Nach Mukałovsky fungiert der Rhythmus auch als primäres Kriterium bei der Wahl der Wortsemantik, und auch in der Komposition der motivischen und thematischen Schicht kommt er deutlich zur Geltung.

36 M. Cervenka, _Bỉezinưv vers", in: Ceská literatura, 13, 1965, S. 113-146. Hier knüptt Cervenka an die Resultate seiner Dissertation Cesky volný verš devadesátych let (Praha 1963) an.

37 J. Mukaroovsky், „O jazyce básnickém”, in: ders., Kapitoly z ceské poetiky I, Praha 1948, S. 78-128.

38 M. Cervenka, _Błezinưv vers", a.a.O., S. 116.

39 Die "semantische Geste" kann als einer der Schlüsselbegriffe des tschechischen literaturwissenschaftlichen Strukturalismus schlechthin gelten, der auch fünt Jahrzehnte nach seiner ersten Verwendung zu diversen anregenden Deutungen 'verleitet'. In seiner bekannten Studie .Genetika smyslu v Máchové poesii" (in: Torso a tajemství Máchova dila, hrsg. J. Mukałovsky. Praha 1938, S. 13-110. Deutsche Ubersetzung: "Die Genese des Sinns in Máchas Dichtung", in: Jan Mukarovsky. Schriften zur Ästhetik, Kunsttheorie und Poetik, übers. u. hrsg. v. Holger Siegel. Tübingen 1986, S. 194-272) betont Mukařovsky \%/../ die Rekonstruktion jener inhaltlich nicht spezifizierten Geste /.../, mit der der Dichter die Bestandteile seines Werkes ausgewăhlt und zu einer bedeutungsmäBigen Einheit vereinigt hat" (ibid. S. 194-195) Der Begriff der "semantischen Geste" wurde in den Arbeiten von Mukařovskỳ mehrmals umdefinient und umgedeutet. (Vgl. dazu: M. Jankovič, „Ješté jednou k pojmu "sémantickẻ geston", in: Ceská literatura, 40, 1992, S. 158-163). Jankovic interpretiert die 'semantische Geste" nicht nur als ein einheitsstiftendes Prinzip bzw. als einen wichtigen Faktor der ästhetischen Wirksamkeit des Bedeutungsaufbaus der Texte, sondern auch - und vor allem - als ein "Bindeglied" der zeichenhaften (kommunikativen) und sozialen Existenz des Menschen und seiner auBersozialen und auBerzeictienhaften Existenz. Dabei geht es Jankoviz in erster Linie um die Erfassung eines der grundlegenden Merkmale der Kunstwerke überhaupt: Die "semantische Geste" scheint auf dieses Merkmal hinzudeuten, nămlich auf die Spannung zwischen geschlossener und (lediglich) indizierter Gestalt, zwischen Zeichen und Nicht-Zeichen, zwischen Sprache und G e s t e. (Vgl. M. Jankovic. .Perspektivy sémantického gesta", in: K interpretaci uméleckého literárniho dila, Praha 1970, S. 7-28). H. Schmid untersucht in ihrer Abhandlung .Die 'semantische Geste' als Schlüsselbegriff des Prager literaturwissenschaftlichen Strukturälismus' (in: Schwerpunkte der Literaturwissenschaft, hrsg. v. E. Ibsch, Bd. 15, Amsterdam 1982, S. 208-259) eingehend die einzelnen Etappen des Definierens, Um-Definierens und der Verwendung der "semantischen Geste" in Mukarouskýs theoretischen Aufsätzen und in seinen Werkanalysen. Sehr aufschlußreich ist die Feststellug der Autorin, daß das Gestaltprinzip als 'Residuum' der formalistischen Phase später in Mukarovskýs semantische Interpretation eindringt. wie sich das auch im Terminus der "semantischen Geste" widerspiegelt, d. h. als gestisch organisierte Bedeutungseinheit. Der Aspekt des Gestischen zielt gleichzeitig auf die Möglichkeit der Umgestaltung der "bestehenden Vernăltnisse des Subjekts zur Wirklichkeit" (ibiơ. S. 247) und schließlich auf die Änderung der Wirklichkeit selber. In der Studie .Tłífázový model ceského literámévẻdného strukturalismu" (in: Ceská literatura, 1991) erörtert $\mathrm{H}$. Schmid die potentiellen Operabilitătsmöglichkeiten der "semantischen Geste", die Mukałovský in seinem Aứsatz "Zámémost a nezámérnost v uméni" (in: Jan Mukařovský. Studie z estetiky. Praha 1971, S. 89-108) für eine zukünftige strukturale 
inhaltsbezogen dargestellt und entfaltet. Das "Konstruktionsprinzip" des literarischen Kunstwerkes begreift Mukařovský als das sich in allen Elementen und Schichten eines Werkes durchsetzende Prinzip der Sinnkonstituierung. Alle Komponenten der künstlerischen Struktur, auch die "formalen", fungieren als "Träger der Bedeutung".40 "Die wirklich strukturale Analyse", betont Mukaǐovský zum Schluß seiner Studie Zámèrnost a nezámérnost v umèni (Die Absichttichkeit und Unabsichttichkeit in der Kunst, 1943), "ist daher eine semantische; die semantische Analyse erfaßt dann alle Komponenten des Werkes, „inhalttiche" wie "formale". ("Skutečnè strukturálni rozbor uméleckého díla je proto sémantický; sémantický rozbor pak týká se všech složek díla, "obsahových" i "formálnich". ${ }^{11}$ Unter Inhalt (bzw. Sinn oder Bedeutung) versteht Mukaroovský n i ch t (lediglich) den thematischen Inhalt wie Králik u. a., sondern den "gemeinsamen Nenner" ("spolecný jmenovatel"), auf den alle einzelnen Komponenten des Werkes zu bringen seien. In Bïezinovské úvahy knüpft Cervenka zwar direkt auf die Resultate seiner versologischen Analyse Br̈eziniv verš an, aber er ergänzt sie durch die Konzentration auf die "inhalttichen Komponenten" ("obsahové složky") Bïezinas lyrischen Werkes und auf die "Ganzheit des künstlerischen Aufbaus" ("celistvost umélecké výstavby") seiner Gedichte. Die Betonung der "vereinigenden nHandlungslinie " ("jednotía ndéjová linie “"), des "vereinigenden Prinzips" ("jetnotici princip"), des "einheitlichen Sinnes des Gedichtes" ("jednotný smysl básné") oder des "gemeinsamen Nenners" ("společný jmenovatel") signalisiert, daß es hier in erster Linie um die Erfassung der "vereinigenden semantischen Intention" ("jednotici sémantická intence"), der semantischen Geste, geht. Im Gegensatz zu der traditionellen Stil- und Kompositionsanalyse, die das literarische Kunstwerk in "relativ selbständige Gruppen der Stilmittel" zerlegt, fordert Cervenka eine dynamische Analyse, die die einzelnen Bedeutungskomplexe des Werkes als "Quellen von Bedeutungsenergien" ("zdroje významových energii") ${ }^{42}$ vereinigt. Signifikanterweise konzentriert sich Cervenka in Brezinovské úvahy im Anschluß an seine Analyse des rhythmischen Baus ("rytmická stavba") und der Versstruktur (in Bïezinuv verš) vor allem auf die außersprachlichen Bedeutungskorrelate (kennzeichnend scheint bereits der Titel Brezinouské úvahy / Brezinasche Betra chtungen - im Vergleich zu Bïezinív vers I Biezinas Vers - zu sein). ${ }^{\mathbf{4 3}}$ die den thematischen Plan des Werkes bilden, $d . h$. Motive, Motivgruppierungen, Symbole und das Sujet der einzelnen, in diesem Aufsatz erörterten Gedichte. Als den "gemeinsamen Nenner" der Sinn- und Lebenseinheit in Bïezinas Werk betrachtet Cervenka das Bild des "Hőchsten" ("Nejvyšši"). Als "resultierende Größe des ästhetischen Baus von Bïezinas Gedichttexten" hat der "Höchste" den "Charakter des vereinigenden Prinzips der unzähligen Abentever der Sinne und des Geistes" ("jednotici princip nescetných dobrordužstvi smyslü a ducha") und "der Wirklichkeit" ("jednotici princip skutečnosti"). ${ }^{44}$ Doch auch in dieser Arbeit wird die Inhaltsseite als eine der vielen Manifestationen der Form, als ein Teil ästhetisch wirksamer Konstruktion (und des "Zusammenhaltes" / "soudržnost") des sprachlichen Materials begriffen. Noch in seinem Nachwort zu einer Biezina-Anthologie (1988) hebt Cervenka ausdrücklich u.a. die "Dynamik der Metapher, die kompositionelle Kühnheit, die

Literaturwissenschaft konzipiert. Die "semantische Geste" als führender Begriff der semantischen Analyse solte nicht mehr mit der Geste des Rezipienten, sondern mit der des Autors verbunden bleiben. Dann kōnnte sie als Indiz für die āsthetischen Qualităten des Kunstwerkes als "Sache" sui generis und darüber hinaus als Begriftsinstrument in der Ontologie des Kunstwerkes fungieren.

$40 \mathrm{~J}$. Mukaroovskỳ, „Genetika smyslu v Máchové poesii“, in: ders.: Kapitoly z ceské poetiky III, Prana 1948, S. 239.

4126 J. Mukaỉovskỳ, "Záměmost a nezámèmost v umęni”, a.a.O., S. 146.

42 M. Cervenka. „Błezinovské úvahy”, a.a.O., S. 38.

43 Nicht weniger kennzeichnend scheint auch die Tatsache zu sein, daß Cervenka in Błeziovské úvahy beinahe ausschließlich die im freien Vers abgefaßten Schlüsselgedichte erötert (Králowna nadejii I Die Kónigin der Hoffnungen, S. 31-32; Vedra / Gluthitzen, S. 33-34; Ranni modlitba / Das Morgengebt, S. 43-46; Se smrti hovori spici... I Mit dem Tode reden die Schläfer.... S. 52 u.a.). Zu den signifikanten Merkmalen des Blezinaschen vers libre, der dem 'Druck' der Form (d.h. des sprachlichen Materials und der verbindlichen inythmischen Norm) nicht unterliegt, gehört die Konzentration auf den Bedeutungsaufbau der Aussage, die Aktualisierung der sprachlichen Bedeutungen und Metaphem, die Entfaltung der komplizierten, abstrakten Vorstellungen und Erlebnisse usw.

44 M: Cervenka, „Błezinovské úvahy, a.a.O., S. 48-49. 
Vollkommenheit der Form" ("Dynamika metafory, odvaha kompoziční, dokonalost formy (.... $\left.\mu^{\prime}\right)$ als die wichtigsten Komponenten ästhetischer Wirksamkeit von Br̈ezinas Werk hervor 45 Auf die Problematik des energetischen Organisations- und Integrationsprinzips im Br̈ezinas Werk konzentriert sich $M$. Cervenka auch in zwei späteren Aưsätzen, die zu den wichtigsten Beiträgen der bohemistischen Brezina-Forschung aus den beginnenden achtziger Jahren zählen. Es ist die Analyse der metatextuellen Beziehung zwischen Br̈ezinas Autointerpretation seines zweiten Gedichtzyklus Svitáni na západé (Tagen im Westen, 1896) und dem Zyklus selbst (bzw. Seinem axiologischen Stellenwert von Motiven, Symbolen und thematischen Komponenten / "tematické složky"; Bíeziniv vyklad Svitáni na západè / Br̈ezinas Deutung von Svitáni na západẻ, 1979) ${ }^{46}$ und die Einzeltextanalyse Modlitba za neprátele (Gebet für die Feinde: aus dem Gedichtzyklus Větry od polú I Polarwinde, 1897). Die Frage nach dem Integrationsprinzip des Bedeutungsaufbaus des literarischen Werkes steht auch in diesen Arbeiten im Vordergrund und zwar in bezug auf die außertextuelle bzw. außerästhetische Axiologie. Aus dieser Perspektive interpretiert Cenvenka "Gebet für die Feinde" u. a. als "dichterische Projektion der tieferen Schichten jener Problematik, die das Fundament der literarischen Kämpfe der neunziger Jahre bildete". Auf dem Hintergrund des realen außertextuellen (und außerästhetischen) Ereignisses konstituiert sich der semantische Nukleus von Modlitba za neprátele, nämlich der "allgemeine Archetypus des Erlebnisses der zwischenmenschlichen Konflikte, des aus dem Zerwürfnis resultierenden Schmerzes und der Hoffnung auf seine Überwindung". 47

Ich komme nun zur Darstellung meiner eigenen Position und meines eigenen Deutungskonzeptes im Hinblick auf die oben erörterten Deutungskonzepte von Bïezinas Werk in der bisherigen Forschung. Den Ausgangspunkt der vortiegenden Arbeit bildet die These, daß das literarische Kunstwerk aufgrund seines inneren Aufbaus in erster Linie zu ästhetischem Wirken tendiert. Das ästhetische Wirken, das von allen Schichten des Werkes gemeinsam ausgeübt wird, ist in seinem Inhalt fundiert. Über den Inhalt, der hier im Anschluß auf die Inhalt-Auffassung von W. Schmid 48 als das Bedeutungskorrelat aller ästhetisch aktiven Werkkomponenten begriffen wird, übt das literarische Kunstwerk als Sprachgebilde seine Funktionen aus. Im Unterschied zu den gehaltsästhetisch orientierten Konzepten Králíks, Heftrichs u.a., die den Inhalt reduktionistisch, nämlich als bloßes Konzentrat aus bestimmten thematischen Einheiten (2.B. als Summe der Ereignisse auf der thematischen Ebene) behandeln, die dann in der Form einer resümierenden Nacherzählung quasi-psychologisch (Králik) ${ }^{49}$ oder völlig isoliert als Summe von Gedanken (Resultate der Rezeption philosophischer Werke), als Philosopheme (Heftrich), gedeutet werden sowie im Unterschied zu dem formästhetisch orientierten Konzept M. Cervenkas, das dazu tendiert, den Inhalt als eine der vielen Erscheinungen der Form zu betrachten, konzentriert sich meine Untersuchung primär auf den àsthetischen Inhalt (und seinen Aufbau) - d.h. auf die Be d e u t u n g 50 - von Biezinas Gedichten, die hier als (in

45 M. Cervenka (unter dem Namen Jan Adam), .Prchavé symboly sněni”, in: O. Błezina, Nevlastni déti zemé, Praha 1988, S. 207. $32-46$

46 M. Cervenka, .Bíezinưv výklad Svitáni na západè", in: ders., Styl a význam, Praha 1991, S:

47 M. Cervenka. „Modlitba za nepłátele", ibid., S. 11-31, hier insbesondere S. 25, 29.

$48 \mathrm{~W}$. Schmid, Der ästhetische Inhalt. Zur semantischen Funktion poetischer Verfahren. Utrecht 1977, S. 13if.

49 Hierzu gehōren auch die Aufsätze von Milos Dvởák (s. Literaturverzeichnis) sowie die Arbeit von Pavel FraenkJ Otokar Biezina. Mládi a pierod. Genese dila. Praha 1937, die sich auf die literarischen Anfănge Błezinas konzentrient. Abgesehen von den spătrealistischen Anfăngen Błezinas geht Fraenki bedauerlicherweise nur noch auf die ersten Gedichte des ersten Zyklus Tajemné đálky (Geheimnisvolle Fernen, 1892-1895) ein.

50 Wie W. Schmid betont, muß man den Inhalt im literarischen Werk als eine B e d e u t u n g denken, da die spezifische Funktion des Kunstwerkes (nämlich die ästhetische Funktion) "stets diejenigen Schichten umfaßt, in denen die Hauptfunktion des Sprachprodukts fundiert ist". Die Bedeutung wird dann „durch die Totalität der auf den heterogenen Ebenen auftretenen Substanzen und Formen ausgedrückt. W. Schmid, Der ästhetische Inhalt . Zur semantischen Funktion poetischer Verfahren, Utrecht 1977, S. 15. 
der Wahrnehmung gebildete) ästhetische Objekte51 (Signifikate des Werkganzen) betrachtet werden. Wie schon oben dargelegt, gehe ich davon aus, daß der Inhalt des literarischen Werkes sich nicht im Thematischen erschöpft, sondern alle Schichten (d.h. a u ch die des Themas) des Werkes als Zeichenträger umfaßt. Darüber hinaus wird hier der ästhetische Inhalt nicht als statisches Ergebnis ("výsledek"; wie dies der Fall in der Arbeit von Králík ist), sondern als Prozeß und Bedeutungsbewegung begriffen. Die Deutungskonzepte von Králík oder Heftrich, die durch erstaunliche interpretatorische Willkür gekennzeichnet sind, zeigen überaus deutlich, daß es kaum möglich ist von der künstlerisch organisierten Werkstruktur zu sprechen, ohne das Werk eingehend und systematisch zu intrepretieren. Man denke an die These, die Arthur C. Danto in seiner "analytischen Ästhetik" (und im ähnlichen Sinne auch W. Iser in seiner Rezeptionsästhetik) vertritt: kein Kunstwerk ist Kunstwerk ohne seine Interpretation, d.h. das Kunstwerk existiert nur durch seine Interpretation. 52 Im scharfen Gegensatz zu den bisherigen "philosophischen" oder psychologisierenden, von vornherein vereindeutigenden Interpretationsversuchen und Erklärungsmodellen, wird in der vorliegenden Arbeit die Untersuchung der se mantis chen $P$ a ra dig $m$ a tik von Brezinas Werk durch eingehende Texti n terp re ta ti o n e n abgesichert, die sich bei der Konzeptualisierung der Textsemantik auf eine gründliche Analyse der Sujetlogik, der Komposition und der kommunikativen Struktur (dazu gehören auch Überlegungen

51 Im Aufsatz .Umění jako semiologický fakt" (1936; .Die Kunst als semiologisches Faktum", dt. in: ders., Kapitel aus Ästhetik, Frankfurt am Main, 1970, S. 138-147) definiert Mukarovský das literarische Kunstwerk als Zeichen. Als dessen Signifikant fungiert das Wert als materielles Artefakt, als dilo-vèc (Werk-Sache). Das ásthetische Objekt (estetický objekt) konstituiert sich als Signifikat des Werk-Zeichens (dik-znak) und als "Korrelat" des materiellen Artefakts im Bewrußtsein des Rezipienten bzw. im "kolektiven BewuBtsein" (so in der Studie Estetická funkce, norma a hodnota jako sociálni fakty, 1936, in: ders.. Studie z estetiky, Praha 1971. S. 7-65; hier insbesondere S. 58-63). Das assthetische Objekt (diesen Begriff hatte Mukaroovský der bekannten Arbeit des Neukantianers B. Christiansen Philosophie der Kunst. Berlin 1912 [vgl. Kap. .Das ăsthetische Objekt", S. 49-131] entlehnt) repråsentiert also die Hierarchie der werkimmanenten Konstruktion. In der asthetischen Reaktion auf das Werk als Sache konstituiert der Rezipient das ásthetische Objekt. Durch seine Strukturiertheit als Sprachprodukt appelliert das Werk als Sache zur Einnahme einer Haltung, in der der Rezipient alle Schichten des Werkes als Sache sowohl kognitiv als auch sinnlich erfaßt und semantisiert. Vgl. W. Schmid, Der assthetische Inhalt, in: a.a.O., S. 27ft. Vgl. auch: M. Cervenka, „Literámi artefakt, in: ders.: Obléhání zevniť, Praha 1996. S. 40-74. Doch abgesehen von der Konstituierung des asthetischen Objektes im Rezeptionsakt besitzt die Struktur eines Kunstwerkes, wie R. Ingarden betont (Erlebnis, Kunstwerk und Wert. Vortráge zur Ästhetik 1937-1967. Darmstadt 1969, S. 153-179), ihre eigene Existenz und eigene, unabhăngig von den variablen Aktualisierungen bestehende und objektinhărente ásthetische Qualităt, gleichgültig. ob sie jemals mit dem kollektiven Normensystem konfrontiert oder Objekt einer bedeutungserüllenden Rezeption wird. Diese essentialistische Auffassung des ästhetischen Objektes (vgl. R. Ingarden; vgi. auch die Auffassung des asthetischen Objekts als so-bytije bei Bachtin, in: Problema soderzanija. materiala i formy v slovesnom chudozestvennom tvorcestve, Moskva 1924, S. 6-71; vgl. auct: ders., Voprosy literatury i estetiky, Moskva 1975, S. 234-407), die die Relevanz der Rezeptionsnormen erheblich relativiert, kommt auch bei Mukałovský zum Ausdruck und zwar in seiner schon ewähnten bedeutenden Studie Zámérmost a nezámérnost v umèni (Die Absichtlichkeit und die Unabsichttichkeit in der Kunst (1943). Als "unabsichtliche" (d.h. 'zeichenlose') "Sache" ("vëc") in der realen Welt befindet sich das Kunstwerk außerhalb der sozialen und historischen Bedingungen seiner Rezeption und des literarischen Normensystems. Daraus resultiert auch die Unabhăngigkeit der ăsthetischen Eigenschaften und Qualităten des Kunstwerkes.

52 A.C.Danto, The Transfiguration of the Commonplace. A Philosophy of Art. Cambridge, Mass. [Harvard University Press] 1981; dt. Die Verklärung des Gewöhnlictien: eine Philosophie der Kunst. Frankfurt am Main 1984, S. 178-208. Zum SchluB des Kapitels interpretation und Identifikation" betont Danto noch einmal: „Deshalb ist für unsere Untersuchung entscheidend, daß wir das Wesen einer Kunsttheorie verstehen, die etwas so máchtiges ist, daß sie Objekte aus der realen Welt herausheben kann und zum Bestandteil einer anderen Welt zu machen vermag: einer Kunstwelt, einer Welt interpretierter Dinge. Diese Überlegungen zeigen gerade, daß ein innerer Zusammenhang besteht zwischen dem Status eines Kunstwerks und der Sprache, mit der Kunstwerke als solche identifiziert werden, insofern nichts ein Kunstwerk ist ohne eine Interpretation, die es als solches konstituiert' (ibid., S. 208). Auch in der Rezeptionsåsthetik Wolfgang Isers (Akte des Lesens) spielt diese These eine wichtige Rolle. Nach dieser These ist der eigentliche Künstler der Interpret. 
über die ästhetische Funktionalisierung verschiedener Gattungsformen religiöser Rede bei Bïezina) der interpretierten Gedichttexte stützen. Dabei geht es darum, die Semantik von Bïezinas Gedichten in ihrer konkreten, vieldeutigen, bildhaften und manchmal auch paradoxen Mytho-Logik zu erfassen. Zum Gegenstand der vorliegenden Untersuchung wird also gerade das gemacht, was die ästhe ti sche Wirkung von Briezinas Gedichten als künstle rische Texte eigenttich begründet, nämlich ihre reiche Bildlichkeit und das ihr zugrundeliegende bildhaft-konkrete, mytho-logische Denken.

Da die motivische Semantik des lyrischen Werkes von Otokar Bïezina nicht nur synchron, sondern auch in ihrer inneren Entwicklungsdynamik untersucht werden soll, wird hier zunächst ein diachron-typologisches Periodisierungsmodell seines Schaffens ${ }^{53}$ aufgestelt:

\section{Phase (1892-1895): DEKADENTER SYMBOLISMUS \\ Prinzip der Trennung und Isolation unter der Herrschaft des Thanatos \\ Gedichtzyklus Ta je m n é dálky (TD, Geheimnisvolle Fernen, 1895) \\ Ästhetische Existenz - Prinzip der Irrealisierung}

\section{Phase (1896-1901): ESCHATOLOGISCHER SYMBOLISMUS \\ Prinzip der Vereinigung unter der Herrschaft des Eros}

I. GNOSTISCHESCHATOLOGISCHES MODELL

Gedichtzyklus $S$ vitá $n i$ na záp a dè (SZ, Tagen im Westen, 1896)

Der (Existenz-)'Weg' (zum Eschaton) der Erkenntnis (rvïors)

II. THEO-LOGLCH-ESCHATOLOGISCHES MODELL.

Gedichtzyklus Vè try od pólù (VP, Polarwinde, 1897)

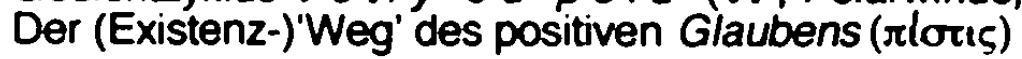

53 In seiner groB angelegten Habilitationsschrift Der russische Symbolismus. System und Entfaltung der poetischen Motive. Band I., Diabolischer Symbolismus, Wien 1989, entwickelt Aage A. Hansen-Löve eine paradigmatische Typologie des russischen Symbolismus, die drei Modelle unterscheidet, die jeweils einen Subkode des Periodensystems "Symbolismus" konstituieren: S I (Diabolischer Symbolismus; die neunziger Jahre), S II (mythopoetischer Symbolismus; 19001907). S III (grotesk-karnevalesker Symbolismus; $1907 / 8$ bis in die 2 wanziger Jahre). Jedes Modell gliedert sich in jeweils zwei 'Programme' (z. B. S 1/1: Ästhetismus/negative Diabolik, S II/2: Panásthetismus/positive Diabolik, "magischer Symbolismus), die chronologisch und evolutionár wechselseitig korrelieren. Dem jeweils negativen Programm innerhalb eines Modells folgt jeweils ein positives Programm (SII/1, Sili/1). Dieses Gliederungsmodell ermöglicht nicht nur die Korrektur der bisherigen Interpretationen der zwischen heterogenen Programmen aufgetretenen Analogien. die sich nun als Konvergenzen und Interterenzen (d. h. nicht als bloBe Überschneidungen, Kontaminationen oder Inkonsequenzen) erfassen und deuten lassen, sondern auch eine anschauliche Darstellung sowohl des entwicklungsdynamischen Aspektes der Diachronie als auch der Synchronizität heterogener Modelle und Programme. (Vgl. ibid., S. 7-24). Ein 'Fünt-PhasenModell' des russischen Symbolismus entwickelt in der Symbolismus-Forschung der Tartuer Schule A. S. Pustygina (.K izuČeniju evoljucii russkogo simvolizma", in: Tezisy I. vsesojuznoj (III) konferencii, Tartu 1975, S. 143-147). Die ersten drei Phasen des Symbolismus der neunziger Jahre und der Jahrhundertwende (bis etwa 1910) konvergieren mit dem von A. A. Hansen-Love entwickelten Periodisierungsmodell. Pustygina enweitert das Modell auch auf die Formationen und Gruppierungen der zehner bis dreißiger Jahre (4.-5. Phase), die die Tendenz zur Historisierung. Utopisierung oder zum Autobiographismus einerseits und zu autoreflexiven Diskursen sowie zur 'Mythisierung' der eigenen Epoche, des Symbolismus, andererseits (5. Phase), kennzeichnet. $Z$. G. Minc ("Blok i russkij simvolizm", in: Literaturnoe nasledstvo, 92/1, Moskva 1980, S. 98-172) unterscheidet mehrere Etwicklungsperioden des Symbolismus: erste Periode der neunziger Jahre. die den Kult des Ästhetizismus, die Autonomie des Ästhetischen, charakterisiert. Die 2. Periode, der "Symbolismus zweiter Welle" (1907-1910), ist die der 'Mythologisierung'. Die dritte Periode (um 1910) steht unter dem Zeichen der Symbolismus-Kritik. Die Entwicklung nach 1910 betrachtet Minc als 'postsymbolistisch'. 
III. KOSMOGONISCHESCHATOLOGISCHES MODEUL

Gedichtzyklus Sta vi te lé chrámu (SCh, Baumeister am Tempel, 1899)

Der (Existenz-)'Weg' der Gnade (xápıs)

IV. VTTALSTISCH-ESCHATOLOGLSCHES MODELL

Gedichtzyklus R u ce (R, Hände, 1901)

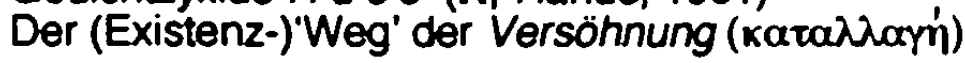

\section{Letzte Gedichttexte (1901-1907) - Auflösung der poetischen Welt - Verstummen}

Die Hauptthese meiner Auseinandersetzung mit dem dichterischen Werk O. Biezinas ist also die folgende: Wie es scheint, kann man seine Entwicklungsdynamik als ein 'Zwei-Phasen-Modell' darstellen: Die erste Phase des dekadenten Symbolismus und die zweite (nachdekadente) Phase des eschato logischen Symbolismus. Aus dieser Perspektive gesehen, erscheint sich die gesamte $\mathrm{n}$ a ch dekadente schöpferische Entwicklung von Otokar Bïezina als permanente Konfrontation und Auseinandersetzung mit der ersten d e $k$ a d e $n t$ e $n$ Schaffensphase und darüber hinaus als Versuch, die dekadente 'Vergangenheit', die Erfahrung des descensus in die Sphäre des (dekadenten) Kunst-Todes, in das Wertsystem des eschatologischen Symbolismus zu integrieren. Die Phase des dekadenten Symbolismus, mit dem Postulat der ästhetischen Existenz in der autonomen (mythisierten) Kunst-Welt, wird als eine wichtige Durchgangsphase der schöpferischen Entwicklung und als eine notwendige Voraussetzung für den produktiven ascensus in der Phase des eschatologischen Symbolismus begriffen. Dieses 'Zwei-Phasen-Modell' geht im Prinzip von der in der Bïezina-Forschung allgemein anerkannten grundsätzlichen Entwicklungszäsur nach der dekadenten Schaffensphase Biezinas aus; deren Bedeutung in der Entwicklungslogik von Biezinas Werk wird jedoch in der vorliegenden Arbeit auf eine völlig neuartige Weise interpretiert. Die Auffassung der gesamten nachdekadenten Entwicklung Bïezinas als eine übergreifende Gesamtphase mit mehreren Subphasen liegt schon den älteren Periodisierungsversuchen implizit (Králík) oder explizit (Heftrich) zugrunde. Doch sie alle orientieren sich an der Vorstellung einer "Überwindung" des Pessimismus und der Dekadenz zugunsten einer neuen "optimistischen" Schaffensphase. Dabei wird diese "Überwindung" ganz in der Intention einer "philosophischen Interpretation" als ein denkerischer Prozeß und nicht als Prozeß der Umsemantisierung. des Umbaus des gesamten ästhetischen Bedeutungsaufbaus, begriffen.

Das $\mathrm{Ne}$ u e an dem in der vorliegenden Arbeit präsentierten Periodisierungsmodell ist zum einen die Bestimmung des einheitlichen Telos der gesamten nachdekadenten Entwicklung von Biezina als Streben nach der Herstellung der kosmischen Einheit unter der Herrschaft des allverbindenden Eros ${ }^{54}$ im Gegensatz zu dem im dekadenten Symbolismus dominierenden Prinzip der Dissoziation und der Irrealisierung unter der Herrschaft des Destruktionstriebes und in-der darauf basierenden Konzeptualisierung der einzelnen Subphasen des so definierten eschatologischen Symbolismus als verschiedene Lösungsmodelle auf dem Weg zur Herstellung der eschatologischen Einheit. Zum anderen wird hier die nachd'ekadente Entwicklung Biezinas nicht einfach als "Überwindung" der Dekadenz, sondern als ständige produktive Auseinandersetzung mit ihr im Sinne eines permanenten autointertextuellen Dialogs des Autors mit sich selbst aufgefaßt. Der Telos dieses Dialogs wird im Sinne der Jungschen Psychologik in der Suche nach einer erfolgreichen Integration des "Schattens" der eigenen dekadenten Vergangenheit gesehen. In diesem Hinblick stellt sich die gesamte Entwicklungslogik von Bïezinas Werk als Geschichte der wiederholten Versuche der produktiven Integration der dekadenten Schattenwelt und deren Symbolik in das semantische System des eschatologischen Symbolismus dar, wobei die einzelnen Modelle der Herstellung der eschatologischen Einheit zugleich auch als Modelle der Herstellung der p s y ch i s ch e n Einheit erscheinen. Dieses komplexe Erklärungsmodell basiert also auf einer Kombination von drei methodologischen Zugängen: dem

$54 \mathrm{Vgl}$. auch die Darlegung in Kap. 3. 
mythopoetischen, dem psychopoetischen 55 und dem intertextuellen.Im folgenden sollen in nuce die verschiedenen Lösungsmodelle ('Existenz-Wege') im System des eschatologishen Symbolismus von Bïezina, die zum Erreichen des postulierten Zieles, der endzeitlichen Synthese und des Eschatons führen, spezifiziert werden.

Im ersten nachdekadenten Gedichtzyklus des eschatologischen Symbolismus, in Svitáni na západè (Tagen im Westen, 1896), ist das der (Existenz)'Weg' der Gnosis. Darunter ist in erster Linie das Streben nach der Erkenntnis nicht nur sich selbst, sondern auch die Schöpfungen des "Höchsten" ("Nejvyšs"i") und ihre Geheimnisse zu verstehen. Auf diesem Wege soll - durch gnostische 'Mittel' - auch die Integration der dekadenten Myth(opoet)ik in das gnostisch-eschatologische Modell erreicht werden. Diese Integration wird dadurch 'vorbereitet', daß das in SZ modellbildende gnostisch-mythische Substrat bereits in einigen Gedichttexten des gekadenten Symbolismus (Zyklus TD) wirkt.

Im Gedichtzyklus Vètry od pólü (1897; theologisch-eschatologisches Modell) ist das der (Existenz-)'Weg' des positiven Glaubens ("vira"-лíouç), d. h. der christlichen Grundbestimmungen der eschatologischen Existenz (Hoffnung-Glaube-Liebe). Diese neue Orientierung vom gnostisch-mythischen auf das biblisch-(bzw. neutestamentlich-) mythische Denkgut deutet auf eine wichtige Änderung hin: Auf die Theo-logisierung und Rationalisierung des in Tajemné dálky und in Svítáni na západè mythisierten poetischen Weltbildes. Anders gesagt: das im dekadenten Symbolismus Brezinas entwickelte und in Svitáni na západẻ weiter wirksame gnostisch-mythische Substrat wird in Vètry od pólù (Polarwinde, 1897), wie es scheint, mit der (neutestamentlichen) Theologie der Grundbestimmungen der eschatologischen Existenz gleichsam überlagert. In diesem Sinne stellt der Gedichtzyklus Vẻtry od pollú, wie noch zu zeigen sein wird, einen gewissen 'Bruch' in der schöpferischen Entwicklung Bǐezinas dar.

Im nächsten Gedichtzyklus Stavitele chrámu (Baumeister am Tempel, 1899), in dem die Vollendung der Schöpfung und das Eschaton durch das Charisma der Gnade ("milost"

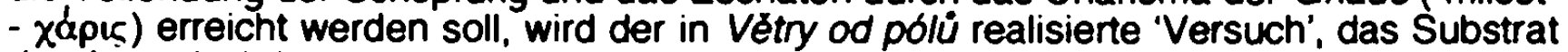
des (gnostisch-) mythischen Denkens durch seine Theo-logisierung zu integrieren, nicht als eine Integration, sondern als eine 'Vedrängung' gewertet. Daher charakterisiert den Zyklus Stavitelé chrámu (kosmogonisch-eschatologisches Modell) die Tendenz zur Restituierung des in inm konstituierten poetischen Weltbildes, vor allem durch die ReMythisierung der dekadenten Kunst-Schöpfung-Mythik. Diese wird in Stavitelé chrámu in den Gesamtplan der L e b e n s schöpfung in der Sphäre der Lebenswelt (koouos) integriert und 'eschatologisiert'. Man kann also von einer Korrelation zwischen der in Tajemné dálky (Geheimnisvolle Fernen) entfalteten Kunst-Schöpfung -Mythik und der Kunst- und $L$ e b e n s schöpfung-Mythik im Rahmen des kosmogonisch-eschatologischen Modells von Stavitelé chrámu sprechen.

Im letzten vollendeten Gedichtzyklus Ruce (Hände, 1901; vitalistisch-eschatologisches Modell) wird der Prozeß der Re-Mythisierung mit dem Ziel der Intensivierung aller vitalen Prozesse und deren Integration in den eschatologischen Plan fortgesetzt. Den Kulminationspunkt stelit das "Zusammenfließen" ("slit") und die endzeitliche "Versöhnung"

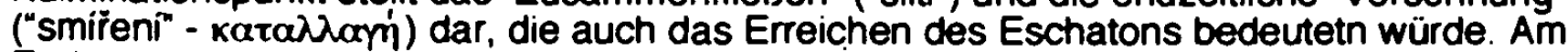
Ende des erwarteten eschatologischen Geschehens steht (in Ruce) der "Einzige Mensch, der Erlöste" ("Jediný Človêk, vykoupeny"). Diese Terminologie ist offensichtlich auf den gnostischen Erlösungsmythos zurückzuführen, in dem - wie noch nachzuweisen sein wird - die Vorstellung des göttlichen Wesens, des Sotērs, der anthropos genannt wird, sowie die des "erlösten Erlösers" eine der Schlüsselpositionen einnimmt. Daraus resultiert, daß das vitalistisch-eschatologische Modell von Ruce (1901) das gnostisch-eschatologische Modell von Svitáni na západẻ (1896) tangiert. Diese innere Entwicklugslogik des dichterischen Schaffens von Brezina ließe sich nun durch folgendes Schema veranschaulichen

55 Die Darlegung der Psychologik des lyrischen Werkes von Otokar Biezina erfolgt aus bestimmten Gründen im abschließenden achten Kapitel der vorliegenden Arbeit. Dieses Kapitel ist als Ausblick auf einen wichtigen Aspekt der künftigen Bïezina-Forschung und darüber hinaus als eine tentative psychologische $\mathrm{R}$ e interpretation der schōpferischen Entwicklung Błezinas konzipiert. 
Remythisierung $u$. Eschatologisierung

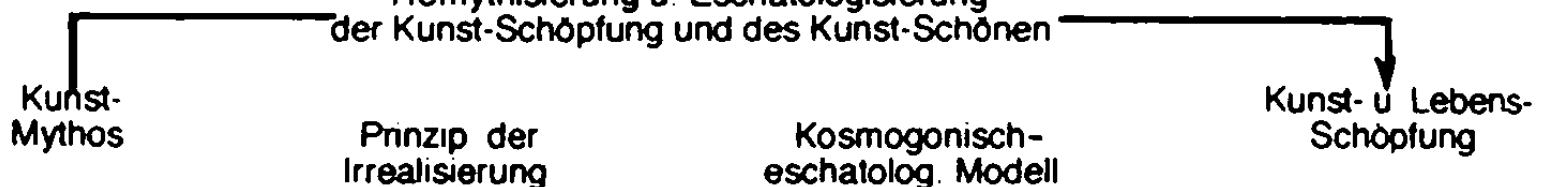

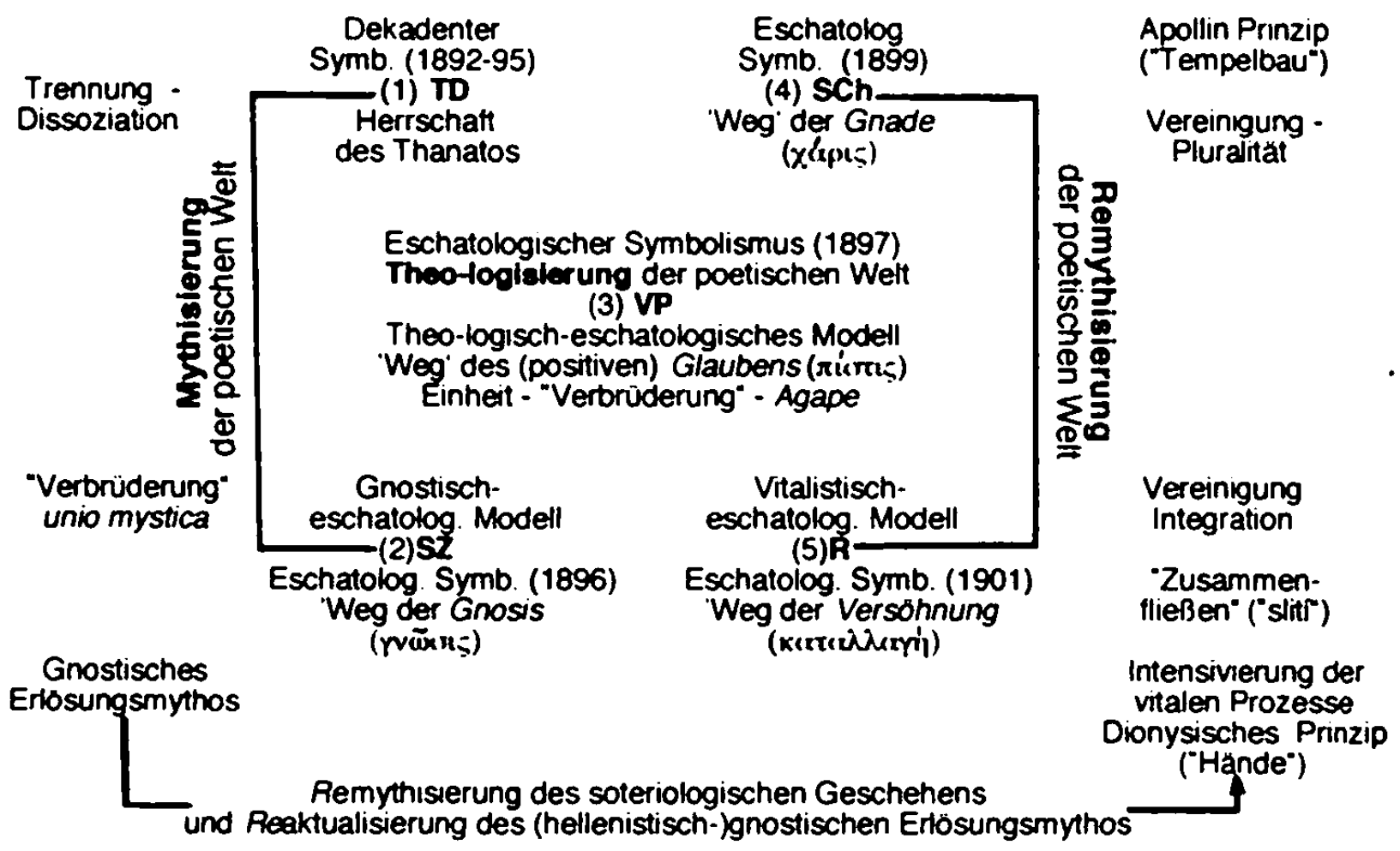

Die Gliederung der Arbeit ist folgende: Um Bïezinas poetische Semantik in inrer evolutionären Dynamik zu erfassen, wird Bïezinas schöpferische Entwicklung in insgesamt sechs Phasen zerlegt, die im wesentlichen mit den fünf vollendeten Gedichtzyklen korrespondieren und als abschließende Phase auch die letzten vom Autor nicht mehr zu einem Zyklus komponierten Gedichte umfassen. Die poetische Semantik dieser Entwicklungsphasen wird in sechs gesonderten, streng parallel aufgebauten Kapiteln untersucht, in denen zunächst immer das semantische Gesamtmodell der betreffenden Phase aufgestellt wird. Im Anschluß daran werden die jeweils dominierenden motivischen Paradigmen untersucht, um dann die hierbei gewonnenen Erkenntnisse anhand einer detaillierten exemplarischen Analyse einiger paradigmatischer Einzeltexte der betreffenden Phase zu verifizieren und zu vertiefen.

An dieser Stelle sollen noch einige Aspekte der Erscheinung der auto. intertextuelle n Interferenzen von Gedichten im lyrischen Werk von Biezina erörtert werden, deren grundlegende Untersuchung man auch als die nächste Aufgabe der Bïezina-Forschung betrachten kann. Die a u to - i n te r t e x tu e l l e (dialogische) Dimension von Bỉezinas CEuvre bleibt in der bisherigen Fachliteratur unberücksichtigt. Králík verweist zwar in seiner Monographie auf die Reziprozität einiger Motivkomplexe oder axiologischen Kategorien ("sen" $/$ Traum", "samota" / "Einsamkeit", "vzpominka" / "Erinnerung", "dálka" I "Ferne", "bolest" I "Schmerz" usw.), die Semantik ihrer neuen Variationen und Kodierungen bleibt jedoch in seiner Darstellung gănzlich unreflektiert. Es handelt sich keinesfalls um irgendeine 'Überwindung' bzw. 'Ablösung' der älteren Symbolkomplexe durch andere, 'positiv' konnotierte (nach dem einfachen Schema 'Pessimismus' vs. 'Optimismus' usw.), sondern um deren Umsemantisierung. ReFormulierung. Paraphrasierung usw.. Bïezinas fünf Gedichtzyklen, die - bis auf den ersten Zyklus Tajemné dálky - die beinahe identische Anzahl von Gedichten 56 autweisen,

56 Von neunzehn bis einundzwanzig Gedichttexten; eine Ausnahme stellt mit seinen dreißig Gedichten der erste Gedichtzyklus des dekadenten Symbolismus Tajemné dálky (Geheimnisvolle Femen, 1895) dar. Ein gemeinsames Merkmal ist jeweils ein Prolog- und ein Epilog-Gedicht sowie die Situierung des semantisch exponiertesten Gedictttextes jeweils auf die zweite Stelle im Zyklus 
kreuzen und tangieren sich gegenseitig, korrespondieren und 'kommunizieren' miteinander, sie 'zitieren' sich gegenseitig usw. Es scheint, als ob Biezina durch diese Strategie eine möglichst große Transparenz'57 des in seinem Werk konstituierten poetischen Weltbildes erzielen wollte. 58 Das lyrische Werk Biezinas scheint - wie schon gesagt - ein (intendiertes) 'einziges Buch', einen einzigen 'Auto-Intertext' bzw. ein 'Palimpsest' zu bilden durch dessen 'Érstschrift' die späteren 'Neu-Schriften' hindurchschimmern:

\%... / palimpsesty, kde vesmirem dneska prosvitá vesmir prvniho slunce" (Mythus duše / Mythos der Seele, Sz: 1896: "\%... Palimpseste, wo durch das Weltall von Heute das Universum der ersten Sonne durchschimmert"). "Z duši vzdálených od sebe celá staletí a tisicileti zaznéla v těchto chvilich slova doplńujici se navzájem $v$ jediný text, jehoż rozluštěni bude zároveñ ukonŁenim, aż se naplni věky" (Rozhodujici okamžiky / Entscheidende Augenblicke; Essay, 1897; -In diesen Augenblicken ertōnten aus jahrhundert- und jahrtausendgetrennten Seelen Worte, die einander zu einem einzigen Text ergănzten, dessen Entzifferung zugleich die Vollendung sein wird, wenn die Zeit sich ertült hat".)

Einige der letzten Gedichttexte (Návrat / Die Heimkehr, 1907) führen sowohl motivals auch verssemantisch wieder zu den ersten Gedichten (Návrat / Rückkehr, 1894). Hinter Br̈ezinas "Věčné znova" ("Stets aưs Neue", eines der letzetn Gedichte) verbirgt sich, wie es scheint, auch der Unwille des Autors, das 'letzte Wort' auszusprechen und

hinter dem Prolog-Gedicht, das in jedem der fünf Zyklen, im Unterschied zu den anderen Gedichten, onne Titel bleibt.

57 Hier mag die platonische Lehre bzw. das platonische oder neoplatonische Welt-Bild (mit seiner Hierarchie von "Seinsschichten") einen starken Einfluß ausgeübt haben. Die Vorstellung von der Transparenz einer diaphanen transzendenten Welt ist als ein merkmalhaftes Symbol anzusehen. Ich verweise auf die zahlreichen signifikanten Motive der gläsernen (bzw. kristallinen) Kugeln (Vẻzeñ / Der Gefangene. Stavitelé chrámu / Baumeister am Tempel), der Grotten "aus strahlendem Gestein" (Motiv z Beethovena I Ein Motiv aus Beethoven, Stavitelé chrámu I Baumeister am Tempel u. a.), der gläsernen Türe und Fenster (Vino silných / Der Wein der Starken. Kde jsem uż słyšel?... Wo denn vemahm ich schon?... Kdyż nebe vaše okna ozáñ I Fültt eure Fenster Himmelsglanz...), der Spiegelbilder (Královna nadèji I Die Kónigin der Hoffnungen. Láska / Liebe), der strahlenden Aureolen (Stráż nad mrtvými / Totenwache) u. a. In Vêzen (Der Gefangene. TD) formt der Kunst-Schöpfer das Welt-Bild (seiner Seele) aus der Glasmaterie: " $\%$... do skelnẻ hmoty vrouci / jsem smácel pišttalu a vydechl té tvarem" ("I../ in siedend heiße Glasmaterie tauchte ich / die Pfeife und blies Dich zur Form", V, 3-4). Vgl. auch die Verse aus Vino siných (Der Wein der Starken, SZ): "Hledéti budeme ładou dni budoucich, jak ładou skleněnych dvểi, za sebou ležicich siní, / jimiž nám naproti pricházi slunce /...F ("Schauen werden wir durch die Fluchten der künftigen Tage, I wie durch eine Reihe von gläsernen Türen hintereinanderliegender Sale, / durch welche uns Sonne entgegenkommt /... . V. 29-30). Das Bild der Welt als das einer gläsernen oder kristallinen Kugel, deren Mitte die Erde bildet (siehe die Außenseite der Flügel von Hieronymus Boschs "Garten der Lüste", um 1500, Madrid, Prado oder das Gemälde von Jos van Cleves "Salvator Mundi" im Louve [frühes 16. Jhd.], auf dem Christus die Welt-Kuget wie einen kostbaren kristallinen Reichsaptet als Insignium seiner Weltherrschatt in der $\mathrm{Hand}$ hălt u. a.), entspricht der Kosmologie von Platon (in seinem Timaios), die bekanntlich einen tiefreichenden Einfluß auf die kosmologischen Vorstellungen des Mittelalters ausübte und die im Symbolismus aktualisiert wurde. Bỉezinas Faszination für die Ideen Platons bestătigen nicht nur die Zitate in seiner Korrespondenz, sondern auch seine Gedichte und Essays. Einen beeindruckenden Reflex der Platonschen Anamnesis-Idee stellt das Gedicht Kde jsem uZ stysel?... (Wo denn vernahm ich schon?... VP) dar. Das in der Dichtung des Symbolismus sehr verbreitete und thematisierte Prinzip der 'Transparenz' beleuchtet Jurij Striedter: .Transparenz und Verfremdung. Zur Theorie des poetischen Bildes in der russischen Moderne in: Immanente Ásthetik. Lyrik als Paradigma der Modeme, Poetik und Hermeneutik, München 1966. S. 263-296.

58 Mit diesem paläographischen Terminus arbeitet Gérard Genette in seinem Buch Palimpsestes. La litterature au second degré, Paris 1982. Hierin versucht Genette eine Typologie der intertextuellen Relationen mit Hilfe von diversen Typen und Subtypen zu erarbeiten. Die Intertextualität (die unmittelbare Präsenz eines oder mehrerer Texte in einem Text: Zitat. Allusion oder Plagiat), wird dem übergeordneten Begriff der "Transtextualität" subordiniert. Neben dem Typus der Intertextualitāt unterscheidet Genette noch die "Paratextualität" (Relation zwischen Text und Nebentexten - Vorwort, Nachwort, Umschlag - und zwischen Text und Titel), die "Metatextualităt" (kommentierender Bezug auf einen anderen Text: Konkretisationsakte), die "Hypertextualität" (Folie fūr weitere Texte, die jedoch nicht präsent sein muß: Imitation, Parodie etc.) und die "Architextualität" (Bezug eines textes auf seine text- oder gattungstypologische Vorlage: 2 . B. de Lorris' "Le roman de la Rose"). 
dem Werk dadurch eine 'eindeutige' Wahrheit einzuprägen. Bïezinas Worte aus einem seiner Briefe an A. Pammrová: "Nevažte se nikdy na slova prì Cetbè mých věci" ("Klammern Sie sich bei der Lektüre meiner Sachen nie an Worte") sind geradezu symptomatisch für den von inm postulierten polysemantischen Charakter des poetischen Wortes, für den Synkretismus von mannigfachen Bedeutungspositionen. Die dialogischauto-intertextuelle Struktur seiner Gedichte scheint dieser Tendenz maximal entgegenzukommen. Br̈ezina wurde von einer nahezu obsedanten Vorstellung von der Begrenztheit bzw. Unvollkommenheit des sprachlichen Zeichens und vom Bewußtsein der limitierten Lexik-Anzahl heimgesucht. Das explizit thematisierte Motiv der 'Gebärdensprache',59 des 'Gestischen' (auch im Sinne eines mnemo(tech)nischen Mediums), das aus der Spannung zwischen Zeichenhaftigkeit und (außersozialer) Zeichenlosigkeit, zwischen Sprache und stummer Gebärde resultiert (die der Terminus "semantischen Geste"von Mukařovský - u. a. - impliziert), scheint für Bïezinas Lyrik, insbesondere in der Schlußphase 1899-1907, von eminenter Relevanz zu sein.

Es lăßt sich nun sagen, daß die Auto-Zitate, Auto-Paraphrasen, Re-Formulierungen, Allusionen, Wiederholungen sowie Reminiszenzen usw. auch als gewisse mnemonische (bzw. anamnestische) Indizes fungieren, 60 die nicht nur den Leser während des

$59 \mathrm{Vgl}$. die Verse: "\%/../ gestem, jež duhové brány nad věky klene, vše posvécuješ" (Mista harmonie a smîtení I Orte der Harmonie und der Versőhnung. VI, $2 ; \%$..l mit der Geste, die Regenbogenpforten über den Zeitaltern wölbt, weihst du alles"): “.../v extasi dila ve chvatu / jen gesty symbolü svych hovoriš" (Neděle svatodušni / Der Pfingstsonntag. V. 23-24; " .../ in der Extase des Werkes in der Hast / nur mit Gesten deiner Symbole sprichst du"). In seinem Aufsatz "Ásthetische Funktion, semantische Geste und der Wirklichkeitsbezug des ästhetischen Zeichens" (in: Zeichenkonstitution. Akten des 2. Semiotischen Kolloquiums In Regensburg 1978, hrsg. v. A. Lange-Seidl. Bd. I,Berlin-New York 1981, S. 267-272) stellt Milos Sedmidubský die Auffassung des bekannten Konzeptes der "semantischen G e s te (vgl. unten Anm. 39) von J. Mukałovský auf. M. Sedmldubský interpretiert die "semantische Geste" als theoretisches Konzept für die dritte Stufe der Semiose: Auf der ersten Stufe manifestiert sich das Kunstwerk als "kommunikatives Zeichen", auf der zweiten Stufe als "autonomes Zeichen" und auf der dritten Stufe als eine in sich bedeutungshaltige "Bedeutungseinheit" (in Anlehnung an Mukaroovskýs Modell; vgl. Ders.. .L'art comme fait sémiologique", in: Actes huitième Congrès international de philosophie à Prague 2-7 Septembre 1934. Prag 1936. S. 1056-1072). Laut M. Sedmidubský erscheint diese "Bedeutungseinheit" als "Index-Zeichen", das auf die Ver-Haltung des Urhebers zur Welt verweist und als "Spur" dieser Ver-Haltung im Werk fungiert. Als das oben erwähnte Bindeglied zwischen Zeichen und Nicht-Zeichen, zwischen Sprache und Geste (stummer Gebärde) einerseits und/oder als "Index-Zeichen" (in der Auffassung von M. Sedmidubský) andererseits, scheint sich die "semantische Geste" auch im Werk von Brezina zu realisieren. In dem Sinne, daß die "IndexZeichen' offensichtlich auch als 'mnemo(tech)nische Zeichen' (im Sinne A. Warburgs) fungieren. Die Warburgschen "Pathosformein", d. h. die Ausdrucksformeln der Künstlersprache (in seinem fragmentarischen "Mnemosyne-Atlas" sind die einzeinen Tafeln mit den abgebildeten Kunstwerken so angeordnet, daß voran das antike Kunstwerk reproduzient ist, dann seine mittelalterliche Umformung/Umsemantisierung und schließlich die Resemantisierung der antiken 'Formel' in der Renaissance-Kunst), werden in den Bildern (Kunstwerken) vergegenwärtigt. Dadurch wird auch das Weiterleben einmal geprägter Formen im menschlichen Bewuß̉tsein gesichert. Die Gebărden oder Gesten fungieren dann als 'Indizes', die nicht nur auf die idividuelle Art und Weise der Weltaneignung, sondem gleichzeitig auf die vergangene Kultur, die durch die imagines $\mathrm{r}$ e vozient werden muß, hinweisen. Im ähnlichen Sinne scheint die semantische Gestation auch bei Błezina (individuell sowie überindividuell, produktions- sowie rezeptionsãsthetisch) zu fungieren: Sein lyrisches Werk wird zum "Gedächtnisraum" (in Anlehnung an R. Lachmann, .Mnemotechnik und Simulakrum", Gedächtnis und Literatur, Frankfurt am Main, S. 13-50). Warburg betrachtet die Gebärde als eine 'symbolische Form'. Der Einfluß E. Cassirers ist hier uverkennbar, und gerade die Philosophie der 'symbolischen Formen' kónnte $m$. E. als Bindeglied zwischen dem Warburgschen Konzept der 'Autoplastik' von Gesten und Ausdrucksgebärden als Indizes auf die im Bewußtsein gelagerten (Gedanken-)Bilder der vergangenen Kultur und zwischen dem Konzept der "semantischen Geste" von Mukatovský als einem 'Index-Zeichen' betrachtet werden. In der Zeit des Entstehens dieses Begriffes (zweite Hälfte der dreißiger Jahre) befaßte sich Mukarovský mit den Schriften E. Cassirers. Diese Problematik wäre eine selbständige Studie wert!

60 Man denke nur an die drei 'Gebet'-Gedichte: Modlitba vecerni (Das Abendgebet, TD), Ranni modlitba (Das Morgengebet, SZ) und Modlitba za neprátele (Das Gebet für die Feinde, VP), die sich nicht nur gegenseitig 'kornmentieren' (vor allem Modlitba vecerni und Ranni modlitba) und 'ergänzen', sondern auch re-interpretieren und innerhalb des Textes (Ranni modlitba) in eine gegenseitig 'konfliktgelade' Beziehung treten. 
Rezeptionsprozesses, sondern den Autor selbst - während des Schaffensprozesses - an konkrete, bereits anders formulierte 'Gedankenbilder' erinnern sollen. Das ganze Werk Otokar Bïezinas tendiert somit zum gewissen Warburgschen "Mnemosyne-Atlas" 61 des permanenten 'Sich-Erinnerns' an die im Gedächtnis 'gelagerten' Gedankenbilder als deutbare Urkunden - dem mnemonischen Vorgang angeglichen - der Weltaneignung sowie der Erfahrungen und Kenntnisse, die die Kultur-Geschichte als einen dynamischen und andauernden Prozeß konstituieren, und zugleich an das bereits (früher) Geschriebene und Formulierte, was nun zum Objekt eines 'Dialogs' geworden ist. Dieser Dialog signalisiert gleichzeitig den Akt der 'Transformation' oder den des Um- bzw. NeuSchreibens. Durch die ständigen Rekurrenzen auf eigene Texte, durch ihre ReInterpretationen, soll offensichtlich sowohl der Leser als auch der Dichter fortwährend an die 'Bilder' bzw. Mythologeme usw. aus den Gedichten der vorangehenden Gedichtzyklen erinnert werden.62 Die vorangehenden Texte bilden quasi Prätexte bzw. Intertexte der

61 Gemeint ist das fragmentarische Hauptwerk des Hamburger Kunsthistorikers und Gründers der ikonologischen Forschung der Kunstgeschichte Aby Warburg (1866-1929). In diesem 'Atlas' gruppieren sich geschichtliche Zeugnisse zu 63 Bildertafeln mit 1000 Abbildungen. Das historisch Vergangene soll in Erinnerung gerufen und im Bewußtsein als Bild vergegenwărtigt werden. Das Phänomen des Weiterlebens einmal geprägter Formen soll in diesem Atlas durch die Instanz der Erinnerung, durch die kollektive Mneme, begründet werden. (Vgl. die Konzeption der Kultur als 'Gedächtnis' von Lotman und Uspenskij; vgl. Ju. M. Lotman, B, A. Uspenskij, .O semioticeskorm mechanizme kul'tury", in: Trudy po znakovym sistemam, 5, Tartu 1971, 144-166). Möglichenweise rekurriert Warburg in diesem Punkt auf den Begriff des 'kollektiven Gedächtnisses' der DurkheimSchule. R. Lachmann zitiert A. A. Potebnja, der in Mys' i jazyk auf das Weiterleben einmal geprägter Formen und Kunstwerke in der 'kollektiven Mneme' verweist: "Denn die Kunstwerke bewahren nur solange ihren ästhetischen Wert, bis diejenigen Züge aus dem Gedächtnis der Menschen geschwunden sind, aus denen die Bilder gefügt sind" (vgl. Renate Lachmann. -Vergangenheit als Aufschub: Die Kulturosophie der Akmeisten", in: Dies., Gedãchtnis und Literatur. Intertextualitãt in der russisctien Moderne, Frankturt am Main 1990. S. 366). Warburg geht von der Kultur des heidnischen Altertums, von der antiken rauschnaften Ertahrung der Welt aus, in der (d. h. im orgiastischen Massen-Tanz, in kultischer Handlung etc.) dem Gedăchtnis die prägnantesten Ausdrucksformen des inner(st)en leidenschaftlichen Ertebnisses eingeprägt werden. Die expressive Körperlichkeit ist für Warburg (und für die ikonologische Forschung) der Bezugspunkt der Renaissance auf die Antike. Eine immense Rolle spielt dabei das Phănomen der Gebărde, denn die Erinnerung bedart der "Pathosformeln" (Ausdrucksgebărden - in der Komplementarität von Leib und Seele - der antiken Kunst, d. h. die festgehaltene Geste), in denen die Erfahrung 'kristallisiert' und gleichsam 'kondensiert' wird. Sie kơnnen weiter übermittelt werden, indem sie als Inhalte der Kunst wiederaufgenommen und im Kode der nonverbalen Zeichen (weiter-)zitient werden. Dem Korperausdruck, der Mimik und Gestik mißt Warburg eine quasi geistestechnische Funktion" bei. Die 'Autoplastik', die Ausdrucksformen und Gesten fungieren nun als anamnestische bzw. als mnemo(tech)nische 'Indizien'Spuren oder Signale, die auf jene im (kollektiven) Bewußtsein gelagerten 'Gedankenbilder' verweisen. (Vgl. Aby M. Warburg, Ausgewăhlte Schriften und Würdigungen I., hrsg. v. Dieter Wuttke, Baden-Baden 1992. Vgl. auch: Fritz Saxl, „Die Ausdrucksgebarden der bildenden Kunst", in: ibid., S. 419-431). Auch der Terminus der "semantischten Geste* (Mukařovskÿ) scheint solche mnemo(tech)nische Intention aufzuweisen.

62 Das Konzept der Intertextualität/Dialogizität als 'Gedächtnis' entwickelt im Anschluß an die Dialogizitätstheorie M. Bachtins Renate Lachman, die in der Intertextualitätsdebatte den text deskriptiven (produktionsästhetischen) Ansatz in einer Reihe von glänzenden komparativen Textanalysen vertritt (vgl. Renate Lachmann. Gedächtnis und Literatur. Intertextualität in der russischen Moderne, Frankfurt am Main 1990), weiterentfaltet und spezifiziert. R. Lachmann versteht die Intertextualität als spezifische Form der Sinnkonstitution, und sie erweitert den Dialogizitătsbegriff, den Bachtin in seiner Theorie lediglich auf die Romankunst bezieht (der lyrische Text sei monologisch) auch auf die Lyrik, wodurch ein völlig innovativer Zugang zum 'Paradigma der dialogischen Lyrik' ermóglicht wird. (Vgl. Renate Lachmann, .Dialogizităt und poetische Sprache", in: Dialogizităt, hrsg. v. R. Lachmann, München 1982, S. 51-62). R. Lachmann betrachtet die Intertextualităt als dominant semantisches Phänomen, das terminologisch im Termin der 'Doppelkodierung' festgemacht wird. Dieser Terminus signalisiert. daß die Sinnkonstitution "nicht durch den Zeictenvorrat des gegebenen Textes programmiert ist, sondern aut den eines anderen verweist" (vgl. R. Lachmann, Gedãchtnis und Literatur, a. a. O., S. 58). Während Bachtin aus seinem Dialogizitätskonzept die 'monologische' poetische Sprache, die nach seiner Meinung einen autoritären Status 'usurpiert', de facto ausschließt, verweist $R$. Lachmann auf die Ambivalenz zwischen Primär- und Sekundärkode. Als Sekundärzeichen manifestieren sich Z. B. die Tropen, die die semantische Ambivalenz des Textes potenzieren (das 
neuen Texte, und die Lektüre von Br̈ezinas Gedichten erweckt somit den Eindruck eines ununterbrochenen 'In-Gedächtnis-Rufens', eines déjà-vu-Erlebnisses. ${ }^{3}$ Mit der Unabschließbarkeit bzw. Offenheit des schöpferischen Prozesses ("Věcnè znova pỉemożeni, pisen̉ pisní pocináme", Vèčnè znova / Stets aufs Neve, 1,1; "Stets aufs Neve, überwunden, beginnen wir mit dem Lied der Lieder") korreliert die Offenheit und Unabschließbarkeit des Rezeptionsprozesses, denn es scheint nicht möglich zu sein, den (Text-) Sinn, der einer stăndigen Modifikation unterliegt, auf einen bestimmten Standpunkt zurückzuführen, von dem aus man inn 'zuverlässig' dechiffrieren könnte.

Bỉezinas lyrisches Werk, dem eine stark ausgeprägte Gesprächstruktur64 zugrundeliegt, kann man auch als einen ständigen Dialog des Autors mit sich selbst bzw. mit seiner Seele (Prod odvracís se, o slabá? I Warum wendest du dich ab, oh Du Schwache?; Kde jsem už slyšel... ? / Wo denn vernahm ich schon...?, Têlo / Der Leib u. a.), mit dem Tod (AŻ sednes za müj stül... I Wenn du an meinen Tisch dich setzt...) und. in einer Reihe von Gedichten - mit einer höheren Instanz, mit dem Subjekt des "Höchsten" (z. B. Slysím v duši I lch höre in der Seele; Kayż z lásky tvé... I Wenn aus deiner Liebe ..... Odpovedi / Antworten. Tisice srdci pelo v srdci tvém / Tausende Herzen sangen in deinem Herz; Za vsechno diky.../ Danke für alles...),65 lesen. Die intertextuellen Bezüge auf andere Texte kommen bei Biezina am häufigsten als 'kryptierte' Referenzsignale vor, die den angespielten Text indizieren. Es scheint, daß die Auto-Intertextualität bei Bíezina $u$. a. als Relation zwischen altem und neuem Text und als eine der dominanten

Sekundãrsprachliche fungiert als Replik auf das Primärsprachliche). Als Beispiel nennt $R$. Lachmann den manieristisch/barocken Concettismus, der den dialogischen Bezug durch die Verletzung und Deformation der Normsprache konstituiert. In den charakteristischen Figuren der Concetti (Oxymoron, Paronomasie, Antanaklasis etc.) gründet der "Doppelsinn als Zweifel-Sinn" die Doppelsinnstruktur der Sprache. Eine ăhnliche 'subversive' Tendenz zur Entautomatisierung der (offiziellen) Sprache kennzeichnet die Dichtung des Akmeismus (Dialogisierung sprachlicher Formen) und die des Futurismus (Redevielfalt bei Majakovskij). R. Lachmann unterscheidet zwischen 'metonymischen' und 'metaphorischen' Relationen bzw. 'Kontiguitäts'- und 'SimilaritätsRelationen', zwischen Texten, wodurch die intertextuellen Relationen in den Zusammenhang mit der ihetorischen Tropenkonzeption gebracht werden. Die Kontiguitätsrelationen liegen vor, wenn "ein konstitutives Merkmal eines fremden Textes (seine thematische, sequenziell-narrative oder stilistische Ebene betreffend) im manifesten Text wiederholt wird, das den Referenztext als ganzen evoziert, oder wenn eine signifikante Textstrategie eines fremden Textes repräsentiert wird, die den literarischen Text zu einer Poetik, zu einer literarischen Konvention mit spezifischen stilistischen, thematischen oder narrativen Mustern aufruft" (ibid. S. 60-61). Die Similaritätsrelationen realisieren sich hingegen "nicht in zitierten Elementen oder Verfahren, sondern im Aufbau von analogen Strategien, die ihre Entsprectungen in einem bestimmten Referenztext haben" (ibid. S. 61).

63 In diesem Sinne, nämlich als "Gedăchtnisspiel" und "Erinnerung", versteht die Perzeption literarischer Texte Charles Grivel (Ders., . Serien textueller Perzeption. Eine Skizze*, in: Dialog der Texte. hrsg. v. W. Schmid, W.-D. Stempel. Wiener Slawistischer Almanach. Sonderband 11. Wien 1983. S. 53-83). Das Phánornen der Intertextualitat interpretient er als Prozeß des Implizierens, als sukzessive Reduktion des impliziten im Text. Er unterscheidet die Kategorie der "Ableitungen" ("ein Text entsteht aus einem bzw. mehreren Texten, die seine "Quellen" darstellen"), der "Verweise" ("ein Text weist auf einen bzw. mehrere andere Texte hin, die "zitiert" werden"), der "Variationen" ("ein Text moduliert ein Element aus einem beliebigen begrenzten Intertext") und jene der "Serien" (ibid. S. 65-66). Die 'sekundären' Texte (Texte der Nachfolge) fungieren quasi als 'Kondensate' der 'primären' Texte. Der Intertext bedeutet den Prozeß des Implizierens, den Grivel als das Problem der Verstăndlichkeit von Texten denkt (ibid. S. 60). Er führt den enwähnten "aleatorischen" Begriff der "Serien" ein, worunter "thematisierte Stränge" samt ihrer Bewertung auf bestimmte analogische Bündel von Motiven (ebda. S. 64) verstanden werden. Solch eine "Serie" umfaßt ein Bündel von verwandten Texten, die ein identisches Thema variieren. In diesem Konzept wird also jeder Lektüre (a priori) der intertextuelle Status imputiert. Die Kategorie der "Serien" ist offensichtlich (ähnlich wie die der "Architextualität" von Genette) auf die Vorstellung einer Äquivalenzrelation zwischen Texten zurückzuführen. die auf der Realisierung von gattungstypischen Merkmalen basieren.

64 Damit korrespondiert auch die Präferenz der Poetik der religiösen Sprache (Gebet, Psalm. Beichte, Predigt, Hymnus). Zur Gattungspoetik der religiösen Sprache bei Bỉezina, vgl. die Darlegung in Kap. 2.2.1.

65 Zwei in die Gesamtausgabe nicht aufgenommene Gedichte heißen: Co chceš mi rici? (Was willst du mir sagen?) und Vim, dobrý jsi (Ich weiß, gütig bist du). 
sinnkonstitutiven Strategien fungiert. 66 In diesem Sinne ist auch der Aspekt des 'SichErinnerns' zu verstehen, nämlich als ein sinnkonstitutiver Faktor, der auch die Unabschließbarkeit des Werkes garantiert und die Möglichkeit einer Fortsetzung des (zukünfitigen) 'Weiter-Schreibens' bzw. 'Weiter-Denken' offen läßt.

Zusammenfassend kann man sagen, daß die Auto-Intertextualität bei Bïezina zwei Hauptfunktionen aufzuweisen scheint: als Gedächtnis/ Erinnerung und/als Dialog, wobei der mnemonische Akt wiederum zwei spezifische Leistungen zu erbringen hat: 1) die Erinnerung an bereits konstituierte und 'gespeicherte' Gedanken-Bilder und deren Umkodierung. Umkontextierung. Reformulierung bzw. Revokation im ständigen anamnestischen Dialog mit sich selbst, d. h. die Intertextualität fungiert als konstitutiver Faktor des Sinnaufbaus des eigenen Werkes (produktionsästhetischer Aspekt) und 2) die daraus resultierenden Konsequenzen für den Rezipienten, $d$. $h$. die Bewahrung der 'Gedankenbilder' im Gedächtnisspeicher der "Text-Architektur' 67 und deren Fortsetzung im zukünftigen Dialog mit zukünftigen "Brüdern" (wirkungs- und rezeptionsästhetischer Aspekt):

"Vécnè znova, premoženi, piseñ pisni počináme /.../ // Na sta slunci zapadalo v dálku klasủ nedohlednou, / ale den a léto nad véky se nešeři, / a až naše píseñ dozni, neznámi se bratři zvednou, I v struny naše utišené ruce jasné uderî" (Véčnè znova... I Stets auts Neue.... I. 1, III, 1. 4; "Stets aufs Neue, überwunden, beginnen wir das Lied der Lieder /.../ Hundert Sonnen untergingen in der Ähren grenzlos Wogen, / doch der Seelen Tag und Sommer schimmert nicht im Zeitengrau'n. / und bis unsere Lieder verklingen, unbekannte Brüder kommen, / und in unsere stummen Saiten schlagen helle Hānde ein").

66 Im Zusammenhang mit dem "exzessiv monologischen Charakter" des diabolischen Diskurses definiert Aage A. Hansen-Love (Der nussische Symbolismus. System und Entfaltung der poetischen Motive, Bd. I, Diabolischer Symbolismus, Wien 1989, S. 459fi.) die Funktion der AutoIntertextualităt in den Gedichten der russischen Symbolisten der neunziger Jahre (insbesondere bei Brjusov und Bal'mont). Wie der Autor feststellt, handelt es sich eigentlich um (autointertextuelle) Konvergenzen zwischen (parallel) ablaufenden Monologen, die die Identităt der Sprecher nur simulieren. Den 'diabolisch'-dekadenten 'Dialog' führt der Dichter eigentlich nur mit einem anderen Aspekt (bzw. mit anderen Aspekten) seiner Selbst. Die hypertrophierte Autokommentierung (sowie Autokommunikativităt) spiegelt gleichzeitig den 'Narzissmus' des 'egozentrischen,' diabolischen Autors wider. Der (Auto-)Intertext wird de facto zu einem 'katoptrischen Kabinett', in dem der autistische Kunst-Schopfer nur sich selbst reflektiert.

67 Renate Lachmann verweist auf die Vorstellung der Akmeisten über die aus den "Stein. Worten" erbaute Text-Architektur, die als "dynamischer andauernder Zeitspeicher" gedacht wird. In der Vorstellung Osip Mandel'stams ist diese "Text-Architektur" mit der gotischen Kathedrale verbunden. (Vgl. Renate Lachmann, .Vergangenheit als Aufschub: Die Kulturosophie der Akmeisten", in: Dies.: Gedächtnis und Literatur, Frankfurt am Main 1990, S. 368). Das architektonische Erhabenheitsmotiv bei Mandel'stam, die gotische Kathedrale, erwāhnt auch Aage A. Hansen-Löve in seiner Studie Zur Typologie des Emabenen in der russischen Moderne', in: Poetica, Bd. 23, 1991, S. 190-191. Die Vorstellung der Kathedrale (_chrám") als archi-tektonischer '(Zeit-)Speicher' der Kultur, der die "Zeiten überdauert", spielt auch in Bïezinas Werk, vor allem in seinem vierten Gedichtzyklus Stavitelé chrámu (Baumeister am Tempel, 1899) eine nicht unbedeutende Rolle. Das "Wort" ist für Mandel'štam nichts anderes als der "Felsstein", der sich erst „unter den Hānden des Baumeisters /.../ in Substanz /.../ verwandelt" (Utro akmeizma, 1913). Wie ein Baumeister hat auch der Dichter sein Material in die Sphäre der Leichtigkeit, der Schónheit und des Geistes zu erheben und in (poetische) Substanz zu verwandeln. Dieses "Bauen" bedeutet für Mandel'stam, "gegen die Leere zu kämpfen, den Raum zu hypnotisieren", den Stein "ins Kreuzgewölbe" (des Kulturtempels) einzusetzen. 


\title{
2. DEKADENTER SYMBOLISMUS
}

\section{Gedichtzyklus Tajemné dálky (Geheimnisvolle Fernen) 1895 ÄSTHETISCHE EXISTENZ - PRINZIP DER IRREALISIERUNG}

\author{
„Já. toữici po rafinované a etherické stravé francousských dekadentů \\ a sumbolistü /.... ..Jsem sun moderni dobv. fin de siècle /.... Jsem \\ básnikemsvêtel, tónù a tajemného sivota ... A stínu a smrti. I..J \\ rakové nás vychovává Umèni: děri nervosni. chorobnè citlivé před \\ mräivin dechem surově Reálniho".
}

\begin{abstract}
"Ich. der sich nach der raffinierten und ätherischen Nahrung der französischen Dekadenten und Symbolisten sehnt /... Ich bin ein Sohn der modernen Zeit. fin de siecle l...J. Ich bin ein Poet der Lichter. der Töne und des geheimnisvollen Lebens... Und der Schatten und des Todes. I.t so erzieht uns die Kunst: nervöse Kinder, gegen den eisigen Hauch des hrutal Realen krankhafi empfindlich".
\end{abstract}

Otokar Březina an František Bauer

(XII. 1892; 21. V. 1893; 20. XII. 1894)

Die Bedeutung Otokar Br̈ezinas beruht heute in erster Linie auf seinen fünf Gedichtzyklen, die in knapp einem Jahrzehnt (zwischen 1892-1901) entstanden sind. Die Frage nach der Entwicklung Biezinas vom Autor einiger Novellen im Stil des GenreRealismus (bis 1892) zum Dichter eines mit "in den neunziger Jahren einzigartiger Konsequenz und Vollkommenheit realisierten" 68 symbolistischen Werkes wird in der bohemistischen Symbolismus-Forschung oft aufgeworfen. 69 Bíezina, der vor 1892 von seiner Berufung zum Romancier überzeugt war, 70 verfaßte zwischen 1890-92 einen sozial-psychologischen Roman, dessen Manuskript er jedoch vom Verleger zurückforderte und verbrannte, da ihn das Werk künstlerisch nicht mehr befriedigte. ${ }^{71}$ in diesem Manuskript-'Autodafé' kann man Brezinas manifeste Abrechnung mit dem Realismus sehen, dessen Tendenz zur erschöpfenden veristischen Darstellung, zum Empirismus usw. Brezina nach 1890 als verengend ablehnte. ${ }^{72}$ Diese 'Umorientierung' kam allerdings

68 Vgl. M. Ćervenka. .Březinovské úvahy”, in: Symboly pisnè a mýty, Praha 1966. S. 51.

69 Man versuchte diese Umorientierung $u$. a. mit Hilfe von individualpsychologischen Spekulationen zu deuten (der Tod der Eltern innerhalb einer Woche, die unbefriedigende Situation des privaten Lebens usw.), vgl. Z. B. Jaroslav Durych, Josef Stanék, .Otakar [sic] Bł̉ezina (18681918)". Płerov 1918 Vgl auch: Jaroslav Durych. .Otokar Błezina", in: Rozpravy Aventina, 4, 1928-1929, Nr. 1. S. 1. Vgl. auch: Pavel Fraenkl. .Básnický typ Otokara Bỉeziny", in: Rozpravy Aventina, 4, 1928-29, Nr. 1, S. 3, 5; Nr. 2, S. 16-17; Nr. 3, S. 26-27; Nr. 4, S. 38-39.

70 Vgl. O. Bỉezina, Dopisy Františku Bauerovi, Praha 1929, S. $112 f f$.

71 Vgl. Emilie Lakomá, Úlomky hovoru s Otokarem Bł̌ezinou, Brno 1992, S. 176.

72 An Anna Pammrová. Dopisy O. Březiny Anné Pammrové z let 1889-1905. Praha 1931. Brief vom 16. VII. 1891) schreibt Bỉezina: $\%$.../ moji literárni miláčci se zménili /.../ zajimaji mne dnes dekadenti záríci svou formou a myšlenkami jemnẻ odstinẻnými, symbolisté, jimź cilem jest stihnouti prchavý dojem a jejichž verše zaznivaji v duši tajemnou hudbou. Verlaine, Mallarmé, Moréas, Baudelaire i Allan Edgar Poe". (")../ meine literarischen Lieblinge haben sich geändert I.../. heute interessieren mich die Dekadenten mit strahlender Form und fein nuancierten Gedanken, mit geheimnisvoller Musik. Verlaine. Mallarmé. Moréas, Baudelaire und Allan Edgar Poe".) Und ein Jahr später an seinen Jugendfreund František Bauer: (Brief vom 3. IV. 1892): "My mladi rostem velice rychle; nedávno shodili jsme romantický havelok a oblekli striizlivy realisticky svrchnik a uż je nám pomalu i v samém tom realismu tésno /.../. Prijidou také chvile duševniho vysileni /.../ kdy bych nejradéji hođil do plamenu všecky rukopisy, všecky knihy, a kdyby bylo możno i všecky myšlenky." ("Wir, die junge Generation, wachsen sehr schnell; unlängst haben wir den romantischen Havelock abgelegt und den nüchternen realistischen Überzieher angezogen und schon fühlen wir uns in diesem Realismus eingeengt $/ . . /$. Es kommen Augenblicke der geistigen Erschöpfung I.../, da würde ich am liebsten alle Manuskripte, alle Bücher, und wenn es 
nıcht unvermittelt und überraschend; 73 sie konnte durch die Koexistenz der Spätphase des Realismus (um 1880) mit der Frühphase des Symbolismus antizipiert bzw. initiiert werden. ${ }^{74}$ Eine ähnliche Entwicklung bekundet sich auch im Werk anderer Repräsentanten der tschechischen (spät-)realistischen Erzählkunst (z. B. Vilém Mrštik oder auch $A$. Sova). 75

Ein wichtiges Indiz für die Umorientierung Brezinas ist die Betonung der "magischen", bannenden "Kraft der Kunst", die Brezina in der Korrespondenz (ab 1892) immer wieder in den Vordergrund stellt: "Něcekám ničho od života, poněvadż múj život mi nepatrii. Patři uměni, jehož jsem nedokonalým médiem". ("Vom Leben erwarte ich gar nichts, denn mein Leben gehört mir nicht. Es gehört der Kunst, deren unvollkommenes Medium ich bin") ${ }^{76}$ Die Kunst (Briezina spricht von "l'art pour l'art'،) bezeichnet er als "Höhepunkt der individuellen Kraft", dabei meint er solche Kunst, die aus "der Notwendigkeit zu schaffen erwächst" ("umëni vyrưstajici z potřeby tvořiti“). 77 in der Autocharakteristik der ersten symbolistischen Gedichte, die im gleichen Jahr veröffentlicht wurden, spricht Brezina vom "berauschenden, verführerischen Zauber der leidenschaftlichen Musik der neuen Verse" ("opojné. svưdné kouzlo vášnivé hudby novẻ napsaných veršü). ${ }^{78}$ Diese Charakteristik signalisiert ein neues Verständnis der (Referenz-)Funktion der Dichter-Sprache und der Kunst kat exochēn. 79 Die Hinwendung zur Verssprache, zur imaginativen Wortkunst, 80

möglich wäre auch alle Gedanken in die Flammen werfen.") Vgl. O. Br̈ezina, Dopisy Františku Bauerovi, Praha 1929, S. 165.

73 Bỉezina war sich der heftigen Dynamik in der Entwicklung der Stile bzw. Richtungen in den neunziger Jahren sehr wohl bewußt und 'rechnete' quasi mit einer derartigen 'Umorientierung' seines eigenen Stils: $\%$.../ kde pak uż za dvẻ léta zase budut" $(\% / . . /$ wo aber werde ich in zwei Jahren wieder sein!"), schreibt er an Bauer (vgl. ibid., a.a.O) im Zusammenhang mit seinem realistischen Roman, der damals (1892) erst in zwei Jahren verlegt werden solte.

74 Die These von der schöpferischen Entwicklung $O$. Bỉezinas aus der Logik des Spätrealismus vertritt Z. B. Jaroslava Janácková. Román mezi modernami, Praha 1988, S. 24ff. I. R. Dering-Smimova, I. P. Smimov: „Realizm: diachroničeskij podchod", in: Russian Literature, 8 , S. 1-39. Dabei wird der Realismus als "primärer" Stil, der Symbolismus dagegen als "sekundärer" Stil betrachtet. Zur Unterscheidung in "primäre" und "sekundäre" Stile in der Konzeption der diachronen Semiotik I. P. Smirnovs vgl. den Forschungsbericht von Aage A. Hansen-Löve, Semantik der Evolution und Evolution der Semantik. Ein Forschungsbericht zu I. P. Smimovs Modell einer diachronen Semiotik", in: Wiener slawistischer Almanach, 6, 1980, S. 131-190. I. P. Smirnov entwickelt u. a. die Konzeption einer kultur-bzw. literaturtypologischen Evolution und deren Gliederung (im Anschluß an Lichačev) in primäre (zu denen Romanik, Renaissance. Klassizismus, Realismus, Postsymbolismus u. a. gehören) und sekundäre Stile (Gotik, Manierismus/Barock, Romantik. Symbolismus und die zeitgenössische Kunst) oder Kunstsysteme. Die literarische Evolution 'gliedert sich' in einige Megasysteme (Renaissance-Barock, Klassizismus-Romantik), die wiederum zwei evolutionäre Stadien - ein früheres und ein späteres Stadium - aufweisen. Nach Smirnov bildet das System des Symbolismus zwei Subsysteme: die Frühphase der Dekadenz und die Spätphase des "eigentlichen" Symbolismus. Der Realismus (primärer Stil) bildet den ersten 'Pol' einer Megaperiode, deren zweiten 'Pol' der Symbolismus (sekundärer Stil) bildet. Während die Anfagsphase (die "analytische Phase", etwa zwischen 1840. 1850) des Realismus mit der Romantik koexistiert, tangiert seine Endphase (die "synthetische P.. etwa um 1880) den (Früh-)Symbolismus. (Ibid. S. 1381). Nach Smirnov erlangt im Symbolismus jedes Ding einen zeichenhaften Charakter; im Frühsymbolismus sind alle Zeictien lediglich auf der Grundlage eines bestimmten Textkorpus dechiffrierbar. Kennzeichnend ist ebenfalls die 'Musikalisierung' des künstlerischen Zeichens. Im "eigentlichen" Symbolismus dominiert die Vorstellung eines Erfahrungsuniversums (als Analogon der "semiotiscten Umgebung"). Vgl. A. A. Hansen-Löve, ibid., S. 140-145. Vgl. auch: I. P. Smirnov. .Chudožestvennyj smysl i evoljucija poeticeskich sistem". Moskva 1977. S. 54f.

75 In diesem Zusammenhang könnte man auch die (psycho-)naturalistische Prosa eines der Hauptrepräsentanten der tschechischen Dekadenz Jirii Karásek ze Lvovic erwähnen.

76 Vgl. O. Bíezina, Dopisy Františku Bauerovi. Praha 1929, S. 191 (Brief v. 21. V. 1893).

77 Vgl. ibid., S. 167ff. (Brief vom 13. IX. 1892). In diesem Brief bezeichnet Bïezina die Kunst als "Heilmittel" gegen die "Misere des Lebens" (S. 171). Im Brief vom 1. XII. 1892 spricht Bíezina bereits von "krankhaften, nervösen und schweren Versen" seines "neuen Schaffens" (S. 176).

$78 \mathrm{Vgl}$. a.a.O. S. 171

$79 \%$ uméni neužitečné, exquisitni, vysoké, stigmatisujici nejvyšši duševni body $/ . . . /$ (" $/ . . /$ eine nutzlose, exquisite, hohe Kunst, die die höchsten geistigen Punkte stigmatisiert l... $r$; vgl. $O$. Br̉ezina. Dopisy Františku Bauerovi, 1929, S.167). "Nejde mi o to. abych čtenáre bavil; uméni, jak 
führt Br̈ezina auf die Fähigkeit der Dichtung die Ideen zu "kristallisieren", zu "symbolisieren" und zu "verdichten" zurück: "Proto dnes piši výhradně veršem, kde toto zhuštěni ideji nalézá nejpriznnivêjši terén" ("Daher schreibe ich heute ausschließlich in Versen, wo die Verdichtung der Ideen das geeigneteste Terrain findet"). ${ }^{81}$ Die Begriffe "Musikalität", "Vibration" "Zauberkraft" oder "Suggestivität", mit denen Brezina die intendierte Wirkung seiner symbolistisch-dekadenten Gedichttexte zu spezifizieren sucht, deuten auf die Tendenz zur Reduktion der Kommunikativität der poetischen Sprache hin. die 'zugunsten' der "Musik der Ideen" neutralisiert werden soll. Wegen ihrer Abstraktheit. Athematizität und Referenzlosigkeit scheint die Musik(alität) prädestiniert zu sein, auch die tiefsten seelischen Regungen und die un(ter)bewußten Zustände auszudrücken bzw. - im Hinblick auf die wirkungsästhetische Funktion - den Wahrnehmenden in eine "andere Welt" ("jiný svěr") zu versetzen.82 Die Außenwelt - ihr Wirklichkeitsstatus - wird als bloßes

dneska je citim celou duši, neni a nebude potravou davu I... $/$ ("Es geht mir nicht darum, den Leser zu amüsieren; die Kunst, so wie ich sie heute mit meiner ganzen Seele fühle, ist und wird nie und nimmer die Nahrung der Meute sein I... ; ibid. S. 181). "Nezáleži mi na potlesku masy" ("Auf den Beifall der Masse lege ich keinen Wert; ibid. S. 191)

80 Die Unterscheidung "imaginative Wortkunst" - "fiktionale Erzählkunst" schlägt Aage A. Hansen-Löve in seiner Studie "Die .Realisierung" und .Entfaltung" semantischer Figuren zu Texten", in: Wiener Slawistischer Almanach, 10, 1982, S. 2081., 231-232, vor. Dadurch soll die tradierte Gegenüberstellung von "Lyrik" und "Prosa" ersetzt werden. Laut Aage A. Hansen-Löve ist das imaginative (das Sprachdenken der Wortkunst determinierende) Vorstellen an das un(ter)bewußte Sprachdenken und an die inm inhärenten Primärprozesse (wie Verdichtung. Verschiebung. Symbolisierung) gebunden. Das Imaginative der Wortkunst kann das archaisch. mythische Denken (sowie die unbewußten Denkprozesse) bewußtseinsgenetisch wiederherstellen, wohingegen das fiktionale Vorstellen an das bewuBte Denken und an die 'Aktivität' des reflektierenden Ich-Bewußtseins (seine Fähigkeit zur Identifikation und Projektion eigener Denkkategorien in die außersprachliche Realität) gebunden ist. Im fiktionalen Text dominiert die interpersonale (konventionelle) Kommunikation, wogenen die imaginative Wortkunst die intrapersonale Verständigung zwischen unbewußten und bewußten Prozessen modelliert.

\section{Vgl. Dopisy O. B. Frantisku Bauerovi, Praha 1929. S. 181}

82 Mit der 'Musikalität' korrespondiert in Bỉezinas ersten Gedichten auch die Virtuosität und Exaktheit der Versform. Das charakteristische Metrum dieser Gedichte, der sechsfüßige jambische Alexandriner, gilt als eines der anspruchsvollsten und kompliziertesten Metren der tschechischen Prosodie überhaupt. Die limitierte Anzahl der Silben erzwingt im Tschechischen eine strenge Lexikwahl, die den Dichter vor den Konflikt zwischen der überindividuellen technischen Vollkommenheit und der individuellen Wortsemantik stellt. (Vgl. hierzu: M. Cervenka: "Bíezinüv verš", in: Ceská literatura, 13. 1965, S. 113ff.). Auf den für Les Fleurs du mal charakteristischen Alexandriner bezieht sich Br̈ezina explizit in seiner Korrespondenz: "Jak zvonil mi Charles Baudelaire tvrdými svými alexandriny o duši v pủvabném tichu lesnich zákouti. Tvrdými alexandriny, $v$ nichż zvoni kov o kov, litina, bronz, cin. méđ', tẻżce zbarvené nerosty, jaspis, achát. mramor a opál. tento zázračnỳ kámen, který v sobé pièlévá svétlo" (vgl. O Bíezina. Dopisy Františku Bauerovi. Praha. 1929. S. 167-170; "Wie klang Charles Baudelaire in meiner Seele auf mit seinen harten Alexandrinern in zauberhafter Stille der Waldeinöde. Mit harten Alexandrınern, in denen Metall an Metall läutet, das Gußeisen, die Bronze, das Zinn, das Kupfer, die stark gefärbten Mineralien, der Jaspis. Achat, Marmor und Opal, dieser wunderbare Stein, der das Licht in sich umgießt".) Die erste ausführliche Untersuchung der Bezięhung Baudelaire - Br̈ezina liefert der Aufsatz .Biezina a Baudelaire" von Felix Vodička (in: Casopis Národniho Musea, 197 lodd. duchovëđný]. 1933, S. 86-104). Vodickka verweist auf die einzelnen Aspekte der Rezeption der Lyrik von Baudelaire in der tschechischen Dichtung der achtziger und neunziger Jahre des 19. Jahrinunderts und betont vor allem den Einfluß der Verssemantik von Les Fleurs du Mal auf den dekadenten Symbolismus von Biezina. Vodicka nennt den Rhythmus (die Dominanz des alternierenden Zwölf- oder Dreizehn-Silblers, des Alexandriners), die Syntax, die Metaphorik und Motivik ( $v$. a. die zahlreichen liturgischen Motive), die exklusiven 'grammatischen' Reime auf Fremdwörter ("Eliás-plás", "nassát-passát", "agonii-piji") etc. Laut Vodička ist die Parallele zwischen Baudelaire und Biezina von rein artistischer, assthetischer Natur. Im Hinblick auf die Ästhetik und die Weltanschauung der beiden Dichter lassen sich allerdings auch gravierende Differenzen feststellen. Baudelaire glaubt an die Fähigkeit der Kunst (seiner 'Alchemie') selbst das Morbide. Perverse. Häßliche in das Kunst-Schöne zu verwandeln ("Car j'ai de chaque extrait la quintessence, I Tu m'as donné ta boue et j'en ai fait de l'or". Vodička zitient den Vers: "De Satan ou de Dieu, qu'importe /...". Biezina postuliert zwar die ästhetische Existenz in einer autonomen Kunst-Welt, doch die für die Dekadenz signifikante Diabolisierung des Kosmos, der Agnostizismus usw.. scheinen seiner Poetik fremd zu sein. Die wohl wichtigsten Aspekte der Rezeption Baudelaires in der Lyrik von Biezina (ob Differenzen oder Interferenzen) läßt Vodicka außer Acht: 
Produkt der Imagination, als Sinnestäuschung und Halluzination angezweifelt.83 An die Stelle der rhetorisch überzeugenden Argumentation tritt die "Suggestion" (der "verführerische Zauber" I "svüdné kouzlo"; siehe oben) der Verse. 84 "Auch dieses Verfahren zielt auf die von Bïezina postulierte "sráżeni" ("Verdichtung") und "syntetisaci" ("Synthetisierung") der (dichterischen) Ideen hin. 85 Die Kunst (sogar der Kunst-Tod) übernımmt auch die noetische Funktion; das Erreichen der absoluten Erkenntnis der immanenten Welt durch den Tod, der aporetisch als Bedingung der völligen Entgrenzung der Erkenntnis apostrophiert wird, ist das Thema eines der ersten Gedichte Brezinas: Modlitba večerni (Das Abendgebet, 1892).

Bei der Formulierung der neuen Kunstauffassung in kleinen poetologischen 'Briefkommentaren' zu eigenen Gedichten bezieht sich Biezina explizit86 auf die Konzeption des "Synthetismus" von F. X. Salda (1891-92), die - ursprünglich als Replik gegen die von T. G. Masaryk ${ }^{87}$ vertretene mechanische Unterscheidung von Kunst und Wissenschaft konzipiert $\cdot$, die Induktivität der Wissenschaft einerseits und den

d. h. 1) Die Berūhrungspunkte mit dem Naturalismus; dazu gehơrt das Postulat, die Kunst müße sich der Wirklichkeit öftnen und die 'Aktualität' des modernen Lebens reflektieren (vgl. Manfred Gsteiger, Französische Symbolisten in der deutschen Literatur der Jahrthundertwende 1869-1914, Bern-München 1971. S. 20f.), die für die Poetik von Baudelaire von großer Relevanz, für die von Bỉezina hingegen irrelevant sind. 2) Die im Symbolismus einflußreiche Theorie der "Correspondances" (s. dazu Kap. 2.3.2) der sowohl bei Baudelaire als auch bei Brezina (vor allem in TD) eine wichtige Funktion zuerkannt wird. 3) Die Faszination Baudelaires und Biezinas von dem Anorganischen und vor allem Kristallinen, die sowohl in Les Fleurs du Mal als auch in Tajemné dálky (Geheimnisvolle Femen) auf der Ebene der Motivsemantik eine konstitutive Rolle spielt. Vgl. dazu: Ulrich Johannes Beil, Die Wiederkehr des Absoluten. Studien zur Symbolik des Kristallinen und Metallischen in der deutschen Literatur der Jahrhundertwende. (speziell Kap. .Baudelaire und die Ambivalenz des Kristallinen") Frankfurt am M. 1988, S. 91-144.

$83 \% /$ shledávám všechen vnějši svět jako pouhý klam vlastnich mých smyslü" ("/../ die ganze Außenwelt erscheint mir als bloße Sinnestäuschung"). Vgl. Dopisy O.B. Frantisku Bauerovi. Praha 1929. S. 167.

84 Solche Wirkung wird auch den synästhetischen Erlebnissen zuerkannt (Vünè zahrad mé duše I Der Duft meiner Gärten Seele: Vonné soumraky / Wohlduftende Dämmerungen), die als metaphorische Symbole entfaltet werden. Hierin muß allerdings betont werden, daß es zwei Arten von Rhetorik gibt, je nach der Auffassung der persuasio-Funktion: 1) klassizistische Rhetorik, die durch rationale, an das Urteilsvermögen appellierende Argumentation überzeugen will, während die 2) manieristische Rhetorik 'überlisten', überreden und unter der Ausschaltung des rationalen Urteilsvermögens 'vertühren' will. Die Mittel, deren sich die manieristische Rhetorik bedient, sind die aus der Dekadenz wohlbekannten 'Suggestion'. 'Hypnose'. 'Faszination', 'Evokation' usw.. deren Ziel es ist, das rationale Urteilsvermógen außer Kraft zu setzen und den Hörer in das magische Reich der Kunst zu vertühren. Die Konzepte und Funktionen der Rhetorik (am Beispiel der polnischen und russischen Barock-Dichtung) untersucht Renate Lachmann in der Aufsatzsammlung zu diesem Thema: Die Zerstörung der schönen Rede. Rhetorische Tradition und Konzepte des Poetischen. München 1994.

85 Diese Intention formuliert Biezina explizit in einem Bnef an Bauer (vgl. a.a.O., S. 181): \%...I modemi báseñ uzavirá určity komplex myšlenek, obrazủ, nálady, barev, již prožije. vsaje, otiskne v sobé jen duše pribuzná. schopná meditace, vzletu a nadšeni; każdé slovo, kaźdý obraz musi bỳt studován, odhadnut, odkryt, chutnán, váżen, pojat. Jako byl umélcem $v$ inspiraci fixován. prohlouben, v mosaiku rythmú zasazen. Proto dnes piši vỷhradné veršem, kde toto zhuštěni ideji nalézá nejpriznivéjši terén". (".../ das moderne Gedicht wird von einem bestimmten Komplex der Ideen und Bilder, der Stimmung, der Farben abgeschlossen, die lediglich eine verwandte, der Meditation, des Aufschwungs und der Begeisterung fähige Seele erlebt. aufsaugt und in sich abdruckt; jedes Wort, jede Wendung, jedes Bild muß studiert, abgeschătzt, aufgedeckt, gekostet, gewogen, aufgefaßt werden. So wie es vom Künstler in der Inspiration fixiert, vertieft und in das Mosaik der Rhythmen eingesetzt wurde. Daher schreibe ich heute ausschließlich in Versen, in denen diese Verdichtung der Ideen das geeigneteste Terrain findet.")

86 -Salda uż dnes je jeden z prvnich našich kritikủ, jediný. který dovede dýchati duši uměleckého dila; nečetl jsem jak żiv v naši rẻeci pronikavẻjši studii o modemi poesii jako v Saldovẻ mistrné .Synthesi v uméni" $I . . F$. ("Salda ist heute schon einer der ersten unter unseren Kritikern, und der einzige. der mit der Seele des Kunstwerkes atmen kann; solange ich lebe habe ich in unserer Sprache keine so eindringliche Studie über moderne Poesie gelesen, wie in Saidas meisterhafter "Synhtese in der Kunst ${ }^{*}$ ). Vgl. a.a.O.. S. 183.

87 Vgl. hierzu: Rio Preisner, .T. G. Masaryk v zrcadle F. X. Saldovy kritiky let devadesátych", in: Svédectvi, XVII, Nr. 66, S. 283-318. 
"Synthetismus", die Strukturiertheit und Suggestivität der Kunst(-Werke) andererseits, betont. Zu den anderen wichtigen Aspekten Saldas ästhetıschen Programms Synthetism v novém uméni (Der Synthetismus in der neuen Kunst), ${ }^{88}$ zählt die Nivellierung von 'Inhalt' und 'Form' zugunsten des 'Ausdrucks', der alle Symptome der Individualität des Dichters, seiner 'Psyche', integrieren und "synthetisieren" soll und der auch als Garant der "Synthese" des Kunstwerkes fungiert. 89

Die Tendenz zur 'Neutralisierung' der Kommunikativität der Sprache zugunsten der 'Suggestion' und 'Musikalität' geht bei Brezina Hand in Hand mit der in der Korrespondenz immer wieder explizit artikulierten Sehnsucht nach der Isolierung von der Außen-Welt, nach der Flucht in die Abgeschlossenheit der inneren Welt, $d . h$. in das Kunst-Reich, das als faszinierende Sphäre des (Kunst-)Traumes und des (Kunst-)Todes konnotiert ist. Eıne Intention, die die Irrealisierung-Semantik der in den ersten Zyklus aufgenommen Gediche in besonderer Weise prägt. Die Existenz des Kunst-Schöpfers wird auf die ästhetische Existenz im Kunst-Reich, auf den 'Dienst' am Kult der Kunst reduziert. 90 Das dichterische

88 Vgl. F. X. Salda .Synthetism v novém uměni" (1892; in: Boje o ziť̌ek. Praha 1937. S. 11 54.). Salda prägt hier den Begriff "symbolisace" (Symbolisierung), den er - im Anschluß an die Philosophie Kants und an die Kunstauffassung Goethes - als "abstrakt-philosophisches Streben" nach der symbolischen Hypostase der reinen Ideen (ibid. S. 44-45) interpretiert. Er versucht den "zu begrenzten". "zu dichotomen" (S. 46) Begriff des "Symbolismus" dem des "Synthetismus" zu subordinieren, den er als epistemologische Basis und gleichzeitig als Methode der "integralen Kunst" betrachtet, da der "Synthetismus" alle Formen der Noesis (die empirischen, rationalen. ideellen) 'synthetisieren' kann. Mit anderen Worten wird hier der Symbolismus'synthetismus" als Welterkenntnis durch (poetische) Bilder definiert. Durch den Akt der "Symbolisierung" erlangt das Wort den Status eines möglichst transparenten "symbolischen Zeichens", das die "Substanz" ("Podstata") nicht (mehr) verdeckt. Denn als das finale Ziel der Kunst postuliert Salda die transzendente Idealität (ibid. S. 52-53). Diese Konzeption der Vergeistigung der künstlerischen Substanz scheint mit jener der russischen Symbolisten der neunziger Jahre (vor allem bei Mereżkovskij oder $V_{j}$. Ivanov) zahlreiche Berührungspunkte aufzuweisen. (Vgl. hierzu: Jurij Striedter, .Transparenz und Verfremdung. Zur Theorie des poetischen Bildes in der russischen Moderne", in Immanente Ästhetik, Lyrik als Paradigma der Moderne. Poetik und Hermeneutik. München 1966, S. 268f). Saldas neoidealistische Konzeption vom "Synthetismus in der neuen Kunst" richtet sich zwar vehement gegen Positivismus und Scientismus des späten neunzehnten Jahrhunderts, ohne jedoch auf wissenschaftliche Aspirationen zu verzichten. Daher verwendet Salda - im Anschluß an Hennequin - den Terminus der "Estopsychologie", worunter er die Synthese von bestimmten Besonderheiten des Kunstwerkes und bestimmten psychologischen bzw. Soziologischen Besonderheiten versteht. Die estopsychologische Auffassung des Kunstwerkes definient dieses als 'Zeichen'. Die estopsychologische Analyse definiert Salda als ein spezifisches Verfahren, das von der Untersuchung der "äußeren Zeichen" (d. $h$. der formalen 'Zeichen') zu der der "inneren Zeichen" (d. h. der 'psychischen') führt. Die Saldasche Interpretation der 'estopsychologischen' Konzeption von der 'zeichenhaften' Beschaffenheit des Kunstwerkes antizipiert die semiotische Auffassung des Kunstwerkes im Sinne von Mukaroovský (vgl. seine Abhandlung ."'art comme fait sémiologique". in: Actes du Huitième Congrès international du philosophie à Prague 2.7 septembre 1934. Praha 1936, S. 1065-1072). Daruber hinaus sollte die 'estopsychologische' Auffassung des produktiven Prozesses auch die von Salda postulierte Synthese von Kunst und Leben im Sinne der 'Lebenskunst'-Konzeption ermöglichen. Von großer Bedeutung war ebenfalls die von Salda entworfene Genealogie der Modernisten sowie zahireiche Hinweise auf verschiedene Ideen bzw. Werke der modernen Literatur und bildenden Kunst. Von ausschlaggebender Bedeutung waren für die tschechischen Symbolisten die Hinweise auf Wordsworth. Mallarmé, Maeterlinck, Morěas, Nietzsche und vor allem auf Wagner, dessen Werk Salda als "nejmocnèjši inkarnaci synthetických tendenci" bezeichnet ("die mächtigste Inkarnation der synthetischen Tendenzen"; Salda rekurriert auf die 'Neomythologisierung' bei Wagner und zitiert aus seiner Kunst und Religion (ibid. S. 48-49]). Zur 'Neomythologisierung' in der deutschen Romantik vgl. Karl H. Bohrer (Hrsg.), Mythos und Moderne. Begriff und Bild einer Rekonstruktion. Frankfurt am Main 1983, S. 57f. Vgl. auch die Darlegung von S. Bielfeldt, Die cechische Moderne im Frühwerk Saldas. Münctien 1975.

89 Interessanterweise versuchte vierzig Jahre später Jan Mukariovský dieses Problem, d. $h$. die Aufhebung von Inhalt und Form durch die Definition einer einheits- und sinnstiftenden semantischen Intention, durch die "semantische Geste" ("sémantickè gesto"), zu aktualisieren.

90 "Ale takto żiji osaměle. nepoznán, neslyšen, dušen /.../ Ċlověk se zavirá sám v sebe jako jisté květiny dotknutim. I... I odcizuji se všemu, co nesouvisi s uménim". ("Aber so lebe ich in der Einsamkeit, unerkannt, ohne gehört zu werden, am Ersticken nahe $/ . . /$ [so] schließt sich der Mensch in sein Innere ein wie bestimmte Blumen bei der Berührung. /.../ ich entziehe mich all 
Subjekt verzichtet auf eigene (reale) Existenz, sein Ich soll gänzlich von der Kunst ("Umēni“, bei Brezina oft großgeschrieben) absorbiert, in ihr gleichsam 'aufgelöst' werden. Brezına betrachtet sich nur als ihr "unvollkommenes Medium" ("/.../ mein Leben gehört mir nicht. Es gehört allein der Kunst, deren unvollkommenes Medium ich bin"), 91 das die 'Sprache' des Untbewußten (bzw. die der Kunstextase), durch welche sich die Kunst manifestiert, vermittelt. 92 Das dekadente Gedicht ist zugleich ein autokommunikativer Text in/aus der Einsamkeit, Isolation und Leere der irrealisierten Welt. Kennzeichnenderweise ist diese Welt auch menschenleer, 'bewohnt' lediglich von abstrakten, personifizierten Ideen (oder von den Schatten der Toten), die als solche apostrophiert werden. Die lebendigen Menschen sind abwesend. Die ersten dekadenten Gedichte Bïezinas haben meistens auch einen - allerdings nur abstrakten oder unerreichbaren, nicht-mehr-seienden - Adressaten: "smrt" ("Tod"), "Nejvyšši" ("Höchster"), "duše" ("Seele"), "myšlenka" ("Gedanke"), "umẻni" ("Kunst"), verstorbene Mutter, "Mrtvé mládi" ("Tote Jugend") usw. Es ist aber nicht nur die Irrealisierung des mundus sensibilis, sondern auch des eigenen Selbst, mit jenem charakteristischen Merkmal der Fremdheit (bzw. des 'Fremdseins') des eigenen Ich-Bewußtseins: "Dech vlastni zdál se mi cizi" (Den výročni / Der Gedenktag, I. 1-3: "Der eigene Atem schien mir fremd zu sein").

Die Irrealisierung stellt eine der Bedingungen für die Verwirklichung der ästhetischen Existenz und für die Hervorrufung und Potenzierung des ästhetischen Erlebnisses dar. Es ist gerade, wie noch zu zeigen sein wird, das Unwiederbringliche bzw. das 'für immer' Entschwundene und Verlorene, was die ästhetische Existenz valorisiert. Das von Biezina postulierte Leben nur für die Kunst, muß dem (wahren) Kunst-Schöpfer zur "fixen Idee", zu einem circulus vitiosus, zu seinem Fatum werden, vor dem es für inn kein Entrinnen gibt und das inn absolut und endgültig unfrei macht. ${ }^{93}$ Der hohe ästhetische Wert und Genuß

dem, was nicht mit der Kunst zu tun hat"). Vgl. Dopisy O. Bieziny F. Bauerovi, Praha 1929, S. 177. Gleichzeitig betont Bỉezina in der Korrespondenz die Qual der alltäglichen Existens eines Dorflehrers, der mit der Armut kämpfen muß.

91 Vgl. ibid., S. 191.

92 Die Flucht vor der utilitären, vulgären, materiellen und verständnislosen Gesellschaft in die autonome Kunst-Welt wird auch im Werk anderer Dekadenten dieser Zeit, mit mannigfaltigen. diesem Gestus entsprechenden Stilisierungen (als "Ausgestoßener", hypersensibler "Aristokrat", "Rebell", "trauriger Ritter". "Kind von Sodom" u.a..) thematisient, vor allem und am prägnantesten in den ersten Gedichtsammlungen Jiři Karáseks ze Lvovic: Zazdèná okna (Zugemauerte Fenster. 1894) Sodoma (1895) und Kniha aristokratická (Das aristokratische Buch, 1896). Die Semantik der Autostilisierung und Mystifikation im tschechischen Symbolismus untersucht Lubos Merhaut in seiner Monographie Cesty stylizace. (Stylizace. "okraj" a mystifikace v ceské literature prelomu devatenáctého a dvacátého stoleti). Praha 1994. Bỉezinas Werk wird hier bedauerlicherweise nicht berücksichtigt. Karáseks ostentative Negation der alltaglichen Wirklichkeit findet ihren (für Karásek) typischsten Ausdruck in der Adoration der Kunst, des Traumes und des dionysischen Kultes der orgiastischen "verbrennenden Lust", die der "verkommenen Rasse" ("vyżilá raca") der kränklichen Dekadenten den letzten Todesstoß versetzt. Doch all dieses Gehabe und kulissenähnliches Ambiente in der Manier einer cena Trimalchionis bleibt Biezina genauso fremd wie die von Karásek konstruierten historischen Situationen (Kniha aristokratická / Das aristokratische Buch, 1896), mit zahlreichen Allusionen auf das klassische Bildungsgut. Die verträumt-phantastische Atmosphāre der Melancholie und die intendierte Musikalität der Dichtersprache, das sinnstiftende Motiv der "Ferne" ("dálka"), kennzeichnen auch die erste Gedichtsammlung von Karel Hlavácek Pozdé k ránu (Spät gegen Morgen, 1896). die dank ihrer formalen Experimenten eine besondere Position im tschechichen Symbolismus einnimmt. Während jedoch die (anderen) Repräsentanten des tschechischen Symbolismus an dem geradezu stürmischen gesellschaftlich-kulturellen Leben der neunziger Jahre in seinem Zentrum. in Prag, durch mannigfaltige kulturelle Aktivitäten partizipierten, lebte Bíezina in einer wirklichen, nicht stilisierten Vereinsamung, von kulturellem Leben der Großstadt völlig isoliert, in einem kleinen westmährischen Dorf, wo er tagsüber Erstkläßler unterrichtete. Diese gesellschaftlichkulturelle Isolation kompensierte Brezina durch intensives Selbststudium der Philosophie. Theologie, Kunstgeschichte und der Sprachen, $u$. a. in der reichen Klosterbibliothek in seinem ersten Wirkungsort (1888-1901) Nová Ríse (Neureisch).

$93 \%$ / nám, kteri tvořime, musi státi se umẻni fixni ideou, s niż leháme, spime a vstáváme. žijeme, pohybujeme se, vnimáme; jen tak, zesileným timto intemim żivotem, obráceným v jediny் kruh, rozpadne se píed námi ztuhlá pečet' neznámého a promluvi myšlenka". Vgl. O. Bŕezina, Dopisy F. Bauerovi. Praha 1929, S. 187. (")...uns, die wir schöpfen, muß die Kunst zur fixen Idee werden, mit der wir uns hinlegen, schlafen und aufstehen, leben, uns bewegen, wahrnehmen; nur 
resultieren aus der Unmöglichkeit der unmittelbaren Erlebbarkeit und aus der Fähigkeit, das Abwesende. Nicht-mehr-Seiende, Vergangene und Irrealısierte im Modus der Erinnerung gleichsam 'wiedererleben' oder rekonstruieren zu können. Die autonome Kunst-Welt von Brezinas dekadenten Gedichten ist daher stets eine irrealisierte, selbstgenügsame Welt. Während das alltägliche Leben als "banal" und "unerträglich" negiert wird, 94 findet die ästhetische Existenz ihren idealen Ausdruck in einem (autonomen) Kunst-Werk bzw. in einem Kunst-Text. Im Akt der absoluten Hingabe an die Kunst wird dem Adepten der 'Eintritt' in ihr "Heiligtum" gewährt: " /../ allmählich nähere ich mich jenem geheimnisvollen Heiligtum der Heiliger, in dem sich das Unerkannte in der Kunst verbirgt" ("I.../ znenáhla počinám se bližiti tajemné oné Svatyni Svatých, v nichž skrȳvá se Nepoznané v Uměni".) 95

In der ähnlichen Weise wie das (alltägliche) Leben, wird auch die Natur-Welt, die Bíezina als "bloße Täuschung eigener Sinne" ablehnt, negiert bzw. durch die Macht der Kunst irrealisiert, 'denaturiert' und zum Kunst-Schönen, zum Artefakt transformiert: die Wasserfläche wird zur Spiegelfläche, das Laub erscheint "wie aus dünnem Goldblech gestanzt" ("jak vyráženy ze zlatého plechu". Apostrofa podzimni / Die Herbstapostrophe). die Märzlandschaft wird zum "frischen Aquarell" ("svěži akvarel", Bíezen I März) denaturiert. Die I r r e a l i si e rung ${ }^{96}$ der Lebens-Welt kann daher als das semantisch

so, mit einem derartig intensivierten internen nach innen, in einen einzigen Kreis gewandten Leben, wird vor uns das erstarte Siegel des Unbekannten zerfallen und der Gedanke sprechen").

94 In der Korrespondez spricht Bïezina von der unerträglichen Qual des Alltags in der Schule: die Schüler erscheinen ihm als "kleine animale Seelen". "kleine Peiniger" ("mali mučitelè"). Es ist aber auch die Qual der Armut, der Kälte ("Vim zcela jistě, że v dlouhých veðerech zimnich, kdy zimou zkr̉ehlý I...r, vgl. a.a.O., S. 171), auf die er immer wieder zurückkommt. Als Kompensation, als einziges "universales Heilmittel" betrachtet er den Dienst am Kunst-Schönen: "Jak krásný by byl volný umẻlecký život, ztrávený pouze a jediné ve službách krásy, zahǐivaný sedmibarevným jejich paprskem, rozloženým v prismatu ducha!" (Vgl. a.a.O., S. 170). "Tvému duševnimu stavu odporučuji universálni prostredek, jimž léčim s úspéchem každé żivotni zlo: uměni." (Vgl. a.a.O., S. 171).

95 Vgl. O. Brezina, Dopisy Františku Bauerovi, Praha 1929, S. 171. Wie Aage A. Hansen-Löve in seiner Deutung der ästhetischen Lebenshaltung im russischen Symbolismus (Der Russische Symbolismus, Bd. I. Diabolische Symbolik, Wien 1989. [Kap. 19. „Diabolisches 'Kunst-Leben'], S. 448ff.) feststellt, tendiert der dekadente Diabolismus dazu, das Moralisch-Ethische bzw. allgemein Pragmatisch-Utilitätre zu negieren, was eine automatische Ästhetisiereung aller Lebensprozesse nach sich zieht. Die Kunst substituiert somit die institutionalisierte Religion. Im 'Panästhetismus' sprengt die Kunst-Schöpfung die pragmatischen Grenzen des Lebens und findet als 'Kunst-Leben' die Erfüllung in sich selbst. Der Text des LEBENS wird zum KUNST-Text (ibid. S. 450).

96 In seinem aufschlußreichen, wenn auch problematischen Aufsatz .K morfologii ceské dekadence" (in: Ceská literatura, 36, 1988, S. 168-181) versucht Robert B Pynsent ein charakteristisches Phänomen der tschechischen Dekadenz zu erfassen und zu verifizieren. Dieses Phänonem bezeichnet er als "Interstatualität" Nach Pynsent handelt es sich um einen spezifischen gesellschaftlich-politischen und kulturellen Status der tschechischen Gesellschaft der Jahrhundertwende, den das Erlebnis des 'Da-Zwischen-Stehens" (auch geopolitisch) bzw. das eines Übergangs charakterisiert. Als symptomatische Situationen oder Zustände nennt Pynsent die an der Grenze zwischen Krankheit und Tod, Tod und sexueller Extase. Tag und Nacht etc. Als andere typische interstatuelle Situationen und Topoi nennt Pynsent den Herbst, die Wüste, unerreichbare Inseln. Ruinen, ferner die Pubertät, die Androgynie, die Unfruchtbarkeit, den Traum und die Halluzination, den Zustand der Erwartung etc. Zu der These des Autors ist jedoch anzumerken, daß er mit dem Terminus der Dekadenz in der tschechischen Literatur, die er als "Frustration-Literatur" (die Frustration als Thema und Motivation) bezeichnet, sehr eigenwillig arbeitet und vor allem, daß die von ihm beschriebenen 'interstatuellen' Topoi keineswegs nur für die tschechische, sondern auch für die gesamteuropäische Dekadenz kennzeichnend sind. Das Problematische dieser These resultiert daraus, daß Pynsent das Phänomen der geopolitischen 'Intrestatualität' der tschechischen Länder in der Habsburger Monarchie als etwas Spezifisches und Signifikantes restlos auch auf die künstlerische Evolution übertrāgt. Nichtsdestoweniger stellt sein Aufsatz einen interessanten Beitrag zur Emellung der Entwicklungsdynamik der tschechishen Dekadenz dar. Es stellt sich außerdem die Frage. ob man den Begriff der "Interstatualität" im Zusammenhang mit dem der Irrealisierung (in bezug auf Brezina) als eine gewisse 'Radikalisierung' weiterdenken könnte. Während die "Interstatualität" de facto einen 'Weder-nochZustand' bezeichnet, bezieht sich der Begriff der Irrealisierung auf die ästhetische (und ästhetisierte) Existenz des dichterischen Subjektes in Tajemné dálky. die gerade durch die Ästhetisierung irrealisiert wird. Dadurch wird dem realen Sein jeglicher Wirklichkeitsstatus 
relevante Konstruktionsprinzip des dekadenten Symbolismus Bïezinas (1892-1895) betrachtet werden. Als die signifikanten Modi der Irrealisierung erscheinen der "Tod" ("smrt") und der "Traum" ("sen"). Im Modus der "Erinnerung" ("vzpominka"), die im semantischen Arrangement des ersten Zyklus ebenfalls eine wichtige Position einnimmt, werden die Schatten der Verstorbenen (Moje matka / Meine Mutter), die unerreichbare geliebte Person (Prátelstvi duši / Freundschaft der Seelen), die "Tote Jugend" (gleichnamiges Gedicht), die irrealisierte Welt (Snad potom... I Vielleicht dann...) 'heraufbeschwört'. Eines der ersten drei dekadenten Gedichte Brezinas, das noetischmystische Gedicht Modlitba večerni (Das Abendgebet, 1892), ist als Gebet an den Tod. der zur absoluten Erkenntnis führen soll, strukturiert. Biezinas Faszination vom Todesmysterium verrät in dieser Schaffensphase auch sein Selbst-Verständnis als Dichter: "Jsem básnikem světel, tónú, tajemněho żivota, jenż dýchá z věcí. A stínư a smrti". ("Ich bin ein Poet der Lichter, der Töne, des geheimnisvollen Lebens, das aus den Dingen atmet. Und der Schatten und des Todes" ${ }^{\prime \prime} .97$

Im Zusammenhang mit der dekadenten Axiologie und der Irrealisierung-Semantik von Tajemné dálky soll noch die hochrelevante Problematik der Wirkung des gnostischen Denkens in TD eingehender betrachtet werden. Die Reflexion des gnostich-mythischen Vorstellungsgehaltes kommt bereits in der dekadenten Schaffensphase deutlich zur Geltung ( $O$ silo extasi a snü I O Kraft der Extasen und Träume, Modlitba vecerni I Das Abendgebet, Uméni / Die Kunst) und es scheint gerade der gnostische Vorstellungsgehalt zu sein, in dem offensichtlich auch die vielbesprochene "Religiosität" von Brezinas CEuvre ursprünglich wurzelt. Březina selbst äußert sich zu dieser Frage in einem Brief an Anna Pammrová:98

-Nepovidám, że studium nẻkterỷch dẻl starých literatur a mystických dẻl středověkých, které jsem měl prïležitost studovat ve zdejšim klášteře, proběhlo mou duši bez významu /.../. I.../ mé dilo, neodvislè od dogmatu, dotýká se jen esoterickỷch fundamentủ nábożenstvi a nic dál. Véricim $v$ jeho smyslu nejsem. Pojem Věčného a Nejvyššiho, jak se objevuje $v$ mém dile, je symbolem véčného Tajemstvi ...". ("Ich sage nicht, daß das Studium einiger Werke der alten Literaturen und der mystischen mittelalterlichen Werke, zu deren Studium ich die Gelegenheit im hiesigen Kloster hatte, für meine Seele ohne Bedeutung geblieben ist $/ \ldots /$. I..l mein Werk, von Dogma unabhängig, berührt nur die esoterischen Fundamente der Religion und weiter nichts. Gläubig in seinem Sinne bin ich nicht. Die Begriffe des Ewigen und Höchsten, wie sie in meinem Werk erscheinen, sind Symbole des ewigen Geheimnisses". Unterstrichen von O. B.).

Die Formulierungen "von Dogma unabhängig", "esoterische Fundamente der Religion", das Studium der mystischen Literatur, die betonte unorthodoxe bzw. h e t e r o doxe Auffassung des Glaubens und der Gläubigkeit, dies alles deutet auf eine völlig ästhetisierte ("svatynẻ umẻni" "Heiligtum der Kunst", "uměni u mne jest kultem"/die Kunst wird bei mir zum Kult"). 99 mystisch-hermetische Denkstruktur hin, wie sie für den dekadenten Symbolismus Biezinas signifikant ist, und die offensichttich von der Tradition der $h$ e rm e ti s ch en 100 Gnosis herrührt. Die hermetisch-gnostischen Vorstellungen

entzogen, $d . h$. nicht die Weder-noch-Position der "Interstatualität", sondern - in der Intention der konsequenten Absage an die reale Existenz- die 'Nicht-mehr'-Position der Irrealisierung. In Tajemné dálky schwankt das dichterische Ich nicht zwischen Tod und sexueller Extase bzw. Tod und Krankheit, es bewegt sich nicht an der Grenze zwischen Tag und Nacht usw., sondern verzichtet von vornhere in und ohne zu zogern auf das luzide Sein in der Sphäre der Tagwelt. In Prolog-Gedicht $O$ silo extasi a snú (O Kraft der Extasen und Träume...) wird diese Intention explizit zum Ausdruck gebracht: "Netoužim žiznè své u żiti svlażit brehü" (IX, 1; "Ich sehne mich nicht danach, meinen Durst an den Ufern des Lebens zu netzen") oder: "a jenom nad svých snú jsem záhonem se shýbal $I . . /$, a pielud miloval a páru tuh svỷch libal" (IV. 2,4 ; "und nur über dem Beet meiner Träume beugte ich mich $/ . . . /$, und liebte ein Phantom a küßte den Dunst meiner Sehnsüchte").

97 Vgl. O. Bỉezina, Dopisy Františku Bauerovi. 1929. S. 191.

98 Vgl. O. Bỉezina, Dopisy Annè Pammrové z let 1889-1905, Praha 1931, S. 147

99 Vgl. O. Biezina, Dopisy Františku Bauerovi, Praha 1929, S. 171 (13. IX. 1892); S. 202 (20. XII. 1894).

100 Auf die Bedeutung der Hermetik hat nach langer Zeit zu Beginn dieses Jahrhunderts erneut der bekannte Kirchenhistoriker und Gnosisforscher Richard Reitzenstein mit der herausragenden Monographie Poimandres. Studien zur griechisch-ägyptischen und frühchristlichen Literatur (Leipzig 1904) aufmerksam gemacht. Reitzenstein versuchte damals den ägyptischen Ursprung der hermetischen Lehren nachzuweisen. Diese Hypothese wurde seinerzeit 
wirken sich auf die Grundstimmung des ganzen Gedichtzyklus Tajemné dálky aus, die im Postulat der Irrealisierung bzw. 'Sich-Entfremdung' der Welt begründet liegt. Diese wiederum scheint der gnostischen Lehre vom illusiven, trügerischen Charakter der Welt zu entspringen. Die Welt erscheint als bloße lllusion und Täuschung (Vèzen / Der Gefangene), in der der Mensch, an seinen materiellen Körper gefesselt, als deren 'Gefangene' verharrt. Diese 'Gefangenschaft' ist die Quelle seines Leidens. Um dieser Qual zu entrinnen und die (Selbst-)Erkenntnis - die die Erkenntnis des Göttlichen in eigenem Selbst bedeutet - zu erreichen, muß der materielle Körper (hyle) abgelegt werden. Erst dann kann die Seele (bzw. der Geist) zur himmlischen Lichtheimat emporsteigen:101

"O smrti Żivych tẻl, již noc se stává dnem, / svou štrávu tajemnou lej v moji teplou krev, /.../. /I Od moji myšlenky odpoutej zemskou tižz, / at světla rychlosti prostorem šlehá v let" (Modlitba veð̌rni I Das Abendgebet, I, 1-2, IV, 1-2; "O Tod der lebendigen Leiber, durch den die Nacht zum Tag wird, / gieße deinen geheimnisvollen Saft in mein warmes Blut, I.../. / Von meinem Gedanken entfessle die irdische Schwere, daß er mit Lichtgeschwindigkeit durch den Raum im Flug saust".)

In den gnostisch-hermetischen Schriften (2. B. Corpus Hermeticum, Nag-HammadiCodex u. a.) wird die Menschenwelt als Sphäre des Todes und der Finsternis dargestellt, eine Vorstellung, die ihren deutlichen Reflex in der johanneischen koouos-Auffassung findet. 102 Die Menschen verharren in dieser Finsternis, $d . h$. in der Unwissenheit (Agnosia) um sich selbst, die dem Zustand der Trunkenheit oder des Schlafes gleicht. Daraus resultiert die typisch gnostische Zwei-Welten-Lehre (des Lichtes und der Finsternis), so wie das gnostische Denken überhaupt ein radikaler Dualismus kennzeichnet: Licht (Leben) - Finsternis (Tod). Gnosis - Agnoia, Geist - Körper usw. Das Ziel der hermetischen Gnosis ist es, den nach der Erlösung sich sehnenden Menschen zum Licht der Erkenntis ( $\gamma$ wwợc) zu führen. In Tajemné dálky kommen die für hermetisch-gnostische Traktate charakteristischen Mysterienvorstellungen hinzu, vor allem die Extase und die Mahl- und Opfervorstellungen (s. Gedichte $O$ silo extasi a snu் I O Kraft der Extasen und Träume. Modlitba vě̉erni I Das Abendgebet, Vẻzeñ I Der Gefangene, $Z$ vẻčných dálek... I Aus ewigen Fernen.... Umèni I Die Kunst). In der Schlußstrophe von $Z$ vẻcných dálek... (Aus ewigen Fernen...) heißt es: "/... / a na żhavých plotnách mého žiti / v pénivém klokotá varu / nápojem smrti mé, $z$ néjž budu píti / Mysterium zmaru". ("I.../ und auf meines Lebens glühendem

mehr oder weniger zurückgewiesen und Reitzenstein der "Ägyptomanie" bezichtigt (vgl. Th. Zielinski. "Hermes und die Hermetik 1: Das hermetische Corpus" in: Archiv für Religionswissenschaft, 8, 1905, S. 321-372; .I1: Der Ursprung der Hermetik", in: Archiv für Religionswissenschatt, 9, 1926, S. 25-60). Doch im Jahre 1945 wurden mehrere hermetische Schritten in Nag Hammadi (Oberägypten), der berühmte Nag Hammadi-Codex, gefunden. Auch die spätere Forschung hat die ägyptischen Wurzeln der Hermesmystik (nämlich in ägyptischen Mysteriengemeinden) bestätigt. Der griechische EinfluB in einigen bedeutenden Schritten (Corpus Hermeticum) resultient aus der ungemein einflußreichen neoplatonischen Philosophie in Alexandrien (um 200/250), so daß eine gegenseitige Beeinflussung von Philosophie. Hermetik und Gnosis als durchaus selbstverständlich erscheint. (Vgl. dazu: N. P. Nilsson. Geschichte der griechischen Religion II", Abschnitt IV A. .Hermetik und Gnosis", Munchen 1961, S. 582tt.). Die zentrale Figur der Hermetik ist bekanntlich Hermes Trismegistos (der griechische Name für den ägyptischen Gott Thot). der von den Hermetikern als deren Offenbarer verehrt wurde. Der charakteristische gnostische 'Zwei-Welten-Dualismus', die Vorstellung von der Illusivität der immanenten Welt sowie die Vorstellung von der Gefangenschaft des Geistes im materiellen Körper, der Weg zur Erlösung durch die Erkenntnis, all das gehört auch zu den Haupthemen der hermetisch-gnostischen Schriften. Signifikant für die hermetische Gnosis waren spiritualisierte Mysterien innerhalb der "Hermesgemeinden". Es handelte sich wahrscheinlich um eine Art religiöser Bruderschaft, die sich täglich in Konventikeln zusammenfand, um Gott hymnische 'Opfer' und Gebete darzubringen und am gemeinsamen Mahl zu partizipieren. (Vgl. dazu. F. Bräuninger, Untersuchungen zu den Schriften des Hermes Trismegistos, Berlin [Phil. Diss.] 1926. S. 14ff). Es ließe sich sagen, daß gnostische Hermetiker eine konsequent antinaturalistische (rigorose Verwertung des Opfers), esoterisch-religiöse Gruppe eigener Prägung repräsentierten, die sich in Kleinkreisen zusammentraf, um sich in die Geheimnisse der Gnosis einzuüben und den Neulingen und Noch-Suchenden mit Wissen zu helfen. Die gemeinsamen Gebete, Hymnen, Gesänge, die Praktik des Bruderkusses, spielen in hermetisch-gnostischen Traktaten eine wichtige Rolle.

$101 \mathrm{Vgl}$. S. Arai, .Zur Definition der Gnosis in Rücksicht auf die Frage nach ihrem Ursprung". in: Gnosis und Gnostizismus, hrsg. v. K. Rudolph, Darmstadt 1975, S. $646 \mathrm{ff}$.

102 Vgl. R. Bultmann, Theologie des Neuen Testaments, Tübingen [6. Aufl.] 1968, S. 367ff. 
Herd / brodelt es im schäumenden Sieden / im Trunk meines Todes, aus dem ich / das Mysterium der Vernichtung trinken werde ${ }^{*}$.

Daß es sich dabei in TD nicht um eine für die Dekadenz sehr charakteristische 'diabolische' (bzw. 'satanistische') und blasphemische Einstellung (Przybyszewski, Baudelaire, Huysmans, in der tschechischen Literatur S. K. Neumann, temporär auch Karásek ze Lvovic), offensichtlich auch nicht um Agnostizismus (das Postulat der absoluten Erkenntnis wird in einem der zentralen Gedichte von TD, in Modlitba vecerni I Das Abendgebet, aufgestellt) handelt, scheint der oben zitierte Satz "Věrícím $v$ jeho smyslu nejsem" ("Gläubiger in seinem Sinne [d. h. im Sinne des Dogmas; Anm. J.V.] bin ich nicht") anzudeuten, der eine eher heterodoxe Position impliziert. Diese in der älteren Březina-Literatur als "religiös" definierte, in Wirklichkeit jedoch stark ästhetisierte Position, stellt eine Art 'Kunstreligion' dar. Brezina bezeichnet die Kunst als Kult, sie bedeutet ihm ein sacrum und Geheimnis. Heiligtum, Gottesdienst und Opferhandlung zugleich. Der "Ewige" ("Věčny̆) oder der "Höchste" ("Nejvyšsi") für den der dekadente Künstlermensch - als sein "Priester"- eine Messe zelebrieren will, wird signifikanterweise als 'Kü n s tl e r gott', als 'Hüter' des "ewigen Geheimnisses" ("věčné Tajemstv") adoriert: " $O$ Věčný, rci, zda smim/...l, / prii malém oltáríi, pod klenbou pobočni / Ti mši svou tichou prečist?" (Uméni / Die Kunst, IV, 1, 3-4; "O Ewiger, sag, ob ich darf, /.../ / an einem kleinen Altar unter der Seitenwölbung / Dir meine leise Messe vorlesen?"); "Bol tužeb spálených I... I/ v Żeñ mou uzrálou tỉás touhu k Nejyyššimu / jak rosu sladké manny v klasech" (Tichá bolest / Der stille Schmerz, IV, 1, 3-4; "Der Schmerz der verbrannten Sehnsüchte /.../ I schüttelte in meine reife Ernte das Verlangen nach dem Höchsten, / wie den Tau des süßen Mannas in den Âhren".) Es ist im Prinzip eine 'egoistische' und durchaus persönliche ('intime') Beziehung zwischen dem isolierten, autistischen Ich und dem "Ewigen", die sich zwar schon im zweiten Zyklus Svítáni na západẻ (Tagen im Westen, 1896) wesentlich ändert, in der Phase des dekadenten Symbolismus (TD) sich jedoch mehr oder weniger auf sorgfältig arrangierte hieratische Gestik beschränkt (Uméni / Die Kunst), die das dichterische Ich natürlich nicht für Gott, sondern für ein kultisches Bild, ein simulacrum seiner eigenen Kunst-Welt, inszeniert. Das, worum es in dieser Beziehung geht, ist in erster Linie die (vergebliche) Entschleierung des "ewigen Geheimnisses"; in Moditba vecerni (Das Abendgeben) steigert sich das Verlangen nach der absoluten Erkenntnis dieses "Geheimnisses" bis zur Aporie und zur dekadenten Sakralisierung des Tode:

"Oltáí / ... / Neznámèho"; "hrưza Neznámého"; "v chrámu Tajemstvi jsem klekl zadumanē" ("Altar des Unbekannten": "Grauen des Unbekannten; "im Tempel des Geheimnisses kniete ich in Gedanken versunken nieder": $O$ silo extasi a snú / O Kraft der Extasen und Träume, II, 4, Vill, 2 , IX. 4): "a $v$ tisicich ilusi jásot a úzkost a żel / ţ̉ese se na napjatých strunách Tajemstvi" (Żeh bilý svètla ... / Des Lichtes weiße Glut.... IV. 3-4; "und in tausend Illusionen zittern Jubel und Beklommenheit und Wehmut / auf den gespannten Saiten des Geheimnisses"); "at' douskem jediným já žizniv opiji / na brezzich vẻčnosti se vinem Tajemstvi" (Modlitba vecerni / Das Abendgebet, VI, 7-8; "daß ich mich, durstig mit einem einzigen Schluck / an den Ufern der Ewigkeit mit dem Wein des Geheimnisses berausche"): "Z oltárủ Věcněho až na obzor / sloup ohnivy் se prochvi ethernem. I.../ // nad hłichem zemé stiny priikryje. / otevłe hvězdná okna Tajemnu" (Vonné soumraky / Wohlduftende Sonnenuntergänge, I, 1-2, III, 1-2; "Von den Altären des Ewigen wird sich bis zum Horizont / eine Glutsäule durch den Äther durchwehen, /.../ // die Sünde der Erde mit Schatten zudecken. / [und] die Stemenfenster in das Geheimnisvolle öfnen").

Aber hinter diesem simulacrum scheint sich gerade nur die "ewigen", trostlose und endlose Ferne. der Hauptkode von TD, auszubreiten. Der "Ewige" und "Höchste" offenbart sich als Synonym dieser endlosen, leeren Ferne, ja er selbst ist die unerreichbare, furchteinflößende Ewigkeit und das "höchste Geheimnis". Seine Welt ist die der Leere und der "ewigen Ferne", man denke nur an den Vers aus Podzimni večer (Der Herbstabend): "Do prázdna véká cas..." (V. 1; "Ins Leere fließt die Zeit...").

Das (immanente) Leben in der irdischen Welt bedeutet in TD das Verharren in der Sphäre der Finsternis, der Kälte, der Trauer und des Todes. Doch die "jiný svět"r"andere Welt" (Modlitba vecerni I Das Abendgebet), die Sphäre des 'Anderen', d. h. des Ästhetischen, Kunstvollen ("svatyné Uméni" I "Heiligtum der Kunst"), deren Érreichen die ästhetische Existenz als das höchste Ziel bedeutet (Motiv z Beethovena / Ein Motiv aus Beethoven, Uméni / Die Kunst), scheint genauso irrealisiert, d. h. rein fiktiv. (bloß) ein Produkt eigener Einbildungskraft (Vèzen $/$ Der Gefangene) zu sein und irgendwo in der "leeren Ferne" situiert, aber gerade deshalb so wertvoll, faszinierend und verlockend. Das verleiht dem ästhetischen Erlebnis seinen vollkommen einzigartigen Reiz: erst als 
irrealisiert, desontologisiert, nicht-mehr-seiend erlangt die phänomenale Welt ihren (ästhetischen) Wert (vgl. die Interpretation des Gedichtes Snad potom.../ Vielleicht dann..., Kap. 2.1.2).

Einige Gedichte des Zyklus Tajemné dálky sind als hermetische Initiationstexte arrangiert, die ein 'Initiationsritual' in einen geheimnisvollen Kultus (der Kunst; "Umèni u mne jest kultem") oder in die hypnotisierende, bannende und 'magnetisierende' Sphäre des Kunst-Todes thematisieren ( $O$ silo extasi s snu I $O$ Kraft der Extasen und Träume, Tichá bolest / Der stille Schmerz, Svưj żal jsem položil... I Mein Leid legte ich..., Motiv z Beethovena / Ein Motiv aus Beethoven, Uméni / Die Kunst). Dabei spielt die Semantik der "Grenze" ("hranice") eine wichtige Rolle (s. u. Kap. 2.3 Kunst als sacrum). Das dichterische Ich wird ver-führt, verzaubert, verlockt und initiiert (und zugleich 'mortifiziert') durch die 'Suggestion', 'Hypnose' der Musik-Sprache (Motiv z Beethovene), durch die personifizierte und 'peinigende' ars poetica (Tichá bolest / Der stille Schmerz, Svij žal jsem polożil...। Mein Leid legte ich ...), die das Ich zu den "Polen des Geheimnisses führt":

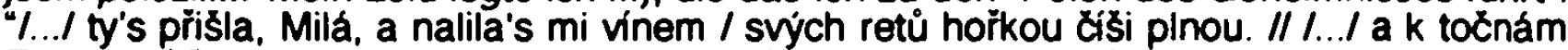
Tajemstvi šla's ruku v ruce se mnou" (Tichá bolest / Der stille Schmerz, I, 3, II, 5; "/... du kamst, meine Liebe, und schenktest mir mit dem Wein / deiner Lippen einen vollen, bitteren Pokal ein. // I.../ und zu den Polen des Geheimnisses gingst du Hand in Hand mit mir'). Umgekehrt soll aber auch die Sprache des Dichters wie 'Suggestion' und 'Hypnose' - als intendierte Wirkung des dekadenten Gedichtes - auf den Hörer bzw. Leser wirken.

Die Schaffensphase des dekadenten Symbolimus O. Br̈ezinas kulminiert mit der Herausgabe des Gedichtzyklus Tajemné dálky. Es ist zugleich die längste Schaffensphase 103 und Tajemné dálky nicht nur der umfangreichste, sondern auch der im Hinblick auf seine Motiv-Paradigmatik - wohl mannigfaltigste Zyklus. Im folgenden geht es darum, die Modi der Irrealisierung - Hypnos, Oneiros und Thanatos - weiter zu spezifizieren. An diese Problematik knüptt das Kapitel Irrealisierung und Denaturierung der Natur durch die Kunst an, in dem - an einer kleinen Gruppe der Naturtyrik in Tajemné dálky - die Semantik der Substitution des Natur-Schönen durch das Kunst-Schőne analysient wird. Im Anschluß daran wird die für die dekadente Axiologie signifikante Ästhetisierung des Mythischen zu einer 'Kunst-Mythik' bzw. 'Kunst-Liturgie' (Kap. 2.3) untersucht. Die in diesem Kapitel gewonnenen Resultate (die Spezifika dieser Transformation in Tajemné dálky) sollen anhand der Analyse von zwei paradigmatischen Gedichttexten verifizient werden.

103 Die übrigen vier vollendeten Gedichtzyklen sind im Zeitraum vom Mai 1896 bis August 1901 erschienen. In Tajemné dálky hat Bł̉ezina nach einer strengen Auswahl dreißig Gedichte aufgenommen. Die Gedichtzahl der vier folgenden Zyklen ist im Durchschnitt zwanzig Gedichte (SZ 21, VP 20, SCh 19, R 20). Bekanntlich überlegte Bỉezina die Reihenfolge der einzelnen Gedichte im jeweiligen Zyklus (mit einem Prolog- und einem Epilog-Gedicht) immer mit höchster Sorgfalt. 


\title{
2.1 Modi der Irrealisierung: Hypnos, Oneiros und Thanatos Erinnerung als 'Initiatorin' des ästhetischen Erlebnisses (der irrealisierten Welt)
}

"Le rêve est une seconde vie".

"Der Traum ist ein zweites Leben“.

Gérard de Nerval: Aurélia (1855)

\author{
„Ó Sinrri, kně̃̌no snů ...“ \\ „O Tod. du Fürst der Träume ..."
}

Ot. Březina: V úzkostech (In Beklommenheiten, 1893)

Der Topos des Traumes (bzw. des Träumens) spielt nicht nur im dekadenten Symbolismus eine sinnkonstitutive Rolle, sondern nimmt im gesamten lyrischen Werk Brezinas eine der Schlüsselpositionen ein. Doch im Gegensatz zur "Traum"-Semantik des eschatologischen Symbolismus, die den Traum als einen visionären bzw. prophetischen Zustand (als 'Traum-Vision') determiniert, fungiert er in der Phase des dekadenten Symbolismus als Antipol zum immanenten, luziden Leben, als vollkommen autonomes Reich jenseits der defizitär empfundenen Realität bzw. als 'Pforte' der faszinierenden Sphäre des Kunst-Schönen und des Kunst-Todes:104 "sen věcný, posledni" ("der ewige, letzte Traum"; Modlitba večerni / Das Abendgebet, VII, 8), "dusivý sen" ("der drosselnde Traum"; Snad potom... / Vielleicht dann, II, 4) usw. Im dekadenten Symbolimus der Geheimnisvollen Fernen stellt sich der Traum (Oneiros) als 'fi nale r Zustand' des Sich-im-Nichts-Aufgehens dar; Hypnos und Thanatos bilden in diesem semantischen Kontext eine zueinander korrelierende Einheit. Im nachdekadenten, e sch a to log i schen Symbolismus besteht zumindest noch eine gewisse Hoffnung auf die zukünftige 'Auferweckung' ('probuzeni', 'vzkrî̉šeni'). Ein anderes distinktives Merkmal der Traum-Semantik im System des dekadenten Symbolismus ist ihre auffallende Korrelation mit der Semantik des 'Vergessens' / 'SichErinnerns'. Der Traum wird zum Medium der Erinnerung an das Vergangene: an die tote Mutter (Moje matka / Meine Mutter, Zapomenuti / Das Vergessen, Den výrocni / Der Gedenktag), an die 'tote' Jugend (Mrtvé mládi / Tote Jugend) oder an die verlorene Freundschaft (Prátelstvi dusi / Freundschaft der Seelen, Vzpominka / Die Erinnerung). Dieser Typus von Erinnerungstexten scheint allerdings nur für den dekadenten

104 Auf die Semantik des Traumes als des 'Vorraums' des Todes, die auf die romantische Tradition zurückzuführen ist, verweist $\mathrm{M}$. Praz (Liebe, Tod und Teufel. Die schwarze Romantik, München 1988, S. 43 ff;). Vgl. auch: A. A. Hansen-Löve. Der russische Symbolismus, 1989, S. $268 \mathrm{ft}$. Auch der Einfluß der Lehre Schopenhauers kormmt hier deutlich zur Geltung. U. Heftrich, Otokar Br̈ezina, Heidelberg 1993, S. $156 \mathrm{ff}$. Doch bei Bỉezina ist der Tod nur selten oder kaum in der Weise konnotiert, wie es in der Lyrik anderer tschechischer Symbolisten dieser Zeit (Karásek ze Lvovic, A. Procházka, J. Opolský, S. K. Neumann) der Fall ist. Der auffallendste Unterschied besteht darin, daß in den Gedichten Bïezinas die (Baudelairesche) manirierte Ästhetisierung des Sterbens, des Häßlichen bzw. Gräßlichen und Abstoßenden oder die naturalistischen Darstellungen der Todessymptome 'ausgeblendet' werden, die insbesondere in der Lyrik von Karásek ze Lvovic (aus den neunziger Jahren) eine konstitutive Rolle spielen, so $\mathbf{z}$. B. im Rondell In memoriam (Zazdéná okna / Die zugemauerten Fenster, 1894): "Tvých hebkých vlasủ krása, príteli, / Ted' $v$ hrobẻ dèsném zvolna, zvolna sttivá, / A rubáś praskajici, zpuchỉelý / Tvé tèlo hnijici a hnusné skrývá." ("Deiner samtweichen Haare Pracht, mein Freund, I modert jetz langsam, langsam im entsetzlichen Grab. I Und das berstende, morsche Totenhemd / hüllt deinen verwesenden, ekelhaften Leib."). Der 'Tod' in der Darstellung Brezinas erscheint nicht als (manieristisch) schauriger und entsetzlicher Gegenpol (oder Doublette) des Lebens (Karásek, Procházka), sondern vielmehr als erhabene, siegreiche Macht, die unserem Leben obwaltet (s. $\mathbf{Z}$. B. das Gedicht Pohled smrti / Der Blick des Todes). Kennzeichnenderweise wird in einigen Gedichten das Substantiv "smit" (Tod) durch das Epitheton "vitézná" (siegreich) spezifiziert. Das letzte veröffentlichte Gedicht Tisice srdci pẻlo v srdci tvém (Tausende Herzen sangen in deinem Herz) beginnt: "Šla životem tvÿm smrt a mlટ̌enimi vládla" ("Der Tod schritt durch dein Leben und herrschte durch das Schweigen"). 
Symbolismus paradigmatisch zu sein, in den späteren Phasen Br̈ezinas Schaffens wird er durch einen anderen Typus substituiert, der mit der Vertikalität des Erinnerungsaktes verbunden ist. 105 Es handelt sich dabei um visionäre, positiv konnotierte Erinnerungsakte der Seele an neue Formen des kosmischen Seins, die in die überirdische Sphäre oder als 'Erinnerungen' an die vergangenen Ufformen des 'geologischen' Lebens bzw. an das diesseitige Leben aus der Perspektive des postmortalen Zustandes - in die unterirdische Tiefe der Urnacht einer Schattenwelt führen. Im System des dekadenten Symbolismus kann man dagegen von der Horizontalität und Linearität des Erinnerungsaktes und von seiner biographischen Motivation sprechen. Kennzeichnenderweise führt er in die "Ferne" ("dálka") oder seine Impulse kommen aus der "Ferne": "To z dálky staleti /../ // kde v dálkách šumi vesla / odplulých staleti“ (Motiv z Beethovena / Ein Motiv aus Beethoven, I. 1: "Aus der Ferne der Jahrhunderte /... I// wo in der Ferne die Ruder rauschen / entglitner Jahrhunderte"). "Jak plovouci ostrov urvaný z břehu mizíš mi v dáii" (Piátelstvi duši / Freundschaft der Seelen, VI, 2; "Wie schwimmende Insel, der Küste entrissen, schwindest du mir in der Ferne"). Seine Merkmale sind Passivität oder sogar Gleichgültigkeit, Depressivität, Hoffnugslosigkeit, seelische Qual, Absage an die Welt und die Lebensfreude und der W ill e zum Unterliegen dieser Stimmung. 106 Im Hinblick aut die Raum- und Zeitgestaltung dieser Gedichte kommt in allen Fällen die Chronotopie der Nacht, der Iunaren Welt, der frostigen Sterne, der Krypten und Gräber, der Mineralien und der kristallinen Strukturen zur Geltung

"mramor" ("Marmor", Moje matka / Meine Mutter, IV, 1). "diadem", (Mrtvé mládi / Tote Jugend, IV, 2); "zkamenělá príroda" ("versteinerte Natur", Pŕátelstvi duši / Freundschaft der Seelen, II, 2), "vỳpary solné" ("Salzausdūnstungen", ibid.. IV, 2), "lampy krystal" ("Kristall der Lampe", Motiv $Z$ Beethovena ( Ein Motiv aus Beethoven, $X, 1)$ etc;

"závěje" ("die Schneeverwehungen", Moje matka, II, 3), "snih" ("der Schnee", Pohled smrti I Blick des Todes, V. 10), "chlad"rmráz" ("Kälte"rFrost", ibid., V. 8), "vyhaslý snih" ("der erloschne Schnee", Den výočni I Der Gedenktag, 1, 2);

"I... ty 2 hrobu povstávás" (Moje matka / Meine Mutter, VII, 2; "da erhebst du dich aus dem Grabe"). $\%$... I nad mládi mrtvolou jsem stanul v zadumáni" (Mrtvé mládi / Tote Jugend, VIII, 3; "I../ über dem Leichnam meiner Jugend stand ich im Nachsinnen"). $\%$... a jenom nad hroby minulych jar, na hỉbitovech snü" (Piátelstvi duši I Freundschaft der Seelen. VII. 3: "und nur über den Gräbern der vergangenen Lenze, auf den Friedhöfen der Träume"). $\% . . / 2$ kamenú svíticich jsem

105 Die reichgegliederte Typologie der Erinnerungsparadigmatik im russischen Symbolismus untersucht ausführtich Aage A. Hansen-Löve (in: Der russische Symbolismus, Wien 1989, S. 281332). Wie der Autor feststellt, scheinen die Grundpositionen von 'Erinnern' vs. 'Vergessen' um eine 'Nullachse' zu rotieren, wo sich Bedeutungen und axiologische Positionen des ganzen Paradigmas annähern. Der gemeinsame Nenner dieser Konvergenz, ihre 'Nullachse', stellt das Motiv des Augenblickes dar, wobei der "Augenblick der Erinnerung" und der des "Vergessens". laut A. A. Hansen-Löve, eine Äquivalenzrelation bilden. Das Motiv des "Augenblickes" (Russ. "mıg") bzw. das der "Augenblicklichkeit" kommt, was die Frequenz der einzelnen Motive anlangt. bei allen Repräsentanten des sog. "diabolischen Symbolismus" (Brjusov, Bal'mont, Sologub, Gippius) am häufigsten vor. Bei Biezina kommt das Motiv des "Augenblickes" als ein Teil der Polaritat "okamżik" (Augenblick) vs. "vẻcnost" (Ewigkeit), allerdings erst in der Phase des eschatologischen Symbolismus vor: "vẻky prożili ve vuerinách" ("Äonen durchlebten sie in einer Sekunde". Mučenici / Die Märtyrer. VI, 1, VP): "a vir, y nẻmž okamžiky sviti staletím" ("und Wirbel. in dem Augenblicke durch Jahrhunderte strahlen", Usmév Żivota / Des Lebens Lächeln, I, 3) Im dekadenten Symbolismus dominiert eher die Kategorie des 'letzten' Augenblickes, in dem das lyrische Ich seine "letzte Stunde" auf der Uhr der .Großen Nacht" zu schlagen hört (Zeh bily svêtla... / Die weiße Lichtglut...). Der Augenblick der 'letzten Stunde' scheint mit dem Motiv der "ewigen Ferne" zu koinzidieren in dem Sinne, daß sie den 'langen Weg' in die 'unabsehbare'. 'ewige' Ferne gleichsam antizipiert.

106 Alle diese Symptome prägen auch einige Gedichte des zweiten Gedichtzyklus Svitáni na západě (Tagen im Westen), der eigentlich eine neue Schaffensphase antizipiert. Sie problematisieren stark die Periodisierung des Werkes von Biezina, denn einerseits entfalten diese Gedichte noch die Paradigmatik des dekadenten Symbolismus, andererseits jedoch signalisieren einige von innen (Vteriny / Sekunden. Nálada / Stimmung, Vladaři snú / Herrscher der Träume) bereits einen anderen poetischen Kode. Das, womit sie sich von den Gedichten des dekadenten Symbolismus (TD) unterscheiden, ist das auto-intertextuelle Verfahren des 'ironischen' bzw. 'ironisierenden' Auto-Zitats (in einer sehr subtilen Form), das innen eine gewisse Distaz gegenüber den früheren Gedichten verleiht (Vteriny / Sekunden, letzte Strophe; Nálada / Stimmung $u$. a) und das man im AnschluB an G. Genette der intertextuellen Relation der Hypertextualität zuordnen kann. 
sklenul kryptu tvou" (Motiv z Beethovena / Motiv aus Beethoven. X, 2;"aus strahlendem Gestein wölbte ich deine Gruft"). "I../ chor pohr̉ebnich pisni" (Zapomenuti / Das Vergessen, II, 2; "der Chor der Grablieder")

Die zahlreichen funeralen Merkmale indizieren die frappierende Präsenz der Thanatosmotive ("Grabeskälte", "Nacht", "Totenmesse", "Kerzen" usw.). Das (ursprünglich) Organische und Vegetabilische "erstart", "verflüchtigt sich", "löst sich auf" oder "erkaltet": "O matko má, dnes v světlo proměněná" (Moje matka / Meine Mutter, V, 1; "O Mutter mein, heute zu Licht verwandelt"); "Tvé mrtvé krve vychladlé I..." (ibid., VI, 1; "Deines toten erkalteten Blutes /..." usw.). Der Akt des '(Sich-)Erinnerns' wird oft mit der Musik, mit einem musikalischen Erlebnis assoziiert oder die Erinnerung wird zur "Musik", zum "Lied" (zum "Grablied"), zum wehmütigen "Refrain" usw., um weiter inspirativ wirken zu können. ${ }^{07}$ In der Phase des dekadenten Symbolismus werden die musikalischen Motive auch 'thanatoid' (am deutlichsten in Motiv $z$ Beethovena / Ein Motiv aus Beethoven) konnotiert, oft im Zusammenhang mit mannigfaltigen akustischen Erscheinungen, die die Eindrücke des "leisen Verklingens" in der Ferne, des "lang nachhallenden Echos", der Wehmut usw. heraufbeschwören sollen:

"Na starém pianè, v kovových strunách spicich, / jak z rozvlnění hart". (Mrtvé mládi / Tote Jugend, I, 1-2; "Auf einem alten Piano, in schlummernden Metallsaiten, I wie im Wellen der Harten"). "Nám v jediný refrén roztála romance mládi" (Prátelstvi duši I Freundschaft der Seelen, I. 1: "Zu einem einzigen Refrain verschmolz unsere Jugendromanze"). "/../ tvých tónu் byl to hlas pod okny duše mé" (Motiv z Beethovena / Motiv aus Beethoven, I, 2; "Klang deiner Töne war es vor meiner Seele Fenstern"). ".../ chor pohrebnich pisni" (Zapomenuti/ Das Vergessen, II, 2; "der Chor der Grablieder").

Die musikalischen Motive scheinen in diesen Gedichten die Flüchtigkeit bzw. die Augenblicklichkeit der Erinnerung, ihre Flatterhaftigkeit und Intensität zugleich - als einprägsames "Nachklingen" eines längst entschwundenen Erlebnisses - zu potenzieren. Die Musik wird auch als Ersatz für die verbale Kommunikation funktionalisiert. Der Aspekt des Nicht-Kommunizierbaren bzw. Non-Verbalen resultiert in erster Linie daraus, daß das lyrische Subjekt (oder seine Anima) das Nicht-Mehr-Existierende, das bereits Entschwundene und Unerreichbare anspricht: die tote Mutter (Moje matka / Meine Mutter, Den výročni I Der Gedenktag. Zapomenuti I Das Vergessen) die tote Freundschaft (Prátelstvi duši I Freundschaft der Seelen) die tote Jugend (Mrtvé mládi) oder die erlöschende, tote Hoffnung auf die Liebe (Vzpominka / Erinnerung). Das dichterische Ich vernimmt nur noch die "Musik der Worte" oder die "Stimme der Töne" (Motiv z Beethovena I Ein Motiv aus Beethoven, I, 2): das Sprechen wird zum "Seufzer", zum "Echo", zu "geheimnisvollen", "klagenden" und "fahlen" Tönen der jenseitigen Sprache:

\%.../ a vinou mého hlasu ożivená kviliš" (Moje matka / Meine Mutter, VII, 4; "und in meiner Stimme Welle erwacht deine Klage"). I.../ zaštkánim smrtelným se tỉáslo ozvěnou" (Mrtvé mládi I Tote Jugend. VIII, 1-2; "/../ im Todesseufzer vibrierte es in einem Echo"). "V̌̉ak oněmlá táhla tvá hudba Neznámého hlasem v mém sluchu smrtelném.": ( Tichá bolest / Der stille Schmerz, V, 3-5; "Doch verstummt wehte deine Musik in der Stimme des Unbekannten durch mein todgeweihtes Gehör")

Das Motiv des 'wortlosen', 'musikalischen' Sprechens entspringt dem Solitudo des lyrischen Subjekts, dem "stillem Schmerz" (Tichá bolest) seiner Einsamkeit, der in das autistische Mit-Sich-Selbst-Kommunizieren mündet. Diese mnemonischen Erlebnisse führen schließlich unvermeidlich in einen Zustand der elegischen Resignation und Desillusionierung: "A jako troje kdys i moje cesta smutná" (Moje matka / Meine Mutter, IX, 1: "Und so, wie einstens du, muß ich jetzt traurig schreiten"). "/../ vše vzplálo v duši mé a $\checkmark$ hudbé mrtvých práni" (Mrtvé mládi / Tote Jugend, VIII, 1; "alles entflammte in meiner

107 Ein schönes Beispiel der Semantisierung der Musik als 'Initiatorin' der Erinnerung liefert im tschechischen (Prä-)Symbolismus das Gedicht Kytara von Jaroslav Kvapil. Bỉezina selbst bezeichnet das im sechsfüßigen Jambus verfaßte Rondell als Vorbild für das maßgebende Metrum (den Alexandriner) seines ersten Gedichtzyklus Tajemné dálky: "A nyni po letech já z hrobky vstávám nẻmý / a vidim oblohu a vidim starou zemi, / kde v tónech ospalých zas novẽ vzpominám si, że snèni opojné mne svedlo v dálku kamsi, / a vzdech jen posilám ted' za mrtvými jary. I vé prsty voskové kdyz tlukou do kytary". (Kytara / Gittare, Str. III; "Und nun erhebe ich mich nach Jahren stumm aus der Krypta / und sehe das Firmament und das alte Land, / wo ich mich in schläfrigen Tönen wieder erinnere, daß das berauschende Träumen mich irgendwohin in die Ferne verlockte. I und den Seufzer nur sende ich jetzt den toten Lenzen nach, I wenn deine Wachsfinger auf die Gittarensaiten schlagen.") 
Seele und in der Musik der toten Wünsche"). "A cizi mi touha tvá, jak žena, z niž piješ rozkoš svých dnü" (Prátelstvi duši / Freundschaft der Seelen, VII, 1; "Und fremd ist dein Verlangen mir, wie eine Frau, aus der du die Wollust deiner Tage saugst"). "/.../ noc lítostné touhy stiskne ti prsa, smutek věci a casu" (Návrat / Rückkehr, VIII, 1; "die Nacht der wehmütigen Sehnsucht drückt deine Brust, die Trauer der Dinge und der Zeit").

Dem 'Vergessen', das mit dem 'Sich-Erinnern' in TD eine Aquivalenzrelation bildet, wird hier eine positive Semantik zuerkannt. In Zapomenut' (Vergessen), wo das Motiv der 'toten Mutter' wiederaufgenommen wird, erlangt das wehmütige 'Sich-Erinnern' aus dem bekannten Gedicht Moje matka (Meine Mutter) eine andere Bedeutung. In Zapomenut' figuriert die tote Mutter nicht mehr als phantomhafte Revenantin und Heraufbeschwörerin des tragischen Bewußtseins der trostlosen Existenz des dichterischen Ich, sondern als Bewohnerin eines paradiesischen Gartens, aus dem ein Engel den tröstenden "Trank des Vergessens" dem Dichter bringt: "To z br̉ehú Ml¿eni vítr mým osením táh, / v nẻm treseni neviditelných krídel jsem cítil / a anděl mé myšlence, jak v Gethsemane na modlitbách, I Cís tajemnè útěchy nalil" (Zapomenuti / Vergessen, Str. IV; "Da zog ein Wind von den Ufern des Schweigens durch meine Saat, $Y$ in inm spürte ich das Zittern unsichtbarer Schwingen, / und ein Engel gOß meinem Gedanken, wie in Gethsemane beim Gebet, / einen Kelch geheimen Trostes ein"). 108

Im dekadenten Symbolismus fungiert der Traum nicht $n$ u r als 'Heraufbeschwörer' (oder umgekehrt als 'Spender') des Vergessens, der längst vergangenen tempi passati, des Verlorenen und Nicht-mehr-Seienden; vielmehr symbolisiert er das erste 'Stadium' der künstlerischen Extase (Motiv z Beethovena / Ein Motiv aus Bethoven), den s chöpferi sch en Traum, der dem Dichter ungeahnte Möglichkeiten eröffnet. Zu dieser Zeit (um 1894) erwähnt Bïezina in seiner Korrespondenz das "vage Träumen" ("Nevykoriistěné, vágni snéni"), das die Seele vergiftet und den schöpferischen Willen schwächt. ${ }^{109}$ Ein Jahr später spricht er dagegen von gewaltiger Kraft und Intensität des Traumes, in dem sich die wahre schöpferische Potenz offenbart. Das kreative Träumen (als aktive Imagination) wird dem schwächenden, "nutzlosen" Träumen (der passiven Imagination) gegenübergestellt: "Mám $v$ duši lítost spoutaného $v$ loži" (Lítost / Die Wehmut. V. 1; "In meiner Seele weilt die Wehmut eines im Lager Gefesselten"). "Jak somnambul svedený z lože, bledý, spoután a ném / pod hypnosou Nepoznaného jdu se svym snem" (Pohled smrti / Blick des Todes, V. 15-16; "Wie ein Bettentlockter, bleich, gefesselt und stumm, / geh unter des Unerkannten Hypnose mit meinem Traume ich um"). Die Passivität des "vagen" Traumzustandes wird mit dem 'Gefesselt -' und 'OhnmächtigSein', mit der Unerfülltheit des traurigen Daseins oder mit der erotischen Sehnsucht assoziiert. In diesem Fall stellt der "sen" ("Traum") jenen spezifischen Zustand eines wehmütigen, leiderfüllten 'Sich-Bewußt-Werdens' der Unerfülitheit (Litost / Die Wehmut) dar. Die schöpferische Traum-Extase des fieberhaften 'Niederschlags der Ideen' (Modlitba vecerni / Das Abendgebet, $O$ silo extasi a snú / $O$ Kraft der Extasen und Träume, Motiv $z$ Beethovena), die die Offenbarung des "größten Geheimnisses" und die Erkenntnis des "Unbekannten" und "Unerkannten" ("Neznámého", "Nepoznaného") ermöglichen soll, wird

108 In der Phase des eschatologischen Symbolismus entährt das 'Vergessen' eine völlig andere, vorwiegend negativ konnotierte Semantik einer ominösen 'Amnesie'. die den Identitāsverlust bedeutet, mit dem der träumende autistische Künstler-Mensch für seine gewollte Isolation bestraft wird: "Trest slabých bude, że zapomenou své jméno pr̂i procitnuti, / a odmèna silných, że v záfíci tmè vzpomenou na ostrovy zajeti svého" (Vino silných / Der Wein der Starken. V. 45-46; "Strafe der Schwachen wird sein, daß sie beim Erwachen ihren Namen vergessen. / und Lohn der Starken, daß sie in strahlender Dunkelheit der Inseln ihrer Gefangenschaft gedenken"). Âhnlich in Mučnnici (Märtyrer; dritter Gedichtzyklus Vètry od pólü / Polarwinde, 1897), wo die Polarität von 'Ewigkeit' und 'Augenblick' hervorgehoben wird: 'Mučennici ticha: Mystického ptáka slyšeli péti, věky prožili ve vterinách, / a když se procitli vrátili do mést, nikdo uż neznal jejich jména" (VI, 1-2; "Märtyrer der Stille: Den mystischen Vogel hörten sie singen, die Äonen durchlebten sie in einer Sekunde, / und als sie, erwacht, in die Städte heimkehrten, da wußte schon niemand mehr ihren Namen"). In Vteriny (Sekunden; zweiter Gedichtzyklus Svitáni na zapadẻ / Tagen im Westen, 1896) symbolisiert das gespenstige "Ticken" der "hundertiährigen Uhr" die Kurzfristigkeit und Vergänglichkeit des (immanenten) Lebens.

109 -Nevykơristěné, vágni snéni, tak drahé umělaim, jest a zủstane rezem, jenż rozžirá duši a zeslabuje vüli I...F. Vgl. Dopisy Otokara Bïeziny Frantisku Bauerovi, 1929, S. 187 (Brief v. 20. IV.

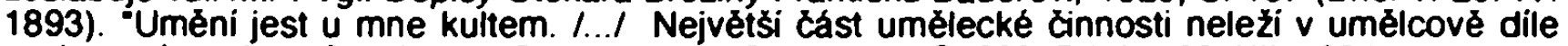
zachyceném, ale v sile a intenzité jeho snu I...." (vgl. ibid., S. 200; Brief v. 20. XII, 1894). 
in den späteren Gedichten dieser Phase durch erschöpfende, betörende und betäubende, bannende und deaktivierende Sinneseindrücke und Erlebnisse verdrängt: "dusivý sen" ("drosselnder Traum", Snad potom...I Vielleich dann...); "Ó dálky a noci, I mdloby a sny!" ( $Z$ vẻčných dálek... / Aus ewigen Fernen... VI, 1-2; "O Fernen und Nächte, / Ohnmächte und Träume!") usw. Die Hoffnung auf die Offenbarung des "ewigen Geheimnisses" 'verfüchtigt sich', 'schmilzt', 'zerfließt', 'destilliert', 'schwindet' im Unwiederbringlichen, in der Ferne usw.

"/... I nastala doba soumrakủ, vitr Neznámého se zdvihá $v$ alejich / a ani jedna veselá pisen̆ nezni mi z dálky" (Lítost / Die Wehmut, letzter Zweizeiler; "die Zeit der Dämmerung brach an, der Wind des Unbekannten erhebt sich in den Alleen / und kein einziges fröhliches Lied tönt zu mir aus der Ferne"). "/../ zpěv marné touhy hlaholici v snech" (Vonné soumraky / Wohlduftende Fernen. VIII, 1; "Der Gesang der vergeblichen Sehnsucht, der in den Träumen schallt"). "V těch chvilich smutek mủj byl jediným vzedmutim vẻćného smutku /../ pod nẻmými klenbami noci, / z nichž vỷkřiky otázek vraceji se echem vysileným dálkou / bez odpovědi" (Slavný smutek / Erhabene Trauer, IV, 1. 4-6; "In diesen Augenblicken war meine Trauer ein einziges Emporheben der ewigen Trauer /.../ unter den stummen Gewölben der Nächte, / aus denen die Schreie der Fragen wie ein von der Ferne entkräftetes Echo zurückkehren, / ohne Antwort").

In Návštěva (Besuch) und vor allem in Znameni duše (Das Zeichen der Seele) wird der hypnotisierende Traum durch das Gift des "süßen Erinnerungskusses" vergiftet. 110 In einem der Schlüsselgedichte des zweiten Gedichtzyklus, in Vino silných (Der Wein der

110 In der weiblichen Gestalt aus dem Gedicht Znameni duše (Das Zeichen der Seele) glaubt O. Králik (Otokar Briezina, Praha 1948, S. 65) das Phantom der toten Mutter zu erkennen. Diese Deutung scheint auch das verwandte Motiv der den Sohn küssenden (toten) Mutter in Moje matka (VI, 3-4) zu unterstützen. Daß die beiden Gedichte miteinander 'dialogisieren' ist außer Zweifel. In Znameni duše wird allerdings (in der letzten Strophe explizit) das Thema der erotischen Liebe aktualisiert, das die biographische Motivation, die in Moje matka dominiert, sprengt. Das Bild der toten Mutter in Znameni duše changiert zum Bild des betörenden, durch das 'süße' Liebesgift 'tötenden' Weibes, das die Seele sogar mit (latentem) Inzestwunsch vergiftet: "A púlnoc zelená kdyż sviti nočnim tišim, / ty z hrobu povstávás a se mnou lože sdilíš; / v svém dechu známý rythmus svého dechu slyšim / a vinou mého hlasu oživená kvilis" (Moje matka / Meine Mutter, VII. Str.: "Und wenn die grüne Mitternacht in die nächtliche Stille leuchtet, / da schwebst du aus dem Grabe und teilst mit mir das Lager / in meinem Atem höre ich bekannten Rhythmus deines Atems / und belebt von der Welle meiner Stimme klagst du"). "Nikdy nezr̉el jsem Żeny, jíz z tvári svitil by úsmèv jak z tvých, / a kdybych ji už̉el, květen bolestné lásky v má okna by dých (Znameni duše / Das Zeichen der Seele. III, 1-2; "Niemals erblickte ich eine Frau, auf deren Wangen das Lächeln so strahlen würde wie auf den deinigen, / und wenn ich sie erblicken würde, würde der Mai der peinigenden Liebe an meine Fenster hauchen"). Der ' $G$ if $t$ kuß' des (mythischen) MutterMeibes führt zur Symbolik der Giftschlange, deren fakultative Bedeutung in Znameni duse nicht nur die des (in der Jungschen Terminologie) der Mutter gegenüber verbotenen "negativen Phallus". sondern auch (als eines der Symbole der Introversion) die der "Hütterin der Schwelle" sein kann. In bezug auf die Tiefenpsychologie muß die Schlange überwunden werden, $d . h$. das Unbewußte muß besiegt und die sohnhafte. schmerzvolle und unbewußte Fixierung an die Mutter aufgegeben werden. (Vgl. dazu: C. G. Jung. Studien über alchemistische Vorstellungen, Gesammelte Werke, Bd. 13. Olten-Freiburg im Breisgau, 1978. S. 362f.). Signifikanterweise fürchtet sich das lyrische Subjekt die "Süße" dieses 'Giftkusses' auszukosten: "jak otráven sladkosti polibku, jejż by se utrhnout bár (Znameni duše / Das Zeichen der Seele. III, 4; "wie von der Süße des Kusses vergiftet, den ich zu pflücken fürchten würde"). Ein intertextuelles Indiz mag der Vers "kvèten bolestné lásky" (Znameni duše, III, 2; "Mai der schmerzvollen Liebe") bergen, wenn man ihn als eine Allusion auf den bekannten Vers der lyrisch-epischen Erzählung Máj (Der Mai, 1836) von K. H. Mácha liest: "veðerni máj - byl lásky Cas" ("ein Abendmai - der Liebe Zeit"). Bỉezinas "Mai der schmerzvollen Liebe" ("květen bolestné lásky") kann möglicherweise als eine Kontamination von zwei Máj-Versen ("večerni máj - byl lásky Cas" und "Bez konce láska je! - Zklamánat' láska má!"), d. $h$ als Anspielung auf die Auffassung der erotischen (profanen) Liebe als Quelle der unendlichen, schmerzvollen Enttäuschungen verstanden werden, wie sie in Máchas Máj thematisiert wird. Die Allusion auf Máj scheint nicht zufällig zu sein; im folgenden Gedicht Litost (Die Wehmun charakterisiert das lyrische Subjekt seine seelische Verfassung: "Mám v duši lítost věznè v den slavnosti májovych" (V. 26; "In meiner Seele weilt die Wehmut eines Gefangenen am Tage der Maifeste"). Auf die Analogie zwischen "Gefangenem" ("vězeñ") aus dem zweiten Gesang von Máchas Maj und "Gefangenem" aus dem gleichnamigen Gedicht von Biezina hat bereits $F . X$. Salda aufmerksam gemacht. Das Motiv der paralysierenden, wie ein Gift wirkenden Erinnerung in der Lyrik des russischen Symbolismus untersucht A. A. Hansen-Löve (Der Russische Symbolismus. Wien 1989, S. 291). 
Starken), wird das Motiv des 'Gift-Kusses' (der Erinnerung) aus Znameni duše zum 'GiftTraum' des diesseitigen Lebens umkodiert: "a otráveni snem zemreme pied svou smrti a po smrti budeme Ziti" (V. 11; "und vergiftet von Traum sterben wir vor unserem Tode. um nach dem Tode zu leben"). In Litost (Die Wehmut) fungiert der 'luzide' Traum nur als Folie des wehmütigen Sich-Bewußt-Werdens der Unmöglichkeit sich von der entkräftenden Lethargie zu befreien und am "Fest der Erde" ("slavnost zemë") teilzunehmen: "Mám v duši lítost vězně $v$ den slavnosti májových, / litost milence u dverí chrámu $v$ den zasnoubeni", V. 25-26; "In meiner Seele weilt die Wehmut des Gefangenen am Tage der Maifeste, I die Wehmut des Liebhabers an der Tür des Tempels am Tage der Verlobung"). im pessimistischen Gedicht Svij żal jsem polożil ... (Mein Leid legte ich ...) wird die schon ausgetrocknete Quelle der schöpferischen Kraft, die Traum-Inspiration, noch einmal 'wiederbelebt'. Der Preis dafür ist allerdings der ewige und ziellose "Galvanismus des Leidens" ("galvanismus bolu"): "V květ sněni uvadlý tvưj soucit rosou dých / a v lože vihké slét mi, kdyż $v$ nẻmé bolesti jsem poklad hodin tvých / jak cerné krystaly ti vylamoval ze tmy" (I, 5-8; "In die verwelkte Blüte des Träumens hauchte dein Mitleid mit Tau / und sie sank auf mein feuchtes Lager, / als ich im stummen Schmerz den Schatz deiner Stunden / wie die schwarzen Kristalle dir aus dem Dunkeln brach"). ${ }^{111}$ In einigen Gedichten von TD (Snad potom ... I Vielleicht dann...; Litost / Die Wehmut; Slavný smutek / Die erhabene Trauen pervertiert der positiv semantisierte Traum - das Refugium, in dem sich das dichterische Ich vor dem unerträglich profanen (Alitags-)Lebens verschanzen will, die Quelle seiner Inspiration und schöpferischen Extase - zum "drosselnden" Alptraum des von Resignation, Trauer und Nihilismus paralysierten Künstler-Daseins.

In einer ähnlichen Weise verwandelt sich in diesen Gedichten auch der positiv konnotierte und gewertete 'Kunst-Tod', der in Modlitba vecerni (Das Abendgebet) oder in Motiv z Beethovena (Ein Motiv aus Beethoven) als 'Befreier' aus der Knechtschaft der irdischen Existenz, aus der Gefangenschaft der Materie und als 'Initiator' der Offenbarung des "ewigen Geheimnisses" ("věnè Tajemstvi") semantisiert wird, in zerstörerische Auflösung des Seins im Brand der Apokalypse:

" .../ a k vychladlé zemi jak uhelný milií, setlelý v kourii, / se zríti udušen život pod nánosem vékủ a bourf" (Snad potom.../ Vielleicht dann ... III, 3-4, \%.../ und zur erkalteten Erde wie ein im Qualm erlosctiener Kohlenmeiler, / wird das Leben erstickt unter der Ablagerung von Äonen und Gewitter herunterstürzen"). "I../ a na žhavých plotnách mého żiti / v pẻnivém klokotá varu I nápojem smrti mé, 2 nějž budu piti / Mysterium zmaru* ( $Z$ věčnỳch dálek .../ Aus ewigen Femen. IX, $1-4 ; \%$ I... und auf meines Lebens glühenden Herdplatten / brodelt es im schäumenden Sieden / im Trunk meines Todes, aus dem ich / das Mysterium des Verderbens trinken werde"). "Do prázdna vtéká cas a chvi se nočni stíny. I U Cemých morii prostoru se strhly hráze. I Vystriikla hustá péna tmy a do hlubiny / zem pohlcená sesmykla se na své dráze" (Podzimni večer / Herbstabend. V. 1-4; "Ins Leere fließt die Zeit und es beben die nächtlichen Schatten. I An schwarzen Meeren des Raumes brachen die Dämme. / Ein dicker Schaum der Finsternis spritzte hoch und in die Tiefe / rutschte die aufgesaugte Erde von ihrer Bahn ab")

Signifikanterweise schwinden nicht nur die Träume, sondern auch das Sein in 'unermeBliche' Leere, in 'bodenlose' Tiefe oder in 'undurchdringliche' Finsternis. $d . h$. in einen Raum der definitıven Annihilierung (Podzımni vecer I Der Herbstabend, $Z$ vécných dálek... I Aus ewigen Fernen.., Pohled smrti / Der Blick des Todes, Litost / Die Wehmut, Slavný smutek / Erhabene Traver). Die "ewige Ferne" ("vě̌ná dálka") ist auch das Schlüsselmotiv dieser Gedichte; eine ominöse, furchteinflößende Vision der 'unbekannten', 'unendlichen', 'entkräftenden' und 'trostlosen' Ferne, die dem ganzen Gedichtzyklus seinen Titel einprägt. ${ }^{112}$ In Modlitba vecerni (Das Abendgebet) gibt sich der Dichter, wie es scheint, der Illusion hin, das Ziel, das in der 'Ferne' liegt, erreichen und das "ewige Geheimnis" durchdringen zu können. In den letzten Gedichten des Zyklus wird das Erreichen dieses Ziels resigniert als 'Trugbild' bloßgelegt. Die Kluft zwischen Immanenz und Transzendenz, zwischen den begrenzten Möglichkeiten des Menschen und der

111 In seinem Brief an Anna Pammrová aus dieser Zeit (Frūhjahr 1895; Dopisy Annè Pammrové z let 1889-1905, Praha 1931) nennt Bỉezina die Dichter "geniálni lamaći ve věćných dolech snu" ("geniale Steinbrecher in ewigen Steinbrüchen des Traumes").

112 Die Vorstellung des weiten, endlosen Weges wurzelt, wie Hans Jonas (Gnosis und spätantiker Geist", Teil 1,2, Göttingen 1964. S. 99t.) an stattlichem Material behandelt, in der gnostischen Tradition. Die Seele (des Gnostikers) irt in der diesseitigen Welt wie im Labyrinth "voller Pein". 
Omnipotenz des "Höchsten" scheint unüberbrückbar zu sein. Das "Geheimnis" ("Tajemstvi") wird zum Äquivalent der unendlichen, erschöpfenden 'Ferne' und die Ambitionen des Kunst-Schöpfers, der die Natur-Welt, das ganze Universum durchdringen will, um die absolute Erkenntnis zu erreichen ("At všecko obsáhnu, všech cile drah a cest. I co vidim a mrít a rủst a kvést a zrát", Modlitba večerni / Das Abendgebet, VI, 1-2; "Daß ich alles erfasse, die Ziele aller Bahnen und Wege, I was ich leben und sterben sehe. wachsen und blühen und reifen"), schrumpfen zum freiwilligen 'Eingemauertsein' im Gefängnis einer 'Schein-Welt', in der "Grabesstille der Bibliotheken" ("v hrobových tišich biblioték", Z věčných dálek / Aus ewigen Fernen, VII, 2) oder zum 'erhabenen' Solitudo "unter den stummen Sterngewölben der Nächte" ("pod hvězdnými klenbami noci", Slavný smutek / Die Erhabene Trauer, V. 17). Die positiv konnotierte Initiation durch den KunstTod wird zum quälenden Irrsal, zum Sich-Verlieren in der trostlosen Endlosigkeit der Ferne; ein Motiv, das in den letzten Gedichten Brezinas (nach 1901) in eindringlich expressiver Weise wiederaufgenommen wird: "Nad hlavou listi šumici v neviditelné doubravě, / jou vẻčnẻ, dálkou šlleni a bičovani v únavě" (Ztraceni / Die Verlorenen, V, 12; "Rauschendes Laub über dem Haupt im unsichtbaren Eichenwald, / so schreiten sie ewig. wahnsinnig von der Ferne und gepeitscht von der Müdigkeit"). 


\subsubsection{Entgrenzung der absoluten Erkenntnis durch den Tod Modlitba večerni (Das Abendgebet)}

\section{Modlitba večerní}

I. O smrti Ł̌ivých têl, jỉ̌̉ noc se stává dnem. svou Šcávu tajemnou lej $v$ moji teplou krev, svou mdlobou smrtelnou mne spoutej v loži mém. je mèkká nárué tvá. jak bilé lokty děv. Ty vůni zázračná, $z$ niž voni jiný svêt, mủj zemský Żivot ztaj a nadpozemský zvlñ a proseb Zár a šleh. jenž spaluje mi ret a $v$ tvári rudý plá, mi v duši ztiš a splň!

II. V mých ởi tmavou svítilnu, se svatá. schyl. lej nový olej $v$ ní a zapal poznáni. at zrakú paprskem žrím na tisíce mil $v$ šer mờských pralesủ a výsí rozpláni; jak krystal s krystalem se skládá v lủnè skal. jak květů pletivem se prýská barev jas. jak život vzbouzí se, jenž $v$ lüně hmoty spal $v$ bytostí nekonex̃ný kvêt a vír a kvas.

11I. A silou zvýšenou můj obdar̆ lidský sluch. at $v$ resonaněni nástroj se mi promění. jímž preléváni štáv a vzrưstu skrytý ruch jak hudby tajemné at slyším vlnění: at citim rostlin puls i hudbu hvězdných dráh. paprsků svêtla lom a vzduchu ráz a క̌um. motýlů tichý let a $v$ duši hlubinách myక̧lenek tajný vznik a zápas, vír a tlum.

IV. Od mojí myšlenky odpoutej zemskou tíž. at svêtila rychlostí prostorem šlehá $v$ let. nad mołi zelenou a kfiłš́lovou fî́s $v$ hloub sopek vyhaslých i $v$ zemé žhavý střed; $\checkmark$ noc vexnou propastí al bleskem zaletím. kde z złídel ohnivých se žhavý tryská var. do jeskyñ plačících. jichž slzy staletím $v$ sen tuhnou kamenný pod baldachýnủ tvar.

V. A v tocen dlouhou noc, kde věnný led a sníh na skalách krištálu polárni záfí plá. i v jihu smavý kraj, kde odalisek smich $v$ zahradách sultánù jak hudba vł̌e a vlá. nad vłavou národủ a poušti němý stesk. kde rythmem sesláblým umirá žití tep. nad cemé pralesy a horských štítủ lesk. nad zeleñ prerií a zádumçivou step.

VI. Al vక̌ecko obsáhnu, vłech cille drah a cest. co vidím Zít a mř́t a ri̊st a kvést a zrát. sil Ł̌vých věxný krah, jenž konstelace hvězd v své sítě navléká a fídí vzlet a pád. jenž trpi v duši nám a voní v liliji a modrým plamenem nad bažinou se stkví: ai douškem jediným já žizniv opiji na błezích vě̌nosti se vínem Tajemství. 
VI. V mé tělo pronikni a v každý nerv a sval se $z$ tajných zdrojủ svých mi rozlej balsámem. jak láva vytryskni a hờ a teč a pal. $\checkmark$ rozkoši క̌ilených vzplanutí neznámém: až smolnou pochodní zádostí zhavý dech na popel dohoři tajemným ohnêm tvým. tu dechni $v$ zelo mé a usnouti mne nech $v$ sen věcný, poslední, z něhož se nevzbudím.

\section{Das Abendgebet}

I. O Tod der lebendigen Leiber, durch den die Nacht zum Tage wird, gie $B$ deinen geheimnisvollen Saft in mein warmes Blut. fessle mich mit deiner Todesermattung in meiner Schlafstätte. deine Arme sind weich wie weiße Ellbogen der Mädchen! Du wundersamer Duft, aus dem die andere Welt duftet. verhülle mein irdisches Leben und laß das überirdische sich wellen. und der Bitten Glut und Brand, der meine Lippen sengt. und als rote Flamme im Antlitz. lodert, stille in meiner Seele und erfülle ihn!

II. In meiner Augen dunkle Laterne senke dich, Heilige, gieß neues Öl hinein und zünde die Erkenntnis an. daß ich mit strahlendem Blick tausend Meilen weit sehe in die Dämmerung der Meeresurwälder und in die Entflammung der Höhen. wie Kristall sich mit Kristall im FelsenschoB aneinanderfügt. wie der Farben Glanz durch das Blütengeflecht spriht, wie das Leben erwacht, das im SchoB der Materie schlummerte in endloses Blühen und Wirbel und Gärung der Wesen.

III. Und schenke meinem meschlichen Gehör die erhöhte Kraft. daß es sich in ein Resonanzinstrument verwandle. mit dem ich das Umgießen der Säfte und das verborgene Treiben des Wachsens wie das Vibrieren einer geheimnisvollen Musik höre: daß ich den Puls der Planzen und die Musik der Stemenbahnen fühle. die Brechung der Lichtstrahlen und den StoB und das Rauschen der Luft. den leisen Flug der Schmetterlinge und in den Abgründen der Seelen die geheime Entstehung der Gedanken und den Kampf. Wirbel und die Dämpfung.

IV. Von meinem Gedanken entfessle die irdische Schwere. daß er mit lichtgeschwindigkeit durch den Raum im Fluge saust in gruines und kristallines Reich über den Meeren. in die Tiefe erloschener Vulkane und in gluhende Erdmitte: $\mathrm{daB}$ ich in ewige Nacht der Abgründe wie ein Blitz fliege. wo aus feurigen Quellen glühende Siedenhitze sprudelt. in weinende Höhlen, deren Tränen in Äonen zu steinemem Traum in der Form der Baldachine erstarren.

V. Und in die lange Nacht der Pole, wo ewiges Eis und Schnee auf Kristallfelsen im Polarlicht glitzem,

und in ein sonnenverbranntes Land im Süden. wo das Lachen der Odalisken. in Gärten der Sultane wie Musik brodelt und weht. über das Getöse der Völker und die stumme Wehmut der Wüsten. wo im geschwächten Rhythmus der Pulsschlag des Lebens stirbt. über die schwarzen Urwälder und den Glanz der Bergspitzen. über das Grün der Prärien und die schwermütige Steppe.

VI. Daß ich alles erfasse, die Ziele aller Bahnen und Wege. was ich leben und sterben sehe und wachsen und blühen und reifen. den ewigen Kreis der Lebenskraft. der die Stemenkonstellationen in seine Netze zieht und den Aufstieg und den Fall lenkt. 
der in unserer Seele leidet und in der Lilie duftet und als blaue Flamme über dem Moor leuchtet. $\mathrm{da} B$ ich mich, durstig, in einem einzigen Zug an den Ufern der Ewigkeit mit dem Wein des Geheimnisses berausche.

VII. Meinen Körper durchdringe und ergieß' dich in jeden Nerv und Muskel, wie der Balsam aus deinen geheimnisvollen Quellen, spritze wie Lava auf und glühe und fließe und brenne. in unbekannter Wollust wahnsinniger Entflammungen: wenn als Pechfackel der glühende Atem der Sehnsüchte zur Asche verglimmt in deinem geheimnisvollen Feuer, dann hauche auf meine Stim und laß mich einschlummern, in ewigen, letzten Traum, aus dem ich nicht mehr erwache.

Die Irrealisierung der diesseitigen Welt durch das Erlebnis des Todes wird in Moditba vecerni (Das Abendgebet) als eine paradoxe Bedingung für die absolute Erkenntnis postuliert. Dieses aporetische Gebet an den Tod weist auch andere charakteristische Merkmale eines dekadenten Diskurses auf: die Sakralisierung und gleichzeitig auch Erotisierung des Todes, die Asthetisierung des Untergangs, das Verlangen nach der Entgrenzung bzw. Auflösung von Raum- und Zeit im Traum-Zustand, der wiederum als das Tor in das Reich des Thanatos apostrophiert wird. Biezina selbst betrachtete Moditba vecerni als einen der Schlüsselgedichte seiner ersten Schaffensphase, was auch die spätere Auseinandersetzung mit ihm, vor allem in Ranni modlitba (Das Morgengebet, SZ, Kap. 3.1.2), zu bestätigen scheint.

In der Sehnsucht nach der Entschleierung des "ewigen" (kosmischen) Geheimnisses ("vě̉né Tajemstvi") und der Naturgesetze der immanenten Welt durch die absolute Erkenntnis, postuliert der Dichter die Erforschung des gesamten Kosmos durch den (mystischen) Tod, denn nur er, der Grenzen lose, kann alle zeitlich-räumlichen Grenzen niedereißen. Die Vorstellung, daß bei dieser Erkenntnis gerade die sinnliche Erfahrung (durch sensi exteriori) eine eminente Rolle spielt, scheint den (noch) positivistisch fundierten Hintergrund dieses Gedichts zu verraten. Unter diesem Blickwinkel betrachtet. stellt Modlitba vecerni einen noetisch-mystischen, als ein Gebet an den Tod arrangierten Gedichttext dar.

In der bisherigen Bïezina-Forschung liegen mehrere Interpretationen des "Abendgebets" 113 vor; seine exponierte Position in Březinas Werk wird von allen Interpreten hervorgehoben. ${ }^{114}$ Große Aufmerksamkeit gilt nach wie vor der vieldiskutierten

113 Aus dem Jahre 1892. Das Gedicht besteht aus sieben achtzeiligen Strophen, wobei jede Verszeile - im sechsfüßigen Jambus mit zum größten Teil männlich klausulierten Reimen - in zwei Halbverse unterteitt ist.

114 Die bisher ausführlichste Analyse der formalen Besonderheiten von Modlitba vecerni veröffentlichte Pavel Fraenkl (Otokar Blezina. Genese dila. Praha 1937. S. 217ff). Er untersucht zunachst den Vershythmus und stellt fest, daß der sechsfüßige Jambus hier die Funktion eines "Wegweisers des psychischen Tempos" erfült. Im folgenden weist er darauf hin, daß Brezina jeweils drei einsilbige Substantiva mit ebenso einsilbigen Infinitiva kombiniert, die er mit der kurzen, unbetonten Konjunktion "a" verbindet, wobei dieses Verfahren im ersten Fall (II, 8) das sich entfaltete organische Leben, im zweiten Fall aber (III, 8) die Entfaltung der geistigen Potenz symbolisiert. Diese verssemantischen Spezifika werden einerseits durch die Verwendung von inythmisch-äquivalenten einsilbigen Imperativa ("a hor a tec a pal", VII, 3) oder andererseits durch die Entfaltung einer solchen Reihe in eine fünfgliedrige Infinitiva-Einheit der gieichen mythmischen Kette ("co vidím żit a mrít a rủst a kvést a zrát". VI, 2) verstärkt. Aufschlußreich ist Fraenkis Untersuchung zur Zeit-Raum-Darstellung in Modlitba vecemi und sein Vergleich der Versstruktur von Modlitba večemi mit der von Máchas Máj. Als das gemeinsame Merkmal betont Fraenkl die Verwendung des einsilbigen Substantivs im Nominativ (z. B. Mácha: 'tón' - 'déj' - 'ráj'; Bíezina: 'lom' - 'let' - 'vznik') sowie die charakteristischen Anhäufungen von attributiven Genitiva (z. B. Mácha: "zborténé harty tón" - Bỉezina: "paprskú světia lom", III, 6). Problematisch ist allerdings Fraenkels Erfassung der Position von Modlitba večerni innerhalb des ersten Gedichtzyklus (er sieht in ihm ein Initiationsgedicht der Natur-Lyrik von Tajemné dálky) und vor allem seine Erfassung der hauptsemantischen Werte von Modlitba vecerni. Er erkennt zwar richtig den faustischen Typus des dichterischen Ich, seine Schlußfolgerung ("Seine Isolierung versucht Otokar Biezina durch den Todesmystizismus zu überwinden". " "Svou isolaci touži prekonat Otokar Błezina aktem mysticismu smrti") ist jedoch eine ad hoc formulierte Behauptung. die im Text 
ersten Verszeile: "O smrti živých těl, již noc se stává dnem" ("O Tod der lebendigen Leiber, durch den die Nacht zum Tage wird". 115 Der "Tag" ("den") kann in diesem Zusammenhang als ein metonymisches Symbol der postulierten Erkenntnis gelesen werden. Die bisherigen Interpretationen lassen außer acht, daß der letzte Zweizeiler ("tu dechni v čelo mé a usnouti mne nech / v sen věčný, posledni, z něhož se nevzbudím", VII, 7-8: "dann hauche auf meine Stirn und laß mich einschlummern, / in ewigen, letzten Traum, aus dem ich nicht mehr erwache") eine Art inversen Spiegel-Bildes der zitierten ersten Verszeile $(I, 1)$ bildet, nämlich als Sinn-Konkretisierung des Anfangsverses. Die absolute Erkenntnis, der "Tag" (der zugleich die Helligkeit impliziert, in der sich die Welt, deren Gesetze nun erforscht und erkannt werden sollen, artikuliert), soll paradoxerweise durch den "Sturz" in den "letzten, ewigen Traum", ja durch den Tod (VII, 8), erreicht werden. Diese Inversion ist hier offensichtlich auf die Tradition des gnostisch-christlichen Diskurses zurückzuführen. Nach dieser Tradition wird die pneumatische Auslegung im 'Hintersinn', der den 'Vordersinn' paradoxerweise umkehnt, gesucht. 116 Demnach ließe sich das irdische Leben - als das luzide Leben - auf dem Territorium der immanenten Welt auch als Todesmetapher deuten; die "lebendigen" (hyletischen) "Leiber" des Tages sind eigentlich, wie es scheint, die "toten", mortifizierten und im Nichts (der Nacht) annihilierten Leiber. Erst durch den Tod, durch die Absage an das in zeit-räumlichen Grenzen gefangene Leben, erst durch das Überschreiten jeglicher Grenzen und nach der Verwerfung des Körpers als Seelengefängnis, wird die "ewige Nacht" zum Tag des "ewigen Traumes", des ewigen, rein pneumatischen Lebens, das in der gnostischen Tradition mit der (absoluten) Erkenntnis eine Einheit bildet. Eine ähnliche, doch nur scheinbare Paradoxie manifestiert sich darin, daß die totale Entgrenzung des geistigen Erkenntnisvermögens die totale Bogrenzung und Fesselung des (hyletischen) Körpers voraussetzt: "svou mdlobou smrtelnou mne spoutej v loži mém" (1, 3; "fessle micht mit deiner Todesermattung in meiner Schlafstätte ${ }^{\prime}$ ). Das Verlangen nach der absoluten Erkenntnis schreckt selbst vor der Vernichtung nicht zurück. Im Gegenteil. Der erotisierte und ästhetisierte Tod wird als "Silená rozkos" ("wahnsinnige Wollust", VII, 4) konkretisiert und nicht nur als Medium der Erkenntnis, sondern auch als Wert 'an sich' postuliert. Die Sehnsucht der von absoluter Erkenntnis faszinierten Seele des dichterischen Ich nach der Erforschung der kosmischen Gesetzte steigert sich beinahe zur Besessenheit, in die

keinen Anhaltspunkt findet. Fraenki untersucht zwar eingehend die formalen Aspekte, die hochrelevanten semantischen Prăssupositionen des Textes lăßt er völlig außer acht. Sehr kompetent interpretiert Modlitba vecemi Urs Heftrich (Otokar Błezlna, Heidelberg 1993, S. 71ff.). Das Neue an seiner Interpretation ist die Feststellung, daß das postulierte "noetische Wunder". das mit den natürlichen Wahrnehmungsorganen erreicht werden soll, in eine "erkenntnistheoretische Aporie" mündet. Die Paradoxie: "Tod" als Weg zum reinen Erkennen rückt $U$. Heftrich in die unmittelbare Năhe des Schopenhauerschen "willenlosen Erkennens".

115 Salda (.Vjuoj a integrace v poesii Otokara Bleziny“, in: Duše a dilo, Praha 1937, S. 207f.) interpretient die Todessymbolik in Modlitba vecerni einerseits als erotische Metapher - "smrt" ("Tod", im Tschechischen ein Femininum) als faszinierende, verlockende 'Geliebte -, andererseits als Ausdruck des "hedonistischen Pessimismus" Bỉezinas, der in diesem Gedicht bis zu einem "selbstmörderischen Krampf" ("kỉeč sebevražednou", ibid. S. 211) gesteigert wird. Vgl. dazu auch die Deutung von Jaroslav Kabeš. "Filosof vủle a jeho myslitelské dilo", in: Stavitel chrámu. Památnik bảsniką a myslitele Otokara Bł̌eziny, hrsg. v. Em. Chalupný u. a., Prana 1941, S. 100. Die Auffassung Saldas teilt Kabes nicht und weist die These von dem "selbstmörderischen Krampf" zurück. Z. Záhớ (in: Ders., Otokar Bỉezina. Essaye, Praha 1928, S. 26) deutet die zitierte Verszeile als Ausdruck des "somnambulen Schlafes". O. Králik (Otokar Brezina. Praha 1948, S. 46) stimmt dieser Deutung mehr oder weniger zu. U. Heftrich (Otokar Březina, Heidelberg 1993, S. 369. Anm. 173) weist sie energisch zurück mit der schlüssigen Begründung, jene die zitierte Verszeile durchwirkende Paradoxie wäre dann lediglich eine "manierierte Umschreibung eines psychologischen Phänomens; während sie nach der vorgeschlagenen Deutung die Einsicht in die erkenntnistheoretische Aporie pointiert zum Ausdruck bringt". (Ibid.). Brezina-Übersetzer Emil Saudek versucht sogar Modlitba vecerni als Dialog der Seele des dichterischen Ich mit der Hoffnung zu deuten. (Vgl. E. Saudek. E.. . Tři modlitty Ot. Br̉eziny", in: Kalendár cesko-židovský. 70. 1934, S. 98ft). Dieser Fehlinterpretation liegt ganz offensichtlich ein Mißverständnis zugrunde. Das dritte Gebet-Gedicht Br̉ezinas, das Saudek im Sinne hat, ist Modlitba za neprátele (Das Gebet für die Feinde [1896] aus dem dritten Gedichtzyklus Vëtry od pólü / Polarwinde), das jedoch einem völlig anderen thematischen und semantischen Kontext angehört und weder mit Modlitba večemi, noch mit Ranni modlitba Berūhrungspunke aufweist.

116 Vgl. dazu: Hans Jonas, Gnosis und spätantiker Geist, Teil 1,2, Göttingen 1964, S. 2211. 
verborgene Intimität des Universums eindringen und bis zu unerträglichen Exzessen vordringen zu können. Das Exzessive und vollkommen Entgrenzte eines noetischen und ästhetisierten, thanatophil-masochistischen Aktes wird in der letzten Strophe zum Ausdruck gebracht: " $V$ mé télo pronikni a v každý nerv a sval / se z tajných zdrojü svých mi rozlej balsámem, I jak láva vytryskni a hoí a teć a pal, I v rozkoši ślených vzplanutí neznámém" (VII, 1-4; "Meinen Körper durchdringe und ergieß' dich in jeden Nerv und Muskel, / wie der Balsam aus deinen geheimnisvollen Quellen, / spritze wie Lava auf, und fließe und brenne, / in unbekannter Wollust wahnsinniger Entflammungen ${ }^{4}$ ).

Die gnostisch-ästhetische Handlung von Modlitba vecerni scheint jedoch einer Doppelkodierung zu unterliegen. Die Suche nach der absoluten Erkenntnis 'verläuft' parallel mit einer anderen Handlung, die man als (mystische) Wanderung der Psyche spezifizieren kann. Diese dualistische Paradoxie manifestiert sich auch darin, daß die unbegrenzte, absolute Erkenntnis der kosmischen Gesetze mit begrenzten - de facto physiologischen - Mitteln, nämlich durch die Sinnesorgane, erreicht werden soll. Auf den Psyche-Mythos (auch im Sinne der Durchgeistigung von amor vulgaris) alludiert eines der dominanten Motive des Gedichts, das lodernde Ö (bzw. die lodernde Öllampe oder die brennende Pechfackel) und die Varianten dieses Motivs: "svou కtávu tajemnou lej $v$ moji

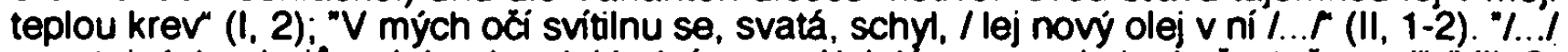
se z tajných zdrojü svych mi rozlej balsámem, / jak lava vytryskni a hoỉ a teč a pal" (VII, 2 3). Das Motiv der Entflammung (und des anschließenden Verglühens) bezieht sich offensichtlich auf die Transmutation des Körpers, der fleischlichen Behausung, ${ }^{117}$ zum Übersinnlichen und Transmateriellen.

Bei der Analyse dieses dekadenten Abendgebets kann man von der Sa kra lisierung ("svatá" / "die Heilige", II, 1) und Erotisierung ("svou mdlobou smrtelnou mne spoutej v loži mèm / je mẻkká náruč tvá, jak bílè lokty dẻv' 1,4 ) des Todes in der ersten Strophe ausgehen. Diese Sakramentalisierung ist schon dadurch gegeben, daß die Form, in der sich das dichterische Ich an den "Tod" wendet, die eines G e b e t s ist. Die Attribute der magischen Kraft des Todes, der "geheimnisvolle Saft" ("svou Štávu tajemnou", I, 2) und der "wundertätige Duft" ("Ty vưni zázračná", I, 5), indizieren das Verlangen nach der (gnostischen) "nüchternen Trunkenheit", nach der Erkenntnis. ${ }^{118}$ In der II. Strophe konzentriet sich diese magische Kraft ihre Wirkung auf die Sphäre des Visuellen, explizit auf die Stärkung und maximale Schärfung der Sehkraft. $d$. $h$. des rationalen Sehens ("V mých odi I... I/ a zapal poznáni / at" zrakú paprskem zrím na tisice mil", II, 1-3), das dem dichterischen Ich zum neven, bisher unbekannten und unerahnten Sehen der Prozesse im Reich der geologischen und botanischen Natur (II, 4-8) verhelfen soll. Die irdische Welt "pulsiert" (III, 5) und bewegt sich nicht per se, sondern durch die translunare, 'himmlische' Welt, nach deren Erreichung sich die anima prima, die höhere, vollkommene Seele (vs. anima secunda, die niedere Seele, die im unmittelbaren Kontakt zum Physischen besteht) sehnt. Deshalb führt der Weg - im Bereich der Sinneswahrnehmung - vom Sehen (mehr konkret, mehr äußerlich) zum Hören (abstrakt. innerlich): "A silou zvỷšenou múj obdaỉ lidský sluch, at v resonančni nástroj se mi proméni, I... I jak hudby tajemné at slysím vinéni", III, 1-2, 4). Das Wachstum und die Fortpflanzung ("jak żivot vzbouzi se, jenż v lüné hmoty spal / a bytosti nekonecný kvêt a vir a kvas", II, 7-8; "pieléváni štáv a vzrưstu skrytý ruch", III, 3) gehören dem Bereich der Natur(funktionen), dem Tellurischen an. Im Prozeß der Erhebung der Seele verläßt diese

$117 \mathrm{H}$. Jonas verweist (a.a.O., S. 144) auch auf die in der orphischen Theologie des Griechentums vertbreitete Analogie "Leib ( $(r) \mu(x)$ - "Grab" ( $m \mu(x)$. Der 'Leib' heißt in der Gnosis ein 'Produkt' der diesseitigen Welt.

118 Die christlich-gnostische Tradition kennt die "Trunkenheit" (der Welt) auch als Zustand der Unwissenheit der Seele um sich selbst und ihren Ursprung. (Vgl. H. Jonas, a.a.O., S. 115-119). Diese Art der 'Trunkenheit' wird in einigen Gedichten Błezinas ebentalls thematisien (Kdyż napoj unavy ... / Wenn ich den Trank der Müdigkeit .... Motiv z Beethovena / Ein Motiv aus Beethoven. Vüné zahrad mé duše... I Der Dutt meiner Seele Gárten.... Zapomenuti / Das Vergessen u. a.). In Modlitba vecemi ist jedoch offensichtlich die "Trunkenheit (der Trank) des Wissens gemeint. $H$. Jonas zitiert in diesem Zusammenhang die Verse aus der 11. Ode Salomos: .Redendes Wasser kam an meine Lippen aus des Herrn Quell überreichlich. Ich trank und ward trunken von dem Wasser der Unsterblichkeit, doch meine Trunkenheit war nicht die der Unwissenheit, sondem ich verließ die Nichtigkeit". (Vgi. H. Jonas, a.a.O., S. 116 (Anm. 1]). In Modlitba vecerní heißt es: "At" všecko obsáhnu, všech cile drah a cest / $\infty$ vidím zít a mrít a nust a kvést a zrát, I .../ at douškem jediným já žizniv opiji / na bł̌ezich věcnosti ve vinem Tajemstvi" (VI, 1-2, 7-8). 
die tellurische Sphäre, sie wird von ihren irdischen Veranlagungen befreit und erreicht die kosmische (bzw. translunare) Sphäre. Das Organ der akustischen Wahrnehmung (sensus exterion), das die Signale der Außenwelt vernimmt und vermittelt, soll in ein "Werkzeug" ("at" $v$ resonanční nástroj se mi promèní" III, 2) transformiert werden, das die Wahrnehmung der Signale der höchsten Zone des Universums ermöglicht: "jak hudby tajemnè at slyším vinêni /.../ / i hudbu hvězdných dráh $/ . . / / /$ /../ a v duši hlubinách / myšlenek tajný vznik" (III, 4-5, 7-8). Ähnlich wird das Materielle in die Sphäre des Immateriellen intergriert ("a v duši hlubinách / myšlenek tajný vznik", III, 7-8). Die Phänomene der materiellen Welt ("krystal s krystalem", "v lưnẻ skal", "květư pletivem", "barev jas", "v lưnè hmoty", "bytosti nekonečný květ", II. Str.) werden durch abstraktere. an sich unsichtbare, unhörbare, sensoral nicht wahrnehmbare Phänomene substituiert (Adjektiva: "skrytý", "hvězzný", "tajemny", "tajny": Substantiva: "rostlin puls", "světla lom", "vzduchu ráz". "myšlenek /.../ vznik". III. Str.). Das Verlangen nach der totalen Entgrenzung, nach dem Loslösen des Gedankens von der Schwere der Materie, kommt in der vierten Strophe explizit zum Ausdruck: "Od moji myšlenky odpoutej zemskou tiž" (IV. 1). ${ }^{119}$ Die postulierte Befreiung von den Fesseln der natura naturata wird durch die Lexeme der Schnelligkeit und durch die wirkungsvoll kontrastive Gegenüberstellung der Oppositionspaare intensiviert: "at' světla rychlosti prostorem slehá v let": "hloub sopek vyaslých" vs. "zemè žhavý stred": "ze zrídel ohnivých" vs. "do jeskyñ placicich" (IV. Str.). Die Emporhebung des von der Materie der Natur-Welt - die der Zeit unterworfen ist gelösten Geistes mündet in eine "Entflammung wahnsinniger Leidenschaft" (" $v$ rozkoši silených vzplanuti neznámém", VII, 4), in eine Verzückung der Extase (furor divinus) des faustischen Künstler-Menschen. Die Erotisierung des Thanatos in der ersten Strophe scheint gerade in diesem Aspekt ihre Erklärung zu finden. Das Feuer manifestiert sich als Attribut des Geistes. Im semantischen Plexus von Modlitba vecerni scheint es auch als Allusion sowohl auf den Psyche-Mythos (als Katharsis und Befreiung der Seele durch das Leiden) als auch auf den Prometheus-Mythos zu fungieren. Das Feuer ist in der Tat das einzige Element, das mit der gleichen Bestimmtheit die beiden entgegengesetzten Werte symbolisiert: das Gute und das Böse. Als ignis coelestis erstrahlt es im Paradies, als ignis gehennalis brennt es in der Hölle. Es ist das lebenspendende Labsal und der destruktive Brand der Apokalypse, in dem der Leib, unsere irdische Wohnstatt, zum Opfer des infernalen Malefiziums fällt. Auch das Feuer der Erkenntnis kann jedoch zum ignis nocans - zum tötenden Feuer der Leidenschaft - ausarten: "aż smolnou pochodni zádostí żhavý dech / na popel dohoîi tajemným ohněm tým" (VII, 5-6; "wenn als Pechfackel der glühende Atem der Sehnsüchte / zur Asche verglimmt in deinem geheimnisvollen Feuer"). Wenn aber der "wahnsinnigen Leidenschaft" (amor vulgaris) das Chthonische entnommen wird, wenn das 'natürliche Verlangen' durch die Erkenntniskräfte kontrolliert wird, kann das "ewige Geheimnis" entschleient werden. Das Feuer der Erkenntnis von der Fackel des Prometheus, die an den Rädern des Sonnenwagens (rota solis) entzündet wurde, zieht Bestrafung nach sich: Für sein geistiges Erwachen wird der Mensch durch das Nachdenken, durch die quälende Sehnsucht nach der Erkenntnis bestraft, und in dem Augenblick, in dem der Gequälte wieder zu sich kommt, beginnt die Marter von neuem. Die einzige Möglichkeit dieser Pein zu entrinnen, wäre für das Ich ein Endzustand der

119 Vgl. hierzu die Vorstellungen der neoplatonischen Tradition des 15. und 16. Jahrhunderts. Die Florentinischen Gelehrten Marsilio Ficino (Theologica Platonica), Pico della Mirandola u. a. unterscheiden vier Rangordnungen des Universums: 1. den Weltgeist (Novis. mens mundana), der

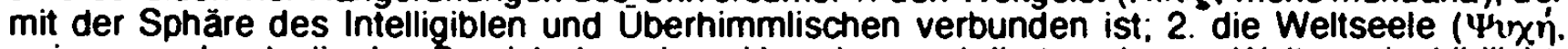
anima mundana), die den Bereich der reinen Ursachen und die translunare Welt versinnbildlicht: 3. das Reich der Natur (die sublunare oder irdische Welt), die vergänglich ist, denn sie besteht aus Form und Materie und, 4) das Reich der Materie, die formlos und leblos ist. Diese Rangordnungen, die das ganze Universum (als divinum animal) bilden, werden miteinander verbunden und durch eine 'göttliche Einwirkung' belebt. Der spiritus mundanus verbindet die sublunare Sphäre wird mit der translunaren Sphäre und in einer ähnlichen Weise verbindet der spiritus humanus den Leib mit der Seele miteinander. Der Seele erkennen die Neoplatoniker fünf Fähigkeiten zu, die sich in zwei Bereichen konzentrieren: in anima prima (die 'höhere Seele'; $d$. $h$. Vernunft / ratio und Geist / mens) und anima secunda (die 'niedere Seele'; $d$. $h$. die sensorale Wahrnehmung / sensus exterior; die Fortpflanzung / potentia generationis und die innere Wahrnehmung oder die Imagination I sensus intimus). Vgl. dazu: E. Panofsky. .Die neoplatonische Bewegung in Florenz und Oberitalien", in: E. Panofsky. Studien zur Ikonologie. Humanistische Themen in der Kunst der Renaissance, Köln 1980, S. 203-239). 
Erkenntnis, nach dessen Erreichen man im "ewigen Traum" versinken würde: "až smolnou pochodni Żádosti Žhavý dech / na popel dohori tajemným ohněm tvým, tu dechni v celo mé a usnouti mne nech / v sen věčný, posledni, z něhoż se nevzbudím" (VII, 5-8). Der Tod entzündet paradoxerweise die Flamme der Erkenntnis und er löscht sie auch; er erscheint in einer bipolaren Gestalt. Das Ende führt erneut zum Anfang, so wie der letzte Vers von Modlitba vecerni zu dem ersten führt. In diesem Sinne manifestiert sich der im letzten Vers apostrophierte "ewige Traum" als Doublette des "ewigen Lebens". Der Tod, der die im Körper eingekerkerte unsterbliche Psyche von der Tyranei der sinnlichen Triebe und der Materie der Natur-Welt befreit ("sii živych věcný kruh, jenż konstelace hvězd / v svẽ sítè navléká a rídi vzlet a pád, jenż trpi v duši nám $/ . . \%$. VI, 3-5), wird auch in anderen Gedichten aus der Phase des dekadenten Symbolismus adoriert (Apostrofa podzimni I Herbstapostrophe, Motiv z Beethovena / Ein Motiv aus Beethoven). Das irdische Leben wird als eine unvollkommene Form des Daseins denunziert. In Modlitba vecerni kommt diese Intention bereits in jenem 'hermetischen' (ersten) Vers zur Geltung. Das ganze Gedicht strukturieren (zeitlich) drei Tagesabschnitte: der Abend, die Nacht und die Morgendämmerung, die im semantischen Repertoir des Textes explizit erwähnt werden. Als 'Ausgangspunkt' fungient die Perspektive des Abends (Modlitba vecemi). Vom Abend führt der Weg zu der fruchtbaren Nacht, die mit ihrer Dunkelheit die optimalen Bedingungen für das Durchdringen des Geheimnisses schafft. Durch 'Betäubung' und 'Blendung' der (äußeren) Sinneswahrnehmung ("svou mdlobou smrtelnou mne spoutej v loži mémn, I, 3) entfacht die Nacht als 'Verbündete' des Todes die innere Wahrnehmung ("mưj zemský život ztaj a nadpozemský zviñ", I, 6). Vor dem Hintergrund der nächtlichen Dunkelheit loht das innere, geistige Auge, das Organ der Erkenntnis: "V mých oxich tmavou svitilnu se, svatá, schyl, / lej nový olej v ní a zapal poznáni, I at zrakú paprskem žlim na tisíce mil" (II, 1-3). Die Blindheit (bzw. Dunkleheit) des Auges der äußeren Wahrnehmung, die mit der Semantik des Tages korreliert ("V mých oči tmavou svitilnu", II. 1), stimmt mit der Leblosigkeit des "lebendigen Leibes" (= des Tages; "O smrti Živých tè́l, již noc se stává dnem", I, 1) überein. Auch die dritte Tageszeit, die Morgendāmmerung, wird in Modlitba vecerni mit der Erkenntnis der mannigfaltigen Prozesse der immanenten (Natur-)Welt gleichgesetzt: "jak Zivot vzbouzi se, jenż v lüné hmoty spal" (II, 7). Nur durch das aktive ("kvêt a vir a kvas', II, 8; "co vidím żit a mrít a rủst a kvest a zrát". VI, 2; wobei hier die geistige Aktivität gemeint ist) und kontemplative ("myšlenek tajný vznik a zápas, vir a tlum", III, 8) Dasein kann der Mensch dem naturbedingten Existieren entfliehen, die Sphäre des "ewigen Traumes" (d. h. des "ewigen Tages") erreichen und die Unsterblichkeit erlangen. Die hyletische Existenz muß zugunsten der pneumatischen aufgegeben werden, die das Tor zur gnostischen Extase eröffnet. Signifikanterweise kommen in Modlitba vecerni keine expliziten Tages-Motive vor: Der Tag - als Personifizierung des (luziden) Erdenlebens - wird von der Nacht - als Verheißung des transzendenten, translunaren "ewigen Tages" - gleichsam absorbiert ("A jitro věčných dni" I "die Morgenröte der ewigen Tage". Motiv z Beethovena, XII, 1). Der in den bisherigen Interpretationen oft konstatierte Dualismus, der das ganze Abendgebet durchwirkt, sei es der paradoxe, zur "erkenntnistheoretischen Aporie" führende Dualismus, der sich im Postulat der Erfahrung des Übersinnlichen durch die natürlichen Sinne bekundet, sei es der Dualismus von hyle und pneuma, von Leben und Tod usw., deutet unverkennbar auf die gnostische Tradition hin, in der er in erster Linie mit der Vorstellung von der sichtbaren Welt als einem Reich der Finsternis und des Bösen und mit dem Körper-Geist-Dualismus koinzidiert. ${ }^{120}$

120 Vgl. dazu: K. Rudolph, Die Gnosis. Wesen und Geschichte der spätantiken Religion, München 1990 [3. Auflage], S. 68-76. Wie der Autor nachweist, durchwirkt der Dualismus sowohi die gesamte gnostische Kosmologie als auch die gnostische Anthropologie. Besonders deutlich kommt der gnostische Dualismus in der Unterscheidung von einem bösen Gott als Weltschöpfer und einem guten Gott als Erlöser zu Geltung (nicht der Dualismus von Gott und Teufel). Die Welt erscheint als "Produkt der göttlichen Tragik" und Disharmonie, als Resultat einer ominösen Schuld, in die der Mensch verwickelt ist, ein Aspekt, der in einigen Gedichten Biezinas mitschwingt, ganz explizit in Legenda tajemné viny (Die Legende der geheimnisvollen Schuld, SZ), die den Interpreten bisher große Schwierigkeiten bereitet hatte. U. Heftrichs Deutung (Otokar Bỉezina, Heidelberg 1993, S. 1421.) der Bỉezinaschen Schuld-Auffassung im Sinne des KarmaGedankens und im Anschluß an die Ethik Schopenhauers, ist wesentlich differenzierter und plausibler als die älteren Interpretationen, die den 'Schuld'-Begriff bei Březina zu sehr vereindeutigen. Hochrelevant scheint in diesem Zusammenhang die Feststellung Rudolphs zu 
Die besondere Position des Abendgebets innerhalb des lyrischen Werkes von Bíezina resultiert daraus, daß es später, wie noch zu zeigen sein wird, als Subtext einiger für das axiologische System des eschatologischen Symbolismus zentraler Gedichte (Ranni modlitba / Das Morgengebet, Vladarii snu் / Die Herrscher der Träume, SZ; oder Poledni zráni / Mittäglich Reifen, VP) aktualisiert und in den neuen Gebet-Texten 'kommentiert' wird. Das Abendgebet wird zum 'Palimpsest', auf dem neue Gebet-Gedichte geschrieben werden, das jedoch unter der neuen 'Textur' ständig durchschimmert.

\subsubsection{Inszenierung der Apokalypse und der 'Auferstehung' (im Modus der Erinnerung): Sn ad potom ... (Vielleicht dann ...)}

\section{Snad potom ...}

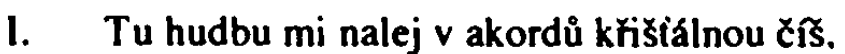

kde $\mathbf{z}$ tónů zvětralých jisker se zdvihá mámivá tíz. jak výpar $z$ nejhlubšich sklepeni duše, kde $v$ stínech zrá výzitek oheñ ve vzpomínek kvasících vínech.

II. Na úpatí pohơ̌i Smrti. kde v ledovců závratný spád se smývá Věčnosti přival, chci umdlený spát. a ilusi dni, klam krve a šero vlastniho žití. jak dusivý sen, jenž na prsa kleká. chci sníti.

III. A probuzen lítosti duši svou povstat za tisíce jar pod sestárlým sluncem až blankytu vyhasne zár a $k$ vychladlé zemi jak uhelný milî́, setlelý $v$ koữi. se žríti udušen život pod nánosem věkủ a bouťi.

IV. Snad potom, v žal poslednich soumraků, vzpomenu zpět na svêtla vyhaslých lilií, a západủ krvavý květ, na hudbu pènících vod, jak v ztlumeném zachvění citer $v$ ruch rüzových slavnosti zvonila za vyhaslých jiter,

V. a v zeleních niv na zátivé privody slunex̌nich dní, jak $v$ triumfech táhly, $v$ jásotu barev a šelestu żní pod rozpjaté stany cekajícich noci, z nichż lila se jednou na hlavy dávných národů vủnè. A procitlé zvednou

VI. Se pisnè bývalých tužeb. pohledũ doznelý smich a rozkởi łar, jímż dýchal těl vonný a chvicí se sníh a $\mathbf{z}$ dýmu vyhaslých věkủ a ve tmy zapadlých vodopádech snad s lítosti ucítím vlastního Żivota teplo a vủni a zádech.

\section{Vielleicht dann ...}

1. Die Musik gieße mir in den Kristallpokal der Akkorde. wo sich aus verwitterten Funken betäubende Schwere erhebi wie eine Ausdünstung aus den tiefsten Gewölben der Seele. wo in den Schatten das Feuer der Vorwürfe in den gärenden Weinen der Erinnerungen reift.

sein, daß die gnostische Gottesidee einerseits aus dem weltfeindlichen Dualismus resultiert, andererseits als eine Konsequenz des esoterischen Erkenntnisbegrifts zu verstehen ist, $d . h$. die Gnosis bedeutet den Weg zum Geheimnis und den Ausweg aus der Unwissenheit über den wahren Gott. In Ranni modlitba (Das Morgengebet) versucht Bïezina diesen gnostischen Dualismus in der Welt-Auffassung gleichsam zu 'revidieren'. Kennzeichnenderweise kulminiert dieses Gedicht in der Vision der unio mystica. 
II. Am Fuß des Todesgebirges, wo in der Gletscher schwindelndem Fall, sich der Ansturm der Ewigkeit auswäscht, will ich müde schlafen, und die lllusion der Tage, den Trug des Blutes und den Dämmer des eigenen Lebens. will ich wie einen Alpdruck, der auf der Brust kniet, träumen.

III. Und durch das Leid erweckt [ will ich] in meiner Seele in tausend Lenzen auferstehen unter der gealterten Sonne, wenn die Glut des Azurs erlischt und zur erkalteten Erde wie ein Kohlenmeiler, vermodert im Rauch, das Leben hinstürzt, erstickt unter der Anschwemmung der Zeiten und Stürme.

IV. Vielleicht dann, im Leid der letzten Dämmenungen, werde ich mich zurückerinnem, an die Lichter der erlosch'nen Lilien und die blutrote Blüte der Sonnenuntergänge. an die Musik der schäumenden Wässer, wie sie im gedämpften Beben der Zither, an erlosch nen Morgen ins Treiben rosiger Feste läutete.

V. und im Grün der Gefilde an strahlende Prozessionen sonniger Tage,

wie sie im Triumph einherzogen, im Jauchzen der Farben und im Rauschen der Ernten unter die aufgeschlagenen Zelte wartender Nächte, von denen sich einst auf die Köpfe altertümlicher Völker der Duft ergoB. Und erwacht werden

VI. sich die Lieder einstiger Sehnsüchte, das Lachen der Blicke, das verklang, und die Glut der Lust emporheben, die der duftende und bebende Schnee der Leiber

ausatmete und aus dem Rauch der erlosch'nen Äone und in den im Dämmer versunk'nen Wasserfällen werde ich vielleicht mit Wehmut die Wärme und den Duft und Hauch des eigenen Lebens

fühlen.

Als eine Art Kompendium der Irrealisierung-Semantik in TD erscheint das Gedicht Snad potom... (Vielleicht dann...), in dem die dominanten Modi der Irrealisierung - Hypnos, Oneiros und Thanatos - vereinigt und durch den Modus der Erinnerung komplementiert werden. Die Inszenierung des "Sturzes" in den Todesschlaf und die apokalyptische Annihilierung und Nekrotisierung der diesseitigen Welt haben im semantischen Plan dieses Textes eine konrete Funktion: Sie bilden einen (paradoxen) 'Gedächtnisraum', in dem sich das dichterische Ich nach seiner Auferstehung im Modus der E r in n e ru ng die nicht-mehr-seiende, gewesene, desontologisierte und deshalb wertvolle, den ästhetischen Genuß potenzierende Herrlichkeit der irrealisierten Welt vergegenwärtigen kann. Denn erst in diesem Zustand kann die gewesene, nicht mehr vorhandene Schönheit des mundus sensibilis zum Objekt des ästhetischen Erlebnisses werden.

Das Sujet von Snad potom... entfaltet eine dekadente Version der Auferstehung am Ende der Zeiten nach dem Untergang der Erde im apokalyptischen Brand. Die Bedeutung dieses Gedichts ${ }^{121}$ für Br̈ezinas schopferische Entwicklung hat bereits F. X. Saida erkannt und hervorgehoben ("/.../ eines der originellsten Gedichte, die jemals geschrieben wurden. I.../ ein Meilenstein in Bíezinas Werk'). 122 Salda vertritt die Meinung, daß Snad potom.... trotz seiner starken Annäherung an die Pathodicee letzten Endes die paradoxe Liebe zum Leben "trotz allem und allem zum trotz", 123 die hier in "schöpferische Tat" ("tvưrč cin") transformiert, offenbart.

Die Sinnbewegung von Snad potom... realisiert sich in zwei thematischen Sujetsequenzen. Während die erste Sequenz in drei abgeschlossenen Strophen (1-III) verschiedene apokalyptische Ereignisse thematisiert, entfaltet die zweite Sequenz (IV.-VI. Strophe) eigentlich nur den mnemonischen Akt als das einzige Thema, das die letzten drei

121Das Gedicht besteht aus sechs Strophen von jeweils vier Verszeilen im jambischen Versmaß, die wiederum in jeder Strophe jeweils zwei Versperioden von variablem Silbenschema bilden.

$122 \%$.../ básen̉ $z$ nejoriginálnějšich, jeż byly kdy napsány. /.../ meznik $v$ dile Bỉezinovẽ Salda, .Vývoj a integrace $v$ poesii Otokara Breziny" [1913], in: Duše a dilo. Podobizny a medailony, Praha 1937, S. 208-209.

123 \%.../ pies vsecko a vsemu na vzdory. Vgl. a.a.O., S. 209. 
Strophen auch auf der stilistischen Ebene miteinander verknüpft: die vierte Strophe mit der fünften durch die kopulative Konjunktion "a" ("und") und die fünfte Strophe mit der sechsten durch das Enjambement "zvednou // se pisnè /..." ("erwacht werden // sich die Lieder emporheben /... $\mu^{\prime}$ ). Die erste Sequenz entwickelt (im Präsens) drei Phasen eines progressiven Prozesses: die Annihilierung und Selbstauflösung des Ich und seine anschließende Auferstehung (III. Str.) vor dem Hintergrund der Irrealisierung der ganzen Erde. Die Handlung der zweiten Sequenz ist konsequent auf den mnemonischen Akt des Sich-Erinnerns an das gewesene irdische Dasein und die nicht-mehr-seiende. desontologisierte Schönheit der (irrealisierten) Erde - aus der Perspektive eines postmortalen Zustandes - fokussiert. Die Funktion eines mnemo(tech)nischen Mediums wird in Snad potom... der Musik zuerkannt; sie ist die Initiatorin der Gedächtnistätigkeit. doch sie kann das dichterische Ich auch in den Zustand des Unbewußten, in das Reich des Hypnos und des Kunst-Todes ver-führen.

Als ambivalente Macht, die es vermag, den Dichter der Realität des Normalbewußtseins zu entrücken, inm eine änigmatische Dimension der Wirklichkeit und gleichzeitig einen Gedächtnisraum zu eröffnen, wird die "hudba" ("Musik") gleich in der ersten Strophe indiziert: "Tu hudbu mi nalej v akordủ křištálnou Ciš" (1, 1; "Die Musik gieße mir in den Kristallpokal der Akkorde"). Die Musik soll dem dichterischen Ich wie ein in die betäubende Ermattung eines Oneiroids versetzender "Trank der Müdigkeit"124 'verabreicht' werden. Daher wendet sich das dichterische Ich mit seiner Aufforderung an jemanden, dessen/deren Identität im gesamten Text verhehlt und anonym bleibt. Die Musik erscheint hier als 'integraler Bestandteil' sowohl der anorganisch-artifiziellen KunstWelt ("v akordü krištálnou cis's" / "Kristallpokal der Akorde", I, 1) als auch der organischen Natur-Welt ("hudbu pénicich vod" r die Musik der schäumenden Wässer", IV, 3). Darüber hinaus scheint die Signifikanz der Welt, an die sich das Ich (zukünftig) erinnen will, gerade in ihrer Musikalität zu gründen:125 "Snad potom, v Żal poslednich soumrakủ, vzpomenu zpèt / /... I na hudbu pénicich vod, jak v ztlumeném zachvěni citer" (IV. 1, 3; "Vielleicht dann, der letzten Dämmerungen, werde ich mich zurückerinnern /... / an die Musik der schäumenden Wässer, wie sie im gedämptten Beben der Zither $(. . . /$ ). "A procitlé zvednou se pisné I... ${ }^{\mu}(\mathrm{V}, 4$ - VI, 1; "Und erwacht werden sich die Lieder emporheben I... $\mu$ ). Das Ich will in eine Todes-Ohnmacht, in einen Kunst-Tod versetzt werden: "Na úpatí pohori Smrti, kde v ledovcú závratný spád / se smývá věčnosti príval, chci umdlený spát" ( II, 1-2; "Am Fuß des Todesgebirgs, wo in der Gletscher schwindelndem Fall / sich der Ansturm der Ewigkeit auswäscht $/ . . . /$ ). Signifikanterweise will das dichterische Ich hinunterstürzen, "wo der Gletscher schwindelnder Fall $/ \ldots \mu^{\prime},{ }^{126}$ In diesem de facto postmortalen Zustand

124 Gemeint ist das in Tajemné dálky (Geheimnisvolle Fernen) nicht aufgenommene Gedicht Kdyż nápoj únavy ... (Als der Müdigkeit Trank ... 1893): "Kdyż nápoj únavy jsem vypil $z$ hodin ćše. I kraj ztichlý duše mé šer podvečerni zasán'; / žal vưni opii mne, jeż z kvêtu noci dýse, / a żivých sladká smrt mi stinem sedla v raasách" (I. Str.: "Als der Müdigkeit Trank ich aus dem Pokal der Stunden schlürtte, / ergriff die stille Landschaft meiner Seele der vorabendliche Dämmer; / der Düfte Wehmut berauschte mich, die aus der Blüte der Nacht atmet, / und der süße Tod der Lebendigen senkte als Schatten sich in meine Wimpern nieder').

125 Diese Vorstellung ist offensichtlich auf die Lehre Schopenhauers (in Anschluß an Pythagoras) zurückzuführen, in der das wahre Abbild des Weltgrundes nur die Musik zu geben vermag. Die Musik ist das Wesen der Welt. (Die Welt als Wille und Vorstellung, § 52, Bd. I, 1977. S. 324). Die Reaktualisierung dieser Idee in Březinas Werk erörtert Urs Heftrich (Otokar Bírezina, Heidelberg 1993, S. 114-116). Es kann jedoch nicht außer acht gelassen werden, daß die Musik(alităt) bzw. das Lied und der Gesang in Březinas Werk auch als Medien der Kommunikation und metapoetische Topoi fungieren: „Nezapomeñte na hudbu pri mé práci! / ... / Je integrujici cásti mého dila, bojuje svou sonorni sugesci pro mou myšlenku, a mluvi, kde myšlenka uź nemúże". ("Vergessen Sie die Musik bei meiner Arbeit nicht! /.../ Sie ist ein integrierender Bestandteil meines Werkes, sie kämpft mit ihrer sonoren Suggestion für meinen Gedanken und spricht, wo der Gedanke es nicht mehr vermag". An A. Pammrová (28. 6. 1896), vgl. O. Br̈ezina, Dopisy Annè Pammrové $z$ let 1889-1905, Praha 1931. S. 113-114.

126 Das Arrangement des Sturzes und des 'friedlichen' Schlummerns 'Am Fuß des Todesgebirges" in Snad potom... erinnert intensiv an die Schlußsequenz aus Máchas phantastischer Kurzerzählung Pout krkonošská (Wanderung ins Riesengebirge, 1834), in der der Jüngling/Anachoret nach seinem Struz in die Tiefe zum "leisesten Traum" eingeschlummert wird: "Krásné jitro vzešlo nad hlubokým dolem na vychodu hor krkonošských. I ... / z vysoké skály padala reka ve vymletou hlubinu I...I. V hlubinách téchto drímal poutnik, hlučnỳ spád vody uspival jej v 
wünscht es sich: "die Illusion der Tage, den Trug des Blutes und den Dämmer des eigenen Lebens, I will ich wie einen Alpdruck, der auf der Brust kniet, träumen" (II, 3-4; "illusi dni, klam krve a łero vlastniho žit́, I jak dusivý sen, jenž na prsa kleká, chci sníti"). Das Modalverb "chci" ("ich will") 'denunziert' die postulierten Erlebnisse als eine Wunschprojektion des dichterischen Ich. Selbst die Erinnerung, der mnemonische Akt und die Irrealisierung der Erde haben hier den Status eines (bloß) zukunftsorientierten Wunsches, dessen Effüllung völlig unsicher bleibt: "Snad potom /.../ vzpomenu zpět" (IV, 1: "Vielleicht dann /.../ werde ich mich zurückerinnern").

Die in der dritten Strophe thematisierte apokalyptische Katastrophe der Erde und die anschließende (zukünftige) Auferstehung, erscheinen als zwei gegenseitig implizierende Prozesse, die jedoch - wie schon erwähnt - lediglich im Modus der Erinnerung stattfinden. Das lyrische lch gibt sich der Hoffnung hin, die (vergangene) Herrlichkeit des irdischen Lebens am Ende der Zeiten, "unter der veralteten Sonne" (III, 2), als ein mnemonisches 'Konstrukt', ein Phantasma der G e dä c h tn i s tätigkeit, 'nachleben' zu können: 'Snad potom/... / vzpomenu zpèt /.../ na zárivé prưvody slunečních dní, / jak $v$ triumfech táhly, $v$ jásotu barev a selestu žni" (IV, 4, V, 1-2; "Vielleicht dann, werde ich mich zurückerinnern I... I an strahlende Prozessionen sonniger Tage, / wie sie im Triumph einherzogen, / im Jauchzen der Farben und im Rauschen der Ernten"). Die "Lieder" ("pisné") sollen diesen ascensus des dichterischen Ich quasi miterleben: "A procitlé zvednou se písnè I... $/$ " $\mathrm{V}, 4$ VI, 1; "Und erwacht werden sich die Lieder emporheben $/ . . . \mu$ ), d. h. die Welt soll neu komponiert, harmonisiert bzw. 'musikalisiert' werden; ein Mythologem, das in besonderem Maße an der Konstituierung der semantischen Welt in den letzten Gedichtzyklen Stavitelé chrámu (Baumeister am Tempel, 1899) und Ruce (Hände, 1901) partizipiert:

"Zpév staletimi bloudici" ("Ein Sang, der durch die Jahrhunderte irrt"; das Prolog-Gedicht von SCh). "Slyšte! Paprskủ piseñ, I... / zaznivá k našim duším / přes celou hiloubku zemè!" (Vigilie II, SCh, V. 1, 5-6; "Höret! Das Lied der Strahlen, I.../ tönt er an unsere Seelen / über die ganze Tiefe der Erde!"). "V oslñujici bélosti svétla ležela zemé, jako kniha pisni / otev̛̌ená pred našimi zraky. A takto jsem péli /... (Ruce / Hănde, V, 1-2; "In blendendem Weiß des Lichtes lag die Erde, wie ein Gesangbuch / geöffnet vor unseren Blicken. Und so sangen wir /... $/$ ). "Véčnè znova, piemoženi, piseñ pisni pocináme" ( Věčně znova / Stets aufs Neue, I, 1; "Stets auts Neue, besiegt, beginnen wir mit dem Lied der Lieder).

Die Paradoxie von Snad potom... besteht darin, daß die Herrlichkeit der Erde, inre Farbenpracht und ihre lebenspendende Wärme, ihr Glanz und Duft, erst nach ihrem Erlöschen und Erkalten, Vermodern und Ersticken, $d . h$. nach ihrer Destruktion, von der das dichterische Ich fasziniert ist, zum Objekt des ästhetischen Erlebnisses werden kann. Es ist gerade der Aspekt des Abwesenden und des Unerreichbaren, des NichtGegenwärtigen und des Nichtmehrseins, der die besondere Anziehungskraft (der irrealisierten Erde) ausmacht. Das lustvoll-nostalgische "snad potom..." ("vielleicht dann") scheint den Wert des irrealisierten mundus sensibilis noch zu potenzieren. ${ }^{127}$ Nicht von ungefähr erscheint sowohl das diesseitige und alltägliche Leben des dichterischen Ich als

nejtišsi sen, a viny hỉné táhly te̛ơ nad nim $\infty$ zvučné Ikáni zvonủ vecernich tichou krajinou svüj rad, však jiż neuvadély $\infty$ druhdy zvonú zvuk $v$ ducha poutnikova minulé dny". Das Ende der Erzählung führt möglicherweise zu ihrem Anfang zurück, nämlich zu dem änigmatischen VersProlog, in dem ein Pilger, der auferstandene Jüngling/Anachoret (?), ein narratio seiner Geschichte proponiert.

127 Zur Semantik der Unerreichbarkeit (der Schönheit) in den apokalyptischen Diskursen des russischen Frühsymbolismus, vgl. Aage A. Hansen-Löve. Apokalyptik und Adventismus im russischen Symbolismus der Jahmundertwende", in: Russische Literatur an der Wende vom 19. zum 20. Jahrhundert, hrsg. v. R. G. Grübel. Amsterdam/Atlanta 1993. S. 231-325. In den Gedichten von Bal'mont, Sologub. Brjusov u. a. resultiert diese Unerreichbarkeit, wie der Verfasser mit zahlreichen Zitaten belegt, aus der totalen Verabsolutisierung des Ich und der "erschaffenen Projektionswelt' (S. 241-242). Die 'Endlosigkeit', 'Ziellosigkeit', 'Unerreichbarkeit' charakterisieren die Bewegungssymbolik des russischen "diabolischen Symbolismus". Aage A. Hansen-Lơve, Der russische Symbolismus, Wien 1989, S. $133 \mathrm{ff}$. Das (scheinbar) erreichbare Ziel verschwindet im Unabsehbaren, in der 'Leere' oder im 'Nichts' der Welt. Ähnlich mündet der "diabolische" Weg des Künstler-Demiurgen in seine Selbstauflösung. Die Semantik von Březinas "tajemné dálky" ("geheimnisvolle Fernen"). "věčné dálky" ("ewige Fernen"). "ünavná dálka" ("ermüdende Ferne") steht dieser "Endlosigkeit -" bzw. "Unerreichbarkeit"-Semantik sehr nahe, dennoch ist sie bei Bfezina nicht 'absolut', es bleibt schließlich doch ein "s n a d p o to m ..." ("vielleicht dann..."), wenn auch ein "snad potom"... des (bloßen) 'Sich-Erinnern. Könnens". 
auch das in der ersten Sujetsequenz (I.-III. Str.) modellierte Welt-Bild als eine Grisaille, rein monochromatisch und ausschließlich durch die 'unbunten' Farben (Grau, Schwarz, Schatten-Grau) charakterisiert: 128 "kde $v \operatorname{stinech}^{\text {" }}(I, 3$; "wo in den Schatten"), "šero vlastního żiti": "Dämmer des eigenen Lebens"), "jak uhelný miliri, setlelý v kouri" (III, 3; "wie ein Kohlenmeiler, vermodert im Rauch ${ }^{\prime}$ ). Ihre Farb-Werte, ihren Duft und Klang, erlangt der mundus sensibilis erst nach seiner Irrealisierung im Brand der Apokalypse, kraft der Erinnerung und Imagination (IV.-VI. Str.). Es ist die "andere Welt" ("jiný svět"), die alle diese Qualitäten, als correspondances der transzendenten Welt, innehat. Das alltägliche Leben in der realen, diesseitigen Welt ist "ohne Duft I.../, ohne Farben, Blüten und Glanz" (Moje matka / Meine Mutter, I, 2, IX, 2; "bez vưnè I.../, bez barev, kvëtú, jasu“). Doch die magische "andere Welt" von Snad potom... bleibt nur eine Wunschprojektion. Wie es scheint, geht es hier um zwei Modi der Erinnerung, denen eine Art Doppel-Irrealisierung entspricht: 1) die Erinnerung als solche und 2) eine Erinnerung, die nicht zustandekommt, weil es sich nur um einen zukunftsbezogenen Wunsch handelt. Das "(snad) potom..." ("[vielleicht] d a n n ...") bezieht sich auf den Moment des Erwachens am Ende der Zeiten, gesehen vom Standpunkt des hic et nunc sprechenden Ich, das hofft, sich an die a ktu e ll e Wirklich ke it (auf das "jetzt") zukünftig zu erinnern. Und auf dieses Erinnern bezieht sich wiederum das "vielle icht": "Snad potom, v žal poslednich soumrakú vzpomenu zpět I..." (IV, 1; "Vielleicht dann, im Leid der letzten Dämmerungen, werde ich mich zurückerinnern /... $\left.{ }^{\mu}\right)$; "snad s lítostí ucitim /.../ (VI, 4; "vielleicht werde ich mit Wehmut I...."). Die (erhoffte) 'Auferstehung' des dichterischen Ich nach seinem Kunst-Tod bedeutet in diesem semantischen Kontext kein soteriologisches Geschehen. Sie hat nur einen einzigen Sinn: den eines stimulus des ästhetischen Erlebnisses der absenten, irrealisierten Phänomene der Dingwelt und schließlich auch des eigenen irrealisierten Lebens und seiner Reize: "snad s lítosti ucitím vastního żivota teplo a vưni a zádech" (VI, 4; "mit Wehmut werde ich vielleicht die Wärme und den Duft und Hauch des eigenen Lebens fühlen").

\subsection{Irrealisierung und Denaturierung der Natur durch die Kunst}

Biezinas Überzeugung, die Natur-Welt sei nur eine bloße "Sinnestäuschung" ("pouhý klam vlastnich smyslü", an F. Bauer, 13. IX. 1892), findet in der dekadenten Schaffensphase ihren prägnanten Ausdruck in der Intention, die 'unvollkommene' NaturWelt durch das Kunst-Schöne zu denaturieren, sie als ein Artefakt neu zu erschaffen. Das an sich vergängliche Natur-Schöne soll ebenfalls irrealisiert und durch das ewige KunstSchöne substituiert werden. Diese Intention kommt vor allem in den ersten symbolistischen Gedichten Brezinas aus den Jahren 1892-1894 zur Geltung, die innerhalb des ersten Gedichtzyklus Tajemné dálky einen 'Mikro-Zyklus' der Natur-Lyrik bilden. Im lyrischen Gesamtœuvre Biezinas nehmen diese Gedichte eine eigenartige Position ein. denn nach 1894 verzichtete der Dichter endgültig auf die Thematisierung des NaturSchönen

Was kennzeichnet Brezinas Natur-Lyrik? Was sind die signifikanten Merkmale dieser Gedichte? Auf der motivsemantischen Ebene ist es vor allem der ausgeprägte Kolorismus des changierenden Farbenspiels der Naturphänomene (Herbstlandschaft-Farben. Sonnenuntergang. Edelsteine usw.) und die damit zusammenhängende starke Tendenz zur Artifizialisierung der (realen) Natur. Das Organisch-Vegetative wird mehr oder weniger auf das Anorganisch-Kristalline reduziert. Obschon man bei Biezina nicht direkt von einer

128 Das trostlose Grau des eigenen Alltag-Lebens in der diesseitigen Welt thematisiert Biezina im bekannten Gedicht in Moje matka: "bez vúnẻ den je múj, bez barev, kvẻtú, jasu; / plod žiti suchý jen, jenż jako popel chutná, / tvým stinem oviván se stromu trhám casu" (letzte Str., 3-4; "ohne Duft ist mein Tag, ohne Farben, Blüten und Glanz; / nur die trockene Frucht des Daseins, die wie nach Asche schmeckt, von deinem Schatten umweht, pflücke ich vom Baum der Zeit"). Nur im Zustand der Irrealisierung (hier durch Hypnos und Thanatos) der diesseitigen Welt, kann das dichterische Ich die sensoralen Qualitäten und Besonderheiten der "anderen Welt", wie in Modlitba vecerni (Das Abendgebet) oder in Snad potom.... ertahren. 
- für die Dekadenz charakteristischen - Naturverachtung sprechen kann, ${ }^{129}$ lehnte er die Annahme von objektiv gegebener Schönheit in der Natur strikt ab. 130 Das Gedicht Vëzeñ (Der Gefangene) galt in der bisherigen Biezinas-Forschung als die radikalste und zugleich definitive Auseinandersetzung des Dichters mit dem Thema der phänomenalen Natur. ${ }^{131}$ Auch die im Symbolismus sehr verbreitete und auf Baudelaires Correspondances rekurrierende synästhetische Metaphorik, wird in der Natur-Lyrik von Tajemné dálky sehr wirkungsvoll entfaltet (Podzimni vecer / Der Herbstabend, Apostrofa podzimni / Die Herbstapostrophe, Siesta, Brezen / März, Vězeñ / Der Gefangene). ${ }^{132}$ In diesen Gedichten wird das Natürliche bzw. Natur-Schöne durch das Kunst-Schöne substituiert, die Natur-Evidenz transformiert in bildnerische, skulpturale oder architektonische Artefakte:

"Dny jasnẻ, fijinnové, v nichž zári azur cistý / a z větvi bronzových se níti rudé listy, / jež sváty ostrým vanem podzimniho dechu / se skvi jak vyráżeny ze zlatého plechu! /... / Svưj rozestỉete lesk a plajte $v$ chladný rỉjen / svou zári karminưv a minii a sien". (Apostrofa podzimni / Die Herbstapostrophe, I, 1-4; II, 5-6; "Helle Oktobertage, die vom reinen Azur strahlen, I und an Bronzeästen flammt der dunkelroten Blätter Brand, / die, vom scharfen Herbsthauch verweht, / blinken wie gestanzt aus dünnem Goldblech! I.../ Breitet euren Glanz und flammt in den kühlen Oktober I in eurem Glanz von Karmesin, Siena und Mennige"). "Sen modri sedivých ve stinech sněhu ožil, I vふ̌ak záre usnula ve zrủżovẻlých žlutich" (Siesta, I, 1-2; "Der Traum der grauen Blautơne erwachte im Schneeschatten, / der Glast jedoch schlief in rosafarbenen Gelbtönen ein"). "/.../ na květech akátủ zor zrủžovẻlý pocel, / jenž zemi zažehne a rozleje se nachem /.../ v křidla motỷlú jak jemných barviv prachem" (Br̈ezen / Mărz, V, 1-4; $\%$... der KuB des rosenroten Morgenrotes auf Akazienblüten, / der die Erde entfacht und sich als Karmin ergießt /.../ in die Flügel der Schmetterlinge wie in feinem Farbenstaub"). "/../ Ser vlastnich ilusi jsem $z$ tebe barvou vyssál I.../ Mỳm snem jsou barvy żhouci" (Vẻzen / Der Gefangene, II, 2, V, 1; "den Dämmer der eigenen Illusionen sog ich als Farbe aus dir $/ . . /$. Mein Traum sind die glühenden Farben"). ".../ jak slabý nácrtek ćni kł̧iže z seré kresby /... / nad zemi obloha jak těžká klenba sedá / a v kämen tesaná se zdvihá dutou kouli" (Podzimni vecer/ Der Herbstabend, II, 2; IV, 3-4; ".../ wie eine

129 Aage A. Hansen-Lōve nennt die 'Naturverachtung' und sogar den 'Naturhaß' als signifikante Merkmale der Natur-Auffassung im russischen diabolischen Symbolismus (vor allem bei Brjusov). Diese Natur-Negation entwickelte sich als Reaktion gegen die romantischen NaturTopoi. A. A. Hansen-Löve, Der russsische Symbolismus, 1989, S. 336 ff. Der Natur-Schöpfung wird die Kunst-Schöpfung entgegengestellt. In dieser 'Naturverweigerung' bekundet sich der Einfluß Baudelaires: seine Negation der Natur-Realităt. die als etwas Chaotisches, Wildes und Rudimentăres die Idealităt der Kunst- und Traum-Welt 'verunreinigt' und stört. Daher muß die "grausige Landschaft" ("terrible paysage") kraft der Imagination und der 'Magie' der Musik-Sprache neuerschaffen werden. Das organische Leben wird vertrieben und aus der organischen Natur bleibt als Residuum nur das Anorganische und Artifizielle. Vgl. Ralph-Rainer Wuthenow, Muse, Maske, Meduse. Europäischer Ästhetizismus, Frankfurt am Main, 1978. S. 115f. Ein feindliches Naturbild liegt bereits der Naturauffassung der französischen Aufklärung zugrunde (Natur wird als Sphăre des Amoralischen betrachtet); eine Linie, die u. a. zu Rousseau und zur heftigen Naturverachtung de Sades tūhrt. Baudelaires Interesse tür de Sade ist bekannt. Als Vorbild der artifiziellen Landschaften des Symbolimus kŏnnen die imaginären Landschaften des Manierismus gelten. Vgl. dazu die schartsinnige Darstellung von Jurgis Baltrušaitis, .Gärten und Illusionslandschaften", in: J. Baltrušaitis, Imaginäre Realitäten. Fiktion und Illusion als produktive Kraft, Köln 1984. S. 114 ff. Gerade die Vorstellung von der Natur als einer wundersamen Sphäre mit geheimnisvollen Gewässern und kristallklaren Seen, seltsam geformten Bäumen und Grotten aus Edelstein, prägt sowohl das manieristische (Ronsard, Milton, Tasso; in der Malerei die Paradiesgärten von Patinir, Altdorfer, Bassano, El Greco u. a.) als auch das symbolistische NaturBild.

130 Im Gegensatz zu den anderen tschechischen Symbolisten, namentlich zu Antonin Sova, Karei Hlavácek oder Jan Opolský.

131 Vgl. O. Králík, Otokar Błezina, Praha 1948, S. 62-63.

132 In einem Briet an seine Vertraute Anna Pammrová betont Biezina: .PYirozeným je u me̊ svèt, o nẻmż ziskáváme si vèdomosti prostrednictvim smyslư, sen barev tónủ, vủní, tvaru, casu. prostoru, Mája, o niž s takovou hloubkou mluvi vznešená filosofie indická /.... . (.Als natürliche gilt mir diejenige Welt, über die wir durch die Sinne Kenntnisse gewinnen: der Traum der Farben, Düfte, Formen, der Zeit, des Raumes, die Maja, von der mit solcher Tiefe die erhabene indische Philosophie spricht I...F. Vgl. Bỉezina, Otokar, Dopisy Anné Pammrové z let 1889-1905, Praha 1931. (Brief vom 25. 9. 1896). 
schwache Skizze heben sich die Kreuze gegen graue Zeichnung ab /.../ auch der Himmel erhebt sich über die Erde wie ein schweres graues Gewölbe / in Stein gehauen wie eine hohle Kugel").

Die in der älteren Bỉezina-Literatur geäußerte Annahme, diese Gedichte seien ein einzigartiges Beispiel Bỉezinas dichterischen Impressionismus, ${ }^{133}$ muß endgültig als Irrtum abgelehnt werden. Die Lesart und Deutung dieser Gedichte als (bloße) Darstellung der (momentanen) Atmosphäre eines sensoralen Eindruckes ist ein "passionate error", um den Ausdruck Paul de Mans zu benutzen. ${ }^{134}$ Es wurde ignoriert, daß sie kaum konkrete Natur-Referenz aufweisen. Die in diesen Gedichten entworfenen 'Landschaften' sind rein mentale 'Konstrukte' bzw. Projektionen eines 'Hirnspiels': "Známá cesta, kterou jsem sel, se změnila v mých zracich" (Den výrocni / Der Gedenktag, I, 1; "Der bekannte Weg, auf dem ich ging, verwandelte sich in meinen Blicker"). "I... Jen Velká Myšlenka, jak obiak tánla nivou" (Siesta, III, 1; "... I nur der Große Gedanke zog wie eine Wolke durch die Gefilde"). Die phänomenale Natur-Welt betrachtet Br̈ezina als Produkt unserer Einbildungskraft (Vězeñ / Der Gefangene): 135 Die Natur-Welt erscheint in diesen Gedichten wie "unter dem Schleier" der "Asbestfasern" (Motiv z Beethovena / Ein Motiv aus Beethoven), des "Nebels" (Podzimni vecer / Der Herbstabend, Vězeñ / Der Gefangene) oder des "Dunstes" (Brezen / März).

Der Hauptakzent der Natursymbolik in Tajemné dálky liegt auf der Gegenüberstellung von ('vergänglicher') Natur- und ('ewiger') Kunst-Schöpfung. Die geradezu emblematische Jahreszeit Brezinas Natur-Lyrik ist der Herbst (Podzimni vecer, Apostrofa podzimni), die Zeit des Übergangs (in der Natur) vom Leben zum Tod (des Winterschlafs), der eine "höhere Offenbarung des Lebens" (Novalis) bedeutet. Die signifikanten Motive des Absterbens, der Kälte, des Welkens und der Melancholie der Herbstnatur (Podzimni vecer I Der Herbstabend. Apostrofa podzimni / Die Herbstapostrophe) konnotieren die Einsamkeit und Isolation, das Schweigen und die Leere des (inneren) Lebens des dichterischen Ich, das dem Untergang geweint ist. In Podzimni vecer (Der Herbstabend) verfließt die Organik der Natur in der Anorganik der Artefakten; die Herbstlandschaft wird zu einer "grauen Zeichnung" denaturiert:

"Nad pusté hỉbitovy své stíny mlha házi, / jak slabý nácrtek čni křiže z seré kresby /... / Na mramor placica se slzná rosa ssedá; / do plástú sedivých se kostry stromủ chouli /.../ (II, 1-2, IV, 1-2; "Über öde Friedhöfe wift der Nebel seine Schatten, / wie eine schwache Skizze heben sich die Kreuze gegen graue Zeichnung ab /.../. Auf weinendem Marmor gerinnt der Tau zu Trânen; / in graue Măntel kauem sich die Skelette der Bäume $/ . . . r$ ).

Am Ende der Zeiten wird die organische Welt im visionären Akt der absoluten Destruktion und des erlösenden Todes ("jásot duši smrti vykoupených", VI, 3; "Jubel der vom Tode erlösten Seelen") vom zeitlosen Raum des Nichts und der Leere aufgesaugt. Die schauderhaft bodenlose Tiefe des Universums bildet ein Pendant zu der 'dunklen', unergründlichen Tiefe des meschlichen Un(ter)bewußtseins ${ }^{136}$

"Do prázdna vtéká cas a chvi se noćni stiny. I U Cerných mori prostoru se strhly hráze. I Vystfikla hustá péna tmy a do hlubiny / zem pohlcená sesmykla se na své dráze" (Podzimni veder / Der Herbstabend, V, 1-4; "Ins Leere fließt die Zeit und es beben die náchttichen Schatten. I An schwarzen Meeren des Raumes brachen die Dămme. / Ein dicker Schaum der Finsternis spritzte hoch und in die Tiefe / rutschte die aufgesaugte Erde von ihrer Bahn ab").

In Modlitba vecerni (Das Abendgeben) wird der Tod als Pforte zur absoluten Erkenntnis durch das Prisma der Natur adoriert: "O smrti živých tẻi, jiż noc se stává dnem, I svou stávu tajemnou lej v moji teplou krev /... I // At všecko obsáhnu, v'sech cíle drah a cest, / co vidim zít a mrìt a rủst a kvést a zrát $/ . . /$ " $(I, 1-2, V I, 1-2 ;$ "O Tod der lebendigen Leiber, durch den die Nacht zum Tage wird, / gieße deinen geheimnisvollen Saft in mein warmes Blut /.../ Daß ich alles enfasse, die Ziele aller Bahnen und Wege, / was ich leben und sterben sehe, wachsen und blühen und reifen $/ . . . /$ ). In Apostrofa podzimni (die Herbstapostrophe) wird die Natur explizit als Spenderin des Todes semantisiert; inre herbstliche Luft, mit "schwerem Odeur" der welkenden Blätter durchsetzt, assoziiert das

133 Vgl. Miloš Marten, „Brezina”, in: Akkord, Praha 1916, S. 88-133.

134 P. de Man, Metaphor. (Second Discourse)", in: P. de Man, Allegories of Reading. New Haven 1979, S. $154 f$.

$135 \mathrm{U}$. Heftrich verweist auf die Wirkung der Schopenhauer-Lektüre und untersucht sie eingehend. Otokar Brezina, Heidelberg 1993, S. 58ff.

136 Zum Motiv der Meeres-Tiefe im russischen Symbolismus (diabolische Symbolik), vgl. Aage A. Hansen-Löve, Der russische Symbolismus, Wien 1989, S. 339 f. 
dichterische Ich mit "Giftgas": "Vaše vưně těžká / jak otrávený plyn v mé duši na dně mešká, a barev, kvétú, żiti velkou agonii / ze vzduchu vašeho jak hởký nápoj pijił (II, 912: "Euer schwerer Dutt / sinkt wie Giftgas an meiner Seele Grund, und der Farten, der Blüten und des Lebens große Agonie / trinke ich als bitteren Trank aus eurer Luft!). Das Organisch-Vegetabilische metamorphiert im Prozeß des Welkens, Verlöschens und Absterbens in das Artifizielle und Anorganisch-Stoffliche. Daraus resultiert die fast hypertrophierte Stoff-Ästhetik: "s vétvi bronzových se níti rudé listy /.../ se skvi jak vyáżeny ze zlatého plechu! /.../ svưj rozestiete lesk a plajte v chladný rijjen / svou zári karminưv a minií a sien /.../, a rozlévejte smrt /... z z tĭpytných paprskú, jak z cúse vytepané I... $(1,2-4$; 11, 5-8; "an Bronzeästen flammen rote Blätter, I.../ die, wie gestanzt aus dünnem Goldblech, blinken! /.../ breitet euren Glast und flammt in den kühlen Oktober / in eurem Glanz von Karmesin, Siena und Mennige, /.../ und laßt den Tod in glänzenden Strahlen, wie aus einem gehämmerten Pokal ergießen $/ . . \mu^{\mu}$ ). Die Kunst wird nicht nur als Medium der Irrealisierung bzw. Denaturierung der (vergănglichen) Natur, sondern auch als Medium ihrer Vervollkommnug und sogar ihrer Wiedererschaffung durch die artifizielle (unvergängliche) Schönheit der Kunstgegenstände funktionalisiert. ${ }^{137}$ In Apostrofa podzimni aktualisiert Bỉezina das Phănomen, das Dimitrij Tschižewskij in seiner bekannten Mácha -Studie prägnant als "Desontologisierung des Seins" spezifiziert. ${ }^{138}$ Den Lebewesen und Dingen wird inr ontisches Fundament, ihre letzte ontische "Festigkeit" entnommen, indem sie nicht an existierenden Dingen, "an festen Realităten" haften, sondern von den nicht mehr existierenden Dingen als längst abgeschlossene Prozesse oder als irrealisierte, tote, nicht-mehr-seiende Dinge oder Wesen ("fortgeflogene Vögel". "tote Schmetterlinge") in die Gegenwart ausgesandt werden" :

\section{Mácha: Máj / Der Mai, (1836. Deutsch v. E. Neumann, Karlsbad 1933)}

"dávná severni zár, vyhaslé svẻtlo s ni, / "Verschwundner Nordlichtschein, mit inm die Helle auch. zborténé harfy tón. ztrhané strüny zvuk. / Gekrümmter Harfe Ton, gezerrter Saite Klang.

zašlecho véku dêj, umrlé hvězdy svit, / Vergangner Zeit Geschehn, verblichnen Sternes Glanz, zašlé bludice pout', mitvé milenky cit, I Der versunknen Planeten Bahn, des toten Liebs Getühl, zapomenuty hrob, věcnosti skleslý byt, / Vergessne Grabesstaat, der Ewigkeit verfallnes Asyl. vyhasla onnẻ kouř, slitého zvonu hlas, I Erloschnen Feuers Rauch, geschmolzner Glock' Geläut, mrtvé labuté zpév, ztracený lidstva ráj". I Des toten Schwans Gesang, verlornes Paradies".

\section{Biezina: Apostrofa podzimni / Herbstapostrophe (V. 9-18)}

"a duše vonnȳch vęerù, jež uhởely $\checkmark$ purpurných ohnich západu. $Z$ vás onèmlỳ

sbor ptákủ odlettỷch mi kvili, jásá, zpivá
1 "und Seelen duttiger Abende, die vergluteten I im purpurnen Brand des Sonnenuntergangs. Aus euch

I jammert, jubelt, singt für mich verstummter Chor fortgeflogener Vögel

orchestrem tónu். Ve vás misi se a splỳvá / im Orchester der Töne. In euch einigt sich und verfließt sen kvêtüv uvadlych, sum pokosenỵch klasú / verwelkter Blüten Traum, gemáhter Áhren

Rauschen. svit zhaslych barev, smytych nuanci a jasu / erloschner Farben, verschwommner Nuancen

let mrtvych motylüv a kolotavé vieni tisice zhastých żvotù ve zlaté lázni denni!"
I toter Schmetterlinge Flug und wirbelnde Wallung und Glanze.

I Tausender erloschner Wesen im goldenen Bad des Tages!"

137 Vgl. hierzu: Heide Eilert, „Die Vorliebe für kostbar-erlesene Materialien und inre Funktion in der Lyrik der Fin de siécle", in: Fin de siècle, hrsg. v. Roger Bauer, Frankfurt am Main 1977, S. $421-441$.

138 Vgl. Dimitrij Tschižewskij. .Zu Máchas Weltanschauung", in: D. Tschiževskij. Kleinere Schriften, II. Bohemica. München 1972. S. 240-293. Eine komparative Untersuchung zum Phănomen der Desontologisierung bei Mácha und bei Br̉ezina (Tajemné dálky), die zweifelsohne ein höchstinteressantes Ergebnis (im Hinblick auf Bl̉ezinas Rezeption von Máchas Poetik) ans Tageslicht bringen mürde, bleibt (immer) noch aus. 
Auch in Siesta, die eine 'schlichte', kristallin-transparente Komposition ("ve štolách světla vzduch se v ztuhlých vrstvách složil"; I, 3; "in den Stollen des Lichts schlug sich die Luft zu erstarrten Schichten nieder"), ein leises Nachklingen der wirbelnden Prozesse und Metamorphosen der "Herbstapostrophe" (Apostrofa vs. Siesta) in einer stillen Winterlandschaft evozieren soll ("Klid bilych linii se tiše krajem snoval", II, 1; "Die Ruhe der weißen Linien breitete sich leise in der Landschaft"), wird das Natur-Schöne durch das Kunst-Schöne (Malerei, Musik, III, 4) ersetzt. Die Kunst-Welt, das Reich des Ästhetismus (als Sphäre der Linearität, Geometrizität und Kristallinität), wird der Natur Welt übergeordnet: "Klid búlých linii" (II, 1; "Ruhe der weißen Linien"); "let ptáků v azuru car sitẻ nerýsoval", II, 3; "der Flug der Vögel zeichnete kein Netz der Linien im Azur"); "sipot os", I. 4; "das Zischen der Achsen").

Das Gedicht Brezen (März) scheint Apostrofa podzimni und Siesta zu komplettieren; diese drei Gedichte bilden innerhalb von Tajemné dálky eine Natur-Lyrik-Triade, die zu einem 'Jahreszeiten-Zyklus' (Apostrofa podzimni - Herbst, Siesta - Winter, Bíezen Frühling) komponiert wird. Doch auch die Frühlingsnatur (Bïezen / März) wird letzten Endes als eine zum artifiziellen Kunst-Werk denaturierte Natur-Welt bloßgelegt. ${ }^{139}$ Während in Apostrofa podzimni das Metallische und Ziselierte (als Attribute des KunstHandwerks) dominiert, ist die denaturierte Natur-Welt in Siesta der geometrischen Vollkommenheit der Linien, der (Kristall-)Achsen und der Musik verpflichtet. Die Frühlingsnatur in Br̈ezen (März) kennzeichnen wiederum koloristisch-malerische Werte, die - signifikanterweise - das Natur-Bild in diesem Gedicht als ein "frisches Aquarell" (letzte Verszeile; "svězzi akvarel") konnotieren. Durch die metapoetische Pointe ("I.../ pisně básnikủ, jimž analysa v duši / snư svẻżi akvarel svým chladným deštēm smyje“, VI, 3-4: "/... / Lieder der Dichter, denen die Analyse in der Seele / der Träume frisches Aquarell mit ihrem kalten Regen abwischt") wird dieses Natur-Bild als (bloßes) mentales Konstrukt eines poeta doctus, ja als Produkt seines analytischen Denkens, das in Widerspruch zur dichterischen Intuition gerät, 'demaskiet'. Die "Sehnsucht" ("tep Zhavých Żádosti". VI, 1; "Puls glühender Sehnsüchte") nach der Vereinigung der beiden Welten erweist sich als illusiv, da die Natur-Welt nur eine betörende Traum-Vision, ein 'Produkt' des imaginierenden Bewußtseins ("snů svězí akvarel", VI, 4; "der Träume frisches Aquarell") ist.

139 Brezinas radikale Wegwendung von der Natur-Symbolik, die in seinen ersten, in den Gedichtzyklus Tajemné dálky nicht aufgenommenen (!) Gedichten (Smutek západu / Die Trauer des Sonnenuntergangs, Zimni ráno / Der Wintermorgen. Mlhavá noc / Die neblige Nacht, Mir samot odvékých / Der Friede der urewigen Einóden u. a.) eine semantisch konstitutive Rolle spiett, rührt $\mathrm{m}$. $\mathrm{E}$. von seiner Übezeugung her, daß die von inm postulierte Erkenntnis des "Unbekannten", des "ewigen Geheimnisses", durch das Prisma der Natur vollkommen unmöglich ist. Die Natur kann nicht zur Quelle der Erkenntnis des "ewigen Geheimnisses" werden, da sie lediglich ein Trug unserer Sinne ist. Aus diesem Grund lehnt auch die Gnosis die "Naturerkenntnis" konsequent ab, denn $\%$... Gott und Natur trennen sich, werden einander fremd. werden Gegensätze". Hans Jonas, Gnosis und spätantiker Geist, Teil 1,2, Göttingen 1964, S. 149. Jonas zitiert in diesem Zusammenhang Lactanz: "Die Zerstörung der Religion hat den Namen 'Natur' ertunden". (Ebd. S. 178). 


\subsubsection{Die (Natur-)Welt als Produkt der eigenen Einbildungskraft Vè z eñ (Der Gefangene)}

"Vicdaluji se systematicky lidské společnosti a mivám chvile nelibosti a smutku jen ienkrat. kdỹ se vracím ze společnosti lidi. I... Umèní je mi nejvyšsim vrcholem individuelni sily, ale umèni pro uměni. /...

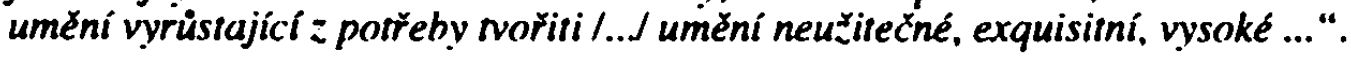

"Ich entziehe mich systemutisch der menschlichen Gesellschaft und Augenblicke des Unbehagens und der Trauer habe ich nur dann, wenn ich aus der Gesellschaf: der Menschen jurückkehre. Die Kunst ist für mich der Höhepunkt der individuellen Kraft, aber nur als l'art pour l'art, I...J, eine Kunst, die aus der Notwendigkeit zu schöpfen erwächst /...J eine unnützliche, exquisite, hohe Kunst ...".

Olokar Błezina an Frantiłek Bauer (13. IX. 1892)

\section{Vězeň}

I. V tvých zracích, Nejatá, jsem mamé duši koupal. jak temny oblak mlh nad kraje Sífí zaleh':

koư̆ vlastních myక̌lének mi $z$ tvojích vủni stoupal.

a vlastní krve vzdech jsem cítil ve tvých žalech.

II. Mé srdce tráslo se. $k$ dyż $k$ tvému jsem se chýlil,

Ser vlastnich ilusí jsem $z$ tebe barvou vyssál.

a vlastni duše hlas $z$ tvých modliteb mi kvilil,

když na svém oltáfi mi otevf̌elas missál.

III. Ros marné bohatství, jež bílý požár žehne a v slzách ohnivých na ñadrech květú pálí. i výheñ západú. jež teplou krví šlehne. jak $\mathbf{z}$ poranẽných żil by stł̌ikala ti dáli.

IV. mlh hábit kajicí nad nahotou tvých pláni a dusot Cemých dni, jež slyším z dálky cválat, tvých stromú němý żal a smutek odkvétání i tłesoucí hlas vod a noci teskných nálad

V. z mé krve vyrostly. Mým snem jsou barvy žhoucí, když z hlubin umdlených se zdvihás̆, smutná jarem. Nad výhni duše své do skelné hmoty vroucí jsem smázel pî́lalu a vydechl té tvarem.

VI. A v teskném nadŠení když vzlétám osvobozen $z$ tvých loktů vysněných, i tu se zpijím vínem. na vlastních vinicích, jež uzrálo mi $v$ hrozen. mou krví zahołklé a mrivých dnư mých stínem.

VII. Svưj hrad jsem vystavěl na mraěné výši spádné. ser vlhkých katakomb se $v$ jeho skály vrývá. a v klenbách plačících, kde zal a ticho vládne. za živa zazdéná má píseñ nocí zpívá. 
I. In deinen Blicken, du Nichtgefangene, badete ich vegebens meine Seele, als eine dunkle Wolke des Nebels sich breit über das Land legte: der Rauch meiner eigenen Gedanken stieg mir aus deinen Düften empor, und des eigenen Blutes Seufzer fühlte ich in deinen Kümmernissen

11. Mein Herz bebte, als ich mich zu deinem neigte,

das Dämmern der eigenen Illusionen sog ich als Farbe aus dir, und der eigenen Seele Stimme wimmerte zu mir aus deinen Gebeten, als du das Meßbuch mir auf deinem Altar öffnetest.

III. Des Taus vergebliche Reichtümer, die ein weißer Brand versengt und die in feurigen Tränen auf dem Busen der Blumen brennen, und die Glut des Sonnenuntergangs, die als warmes Blut auflodert. als spritzte es aus verletzten Adern durch die Ferme,

IV. der Nebel Büßerkleid über der Nacktheit deiner Wiesen und das Gestampfe schwarzer Tage, die ich aus der Feme galoppieren höre. deiner Bäume stummer Gram und die Trauer des Verblühens und die bebende Stimme der Wässer und die Nächte wehmütiger Stimmungen

V. erwuchsen aus meinem Blut. Mein Traum sind die glühenden Farben, wenn du dich im Fruhling traurig aus ermatteten Tiefen erhebst.

Über der Glut meiner Seele in die siedende Glasmasse tauchte ich die Pfeife und blies dich zur Form aus.

VI. Und wenn ich in wehmütiger Begeisterung befreit aus deinen erträumten Armen mich emporschwinge, auch dann berausche

der mir auf meinen eigenen Weinbergen zur Traube reifte, ich mich mit dem Wein, herb von meinem Blut und vom Schatten meiner toten Tage.

VII. Meine Burg erbaute ich auf einer abfallenden Wolkenhöhe, der Dämmer feuchter Katakomben dringt in ihre Felswände hinein. und in weinenden Gewölben, wo Leid und Stille herrschen, singt, bei lebendigem Leibe eingemauert, mein Lied durch die Nacht.

Das Gedicht Vězeñ nimmt im System des dekadenten Symbolismus eine Sonderstellung ein. In ihm kulminiert Bíezinas Auseinandersetzung mit der Problematik der Illusivitàt der phänomenalen Welt, der die Idealităt der Kunst-Schopfung entgegengesetzt wird. Die ästhetische Existenz des Kunst-Schöpfers gleicht einer "Gefangenschaft" in der Welt der eigenen, die künstlerischen und ästhetischen Werte schaffenden Imagination, die imstande ist (auch) die unvollkommene Natur-Welt zum ästhetischen Artelakt zu valorisieren.

Den semantischen Nukleus dieses quasi sujetlosen Gedichts bildet die noetische Problematik, im engeren Sinne die Noesis. Die ästhetische Existenz des (solipsistischen) Kunst-Schopfers wird hier als ein idealer (weil das Erlebnis des Nichtmehrseins potenzierender) Zustand der totalen Gefangenschaft und Abkapselung des Ich in seinem eigenen Selbst semantisiert. Diese Gefangenschaft im ästhetizistischen Autismus - oder autistischen Ästhetismus - erscheint als Voraussetzung für die Hervorbringung der ästhetischen Werte.

In Vẻzenh, 140 dessen Titel aư den Gefangenen aus dem zweiten Gesang von Máchas Máj (Der Mai) alludiert"141 und das als Monolog des lyrischen Ich, des "Gefangenen",

140 Eine kompetente und aufschlußreiche Interpretation dieses Gedichts im Hinblick auf die in der älteren Bỉezina-Literatur vielfach erwähnte Schopenhauersche "Befangenheit im Daseinstraum" präsentient Urs Heftrich in seiner Monographie (Otokar Bł̌ezina, Heidelberg 1993. S. 61-65). In einem Brief (vom 13. IX. 1892) an Frantisek Bauer schreibt Błezina: "Největši životni 
strukturiert ist, werden verschiedene Aspekte ein und desselben Sachverhaltes entfaltet: das Sich-Bewußt-Werden der aktiven Teilhabe an der Kunst-Schöpfung, an der Hervorbringung der ästhetischen Werte im Zustand des (freiwilligen und postulierten) Eingemauertseins in der Welt der eigenen Imagination, in die auch die apostrophierte Instanz, die "Nejatá" (möglicherweise die Natur selbst) projiziert wird. Unter diesem Blickwinkel betrachtet, kann Vẻzen als ein (metapoetisches) Gedicht gelesen werden, das die Entwicklung des Gedankens zum Thema hat. Im semantischen Repertoir des Textes kommt das Lexem "Gedanke" gleich in der ersten Strophe vor: "kouř vlastnich myšlének mi $z$ tvojích vưní stoupal" (1, 3; "der Rauch eigener Gedanken stieg mir aus deinen Düften empor). 142

Die phänomenale Natur-Welt wird in der ersten Strophe von dichterischem Ich als Illusion, als fahler Reflex seiner eigenen mentalen Welt, deren Erkenntnis zwecklos ist, bloßgelegt: "V tvých zracich, Nejatá, jsem marně duši koupal /.../ kour̉ vlastnich myšlének mi $z$ tvojich vưni stoupal, / a vlastni krve vzdech jsem citil ve tvych Zalech" (I, 1, 3-4). In den Blicken der "Nichtgefangenen" ("Nejatá") sieht das Ich, wie in einem Spiegelkabinett, nur sich selbst; die äußere Natur erscheint nur als Spiegelbild ${ }^{143}$ des eigenen

moudrost nalezl jsem v Schopenhauerově negaci; nehledám ničeho v żivoté, shledávám všechen

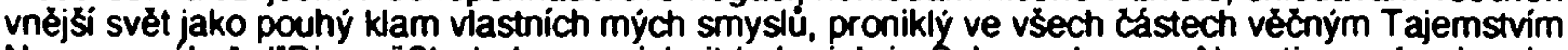
Nepoznaneho". ("Die größte Lebensweisheit habe ich in Schopenhauers Negation gefunden; im Leben suche ich gar nichts, die ganze Außenwelt befinde ich nur als meine eigene Sinnestăuschung. durchdrungen in allen Teilen von ewigem Geheimnis des Unerkannten").

141 Máchas "Gefangenen" aus seiner bekannten lyrisch-epischen Erzăhlung Máj enwähnt zum ersten Male im Zusammenhang mit Bïezinas Vêzen F. X. Salda (.Vývoj a integrace $v$ poesii Otokara Bleziny". [1913], in: Duse a dillo. Podobizny a medaillony, Praha 1937. S. 203). Die Symbolik des Gefangenen war auch in der Kunst der Spătrenaissance bzw. in der des Manierismus sehr verbreitet. Man denke an Michelangelos berühmte Skulpturen des Gefesselten und Sterbenden Sklaven (Lo schlavo ribelle; Lo schiavo morente, 1513) im Louvre. In der Kunst der Spătrenaissance symbolisiert der Gefangene - im Anschluß an die gnostisch-hellenistische Tradition - die Gefangenschaft der Seele im Kerker des materiellen Leibes. Mit besonderer Prägnanz bringt Herman Grimm diese Intention in seiner berühmten Michelangelo-Monographie zum Ausdruck: "Dieser äußerste Moment zwischen Leben und Unsterblichkeit, dieser Schauder des Abschieds zugleich und der Ankunt, dies Zusammensinken kraftvoller, jugendlicher Glieder, die wie ein leerer, prachtvoller Panzer gleichsam von der Seele fortgestoßen werden, die sich emporschwingt, und nun, indem sie ihren Inhalt vertieren, inn dennoch so ganz noch zu umhüllen scheinen." H. Grimm, Leben Michelangelos, 1913, S. 311-312.

142 Das Thema der 'noetischen Fahrt' des (eigenen) Gedankens wird in Tajemné dálky in mehreren Gedichten entfaltet: so z. B. in Pohled smrti (Der Blick des Todes), wo der Ekenntnisprozeß (der Todes-Geheimnisse) als allegorische Wanderung des personifizienten Gedankens (des Ich) inszeniert ist: "a v jeho zrcadle myšlenku vlastni uvidél jsem. // Sla bledá a zmatená v dálku zavátyjch, neznámých Mẻst / do šera a polárnich noci nẻmou únavou cest" (V. 4. 5-6: "und im Spiegel sah ich meinen eigenen Gedanken. // Er ging blaß und verwirn in die Ferne der verwehten, unbekannten Stådte / in Dảmmer und polare Nảchte in stummer Müdigkeit des Wandermühs"). In Mrtvé mládi (Tote Jugend führt der personifizierte Gedanke das Ich in die Sphăre der Vergangenheit: "V mé pisni myšlenka jak tẻżká vưné vstala. /... do tvấi đýchla mi a za ruku mé jala / a ztichlych do zahrad mé vedla zastych let (II, 1, 3-4; "Wie schwerer butt hob sich der Gedanke in meinem Lied empor, I.../ auf meine Wangen hauchte er, nahm mich an dier Hand und führte mich in die Gärten vergangener Jahre").

143 Das Spiegel-Motiv nimmt eine der dominanten Positionen - auch im direkten Anschluß an die Ikonographie des Manierismus (Medusenschild, Narziss-Mythos u. a.; G. R. Hocke, Manierismus in der Literatur, Hamburg bei Reinbeck 1959. S. 135f.) - in der Kunst des Symbolismus ein. Zahireiche Beispiele nennt auch A. A. Hansen-Löve (Der russische Symbolismus. Wien 1989, S. 19-132). Sehr verbreitet war die Symbolik der Welt als verkehrtes Spiegelbild. Von großem Einfluß war freilich die Schopenhauersche Metapher von der Welt als Spiegel, in den der Wille blickt und lediglich sich selbst findet. Die Aktualisierung des NarzißMythos in der Kunst des Symbolismus geht auf den narzißtischen Typus des dekadenten Künstler-Menschen zurück, der sein Leben wie in einem fiktionalen Spiegel betrachtet (Dorian Gray u. a.). Hinzu kommt die Faszination der Epoche fin de siècle für Metall, Kristall und Wasser, die die Funktion des Spiegels imitieren. Signifikanterweise sind die Prototypen des dekadenten Künstler-Menschen, Dorian Gray und Des Ësseintes, auch leidenschaftliche Edelstein-Sammler. Unter dem Einfluß von Swedenborgs Geistervisionen wurde auch der Topos des dămonisierten bzw. nekromantischen Spiegels aktualisiert. Man denke an Nietzsches Parabel Kind im Spiegel zu Beginn des zweiten Teils von Also sprach Zarathustra. Der Ikonographie des Spiegels von der 
Metabewußtseins und als solches wird sie auch denunziert, indem das scheinbar Fremde ("tvých..." / "in deinen"; nämlich die Merkmale der äußeren Natur) von lyrischem Ich als das "Eigene" ("vlastni") empfunden und reflektiert wird: "kouŕ vlastnich myšlenék mi z tvojich vuni stoupal, I a vastni krve vzdech jsem citil ve tvých zalech" (1, 3-4; "der Rauch meiner eigenen Gedanken stieg mir aus deinen Düften empor, / und des eigenen Blutes Seufzer fühlte ich in deinen Kümmernissen“). Die natürliche Welt befindet sich im lyrischen Ich und nicht das lyrische Ich in der Welt. Dieses Bewußtsein wird in der vierten Strophe noch einmal zum Ausdruck gebracht bzw. das Vorhergesagte zusammengefaßt; nämlich das Bewußsein, daß die Natur-Welt, die "Nacktheit der Natur" 144 ("mlh hábít kajici nad nahotou twých pláni", IV, 1), von einem "Schleier" ("závoj", man denke an "Schleier der Maja") der lllusion verhüllt ist. Das Motiv der nahenden "schwarzen Tage" ("a dusot cerných dni, jeż slyším z dálky cválat", IV, 2; "das Gestampfe schwarzer Tage, die ich aus der Ferne galopppieren höre ${ }^{\prime}$ ) antizipiert - als Vorzeichen der erlöschenden Hoffnungen, der Trauer und der Todesnähe - das Motiv der "toten Tage" ("a mrtv'ch dnü mých stínem", VI, 4; "Schatten meiner toten Tage"). Die Trauer der Seele (des lyrischen lch) hat ihre Parallele in der Trauer der Natur, die jedoch auch als Produkt der eigenen ("z mé krve vyrostly", V, 1; "erwuchsen aus meinem Blut") Einbildungskraft bloßgelegt wird: "tvých stromú němý żal a smutek odkvétáni / i tresouci hlas vod a noci teskných nálad /... / / z mé krve vyrostly" (IV, 3-4, V, 1; "deiner Bäume stummer Gram und die Trauer des Verblühens I...I /I erwuchsen aus meinem Blut"),

Ein neuer Aspekt des Illusionären der in Str. I-IV thematisienten Gefangenschaft in der Welt der Imagination, wird in der füntten Strophe als eine quasi n e u e Perspektive des gleichen Sachverhaltes konkretisiert. Es ist der Aspekt der Hervorbringung der ästhetischen Werte, der Kunst-Schöpfung in der irrealisierten, imaginierten Kunst-Welt, deren 'Erscheinungsformen' den einzelnen Teil-Aspekten des Gefangen-Seins parataktisch und adversativ zugefügt werden (IV, 4 - V, 1; V, 4 - VI, 1). Das Motiv der glühenden gläsernen Materie verleiht der Sinnstruktur von Vẻzen ihre besondere Prägnanz. Einerseits rekurriert dieses Motiv auf die Vorstellung der Entstehung und Erschaffung der Welt aus der glühenden chaotischen Materie (massa confusa), andererseits auf die Fähigkeit und Gabe des Kunst-Schöpfers, das Chaos wieder in Kosmos zu transformieren. Das Motiv der Glasbläserpfeife ("jsem smácel pištalu /... $r$, V, 4) hat - durch die Verwandschaft mit dionysisch / apokalyptischen Musikinstrumenten der Metapoesie, wie dionysische Flöte, Schalmei usw. - eine metapoetische Bedeutung. Diese Schöpfung bedeutet die Verwirklichung des (Kunst-)ideals - "Mým snem jsou barvy Znnouci I..." (V. 1; "Mein Traum sind die glühenden Farben") -, wobei der "Traum" ("sen") hier einen anderen bzW. neuen Aspekt des oben (I.-IV. Strophe) thematisierten lllusionismus darstellt. Das gilt auch für das Motiv der 'Befreiung' ("kdyż vzlétám

Antike bis ins 20. Jahrhundert ist die vorzügliche Monographie von Jurgis Baftrusaitis gewidmet: Der Spieget. Entdeckungen, Täuschungen, Phantasien, Gießen 1986.

144 Das Motiv der Nacktheit der Natur, das in Vêzen aktualisiert wird ("nahotou tvých pláni" I "Nacktheit deiner Wiesen", IV. 1), taucht bereits in der Ikonographie der hellenistischen Kunst auf und eine konstitutive Rolle spielt dieses Motiv im Bedeutungsaufbau vieler herausragender Werke der Renaissance- und der Barock-Kunst (man denke an Tizians L'amor sacro e l'amor profano. 1515, Rom, Galleria Borghese). Auf einigen Plinius- und Aristoteles-lilustrationen aus dem 15. Jahrhundert wird die Natur - nach der antiken Tradition - als nackte, milchspendende Frau dargestellt. Diese Darstellung übernimmt (1603) auch Cesare Ripa in seine "Iconologia". (Wolfgang Kemp, Natura. Ikonographische Studien zur Geschichte und Verbreitung einer Allegorie, Tübingen 1973. S. 17ff.). Die topischen Bedeutungen, die die 'Nacktheit' (der Natur) impliziert (Natürlichkeit, Unschuld, platonische Liebe, Wahrheit - als nuda veritas usw.), sind zwar für das Nacktheit-Motiv in Vézen offenkundig nur potentiell relevant, doch nicht ohne Interesse, vor allem in bezug auf die religiósen bzw. liturgischen Motiven, die in vézeñ funktionalisient werden: "a vlastni duše hlas z tvých modliteb mi kvilil, / kdyż na svém oltári mi otevỉelas missál" ("und eigener Seele Stimme wimmerte zu mir aus deinen Gebeten, / als du das Meßbuch mir auf deinem Altar offnetest", II, 4): "hábit kajici" ("Büßerkleid", IV, 1). In diesem semantischen Kontext kann das Nacktheit-Motiv der Natur auf ihre Funktion als "filia" oder "vicaria Dei" bzw. auf die ethische Dimension verweisen. W. Kemp (a.a.O.) erwähnt auch die Bedeutung der Nacktheit der Natur als Unverhülltheit, d. $h$. als Offenbarung der Ideen (ihrer Schönheit). Die Symbolik der "NaturEntschleierung" als 'Entschleierung der Idee' geht offensichtlich auf die neoplatonische Tradition zurūck. Die Darstellung der natura als (halb-)nackte Frauengestalt gehörte noch im 19. Jahrhundert zu bereits konventionalisierten Natura-Allegorien (Moritz von Schwinds NaturAllegorie, 1840 u. a.). 
ysvobozen / z tvých loktü vysněných", VI, 1; "wenn ich befreit / aus deinen erträumten Armen mich emporschwinge"); diese paradoxe Befreiung führt in den Zustand des kreativen Eingemauertseins, der in der letzten Strophe expliziert wird. Der Kunst-Schöpfer gibt seinem Traum die Form ("I.../ a vydechl tê tvarem", V, 4; "und ich blies dich zur Form aus") und 'valorisiert' die Natur durch die geistige Schönheit, durch das Kunst-Schöne, als ästhetisches Artefakt. Die Kunst der Glasbläserei (als Symbiose von Schönheit und Handwerk) impliziert die Kugel-Form, die wiederum - als die vollkommenste Form schlechthin - die Harmonie, zugleich aber auch die Zerbrechlichkeit der Welt symbolisiert. 145 Durch ihre mathematische Beschaffenheit, durch die Gleichneit der Teile im ganzen ist die Kugel der vollkommenste Körper, die absolute Schönheit. Als Überwindung des Urchaos erhält der schöpferische Akt des Künstlers auch eine philosophisch-sittliche Dimension. Das Gedicht Podzimni vecer (Der Herbstabend) thematisiert in der Schlußstrophe die Vision der Annihilierung der Erde, die wie eine graue "ho h l e Kugel" ("đu tá koule"; IV, 2-3) von ihrer Bahn in die Tiefe abrutscht: "Vystrikla hustá pèna tmy a do hlubiny / zem pohlcená sesmykla se na svè dráze" (IV. 3-4; "Ein dicker Schaum der Finsternis spritzte hoch und in die Tiefe / rutschte die aufgesaugte Erde von ihrer Bahn $a b^{\prime \prime}$ ). In Vézeñ versucht der Kunst-Schöpfer als creator microcosmi die phänomenale (Natur-)Welt - kraft seiner Imagination - aus der siedenden massa confusa neu zu formen: "I... I a vydechl té tvarem", V, 4; "ich blies dich zur Form aus").

Doch die "glühenden Farben" (V, 1; "barvy Zhouci", als Manifestation von sensus exterior ) reichen offensichtlich nicht, den Kunst-Traum zu realisieren. Das "warme Blut" ("teplou krv", III, 3; V, 1), die Substanz des Lebens und der Liebe, die den Dichter an die Sphäre des Chthonischen fesselt, wird durch die "výheñ duక̌e" (V, 3; "Glut der Seele", als Manifestation von sensus intimus), d. h. durch die geistige Glut substituiert, die allein imstande zu sein scheint, diese Transformation zu verwirklichen. Die anima secunda, die 'niedere Seele', die mit dem Körperlichen und Chthonischen im Kontakt war, soll erneut zur anima prima ('höhere Seele') erhoben werden, und zwar durch die Vernunft, die eine der Fähigkeiten der anima prima ist und als 'Vermittlerin' zwischen inr und der anima secunda fungiert. ${ }^{146}$ In der folgenden Strophe wird der befreiende Schöpfungsakt oxymoral als "teskné nadšeni" ("wehmütige Begeisterung") charakterisient. Dem KunstSchöpfer wird seine eigene Schöpfung zum Gefängnis; diese Befreiung ist synonym mit der Entscheidung für das Eingemauertsein in der autarken und autistischen Kunst-Welt, mit deren Wein sich der Dichter berauschen will: "i tu se zpijím vinem, na vastnich vinicich, jež uzrálo mi v hrozen, I mou krvi zahořklě a mrtvých dnú mých stínem" (VI, 3-4; "und dann berausche ich mich mit dem Wein, I der mir auf meinen eigenen Weinbergen zur Traube reifte, / herb von meinem Blut und vom Schatten meiner toten Tage") Das Blut, von dem der Wein herb wurde, ist das gleiche Blut (der eigenen Imagination), aus dem die ganze (Natur-)Welt-Illusion erwuchs ("a vastni krve vzdech /... $/$. I. 4; "des eigenen Blutes Seufzer" - "z mé krve vyrostly", V, 1; "erwuchsen aus meinem Blu'́). Der Eingekerkerte und der Kerkermeister sind eine Person. Das "unreine Blut" als Folge der "geheimnisvollen Schuld", durch die der Mensch mit der Sphäre des ChthonischTriebhaften verbunden bleibt ("Cerné vino tuh" / "der Begierden schwarzer Wein": Motiv Z Beothovena. " . ../ brutální rozkos z necisté cise mé krve". $/ \%$ / brutale Lust aus unreinem Pokal meines Blutes"; Návrat / Rückkehr), macht auch den Wein der Kunst-Extase zu bitterem Trank ("mou krví zahořkle". VI, 4; "herb von meinem Blut"). Die Vision der Existenz in der Isolation der autistischen Gedanken- und Kunstwelt, das 'Totsein' für die reale Welt ("a dusot cerných dni, jeż slyším z dálky cválat". IV, 2; "das Gestampfe schwarzer Tage, die ich aus der Ferne galoppieren höre"), wird in der sechsten Strophe als "Schatten meiner toten Tage" (VI, 4; "a mriv'ch dnú mých stínem") konkretisiert.

In der letzten Strophe wird die oneiroide Innenwelt des dichterischen Ich, die sich wie eine finstere Zitadelle hoch über die immanente Welt (und das irdische Leben) emporhebt ("Svưj hrad jsem vystavěl na mračné výši spádné". VII. 1; "Meine Burg erbaute ich aư

145 Es handelt sich um ein ikonographisch vieldeutiges Symbol. Die Interpretation der Glaskugel als Sinnbild der Harmonie schlägt Otto J. Brendel vor in seiner hochinteressanten, ikonologisch orientienten Studie zur 'Kugel'-Symbolik: Symbolism of the Sphere. A contribution to the history of eartier Greek philosophy, Leiden 1977.

146 Vgl. E. Panofsky, "Die neoplatonische Bewegung in Florenz und Oberitalien", in: E. Panofsky. Studien zur Ikonologie. Humanistische Themen in der Kunst der Renaissance. KöIn. 1980, S. 203-239. 
einer abfallenden Wolkenhöhe"), als Projektion seiner Einbildungskraft, in der der KunstSchöpfer eingemauert bleibt, bloßgelegt. Doch die postulierte autistische Abwendung von der Realität erweist sich letzten Endes auch als Illusion. Nicht einmal in der (idealen) Projektionswelt läßt sich das eliminieren, was den Menschen an seine bedrückende irdische Determiniertheit erinnert: das Leid ("Zal") im Sinne von Schopenhaver, daß "alles Leben Leiden ist". 147 Signifikanterweise kommt das Lexem "Zal" - im Zusammenhang mit dem Motiv des "e i g e n e n Blutes" - sowohl in der ersten ("a vastni krve vzdech jsem citil ve twých zalech", I, 4; ") als auch in der vorletzten und in der letzten Strophe vor: "mou krvi zahơ̈klé I...I a v klenbách placicich, kde Żal a ticho vládne" (VI, 4, VII, 3). Der Text selbst scheint Spiegelbilder zu ent-werfen, worauf die auffallenden Doppelungen, die 'symetrische' Wiederholung einzelner signifikanter Lexeme ("Zal" I "Leid", "duše" I"Seele", "krev" / "Blut", "temný oblak mlh", I, 2; "dunkle Wolke des Nebels" - "ser vlhkých katakomb", VII, 2; "Dämmer feuchter Katakomben") usw. hindeuten. Die unvollkommene Existenz in der phänomenalen (Natur-) Welt spiegelt sich in der (scheinbar) idealen ästhetischen Existenz des dichterischen Ich, in der von inm kreierten und auf die Außenwelt projizierten Traum-Welt (Str. V-VII) wider. Während jedoch in der Sphäre der Natur-Welt das Leid als "wehmütiger Seufzer" oder als elegisches Echo quasi von außen wahrgenommen wird $(1,4)$, wird es in der Kunst-Welt zum 'Mitherrscher' ("a v klenbách placicich, kde żal a ticho vádne", VII, 3; "und in weinenden Gewölben, wo Leid und Stille herrschen"). Die ästhetische Existenz als Eingemauertsein in der Schattenwelt ("ser vihkých katakomb". VII, 2; "der Dämmer feuchter Katakomben") gleicht einem akommunikativen Akt ("ticho" I "Stille", VII, 3). Das "lebendig eingemauerte Lied" ("za Żiva zazdẻná má pisen̉ noci zpivá", Vil, 4), das nur nachts ertönt, bleibt für die 'Schlafenden' unhörbar, weil es im Prinzip (hauptsächlich) dem narzißtisch-autistischen Sebstausdruck dient. Vom Standpunkt der Logik der Irrealisierung-Semantik Briezinas dekadenten Symbolismus aus, stellt diese autistische Abkapselung in die illusionäre und oneieroide Kunst-Welt einen idealen Zustand dar, denn in der phänomenalen (Natur-)Welt, in welcher der Dichter ohnehin nur sich selbst - wie in einem katoptrischen Kabinett - erblickt, gibt es für inn "nur die Wahl zwischen Einsamkeit und Gemeinheit". 148

\subsection{Kunst als sacrum}

\section{„/.../ umèni mne cele prosıoupilo, absorbovalo, vsálo /.../". "/..J die Kunst hat mich gänzlich durchdrungen, absorbiert, aufgesaugt /...".}

O. Błezina an F. Bauer (21. V. 1893)

Die von Bïezina in seiner Korrespondenz aus der Zeit zwischen 1892-1895 (die Abfassungszeit von Tajemné dálky immer wieder artikulierte Vorstellung. die völlige Absage an die immanente Welt und das (reale) Leben ( $/ / . /$ mujj Żivot mi nepatîi. Pattí

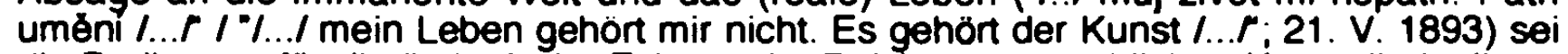
die Bedingung für die ästhetische Existenz im Reich der unsterblichen Kunst, findet ihren Reflex und ihre Verwirklichung im semantischen und kompositorischen Aufbau des gesamten Zyklus. Der Prozeß der Irrealisierung des immanenten Lebens durch Hypnos, Oneiros und Thanatos, der auch die 'unvollkommene' phänomenale Natur-Welt erfaßt, die durch das Kunst-Schöne denaturiert wird, erreicht seine Vollendung in der postulierten ästhetischen Existenz als kathartischer Dienst am Kult der Kunst ("Umëni jest u mne

$147 \mathrm{Vgl}$. Arthur Schopenahauer, Die Welt als Wille und Vorstellung. Bd. I. $\$ 56,2$. Werke in zehn Bänden. Hrsg. von Arthur Hübscher. Zürich 1977. S. 389. Vgl. dazu auch: Georg Simmel, .Die Metaphysik des Willens", in: G. Simmel, Schopenhauer und Nietzsche, Hamburg 1990. S. 89: 122.

$148 \mathrm{Vgl}$. Arthur Schopenhauer, Die Welt als Wille und Vorstellung. Bd. II. Kap. 31. S. 459. Diese Intention koinzidiert mit Błezinas Äußerungen in seiner Korrespondenz mit F. Bauer: "Chci vysoké, aristokratické umẻni pro vyvolené". (Vgl. O. Bł̉ezina, Dopisy Františku Bauerovi, Praha1929, S. 202; "Ich will eine hohe, aristokratische Kunst nur für Auserkorene"). 
kultem" / "Die Kunst wird bei mir zum Kult", 20. XII. 1894). ${ }^{149}$ Es kein Zufall, daß sowohl das Prolog-als auch das Epilog-Gedicht des Zyklus ( $O$ silo extasi a snú... I $O$ Kraft der Extasen und Träume... und Uméni I Die Kunst) programmatisch die Initiation in das "Heiligtum der Kunst" zum Thema haben. ${ }^{150}$

Die Sakralität ("svatost") der Kunst läßt die Misere des Alltagslebens vergessen ("universálni prostriedek/...l, jímż léčim s úspęchem každé żivotní zlo: uméni"), zugleich aber "übeschwemmt" sie den Künstler mit "Augenblicken erregender Wollust" "chvile dráždivých rozkoši, jimiž mne zatopuje uméni“). ${ }^{i 51}$ Daher fordert Březina (auch und vor allem in den Briefen an Bauer aus den Jahren 1893-1895) die bedingungslose Hingabe an die Kunst. Es fällt auf, daß die Vorstellung Bïezinas von seinem "Dienst" am Kult der Kunst, sein in der Korrespondenz explizit artikuliertes Selbstverständnis als (dekadenter) Dichter-Künstler ("Sohn der modernen Epoche, fin de siecle /... ${ }^{\prime}, 21$. V. 1893) eine frappierende Ambivalenz kennzeichnet: Die Kunst "überschwemmt" den Dichter mit "Augenblicken erregender Wollust" und gleichzeitig empfindet er sie als "schwere Mühewaltung" oder als "hartnäckigen Kampt" ("tvrdošijný zápas"; 20. IV. 1893). Die Kunst erregt und "stigmatisiert" alle seine Sinne, "fesselt" inn "an das Lager" (des Kunst-Todes; Motiv z Beethovena / Ein Motiv aus Beethoven), "hypnotisiert" ihn, läßt inn in "ewigen Traum" versinken (Motiv z Beethovena, Snad potom... I Dann vielleicht.... Svüj Zal jsem polożil ... / Mein Leid legte ich.... Uméni / Kunst) usw. Der Dichter als opfernder KunstPriester ist gleichzeitig das Opfer (Uměni / Die Kunst). In Br̈ezinas Auffassung bedeutet die Kunst ein sacrum, mit all der Polysemie (bzw. Polyvalenz) dieses Lexems: Heiligtum ("svatynë"), heiliger Brauch ("Uměni u mne jest kultem" / "Die Kunst wir bei mir zum Kult". s. 0.). Opfer ("obét"; $O$ silo extasi a snú... I O Kraft der Extasen und Träume...).

149 An F. Bauer (21, V. 1893): "Mohu-li Ti radit, učiñ jako já. V uméni najdeš ođisty, sily, vzletu,

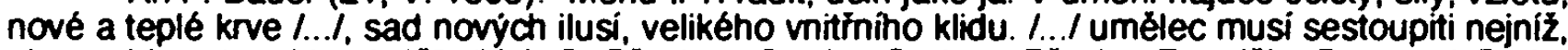
aby mohl vystoupiti nejvýs". (Vgl. O. Biezina, Dopisy Otokara Breziny Frantisku Bauerovi, Praha 1930, S. 192;"Wenn ich Dir raten kann, tu wie ich. In der Kunst findest Du Reinigung. Kraft, Aufschwung, neues und warmes Blut $/ . . /$, Garten neuer Illusionen, große innere Ruhe. I... . der Künstler muß sehr tief hinabsteigen, um den Höhepunkt zu erreichen".)

150 Die (Selbst-)Thematisierung der Kunst-Schöpfung und Dichtung, die metapoetischen Aussagen und Selbstreflexionen, die in die poetische Welt der nach 1893 abgefaßten Gedichte immer intensiver vordringen, wurde $u$. a. durch die Resonanz und Anerkennung motivient, die Błezinas Gedichte bei seinen Dichter-Kollegen Prag, im Zentrum des damaligen tschechischen kulturellen und gesellschaftlichen Lebens, fanden. Man muß sich vergegenwärtigen, daß Błezina bis zu diesem Zeitpunkt ein unbekannter Dorflehrer in einem kleinen westmăhrischen Ort war, weit entfernt von Prag. Nach diesem Durchbruch wurde er sozusagen in die Prager DichterGemeinschaft der 'Eingeweihten' aufgenommen. In einem Brief vom 21. V. 1893 schreibt Bfezina an F. Bauer: "Rohácek (Name des Chefredakteurs der Literaturrevue Niva) mi onehdy psal /.../. Že $\checkmark$ prażských literámich kruzich prorazil jsem ukázkami básnické své produkce na celé cáre. Slibuje a płedpovidá mi úspéch". ("Rohácek hat mir neulich geschrieben $1 . . . /$, daß ich mit der Veröffentlichung meiner dichterischen Produktion einen völligen Durchbruch in die Prager Literaturkretse geschaftt habe. Er verspricht, prophezeit mir Erfolg". A.a.O., S. 192-193.) Ein Jahr später, in einem Brief vom 20. XII. 1894: "V uméni docilil jsem v poslednich mésicich nejvyšsich posavadnich úspéchú. Výbor z mých poesii vyjde v prekladẻ polském z pera Zenona Przesmyckého, Miriama, s mým životopisem v Anthol. básnikú ceských". (Ibid., S. 199; "In der Kunst habe ich in den letzten Monaten die bisher größten Erfolge erreicht. Eine Auswahl aus meiner Poesie erscheint in polnischer Übersetzung von Zenon Przesmycki, Miriam, mit meinem Lebenslauf, in der Anthol. [ogie] der tschechischen Dichter") Bald darauf, im Jahre 1894, wurde die führende, maßgebende Revue der tschechischen Moderne - Moderni revue (1894-1925) gegründet, zu deren Stamm-Autoren Biezina von Anfang an bis zu seinem Verstummen (1907) gehörte. Durch seine Mitunterschrift unter dem Manifest Ceské moderny (u. a. von Salda konzipiert) ein Jahr später, deklarierte Błezina seine Zugehörigkeit zu der tschechischen Moderne der neunziger Jahre. Im Zusammenhang mit der Kritik seiner Gedichte in der Revue der Parnassisten Lumir, schreibt Bł̉ezina an Bauer (12. VI. 1893): "Jsem ostatné pỉesvèdZen, Že surový útok .Lumira" s naši strany bez odpovédi nezústane". ("ich bin allerdings überzeugt, daß der brutale Angriff in "Lumir von unserer Seite [seitens der Modemisten; Kursivsetzung vom Verf.] nicht ohne Antwort bleibt". Ibid., S. 194.)

151 Ibid, S. 171, 175. $\%$.../ ein universales Mittel /.../, daß ich gegen jede Lebensbosheit anwende: die Kunst'. Biezinas Briefe an Bauer können als aufschlußreiche poetologische und 'psychopoetische' Kommentare zu seiner eigenen schöpferischen Enwicklung in der Phase des dekadenten Symbolismus (1892-1895) gelesen werden. 
Gottesdienst (Umęni I Die Kunst), Mysterium oder Geheimnis (Svüj żal jsem polożil.. I Mein Leid legte ich..., Tajemné dálky / Geheimnisvolle Fernen ). Diese Mehrdeutigkeit, die (Grenz-)Position des Dazwischen-Stehens, die Grenz-Erlebnisse zwischen schöpferischer Extase und hypnotischer Ermattung, zwischen - an ästhetisiertem Masochismus grenzender - Lust und Leid, zwischen "Realitätsprinzip" und "Lustprinzip“, zwischen Traum/Kunst-Welt und Alltag-Welt und schließlich auch zwischen Kunst und Religion, diese peinigende und zugleich erregende Verstrickung von Gegensätzen, scheint für die ästhetische Existenz des dekadenten Dichtertypus geradezu signifikant zu sein. ${ }^{152}$ Dabei spielt die (gnostische) Symbolik der "Grenze" eine sinnkonstitutive Rolle. Die "Grenze" ("hranice"; "Na hranicich svých dni", Uméni I Die Kunst, VII, 1; "hranice"), im Tschechischen ein Homonym, das sowohl die "Grenze" als auch den "Scheiterhaufen" bedeuten kann. Im gnostischen Raum hat die "Grenze" eine durchaus negative Bedeutung, einen "tyranischen Charakter", weil sie die Welt zu einem Zwangssystem devalviert und daher überschritten werden soll/muß.153 Das Feld der gnostischen Denktradition betritt Bíezina bereits in einem seiner ersten symbolistischen Gedichte, in Modlitba vecerni (Das Abendgebet, s. 0. Kap. 2.1.1). Es ist vor allem die Verwerfung des in der hellenistischen Gnosis als Seelengefängnis verabscheuten hyletischen Leibes, der durch das U be r schre it e n der Schwelle zur höheren Welt, d. h. durch eine Art EntGrenzung, 'abgelegt' werden muß. Die Existenz in der Sphäre der immanenten Welt bedeutet in der Gnosis den verhängnisvollen Schlaf, den Zustand der Unwissenheit um 'sich selbst', aus dem der Schlafende (oder 'Berauschte') durch den Weckruf geweckt werden muß. Hinter dieser Grenze verbirgt sich 'Etwas' (ein Rätsel, Geheimnis usw.), was zu ihrer Überschreitung geradezu unwiderstehlich verführt. Es ist das quälende und gleichzeitig verlockende "ewige Geheimnis" ("věčné Tajemstvi"), das Designat des ganzen Zyklus und sein höchstes Ziel, das in der "geheimnisvollen "Ferne" liegt und kraft der Erkenntnis (yväous) entschleiert werden kann, das aber schließlich (doch) unerreichbar bleibt. Von dem ersehnten Ziel trennt den Kunst-Schöpfer die endlose und entkräftende Ferne:

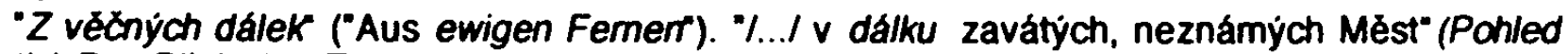
smrti / Der Bllck des Todes, III, $1 ; \%$... in die Ferme der verwehten, ubekannten Städte $") . \%$... vỷkfiky otázek vraceji se echem vysileným dálkớ (Slavný smutek I Die emabene Traver, IV, 5; "Schreie der Fragen kehren als Echo zurück, erschöptt von der Feme $\%$ ). \%... Do véčného sera. kde úsmẻv tvưj lepý / ti uhasne v tvárí, zbẻli ti na rtech a únavná dálka l...r (Návrat / Rückkehr, VI, 3-4; "In die ewige Dämmerung, wo dein zauberhaftes Lăcheln / in deinem Antlitz erlischt, auf deinen Lippen erbleicht und die erschöpfende Ferne /... $)$. " \%.../ a dusot ¿erných dni, jež slyším z dálky cválat" (Vézeñ / Der Gefangene. IV, 2; "das Gestampfe schwarzer Tage, die ich aus der Feme galoppieren höre").

Es ist die Kunst als sacrum, d. h. als Heiligtum. Mysterium ( $Z$ vécných dálek...l Aus ewigen Fernen.... IX, 4) oder Opferhandlung. die den Zugang zum "ewigen Geheimnis" erschließBt. Im Epilog-Gedicht Uméni (Kunst) tritt das dichterische Ich als zelebrierender Kunst-Priester ${ }^{154}$ aut, der sich dem Kunst-sacrum in einem Initiationsritual aufopfert:

-Svou dusi v żhavý sloup vysálám do nebes / a v rakev sily své jak $v$ cín se složím ke snu, / aż k’̉edi Tajemstvi jako porażený knéz / u oftárú Trých klesnu" (Uméni I Die Kunst, IX, 1-4; "Meine Seele lasse ich als Glutsăule zum Himmel lodem / und in den Sarg meiner Kraft lege ich mich hin zum Trăumen wie in Zinn, / bis ich im Krampf des Geheimnisses wie ein besiegter Priester / an

152 Die Thematisierung des 'Dazwischenseins' betrachtet Aage A. Hansen-Love (Der russische Symbolismus, Bd. I, Diabolische Symbolik, Wien 1989, S. 433tf.) als entscheidend für den dekadenten Kunst-Schöpfer. Dazu gehớt die Reversibilität des Verhăltnisses zwischen dem 'Einen' und dem 'Anderen', zwischen Diesseits und Jenseits usw.

153 Vgl. hierzu: Hans Jonas, Gnosis und spätantiker Gelst" I, Göttingen 1964, S. 40 off.

154 Die Stilisierung des Dichters zum Priester (bzw. Magier) geht offensichtlich auch bei Bỉezina auf Les Fleurs du Mal zurück. In einem Brief an Bauer nennt Błezina den Dichter - im direkten Anschluß an Baudelaire - "Priester der absoluten Schönheit, Liebhaber des Unendlichen, Unfaßbaren I... ("knẻzem absolutni Krásy, milencem Nekonečného, Nepostižitelného /... $\digamma$ ). $O$. Błezina, Dopisy Fr. Bauerovi, Praha 1930, S. 169-171. Die Vorstellung der Kunst als einer neuen Religion ist wiederum, wie U. Heftrich nachweist (Otokar Biezina, Heidelberg 1993, S: 116f.), auf Schopenhauer zurückzưühren. Schließlich reprăsentiert der Kunst-Priester in Tajemné dálky jene metaphorisch-mythogene Figur, die in einer der Empirie entrückten und irrealisierten Kunst-Welt dem ldeal der absoluten Schónheit dient. 
Deinen Altären niedersinke"). Das Opfer-Motiv kommt auch im Prolog-Gedicht $O$ silo extasi a snü... (O Kraft der Extasen und Träume...) vor:

"O silo extasi a snù, z niż umèni / plá barev vẻjiỉem a v tónech buráci ! / Na obèt' ouše mé svưj żhavý sešli prival, I ó moci vítézná, jeż v inspiraci pláš, jak v ottár kamenný se onen̉ s nebe slival, kdyż obèt' krvavou nañ kladi Eliás". (I, 1-4, XI, 1-2; "O Kraft der Extasen und Trăume, aus der die Kunst / als Farbenfächer flammt und in Tönen tost! // Auf das Opfer meiner Seele sende deine Feuerflut herab, / o siegreiche Macht, die du in der Inspiration loderst / wie das Feuer vom Himmel auf den Steinaltar strömte. / als Elia an inm das blutige Opfer darbrachte").

Im Akt der (Selbst-)Annihilierung. (Selbst-)Irrealisierung durch den Kunst-Tod kann man das Reich der Kunst, das Künstler-Elysium ("O teskný hřbitove, kde duše Velkých sni", Umeni / Die Kunst, I, 1; "O du trauriger Friedhof, wo die Seelen der Großen träumen") betreten. Die irrealisierte Welt ist die autarke Kunst-Welt. Der Traum-Tod, das Vergessen - oder die Erinnerung an das Verlorene, Entschwundene, Nicht-Mehr-Seiende -, die Ablehnung des Natur-Schönen und dessen Valorisierung durch das Kunst-Schöne, ${ }^{155}$ dies alles sind Phänomene und in Tajemné dálky durchaus positiv konnotiente Qualitäten, die die Irrealisierung der Welt (als Ausweg aus der "Befangenheit im Daseinstraum") und dadurch auch die ästhetische Existenz par excellence möglich machen ("/.../ odcizuji se všemu, co nesouvisi s uměnim $/ . \ldots / \% / . . /$ ich entziehe mich allem, was nicht mit der Kunst zusammenhängt $I . . . \mu$; an F. Bauer, 1. XII. 1892). Die Kunst soll in alle Formen der Existenz expandieren und umgekehrt die Kunst soll, wie ein Gravitationsfeld, alle Existenzformen in sich konzentrieren und schließlich auch alle Kultur- und Gesellschaftsfunktionen substituieren. ${ }^{156}$ Die Kunst absorbiert das Leben des KunstSchöpfers ("uméni mne cele... absorbovalo" I "die Kunst hat mich gänzlich... absorbiert": an F. Bauer, 21. V. 1893), sie erschafft die 'vergängliche' Natur als ästhetisches Artefakt wieder, transformiert das stofflich-substantielle und materielle Sein in das imaterielle, rein mentale, ideelle Sein. Mit derartiger Reduktion der Existenzformen aut die ästhetische Existenz koinzidiert auch die Reduktion der Referenzfunktion der Dichtersprache, die sich der Mitteilbarkeit entzieht, auf Autokommunikativität und Monologizität. Die Gedichte von Tajemné dálky haben zwar oft explizite Adressaten, es sind aber ausschließlich nur personifizierte Ideen ("myšlenky"), abstrakte 'höhere' Instanzen ("Nejvyšši" I "der Höchste": "smrt" / "Tod"), die "Seele" ("duše"; Návrat I Die Rückkehr, Návšstéva / Der Besuch) des lyrischen Ich, die personifizierte Kunst/Musik (Motiv z Beethovena / Ein Motiv

155 Die in der Romantik - in der der Begriff des Schönen, infolge der Destruktion des klassischen Schönheitskanons, stark problematisiert wurde - sich gründende Idee des KunstSchönen, die der Drang nach der ăsthetischen Entgrenzung, nach dem Gewinn neuer Sensibilităt, nach der Erforschung der Tiefen des Inneren oder nach dem Formensynkretismus kennzeichnet, wurde bekanntlich von den Vorahnen des Symbolismus, E. A. Poe und Ch. Baudelaire, weiterentfaltet, vor allem in bezug auf das Kriterium des Neuen. Ungewöhnlichen, Geheimnisvollen oder Traumhaften. (Vgl. Walter Höllerer, Theorie der modernen Lyrik. Dokumente zur Poetik I. Hamburg 1966, S. 22ff.). Insbesondere der Phantasie wird von Poe und anschließend auch von Baudelaire eine besondere Kraft bei der Erschaffung des postulierten Neven (der 'neuen Welt') und Bizarren zuerkannt. Die Kombination von Intellekt (als Triebkraft der Phantasie) und hoher Sensitivität für die Klangwerte der Sprache, die auf die Tradition des Manierismus rekurrierende Orientierung an der Kombinatorik der Musik (und der Mathematik) im Prozeß des Dichtens, die die imaginative Wort-Kunst Baudelaires und Mallarmés (der diese Linie wohl am prăgnantesten fortsetzt) charakterisiert, findet, wie bereits erwähnt, in der Struktur von Tajemné dálky einen unverkennbaren Reflex. In seiner Korrespondenz (1892-1893) betont Biezina den gewaltigen Eindruck, den Les Fleurs du Mal in inm hinterließen (O. Biezina, Dopisy Frantisku Bauerovi, Praha 1929, S. 167f.). Baudelaire und Maliarmé nennt er "meine Meister" (ibid., S. 196, 201). In der Korrespondenz mit Anna Pammrová erwăhnt er auch Kant, dessen Hervorhebung der Rolle der Einbildungskraft für den Erkenntnisprozeß und der "aktiven Făhigkeit zur Synthesis" (I. Kant, Kritik der reinen Vemunt, Werkausgabe, Bd. 3, hrsg. von W. Weischedel, Frankfurt am Main 1983, S. 165) für Błezina sicherlich nicht weniger bedeutend war: $\%$... má mystika /.../ divala se dlouho do pyšných idealistických perspektiv školy Kantovy (" $/ .$. / meine Mystik /.../ schaute lange in die stolzen idealistischen Perspektiven der Kant-Schule hinein $\left.{ }^{\circ}\right) .0$. Błezina, Dopisy Annẻ Pammrové 1889-1905, Praha 1931, S. 147.

156 In der Schaftensphase des dekadenten Symbolismus betrachtet Biezina das KunstSchōne als absoluten Wert und höchstes (synthetisches) Ideal, das auch über Vernunft und Ethik steht: "Mám vysoký a cistý ideál I...I. V boj za Cisté, vysoké, jediné Uměni!" ("Ich habe ein hohes und reines Ideal l... I. Auf in den Kampf für die reine, hohe, einzige Kunst!"). Otokar Brezina. Dopisy Frantisku Bauerovi, Praha 1929, S. 171-172. 
aus Beethoven) oder nur abwesende Personen (tote Mutter; Moje matka / Meine Mutter, Den výrocnni / Der Gedenktag. Znameni duše / Das Zeichen der Seele) usw. In einigen Gedichten wird das angesproche "Du" nicht weiter spezifiziert, seine Identität bleibt 'incognito' (Cas lije se ...I Die Zeit ergießt sich....Snad potom... I Velleicht dann...). Die 'Stimme' der Kunst'157 bzw. die des Kunst-Todes vernimmt das dichterische Ich als "Suggestion", 158 "Hypnose", "Resonanz" (Motiv z Beethovena, Z vẻčných dálek... / Aus ewigen Fernen ...), als "monotones" ("piseñ monotonni"; $Z$ vẻčných dálek...), "lebendig eingemauertes Lied" ("píseñ za živa zazděná"; Vẻzeñ / Der Gefangene) oder als "Grablied" ("piseň pohrebni"; Motiv z Beethovena) usw.

"Z vẻcných dálek $v$ duši mi zpivá / piseñ monotonni, / spodni oktáva zádumčivá mé klaviatury ji zvoní. l... / V rozkoši krví mou se pẻni / a na samotách, / v dlouhá adagia polosnèni / v pochmurných notách // mi vzrưstá. / Paprskủ umdlených mirem / neusíná, / jak oblaky hmyzủ kovovým vírem / $v$ Cerné klenby svých zvukư mne spiná // a vyssává /... I ( $Z$ vèchých dálek... / Aus ewigen Fernen... I, 1-4, IV.-V. Str., VI, 1; Aus ewigen Fernen singt mir in der Seele ein monotones Lied, / die schwermütige untere Oktave / meiner Klaviatur erklingt in inm. /... I In der Lust schäumt es von meinem Blute auf, / und in den Einöden, / sich zu langen Adagios des Halbträumens / in dūsteren Noten // steigert. / Durch die Strahlen, von der Ruhe ermattet, / schläft es nicht ein, / wie die Wolken von Insekten fesselt es mich mit metallischem Wirbel / in schwarzen Gewölben seiner Tone // und saugt mich aus /...\%).

157 In Błezinas Gedichten kommen weder Personen- noch Ortsnamen vor (bis auf drei Ausnahmen in TD: Eliás / Elia und Gedeon, in $O$ silo extasi a snu... I O Kraft des Extasen und Träume, und Beethoven im Gedichttitel Motiv z Beethovena / Ein Motiv aus Beethoven). Ein anderes Spezifikum steltt die Raum-Zeit-Semantik seiner Gedichte dar: Raum- und Zeit verschmelzen oder sie lösen sich auf in psychische Zustảnde wie Traum[unter]bewußtsein, Hypnose usw. Symptomatisch ist ebenfalls die Reversibilităt im Verhältnis zwischen "Augenblick" ("okamžik") und "Ewigkeit" ("věcnost"), zwischen einem begrenzten Raum und der "unabsehbaren Ferne" ("nedozímá dălk") usw. Bei der Rezeption einiger Gedichte aus Tajemné dálky wăhnt man sich im Umfeld des Symbolismus Stéphane Mallarmés oder Maurice Maeterlincks. Man denke $\mathbf{Z}$. B. an Mallarmés "Musik der Ideen" und an Błezinas Gedichte, die die Entwicklung des (personifizierten) Gedankens zum Sujet haben oder an die Orientienung der Kunst-Schöpfung der beiden Künstler auf das rein Mentale, Ideelle. Man denke auch an die intendierte Evokation von Un(ter)bewußtseinszuständen, die sich einer begrifflichen Bennenung widersetzten und sich lediglich kraft der Suggestion ausdrūcken lassen. Darüber hinaus muß man ebenfalls die unerhörte Kühnheit metaphorischer Symbole der beiden Dichter erwähnen, mit der sie die sprachlichen Konventionen sprengten und die - bei Blezina - seitens der Parnassisten heftig als vőllig unverstăndlich kritisiert wurde. In einem Brief vom 12. VI. 1893 schreibt Biezina an Frantisek Bauer: "Studuji Stéphana Mallarméa, velikého a nepristupného mistra, haleného v posvátný. modrý dým symbolú koửicich ze zlatých pánvi, zdobených bas-reliefy dávných, vymíelých bożstev, velebených a oslavovanch krvi otrokú v hlubinách vyhaslých tisícileti". $O$. Błezina, Dopisy Frantisku Bauerovi, Praha 1929. S. 196. Und im Brief vom 20. XII. 1894 nennt Bł́ezina Mallarmé "mein großer Meister" ("mủj veliký Mistr"): "Nejsem, a vidím to Cím dále tím zł̌etenêji, uzpúsoben. abych chutnal míháni svých dni jako stavnatý plod. plný zdravé vưnè: ma faim d'aucuns fruits ici ne se régal, jak łekl veliký múj Mistr Mallarmé". (Ibid., S. 201).

158 Mit der Bedeutung der 'Suggestion' im (dekadent-)symbolistischen Diskurs der polnischen Symbolisten der Bewegung Mioda Polska beschäftigt sich Maria Podraza-Kwiatkovska in ihrer Monograpfie Symbolizm i symbolika v poezji Młodej Polski, Kraków 1975, S309tf. Die Autorin unterscheidet zwei 'Suggestion'-Konzepte. Das erste, das auf Mallarmé zurückgeht, beruht auf der Substitution der mitteilenden Funktion der (Dichter-)Sprache durch die suggestive Funktion der rhythmisch-klanglichen Potenzen der Sprache und ihrer 'm u s ik alis che $n$ " Wirkung und durch die Metaphorik (Synästhesie) und mannigfaltige stilistische Mittel wie Elipse, Anapher. Alliteration, Tautologie, Andeutung (z. B. bei der Darstellung der diaphanen Medien wie Dampf, Nebel, Wasser, Qualm usw.), Onomatopoetik u. a. Dazu kommen auch verssemantische bzw. versrhythmische Mittel wie Liedform (mit Allusionen auf Volkslied), Refrain, Leitmotiv usw. Die andere Konzeption der suggestiven Wirkung der Lyrik ist eng mit der 'Hypnose' verbunden. Dabei spielen - zusammen mit den schon erwähnten stilistischen und versrhythmischen Mitteln - auf der motivsemantischen Ebene gerade solche Motive eine eminente Rolle, die den Akt des Hypnotisierens implizieren, d. h. vor allem die Hände, ferner Motive des Fallens, Einschlafens, des Traums, der monoton fallenden Regentropfen, der lang nachhallenden Schritte usw., die auf den Hypnotisierten eine magisch-bannende Wirkung ausüben sollen, mit dem Ziel seiner Versetzung in das Reich des absolut Schönen, des Kunst-Traums usw. Die intendierte Wirkung der 'Suggestion' und 'Hypnose' der'Musik-Sprache' war die Substitution der Mitteilbarkeit, der Rhetorik und der rationalen Argumentation. 


\subsubsection{Leiden und (Selbst-)Opferung: Bedingungen für die Initiation in das Kunst-Reich: Uměn}

"I..J inendhla pocínam se bliziti tajemné oné Svatyni

Svarúch, v niz skrývá se Nepoznané v Uměni".

„/... allmählich nähere ich mich jenem geheimnisvollen Heiligrum

der Heiligen, in dem sich das Unerkannie in der Kunst verbirgt".

O. Březina an F. Bauer (13. IX. 1892)

\section{Umění}

I. O teskny hłbitove, kde duše Velkých sni a $v$ hroby staletí sbor skvoucích stínů vchází Zár ohłứ mystických jak zážeh polámí ti k branám reflex hází!

1I. Trých jasů somnambul se bližím ve tvũj sad, kam prolévá se noc, jak záliv cerných moťi na mrtvých květư luh. jenž v modrých zárí Łat jak siny fosfor hoti.

III. Slov nêmých výchvěje, dým vâšní vyhaslých, $v$ Žal tvého mléeni Cas napjal płízi serou; vzdech mrtvých zástupủ ti tězký stoupá z lích a tlí tvou atmosférou.

IV. O Vě̌ný, rci, zda smím, kde chrám tvưj z kovu ěni nad méstem mramorn, své krve touhou necist. phi malém oltáti. pod klenbou pobox́ní Ti mši svou tichou prexíst?

V. Do vína extasí Zivota mácet chléb na stole obětním, jenž posvěcené kryje pod snú mých rưzemi a svêtly modliteb Tvých mrtvých relikvie?

VI. Zda v zlato kalicha. mých rukou slabých tiz. krev svoji zázračnou dá têla Tvého hrozen. a světlem andělư zda zrak můj roznitî́s. jenž k pološeru zrozen?

VII. Na hranicích svých dní Ti volám: muẽ a pal a v bolủ Zaláfích mi tvár̆ mou vybèl na snîh: já v díkủ kadidio do vủní spálím žal Ti ohêm rythmủ v básních!

VIII. A pěnu rozkoše, již hází lásky var, na purpur kobercú Ti $v$ bilé kvíti nastru. i blaho divexích těl, kde $v$ ñader lita tvar spi vůné $v$ alabastru.

IX. Svou duši v žhavý sloup vysálám do nebes a $v$ rakev síly své jak $v$ cín se složím ke snu. až kłexi Tajemství jak poražený kněz u oltáłù Tvých klesnu. 


\section{Die Kunst}

1. O melancholischer Friedhof, wo die Seelen der Großen träumen und in die Gräber der Jahrhunderte der Chor der glänzenden Schatten hineingeht, die Glut der mystischen Feuer wirft dir wie ein Polarbrand einen Reflex zu den Toren!

II. Deines Glastes Somnambule nähere ich mich deinem Garten. wohin sich die Nacht ergießt, wie eine Bucht schwarzer Meere auf die Gefilde der toten Blumen, die im Kleid des bläulichen Scheins wie fahler Phosphor brennt.

IIl. Das Aushauchen der stummen Worte, der Qualm der erlosch'nen Leidenschaften spannte die Zeit ins Leid deines Schweigens als graues Gam: der schwere Seufzer der toten Scharen steigt zu dir aus den Âckem und modert in deiner Atmosphäre.

IV. O Ewiger, sag, ob ich darf, wo Dein Tempel aus Metall emporragt uber der Stadt aus Marmor, unrein von meines Blutes Verlangen, an einem kleinen Altar unter der Seitenwölbung Dir meine leise Messe vorlesen?

V. In den Wein der Extasen das Brot des Lebens zu tauchen auf dem Opfertisch, der unter den Rosen meiner Träume. und den Lichtern meiner Gebete die Reliquien deiner Toten birgt?

VI. Ob in des Kelches Gold, meiner schwachen Hände Kraft. deines Leibes Rebe ihr wundersames Blut legt. und ob du mit dem Licht der Engel meine Sehkraft entfachst, die für das Halbdunkel geboren wird.

VII. An den Grenzen meiner Tage rufe ich Dir zu: quäle und senge und bleiche mir in der Kerker Qualen mein Antlitz zu Schnee: ich verbrenne in den Weihrauchduft des Danks mein Weh Dir im Brand der Rhythmen der Gesänge!

VIII. Und den Schaum der Lust, den das Sieden der Liebe wirft, auf das Purpur der Teppiche, werde ich Dir in weiße Bluten streuen. und auch die Wonne der Mädchenkörper, wo in die Form der Briste eingegossen der Duft im Alabaster schläft.

IX. Meine Seele lasse ich als Glutsäule zum Himmel lodern und in den Sarg meiner Kraft lege ich mich zum Träumen wie in Zinn. bis ich im Krampf des Geheimnisses wie ein besiegter Priester an Deinen Altären niedersinke.

Im Gedicht Uméni, in dem sich das Verständnis der Kunst als sacrum besonders prägnant bekundet, werden die Bedingungen für die Verwirklichung der ('höheren') ästhetischen Existenz artikuliert. Aus dieser Perspektive kann Uméni als eine Art Summe der Kunstauffassung Brezinas in der dekadenten Schaffensphase gelesen werden.

Das Sujet von Úméní konzeptualisiert ein Initiationsritual, die Aufnahme eines jungen Kunst-Adepten in das Reich des Kunst-Schönen, das als (dekadent-)melancholisches Künstler-Elysium apostrophiert wird: "O teskný hr̈bitove" ("O melancholischer Friedhof", I. 1) Was ist die Bedingung für die Initiation des Kunst-Adepten, der sich an der Grenze ("Na hranicich“, VII, 1) zwischen Diesseits und Jenseits, Körper und Geist, Lust und Leiden, zwischen profaner und sakraler Sphäre befindet, in das 'Heiligtum' der Kunst? Es ist das Leiden und die Vernichtung des 'alten' Selbst. Der Kunst-Tod, in dem das Initiationsritual kulminient, bedeutet zugleich die Verheißung der ersehnten ästhetischen Existenz. 
Das Kunst-Reich, die Sphäre des 'Künstlertums', wird in der ersten - deskriptiven Sujetsequenz des Textes (I.-III. Str.) als eine Nekropole, eine Art Gemeinde der Auserwählten, dargestellt, in der die "Seelen der Großen" ("duše Velkých", I, 1, der 'Ahnherrn' der Kunst-Schöpfung, träumen. ${ }^{159}$ Das lyrische Ich nähert sich dieser Kunst(und Künstler-)Nekropole, zu der er sich unwiderstehlich hingezogen (II. Str.) fühlt und die er als "Garten" ("sad") ${ }^{160}$ apostrophiert, wie ein willenloser Schlafwandler: "Tvých jasủ somnambul se bližim ve tvưj sad" (II, 1). Der "melancholische Friedhof" ("teskný hibitov") liegt in der Sphäre des Lunaren, der Kälte und des gefährlichen, ominösen, in den Untergang ver-führenden 161 Mondscheins und giftigen Phosphorlichtes: "Tvỳch jasủ somnambul se bližím ve tvưj sad, /.../ na mrtvých květư luh, jenž v modrých zári sat / jak siný fosfor horï" (II, 1, 3-4; "Deines Glastes Somnambule nähere ich mich deinem Garten I...I, auf die Gefilde der toten Blumen, die im Kleid des bläulichen Scheins / wie fahler Phosphor brennt"). In bezug auf die alchemistische Tradition symbolisiert der Mondschein auch in diesem Kontext die funeral-lunare Sphäre, in der die "Seelen der Großen träumen" (I. 1): zugleich weist er den Weg in das Territorium des Un(ter)bewußten und des Traums. Die phantomhaften "Schatten" ("stiny") der Verstorbenen-"Großen", die dieses Territorium bewohnen (I, 2; III, 2), signalisieren das Vordringen des "Unbewußten" in das Bewußtsein. Das lyrische ich betritt diese Sphäre, die zugleich die Sphäre der Stummheit, der "stummen Wörter". (III, 1), des unheilverkündenden Silentiums (III, 2) und der Indexikalität (III, 1,3 ) ist, die sich durch völlige Absenz des Logos (d. h. des [männlich] Bewußten, Rationalen) kennzeichnet. Die Sphäre der Kunst ist die des Un(ter)bewußten, Hypnotischen und Somnambulischen, 162 aber auch des Irrealisierten. Absenten. Toten oder Nekrotisierten ("tli" I "modert", III. 4). ${ }^{163}$ Die Zurückdrängung des Bewußten und die

159 In der Korrespondenz mit F. Bauer spezifiziert Bỉezina diese Genealogie der "Großen" ("Velci" - in der symbolistischen Dichtkunst): Tasso, Shakespeare, Goethe, Schelley, Poe, Baudelaire, Verlaine. O. Bł̌ezina, Dopisy Frantisku Bauerovi, Praha 1929, S. 167-168, 177, 182, 206, 209.

160 Die funerale Raumgestaltung in Uměni verrät den Einfluß der (spät-)romantischen Ästhetisierung des Todes mit inrem charakteristischen Thanatos- und Friedhofskult. Der kalt phosphoreszierende Mondschein und die metaphorische Bennenung "sad" ("Hain" bzw. "Obstgarten") für "Friedhof", scheint auf die Friedhotsszenerie aus der bekannten tschechischen Adaptation des "Lenore"-Stoffes, Svatebni kosile (Die Hochzeitshemden) von Karel Jaromir Erben, zu alludieren: "A byla cesta nižinou, I prees vody, luka, bažinou; / a po bažiné, po sluji / modrá

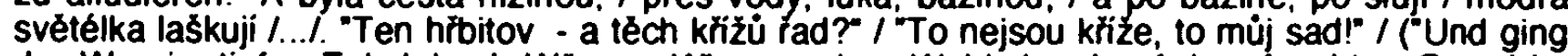
der Weg im tiefen Tal, / durch Wässer, Wiesen, onne Wahl; / und auf dem feuchten Grund im Moor / da schweben Irrlichter im Chor I... / Der Kirchhof und der Kreuze Reih'n?" / "Nicht Kreuze sind's, das ist mein Hain!" Übers. v. E. Albent.) Vgl. auch die Gedichtsammlung des tschechischen Dichters der Realisten-Generation Jan Neruda. Hß̈bitovni kvití (Friedhofsblumen, 1856).

161 Im antiken Glauben ist der Mond ein Sammelort der a b g e s c n i e de n e n S e e I e n In alchemistischen Vorstellungen ist der Mondschein stets mit Geheimnis und Gefahr verbunden, da es Mondsucht (Somnambulismus: "Tvych jasú somnambur, II, 1) verursacht. C. G. Jung. Mysterium coniunctionis, Erster Teil, Zürich 1955, S. 188ff. Darüber hinaus gilt die Luna nicht nur als Inbegriff der Anima und des Unbewußten, sondern auch als Inbergriff der Metallnaturen, die von ihrer changierenden Weiße gleichsam absorbiert werden. Dem Mondschein wird ebenfalls die annihilierende Wirkung als Verursacher der Fäulnis zugesprochen (ibid., S. 159). Vgl. " .../ vzdech mrtvých zástupú ti téžký stoupá z lich / a tli tvou atmosferou" (Uméni, III, 3-4; - ..I der schwere Seutzer der toten Scharen steigt zu dir aus den Äckern / und modert in deiner Atmosphäre").

162 Eine ähnliche Situation, in der das lyrische Ich wie ein Somnambule von der bannenden, hypnotisierenden Macht des Geheimnisses des "Unerkannten" fasziniert wird, wird in Pohled smrti (Der Blick des Todes) inszeniert: -Jak somnambul svedený z lože, bledý, spoután a ném / pod hypnosou Nepoznaného jdu se svym snem" (V. 15-16; "Wie ein Somnambule, vom Lager verführt, bleich, gefessett und stumm / unter der Hypnose des Unerkannten gehe mit meinem Traum ich um").

163 Die oxymorale Semantik der dritten Strophe ("Slov němẏch vỷchvěje, dỷm vášni vyhaslych", III, 1: "Das Aushauchen der stummen Worte, der Qualm der erlosch'nen Leidenschaften") alludiert aư die oxymorale Semantik der berühmten .Máj"-Oxymora von Mácha, die das unaufhaltsame Dahinfließen der Zeit, das alle Dinge und Phänomene der (realen) Welt hinwegrafft, die dadurch ihre "ontologische Festigkeit" einbüßen, konkretisieren (vgl. die ausführlichere Darlegung in Kap. 2.2). Während jedoch bei Mácha das Bewußtsein von der destruktiven Macht der dahinfließenden Zeit metaphysischen Schauder hervorruft, hat bei Bỉezina 
Dominanz des Schattens deuten - im Hinblick auf die psychopoetischen Aspekte des Gedichts - auf verschiedene Unfreiheiten (Zwangsphänomene, Obsessionen, Affekte, abnorme Psychismen usw.) hin, die in den semantischen Bereich der zweiten Sujetsequenz vordringen. ${ }^{164}$ Die mythische Folie des Textes schließt eine 'psychopathologische' ein.

In der zweiten Sujetsequenz (IV.-VII. Str.) wird der deskriptive Redemodus durch den optativen ersetzt. Der Adept der Kunst-Schöpfung wendet sich an den "Ewigen" ("O Vécný I... $r$. IV, 1) mit seiner Bitte, in das Kunst-Reich, in sein Elysium, ${ }^{165}$ aufgenommen zu werden, wo er (d. h. im Tempel der Kunst, IV, 1) in der Gestalt eines Kunst-(Opfer-) Priesters eine Messe für den "Ewigen" zelebrieren (IV, 4) will ("zda smím /.../ / pri malém oltári, pod klenbou pobozni / Ti msi svou tichou piecist?" IV, 1; "ob ich darf /...// an einem kleinen Altar unter der Seitenwölbung / Dir meine leise Messe vorlesen?"). Der "Ewige" erscheint hier in der Position eines Künstler-Gottes, eines Herrschers des KünstlerElysiums, in das der Zelebrant aufgenommen werden will. Der "Ewige" hütet auch das (ewige, numinose) Geheimnis ("Tajemstvi", IX, 3), das sich im Kunst-Tempel verbirgt. Was sich der Zelebrant auch erhofft, ist die Gabe der visionären, übersinnlichen (und imaginativen) Fähigkeiten, die zur Erkenntnis jenes Geheimnisses führen können: "a svêtuem andélư zda zrak mujj roznitís, / jenž k pološeru zrozen?" (VI. 3-4; "ob du mit dem Licht der Engel meine Sehkraft entfachst, / die für das Halbdunkel geboren wird"). Doch erst das exstatische Aus-Sich-Selbst-Heraustreten durch den Krampf des Geheimnisses im Ritual der Selbst-Aufopferung, 166 kann zu der postulierten Erkenntnis führen. Dieses Ritual wird in der letzten Strophe inszeniert. Zu inm gehört, als sein unumgänglicher Teil und als Bedingung für die Aufnahme in das Kunst-Reich, das Erlebnis des (ästhetisierten) Schmerzes, nach dem es den Kunst-Adepten verlangt (Str. VII).

Das Leiden ermöglicht das Überschreiten der "Grenze" (bzw. des Grenz-Zustandes) zwischen Diesseits und Jenseits, Schmerz und Lust usw., auf der sich das dichterische Ich befindet, und dadurch auch die Verwirklichung der ästhetischen Existenz: "Na hranicích svých dni Ti volám: muč a pal / a v bolự żalárich mi tvár mou vybẻl na sníh: / já v díkú kadidlo do vưni spálím Żal / Ti ohnèm rytmú v básnich!" (VII. Str.; "Aư den Grenzen meiner Tage rufe ich Dir zu: quäle und senge / und bleiche mir in der Kerker Qualen mein Antlitz zu Schnee: / ich verbrenne in den Weihrauchduft des Danks mein Weh / Dir im Brand der Rhythmen der Gesänge!) Das Homonym "hranice" (VII, 1) kann sowohl die "Grenze" als auch den "Scheiterhaufen", auf dem der Adept des Kunst-Schönen sein Auto-da-fé - als actus fidei an die Unsterblichkeit des Kunst-(bzw. Künstler-)Lebens erfahren will. Das Leiden wirkt als vehiculum der Entstehung der Kunst-Werke, insbesondere der Dicht-Kunst ("v básnich!", VII, 4; "in Gedichten!"). ${ }^{167}$ Diesen

die Zeit als destruktiver Faktor eine positive, re-valorisierende Konnotation, nach der Formel: Nur das, was absent, irrealisiert, unerreichbar ist, ist wertvoll.

164 C. G. Jung, a.a.O., S. 196.

165 Die Semantisierung des Kunst-Reichs als eines Toten-Reichs rekurriert offensichtlich auf die Tradition der Elysium-Mythen (Hesiod, Lukian u. a.). Als Gegenpol des Tartaros symbolisien Elysium die Sphăre der Seligkeit, in der die Schatten ("a $v$ hroby staleti sbor skvoucich stínu vcházi". I. 2) der Gerechten und Guten weilen und Dialoge führen. Hesiod (Werke und Tage) situiert das Elysium nicht in die Umerwelt, sondern aut die "Insel der Seligen", die 'weit' im Westen liegen und die die Heroen bewohnen. Diese Heroen heißen bei Błezina "Velc" (die "Großen").

166 Die "Heiligkeit" und "Erhabenheit" der Kunst rühren von ihrer Fähigkeit her: "/.../ daß sie die Seeten der Auserwählten auf die Entfernung von hunderten von Meilen und tausenden von Jahren vibrieren lăßt, daß sie uns die Großen und Heiligen unter uns, die zum Medium des Ewigen Gedankens geworden sind, lieben lăßt, $/ \ldots l$ irgendein Freimaurertum der Schönheit, zusammengeleimt vom Geist und erhoben über die schwere Erniedrigung der Materie...-. (O.) Bł̌ezina, Dopisy Frantisku Bauerovi, Brief vom 22. VIII. 1893, Praha 1929, S. 197; \%.. Że rozechvivá duše vyvolených na vzdálenost sta mil a tisice let, że nechává nás milovati ty veiké a svaté mezi námi, kteři byli mediem Vẻcné Myšlenky, l.../, jakési svobodné zednáristvo krásy. skližené duchem a povznesené nad téǩ́ké poniženi hmoty.--").

167 In der Korrespondenz mit Bauer charakterisiert Bỉezina die Dichtkunst explizit als "hartnäckigen Kampf". ("Umélecká práce neni jen rozkoši, je /.../ tvrđośijným zápasem /.../. Tectnika umẻni vyżaduje krve a ustaviěnỳm úsilim spalovaných nervü"). O. Bíezina, Dopisy Frantisku Bauerovi, Praha 1929, S. 186-187. Im Brief v. 20. XII. 1894 erwähnt Bł́ezina den "Schmerz in der Kunst" im Zusammenhang mit der Lust: "/.../ piši pro své bratry, pro ty, kterí cíti a smýslí jak já /...I. A tẻm dám dosis rozkoše, kterou jsem prijal, chvili sladkého pocitu, který vznikne. 
masochistischen Ästhetismus oder ästhetisierten Masochismus indiziert der kalte, silbrige Mondschein, der in der alchemistischen Tradition verschiedene Metalle in sich konzentriert. Signifikanterweise ist der (Kunst-)Tempel des "Ewigen" aus Metall ("kde chrám Tvưj z kovu čni", IV, 1) und er ragt über einer "Marmorstadt" ("nad mèstem mramoru“, IV, 2) empor. Die Kälte der Mineralien, der skulpturalen oder gestanzten Kunstwerke ("zlato kalicha", VI, 1; "des Kelches Gold"; "Zinn[sarg]", IX, 2), das Erstarte (Skulptur, Säule usw.), das Lunare (das "Mondweib", dessen Prototyp die "Venus im Pelz" von Sacher-Masoch ist), die distanzierte, 'kalte' Ästhetik, so wie alle Formen der (alogischen) kultischen, abgöttischen Verehrung - auch die des Kunst-Schönen -, gehören zu den Wesensmerkmalen des Masochismus. ${ }^{168}$ Wie es scheint, beansprucht das dichterische Ich für sich das Leiden des "Ewigen" zu durchleben: "Zda v zlato kalicha, mých rukou slabých tíz / krev svoji zázračnou dá tẻla tvého hrozen I...I. I/ Na hranicich svých dni Ti volam: muč a pal I..." (VI, 1-2 - VII, 1; "Ob in des Kelches Gold, meiner schwachen Hände Kraft, I Deines Leibes Rebe ihr wundersames Blut legt /... I. II An der Grenze meiner Tage rufe ich Dir zu: quäle und senge /... $/$ ). Die positive Bedeutung des Leidens für den Prozeß der Kunst-Schöpfung wird explizit durch das Versprechen der Aufopferung der (passiven) Wehmut "im Brand der Rhythmen" (VII, 3-4) und durch das Motiv des skulpturalen Kunstwerkes (einer als Mädchenkörper konnotierten Alabasterstatue) ${ }^{169}$ zum Ausdruck gebracht: "i blaho divcich têl, kde v hader lita tvar / spi

uleti-li duše z želez a pout, volná, dýchajici všemi paprsky, které vyzả̛uje, vưnẻmi, barvami, tóny, touhami a bolesti. Nebơ' i bolest v uméni, zachycená ztooźnẻ a vroucné, je stadkou" (Ibid., S. 202; "Ich schreibe für meine Brüder, für die, die tühlen und denken wie ich. I.../ Und diesen gebe ich eine Dosis der Lust, die ich im Augenblick eines süßen Gefühls empfing, das eintritt, wenn die Seele den Ketten und Fesseln entflieht, frei, durch alle Strahlen atmend, die sie ausstrahlt, durch Dưfte, Farben, Töne, Sehnsüchte und Schmerzen".).

168 Der Kult der Kunstgegenstände, des Artifiziellen schlechthin, scheint für den masochistischen Psychotypus symptomatisch zu sein. Man denke an das Ambiente der Romane und Erzählungen von Sacher-Masoch: Fresken, Plastiken, Spiegel, prunkvolle Schloßgemächer. Vorliebe für orientalischen Luxus, kunstvoll gestaltete Parkanlagen, beleuchtet vom kalten, silbrigen Mondschein usw. Gilles Deleuze (.Sacher-Masoch und der Masochismus", in: $L$. von Sacher-Masoch, Venus im Pelz, Frankfurt am Main 1997, S. 220tf.) nennt u. a. "das Warten im Reinzustand" und die Verneinung als die typischen Merkmale des masochistischen Typus. Den Verzicht auf die Geschlechtsliebe, im engeren Sinne die Verneinung des Geschlechtsaktes, hat als eines der typischen Symptome der Masochisten-Psychologie bereits Wilhelm Stekel erkannt und hervorgehoben (Sadismus und Masochismus. Storungen des Trieb- und Affekttebens, Bd. VIII, Berlin-Wien 1925, S. 40f.) Stekel betont auch den rigoros asketischen und natürtich religiósen Aspekt des Masochismus (charakteristisch sind die Christus-Phantasien vieler Masochisten). "Jen ten, kdo potlačil pohiavi, múže bỳt Magem, despoticky vtádnoucí vúlí ("Nur derjenige, der das Geschlecht überwunden hat, kann zum Magier werden, der über den Willen despotisch herrscht"). schreibt Bỉezina (1896) an Anna Pammrová (Dopisy Anné Pamrové 1889-1905, Praha 1931, $\$$. 122.). Es sind Motive der kalten skulpturalen Kunstwerke, die bei Biezina den weiblichen Körper konnotieren (Modlitba vécerni / Das Abendgebet, Uméní / Die Kunst), oder das eisige. rūstungsảhnliche "Metallgewand" ("kovový satr. Pohled smrti I Der Blick des Todes), das kalte, silberne Mondlicht, die Fetischisierung und Ästhetisierung des Nichtmehrseins, des Irrealisierten und Annihilierten (Snad potom... / Vielleicht dann...), die die Semantik der Irrealisierung in TD bestimmen und die Deleuze als Symptome der masochistisctien Welt hervorhebt.

169 Die Alabaster-Metapher zählt zu den wohl beliebtesten Kristall- bzw. Edelstein-Metaphern des (Früh-)Symbolismus. Bekannt ist die Allegorie der Symboldichtung von Merezkovskij, in der die Transparenz der poetischen Bilder die dünnen Wände einer Alabasteramphora versinnbildlichen, in der die Flamme lodert, die den Inhalt - die poetische Substanz - als transparent ersctieinen läßt. Jurij Striedter, .Transparenz und Verfremdung“, 1966, S. 266ff in Umêni indiziert das Motiv der weiblichen Alabasterstatue die Sublimierung des Eros zum (vollkommenen) Kunstwerk. Ein schōnes Beispiel der Semantisierung des Alabaster-Motivs im tschechischen Frühsymbolismus findet sich in der Gedichtsammlung Zpivajici labutè (Die singenden Schwảne, 1891) von Otakar Aửednícek: "Tvé tẻlo, z alabastru vása bilâ, / z niż dỵchaji vsech zahrad bilé kvèty, I mou duş vinou vưné vyplnila. I Mnè kouzli mystické a divné svẻty / tvé tẻlo, z alabastru vása bilá. (Co tobé rek' bych...I Was würde ich dir sagen....; "Dein Kơrper, weiße Alabastervase, I aus der aller Gärten weiße Blüten hauchen, / füllte meine Seele mit einer Duftwelle aus. I Mystische und sonderbare Welten zaubert mir I dein Körper, weiße Alabastervase"). Das Motiv des weißen weiblichen 'Alabaster-Körpers' geht sowohl in der Dichtung als auch in der bildenden Kunst des Symbolismus auf die Darstellungen des Manierismus zurūck, man denke 2. B. an die bekannte Allegorie der Zeit, Vergänglichkeit und der 
vưně v alabastru" (VIII, 3-4; "und die Wonne der Mädchenkörper, wo in die Form der Brüste eingegossen / der Duft im Alabaster schläft'). Die skulpturale Körperform impliziert auch das Säule-Motiv in der letzten Strophe ("Svou duši v Zhavý sloup vysálám do nebes". IX, 1; "Meine Seele lasse ich als Glutsäule gen Himmel lodern"). 170

in der letzten Strophe kulminiert das Initiationsritual des Adepten/Zelebranten in seiner Absage an das Leben und die erotische Liebe (VIII, 1-2), die auf dem Altar der Kunst ("u oltárü tvých“, IX, 4) aufgeopfert werden sollen und zwar durch die Glut der Extase, in der sich die Erhebung des seelischen Selbst vollendet: "Svou duši v Žhavý sloup vysálám do nebes" $(I X, 1) .{ }^{171}$ Das Erlebnis der (Kunst-)Extase fordert der Zelebrant schon in der fünften Strophe: "Do vína extasi Života mácet chlěb" (V, 1; "In den Wein der Extasen das Brot zu tauchen"). Nach der Selbstaufopferung im "Krampl" des undurchdringlichen "Geheimnisses" ("kỉeč Tajemstv", IX, 3) versinkt der Zelebrant wie ein "besiegter Priester" ("jak poražený knẻz", IX, 3) in den Kunst-Tod: "a v rakev síly své jak v cín se složím ke snu" (IX, 3; "in den Sarg meiner Kraft lege ich mich zum Träumen wie in Zinn"). Durch den konsequenten Verzicht auf das (reale) Leben und durch die absolute Hingabe an die Kunst wird auch inm, dem Adepten der Kunst-Schöpfung, das Privileg der im KünstlerElysium träumenden "Großen" (1, 1) zuteil: Das Träumen als Höhepunkt der imaginativen Kraft, ein Gedanke, den Briezina auch in seiner Korrespondez zum Ausdruck bringt: "Nejvétši đást uměleckě cinnosti neleži $v$ umělcově díle zachyceném, ale $v$ sile a intenzitè jeho snu" (an Bauer, 20. XII. 1894; "Der größte Teil der Kunst-Schöpfung liegt nicht im fixierten Werk des Künstlers, sondern in der Kraft und Intensität seines Traumes ${ }^{\prime)}$.

Eifersucht von Bronzino, an die Werke der Maler der Schule von Fontainebleau oder an de Góngoras Fábula de Polifemo y Galatea. Die Poesie, die Kunst kat' exochen, soll die (Welt-) Erkenntnis, die Offenbarung der Geheimnisse, das "noetische Wunder" (s. Kap. 2.1.1) erschließen. Interessanterweise berief sich Blezina noch kurz vor seinem Tode (1929) in seinen Gesprächen aut Whitehead, der in seiner Science and the modern World (1927) die These vertritt, die Poesie sei - wie jede andere Wissenschaft - Quelle der Welterkenntnis. Vgl. J. Demi, Mé svédectvi o Otokanu Błezinovi, Praha 1931, S. 423.

170 Der Gnosisforscher Hans Jonas weist (im Anschluß an Spengler) in Gnosis und spåtantiker Geist (Göttingen 1964, S. 163-164) nach, daß die antike Raum-Vorstellung das Symbol der vereinzelten Korperform der Săule oder Statue kennzeichnet, wăhrend in der Gnosis das Hőhlenhafte (Weltraum als Welthŏhle, der gnostische Raum als Hohlraum) dominiert. Daraus resultiert auch das konträre Verständnis der Grenze bei den Griechen und in der Gnosis. Im klassisch-griechischen Denken wird der Grenze eine Positive Bedeutung zuerkannt. "durch sie "ist" also überhaupt erst etwas" (ibid. S. 164), sie ist identisch mit dem "Seienden", "Ganzen", sie ist die "oberste Form", im Unterschied zu dem "Höhlenhaften" und "End-Losen" ("Grenzenlosen"). das im Klassisch-griechischen Denken das durchaus Negative und Böse symbolisiert - des gnostischen Raumes. In der Gnosis weist wiederum die Grenze einen "tyrannischen Charakter" (ibid. S. 165) auf, indem sie die Welt zu einem "Gefängnis" macht. Gleichzeitig garantiert die Grenze, daß sich 'etwas' hinter ihr befindet, was zu ihrem Überschreiten verlockt. Um die "Einklammerung" zu überwinden und die Sphäre des Absoluten zu erreichen, muß die Grenze überschritten und die (physische) Form aufgehoben werden. In Uméni scheint sich das Uberschreiten der Grenze, das in Modlitba vecemi (Das Abendgebet) ein Selbstverständnis war, gewissermaßen zu problematisieren. Es wird zwar auch weiterhin angestrebt, die Form soll jedoch aufrechterhalten bleiben und mehr noch, die Anima des lyrischen Ich soll die Sphāre des Transzendenten als "Glutsăule* erreichen, während der physische Leib in einen Traum - "wie in Zinn"- versinkt.

171 Man denke an die Entrūckung des Propheten Elia im Feuerglanz gen Himmel, möglicherweise auch als Reflex des gnostischen Erlösungsdramas, in dem es um die Befreiung der Lichtfunken, die das eigentliche Selbst in der Menschenseele bilden, und ihre Emportührung in die himmlische Lichtwelt geht. Dieser Akt kulminiert im extatischen Erlebnis der Schau des göttlichen Lichtes. Vgl. H. Jonas, Gnosis und spåtantiker Geist I, Göttingen 1964, S. 149ff. 
"Denn die Musik ist, wie gesagt, darin von allen Künsten verschieden, daßß sie nicht Abbild der Erscheinung. nder richtiger der adäquaten

Objektivitäl des Willens, sondern unmittelhar das Abbild des Willens

selbst ist und also zu allem Physischen der Welt das Metaphysische.

zu aller Erscheinung das Ding an sich darstellt".

Arthur Schopenhauer

Die Welt als Wille und Vorstellung (3. Buch)

\section{Motiv z Beethovena}

1. To z dálky staletí van tichý $v$ tváł mi nedých, tvych tónú byl to hlas pod okny duse me. jenž na mne volal: Pojơ a v svitu záfí bledých a v zlatém dešti hvězd se koupat budeme.

II. Spí vơnè v zahradách a blankyt na jezerech zor pristích andante do poupat zavfel květ. spí vủně $v$ teple hnízd a $v$ dálek poloserech vír barev zpeñèny kles' ke dnu tich a sed.

III. Par oddech stłíbmý nad zemi závoj potáh do světla zasnován jak $z$ vláken azbestu. a $v$ ¿emých táborech ¿al lesư na samotách do mechu $v$ umdleném si lehl selestu.

IV. Tma kleneb závratná nad lustry hvězd se vznesla. pel prachu kosmický, z níz tichá padá tưz nad šífi prostori, kde $v$ dálce šumi vesla odplulých staletí. $\delta$ pověz. necítî́.

V. jak noci narkosou dech unaven se úżi? A lehký šumot snú jak letêl kolem nás a úsmév jasminú a bázlivý dech rủž́ do váni kłridel svých ze svého satu tłás'?

VI. Vzpomínek červenec jak v duše žár ti vzrnistá. zdroj zadržených sil ti bije $v$ stěny cév. žeh prudký polibkú ti zapaluje ústa a svêtlem narudlým ti v żilách svítí krev?

VII. Že pigment ž́ítelnic ti vniťni požár prožih'. stín, fetěz krokú tvých ti rozlomil a sñal a $v$ duß̌e komnatách na myšlenky tvé ložích mou spoután hypnosou se položil tvưj zal?

VIII. A cítî̉ jeho dech, jak $z$ mlží mlex̃né dráhy na rosu stribmou se $v$ hvezzdný srází luh. a touha po smrti. jak príliv sladké vláhy a rozkở vítězná a čemé víno tuh.

IX. na hader úbèlích jak spoxinutí měkká. a nahých ramen dvou jak chtivé sepjetí. $v$ tvou bytost pohnutou a opojenou stéka ve smyslủ umdleném a těžkém zajetí? 
X. Pojđ, olej tónů svých jsem nalil v lampy krystal,

z kamenư svítících jsem sklenul kryptu tvou

a z kvêtư zázrą̌nych jsem měkký polštáł schystal.

kde $v$ řasy vưní mdlých, dáš hlavu zemdlenou.

XI. Pojđ, slyšîs zvony mé? Než v procitnutí chladné

żal kouzlem uspaný ti $v$ duši ožije.

má píseñ pohłební ti sladká na rty padne

a v jednom pocelu tvé Žití vypije.

XII. A jitro věxných dní až vzplá ti zruiměněné

(désí rưzí ohnivých), tu bude se ti zdát,

jak kdybys v ložnici mèl okno otevłené

a ranních písni mír tě ovál ze zahrad.

\section{Ein Motiv aus Beethoven}

I. Das war kein leiser Hauch aus ewigfemen Jahren, der mir ins Antlitz hauchte.

deiner Töne Stimme war es vor meiner Seele Fenstem.

die mich anrief: Komm und im Schein der blassen Glanze

und im Goldregen der Steme baden wir.

II. Die Düfte schlafen in den Gärten und Himmelsblau in Teichen,

das Morgenrot künftiger Andante verschloB die Blüten zu Knospen.

Die Lieder schlafen in der Nestern Wärme und in der Ferne des Halbdunkels, sank der aufgeschäumte Farbenwirbel grau und leise auf den Grund.

III. Der silberne Dunsthauch breitet sich wie ein Schleier uber der Erde. mit Licht verwebt, wie aus Asbestfasern.

und in schwarzen Lagern ließ sich das Leid der Wälder in den Einsamkeiten ins Moos im matten Geräusch gleiten.

IV. Das berauschende Dunkel der Gewölbe erhob sich über die Stemenlüster, kosmischer Samenstaub. von dem stille Schwere sinkt Uber des Raumes Weite, wo fern die Ruder rauschen entglittner Jahrhunderte. O sage, fuhlst du denn nicht.

V. wie sich der Atem engt, betäubt von Narkose der Nacht?

Und wie ein leichtes Rauschen der Träume an uns vorbeiflog

und wie es das Lächeln des Jasmins und den ängstlichen Rosenhauch

in seiner Schwingen Wehn von seinem Kleid schüttelte?

VI. Wie dir die Juliglut der Erinnerungen in der Seele auflodert, verhaltener Kräfte Quell dir an die Schläfen schlägt.

der Küsse heftiger Brand entzündet dir Mund

und vom roten Glanz dir dein Blut in den Adern leuchtet?

VII. Daß das Pigment der Pupillen dir ein innerer Brand durchbrannte. den Schatten, deiner Schritte Kette, brach und nahm. und daB in der Seele Kammern auf des Gedankens Lager von meiner Hypnose gefesselt sich dein Leid hinlegte?

VIII. Und fühlst du Seinen Hauch, wie er aus dem Nebel der Milchstraße zum Silbertau der Stemenwiesen gerinnt. und Sehnsucht nach dem Tod, wie der wonnigen Nässe Flut und siegreiche Lust und der Begierden schwarzer Wein.

IX. wie milde Ruh auf dem Weiß der Briste. und zweier nackter Arme gierige Umschlingung.

in dein erregtes und betörtes Wesen rinnen

in matter und betäubender Gefangenschaft der Sinne? 
X. Komm, mit dem Öle meiner Töne füllte ich der Lampe Kristall. aus strahlendem Gestein wölbte ich deine Krypta und aus Zauberblumen bereitete ich ein weiches Kissen vor auf das du in Falten matten Dufts dein muides Haupt hineinlehnst.

XI. Komm, hörst meine Glocken du? Ehe dir in kühles Erwachen das vom Zauber betörte Leid in der Seele aufwacht. wird mein süßes Grablied auf deine Lippen fallen und in einem $\mathrm{KuB}$ dein Leben aus dir trinken.

XII. Und bis dir der ewigen Tage Morgenrot aufflammt (Regen der Feuerrosen), da wird es dir scheinen. als wärst bei offenem Fenster du im Schlafzimmer und Morgenlieder Friede wehte zu dir aus den Gärten herein.

Die Bedeutung der 'Musikalität' der poetischen Textur, die suggestive Kraft der beschwörenden, die rhetorischen Mittel neutralisierenden Musik-Sprache, die als intendierte Wirkung des (dekadenten) Kunst-Textes postuliert wird, kommt in Motiv $Z$ Beethovena mit besonderer intesität zum Ausdruck. In Motiv z Beethovena wird der suggestiven, hypnotisierenden Musik-Sprache eine magische Funktion zuerkannt: der Hörer/Rezipient soll hier - wie in einer romantischen, naturmagischen Ballade ${ }^{172}$ - durch die betörende, einschläfernde Stimme der Musik in das Reich des Hypnos, das zugleich das Reich des Kunst-Schönen und des Kunst-Todes symbolisiert, verführt werden. Die bannende Stimme der Musik soll auf den Rezipienten wie die bannende Stimme der Wassernixe wirken. Signifikanterweise scheint dieses magische Kunst-Reich in den düsteren und dennoch faszinierenden Tiefen des Meeres zu ruhen. Die Magie der Natur wird hier durch die Magie der Kunst ersetzt; die 'Natur' in Motiv z Beethovena ist eine durch die Kunst denaturierte und ebenfalls nur s u g g e ri e r te Natur. Dabei scheint die im Symbolismus vielbesprochene Theorie der Correspondances ${ }^{173}$ nicht ohne Bedeutung zu sein.

172 Mit dem Terminus "naturmagische Ballade" arbeitet Paul-Ludwig Kämpchen in seiner Monographie Die numinose Ballade, Bonn 1930. Als Beispiele bekannter naturmagischer Balladen, in denen der Held durch die Stimme einer Wassernixe in den Wassertod gelockt wird, können Goethes Fischer, seine russische Adaptation von Zukovskij (Rybak) oder Puškins Rusalka erwähnt werden. In der bekannten tschechischen Ballade von Frantisek $L$. Celakovsky Toman a lesni panna (Toman und die Waldjungfrau) wird der Held durch die Stimme einer Waldeffe in den Untergang vertühnt.

173 Das Konzepl der Correspondances, das insbesondere für die Dichtung Baudelaires von großer poetologischer Relevanz ist, beruht aut der (in der Romantik aktualisierten) Vorstellung des transzendenten Analogiedenkens (auch unter dem Einfluß der mystischen Erlebnisse Swedenborgs, vermittelt durch Balzac), der analogen Struktur des Universums und der inneren Korrelierbarkeit der Naturbereiche. Diesem Konzept entspricht auch die Auffassung der Natur als Spiegel der geistigen Welt. Dabei wird die konstitutive Funktion der Erfahrung der Synāsthesie. der Korrespondenz der sinnlichen Erlebnisse untereinander, zuerkannt. Düfte. Farben. Töne verschmelzen ineinander ("Les parfums, les couleurs et les sons répondent", Baudelaire: Correspondances, II, 4) und bilden eine Einheit. Im Erlebnis der Synāsthesie offenbart sich auch der innere Zusammenhang der äußertich zusammenhanglosen Phảnomene. Daher können die 'Korrespondenzen' als Inbegriff für vollkommen neue und bisther unbeachtete seelische Zustände gelten. Eine enorme Rolle spielt dabei die dichterische Phantasie, die das 'sichtbare Universum' als eine "neue Welt" (Baudelaire) quasi neu erschaffen kann. Ein bestimmter Sinneseindruck kann eine Serie von mannigfaltigen Vorstellungen auslösen. Auf diese Weise können auch disparate Kategorien (poetischer Sprache) syntaktisch verbunden werden. (Friedhelm Wilhelm Fischer, -Geheimlehren und moderne Kunst", in: Fin de siède. Zu Literatur und Kunst der Jahmundertwende, hrsg. von Roger Bauer u. a.. Frankfurt am Main 1977, S. 344ff.). Der Musik vor allem - wird jene außergewöhnliche evokative Macht zugesprochen, den Hörer in eine überirdische, transzendente Sphäre zu versetzen, inn "von den Banden der Schwere" (Baudelaire) zu befreien. Baudelaire schildert in seinem Dankesbrief (vom 17. Februar 1860) an Wagner (nach dem Erlebnis des Pariser Wagner-Konzertes vom 25. Januar 1860) seine extatischen Eindrücke als "eine fast sinnliche Freude, wie das Gefühl, in die Luft zu steigen, oder auf dem Meer zu treiben". ("I.../ volupté vraiment sensuelle, et qui ressemble à cellede monter dans l'air ou de rouler sur la mer"). Er empfand "Sensationen, welche wahrscheinlich aus der Natur meines Geistes 
Die intendierte 'musikalische' Wirkung des dekadenten Kunst-Textes hat - im Hinblick auf die Poetik der Rezeption - in diesem Gedicht, dessen intermedialen ('musikalischen') Sub-Text Beethovens "Mondschein-Sonate" 174 darstellt, ihren zentralen semantischen Ort. Von sinnkonstitutiver Bedeutung ist bereits die Verteilung der Rederollen. In der älteren Brezina-Literatur wird die Kommunikationsstruktur von Motiv z Beethovena mißverständlich als Dialog des lyrischen Ich mit der Poesie oder sogar als Dialog seiner Seele mit der Seele des Komponisten gedeutet. ${ }^{175}$ Das lyrische Ich spricht nur in den ersten zwei Verszeilen der ersten Strophe, um die Rede der Töne einzuleiten: "To z dálky staleti van tichých $\vee$ tvár mi nedých, / tyých tónú byl to hlas pod okny duše mé, I jenż na mne volal" (1, 1-3; "Das war kein leiser Hauch aus ewigfernen Jahren, der mir ins Antlitz hauchte, I deiner Töne Stimme war es vor meiner Seele Fenstern). Ab der dritten Verszeile handelt es sich um eine (vom Sprecher) ziti e rte Re de der Musik bzw. ihrer Stimme, die das dichterische Ich - als ein metasprachliches Medium - durch den sensus exterior ("pod okny duše mé", I, 2; "vor meiner Seele Fenstern") vernimmt. Die suggestive und suggerierende "Sprache der Töne", 176 ihre Verheißungen - nicht zuletzt durch die Aktivierung der suggestiven Kraft des Wortes als direkter Ausdruck der Abkehr von der Mimesis zugunsten der Autonomie des dichterischen Konzeptes - soll den Rezipienten zu einer anspruchsvollen Art des Hinhörens 'zwingen'. Die Aufforderungssätze $(1,3-4 ; X, 1 ; X I, 1)$ und die Fragesätze (V. - IX. Str.) sollen diese Suggestivität der Dichtersprache noch intensivieren. Das lyrische Ich (und der intendierte Leser mit inm) vernimmt die "gesproche Musik" in seiner Seele, die sich im Hypnagogium vom hyletischen Körper gleichsam loslöst; ein Motiv, das zu den wichtigsten in Brezinas Dichtkunst des dekadenten Symbolismus zähit.

In Motiv z Beethovena lockt die Stimme der Musik ("tvych tónů byl to hlas", I, 2; "deiner Töne Stimme war es*), ähnlich dem Lied der Wassernixen oder dem betörenden Gesang der Sirenen, das lyrische Ich, an einem geheimnisvollen nächtlichen Bad teilzunehmen: "Pojd I...I a v zlatém dešti hvézd se koupat budeme"; I, 4; "Komm und im Schein der blassen Glanze / und im Goldregen der Sterne baden wir"). Die Schlaf/TraumDissoziation, die Semantik der Irrealisierung durch die "Hypnose" (der Musik-Sprache; VII, 4) bzw. "Narkose" (V, 1), spiett dabei eine zentrale Rolle. Sie wird bereits in der ersten Strophe durch die Atmosphäre der lunaren Nacht-Welt antizipiert (I, 3-4), die auch auf den musikalischen Sub-Text, die "Mondscheinsonate", verweist. Die lunare Sphäre hat hier die gleiche Semantik wie in Uméni (s. Kap. 2.3.1). Das dichterische Ich (und der intendierte Leser) soll in das lunare Reich des Hypnos, d. $h$. in die Sphäre des Un(ter)bewußten, Animischen und Irrationalen eintauchen. Nach der antiken Tradition ist Luna die Spenderin der Feuchtigkeit, die Herrin des wäßrigen Sternzeichens und - in der Bedeutung als Silber ("Par oddech stribrny I... I, III, 1; "silberner Dunsthauch") - auch das

stammen und aus meinen hauptsăchlichen Beschăftigungen. Es schien mir etwas da zu sein, das emporhob und emporgehoben wurde, etwas, das danach strebte, hoher zu steigen, etwas Erhabenes $/ . . . \%$. ( $\%$.../ sensations qui dérivent probablement de la tournure de mon esprit et de mes préoccupations fréquentes. II y a partout quelque chose d'enlevé et d'enlevant, quelque chose aspirant a monter plus haut, quelque chose d'excessif et de superlatif." Ch. Baudelaire, Correspondance I., ed. Claude Pichois. Paris [Gallimard] 1973. S. 673). In Brezinas Werk, vor allem in Tajemné dálky, spielen die synästhetischen Erlebnisse eine sehr wichtige Rolle. Man denke nur an das Gedicht Vünẻ zahrad mé duše... (Der Dutt der Gärten meiner Seele...) oder an die Bedeutung der Sinnesertebnisse in Modlitba večerni (Das Abendgeben). In Kde jsem už słyšlel...? (Wo denn vernahm ich schon...?; Gedichtzyklus Vêtry od pólú / Passatwinde, 1897), spricht das lyrische Ich, "Sladká tvá vzpominka zbyla mi v duši, jak vonná tma po uhaslém svétle" ("Süß blieb Erinnerung in meiner Seele, wie wohlduftendes Dunkel, wenn lang schon das Licht auslosch").

174 -.../k .Beethovenovi" mne inspirovala tak zvaná Mondscheinsonata, již jsem slyšel v Telč". O. Bïezina, Dopisy Frantisku Bauerovi [Brief vom 20. XII. 1894], Praha 1929, S. 200. ( $/ . . /$ zu .Beethoven" hat mich die sogenannte Mondscheinsonate inspiriert, die ich in Teltsch gehört habe").

175 O. Králík, Otokar Březina, Praha 1948, S. 61. Vgl. auch: J. de Challupper, .Tvých tónủ byl to hlas pod okny duše mé, in: Stavitel chrámu - Památnik básnika a myslitele Otokara Březiny. hrsg. E. Chalupny et all., Praha 1941, S. 199-201.

176 Zum Konzept der Suggestion der Sprache im Symbolismus, vgl. Kap. 2.3. 
Synonym für das Arcanum.177 Die lunare Nacht-Welt "noci narkosou", V, 1: "Narkose der Nacht") ist eine irrealisierte Welt der Fe rne und der A b w e se n h e it ("z dálky staleto", I, 1; "aus ewigfernen Jahren"; "a v dálek pološerech", II, 3; "in der Ferne des Halbdunkels"; "v dálkáctr", IV, 3; "in der Ferne"), der Kä I te und der F a h I h e i t ("v svitu zári bledých", I, 3; "im Schein der blassen Glanze"; "Par oddech strïbrny", III, 1; "silberner Dunsthauch"), des gre nz enlo sen (kosmischen) Raumes ("pel prachu kosmicky. IV, 2; "kosmischer Samenstaub"; "nad šin prostorü", IV, 3; "über des Raumes Weite"), des Ve r s i n k e n s ("kles ke dnu", II, 4; "sinkt leise aut den Grund"; "tichá padá tiž". IV, 2; "stille Schwere sinkt"), des Schwindens (im Unwiederbringlichen: "odplulých staleti". IV 4; "entglittene Jahrhunderte"), des Si c h-Ver s c h I i e Ben s ("do poupat zavrél kvét", $\mathrm{Ml}, 3 ; " \%$... verschloß die Blüten zu Knospen") und Verlös che ns ("vír barev zpëněný kles' ke dnu tich a seo", II, 4; "aufgeschäumter Farbenwirbel sank grau und leise auf den Grund"). Im Hinblick auf die psychopetischen Aspekte dieses Gedichts soll hier das dichterische Ich den Abstieg zum Unbewußten wagen, eine Art 'Nachtmeerfahrt' als descensus ad inferos, in das untermeerische bzw. chthonische Reich der (sexuellen) Libido. Denn dieses Eintauchen in die Wasssertiefe, mit dem die unmittelbare Annäherung an das rein Physische einhergeht, scheint die unerläßliche Bedingung für die Vollendung der transzendenten Ganzheit des Menschen zu sein.

In Motiv z Beethovena wird ein Prozeß suggeriert, der vom Einschlafen (Hypnagogium) zum Erwachen (Hypnexagogium) im "ewigen Morgen" ("A jitro věcných dni", XII, 1) führt. Die Situation des Einschlafens (I. Str.) mit ihren für das Hypnagogium charakteristischen Merkmalen (z. B. die musikalische Reverberation: "To z dálky staletí van tichý v tvár mi nedých / tvých tónú byl to hlas pod okny duß̌e mé, I jenż na mne volar", I. 1-3), korreliert mit der des Enwachens in der letzten Strophe. Hinzu kommen auch andere Äquivalenz- und Oppositionsrelationen: die akustisch-musikalische Wahrnehmung ("tyjch tónu byl to hlas pod okny duše me"; I. 2; "deiner Töne Stimme war es vor meiner Seele Fensterm" - "jak kdybys v ložnici mël okno oteviené / a rannich písní mír tè ovál ze zahrad"; XII, 3-4; "als wärst bei offenem Fenster du im Schlafzimmer / und Morgen lieder Friede wehte zu dier aus den Gärten herein"), die Parallelität auf der Ebene der Wortmotive: "okny" ("Fenster", I, 2) - "okno" (XII, 3), "déstr" (I, 4) - "dést" ("Regen", XII, 2) oder "nedych" ("hauchte", I, 1) - "ovál" ("wehte", XII, 4). Diese Wiederholungen und Äquivalenzen lassen die letzte Strophe als ein Quasi-Spiegelbild der ersten erscheinen. Von besonderer Relevanz ist in diesem Zusammenhang der Fenster-Topos ("okno", I, 2. XII, 3), das im Symbolismus oft als Übergangs-Topos, ein medialer Ort der visionären Erwartung bzw. als Grenze zwischen polar entgegengesetzten Sphären - zwischen Tag und Nacht, Leben und Tod, innen/eigen und außen/fremd usw.- semantisiert wird. Hinter dem Fenster brennt oft das Licht, loht die Flamme, schimmert der neue Tagesanbruch usw: 178 "A jitro věčných dni až vzplá ti zrưmènéné / (déšt rủži ohnivých) /..." (XII, 1-2; "Und bis dir der ewigen Tage Morgenrot aufflammt / (Regen von Feuerrosen) /... $r$ ).

Auch die in diesem Gedicht modellierte - aber $n$ u r suggerierte - $N$ a t $u r$-Welt wird in einen Schlaf-Zustand versetzt" "Spi vinè v zahradách I I. spi pisnè v teple hnizd I. $r$ (II, 1. 3: "Die Düfte schlafen in den Gärten I.../, die Lieder schlafen in den Nästern I... $\digamma$ ); "do mechu $v$ umdleném si lehI ßelestu" (III, 1; "ließ sich das Leid ins Moos im matten Geräusch gleitert). Es ist zwar eine Natur- Welt, die man von außen, sensorisch wahrnehmen kann, es darf aber nicht übersehen werden, daß auch diese Natur-Welt das lediglich s u g g e r i e r te Natur-Bild einer ästhetisierten, durch das Medium der (Musık)Kunst quasi wiedererschaffenen, rein subjektiven paysage intime ist.

Das Frage-Enjambement "O pověz, necitiš, / jak noci narkosou dech unaven se úżi?" (IV, $4-\mathrm{V}, 1$; "O sage, fühlst du denn nicht, / wie sich der Atem engt, betäubt von Narkose der Nacht"), mit dem sich die Stimme der Musik an das dichterische Ich wendet, antizipiert den Inhalt der fünften Strophe, in der die Semantik der II.-IV. Strophe als narkotischer Schlaf/Traum-Zustand des IchDu weiter entfaltet wird. Die in Str. IV-V formulierten Fragen implizieren zugleich die Aufforderungen der Musik-Stimme an das lyrische Subjekt, das

177 Zur alchemistisch-psychologischen Symbolik der "Mondnatur" vgl. C. G. Jung. Mysterium coniunctionis, erster Teil, Zürich 1955, S. 142ff, $188 \mathrm{ff}$.

$178 \mathrm{Vgl}$. Aage A. Hansen-Löve, .Apokalyptik und Adventismus im russischen Symbolismus der Jahrhundertwende" in: Russische Literatur an der Wende vom 19. zum 20. Jahrhundert, hrsg. v. R. G. Grübel, Amsterdam-Atlanta 1993, S. 2691. 
sich die Vergangenheit im Modus der Erinnerung ("vzpominek červenec", VI, 1; "Juli der Erinnerungen") vergegewärtigen soll. Die in Str. II-IV. thematisierten sensorischen Eindrücke, die den Schlaf-Zustand der Natur-Welt (der Außen'-Welt) kennzeichnen, werden in Str. V-VII durch extrem gesteigerte Emotionen substituiert, die sich nun auf den Schlaf-Zustand des (erlebenden) Ich/Du beziehen und die von Innen her das Äußere (den hyletischen Körper) verbrennen und destruieren, mit dem Ziel, eine neue Form der höheren (ästhetischen) Existenz zu erlangen. Das Körperlich-Materielle soll durch den Kunst-Tod im Akt des inneren Selbstverbrennens ("vnitrni požár, VII, 1; "innerer Brand") annihiliert werden, um das Geistige, das Mentale, die im Kerker des Leibes eingemauerte anima zu befreien und das 'neue Sehen' durch die "Hypnose" ("mou spoután hypnosou", VII, 4) ermöglichen zu können.

An dieser Stelle muß noch einmal betont werden, daß das 'Natürliche' (bzw. 'Vegetabilische') der Natur-Welt bloß s u g g e r i e r t wird, denn beim näheren Zusehen handelt es sich, wie bereits erwähnt, um eine durch die Kunst denaturierte 'Natur': "/.../ zor prístích andante do poupat zavǐel květ" (II, 1-2; "das Morgenrot künftiger Andante verschloß die Blüten zu Knospen"); "Par oddech str̈ibrny" (III, 1; "silberner Dunsthauch"); "jak z vláken asbestu" (III, 2;"wie aus Asbestfasern"); "lustry hvězo" (IV, 1; "Sternenlüster"). Hinzu kommen zahlreiche Motive der ebenfalls suggeri erten k ristalli ne $n, 179$ a n o rg a n i s che n Welt: "Pojd, olej tónú svých jsem nalil v lampy krystal, / z kamenú sviticich jsem sklenul kryptu tvou"; $X, 1-2$; "Komm, mit dem Ole deiner Töne füllte ich der Lampe Kristall, I aus strahlendem Gestein wölbte ich deine Krypta"); Motive der Fa rb l o s i gke i t (Lexeme der 'farblosen' Farben): "v dálek poloserech" (II, 3; in der Ferne des Halbdunkels"), "vir barev zpẻněný kies' ke dnu tich a sed (II, 4; "der

179 Die kristallinen und metallischen Konfigurationen, die an der Konstituierung des dekadentsymbolistiscten Wett-Modells von TD in hohem Maße partizipieren, stehen in Motiv $z$ Beethovena in einer engen Beziehung zur Symbolik des ICh, des Künstler-Daseins, zum Prozeß der Individuation usw. Der Dichte wird durch die Zauberkraft der Musik, die "mit dem Ole der Töne das Kristall der Lampe anfüllt", in eine "Krypta aus strahlendem Gestein" (X, 1-2; "Pojd, olej tónú svých jsem nalil v lampy krystai, / 2 kamenu sviticich jsem sklenul kryptu tvou") geführt. Durch diesen "Sturz" in das Kunst-ldeal, in das Vollkommene, MaBvolle, geometrisch strukturierte, kann sich das autistische Ich von der unvollkommenen Außenwelt abkapseln. Die "Krypta aus strahlendem Gestein" symbolisiert hier offensichtlich eine durch die Macht der Kunst neuerschaffene ideale Kunst-Welt, in die (auch) der Rezipient eingeführt werden soll. Noch deutlicher bekundet sich diese Intention in einem der ersten Gedichte Biezinas, in Modlitba vecerni (Das Abendgebet): "jak krystal s krystalem se skládá v lüné skal /... / // Od moji myslenky odpoutej zemskou tiž, / at svétla rychlosti prostorem šlehá v let, I nad mới zelenou a kf́st'allovou hís" (II, 5; IV, 1-3; "wie Kristall sich mit Kristall im Felsenschoß aneinanderfügt /.... // Von meinem Gedanken enfessle die irdische Schwere, / daß er mit Lichtgeschwindigkeit durch den Raum im Fluge saust, I in ein grünes und kristallines Reich über dem Meer"). Der Kristall (die Kristallisierung der Formen) indiziert eine andere, id e a le Welt. Vgl. Ulrich Johannes Beil, Die Wiederkehr des Absoluten. Studien zur Symbolik des Kristallinen und Metallischen in der deutschen Literatur der Jahmundertwende [Univ. Diss.], Frankfur/ Main, Bern, New York, Paris 1988, S. 259 ff. Die Semantik des Kristallinen spielt noch in der Phase des 'kristallinen' Kubismus und im deutschen Expressionisms (1907-18) eine wichtige Rolle, Z. B. im Werk von A. Mombert, H. v. Hofmannsthal oder in den utopistischen architektonischen Entwürfen der österreichischen, tschechischen und deutschen Architekten Wenzel A. Hablik, Bruno Taut, Hermann Obrist, Fritz Kaldenbach, Josef Gocár, Vratislav Hofman u. a. Vgl. The Crystal Chain Letters. Architectural Fantasies by Bruno Taut and His Circle. Ausstellungskakalog, hrsg. v. lain Boyd Whyte, Massachusetts 1985. Vgl. auch: Fracois Burkhardt. Vratislav Hofman-Architektur des bohmischen Kubismus, Ausstellungskatalog, Berlin 1982. Die Transposition der organischen und anorganischen bzw. geometrischen Formen in die Architektur des Kubismus, ihre Dynamisierung und schließlich die grundlegende Auffassung der Architektur als Verwirklichung der bildnerischen Idee, geht noch auf die Ästhetik des Jugendstils zurück. Als ein geradezu paradigmatisches Bauwerk kann das Hauptwerk des Architekten Hans Poelzig (1869-1936), der Innenraum des Großen Schauspielhauses in Berlin (1918-1919) getten, wo Poelzig im überwölbten Zuschauerbereich durch stalaktitenförmige Verkleidungen einen monumental wirkenden höhlenartigen Raum schuf. Der Bruch mit dieser Tradition vollzog sich erst in der puristisch und funktional orientierten Architektur der zwanziger Jahre dieses Jahrhunderts (Addf Loos. Mies van der Rohe u. a.). Einen nicht unbedeutenden EinfluB übten auf die åsthetischen Konzepte der symbolistischen und postsymbolistischen Moderne auch die naturphilosophischen und naturmystischen Spekulationen von Ernst Haeckel über das "anorganische Leben" (Kristallseelen. Studien über das anorganische Leben oder die Schrift Die Kunstiormen in der Natur, 1899-1903). 
aufgeschäumte Farbenwirbel sank grau und still auf den Grund"), "a v cerných táborech" (III, 3; "in schwarzen Lagern"). "Cerné víno tuh" (VIII, 4; "der Begierden schwarzer Wein"). "na ñader úbellich" (IX, 1: "Weiß der Brüste") oder Motive der kristallinen Transparenz: "lampy krystal", "z kamenú sviticich" (X, 1-2; "Kristall der Lampe", "aus strahlendem Gestein"). In den Strophen IX.-XI. werden auch erotische Motive explizit thematisiert "a rozkoš vitězná a cernè vino tuh, // na hadrech úbělích jak spočinutí mèkká, I a nahých ramen dvou jak chtivé sepjeti" (VIII, 4 - IX, 1-2; "siegreiche Lust und der Begierden schwarzer Wein, // wie milde Ruh auf dem Weiß der Brüste, / und zweier nackter Arme gierige Umschlingung "). ${ }^{180}$ Im selbstzerstörerischen Akt des Verbrennens verwandelt sich das Maßlose und Triebhafte in das Gegenteil: in das Maßvolle. Kultivierte, Ideale und Vollkommene. Der Liebes-Tod wandelt sich in Kunst-Tod, der die Leidenschaft (den Eros), jenen "inneren Brand" ("vnitíni požár. VII, 1) im Menschen löscht und in die "siegreiche Lust", in die Kunst-Leidenschaft, verwandelt (VIII, 1-2). Nun kann das lyrische Ich Du den Lockrufen der Musik-Stimme ("Pojd I... ${ }^{\prime}, \mathrm{X}, 1$; XI.1; "Komm I... ${ }^{\mu}$ ), "Pojd I... ${ }^{\mu}$ ) in das (Wasser-)Reich des Kunst-Todes folgen: "a z květứ zázračných jsem mékký polštár schystal, / kde v rasy vưni molých dás hlavu zemdlenou" (X, 3-4; "und aus Zauberblumen bereitete ich ein weiches Kissen vor / auf das du in Falten 181 matten Dufts dein müdes Haupt hineinlehnst") Die Musik - als eine Art ars necans ("piseň pohŕebni" / "Grablied". XI, 3) - saugt wie ein Vampir (signifikant ist in diesem Kontext auch die lunare Sphäre) in einem Todeskuß aus dem lyrischen Ich/Du sein Leben aus: "má piseñ pohr̉ebni ti sladká na thy padne / a v jednom pocelu tvě żiti vypije" (XI, 3-4; "mein süßes Grablied wird auf deine Lippen fallen / und in einem Kuß dein Leben aus dir trinken“). Durch die suggestive, hypnotisierende Wirkung der Musik ${ }^{182}$ wird das Ich/Du (der intendierte Leser) ${ }^{183}$ in Motiv $Z$

180 Der "Begierden schwarzer Wein" ("Cerné vino tuh", VIII, 8) bezieht sich in diesem Kontext nicht nur auf die rauschhafte Leidenschaft, sondern auch auf die 'Welttrunkenheit' als Ausdruck der "Unwissenheit der Seele um sich selbst". Gerade Eros, Umarmung, Lust usw. sind die "vorzügliche Seinsformen der Welt- und Vergänglichkeitsverstrickung" ( $\mathrm{H}$. Jonas, Gnosis und spătantiker Geist i. Götingen 1964, S. 115-116). Diese fakultative Bedeutung des zitierten Verses korrespondiert mit der Überzeugung Bỉezinas vom Trugcharakter der phänomenalen Welt, die auch in Motiv z Beethovena präsent ist; explizit im Motiv des Schleiers, der sich über die Erde ausbreitet: "Par oddech stríbmý nad zemi závoj potáh" (III, 1). Die phänomenale Welt und das irdische Leben verhültt der trügerische Schleier (der Maja). In Slyšim v duši (Ich höre in der Seele. SZ) wird das Gefangensein im 'Lebenstraum' dem Menschen von einer höheren Instanz aufertegt: "Pred zrakem duše tvé jsem utkal závoj żiti" (III. 1: "Vor dem Blick deiner Seele webte ich den Lebensschleier"). Vgl. auch U. Heftrich: Otokar Brezina, 1993, S. 61ff.

181 Das tschechische Wort "Fasa" (PI. "Fasy") aus der oben zitierten Verssequenz, ist ein Homonym, das in Motiv z Beethovena sowohl die Falte $(n)$ als auch die Alge( $n)$ bedeuten kann.

182 Die Vorstellung von der Korrespondenz der Schöptung mit der Sphärenmusik geht aut das solare, apollinische Prinzip zurück. In den myth(olog)ischen Vorstellungen strukturient Apollon das Leben in der Weise einer Liedkomposition. Diese Vorstellung scheint seine Parallele in der visionären Lichterscheinung in der letzten Strophe von Motiv z Beethovena zu haben, in der nicht nur die Sphärenharmonie, sondern auch die 'existentielle' Harmonie des vom Chaos der Leidenschaft erfaßten Individuums wiederhergestellt wird: "a rannich pisni mir té ovál ze zahrad" ("und der Morgenlieder Friede wehte zu dir aus den Gärten herein").

183 Man könnte die Hypothese aufstellen, daß die intendierte Wirkung von Motiv z Beethovena (auch) einen konkreten Adressaten hat: den Jugendfreund Frantisek Bauer, der, wie aus der Korrespondenz Biezinas hervorgeht, ein Bewunderer von Beethovens Musik war und selbst kleinere vokalische Werke komponierte. Interessanterweise erscheinen die magischen Lockrufe der 'Musik-Stimme', die den Rezipienten in das Reich des Kunst-Todes verlocken und ver-tühren sollen, als Reformulierungen der 'Lockrufe', die Bíezina in seinen Briefen an Bauer adressiert. Immer wieder versucht er îhm den Gedanken zu suggerieren, sein Leben und sein Talent gehören der Kunst, und immer wieder versucht er auch inn auch für den gemeinsamen 'Dienst' am Kult der Kunst zu gewinnen: "Co bych za to dal, kdybych mohl żiti v tvém ovzdusí, nalézti v tobè onoho prítele studentských našich let, kdy spávajice na jedné posteli, umirali jsme rozkoši prii vzpominkách na naši budouci slávu. Abych Ti mohl vypravovati své sny, /.../ rozćilovati vášni pro uméni, bodati tvou ctiźádost I...F. (O. Błezina, Dopisy Fmtišku Bauerovi, Praha 1929, S. 177; Brief vom 1. XII. 1892; "Was würde ich dafür geben, wenn ich in deiner Atmosphäre leben, in dir den atten Freund aus den Jahren unseres Studiums finden kŏnnte, als wir, in einem Bett sctilafend, bei der Erinnerung an unseren künftigen Ruhm vor Lust starben. Damit ich Dir meine Träume erzählen, /.../ Dich mit der Leidenschaft für die Kunst erregen, Deinen Ehrgeiz anspornen könnte I... I). J Jednej jako já /.../ Jsme umélci. Byli jsme jimi a jsme. $V$ dobrém i v zlém. $V$ boj za čisté, 
Beethovena184 in die magische Sphäre der Kunst (bzw. des Kunst-Traums) versetzt. Das (apollinische, maß- und kunstvolle, ästhetische) Prinzip des Tages und des Lichts, der Klarheit und der Harmonie ("mir". XII, 4; "Friede") prägt die Situation der letzten Strophe, die man als einen 'Traum im Traum' bzw. 'Traum im Tod' spezifizieren kann. Die Wiederaufnahme des medialen 'Fenster'-Topos ("jak kdybys v ložnici mël okno otevĩené", XII. 3) scheint erneut zur Ausgangssituation des Versinkens in den Kunst-Traum ("tvých tónư byl to hlas pod okny duse mé", I, 2) zu führen. Das Versinken in den Traum - als Zustand der höchsten imaginativen Potenz - durch die Selbst-Aufopferung am Altar der Kunst, das in der Schlußstrophe von Umëni der Adept der Kunst anstrebt, soll in Motiv Z Beethovena auch der Rezipient - aus der Perspektive der Wirkungsästhetik - erleben. Die Assoziationen der empirischen Wirklichkeit und die rhetorische Argumentation sollen dabei zugunsten der höchst suggestiven Wirkung des (Vers-)Musik-Zaubers neutralisiert werden. Zu dieser intendierten Wirkung des dekadenten Gedichttextes gehört auch die Aufforderun an den Rezipienten, sich (ähnlich wie in der Psychoanalyse) durch den Abstieg in die Sphäre des Un(ter)bewußten, durch den Schlaf/Traum oder die Hypnose (VII, 4), zu erinnern.

Hier drängt sich noch die Frage auf, was - im Hinblick auf die schon erwähnten psychopoetischen Aspekte - der Abstieg in die Wasser-Tiefe des Unbewußten für das dichterische Ich bedeutet? Das Eintauchen in das Unbewußte, in die chthonische Sphäre, koinzidiert mit dem Herandrängen einer sexuellen Libido, die das Ich wie ein "innerer Brano" ("vnițini požár". VII. 1) zu verzehren droht. In Phantasien und Träumen manifestient sich das Unbewußte als Meer (als Gewässer allgemein), Symbol des Entstehens und der Wiedergeburt eines neuen Wesens. Wie es scheint, bezieht sich das Eintauchen in die (Wasser-)Tiefe in diesem Kontext auch auf den Prozeß der Herstellung der Ganzheit des Menschen. Um die postulierte Ganzheit zu vollenden, muß die Seele ihre andere Seite "in

vysoké, jediné Umènit" (13. IX. 1892, ibid., S. 171-172; "Tu wie ich /.../. Wir sind Künstler. Wir waren und wir sind Künstler. Im Guten wie im Schlechten. Auf in den Kampf für die reine, hohe, einzige Kunst!" ) "Tvoje misto jest nad Cistým archem notového papiru, s brkovjm pérem v ruce, s ocima svítícima extasi, s dusi utonulou ve vécných kataraktech Neznámých krás. I...IV té chvili płál jsem si míti Té pobliź sebe a všechno nadseni, jeż jsem cítil płelelt do Tvé duše, aby ji celou zapálilo pro umẻni, jež jediné má nesmrtelnost ze všeho lidského, nesmrtelnost proto, ponévadž je zrażenim, ztuhnutím, łekl bych zkapalněnim myšlenky, která je nesmrtelná". (21. II. 1893, ibid. S., 182. 185: "Dein Platz ist über einem weißen Notenblatt mit der Feder in der Hand, mit von der Ekstase lodernden Blicken, mit der in ewigen Katarakten der Unbekanten Schönheit ertrunkenen Seete. I.../ In diesem Augenblick wünschte ich mir, Dich in meiner Năhe zu haben, um die ganze Begeisterung, die ich empłand, in deine Seele einzugießen, um sie dadurch gånztich für die Kunst zu entfachen /...l.). Im Brief vom 20. XII. 1894 (ibid., S. 200) macht Bfezina Bauer auf die Veroffentlichung von Motiv $z$ Beethovena aufmerksam. Die 'Stimme' der Musik in Motiv $Z$ Beethovena, gehört, dem grammatischen Genus nach, offensichtlich einer $m$ á $n \mathrm{n}$ li c h e n Person: "jsem nalil /.../, jsem sklenur /.../, jsem schystar $(X, 1-3) . " / . . /$ na hader ubèlich jak spocinuti mêkká" (IX, 1; "wie milde Ruh aut dem Weiß der Brūste"); vgl. dazu das Motiv der "weißen Brūste" in Máchas Máj: "Obnażil vězeñ /.../ hadra bilé" (3. Gesang). Frantisek Bauer spricht Biezina sehr wahrscheinlich auch in Prátelstvi duši (Die Seelentreundschafi) an: "pohledy naše se líbaly. jak $v$ jednom objetí zachvěni dvoji. [vgl. "a nahých ramen dvou jak chtivé sepétî", Motiv z Beethovena, IX, 2] / S rozkosi dýchal jsem vưné tvé krve a v zahradách snú / jak milenku u pejicich vod má duše hledala tvoji. // K nám mluvila touha a váseñ, hrúza a sila a hrích /... $/$ (I, 2-4. II, 1: "unsere Blicke küBten sich wie zwei Zuckungen in einer einzigen Umschlingung.|VgI. "und zweier nackter Arme gierige Umschlingung". Ein Motiv aus Beethoven, IX, 2) / Mit Lust atmete ich deines Blutes Duft und in den Gărten der Trăume / suchte meine Seele die deinige wie eine Geliebte an singenden Wassern. / Zu uns raunte das Verlangen und die Leidenschaft, das Grauen und die Kraft und Sünde $/ . . . r$ ). Vgl, dazu den Passus aus Błezinas Brief an Bauer (vom 20. XII. 1894): ".../ Ale płedevšim, ¿ekám od Tebe list /.../, takový, kdy z każdého łádku smẻje se Tvá duše. kterou m il u ji a kterou jsem vždy m il o v a l, ackoliv nechtéla jít vžody vedle mne, a kterou budu mil ov a t i i tenkrát, kdyby už nikdy ke mně s bývalou vroucnosti neprilnula" (vgl. a.a.O., S. 203: "\%... Vor allem aber enwarte ich einen Brief von Dir /.../, einen solchen, wo aus jeder Zeile deine Seele lachelt, die ich l i e b e und die ich immer $g$ e l i e b t habe, obwohl sie nicht immer neben mir gehen wolte, und die ich auch dann I $i$ e b e n werde, wenn ihre Anhănglichkeit an mich die einstige Inbrunst einbüßen würde*. Sperrungen von Błezina).

184 Wagner, Beethoven, Schubert, Schumann, Chopin sind die bewunderten Komponisten der dekadenten Künstlermenschen. Des Esseintes in $A$ rebours ist bewegt, wenn er an Schuberts Streich-Quartett Der Tod und das Mädchen oder an die Musik von Beethoven denkt. 
der Verbindung des Ich mit all dem, was sich als Projektion im "Du" birgt", 185 finden. Das Ich und Du bilden eine transzendente Einheit, deren Wesen das Runde, die "coniunctio Solis et Lunae" oder die R o se, das transzendente Einheit-Symbol par excellence. versinnbildlichen. Durch den 'riskanten' Abstieg in die Wasser-Tiefe des Unbewußten, die die unmittelbare Annäherung an das versengende Feur der Libido bedeutet, können die Gegensätze (lunare Sphäre der Nacht [erste Str.] - solare Sphäre des Tages [letzte Str.], Wasser / Ursprungsort alles seelischen Lebens / Lebensstrom - Feuer Libido, Körper Geist) bzw. verschiedene Teile einer transzendenten Einhet vereinigt werden. Es ist daher kein Zufall, daß die Morgenröte, in die das dichterische Ich nach seiner symbolischen Wiedergeburt (aus dem Wasser) erwacht, als "Regen der Feuerr o s e n " "déšt' r ủ zi

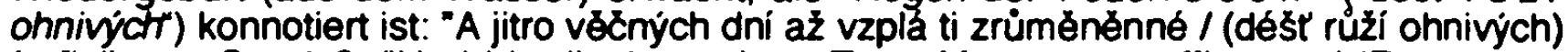
I... $\mu$ (letzte Str, 1-2; "Und bis dir der ewigen Tage Morgenrot aufflammt / (Regen von Feverrosen) I... $r$ ).

Zu s a m m e $\mathrm{n}$ f a s s u n g: Die Irrealisierung als das Konstruktionsprinzip des ersten Gedichtzyklus Tajemné dálky bestimmt die ästhetistischen Lebenshatung des dekadenten Künstler-Schöpfers als Existenz in einer isolierten, verabsolutisierten Ästhetik. Sowohl die phänomenale als auch die (ideale sowie ideelle) "andere Welt" ("jiný svět", Modlitba vecemi / Das Abendgebet, Vèzeñ / Der Gefangene) erweisen sich als 'leer', 'fremd' und 'irrealisiert', d. h. rein fiktiv, nicht-mehr-seiend, nur als Illusion und Projektion eigener Einbildungskraft. Als Modi der Irrealisierung und der Entrücktheit in die Kunst-Welt fungieren Hypnos, Oneiros und Thanatos, die der Modus der Erinnerung - an das Irrealisierte, Nicht-mehr-seiende, Unerreichbare uws. - und die Denaturierung der NaturWelt durch das Kunst-Schöne ergänzen. Diese Irrealisierung-Modi manifestieren sich als Erscheinungsformen des Destruktionstri e bes, der dem in TD konstituierten Welt-Modell obwaltet. Daraus resultiert die auffallende Thanatophilie, die Faszination vom Zerfall, von allen Arten der Annihilierung (durch Verbrennen, Ertrinken, Ersticken, Vermodern, Erfrieren, Verfaulen usw.), die die ganze Erde zu erfassen scheint (vgl. Snad potom... I Velleicht dann....). Das höhste Ziel der ästhetischen Existenz, die Entschleierung des "ewigen Geheimnisses" ("vëcného Tajemstv"), erweist sich schließlich auch als illusiv, weil dieses Geheimnis in der "ewigen", "entkräftenden", "geheimnisvollen Ferne" liegt und unerreichbar bleibt, worin jedoch zugleich sein höchster Wert, seine magische und hypnotisierende Anziehungskraft gründet. Die Vorstellung des Dienstes am Kult der Kunst, die im Kontext Biezinas dekadenten Symbolismus das Numinose und

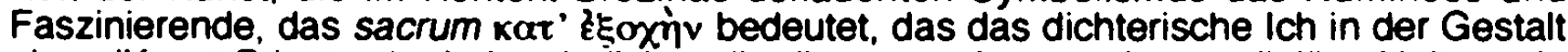
eines 'Kunst-Priesters' adoriert, indiziert allerdings nur eine quasi parareligiöse Haltung, in dem Sinne, daß das Ästhetisch-Künstlerische die Position des Religiösen einnimmt. Der in den Gedichten von TD apostrophierte "Höchste" offenbart sich als 'Künstler-Gott", als magisches (und 'magnetisierendes') Götzenbild (Uméni I Die Kunst). Dementsprechend wird auch der actus fidei des dichterischen Ich auf eine pathetisch-hieratische Inszenierung seines eigenen Auto-da-fé am Altar der Kunst reduziert. Mit der Illusivität und Irrealităt der ästhetistischen Kunst-Welt geht der Rückgriff auf die Tradition der manieristischen, antirationalen Rhetorik einher, deren Ziel es ist, den Wahrnehmenden zu 'überlisten', inn durch die 'Suggestion' und 'Hypnose' zu 'verführen'.

$185^{\circ}$ C.G. Jung, .Die Psychologie der Übertragung", in: Gesammelte Werke, Bd. 16, OltenFreiburg im Breisgau 1991, S. 244. 


\section{ESCHATOLOGISCHER SYMBOLISMUS I Gnostisch-eschatologisches Modell Gedichtzyklus Svitáni na západẻ (Tagen im Westen) 1896 Zwischen ästhetischer und eschatologischer Existenz}

„Jsem mystický poet, který věri, ¿̃e posledni cil věcí je světlo. přede v̌̌emi diny a po v̌̌ech dnech. ¿̌e otviraji se skrvtá bohatstvi nekonečnosti ¿̇vota a světü, závratné evoluce směrujici k osvobozeni spirituelniho".

"Ich bin ein mystischer Poet, der glaubt, daß Licht
das letzte Ziel der Dinge ist, vor allen Tagen und nach allen
Tagen, daß sich verborgene Reichtümer der Unendlichkeit
des Lebens und der Welten öfnen, schwindelerregende
Evolutionen, die auf die spirituelle Befreiung hinzielen".

Or. Błezina an A. Pammrová (1896)

Der zweite Gedichtzyklus Svitáni na západé (Tagen im Westen, 1896), der den Geheimnisvollen Fernen (Tajemné dálky) bereits nach einem Jahr folgte, leitet eine neue, nachdekadente Schaffensphase in Bïezinas Werk ein: die des eschatologischen Symbolismus. Daher kann Svitáni na západé als ein Gedichtzyklus des Ü b e r g a n g s vom dekadenten zum eschatologischen Symbolismus charakterisiert werden. Im folgenden soll erörtert werden, worin die spezifischen Qualitäten, Besonderheiten sowie Verschiebungen in der Axiologie dieser Übergangsphase - im Vergleich mit der des dekadenten Symbolismus - gründen, für die M. Sedmidubský 186 den Begriff der Metadekadenz vorschlägt. Es soll zunächst die prinzipielle Frage gestellt werden, in welchem Verhältnis der Begriff der Metadekadenz, der für die Untersuchung der in Svítáni na západè modellierten poetischen Welt fruchtbar zu sein scheint, zu dem des eschatologischen Symbolismus steht.

Daß Br̈ezina die dekadente Schaffensphase als eine für seine schöpferische Entwicklung sehr wichtige, ja unentbehrliche Übergangsphase ansah, geht aus einem Brief an F. Bauer deutlich hervor:

"A vzdor tomu, Ze kniha má [Tajemné dálky. Anm. J. V.] jevi se mi dnes stanovištěm pr̉ekonanym, kusem zahrady, kterou jsem prošel a kam se již nikdy nevrátim, hlásim se $k$ ni otevỉené a hrdè; realisoval jsem v ni préce jen s jistou vehemenci nẻkteré zásadni rozlohy svěho snu /...l. Druhá má kniha bude vypjatějši a sytějši, šrši a hlubši, jak doufám". ("Und trotz dem, daß mir heute mein Buch [Geheimnisvolle Fermen, Anm. J. V.] als ein überwundener Standpunkt erscheint, ein Stück Garten, den in durchwanderte und wohin ich nimmer zurückkehren würde, bekenne ich mich offen und stolz zu ihm; mit einer gewissen Vehemenz realisierte ich in ihm doch einige grundlegende Plăne meines Traumes I...I. Mein zweites Buch wird extremer und satter, breiter und tiefer sein, wie ich hoffe $\left.{ }^{*}\right)^{187}$

Die im zitierten Passus zum Ausdruck gebrachte Stellungnahme zum Gedichtzyklus Tajemnẻ dálky, nämlich das stolze Bekenntnis zur dekadenten Vergangenheit, bestimmt zwar im wesenttichen die Eigenart von Svitáni na západè, kann aber nicht verallgemeinert und auf alle Gedichte des neuen Zyklus bezogen werden. In den zwölf Monaten, die zwischen Tajemné dálky und dem neuen Gedichtzyklus liegen, machte Br̈ezina eine nicht nur wechselreiche, sondern auch prinzipielle schöpferische Entwicklung durch, die sich auf allen Ebenen der (Sinn-)Struktur des Zyklus offenbart. Der Dichter scheint seine eigene künstlerische Entwicklung, deren Telos man, wie noch zu zeigen sein wird, in der Suche nach dem Aus-Weg aus dem Labyrinth der dekadenten Kunst-Welt sehen kann, aus etwa drei verschiedenen Perspektiven zu reflektieren. Man kann in diesem

186 In der Diskussion im literaturwissenschaftlichen Seminar Otokar Biezina. Zur Poetik der symbolistischen Lyrik in der tschechischen Literatur. Sommersemester 1995, Institut für slawische Philologie, Ludwig-Maximilians Universität München.

187 Vgl. O. Brezina, Dopisy Františku Bauerovi. [Brief vom Herbst 1895], Praha 1929, S. 210. 
Zusammenhang von einer gewissen 'Typologie' der metadekadenten Gedichte bzw. von deren drei Kategorien sprechen:

- Es ist zunăchst der - von Bïezina selbst definierte - Standpunkt von jemandem, der die Dekadenz als eine überwundene Schaffensphase betrachtet und sich bereits auf dem 'sicheren Boden' des eschatologischen Symbolismus befindet, von wo aus er seine nun bewältigte dekadente Vergangenheit reflektient. Zu dieser Kategorie gehören vor allem die drei Schlüsselgedichte: Ranni modlitba (Das Morgengebet). Vino silných (Der Wein der Starken) oder Mythus duše (Der Mythos der Seele).

- Ferner handelt es sich um einen (zum Teil) retrospektiven Standpunkt von jemandem, der die 'Irrtümer' und 'Schwächen' der dekadenten Position erkannt und zu ihr jetzt eine distanzierte, ja kritische Haltung eingenommen hat. Doch trotz dieser (selbst)kritischen Position wird die dekadente Schaffensphase als ein integraler Bestandteil der eigenen schöpferischen Entwicklung gewertet, was man als gemeinsames Merkmal aller drei Perspektiven betrachten kann. Die Konsequenz dieser Erkenntnis ist die Bemühung, den richtigen Weg zu finden: Vteriny (Sekunden), Nálada (Die Stimmung). Tys nešla (Du kamst nicht). Slyšim v duši (Ich höre in der Seele), Mé dèdictvi položil's... (Mein Erbe legtest du...). Ples věcných svítáni (Der Reigen ewiger Morgenröte) oder das Titelgedicht Suítáni na západẻ (Tagen im Westen);

- daraus resultiert schließlich, daß es sich zugleich um eine aktuelle Perspektive eines Suchenden und eines Übergangs - mit einem noch unklaren, unbekannten Ziel - handelt: Vladari snư (Herrscher der Träume), Až sedneš za mưj stül ... (Wenn du an meinen Tisch dich setzt...), Zalm ke cti nejusšsiho Jměna (Der Psalm zu Ehren des höchsten Namens), Legenda tajemné vinny (Die Legende der geheimnisvollen Schuld) u. a.

Man kann davon ausgehen, daß die Metadekadenz eine für die Übergangsphase vom dekadenten zum eschatologischen Symbolismus Biezinas charakteristische Erscheinung darstellt. Eines inrer Hauptmerkmale ist das Streben nach einer gleichsam o bj e k ti v distanzierten, $\mathrm{k}$ r i t i s c h reflektierenden Betrachtungsweise der dekadenten Poetik und ihrer Axiologie. Die spezifische Leistung der metadekadenten Poetik des Übergangs bzw. der Bewegung zwischen nicht mehr und noch nicht, kann an dieser Stelle und bei erster Annäherung an zwei kürzeren paradigmatischen Gedichten erörtert werden: Mé dẻdictvi polożils... (Mein Erbe legtest du...) und Slyšim v duši (Ich höre in der Seele). Im Gedicht Slysim v duši, das man als objektive Beschreibung der dekadenten Ästhetik in der Form der zitierten fremden Rede (das lyrische Ich tritt als angesprochenes "Du" auf) und zugleich als Beschreibung der Gefangenschaft durch eine höhere Instanz lesen kann, wird die Ästhetik der Dekadenz als 'Produkt' der Fremdbestimmung dargestellt: "Kdyż slunce zpívalo, tys na svuji nástroj nesáh', I jen pod mým bodnutím krev tryskla tónü tvých; I... /. II I... I tvé dni jsem uvéznil a sugesci své vule / tvých pisni zahorkkl jsem mizu, dech a květ" ( 1 . 1-2, V, 3-4: "Als die Sonne sang. griffest du nicht nach deinem Instrument, I nur unter meinem Stich spritzte das Blut deiner Töne; /../ // /../ ich machte deine Tage zu Gefängnis und durch die Suggestion meines Willens / ließ ich den Saft, den Atem und die Blüte deiner Lieder bitter werden"). In Mé dédictvi polozzil's... 188 bilden die dritte und die

188 Mé dédictvi polozil's: I. Má slova nejlahodnějši mi zemỉela v bolestném mılceni, I mé pohledy nejvýmluvnéjši uhasly bez odpovědi: / kdyż mrtvá slova mne probudi vỷčitkou ze sněni, I mrtvé pohledy $z$ bezesných noci mi do duše hledí. IIII. Ussmévy. jeż v tvárich mi zkvetly, v cizich dušich mi uvadly. I a které v cizich tvárich mi svadly, $v$ dusi mi rozkvetlé boli. I Krưpèje, jeż z nał̌iznutých vêtvi rozkoše na ty mi nepadly, I v snéni na rtech mi roztály, jak sestydlé v krystaly soli. II III. Na cestách mých krokủ leżely stíny z oblakú staleti, / na cestách mých zrakủ obrazy vzdušné. odražené z nekonečna; / na cestách mé touhy tmělo se mystických blankytú rozpétí. I na cestách mé duše teskno a dvojsmysiné mlčeni vécna. I/ IV. Mé dédictvi položil's v krajinu sněni a tušeni. / mé rủże jsi vytrhal a presadil do jejich zázračnỳch sadú; jejich vưné mne omdlivá v extasich modlitby a uméni / a nádhera jejich barev hới mi ze Západú". (I. Meine köstlichsten Worte verstarben mir im schmerzvollen Sctiweigen, / meine vielsagendsten Blicke erloschen ohne Antworten: / wenn die toten Worte mich mit Vorwurt aus Träumen erwecken / schauen die toten Blicke aus den Nächten ohne Träume in meine Seele hinein. /I II. Die Lächeln, die auf meinem Antlitz erblühten, verwelkten mir in fremden Seelen, / und die, die mir auf fremden Antlitzen verwelkten, schmerzen mich erblüht in der Seele. I Die Tropfen, die aus den angeschnittenen Zweigen der Lust auf meine Lippen nicht herabrannen, / tauten mir auf den Lippen zu Träumen, wie zu Salzkristallen erstarrt. II III. Auf den Wegen meiner Schritte lagen die Schatten aus den Wolken der Jahrhunderte, I auf den Wegen meiner Blicke [lagen] luftige Bilder, aus dem Unendlichen reflektiert; / auf den Wegen meiner Sehnsucht dämmerte die Spannweite des mystischen Azurs, I auf den Wegen meiner Seele [lagen] die Trauer und das doppelsinnige 
vierte Verszeile der zweiten Strophe ein quasi verzertes, anamorphotisches (Spiegel-) Bild der ersten und der zweiten Verszeile, in dem Sinne, daß die Aussage der jeweils vorangehenden Zeile invertiert wird. Das inversive (Vers-)Bild erweist sich allerdings als das 'richtige', wenn man die Inversion quasi 're-invertiert' und aus dem richtigen Blickwinkel liest. Bei der richtigen Wiedergabe werden die (Vers-)Bilder-Anamorphosen entsprechend entzert. Diese Inversionen und Doppelungen werden in der vierten Verszeile der dritten Strophe durch das Adjektiv "dvojsmysiny" ("doppelsinnig") explizit markiert. Die zweite Hälfte des Gedichts (Str. III.-IV.) scheint den richtigen Blickwinkel anzugeben. Signifikanterweise strukturiert die ganze dritte Strophe die Anapher "na cestách I... ${ }^{\prime \prime}$ ("auf den Wegen"). Es sind die "Wege" der in sich eingeschlossenen Ich-Welt (kennzeichnend ist die Frequenz des Possessivpronomens "mé" bzw. "mých" $/$ mein[er]": "na cestách mých I.../ mých I.../ mé /.../ mé), die nur von sich selbst und wieder zu sich selbst führen, ausgespannt ("rozpét", III, 3) zwischen zwei Konstanten, zwei Kategorien, die axiologisch wechselseitig korrelieren und kein Telos haben: "nekonezno" ("Endlosigkeit") und "věčno" ("Ewigkeit"). Dementsprechend erscheinen aut den Wegen dieser apophatischen und irrealisierten Ich-Welt ("teskno" I "Wehmut", "ml¿eni" I "Schweigen") lediglich dematerialisierte, irrealisierte, diaphane oder ätherische Phänomene ("stíny z oblakü" / "Schatten aus den Wolken", "obrazy vzdušné" / "Luftbilder", "mystických blankytú rozpéti" / "Spannweite des mystischen Azurs"; III, 1-3). In der letzten Strophe ändert sich die Perspektive gravierend durch die Änderung der grammatischen Person (IV, 1-2): Es wird plötzlich ein "Du" apostrophiert, eine höhere Instanz (offensichtlich der "Höchste"), die die reale Welt des Ich in einen inexistenten, traumähnlichen alter mundus verpflanzte. Durch diese Fremdbestimmung wird die Kataphatik des dichterischen Ich zu quälender Apophatik (I. Str.). Das Ich-Bewußtsein sowie die Emptindungen des Ich werden irrealisiert und das Ich selbst erscheint als Projektion eines anderen (Traum-)Bewußtseins. Das Eigene wird ent-fremdet und das Fremde soll - kann aber nicht - zum Eigenen werden (II. Str.). Die Ich-Welt wird somit zum bloßen Reflex-(Trug-)Bild (III. Str.) devalviert. Die wahre Entzerrung dieser paradoxanamorphotischen Verzerrungen geschieht aber erst in der vierten Strophe durch das Heraustreten des dichterischen Ich aus seiner (autistischen) Ich-Welt, $d$. $h$. durch das Bewußtwerden des eigenen Zustandes von einem Außenstandpunkt her. In der vierten Strophe wiederholt sich die gleiche Situation wie in Slyšim v dusi (Ich höre in der Seele). Dadurch erlangt die Situation der letzten Strophe, in der die Inversionen bzw. Verdoppelungen aufgehoben werden, ihre Logik. Nach dem Heraustreten aus der autistischen Ich-Welt gewinnt der (Lebens-)Weg seine positive Teleologie ("a nádhera jejich barev hor̂́ mi ze Západư", IV, 4).

Doch die Metadekadenz bedeutet auch eine schöpferische Auseinandersetzung mit der Ästhetik der Dekadenz, die als wichtiger Meilenstein Bỉezinas schöpferischer Entwicklung betrachtet wird (Mythus duše / Mythos der Seele, Vino silnych / Der Wein der Starken). Im Hinblick auf die mythopoetischen Aspekte stellt der descensus in die chthonische Tiefe der Dekadenz, der seine Parallele in der Gefangenschaft und Isolation des Ich in eigener (dekadenten) Schein-Welt hat, die notwendige Voraussetzung für den produktiven und schopperischen ascensus dar. ${ }^{189}$ Diese Intention wird in der letzten Verszeile von Vino silných (Der Wein der Starken) explizit zum Ausdruck gebracht: "Trest

Schweigen der Ewigkeit". // IV. Mein Erbe legtest du in die Landschaft des Träumens und der Vorahnung. / meine Rosen rissest du aus verpflanzest sie in ihre zauberhaften Gärten; / deren Duft mich onnmächtig in Extasen des Gebets und der Kunst macht / und deren Farbenpracht für mich aus den Sonnenuntergängen brennt .")

189 In seiner Studie .Die Ursprünge der indoeuropäischen Poetik", in: Poetica, Bd. 13, 1981, S. 189-251, verweist Vladimir $N$. Toporov auf die mythische Bedeutug der 'Verwandschaft' des Dichters mit dem Jenseits, auf seine Faszination vom dämonischen und destruktiven Prinzip des poetischen Schaffens, die sich oft bis zum Verlangen nach der Selbstvernichtung und Selbstopferung steigert (s. unten die Analyse des Gedichts Uméni, Kap. 2.3.1). Der Dichter steigt hinab in die Hölle (Örpheus-Mythos), um den Tod zu überwinden und als Sieger zurückzukehren. Der 'Aufenthalt' in der Sphäre der Chithonos gibt inm die Kraft das "Wasser des Lebens" zu finden, mit dessen Hilfe er nach seiner Rückkehr als Hapostase die chaotische Welt kreativ neu umformt (ibid. S. 219ff.). In den mythischen Vorstellungen ist der Dichter als creator microcosmi mit den Polarităten und Extremen wie Himmel und Erde, Zukuntt und Vergangenheit, Leben und Tod eng verbunden und bewegt sich zwischen innen als deren 'Vermittler'. Die Welt der Poesie, der Kunst, ja das Kunst-Werk ist der 'Ort' deren Synthetisierens bzw. Sym-bolisierens. 
slabých bude, że zapomenou své jméno prii procitnuti, / a odmēna silných, že v zárici tmè vzpomenou na ostrovy zajeti svého" (V. 45-46; "Strafe der Schwachen wird sein, daß beim Erwachen sie ihren Namen vergessen, / und Lohn der Starken, daß sie in leuchtendem Dunkel ihrer Gefangenschaft Inseln gedenken").

Was die drei oben genannten Perspektiven und damit auch die drei grundlegenden Text-Kategorien von Svitáni na západè zu vereinigen scheint, ist - wie noch zu zeigen sein wird - das für die Axiologie und Semantik des Zyklus zentrale, bereits erwähnte Thema des Weges. Gemeint ist der Weg vom 'leeren' Solipsismus der Trennung und Dissoziation in der Dekadenz, zur Kollektivität der Vereinigung bzw. Verbrüderung im eschatologischen Symbolismus (gnostisch-eschatologisches Modells). Was hat sich in Svitáni na zapadè im Vergleich zur Werthierarchie und den formalen Besonderheiten des ersten Gedichtzyklus (Tajemné dálky) - prinzipiell gerändert? Was kann man als harakteristische Merkmale des 'Programms' der neuen Schaffensphase-des e s ch a to log is chen Symbolismus - hervorheben?

Es ist in erster Linie das Streben nach der Herstellung der Einheit (unio) als das zentrale und sinnstiftende Prinzip a lle r $n$ a $c h d e k$ a de $n$ te $n$ Schaffensphasen Bỉezinas und als Gegensatz zur Negativität, die aus dem Prinzip der Irrealisierung sowie der Abwesenheit, Dissoziation und Isolation unter der Herrschaft des Destruktionstriebes (des Thanatos) der Dekadenz resultiert. In einem Brief an A. Pammrová (1896) benennt Bïezina klar die Ursache des Leidens: die Trennung. ("Pňčinou bolesti je rozdéleni".) 190 Ihr $\mathrm{g}$ e $\mathrm{g}$ e $\mathrm{n}$ ü b e r stellt Bỉezina das positive Prinzip der Einheit und der "Bindung" unter der Herrschaft des allverbindenden, allumfassenden Eros, im Sinne der Kulturtheorie Freuds. ${ }^{191}$ In Svitáni na západẻ soll diese Einheit durch gnostische Mittel erreicht werden.

190 O. Błezina, Dopisy A. Pammrové z let 1889-1905, Praha 1931, S. 141.

191 In seiner Kulturdeutung .Das Unbehagen in der Kultur" (1930) betont Freud die einigende Funktion des Eros als vitale Kraft: "Wir können uns also erst bei der Aussage beruhigen, der Kulturprozeß sei jene Modifikation des Lebensprozesses, die er unter dem Einfluß einer vom Eros gestalteten, von der Ananke, der realen Not angeregten Aufgabe erfähn, und diese Aufgabe ist die Vereinigung vereinzelter Menschen zu einer unter sich libidinös verbundenen Gemeinschaft" (.Das Unbehagen in der Kultur", in: S. Freud, Studienausgabe, Bd. IX. Frankfurt am Main 1980, S. 265). Doch warum dann das "Unbehagen"? Für Freud resultiert es aus der quasi unrealistischen Forderung der Năchstenliebe, aus der Forderung, die Feinde zu lieben; ein Thema, das für den eschatologischen Symbolismus Bỉezinas von großer Bedeutung ist (man denke an das bekannte Gedicht Modlitba za neprátele / Das Gebet für die Feinde, VP). Was der libidinös motivierten und orientierten Vereinigung im Wege steht, heißt bei Freud "antikultureller Trieb", $d . h$. der Todestrieb: -Diesem Programm der Kultur widersetzt sich aber der Aggressionstrieb der Menschen /.../. Dieser Aggressionstrieb ist der Abkömmling und Hauptvertreter des Todestriebes, den wir neben dem Eros gefunden haben, der sich mit inm die Weltherrschaft teilt. Und nun, meine ich, ist uns der Sinn der Kulturentwicklung nicht mehr dunkel. Sie muß uns den Kampf zwischen Eros und Tod, Lebenstrieb und Destruktionstrieb zeigen, wie er sich an der Menschenart vollzieht Dieser Kampi ist der wesentliche Inhalt des Lebens überhaupt, und darum ist die Kulturentwicklung kurzweg zu bezeichnen als der Lebenskampt der Menschenart" (Ibid. ibid., S. 249) Freud identifizient den Todestrieb auf drei Ebenen: der biologischen, psychologischen und kulturellen. Als der 'Schutz' gegen die Aggressionsneigungen und den Todestrieb, der mit dem narzißtischen Ich verbunden ist, erklärt Freud das Schuldgefühl: Daher solte sich die Kultur auf die Seite des Eros g e $g$ e $n$ das 'thanatophil' orientierte, autistische und egomanische Ich stellen. Freud schreibt: "/.../ das Schuldgetühl ist der Ausdruck des Ambivalenzkonflikts, des ewigen Kampfes zwischen dem Eros und dem Destruktions- oder Todestrieb" (ibid. S. 258). In der Sprache Bfezina eschatologischen Symbolismus gründet diese "geheimnisvolle Schuld" einerseits im Willen des Menschen, den dämonischen Mächten immer wieder zu verfallen, was die schweren moralischen Verfehlungen (und den Fluch!) nach sich zieht, und andererseits im Verzicht auf die offenstehenden Möglichkeiten der Gotteserkenntnis. Das Schuldgefühl, von dem Freud spricht, bleibt aber oft unbewußt oder es manifestiert sich als ein Unbehagen. Die Kultur jedoch, die -einem inneren erotischen Antrieb gehorcht" (ibid., S. 258), 'eliminiert' quasi das egozentrische, isolierte Individuum, und läßt dadurch das Destruktive zum Konstruktiven und 'Lebensschaffenden', den Todestrieb zum Lebenstrieb mutieren. Dies betrachtet Freud als die Hauptfunktion jenes erotischen Antriebes in der Kultur, die "Menschen zu einer innig verbundenen Masse" (ibid., S. 258) zu vereinigen, d. $h$. die Herstellung der Einheit. Bereits in der Schrift .Jenseits des Lustprinzips" (in: S. Freud, Studienausgabe, Bd. 3, Frankfurt am Main, 1980, S, 217-272), die Freud zehn Jahre vorher (1920) unter dem schockierenden Eindruck der Schrecken des Weltkrieges verfaßte und veröffentlichte, macht er direkt ein Gleichheitszeichen zwischen "Ichtrieben" und "Todestrieben" sowie zwischen "Sexuattrieben" und "Lebenstrieben" (S. 261). Vor 
An dieser Stelle können auch die zwei anderen grundlegenden Merkmale des Übergangs vom dekadenten zum (gesamten) eschatologischen Symbolismus genannt werden. 1) Es ist die teleologische Orientierung auf ein $\mathrm{E}, \mathrm{Ch}$ a to $\mathrm{n}$ hin, auf die Vollendung (der Schöpfungsprozesse) und auf die Herstellung der (Ur-)Einheit, die in das soteriologische Geschehen einmündet und die im krassen Gegensatz zu der negativ(istisch)en Endlosigkeit bzw. Ziellosigkeit der "ewigen" geheimnisvollen Fernen und zu der dekadenten Irrealisierung und Annihilierung steht. 2) Daraus resultiert: a) das Motiv der Ahnen(reihe) und des Heils (bzw. der Heilsgechichte), das in Svítáni na západĕ. insbesondere in Rannni modlitba (Das Morgengebet) und in Mytus duše (Der Mythos der Seele), einen wichtigen semantischen Ort hat;192 b) die prinzipielle Anderung in der Beziehung des dichterischen Ich zur Autorität des "Höchsten" ("Nejysšsi"). Diese bekundet sich vor allem darin, daß der "Höchste" nicht mehr - wie in der Phase des dekadenten Symbolismus - als 'Hüter' des "ewigen Geheimnisses" oder als Künstler-Gott (Uměni / Die Kunst, TD), sondern als Herr des erschaffenen kóouos und als (nahezu alttestamentlich) strenger Schöpfer begriffen wird, der über die Menschenwelt (nach seinem Plan) herrschet und sie zu einem Telos, zum Eschaton, führt.

Das erwähnte Thema der Heils-Geschichte deutet auf einen der gravierendsten Unterschiede zwischen dem gnostischen und dem christlichen Denken bzw. zwischen dem gnostischen Mythos und der monotheistischen Offenbarungsreligion hin: Während der gnostische Mythos den Weg der Seele mit all seinen Peripetien thematisiert, dessen Ziel die Einheit mit dem überweltlichen Gott darstellt, postuliert die monotheistische Offenbarungsreligion die Begegnung von Gott und Mensch nicht in der Natur, wie es im Mythos der Fall ist, sondern in der Heils-Geschichte. Die Bühne, auf der sich das gnostische Erlösungsdrama abspielt, ist das "Innen des Menschen", die rein mentale Sphăre: Seele, Geist usw. In der Offenbarungsreligion steht auf der einen Seite Gott als Schöpfer und auf der anderen die Welt und der Mensch in inr. 193 Signifikanterweise wird der "Höchste" in Svítáni na západẻ nicht n u r als Gott der elitären Künstler-Menschen,

allem in "Das Ich und das Es" (1923; in: S. Freud, Gesamtausgabe, Bd. 3, Frankfurt am Main 1980, S. 275-330) betont Freud den - man könnte vielleicht sagen - 'apophatischen' Charakter des Todes im Gegensatz zur 'Kataphatik' des Lebens: $\%$... wir mussen den Eindruck gewinnen, daß die Todestriebe im wesentlichen stumm sind und der Lărm des Lebens meist vom Eros ausgeht" (ibid., S. 313). Der Tod ist also eine 'stumme' Energie ("Energie des Todestriebs", vgl. "Das Unbehagen in der Kultur", a.a.O., S. 248), die in der Stille, in der Isolation und im Autismus ihre Domăne hat. In bezug auf die Irrealisierung-Semantik Błezinas dekadenten Symbolismus låßt sich diese Distinktion, was die 'Kataphatik' des Todes anlangt, mit zahlreichen Beispielen belegen. Die 'Stille'-'Stummheit'-'Gefangenschaft'-'Isolation'-'Kalte'-Tod' bilden (in TD) eine semantische Reihe. Ein charakteristisches Beispiel: "A ticho se kourilo z dálek, padalo s výš a príserné slavné / dusilo kroky" (Den v'́roćni I Der Gedenktag, III, 1-2, TD; "Und die Stille damptte aus den Fernen, sie fiel aus den Hōhen und grauenvoll ruhmreich / ließ sie die Schritte ersticken"). Oder; "a v klenbách

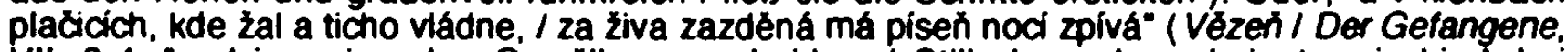
VII. 3-4; "und in weinenden Gewölben, wo Leid und Stille herrschen, / singt mein Lied, bei lebendigem Leib zugemauert. durch die Nacht"). Erich Fromm (The Heart of Man, New York 1964) nimmt zu der dualistischen Theorie Freuds eine kritische Haltung ein. Bereits vor Fromm waren es 2. B. C. G. Jung oder O. Fenichel, die diese Hypothese mit groBiter Skepsis betrachteten. Im Gegensatz zu Freud, der den Todestrieb als Bestandteil der normalen Biologie interpretiert, sieht Fromm in inm eine psychopathologische ("nekrophile") und sekundäre Erscheinung. wăhrend die "Biophilie" die primăre ist, weil die primăre und fundamentale Tendenz des Lebens die "Lebenserhaltung" ist. In der Sprache Błezinas: "Úcelem Zivota je vývoj, stoupáni do výse". (O. Błezina, Dopisy Anné Pammrové z let 1889-1905, Praha 1931, S. 165: "Der Zweck des Lebens ist die Entwicklung, der Aufstieg in die Hŏhe".) "Právé proto, že uméni tryská ze zdrojú, do nichż odráżeji se hvêzdy druhého nebe, je výsledni sugesci każdého velkého uméni zesileni żivota paprsky druhého slunce". (O. Bíezina, tajemné v uméni", in: O. Błezina, Eseje, Olomouc 1996, S. 10-11: "Gerade deshalb, weil die Kunst aus Quellen hervorspritzt, in denen sich die Sterne des anderen Himmels spiegeln, ist die resultierende Suggestion jeder großen Kunst eine Stărkung des Lebens durch die Strahlen der anderen Sonne-) "Krása je kvèt z płebytku stoupajićno żivota. popieni smrti". (O. Błezina, .Smysi boje", in: Eseje, Olomouc 1996, S. 80-81; "Die Schónheit ist die Blüte aus der Übertülle des steigenden Lebens, eine Leugnung des Todes").

192 Vgl. auch: Legenda tajemné viny (Die Legende der geheimnisvollen Schuld) und Żalm ke cti nejussíno Jména (Der Psalm zu Ehren des hochsten Namens).

$193 \mathrm{Vgl}$. dazu die aufschlußreiche Darlegung von Jacob Taubes, „Der dogmatische Mythos der Gnosis", in: Terror und Spiel. Probleme der Mythenrezeption, hrsg. v. M. Fuhrmann, München 1971. S. 148ff. 
sondern als Gott a II e r apostrophiert, dessen Diener a II e sind: "Všichni viditelni a neviditelni služebnici vyšli na souvratě tvé" (Ranni modlitba / Das Morgengebet, V. 18; "Alle sichtbaren und unsichtbaren Diener gingen hin auf deine Gewande"). Die quasi persönliche, egoistische Du-lch-Beziehung wird nun zur Du-Wir-Beziehung umgepolt. Dieses Verständnis der Autorität des "Höchsten" und seines eschatologichen Plans signalisient die Umwertung des radikalen Nihilismus und Solipsismus solcher Gedichte wie Modlitba vecerni (Das Abendgeben. Vězeñ (Der Gefangene) oder Snad potom... (Vielleicht dann...), in denen die Lebenswelt als Gefängnis negiert wird. Auch wenn in Legenda tajemné viny (Die Legende der geheimnisvollen Schuld) der "Jemand" (II, 2) als Gestalt eines bösen Schöpfers (eines Antipoden des biblischen Schöpfers) - "ein gnostisches Symbol ersten Ranges “194 - erscheint, dominiert in Svítáni na západẻ das Bild des "Höchsten" als des wahren S chö p fers dieser Welt (Ranni modlitba / Das Morgengebet, V. 17, 71-73; Vino silných / Der Wein der Starken, V. 12). Diese Vorstellung fußt auf dem christlichen Kerygma und stellt - wie im Zusammenhang mit der Semantik und Axiologie des nächsten Zyklus Vètry od polú (Polanwinde) noch ausführlich dargelegt wird - einen Gegensatz zur Gnosis dar. ${ }^{195}$

Die gnostische Ablehnung der Welt, inre radikale Verwerfung als unvollkommene Nachmachung oder Fälschung, ein "kennzeichnendes Thema der Gnosis", 196 das gewisse Kongruenzen mit dem Irrealisierung-Prinzip von Tajemnè dálky aufweist, scheint in Svitáni na západẻ keine Parallele zu haben. Das charakteristisch gnostische Motiv der Befreiung der Seele (durch den Tod) aus dem Gefängnis des Leibes (d. h. der physischen Welt) und ihre Rückkehr in ihre 'Lichtheimat', wird zwar auch in Svitáni na západẻ aktualisiert, am deutlichsten wohl im Titelgedicht, es läßt sich allerdings nicht übersehen, daß die irdische Existenz, der "irdische Traum" ("sen zemský". Svítáni na západẻ, IV, 4), dabei nicht (d. h. nicht mehr wie in TD) als 'nieder'und profaniert, sondern im Gegenteil als Voraussetzung für den ascensus und die Integrität der eigenen Identität (Vladari snü) Die Herrscher der Träume) revalorisiert wird. Aus diesen Beispielen geht hervor, daß die Tradition des gnostischen Denkens in Svitáni na západè in einem deutlich ambivalenten Licht erscheint. Mit kaum zu überbietender Prägnanz kommt diese Ambivalenz im Schlüsselgedicht Ranni modlitba (Das Morgengeben zur Geltung. Einer der Hauptgedanken der Gnosis und eines ihrer Hauptziele, die Erlösung als Selbsterkenntnis, in der sich die Vereinigung des Selbst mit dem Götlichen realisiert, wird in Ranni modlitba (IV. Sujetsequenz, V. 61-86) zunächst beinahe offensiv angestrebt, dann aber - in der gleichen Sujetsequenz - demütig aufgegeben. Es sind nun vor allem die Anerkennung der Autorität Gottes als Weltschöpfer und Herrscher, die (in der Gnosis verkannte) Bedeutung der Lebens- und Menschenwelt als kdofuos, ${ }^{197}$ die teleologische Orientierung auf ein Eschaton hin, die den Glauben an das christliche Kerygma voraussetzt, die die Interpretation des gnostischen Modells Br̈ezinas eschatologischen Symbolismus problematisieren. Und dennoch ist die Bezeichnung g n o s ti s ch - eschatologisches Modell, im Hinblick auf die schöpferische Entwicklung Brezinas, wie diese in Svitáni na západè zutage tritt, durchaus berechtigt und treffend. Nach den contra-Argumenten sollen im weiteren die pro-Argumente genannt werden.

Die Einheit, das dominante und konstitutive Prinzip der ganzen nachdekadenten schöpferischen Entwicklung Br̈ezinas, soll in Svitáni na západé durch gnostische 'Mittel'

$194 \mathrm{Vgl}$. H. Jonas. .Typologische und historische Abgrenzung der Gnosis", in: Gnosis und Gnostizismus, hrsg. v. K. Rudolph, Darmstadt 1975, S. 634.

$195 \mathrm{Vgl}$. R. Bultmann. Theologie des Neuen Testaments [6. Aufl.], Tübingen 1968, S. $171 \mathrm{ff}$. Eine andere, sehr wesentiche Differenz resultiert daraus, daß Gnosis die Jesu Fieisch und Blut für einen "Scheinleib" erklärt und die Gestalt des Erlösers vom geschichtlichen Menschen Jesu konsequent unterscheidet. Für die echte Menschheit Christi kämpften, wie R. Bultmann austührt, erst die christlichen Gnostiker (1. Joh. 2. 22; 4. 2; 5; 2. Joh. 7. u. a).

196 Vgl. H. Jonas: "Typologische und historische Abgrenzung der Gnosis", in: Gnosis und Gnostizismus, hrsg. v. K. Rudolph, Darmstadt 1975, S. 635.

197 In Ranni modlitba (Das Morgengebet) heißt es: "Zpivati budu tvé dẻjiny. jeż v dušich mrtvych národủ jásaly zárenim dneška / a v dušich živých neznámým jazykem budoucna mluvi" (V. 68-69; "Deine Geschichte will ich singen, die in Seele toter Völker jauchzte als strahlendes Heute / und in den Seelen der Lebenden spricht mit der unbekannten Sprache der Zukunft"). Die Vorstellung, daß das Zukünftigsein der menschlichen Existenz in ihrer Geschichtlichkeit gründet, wäre in der Gnosis undenkbar. 
erreicht werden. Darunter ist in erster Linie das Streben nach der Erkenntnis der Schöpfungen des "Höchsten" und deren Geheimnisse zu verstehen. In bezug auf die metapoetischen Aspekte geht es in Svítáni na západẻ auch um die (postulierte) Erkenntnis der eigenen schópferischen Entwicklung, der neuen Wege und des (in einigen Gedichten noch nicht bekannten) Zieles. ${ }^{198} \mathrm{~lm}$ wörtlichen Sinne, d. $\mathrm{h}$. als "Erkenntnis" ( $r v \bar{\omega} \sigma \imath \varsigma)$ oder "Wissen", kann "Gnosis" als der Schlüsselbegriff des gnostisch-eschatologischen Modells gelten, wobei die gnostischen Vorstellungen in Svítáni na západé mit der pneumatischen Tradition der Gnosis bzw. des gnostischen Pneumatikertums, eng zusammenhängen. Die charakteristische Vorstellung der gnostischen Mythik von der Einheit, zu der alle aus der (immanenten) Welt ausgegrenzten Pneumatiker 'unter sich' verbunden sind, nimmt in den zentralen Texten von SZ eine hochrelevante Position ein. In Vino silných (Der Wein der Starken) wird sogar eine Gemeinde der gnostisierenden Pneumatiker kreiert, die mit wunderbarer Kraft begabt und von den "Gesetzen der Erde" befreit, auf ihre Erkenntnis stolz sind. Die Pneumatiker sind sich ihrer Erlösung sicher, denn sie besitzen die absolute Erkenntnis. Mit dem gnostischen Pneuma-Mythos kommt auch ein anderes pro-Argument ins Spiel: Die (Fort-)Wirkung des mythischen Substrats als 'Erbe' der in der Phase des dekadenten Symbolismus stark ausgeprägten, ja dominanten mythogen-archaischen Schicht des Denkens. In diesem Zusammenhang bedürfen zwei Begriffe einer noch ausführlicheren Erwăgung: mythologische Gnosis und christliche Gnosis.

Der Bultmann- und Heidegger-Schüler Hans Jonas, der der Erforschung und Darstellung des (u. a.) mythologischen Charakters der Gnosis seine bahnbrechende Monographie Gnosis und spätantiker Geist (Bd. 1, 1934, Bd. 2,1, 1954) gewidmet hat. betont, die mythologische Form gehöre zur Natur des Gnostizismus, sie sei seine Substanz. Der Mythos sei vorherrschend, weil er sich selbst als Werkzeug der Erlösung verstehe. Als typisch sukzessive Stadien des gnostischen Mythos nennt $H$. Jonas die Lehre von der göttlichen Transzendenz und ihrer ursprünglichen Reinheit, die Entstehung der Welt, die entscheidenden Episoden des Dramas (die Erschaffung des Menschen) und schließlich die Erlösung des Menschen, die die definitive Auflösung des kosmischen Systems mit einbezieht und somit zum Werkzeug der Selbsterlösung Gottes wird. ${ }^{199}$ Auch der gnostische Mythos hat seine Gestalten: Götter, Heroen, Archonten, Äonen usw. Zu seinen wichtigsten Motiven gehören die Entweltlichung durch die Erkenntnis, die Stimme und der Ruf von Jenseits, die den in der Unwissenheit Verharrenden zum Bewußtsein erwecken, der Aufstieg sowie die reichgegliederte Symbolik der Bewegung, das Fallen, Sinken, Geworfen- und Erhöhtwerden, das Aufsteigen usw., die den gnostischen Mythos, in dem der Gnostiker seine Situation und sein Schicksal erfährt, dramatisieren. Laut $H$. Jonas fällt die Gnosis - grob gesprochen - zeitlich mit den Anfängen des Christentums zusammen und durch eine rege gegenseitige Beeinflussung weist sie auch Berührungspunkte mit ihm auf. 200 Der Kirchenhistoriker Adolf von Harnack legt in seinem Lehrbuch der Dogmengeschichte (1886) die berühmt gewordene Definition der Gnosis

198 Dabei geht es, wie schon gesagt, auch um die Erkenntnis der dekadenten Schaffensphase als einer 'Fremdbestimmung' (Slyšim v duši I lch höre in der Seele, Mé dédictvi položil's... I Mein Erbe legtets du...) sowie um die Erkenntnis, daß die dekadente Phase zwar eine Voraussetzung für die künftige positive und die Einheit anstrebende Entwicklung (Mytus duše / Der Mythus der Seele, Víno silnych / Der Wein der Starken) bedeutete, aber dennoch eine Phase der Vereinsamung, Isolation (Tys nešla / Du kamst nicht, Nêmé setkáni I Die stumme Begegnung) und der Irrealisierung. Destruktion und des Untergangs (Podobná noci / Der Nacht ăhnlich, Aż sedneš za müj stül... I Wenn du an meinen Tisch dich setzt..., Vitézná piseri / Das siegreiche Lied) war.

$199 \mathrm{Vgl}$. H. Jonas, "Typologische und historische Abgrenzung der Gnosis", in: Gnosis und Gnostizismus, hrsg. v. K. Rudolph, Darmstadt 1975, S. $630 \mathrm{ff}$. Die Jonassche Interpretation der Gnosis fuBt bekanntlich auf der existential-ontologischen Analytik, die die gnostische Grundhattung als eine Art Synthese zwischen persischer und platonischer Vorstellung betrachtet (vgl. H. Jonas, Gnosis und spätantiker Geist I, Göttingen 1964, S. 47, Anm. 1). Laut H. Jonas resultieren die hauptsächlichen Wesenszüge der Gnosis aus bestimmten Ideen bzw. Religionen (Platonismus, Zoroastrismus, Judentum), deren Synthese "das ganz Neue in der Gnosis" ausmacht, nämlich eine dahinterliegende antroposophische und antikosmische 'Daseinshaltung' (H. Jonas, a.a.O., S. 80). Die Gnosis stellt also eine ausgesprochen synkretistische Religion dar, deren Wesenszüge von den anderen Religionen ableitbar sind.

$200 \mathrm{Vgl}$. H. Jonas, .Typologische und historische Abgrenzung der Gnosis", in: Gnosis und Gnostizismus, hrsg. v. K. Rudolph, Darmstadt 1975, S. 643. 
vor, die eine tiefgreifende Reaktion ausgelöst hat und die die Problematik der christlich en Gnosis tangiert:

-Der grosse Unterschied hier ld. h. zwischen dem Christentum der katholischen und dem der gnostischen Prägung; Anm. J.V.] besteht aber wesentlich darin, dass sich in den gnostischen Bildungen die acute Verweltlichung, resp. Hellenisierung des Christenthums darstelt (mit Verwerfung des A. T.), in dem katholischen System dagegen eine allmählich gewordene (mit Conservienung des A. T.)". 201

Es erhebt sich die Frage, ob man von einer Opposition mythologische vs. christliche Gnosis sprechen kann. R. Bultmann stellt die Einflüsse des gnostischen Denkens sowohl im Rahmen des Urchristentums (die Lehre von der "Selbstentfremdung" aus dem WeltGefängnis des einsamen Menschen, die Erlösung von den Mächten dieser Welt durch die "Entweltlichung" usw.), 202 als auch in der paulinischen (der von Paulus zitierte und kommentierte Christus-Hymnus der hellenistischen Gemeinde; Phil. 2, 6-11; die Korintherbriefe) und in der johanneischen Theologie (die gnostische Anthropologie der johanneischen Christologie) fest. Den Einfluß des gnostischen Denkens, des gnostischen Mythos und seiner Begrifflichkeit auf das christliche Denken, sieht Bultmann in mehreren Aspeketen, die er in seiner Theologie des Neuen Testaments203 ausführlich erörtert und interpretiert (so z. B. die begriffliche Entwicklung des eschatologischen Dualismus, die Situation des Menschen in der Welt, die Vorstellung vom Heilsgeschehen, den ursprünglich gnostischen Gedanken von der Einheit usw.). Die dualistische Erscheinungsweise des gnostischen Denkens im Neuen Testament bezeichnet Bultmann einerseits als Christianisierung der Gnosis, andererseits als Gnostisierung des Christentums. Das Resultat beider Prozesse stellt a) die Kanonisierung des Christentums zu einer rechtgläubigen Kirche, b) die Eliminierung des Gnostizismus als einer Hăresie dar. Daher bekundet sich die Gnosis im Neuen Testament als eine "innerchristliche Erscheinung". ${ }^{204}$ Es läßt sich nun sagen, daß der Begriff der $\mathrm{ch}$ ris $\mathrm{tl}$ i ch en Gnosis nicht unbedingt einen Gegenbegriff zu der $m$ y th o $\mathrm{log}$ i s $\mathrm{ch}$ e $\mathrm{n}$ Gnosis bedeutet, weil - wie schon gesagt - der Mythos prinzipiell die Substanz der Gnosis darstellt und weil bestimmte Motive des gnostischen Mythos auch im Denken des Christentums in modifizierter Form weiter wirkten.205 Die Auffassung der Gnosis als eine ("merkwürdige") Formation des Spätplatonismus und die Auffassung des Christentums als ein Gebilde 250.

$201 \mathrm{Vgl}$. Adolf von Harnack, Lehrbuch der Dogmengeschichte I. [5. Aufl.] Tübingen 1931, S

$202 \mathrm{Vgl}$. R. Bultmann, Das Urchristentum im Rahmen der antiken Religionen, Zürich 1949. S. 184. Vgl. auch: Ders., Theologie des Neven Testaments, [6. Aufl.] Tübingen 1968, S. $175 \mathrm{ft}$.

203 Vgl. a.a.O., S. $175 f$.

204 Vgl. a.a.O., S. 174.

205 Einige Gnosistorscher betrachten die gnostische Bewegung direkt als eine Verbindung des Christentums mit philosophischen und religiósen Ideen seiner Umwett. So Z. B. der Hegelianer F. Ch Baur in seiner Monographie Christliche Gnosis oder die christliche Religionsphilosophie in ihrer geschichttichen Entwicklung. Tübingen 1835 (Nachdruck 1967), ferner der oben zitierte Kirchenhistoriker Adolf von Harnack oder der Englānder F. C. Burkitt, der den Kern des Vermischungscharakters (der Gnosis) im Christentum sieht (vgl. seine Arbeit Church and Gnosis, Cambridge 1932). Ein interessantes zweistufiges Konstitutionsmodell des gnostischen Denkens schlägt der tschechische Gnosisforscher Petr Pokorny vor. Nach seiner These erscheint die Gnosis als Produkt einer Synthese der "biblischen Welt" mit dem "orientalischen, spiritualistischen Synkretismus", wobei der Vermischungsprozeß sich in zwei Etappen realisierte: 1) Durch die Vereinigung des alttestamentlichen Ideengutes mit dem Synkretismus entstand die außerchristliche Gnosis, 2) aus deren Vereinigung mit der christlichen biblischen Welt hingegen die "klassische" Gnosis hervorging (vgl. P. Pokorny, .Die gnostischen Richtungen", in: Communio Viatorum, 5, 1962, S. 24ff.). Allerdings betrachtet Pokorny die Gnosis als einen "wirklichen Antipoden des Christentums", da im Christentum der eschatologisch orientierte Inkarnationsglaube den gnostischen Schicksalsmythus überwindet und (den Glaubenden) eine konkrete Hoffnung auf 'eschatologische Zukunft' eröffnet (vgl. P. Pokorný, Der Ursprung der Gnosis", in: Gnosis und Gnostizismus, hrsg. v. K. Rudolph, Darmstadt 1975, S. 766f.) Nach der Meinung anderer Forscher, wie 2.8. 8.C. Schneider, gehört die gnostische Bewegung "in die Geschichte des Spätplatonismus als eine seiner Abzweigungen, allerdings eine sehr merkwürdige". Schneider definiert den "Geist" der Gnosis als "nur griechisch, und zwar vorwiegend platonisch". ImChristentum selbst sieht er lediglich eine Vollendungsstufe griechischer religiöser Impulse. C. Schneider, Geistesgeschichte des Antiken Christentums I, München 1954, S. 268. 
griechischen Geistes scheint in bezug auf Bïezinas Werk von besonderer Relevanz zu sein, denn Biezina äußert sich zu dieser Problematik wie folgt:

"Církev katolická je vastnẻ pokracovánim starovékě, odvěké Pravdy, dẽoiěkou a dovršitelkou všeliđské kultury, která mẻla svou cestu z Egypta do Asie, z Asie do Recka, z Reecka do Řima. Prvni svati Otcové vycházeli z Platona a z Novoplatonikú". I...I "Katolicism byl pripraven łeckou gnosi filosoficky a rimským imperiem politicky". ("Philosophisch wurde der Katholizismus durch die griechische Gnosis, politisch durch das römische Imperium vorbereitet". I... rDie katholische Kirche ist eigentlich die Fortsetzung der altertümlichen, ewigen Wahrheit, die Erbin und Vollenderin der allgemein menschlichen Kultur, deren Weg von Ägypten nach Asien, von Asien nach Griechenland, von Griechenland nach Rom führte. Die ersten heiligen Väter gingen von Plato und von den Neoplatonikem aus".). 206

Was ergibt sich nun aus dem oben Gesagten für die Untersuchung der Spuren des gnostischen (mythischen) Denkens im Br̈ezinas eschatologischen Symbolismus? Da Brezina in seiner Korrespondenz keine konkreten gnostisch-hermetischen Quellen erwähnt, 207 muß man wohl in erster Linie von seiner 'gnostisierenden' Lektüre des Neuen Testaments ausgehen. Dafür spricht auch der Umstand, daß die gnostischen Vorstellungen in den Gedichten von Svitáni na západè (wie noch zu zeigen sein wird) im christlichen 'Gewand' bzw. durch das Prisma des christlichen Denkens entfaltet werden. Es ist vor allem die eschatologische Orientierung des nachdekadenten Symbolismus Bỉezinas und die damit zusammenhängende, in seinen späteren Gedichten stets deutlicher manifeste "Sozialität" des christlichen Glaubens, 208 die, wie P. Pokorný prägnant formuliert, den wahren Gegensatz zur Gnosis darstelit, denn: "Das Christentum hat nicht nur die Erlösung aus der Welt, sondern vor allem eine Erlösung mit der (wohl verwandelten) Welt verkündigt". 209

Eine in der bisherigen Bïezina-Forschung noch offene Frage bleibt die Religiosität des gnostisch-eschatologischen Modells von Svitáni na západé. Es geht darum, die religiöse Basis, auf der sich Brezina in $S Z$ befindet, genauer zu definieren. Es ist sehr wahrscheinlich, daß die Freundschaft mit den Initiatoren der Katholischen Moderne, vor allem mit dem Priester, Dichter und Redakteur Sigismund Bouska, der in Nový Zivot (1896) einen Essay über Březina publizierte, für die nachdekadente schöpferische Entwicklung Březinas nicht ohne Bedeutung war. ${ }^{210}$ Selbst wenn Bỉezina in seiner

\section{Zit. nach: J. Demi, Mé svédectvi o Otokaru Br̈ezinovi, Praha 1931, S. 429, 469.}

207 Mit den wichtigen Quellen der Gnosisforschung (die Schriften der Hăresiologen, der Apologeten des Christentums, Adversus haereses von Irenäus von Lyon, Corpus hermeticum. De praescriptione haereticorum von Tertullian u. a.) konnte Brezina in der Klosterbibliothek in Nová Ríse (Neureisch) in Berūhrung kommen. Diese Annahme unterstützt Błezina in einem Brief (vom 15. XI. 1896) an Anna Pammrová: "Nepovídám, že studium nékterých dẻl starých literatur a

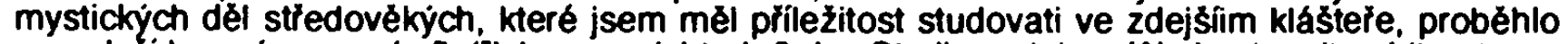
mou dusi bez významu I... . ("Ich sage nicht, daB das Studium einiger Werke der alten Literaturen und der mystischen Werke des Mittelalters, zu deren Studium ich im hiesigen Kloster die Gelegenheit hatte, durch meine Seele ohne Bedeutung durchlief $I . . . r$ ).

208 An dieser Stelle verweise ich lediglich auf die auffallende Dominanz der pluralischen Terme "my" I "wir". "vy" I "ihr" und der unstrukturierten Kollektiva "všichni" I "alle", "nesčisıné" I "ungezählte" usw. in Brezinas Gedichten der nachdekadenten Schaftensphase

209 P. Pokorny, .Der sozjale Hintergnund der Gnosis", in: Gnosis und Neves Testament, hrsg. v. K.-W. Tröger, Berlin 1973, S. 84.

210 Auf Bouškas Wunsch verfaßte Błezina (in einem Brief an Bouska, Juni 1896) auch eigene Interpretation des gesamten Gedichtzyklus Svitáni na západé (abgedruckt in: $M$. Cervenka, Bł́ezinúv výklad Svitáni na západé", in: M. Cervenka, Styl a význam, Praha 1991. S. 32-46). Cervenka weist nach, daB Biezina in seiner Autointerpretation 1) eines der zentralen Motive seines bisherigen dichterischen Schaffens, den Tod, verdrängt, 2) daß aber die in der Autointerpretation vertretene "ǎsthetische Haltung", die Akzentuierung des kosmischen Optimismus und der siegreichen Spiritualităt mit der Semantik von SZ kollidiert. Diese Kollision resultient $u$. a. daraus, daB Bỉezina mit seiner Autointerpretation gerade zu dem Zeitpunkt beschäftigt war, zu dem er auch einige neue Gedichte abfaßte, die bereits neue Aspekte, nämlich die Theo-Logisierung und die Spiritualisierung der im dritten Gedichtzyklus vêtry od pólú (Polarwinde, 1897) konstituierten poetischen Welt, ins Spiel bringen. Diese Tendenz hängt offensichtlich mit Bỉezinas Annảherung an die von Katolická Moderna repräsentierten religiōsen, philosophischen und ästhetischen Positionen zusammen. Daß eines der Schlüsselgedichte des dritten Zyklus, Královna nadéji (Die Königin der Hoffnungen), gerade in Bouskas Revue Nový żivot 
Korrespondenz mit Bouška aus dieser Zeit stets seine Position außerhalb der orthodoxen Kirchenlehre betonte, stand er dem Programm der Revue Nový zivot sehr nahe ${ }^{211}$ Es läßt sich sagen, daß die Religiosität Br̈ezinas eschatologischen Symbolismus vor allem darin gründet, daß die Orientierung auf ein Eschaton hin notwendigerweise das (positive) "religio", den Glauben, voraussetzt, der vom Tod und von der vergehenden Welt befreit. Es scheint, daß die Religiosität des gnostisch-eschatologischen Modells weder negativ (im Sinne der "negativen" hermetischen Gnosis, wie in der Phase des dekadenten Symbolismus) noch orthodox, sondern vielmehr heterodox bzw. 'inoffiziell' ist. Dieser 'Noch-nicht'-Standpunkt erklärt auch, warum Bỉezina seine eigene Interpretation von Suítáni na západé als "vage, zu allgemein formuliert" ("vágni, príliš všeobecné pojatou") 212 charakterisiert. Darüber hinaus koinzidiert der 'Noch-nicht'-Standpunkt auch mit der metadekadenten Semantik des Suchens des neuen Weges, der von der negativen gnostischen Hermetik des dekadenten Zyklus Tajemné dálky zur positiven Theologie des dritten Zyklus Vètry od pólü (Polarwinde, 1897) führt.

Mit dieser Entwicklung geht bei Bïezina Hand in Hand auch der Rückgriff auf die Formen und die Gattungspoetik der r e l i g i ö s e n Rede. Diese Tendenz signalisiert die immer dominantere Position des freien (vers libre) oder gelockerten (vers liberé) Verses in Svitáni na západè. ${ }^{213}$ Im freien Vers sind die Schlüsselgedichte des Zyklus (Ranni modlitba I Das Morgengebet, Mythus duše / Der Mythos der Seele, Vladari snù / Die Herrscher der Träume, Vitézná piseñ I Das siegreiche Lied, Vino silných I Der Wein der Starken) abgefaßt. ${ }^{214}$ Die Lockerung des Verssystems und die daraus resultierende Dekomposition des traditionellen Reimes, $d . h$. die Abwendung von dem maßgebenden Metrum des dekadenten Symbolismus, dem Alexandriner, mit seiner fixen Silbenzahl, die die Auswahl der Lexika limitiert, war für Bïezina offensichtlich die Voraussetzung dafür. die Poetik und Rhetorik der religiösen Rede215 innovativ zur Geltung zu bringen. Welche Gattungen der religiösen Rede aktualisiert Bïezina in seinem Werk?

zum ersten Mal abgedruckt wurde, scheint diese Annahme zu unterstützen. Cervenka deutet darauf hin, daß die Autointerpretation eine ganze Serie von Dichotomien strukturiert, die sich auf die von Bỉezina erwähnten "zwei Gedankenströme" ("pomèr lidské duß̌e k věćnému tajemstvi" I "die Beziehung der menschlichen Seele zum ewigenn Geheimnis" und "piesvédženi o mystickém urceni bolesti jako nástroje vyšši ekonomie" / "die Überzeugung von der mystischen Bestimmung des Schmerzes als einem Werkzeug der höheren Okonomie') in Svitáni na západé beziehen: 'niedriger' - 'hōherer', 'passiv' - 'aktiv', 'irdisch' - 'überirdisch', 'Vergangenheit' - 'Zukunft' usw.

211 Bouska war nicht nur mit den prominenten Persönlichkeiten des Prager Kultur-Lebens der neunziger Jahre, mit J. Zeyer, F. X. Salda U. a., befreundet, sondern pflegte auch persönliche Kontakte mit bedeutenden Künstlerpersönlichkeiten der westeuropäischen Moderne, Z. B. mit Maurice Maeterlinck. Vgl. hierzu: Vlidné setkáni. Vzájemná korespondence Otokara Bíeziny a Sigismunda Bousky, hrsg. M. Cervenka a P. Holman. Olomouc 1996.

212 Zit. nach: M. Cervenka. Bíezinưv výklad Svitáni na Západè". vgl. a.a.O., S 33. Die Freunde Bỉezinas aus der Revue Nový Żivot hatten keine Probleme damit, Svitáni na zapadé als ein der orthodoxen Kirchenlehre sehr nahe stehendes Werk zu rezipieren und zu interpretieren. und zwar deshalb nicht, weil die Autointerpretation Biezinas gerade in dieser Hinsicht so allgemein formuliert ist, daß man sie problemlos auch im Sinne der offiziellen Kirchenlehre verstehen konnte.

213 Zur Charakteristik des vers libéré ("verš uvolněnÿ") in der tschechischen symbolistischen Lyrik vgl. M. Cervenka, Z vecerni skoly versologie II. Praha 1991. S. 41f. Vgl. auch: Ders., .Bł̉ezinuv vers", in: Ceská literatura, 13, 1965, S. 113.145. Zur Funktion des vers libéré im Symbolismus vgl. auch: F. Rinner, Modellbildungen im Symbolismus. Ein Beitrag zur Methodik der Literaturwissenschaft. Heidelberg 1989, S. $227 \mathrm{ff}$. Zu den signifikanten Merkmalen des vers libéré gehört. daß seine innere metrische Struktur zwar aufgelöst (z. B. die Zäsur oder die verbindliche Silbenzahl), die strophische Gliederung und der Reim dagegen berücksichtigt werden. Unreine oder umschlungene Reime, Assonanzen. Enjambement, Wortkombinatorik und Ablehnung jeglicher metrischen Klischees machen seine Spezifika aus. Das Ziel ist die Hervorrufung des Eindruckes der gesprochenen Sprache sowie grőßere Originalität und Suggestivităt des Verses.

214 Im freien Vers von Bỉezina erkennt $M$. Cervenka ( $Z$ vecerni školy versologie I, Praha 1991. S. 59ff.) deutliche Allusionen auf den antiken Vers (an klassischen Hexameter). $\mathrm{Zu}$ seinen Merkmalen gehören, laut Cervenka, neben den langen Sequenzen auch seine starke daktylische Tendenz, seine große semantische Wirkungskraft und gewisse Monotonie in der Intonation.

215 Die Dimension der religiösen Sprache bei Biezina, genauer gesagt, das hymnische und das konfessorische Element seiner Gebetssprache, wurde bisher lediglich als eines der formästhetischen Elemente seines Werkes oder als eines der allgemeinen Merkmale der symbolistischen Lyrik interpretiert. Vgl. M. Cervenka, .Błezinùv vers", in: a.a.O., S. 136. 
Es ist vor allem das "Gebet" ("modlitba": Modlitba vecerni / Das Abendgebet, TD; Ranni modlitba / Das Morgengebet, SZ; Modlitba za neprátele / Gebet für die Feinde, VP). Das Wesen der (ursprünglichen) Gebetssituation, die "Bitte" um Gottes Wort in "äußerlichem" Reden in der Not, d. $h$. die individuelle Form der Kommunikation des Ich mit Gott, ist auch für Bïezinas "Gebete" des eschatologischen Symbolismus von großer Relevanz. Auf dieses grundlegende Gebetselement, auf die Anrede, stützt sich auch bei Br̈ezina die Semantik seiner Gebetssprache. Die Auseinandersetzung mit dem unfaßbaren Gegenüber (mit dem "Höchsten", "Ewigen", "Allgegenwärtigen", mit dem "Vater des Ungeborenen" usw.), mit dem "unvergleichlichen Partner". kann als die grundlegende interpersonale Kommunikationsform aller Schlüsselgedichte Br̈ezinas betrachtet werden. Durch die postulierte (spannungsvolle) Einheit von Gott und Mensch, die die Dichtung in sich sprachlich realisient, erreicht diese den Rang der "Theo-Logie" (bzw. der "Dichter-Thoologie"). 216

Neben dem "Gebet" ist es der "Psalm" ("Zalm"), den Bỉezina im System seines eschatologischen Symbolismus aktualisiert (Zalm ke cti nejušš́ho Jména / Der Psalm zu Ehren des höchsten Namens, SZ; Zalm odcházejicich pokoleni I Der Psalm der dahingehenden Generationen, letzte Gedichte). In bezug auf die Genretypologie der Psalmen kann man bei Bïezina vom elegischen Psalmen-Typus sprechen. 214 Im Hinblick auf die formalen Aspekte aktualisiert Blezina in seinen "Psalmen", in denen sich das dichterische Ich mit seinen Klagen an die Majestät des "Höchsten" oder an einen anderen Adressaten (Zalm odcházejicich pokoleni) oft in der Form eines Refrains wendet, die signifikanten stilistischen oder euphonischen Figuręn des Psalmes: Parallelismus, Refrain oder Anapher: "Ach, neodejít, vy trikráte Stastnil" (Zalm odcházejicich pokoleni, III, 11, 25. 31: "Ach, nicht fortzugehen, ihr dreimal Glücklichen!".). "Tvé jméno jsem vzkrikl /...". (Zalm ke cti nejusš́ího jména, I, 1; VI, 1; "Deinen Namen habe ich gerufen I... ${ }^{\prime}$ ). Im Gegensatz zu der elegischen Psalmodie aktualisiert Bïezina vor allem in seinem letzten vollendeten Gedichtzyklus Ruce (Hände, 1901) die chorische ('dionysische') Hymnik, um die Euphorie der rauschähnlichen vitalen Prozesse auszudrücken (Gedichte: Zpivaly horící hvẻzdy / Es sangen die brennenden Sterne, Kolozpév srdci I Der Rundgesang der Herzen, Dithyramb sưtü / Dithyrambus der Welten u. a.). 218

Eine andere Gattung der religiösen Rede, die sich Br̈ezina zunutze macht, ist die "Predigt" ("kázáni"). An eine (wohl aber verfremdete) eucharistische Predigt erinnert der Redemodus von Vino silných (Der Wein der Starken), z. T. auch der von Vladari snú (Die Herrscher der Träume, SZ) und von Láska (Die Liebe, VP). Doch so, wie die Funktion der

216 Vgl. H. Timm, .Die Botschaft hör ich wohl ... Dichter-Theologie nach der Aufklărung", in: Was aber bleibt, stiften die Dichter? Zur Dichter-Theologie der Goethezeit, hrsg. v. H. Timm u. a., München 1986, S. 19-36: "Darstellung sei «die beste Art von Gott zu denken «, meinte Klopstock. weil der Darsteller das, wofür er steht, leibhaftig inszeniert. /.../ Der Dichter des Heiligen müsse theodramatisch zu Werke gehen" (ibid., S. 32).

217 Das fragmentarische, erst postum erschienene Werk Zalmy (Die Psalmen) eines Dichterkollegen Bł̉ezinas, Karel Hlavácek (1874-1898), ist durch den für Bỉezina charakteristischen Psalmen-Typus eindeutig geprägt worden. Vgl. J. Mukar̉ovský, Pledmluva k vydáni Hlaváckových »Zalmú «", in: J. Mukarovský, Kapitoly z ceské poetiky, Bd. 2, Praha 1948, S. 219-234.

218 R. Leuenberger (.Die dichterische Dimension der Gebetssprache", in: Wirkungen hermeneutischer Theologie, hrsg. v. H. F. Geisser U. W. Monstert, Zürich 1983, S. 193 f.) verweist auf die Übertragung der hymnischen Gebetssprache auf weftliche Phănomene, vor allem auf die Natur, im Zusammenhang mit der Entwicklung des neuzeitlichen Naturverständnisses. Nach Leuenberger kann das (hymnische) Gebet zu einem Element der autonomen Naturbetrachtung (durch die Spractidimension der Anrede, indem die An-Sprache an Gott, an das Heilige und seine Attribute schlechthin, nun auf Welt übergeht) werden. Diese Beobachtung erweist sich als aufschlußreich im Zusammenhang mit der Semantik von Modlitba vecerni (Das Abendgebet. TD). wo die postulierte Erkenntnis zunăchst durch die Erforschung der Natur (und ihrer Phănomene) erreicht werden soll. Für die Entwicklung Bł̌ezinas Hymnik war offensichtlich auch die Rezeption der Hymnen Walt Whitmans von Bedeutung. In einem undatierten Brief (vom Herbst 1895?) schreibt Bỉezina an František Bauer: "Nakoupil jsem si anglických praci novějsí literatury a studuji dnes Walt Whitmana, velikého, originelního umélce, který hrimá v tvrdé, nemotorné stavêných veršich mocné hymny amerických jezer, prerii a pralesu". (O. Bíezina, Dopisy Frantisku Bauerovi, Praha 1929, S. 211; "Ich habe mir englische Werke der neueren Literatur gekauft und studiere heute Walt Whitman, einen großen, originellen Künstler, der in harten, ungeschickt gebauten Versen seine gewaltigen Hymnen der amerikanischen Seen, Prărien und Urwälder donnert".). 
Gebetssprache bei Brezina verfremdet wird (z. B. Modlitba večerni / Das Abendgebet, TD), wird auch die Funktion der Predigt verfremdet. Einige charakteristische Themen der Predigt (Aufforderung zum Einhalten einiger ethischer Grundsätze, Darstellung von Visionen des Heilsgeschehens mit Allusionen auf bestimmte Motive aus apostolischen Predigten, so z. B. in Láska, [VP] usw.) schwingen auch in Brezinas 'Iyrisierten' "Predigten" mit. Doch konzeptuell wie stilistisch weichen Br̈ezinas "Predigten" von dem 'klassischen' Predigtgenre - wie übrigens a l l e oben erwähnten Genres der religiösen Sprache - ab. Der Grund dafür liegt nicht (nur) in ihrer (gnostisch-)hermetischen Filiation vor allem in den Gedichten von Tajemné dálky und Svítáni na západè -, sondern und vor allem darin, daß sie durchaus bewußt inszeniert sind. Inre Perspektive ist die des expliziten Autors und expliziten Lesers, jedoch komplett vom impliziten Autor inszeniert. Jene Anpassung des Verses an den 'Bedarf' der religiösen Sprache geschieht bei Br̈ezina im Rahmen einer schöpferischen 'Erprobung' und Applikation neuer Möglichkeiten ausschließlich im Medium der Dichtkunst.

An dieser Stelle soll in Kürze noch ein anderer Genretypus der religiösen - aber nicht wie das Gebet oder die Predigt liturgischen - Rede angesprochen werden, der sich zur allegorischen Disputation entwickelte: Das sog. Streitgespräch (certamina oder altercationes), auf das auch Brezina (in modifizierter Form) in der nachdekadenten Schaffensphase zurückgreift. In seinen Gedichten handelt es sich um den geistigen Typus des Streitgesprächs zwischen Körper und Geist (bzw. Seele; Vitëzná piseñ I Das siegreiche Lied, SZ; Královna nadejji I Die Königin der Hoffnungen, VP; Télo I Der Körper, SCh). Die Dialogizität der Streitgespräche arrangiert Brezina meistens als Wechselbeziehung von Arede und Angeredetsein ("Vysuètli, duše má, I...l. Vitézá piseñ I Das siegreiche Lied, I, 1; "Erkläre, meine Seele, I... ( ) in einem Gespräch, in dem auch der Aspekt des Mithörens, des Performativen oder der inneren Zwiesprache eine wichtige Funktion innehat.219 Die Aktualisierung der Form des Streitgesprächs dient bei Brezina so z. B. in Vítézná piseñ (SZ) - zur Markierung der distanzierten Position des dichterischen Ich, das sich (bereits) auf dem Wege zum eschatologischen Symbolismus befindet, gegenüber der von seiner "Seele" vertretenen (immer noch) 'dekadenten' axiologischen Position.

Zusammenfassend lassen sich zwei Hauptfunktionen der religiösen Sprache im System des eschatologischen Symbolismus hervorheben: 1/ die s o te r i o- $10 \mathrm{~g}$ i s c h e Funktion, wobei das soteriologische Geschehen a) noetisch - Soteriologie als Modus der Erkenntnis - b) ethisch bzw. therapeutisch, d. $h$. nicht nur im Sinne des christologischeschatologischen Heils, sondern auch im Sinne der heilsamen 'Lebensbewältigung', orientiert ist (z. B. Ranni modlitba / Das Morgengebet, V. 30-60); 2/ die the ol o g i s che Funktion im Sinne der grundlegenden theologischen Arbeit, insbesondere jener der Gotteserkenntnis. Durch die religiöse Sprache, durch das Gebet, wird die Erkenntnis Gottes als des Vaters ermöglicht, so wie sich in der Gebetssprache des weltlichen Gedichts der Glaube an Gott "zur inneren Erfahrung von Welt"220 säkularisiert.221 Es muß aber noch einmal betont werden, daß die Hieratik Brezinas religiöser Sprache vom impliziten Autor in $\mathrm{s} z$ e $\mathrm{n}$ i e $\mathrm{r} \mathrm{t}$ ist. In diesem Sinne scheint auch die Aussage Bỉezinas in einem Brief (vom 20. VII. 1896) an Sigismund Bouska kennzeichnend zu sein: "Vsechny nejvyšsi myšlenky člověka jsou modlitbami". ("Alle höchsten Gedanken des Menschen sind Gebete").

Im Anschluß an die Überlegungen über die ästhetische Funktionalisierung verschiedener Gattungsformen religiöser Rede bei Br̈ezina soll nun die Frage nach dem obersten Organisationsprinzip der Semantik und Axiologie des eschatologischen Symbolismus aufgeworfen werden. Man kann vom Titel des Zyklus "Svítání na západe" 205.

219 Vgl. R. Leuenberger, „Die dichterische Dimension in der Gebetssprache", a.a.O., S. 191-

220 Vgl. ibid., S. 195.

221 -Vater! Das Wort will, wenn es im Denken und in der Sprache christlicher Menschen Gott bezeichnen soll. genau in dem Sinn gebraucht und verstanden sein, den es hier, im Introitus des Herrengebets hat: als Vokativ. Man kann und muß das geradezu als Grundregel zu seinem christlichen Gebrauch und Verständnis nennen. I.../ Es dart das [d. h. die Rede über Gott] /.../ nur so geschehen, daß die Funktion des Nominativs als Platzherr des Vokativs in Erinnerung bleibt und im näheren oder ferneren Zusammenhang auch der betreffenden Aussagesătze irgendwie kenntlich gemacht wird" Karl Barth, Die kirchliche Dogmatik, IV/4, Zollikon-Zürich, 1932, S. 79. 
ausgehehen. Dem Titel liegt eine oxymorale Fügung, eine Verbindung zweier Lexeme, zugrunde: "svitáni" ("Tagen", wörtl. "Sonnenaufgang") "na" ("im") "západē" ("Westen", wörtl. "Sonnenuntergang"). Auch im Falle dieses Oxymorons handelt es sich um eine semantische Figur, 222 zu deren charakteristischen Eigenschaften die Doppeldeutigkeit und der (manieriert) arrangierte Vexier- bzw. Spiegelbild-Charakter der "unähnlichen Ähnlichkeit" - genau auf diesem Prinzip basiert die Wirkung des oben erörterten Gedichts Mé dédictv' položil's...(Mein Erbe legtets du...) - gehören. Die Bedingung für die 'Wirkfähigkeit' eines Oxymorons ist es, daß die in inm verschränkten Extreme einander spiegeln und aneinander partizipieren. "Zwischen beiden entsteht ein 'gleitender' Sinn, eine semantische Schaukelbewegung, die zwischen dem positiven und dem negativen Konzept (Wert oder Kategorie) stattfindet" 223 Die Funktion des Oxymorons ist es, das Phänomen zu erfassen, das an beiden konträren Gliedern der Konstruktion als ein "versöhnendes Element"224 (d. h. als 'mitgedachtes' tertio) partizipiert. R. Lachmann verweist auf die hermetisch-mystische Tradition des Oxymorons, die es als eine rational nicht verifizierbare und paradoxe semantische Figur erscheinen läßt. 225 Eine mystische Vorstellung liegt zweifelsohne auch dem Titeloxymoron "Svítání na západè" zugrunde. Es stellt sich nun die Frage, ob diese Vorstellug eigentlich auf das gnostische oder auf das christliche Gedankengut zurückzuführen ist. Oder geht es in diesem Oxymoron vielleicht darum, zwei konkurierende Gedankengüter zu 'synthetisieren'?

Die Oxymoron-Semantik partizipient bereits an der Modellierung des in Tajemné dálky konstituierten poetischen Weltbildes. Es scheint, daß das Oxymoron - als Paradoxon - in $\mathrm{TD}^{226}$ einer anderen, periphrastischen Figur sehr nahe steht: dem Andynaton. Diese Figur soll durch Formulierungen, die das Ungewöhnliche, Irreale, Phantastische, Übernatürliche usw. konkretisieren, solche Erscheinungen und Erlebnisse umschreiben, die entweder niemals stattfinden könnten oder nie mehr, nie wieder stattfinden werden (bzw. können), weil sie nicht mehr präsent und erreichbar, sondern bereits irrealisiert, annihiliert oder nicht-mehr-seiend, entschwunden und absent sind und als solche vom lyrischen Ich beschwört werden. Und gerade im Erlebnis des Unrealisierbaren oder Nicht-MehrErreichbaren gründet der maximale ästhetische Genuß der irrealisierten Welt und der Wirklichkeit:

"I uvidè jsem ji, duši svou, I...I. // V závoji bilém a veselou, jak družicku v prưvodu pohrebním, I a štastnou, jak $v$ domé, kde oheh vypuki $v$ noci, dech spicich, / panenskou nevěstu $v$ modlitbách płede dnem svatebnim / nad loži umirajicich". (Návštéva / Der Besuch, TD, II, 1, III, 1-4; "Und so sah ich sie, meine Seele, I...I. II Im weißen Schleier und frohlich, wie Brautjungfer im Begräbniszug. I und glücklich, wie in einem Haus, in dem das Feuer in der Nacht ausbrach, der

222 Zur Funktion des Oxymorons vgl. die aufschlußreiche Darstellung von Renate Lachmann .Acumen-Tradition und Stilistik des Oxymorons bei Daniet Naborowski (Exkurs)", in: R. Lachmann, Die Zerstörung der schónen Rede. Rhetorische Tradition und Konzepte des Poetischen, München 1994, S. 135-147.

223 Ibid., S. 137. In der Blütezeit des Oxymorons, in der Epoche des Manierismus und Barock, kommen die 'oxymoronartigen' Verschränkungen, Vexierbilder, Spiegelungen oder Doppelungen, die starke Tendenz zur Verbindung der Extreme, zur Reversibilitắt mannigfacher Phănomene. kurzum die Tendenz zum geradezu ostentativen Anti-Naturalismus, auf die E. R. Hocke in seinem bekannten Manierismus-8uch hinweist (Manierismus in der Literatur, Reinbeck bei Hamburg 1959, S. 93), auch in der visuellen Kunst des Manierismus deutlich zur Geltung. Man denke an das antinaturalistische Kolorit, an die Künstlichkeit der Komposition mit beinahe krampthatten Verschränkungen der Extremitäten (Bilder von Bronzino, Tintoretto, El Greco, Spranger u. a.), an die Suche nach krassen Kontrasten und an den Synkretismus, an die Reversibilităt des Organischen und Anorganischen (die Leiber als Felsen, das Terrain als Wolken; Bilder von J. Patenier, die Körper-Amalgame von Arcimboldo) usw.

224 R. Lachmann, a.a.O., S. 136.

225 Ibid., S. 136.

226 "O smrti Živých têl, jiż noc se stává dnem" (Modlitba vecermil Das Abendgebet, 1, 1: "O Tod der lebendigen Leiber, durch den die Nacht zum Tage wird"). " $/ .$. / let mrtvých motylüv a kolotavé v̛̉ení / tisicú zhaslých životù ve zlaté lázni denni!" (Apostrofa podzimni / Die Herbstapostrophe, V. $15-16 ; \%$ toter Schmetterlinge Flug und wirbelnde Wallung / Tausender erloschner Leben im goldenen Bad des Tages!"). "/.../ v teskném nadšni" ( Vězeñ / Der Gefangene, VI, $1 ; \%$.. in wehmütiger Begeisterung") u. a. 
Atem der Schlafenden, I die jungfrăuliche Braut in Gebeten vor dem Hochzeitstag / über den Lagern der Sterbenden'). 227

In Tajemné dálky fungient das Oxymoron (bzw. das Andynaton), das im dekadenten Symbolismus Brezinas offensichtlich eine ontologische Bedeutung hat, als Figur der Irrealisierug. Wie aber fungiert das Oxymoron in Svitáni na západè? Die mystische Auslegung des Titeloxymorons ist bekannt; im Gesprăch mit dem Redakteur der Revue Noý Żivot, K. Dostál-Lutinov, bietet Br̉ezina seine eigene (autorisierte) Interpretation an:

Západ nás je smrt. Po smiti - na západé - nám teprve svítá vẻcnỳ den poznání a rozkoše života. /.../ den-zivot, slunečni zẩ - palčivá, únavná nejistota pozemského poznáni, zdánlivě tak jasného a płece celé svéty nám skrývajiciho. Noc - vyšši zále jiného żiti". ("Unser Sonnenuntergang ist der Tod. Erst nach dem Tod - im Sonnenuntergang [bzw. Westen; Anm. J.V.] - tagt für uns der ewige Tag der Erkenntnis und der Lebens Wonne. /.../Tag-Leben, Sonnenschein - brennende, ermüdende Unsicherheit der irdischen Erkenntnis, die scheinbar so klar ist und dennoch ganze Welten vor uns verhehlend". Die Nacht - der höhere Schein des anderen Lebens"). 228

Es lăßt sich kaum übersehen, daß im Titeloxymoron "Svítání na západē" die gnostische Symbolik mitschwingt. 229 Auf den ersten Blick ist das der radikale gnostische Dualismus der 'Zwei-Reiche-Lehre': Licht (Leben) - Finsternis (Tod); Pneuma - Hylë; Gnosis - Agnoia. Dieser Dualismus gilt in der Gnosis als unvereinbar. Im gnostischen Erlösungsdrama geht es um die Befreiung des Lichtfunken und seine Emporführung in die himmlische Lichtwelt. $230 \mathrm{Im}$ Titelgedicht Svitáni na západé fühnt der mystische Weg der Seele - paradoxerweise - in die Finsternis. Biezina neutralisiert den typisch gnostischen Dualismus 231 durch katachretische Verschränkung im Sinne der Integration des Lichts in die Finsternis nach dem paradoxen Prinzip der Präsenz in Absenz. Nach diesem Prinzip birgt das Negative das positive Gegenteil in sich. Für Biezina existiert nicht entweder das Licht oder die Finsternis, sondern das Licht in der Finsternis: die "strahlende Finsternis" ("záríci tma"; Víno silných / Der Wein der Starken, letzte Verszeile). Das scheint auch die Hauptfunktion des oxymoralen Organisationsprinzips Bïezinas eschatologischen Symbolismus zu sein: die Positivierung des Negativen. Die menschliche Welt, ja die Existenz des Menschen, ist eine seltsame Mischung von Licht und Finsternis. Mit dem Titeloxymoron "svítání na západe" hebt Bỉezina die Unvereinbarkeit der gnostischen Gegensätze auf; Licht und Finsternis existieren für inn in einer Wechselbeziehung. In der gnostischen Tradition wăre diese Vorstellung (noch bei Plotin) undenkbar, nicht aber in der (früh-)christlichen Tradition. Schon Dionysius Areopagita spricht (um 500) im Sinne

227 Vgl. auch das Gedicht Snad potom... (Vielleicht dann..., TD), vor allem Str. IV-VI. s. 0., Kap. 2.1.2.

228 O. Błezina, Básnické spisy, Gesamtausgabe des Werkes von O. B., Bd. I, hrsg. v. M. Hýsek. Praha 1933, S. 260-262. Ursprünglich in: Nový Zivot, 1, Nr. 6, 1896, S. 139-140). Brezina macht (im Brief vom 30. VI. 1896) seine Vertraute Anna Pammrová auf diese Interpretation aufmerksam: "V casopise katolické Modemy otištén rozhovor se mnou o jedné z básni Svitáni na Z." ("In der Zeitschrift der katholischen Moderne ist ein Interview mit mir über ein Gedicht aus Svitáni na Z. [ápadẻ] abgedruckt").

229 Dazu gehört auch die Vorstellung vom Körper (hyle) als Gefăngnis des Geistes (pneuma). die Błezina im gnostischen Sinne interpretient: "Horici trámovi vézeni naśeho s praskotem ohné sé láme" (I, 3; "Brennendes Gebălk unseres Gefăngnisses bricht mit Feuerprasseln zusammen"). Dazu die Deutung: "Télesné vêzeni se borti a otevirá rozhled do věčnosti" ("Das Körpergefăngnis bricht zusammen und es öffnet sich die Aussicht in die Ewigkeit"). O. Bł́ezina, Básnické spisy I. hrsg. M. Hýsek, Praha 1933, S. 260.

$230 \mathrm{Vgl}$. H. Jonas. "Typologische und historische Abgrenzung der Gnosis", in: Gnosis und Gnostizismus, hrsg. v. K. Rudolph, Darmstadt 1975, S. 627f.

231 In einem Brief (vom 25. IX. 1896) an A. Pammrová lehnt Błezina den (gnostischen) Dualismus zwischen Leib und Seele ausdrücklich und energisch ab: "Ne, dualistická teorie je abstrakce prilils hrubá, aby dovedla vystihnouti tisice tajemnỵch spojeni hmotného s psychickȳm, která ve svém souhrnu tvới naše dni a noci ve védomi". ("Nein, die dualistische Theorie ist eine allzu grobe Abstraktion, als daß sie Tausende geheimer Verbindungen des Materiellen mit dem Psychischen zu erfassen vermochte, die in ihrer Gesamtheit unsere Tage und Nảchte im Bewußtsein bilden"). Im gleichen Sinne auch in einem späteren Brief vom 4. VII. 1897: "Dualismus mezi têlem a duši je mi dánno płekonaná vẻc". ("Der Dualismus zwischen Leib und Seele ist für mich eine längst überwundene Sache“). O. Biezina, "Dva listy”, in: Wiener Slawistischer Almanach, 4, 1979, S. 211. 
seiner 'apophatischen Theologie', die sich der oxymoral-paradoxen Rhetorik bedient, von der "göttlichen Finsternis". 232 Der (gnostische) Weg ins absolute Licht auch ohne in die Dunkelheit zu schauen, das wäre die Absage an die Mannigfaltigkeit der Welt. Man muß in das Dunkel schauen, um lux in tenebris zu sehen. Man muß - als Künstlermensch - den Schmerz des descensus erfahren, um inm den positiven und produktiven Sinn geben zu können. Br̈ezina knüpft auch in Svitáni na zapadè an die Tradition des gnostischen Denkens an, in dieser Hinsicht ist sein Werk (TD und SZ) in der Tat "von Dogma unabhängig" ("neodvislé od dogmatu"), wie er an Anna Pammrová schreibt,233 und in bezug aư die offizielle Kirchenlehre tatsächlich inoffiziell und heterodox. Die gnostischen Vorstellungen, die er in seinen Gedichten aktualisiert, pointiert er aber - wie das Titeloxymoron zeigt - durchaus in der Tradition der ch ristlich en Mystik. Daraus ergibt sich wohl auch das Wesentliche für den schöpferischen Weg Br̈ezinas vom dekadenten zum eschatologischen Symbolismus: Aus dieser Ambivalenz - oder Spannung - resultiert der spezifische Charakter des gnostisch-eschatologischen Modells von Svitáni na západè, der den zweiten Gedichtzyklus als einen 'Transfer'-Zyklus des Suchens des richtigen Weges, des positiven Telos, erscheinen läßt. Dieser Weg führt nach dem notwendigen Erlebnis der finsteren dekadenten Unterwelt - in das blendende Licht des "mittäglichen Reifens", vom manichäischen Zweifeln zur Sicherheit des positiven religio, vom gnostisch-pneumatologischen zum christlich-pistologischen SelbstVerständnis (in VP), von der ästhetischen zur eschatologischen Existenz. Auch deshalb kann, wie schon erwähnt, die Symbolik des (Lebens-)Weges als das dominante Thema des ganzen Gedichtzyklus Svítáni na západẻ betrachtet werden. Diese Intention bringt Brezina auch in einem Brief (Herbst 1896) ${ }^{234}$ an Anna Pammrová klar zum Ausdruck:

-A snad aż se múj zrak zesili ještě pro vyzarováni polosvětel, která se dnes ztráceji v mých osıněnich, dovedu postîehnouti jemnẻjši souvislosti bolestného. Ale pochybuji, że z cesty na niż dnes jsem, vedla by nějaká oklika do krajin sousedicich s těmi, které jsem opustil. Nedovedu si píedstavit, že by život byl nerozumným potácenim se z temnot do temnot, kruhem, který sám sebe bezúcelnè hledá, prỉ̉ernỳm kouzlem, které vyvolává bytosti z ničcho, aby je nechávalo se pohlcovat navzájem, se zpupným smichem vítěziciho; vím, Z̉e tento náhled je eminentné modemi l...l - ale dnes nemohu vểit jinak, než věrím. Ani Nietzsche, ani nikdo jinỳ mne nepłesvědži, że neni druhého světa, nedostupněho smystùm země". ("Und vielleicht, wenn sich mein Blick tür das Ausstrahlen der Halblichter noch schärtt, die sich heute in meiner Geblendheit verlieren, wird es mir gelingen, die feineren Zusammenhänge des Leidens zu erfassen. Aber ich bezweifle, daß von der Bahn, auf der ich heute stehe, irgendein Umweg in jene Landschaften führen könnte, die an die grenzen, die ich verlassen habe. Ich kann mir nicht vorstellen, daß das Leben ein unvernünftiges Wanken von Dunket zu Dunkel sei, ein Kreis, der sich selbst zwecklos sucht, ein schauderhafter Zauber, der Wesen aus Nichts hervorruft, um sie untereinander verschlingen zu lassen, mit hochmütigem Lachen des Siegers; ich weiß, daß diese Ansicht eminent modern ist /.../ - aber ich kann nichts anderes glauben, als was ich glaube. Weder Nietzsche noch sonst jemand anderer wird mich überzeugen, daß es keine andere, den Sinnen der Erde unerreichbare Welt gibt').

\subsection{Symbolik des (Lebens-)Weges}

Der Übergangscharakter des zweiten Gedichtzyklus Svitáni na západẻ tritt auch auf der paradigmatischen Ebene in der Dominanz der 'Weg'-Symbolik deutlich zutage. Man kann die These aufstellen, daß die Topik des Weges, die die Sujetlogik der Schlüsselgedichte von Svitáni na západè begründet und ihre Sinnfolien zusammenfügt, im gesamten Zyklus ihren zentralen semantischen Ort hat.

In der Bewegungssymbolik der "Geheimnisvollen Fernen" koinzidiert der "Weg" ("cesta") mit dem Titelmotiv der "Ferne" ("dálka"): es ist der "ermüdende", "erschópfende"

232 Vgl. R. Roques, .Contemplation. Extase et Teněbre selon le Pseudo-Denys": in: Dictionnaire de Spiritualité, fasc. XIV-XV, Paris 1952.

233 -.../ mé dílo, nedovisłé od dogmatu, dotỷká se jen esoterických fundamenủ náboženstvi I...F. ("I.../ mein Werk, von Dogma unabhängig, berührt nur die esoterischen Fundamente der Religion (... F). O. Bł̉ezina, Dopisy Annè Pammrové z let 1889-1905, Praha 1931. S. 147.

234 Ibid., S. 141. 
und "endlose" Weg, der zu irgendeinem, in der unabsehbaren Ferne liegenden und daher unerreichbaren Ziel führt. Ber dekadente Weg durch die Lebenswelt ähnelt einer trostlosen, sogar quälenden und "selbstzweckhaften" Wanderung:

"Sla žitim matka má, jak kajícnice smutná, / den jeji nemél vưné, barev, květủ, jasu; /.../. // A jako tvoje kdys i moje cesta smutná; / bez vưnè je den mưj, bez barev, květù, jasu /... $/$ (Moje matka I Meine Mutter, I, 1-3, IX, 1-2; "Ging meine Mutter durch das Leben wie traurige Büsserin, I ihr Tag war ohne Duft, ohne Farben, Blütenn und Glanz; /.../. // Und wie einst dein Weg ist auch der meinige so traurig: / mein Tag ist ohne Duft, ohne Farben, Blüten und Glanz /... F). "Sla bledá a zmatená $v$ dálku zavátých, neznámých Mést / do šera a polárnich noci nèmou únavou cest" (Pohled smrti I Blick des Todes, V. 5-6; "Und bleich und verwirt schritt er zu auf verwehte. unbekannte Städte / in Dämmerschein und Polarnacht hin durch die Wege lauttoser Müdigkeit"). "/... / výkłiky otázek vraceji se echem vysileným dálkou / bez odpovédi" (Slavný smutek / Die erhabene Traver, IV , 5-6; \%.../ die Schreie der Fragen kehren als Echo, von der Ferne erschöptt, zurück / ohne Antwort").

Doch die 'Ferne' ist ein ambivalenter Topos: Auf das dichterische Ich übt sie eine hypnotisierende, bannende, faszinierende Wirkung, der es kaum widerstehen kann, weil die 'Ferne' das große "ewige Geheimnis" der "anderen Welt" (Modlitba vecerni / Das Abendgebet), das 'Andere', 'Fremde', 'Unbekannte' oder 'Rätselhafte' - in der Axiologie des dekadenten Symbolismus Werte 'an sich' - hinter ihrer Grenze verbirgt. Der für den dekadenten Symbolismus (TD) signifikante Bewegungstyp ist paradoxerweise eine 'Alsob-Bewegung', die (lediglich) im Traum, in der Phantasie, in Erinnerungen, Gedanken oder Vorstellungen stattfindet: "Známá cesta, kterou jsem łel, zménila se v mých zracích". (Den výrocni I Der Gedenktag. I, 1; "Der bekannte Weg, auf dem ich ging, verwandelte sich in meinen Blicken"). Daher bewegen sich (hin oder zurück) in Tajemné dálky nur Tote (die tote Mutter) oder (für immer) unerreichbare, in der "unbekannten Ferne" verschwundene Personen (der Jugendfreund) und sogar personifizierte Abstrakta: "Gedanke" ("myšlenka"). "Antwort" ("odpověơ"), "Lächeln" ("úsmév"), "Bangigkeit" ("úzkost") usw. Das lyrische Ich bewegt sich eigentlich nicht, es bleibt in seinem "Lager gefesselt" (Modlitba vecerni / Das Abendgebet, I, 3; Litost / Die Wehmut, V. 1) oder es "bewegt" sich gerade nur wie ein "Nachtwandler" im Traum, $d$. $h$. nur in seiner Vorstellungswelt, deren "Gefangene" ("Vězeñ") er ist: "Jak somnambul svedený z lože, bledý, spoután a ném / pod hypnosou Nepoznaného jdu se svým snem". (Pohled smrti I Blick des Todes, V. 15-16; "Wie ein Schlafwandler, dem Bett entlockt, bleich, gefesselt und stumm / unter des Unerkannten Hypnose gehe mit meinem Traum ich um'). Erst in Svitáni na západé tritt das lyrische Ich - nach dem 'dekadenten' descensus - auf den solaren 'Lebensweg' (Ranni modlitba / Das Morgengeben) heraus.

Was sind die signifikanten Topoi der Weg- und Bewegungssymbolik in Svitani na západe? Es ist die positive Symbolik der 'Reise' und der 'Rückkehr', des 'Hinausgehens', der 'Schritte', die Symbolik der Distorsion und Dilatation der Raum-Zeit-Perspektive, die die Bewegungstypologie von SZ bestimmen. 235 Hinzu kommen auch die mannigfaltig variierten und funktionalisierten Motive des (Augen-) Blickes, der Schnelligkeit oder des Blitzes. Was hat sich in Svitáni na západẻ - im Vergleich mit den Bewegungstypen des dekadenten Symbolismus (TD) - prinzipiell geändert? Das grundsätzlich Neue ist die Dominanz der positiven, zukunftsorientierten und zielgerichteten Entwicklung. Das passive Eintauchen in die un(ter)bewußte Sphäre des Hypnos und Oneiros, die Isolation in der autistischen Kunst-Welt, die postulierte Selbstauflösung im postmortalen Nichts (Modlitba vecerni I Das Abendgebet, Snad potom...I Vielleicht dann...) oder die wehmütige

235 Zur Bewegungssymbolik (im russischen Symbolismus) vgl. Aage A. Hansen-Löve, .Weg und Ziel. Zum System der Bewegung im russischen Symbolismus der Jahrhundertwende", in: Wiener Slawistischer Almanach 23, 1989, S. 151-174. Für die im russischen Symbolismus der mythopoetischen Phase (in den Jahren 1900 bis etwa 1907) dominierende Symbolik des Lebensweges ist, wie der Autor mit zahlreichen Zitaten belegt, der visionäre, vertikal gerichtete Weg ins Jenseits charakteristisch. Der ascensus symbolisiert das illuminatio der Seele, wobei das Verlassen der năchtlichen, lunaren und kalten ('thanatophil' konnotierten) Sphăre und das Betreten des Lichtweges mit der Symbolik des Sonnenaufgangs korrespondiert, die gerade in Błezinas Svitáni na západẻ von konstitutiver Bedeutung ist. Allerdings fungiert in einigen metadekadenten Texten (Mythus duše, Vino silných, Svitáni na západé) gerade der Tod als 'Initiator' der "Himmelsreise der Seele" und ihrer Befreiung; ein Aspekt, der auf die gnostische Tradition zurückgeht. Zur Symbolik des "Seelenaufstieges" in der Gnosis vgl. Kurt Rudolph, Gnosis. Wesen und Geschichte einer spätantiken Religion, Göttingen 1994, S. 186 ff. 
Resignation vor der entkräftenden Ferne und dem 'unabsehbaren', 'unbekannten' Ziel ( $Z$ vëcných dálek...I Aus ewigen Fernen, Lítost, I Die Wehmut, Slavný smutek / Die erhabene Trauer), alle diese aporetischen Bewegungstypen und '(Aus-)Wege' entwickeln sich in Svitáni na západẻ zum teleologisch orientierten und dynamischen Typ der Bewegung. Selbst der lange und mühevolle (irdische) Weg erlangt nun ein e r r e i c h b a r e s Ziel. auch wenn dieses nicht in der immanenten Welt liegt: "Nežel má duše, že dojdem až v noci k tvému rodnému mèstu" (Svitáni na západè / Tagen im Westen, II, 1; "Klage nicht, meine Seele, daß wir erst in der Nacht deine Geburtsstadt erreichen"). Das Erreichen des ersehnten Ziels fordert allerdings das bedingungslose 'Heraustreten' auf den 'LebensWeg'. Der passive 'Sturz' in den Traum, in die lähmende, todähnliche "Narkose der Nacht" (Motiv z Beethovena, V, 1), wird in Svitáni na západè - von einem metadekadenten Außenstandpunkt her - als 'Resultat' einer Fremdbestimmung (des "Namenlosen" I "Bezejmenný". Zalm ke cti nejuššího Jména / Der Psalm zu Ehren des höchsten Namens) und als 'Irrweg' demaskiert:

-Pied zrakem duše tvé jsem utkal závoj żiti, / svit záre tajemné jak rosa prýšti v nèm, / kdyż žizni prahl jsi, tvým snủm jen dal jsem píti, I však jejich żádosti tvé rety spálil jsem". (Slyš́m v duši I Ich höre in der Seele. III, 1-4; "Vor dem Blick deiner Seele webte ich des Lebens Schleier, I der Schein geheimnisvollen Glanzes sprudelt wie der Tau in inm, / als du vor Durst verschmachtetest, gab ich nur deinen Träumen zu trinken, / mit deren Vertangen jedoch versengte ich deine Lippen").

Auf dem teleologischen 'Lebensweg' richtet sich alles - sogar die Erinnerungen ("na noci budouci své lásky vzpomínám", Aż sednes za mưj stül.. I Wenn du an meinen Tisch dich setzt..., III, 4; "an die Nächte meiner zukünftigen Liebe erinnere ich mich") - in die Zukunft. 236 in einigen Gedichten (vor allem in Ranni modlitba / Das Morgengebet, Svitáni na západé / Tagen im Westen, Vino silných / Der Wein der Starken, Mytus duse I Der Mythos der Seele) gewinnen alle Zielsetzungen, Prozesse und Erwartungen ihren Sinn erst in der Zukunft, in der auch die hic et nunc unlösbaren Probleme gelöst werden. Daher rührt auch die paradoxe Bereitschaft den 'Lebens-Weg' zu verlassen und in das "Tal des Todes" (Mytus duše / Der Mythos der Seele) hinabzusteigen. Selbst nach dem Übergang der Seele durch die "enge Pforte" (ibid.) zur höheren Form des transzendenten '(Meta-)Lebens' wird ihr 'irdischer Gang' auf "dem langen Weg der Väter" (ibid.) durch die Seelen "zukünftiger Scharen" ("zástupy prísti") fortgesetzt.237 Der 'Tod' scheint nur potentiell 'Tod' zu sein; erst durch inn erreicht man die Sphäre des Ur-Lichtes und der Transzendenz:

'O Věcnỳ! At tušení naše jsou sladká těm, kteři v bolestech tonou. / Pějme hymnu ze slov, jež znaci smrt ve všech jazycich zemẻ. I Nebot nám, ktefii věfime, je den tvưj dobou zráni, zahởkle vonnou, I praskajíd v bolestných klasech a vecerem chlazenou jemne" (Svítáni na zapadé / Tagen im Westen. V. 1-4; "O Ewigerl Mögen unsere Vorahnungen denjenigen süß sein, die in Schmerzen ertrinken. I Wir singen eine Hymne aus Worten, die Tod heißen in allen Sprachen der Erde. I Denn uns, die wir glauben, ist dein Tag eine Zeit des Reifens, bitter duftig, / in schmerzerfülten Ähren berstend und vorn Abend sanft gekühlt"). 238

Die Ungewißheit eines "snad potom" ("vielleicht dann", TD, Kap. 2.1.2) nach der Apokalypse der Erde wandelt sich zur Gewißheit des zukünttigen transzendenten Seins und zur verheißungsvollen Erwartung der "Formen eines neuen Lebens", denen die

236 "Ve vášnivém tepotu věcněho srdce, jež tisici üdery buši, / v tušeni, jež procházi hroby a svití $z$ budoucich zorf" (Tys nes/a / Du kamst nicht. VIII, 1-2; "Im leidenschaftlichen Puls des ewigen Herzens, / das mit tausend Schlägen schlägt, / in der Ahnung, die durch die Gräber geht und aus der zukünftigen Morgenröte erstrahlt"). 'Zpivám: $O$ Bezejmenný všech mrtvȳch i budoucich jmen". (Zalm ke cti nejušsiho jiména / Der Psalm zu Ehren des höchsten Namens, II, 1; "Ich singe: O Namenloser aller toten und zukünttigen Namen"). Femer: Predtuchy (Vorahnungen, I, II Str.). Mytus duse (Der Mythos der Seele) und andere Gedichte.

237 Das Telos des Weltgeschehens sieht Biezina im Mythos der Seele. Die Geschichte scheint er mit der Geschichte der Seele(n), mit der 'Evolution' der Seele zu identifizieren, die im Verlauf der Zeiten immer hōher und hǒher steigt.

238 In Pfiroda (Natur) aus dem dritten Gedichtzyklus Vètry od pólu (Polarwinde, 1897), wird diese Intention noch prägnanter zum Ausdruck gebracht: "Světlo umirá jenom prichodem jestě vêtšino svẻtla. / ješté vétšino, vêtšino svétla" (letzte Verszeile; "Das Licht stirbt nur beim Nahen eines noch größeren Lichtes, / viel größeren, größeren Lichtes"). 
(personifizierte) Seele auf dem langen Weg "meiner Väter durch die Jahrhunderte" ("mých otcu staletími") entgegenschreitet. 239

"A zastavi-li se má duß̌e na dlouhé pouti mých otcú staletími, /.../ pozdravem zulíbám stiny a pisen zazpivám żivym / i poutníkủm budoucim, Ktě̛i odváži se trhati kvíti v údoli smrti / a utrpenim Cisti v mystické Myšlence, jež zraje pro nás rozkvẻtem tvarư / a od věkư dumá o plemenu silném. I.../ o vinařich, jeż zapáli siru $v$ sudech, kde se zkazila staletá vína, sílici slabé, /.../ aby vyđistily dálky a vzkřisily vủnẻ ve vzduchu, / jejż budou dýchati zástupy prišsti". (Mytus duše / Der Mythos der Seele, V. 50-60; "Und wenn meine Seele auf dem langen Weg meiner Văter durch die Jahrhunderte einhält, /.../ grüßend küsse ich die Schatten und singe ein Lied den Lebendigen / und den zukünftigen Pilgern, die es wagen im Tal des Todes Blüten zu pflücken / und durch das Leiden im mystischen Gedanken zu lesen, der für uns durch das Aufflühen der Formen reift und seit Äonen über ein starkes Geschlecht grübelt I.../, von Winzern, die den Schwefel in Fässern anzünden, in denen die hudertjährigen Weine, die die Schwachen kräftigen, verdarben, /.../ um die Femen zu reinigen und die Düfte in der Luft zu beleben, die die zukünftigen Scharen atmen werden.")

im Unterschied zu dem zukunftsorientierten 'Lebens-Weg', der schließlich in die mystische 'Begegnung' mit den Seelen der Vorväter auf ihrem Weg durch die Zeiten führt (Ranni modlitba, Mythus duße, Víno silných), bleibt der Weg des autistischen KünstlerMeschen (in den metadekadenten Texten) ${ }^{240}$ ein 'unfruchtbarer' Allein-Gang durch die Nacht und Finsternis der isolierten, in sich völlig abgekapselten Ich-Sphäre:

"V tèch krajích duše mé, kde neplá svêtlo denni /.../. // Jdu teskný duši svou, kde setba noci zraje. I bezdẻtný hospodár po zkvetlých mezich, sám". (Až sedneš za müj stül... / Wenn du an meinen Tisch dich setzt ...; I, 1, III, 1-2; "In den Landschaften meiner Seele, wo das Tageslicht nicht lodert /... / / Traurig gehe ich in meiner Seele, wo die Saat der Nacht reift, / ein kinderloser Wirt, allein durch die erblühten Raine"). "Však marně jsem králel, kde $v$ závratných rytmech se tłás' / zpèv Żití. Stin Nékoho, jenż za mnou sel, piede mnou splyval". (Legenda tajemné viny / Die Legende der geheimnisvollen Schuld, II, 1-2; "Doch schritt ich umsonst; wo in taumelnden Rhythmen voll Überschwang / der Sang des Lebens vibrierte. Der Schatten von Jemand, der hinter mir herging, floß vor meinen Schritten"; übers. v. Paul Eisner). "/.../ na cestách mé duše teskno a dvojsmysiné miženi věcna" (Mé dédictvi polożil's.../Mein Erbe legtest du ..., III, 4; "/.../ auf den Wegen meiner Seele liegt die Trauer und das doppelsinnige Schweigen der Ewigkeit").

An Stelle der visionären Begegnung erlebt das dichterische $\mathrm{Ich}$ in den metadekadenten Texten nur die 'apophatische' ("se slovy némými" / "mit stummen Worten". "mrtvá slova" / "tote Worte" usw.) "stumme Begegnug" mit dem Tod, 241 in der Kälte der quälenden Einsamkeit, 242 beleuchtet vom blassen Mondschein: "Á chiéb až

239 Sehr richtig hebt U. Heftrich (Otokar Brezina, Heidelberg, 1993, S. 66-67, 162-163) die Bedeutung von Mythus duše für die Entwicklungslogik von Br̈ezinas CEuvre hervor. Er betont die Vertiefung der idealistischen Weltsicht Błezinas, die die Neuorientierung des Dichters signalisiert und die sich gerade in Mythus duse (u. a.) deutlich offenbart. Heftrich charakterisiert diese als Entscheidung des Dichters dem Weltgeschehen ein positives Ziel zu unterstellen (ibid. S. 163), wobei das in diesem Gedicht entwortene "evolutionäre Programm" (V. 50-60), laut Heftrich, die Inspiration durch Nietzsche zu erkennen läßt. Insbesondere das Motiv des "starken Geschlectites" ("plemeno silné") scheint auf Zarathustra zu alludieren, den Brezina gerade zur Entstehungszeit von Mythus duse rezipient hat.

240 Legenda tajemné viny / Die Legende der geheimen Schuld, Vladař snú / Die Herrscher der Träume, Tajemstvi bolesti / Das Geheimnis des Schmerzes, Némé setkáni / Stumme Begegnung. Až sedneš za müj stül / Wenn du an meinen Tisch dich setzt, Mé dédictvi položils's ... / Mein Erbe legtest du

241 "Kam padnou, tam rostou mystickè květy, vyzariujici unaslá světla, I a 2 jejich listủ rozemnutých, voni mi lítost nẻměho setkáni v smnti' (Némé setkáni / Stumme Begegnung. V. 13. 14; "Wohin sie fallen, dort wachsen mystische Blüten, die erloschten Lichter ausstrahlend, / und aus inren zermalmten Blättern, duftet mir die Wehmut der stummen Begegnung im Tode"). "Až sedneš za mủj stủl, cekaná, Nepozvaná, / se zraky tajemstvi, se słovy némými. I s bohatstvim

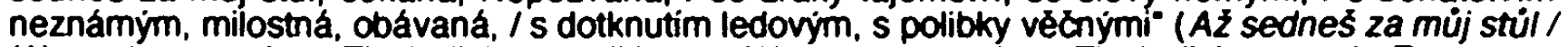
Wenn du an meinen Tisch dich setzt, IV, 1-4; "Wenn du an meinen Tisch dich setzt, du Erwartete, du Ungerufene, I mit Blicken des Geheimnisses, mit stummen Worten, / mit unbekanntem Reichtum, du Liebevolle, Gefürchtete, / mit eisiger Berührung, mit ewigen Küssen").

242 In den Gedichten, die die neue eschatologische Symbolik entfalten (Ranni modlitba, Svítáni na západé, Vino silných) wird der Zustand des isolierten Künstler-Menschen auch als "Ertrinken in Schmerzen" charakterisiert: "O Vêcný! At' tušeni naše jsou sladká těm, kterí v 


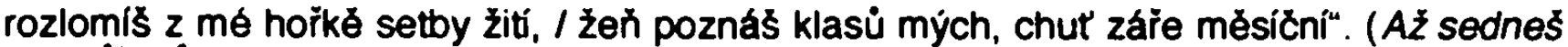
za müj stül / Wenn du an meinen Tisch dich setzt, V, 3-4; "und wenn du das Brot brichst von bitterer Saat meines Lebens, / erkennst du die Ernte meiner Ähren, den Geschmack des Mondscheines"). Der 'Wegweiser' des dekadenten Künstler-Menschen ist der kalte Mondschein (bzw. die 'blauen Irrlichter'), der ihn in die entkräftende "Ferne" (ver-)führt, während die visionären (erlösten) Ausnahmepersönlichkeiten (die "Starken" in Vino silnych / Der Wein der Starken) sich von den 'translunaren' Sternen führen lassen, deren Glast nicht nur die chthonischen Schatten des lunaren Lichtes (als 'Projektion' des desontologisierten Selbst) zerstreut, sondern auch, indem er die "Starken" autwärts, in die astrale Sphäre 'zieht", die "ewige Ferne" besiegt: "Stíny složi se nám jak péra v krídlech, posetá hvězdami, smějíci se dálkám. /.../ Bratrí z ruky do ruky podávejime víno silných ve svẻ đási: / hvězdy, ktere nañ pršely v kvêtu, at naházi do našich zrakư.. (Víno silných / Der Wein der Starken, V. 25, 43, 44; "Die Schatten werden sich für uns wie die Feder in den Schwingen zusammenfalten, übersät mit Sternen, über die Fernen lachend. I.../ Brüder, von Hand zu Hand reichen wir uns den Wein der Starken in unserem Kelch: / die Sterne, die auf ihn in der Blütezeit regneten, soll er in unsere Blicke werfen"). Ähnlich signalisiert das furchtlose Offnen der Fenster in Tys nešla (Du kamst nicht, letzte Strophe) das 'Heraustreten' des wartenden Dichter-Magiers aus der Isolation seines Innern auf den visionären Weg. Die Sternenmusik vernimmt das lyrische Ich als 'Aufforderung' zur Partizipation am kollektiven Lied des kosmischen Geschehens; ein Ziel, dem auch die individuelle (erotische) Liebe - zugunsten der allumfassenden (spirituellen) Liebe aufgeopfert wird:

"Je pozdẻ již. Záclony zdvihám, okna svá bez bázné otvirám výšim / a od hvězd zvoni mi piseñ započatá pr̉ed staletími; // V noci všech padá, kde polibkú jásavá boữe se sráżi, / jeż rozžehá v

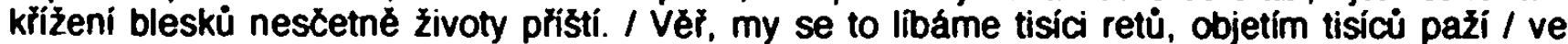
věcnosti bolestné něhy, jež od věkủ do věkú prỷsti!" (Tys nešla / Du kamst nicht, VI, 1-2, VII, 1-4; "Es ist schion zu spăt. Die Vorhănge hebe ich hoch, meine Fenster öftne ich furchtlos den Höhen I und von den Sternen klingt mir ein vor Jahrhunderten begonnenes Lied; // In die Nacht aller Welten fällt es, wo der Küsse jubelndes Gewitter niedergeht, / das in sich kreuzenden Blitzen ungezählte künttige Leben entfacht. / Glaube, wir sind es, die wir uns mit tausenden von Lippen küssen, in der Umarmung tausender Armen / in der Ewigkeit schmerzvoller Zărtlichkeit, die von Äonen zu Äonen sprudett!").

Es ist kein Zufall, daß dem paradigmatischen Gedicht des 'Heraustretens' auf den (solaren) 'Lebens-Weg', Ranni modlitba (Das Morgengeben), und dem Titelgedicht Svitáni na západé, die exponierten Positionen des zweiten und des vorletzten Gedichts im Zyklus zuerkannt werden. Den "Tagesanbruch", eine der semantischen und kompositorischen Konstanten des Zyklus, antizipient bereits das Prolog-Gedicht Ples véných svítáni (Der Reigen des ewigen Tagesanbruchs). Der Tagesanbruch ("svítáni") wird quasi in die Sphäre des Sonnenuntergangs ("zapad") transferiert. Der Tod ("západ") ist das 'letzte Tor', hinter dem den 'Wanderer' ein neues Leben ("svitáni"), eine neue Existenzform, erwartet. Der lichtvisionäre Weg mündet in die Begegnung und Verschmelzung mit der Gemeinschaft der "Toten und Lebendigen": "Všichni viditelni i neviditelni služebníci vyšli na souvraté tvé" I... I l já, jeden z nejchudšich, yycházim poslušen na hlas twého zvonu, I na zdëdënou líchu mých mrtvých". (Ranni modlitba / Das Morgengebet. V. 18, 27-28; "Auch ich, einer der Armsten, komme, gehorsam dem Klang deiner Glocke, / auf die Erbscholle meiner Toten").

Die Symbolik des 'Lebens-Weges' läßt sich an drei paradigmatischen Gedichten des Zyklus darstellen und interpretieren: Vladari snú (Die Herrscher der Träume), Ranni modlitba (Das Morgengebet) und Vitezzná piseñ (Das siegreiche Lied). Denn diese drei Gedichte thematisieren nicht nur drei 'Schritte' auf dem visionären 'Lebens-Weg', sondern auch drei 'Stadien' der in neren Entwicklung des gnostisch-eschatologischen Symbolismus. Doch der letzte 'Schritt' auf diesem Weg wird erst in Vino silnych (Der Wein der Starken) vollzogen. Es geht im folgenden um die Analyse des ersten Gedichts dieses 'Triptychons': Vladari snu (Die Herrscher der Träume). Das Gedicht ist als 'Rekonstruktion' der einzelnen 'Stadien' des Irrweges der dekadenten Künstlermenschen arrangiert, der schließlich zum Scheitern des gewagten 'Erlösungsversuches' führt.

bolestech tonou". (Svitáni na západẻ / Tagen im Westen, V, 1; "O Ewiger! Mögen unsere Worte denjenigen süß klingen, die in Schmerzen ertrinken"). 
más docela pravdu: ¿ena! /... J Jeji úsměv drímá na dně v̌̌ech duší.

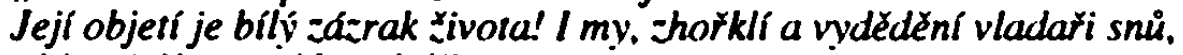
citíme její mocré kouzlo! “"

\author{
„.Du hast völlig recht: die Frau! /..J Ihr Lächeln schlummert \\ auf dem Grund aller Seelen. Ihre Umarmung ist das weiße Wunder \\ des Lebens! Auch wir, die verbitterten und enterbten Herrscher \\ der Träume spüren ihren mächtigen Zauber! “"
}

O. Błezina an F. Bauer (Sommer 1895)

\title{
Vladaři snů
}

l. Braţi, jichž duše klekají vedle duše mé ve svatyních Nepoznaného, jichž nuce dotýkají se mých, když sypeme zmí na uhlí spolex̌né kadidelnice, sblízeni opojením spoležné modlitby, již prijali jsme dédictvím vêkủ, sesláblí zádumčivým viněním hudby, jîz chvěje se rytmicky vesmír!

II. Vy, ktełi vracíte se unaveni hrubými výdechy pozemských barev, płemoženi vladałi snú, inspirovaných hvězdami neznámých konstellací. vy, jimž krev vyhmula se z pónu ve výších ztmulých odvěkým mrazem a dýchání kł̌ečovitě se trhalo v ovzduši, jímž proletují světy!

III. Vy, kteři jste zsinali omámeni tajemstvím hlubin, kde hasne pozemské svêtlo $v$ koư̌i plynů stoupajících $z$ utajených plamenủ vex̃ného tlení, a zavěsili Žití na pavučinná vlákna myšlenky, $v$ pýse snovaná v lano! Poutníci, kteři jste navštivili svatá místa, spustošená sillenstvím davu!

IV. Milenci pološera, jichž zraky uvykly rozeznávati formy v zalmění noci! $V y$, jimž zhołkl výpar krve, jenž sládne ot̛́ásanými vlnami vášní. nemocní touhou po objetí duší. jemném jak slití paprskủ zbratłených barev! Hymnus jste zapêli xistěmu Políbení!

V. Hymnus koupaný v reminiscencích kantát k oslavę Nanebevzetí. ozáfený oblak pršicích iónủ, jež rozplývaji se jak sladkost na nech milujících. sníh hvězdných krystalú vưní. padajicí v rozłhhaveni záłení bîyých linií těla. jež vítězné od věkủ pálí dexdiěným sněním i vaši zachmułenou żádost.

VI. Duše vaše v lítostech pohlcovaly narážení neviditelných barev prodlouženěho vidma. trpěly ovíváním neznámého chvění a smutkem neslyšeného pláxe: (iluse věcí - f̌ekli o vás - hơ̌ela chorobným klamem ve vaši duši, kdyż smutek nekonex̌na dýchal ve vašich odmítnutých a zapł̌ených rytmech.)

VII. Životem proß̌li jste od plamenủ extasí, tepajících jak nedoxkavé tłesení khídel. až $k$ omdlévání duše. když pruty bolesti, žhavê. v pátełi provlékaji se míchou; úzkostné tajemství, tuß̌eni Porozuméní, zpracovalo vaše rysy. jak idea mistra płehnětenou formou. Lex vašich ox́i slzy nejpalěivějł̌i

VIII. uschly ve vaši duši, by nikdo jich nevidęl chvíti se v łasách. o Hrdí! Trpěli jste sílenstvím groteskních vidin, mozek raněný úpalem krásy. Irpěli jste bolestí slova, sesláblěho a znechuceného nánosem let. osleplého jak zrcadla kovu ve vzduchu, do něhož dýchalo množství.

IX. Ó Vítézi, jichž kơ̌ist je posměchem neprátel a lítostí prátel! Hynete samotou v ostrovech, o nichž vám zpívaly hvézdy a oceány! 
Ponižení vracíte se $v$ domov, $k$ vápenným bł̌ehům, jež houbovité se drolí nárazem věků, a kde nikdo nevěrí vašim zvěstem, syceným vủněmi jihu.

$X$. Bledost vašeho procitnutí, jak znamení tajného hříchu vás zrad,í

Úsměvy druhů zhasnou płed vał̌imi zraky, $v$ nichž třese se záreni dálek!

(Nebơ milovaná je tváf, v níz krev prosvítá rủžemi usmívání,

ale hrozná, zjeví-li se $\mathbf{z}$ druhého žití nocím milenky $v$ halucinacích.)

XI. Truchlí pưjdete zahradami žertujícími s jarem, květy, jichž vůnẽ vám cizí, vase setba tropických nádher vyrưstá bíá a mroucí v sevemích sluncích. studené je dotknutí ženy, Ihostejné potkání duší, únava mihami padá, a vaše pýcha, jež povrhla nasycením země, zvrhne se výsmę̌ñ ssáti vyschlou štávu těch hroznů.

které jste rozmačkali, bezděčnè, ve vašem královském snění.

\section{Die Herrscher der Träume}

I. Brüder, deren Seelen neben meiner Seele im Tempel des Unerkannten niedersinken, deren Hände die meinigen berühren, wenn wir das Korn auf die Kohle des gemeinsamen

Rauchfasses streuen, verwandt durch den Rausch des gemeinsamen Gebets, das wir als Erbgut der Äonen empfingen, ermattet von schwermuitigem Wogen der Musik, von der das All thythmisch bebt!

II. Ihr, die ihr von groben Ausdünstungen irdischer Farben ermüdet zuruickkehrt. besiegte Herrscher der Träume, von Sternen unbekannter Konstellationen inspiriert ihr, denen das Blut in den von ewigem Frost erstarrten Höhen aus den Poren herausströrnt und das Atmen kramphaft stockt in der Atmosphäre, welche die Welten durchsausen!

III. Ihr, die ihr berauscht vom Geheimnis der Tiefen erblaßtet, wo das irdische Licht erlischt im Rauch der Gase, die aus verborgenen Flammen des ewigen Moderns emporsteigen, und die ihr das Leben auf Spinnennetzfasem des Gedankens aufhinget, im Hochmut zu einem

Pilger, die ihr heilige Stätten besuchtet, verwüstet vom Wahnsinn der Menge!

Seil gewunden!

IV. Liebhaber des Halbdunkels, deren Blicke sich gewöhnten, die Formen in der Finstemis der Nacht zu unterscheiden! Ihr, denen die Ausdünstung des Blutes, die von bebenden Wogen der Leidenschaften süß wird, verbitterte, krank vor Sehnsucht nach der Umarmung der Seelen, zart wie das Verfließen von Strahlen Ihr sanget den Hymnus auf den reinen KuB! der verbruderten Farben!

V. Einen Hymnus, gebadet in Reminiszenzen der Kantaten zum Lob der Himmelsfahrt, Erleuchtete Wolke regnender Töne, die wie Süße auf den Lippen der Liebenden zergehen, Schnee von Stemkristallen der Düfte, der ins glühende Strahlen der weißen Linien des Körpers des siegreichen, der seit Äonen mit erblichem Träumen auch eure düstere Begier sengt.

VI. Eure Seelen verschlangen in der Wehmut das Andrängen der unsichtbaren Farben des verlängerten Spektrums auf, sie litten unter dem Fächeln des unbekannten Bebens und unter der Trauer des unhörbaren Weinens: (die Illusion der Dinge - so sagte man uber euch - brannte in eurer Seele als krankhafter Trug, als die Trauer des Unendlichen in euren abgelehnten und verleugneten Rhythmen atmete,

VII. Ihr wandertet durch das Leben von Flammen der Extasen, die wie das ugeduldige 
bis zur Ohnmacht der Seele, wenn die Stäbe des Schmerzes, die glühenden, sich durch

das bange Geheimnis, das Ahnen des Verständnisses, verarbeitete eure Züge.

das Rückenmark schlängeln;

wie die Idee des Meisters in einer durchgekneteten Form. Aber die brennendsten Tränen

eurer Augen

VIIl. trockncten in eurer Seele, damit sie niemand in den Wimpern beben sieht, o ihr Stolzen! Ihr littet am Wahnsinn grotesker Visionen, das Gehim getroffen von der Sonnenglut der

ihr littet am Leiden des Wortes, das schwach und schall wurde unter dem Angeschwemten

Schönheit,

das erblindete wie metallene Spiegel in der Luft, in die die Menge atmete.

der Jahre,

IX. O ihr Sieger, deren Beute den Feinden zum Spott und den Freunden zum Mitleid wird!

Ihr verschmachtet vor Einsamkeit auf den Inseln, von denen euch Sterne und Ozeane sangen!

Emiedrigt kehrt ihr nach Hause zuruck, zu den Kalkufern, die wie Schwämme zerbrösseln unter dem Anprall der Äonen, und wo keiner euren Botschaften glaubt, die gesättigt sind

von Düften des Suidens.

$X$. Die Blässe eures Erwachens wird euch wie ein Zeichen der heimlichen Sünde verraten.

Das Lächeln der Gefährten erlischt vor euren Blicken, in denen das Strahlen der Fernen bebt!

(Denn es ist ein geliebtes Antlitz, dessen Blut durch die Rosen des Lächelns schimmert, ein schreckliches aber, wenn es aus dem zweiten Leben in den Nächten der Geliebten

in Halluzinationen erscheint.)

XI. Traurig werdet ihr durch die Gärten, die mit den Lenzen scherzen und deren Dufte euch

fremd sind, schreiten.

eure Saat der tropischen Herrlichkeiten wächst weiß und kränklich in der nördlichen Sonne,

kalt ist die Beruhhrung der Frau, gleichgültig die Begegnung der Seelen, die Ermattung fältt

im Nebel,

und euer Hochmut, der verächtlich die Sättigung der Erde ablehnte, wird sich spöttisch

in die Sehnsucht verwandeln,

den ausgertockneten Saft jener Weintrauben zu saugen,

die ihr, unwillkürlich, in eurem königlichen Träumen zerquetschtet.

Das Gedicht Vladari snü243 thematisiert $z$ w e i verschiedene Entwicklungszustände e in er und der $\mathrm{gl}$ l i ch e n Personengruppe, der "Herrscher der Träume", und ihre Suche nach dem 'wahren' Erlösungskonzept, d. h. nach dem Ausweg aus dem Zustand des 'Unbehagens' in der irrealisierten Traum-Welt. Das Gedicht ist, im Hinblick aut die Textkategorien der metadekadenten Poetik, aus der Perspektive eines Suchenden geschrieben, der an der 'Richtung' seiner bisherigen (schöpferischen) Entwicklung zwerfelt, sich aber über den richtigen Weg, über die wirkungsvolle und zufriedenstellende Lösung, noch nicht im klaren ist. Daher bezieht er eine distanzierte Position gegen seine eigene künstlerische Vergangenheit.

Das Gedicht Vadari snú gehört zu der kleinen Textgruppe, die Biezina im Juni 1895, zwei Monate nach der Herausgabe des ersten Zyklus Tajemné dálky, in der Literaturrevue Rozhledy (Ausblicke) veröffentlichte. Zu dieser Gruppe zählen u. a. die Gedichte Proc odvracis se, 6 Slabá? (Warum wendest Du dich ab, o Schwache?) und vor allem $O$ Minulá, kdyź smrti vécný pasát... (O Vergangene, wenn des Todes ewiger Passat...). die ganz evident noch der Axiologie des dekadenten Symbolismus angehören, während Slysim v duši (Ich höre in der Seele) und Vladari snù die dekadente Axiologie bereits in Frage stellen, ohne jedoch die richtige Lŏsung und das positive Telos zu kennen. Zur

243 Im Hinblick auf die Verssemantik dieses Gedichts repräsentieren Vladari snú die strophische Variante von vers libre mit deutlich daktylischer Tendenz, die gerade für die Anfangsphase von Biezinas Verslibrismus charakteristisch ist (vgl. dazu: Miroslav Cervenka. . Otokar Blezina", in: Z vecerni skoly versologie II, Praha 1991, S. 59-60). Das ganze Gedicht besteht aus elf vierzeiligen Strophen mit Ausnahme der letzten Strophe, die von sechs Verszeilen gebildet wird, wobei die letzten zwei $(5+6)$ das Gedicht pointieren. 
Abfassungszeit von Vladari snư identifizierte sich der Dichter mit der Personengruppe der ratlos suchenden "Herrscher der Träume": "I my, zhoǐklí a vydẻdëni vladarî snu l...". ("Auch wir, die verbitterten und enterbten Herrscher der Träume /... ${ }^{\prime}$ ). ${ }^{244}$

Das Gedicht proponiert jedoch zwei durchaus verschiedene Charakteristiken, zwei konträre 'Psychogramme' der "Herrscher der Träume"; die Apostrophen "Bratrī" ("Brüder", I, 1) und "Milenci polosera" ("Liebhaber des Halbdunkels", IV, 1) gelten einer und der gleichen Personengruppe. Die Entwicklung der "Herrscher" wird als ein "Zwei-Stadien Prozeß' dargestellt: der erste, im P r ä s e n s beschriebene Zustand (Str. I, IV, 3-4, V, 13) ist der des noch nicht gefundenen richtigen Weges, da noch etwas fehit: Die gnostische Offenbarung des zur Vereinigung mit dem "Höchsten" führenden Heilsweges? Oder die Kraft zum Heraustreten auf den solaren 'Lebens-Weg' durch das stärkende Erlebnis des descensus?

Der zweite, im P r ä te r i t u m beschriebene Status (Str. II, 2, III, IV, 1-2, V, 4- XI) des Unbehagens (Str. VI) in einem 'Noch-Nicht-Zustand' (I), weist charakteristische Symptome eines leidvollen R e z i d i vs auf: "litost" ("Wehmut"), "trpęt" ("leiden"), "chorobný klam" ("krankhafte Halluzination"), "bolest" ("Schmerz"), "slzy" ("Tränen"), "Silenstvi grotesknich vidin" ("Wahnsinn grotesker Visionen", Str. VI-VIII usw.). Dieses eigenartige Zustandsbild kündigt sich bereits im vierten Vers an: "/.../ záreni bílých linii těla, / jež vítězné od věkủ pálí đẻdižným snēním i vaši zachmuỉenou Zádost" (V. 3-4; "Der Schnee von Sternenkristallen der Düfte, der ins glühende Strahlen der weißen Linien des Körpers fällt, I des siegreichen, der seit Äonen mit erblichem Träumen eure düstere Begierde sengt"). Dabei soll nicht außer acht gelassen werden, daß die Handlung in der neunten Strophe wieder ins Präsens und in der zehnten ins Futur übergeht. Die fakultative Bedeutung dieser temporalen 'Aberration' koinzidiert mit der Sujetlogik des Textes, die sich in drei Sujetsequenzen rekonstruieren läßt:

1. Sujetsequenz: Die Ausgangssituation des Entwicklungszustandes | (Str. II - IV, 12). die sich durch die Unzưfriedenheit mit diesem leiderfüllten (II, 3-4) Zustand der Niederlage ("piemożeni vadaři snü", II, 2) und durch die Sehnsucht nach der 'Ertósung' aus ihm kennzeichnet: "nemocni touhou po objeti duši, jemném jak sliti paprsku zbratrených barev!" (IV, 3).

2. Sujetsequenz: Ihr Thema ist der Befreiungsversuch (IV , 4; V, 1-3 + I, Inversion der Sujetsequenzen), wobei die Exklamation "Hymnus jste zapéli cistému Polibeni!" (IV, 4; "Ihr sanget den Hymnus auf den reinen Kuß!") das Resultat des Entwicklungszustandes und zugleich den Übergang zum (präsentischen) Entwicklungszustand I markiert. Diesen Entwicklungszustand strukturieren zwei kultische Handlungen der gleichen Art, deren Aktanten die "Brüder" ("bratî"i") sind: "společná modlitba" ("gemeinsames Gebet", I, 3) und der gemeinsam gesungene "Hymnus cistému Políbeni ("Hymnus auf den reinen Kuß", IV, 4). Dem entspricht auch die Syntax einer einzigen Satzperiode, die die Strophen I-IV miteinander verknüptt.

3. Sujetsequenz hat das Scheitern des Befreiungsversuches und den Zustand des Rezidivs (VI-XI) zum Thema. Die Futur-Form der Strophen X-XI kann man als eine Art 'Warnung' verstehen, auch in Zukunft derartige vergebliche Befreiungsversuche wiederholen zu wollen, bevor der richtige Weg der Erlösung, dessen Absenz die Unzufriedenheit des Entwicklungszustandes I (I, IV, 4, V, 1-3) stiftet, gefunden wird. Die Semantik der einzelnen Sujetsequenzen soll nun näher betrachtet werden.

1. Der Entwicklungszustand (II) der Unzufriedenheit, der Niederlage und der daraus resultierenden Sehnsucht nach der Erlósung (zweite Sujetsequenz, IV, 1-2) rührt vom Zweifel an der ästhetischen Existenz (und ihrer Werthierarchie) der dekadenten, nun als "Liebhaber des Halbdunkels" ("Milenci polosera", IV, 1) apostrophierten Künstlermenschen her. Das 'Eintauchen' in die fiktionale Traum- und Kunst-Welt des kulti s ch en Ästhetizismus wird vom lyrischen Ich, das sich mit Ausnahme der ersten Strophe an seine "Brüder" - "Liebhaber des Halbdunkels" - direkt wendet ("Vy".I "Ihr", II, 1), als ein verhängnisvoller, zur schmerzvollen Niederlage führender Irnweg gleichsam denunziert: "píemoženi vadaři snú, inspirovamjch hvězdami neznámých konstelac" (II, 2). Die elitäre Isolation vor der vulgären Masse245 (III, 4) pervertient zur physischen Qual (II, 3-4), die die

244 Vgl. O. Błezina, Dopisy Frantisku Bauerovi, Praha 1929, S. 209.

245 Die Verachtung der Masse kennzeichnet das ganze Werk und die Persönlichkeit Biezinas. Seine Korrespondenz und seine (mündlichen) ÂuBerungen liefern zahlreiche Bewise hiertür: -Uméni neni hračkou pro dètské ruce davu. Nenávidím banálni píseñ, volám s Carduccim. Chci 
"Herrscher" passiv ertragen müssen. Sie sind Fremde in der immanenten Welt, in die sie aus der Abgeschiedenheit ihrer 'Schein-Welt' zurückkehren: "Vy, kteř vracite se unaveni hrubými výdechy pozemských barev" (II, 1: "ihr, die ihr von groben Ausdünstungen der irdischen Fahrben ermüdet zurückkehrt"). 246 Das irdische Leben kommt innen nicht nur banal, sondern auch brutal, vulgär, barbarisch und animalisch (II. Str.) vor.

Die fiktionale "andere" Welt ("jiný svĕt"), die das lyrische Subjekt in Modlitba vecerni (Das Abendgeben) als ein faszinierendes ("zázračný") 'Territorium' durchdringen und erforschen will ("Ty vưni zázračná, z niž voní jiný svết / mưj zemský život ztaj a nadpozemský zvlñ", I, 5-6; "Du wunderbarer Duft, aus dem die andere Welt duftet I verhülle mein irdisches Leben und laß das überirdische sich wellen"), wird auch in Vladari snù thematisiert: "piemožení vladaři snú, inspirovaných hvézdami neznámých konstelaci" (II. 2; vgl.: "At" všechno obsáhnu /.../// sil živých vẻzný kruh, jenż konstelace hvẻzd / v své síté navléká". Modlitba vecerni / Das Abendgebet, VI, 1, 3-4; "Daß ich alles erfasse /.../ II der Lebenskräfte ewigen Kreis, der die Sternenkonstellationen / in seine Netze zieht"). Doch das inspirative Potenzial dieser "anderen" bzw. "unbekannten" Welt, die in Tajemné dálky (Geheimnisvolle Fernen) eine durchaus positive Konnotation hat, wird in Vladari snú angezweifelt. Außerhalb der fiktionalen Traum-Welt, in der Sphäre der Lebens-Welt, versagt die in Modlitba vecemi postulierte absolute Erkenntnis:

"/... / vy. jimż krev vyhmula se 2 pórú ve výšch ztrnulých odvěkým mrazem / a dýcháni kł̉ecovité se trhalo $v$ ovzduši, jímż proletuji světy! // Vy, ktef̌i jste zsinali omámeni tajemstvím hlubin, kde hasne pozemské světlo / /... / a zavésili žití na pavučcinná vlákna myšlenky /... I (Vladari snu / Die Herrscher der Tráume, II, 3-4; III, 1-3, " .../ ihr, denen das Blut in den von ewigem Frost erstarrten Hohen aus den Poren herausströmt / und das Atmen kramphaft stockt in der Atmosphăre, welche die Welten durchsausen! // Ihr, die ihr berauscht vom Geheimnis der Tiefen erblaßtet, wo das irdische Licht erlischt / /... / und die ihr das Leben auf Spinnennetzasern des Gedankens aufhinget, im Hochmut zu einem Seil gewunden!"; vgl.: "Od moji myšlenky odpoutej zemskou tíz, I at svètla rychlostí prostorem stehá $v$ let /.../ $v$ hloub sopek vyastých i $v$ zemé žhavý

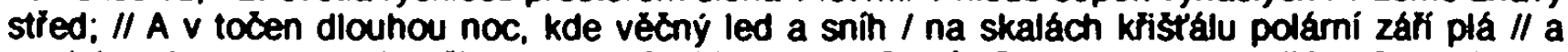
modrym plamenem nad bażinou se skvi"; Modlitba vecerni / Das Abendgebet, IV, 1-2, 4; V, 1-2; VI, 6; "Von meinem Gedanken entfessle die irdische Schwere, / daß er mit Lichtgeschwindigkeit durch den Raum im Fluge saust /.../ in die Tiefe der ertosch'nen Vulkane und in die glühende

vysoké, anistokratické uméni pro vyvolené. O dav a o zábavu davu at se stará kdo chce. Potom mi nic neni.l... písi pro své bratry, pro ty, ktełi çtí a smýsti jak já /...r. (O. Błezina, Dopisy F. Baverovi, Praha 1929, S. 202. "Die Kunst ist kein Spielzeug für die kindlichen Hănde der Masse. Ich hasse das banale Lied, rufe ich mit Carducci. Ich will eine hohe, aristokratische Kunst für die Auserwählten. Um die Masse und ihre Unterhaltung soll sich kümmern, wer will. Das geht mich nichts an. I.../ich schreibe für meine Brüder, für diejenigen, die fühlen und denken wie ich").

246 Urs Heftrich (Otokar Biezina, Heidelberg 1993, S. 122t.) vergleicht die "Herrscher der Träume" mit Platons "aus der Hölle Herausgekommenen", deren Wissen vom Jenseits sie in der Welt der realia in die Isolation treibt. Sosehr die Reminiszenz an Platons Hohle-Parabel auch einfallsreich ist, dart man nicht übersehen, daß es nicht (nur) das Wissen vom Jenselts ist, das die Traumherrscher zur ominōsen Entfremdung verurteilt, sondern und vor allem ihre bewußte. absichtliche Abkapselung in der fiktionalen Kunstwelt und inre Verachtung der "Săttigung durch die Erde". Die charakteristische Eigenschaft der Traumherrscher ist doch ihre Hochmütigkeit (III. 3; "a vaše pýcha", XI, 4). Die Kritik an Vladari snú richtet sich doch gerade gegen inre "Reduktion' des (realen) Lebens auf ein 'ideelles Abenteuer': "zavésili żiti na pavučinná vákna myšlenky "(III, 3: "die ihr das Leben auf Spinnennetzfasern des Gedankens aufhinget"). Diese Kritik kann auch als eine Auto-Kritik gelesen werden, denn in einem Brief (1895) an Fr. Bauer schreibt Biezina: "Jenom za to dékuji bohu, že jsem I...I nauxil se žíti i trpéti Cistým żivotem myšlenky" (in: Dopisy Otokara Bieziny Frantisku Baverovi, Praha 1929, S. 211; "Schon dafür danke ich Gott, daß ich I...' gelernt habe, das reine Gedankenleben zu leben und daran zu leiden"). Sehr richtig sieht U. Heftrich (a.a.O., S. 123) den Unterschied zwischen dem "Wahnsinn" der Traumherrscher ("Trpèli jste šlenstvim grotesknich vidin", VIII, 2) und dem der Masse ("I.../ svatá místa, spustosená silenstvim davu?" III, 4). Heftrich deutet den "Wahnsinn" der Traumherrsche als Analogon des Schmerzes der "aus der Höhle ins Überhelle Hinausgetretenen" und als "heiligen Wahnsinn" ("svaté Ślenstvi". Tajemstvi bolesti / Das Geheimnis des Schmerzes, [SZ] V, 6), d. h. als Attribut des Genies. Allerdings dart man auch in diesem Falle ein wichtiges Detail nicht außer acht lassen: der "Wahnsinn" der Traumherrscher ist nicht der "heilige Wahnsinn" aus Tajemstvi bolesti. sondern der "Wahnsinn grotesker Visionen" ("Silenstvi grotesknich vidin", VIII, 2), wodurch die Werthaltung der Traumherrscher (in ihrer fiktionalen Schein-Welt) in Frage gestellt, ja devalviert wird. Der ironisch-herabmindernde Akzent dieser Verszeile (VIII, 2) ist offenkundig. 
Erdmitte; / Und in die lange Nacht der Pole, wo das ewige Eis und der Schnee auf Kristallfelsen im Polarlich glitzert // und als blaue Flamme über dem Moor leuchtet).

In diesem status quo des 'Sich-Einspinnens' in eigener Gedanken- und Traumwelt fristen die "Herrscher" ihr Desein als überreizte "Liebhaber des Halbdunkels" ("milenci polosera", IV, 1), die sich vergeblich nach der Erlösung aus dieser Lage sehnen: "nemocni touhou po objeti duši" (IV, 3; "krank vor Sehnsucht nach der Umarmung der Seelen"). Die im Text präsenten Motive der Dunkelheit und Finsternis ("zatměni nocr", IV, 1; "zachmurenou Żádost", V, 4), des 'abgeschwächten' Blickes ("Milenci pološera", IV, 1), des erloschenen Lichtes ("kde hasne pozemské svètlo", III, 1) oder des unsichtbaren Spektrums ("Duše vaše v lítostech pohlcovaly naráženi neviditelných barev prodlouženého vidma", VI, 1), konkretisieren die paradoxe, passive und tragische Weder-noch-Position der "Herrscher" in der Rolle der bizarr exaltierten "Liebhaber des Halbounkels" ("Milenci polosera"). Die Finsternis, die sie umgibt, ist die Folge des schmerzhaften Sich-in-sichselbst-Zusammenkrampfens im gedämpften, für das Urlicht undurchdringlichen Halbdunkel ihrer eigenen Projektionswelt. Aus diesem (psychischen) Ausnahmezustand versuchen sich die "Herrscher" zu befreien. Zunächst durch den "Hymnus an den reinen Kuß" ("Hymnus jste zapéli cistému Políbeni!" (IV, 4).

2. Der Befreiungsversuch (IV, 4-V, 1-3 + I, 1-4). Gemeint ist die "reine" spirituelle Bruderliebe ("nemocni touhou po objetí dusi, jemném jak sliti paprskủ zbratíených barev!": IV, 3) einer 'Gemeinde', die zur $g$ e $m$ e i n s a m e $n$ Eucharistiefeier zusammenkommt, um am $g$ e $m$ e i $n$ s a $m$ e $n$ Glaubensakt zu partizipieren. Das ist das Thema der ersten Strophe, deren Handlung im Präsens und in der 1. Pers. PI. wiedergegeben wird, um den Eindruck der Gemeinsamkeit und Verbundenheit zu potenzieren. Daher liegt hier der Hauptakzent auf dem Aspekt des Gemeinsamen: "společné kaditelnice" (I, 2), "spoleché modlitby" $(I, 3)$. Das lyrische Ich identifiziert sich mit dieser Gemeinde:247 "Bratưi, jichż duše klekaji vedle duše mé v svatynich Nepoznaného" (l, 1). Die Vorstellung des gemeinsamen Schicksals verstärkt noch die somatische Semiotik (taktile Berührung, unmittelbare Nähe des körperlichen Kontakts usw.) der thematisierten Handlung: "jichż duše klekaji vedle duše me" (I, 1); "jichż ruce se dotýkaji mých" (I, 2): "sbliženi opojenim spolecné modlitby" $(1,3)$. Das, was die "Brüder" verbindet, ist die hieratisch-performative Gestik: der "Rausch" ("opojeni") das gemeinsame Gebet, der gemeinsame Weihrauchkessel (1, 1-2), das Geheimnis der Eucharistie, d. h. der Glaube und das mit ihm verbundene Ritual ("sypeme zrni na uhli společné kaditelnice", I, 2; "wenn wir das Korn auf die Kohle des gemeinsamen Rauchfasses streuen"). Explizit wird auch das Medium dieser Ver-Einigung genannt: "sblízeni opojením společné modlitby, již prijali jsme dèdictvím vékü" (1, 3; "verwandt durch den Rausch des gemeinsamen Gebets, 248 das wir als Erbgut der Äonen empfangen"). ${ }^{249}$ Doch der "Hymnus auf den reinen Kuß" (IV, 4), die

247 Die Vorstellung von einer elităren Gemeinschaft der Ausnahmepersönlichkeiten, einer Bruderschaft der Glaubenden", kommt der gnostischen Tradition sehr nahe. Das letzte Gedicht von SZ, Vino silných (Der Wein der Starken) stellt ein Beispiel par excellence dar. Die Schopenhauer-Rezeption machte Błezina auch auf die Upanishaden aufmerksam. Diese Vorstellung deutet auf gewisse Berühnungspunkte mit der Tradition der christlichen Gnosis hin. Die christlichen Gnostiker verstanden sich als Christen und sie bezeichneten sich sogar als "Jünger Christi". Selbst der Ausdruck "Kirche" (ekkesia) wurde, laut K. Rudolph, von der Gnosis übernommen; sie stellt die "Gemeinschaft der aAuserwählten», der Pneumatiker, des Lichtsamens" dar. Vgl. Kurt Rudolph, Die Gnosis, Göttingen 1990, S. 223f. Die 'Brüdergemeinde' der ersten Strophe erinnert an eine gnostische Gemeinschaft (der auserwăhlten Pneumatiker), die an einem Mysterium teilnimmt. Signifikanterweise findet dieses Mysterium im Tempel des "Unerkannten" ("Nepoznaného") statt. Die von Błezina verwendeten Bezeichnungen ("Ewiger", "Höchster", "Allgegenwärtiger" usw.) der höchsten Instanz, erinnern an die Ausdrücke der Gnostiker, die 2. 8. mit dem Ausdruck "der Ewige" im engeren Sinne den Weltherrscher bezeichneten. Vgl. Wolfgang Schulz, .Dokumente der Gnosis", in: Gnosis und Gnostizismus, hrsg. v. K. Rudolph, Darmstadt 1975, $252 f$.

248 K. Rudolph (Die Gnosis, Göttingen 1990, S. 328ff.) zitiert einige Gebete der christlichgnostischen Gemeinden. Das gnostische Gebet ist vor allem ein inneres Bedürnis des "Verstandes", das der Erkenntnis dient.

249 Man kann in diesem Zusammenhang von der sog. "soteriologischen Brüderethik" sprechen, deren Bedeutug in der gnostischen Tradition Hans Jonas (Gnosis und spätantiker Geist, Teil 1,2, Tübingen 1964, S. 170 f.) als einer der ersten in der Gnosis-Forschung erkannt und treftend formuliert hat: "Dem Solipsismus, der zunächst aus der Vereinsamung des für sich 
"Kantaten zum Lob der Himmelsfahrt" (V, 1), d. h. die Verlagerung der "Leidenschaften" ("vinami vášnt, IV, 2) und der "finsteren Begier" ("zachmurenou zádost", V. 3-4) der "Herrscher" auf kultisch-liturgische 'Performanz', bieten - genauso wenig wie das sublime Projekt ("Hymnus jste zapęli /... / // Hymnus koupaný $v$ reminiscencich kantát $k$ oslavè Nanebevzeti", IV, 4; V, 1) und die gemeinsame Eucharistiefeier (I. Str.) - keine wirksame 'Erlösungsmethode' an und können daher nicht zur ersehnten Befreiung führen. Der Befreiungsversuch scheitert und dieses Scheitern zieht auch das fatale Rezidiv nach sich (Str. VI-XI). Die Ursache kommt in der fünften Strophe klar zum Ausdruck: "/.../ záreni

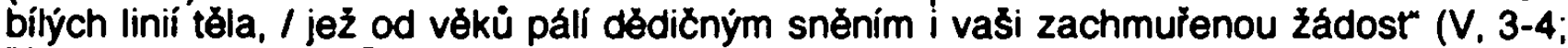
"I...I das glühende Strahlen der weißen Linien des Körpers, des siegreichen, der seit Äonen mit erblichem Träumen auch eure düstere Begier sengt"). Es is der "siegreiche Körper" ("vítěznè tělo"), den die "Herrscher" besiegen müssen, um die postulierte Befreiung zu erreichen. Das, was (noch) fehlt, ist offensichtlich die Kraft, von dem geradezu verhaßten irdischen Körper - und damit auch von der peinigeden "düsteren Begier" (V. 4) - loszukommen: das Ziel aller Gnostiker. 250

3. Scheitern des Befreiungsversuches - das Rezidiv (Str. VI-XI). Das Rezidiv des Zustandes der Unzufriedenheit scheint nach dem Scheitern des Befreiungsversuches noch unerträglicher zu sein, weil die (vergebliche) Sehnsucht jetzt noch der Hohn (" $O$ Vitězi, jichž kởist je posměchem neprátel a lítostí pł̌átel!", $\mid X, 1)$, die Demütigung ("Poniżeni vacite se $v$ domov $/ . . . ", I X, 3)$, die "grotesken Halluzinationen" ("Trpéli jste šlenstvim groteskních vidin, mozek ranéný úpalem krásy" (VIII, 3) und die (schöpferische) 'Impotenz' ("vaše setba tropických nádher vyrüstá bilá a mrouci v severnich sluncích", XI. 2) komplettieren. Das signifikante Merkmal dieses Rezidivs ist die Pervertierung: das Verb "zvrhnout" ("ausarten"), das das bittere Los der besiegten "Herrscher der Träume" konkretisiert ("a vaše pýcha, jeż povrhla nasycením zemę, zvrhne se výsmèšné v touhu I... $\mu$. XI, 4), deutet darau' hin, daß das autistische 'Sich-Einspinnen' in der autarken Kunst-Welt zur psycho-physischen Qual p e r ve r t i e r e n kann. Ähnlich pervertiert auch die kreative Traum-Imagination zu "grotesken Visionen" ("Trpéli jste šlenstvím groteskních vidin", VIII, 2), zur 'leeren' Fiktionalităt und Wirkungslosigkeit ("nikdo nevēri vašim zvěstem", IX, 4: "keiner glaubt euren Botschaften") und die schöpferische Potenz zum

entdeckten, puren Selbst in der entfremdeten Welt folgt und nach seiner praktischen Seite einzig die Lösung von den weltlichen Verklammerungen. Steigerung der Differenz, kurz die Entweltlichung des is olie rten Selb st fordert, gesellt sich, ohne inn aufzuheben, eine soteriologische Brüderethik, die aber von der diesseitigen Gesellschaftsethik der Antike weltenweit absteht. Nicht mehr wie dort positive Gestaltung des welttichen Miteinanderseins, das durch die gemeinsamen innerwelttichen Interessen vermittelt wird, und als letzter Sinn dieser Gestaltung die Eingliederung des Menschen in den Kosmos, sondern, unter Überspringung der ganzen diesseitigen Sphăre und ihrer Individuation, einzig die Förderung der Erlösung im Anderen, $d . h$. seiner Entweltlichung, die Jedem zum vehiculum der eigenen wird, ist das Ziel dieser Ethik; ihr Subjekt nicht das konkrete Individuum, sondern nur noch sein unpersönlicher, nichtweltlicher Kern, der <Funke>, der in allen identisch ist; und die Basis, die dieses Miteinander stiftet, worin seine konstitutive Begegnung stattfindet - gemeinsame Einsamkeit in der zur Fremde gewordenen Welt". Einige Aspekte der (so charakterisierten) gnostischen "Brüderethik" scheinen vor allem für das Gedicht Vino silných (Der Wein der Starken) von zentraler Bedeutung zu sein, denn in diesem Text wird das Thema der aristokraktischen Isolierung von den 'Anderen' wiederaufgenommen. Allerdings geht es in diesem Text nicht um die solipsistische isolierung des Individuums, des dekadenten Künstler-Menschen, sondern um einen gewissen 'aristokratischen Separatismus' einer elitären 'Brüdergemeinde': der "Starken". Die Teleologie Blezinas lyrischen Schaffens, seine Semantik und Axiologie, sind bei weitem nicht so geradlinig und 'überschaubar', wie einige Brezina-Interpreten meinen. Immer wieder werden ganze Symbolkomplexe und Werthaltungen in seinen Gedichten reaktualisiert, überlagert, transformiert usw., allerdings unter einem neuen semantischen Kode. Aus dieser Perspektive erscheinen einige Gedichte als "Vor-Texte", in der Terminologie Starobinskis (Worter unter Wortern. Die Anagramme Ferdinand de Saussures, Frankfurt am Main 1980. S. 17). Die in der ersten Strophe von Vladari snú dargestellte kultische Handlung wird in Vino silnych als eine Eucharistiefeier (weiter-)entfaltet. Es ist kein Zufall, daß die beiden Gedichte mit der identischen Apostrophe "Bratti..." ("Brüder...") beginnen.

250 Błezina formuliert diesen Gedanken explizit in einem Brief an Anna Pammrová (Sommer 1896. noch zwei Monate nach der Herausgabe von SZ): "Vúle dominujici, vitézná a jasné oú nepotrhané vášni. I.../ Jen ten, kdo potlacil pohlavi, mủže by̆t Magem, despoticky vládnouci vưli" ("Der dominierende Wille, der siegreiche, und die von der Leidenschaft nicht verblendeten Augen. I... / Nur derjenige, der die Geschlechtlictikeit überwunden hat, kann zum Magier werden, der ûber den Willen despotisch herrscht") 
Erlebnis der Selbstverneinung, der peinlich erniedrigenden Autoerotik (IX. - XI. Str.), konnotien als "Wahn", "lllusion", "Trug", "Unsichtbarkeit", "Stummheit", "geheime Sünde", "Erniedrigung" oder "Wehmut": "Duše vaše v lítostech pohlcovaly narázeni neviditelných barev prodlouženého vidma, / trpély oviváním neznámého chvẻní a smutkem neslyšeného pláce; illuse véci - iekli o vás - hořela chorobným klamem ve vaši duši“ (VI, 1-3). Die "besiegten Herrscher" leiden auch unter der Devaluierung des (poetischen) Wortes und der a ktiven schöpferischen Imagination ("trpéli jste bolest́ slova, sesláblého a znechuceného nánosem let, / osleplého jak zrcadla kovu /... $\mu$ : VIII, 2-4), sie scheinen jedoch nicht mehr imstande zu sein, den Zustand der unheilvollen Passivität und Unzufriedenheit zu ändern. 251

Während in der neunten Strophe das Tempus erneut ins Präsens wechselt, um die Schwächen und das Scheitern des Befreiungsversuches noch einmal zu verdeutlichen, wechselt das Tempus in der zehnten Strophe ins Futur. Dies ließe sich, wie schon erwähnt, als 'Warnung' für die Zukunft interpretiert: die weiteren Befreiungsversuche dieser Art ("Bledost vaseho procitnutí jak znameni tajného hr̈íchu vás zradi", X, 1) können erst dann erfolgreich und sinvoll werden, wenn die richtige - jetzt noch fehlende 'Erlösungsmethode' gefunden wird. Bis dahin müssen die "Herrscher der Träume" ihre eigene schöpferische Wirkungslosigkeit und Impotenz als 'Leere', 'Entfremdung', 'Irrealităt', 'Halluzination' und 'Gefühlskälte' ertragen. Das Opus der "Herrscher" wird als reines Auto-Produkt des Ich-Bewußtseins demaskiert. Diese "Beute" ("korist") ihrer schöpferischen Individuation gleicht einem Pyrrhussieg: "O Vitézi, jejichż kořist je posmẻchem nepiátel a lítostí prátel! / Poniżeni vracíte se v domov /.../ kde nikdo neverri vašim zvéstem, sycemým vưnémi jihu" $(I X, 1,3-4)$. Daraư bezieht sich auch das Motiv der "Erniedrigung" ("ponizeni"); es ist die "Erniedrigung" des Versagens, das wiederum mit dem "Zeichen der heimlichen Sünde" $(X, 1)$ korreliert: "Bledost vašeho procitnutí jak znameni tajného hríchu vás zradi" $(X, 1)$. Die Wiederkehr aus der fiktionalen Traum-Welt in die Welt der realia hat nicht nur die Wirkungslosigkeit $(I X, 4)$, sondern auch die Entfremdung zur Folge: "Úsměvy druhư zhasnou pỉed vašimi zraky, $v$ nichż třese se zárení dálek! (X, 2; "Das Lächeln der Gefährten erlischt vor euren Blicken, in denen das Strahlen der Fernen bebt!"); "Truchlí pưjdete zahradami /.../, jichž vưnẻ vám ciż" (XI, 1; "Traurig werdet inr durch die Gärten schreiten $/ . . . /$, deren Düfte euch fremd sind"). Die "blutleere Blässe" ("Bledost vašeho procitnutf", $X, 1$ ), die erotische Kälte ("studené je dotknuti Zeny", XI, 3; "kalt ist die Berührung der Frau"), die Müdigkeit ("únava mihami padá", XI, 3), die Erfahrung der Gleichgültigkeit ("Ihostejné potkání duši", XI, 3), lassen die postulierte schöpferische Isolation in frustrierende Wirkungslosigkeit ausarten. Die hieratisch-performative Verbrüderungsgestik der ersten Strophe ("Brat̛̃i, jichž duse klekaji vedle duše mé ve svatynich Nepoznaného, I jichż ruce dotýkaji se mých, kdyż sypeme zrni na uhlí společné kaditelnice, I sblizeni opojenim společné modlitby /... $r, 1,1-3$ ) verkehrt sich in der letzten Strophe ins genaue Gegenteil: "studené je dotknuti Zemy, lhostejné potkáni dus'" (XI, 3; "kalt ist die Berührung der Frau, gleichgültig die Begegnung der Seelen" vs. "objetí duši" I "Umarmung der Seelen", IV, 3), unava mlhami padä" (XI, 3; "die Ermattung fällt im Nebel"). Diese spöttische Pervertierung der ästhetischen Existenz der "Herrscher der Träume" wird in der letzten Strophe als Strafe für ihre hochmütige Ablehnung der "Sättigung" durch die Erde indiziert: "a vaše pýcha, jež povithla nasycenim zemé, zvrhne se výsmésnè v touhu / ssáti vyschlou štávu téch hroznủ, / které jste rozmačkali, bezděčnè, ve svém královském sněni" (XI, 4-6; "und euer Hochmut, der verächtlich die Sättigung der Erde ablehnte, wird sich spöttisch in die Sehnsucht verwandeln, / den ausgetrockneten Saft jener Weintrauben zu saugen, / die ihr, unwillkürlich, in eurem königlichen Träumen zerquetschtet" ${ }^{\prime \prime}$.

251 Interessant ist die Parenthese in der sechsten Strophe: "iluse věci - łekli o Vás - hớela chorobným klamem ve vaši dusi" (VI, 3). Die Formulierug "felki o vás" ("man sagte von euch") läßt mehrere Interpretationen zu. Sie könnte z. B. eine distanzierte Position des dichterischen Ich gegenūber der Kritik seitens des konservativen Lagers in der zeitgenossischen tschechischen Kultur markieren, als 'Verteidigung' des 'Dienstes' am Kult der Kunst, dieses raison d'être des dekadenten Künstlermenschen. Daß Błezina in seinem Werk auch zu aktuellen kulturgesellschaftlichen Ereignissen und Problemen Stellung einzunehmen wuBte, betont und beweißt $M$. Cervenkas originelle Interpretation des bekannten Gedichts Modlitba za nepprátele (Das Gebet für die Feinde) aus dem dritten Gedichtzyklus Vẻtry od pólú (Polarwide). M. Cervenka, .Modlitba za neprátele", in: Styl a význam. Praha 1991, S. 11-31. 
Liegt dieser Pointe nicht ein evidenter Widerspruch zugrunde? Denn der Befreiungsversuch der "Herrscher" scheitert doch an der Macht des "siegreichen Körpers", der (in der gnostischen Tradition) durch seine stumpfe Materialität den nach der Erlosung sich sehnenden Menschen an die gegenständliche Welt fesselt. Und in dieser Welt, für deren Negation als eines Machtsystems die "Herrscher der Träume" bestraft werden, sollen sie ihre schöpferische Potenz durch die "Sättigung der Erde" ("nasycením zemé", $X I, 4)$ wiedererlangen? Mit der "Sättigung der Erde" meint Bïezina offensichtlich die für den (künftigen) ascensus notwendige produktive Enfahrung der tellurischen Existenz, den descensus: eine der Leitideen des gesamten Zyklus. Oder: Das Gedicht Vladari snú disponiert noch über ein anderes Sinnangebot, auf das ein Brief Biezinas (vom Sommer 1895) an seinen Freund František Bauer hindeutet, der das Gedicht als eine fiktive Polemik mit Bauer erscheinen läßt. In diesem Brief bezeichnet Bïezina sich selbst als "Herrscher der Träume": "I my, zhor̈klí a vyděděnii vadarii snú ...". ("Denn auch wir, die verbitterten und enterbten Herrscher der Träume..."). Wie schon erwähnt (Kap. 2.3.2), antwortet Br̈ezina auf einen Brief seines Freundes Bauer, in er dem Dichter seine Heiratspläne offenbart. Bïezinas Antwort, ihr Unterton, birgt eine beinahe schmerzvolle Enttäuschung in sich. Im Zusammenhang mit der Analyse der kommunikativen Struktur des Gedichts Motiv z Beethovena (Kap. 2.3.2) wurde gezeigt, wie sehr Bïezina bemüht war, seinen einstigen Kommilitonen für den $\mathrm{g}$ e $\mathrm{m}$ e in s a $\mathrm{m}$ e $\mathrm{n}$ 'Dienst' am Kult der Kunst zu gewinnen, ihm den Gedanken zu sugge ri e re n, er sei für das Los des Künstlerschöpfers auserkoren. In diesem Ton ermahnt ihn Bïezina an die gemeinsamen Pläne und Ideale des Kunstschaffens. Nun schreibt Bïezina an Baver:

"Beztoho, máš docela pravdu: žena! Tady konçi všechny aspirace krve a snu, nadšeni i sily. Jeji úsmèv dřimá na dnẻ všech duši. Jeji objetí je bilý zázrak života!252 I my, zhởkli a vyděděni vladałi snu், cátime jeji mocné kouzlo! Płeji Ti, aby vstoupila ve Trujj żivot se světlem v ruce, jak si to malujes ve zpivajicich ilusich. Ve snu, kterým jest żivot, uvítej sen, kterým jest láska. Jak to povidá Mistr Verlaine?253 /... / Je to věcná iluse Clověka bỷti štastným. A bylo by marné diskutovati dnes s Tebou o tom. Zrovna tak jako diskutovati o novém rozpéti uměleckých aspiraci, połom... jak píseš. Reknu Ti zpríma: jsi štastně organisovaná bytost, nadaná uměleckými disposicemi v tẻ mî̉e. že chutnás uméni v sladkém jeho povichu jako vonný desent - ale tu prudkou vášeñ zžirajici ideje, tlukouci všemi kłidly, pijici všechnu krev, stỉebajici ze všech miz, vítéznou, transcendentni, hlubokou rozkoš zoufalstvi a sily, vášen bezohledné tvorby, která je sama sobẻ úcelem a sotva z Cásti dá se nalíti v nejdelši živơ - tu nehledej v sladkém zapomenutí, které prináśi láska, jakou je podle vsech přznakủ Troje. I.../ Zamysli jsem se teskné nad Trým psanim; ale - marnẻ utápẻt se $\checkmark$ nedostižitelném - mné nezbývá neż jíti kupł̉edu, dál, kam musím, na horká výsluní, kam jsem zamífil a kam doj du. l.../ Budu-li Żv , dojdu, kam chci dojíti a musim dojíti. A kdyby mủj Żivot mél na to padnout, dojdu. Nikdy dosud jsem nevidél svou dráhu jasnéji píed sebou, neż dnes. Jaká kletba, płíteli! A jaká rozkoš! Ale nebudu Té nudit lícenim śleného toho buráceni duše spoutávané a vedené, klesajici a vztyčené - toho prilivu a odlivu sil, které tvori bolest a żivot". 254

252 Vgl. \%... nemocni touhou po objeti dusi /... (IV, 3; \%../ krank vor Sehnsucht nach der Umarmung der Seelen"). \%... snih hvêzdných krystalù vưni, padajici v rozžhaveni záreni bilých lini tẻla, I jeż vítězné I... (V, $3 ; \%$... S Schnee von Sternenkristallen der Düfte, der ins glühende Strahlen der weißen Linien des Körpers fällt, des siegreichen /... $\digamma$ ).

253 An dieser Stelle zitiert Blezina die Verse von Verlaine: "L'heure du thé fumant et de livre fermés; / La douceur de sentir la fin de la soirée; / La fatigue charmante et l'attente adorée / De l'ombre nuptiale et de la douce nuit, I Oh! tout cela, mon réve attendri le poursuit / Sans reláche $\therefore$ ("Die Bücher zu, der Tee heißdempfend eingeschenkt; / Das Glücksgefühl, daß bald der Tag zu Ende ist, / Die schöne Schläfrigkeit, das göttliche Gelüst / Auf hochzeitliches Dunkel, auf die süße Nacht - / All das verfolgt mein Traum /... F. Paul Verlaine, Gedichte, Franzōsisch / Deutsch, übers. und hrsg. v. Richard Berger, Stuttgart, 1988). Es handelt sich um ein Gedicht (Nr. XIV) aus Verlaines La Bonne chanson. Der Umstand, daß Biezina gerade Verlaine zitiert, scheint kein Zufall zu sein. Man denke nur an die Peripetien der unglücklichen Ehe Verlaines, an seine Beziehung zu Rimbaud usw.

254 Vgl. O. Biezina: Dopisy Franisku Bauerovi, Praha 1929, S. 209-211. "Außerdem, Du hast völlig recht: die Frau! Hier enden jegliche Aspirationen des Blutes und des Traumes, der Begeisterung und der Kraft. Ihr Lächeln schlummert aư dem Grund aller Seelen. Ihre Umarmung ist das weiße Wunder des Lebens! Auch wir, die verbitterten und enterbten Herrscher der Träume, spüren ihren mächtigen Zauber! lch wünsche Dir, daß sie in Dein Leben mit dem Licht in der Hand eintritt, wie Du es Dir in den singenden Illusionen malst. In einem Traum, namens Leben, begrüße 
Dieser Passus scheint ein klärendes Licht aut den Hintersinn von Vladarii snú zu werfen und umgekehrt kann man jetzt - nach der Rekonstruktion der Sujetlogik dieses Gedichts - den Sinn der oben zitierten Zeilen besser verstehen. "I my, zahoikklí a vydëdëni vladarii snú $I . . . /$ ("Auch wir, die verbitterten uns enterbten Herrscher der Träume $/ . . . r$ ): Nicht nur Biezina, auch Bauer ist ein "Herrscher der Träume", weil er sich dem Traum, der Selbsttäuschung der Liebe, hingibt. Der Illusion des (Liebes-)Glücks das Kunst-Ideal ("jegliche künstlerische Aspirationen") zu opfern, gleicht einem Pyrrhussieg: "O Vitězi, jejichž kořist je posmẻchem neprátel a lítost práter (IX, 1). "Tady konďi vł̌echny aspirace krve a snu, nadseni i síly" ("Hier enden jegliche Aspirationen des Blutes und des Traumes, der Begeisterung und der Kraft"), schreibt Bïezina an Bauer. Den "siegreichen Körper" kann man nicht mit einem "Hymnus auf den reinen KUß" besiegen. Das meint Bỉezina offensichtlich auch allgemein, nämlich als Replik auf die Kritik der symbolistischen Kunst (s. die Paranthese: "(iluse věci - rekli o vás - hoỉela chorobným klamem ve vaśí duši)", VI, 3). Man kritisiert das Eintauchen der Symbolisten in die illusive Traum-Welt und dabei verharrt man "ve snu, kterým jest živor" ("im Traum namens Leben"). Auch Biezina ist ein "Herrscher der Träume“. Seine Faszination von den "geheimnisvollen Fernen" (ver-)führte inn zwar auf den Irrweg des Ästhetizismus, aber den Ausweg, die (Er-)Lösung, kann man nur dann finden, wenn man vorwärts schreitet und weiter s u c h t ("mnë nezbývá neż jíti kupiedu, dál ..." I "mir bleibt nichts anderes übrig als vorwärts zu gehen, weiter ..."; an Bauer, s. o.), ohne Rücksicht auf schmerzvolle Rezidiven, Teilerfolge, Verluste usw. Die "Leidenschaft des rücksichtslosen Schaffens" ("vášeň bezohlednẻ tvorby"; an Bauer) scheint die Triebkraft, die exhortatio dieses Weitersuchens zu sein. Damit koinzidiert ein anderer wichtiger 'Schritt' auf dem 'Lebens-Weg': das Streben nach der Entdeckung des Positiven und Produktiven im Negativen, die das Verständnis des Negativen als eines (notwendigen) Elements des Positiven ermöglichen würde. Die "Flut und Ebbe der Kräfte, von denen der Schmerz und das Leben herrühren" ("príliv a odliv sii, kterẻ tvorí bolest a Żivot"), heißt es im zitierten Brief an Bauer. Die eigene schöpferische Entwicklung beschreibt Bïezina als "Fluch" und "Wonne" zugleich: "Jaká kletba, príteli! A jaká rozkos? ?. "rozkos zoufalstr' a sily" ("die Wonne der Verzweiflung und der Kraft"). Das ist das Prinzip der oxymoralen Semantik von "Svitáni na západë". Es ist aber nicht der "siegreiche Körper", der das "Vergessen" ("zapomenuti") der bedrückenden Realität bringt, sondern die schöpferische Arbeit, das Kunstschaffen. 255 Daher schließt Biezina diesen wichtigen Brief an seinen Freund mit dem Bekenntnis ab: "Jenom za to dékuji bohu, ze jsem se emancipoval z hloupého piemítnutí hodnot a naučil se żíti i trpěti $Z$ i s tý $m$ Żivotem myšlenky". ("Schon dafür danke ich Gott, daß ich mich vom dummen Nachdenken über die Werte emanzipierte und daß ich lernte, das r e i n e Leben des Gedankens zu leben

den Traum namens Liebe. Wie sagt das denn Meister Verlaine? /... / Es ist die ewige lllusion des Menschen glücklich zu sein. Und es wăre vergeblich heute mit Dir darüber zu diskutieren. Genauso wie eine Diskussion über die neue Spannweite der künstlerischen Aspirationen. nachdem ... wie Du schreibst. Ich sage es Dir direkt: Du bist ein glücklich organisiertes Wesen, mit künstlerischen Dispositionen in dem Maße begabt, daß Du die Kunst auf inrer süßen Oberflăche wie ein wohlduftendes Dessert genießt - aber die heftige Leidenschaft der verzehrenden Idee, die mit allen Flügeln schlägt, alles Blut trinkt, aus allen Săften die siegreiche, transzendente, tiefe Lust der Verzweiffung und der Kraft einsaugt, die Leidenschaft des rücksichtslosen Schaffens, das selbstwertig ist und sich kaum, auch nur teilweise, in das lảngste Leben eingießen lảßt - die kannst Du nicht im süßen Vergessen suchen, das die Liebe bringt, die glückliche Liebe, wie die Deinige es nach allen Merkmalen ist. I.../ Wehmütig dachte ich über Deinen Brief nach; aber - es ist sinnlos sich im Unerreichbaren zu ertränken - mir bleibt nichts anderes übrig als vorwărts zu gehen, weiter, wohin ich muß, auf die heiße Sonnenseite, zu der ich meine Schritte gelenkt habe und die ich auch e r r e i ch e. I.../Solange ich lebe, komme ich hin, wohin ich kommen will und muß. Auch wenn es mich mein Leben kosten sollte, komme ich hin. Ich habe noch nie meine Laufbahn so klar vor mir gesehen wie heute. Welch ein Fluch, mein Freund! Und welch eine Wonne! Aber ich werde Dich nicht mit der Schilderung dieses wahnsinnigen Tosens der gefesselten und getührten, niedersinkenden und aufgerichteten Seele -, dieser Flut und Ebbe der Krätte, von denen der Schmerz und das Leben herrühren, langweilen"

255 "Jinak je mưj żivot smutný, zahởklý chudobou, která mne mláti na každém kroku, bez jedinéno okamżiku rozkosee, mimo chvili zapomenutí v práci /... . ("Ansonsten ist mein Leben traurig, verbittert von der Armut, die mich auf Schritt und Tritt prügelt, ohne einen einzigen Augenblick der Lust, bis auf eine kleine Weile des Vergessens in der Arbeit /...F). Vgl. den oben zitierten Brief an Bauer, S. 211. 
und zu leiden“. Sperrung von O.B.) ${ }^{256}$ Diese Aussage bildet allerdings das genaue Gegenteil zum 'kritischen Korrektiv' der Verszeile: "Vy, kteři jste /.../ / zavěsili żiti na pavučinná vlákna myšlenky, v pýše snovaná v lano!" (III, 1, 3; "Ihr, die ihr /.../ / das Leben auf Spinnennetzfasern des Gedankens aufhinget, im Hochmut zu einem Seil gewunden'"). Daraus resultiert, daß es sich offensichtlich nicht um eine Selbstkritik des dichterischen Ich, sondern um eine Kritik 'von a u Be $n$ ' handelt, vielleicht sogar um ein kritisches Argument - gegen die von Biezina postulierte 'Hingabe' an die Kunst - von Bauer, auf das Brezina mit seinem Brief und seinem Gedicht Vladari snú antwortet.

\subsubsection{Der Weg zur (Selbst-)Ertösung durch die Gnosis (rvw̃ots) Ranni modlitba (Das Morgengebet)}

"In Goll wird nichts erkannt: Er ist ein einig Ein.

Was man in ihm erkennt, das muß man selber sein."

"Weil ich das wahre Licht, so wie es ist, soll sehn. So muß ich selher sein. sonst kann es nicht geschehn."

Angelus Silesius: Cherubinischer Wandersmann, I, 285, II, 46

\section{Ranní modlitba}

Stan đemý smri, jež rozpíná duše na cestě své, aby odpox̌inula jsem svinul podle rozkazu tvého a obrácen $k$ východu světla fekl jsem myšlenkám, klečicím na nižových kobercích jitra: Modlete se!

5 Ó Nejvyక̌sí!

5 Tvůj úsměv mystický zatłásl zemi šlehnutím úrodné mdloby, nedox̌kavé hlasy v̌̌ech vưní zmateně vyvalily se $z$ nízin, żíznivé klasy prohnuly se s bolestnou rozkoši pod sesutím světla a zdravé vtáhnuti dechu radostně rozesmálo žijicí formy. Ale zraky milencủ se zatmèly bázní, vyhýbavé a kleslé

10 pod jiskfivým pohledem dne, $v$ němž svítí divoká Zádost nezrozeného. Jako hněvivý zrak dozorce daví a sil płelétl krajiny zemé. zachvěl se před ním zivot. zabourily dilny všech krví.

(blaky s drápy ohnivými vyhnal $z$ vod (schoulcné $v$ moři zárici hnizda). vpadl do stáda opilých vủní a hlas jejich zakfikl hněvem bilého záru.

15 ve varu svètel rozkypexl harvy, ţhavé je nastłikal v dušc a palčivým popelem okamžikủ posypal hlavy litujicích.

Hodinami zazvonil všem duším pơátek žné. ó Majiteli rolí a stád! Všichni viditelni i neviditelni služebníci vyšli na souvratě tvé, ale rachot tvých vozủ, naplněných úrodou, zahřmi jen do snění básnikú.

20 Trá bude úroda na polích lásky a $v$ zahradách, kde jaro omdlelo vưní. úroda chudých, zmờená suchem $v$ den setí a deštếm $v$ den metání klasủ. úroda těch, kteňi pohledy silly určují hranice majetku svého, úroda bolesti, s kvéty, jež hoři všemi barvami duši a jako přiliłs vytažené lampy. jež. kouři dusnými vůněmi smrti.

25 UUroda setby. jeż ceká pod sněhem času na dobu staletých táni. a královská úroda zmí nezasetého.

I já. jeden z nejchudక̌ich. vycházím poslušen na hlas tvěho zvonu na zdẽděnou líchu mých mrtvých. kde klekání ztichlá mi hlaholí z hučeni větrů. a onémlé hlasy $z$ šepotu stvolứ mne sili povzdechem dávna. 
30 Ó Věxny! Až zárem se rozpuká zemè, dej at sednouti mohu do tvých stínủ! Až umdlím, płrej, aby mé nadx̌je se napily vína Sumného budouci záři!

Až prací zrudnou mi tváre, nech je zlíbati pohledy mrtvých. a pot mého cela at ovivají étemé ruce těch, ktełí mne milovali.

Dej požehnání mým zrakủm, když utkví na bujném obilí šlastných,

35 a pevnost pohledu mému, když uzťi mystické znamení smrti na květech zahrad a duší! Hlasu mému dej hudbu lahodnou žencủm jak zvonéní o polednách

a písni mé sť̛íbmé kadence potoků uprostłed polí v Čas žíznè!

Dej, aby mé kroky vzbudily $z$ umdlení radostné cekání bratfí,

a na múj pozdrav aby vlídně odpověděli pospíchající!

40 Dej, at $v$ hněvivých pohledech neprátel dovedu uctíti záfení tajemství tvého a chvílím, ktere proti mně vyšlou, ał łeknu s úsměvem: Dẻlníci moji!

A nezasloužími-li, aby má ǩ̛idla se vznásela silou mého zraku,

at lítost má vznásí se silou. po nî̉ teskní má slabost!

Dej duš mé odvahu ml ̌ení, když jsi promluvil znameními,

45 a zahradám mým dosti niží, když nastane doba navíti věncủ!

Učin at pravda má jest podobna knize modlitební,

aby každý $v$ ní našel modlitbu svou, i zavržený a umírající!

A odrazí-li se věxné slunce $v$ mém slově, at $v$ radostnou extasi zardívá bratry

a kvêty jejich touhy at obrací k vex̌nému ohnisku zrání!

50 Dej, at $v$ paprscích úsmévu mého pel 2 polí mých padá na sousední líchy,

a dech bolesti mé at sráži se $v$ krystaly léků têm, ktełi hledáním onemocněli!

Ticho mé samoty naplñ šuměním kř́del sbratłených duší,

a okamžiky radosti mé at vonným deštěm se nad loži beze snů tresou

jako zpíváni harfy $k$ útěše zarmouceného.

55 Dej, aby mé myšlenky byly jak větry jarní, jež płinásejejí rytmus budoucím písním,

a jako vichłice, které nutí $k$ návratu chodce pł̌ed cestami smrti!

A umírajíce at podobny jsou těm kvěrnim (symbolủm setby $z$ jiného světa),

které, když vadnou úpalem denním, ještê jahodami voní.

Unaven prací a láskou a bolestí zlomen at usednu $v$ kvetoucí meze

60 a zbytek dne at strávím pohroužen, němý, ve věčnou hudbu tvých světel.

Až vexer se nakloní k zemi a zakłiknuté vưnè se vrátí,

i já pưjdu, pracovník osamělý, $k$ přibytkủm koư̌e stoupajícího.

Pod tvým stromem usednu, jenž vక̌emi prostory korunu kosatou zdvihá

a $v$ jehož cerném, ledovém listí zvoní tichem hvězdy jak věely v̧̌ech úlù;

65 má hrdost, zamlklá za dne, $k$ moji písni se vrátí,

polỉbením, jež nekonex̌nými ciní paprsky zrakủ, na ox̌i mne zlíbá;

a těm. ktefí poslechnou, s hlavou pyšně vzad skloněnou zpívati budu.

Zpívati budu tvé dějiny, jež $v$ dusích mrtvých národủ jásaly záłením dnełka

a v dư̌ich گ̌vyých neznámým jazykem budoucna mluví.

$70 \mathrm{~V}$ epickém toku vł̌ech barev, $v$ tisících tónù. bizarních rozkvětech hmoty. $v$ prostoru smrtelných tiłích, $v$ nichž buší kladiva skrytých tvých dilen,

kde formujes budoucí slunce pod klenbami nacernalými,

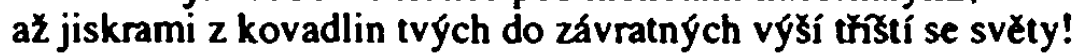

$V$ lyrismech tušení, $v$ silenstvích hrizy, $v$ sinavém tł̌esení záłi,

75 skkálami vášní, v notách dle klíxủ k płedznamenání smrti.

I rozpustí se má slova jak sưl $v$ žíravěm dešti tvé vláhy

a krystalovati budou v sršení jisker a v praskotu neznámé sily.

Barvami neviditelného vidma mé obrazy vzplanou. jiskłící slávou

stíny jejich budou položeny oslnuujicím záłením pozemských světel,

80 však jejich světla tvým stínem; a do tvých úbžżnych bodủ

paprsky jejich perspektiv se $v$ ohniska sleti.

I pozdvihne se mưj sen s křidly ozáłenými reflexy věčného jitra

a jako gigantský fantom orla zem ponese $v$ žhavých svých spárech,

na dvě strany rozhme Cemé oblaky nocí a lehne $k$ tvým nohám

85 a zrak své pýchy nastavi pokomé proklání pohledu tvého

a v syčícím výtrysku krve osleplý zárí. 


\section{Das Morgengebet}

Das schwarze Zelt des Todes, das die Seele auf ihrer Wanderung aufspannt, um zu rasten. rollte ich zusammen nach deinem Gebot und gewandt zum Aufgang des Lichtes sprach ich zu den Gedanken, die knieten auf den rosenfarbenen Teppichen des Morgens: Betet!

O Höchster!

5 Dein mystisches Lächeln erschütterte die Erde mit dem Blitzschlag fruchtbarer Ohnmacht. ungeduldige Stimmen aller Düfte wallten wirt auf aus den Niederungen,

dürstende Ähren bogen sich mit schmerzlicher Wollust unter dem Sturze des Lichtes. und das gesunde Einziehen des Atems machte freudig die lebenden Formen erlächeln. Aber die Blicke der Geliebten des Traumes wurden dunkel vor Angst, ausweichend und

10 unter dem funkelnden Blicke des Tags, in dem das wilde Verlangen des Ungeborenen lesunken Wie zümender Blick des Vogts von Scharen und Kräften durchflog er die Länder der Erde. vor ihm erbebte das Leben, ihm donnerten zu die Werkstätten jeglichen Blutes.

Wolken trieb er mit Feuerkrallen hervor aus den Wassem (geduckt in der Meere strahlende

Nester),

er fiel in die Herde trunkenen Düfte und schrie ihre Stimme zur Ruh mit dem Zorne

15 im Wallen der Lichter ließ er die Farben aufschäumen, spritzte sie glühend in Seelen, und die Loderasche der Augenblicke streute er hin auf die Häupter der Reuigen.

In den Stunden erklang allen Seelen der Emte Anbeginn, o Herr der Furen und Herden!

Alle sichtbaren und unsichtbaren Diener gingen hin auf deine Gewande, aber das Dröhnen deiner emtegefullten Wagen erdonnert nur in die Träume der Dichter.

20 Dein wird sein die Emte auf den Feldem der Liebe und in den Gärten, wo Lenz vor Duft liegt

Emte der Armen, heimgesucht von Dürre am Tage der Saat und von Regen am Tage in Ohnmacht.

Emte derer, welche mit Blicken voll Kraft die Grenzen ihres Besitzes bestimmen,

Emte des Schmerzes, mit Blüten, die in allen Farben der Seelen lodern und wie allzuhoch geschraubte Lampen, die in den schwülen Düften des Todes qualmen.

25 Emte der Saat, die unter dem Schnee der Zeit auf die Schmelze der Jahrhunderte wartet. und die königliche Ermte ungesäeten Saatguts.

Auch ich, einer der Ärmsten, folge gehorsam dem Klang deiner Glocke.

auf die Erbscholle meiner Toten, wo verstummtes Abendläuten mir tönt aus dem Brausen der

Winde,

und stummgewordene Stimmen aus dem Gefluster der Halme mich stärken mit dem Aufseufzen des Fementschwundenen.

30 O Ewiger! Wenn bersten wird vor Glut die Erde, gib, daß ich niedersitzen kann in deinen Schatten!

Bis ich ermude, gönn', daß meine Hoffnungen trinken vom Wein, der schäumt vor künftigem

Bis vor Fron mir die Wangen erglühn, laß sie küssen von den Blicken der Toten,

Glanze! und den Schweiß meiner Stime mögen die ätherischen Hände derer umwehn, die mich liebten!

Gib Segen meinen Blicken, wenn sie verweilen auf üppiger Saat der Begluckten,

35 und Festigkeit meinem Schauen, wenn es gewahr wird mystischen Zeichens des Todes auf

Blüten der Gärten und Seelen!

Gib meiner Stimme Musik, die wohlklingt den Schnittern, wie Läuten zu Mittag.

und meinem Lied die Silberkadenz der Bäche inmitten der Äcker, zu Zeiten des Durstes!

Gib, daß meine Schritte erwecken aus Ohnmacht das freudige Harren der Brider, und daß meinen Gruß die Eilenden guitig erwidern!

$40 \mathrm{Gib}$, daß ich in den zümenden Blicken der Feinde vermag zu verehren deines Geheimnisses

und $\mathrm{da} ß$ ich den Augenblicken, die gegen mich sie entsenden, lächelnd spreche:

Strahlen.

O meine Werkleuxe!

Und bin ich nicht wert, daß meine Flügel mit der Kraft meines Blickes schweben,

mag meine Reue aufschweben mit der Kraft, nach der sich sehnt meine Schwäche! 
Gib meiner Seele den Mut des Schweigens, wenn du in Zeichen gesprochen.

45 und meinen Gärten Rosen genug, wenn anhebt die Zeit, um Kränze zu winden!

Mache, daß meine Wahrheit, sei ähnlich einem Gebetbuch,

daß jeder find sein Gebet in ihr, auch der Verworfene und der, welcher scheidet!

Und wenn sich ewige Sonne in meinem Worte spiegelt, mag sie zur Freudenekstase rot

anhauchen die Brider,

und die Blüten ihrer Sehnsucht mögen sich kehren zum Brennpunkte zeitlosen Reifens!

$50 \mathrm{Gib}, \mathrm{da}$ in den Strahlen meines Lächelns der Blutenstaub von meinen Feldern fällt auf benachbarte Furchen. und der Hauch meines Schmerzes mag sich niederschlagen zu Arzneikristallenfur jene, die vor

Meiner Einsamkeit Stille erfüll mit dem Rauschen verbruiderter Flüge.

Suchen erkrankten!

und die Augenblicke meiner Freuden mögen als duftender Regen obschlummergemiedenen

wie der Gesang der Harfe zum Trost des Betrubten.

Lagem erzittem,

$55 \mathrm{Gib}$, daß meine Gedanken seien wie Frühjahrswinde, die Rhythmus bringen

und wie Sturm, der zwingt zur Umkehr den Wanderer vor den Wegen des Todes!

zukünftigen Liedern,

Und sterbend mögen sie gleichen den Blüten (Symbolen der Saat aus anderen Welten),

die, schon welkend im Brande des Tages, noch duften nach Erdbeer.

Ermuidet von Arbeit und Liebe und gebrochen von Schmerz mag ich niedersitzen auf blühenden

60 und die Neige des Tags verbringen versunken, stumm, in die ewige Musik deiner Lichter.

Rainen

Wenn Abend sich neigt zur Erde und wiederkehren die eingeschichterten Dufte,

schreit auch ich, einsamer Werkmann, hin zu den Wohnstätten steigenden Rauches.

Unter deinem Baume werde ich niedersitzen, der durch alle Räume dieschattige Krone

und in dessen schwarzem, eisigem Laub Steme die Stille durchklingen wie Bienen sämtlicher

65 mein Stolz, verschwiegen bei Tag, wird wiederkehren zu meinem Liede,

Stöcke;

mit einem KuB, der unendlich macht die Strahlen der Blicke, wird er mich auf die Augen küssen, und denen, die horchen werden, will ich stolz zuríckgebeugten Hauptes singen.

Deine Geschichte will ich singen, die in Seelen toter Völker jauchzte als strahlendes Heute und in den Seelen der Lebenden spricht mit der unbekannten Sprache der Zukunft.

$70 \mathrm{Im}$ epischen Fluß aller Farben, in tausenden Tönen, in dem bizarren Erbluhen des Stoffes, in tödlichen Wirbeln von Stille im Raume, in denen die Hämmer deiner verborgenen

Werkstätten dröhnen,

wo du formst die künftigen Sonnen unter geschwärzten Gewölben,

bis funkelnd von deinen Amboßen in schwindelnde Höhn die Welten hinsplittem!

In Lyrismen der Ahnung, der Raserei Grauen, im bläulichen Zittern der Strahlen.

75 in Tonleitem der Lüuste, in Noten nach Schlüsseln und den Vorzeichen des Todes.

Und lösen werden sich meine Worte wie Salz im ätzenden Regenschwall deiner Feuchte

und kristallisieren im Spruhen der Funken und dem Geprassel verborgenen Kraftstroms.

In Farben unsichtbaren Spektrums entzünden sich meine Bilder, schwelgend in Hehre.

80 ihre Schatten werden gelegt sein durch das blendende Strahlen der irdischen Lichter,

doch ihre Lichter durch deinen Schatten; und in deine asymptotischen Punkte

werden sich die Strahlen ihrer Perspektiven zu Brennpunkten vereinen.

Und erheben wird sich mein Traum mit Fügeln, die auffangen die Reflexe ewigen Morgens,

und wird wie das gigantische Phantom eines Adlers die Erde in seinen weiBglühenden Fàngen

wird zu beiden Seiten das schwarze Gewölke der Nacht auseinanderbreiten und nieder sich hintragen.

85 und den Blick seines Stolzes demütig hinhalten deinem durchbohrenden Schauen

im zischenden Blutstrahl geblendet vom Glanze.

Deutsch von Paul Eisner. 
Der nächste Schritt auf dem Weg zur Erlösung wird im "Morgengebet" (Ranni modlitba) gemacht, dessen eminente Bedeutung für die schöpferische Entwicklung Březinas von F. X. Salda erkannt und hervorgehoben wurde: "DDas Morgengebet" /.../ ist ein einmaliges Denkmal der schöpferischen und tragischen Liebe, des gedanklichen und emotionalen Aufschwungs und der Glut, die sich mit den höchsten Momenten aller großen religiösen Bekenner messen kann: Meister Eckharts, Johannes Taulers, Pascals und auch Kierkegaards /.../. [Im Finale des Gedichts; Anm. J. V.] wird der große komplementăre Wert für die Lebensempirie getunden; durch ihn und in ihm erlangt alles nicht nur sein Ziel, sondern auch seinen Sinn: Leid und Freude, Liebe und Haß. Traum und Tat, Vergangenheit und Gegenwart, Leben und Tod. In diesem Gedicht erfaßte und antizipierte Brezina in nuce sein gesamtes künftiges Werk: die Invention dieses Gedichts ist dessen Ursprung".257 Auch für die metadekadente Poetik und Symbolik des Zyklus Svitáni na západé kann Ranni modlitba in vieler Hinsicht als ein paradigmatischer Text gelten. Trotz enger Anknüpfung an die frühere Schaffensphase wird hier die im dekadenden Symbolismus konstituierte semantische Welt gänzlich umkodiert und in ein völlig neues Licht gerückt, so daß Ranni modlitba geradezu als 'Manifest' der neuen Schaffensphase betrachtet werden kann. Das primär $\mathrm{Ne} \mathrm{u} \mathrm{e} \mathrm{ist} \mathrm{die}$ Transformation des Egoismus zum Altruismus mit dem Ziel einer ethisch motivierten kollektiven Erlösung. Dabei läßt sich allerdings nicht übersehen, daß der Text nicht einheitlich ist, er weist einen Isotopiebruch, eine Spur auf, die in seinen semantischaxiologischen Konnex nicht integriert wird. Bei näherer Beleuchtung der für das ganze Gedicht hochrelevanten Elemnte der gnostischen Erlösungslehre und der christlichen Mystik stellt man jedoch fest, daß dieser 'Bruch', der im semantischen Arrangement von Ranni modlitba eine sinnkonstitutive Funktion und Bedeutung hat, zur kalkulierten Strategie des Textes gehört.

Im Vergleich zu anderen metadekadenten Texten von Svitáni na západẻ repräsentiert Ranni modlitba ein Gedicht von neuer Qualität, dem die gnostisch-mystische Symbolik des "Zusammenfließens" ("siiti") und des soteriologischen Geschehens zugrundeliegt. Die solipsistisch-nihilistische und aporetische Position des dichterischen Ich im dekadenten, die Irrealisierung und Annihilierung beschwörenden "Abendgebet" an den Tod (Modlitba vecermi, TD), wird in Ranni modlitba - entsprechend der neuen Axiologie - umgewertet. Als das höchste Ziel wird die mystische Vereinigung mit dem "Höchsten" durch das erlösende Wissen (rvwors) 258 postuliert. Dieser Erlösungsweg führt von der Vision des eschatologischen Geschehens, symbolisiert durch das Verhältnis von (mystischer) Saat und Ernte, über ethisch motivierte, altruistische 'Verbrüderung', bis hin zur noetisch motivierten unio mystica, in der das gnostische (auto-)soteriologische Geschehen kulminiert.

Da es sich um einen umfangreichen Text von komplizierter Binnenstruktur handelt, sollen an dieser Stelle zunächst seine semantischen 'Knotenpunkte' erfaßt werden. Das Gedicht besteht aus vier thematisch-kompositionellen Sujetsequezen: I, V. 5-16 (Symbolik der mystischen Saat. I., V. 17-26 (Symbolik der mystischen Emte), III, V. 27-60 (Symbolik der altruistischen Verbrüderung). N, V. 61-86 (Symbolik der gnostischen AutoSoteriologie), denen ein dreizeiliger 'Prolog' vorangestellt ist, in dem die Kommunikationssituation dieses Textes als die eines Gebets explizit markiert wird: "a obrácen $k$ východu světla / rekl jsem myšlenkám, klexícím na rủżových kobercích jitra. Modlete se!" (V. 2-3; "und gewandt zum Aufgang des Lichtes / sprach ich zu den Gedanken, die knieten auf den rosenfarbenen Teppichen des Morgens: Betet!"). Der Wille zur 'Verschmelzung', zur unio mystica, durchdringt in einzigartiger Weise die Architektur

257 F. X. Saida, .Vývoj a intergrace v poesii Otokara Bieziny", in. F.X. Salda, Duse a dilo, Praha 1937, S. 211-212. "Ranni modlitba", báseñ nejen nedocenèná u nás, ale vúbec neocenèná a necenéná v dile Biezinové. jest z nejvètšich světovych architektur básnických; jedinečný pomník lásky dẻlné i tragické. myłlenkového i citového vzletu a żáru. Který vyrovna se nejvyšsím chvilim všech velkých vyznavaču náboženských, mistra Eckeharta, Jana Taulera, Pascala i Kierkegaarda I.... [Ve finále básnẻ] jest nalezena veliká komplementárni hodnota pro żivotni empirii; ji a v ni má všecko nejen cil, ale i smysl: bolest i radost, láska i nenávist, sen i čin, minulost i budoucnost, život i smrt. $V$ básni této obsáhl in nuce a predjal Brezina všecko svè dílo prístí: invence této básnè jest jeho pozetim".

258 Platon bezeichnet mit rvörrs (Politeia V 477a) gelegentlich das sichere Wissen von metaphysischer Wahrheit. Vgl. auch die Definition von $\mathrm{H}$. $\mathrm{H}$. Schaeder, .Urform und Fortbildung des manichäischen Systems", in: Vorträge Warturg 1924-1925, Leipzig 1927, S. 99: "Gnosis heißt im Sinne der Zeit: richtiges und darum erlósendes Wissen". 
des ganzen Textes. Seine quartäte Gliederung läßt sich auch als zweiteilige Gliederung von jeweils zwei kompositionellen Sujetsequenzen darstellen: $11+11+1111+1 \mathrm{~V}$. Das distinktive Merkmal der ersten Doppel-Einheit $(1+11)$ ist die exponierte Position des "Höchsten"; er ist hier der "Hauptheld" und sein Opus das Thema, während in der zweiten Doppel-Sequenz (III+IV) das sprechende Subjekt, das lyrische Ich, als agens der Handlung figuriert.

Mit dieser Gliederung korrespondieren auch die Redemodi des Textes: Die Haltung der ironischen bzw. wehmütigen Distanz (Vladari snú / Die Herrscher der Träume) verliert in Ranni modlitba an ihrer Bedeutung, wird umfunktionalisiert und durch eine andere kommunikative Situationen ersetzt. In der I. Sujetsequenz (V. 5-16) tritt das dichterische Ich in der Rolle eines (auktoriaien) 'Beobachters' auf - um der Darstellung des 'beobachteten' Geschehens den Anschein der Objektivität zu verleihen -, der außerhalb des 'Schauplatzes' steht und die 'Erleuchtung' der anima mundi durch den "oberen Erlöser", den "Höchsten", gleichsam kommentiert. Daher kommt hier gerade die "Er"-Form zur Geltung. In der M. Sujetsequenz (V. 17-29) wird die auktoriale Position durch die "Du"Form 'aufgelockert' ("na souvraté tvé", V. 18; "ale rachot tvých vozü" V. 19; "Tvá bude úroda", V. 20; "na hlas tvého zvonu", V. 27), die hier immer deutticher als Antizipation der eigenen Position des dichterischen Ich und zugleich als Übergang zu der III. Sujetsequenz fungiert: "I já, jeden z nejchudšich, vycházím poslušen I... ${ }^{\prime}(V .27$; "Auch ich, einer der Ärmsten, komme gehorsam $/ . . . r$ ). Die kommunikative Situation des (Er-)Bittens, des 'therapeutischen' Tröstens, charakterisiert die III. Sujetsequenz (V. 30-60), in der sich das dichterische Ich als "reuiger" Bittsteller bzw. Fürsprecher für die Gemeinde der Glaubenden, in die er integriert werden will, mit einer Serie von Aufforderungssätzen, in denen er um die e th i s c h e Kraft seines "Wortes" bittet, an den "Höchsten" wendet. in der NV. Sujetsequenz kommt es plötzlich zu dem erwähnten Bruch: Der Dichter trennt sich von der Gemeinde, 'verdrängt' seinen Altruismus, stellt ostentativ seinen "Stolz" ("má hrdost", V. 65) zur Schau und kehrt (zu sich selbst und zum "Höchsten") zurück, um den (visionären) Akt der g no sti s chen Autosoteriologie und die postulierte unio mystica zu erfahren.

Die schöpferische, zugleich aber auch vereinigende, synthetisierende Kraft wird im Text in erster Linie der befruchtenden Macht des logos spermatikos des creator macrocosmi zuerkannt. Diese Intention konnotiert (mystische) "Saat" ("seti" I "Befruchtung") und "Ernte" ("úroda"; Schlüsselmotive des Gedichts) als kollektives 'Werk' der "Brüder-Gemeinde", an das wiederum das dichterische Ich mit seiner altruistischen, 'therapeutischen' Gestik (V. 31-60) und letzten Endes (V. 68-81) mit seiner ('individualistischen') gnostischen Soteriologie anknüpft.

Die distanzierte Haltung angesichts der dekadenten Werthierarchie von Modlitba vecerni (Das Abendgebet) bekundet sich in Ranni modlitba nicht nur in der expliziten Opposition "vecemi" (" Abendgebet") vs. "ranni" ("Morgengebet"), sondern bereits in der grammatischen Inversion im Titel: Modlitba vecerni (Subst. + Adj.) - Ranni modlitba (Adj. + Subst.). Die Finalităt des Todes (impliziert durch die Symbolik der Nacht und Dunkelheit), in die das "Abendgebet" mündet, wird im "Morgengeber" durch die Licht-(Leben-)Symbolik substituiert. Die Línearität bzw. Vertikalität von Modlitba vecerni (und anderen Gedichten von TD) mit ihrer signifikanten Polarităt von "v hloub" ("in die Tiefe", IV, 4) - "na skalách" ("auf den Felsen", V. 2), "vzlet a pád" ("der Aufschwung und der Fall", Vi, 4), wird in Ranni modlitba durch die Dramaturgie der Rückkehr neutralisiert: "/... / Aż večer se nakloni $k$ zemi

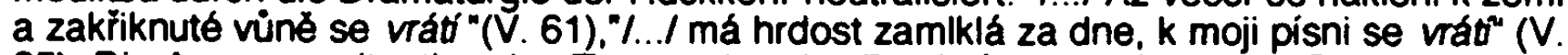
65). Die Ausgangssituation des Tagesanbruchs ("a obrácen $k$ yychodu svêtlä" V. 2; "und gewandt zum Aufgang des Lichtes") führt in der letzten Sujetsequenz (V. 82-86) zur Vision des neuen, "ewigen" Tagesanbruchs ("I pozovihne se sen múj s krídly zachycujicimi reflexy vénéno jitra" (V. 82; "Und erheben wird sich mein Traum mit Flügeln, die auffangen die Reflexe ewigen Morgens"), wobei der Tagesanbruch (I, 1-3) sowohl im Prolog als auch im Epilog des Textes die Dunkelheit (den Tod) 'verschlingt'. 259 Diese

259 Es läßt sich sogar sagen, daß die Umkodierung der dekadenten Axiologie sich manifest durch die Adoration des Lichtes ankündigt, der in Ranni modlitba eine der sinnkonstitutiven Bedeutungen zuerkannt wird. Die 'Hinwendung' zum "Aufgang des Lichtes" (V. 2) als Bedingung für die positive ('luzide') Leistung der Seele, indiziert eindringlich diese Intention. Gleichzeitig antizipiert die Licht-Symbolik die angestrebte Vereinigung mit dem "Höchsten", der das reine innere Licht ist, das die Seele solcherart durchdringt, daß diese über sich hinausgerissen wird. nach der Vereinigung strebend. Der Akt des 'Von-Oben-Úber-Sich-Hinausgerissen-Werdens' 
Intention tritt bereits im Gedicht-Prolog (V. 2) in der Gestik und Dynamik des "Zusammenrollens" (V. 2) und "Auseinanderfaltens" (V. 84) klar zutage: "Stan Cerný smrti I... I jsem svinul dle rozkazu tvěho a obrácen k východu světla" (V. 1-2); "I pozdvihne se mưj sen I... I / na dvè strany rozhrne derné oblaky noc'" (V. 82-84). Das gleiche Motiv erscheint auch in Mýtus duß̌e (Der Mythos der Seele, SZ): "dálky tolikrát svinuté smrtí rozložily priede mnou jiskřici obzor" (II, 5; die Weiten sovielmal vom Tode zusammengerollt breiteten vor mir den funkelnden Horizont aus").

Die demonstrative Abwendung oder Wegwendung von der dekadenten Axiologie des "Abendgebets" manifestiert sich deutlich in der Apostrophe, mit der sich das lyrische Ich an die höchste Autorität, den Adressaten seines "Gebets", wendet. In Modlitba ve¿erni wird der "Tod" ("O smrti", I, 1), in Ranni modlitba der "Höchste" ("O Nejwyšsi", V. 4; als creator macrocosmi) apostrophiert. Noch wichtiger scheint in diesem Zusammenhang die prinzipielle semantische Verschiebung in der Auffassung der Schöpfung und der schöpferischen Prozesse zu sein. Die Kunst-Schöpfung im dekadenten Symbolismus bleibt ausnahmslos ein a u to kreativer Prozeß. Der Künstler-Mensch tritt häufig als 'Schöpfer' und 'Geschöpf' (seiner eigenen Kreativität) in einer Person auf. Seine Schöpfungsakte werden als "eingemauert" ("za Živa zazděná má piseñ", Vězen̉ / Der Gefangene, VII, 4; "mein lebendig eingemauertes Lied") oder als eingefangen in eigener (oneiroiden) Projektionswelt ("Sám $v$ tiché klausuře jsem pocet żití rešil $/$ a jenom nad svých snú jsem záhonem se shýbal", $O$ silo extasi a snú / O Kraft der Extasen und Träume, IV, 1-2; "Allein in stiller Klausur löste ich die Formel des Lebens / und nur über dem Beet meiner Träume beugte ich mich") dargestellt, und sie offenbaren sich (nur noch) als 'Reflexe', 'Spiegelungen', 'Schatten', oder 'Schimmer' der (Traum-)Fiktionalität:

$"$ ".../ paprskú mystických jsem v duši sebral něhu" ( $O$ silo extasi a snú I O Kraft der Extasen und Trăume, IX, 3; \%.../ das Zartgefühl mystischer Strahlen sammelte ich in der Seele"). ".../ a v I... / zrcadle myšlenku vlastni uvidẻl jsem" (Pohled smrti / Blick des Todes, V. 4; "I../ und im /...I Spiegel erblickte ich meinen eigenen Gedanken"). "Sen modri šedivých ve stinech sněhu ožil // jen velká Myšlénka jak oblak táhla nivou, / hrou stínú mluvila, snem světel, hlasem ticha" (Siesta, I, 1, III, 1-2; "Der Traum grauer Blāue erwachte im Schatten des Schnees // nur der Große Gedanke zog wie eine Wolke über dem Gefilde / er sprach durch das Schattenspiel, den Traum der Lichter, durch die Stimme der Stille").

Das Gedicht Ranni modlitba bedeutet den Zusammenbruch dieser autokreativen, autistischen und autarken Position, die durch einen Prozeß "im Werden" verdrängt wird. Dieses "Werden" koinzidiert mit "(Lebens-)Weg": "Stan Cerný smrti, jeż rozprostírá duse na cestè své, aby si odpocinula" (V. 1); "VŠchni viditelní i neviditelní služebníci vyšli na souvraté tvé" (V. 18); "I já jeden z nejchudšich vycházím I... $/$ (V. 27) usw. In der Axiologie der "Verschmelzung" (aller Lebensformen: "a zdravé vtáhnutí dechu radostné rozesmảlo zijić formy", V. 8) und "Verbrüderung" agient das lyrische Ich zunächst in der (effektvollen) Rolle eines "gehorsamen" und "reuigen" Für-Sprechers bzw. Vermittlers, der in das Kollektiv der "Erdkinder", seiner "Mit-Brüder", integriert werden will, ehe er sich in der letzten Sujetsequenz als stolzer Selbst-Erlöser 'entpuppt'

Die Semantik des "Tagesanbruchs" wird (in der III. Sujetsequenz) durch das Motiv des "Rhythmus" komplementiert: "Dej, aby mè myšlenky byly jak vẻtry jarni, jeż prinášeji rytmus budoucim pisnim / a jako vichrice, které nutí $k$ návratu chodce pred cestami smrtil" (V. 55-56). Der "Rhythmus" konnotiert den dynamischen Aspekt der Lebensprozesse, das Leben als 'Aktion', die die Todesstarre besiegt. Der Dichter-Schöpfer soll dem

(raptus) wird im Text thematisiert. Es handelt sich zugleich, wie noch zu zeigen sein wird, um erotische Akte. Der mystische dreifache Stufenweg zu Gott stellt bekanntlich die Trias Reinigung Erleuchtung - Einigung dar. Nach Gregor von Nysa, der als "Vater der christlichen Mystik" bezeichnet wird, ist die Gotteserkenntnis das Leben der Seele. Da aber die Gottesebenbildlichkeit des Menschen durch die Sünde verdunkelt ist, bedarf es stets der Katharsis der Seele. Die Abwendung von der Finsternis durch die Partizipation am Licht ist eine der Voraussetzungen der (Gottes-)Erkenntnis. Dabei wird betont: "Je mehr nun der Geist voranschreitet, durch immer grōßere und vollkommenere Aufmerksamkeit zur Erkenntnis des Seienden gelangt und der Anschauung immer näher kommt, um so mehr sieht er, daß die gōttliche Natur unsichtbar ist. Denn wenn er alle Erscheinung verlassen hat, nicht nur, was die sinnliche Wahrnehmung faßt, sondern auch, was der Geist zu sehen glaubt, dringt er immer tiefer ins Innere, bis er unter großer geistiger Anstrengung zum Unsichtbaren, Unfaßbaren gelangt und dort Gott sieht. Denn darin liegt die eigentliche Erkenntnis des Gesuchten, darin das Sehen im Nicht-Sehen, daß der Gesuchte alle Erkenntnis übersteigt /... $\%$. Gregor von Nyssa, Der Aufstieg Moses, übers. von M. Blum. Freiburg i. Breisgau 1963, S. $91 f$. 
rhythmischen "Wogen" ("viněni") der Sphärenmusik, dem Puls des Lebens, nicht nur passiv und "ermattet" in seinem höchst befremdlichen Oneiroid lauschen ("seslábli zádumčivým vinẻním hudby, již chvěje se rytmicky vesmir // /../ kdyż smutek nekonècna dýchal ve vašich odmitnutych a zapiených rytmech", Vladari snú / Die Herrscher der Träume, I, 4, VI, 4: "ermattet vom schwermütigen Wogen der Musik, von der das All rhythmisch bebt! // I.../ als die Trauer des Unendlichen in euren abgelehnten und verleugneten Rhythmen atmete"), sondern diesen Lebens-Rhythmus in sein "(Kunst-) Schaffen" integrieren. Diese Integration wäre der erste 'Schritt' auf dem Wege zur Wiederherstellung der kosmischen Einheit und zur Wiedererlangung des Stolzes, der Souverenität und Identität, die der Dichter-Schöpfer infolge seines individualistischen Eintauchens in die Sphäre der fiktionalen Traum-Welt eingebüßt hat: "Poniženi vracite se $\checkmark$ domov /.../ / kde nikdo nevěri vašim zvěstem /... $/$. (Vladar̆l snú, IX, 3-4; "Erniedrigt kehrt ihr nach Hause zurück /...// wo keiner euren Botschaften glaubt /... $/$ ).

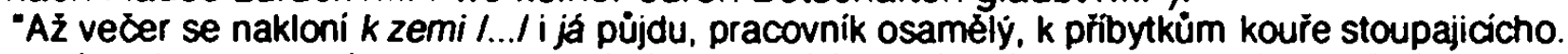
/ /... / má hrdost, zamlklá za dne, $k$ moji pisni se vráti, / polibenim, jeż nekonečnými čini paprsky zrakủ, na ởi mne zlíbá, I a tẻm, kter̂i poslechnou, s hlavou pyšnẻ vzad sklonẻnou zpivati budu I...I" (V. 61-67; "Wenn Abend sich neigt zur Erde I.../ schreit auch ich, einsamer Werkmann, hin zu den Wohnstätten steigenden Rauches. / I.../ mein Stolz, verschwiegen bei Tag, wird wiederkehren zu meinem Liede, I mit einem Kuß, der unendlich macht die Strahlen der Blicke, wird er mich auf die Augen Küssen, I und denen, die horchen werden, will ich stolz zurückgebeugten Hauptes singen $(\ldots r)$.

Diese Intention kommt in der 'Replik' auf das Gedicht Vladari snů (Die Herrscher der Träume), in Víno silných (Der Wein der Starken), deutlich zutage: "Než se nadáme, uslyšime, jak vedle nás rytmicky dýchá mystická piseñ /.../. Myšlenky naše budou míti šîri prostorú, naplnẻných éterem, jímż đýchaji světy" (V. 4, 33; "Eh wir geahnt, vernehmen wir einst, wie neben uns das mystische Lied in rhythmischen Zügen atmet I.../. Unsere Gedanken werden die Weite von Äther erfüllter Räume haben, der der Atem ist der Welten"). Im folgenden sollen die einzelnen thematischen Sujetsequenzen des Textes eingehender untersucht werden.

\section{Symbolik der mystischen Saat}

Die Omnipotenz des "Höchsten" offenbart sich zunächst als "mystisches Lächeln" ("úsměv mystický", V. 5), ${ }^{260}$ als "Lichtsturz" ("sesuti světla", V. 7) und schließlich als "weiße Glut" (V. 14) seines "Blickes" (V. 11), der die Erde (V. 7-10) und die Seelen (V. 15) 'befruchtet' und die unfruchtbare Passivität des Traum-Zustandes der "besiegten Liebhaber der Träume" ("Ale zraky milencú snú se zatměly bázni, vyhýbavé a kleslé", V. 9), die das blendende Licht nicht ertragen können, gleichsam bloßlegt. Doch nicht nur das. Die vom Leben ermüdeten "Herrscher der Träume" und die "Wehmütigen" ("Mám v duši lítost spoutaněho v loži", Litost / Wehmut, V. 1. TD; "In meiner Seele weilt die Wehmut eines im Lager Gefesselten") sollen zur Buße gezwungen werden: "a paľivym popelem okamžikú posypal hlavy litujicich" (V.16; "und die Loderasche der Augenblicke streute er hin auf die Häupter der Reuigen"). Das Motiv der "Asche" fungiert in diesem Kontext auch als Opposition zu jenem der illuminatio der Seelen: "ve varu světel rozkypěl barvy, Žhavé je nastrikal $v$ duše" (V. 15, "im Wallen der Lichter ließ er die Farben aufschäumen, spritzte sie glühend in Seelen").

Das signifikante Merkmal dieser schöpferischen 'Gewalt' ist die beinahe aggressive Invasion des Lichtes und des Odems, die zu zentralen Signifikanten des in dieser Sujetsequenz inszenierten (mystischen) Zeugungsaktes werden: "Žiznivé klasy prohnuly se $s$ bolestnou rozkoši pod sesutím svétla / a zdravě vtáhnutí dechu radostné rozesmálo żijici formy" (V. 7-8; "dürstende Ähren bogen sich mit schmerzlicher Wollust unter dem Sturze des Lichtes, / und das gesunde Einziehen des Atems machte freudig die lebenden Formen erlächeln"). Es wird hier ein geradezu sexueller Akt der 'Urzeugung', ja sogar 'Vergewaltigung' der 'unten' situierten anima mundi (der Erde) durch mystische penetratio ("s bolestnou rozkoši", V. 7; "mit schmerzlicher Wollust") und eiaculatio ("ve varu svêtel rozkypé barvy. zhavé je nastrikal v duš", V. 15. "im Wallen der Lichter ließ er die Farben aufschäumen, spritzte sie glühend in Seelen") des mächtigen logos spermatikos des

260 Die Kraft des "mystischen Lächelns" ist hier offensichtlich als (sexuell-)schöpferische Potenz konnotiert, seine Wirkung ist die "fructtbare Ermattung" ("úrodná molioba"). 
maskulinen 'oberen' Erlösers inszeniert.261 Das noch nicht erleuchtete, unbewußte Weiblich-Anim(al)ische der Welt wird "zur Ruhe geschrien" und (anschließend) sublimiert und vergeistig. (V. 13).

Interessant ist das Motiv der "trunkenen Düfte" ("vpadl do stáda opilých vủni a hlas jejich zakřikl hněvem bílého Żáru", V. 14), das sich gerade auf die 'Unwissenheit' der Seele um ihre Herkunft bezieht. Während die "Zeugung" von 'oben' ein patriarchalischer (und primär-archaischer) Akt ist, konnotieren die "Düfte" in der Lyrik Br̈ezinas das Sekundäre, Dekadente. Hochkultivierte und Betörende (Vüné zahrad mé duše / Der Duft meiner Gärten Seele, Vonné soumraky I Wohlduftende Dämmerungen, TD), oder fungieren als evokatives Merkmal der fiktionalen "anderen Welt": "Ty vưni zázračná, z níz voni jiný svër" (Modlitba večerni / Das Abendgebet, I, 5; "Du wunderbarer Duft, nach dem die andere Welt duftet $(\ldots$,$) ): "Vaše vưné těžká /$ jak otrávený plyn $v$ mé duši na dně mešká" (Apostrofa podzimni / Die Herbstapostrophe, V. 27-28; "Euer schwerer Duft / weilt wie giftiger Dunst an meiner Seele Grund"). In der gnostisch-eschatologischen Axiologie von Ranni modlitba muß zuerst die zur 'leeren Fiktion' annihilierte Lebenswelt (TD) nach dem Willen, ja sogar nach dem Befehl des "Höchsten" ("die rozkazu tvěho", V. 2; "I já jeden z nejchudšich, vycházim poslušen na hlas tvého zvonu", V. 27) in der irdischen (Natur-)Sphäre 'neverschaffen' und 'wiederbelebt' werden: "pod jiskrivým pohledem dne, $v$ nẻmż sviti divoká Źádost nezrozeného". (V. 10). In diesem mystischen Zeugungsakt erhalten die Seelen "neues Licht" und "neue Farben", sie werden quasi 'neu'-erleuchtet (V. 15).

261 Die Vorstellung von der mystischen 'Befruchtung' durch den logos spermatikos entspricht sowohl der biblisctien (im Sinne von Luk. 8,11; 1 Petr. 1,23 u. a.) als auch der mystischgnostischen Tradition, auf die Hans Jonas in seiner Monographie Die mythologische Gnosis (Göttingen [1943] 1964) verweist. Im sog. "valentinianischen" System taucht eine ganze Reihe von Paarungen der Geistwesen (z. B. des vollkommenen Äons, des Voranfangs und Abgrunds ["Bythos"] mit der Sophia, die Christos erzeugen usw.; H. Jonas, ibid., S. 362-375). Der von Bfezina thematisierte mystische 'Zeugungsakt' symbolisiert offensichtlich nicht nur die Weltschöpfung, sondern auch (IV. Sujetsequenz) das Heraustreten des Menschen auf den Weg der Gnosis. Vgl. hierzu: Karl R. H. Frick, Die Erleuchteten, Bd. 1, Graz 1973, S. 9-39: "Die jungfräuliche Seele empfängt den göttlichen Samen des Lichts, wird schwanger und gebiert den neven, den geistigen Menschen in sich selbst. /... / Die Unio mystica, der Hieros Gamos, die heilige Hochzeit erlebt der Gnostiker an sich selbst wie sie dem Weltwerden zugrunde liegt". (Ibid. S. 23). Die gnostische Pneumalehre geht von der Vorstellung einer Weltseele (anima mundi) aus, die als feinster Stoff alle schópferischen Keimkrăfte in sich trägt. K. Frick (Die Erleuchteten, Bd. 2. Licht und Finstemis, Graz 1975, S. 113ff.) erwähnt sogar die sog. Sperma-Gnosis: Nach Frick waren die Sperma-Gnostiker "überzeugte Pneumatiker", deren Sperma-Kult eine năhere Verwandschaft mit den kleinasiatischen Fruchtbarkeitskulten aufweist. Im Anschluß an die griechische Tradition verstanden sie den Begriff des Pneumas in enger Beziehung zum Sperma. Demokrit Z. B. mißt dem menschlichen Samen eine pneumatische Natur bei; in der stoischen Lehre von Logos spermatikos isł crípurx ein feuriges Pneuma. Ähnlich lehrt Aristoteles, daß die Zeugungskraft von Sperma die Wärme ist, die er eben als Pneuma versteht. Auch von den christlichen Pneumatikem wurde der Begriff des heiligen Pneumas, das über den Wassem schwebte und mit Gott den Adam beseelte, im Alten und im Neuen Testament als lebenserzeugender Stoff, als Sperma, aufgefaßt. O. Králik (Otokar Bỉezina, Praha 1948, S. 500f.) weist auf die eminente Bedeutung des Logos in Bỉezinas Werk hin. Aus den Bỉezina-Zitaten, die J. Deml in Mé svẻdectvi o Otokaru Br̈ezinovi (Praha 1931) wiedergibt, geht hervor, daß der Dichter den Logos über die heilige Schrift stellte. "V protestantismu je rozklad a ustrnuti, kdežto cirkev rímská má svưj základ v Logos, v ní pracuje Logos, Slovo; to je tajemnějsí, hlubši, nebot Logos tu byl, jest a bude, i kdyby ani nebylo Pisma" (ibid. S. 428f; "Im Protestantismus wirken Zerfall und Stagnation, während die römische Kirche ihr Fundament im Logos hat, in ihr arbeitet der Logos, das Wort; es ist geheimnisvoller, tiefer, weil der Logos war, ist und wird hier sein, selbst wenn es die heilige Schrift nicht gäbe"). In der "Logos"Auffassung des Dichters sieht Králík den "Schlußstein Bł̉ezinas religiöser Konzeption"; der Logos, "offenbart sich unmittelbar in der Erfahrung großer religiöser Persönlichkeiten, unabhängig von autoritativen Texten und Dogmen" (Králik, ibid., S. 501). Vgl. dazu Gregor von Nyssa: "Wer danach verlangt, Gott zu schauen, wird den Ersehnten dadurch sehen, daß er inm immer folgt, und die Schau seines Angesichts ist der ununterbrochene Weg zu ihm hin, der ihm dadurch gelingt, daß er hinter dem Logos hergeht". $H$. Dörrie, .Gregor von Nyssa", in: Reallexikon für Antike und Christentum XII, hrsg. von Theodor Klausner, Stuttgart 1983, S. 880. 


\section{Symbolik der mystischen Ernte}

Von der mystischen "Saat" und der "Illuminatio" der Seelen führt der Weg zur Symbolik der mystischen "Ernte" 262 (V. 17-29), deren Anbeginn der erste Vers der II. Sujetsequenz markiert: "Hodinami zazvonil všem duš́m pocátek żně" (V. 17, "In den Stunden erklang allen Seelen der Ernte Anbeginn"). Der omnipotente Weltschöpfer wird nun als "Besitzer der Fluren und Herden" ("o Majiteli roli a stád", V. 17; vgl. die Apostrophe "Herr der Ernte", Mat. 9. 38) apostrophiert. An der Ernte nehmen sowohl die Lebendigen wie auch die Toten als eine 'Gemeinde' teil ("VŠichni viditelni i neviditelni služebníci vyšli na souvratě tvé", V. 18). Zum Schiuß dieser Sujetsequenz (V. 27-29) identifiziert sich das lyrische Ich explizit mit dieser Gemeinschaft: " $l$ já, jeden $z$ nejchudsích, vycházím poslušen na hlas tvêho zvonu / na zdẻdënou líchu mých mrtvých" (V. 27-28). Der Dichter ("I já" / "Auch Ict") tritt hier in der Rolle eines (Mit-)Arbeiters auf, der das Werk seiner Vorvăter fortsetzt ("na zdèdẻnou líchu mých mrtv'ch", V. 28; "auf die Erbscholle meiner Toten"). Das Spektrum der Gemeinschaft von denjenigen, die für den "Höchsten" ernten ("Tvá bude úroda", V. 20), reicht von der "Ernte der Armen" (V. 23) bis hin zur "königlichen Ernte" (V. 26). Der Vers "aie rachot tvých vozú, naplněných úrodou, zahỉmi jen do snẻni básníkư" (V. 19; "aber das Dröhnen deiner erntegefüllten Wagen erdonnert nur in die Träume der Dichter") indiziert jedoch den A u f s c h u b der "Ernte", des Erlossungswerks, in die Zukunft. Die Erfüllung, der Zustand der Vollendung, findet offensichtlich erst sub speciae aeternitatis statt, denn das Adjektiv "staletych" (V.25, "hundertiährig") semantisiert die "Saat" und die zukünftige "Ernte" als einen Vorgang, der zwar in der irdischen (menschlichen) Zeit beginnt, aber erst in der Zukunft beendet wird. Auf den (Hinter-)Sinn dieser Verse macht das Arrangement der grammatischen Zeiten aufmerksam: nämlich der Übergang vom epischen Präteritum zum Futur ("zazvonil" / "erklang", V. 17; "vysli" / "gingen hin", V. 18; aber: "bude" / "wird /.../ sein", V. 20). Das eschatologische Futur263 deutet an, daß alles seinen Sinn offensichtlich erst in der Zukunft gewinnt, in der auch alle Probleme gelöst werden. Dadurch wird ein Zustand der "Erwartung" ("Úroda setby, jeż ceká I... r, V. 25) herbeigeführt. Das lyrische Ich hört "oněmlé hlasy z sepotu stvolư" (V. 29); die "verstummten Stimmen" sind die Stimmen der Toten, die in der Erde, in der die Saat der zuküftigen Ernte keimt, liegen. Daher scheinen sich die Aussagen der Verse "Úroda setby, jeż ceká pod sněhem casu na dobu staletých táni" (V. 25; "Ernte der Saat, die unter dem Schnee der Zeiten auf die Schmelze der Jahrhunderte warter") und "a onémlé hlasy 2 sepotu stvolú mne silí povzdechem dáma" (V. 29; "und stummgewordene Stimmen aus dem Geflüster der Haime stärken mich mit dem Aufseufzen des Fernentschwundenen") zueinander komplementăr zu verhalten. Der Traum wird zum Medium (ähnlich wie der prophetische Traum Pharaos dem Joseph in Agypten), in dem die zukünftigen. bevorstehenden Ereignisse - den Dichtern - nicht nur antizipiert, sondern auch prophezeit

262 In Ranni modlitba scheint die sehr verbreitete Symbolik der Ernte das eschatologische Geschehen zu konnotieren. Mit dem Bild des Săens und Emtens verbindet sich der Gedanke des Gerichts (Oftenbarung 14, 15. 16). "Wenn der Same Frucht trăgt, dann ist die Zeit der Ernte angebroctien" (Joel 4, 13). In Matthăus-Evangelium (13, 36-43; "Der Menschensohn ist's, der den guten Samen săt", Mat. 13, 37) bezieht sich die Ernte-Symbolik auf die konkrete Situation der Gemeinde; die Ernte wird als Abschluß dieses Áons verstanden und damit als Abschluß der Bewăhrungszeit der Gemeinde.

263 R. Bultmann (Jesus Christ and Mythology, Oxford 1958) betont den positiven Aspekt der Eschatologie als Beginn der Erlösung und Seligkeit. In diesem Punkt koinzidiert die christliche Eschatologie mit der Platonschen Eschatologie, die nach dem Tode die Seligkeit, $d . h$. die Freiheit der Seele im Sinne ihrer 'Befreiung' vom hylischen Leib, voraussetzt und erwartet. Im christlichen Denken wird die Platonsche Freiheit als Freiheit des Menschen zur vollen Entfaltung seines wahren Wesens ("true, real essence"; ibid. S. 30) interpretiert. Nach Bultmann ermahnt die eschatologische Predigt Jesu Christi den Menschen vor allem zur Verantwortung und Erfüllung des Willens Gottes. Es ist ein ethischer Appell an die Verantwortlichkeit des Menschen. Das eschatologische Futur bedeutet $u$. a. das Vorbereitetsein auf die neue, unbekannte Zukunft Gottes nach dem Tode, die uns "wie ein Dieb in der Nacht" überraschen kann. Aber diese unbekannte Zukunft, die unsichtbar ist, denn das neue "Leben ist verborgen mit Christus in Gott" (Kolosser 3. 3), ist in gewisser Hinsicht in der Liebe, der Heiligkeit und in den Gottesdiensten der Kirche prảsent. Die Kirche ist eine eschatologische Gemeinde der Auserwăhlten, die in Christus leben. Es scheint, daß gerade diese Auffassung der Eschatologie, mit ihrem ethischen Aspekt, wie er auch im Verhăltnis von Saat und Ernte zutage tritt (Galater 6,9$)$, der Auffassung Brezinas sehr nahe kommt. 
werden ("zahǐmi jen do sněni básníkü", V. 19).264 Die "verstummten Stimmen" der dematerialisierten, körperlosen und unsichtbaren Toten ("neviditelni", V. 18; "mých mrtvých", V. 28) verschmelzen gleichsam mit der ebenso 'körperlosen' Flüstersprache der Natur ("z sepotu stvolü", V. 29) und sie stärken den Dichter mit dem "Aufseufzen des Fernentschwundenen" (V. 29). Die evokative und verheißende ("stärkende") Flüstersprache verweist offensichtlich auf die zukünttige Ernte jener "Saat", "die unter dem Schnee der Zeit auf die Schmelze der Jahrhunderte wartet" (V. 25), d. h. auf die "königliche Ernte". (V. 26), deren Same erst in der Zukunft gesät und geerntet wird. Das Werk der Dichter-Schöpfer ist stets zukunftsorientiert, deren Same kann erst in der Zukunft aufkeimen und geerntet $d$. h. 'dechiffriert' und verstanden werden. Man darf allerdings nicht außer acht lassen, daß die Emte dem "Herrn" gehört: "Tvá bude úroda" (V. 20: "Dein wird sein die Ernte"). Die creatores microcosmi, die poetae, als "Jünger" des "höchsten Schöpfers", sind diejenigen, die in der Zukunft ernten: "Ich habe euch gesandt, zu ernten, wo ihr nicht gearbeitet habt; andere haben gearbeitet, und euch ist ihre Arbeit zugute gekommen" (Joh. 4, 38). "VŠichni viditelní i neviditelní služebnici byšli na souvratě tvé, I ale rachot tvých vozú, naplnèných úrodou, zahǐmi jen do snëní básníkü" ("Alle sichtbaren und unsichtbaren Diener gingen hin auf deine Gewande, / aber das Dröhnen deiner erntegefültten Wagen erdonnert nur in die Träume der Dichter, V. 18-19).265 "Die Arbeit der Jünger ist nur Erntearbeit".266

264 Die besondere Rolle, die hier den Eingeweihten, den poetis, zugesprochen wird, lăßt sich nicht übersehen. Man denke an das Bild der eschatologischen Sammlung der Eingeweihten durch den Menschensohn (Markus 4, 29 oder Matthăus 13, 12; 9, 37; "Da sprach er zu seinen Jüngern: Die Ernte ist groß, aber weniger sind der Arbeiter. I Darum bitten den Herrn der Ernte, daß er Arbeiter in seine Ernte sende-. Mat. 9. 37-38). Im Vergleich zur Traum-Symbolik in Tajemné dálky kommt es in Svítáni na západẻ zu einer affalienden bedeutungsverschiebung, die darin gründet, daß der "Traum" nun in erster Linie als visionărer, prophetisctier Zustand semantisiert wird. Der "sen" ("Traum") als "Sturz" in einen Zustand der todesăhnlichen bzw. todnahen 'Ermattung', als Flucht in eine oneiroide Scheinwelt, wird in der Phase des eschatologischen Symbolismus als "umdlená snivost" ("matte Vertrăumtheit", Vteriny). "královské sněnî" ("königliches Trăumen", Vladari snư) oder "mitvé sněni" ("totes Trăumen", Mytus duß̌e) desavouiert. Die 'eschatologisierte" Traum-Semantik gewinnt an Pluralităt: "sny, které d̛̉imou, sny, které záfí, a sny, které tuši, // a všechny, Které se nerozsvítily!" ("Trăume, die schlummern, Trăume, die strahlen, und Trăume, die ahnen, // und alle, die nicht aufleuchteten!". Proc odvracís se, $\delta$ slabá? ) Diese Umsemantisierug geht auf einen gemeinsamen Nenner zurück, den man als 'visionăre Erfahrung', 'Begegnung' (mit dem 'oberen' Sotër; Ranni modlitba) bzw. als 'metaphysische Schau' spezifizieren kann: "I pozdvihne se sen múj s kfidly zachycujicimi reflexy vécnehno jitra" (Ranni modlitba, V. 82. I.../ "a otráveni snem zemíeme płed svou smrti a po smrti budeme żiti /...l. Sny, jeż tisiciletí spaly. neznámy dussim, vzbudime pod prikrytim barev a tónu $/ . .$. . Hledéti budeme radou dni budoucich. jak radou sklenéných dveř za sebou ležicich síni, / jimiž nám naproti pricházi słunce ". (".../ und vergiftet von Traume sterben wir vor unserem Tode. um nach dem Tode zu leben / ./. Trăume. die Jahrnunderte schliefen, vertorgen den Seelen, wecken wir / unter der Decke von Farben und Formen /.../. Schauen werden wir durch die Fluchten der künttigen Tage wie durch eine Reihe von glăsernen Türen hintereinanderliegender Săle / durch die uns Sonne entgegenkommt",Vino silnych, V. 11, 26, 29-30). Der wohl wichtigste Unterschied resultiert daraus, daß das visionäre "Trăumen" (oder der visionăre "Traum') kein 'Nachttraum' in der (unteren) Sphăre der Finsternis ist, sondern nach 'oben', ins Licht, in die Sonne und Wărme - nach dem Überschreiten der "Türschwelle" - führt. Die Symbolik des "Zusammenfließens" ("aller Lieder", "aller vergangenen und kūnftigen Tage und Năchte", Vino silných / Der Wein der Starken, V. 42) weist dabei eine sinnkonstitutive Funktion auf.

265 Was konnotiert die 'hermetische' Metapher der "Saat aus der anderen Welt ("Dej, aby mé myšlenky /... / / A umirajice at podobny jsou tém kvétim (symbolúm setby $z$ jiného svéta, /... $I, V$. $55,57)$ ? Die "andere Weit" symbolisiert in diesem Kontext die Sphăre der Transzendenz, die das dichterische Ich betreten will (als Antizipation der angestrebten unio mystica in der folgenden Sujetsequenz). Seine Bitte ("Dej, aby..." /"Gib, daB..." V. 55-57) bezieht sich offensichttich auf die ethische Reinheit und 'Potenz' des Gedankens.. Die Gedanken ("myšlenk") mogen auch dann ihre 'therapeutische' Kraft behalten ("které, kdyż vadnou úpalem dennim, ješté jahodami voni", $V$. 58), wenn der Dichter die Sonnenglut des Tages nicht mehr erträgt. Das dichterische Ich bittet den "Höchsten" um das Transzendieren des Gedankens, um die Emaltung seiner Botschaft.

266 Rudolf Bultmann, Das Evangelium des Johannes. (Kritisch-exeget. Kommentar über das Neue Testament), Göttingen 1968, S. 147 
Das in der zweiten Sujetsequenz angesprochene Motiv des Dichters und seiner Partizipation am soteriologischen Geschehen strukturiert die Sinnschicht der dritten Sujetsequenz des Gedichts. Der Opfermut des dekadenten Künstler-Priesters metamorphiert in Ranni modlitba zum Gestus der aktiven Ver-Haltung (zur Welt), des Heraustretens (auf den Lebens-Weg: "I já I...I yycházím", V. 27), des Bittens und Betens ("Dej at" I...r. "Uziñ I...", V. 34-5; in bezug auf die Absichte des soteriologischen Geschehens). Der Dichter rückt hier in der Gestalt (V. 27-60) des 'Trösters' bzw. 'Vermittlers' des Willens des "Höchsten" in den Vordergrund. Seine Aufgabe ist es, bei einer (altruistischen) 'Verbrüderung' in der Sphăre der menschlichen Lebenswelt und zwischenmenschlichen Beziehungen mitzuwirken. Die Positionen der agentes des in dieser Sujetsequenz thematisierten Geschehens verschiebt sich (im Vergleich mit der ersten und der zweiten Sujetsequenz) folgendermaßen: das dichterische Ich - das Kollektiv (irdischer Mitbrüder) - der "Höchste". Im Hinblick auf die Symbolik der Saat und der Ernte scheint die Botschaft des Dichters auch eine apostolisch-missionarische Dimension zu haben. Als 'Gesandter' des "Höchsten" 267 soll er auch die "Măher" ("Zenci") motivieren: "Hlasu mému dej hudbu lahodnou Żencúm jak zvonéni o polednách" (V. 36). Sein "Wort" ("a odrazí-li se vécné slunce v mém slovê, at" v radostnou extasi zardivá bratry I...., V. 48), seine "Stimme" (V. 36), sein "Lied" (V. 37) seine "Wahrheit" ("UČñ, at pravda má podobna jest knize modlitebni, aby każdý v ní našel modlitbu svou $/ . .(r, v$. 47-47), sein "Gruß" (V. 39) und schließlich auch sein "Lächeln"268 ("Dej, at v paprscich úsmévu mého I..r. V. 50) und "Atem" ("a dech mé bolesti at" sráži se v krystaly lékú I... ., V. 51), sollen eine ermutigende, man könnte sagen praktisch-pragmatische - nämlich den "Mitbrüdern" den richtigen Weg zum "Licht" zu weisen und einen selbst zu finden - und vor allem 'therapeutische' Funktion269 und Wirkungskraft erlangen. Das Ziel dieses Geschehens ist eine kollektive, eth i s ch motivierte Erlösung. Diese Aufgabe erscheint als eine Art Vorbereitung der 'Mitbrüder' auf die neue, vollkommen unbekante Zukunft im Sinne der Eschatologie, die die Gegenwart im Lichte der Zukunft sieht: "AZ umdlím, pỉej, aby mé nadéje se napily vína šumného budoucich záríl" (V. 31; vgl. auch V. 35, V. 55). Die 'Mitbrüder' sollen für das bevorstehende soteriologische Geschehen aus inrer 'Unwissenheit' "geweckt werden: "Dej, aby mé kroky vzbudily z umdleni radostné cekáni bratîî" (V. 38; "Gib, daß meine Schritte enwecken aus Ohnmacht das freudige Harren der Brüder). 270 Die ethische Dimension ist hier offensichtlich von der

267 Vgl. dazu den oben zitierten Versett: "Darum bittet den Herrn der Emte, daß er Arbeiter in seine Emte sende". (Matthäus 9, 38).

268 Signifikant scheint hier die Parallelităt zwichen dem mystischen, befruchtenden "Làcheln" des Hochsten ("Tvưj úsmév mystický zatfásl zemi șlehnutím úrodné moloby", V. 5) und dem ebenso befruchtenden "Lảcheln" des dichterischen lch zu sein ("Dej, at v paprscich úsmévu méno pel 2 poli mých padá na sousedni lichy", V. 50). Die (ethische) Aufgabe des Dichters ist die in der gnostischen Tradition bekannte "Erweckung des «Licht-Samens" im Denken der Menschen". Vgl. K. Rudoplh, Die Gnosis, Götingen 1990, S. 139.

269 Zu dieser 'therapeutischen' (d. h. Soteriologischen) Funktion des Logos in der Gnosis zitiert K. Rudoiph (Gnosis, Gottingen 1990, S. 159) ein bemerkenswertes Gleichnis aus dem Nag Hammadi Codex. Die menschliche Seele ist 'krank', weil sie in einem 'armseligen Haus" (im Korper) wohnt und die Materie versucht ihre (der Seele) Augen blind zu machen, um sie in Unwissenheit gefangenzuhalten. Daher sehnt sich die Seele nach der eriosenden. 'therapeutischen' Kraft des Logos. "So ist es mit der Seele, indem sie jederzeit ein Wort (logos) [empfangt], um es sich wie ein Heilmittel auf die Augen zu legen, damit sie (wieder) sieht und ihr Licht die Feinde, die mit ihr streiten, verberge, und sie sie durch ihr Licht blende I... $F$.

270 Das, worum der Dichter als 'Vermittler' des "Hochsten" bittet, ist (u. a.), daß sein "Ruf, mit dem er die schlafenden Brüder aufwecken soll, gehört wird. In der gnostisch-christlichen Tradition 'schläft' der Mensch in der immanenten Welt wie in einem 'Trunkenheit'-Zustand. Daher muB der "Ruf" von außen kommen (als Offenbarung des soteriologischen Geschehens), um inn zu 'erwecken' und die Unwissenheit (der Seele) um Gott zu vertreiben. Erst der "Ruf' eroffnet die "Toren der Erkenntnis". In bestimmten gnostischen Texten wird die erlösende Funktion gerade dem "Logos" zugesproctien. K. Rudolph verweist auf einen Versett aus dem Epheserbrief, in dem solch ein gnostischer Weckruf ("im christlichen Gewande") erhalten blieb: "denn alles, was offenbar wird, das ist Licht. Darum heißt es: Wach auf, der du schläfst, und steh auf von den Toten, so wird dich Christus erleuchten" (Epheser 5, 14). K. Rudolph zitiert aus der zur Zeit 
e sch a to logischen nicht zu trennen. Doch das dichterische Ich fühlt sich noch nicht im Besitz dieser Kräfte und deshalb muß es beten und (zunächst) eigene SelbstErlösung durch das (gnostische) 'Sich-selbst-Erkennen' und das Wissen erreichen, um "den Menschen die Schönheit der Frömmigkeit und Erkenntnis ( rvw̃oıs) zu verkünden"271 und das Befreiungswerk fortzusetzen. Durch diese Intention erlangt der erwähnte Bruch im/mit dem Text seine Logik. Der Fokus des ersehnten (eschatologischen) Geschehens ist die (allein durch den Redegestus des Gebets) ewig präsente Autorität des "Höchsten": "A odrazí-li se vę̌né slunce v mém slovē, at v radostnou extasi zardívá bratry / a kvēty jejich touhy at obraci k věčnému ohnisku zrání!" (V. 48-49; "Und wenn sich ewige Sonne in meinem Worte spiegelt, mag sie zur Freudenekstase rot anhauchen die Brüder, / und die Blüten ihrer Sehnsucht mögen sich kehren zum Brennpunkte zeitlosen Reifens!").

\section{Symbolik der gnostischen (Auto-)Soteriologie}

Die Handlung der letzten Sujetsequenz (V. 61-86) erscheint auf den ersten Blick als eine die in den Text nicht intergrierte, durch die Trennung des Dichters vom Kollektiv der 'erdgeborenen' Brüder gleichsam 'installierte' und auf' heftige Kollision mit der Axiologie des Textes (scheinbar) ausgerichtete fremde Spur, 272 die seine (bisher) intakte Sinnfolie auseinanderreißt. Das dichterische Ich kehrt nun als vereinsamter creator ("i já püjdu, pracoumik osamely, V. 62) in seine schöpferische solitudo zurück; interessanterweise ist es die Situation des Abends ("Až veler nakloní se k zemi", V. 61) als 'Chronotop' seiner Rückkehr. Zusammen mit dem Dichter sollen auch die "eingeschüchterten Düfte" zurückkehren ("a zakriknuté vưné se vrát", 61). Der "Abend" ("vecer") und die "Düfte" ("vưnē) indizieren diese Rückkehr als reditio zum ursprünglichen Zustand, in eine noch nicht e r l e u c h te te Welt der frostigen Kălte. Dunkelheit und Stille (V. 63-64) vor dem 'Eingriff" des "Höchsten". Eine Art abrupten 'Rizidivs' stellt auch die Geste eines stolzen, elitären creator und Selbt-Erlösers dar, die sich von der eines reuigen Bittstellers und Trösters (V. 27-60) scharf abhebt: "má hrdost, zamlklá za dne, k mojí písni se vrát" (V. 65). Diese Rückkehr läßt sich allerdings nicht als Rückgriff auf die dekadente Axiologie erklären, weil sie in diesem Kontext ohne Zweifel no eti sch motiviert ist. Das postulierte Ziel ist die Selbst-Erlősung und Offenbarung der Geheimnisse der (Welt-) Schöpfung (V. 70-73). ${ }^{273}$ Das auto-soteriologische Geschehen kulminiert im Akt der unio mystica - kraft der rü̃ơı - mit der Majestät des "Höchsten".

wichtigsten Quelle der Gnosisforschung, dem in koptischer Sprache abgefaßten Nag Hamadi Codex, einen gnostischen 'Weckruf', dessen Symbolik für die ethische Dimension von Ranni modlitba von besonderer Relevanz zu sein scheint: "Noch immer schlaft ihr, indem ihr tråumt. Wacht auf, kehrt um, kostet und eßt die wahre Speise! Verteilt das 'Wort' (logos) und das 'Wasser des Lebens'! LaBt ab von den schlechten Begierden und Wünschen und den (euch) unăhnlichen (Sachen) .... Wichtig ist ebenfalls folgender Hinweis Rudolphs, der meine Deutung (s. 0.) untermauert: "Den antiken Vorstellungen vom «Erlöser» entspricht mehr der Begriff «Befreier», * Retterm. Und dies triftt nun wirklich auch die gnostischen «Erloser $m$-Gestalten. És sind nămlich diejenigen, die dem Menschen überhaupt erst einmal den Weg zur «Befreiung^aus dem Kosmos weisen. Man kann sie ebensogut «Offenbarer» oder «Gesandte» bzw. «Boten » nennen, die im Auftrag des höchsten Gottes die Heilsbotschaft von der erlosenden Erkenntnis vermitteln." Kurt Rudolph, Gnosis, Göttingen 1990, S. 138ff.

271 Corpus hermeticum I 27, zit. nach: K. Rudolph, Gnosis, Gottingen 1990, S. 140. In Odpovédi (Antworten) aus dem létzten vollendeten Gedichtzyklus Ruce (Hände), antwortet der "Höchste" den zweifelnden creatores microcosmi, den "Offenbarern" oder "Verkündern" des Erlósungswerkes: "Tiži vás odẻni těžkooděncui: v zápoleni, / $\mathrm{k}$ vysvobozeni všech bytostí země jste vyvoleni" (V. 7-8; "Schwergewappneter Rüstung bedrückt euch: im Ringen, I Auserwāhlte, Erlösung allen Geschópfen der Erde zu bringen").

272 Kennzeichnenderweise legt in dieser Sujetsequenz das dichterische Ich das Gewand eines in die "Brüder"-Gemeinde intergrierten 'Trósters' ab und kehrt als individualistischer "Einzel gánger"

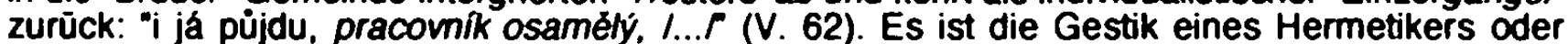
Alchemisten, der in seinem Projektionsraum laboriert. C. G. Jung. Psychologie und Alchemie, 1972, S. 361 .

273 Ein Postulat, das bereits in Modlitba vecerni (Das Abendgebet) aufgestelit wird. Der prinzipielle Unterschied gründet darin, daB in Modlitba vecerni vor allem die Erkenntnis der immanenten Welt angestrebt wird und daß diese Erkenntnis ausschließlich durch mors mystica, durch eine definitive Annihilierung. erreicht werden soll. 
Den Prozeß der Selbst-Erlösung antizipient der "Kuß" ("polibek") des eigenen Stolzes auf die Augen: "má hrdost, zamlklá za dne, k mojí písni se vrátí, / polibením, jeż nekonežnými cini paprsky zrakü, na ocimne zlíbá" (V. 65-66). Der "Kuß"274 auf die Augen, Organ der (rationalen) Erkenntnis, indiziert die Notwendigkeit der (Selbst-) Erkenntnis, die in der Gnosis einen vorrangig soteriologischen Stellenwert hat. Die Bosheit (d. h. die 'Unwissenheit') 275 muß erkannt und vernichtet werden, um die eigentliche soteriologische Funktion der Gnosis, die E r l ö s u n g , zu realisieren. Durch die (Selbst-) Erkenntnis, kraft 'Sehens' und 'Wissens', wird das dichterische Ich selbst zum creator 'inthronisiert', der quasi ex nihilo schafft: "I.../ s hlavou pyšnę vzad sklonęnou zpivati budu. / Zpivati budu tvé dẻjiny I... / / I rozpustí se má slova jak sủl v Żíravém dešti tuê váhy a krystalovati budou v srseni jisker a v praskotu neznámé síly. / Barvami neviditelného vidma mé obrazy se vzejmou, hýríci slávou" (V. 67-68, 76-78). 276 Doch die "Lichter" der "in Hehre schwelgenden Bilder" ("obrazy /.../ hýríci slávou", V. 78; man denke an den oxymoralen Titel und Hauptkode des gesamten Zyklus: "svitáni na západě"). Die mystisch-gnostische Vorstellung, die hier mitschwingt, bedeutet die 'Auseinandersetzung mit dem Anderen', d. h. die Selbst-Findung im Göttlichen oder die restitutio des Göttlichen mit eigenem Selbst. Das Werk des creator microcosmi muß - in der Sphäre der tellurischen Welt - vom "Schatten" des creator macrocosmi 'beschattet' werden, um die angestrebte coniunctio277 erreichen zu können: "stíny jejich budou polożeny oslinujícím záièením pozemských svëtel, I vłak jejich světla tvým stínem; a do tvých úběżných bodủ, / paprsky jejich perspektiv se v ohniska sleti", V. 79-81). Diese Vorstellung strukturiert den letzten Akt von Ranni modlitba, der die Vision der unio mystica mit dem "höchsten Schöpfer" zum Thema hat. In ihm kulminiert auch die Selbst-Erlösung des dichterischen Ich. Als eschatologische Komponente der gnostischen Soteriologie wird hier (zunächst) ein durch das Wissen erlangter 'Seelenaufstieg' inszeniert. Durch die Erkenntnis (des Alls) wird der 'geistige' Mensch erlöst, alles Materielle im Feuer und Licht verschlungen. Die Seele (psyche; oder der Geist, pneuma) kehrt durch das Erlebnis der mors mystica aus der Finsternis in ihre 'Lichtheimat' und in die göttliche Einheit. 278 In Ranni modlitba wird der 'Seelenaufstieg' als eine extatische Vision dargestellt: Die als "Traum" apostrophierte und (von ersehnter unio mystica) beflügelte Seele ("I pozdvihne se sen mujj s krídly zachycujićmi reflexy věcného jitra", V. 82) des dichterischen Ich nimmt die Gestalt eines majestätischen Adlers an ("a jako gigantsky fantom orla", V. 83), der in seinen "glühenden Krallen" die (unerlóste) Erde trägt ("zem ponese ve žhavých svých spárech", V. 83), die ganz offensichtlich

274 In der gnostischen Tradition symbolisiert der "Kuß" u. a. die Erlosungszuversicht der Auserwăhiten. Vgl. Rudolph, Gnosis, Gơttingen 1990. S. 259. Vgl. dazu auch die Kuß-Symbolik in Hohelied (Cant 1,1). Bernhard de Clairvaux spricht vom dreigestuften mystischen Weg. Er unterscheldet: Fußkuß (purgatio, d. h. Buße), Handkuß (illuminatio, Erleuchtung) und Kuß von Mund zu Mund (Vollendung durch den Empfang des Heiligen Geistes). Vgl. Ulrich Kopf, .Hoheliedauslegung. Quelle einer Theologie der Mystik, in: Grundtragen der christlichen Mystik, hrsg. v. Margot Schmidt, Stuttgart-Bad Cannstatt 1987, S. 68.

$275 \%$ I die die Sinnesorgane gefühllos macht I... . (Corpus hermeticum, VII 2. 3.) Zit. K. Rudolph, a. a. O., S. 133.

276 Das Motiv der "Auflosung" des Wortes ("I rozpusti se má slova /... . V. 76) hat hier eine positive Konnotation (als "Stărkung"), die auf die mystisch-alchemistische Tradition rekurriert, in der die "Auflosung" als Voraussetzung der künftigen "Vereinigung" (coniunctio) begriffen wird. Ähnlich konnotiert das Motiv des "Sprühens der Funken" ("v srseni jisker", V. 77) die Vorstellung vorn 'Uberspringen' des göttlichen Funkens aus der menschlichen Seele auf die in der Materie verborgene anima mundi. Vgl. C. G. Jung. Mysterium coniunctionis II, Zürich 1956, S. 8f. Interessant ist in diesem Zusammenhang auch das Motiv der "Feuchte" ("I.../v žíravém dešti tvé vány'. V. 76): Jung verweist auf seine - aus der Königsmystik bekannte - alchemistische Symbolik, nămlich die des "feuchten Osiris", des "wăssrigen Geistes", d. h. des befruchtenden Pneumas. (Ibid. S. 8.)

27 C.G. Jung, Mysterium coniunctionis II, Zürich 1956, 269 ff. Vgl. dazu auch die Lehre vom Seelengrund Meister Eckharts: Eines der wichtigsten Aspekte dieser mystischen Lehre ist die Formulierung, daß wir unser Sein erhalten, indem wir unseren göttlichen Grund anschauen. Nach Meister Eckhart vollzieht sich die Gottebenbildlichkeit primär im Akt des Sich-Abbildens-Gottes im Seelengrund. In diesem Akt ist der Seelengrund imago Dei. Der Sohn Gottes und die Seele sind ein Bild Gottes. Der Mensch kann Gott werden, weil Gott Mensch geworden ist. Vgl. B. Mojsisch, Meister Eckhart: Analogie, Univozität und Einheit, Hamburg 1983, S. 6-18.

278 Vgl. K. Rudolph, Gnosis, Götingen 1990, S. $132 \mathrm{ff}$. 
miter löst werden soll; er durchdringt die Finsternis ("na dvĕ strany rozhrne cernè oblaky noc", V. 84) und läßt sich zu den Füßen des "Höchsten" nieder ("a lehne k tyým nohám". V. 84). Bei năherem Zusehen stellt man fest, daß dieses Bild eine Parallele in der Szene der gewaltsamen Erleuchtung der (unerlösten) anima mundi durch den "höchsten Schöpfer" (erste Sujetsequenz, V. 13-15) hat: "Oblaky s drápy ohniv'mi vythnal $z$ vod I... I / ve varu svêtel rozkypel barvy, Zhavé je nastríkal v duše" (V. 13, 15; "Die Wolken trieb er mit Feverkrallen aus den Wassern hervor I... ${ }^{\mu}$ ). Im Prozeß des (auto-) soteriologischen Geschehens (V. 82-84) nimmt das dichterische lch zunächst die identische Position ein, nämlich die des "höchsten" creator, in der Gestalt des sonnenhaften Adlers mit "Feverkrallen", 279 um die angestrebte (Selbst-)Erkenntnis zu eriangen. Doch im Augenblick der Ver-Einigung verzichtet das dichterische ich auf seinen "stolzen Blick" - d. h. auf seine eigene virilitas -, kehrt zu der (V. 27-60) Gestik eines Demütigen 280 zurück und läßt sich in der w e i b l i c h e n Position, 281 analog zu jener der anima mundi in der ersten Sujetsequenz, vom splendor divinus des "Höchsten", von seiner potentia (solis), in einem mystisch-erotischen Akt des Durchdringens 282 (als Sinnbild der mortifikatio) blenden: "a zrak svẻ pýchy nastavi pokornẻ prokláni pohledu tvého / v sycicím výtrysku krve osleplý zárï" (V. 85-86; "und den Blick seines Stolzes demütig hinhalten deinem durchbohrenden Schauen / im zischenden Blutstrahl geblendet vom Glanze"). Überraschenderweise scheint sowohl die ethische als auch die noetische Intention von Ranni modlitba mit der gleichen Intention eines der gnostischen 'Tagesgebete' zu koinzidieren:

279 In der antiken Mythologie figuriert "Adler" als Attribut des höchsten Gottes Zeus/Jupiter. In der christlichen Tradition konnotient "Adler", das heraldische Tier des Evangelisten Johannes (s. Johannes auf Patmos), u. a. die mystische Vision Gottes. In seinem Gedicht lbo (Les Contemplations VI, 1856) identifiziert sich Victor Hugo mit dem biblischen Adler, der zum Lichtreich Gottes emporsteigt. Die Adler-Symbolik in Ranni modlitba scheint aber vor allem auf die mystisch-erotische Bedeutung des Ganymed-Mythos zu rekurrieren. Ganymed bedeutet, laut Emblemata des 1522 erschienenen bekannten Handbuches allegorischer Bedeutungen von Alciato, die Emebung der Seete und die Extase der sublimierten Liebe. Im Zusammenhang mit der Thematisierung des Adler-Motivs in Ranni modlitba bietet sich der Vergleich mit der Symbolik des "Ganymed"-Blattes für Tommaso Cavalieri von Michelangelo (1533) an. die Charles de Tolnay hervorragend interpretiert. Was die beiden Darstellungen verbindet, ist $m$. $E$. der Gestus des 'Hinausgerissen-Werdens' (raptus, excessus mentis) und des 'Durchdringens' (der anima) durch den "Hochsten" im Akt der Ver-Einigung mit inm. Die scharfsinnige Deutung de Tolnays kơnnte in einigen Aspekten auch auf die Semantisierung des Adler-Motivs in Ranni modlitba bezogen werden: "Michelangelo makes of them an indissoluble group. He confers on the eagle an anthropomorphic expression of passion: the bird seizes avidly in his talons the delicate body of the youth, and the bird's neck is stretched around his torso. The spread wings extend the whole width of the sheet. The boy submits passively to the abduction and seems to be plunged in a dream of delights. From a distance the pair seem to form a single winged being-expression of that mystic union of which Michelangelo speaks in some of his poems (e. g. Frey, Dicht., XLIV): "One soul in two bodies became eternal, both rising to heaven with the same wings: $(X X 1.4)$. The two drawings show the two aspects of Michelangelo's love for Cavalieri: Tityos the tortures of love. and Ganymede the mystic union and rapture." Charles de Tolnay, Mictielangelo III. The Medici chapel, Princenton 1953, S. 112.

280 Gerade im Moment der 'Rūckkehr' des dichterischen Ich zur Demut kann man die Wiederherstellung eines direkten Bezuges auf die Axiologie der ersten drei Sujetsequenzen sehen.

281 Den psychologischen Hintersinn dieses Bildes beleuchte und erörtere ich eingehend im abschließenden achten Kapitel.

282 Die Symbolik des archetypischen 'Durchdringens' bzw. 'Durchbohrens' ist in der mystischen Tradition reichlich vertreten. Sie wird einerseits als 'heftiges (Liebes-)Erlebnis', hl. Teresa von Avila nennt es impetus (im Sinne "heftiges Vertangen'), andererseits als Analogon zu der Seitendurchbohrung Jesu Christi, d. h. als Symbol sich verströmender Liebe, gedeutet. Man denke an die Vision der hl. Teresa von Avila, in der ihr von einem Engel das Herz mit einem feuerflammenden Pfeil durchbohrt wird (s. die faszinierende Darstellung von Bemini in Rom, 16471652). Interessant sind (gerade in bezug auf Ranni modlitba) auch die Beschreibungen der Christusvisionen der hl. Teresa: "lebendiger Christus, "strahlendes Licht". "majestătische Macht" u. a. Vgl. Såmtliche Schniften der hl. Theresia von Jesus, übers. von P. A. Alkofer, Bd. I, München 1933, S. 265. 
"Vater des Alls. laß mich nie von der Erkenntnis (gnosis) /.../ abłallen, gewăhre es mir und gib mir die Kraft. Ich will mit dieser Gnade diejenigen (meines) Geschlechts erleuchten, die in Unkenntnis sind, meine Brüder, deine Söhne. Daher glaube und bezeuge ich: Ich gehe zum Leben und zum Licht. Gepriesen seist du, Vater, dein <Mensch> (anthropos) will mit dir zusammen am Werk der Heilung teilnehmen, so wie du ihm die ganze Macht übergeben hast". 283

\subsection{Teleologie des Schmerzes}

Eine der Voraussetzungen für das Erreichen des produktiven ascensus auf dem Weg zur Erlösung scheint, in der Axiologie des gnostisch-eschatologischen Modells von Svitáni na západè, das Erlebnis des Schmerzes durch den descensus in die Unterwelt der Dekadenz zu sein. In der schon erwähnten Auto-Interpretation von SZ bezeichnet Bïezina das Thema des Schmerzes als den zweitwichtigsten "Gedanken-Strom" ("proud myšlenek") seines neuen Gedichtzyklus. Als semantische Konstante nimmt der Schmerz bereits in Tajemné dálky eine wichtige Position ein, doch in der Axiologie des dekadenten Symbolismus hat der Schmerz kein Telos, er bleibt ein 'zielloser' bzw. 'endloser', zum Selbstzweck hyperthrophierter Erlebniszustand, eine Art hyperästhetischen Einstellungsaffekts, wenn es um die Initiation in das magische und faszinierende Reich des KunstSchönen geht. In dieser Konstellation wird der Schmerz sogar als eine der Bedingungen für die verabsolutisierte ästhetische Existenz postuliert (Umenni / Die Kunst, Kap. 2.3.1) Die In-Frage-Stellung der Werthierarchie des dekadenten Symbolismus, eines der Hauptmerkmale des gnostisch-eschatologischen Modells (SZ), hat Konsequenzen auch für eine sinn- und telosorientierte Transformation bzw. Umsemantisierung des SchmerzMotivs.

In der Analyse Brezinas Autointerpretation von Svitáni na západž stelt M. Cervenka fest, 284 daß Brezina interessanterweise das Motiv des Todes aus seiner Interpretation tilgt und durch das des Schmerzes ersetzt. Cervenka weist nach, daß "Schmerz" und "Tod" sich aber in Svitání na západẻ zueinander komplementär verhalten und die "Situation eines mystischen Abenteuers" in SZ285 (U. a. in Anlehnung an die Symbolik des Leidens und des Kreuztodes Christi) initiieren. Bíezina begreift und definiert den "Schmerz" ("bolest") als "Werkzeug einer höheren Ókonomie" ("nástroj vyšši ekonomie": als Offenbarung des Willens des "Höchsten"?). 286 er spricht inm einen konkreten und vor allem p o s i ti v e n Sinn zu. In Tajemné dálky erlebt das dichterische Ich den "Schmerz", im Hinblick auf seinen 'hedonistischen' Aspekt, als einen aufregenden stimulus der postulierten schöpferischen Isolation:

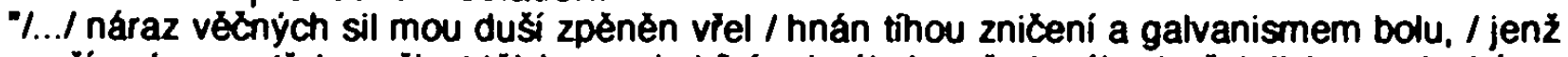
minem žravỳm se sţebe v żivot tél / a zemi obihá ơ pólu krouže $k$ pólu, / v żeh jisker prokmitá se $\checkmark v$ łasách jemných cév, do uzlủ żl se slivá / a pulsem zrychleným na żhavou tepe krev / a skálou bolesti po strunách nervú splývá". (Sviji zal jsem polozzil.. I Mein Leid legte ich.... III. Str., "I... / der Ansturm ewiger Krătte brodelte schăumend in meiner Seele. / getrieben von der Last der Vernichtung und vom Galvanismus des Schmerzes, / der mit ătzendem Blitz sich ins Leben der Leiber einsaugt / und die Erde von Pol zu Pol kreisend umrast, als Funkenglut in den Fasem feiner Adem flimment, / sich in die Venenknoten ergieBt / und mit beschleunigtem Puls im glühenden Blut schlăgt / und als Schmerzensskala über die Saiten der Nerven gleitert).

In Svitáni na západé wird aber gerade die schöpferische isolation als Ursache der ominösen Entfremdung denunziert, von der die in Vladari snú (Die Herrscher der Träume, Str. II, VII) expressiv dargestellten, körperlich-seelischen Schmerzen herrühren. Aus dieser Erfahrung resultiert offensichtlich die Vorstellung der 'zweckmäßigen' Teleologisierung des 'endlosen' und 'ziellosen' Schmerzes, die in Bíezinas Interpretation von Svitáni na západẻ eine so wichtige Position einnimmt. Was verbirgt sich hinter dem Begriff der "Ökonomie"? Es scheint nichts dagegen zu sprechen, die von Bỉezina

283 Vgl. Corpus hermeticum I, 32, zit. nach K. Ruddph, Die Gnosis, 1990, S. 137.

284 Vgl. M. Cervenka, .Bł̌ezinúv výklad Svítáni na západē", in: M. Cervenka, Styl a význam, Praha 1991, S. 32-46.

285 Vgl. a. a. O., S. 36.

286 Vgl. a. a. O., S. 34. 
verwendete Formulierung "höhere Okonomie" mit der Passion Christi, mit dem (erwarteten) soteriologischen Geschehen und der "Heils-Anordnung" 287 in Verbindung zu bringen. In Vitězná píseñ (Das siegreiche Lied) wird eine "neue Ordnung der Dinge" erwartet:

"Avšak hustá krev zemé nám polarisovala v zracich záreni smrti / a radostná odpovẽơ naše sipéla, némá, výklikem hrủzy, I onou hlubokou łeci, již zivot odpovidá Neznámému / (neż prijoe chvile prijmouti nový pơłádek věci). - - Má duše!" (VI, 1-4; "Aber das dickflüssige Blut der Erde polarisierte uns in den Blicken des Todesleuchtens / und unsere freudige Antwort zischte, stumm, vom Aufschrei des Grauens, / von jener tiefen Sprache, in der das Leben dem Unbekannten antwortet / (bevor der Augenblick eintritt, die neue Ordnung der Dinge anzunehmen). - - Meine Seele!").

Die Hauptursache des Schmerzes sieht Biezina in der Teilung288 des Ur-Einen ("príǐinou bolesti je rozdẻlení). Diese Vorstellung bekundet die Transformation einer alchemistischen bzw. gnostischen Folie. Der Schmerz der Seele (Psyche; als Symbol des kollektiven Unbewußten) wird durch ihre Abtrennung vom (männlich) orientierten Bewußtsein verursacht. Dadurch droht der (weiblichen) Psyche sich in der Sphäre der Finsternis zu verlieren:289

"Tys nešla. Kdo tẻ potkal a svedl z mých zahrad? Či leká / tẻ oblak, jež zhasiými slunci se pozdvih' a nad mým domem se prostỉel? / Ci smrt, která zabiji na kł̌izovatkách mé hosty a ceká, I až sám se pribliżim k oknu, blizko na osudnỳ dostłel?" (Tys nešla / Du kamst nicht, V, 1-4; "Du kamst nicht. Wer ist dir begegnet und wer führte dich aus meinen Gärten weg? Oder erschrak dich I die Wolke, die sich durch erloschene Sonnen emporhob und über meinem Haus sich ausbreitete? / Oder der Tod, der auf den Kreuzungen meine Gäste tötet und wartet, / bis ich selbst an das Fenster năherkomme, der verhăngnisvollen Schußweite nahe?"). "Nepoznány se mijeji duše. // každá svou rozżatou svítilnu płi potkáni cloni, nedủvěrivá, / jen dlouhé stiny vzpominek táhnou se za nimi płes celý obzor". (Nẻmé setkáni / Stumme Begegnung. V. 5-7; "Unerkannt

287 Diesen Terminus verwendet in seinem Traktat Refutatio omnium haeresium (Widerlegung aller Hăresien) Hippolytus von Rom (gest. um 235), eine bedeutende Persơnlichkeit der christlichen Gnosis. Vgl. K. Rudolph, Die Gnosis, 1990, S. 180ff. Hippolytus spricht von einer (Heils-)Anordnung, die K. Rudolph - im Zusammenhang mit dem Leiden Christi und seiner "HeilsVeranstaltung" - als "Okonomie" deutet.

288 "Die Ursache des Schmerzes ist Trennung". O. Bł̌ezina, Dopisy O. B. Anně Pammrové, Praha 1931, S. 141

289 Die Symbolik der Qual und inre Beziehung zur coniunctio untersucht C. G. Jung. Studien über alchemistische Vorstellungen, Gesammelte Werke, Bd. 13, Freiburg i. Breisgau 1978. S. 354 If. Jung geht auch aut den psychologischen Aspekt des Mythologems vom Kreuztode Christi ein: Christus (der mănnliche animus) gibt der leidenden psyche ihre Existenz, indem er ihr Leiden anerkennt. Dann wird sie aber sich selber (der Unbewußtheit) überlassen (ibid. S. 361). Die UrEinheit wird in zwei Hălften gespalten, die eine (geistige) verweilt in der Sphäre des Lichtes, die andere (emotionale) wird in die chthonische Sphäre der Finsternis gezogen. Diese Trennung stelt jedoch eine unumgăngliche Bedingung für den Bewußtwerdungsprozeß dar. "Es gibt keine Bewußtheit ohne diese prinzipielle Diskrimination" (ibid. S. 362). Deshalb konstituieren sich die Ganzheitssymbole im/aus dem Unbewußten. Als einen der Topoi der Vereinigung nennt Jung das Kreuz. dessen Symbole von vierzahligen, aus zwei sich durchkreuzenden Gegensatzpaaren gebirdet werden. Durch die Verbindung der vier Punkte entsteht ein Kreis, das einfachste Symbol der Ganzheit und das einfachste Gottesbild zugleich. In der coniunctio kulminiert sowohl das Leben als auch der Tod. Hier spielt die Verwandtschaft zwischen Kreuz und Baum eine wichtige Rolle. In den mythologischen Vorstellungen wird der Baum (auch) mit der Gestalt des Kreuzes assoziiert, das Kreuz wiedenum steht für die Welt, u. a. als Symbol der vier Himmelsrichtungen. Die (irdische) Welt kennzeichnet sich durch den Kontrast der Gegensătze: Links (Luna, weiblich), Rechts (Sol, männlich), Oben (Tag. Licht, Feuertaube, Leben, Freiheit), Unten (Wasser, Finsternis, Schlange, Knechtschaft, Untergang). Die Ganzheit versinnbidlicht das Leben, sie ist die Identifikation unseres (wahren) "Ich" mit Raum und Zeit, Vergangenheit und Zukunft, (Lebens-) Freude und Schmerz. Diese Identifikation entspricht dem 'Ans Kreuz-geschlagen-werden'. Christus wurde mit fünf Stichen durchbohrt; der Zeit-Raum, mit dem sich das "Ich" identifiziet, wird mit fünf Sinnen wahrgenommen, die unser Gedächtnis hoffnungslos an die immanente Welt fixieren. Das Ich-Bewußtsein ist ein circulus vitiosus, aus dem es kein Entrinnen gibt. Daher rührt der unaussprechliche Schmerz, der zur Wonne wird. 
gehen die Seelen aneinander vorbei, mißtrauisch beschirmt eine jede bei der Begegnung ihre Laterne, I nur lange Schatten schleppen sich hinter innen durch ganzen Gesichtskreis". ${ }^{290}$

Es entspricht der Axiologie von Svitáni na západẻ, daß auch ein (scheinbar) negatives Phănomen einen positiven Wert in sich trägt. Diese oxymorale Semantik durchwirkt auch Bíezinas Überzeugung von der "mystischen Bestimmung des Schmerzes", d. h. der Schmerz wird zur (Trieb-)Kraft der Vollendung der "neuen" (Heils-)Ordnung der Dinge". Die Ursache (des Schmerzes; "přcicina bolesti") und Folge ("rozděleni" P "Trennung") werden gleichsam vertauscht, in dem Sinne, daß nicht (mehr) die Trennung, sondern die Vereinigung nun als Folge des Schmerzes erwartet wird. 291 Durch die Vereinigung kann auch die peinigende Ziellosigkeit des Schmerzes getilgt bzw. umkodiert werden:

"Bratưi, z ruky do ruky podávejme víno silných v své đási I...I. Vinarii jeho byli Smutek a Samota. I... I Prival tvưj uhasi staveni naše, hořci se ctyr stran plameny bolesti". (Vino silných / Der Wein der Starken, V. 1, 3, 14; 'Brüder, von Hand zu Hand reichet den Wein der Starken in eurem Becher /.../. Seine Winzer waren Trauer und Einsamkeit. I.../ Deine Regenflut wird unser Gebăude löschen, wenn es von allen vier Seiten steht in den Flammen des Schmerzes").

Im (Heils-)Plan der "mystischen Bestimmung des Schmerzes" werden diesem noch zwei weitere Funktionen zuerkannt: die kognitive und die kreative. Der Schmerz wird auch als vehiculum der Erkenntnis bzw. des Wissens - von Geheimnissen des Universums, von "eschatologischem Futur", von visionärer Begegnung usw. - semantisiert (Tajemstvi bolesti / Das Geheimnis des Schmerzes, II. Str.). Dabei geht es allerdings auch um die Erkenntnis der "mystischen Bestimmung" des Schmerzes 'an sich'. Die Bedeutung des Schmerzes als eines konstitutiven Elements der Denkbewegung, wird bereits im PrologGedicht Ples vẻčných svitáni (Der Reigen der ewigen Morgenröte) akzentuiert: "V̌̉el rojem pỉed bouri, kdyż myšlenka má viela / a ticha vếnyý hlas v ni těžkým echem zmíral, I kdyż radost żivota mi đveře uzaviela / a pokyn bolesti je dálkám oteviral" (III. 1-4; "Als mein Gedanke wie ein Bienenschwarm vor dem Gewitter brodelte / und der Stille ewige Stimme in inm als schweres Echo verschmachtete, / als mir die Freude des Lebens inre Türen verschloß / und der Wink des Schmerzes sie den Fernen öffnete"). In der letzten Verssequenz von Tajemstvi bolesti (Das Geheimnis des Schmerzes) offenbart sich der

290 Noch expliziter und eindringlicher kommt dieser Gedanke im berühmten Gedicht Se smrt' hovori spici (Mit dem Tode reden die Schläfer), aus dem vierten Gedichtzyklus Stavitelé chrámu (Baumeister am Tempel, 1899), zum Ausdruck: "Noc tisicileti odñala bratrskou Cistotu pohledü našim / a rozklenula se mezi dnem muže a mezi dnem Żeny /.../ Dni našich duši nikdy se nepotkávaji. Slunce, jeż nad sebou stejnè vysoko z̛̉ime, je pro ni a pro nás rozdílno v case. I... I Objetí nase stalo se jako znameni do tmy, / jeż volá bolest. (V. 49-50, 54-55, 59-60; "Die tausendjāhrige Nacht hat unseren Blicken die brüderliche Reinheit geraubt / und sich wölbte zwischen dem Tage des Mannes und des Weibes I.../ Es begegnen sich nie die Tage unserer Seelen. Die Sonne, die wir gleich hoch über uns sehen, ist an Zeit verschieden für sie und für uns. I... I Unser Umarmen ward wie ein Zeichen ins Dunkel, I anrufend den Schmerz". Übers. v. Otto Pick.)

291 Sehr aufschlußreich enweist sich an dieser Stelle ein Rekurs auf die Symbolik des Leidens im Neuen Testament. Wie R. Bultmann (Theologie des Neuen Tastaments [4. Auflage], Tübingen 1961, S. 350ff.) darlegt, ermahnt das 'ewige Leiden' - und die in inm manifeste "Todesherrschaft" den Glaubenden, sich von allem Welttichen abzuwenden und den Blick vor allem (und gerade deshalb) auf das ewige Unsichtbare (2. Kor. 4,18) zu richten. Das Leiden, das den Menschen an seine Schwachheit erinnert, wird für den Glaubenden zur Kraft, die eben "in der Schwachheit zur Vollendung kommt", im Sinne von 2. Kor. 12, 9-10: "Und er hat zu mir gesagt: Laß dir an meiner Gnade genügen; denn meine Kraft ist in den Schwachen măchtig. Darum will ich mich am allerliebsten rühmen meiner Schwachheit, damit die Kraft Christi bei mir wohne // I.../, denn wenn ich schwach bin, so bin ich stark'. Vgl. dazu die Bitte, mit der sich das lyrische Ich in Ranni modlittha an den "Hőchsten" wendet: "at" lítost má vznáśi se silou, po niż teskni má slabost"! (V. 43; "mag meine Reue aufschweben mit der Kraft, nach der sich sehnt meine Schwăche!"). Durch die Erkenntnis Christi, durch die "Kraft seiner Auferstehung und [der] Gemeinschaft seiner Leiden" (Philipper 3,10) ist, laut Bultmann, der Leidende aus der Einsamkeit seines Leidens erlost. Vgl. auch die Schlußstrophe des Titelgedichts Svitáni na západè: "O Vécny! At tušeni nase jsou sladká tẻm, kteři v bolestech tonou. / Pějme hymnu ze slov, jeż zną̌ smrt ve všech jazycich zemé. I Nebot nám, kterí věrime, je den tvưj dobou zráni, zahořkle vonnou, I praskajici v bolestných klasech a vęerem chlazenou jemnę." ("O Ewiger! Mögen unsere Ahnungen denjenigen süß sein. die in Schmerzen ertrinken. / Wir singen eine Hymne aus Worten, die den Tod in allen Sprachen der Erde heißen. / Denn für uns, die wir glauben, ist dein Tag eine Zeit des Reifens, bitter duftig, I berstend in schmerzerfülthen Ähren und von der Abendkühle zart gelindert"). 
Schmerz als Wille des "Höchsten"; hier wird der Denkbewegung ein bestimmtes Telos die Erkenntnis des "Geheimnisses" ("tajemstvi") - mit der (Schmerzens-)Peitsche ("biC") gleichsam aufgezwungen: "pochmurných myšlenek mých stádo zmatené / tvým biðem Zene Pán na pastvy tajemstvi" (letzte Str., V, 7-8; "die verwirrte Herde meiner trübsinnigen Gedanken / treibt der Herr mit deiner Peitsche auf die Weiden des Geheimnisses voran"). Explizit wird die kognitive Funktion des Schmerzes in Mythus duse (Der Mythos der Seele) thematisiert: "a utrpenim đisti v mystickẻ Myšlence, jeż zraje pro nás rozkvêtem tvarü" (V. 54: "und durch das Leiden im mystischen Gedanken zu lesen, der für uns im Aufblühen der Formen reift"). Doch das postulierte Wissen (durch Erleuchtung!) ${ }^{292}$ wird hier offenkundig als transzendierendes Wissen gedacht. Dieses Wissen zielt immer deutlicher auf die Geheimnisse der Schöpfung, ja auf das Erlebnis der Theophanie hin; es handelt sich nicht um ein Wissen durch das endliche ratio, sondern um ein transzendierendes, ver-einigendes Wissen.293 Daß gerade die 'Einheitsmystik' (einer "Bruderschaft der Glaubenden") zum Erlebnis der Theophanie führt, zeigt ein Vers aus Vino silných (Der Wein der Starken): "Uslyšime suméni neviditelných reke, jeż protékaji staletími, I uvidíme oblak Věčného, sḱlonẻný k vodám, svitici z hlubin jako slunce" (V. 8-9; "Wir werden das Rauschen von unsichtbaren Flüssen vernehmen, die durch Jahrhunderte strömen, / die Wolke des Ewigen sehn, sich niederbeugend zu Wassern, wie Sonne den Tiefen entstrahlen").

Die Semantik des "schöpferischen Schmerzes" ("tvưrči bolest") wird erst im Gedichtzyklus Vètry od pólù (Polarwinde, 1897) mit voller Intensität entfaltet. Doch sie schwingt bereits in Svitani na západè mit, am prägnantesten wohl in Ranni modlitba (Das Morgengebet, III. Sujetsequenz), wo das lyrische Ich in der Position eines 'Bittstellers' oder 'Trösters' mit "schmerzvoller" Anstrengung am altruistisch und ethisch motivierten (kollektiven) Erlösungswerk partizipiert: "a dech bolesti mé at" sráżi se v krystaly lékủ tém. kterí hledánim onemocnéli! /... I Unaven prací a láskou a bolestí zlomen at usednu v kvetouć meze" (V. 51, 59; "und der Hauch meines Schmerzes mag sich niederschlagen zu Arzneikristallen für jene, die vor Suchen erkrankten! /.../ Ermüdet von Arbeit und Liebe und gebrochen von Schmerz mag ich niedersitzen auf blühenden Rainen".). Es ist der "schöpferische S c h m e r z", der in der Phase des eschatologischen Symbolismus jene Position einnimmt, die in der Phase des dekadenten Symbolismus der "schöpferischen Individuation" vorbehalten war. Auch die "schöpferische Individaution" des dekadenten, autistischen Künstler-Menschen kennt das Erlebnis des Schmerzes, dieser jedoch mündet - wie schon enwähnt - immer in 'Todesstille', in 'frostige Einsamkeit einer kristallinen Nachtwelt der Krypten, Grotten oder der hypnotisierenden Musik, der Apophatik. Autotelie, Passivităt und Erschöpfung durch die "ewige Ferne".294" Das charakteristische Merkmal des "schöpferischen Schmerzes" ist dagegen die "existentielle Aktion". Das Erlebnis des Schmerzes durch den Abstieg in die Unterwelt der Einsamkeit und Vernichtung, gibt dem Dichter die Kraft dazu, den destruktiven Aspekt des

292 -Tajemstvi bolesti! Vỷkriky soumrakủ! / Skubnuti Bliženi po vláknech etherných! / Połkáni onnivá mystickych oblakú, / jeż svití ponledúm do dálek nádhernych! / Stem bleskủ słysel jsem váš reflex $v$ duši hrát" (Tajemstvi bolesti / Das Geheimnis des Schmerzes, II, 1-5; "Geheimnis des Schmerzes! / Autschreie der Dảmmerungen! / Zuckungen der Nảherung an ätherischen Fasern! / Feurige Begegnungen von mystischen Wolken, I die den Blicken in herrliche Fernen leuchten! / Mit hundert Blitzen hơrte ich euren Reflex in der Seele spielen").

293 Im Sinne des Versettes aus der Epheser-Epistel $\%$. I ein Gott und Vater aller, der da ist über allen und durch alle und in allen" (Eph. 4,6). Vgl. auch ein Epigramm aus dem Cherubinischen Wandersmann (II, 39): "Wer in sich über sich in Gott verreisen kann, I Der betet Gott im Geist und in der Wahrheit an".

294 "Mé têlo projala's jak bledá záre đivem, I v mých nervech hởela's jak umiráni pocit, / a pohrben $v$ loktech tvých, jak v chladném hrobé Żivém, I pod tiži polibkú jsem unavený procit. /I Vsak onémlá táhla tvá hudba Neznámého hlasem I v mém sluchu smrtelném. Pood klenby ticha kanul / mé duše ztlumen pláç, a v mlðenlivém stesku / až v okna andélü, jak obèt vưné vanul / żal budouci mých dni a ozon prisstich blesku." (Tichá bolest / Der stille Schmerz, 1, 5-8, V, 4-8; "Meinen Leib durchdrangst du wie fahler Glast mit einem Wunder, / lodertest in meinen Nerven wie das Agonie-Gefühl, I und in deinen Armen begraben, wie in einem kalten lebendigen Grab, / wachte ich ermüdet unter der Last der Küsse auf. // Doch verstummt zog deine Musik durch die Stimme des Unbekannten / in meinem sterblichen Gehör. Unter die Wölbungen der Stille rann / gedämptt meiner Seele Weinen, und in schweigsamer Wehmut / bis zu den Fenstern der Engel, wehte wie des Duftes Opfer / Leid meiner kūnftigen Tage und Ozon künftiger Blitze".) 
Kunstschaffens in den kreativen Aspekt zu wenden. Darüber hinaus: Durch das Erlebnis des Schmerzes partizipiert der Mensch am Leiden des "Höschsten" und dadurch auch an der Glorie des Erlösungswerkes; eine Intention, die im sematischen Plan des dritten Gedichtzyklus Vètry od pólì (Polanwinde) eine der sinndominierenden Funktionen übernimmt : "A bolest tvá tvưrči / Aż k poslednim končinám vesmiru zalká, / nesmírná, rozlitá tisiciletimi /...l. A my všichni, nesmrtelni tvou vüli, / bolesti svoji / tvé bolesti soilime słávu!" (Kdyż z lásky tvé.../ Wenn aus deiner Liebe ..., V. 6-8, 27-29, VP: "Und dein schopferischer Schmerz I stöhnt bis an die letzten Grenzen des Alls, / maßlos, vergoßen in die Jahrtausende /.../. Und wir alle, unsterblich durch deinen Willen, / durch unseren Schmerz / teilnehmend am Heil Deines eigenen Leids!")

Im folgenden gilt es, die Umkodierung der Schmerz-Semantik in der Axiologie des eschatologischen Symbolismus an zwei Gedichten, Vitézná piseñ und Vino silných, in denen das postulierte Ziel, die erlösende unio mystica, durch das Erlebnis des Schmerzes erreicht werden soll, zu untersuchen und weiter zu spezifizieren. Während jedoch die angestrebte Vereinigung in Vitězná piseñ (Das siegreiche Lied), das zugleich als eine Art Auseinandersetzung mit dem dekadenten Prinzip der Irrealisierung strukturiert ist, nicht gelingt. geht sie (erst) in Vino silných (Der Wein der Starken) - kraft des erlösenden Wissens - in Erfüllung.

\subsubsection{Der leidvolle Weg durch die Unterwelt der Dekadenz: In-Frage-stellung der suggestiven Wirkung der 'Kunst-Sprache'? Vítèz ná piseñ (Das siegreiche Lied)}

„Je suis le ténébreux. - le veuf. - l'inconsolé, / le prince d'Aquitaine à la tour abolie:

Ma seule étoile est morte. - et mon luth constellé / Porte le soleil noir de la Mélancolie“.

Gérard de Nerval, El Desdichado (,Les Chimères“)

\section{Vítězná píseň}

I. Vysvětli, duše má, extatickou slávu té písnę něm ých, nejvyšzích oktáv, když bolest železným klíxem napjala struny tvé v poslední, nejhlubł̌́ závit dle základního tónu tajemného ladéní, v němž vesmírem zvoní hymna Nepoznaného! - -

II. Opojení nás vedlo v nejniž̉i rozlohy snéní se svahư denního svêtla a mlhy nám stoupaly vstł́c ze zdrojư, jimiž omamovaly se véky a karavany nesxíslných duši. Cemé slunce smrti tam plálo a házelo paprsky podmíněné jinými zákony chvění.

III. Na květy naši lásky a touhy se płissálo zsinalou Žizní. pilo $z$ nich rủžové dechnutí jiter, zandelých svatebním procitnutím; ledovým ohněm je strávilo, až barvy $z$ nich koufily špinavým dýmem a v slzách tekla z nich vyhnaná vủně a rozkoł pozemských zrakủ.

IV. Dráhy našeho letu, jenž vif́il královstvími sluncí, v uzly zaklesla tíze, síl mystická, jak motýly chytající světy a lovící k Stredu.

Uhaslé rytmy staletých pochodủ táhly po výkłicich, oněmlých vêky! Mrtvá vichfice vyvrácených uhelných lesủ slova nám traly u rtủ!

V. Bohatství nesčetných pozemských zrakủ padala spálená v hlubiny dálek. jež v žití dělily duše a naplnily nám okmžiky přistí tisíciletími.

Cítili jsme blízkost bratrského množství, objetí nesčislných dechü. polibky beze rtủ které jsme vraceli silnými polibky omdlivání.

VI. Avšak hustá krev zemex nám polarisovala v zracích zárení smrti a radostná odpověđ naše sípêla, němá, výktikem hrủzy, onou, hlubokou rexí, jîz zivot odpovídá Neznámému

(než prijde chvile přijmouti nový pơ̌ádek věci). - - Má duše! 
VII. Je teskná tvá vítězná píseñ, transponovaná do oktáv pozemských tónủ! Šiasten, kdo ji neslyší zníti dfíve, než zemdlením nabude síly!

V̌̌ak kdo ji uslyši jednou, zvoní mu pł̌išemè ze sladkého płriznání lásky, zvoní mu $z$ tlukotu srdce $k$ srdci přǐehnutého.

VIII. Z Sepotu rozestýlaného lože, z tepolu křidel zpívajícího jara, ze chvěni obracených listů v knize básníka milovaného i z lepkavého కeelestu malîfského štétce na plátně. kde zárí kouřící do tmy uměni maluje prchavé symboly snění tahy fosforovými.

\section{Das siegreiche Lied}

I. Erkläre, meine Seele, die extatische Hehre des Liedes der stummen, höchsten Oktaven, wenn der Schmerz mit eisernem Schlüssel deine Saiten spannte in letzter, tiefster Windung gemäß dem Grundton eines geheimnisvollen Einstimmens, in dem über das Weltall läutet die Hymne des Unerkannten! - -

II. Die Trunkenheit führte uns in die niedersten Traumgefilden aus den Hängen des Tageslichtes und die Nebel stiegen uns entgegen aus den Quellen, an welchen sich die Äonen und Karawanen unzähliger Seelen berauschten. Die schwarze Sonne des Todes loderte dort und warf Strahlen, bedingt durch andere Gesetze des Bebens.

III. Auf die Bluten unserer Liebe und Sehnsucht saugte sie sich mit fahlem Durst. sie trank aus ihnen rosenroten Anhauch der Morgen, gerötet von hochzeitlichem Erwachen: mit eisigem Feuer verzehrte sie, bis daraus die Farben in schmutzigem Qualm rauchten und in den Tränen floB aus ihnen ausgetriebener Duft und Wonne irdischer Blicke.

IV. Die Bahnen unseres Fluges, der durch die Königreiche der Sonnen wirbelte, verknüpfte die Schwere zu Knoten, ein mystisches Netz, wie Smetterlinge die Welten einfangend und jagend zur Mitte. Erloschene Rhythmen hundertjähriger Umziuge zogen mit Aufschreien, die in Äonen verstummten!

Tote Stürme entwurzelter, zu Kohle gewordener Wälder rissen uns die Wörter von den Lippen!

V. Die Reichtümer unzähliger irdischer Blicke fielen vebrannt in Tiefen der Femen, welche die Seelen in Leben trennten und uns die kommenden Augenblicke mit Jahrtausenden füllten.

Wir verspürten die Nähe bruderlicher Menge, die Umarmungen unzähliger Alemzüge. Küsse ohne lippe, die wir erwiderten mit kräftigen Küssen der Ohnmachi.

VI. Aber das dickflüssige Blut der Erde polarisiente uns das Todesleuchten in Blicken und unsere freudige Antwort verzischte, verstummt, mit Aufschrei des Grauens. mit jener tiefen Stimme, mit der das Leben dem Unbekannten antwortet (bevor der Augenblick kommt, um eine neue Ordnung der Dinge anzunehmen).

- Meine Seele!

VII. Bange ist dein siegreiches Lied, transponiert in die Oktaven irdischer Töne! Gluicklich, wer es nicht eher tönen hört, bevor er durch Ohnmacht Kräfte gewonnen! Aber wer es einmal hört. dem tönt es unheimlich aus dem süßen Eingeständnis der Liebe. es tönt ihm aus dem Schlagen des Herzens, das zugeschweißt ist ans Herz.

VIII. Aus dem Flüstem des aufgeschlagenen Bettes, aus dem Flattern der Fligel des singenden aus dem Zittern der Blätter im Buche des geliebten Dichters auch aus dem klebrigen Geräusch des Malerpinsels auf der Leinwand, wo mit in die Kunst flüchtige Symbole des Träumens mit phosphoreszierenden Strichen malt. 
Die Eigenart dieses Textes resultiert in hohem Maße aus seiner als 'Dialog' zwischen lyrischem Ich und seiner Seele aufgebauten kommunikativen Struktur. Die hypnotisierende und suggestive Wirkung der annihilierenden 'Musik-Sprache' (Motiv Z Beothovena, Snad potom.... TD) wird in Vitézná píseñ - von einem M e ta standpunkt aus - einer kritischen Reflexion unterzogen. Den Hintergrund bildet die 'Rekonstruktion' des schmerzvollen - zur Erkenntnis der Unvereinbarkeit der Kunst-Sprache mit der 'niederen' Sprache der Erde führenden - descensus ad inferos der Dekadenz. Doch auch dieses selbstzerstörerische 'Bis-an-den-den-Rand-Gehen' hat seinen (positiven) Sinn: Es motiviert zur Suche nach einem Weg zur Integration der dekadenten Vergangenheit durch inr analytisch-kritisches Hinterfragen. Der dialogischen Kodierung des Pextes entspricht die Aufspaltung des lyrischen Ich. Diese Zweistimmigkeit dient der Inszenierung einer 'Disputation' (certamina), eines 'Streitgesprächs', zwischen Ich und der Seele. Die für ein Streitgespräch charakteristische Wechselbeziehung von Anrede und Angeredetsein in einer Zwiesprache, die gleich in der ersten Verszeile zum Ausdruck kommt ("Vysvêtli, duše má l... / "Erklăre, meine Seele (... ${ }^{\mu}$ ), dient hier der Konstituierung eines distanzierten Metastandpunktes, den das Ich gegenüber der von seiner Seele vertretenen - und offensichtlich noch dekadenten - axiologischen Position einnimmt. Das Ich bezieht also einen $A$ u $B$ e $n$ standpunkt, von dem aus es möglich ist, den I $n n$ e $n$ standpunkt der Seele einer kritischen Reflexion zu unterziehen. Die Soele wird vom lyrischen Ich explizit aufgefordert, die suggestive Wirkung ihres schmerzertüliten Liedes zu erklären: "Vysvẻtli, duše má, extatickou slávu tẻ písnê nẻmých, nejvyšsích oktáv, / kdyż bolest Żelezným klícem napjala struny tvé v poslední nejhlubši závit"(I, 1-2; "Erklăre, meine Seele, die extatische Hehre deines Liedes der stummen, höchsten Oktaven, / wenn der Schmerz mit eisernem Schlüssel Deine Saiten spannte in letzter, tiefster Windung"). Die hypnotisierende, den 'Sturz' in den Kunst-Tod herbeiführende Wirkung der dekadenten 'Musik-Sprache' wird hier nicht mehr ungefragt hingenommen, sondern kritisch hinterfragt und in Frage gestellt. Der doppelte Gedankenstrich ("hymna Nepoznanéhol --". I, 4) leitet die Rede der Seele ein, die nach der vierten Verszeile der sechsten Strophe wieder vom doppelten Gedankenstrich beendet wird. Mit der Apostrophe "Má dušl" ("Meine Seele!") ergreift das lyrische Ich erneut das Wort und wendet sich mit seiner Antwort (VII.-VIII. Str.) noch einmal an die Seele. Damit wird die distanzierte Position des reflektierenden Ich, das nicht nur das erste, sondern auch das letzte Wort hat, klar markiert. In den letzten zwei Strophen wird die 'Wirkung der dekadenten 'Musik-Sprache' einer kritischen Analyse unterzogen.

Aus diesem Arrangement der Kommunikationssituation resultieren auch einige formale Besonderheiten des Textes, wie Z. B. die Inversion der grammatischen Zeit; wăhrend das fragende, reflektierende und analysierende Ich im Präsens (aus der Perspektive der aktuellen Gegenwart; Str. I, VII-VIII) spricht, formuliert die apostrophierte Seele ihre Replik im Prăteritum (Str. II-VI, 1-2), d. h. als eine - in die Vergangenheit 'zurückversetzte' - Rekonstruktion der in der Unterwelt der Dekadenz gemachten Erfahrungen. Damit hängt ein anderes Spezifikum zusammen, nămlich die Tatsache, daß die in 2. Pers. S in gul a r angesprochene Seele merkwürdigerweise in der 1. Pers. PI u ra I antwortet. Wie ist diese 'Inkonsequenz' zu deuten? Eine plausible Erklärung wäre die, daß die Seele hier im Namen aller Künstler-Menschen, aller aư den Irrweg verführten ("Opojení nás vedło I...r. II, 1) "Herrscher der Träume" spricht. Diese These scheint die Qualifikation des Liedes als "vítẻzná" ("siegreich") zu unterstützen, wobei das "siegreiche", extatisch "hehre" Lied $(1,1)$ stumm, apophatisch bleibt: "I... písnè némých, nejuyšsich oktáv ("I.../ des Liedes der stummen, höchsten Oktaven"). Es ist kein Zufall, daß der 'Befreiungsversuch' der extrem empfindsamen, überzarten Mimosennaturen, der als "Sieger" ("O Vítézi", IX, 1) apostrophierten "Herrscher der Träume" (Vladarii snú ). gerade an dem "siegreichen Körper" (V, 4) scheitert.

Es erhebt sich die Frage, von welchem Standpunkt aus die dekadente Axiologie hinterfragt wird? Wie es scheint, ist das der Standpunkt von jemandem, der die Aporie der ästhetischen Existenz bereits erkannt und zu ihr eine kritisch distanzierte Haltung eingenommen hat. Diese bedeutet den ersten Schritt auf dem 'richtigen' Wege. Die Erkenntnis der Aporie der dekadenten Existenz wird offensichtlich durch die s chmerzvoll en Erfahrungen des descensus in die Hölle der Dekadenz provoziert. Diese gespenstische Katabasis und das durch sie verursachte peinigende Erlebnis, erscheinen als notwendige stimuli der Bloßlegung der dekadenten Position als eines 
Irrwegs. In diesem Sinne kann man von einem Standpunkt der schon erkannten Wahrheit295 über die Unrealisierbarkeit der ästhetischen Existenz in der isolierten KunstWelt, so wie sie in Tajemné dálky postuliert wird, sprechen. Nicht von ungefăhr wird hier die hypnotisierende Wirkung der 'Musik-Sprache' hinterfragt, der doch in der Phase des dekadenten Symbolismus die Hauptaufgabe als 'Initiatorin' in das autonome und isolierte Kunst-Reich zuerkannt wird. Man denke an die suggestiven 'Lockrufe' der 'Musik-Stimme' in Motiv z Beethovena, die frappierend an die unermüdlichen und leidenschaftlichen Versuche Brezinas, seinem Freund und Kommilitonen Bauer die Idee des gemeinsamen 'Dienstes' am Kuit der Kunst zu suggerieren (s. o. Kap. 2.3.2), erinnern. Als faszinierendes Ideal - bezaubernd, magisch und betörend - klingt die 'Musik-Sprache' in der Sphäre des Kunst-Traumes (Motiv $z$ Beethovena). Sobald man aber versucht, dieses Ideal (der ästhetischen Existenz) in die Sphäre des realen (irdischen) Lebens zu transponieren, klingt die bannende 'Musik-Sprache' grauenvoll - signifikanterweise auch - "aus dem süßen Eingeständnis der Liebe, I.../ aus dem Schlagen des Herzens, das zugeschweißt ist ans Herz" ("ze sladkého priznáni lásky, I.../ z tukotu sroce k sroci priž̌ehnutého", VII, 3-4).

Wie erklärt die "Seele" ("duse") den descesnus in die Unterwelt der dekadenten Traum-Welt?: "Opojeni nás vedlo v nejnižši rozlohy sněni I..." (II. 1; "Die Trunkenheit führte uns in die niedersten Traumgefilden $/ . . . \mu$ ). Auch in Vítèzná píseñ konnotiert die "Trunkenheit" die Sehnsucht nach der Erkenntnis des Absoluten ("hymna Nepoznaněho" I "Hymne des Unerkannten", I, 4; gemeint ist der "Unerkannte"), die hier mit Hilfe der aus Modlitba vecerni (Das Abendgebet, TD) bekannten 'Methoden' der Dekadenz, d. $h$. durch die "Trunkenheit, durch den "Abstieg" in die Traum-Welt (Motiv z Beethovena), in das Jenseits der immanenten Welt, erreicht werden soll. Doch an Stelle der postulierten Erkenntnis erleben die "verbitterten und enterbten Herrscher der Träume"296 an der äußersten Grenze des Exzessiven ("písnẻ nẻmých, nejvyš̉̌́ch otkáv", I, 1; "posledni, nejhlubłsi závit" I, 2; "nejnižsi rozlohy sněni se svahư denniho světla", II, 2) im Reich des Kunst-Todes, die erschütternde und schmerzvolle (Lebens-)Fremaheit, die unheimliche Finsternis ("Cerné slunce smrti tam plálo", II, 3) und die entkräftende Ohnmacht ("a mlhy nám stoupaly vstruic ze zơrojü, jimiž omamovaly se věky / a karavany nesčisiných duši", II. 2-3). In dieser Sphäre, deren Grauen mit "irdischen Blicken" (mit oculis animae; "vùnè a rozkos pozemských zrakư. III, 4) wahrgenommen wird, loht die "schwarze Sonne" (II, 3) all jener, die auf die andere Seite des Lichtes gekippt sind (II, 1) und mit der zerstörerischen Melancholie, der Erzeugerin von Gewissensbissen, Ängsten und Selbstvernichtungen, konfrontiert werden. 297 Kennzeichnenderweise fallen als erste die "Blüten" der L i e b e und der Sehnsucht (der "Herrscher") der vampirhaften "schwarzen Sonne" zum Opfer: "Na květy naši lásky a touhy se prissálo zsinalou źizní, / pilo z nich rủžvé dechnutí jiter I...r (III, 1-2; "Aưf die Blüten unserer Liebe und Sehnsucht saugte sie sich mit fahlem Durst, / sie trank aus innen den rosenroten Anhauch der Morgen /... F).

Das lebensfremde Reich des "flüchtigen Träumens" ("prchavé snéni", VIII, 4) konnotiert hier die Negativität der Welt schlechthin. Interessanterweise wird diese Katabasis offensichtlich von den - aus der dekadenten, hypnotischen Traum-Fiktion bereits 'Erwachten'? (bzw. von deren Seele[n]: "rưżové dechnuti jiter, zardẻlȳch svatebnim

295 Dafür scheint auch die Tatsache zu sprechen, daß Vítězná piseñ im Frühjahr 1896 (d. h. zehn Monate nach Vladari snú I Die Herrscher der Tráume) abgefaßt und zusammen mit einigen anderen Gedichten, in denen sich das lyrische Ich bereits jenseits der Dekadenz befindet, die es nun als - wenn auch für seine schópferische Entwicklung notwendige - tempi passati betrachtet (Vino silných / Der Wein der Starken, Svítáni na zapadé / Tagen im Westen, Mytus duse / Der Mythos der Seele oder Ranni modlitba I Das Morgengebet), verơffentlicht wurde. S. 209.

296 Błezina an Bauer (Sommer 1895) in: O. Błezina, Dopisy Frantisku Bauerovi, Praha 1929.

297 Zur Symbolik der "schwarzen Sonne" vgl. den interessanten Aufsatz von Marian Stala .Od czamego stonca do ciemnego swiecidta", in: Teksty, Heft 6, 1980, S. 105-121. Der Autor verweist (u. a.) auf die apokalyptische Bedeutung dieser oxymoralen Metapher (AT: Ezechiel 32, 7-8, Joel 3. 3-4; NT: MK. 13, 24, Mt, 24, 29 und vor allen in der Offenbarung des Johannes 6, 12-14) als Todessymbol (vgl. Błezina: "Cerné slunce smrt", II, 1) und auf ihre Reaktualisierung in der Literatur der Fin de siècle, in der sie oft auch existential - als "schwarze Sonne" der Seele semantisiert wird, im Sinne der Psychologisierung der Katastrophe des inneren Lebens, als 'Sonnenferne' der Wahrheit, die jeder als seine eigene Hölle erlebt. Stala macht in diesem Zusammenhang auf E. Swedenborg aufmerksam, der überzeugt war, daß jeder Mensch die "Holle" in seinem Innern verbirgt. 
procitnutím", III, 2) gewagt, die aus der Sphäre des (Tages-)Lichtes ("se svahú deního svẻta", II, 2; "dráhy našeho letu, jenż vífil královstvími slunc", IV, 1) erneut in die Sphäre des Todes, der realiora und des dezentrierten Bewußtseins hinuntersteigen. Die Konfrontation mit der annihilierend-destruktiven Kraft der chthonischen Finsternis ("Cerné slunce smrt", II, 3; "Mrtvé vichriice", IV, 4; "Bohatství nescetných pozemských zrakú padala spálená $v$ hlubiny dálek', V. 1) und die ersehnte aber nicht vollendete, weil nur 'gefühlte', fiktive, noch-nicht-realisierbare Vereinigung ${ }^{298}$ (Cítili jsme blizkost bratrského mnożstvi, objetí nesčisIných dechü, / polibky beze rtú, kterè jsme vraceli silnými polibky omdléváni", V. 3-4), münden in eschatologische Prophetik: "Bohatstvi nescetných pozemských zrakú padala spálená v hlubiny dálek, I jež v żit́ délily đuše a naplnily nám okamžiky prísti tisíciletími" (V, 1-2; "Die Reichtümer unzähliger irdischer Blicke fielen verbrannt in Tiefen der Fernen, / welche die Seelen im Leben trennten und uns die kommenden Augenblicke mit Jahrtausenden füliten"). Die Aufgeschlossenheit gegenüber dem Welt-Dasein (d. h. dem Wissen um sich selber: "Reichtümer unzähliger irdischer Blicke" / "Bohatstv' nescetných pozemských zrakü") bzw. dem "In-der-Welt-Sein", wird in der lebensfremden Sphäre des Kunst-Todes getilgt, desintegriert und desontologisiert: "ledovým ohnèm je strávilo, aż baryy z nich kourily spinavým dýmem / a v slzách tekla z nich vyhnaná viné a rozkoś pozemských zrakü" (III, 3-4; "mit eisigem Feuer verzehrte sie, bis daraus die Farben im schmutzigen Qualm rauchten / und in den Tränen floß aus ihnen ausgetriebener Duft und Wonne irdischer Blicke"). Die Konsequenz des Transpositionsversuches ist die Ausartung der "Duft und Wonne irdischer Blicke" ("vinè a rozkoś pozemských zrakú") zum "Todesleuchten" ("Avšak hustá krev zemè nám polarisovala v zracich zárieni smrti", VI, 1; "Aber das dickflüssige Blut der Erde polarisierte uns in den Blicken ein Todesleuchten") und der (erhofften) "freudigen Antwort" zum apophatisch "stummen Aufschrei des Schreckens", 299 zum ohnmăchtigen Zischen (VI, 2). Daher muß die Vollendung der postulierten soteriologischen Vereinigung auf eine

298 Hier wird explizit die erschópfende, endlose "Feme" als die Ursache der Dissoziation und daher auch des Schmerzes genannt. Als eine mógliche Losung wird die soteriologische Brüderethik impliziert. Der solipsistische Individualismus, diese signifikante Haltung des dekadenten Künstler-Menschen kann dem Ziel des soteriologischen Geschehens nicht gerecht werden. In Odpovèdi (Antworten; Gedichtzyklus Ruce / Hände) gibt der "Hóchste" seinen artifices diese Antwort: "S miliony jste $v$ tajemném bratrství spjati / a jenom $v$ radosti milionú se budete radovati" (V. 15-16; "Geheimnisvoll seid ihr verkettet in der Bruderschaft von Millionen / und nur in der Freude von Millionen werdet ihr euch freuen"). DaB diese Bruderschaft' eine eschatologische Gemeinde ist, bekundet sich besonders prăgnant in den Gedichten des dritten Zyklus Vêtry od póti (Polarwinde, 1897) Aber bereits in Vítézná piseñ orientient sich das Geschehen an der Zukunft: Den unmittelbar bevorstehenden Augenblicken wird eine Dimension von Jahrtausenden zuerkannt ("a napinily nám okamžiky priśsti" tisiciletími", V. 2). Denn auch die andere, im Text postulierte coniunctio, die der Kunst-Sprache mit der irdischen Spractie, die in der Gegenwart "nicht mehr" oder "noch nicht" realisiertar ist, wird in die Zukunft hinausgeschoben, in der sie stattfinden soll.

299 Das Phänomen der (wechselseitigen) Beziehung zwischen der Erhabenheit (bzw. Schónheit) und dem Schrecklichen, insbesondere in der (Früh-)Romantik, wurde schon mehmals eingehend untersucht. Neuerdings verweist Klaus Poenicke (im AnschluB an Edmund Burkes Philosophical Enquiry into the Origin of our ldeas of the Sublime and Beautiful, 1757) aut die geradezu genuBvolle Erfahrung des Schrecklichen im Erhabenen als Ausdruck der 'IdentitătsBedrohung'. Das Erlebnis des Erhabenen definiert Burke als "Sprung" des BewuBtseins in etwas "erdrückend Bedrohliches", dem sogleich ein Aưschrei der Ertösung folgt K. Poenicke, .Eine Geschichte der Angst? Appropriationen des Emabenen in der englischen Asthetik des 18. Jahrhunderts", in: Das Erhabene. Zwischen Grenzerfahrung und GroBenwahn, hrsg. von Christine Pries, Weinheim 1989, S. 75-90. Mit einem ăhnlichen "Sprung" des BewuBtseins hat man offenkundig auch in Vítèzná písen zu tun. Während in Tajemné dálky das Ich-BewuBtsein in einer 'Totalitắt' (und 'Kontinuitắt') mit seiner völlig autonomen Welt, in der alle Identităts'Diskontinuitāten' durch das Erlebnis des immer wieder inszenierten (Kunst-)Todes aufgehoben werden, wie in 'sich' abgekapselt existiert, verursacht die - in der Axiologie des eschatologischen Symbolismus - unumgảngliche Offnung auf das Leben hin jenen Schock, der, wie es scheint, umso grőßer wird, weil die in Vitězná piseñ angestrebte Vereinigung scheitert. Die verschiedenen Aspekte und Erscheinungsformen des Erhabenen im russischen Symbolismus untersucht $A$. A. Hansen-Lóve, Zur Typologie des Erhabenen in der russischen Moderne", in: Poetica, Bd. 23, 1991, S. 166-216. 
unbestimmte Zeit hinausgeschoben werden, "bevor der Augenblick kommt, um eine neue Ordnung der Dinge anzuhehmen" (VI, 4; "než prijide chvile prijimouti nový poŕádek véci").

In den letzten zwei Strophen wendet sich das Ich erneut explizit an seine Seele ("Má duše! // Je teskná tvá vítězná písen̉ /... $/ . V I, 4, V, 1$; "Meine Seele! // Bange ist dein siegreiches Lied $/ . . . /$ ), wodurch die distanzierte Position des Ich gegenüber der von seiner Seele wieder hervorgehoben wird. Diese Distanz ermöglicht dem dichterischen Ich die Wirkung des "siegreichen Liedes", das, was passiert, wenn man versucht, die Kunstsprache aus der Sphäre der autarken, 'sekundär-semiotischen' Kunst-Welt, in die (irdische) Sphäre des Immanenten und Profanen zu transponieren, einer kritischen A n a l y s e zu unterziehen: "Je teskná tvá vitẻzná piseñ, transponovaná do oktáv pozemských tónu்!" (VII, 1: "Bange ist dein siegreiches Lied, transponiert in die Oktaven irdischer Töne!"). Der 'Transpositionsversuch' zieht nicht nur die Bangigkeit, sondern auch das Schauderhafte und Furchteinflößende nach sich, in das die "Hehre des extatischen Liedes" $(I, 1)$ umschlägt: "Kdo však ji uslyši jednou, zvoni mu prǐsernè I... $\mu^{\mu}$ (VII, 3; "Aber wer es einmal hört, dem tönt es grauenvoll /... $r$ ). Doch auch diese ominöse Metamorphose trägt den Aspekt des Positiven in sich; in der Ohnmacht liegt die Kraft dazu, das Unheimliche des "siegreichen Liedes" ertragen zu können: "Stasten, kdo ji neslyši zníti dríve, neż zemdlenim nabude sily!" (VII, 2; "Glücklich, wer es nicht ehe tönen hört, bevor er durch Ohnamacht Kräfte gewonnen!'). In bezug auf Bïezinas schöpferische Entwicklung läßt sich folgendes sagen: Die schmerzvolle Erfahrung in der Unterwelt des dekadenten Autismus gibt dem dichterischen Ich die Kraft dazu, die Wahrheit zu erkennen und den 'richtigen Weg' einzuschlagen. Der verheerende Versuch die Sprache der Kunst in die Sprache der Erde zu übertragen, das Wagnis, die irreale ästhetische Existenz zu verwirklichen, rächt sich nicht nur durch die Zurückweisung des "süßen Eingeständnisses der Liebe"300 ("zvoní mu príserernè ze sladkého priznání lásky", VII, 4; "Es klingt inm grauenvoll aus dem süßen Eingeständnis der Liebe"), sondern auch durch die Referenzund (ästhetische) Wirkungslosigkeit (sowohl im Hinblick auf die Rezeptions- [VIII, 2] als auch auf die Produktionsästhetik [VIII, 3]) des Kunstschaffens. 301 Die künstlerische Produktion, in der das "siegreiche Lieo" tönt, büßt ihre Unmittelbarkeit und Evidenz ein und schrumpft zum apophatischen, unausdrückbaren "Geflüster" ("šepot", VIII, 1), zum diaphan-ätherischen und flatterhaften "Beben" ("chvěni", VIII, 2) oder zum änigmatisch phosphoreszierenden, "klebrigen Geräusch des Malerpinsels" ("lepkavy క̌elest malir̂ského stětce", VIII, 3). Diese Kunst, die in leere Fiktionalität führt, bringt nur "flüchtige Symbole des Träumens" ("prchavé symboly Sněni", VIII, 4) hervor, was allerdings als großes Defizit des (bisherigen) Kunstschaffens betrachtet wird, das in Zukuntt beseitigt werden muß. Der

300 Urs Heftrich (Otokar Biezina. Heidelberg 1993, S. 87, 151f.) sieht zwar richtig. daß in Vitézná piseñ dem Individuum "die entósende Erfahrung der Verwandschaft mit dem Năchsten versagt bleibt" (S. 87), er übersieht aber das, worauf eigentlich in Vitězzná piseñ alles ankommt. daß es sich nămlich in erster Linie um ein $m$ e t a p o e t is $c h$ e s Gedicht handelt und daß die Verwandschaft mit dem Nächsten eigentlich durch die Unvereinbarkeit der beiden entgegengesetzten Welten versagt bleibt. Auch die Wirkung des "dickflüssigen Blutes der Erde" ("husta krev zemé", VI, 1), das den dekadenten Künstler-Menschen das Todesleuchten in den Blicken polarisient, interpretiere ich als Folge des schmerzvollen 'Sich-Offnens' dem Welt-Dasein, das sich nicht (mehr) 'rūckgängig' machen läßt. Die auf Isolation und Dissoziation orientierte ästhetische Existenz der autistischen Künstler-Menschen wird nun als 'korrekturbedürttig' gesehen. Die Daseinshaltung wird zwar auch in den Gedichten des eschatologischen Symbolismus (SZ) von der Entwelttichung bestimmt, ihre Motivation ist jedoch eine ganz andere, namlich die Erkenntnis des wahren Lebens, das postulierte Ziel der Gnosis. Diese hochrelevante Umkodierung tritt besonders deuttich in den Schlußversen von Modlitba vecerni (Das Abendgebet, TD) und Vino silných (Der Wein der Starken, SZ) zutage: tu dechni v celo mé a usnouti mne nech / v sen věčný, posledni, z něhož se nevzbudím" (Modlitba večerni, VII, 7-8; "dann hauche auf meine Stirn und laß mich einschlafen / in ewigen, letzten Traum, aus dem ich nicht enwache"). "...l a otráveni snem zemřeme pł̌ed svou smrti a po smrti budeme žiti" (Víno silných, V. $11 ; \%$ und vergiftet vom Traume Sterben wir hin vor unserem Tod, um nach dem Tode zu leben").

301 Das Motiv des "phosphoreszierenden" bzw. "schwefelgelben" Leuchtens indizient die Sphāre des Funeralen und Unheilvollen: "Udery tichem jak znameni v noci, když prítel umirá v dáli I a jeho prizzak se plizzi v sirovẻ ozárených snech!" (Vteriny / Sekunden, III, 3-4; "Schläge durch die Stille wie ein Omen in der Nacht, wenn der Freund in der Feme stirbt / und sein Phantom sich in schwefelleuchtenden Trāumen schleppt"). Das ominöse Leuchten dieser giftigen und entzündbaren Elemente konnotiert die "andere Welt". 
'Transpositionsversuch' wird als eine falsche Methode der Integration der dekadenten Vergangenheit in die neue, nachdekadente Schaffensphase entlarvt. Wie schon erwähnt, stellt das ironisch-paradoxe "siegreiche Lied" ein Pendant zu dem "siegreichen Körper" ("vítěznè têlo") dar, an dem der 'Befreiungsversuch' der "Herrscher der Trăume" scheitert. Es besteht aber ein wesentlicher Unterschied zwischen den "Herrschern" und dem dichterischen Ich von Vitézná piseñ: Das reflektierende Ich distanziert sich bewußt und eindeutig von der Position der Seele, deren dekadente 'Mittel' (die hypnotisierende Wirkung der 'Musik-Sprache') es - von einem Außenstandpunkt aus - in Frage stellt. Die 'Spaltung' des lyrischen Ich, die (dia logische) Kodierung des Textes als 'Streitgesprăch' zwischen inm und der Seele, die Markierung jener kritischen Distanz, all das deutet auf ein Konflikt zwischen dem emotionalen, 'animischen', imaginativunbewußten Pol und dem rationalen, luzid-bewußten, rezenten Pol des dichterischen Ich hin. Es scheint, daß diese spannungsvolle Beziehung, deren 'Psychogramm' das Gedicht Vitézná piseñ darstellt, jene Intention antizipiert, die im dritten Gedichtzyklus Vëtry od pólü realisiert wird: die Theo-logisierung und (daraus resultierende) Rationalisierung der poetischen Welt. In einem Brief (vom 10. II. 1898, fünf Monate nach der Herausgabe von VP) an Anna Pammrová artikuliert Brezina diese Intention mit aller Klarheit: "Realizovat synthesi žhavého snu s rozumem, v tom vidim dnes úcel uméní." ("Die Synthese des glühenden Traumes mit der Vernunft zu realisieren, darin sehe ich heute den Zweck der Kunst").

Im Hinblick auf die (in. Kap. 3.2) entwickelte funktionale Schmerztypologie von Svitáni na západé soll an dieser Stelle zusammenfassend noch die in Vítézná písen semantisierte Schmerz-Erfafrung verortet werden. Auch in Vitězná piseñ ist es vor allem die Dissoziation ("rozdëleni"), von der der Schmerz in all seinen Facetten herrührt: "Bohatství nesčctných pozemských zrakủ padala spálená v hlubiny dálek, / jeż v žití délily duše /... (V, 1-2; "Die Reichtümer unzähliger irdischer Blicke fielen verbrannt in Tiefen der Fernen, I welche die Seelen im Leben trennten I...r). S ch m e r z v oll ist die Enfahrung, die die KünstlerMenschen (bzw. deren Seelen) in der Unterwelt der Dekadenz machen. Der descensus zum Hades des fiktionalen Kunst-Reiches wird ebenfalls durch Dissoziation - des Wachvon dem Traumbewußtsein, der Seele vom Körper - initiiert. Sch m e r z voll ist die Dissoziation in der Liebe (durch erzwungene Absage, Zurückweisung usw.), die hier eine nicht übersehbare Rolle spielt. In der Axiologie von SZ bilden "Liebe" ("láska") und "Schmerz" ("bolest") eine wechselseitige Korrelation; die Liebe potenziert den Schmerz, aber erst der Schmerz gibt der Liebe inren ('wahren') Wert, ihre - in der Terminologie Bíezinas - "Hehre" ("slávu"). In Ranni modlitba (Das Morgengeben heißt es: "Unaven praci a láskou a bolest' zlomen I... (V. 59; "Ermüdet von Arbeit und gebrochen von Liebe und Schmerz I... F). An Anna Pammrová schreibt Bỉezina (13. XII. 1896): "Jako v'se tajemné je láska slavná, príserná a osudná". ("Wie alles Geheimnisvolle ist die Liebe hehr, unheimlich, und verhăngnisvoll"). In vitézná piseñ făllt auch die Liebe, deren Enfüllung der dekadente Kunst-Traum in der autarken Kunst-Welt (Motiv $z$ Beethovena, Kap. 2.3.2) noch zu versprechen schien, dem descensus in die "niedersten Traumgefilden" ("nejnižsí rozlohy snent". II, 1) (III, 1-2) zum Opfer. Und s ch me r z e r fü IIt ist schließlich auch das "siegreiche Lied", das leere Ergebnis des 'Transpositionsversuches'. Aber dieser Schmerz hat ein Telos. Er aktiviert das Ich-Bewußtsein und 'zwingt' es den kritischreflektierenden $\mathrm{Met}$ e standpunkt einzunehmen, von dem aus die dekadente Vergangenheit als "ein Stück Garten, den ich durchwanderte und wohin ich nimmer zurückkehren würde" ("I.../ kus zahrady, kterou jsem prosel a kam se již nikoy nevrátím") bloßgelegt wird. "Dennoch", fügt Bïezina hinzu, "bekenne ich mich offen und stolz zu inr" ("vzdor k tomu hiásim se k ní otevienę a hrdë"). 302 Birgt dieses "stolze Bekenntnis" zur dekadenten Vergangenheit nicht eine (mogliche) Lösung ihrer Integration in das System des eschatologischen Symbolismus in sich? Um diese Frage beantworten zu können, soll nun die Analyse des letzten Gedichts von Svitáni na západé, Vino silných (Der Wein der Starken), in Angriff genommen werden. 


\subsubsection{Befreiung von den "Gesetzen der Erde" kraft des erlösenden Wissens: Gemeinde der gnostisierenden Pneumatiker Víno silných (Der Wein der Starken)}

\section{Víno silných}

Brať̌i, 2 ruky do ruky podávejme víno silných ve své čîsi, věky ho chránily na vinicích pred mrazem jak dýmy ohñù $v$ čas noční. Vinař jeho byli Smutek a Samota.

Než se nadáme, uslył̌íme, jak vedle nás rytmicky dýchá mystická píseñ,

a na rtech ucitime čîs svoji teplou od jejích éternych retủ.

Tajemný proud zavłe se kruhem kol našeho stolu. vymkne nás ze zákonů zemé, a Život a smrt bude našemu sněni odpovídati. Usslyš́me Suměni neviditelných łek, jež protékají staletími, uvidíme oblak Vě̌ného, skleněný $k$ vodám, svítiti $z$ hlubin jako slunce.

10 Opojeni uxini duši naši světelnou jak duši budoucích lidí. a otráveni snem zemfeme płed svou smrtí a po smrti budeme žíti.

Posluక̌ni budeme Císti v tvé knize, 6 Vex̌ný, a k obrazủm jejím urěíme slova. $V$ Carovném kruhu, velkém jak obzor, se uzavf̌eme úzkostem noci.

Płival tvůj uhasí stavení nałe, hơ̌ici se đtył̌ stran
15 a kvasem tvým pokyne nám těsto nového chleba.

Lampy naše budou prameny oleje, jenž bude svítiti, nehnut, uprosţ̌ed vêtrui.

Zahradami budou nám hroby, a smrt svou budeme se zpěvem kolébati.

Hovofiti budeme mlæením, a políbením bude neviditelné potkání touhy.

Odpovédí naši bude záłení zrakủ płi objetí myšlenek v dálce.

$20 \mathrm{~V}$ paprscich upłeného pohledu naseho stane se pruhledným neprühledné.

Nepưjjeme mihami slzí z krajiny snù do země žití, neb obé splyne.

a slzy, jak rosa na osení vêkú, vypitá sluncem, zdvihnou se nad námi v purpurech ranních.

Okna naše ukáži nám barvy umyté nebeskou boư̌i.

a jed ve štávách kvêtư shofi za uzdravujících vưní.

25 Stíny složi se nám jak péra v kł́ídlech, posetá hvězđami, smějící se dálkám.

Sny, jež tisíciletí spaly, neznámy duším, vzbudíme pod prikrytím barev a tvari.

i vstanou $z$ ledovcú toxen, $z$ pralesú mołi, $z$ tajemných dilen hmoty

a spustí se $\mathbf{z}$ neviditelných konstelací.

Hlederti budeme radou dní budoucích jak ładou skleněných dvełi za sebou ležících síní,

30 jimiž nám naproti pticház slunce, véncené zelení zahrad.

Jako nebesa vonného lože milencủ zatmí se nad námi noci.

Minulost ztratí se $v$ dálce jak koứ továren mèsta, $z$ něhož jsme vyjeli dávno.

Myšlenky naše budou míti šifi prostoni, naplněných éterem, jímž dýchaji světy.

35 Unaveni svextlem ruku podáme Prítelkyni, aby nás odvedla odsud,

35 a smrt naše bude jak smrt oxišténých lidí. Podobná chủzi

2 pokojủ płesycených vưnèmi do chrámu $v$ neděli květnou.

Podobná vstoupení na lod za vláni prapori a v orchestrech hudeb.

Podobná odchodu vojska do dobytých zemí, jemuž házejí kytice z oken.

Podobná radostné odpovêdi choru po slovech knéze, zamlžených tajemstvím.

40 Podobná políbení, které potrvá déle než systémy svếtú.

podobná výkłiku vక̌ech písni, skrytých ve vక̌ech minulých i budoucích duších a svêtech. a smísení vłech minulých i budoucích dní a noci $v$ jediný den, $v$ němž nebude noci.

Brattí, 2 ruky do ruky podávejme víno silných v své Xî̃i:

hvězdy, které nañ pršsely v květu, at nahází do našich zrakú.

45 Trest slabých bude, že zapomenou své jméno pri procitnutí.

a odměna silných. že v záfící tmě vzpomenou na ostrovy zajetí svého. 


\section{Der Wein der Starken}

Briuder, von Hand zu Hand reichet den Wein der Starken in eurem Becher; ahrhunderte schutzten ihn auf den Weinbergen vor Frosthauch, wie Qualm von Feuem

Seine Winzer waren Trauer und Einsamkeit.

zur Nachtzeit.

Eh wir geahnt, vemehmen wir einst, wie neben uns das mystische Lied in rhythmischen Zügen

5 und auf den Lippen fühlen wir unseren Becher warm von seinen ätherischen Lippen.

atmet,

Geheimnisvoll schlieBt ein Strom seinen Kreislauf um unser Tischrund,

hebt uns aus den Gesetzen der Erde, und Leben und Tod werden Antwort stehn

unserem Träumen.

Wir werden das Rauschen von unsichtbaren Flüssen vemehmen, die durch Jahrhunderte

strömen,

die Wolke des Ewigen sehn, sich niederbeugend zu Wassern, wie Sonne den Tiefen entstrahlen.

10 Rausch wird unsere Seele licht werden lassen, wie Seele zukünftiger Menschen, und vergiftet vom Traume sterben wir hin vor unserem Tod, um nach dem Tode zu leben.

Gehorsam wollen wir in deinem Buche lesen, o Ewiger, und zu seinen Bildern

die Worte bestimmen.

In einen Zauberkreis, groß wie der Horizont, wollen wir uns den Ängsten der Nacht

Deine Regenflut wird unser Gebäude löschen, wenn es von allen vier Seiten steht verschließen. in den Flammen des Schmerzes,

15 und von deiner Bärme wird uns der Teig neuen Brotes treiben.

Unsere Lampen werden zu Quellen von Öl, das leuchten wird, ohn' Regung, inmitten der

Zu Gärten werden uns Gräber, und singend werden wir unseren Tod einwiegen.

Winde.

Unsere Rede wird Schweigen sein und Kuß das unsichtbare Begegnen der Sehnsucht.

20 Unsere Antwort wird sein Aufleuchten der Blicke bei der Umarmung der Gedanken in Ferne.

20 In den Strahlen unseres unverwandten Schauens wird das Undurchsichtige klärlich.

Nicht sollen wir schreiten durch Tränennebel aus dem Gefilde der Träume ins Land des Lebens denn beides verfließt dann, und Tränen, wie Tau auf den Saaten der Zeiten, getrunken von Sonne, heben sich über uns im Purpur der Morgen.

Unsere Fenster werden uns Farben zeigen, die klar uberspielt sind von himmlischem Sturme,

25 und Gift in den Säften der Blüten verbrennt unter heilsamen Duften.

Schatten legen sich uns zusammen wie Federn in Flügeln, besät mit Sternen spottend der

Träume, die Jahrtausende schliefen, verborgen den Seelen, wecken wir unter der Decke

Weiten.

Träume, die Jahrtausende schliefen, verborgen den Seelen, wecken wir unter der Decke

daß auf sie stehn aus den Gletschern der Pole, den Wäldern, der Tiefsee, der mystischen

Werkstatt des Stoffes

und nieder sich lassen aus unsichtbaren Konstellationen.

Schauen werden wir durch die Fluchten der künftigen Tage. wie durch eine Reihe von gläsemen

30 durch welche uns Sonne entgegenkommt, bekränzt mit dem Grünlaub der Gärten.

Wie der Betthimmel eines duftenden Liebesbettes erdunkeln ob uns dann die Nächte.

Vergangenheit verliert sich in Ferne, wie Rauch von Fabriken der Stadt, die längst wir verlassen.

Unsere Gedanken werden die Weite von äthererfullten Räumen haben, der die Luft ist der Welten. -

Müde des Lichts, reichen wir unsere Hand dem Freund, daß er von dannen uns führe, 35 und unser Tod wird sein wie der Tod gereinigter Menschen. Ähnlich dem Schreiten 
aus duftübersättigten Zimmem in den Tempeln am Palmsonntag.

Ahnlich dem Besteigen des Schiffes unter dem Wehn der Flaggen und der Musik der Orchester.

Ähnlich dem Auszug des Heeres in eroberte Länder, dem man Sträuße zuwirft aus Fenstern.

Ähnlich der freudigen Antwort des Chors nach den Worten des Priesters, die beschlagen sind

40 Ähnlich dem KuB, der länger währt als Systeme von Welten, von mystischem Anhauch.

ähnlich dem Aufschrei aller Lieder, verborgen in allen vergangnen und künftigen Seelen

und Welten

und Vermischung aller vergangnen und künftigen Tage und Nächte zu einem einzigen Tag, in dem es nicht Nacht wird.

Brider, von Hand zu Hand reichet den Wein der Starken in eurem Becher:

Steme, die auf ihn zur Blutezeit niedergeregnet, mag er in unsere Blicke werfen.

45 Strafe der Schwachen wird sein, daß beim Erwachen sie ihren Namen vergessen,

und Lohn der Starken, daß sie in leuchtendem Dunkel ihrer Gefangenschaft Inseln gedenken.

Deutsch v. Paul Eisner.

Der letzte 'Schritt' auf dem Weg zur Erlösung wird, wie es scheint, erst in Vino silných vollbracht. Interessanterweise soll hier die angestrebte unio mystica nicht individuell, wie in der vierten Sujetsequenz von Ranni modlitba, sondern im Kollektiv der gleichgesinnten, "starken" und elitären Ausnahmepersönlichkeiten, der gnostisierenden Pneumatiker, erreicht werden, die "aus den Gesetzen der Erde gehoben", die (nahende) Vollendung des soteriologischen Geschehens erwarten. Diese Erwartungshaltung des 'visionären Kollektivs' ist als eine Eucharistiefeier inszeniert. Die Erfahrung des $k$ a $t h$ a $r$ t i s $c h$ e $n$ Schmerzes, die der Sinnstruktur des Gedichts ihre Prägnanz verleiht, geht hier mit Brezinas Auseinandersetzung mit der dekadenten Vergangenheit eihner. Die dekadenten Werte werden nicht (mehr) negient, sondern - im Sinne der 'Positivierung des Negativen' transformiert.

Die Symbolik der starken Ausnahmepersönlichkeiten, die sich zur gemeinsamen liturgischen Feier versammein, deutet auf ein gnostisches Substrat hin. Beim näheren Zusehen stellt man fest, daß diese Eucharistiefeier, die (äußerlich) christlich-kirchlich aussieht, vielmehr an eine Tafelrunde der "Auserwählten", in der Sprache der Gnosis, der Pneumatiker, erinnert. Die religiöse Rede dieser Feier-Dramaturgie stellt eine Art eucharistischer Predigt an die versammelte Gemeinde dar. Im Hinblick auf die metapoetische Dimension von Vino silných läßt sich das Gedicht nicht nur als 'Legitimierung' der dekadenten Schaffensphase interpretieren, indem diese als eine der Voraussetzungen für die (gnostisch-)eschatologische Schaffensposition gewertet wird, sondern auch als Biezinas Beitrag zu der (um 1896 aktuellen) Diskussion über die 'notwendige Überwindung' der Dekadenz.

Die Kommunikationssituation dieser (eucharistischen) 'Predigt' wird gleich im Prolog (V 1-3) durch die Ansprache und - für eine Predigt charakteristische-Aufforderung an die Brüder-Gemeinde arrangiert: "Bratrí, $\mathbf{z}$ ruky do ruky podávejme vino silných v své Ciši" ( $V$. 1). Die "Brüder" werden zum Empfang des Weines aufgefordert; es handelt sich um ein wichtiges Element in der Dramaturgie einer (gnostischen) Eucharistiefeier, deren 'Rituale' die erste Sujetsequenz (V. 4-11) strukturieren. Zum liturgischen Wein-Motiv kommen noch andere Motive hinzu: "mystická piseñ" ("mystisches Lied", V. 4), "stưl" ("Tisch", V. 6). "obiak Věcného" ("Wolke des Ewigen", V. 9; als Äquivalent der Monstranze), "tvá kniha" ("dein Buch", V. 12; als Äquivalent der Evangelienlesung), "nový chleba" ("neues Brot", V. 16), "lampy /.../ Oleje" ("Lampen /.../Ole", V. 16). Ein anderes wichtiges Indiz - in bezug auf die Schmerz-Semantik, ist die im Prolog (V. 1-3) betonte Herkunft des Weines: "Vinarii jeho byli Smutek a Samota" ("Seine Winzer waren Trauer und Einsamkeit", V. 3; nicht zufällig sind die Versalbuchstaben der beiden tschechischen Substantiva). Der Hinweis auf die Herkunft des Weines antizipiert eine der zentralen Aussagen des Textes, nämlich die positive, stärkende und $k$ ath a rtis che Wirkung der schmerzvollen und beklemmenden ("Smutek" - "Samota") Entrücktheit des dekadenten Künstler-Menschen in eine metaphysische, "geheimnisvolle Ferne", deren Erfahrung die "Starken" ("silni") stark macht und sie zu einer Gemeinschaft der Pneumatiker zusammenschweißt.

Neben den Allusionen auf die Zeremonien einer Eucharistiefeier bildet den semantischen Nukleus der ersten Sujetsequenz (V. 4 bis 22) die Formierung einer (gnostischen) Gemeinschaft, einer Tafelrunde der Ausnahmepersönlichkeiten, mit dem 
Ziel eines extatischen Erlebnisses, das zum Schluß der ersten Sujetsequenz auch erfolgt (V. 10-11). Das Motiv des extatischen Erlebnisses scheint jedoch die Situation der liturgischen Feier zu verfremden. Handelt es sich wirklich um eine Art 'gnostischer' Eucharistiefeier? Was spricht dafür? Es sind vor allem gewisse Parallelen zu den gnostischen Mysterien-Mahlen, wie z. B. das unverzichtbare Weintrinken (bzw. das Trinken ambrosischen Wassers), das Essen unblutiger Speise (vgl. das Brot-Motiv, V. 15) sowie das Hymnen-Singen und der (Bruder-)Kuß, 303 die in Vino silnych vorkommen: "I...I a polibením bude neviditelné potkáni touhy (V. 18; ".../ und der Kuß wird das unsichtbare Begegnen der Sehnsucht sein"): "Podobná polibeni, které potrvá déle než systémy světü" (V. 40; "Ähnlich dem Kuß, der länger wähnt als Systeme der Welten"). Von besonderer Relevanz scheint in diesem Zusammenhang der Zweck des Weintrinkens bei den gnostischen Mahlen zu sein, nämlich die Unterstützung des extatischen Erlebnisses, ein Aspekt, der für die Sinnbewegung von Vino silnych von großem Belang ist. Denn ein wichtiges Element der gnostischen Mysterien bildete gerade die Berauschung mit Wein als stimulus des "Weltentfremdung"-Erlebnisses. Rausch und Extase waren für die Gnostiker das Tor zur Erweckung und Erleuchtung ("= volle Anamnese der Verwandschaft mit Gott = Auflösung des Kerkers der Leiblichkeit = Aufstieg des innern geistigen Menschen durch die einzelnen Zonen /.../ in die himmlische Sphäre"). ${ }^{304}$ Die Berauschung (bzw. Trunkenheit / "Opojeni") ${ }^{305}$ potenziert die "erleuchtende Erkenntnis":306 "Opojení učini naši duši svètelnou jak duši budoucich lidi" (V. 10).

Das Motiv des extatischen Erlebnisses fühnt zurück zu dem der Tafelrunde bzw. der "Bruderschaft" ("Bratiti" I "Brüder", V. 1) der gnostisierenden Pneumatiker. Kann man sagen, daß das "extatische Erlebnis" die Bildung einer solchen Gemeinschaft voraussetzt? Die Gnosis-Forschung bestätigt die Formierung und Organisierung von gnostischen Kultgemeinschaften oder Bruderschaften, die hellenistisch-religíosen (vorchristlichen und frühchristlichen) Ursprungs waren. Insbesondere die christliche Gnosis kennzeichnet die Organisierung von kleinen Gruppen, die an gemeinsamen Mysterien-Mahlen (und extatischen Erlebnissen) partizipierten. 307 'Bei Bỉezina scheint das Kollektive und Gemeinschaftliche auch jene Funktion zu haben, die für die Semantik und Axiologie seines eschatologischen Symbolismus von zentraler Bedeutung ist: die Überwindung der unheilvollen Trennung und Isollation durch Begegnung ("potkáni toumy" I "Begegnen der Sehnsucht", V. 18), durch Gesprăch bzw. Kommunikation ("Hovoriti budeme mlCenim" / "Unsere Rede wird Sctweigen sein"; V. 18; "Odpovédi nasi" / "Unsere Antwort", V. 19), durch körperlichen Kontakt ("políbeni" I "Kuß", V. 18; "objetí myšlenek" I

303 Vgl. hierzu P. Pokorný, .Der soziale Hintergrund der Gnosis", in: Gnosis und Neues Testament, hrsg. v. K.-W. Tróger, Berlin 1973, S. 84f. Vgl. auch F. Brăuninger, Untersuchungen zu den Schriften des Hermes Trismegistos [Diss.], Berlin 1926, S. $14 f$.

$304 \mathrm{Vgl}$. ibid., P. Pokorny. S. 85. Vgl. auch Ders. "Epheserbrief und gnostische Mysterien", in: Zertschnift hür die Neutestamentiche Wissenschaft, 53, 1962. S. 160-194.

$305 \mathrm{Vgl}$. die entsprechende Stelle in Vitězuá piseñ (Das siegreiche Lied) : Opojeni nás vedlo v nejnižsi rozlohy sneni se svahủ denniho světla / a mihy nám stoupaly vstríc ze zdrojü, jimiž

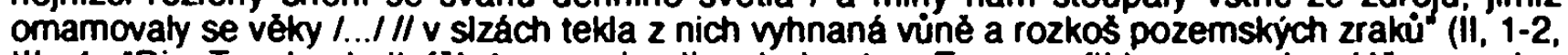
III. 4: "Die Trunkenheit führte uns in die niedersten Traumgefilden aus den Hăngen des Tageslichtes / und die Nebel stiegen uns entgegen aus den Quellen, an welchen sich die Äonen berauschten $/ . . . / /$ und in den Tränen floB aus innen ausgetriebener Duft und Wonne irdischer Blicke.")

306 Diese gnostische Vorstellung, die auf die Darstellung der (christlich-gnostischen) Eucharistiefeier zurückgeht, ist in den spătgnostischen Schriften der Pistis-Sophia-Gruppe mehrfach belegt. Die charakteristischen Elemente dieser Zeremonien sind Wein, Wasser, Brot, Răuchenwerk u. a. Das Alternieren des Weines durch das Wasser deutet auf die Vorstellung vom "Wasser des Lebens" (Symbol der "erleuchtenden Erkenntnis") hin. Durch den Empfang des Weines (Sinnbild des Blutes, gefüllt mit Heiligem Geist) wird die Vollkommenheit, d. h. die Vereinigung des Lichtes mit dem Heiligen Geist, verwirklicht. Wie K. Rudolph betont, sind

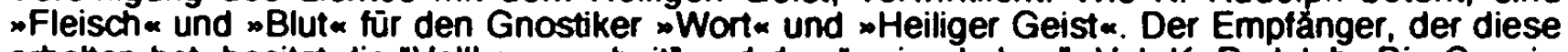
erhalten hat, besitzt die "Vollkommenheit" und das "ewige Leben". Vgl. K. Rudolph, Die Gnosis, Göttingen 1990, S. 248 .

307 Vgl. P. Pokorný, .Der soziale Hintergrund der Gnosis", a.a.O., S. 84. Vgl. auch die Abhandlung von E. Buonaiuti, .Die gnostische Initiation und die christliche Antike", in: Eranos, Jb. III, 1935, S. 289-304. 
"Umarmung der Gedanken", V. 19) usw. Das extatische Erlebnis der unio mystica ist also - auch in Vino silných - an die Kreierung einer gnostischen Gemeinschaft gebunden, weil diese hier offensichtlich die Voraussetzung für die postulierte unio bedeutet. Diese Vorstellung entspricht der (oben erörterten) Logik des mythisch-gnostischen Denkgutes.

Die "Starken" kommen in einem Kreis - in einer Tafelrunde - zusammen: "Tajemný proud zavie se kruhem kol našeho stolu, / vymkne nás ze zákonư zemé, a żivot a smrt bude našemu snẻní odpovidati" (V. 6-7; "Geheimnisvoll schließt ein Strom seinen Kreislaut um unser Tischrund, I hebt uns aus den Gesetzen der Erde, und Leben und Tod werden Antwort stehn unserem Trăumen"); "V Carovném kruhu, velkém jak obzor, se uzaviem úzkostem noci" (V. 13; "In einem Zauberkreis, groß wie der Horizont, wollen wir uns den Ängsten der Nacht verschließen"). Das grammatische Futur antizipiert den Zustand der visionären Erwartung des eschatologischen Futurs, das unmittelbar zu bevorstehen scheint: "Než se nadäme I... ("Eh wir geahnt /... $/$, V. 4). Der Wein, zu dessen Empfang die Brüder-Gemeinde in einer Tafelrunde (im Prolog, V. 1-3, und im Epilog, V. 43-46) aufgefordert wird, verfügt über wunderwirkende Kräfte, die an die Zauberkräfte des heiligen Grals ${ }^{308}$ denken lassen. Diese Brüder-Gemeinde erinnert an eine Gemeinschaft der gnostisierenden 'Ritter der Tafelrunde', die bereit sind, den hyletischen Leib abzulegen, um den Seelenaufstieg vorzubereiten und die Macht der Finsternis zu besiegen: "V Carovném kruhu, velkém jak obzor, se uzavieme úzkostem noci", V. 13; s. o.). Die Symbolik des "geheimnisvollen Stroms", ("tajemný proud", V. 6), des "Zauberkreises" ("kouzelny kruh", V. 13), der sich um die Tafelrunde der "Starken" schließt, ist offensichtlich auf die im zeitgenössischen Kontext sehr populären esoterischen Lehren (Magnetismus, Spiritismus usw.) zurückzuführen. ${ }^{309}$

Die erste Sujetsequenz kulminiert im extatischen Akt der gnostischen Weltentfremdung. Das materielle und daher kerkerähnliche Dasein, dieser ominöse Trug. der "bolestný sen pozemského żivota" ("schmerzvoller Traum des irdischen Lebens"), 310 wird aufgeopfert und das Absterben dieser Welt als Verheißung "des einzigen Tages, in dem es nicht Nacht wiro" (V. 42; "jediný den, $v$ nèmż nebude noci"), erwartet: "a otráveni snem zemřeme preed svou smrti a po smrti budeme zíti. I... / Zahradami budou nám hroby, a smrt svou budeme se zpěvem kolébati" (V. 11, 17; "und vergiftet vom Traume sterben wir hin vor unserem Tod, um nach dem Tode zu leben. I... I Zu Gärten werden uns Grăber, und singend werden wir unseren Tod einwiegen“). Durch die Bereitschaft zum derartig souveränen Verzicht auf das irdische Dasein, die die 'Auserwählten' auch zu wunderbaren

308 Die Bezeichnung "Ciš" ("Kelch"), in dem der Wein in der Tafelrunde dargereicht wird, alludiert freilich auf den heiligen Gral, auf jenen Kelch (des Abendmahls), in den das Blut des gekreuzigten Kristus aufgefangen wurde und den Joseph von Arimathia, laut der Sage (Chrétien de Troyes: Lancelot, um 1170, Perceval, vor 1190; Wolfram von Eschenbach: Parzival), mit sich in die keltischen Lảnder Westeuropas brachte. Die Suche nach dem heiligen Gral symbolisiert die Suche nach dem geheimnisvollen Absoluten; eine Symbolik, die bei Brezina, vor allem in Tajemné dálky, von zentraler Bedeutung ist. In der letzten Sujetsequenz (V. 43-46), die eine Art Epilog darstellt, in der die Aufforderung an die "Brüder" wiederholt wird, fallen in den "Wein der Starken" die Sterne (V. 44). Die takultative Bedeutung dieser Metapher wird zum Schluß des Kapitels erörtert.

309 Das Interesse, wenn man von einem Interesse überhaupt sprechen kann, für diese esoterischen Lehren, könnte bei Bł̌ezina seine intensive Schopenhauer-Rezeption erwecken. Spăter - mŏglichenweise - auch die Péladan-Rezeption, die Bł̉ezina explizit in der Korrespondenz mit Anna Pammrová erwăhnt. Seinen Essay Nejvyšsi spravedinost (Die hóchste Gerechtigkeit) veröffenttichte Bl̈ezina in Sbornik pro filosofii, mystiku a okultismus (Sammelband für Philosophie. Mystik und Okultismus), 1, Nr. 6, 1897, S. 129-133. In seinen Erinnerungen an Bł̉ezina erwăhnt S. Bouska (in: Zvon, 1939, S. 450) ejne Episode mit einer 'spiritistisctien Seance' im damaligen Wirkungsort Bỉezinas (in Nova Ríse), an der auch der Dichter teilnahm und von der er offensichtlich beeindruckt war. Der spiritistische Hintergrund des "Zauberkreis"-Motivs in Vino siných (V. 6, 13), auf den Králík aufmerksam macht (Otokar Bïezina, Praha 1948, S. 354f., 460ff.). låßt sich nicht ausschließen. Allerdings verweist Králik (ibid., S. 466 ff.) objektiv auch auf Błezinas distanzierte und eher skeptische Einstellung zu den esoterischen Lehren. In der Korrespondenz mit Pammrová (Brief vom 4. XII. 1906) spricht Bł̉ezina - im Zusammenhang mit diesen Lehren von der Mystifikation, Pseudowissenschaft und vom Dilettantismus. Die "Suggestion", "Hypnose", "Magie" usw. verbindet Blezina in erster Linie mit der postulierten Wirkung der Kunst im Sinne von Mallarmés "Magie der Sprache" (s. dazu Kap. 2.3.2).

$310 \mathrm{Vgl}$. Błezinas (Auto-)interpretation von Svítáni na západè, zit. nach: Miroslav Cervenka. .Błezinưv výklad Svitáni na západé", in: Ders., Styl a význam, Praha 1991, S. 34. 
Erkenntnissen 311 befăhigt, ihnen das Bewußtsein ihrer Weltüberlegenheit gibt, kann die befreite Seele in die himmlische Lichtwelt emporsteigen. Zu diesen wunderbaren Gaben gehört nicht nur die visionäre Schau ("Uslyšime šuméní neviditelných reke, jeż protékají staletími, uvidíme obiak Věčného, sklonèný k vodám, svítiti z hlubin jako slunce"; V. 8-9; "Wir werden das Rauschen von unsichtbaren Flüssen vernehmen, die durch Jahrtausende strömen, I die Wolke des Ewigen sehn, sich niederbeugend zu Wassern, wie Sonne den Tiefen erstrahlen".), sondern auch die Gabe, im "Buch des Ewigen" zu lesen und seine imagines zu verbalisieren:312 "Poslušni budeme đisti $v$ tvé knize, $\delta$ věčný, a $k$ obrazưm jejím urCime slova" (V. 12; "Gehorsam werden wir in deinem Buch lesen, o Ewiger, und zu seinen Bildern die Worte bestimmen"). Hinzu kommen auch andere, unmittelbar bevorstehende, a u Berordentliche Leistungen, die sich zu einem auf die Kreativităt ("a kvasem tvym, pokyne nám těsto nového chléba", V. 15), ${ }^{313}$ zu anderem auf die mystischen, (kommunikativ-)kognitiven bzw. noetischen Akte beziehen, die mit dem Prinzip der postulierten Vereinigung korrelieren: "Hovoriti budeme mICením, a políbením bude neviditelné potkáni touhy. TOdpovèdí bude záiení zrakú prì objetí myšlenek $v$ dálce. I $\checkmark$ paprscích upieného pohledu našeho stane se prúhledným neprúhledne“ (V. 18-20). Das erwartete, bevorstehende Geschehen ist gänzlich auf die 'Diaphanisierung' bzw. 'Pneumatisierung' und Verklärung des (weltlichen) Seins, auf eine extatische Entgrenzung der Sphäre des Geistes gerichtet:314 "Myšlenky naše budou míti śíri postorú, naplnẻných éterem, jímž dýchaji světy" (V. 33; "Unsere Gedanken werden die Weite von ätherenüliten Räume haben, der die Luft ist der Welten").

311 Solches Wissen um Schöptungen und Geheimnisse des "Höchsten" ist allerdigs nur den Eingeweihten zugānglich. Gerade dieses Wissen macht die eigentliche Stärke der "Starken" aus.

312 Die Symbolik des "Welt-Buches" und die Möglichkeiten seiner Dechiffrierung untersucht eingehend Hans Blumenberg in seiner Monographie Lesbarkeit der Welt, Frankturt am Main 1981. S. 68 ff.

313 Vgl. hierzu das Gleichnis vom Senfkom und S a u e r t e ig (Tschech. "kvas"; Mat. 13, 33; 44-45). Dieses Himmelreich-Gleichnis lehrt (u. a.), daB die Gottesherrschaft vom Menschen ein Opfer verlangt. Zum Opfer gehört auch die Ertahrung des Schmerzes. Die Absage an die Welt ist die Bereitschaft für die Erfüllung des Willens des "Hochsten". Das Tun der "Starken" scheint mit dieser christologischen Symbolik doch nicht (noch nicht!) restlos zu koinzidieren. Das Motiv der gnostischen (Selbst-)Erlosung aus eigener Kraft, das in der IV. Sujetsequenz von Ranni modlitba thematisiert wird, schwingt zwar auch in Vino silnych $\mathrm{mi}$, aber.die hier dargestellte eschatologische Stimmung der Eucharlstiefeier, das Bereitsein für die eschatologische Vollendung sowie der Gedanke von der Einheit der elităren Pneumatiker, die unter sich, in einer "Bruderschaft der Glaubenden", die dem "heiligen Wahnsinn" völlig vertallt, verbunden sind, das alles deutet eigentlich auf die gnostischen Einflüsse hin. Dies führt zu der Kardinalfrage des Gedichts: Worin grundet die Starke der "Starken"? Und wer sind sie eigentlich? In drittem Gedichtzyldus Vetry od poti (Polanwinde) versucht Bíezina das in Vino silnych noch der gnostischen Tradition entsprechende Erkenntnisverlangen mit dem christlichen moglichst eng zu verbinden; seine creatores bteiben jedoch letzten Endes immer die aus der Welt ausgegrenzten Preumatiker, die das BewuBtsein der Ausgegrenztheit und der Übertegenheit über die 'Unwissenden' (bzw. 'Unglăubigen', 'Nicht-Liebenden') teuer bezahien müssen (vgl. das Gedicht Silenci / Wahnbetơte. Gedichtzyklus Ruce, 1901).

314 Die postulierte 'Pneumatisierung' soll selbstverstăndlich auch die erotische Liebe erlassen: "Hovoriti buderne micenim, a políbením bude neviditelné potkáni touhy" (V, 18; "Unsere Rede wird Schweigen sein und KUB das unsichtbare Begegnen der Sehnsucht'). Signitikant ist hier die Symbolik der 'positiven' Apophatik, der eine wichtige Aufgabe im mystisch-gnostischen Mysterium zuerkannt wird. Hans Jonas zitiert in diesem Zusammenhang aus einem Traktat des Platonikers Philo von Alexandria (1. Jh. $\mathrm{n}$. Chr.): "Die es vermögen mehr von der Schau an sich zu reißen, entschlafen oft vom Körper weg zur schónsten Schau. ... Sehen wirst du es dann, wenn du nichts mehr darüber zu sagen weiBt. Denn seine Erkenntnis und Schau ist Schweigen und Stillstand aller Sinnestátigkeit. Denn nichts anderes kann denken wer dieses denkt, nichts anderes schauen wer dieses schaut, von nichts anderem hören noch überhaupt den Korper bewegen. Denn aller leiblichen Sinne und Bewegungen vergessend verhart er regungslos. Umleuchtend den ganzen Geist und die ganze Seele leuchtet es auf und zieht inn hinauf, durch den Körper hindurch, und verwandelt inn ganz ins wesenhafte Sein". Zit. nach: Hans Jonas, Gnosis und spätantiker Geist, Teil 2, 1, Von der Mythologie zur mystischen Philosophie, Göttingen 1954, S. 52f. Es sind gerade die starken optischen Erlebnisse (Feuer- und Blitzglanz, blendende Strahlen oder "unverwandtes Schauen"), die die visionăre Schau und das Verwandiungserlebnis begleiten. 
Das gnostich-mystische Substrat, das diesem Gedicht zugrundeliegt und der auch auf der syntagmatischen Achse 'gnostisch' geprägt ist, bestimmt die Sinnbewegung der folgenden Sujetsequenzen (12-22; 34-42). Nach dem Erreichen der Extase werden die unbegrenzten Formen und phantastischen Möglichkeiten der visionären Schau zum Ausdruck gebracht. Die visionäre Schau hat ihre eigene Werthierarchie: Den höchsten Rang nimmt die Verschmelzung der Gegensätze (coniunctio oppositorum) ein, die ebenfalls der gnostisch-mystischen Tradition Tribut zollt. Diese these unterstützt die Tatsache, das es gerade das Oxymoron ist, das die dominierende semantische Figur dieses Gedichts, wie auch des ganzen Zyklus, darstellt. Die oxymorale Semantik kommt bereits in der ersten Sujetsequenz deutlich zur Geltung: "uvidíme oblak Věčného /.../ svititi z hlubin jako slunce" (V. 9; "die Wolke des Ewigen werden wir sehen /... / wie Sonne den Tiefen erstrahler"); "zemieme pied svou smrti" (V. 11; "vor unserem Tode sterben wir hin"): "zahradami budou nám hroby" (V. 17; "Zu Gärten werden uns Gräber"); "/.../ stane se prưhledným neprưhledné" (V. 20; "das Undurchsichtige wird durchsichtig sein") usw. Die oxymorale Semantik wirkt auch im Sinne der Positivierung des Negativen: "a jed ve Stávách kvêtư shoři za uzdravujicich vưni. I Stíny složi se nám jak péra v krídlech, posetá hvězdami, smějici se dálkám" (V. 24-25; "und Gift in den Säften der Blüten verbrennt unter heilsamen Düften. I Schatten legen sich uns zusammen wie Federn in Flügeln, besät mit Sternen, spottend der Weiten").

Es ist jedoch vor allem die Befähigung zur 'visionären Schau', zur 'visionären Begegnung' (der 'Lichtgestalt' oder Epiphanie), die konsequent zukunftsorientiert ist: "Hledéti budeme radou dni budoucich, jak radou sklenených dveř́ za sebou ležicich sini, I jimiž nám naproti prichází slunce" (V. 29-30; "Schauen werden wir durch die Fluchten der künftigen Tage, wie durch eine Reihe von gläsernen Türen hintereinandertiegender Säle. I durch welche uns Sonne entgegenkommt, bekränzt mit dem Grünlaub der Gärten“). ${ }^{315}$ Das postulierte Ziel ist die Integration der Vergangenheit in die Zukunft, d. h. die eschatologische Zeitlosigkeit: "Minulost ztratí se v đálce jak kouř továren mèsta, z něhož jsme vyjeli dávno. /../ podobná výkřiku všech pisni, skrytých ve všech minulých i budoucich dušich a světech, / a smišeni vł̌ech minulých i budoucich dni a noci v jediný den, v nẻmž nebude noci" (V. 32, 41-42; "Vergangenheit verliert sich in Ferne, wie Rauch von Fabriken der Stadt, die längst wir verlassen. /.../ ähnlich dem Aufschrei aller Lieder, verborgen in allen vergangnen und künftigen Seelen und Welten / und Vermischung aller vergangnen und künftigen Tage und Nächte zu einem einzigen Tag, in dem es nicht Nacht wird"). Die Zeitwelt, und mit ihr auch das zeitliche, welthafte Sein, soll in der eschatologischen Zeitlosigkeit, in der es keine Vergangenheit gibt, aufgelöst werden. Die Zeitwelt ist die Welt des Tageslichts, die in Vino silnych - durchaus in der Intention des gnostischen (Tages-)Licht-Verständnisses - als die Sphäre eines vorläufigen Todes "ostrovy zajet́ svého" / "ihrer Gefangenschaft Inseln", V. 46) konnotiert ist. Deher soll das ermüdende irdische (Tages-)Licht in einem höheren, kathartischen Licht aufgehen: "Unavení světlem ruku pođáme prítelkyni, aby nás odvedla odsud" (V. 34; "Müde des Lichts, reichen wir unsere Hand dem Freund, daß er von dannen uns führe"). Dieses Bild ist ein Euphemismus für die totale Entwelttichung durch den Tod. Das Entscheidende, der

315 Auf die prophetisch-soteriologische 'Topographie' des Gedichts deutet die im mythopoetischen Symbolismus hochfrequentierte "Fenster"- und "Tür"-Symbolik hin: "Okna nase I... (V. 23): "raadou skleněných dver̈ I...r (V. 29). Durch diese medialen Orte (des Übergangs) führt der Weg in die Sphäre der Transzendenz; darüber hinaus ermöglichen sie auch - wie eben in Vino silnych - den Ausblick auf das Bevorstehende, auf die glorreiche Zukunft im Licht der ewigen Morgenröte: "Hledéti budeme /... / jak ładou sklenëných dvể (V. 29; "Schauen werden wir durch die Fluchten der künftigen Tage, wie durch eine Reihe von gläsernen Türen /.../ durch welche und Sonne entgegenkommt"). Signifikanterweise strukturiert eine Sujetsequenz von Vino silných ( $V$. 34-42) gerade die Symbolik des Fortgehens. Wie A. A. Hansen-Löve in seiner Studie .Apokalyptik und Adventismus im russischen Symbolismus der Jahrhundertwende" (in: Russische Literatur an der Wende vom 19. zum 20. Jahrhundert, hrsg. v. R. G. Grübel. Amsterdam-Atlanta 1993, S. 267ff.) nachweist, symbolisieren diese apokalyptischen Orte den Übergang bzw. Umschlag eines Zustandes in den anderen. Die Transparenz bedeutet das 'Schauen', die Diaphanie und das 'Geschaute'. Aufschlußreich ist in diesem Zusammenhang auch die Paronomasie von okno (das Fenster) und oko (das Auge). Vgl. dazu die eschatologische Verkündung Jesu: "Selig sind die Augen, die sehen, was ihr seht. / Denn ich sage euch: Viele Propheten und Könige wolten sehen, was ihr seht, und haben's nicht gesehen, und hören, was ihr hört, und haben's nicht gehört". (Lukas 10, 23-24). 
springende Punkt, ist also nicht sosehr, daß man im Licht sei, sondern daß man das Licht als die Kraft der Unsterblichkeit in sich habe. 316 Wie das Licht ist auch die Dunkelheit eine Kraftsubstanz. Licht und Dunkelheit bilden hier eine Art wechselseitiger Äquivalenzrelation. Das Derivat der beiden Kraftsubstanzen heißt in Vino silných "zánici tma" ("leuchtende Dunkelheit", V. 46; auch als Zeichen göttlicher Epiphanie). Daher feiert in der folgenden Sujetsequenz (V. 34-42) das Absterben der immanenten (Licht-)Welt, das "Führen von dannen" durch die "Freundin" (durch den Tod; im Tschechischen, dem Genus nach, ein Femininum), seine grandiose Apotheose: "Unaveni světlem ruku podáme Prítelkyni, aby nás odvedla odsud, / a smrt naše bude jak smrt očištěných lidi. Podobná chúzi / z pokojư piesycených vưnèmi do chrámu v nedẻli kvétnou. I... $/$ (V. 34-35).

Im Epilog (V. 43-46) werden die "Brüder" erneut zum Kosten des Weines der "Starken" aufgefordert; dabei wird dieser wunderwirkende Wein năher spezifiziert: "hvězdy, které nan̂ naprşely v kvẻtu. at naházi do našich zrakư" (V. 44; "Sterne, die aư inn zur Blütezeit niederregneten, mag er in unsere Blicke werfen`). 317 Die Belohnung, die den Starken zuteil wird, ist die Erfahrung der "strahlenden Dunkelheit", eine Art Erleuchtung, die sie zugleich unsterblich macht. Diese Unsterblichkeit gleicht einer supranaturalen Kraft, die die "Starken" befähigt, die diesseitige Welt des Werdens, die allerdings auch eine Welt der Finsternis, des Schmerzes und des Todes repräsentiert, 'unversehrt' zu ertragen, sie in ihrem Sinn zu verstehen, und die höhere, transzendente Welt mit ihren Geheimnissen zu erkennen. Erst die Entwelttichung durch mortifikatio erschließt die höchste Erkenntnis und das Einflößen der göttlichen Lichtsubstanz oder - in der Terminologie des Dionysius Areopagita - der "göttlichen Finsternis" ("zárící tma", V. 46): "odměna silných, że v zárící tmé vzpomenou na ostrovy zajet́ svěho" (V. 46; "und Lohn der Starken wird sein, daß sie in strahlenderm Dunkel ihrer Gefangenschaft Inseln gedenken").

In der letzten Verszeile führt die oxymorale, die Gegensätze vereinigende Konstruktion "záríci tma" ("leuchtende Dunkelheit") erneut zur Symbolik des Schmerzes zurück. Die "leuchtende Dunkelheit" gehört aber zum "Lohn" ("odme̋na") der "Starken". Die "Winzer"

316 Vgl. die hervorragende Darlegung von Rudolf Bultmann. Zur Geschichte der Lichtsymbolik im Altertum", in: Philologus, 97, 1948. S. 1-36. Bultmann zitiert (S. 26-27) eine Stelle aus Senecas Epistulae, die das Erlebnis der Befreiung aus dem (tellurischen) Gefăngnis des sterblichen Körpers und den anschließenden ascensus der Seele in die Lichtwelt zum thema hat: $\%$... Bald werden die Geheimnisse der Natur dir enthüllt werden, zerteilt werden wird dieser Nebel, und von allen Seiten wird klares Licht auf dich eindringen. Stelle dir vor, wie groß der Glanz sein wird, wenn alle Gestirne ihr Licht untereinander mischen. I.../ In gleicher Weise wird der Himmel ringsum strahlen. Den Wechsel von Tag und Nacht gibt es nur hier in dieser unteren Sphăre. Dann wirst du sagen, du habest im Finstern gelebt, wenn du die ganze Lichttülle als Ganzer schauen wirst, die du jetzt nur dunkel wahrnimmst durch den engen Weg der Augen, - und doch bewunderst du jenes Licht schion von feme. Wie wird dir das gottliche Licht erscheinen, wenn du es in seiner Heimat sehen wirst?" In der Gnosis, die die irdiscte Welt als eine böse Imitation, eine Fălschung der himmlischen Lichtwelt versteht, konzentrient sich das soteriologische Geschehen auf die Befreiung der Lichtfunken aus dem Körper und deren Emporführung in die himmlische Lichtwett. Um diese zu verwirklichen, wird der "Gesandte des Lichtes", eine verkleidete Gestalt der Lichtsphăre herabgesandt, der durch seinen "Ruf" die Seele aus dem tellurischen Territorium ins Reich des Lichtes führt. Sehr aufschlußreich sind ebenfalls Bultmanns komparative Hinweise auf entsprectende Textstellen in der Bibel und in den gnostischen Quellen: .Die Bedeutung der neuerschlossenen mandăischen und manichăischen Quellen für das verstăndnis des Johannesevangeliums", in: Zeitschritt für die Neutestament. Wissenschaft, 24, 1925, S. 100-146: -Da redete Jesus abermal zu innen und sprach: Ich bin das Licht der Welt. Wer mir nachiorgt, wird nicht wandeln in der Finsternis, sondem wird das Licht des Lebens haben. (Joh. 8. 12). "Als ich kam, ich der Gesandte des Lichtes, / der Kónig, der ich vom Lichte hierther ging, / da kam ich, Gemeinschaftlichkeit und Glanz in meiner Hand, I Licht und Lobpreis auf mir, I Glanz auf mir und Erleuchtung. / Ruf und Verkündigung auf mir, / das Zeichen (der Olung) auf mir und die Taufe, / und ich erleuchte die finstern Herzen". (Vgl. ibid. S. 110-111).

317 Aage A. Hansen-Love (Der russische Symbolismus, Bd. II, Lebenssymbolik, Wien 1984, S. 496) macht auf die kosmische Symbolik des "Firmaments" als "Pokal", in dem die Gestirne (Topoi der solaren Welt) "schăumen", aufmerksam. Die Sterne, die in den Wein der "Starken" niederregnen, sollen in deren Blicke geworfen werden ("at' naházi do našich zrakü", V. 44). Die 'Auserwăhlten', die den Wein empfangen, sollen die Kraft zur visionăren Schau (zurück-)erlangen, mit anderen Worten: Das Licht des "Höchsten", das sie unsterblich macht, soll innen eingefioßt werden. Zur gnostischen Stellung zu den Gestimen vgl. Hans Jonas, Gnosis und spatantiker Geist, Teil 1,2, Göttingen 1965, S. $156 \mathrm{ff}$. 
("vinarii", V. 3) des wunderwirkenden Weines waren "Trauer" ("smutek") und "Einsamkeit" ("samota"), die 'Determinanten' der ästhetischen Existenz im dekadenten Symbolismus, die in der neuen Schaffensphase ihren (für die gnostisch-eschatologische Schaffensposition) produktiven Sinn erlangen. Mit der Apostrophe "Brüder" ("Bratï", V.1; V. 43) spricht Brezina auch seine dekadenten Dichter-Kollegen an. Der "Lohn" der "Starken", wenn auch nur im Modus der Erinnerung ("Vzpomenou", V. 46), ist also das aus der Erfahrung der tristen Vereinsamung der ästhetisch-dekadenten Existenz, dieser ambivalenten, "hehr-traurigen" (Slavny smutek / Die hehre Trauer, TD) "Gefangenschaft" in eigener Projektionswelt destillierte schöpferische Potential: "[vzpomenou] na ostrovy zajeó svého" ("V. 46; [sie gedenken] ihrer Gefangenschaft Inseln").

Wer sind aber dann die "Schwachen" ("slabi"), die mit dem Identitätsverlust bestraft werden ("Trest slabých bude, że zapomenou své jméno pr̈i procitnuti", V. 45; "Strafe der Schwachen wird sein, daß beim Erwachen sie ihren Namen vergessen")? Es sind offensichtlich die Künstler-Menschen, die nicht in der Lage waren, oder es ablehnten, die schmerzvolle Erfahrung des (dekadenten) descensus zu einer produktiven Erfahrung (für die künftige schöpferische Entwicklung) zu transformieren. Es sind also auch Dichter, die die Dekadenz nicht als eine (notwendige) Übergangsphase, sondern (pauschal) als einen Irrweg betrachten, den sie zu leugnen und zu verdrängen versuchen. Zur Strafe für diesen künstlerischen Defätismus, diese Verdrängung der eigenen dekadenten Vergangenheit, "vergessen sie ihren Namen" ("zapomenou své jméno", V. 45). Es scheint, daß Bỉezina mit diesem Standpunkt seinen Beitrag zu der zeitgenössischen Diskussion über die 'notwendige Überwindung' der Dekadenz durch künstlerische Konversion zu einer 'neuen Renaissance', zur Neoromantik usw., mit dem Ziel, eine 'positive' Einstellung zum Leben und zum Kunstschaffen zu finden, leistet. In Vino silnych distanziert sich Brezina von derartigen modischen 'Konversionen', die gegen Ende der neunziger Jahre auch von den führenden Repräsentanten der tschechischen Moderne (F.X. Salda, F.V. Krejči oder der Antipode Brezinas und sein Kritiker, der Dichter Viktor Dyk) gleichsam sanktioniert wurden, 318 und antwortet mit einem stolzen Bekenntnis zu seiner eigenen dekadenten Vergangenheit. Dieser Standpunkt eines Einzelgängers entspricht durchaus der Logik Biezinas schöpferischer Entwicklung. Es ist nicht von ungefähr, daß er in einem Brief an Anna Pammrová (vom 25. IX. 1896; vier Monate nach der Herausgabe von SZ) die Notwendigkeit der 'Schatten-Integration' betont: "Člověk by se musel vzdát vši aktivity. kdyby chtêl projît životem bez têchto stínú, které vihá ..." ("Der Mensch müßte aư jegliche Aktivität verzichten, wenn er durch das Leben ohne Schatten, die er wirft, gehen möchte...").

Die offensichtlich gnostische Herkunft der "Starken", der ('verchristlichten') Pneumatiker, die auf ihre Begabung und ihre wunderbaren Fähigkeiten stolz sind und sich von den "Schwachen" absondern, führt zur Frage, inwieweit sie, als mythogene Gestalten, mit den Gnostikern verwandt sind, gegen die sich Apostel Paulus mit seiner Polemik in

318 Diese Umorientierung bekundet sich wohl am deutlichsten im Werk eines der bedeutendsten Reprăsentanten der tschechischen Dekadenz Jiři Karásek ze Lvovic (1871-1951). Bereits in seinem Gedichtband Kniha anistokratická (Das aristokratische Buch, 1896) macht sich (vor allem auf der motivsemantischen Ebene) die Tendenz bemerkbar, die provokativen Stilisierungen und Gesten seiner dekadenten Gedichte (Sodoma. Sexus necans, 1895), in denen das Prinzip der dekadenten Korrelation zwischen Schönheit und Abscheu, zwischen Ästhetischem und Pathologischem (bzw. Perversem), oder die Vorstellung der 'ausweglosen', dem totalen Verfall eingeweihten Zivilisation (Zazdêná okna / Die zugemauerten Fenster, 1894, Sodoma, 1895) dominieren, zu verdrängen. Noch prägnanter kommt diese Tendenz in Karáseks nach 1900 abgefaßten Gedichttexten zur Geltung (Gedichtsammlungen: Endymion, 1909; Ostrov vyhnancú I Die Insel der Verbannten, 1912), in denen fiktive Dialoge mit der Kultur-Geschichte des Hellenismus und der Renaissance entfaltet werden. Signifikant ist auch die Tatsache, daß Karásek seine dekadenten, ursprünglich in vers libre abgefaßten Gedichte später (nach 1910) unter dem Einfluß der neoklassizistischen Ästhetik, 'neu' (d. $h$. in strophischer Variante mit regelmáßigem Reim) verfaßte, ohne jedoch das Thema zu ándern. Die Intention, den 'Ausweg' aus der Dekadenz in einer 'positiv' orientiereten Strömung zu finden, prägt das Werk des Dichters Otakar Theer (1880-1917), wie schon sein programmatisch antidekadentes Gedicht-Debüt Háje. $k d e$ se tanč (Haine, wo getanzt wird. 1897) andeutet. Ein anderes Beispiel dieser Entwicklung stellt auch das Debüt von Viktor Dyk (1877-1931). A porta inferi (1897) und seine kritische Reaktion auf den dekadenten Kult der 'müden Seele', der Gedichtband Sila Zivota (Die Kraft des Lebens, 1898), dar. 
den Korintherbriefen wendet. 319 Auch wenn diese Frage nicht eindeutig beantwortet werden kann, müssen einige Analogien als zweifelsohne erwägenswert betrachtet werden. Im Anschluß an die hellenistisch-christliche Gnosis unterscheidet Paulus zwischen Physikern und Pneumatikern; letztere partizipieren an der Herrlichkeit und sind frei vom Gesetz ${ }^{320}$ ("Tajemný proud zavĩe se kruhem kol našeho stolu, / vymkne nás ze zákonủ zemè I...r, V. 6-7; "Geheimnisvoll schließt ein Strom seinen Kreislauf um unser Tischrund, / hebt uns von den Gesetzen der Erde /...।"). Die irdische Welt als 'gefallene Schöpfung' wird von dämonischen Mächten regiert. Infolge des Falls von Adam wurde Sünde und Tod über die Welt gebracht und seitdem verfiel die Menschheit dem tellurischhyletischen Sein. Daher dominiert bei den Pneumatikern die weltablehnende Haltung ("a smrt naše bude jak smrt očištěných lidi", V. 35; "und unser Tod wird sein wie der Tod gereinigter Menschen"). Erst das soteriologische Geschehen durch Christus ermöglichte eine neue Menschheit des Geistes. Er befreit von dieser fatalen Weltverfallenheit. Der christliche Pneumatiker besitzt Freiheit und wunderbare Fähigkeiten; er ist durch Glauben und (vor allem) Liebe gebunden. Diese Freiheit bedeutet dann auch die Freiheit von der Sünde (vom Eros), sie setzt aber die Askese voraus, ein Thema, das im dritten Gedichtzyklus Vètry od polü (Polarwinde, 1897) eine starke Resonanz findet. Die Beinamen der "Starken" wie "Cisti" (die "Reinen") oder sogar "svat" (die "Heiligen") deuten schon auf die Tendenz zur Theo-logisierung und Spiritualisierung der poetischen Semantik hin. In Vètry od polü (Polarwinde) wird das Schicksal der "Starken" in zwei Schlüsselgedichten vom Standpunkt des (neutestamentlich) theo-logischen Denkens aus weiterentfaltet: in Poledni zráni (Mittäglich Reifen) und in Láska (Liebe). Insbesondere das Gedicht Láska, das O. Králík zwar enthusiastisch, nichtsdestoweniger mit vollem Recht als "eines der brillantesten, wahrhaft zauberhaften Gedichte Brezinas" charakterisiert, ${ }^{321}$ kann als ein kritisches Korrektiv der gnostischen Überlegenheit der "Starken" aus der Perspektive der Christologie rezipiert werden.

Zu s a m m e n fa s se nd kann man den zweiten Gedichtzyklus Svitáni na západë als einen Zyklus des Übergangs vom dekadenten zum eschatologischen Symbolismus betrachten. Für diesen seinen spezifischen Status innerhalb Brezinas dichterischen CEuvres wird hier der Begriff "M e ta de ka de n z" geprägt. Eines der Merkmale der Metadekadenz ist das Streben nach einer objektiv distanzierten, kritisch reflektierenden Betrachtungsweise der dekadenten Poetik und ihrer axiologischen Semantik. Wie die Ergebnisse der Analysen und Interpretationen von vier paradigmatischen Gedichten zeigen, sind die metadekadenten Gedichte von $S Z$ aus drei verschiedenen Perspektiven abgefaßt: 1. Aus der (aktuellen) Perspektive von jemandem, der zwar die 'Irrwege' der dekandenten Weltsicht und der ästhetischen "L'art-pour-l'art «- Existenz erkannt hat, der aber über ein 'richtiges' (Er-)Lösungskonzept noch nicht verfügt und die Erfahrungen der schmerzvollen Rezidive macht (Vladari snú / Die Herrscher der Träume). 2. Die andere (retrospektive) Position ist die von jemandem, der die Schwächen der Dekadenz erkannt hat, sie aber dennoch als einen integralen Bestandteil der schöpferischen Entwicklung

319 Vgl. dazu: Rudolf Bultmann. Theologie des Neuen Testaments, Tübingen 1951, S. $162 f f$. Es ist vor allem der Glaube an die befreiende Erkenntnis, den die Christen mit den Pneumatikem teilen. Laut Bultmann konnte Paulus anstelle vom Glauben (ricrus) auch von der Erkenntnis ( $r v \bar{n}(\mathrm{cus})$ reden (vgl. Phil. 3, 9f). Signifikanterweise ist das gerade der Glaube, der im dritten Gedichtzyklus Vétry od pólü immer stãrker der Erkenntnis (als 'apostolisches' Korrektiv) 'konkurriert'. Diese Entwicklung führt in Láska (Liebe, ibid.) zum Versuch, die Erkenntnis (rvôkrus) in der Liebe (áycirn) zu verwirklichen.

$320 \mathrm{Vgl}$. hierzu: "Uns aber hat es Gott offenbart durch seinen Geist; denn der Geist erforscht alle Dinge, auch die Tiefen der Gottheit. / Denn welcher Mensch weiß, was im Menschen ist, als allein der Geist des Menschen, der in inm ist? So weiß auch niemand, was in Gott ist, als allein der Geist Gottes. I Wir aber haben nicht empfangen den Geist der Welt, sondern den Geist aus Gott, daß wir wissen können, was uns von Gott geschenkt ist. / Und davon reden wir auch nicht mit Worten, wie sie menschliche Weisheit lehren kann, sondern mit Worten, die der Geist lehrt. und deuten geistliche Dinge für geistliche Menschen. / Der natürtiche Mensch aber vernimmt nichts vom Geist Gotttes; es ist ihm eine Torheit, und er kann es nicht erkennen; denn es muß geistlich beurteitt werden." (1. Korinther 2, 10-14).

321 O. Králik, Otokar Brezina, Praha 1948, S. 170. Anders formuliert: Auch diesen Texten liegt gnostische Begritflichkeit zugrunde, der Unterschied resultiert daraus, daß deren Sinnstruktur nun immer deutlicher und immer mehr Elemente und Impulse der Christologie und (apostolischer) Heilslehre mit einbezieht. 
betrachtet und bemüht ist, den 'richtigen Weg' zu finden (Vitézná piseñ / Das siegreiche Led). 3. Schließlich handelt es sich um die Perspektive von jemandem, der die Dekadenz als eine geradezu notwendige, doch bereits überholte Schaffensphase reflektiert und sich schon auf dem Boden des eschatologischen Symbolismus befindet (Ranni modlitba / Das Morgengebet, Vino silných / Der Wein der Starken). Darüber hinaus führte die Untersuchung zur Erkenntnis, daß die Symbolik des (Lebens-)We ges (mit allen Peripetien, Rezidiven usw.) als semantische und kompositorische Konstante dem gesamten Zyklus dominiert. Die in diesem Kapitel analysierten und interpretierten Gedichte thematisieren jeweils einen (weiteren) Schritt auf dem Weg zur Erlösung durch die E in h e it (unio mystica), die in Svitáni na západé mit gnostisch-eschatologischen Mitteln erreicht werden soll. Diese These wird durch die Herausarbeitung und Analyse des gnostisch-mystischen Substrats der interpretierten Gedichte verifiziert. Die (eschatologische) Einheit erscheint - im Gegensatz zum dekadenten Prinzip der Dissoziation und Destruktion - als sinnzentrierendes Prinzip und 'universales' Telos der gesamten nechdekadenten Entwicklung von Biezina. Auf dem Wege zur postulierten Einheit spielt die produktive und daher positive Erfahrung des schöpferischen Schmerzes, als Folge der "Gefangenschaft" in der autistischen Kunst-Welt der Dekadenz und als (notwendige) Voraussetzung für den schöpferischen ascensus, eine sinnkonstitutive Rolle. 


\title{
4. ESCHATOLOGISCHER SYMBOLISMUS II \\ Theo-logisch-eschatologisches Modell Gedichtzyklus Větry od pólü (Polarwinde) 1897 \\ Eschatologische Existenz im Glauben ( $\pi i \sigma \tau \varsigma$ ) Theo-logisierung und Spiritualisierung der poetischen Welt
}

\author{
"Hledám velké a mocné slovo, otvírajicí krajiny \\ zatopené novým sluncem...". \\ "Ich suche das große und mächtige Wort, das die von \\ der neuen Sonne überfluteten Landschafien öffnet..."
}

Or. Brezina an Anna Pammrová (1896)

Die Herausgabe des dritten Gedichtzyklus Větry od pólü (Polarwinde) im September 1897 kündigte Brezina bereits im Sommer 1896 in seiner Korrespondenz an. Es fällt auf, daß er dabei eine völlig neue und höhere Qualität322 der neven Gedichte betont. Bỉezina spricht von einer neuen Orientierung seiner schöpferischen Entwicklung; "síla" ("Stärke"), "vile" ("Wille"), "vira" ("Glaube"), "zodpovëdnost" ("Verantwortung"), "svatost" ("Heiligkeit"), scheinen nun ihre signifikanten Merkmale zu sein. In einem Brief (vom 4. VII. 1897) ${ }^{323}$ an Anna Pammrová schreibt Bł̉ezina: "Nebot silný vērí v zodpovědnost, jen slabý bojí se konsekvená svobodné vile /.../. Do krajin żivota kráči se proti větru. Vủle je krása muže*. ("Denn der Starke glaubt an die Verantwortung, nur der Schwache fürchtet die Konsequenzen des freien Willens /.../. In die Landschaften des Lebens schreitet man gegen den Wind. Der Wille ist die Schönheit des Mannes"). Es erhebt sich die Frage, was sich gegenüber dem gnostisch-eschatologischen Modell des ersten nachdekadenten Gedichtzyklus Svítáni na západẻ prinzipiell geändert hat? Wie wirkt sich die Tendenz zur Theo-logisierung 324 des Weltbildes auf die Semantik und Axiologie von Vëtry od pólü aus? Lassen auch die Gedichte des neuen Zyklus die Spuren des mythisch-gnostischen Substrats erkennen oder wird dieses durch das christlich-theologische Denken verdrängt?325 Welche Wege führen in diesem Welt-Modell zum Eschaton?

322 In einem Brief (vom 13. V. 1896; d. h. unmittelbar nach der Herausgabe von SZ) an S. Bouska, schreibt Błezina: "Ale dnes už jou jinam. A na jasnéjsi mista. Moje tfetí kniha, jejiź hlavni ideové dispozice mám hotovy, bude bữ lepsi neż druhâ, nebo nebude vúbec". ("Aber heute gehe ich schon in eine andere Richtung. Und auf heilere Orte. Mein drittes Buch, dessen ideelle Dispositionen ich bereits fertig habe, wird besser sein als das zweite, oder es wird überhaupt nicht sein". Sperrungen von Bł̉ezina). Vlídné setkání. Vzájemná korespondence Otokara Błeziny a Sigismunda Boushy. Olomouc 1997, S. 45.

323 Vgl. O. Brezina, .Dva dopisy", in: Wiener Slawistischer Almanach, 4, 1979, S. 208.

324 Es soll hier in nuce an die Bedeutung des Terminus Theologia bei Aristoteles erinnent werden. Im ersten Buch der Metaphysik nennt er die epischen Dichter, die die Genealogien der Götter festgelegt haben, vor allem Hesiod. Theologoi (ol itcoloyol). W. Jaeger verweist auf den UnterschiedWiderspruch im Gebrauch von Theotogia bei Aristoteles (W. Jaeger, Die Theologie der frühen griechischen Denker, Zürich 1953, S. 12). Einerseits bezeichnet Theologia die hóchste Form der theoretischen Philosophie, die erste Philosophie, andererseits die mythologischen Spekulationen der Theologoi wie Hesiod, die sich in mythischen Bildern ausdrücken. Aristoteles klassifiziert die Theologie der Dichter als Philosophie. Jaeger glaubt, daB Aristoteles in den uralten religiösen Vorstellungen (der 'Dichter/Theologen') "die Ahnung der Wahrheit" findet, die sich im Mythos der Gotter im religiösen Gewand offenbart. (W. Jaeger, ibid., S. 14). Der Mythos (vgl. Metaphysik I, 3, 983 b; XI, 8, 1074 a) erscheint nun als eigene Erkenntnisform, die einen 'kryptierten' Enfahrungsinhalt reflexiv interpretiert, dessen sich der Dichter bemāchtigen kann, um inn als 'Objekt' einer poetischen Projektion dienstbar zu machen. An die aristotelische Philosophie knüptt die Scholastik an und zwar im Postulat der Vereinigung des Glaubens mit der Vemunft, der Bibel mit Aristoteles.

325 Es ist nicht nur die Gnosis, der eine my th e $n$ bild e n d e Kraft innewohnt, sondern auch das Christentum, dem ein durchaus $m$ y $t h$ i s $c h$ er Vorstellungsgehalt zugrundeliegt. Man kann sowohl von der gnostischen als auch von der christlichen (in einem engeren Sinne neutestamentlichen) Eschatologie sprechen. Wodurch unterscheiden sie sich voneinander? Laut 
Das Streben, das "große, mächtige Wo rt" zu finden, signalisiert die Verschiebung des Schwerpunktes von der gnostischen Auto-Soteriologie und Heterodoxie auf das theologische Denken und die Offenbarungsreligion. Wie wirkt sich die Theo-logisierung (und Spiritualisierung) der poetischen Welt auf der Ebene der poetischen Bildlichkeit und Semantik aus? Hebt die Rationalität326 (des Logos) den Mythos auf?327 Im

Bultmann (Theologie des Neuen Testaments, Tübingen 1968 , 6. Aufl.. S. 175ff.) entspricht dem mythischen Weltbild die Darstellung des Heilsgeschehens, $d$. $h$. der eigentliche Inhalt der neutestamentlichen Verkūndigung, deren einzelne Motive sich auf die Mythologie der jüdischen Apokalyptik zurückführen lassen. Das Kommen der Endzeit; die Sendung des Sohnes, der auf Erden als ein Mensch erscheint (2. Kor. 8.9; Joh. 2,2 usw.); sein Tod am Kreuz (2. Kor. 5,21; Rm. 8,3); die Erschaffung der Sühne für die Sünden der Menschen (Rm. 3,23-26; 2. Kor. 5, 14. 19; Joh. 1,29, 1. Joh. 2,2); die Auferstehung als Beginn der kosmischen Katastrophe (1. Kor. 15,21f.; Rm. 5,12ff.); der Zusammenbruch der dämonischen Weltmächte (1. Kor. 2,6; Apok. 12,7ff.); das Kommen des himmlischen Richters; die Auferstehung der Toten und das Gericht zum Heil oder zum Verderben (1. Kor. 15.23f.; 50tf.; Apok. 21.4 usw.). Die Korrelation zwischen der gnostischen und der neutestamentlichen mythischen Struktur des eschatologischen Geschehens sieht Bultmann konkret in der Darstellung des Erlösers als einer kosmischen Gestalt, eines präexistenten Gottwesens (als Sohn des Vaters), der vom Himmel herabkam; ferner im Gedanken vom Abstieg und Wiederaufstieg des Erlösers oder (u. a.) in der gnostischen Vorstellung vor der Präexistenz der Soelen und in der Verwandschaft von Erlöser und Erlösten, die ihren Reflex im Johannes-Evangelium findet. Vgl. ibid., S. $179 \mathrm{tf}$. Vgl. auch: R. Bultmann, Das Evangelium des Johannes (21. Aufl., Nachdruck der ersten Ausgabe von 1941), Gōttingen 1986, S. 298ff. Der Hauptunterschied gründet im Ziel des eschatologischen Geschehens. Wăhrend dieses in der gnostischen Mythologie in die Selbst-Erlösung von der Welt, $d$. $h$. in eine totale Entweltlichung einmündet, kulminiert das eschatologische Geschehen im neutestamentlichen Mythos, das jenseits der Zeit ist und kein supranaturales (wie in der Gnosis), sondern ein "geschichtliches Geschehen in Raum und Zeit" darstellt, in der Freiheit der "verantwortlichen Entscheidung" zur (heils-)geschichtlichen Existenz. Vgl. Theologie des Neuen Testaments, S. 185f. Im gnostischen Mythos realisiert sich das eschatologische Ereignis als ein "groBartiger Naturprozeß gleichsam an mir vorbei, sie [die Erlösung; J.V.] ist als Geschehen meines eigenen geschichtlichen Leibes gar nicht erfaßbar". Und dementsprechend ist der Enöser in Wahtheit kein konkreter geschichtlicher Mensch, sondem ein "Urmensch". R. Bultmann, Das Evangelium des Johannes, Göttingen, 1986, S. 41. Bultmann versteht den Mythos vom eschatologischen Geschehen als eine vorwissenschaftliche, kosmologisch-eschatologische Erklärung, die ein archaisches Weltbild voraussetzt, das dem heutigen Menschen völlig unglaubhaft geworden ist. Daher sei es notwendig den christlichen Mythos zu entmyhologisieren, $d$. h. die objektiven Vorstellungen des Mythos aut jenes Selbstverstăndnis zurückzubeziehen, das sich in ihnen zeigt und verbirgt. Vgl. R. Bultmann. Neves Testament und Mythologie. Das Problem der Entmythologisierung der neutestamentlichen Verkündigung [Nachdruck der 1941 erschienenen Ausgabe], München 1985, S. 22. In diesem Zusammenhang definiert Bultmann den Mythos religionsgeschichtlich als "die Vorstellungsweise. in der das Unwetliche, Göttliche als Welttiches, Menschliches, das Jenseitige als Diesseitiges erscheint, in der Z. B. Gottes Jenseitigkeit als räumliche Ferne (man denke an die Symbolik der "geheimnisvollen Ferne" bei Bíezina: Anm. J.V.J gedacht wird; eine Vorstellungsweise, der zufolge der Kultus als ein Handeln verstanden wird, in dem durch materielle Mittel nichtmaterielle Krätte vermittett werden. Es ist vorm nMythos a also nicht in jenem modernen Sinne die Rede, wonach er nichts weiter bedeutet als Ideologie". (Ibid.. S. 23). Der Hauptgedanke der Entmythologisierung des neutestamentlichen Mythos (und des Kerygmas) ist es, daß der Mensch im Glaubensakt (durch die Offenbarung, d. h. durch die Anrede Gottes) ein neues Selbstverständnis gewinnt. Das Selbstverständnis meint den lebhaftig existierenden, ve r s t e h e n d e $n$ Menschen. Im Glauben versteht der Mensch Gott als den Unbegreiflichen. Die Unsichtbarkeit, Unbegreiflichkeit Gottes. schlieBt nämlich, laut Bultmann, jede mythische Vorstellung aus, die versucht, Gott und seine Taten sichtbar zu machen. Den Weg der rúr rus kann man n u r trotz der gemachten Erfahrung (der Unsichtbarkeit Gottes) einschlagen. In diesem Punkt knüpft Bultmann an den theologischen Nukleus der Rechtfertigung durch den Glauben im Sinne der paulinischen und der lutherischen Tradition an. Vgl. dazu auch Bultmanns sehr aufschlußreiche Darlegung zur dieser Problematik in seinem Büchlein Jesus Christ and Mythology, New York 1958, S. 83ff. Im Prinzip bedeutet diese Interpretation eine bestimmte Art rationaler, methodisch kontrollierter Argumentation.

326 Daß das mythische Denken eine eigene Rationalităt besitzt und als eine Form der Welterkenntnis, nămlich als Erkenntnis der Welt im ganzen, gewürdigt werden muß, versuchte schon Ernst Cassirer im zweiten Band seiner Philosophie der symbolischen Formen (1926) darzustellen. Mit diesem Thema beschäftigt sich Cassirer auch in seinem letzten, kurz vor dem Tode (1945) im amerikanischen Exil abgefaßten Werk Der Mythus des Staates.

$327 \mathrm{Vgl}$. hierzu das lesenswerte Buch von Paul Veyne. Glaubten die Griechen an ihre Mythen?, Frankfurt am Main 1987. Der Autor beantwortet diese Frage selbstverständlich positiv 
Johannesprolog (Joh. 1) wird ein Mythos328 erzähit, der den Logos zum Thema hat. Mythos und Logos sind hier eng aufeinander bezogen. Für die Semantik von Vẻtry od pólü ist die Wirkung des (göttlichen) Logos, vor allem in seiner Beziehung zum Licht und dadurch zur Lebendigkeit, von großer Relevanz. Vielsagend ist bereits die Tatsache, daß das Lexem "Licht" ("světlo") seine höchste Frequenz gerade in Vêtry od pólü erreicht. In neunzehn von zwanzig Gedichten des Zyklus kommt "světtlo" sechzigmal vor. 329 Auch andere Lexeme des gleichen semantischen Feldes, "slunce" ("Sonne") und "zrak" ("Sehkraft", "Blick"), erreichen ihre höchste Frequenz in VP. Der Mythos vom Logos thematisiert das Verhältnis des "Wortes" zur Lebendigkeit, mit der jeder Mensch begabt ist (Joh. 1,4) und die als Widerschein des Lichtes vom Logos verstanden wird. Doch nicht nur die Lexeme "světlo" ("Licht") oder "slunce" ("Sonne") erreichen in VP ihre höchste Frequenz, sondern auch die ihnen völlig entgegengesetzten Lexeme "noc" ("Nacht") und "stín" ("Schatten").330 Wie es scheint, stehen sich in Vẻtry od pólü zwei entgegengesetzte Weltmodelle gegenüber: die $\mathrm{S}$ ch a tte $n$-Welt der Nacht und des Unbewußten der dekadenten (TD) und der nachdekadenten (SZ) Schaffensphase und die L i c h t -Welt der Sonne und des Logos (des Bewußten). Der Zyklus Vétry od pólü ist ein Zyklus der Extreme, der Polaritäten, die bereits auf der wortsemantischen Ebene zutage treten: "Licht" - "Schatten", "Sonne" bzw. "Morgen" ("jitro") - "Nacht", aber auch "Liebe" ("láska") "Schmerz" ("bolest") oder "Tiefe" ("hlubina") - "Höhe" ("výs", bzw. "výše"), "Gebet" ("modlitba") bzw. "Lied" ("pisen" ) - "Schweigen" ("mlCeni") oder "Stille" ("ticho"). 331 Dem Gedicht Mésto (Die Stadt) wird in VP das Gedicht Pr̈roda (Natur) gegenübergestellt. Der Titel Vètry od $p \delta / \dot{0}$ (Polarwinde) deutet paronomastisch auf diese $P$ o / aritäten hin. Die Herrschaft des Lichtes, das Erhellen der Lebenswelt und des Daseins als die 'Tat' des "Herrschers" ("Vládnouci"), bildet den semantischen Nukleus von Vètry od polú. Als dieses Licht bewegt sich der Logos durch Finsternis ("Und das Licht scheint in der Finsternis /... $\mu$; Joh. 1,5) auf die Menschen zu; darin gründet die Kraft (đynamis) und Bewegung des Logos: in ihm offenbart sich der "Herrscher" in seiner Zugewandtheit zu den Menschen. Geradezu programmatisch wird diese Intention, die Bewegung des Lichtes/ogos, im Prolog-Gedicht von VP thematisiert:

"Vládnouci, jenż rozkazem svẻtla / vyslal jsi nesčetné dni a nesčetné noci, /.../ jako služebniky své před sebou, / by prijaly duše tvé v tisici světech / a vedly je $k$ tobẻ! /.../ At' vzrostou v śícce tvých magických temnot, / paprskủ vẻjî̉, siroká od světa $k$ světu, / jemná a silná, by sméla se opíít I do tvých nejcistšich světel I... (Vládnouć' / Herrscher, V. 1-6, 21-24; "Herrscher, der mit dem Befehl des Lichts / entsandt hat unzählige Tage, unzählige Nächte, /.../ als deine Diener voraus, I daß sie auflesen deine Seelen im Weltentausend / und sie tragen vor dich! /... Daß sie autfalten im Wust deiner magischen Finsternisse/ den Strahlenfächer von All zu All, / zärtlich und stark, daß sie stemmen sich dürten in deine reinlichsten Lichte hinan I... $\%$. Übers. v. F. Werfel.)

Im Prolog-Gedicht erbittet sich das dichterische Ich ein stärkendes "Bad" für seine A uge $\mathrm{n}$ und die Stärkung der S e h k raft

"At' omyji své ới, nemocné soumrakem, / na výsi tvých hor /.../. V extasi lásky chci zpivati bratrským dušim, I... I Że není radosti většich, I neżli je opojeni / zraku věčnosti sesíleného!"

und kommt zum SchluB: "Der ‘Mythos' ist kein transhistorisches Element, keine Invariante; die Gattungen, in denen das mythische Denken wirkt, sind ebenso vielfältig, veränderlich und fließend wie die anderen literarischen Gattungen in den Literaturen aller Völker und Jahrhunderte. Der Mythos ist keine Wesenheit, sondern eher eine Rumpelkammer. (Ibid. S. 185). Mythos und Ratio sind für Veyne keine echten Gegensätze, da weder der Mythos ohne Ration leben kann, noch die abstrakte Ration ohne Bilder, die der Mythos 'kondensiert'.

$328 \mathrm{DaB}$ der Johannesprolog ein Mythos sei, ist nicht allgemein anerkannt (selbst Rudolf Bultmann urteilt in dieser Frage sehr vorsichtig); daß er jedoch deutliche mythologische Züge autweist, bleibt unbestreitbar. Mythologischen Ursprungs ist der Rekurs auf den Uranfang (cxpm). J. Blank, Das Evangelium nach Johannes. Kapiel 1-10, Gütersloh-Würzburg 1979, S. 74f.

329 P. Holman, Frequenzwörterbuch des Iyrischen Werkes von Otokar Bïezina, Bd. II, KölnWeimar-Wien 1983, S. 758, 1171. Im ersten Gedichtzyklus Tajemné dálky (1895) kommt das Substantiv "svétlo" 32x, in Svitáni na západè (1896) 22x, in Stavitelé chrámu (1899) 36x, in Ruce (1901) 18x und in den letzten fünfzehn Gedichten (1902-1907) 11x vor.

330 Das Substantiv "noc" kommt in vierzehn Gedichten 50x, das Substantiv "stin" in elf Gedichten $25 x$ vor.

331 Laut des Frequenzwörterbuchs des lyrischen Werkes von Otokar Brezina. Teil II (S. $1171 \mathrm{ff}$.), erreichen diese Oppositionspaare ihre absolut höchste Frequenz gerade in VP. 
(Vládnouci/ Herrscher, V. 14-15, 29-34; "Daß ich das Aug bade, das zwielichtkranke, / auf deiner Berge Scheitel /.../. In Ekstasen der Liebe will ich verbrüderten Seelen singen, /.../ es gibt keine größeren Freuden / als die Verzückung des Auges, / das schauender taucht aus ewigem Bad!")

Es ist die "Sehkraft", die die ra tio n a le Erkenntnis ermöglicht. Es wird hier offensichtlich der Versuch gewagt, den im zitierten Prolog-Gedicht thematisierten 'Eingriff' des "Herrschers" r a ti o n a I zu ergründen. 332 Damit geht eine wichtige Änderung in der Auffassung des Daseins und der Lebenswelt einher. Das auf eine verabsolutisierte ästhetische Existenz reduzierte Dasein des Künstler-Menschen in der Isolation der KunstWelt wird im zweiten Zyklus Svitáni na západẻ als ein Produkt der Fremdbestimmung (des "Höchsten") reflektiert. Der "Höchste" selbst bleibt im "Schatten" verborgen, geheimnisvoll und unergründbar: "Stín Nẻkoho" (Legenda tajemnè viny I Die Legende der Geheimnisvolen Schuld, II, 2; "Schatten von Jemand"). "O Bezejmenný I...l. Ty, jehoż stinem je tajemstv'“ (Zalm ke cti nejuyšsiho Jména / Der Psalm zu Ehren des höchsten Namens, II, 1, IV, 3; "O Namenloser I...I. Du, dessen Schatten das Geheimnis ist"). In Vètry od pollu tritt der "Namenloser" aus seiner schauderhaften Anonymität heraus und läßt sich als "Herrscher" ("Vládnouci") als "Dreifach Heiliger" ("Třikráte Svatÿ"; Kdyż z lásky tvẻ ... I Wenn aus deiner Liebe...), vor allem jedoch als "V a te $r$ !" ("Otce!"; Kde jsem už slyšlel... IWo denn vernahm ich schon..., V. 27; Poledni zráni I Mittäglich Reifen, V. 1) erkennen und apostrophieren. In Vétry od pólü wird das Dasein als "Wille" des "Vaters" reflektiert: "Byla tvá vúle, o Vẻcný!" (Poledni zráni / Mittäglich Reifen, V. 41: "Dein Wille war es, o Ewiger!"). "A my všichni, nesmrtelni tvou viili" (Kdyż z lásky twè... I Wenn aus deiner Liebe..., V. 27; "Und wir alle unsterblich durch deinen Willen"). Nicht nur das individuelle Dasein, die ganze Lebenswelt wird als 'Produkt' des zeugenden "Hauchens" erkannt: "Dech tvẻho poledniho zráni vali se blankyty tisíciletí! / Bohatstvím jiskrících forem odivá věčnè sny zemè o květech" (Poledni zráni, V. 8-9; "Hauch deines Mittag-Reifens wallt unter ewiger Wölbung! / Mit funkelnder Formen Fülle umhängt er die ewigen Träume der Erde von Blüten"). Das Dasein bedeutet den "Sieg des Geistes", seine "allzu schwere Gabe" (Koyzż z lásky tvě...l Wenn aus deiner Liebe.... V. 30-34).

Der "Vater" ist der creator, er repräsentiert das "Eine" kat exochēn; die Vaterwelt ist die Welt der Einheit, des Bewußten und der Luzidität. In Větry od polù versucht der Dichter das Mythisch-'Animische', das die ästhetische Existenz (TD) prägt, dem Theo-logischen zu subordinieren. Nicht die "Tiefe", die "Dunkelheit" "Nacht", der "Tod", die "Ferne", die "Mutter", das "Unbekannte" (bzw. Unbewußte), der "Mythus der Seele" (Mythus duše, SZ) wie in Tajemné dálky und in Svitáni na západè, sondern die "Höhe" ("vỷse"), das "Leben" (Úsmèv żivota / Des Lebens Lächeln), die "Sonne" $"$ Lich" (Piseñ o slunci, zemi, vodách a tajemstvi ohně / Das Lied von der Sonne. Erde, den Wassern und vom Geheimnis des Fevers; Letni slunovrat / Sommersonnenwende), das Bewußte und der Logos/Vater" sind die Determinanten des theologisch-eschatologischen Modells von Vètry od pólu. Im Hinblick auf die psychopoetischen Aspekte signalisiert die Theo-l o g i s i e r ung der poetischen Welt von Vétry od polú den Prozeß der Bewußtwerdung, der Stärkung des Bewußtseins. Im menschlichen Reflexionsakt wird der "Vater" und seine wunderbaren Geistesgaben - die Charismata Glaube, Hoffnung. Liebe - offenbar Laut Jung symbolisiert der Heilige Geist, wenn dem Menschen gegeben, das "faktische Gewordensein des Selbst". 333

Wie noch zu zeigen sein wird (Kap. 4.3), scheint den semantisch-axiologischen Kern von Vẻtry od polü die Auseinandersetzung Brezinas mit der paulinischen Theologie, im engeren Sinne mit den paulinischen Grundbestimmungen der eschatologischen Existenz-

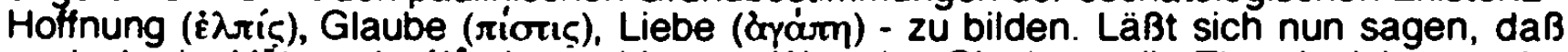
auch der in Vétry od pólư eingeschlagene Weg des Glaubens die Theo-logisierung der poetischen Welt nach sich zieht? Was sind die wichtigsten Schritte auf diesem Weg?

332 In achtzehn von zwanzig Gedichten von VP wird das Substantiv "zrak" ("Sehkraft") neununddreißigmal verwendet. Seine niedrigste Frequenz erreicht es hingegen in den Gedichtzyklen, in denen das $\mathrm{m}$ y $\mathrm{th}$ o g e n e Substrat von Bïezinas poetischem Denken am stärksten zur Geltung kommt: in Tajemné dálky und in Ruce. Das Substantiv "srdce" ("Herz"), das Organ der e motion ale n Erkenntnis, erreicht die höchste Frequenz im letzten vollendeten Gedichtzyklus Ruce. Vgl. P. Hoiman, Fraquenzwörterbuch des lyrischen Werkes von O. B., Teil II, S. 1171.

333 C.G. Jung, Zur Psychologie westlicher und östlicher Religion. Gesammelte Werke, Bd. 11. Zürich-Stuttgart 1963, S. 211. 
Der "Wille" ("vŭle") zur Verantwortung gegenüber dem Leben ist wohl der erste Schritt. Er signalisiert auch die Abwendung von der gnostischen Heterodoxie zur (neutestamentlichen) Theologie auf dem Wege des (positiven) $\mathrm{G} \mathrm{I} \mathrm{a} \mathrm{u} \mathrm{b} \mathrm{e} \mathrm{n} \mathrm{s} \mathrm{( \pi torı).} \mathrm{In}$ einem Brief vom 13. V. 1897 schreibt Bỉezina an A. Pammrová: "Záhada svobodné vưle symbolizuje mi němý rozkaz, abychom věrili $/ . .$. . Jen když věríme, Že se múžeme povzněsti, povznášime se. I... Víra v svobodnou vưli podmiňuje víru v zodpovědnost. Bez zodpovëdnosti neni etiky". ("Das Rätsel des freien Willens symbolisiert für mich den stummen Befehl, daß wir glauben sollen /.../. Nur wenn wir glauben, daß wir uns erheben können, erheben wir uns. I... / Der Glaube an freien Willen bedingt den Glauben an Verantwortung. Ohne Verantwortung gibt es keine Ethik"). Darüber hinaus betont Bïezina auch die Notwendigkeit des (sittlichen) Willens, nicht nur um das "Leben auf Erden zu vermehren und zu steigern", was als "Zweck des Geistes" begriffen wird "nebot úcelem ducha je rozmnożit a stupȟovat żivot na zemi“), ${ }^{334}$ sondern auch, um eigene "Seele strahlend und weiß zu machen" ("svou duši učinit záríci a bílou"). 335 Daß diese ethisch akzentuierten Formulierungen auch metapoetisch konnotiert sind, geht aus dem Kontext der zitierten Briefe klar hervor. Bỉezina spricht in innen ausdrücklich von der Notwendigkeit des Willens, um den Kampf mit dem "nächtlichen Dunkel" in der Seele überstehen zu können. 336 Allerdings deuten diese Formulierungen auch auf eine 'akute' Verdrängung der dekadenten Vergangenheit hin. Nun sieht Bỉezina auch in der "geistigen Lust" ("duchovni rozkos") die "Lockrufe der Dunkelheit" ("lákáni tmy"). ${ }^{337}$

Dieses 'ethische Korrektiv' hängt mit der 'Inthronisierung' der V a te r gestalt in Vĕtry od polü zusammen. Der "Ewige", der "Unerkannte", der "Höchste" wird nun zum ersten Mal auch als "Vater!" ("Ot‘̌!") apostrophiert: "A přece, mưj Otze!" (Kde jsem už slyšel?... I

334 O. Bỉezina an A. Pammrová (Brief vom 2. XII. 1897). Vgl. O. Błezina, .Dva listy”, in: Wiener Slawistischer Almanach, 4, 1979, S. 212.

335 Vgl. ibid., S. 211 (Brief vom 4. VII. 1897).

336 "A byla léta, kđy myšlenka na smrt vylézala a skrabala jako Łerný hmyz za zlacenými bilymimi tapetami luxerióznich komnat téch nejodváżnějš̌ich a nejdobrodružnějsich snéní! Ne že bych smrt volal; vím, že dokud żijeme v tomto svẻtẻ tisicerých zodpovédnosti, je tỉeba s veškerým napétím a heroismem, chcete-li, uvést $v$ sobẻ $v$ żivot všechno, co je schopno $v$ nás vyšsího života I... F. (Brief an A. Pammrová vom 2. XII. 1897, in: Wiener Slawistischer Almanach, 4, 1979. S. 212; -Und es kamen Jahre, in denen der Gedanke an den Tod herauskroch und kratzte wie schwarzes Insekt hinter vergoldeten weißen Tapeten der luxeriösen Gemăcher der kühnsten und abenteuerlichsten Träume! Nicht, daß ich den Tod gerufen hätte; ich weiß, solange wir in dieser Welt der tausenden Verantwortungen leben, ist es notwendig mit der ganzen Anstrengung und mit Heroismus, wenn Sie wollen, in uns alles ins Leben zu rufen, was in uns eines höheren Lebens fahig ist $/ . . . r$ ).

337 Wie ist dieser 'ethische Akzent' zu deuten? Es scheint, daß hier - im Hinblick auf die individualpsychologischen Faktoren - eine nicht unbedeutende Rolle der Abbruch der Korrespondenz mit František Bauer (Herbst 1895; später schrieb Biezina nur noch zwei Briefe an Bauer, im Oktober 1897 und im Juli 1901) spielt. Den Passus über die Liebe aus dem vorletzten Brief an Bauer (23. X. 1897) kann man durchaus als Bïezinas 'Konfession' seines eigenen Liebesgefühls lesen. Die Sehnsucht "der Begierden schwarzen Wein" zu trinken ("Cerné víno tuh", Motiv z Beethovena / Ein Motiv aus Beethoven, VIII, 4) oder Vorstellungen wie "zweier nackter Arme gierige Umschlingung" ("nahỷch ramen dvou jak chtivé sepęti", ibid., IX, 2), wăren jetzt undenkbar. Bereits in Vladarí snü (Die Herrscher der Träume) wird die zitierte, deutlich sexualisierte Vorstellung aus dem Gedicht Motiv z Beethovena durch die spiritualisierte "Sehnsucht nach der Umarmung der Seelen. zart wie das Zusammenfließen der verbrüderten Farben" ("nemocni touhou po objeti duši, jemném jak sliti paprskú zbratỉených barev!", IV. 3) und durch den "Hymnus an reinen Kuß" sublimiert ("Hymnus jste zapéli cistému Políbeni", IV, 4; an Stelle des vampirhaften Kusses der geradezu wollüstigen Thanatophilie in Motiv 2 Beettiovena: "má piseñ pohrebni ti sladká na rty padne / a v jednom pocelu tvé żití vypije", XI, 4; "wird mein süßes Grablied auf deine Lippen fallen / und in einem Kuß dein Leben aus dir trinken"). Aber in der Schaffensphase von VP ("ale dnes, kdy jsem o rok silnějši" / "doch heute, wenn ich um ein Jahr stärker bin") begreift Bỉezina die Lust als "lákáni do tmy" ("Lockrufe der Dunkelheit"; man denke nur an die 'Lockrufe' in Motiv z Beethovena und in den Briefen an F. Bauer aus den Jahren 1893-94!). Nun betont Bỉezina in den Briefen an Pammrová die primåre Piticht ("prvni povinnost") der beiden Geschlechter, die "Seele strahlend und weiß zu machen" ("duši učinit záricí a bilou": Brief vom 4. VII. 1897), und die Askese: $\%$... muži transcendentnich snah sluši jediné askese. A Ženè také" (" $/ . . /$ aber dem Manne tranzendenter Ambitionen steht einzig und allein die Askese. Und der Frau auch". Vgl. ibid.). 
Wo denn vernahm ich schon?..., V. 27; "Und dennoch, mein Vater!"). "Nejvyšši! Oť̌e nezrozeného!" (Poledni zráni I Mittäglich Reifen, V. 1; "Höchster! Vater des Ungeborenen!"). "/.../ pred otcovskỷm pohledem Nejuššiho" (Královna nadéji / Die Königin der Hoffnungen, V. 56; "/.../ vor dem väterlichen Blick des Höchsten"). Die höchste Autorität wird hier mit einem Namen gerufen, der eine signifikante Bezeichnung Gottes bedeutet. Es ist gerade die eschatologische Dimension, die der Anrufung "Otč!" ("Vater!") inre spezifische Semantik verleiht. Wie J. Jeremias betont, realisiert das Neue Testament die Rückkehr der Vater-Figur im Gebet Jesu ("Abba läßt sich mit "Lieber Vater!" übersetzten). ${ }^{338}$ Nach Jeremias ist das eschatologische Reich untrennbar mit der $V$ a te r schaft verbunden. Das Gebet beginnt mit der Invokation des Vaters und fährt fort mit den Bitten, die den Namen, das Reich und den göttlichen Willen symbolisieren und die in bezug auf die postulierte eschatologische Erflüllung verständlich sind. Jesus apostrophiert Gott als Vater (Math. 6, 9-13; Luk. 11, 1-4), er wendet sich an Gott, so wie sich ein Kind an seinen Vater wendet. Dieses Wagnis ist möglich, weil die neue Zeit begonnen hat. $339 \mathrm{Im}$ Geist sind Vater und Sohn durch eine Gemeinschaft vebunden, daher können wir "Abba!" rufen: " /../ ihr habt einen kindlichen Geist empfangen, durch den wir rufen: Abba, lieber Vater! / Der Geist selbst gibt Zeugnis unserem Geist, daß wir Gottes Kinder sind" (Römer 8, 15-16).

Die "Du-Wir"-Beziehung von Svitáni na západẻ wird in Větry od polù um die Vatergestalt bzw. um die Vater-Sohn-Beziehung bereichert. Wie manifestiert sich aber diese Vatergestalt? Seine Erscheinungsweise indiziert bereits die Titelmetapher: Větry od pollu (Polanwinde). Der Odem ("větry" $/$ Winde") Gottes konnotiert jedoch in Vètry od pólü den vereisenden, aus den Psalmen oder Propheten-Büchern bekannten "Polanwind": "Ja, der Mensch ist wie Gras /.../. Geht des Windes Hauch darüber hin, / Ist's fort, und seine Stätte weiß nichts mehr von inm" (Psalm 103, 15-16). "Alles Fleisch gleicht dem Gras / Und alle seine Pracht der Blume des Feldes: / Es verdort das Gras, es welkt die Blume, I Fährt Gottes Odem über sie hin“ (Jesaja 40, 6-7). Es ist nicht Gott als gütiger Vater, sonden (alttestamentlicher) Gott als rätselhafte und furchteinflößende Macht, der der Mensch in seiner Vergänglichkeit ausgeliefert ist und vor der er in seiner Nichtigkeit verstummt. Der Titelmetapher 340 liegt offensichtlich die Idee der Theodizee zugrunde. Die Vorstellung vom frostigen, vereisenden Hauch des unheimlichen "Jemandes" ("Nékdo") kommt bereits in Svitáni na západè.vor: "Na kolik rủžových úsmèvú dechl svưj podzemní chlad?" (Legenda tajemné viny I Die Legende der geheimnisvollen Schuld, III, 4; "Wieviel rosenatmendes Lächeln hat je sein Grabhauch vereist?"). In Vẻtry od polü gleicht der Odem des "Höchsten" einem Sturm, "der Welten aus den Wurzeln reißt" (Boure / Der Sturm, IV, 2; "jeż světy vyvraci"), er wird aber nicht (mehr) als dunkles und rätselhaftes Schicksal, wie etwa in der zitierten Legenda tajemné viny (Die Legende der geheimnisvollen Schuld) oder in Slyšim v duši (Ich höre in der Seele), resigniert hingenommen, sondern (im Sinne der Christologie) als der "heilige Wille" des "Höchsten", der den Gehorsam und die Demut fordert, bejaht: "Byla tvá vủle, o Vécný. Pokorné lëtó tvé zpivám" (Poledni zráni I Mittäglich Reifen, V. 41;"Es war dein Wille, o Ewiger! Demütig singe ich deinen Sommer!"). Der Akt der Bejahung des "heiligen Willens" scheint auch, in einem gewissen Sinne, die Antwort aut die Theodizee in sich zu bergen. Laßßt der "Vater" das Böse zu, um - am Ende der Zeiten, d. $h$. in der eschatologischen Zukunft - das Gute triumphieren lassen zu können?341

$338 \mathrm{~J}$, Jeremias, Abba. Untersuchungen zur neutestamentichen Theologie und Zeitgeschichte, Göttingen 1965.

339 Laut R. Bultmann sind die ersten der drei Bitten des Vaterunsers (nach dem Matthäustext) vermutlich eschatologisch gemeint, "sie bitten, daß die Gottesherrschaft kommen mőge, da Gottes Name geheiligt und sein Wille auf Erde ertült wird". Vgl. R. Bultmann, Jesus, Tübingen 1988.

340 Zur Funktion und Bedeutung der oxymoralen Semantik bei Bỉezina vgl. die Darlegung im einleitenden Kapitel (3) zu Svitáni na západé.

341 Signifikanterweise erwāhnt Bỉezina in der Korrespondenz mit A. Pammrová gerade die Idee der "prädestinierten Harmonie" von Leibniz: "Ovšemže vývoj života jde svým odvěkým vinẻnim, v mystickém vlivu Casu, a Leibnizova predestinovaná harmonie, tak záhadná u Leibnize samotného - všimnète si napí. jeho listủ - nabývá z téchto mist myšlenky nových, do netušené hloubky prolomenych perspektiv". (Brief vom 2. XII. 1897; O. Bfezina, Dva listy", in: Wiener Slawistischer Almanach, 4, 1979, S. 212-213; "Gewiß verläuft das Leben in seinen uralten Sctwingungen, unter dem mystischen Einfluß der Zeit, und die prädestinierte Harmonie von 
"A přece bude naposled světlo. / A bolestné výkřiky naše zvoniti budou jednou jak včely, / když bliži se $k$ ülüm se sladkostí medu, jež sebraly na nivách věkủ. I... / A v tichu bolesti své at' slyšime suméti $v$ duši mystické prameny světla, / nebot' bolest a svétlo jsou formami jediné vibrace tajemstvi tvého!" (Modlitba za neprátele / Das Gebet für die Feinde, V. 32-33, 47-48; "Und dennoch wird am Ende Licht sein. I Und unsere qualvollen Schreie werden dann läuten wie Bienen, / wenn sie schwirren heran zu den Körben mit der süßen Beute des Honigs, den sie gesammelt auf den Gefilden der Zeit. i.../Gib, daß wir in der Stille des Schmerzes hören durch unsere Seele rauschen die mystischen Quellen des Lichts, / denn Schmerz und Licht sind beide Formen der einen, der gleichen Schwingung deines Geheimnisses nur!" Übers. v. Franz Wertel.)

Durch eigenes Leid partizipiert der Mensch auch an der Glorie des "schöpferischen Leides" des "Ewigen": "A my všichni, nesmrtelni tvou vưli, bolestí svoji / tvé bolesti sdílime slávu!" (Kdyżz z lásky tvé... I Wenn aus deiner Liebe..., V. 27-29; "Und wir alle, unsterblich durch deinen Willen, / durch unseren Schmerz / nehmen wir Teil an der Glorie deines Schmerzes!"). Durch das Prisma des "heiligen Willens" läßt sich auch die paradoxoxymorale Semantik von "Větry od pólü" deuten. Ja, auch hier birgt das Negative sein positives Gegenteil in sich, aber das Konzept der Positivierung des Negativen wird in Vétry od pólú im christologischen Sinne und aus der Perspektive der Grundbestimmung der eschatologischen Existenz weitergedacht. Der frostige "Polarwind" (Odem) des strengen "Vaters", der ganze "Welten aus den Wurzeln reißt", wird als "heiliger Wille", als Walten des "Ewigen" begriffen und gerechtfertigt. Der "heilige Wille" wird manifest sowohl im Prolog- (Vládnouci...I Herrscher...) als auch im Epilog-Gedicht (Kdyż z lásky tvé... I Wenn aus deiner Liebe...). die als Quasi-Gebete an den "Vater" kodiert sind, gerechtfertigt. Es scheint kein Zufall zu sein, daß es gerade die paradox-oxymorale Vorstellung des Sieges in der Niederlage ist, die der Sinnstruktur der beiden Texte ihre Prägnanz verleiht. Das Walten des "Vaters" weist auf die eschatologische Zukunft hin (s. o. das Zitat aus Modlitba za neprátele / Das Gebet für die Feinde), es stellt den Menschen schon hic et nunc vor die (freie) Entscheidung nach dem Willen des "Ewigen" zu handeln. Die Hingabe an seinen Willen bezieht sich in erster Linie auf das Gebot der Liebe, denn sowohl die Menschenliebe als auch die Feindesliebe werden nicht nur in der neutestamentlichen Theologie, sondern bereits in der heidnischen Literatur ale eine der höchsten Tugenden betrachtet. Diese (christologische) Auffassung der Liebe als Pflicht und Gehorsam bestimmt die Sujetlogik aller Schlüsselgedichte von Vètry od poliu: Modlitba za neprátele (Das Gebet für die Feinde), Bratrstvi vêrícich (Die Bruderschaft der Glaubenden), Poledni zráni (Mittäglich Reifen), Diouho stáli...(Lange standen sie...), Láska (Die Liebe), Koyż z lásky tvé... (Wenn aus deiner Liebe...). Es sind die Charismata des

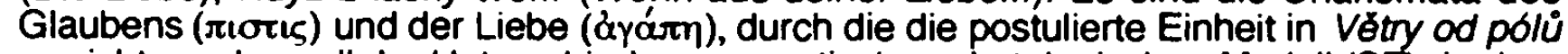
erreicht werden soll. Im Unterschied zum gnostisch-eschatologischen Modell (SZ), in dem die postulierte Einheit durch die Erkenntnis ( $\gamma v \omega \sigma i s)$ erreicht werden soll, verschiebt sich

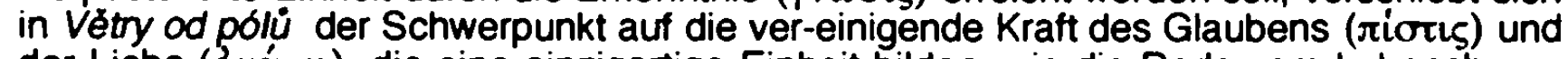
der Liebe ( $\alpha \gamma \alpha \dot{\tau} \eta)$, die eine einzigartige Einheit bilden, wie die Rede vom Lebensbaum (Joh. 15, 1-17) zeigt. In Bratrstvi verícich (Die Bruderschaft der Glaubenden) heißt es:

"/... / silili jsme šilenstvim lásky, jež byla modlitbou k Nejvyšsimu. /.../// I thali jsme svá opojeni, jak zma na jediném mystickém hroznu, / jeż dotknutim pukala vytryskem jednoho vina: / jablka jednoho stromu, jež rozriznuta společnou, naši krvi se zardi, / polibky jediné noci, v nichž duše zpivaji o smrti a budoucich żitich I...r. ("I... wir rasten im Wahnsinn der Liebe, und sie war das Gebet zum Höchsten. I.../ // So pflückten wir unsere Berauschung wie die Beeren eines einzigen mystischen Weinstocks, / die bei der Berührung aufsprangen im Ausbruch eines einzigen Weines: I Apfel eines Baumes, zerschnitten, errötend von unserem gemeinsamen Blut, Küsse einer einzigen Nacht, drin Seelen singen von Tod und künttigen Leben /... $/$ ).

Was aber geschieht mit dem gnostischen Substrat? Es wird, im Sinne der paulinischen und der johanneischen Theologie, in die schon erwähnten Charismata der eschatologischen Existenz integriert. Durch diese Integration realisiert sich das Charisma

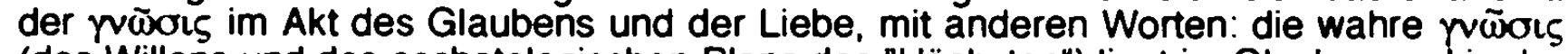
(des Willens und des eschatologischen Plans des "Höchsten") liegt im Glauben und in der 
Liebe. ${ }^{342}$ In diesem Sinne transmutiert in VP auch die Kraft, die "Stärke" der "Starken". das (Geheim-)Wissen der gnostisierenden Pneumatiker (Vino silných / Der Wein der Starken. SZ), zur Glaubenss tärke der eschatologischen 'Bruderschaft' der Glaubenden.

An dieser Stelle muß noch eine der Hauptfragen beantworten werden, die sowohl mit der hier aufgestellten These von der Theo-logisierung der poetischen Welt als auch mit der Problematik der (eventuellen) Fortsetzung bzw. der (eventuellen) Neutralisierung der 'Spur' des gnostischen Denkes in Vètry od pölú aufs engste zusammenhängt: Die Frage nach der Gestalt des Erlösers, Jesus Christus, in Br̈ezinas Werk, vor allem in seinem theo-logisch-eschatologischen Modell. Es wurde in diesem Kontext der Begriff "christologisch" erwähnt. Wo und wie manifestiert sich aber die Gestalt Christi bei Bíezina? Die Gestalt Christi im theo-logisch-eschatologischen Modell koinzidiert. $m$. E., mit dem (Johanneischen) Logos ( $\lambda o ̛$ os)-Begriff. Vor allem die Schlüsselsäzte: "In inm

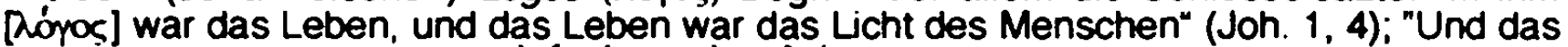

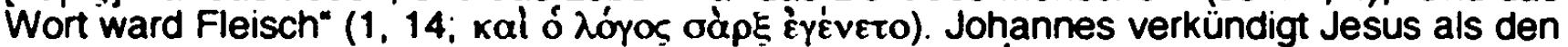
Fleischgewordenen. Jesus als Mensch ist der $\lambda$ óos als Offenbarer (in der Menschlichkeit). Der Erlöser hat sich als Logos in Menschengestalt in die tellurische Welt begeben. ${ }^{343}$ Das "Licht" des "Logos" versteht Bultmann als Erhellung der eigenen Existenz, 344 die das göttliche Geschenk ist. Jesus ist bei Johannes das Licht als der Offenbarer, "der dem Menschen dasjenige Veständnis seiner selbst schenkt, in der er das Leben hat".345 In diesem Sinne versteht Bultmann den Ruf des Offenbarers als

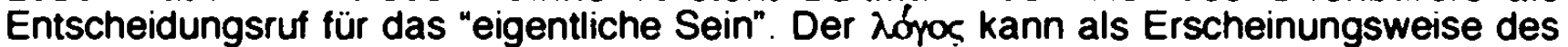
Seins des Menschen, der von inm getragen wird, begriffen werden. Es ist offensichtlich das "erlösende Wort" ("Vysvobozujici slovo"), in dem sich der Erlöser in Bïezinas Werk manifestiert und, wie es scheint, auch als 'Vermittler' zwischen dem "Höchsten" und der Menschenwelt fungiert. ${ }^{346}$ Die Begegnung mit dem "Höchsten" vollzieht sich in seinem "Wort", das in der Predigt Jesu ausgesprochen wird. Und Jesus Christus bedeutet das eschatologische Ereignis. 347 Läßt sich die Suche des Dichters nach dem "großen und

Leibniz, so geheimnisvoll bei Leibniz selbst - denken sie z. B. an seine Briefe - erlangt vom Fluchtpunkt des Gedankens, neue, in ungeahnte Tiefe durchbrochene Perspektiven").

342 Vgl. hierzu: "Ich ermahne euch aber, liebe Brüder, durch unsem Herm Jesus Christus und durch die Liebe des Geistes, daß ihr mir kämpfen helft durch eure Gebete für mich zu Gott" (Römer 15,30).

343 Die Identifikation des menschgewordenen Erlösers mit Jesus hat, nach Bultmann, ihren Ursprung in den christlich-gnostischen Systemen. Sie wurde schon sehr früh vom Christentum übernommen und für die Christologie fruchtbar gemacht. Vgl. R. Bultmann. Das Evangelium des Johannes, Göttingen 1986, S. 10f). Bultmann macht auch auf die zahlreichen gnostischen Metaphern in der Offenbarungsrede des Johannes aufmerksam, sei es die Metapher vom Erloser als Tür und als Hirte, der die Schafe (= die Erlosten) heraustührt oder (u. a.) die Metapher vom Türhüter. (Ibid.. S. 279-281). Trotz vieler Gemeinsamkeiten zwischen dem johanneischen Christus und dem gnostischen Erloser gibt es auch sehr gravierende Unterschiede Johannes verkündigt Jesus als den Fleischgewordenen, was für die Gnosis völlig undenkbar wäre, weil sie keine wirkliche Inkarnation kennt und den leiblichen Tod Jesu nicht denken kann. Darüber hinaus erscheinen in den gnostischen Texten verschiedene Erlöser-Konzeptionen, die die Vorstellung von Christus als dem Ërlöser durchaus sekundăr machen. Vgl. K. M. Fischer, Tendenz und Absicht des Epheserbriefes, Berlin 1972. S. 176ff. Das Ziel der gnostischen Erlösung ist die Selbsterlosung durch die Erkenntnis des Göttichen in sich selbst.

344 Ibid. S. $21 \mathrm{ff}$.

345 Ibid., S. 25.

346 Aus den Äußerungen Biezinas geht hervor, daß er den $\lambda$ ínus mit dem Christentum, mit der christlichen Kultur kat exochēn, identifizierte: "Je to pokracováni antické, staré kuttury ǐecké a fímské. Logos". (J. Deml, Mé svédectvi o Otokaru Blezinovi, Praha 1931, S. 293: "Er ist die Fortsetzung der antiken, alten griechischen und römischen Kultur. Der Logos"). \% ... cirkev rimská má svúj základ v Logos, v ni pracuje Logos. Slovo; to je tajemnějši, hlubši, nebot Logos tu byl, jest a bude, i kdyby ani nebylo Pisma". (Ibid., S. 429; $\%$... die rómische Kirche hat ihr Fundament im Logos; in inr wirkt der Logos, das Wort; es ist geheimnisvoller, tiefer, denn der Logos war hier, ist hier und wird hier sein, auch wenn es die Heilige Schrift nicht gäbe").

347 "Wahrtich, wahrtich, ich sage euch: Wer mein Wort hört und glaubt dem, der mich gesandt hat, der hat das ewige Leben und kommt nicht in das Gericht, sondem er ist vom Tode zum Leben hindurchgedrungen" (Joh. 5, 24). Nach Bultmann ist das eschatologische Ereignis deshalb "einmal 
mächtigen Wort" ("velké a mocné slovo"), das "die von der neuen Sonne überfluteten Landschaften öffnet" ("otvirajici krajiny zatopené novým sluncem"), nicht existential interpretieren? Als Suche nach der 'neuen', von den Schatten der dekadenten Vergangenheit völlig befreiten 'lichten' Existenz unter dem Signum der Einheit von Sein und Logos? Das enwähnte Postulat des Willens zum ethischen Sein scheint diese These zu unterstützen. Signifikanterweise erbittet sich das dichterische Ich in Poledni zráni vom

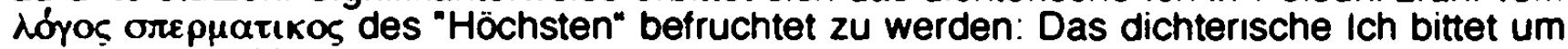
ein neues und höheres (man könnte sagen ethisch determiniertes) Sein in (Bruder-)Liebe und Reinheit:

-Žhavým svým destęm, / v nẻmż zkvetia a svadla staletá setba mých otcủ, duši mou zaplav! I.../ Tkani mých myšlenek vybél mi v labuti cistotu plátna a šupiny vosku bilými učiñ, než do forem naleju svice! Chci plakati světtem!" ("Mit deinem glühenden Regen, / darinen blühte und welkt' die uralte Saat meiner Väter, überschwemm' meine Seele! /.../ Bleiche zur Schwanenweiße des Linnens meiner Gedanken Webe! Mach weiß mir die Schuppen des Wachses, / eh ich die Kerzen gieße in Formen! Licht will ich weinen!").

Die Tendenz zur Spiritualisierung und Theo-logisierung der poetischen Welt tritt in einigen, in diesem Gedichtzyklus sehr dominanten symbolischen B il d f e I d e r n klar zutage. Es sind: Symbolik des Lichtes, der Heiligkeit und die Grundbestimmungen der eschatologischen Existenz: Hoffnung - Glaube - Liebe. Im weiteren werden diese Bildfelder (Paradigmen) in drei Kapiteln eingehender erörtert.

\subsection{Symbolik des Lichtes: Die Rationalisierung des Mythischen}

„Svertlo umírá jenom príchodem ještě většího světla.

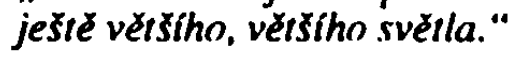

„Das Licht stirbt nur beim Nahen größeren Lichtes. eines noch größeren. größeren Lichtes."

O. Błezina: Pfíroda (Natur, 1897)

Wie bereits angedeutet, geht mit der Tendenz zur Theo-logisierung (in VP) auch eine gewisse Rationalisierung der poetischen Welt einher: Die Rationalisierung meint hier jedoch keineswegs die Auflösung des Mythischen, denn auch das in diesem Zyklus modellierte Weltbild weist mythische Elemente auf: Es besteht aus Himmel, Erde und Meer, ist dreistufig bzw., da unter der Erde die (moderne) Unterwelt gedacht wird (Mésto I Die Stadt: Nocil I Nächte!), vierstufig. Die 'Machtattribute' des "Herrschers" der Welt sind Stürme (Bouie I Der Sturm). Donner, Blitz. Wolken, Polarwind oder glühender Odem (Poledni zráni I Mittäglich Reifen; Kode jsem uz slyšel?... I Wo denn vernahm ich schon?.... Bratrstvi vérícich / Die Bruderschaft der Glaubenden. Vládnouci / Herrscher u. a.) sowie astrale Omnia (Letni slunovrat / Sommersonnenwende). Die Welt durchwalten auch hier Geister und sonstige "höhere" Zwischenwesen: "krídla bytosti yyššch údery svými dávala rytmus jich krokưm" (Śtastni I Die Glücklichen, V. 22; "der Fittich höherer Wesen spannte den Rhythmus ihrer Schritte"). Vielmehr scheint es, daß das in 'Tajemné dálky und in Svitáni na západé wirkende mythogene Substrat in Vétry od polü in ein - wenn man das so sagen darf - 'rationales' Gewand gekleidet wird. Zu dieser Strategie gehört die philosophische Akzentuierung des Mythischen in VP.348 Der

für allemal" eschatologisch, weil der $\lambda$ ójos zum Ereignis hic et nunc in der lebendigen Stimme der Predigt wird. R. Bultmann, Jesus Christ and Mythology. New York 1957, S. 82ft.

348 In Kde jsem už slyšel...? (Wo denn vernahm ich schon...?) oder in Magickè pülnoci (Magische Mitternāchte) wird die Platonsche anamnēsis-Lehre (Menön. Phaidön) thematisiert; in Piseñ o słunci, zemi, vodách a tajemstvi ohné (Das Lied von der Sonne. Erde, den Wassern und vom Geheimnis des Feuers) schwingt die Lehre von den vier Urelementen von Empedokles, die zu Einem durch die Liebe vereinigt werden, mit. Der zur Vollendung der eschatologischen Existenz führende ProzeB manifestiert sich in Vètry od polú als durchdachte und kunstvolle Verknüpfung kosmologischer, ekklesiologischer, christologischer, phänomenologischer und sogar naturwissenschaftlicher Elemente. Der ganz offensichtliche Rekkurs auf Platon (Kde jsem už słyšl?...; vgl. hierzu Bỉezinas Brief v. 28.VI. 1896 an A. Pammrová, in: Dopisy O. Breziny A. 
Zusammenhang zwischen Mythos und Rationalität kommt deutlich zur Geltung, wenn etwa in der naturphilosophischen Darstellung der Weltentstehung - die das Mythische begrifflich ausarbeitet - die E I e m e n te Erde, Wasser, Feuer ${ }^{349}$ (Pisen o slunci, zemi, vodách a tajemstvi ohnè I Das Lied von der Sonne, Erde, den Wassern und vom Geheimnis des Feuers) durch das machtvolle "Wollen" des "Höchsten" entstehen. In diesem Sinne wird auch die Lebenswelt (xóouos) als 'Produkt' des weisen Will e n s des "Vaters" begriffen. Dieser Gedanke wird geradezu demonstrativ im Prolog- und im Epilog-Gedicht von VP explizit zum Ausdruck gebracht: "Vládnouci, jenž rozkazem svẻtla I vyslal jsi nesčetné dni a nesčetné noci I... ${ }^{\prime}$ (Vládnoucil Herrscher, V. 1-2; "Herrscher, der mit dem Befeh/ des Lichtes / entsandt unzählige Tage und unzählige Nächte /... ). "Kdyż z lásky tvé vyšlehnou svètelné proudy tvé vưle, / slavné a těž̉kẻ jak tisicú životủ żivot, /a z prostoru vyrústá prostor sršica světy I... $\mu^{\mu}$ (Kdyż z lásky tvé / Wenn aus deiner Liebe, V. 13; "Wenn deiner Liebe entwallen die Lichtströme deines Willens, / feierlich schwer, wie Leben von tausend Leben, I und wenn Raum aus Raum sich gebiert, überkochend von Welten $(\ldots$, ). Der "höchste Schöpfer" ist die Inkarnation des Willens. Er muß sich selbst offenbaren, seine Befehle bekanntgeben. Der einzige Weg den "Höchsten" zu erkennen, mit inm zu verkehren, ist die Erfüll ung seiner Befe hle und die Befolgung seines Willen s: "Opojeni vక̌ech budoucich snü, jež rozkvetou v horících duhách I novymi slunci na oblacích tvého dechu nesmrtelného! / Věčná ví̄eni némých bleskủ, jimiž pỉeletaji rozkazy svaté tvé vưle l..." (Kde jsem uż slyšel?... I Wo denn vernahm ich schon?..., V. 19-21; "Rausch aller küntigen Träume, die in flammenden Regenbogen / als neue Sonnen am Himmel deines unsterblichen Hauches erblühen! / Ewiger Wirbel der stummen Blitze, in dem deines heiligen Willens Gebote fliegen /.../.") "Byla tvá vưle, o Věcnỳ! Pokornẻ léto tvé zpivám!" (Poledni zráni / Mittäglich Reifen, V. 41; Dein Wille war es, o Ewiger! Ich sing deinen Sommer in Demut!"). Das R a t i o nale des in Větry od pólü modellierten Weltbildes koinzidiert aufs engste gerade mit dem "Willen" und dem Bewußtsein. Dadurch kommt, so scheint es, auch das spezifisch $T$ h e o- I o g i s che des in Vëtry od pólü konstituierten poetischen Welt-Modells zur Geltung: die Darstellung und die Auffassung der Menschenwelt als Numen, als Wille und Walten des absolut transzendenten Gottes (im Mysterium der Trinität), des "Höchsten", in der Sprache Biezinas, und als Orientierung dieses Waltens auf ein Eschaton hin.

Als Synonym des $R$ a ti o nalen. BewuBten und des Willens fungiert in VP das "L i c h t" ("svétlo"), das frequentierteste Substantiv des gesamten Zyklus. Doch gerade im Zusammenhang mit der Logos/Licht-Symbolik von VP sollte man nicht die Trennung des Transzendenten vom Immanenten vergessen. Dem Mythos ist zwar der Unterschied zwischen einer transzendenten und immanenten Sphäre nicht fremd, aber die Trinitätsidee, die für das theo-logisch-eschatologische Modell von besonderer Relevanz ist, sowie die gerade diesem Modell obwaltende "Vater"-Gestalt, sind absolut transzendent und können niemals ein Gegenstand der Erfahrung sein. Es ist kaum vorstellbar, daß der Mythos, der dem Bildhaften verpflichtet ist, sich in derart abstrakter Weise ausdrücken

Pammrové. Praha 1931, S. 114.115) scheint keinesweg zufällig zu sein. In seinem Dialog Gorgias äußert Platon das Verlangen nach Ordnung und Maß. Das Grundprinzip sowohl der stoffilichen als auch der moralischen Welt ist, wie Platon zeigt, die Dreiheit von Vernunft (Logos), Gesetz (Nomos) und Ordnung (Taxis). Auf dieser Dreiheit gründen auch Schönheit, Wahrheit, Moralität. Sie durchwirkt die Kunst, Wissenschaft und Politik. In der Seele erscheint sie als Mäßigkeit (Sophrosyne) bzw. Gerechtigkeit. Diese Dreiheit ist auch die Gewähr für die Menschenwelt (Kosmos) als ein Ganzes und Geordnetes. (Platon, Gorgias, Sämtliche Dialoge, Bd. 1, Leipzig 1922-1923. S. 507ff.) Die Einheit und das Gute bilden den fundamentalen Charakter des Göttichen.

349 Wie C.G. Jung erwähnt, stellten die alten Naturphilosophen die T rin it ät als eine Einheit von drei 'unkörperlichen' Elementen - Wasser, Luft und Feuer - dar. Das vierte Element war das Sómaton (Körper), symbolisiert duch die Erde (s. Piseñ o stunci, zermi, vodách a tajemstvi onnè I Das Lied von der Sonne, Erde, den Wassern und vom Geheimnis des Fevers). C.G. Jung. Zur Psychologie westlicher und ostlicher Religion, Gesammelte Werke, Bd. 11, Zürich-Stuttgart 1963, S. 68. Der trinitarische Gedanke ist bereits in Timaios von Platon enthalten. Der Gegensatz von Feuer und Erde, aus denen Gott den Weltkörper bildete, wurde durch ein Mittleres gebunden: "So stellte denn Gott Wasser und Luft in die Mitte zwischen Feuer und Erde und stellte unter innen die Proportion in möglichster Genauigkeit her, so daß, wie sich Feuer zu Luft, so Luft zu Wasser, und wie Luft zu Wasser, so Wasser zu Erde verhält. Auf diese Weise formte und fügte er den Weltbau zusammen zu einem sichtbaren und fühlbaren Ganzen“. Plato. Timaios, 32 BC, hrsg. v. O. Apelt, Leipzig (Philosophische Bibliothek, 179) 1922, S. 49 f. 
würde. 350 Denn der Mythos beruft sich auf die immanente Erfahrung. der Logos auf das Begründen und Beweisen. Der Logos ist mit der Forderung, für alles eine Begründung und einen Beweis zu geben, in die Welt getreten. Und der Logos ist das "Lebens I i c $\mathrm{h} \mathrm{t}$ ". Es ist aber nicht nur die Trinitätsidee von Vater, Sohn und Heiligem Geist, sondern auch die Trias jener drei grundsätzlichen Bestimmungen der eschatologischen Existenz, der Charismata Glaube-Hoffnung-Liebe und die tri a dische Einheit von Leib, Seele und Geist, ${ }^{351}$ die das theo-logisch-eschatologische Weltmodell von Vétry od polui bestimmen.

Die Spiritualisierung der Phänomene der (ursprünglich) stofflichen, immanenten Welt, erscheint als eine der wichtigsten, sinnzentrierenden 'Strategien' des theo-logischeschatologischen Modells. Mit besonderer Prägnanz tritt diese Tendenz in Pr̈roda (Natur) zutage. Die sensorisch wahrnehmbare, in Materie eingebettete natura naturata der 'leiblich' konstituierten Entitäten, erscheint hier als 'Vor-Form' der geistigen Natur, als 'VorRaum' der transzendenten Sphäre: des Reiches des Geistes. ${ }^{352}$ Daher kann das die äußere Natur beleuchtende, lebensspendende Licht vom "höheren, viel höheren Licht" verzehrt werden: "Světlo umirá jenom príchodem ještě většího světla / ještě většího, většino světla" (II, 6-7; "Das Licht stirbt nur beim Nahen größeren Lichtes, / eines noch größeren, größeren Lichtes".) Was geht hier vor sich? Die materiell belastete Natur wird im theo-logisch-eschatologischen Welt-Modell nicht mehr zu einem $k$ u $n$ s $t$ vollen Artefakt denaturiert, wie dies in der Schaffensphase des dekadenten Symbolismus (Tajemné dálky I Geheimnisvolle Fernen: Gedichte Apostrofa podzimni I Herbstapostrophe, Vèzeñ / Der Gefangene u. a.) der Fall war, sondern das Natur-Sein wird nun zu Licht/Geist verklärt, d.

350 "Nebot' i ty, o Věčnỳ a Trikkráte Svatỳ, / v propastech svěho nitra, / kde tisice vesmirư mrtvých a budoucich drimá, / chovás svưj sen / a k němu se bližiš úzkosti lásky / tajemstvim věkü" (Kdyż z lásky tvé... I Wenn aus deiner Liebe..., V. 21-26; "Denn auch Du, o Ewiger und DreimalHeiliger, I in den Schluchten Deines Innern, I wo unzählig verwest und keimende Welten schlummern, / wiegst deinen Traum, / durch das Wunder der Zeiten beugst Du Dich über ihn / mit dem Augenblick der Liebe").

351 Nur im Zusammenbestehen dieser drei Kategorien (corpus, anima und spiritus) ist die auch psychologische - Ganzheit und Totalität des Menschen denkbar. Die in bestimmter (physisctien) Gestalt fixierte Leibhaftigkeit scheint eine Bedingung für die stoffenthobene geistige Existenz zu sein. Daher sind in Vêtry od polü auch die Motive der sozusagen physischen 'Leiblichkeit' zahireich vertreten, insbesondere im Zusammenhang mit dem Schmerz - und BlutMotiv. Durch den "Schmerz" ("bolest") wird sich der Mensch immer wieder seiner äußerlich leiblichen Konstitution als einer spezifisch materiellen bewußt. Das "Blut" ("krev") ist die Substanz des Leibes, es bedeutet seine Beseelung (Blut = Seele). Es ist signifikant, daß in den Gedichten von VP der sinnlichen Manifestation der Leiblichkeit ihre unmittelbare Vergeistigung und Enthebung in die transzendente Sphäre der vollkommenen Selbstlosigkeit und Lichthaftigkeit folgt. "Bez bolesti neni svêtla", schreibt Błezina an Pammrová ("Ohne Schmerz gibt es kein Licht", Brief v. 25.IX. 1896, in: Dopisy O. Bíeziny A. Pammrové, Praha 1931, S. 132; "\% / / trpíme bolesti vzrústu. mystického mohutněni pro príšti załe $/ \% /$... wir leiden durch die Schmerzen des Emporwachsens, des mystischen Stark-Werdens für den zukünttigen Glanz"): "V broušené oceli naši a neprátel našich odráżís jedno slunce všech jiter, / a semeni z rukou krvácejicich dávás vykvésti lilijemi. I... I A piece bude naposled světlo!" (Modlitba za neprátele / Gebet fúr die Feinde, V. 28-29, 31; "Im geschliffenen Stahl unserer Schwerter und der Schwerter der Feinde entzündest du eine Sonne aller Morgen, / und den Samen von blutenden Händen lässest du aufblühen als Lilien. /.../ Und doch wird am Ende Licht sein!"). "/... na bledých tvárích vž̉ala se nádhera krve / a stoupánim $k$ výši opilé srdce pělo svou piseñ / o slunci, zemi vodách a tajemstvi onnè. I.../ a bolest tisícủ tam bloudi a láme vasé krvavé, chvici se květy, I a nahỷma rukama vythává ze žhavé koruny jejich listi jak $z$ rưżi, I a házi je změněné v svétlo a vưni / na cestu dusí:. (Píseñ o slunci, zemi, vodách a tajemsti onnè / Das Lied von der Sonne, Erde, den Wassern und vom Geheimnis des Feuers, V. 66-69: $\%$... auf bleichen Wangen erlohte die Pracht des Blutes / und steigend zur Höh sang Herz voller Rausch sein Lied von der Sonne, der Erde, den Wassern und vom Geheimnis des Feuers. I.../ und der Schmerz von Tausenden irrt dort und bricht eure blutigen, bebenden Blüten, / und mit nackten Händen reißt er aus ihrer glühenden Krone Blatt um Blatt wie aus Rosen / und wirft sie verwandelt zu Leuchten und Duften / auf den Weg der Seelen").

352 "Smutek dávného żití, z něhož jsem vyšel, dechi mi z vưni, / a z hovoru stromú a z těžkého zvonẻni hmyzu nad vodami, I a celá staleti ležela mezi mou rukou, jeż trhala kuěty, a jimi, I mezi mým zrakem a tajemným svètem I... (Prîroda, I, 3-6; "Die Trauer einstigen Lebens, aus dem ich hervorging, entstieg allen Düften / und dem Flüstern der Bäume und dem schweren Geläut der Insekten über den Wassern, I und ganze Jahrhunderte lagen zwischen ihnen und meiner blumenpfückenden Hand, I zwischen meinen Augen und der Welt voller Geheimnis /... $r$. Übers. v. O. Pick.) 
$\mathrm{h}$. es gelangt wieder zu seinem reinen und $\mathrm{g}$ e i s tigen Sinn. Auch in anderen Gedichten von $V P$ transmutieren die atmosphärischen, astrophysikalischen, spektralen, sensorischen oder körperdynamischen Erscheinungen in rein trans ze ndete, spirituelle und lichthafte Phänomene - Geist und Licht sind einander genau entsprechende Tatbestände -, die als Omnia der höh eren, vollkommen ge istigen Ereignisse wahrgenommen werden:

"I... I v boureni vichrú jsi uslyšel údery svètla a let zemè, jak prostorem virî" (Královna nadéji I Die Königin der Hoffnungen, V. 37; \%... im Toben der Stürme vernahmst du die Schlăge des Lichtes und den Flug der Erde, wie er durch den Raum wirbelt"). "Věčná vî̉eni němých bleskú. jimiž přeletaji rozkazy svaté tvé vưle" (Kde jsem už slyšel?... I Wo denn vernahm ich schon?..., V. 21: "Die ewigen Wirbel der stummen Blitze, auf denen die Befehle deines heiligen Willens fittichen"). "A v tichu bolesti své at' słyšime suméti v duši mystické prameny světla, I nebot' bolest a svẻđo jsou formami jediné vibrace tajemstvi tvého!" (Modlitba za neprătele / Gebet für die Feinde, V. 47-48; "Und daß in der Stille unseres Schmerzes in der Seele die mystischen Quellen des Lichtes uns rauschen, I denn Schmerz und Licht sind Formen der gleichen Vibration deines Geheimnisses!"). "Jahody volaly krátkou svou sladkost a vưni sepotem květü, I marné polibky

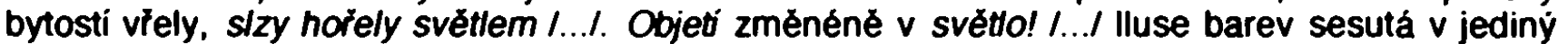
požár! /... I Zahrady plamenủ, ukryté v hlubinách vèc, / kvetouci slávou płechodủ $z$ viditelného $v$ neviditelné"'- (Píseñ o slunci, zemi, vodách a tajemstvi ohně I Das Lied von der Sonne, Erde, den Wassern und vom Geheimnis des Feuers, V. 51-52,56, 58, 60-61; "Der Erdbeere lispelnde Blüte rief mit kurzer Süße und Duft, / glühten vergebliche Küsse der Geschöpfe, brannten Tränen im Licht I...I. Umarmungen gewandelt zu Licht! I... I Illusion der Farben zu einem Feuer zerstürzt sie! I... / Gärten von Flammen, geborgen in der Tiefe der Dinge, / blühend in der Glorie der Wandlung von Sichtbar zu Unsichtbar!). "A když se vrátili, nejhlubšim hiasem je vítala země, / i viděli ji v barvách, které se neměni smrti, transparent vẻcuého ohnẻ, l od obzoru k obzoru nad nimi letẻlo hosanna svétla" (Dlouho stáli... I Stillstanden sie lange... III, 1-3; "Und als sie heimkehrten hieß die tiefste Stimme der Erde sie willkommen. I In Farben sahen sie jene stehen, die im Tod sich nicht wandeln, ein Transparent des ewigen Feuers, I und über ihnen von Umkreis zu Umkreis spannte die Flügel des Lichtes Hosannah"). "/../ zríceninami procházi duše na cestách $k$ vyššmu světlu. I... / a vzpominky slunce na ohnivá vởeni, neż prvni svẻty se odtrhly v dálku. I A v blesknuti jejího zraku ł̌eravi tajemná cára, prítomnost nepoznaněho, jež protíná vidmo mihovin nejvzdálenějšich, I z nichž dosud hvězơy se neutvớily." (Láska / Liebe, 10, 28-31; \% /.. / denn durch Ruinen wandelt die Seele den Weg zum höheren Licht auf. I.../ und Erinnerungen der Sonne im feurigen Wirbel, ehe die Urwelt sich losriß zum Wandel. I Und im Aufblitzen ihres Blicks aufgrellt die Geheime Gerade, in der die Allgegenwart des Unerkannten erscheint / und die das Spektrum durchfähnt des äußersten Stemschaums, / aus dem noch kein Stern sich gebar).

Das L i ch t als das wunderbarste Phänomen der stofflichen Welt und Metapher für alles Gestalthafte und Erkennbare, nimmt in der motivischen Paradigmatik von VP die durchaus zentrale Position ein: Es bedeutet - theo-logisch - die (oben erwähnte) Erscheinungsweise des "Höchsten" und seines Willens, das "Licht der Welt", das die Menschen durch jene inm innewohnende dynamis erleuchtet. Seinsmäßig bedeutet Licht das offenbare Leben und psychologisch das Bewußtwerden des Selbst, das IchB e w u B t sein und den "Willen" - namlich als disponible Energie - des Menschen selbst. Diese Bedeutung kommt in Bratrstvi vẻricich (Die Bruderschaft der Glaubenden) besonders klar zur Geltung: "a svètta našich duši, nalitá v jediný plápol, odẻla barvami neviditelné / a hlasem všech spojených vili nám v zázračné zahrady rozkvetly sily" (III, 45: "und unserer Seelen Lichter, ergossen in eine Lohe, taten das Unsichtbare in Farben, I und in der Stimme unseres geeinigten Willens schossen auf zu zaubrischen Gärten unsere Kräfte". Übers. V. F. Werfel.) Das Lich t, das die Erhelltheit des Daseins ermöglicht, in der der Mensch ein Selbstverständnis gewinnt, ist untrennbar mit dem Begriff des $G$ e i ste s verbunden. Der Geist bedeutet, unter dem psychologischen Gesichtswinkel betrachtet, eine Art "höheren Bewußtseins", einen "seelische[n] Komplex, der schöpferische Keime von noch unabsehbaren Möglichkeiten enthält". 353 Dieses "höhere Bewußtsein" erschließt dem Menschen, dem Sehenden, auch die wunderbaren

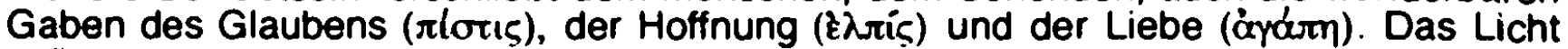
indizient auch - wie schon enwähnt - die Erkenntnis des "Höchsten" und seines Willens. Die Vorbedingung für diese Erkenntnis scheint die Selbsterkenntnis zu sein. Daher rührt wohl

353 C.G. Jung. Geist und Leben", in: Die Dynamik des UnbewuBten, Gesammette Werke, Bd. 8. Zürich-Stuttgart 1967, S. 381. 
die auffallend hohe Frequenz der Substantive "zrak" bzw. "pohled" ("Sehkraft", "Blick"), die die $r$ ationale Erkenntnis signalisieren. Im Prolog-Gedicht Vládnoud (Herrscher) heißt es: "neni radostí většich, / nežli je opojeni / zraku věcností sesileného!" (V. 32-34; "es gibt keine größeren Freuden / als die Verzückung des Auges / das schauender taucht aus ewigem Bad!"). Und in Kde jsem už slyšel?... (Wo denn vernahm ich schon?...): "O Věcny! $\checkmark$ té chvili, kdyż ruce mé bez vaády klesly, sesláblé láskou, / vlastni svưj żivot vidël jsem, zmènèný neznámým svètlem" (V. 23-24; "O Ewiger! In dem Augenblick, da machtlos, von Liebe geschwächt die Hände mir sanken, / erschaute ich mein eigenes Leben, von unbekanntem Licht verwandelt"). Zur wahren Erkenntnis führen jene drei Charismata Glaube-Hoffnung-Liebe, die im Licht des "ewigen Meisters" 354 ("věčného Mistra"; Královna nadëji I Die Königin der Hoffnungen, V. 1) leuchten, und diese Erkenntnis geschieht im und durch das L i c h t des "Höchsten":

"Vふak, procitlá, odpovidala jsem pokorné ubohým radostem zemé, / /..l oči odvracejice. I abych neviděla słzí, jeż kanou jim z osinẻni mého priliš jasného světla. I... I V záreni pohledu jejîho uvidè jsem do hlubin tisiciletim" (Královna naději / Die Königin der Hoffnungen, V. 38-40, 58; "Aber erwacht gab ich demütig die Antwort der armen Freuden der Erde, / /.../ zur Seite wandten sie die Augen, I daß ich die Tränen rollen nicht sehe, die mein allzu blendendes Leuchten lockt. /.../ Im Strahlen ihres Blicks durchsah ich tief die Jahrtausende"). "Od vẻkủ, nehnutè, sálá tvé mystické slunce do vieni miz a zpẻněni sily l...l. Chci plakati světlem!" (Poledni zráni I Mittäglich Reifen, V. 2, 46; "Unregsam, von ewig her, loht deine mystische Sonne ins Sieden der Sătte, ins Kochen der Kräfte. I... I Licht will ich weinen!"). "Odmènou vaši budou chvile, kdy uzứte zemi svèttem své lásky I...I. I bude poznáni vaše jak potkáni noci a đne I...I. I rozširí se pohled váś jako cas plný světla a obejme zemi“" (Láska / Liebe, V. 65, 69, 71: "Es wird euer Lohn der Augenblick sein, da ihr erblickt durchs Licht eurer Liebe die Erde I...I. Und eure Erkenntnis wird sein wie Begegnung von Nacht und Tag I...I. Es weitet sich euer Blick wie die Zeit voll von Licht, und umarmt die Erde").

Die Erkenntnis jeder Art - der sinnlichen wie der inneren Welt zum Beispiel - ist das Resultat einer Erleuchtung durch die ewige Quelle des Lichtes. Der "ewige Meister" ("věcný mistr") ist "pater veritatis, pater sapientiae /.../ pater intelligibilis lucis /.../, pater evigilationis atque illuminationis nostrae" ("der Vater des Lichtes, der Erkenntnis und der Vater unserer eigenen Erleuchtug"). 355

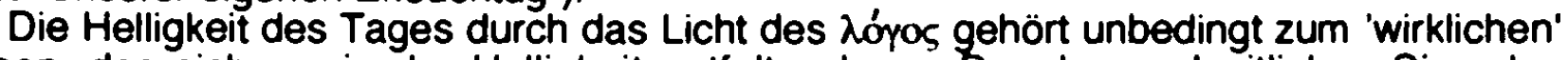
Leben, das sich nur in der Helligkeit entfalten kann. Der den endzeitlichen Sieg des Lichtes $/$ ebens verheißende Vers aus dem Gedicht Modlitba za neprátele (Das Gebet für die Feinde, V. 31) - "A prece bude naposled svétlo" ("Und dennoch wird am Ende das Licht sein") - könnte als Leitsatz des theo-logisch-eschatologischen Modells gelten.

Wie bereits erwähnt, durchwirkt die Lichtsymbolik den gesamten Gedichtzyklus: als charakteristische Wortmotive dominieren "svétlo" / "Licht", "poledne" / "Mittag, "plamen" I "Flamme". "oheñ" / "Feuer", "Iéto" I "Sommer", "záre" / "Glanz", "blesk" / "Blitz", "požár" I "Brand", "žhavy" / "glühend", "horici" / "brennend" usw. Das Licht wird auch zum Medium der Transparenz und Diaphanie. Von besonderer Relevanz scheint die Situation des "Mittags" zu sein: weder die "Nach", die in Tajemné dálky dominiert, noch der "Morgen", der wiederum für die Symbolik von Svítáni na západe ("vécné jitro") signifikant ist (wohl als Antithese' zur Nacht), sondern der "Mittag" mit seinem grellen Sonnenlicht. Die Erhelltheit der (eschatologischen) Existenz, die das Geschenk des "Höchsten" ist, bedeutet zugleich die Freiheit vom Tod. "Leben" und "Licht" bilden eine Äguivalenzrelation ("In inm war das Leben, und das Leben war das Licht des Menschen"; Joh. 1.4). 356

Sowohl in Svitáni na západẻ als auch in Vètry od pólu ist die Nacht eine der 'Bedingungen' für das Erlangen der "Kraft zur Empfängnis des höheren Lichtes" (Noci! I Nächte!, V. 20; "sily pro prijetí vyššiho světla"). Noch prägnanter wird diese Intention in

354 Man denke an die Abhandlung De magistro von Augustinus.

355 Augustinus, Soliloquia /1,2.

356 Darüber hinaus ist (im eschatologischen Sinne) Jesus in der johanneischen Theologie das "Licht" (qüx): "ich bin in die Welt gekommen als ein Licht, damit, wer an mich glaubt, nicht in der

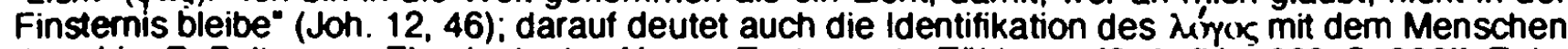
Jesu hin. R. Bultmann, Theologie des Neven Testaments, Tübingen [6. Aufi.], 1968, S. 362tt. Er ist das wahre "Licht" des fleischgewordenen Logos; damit ist auch der Sinn seines Kommens charakterisiert, daß er als das "Licht in die Welt gekommen ist" (Joh. 12, 46). 
Pr̈roda (Natur) zum Ausdruck gebracht. Im letzten Zweizeiler 357 handelt es sich um zwei verschiedene Lichtquellen: um das natürliche Tages-Licht (lumen naturae) und um ein "höheres Licht" als Sinnbild des Geistes. Vor dem Kommen des "höheren Lichts" waren alle blind (vgl. Joh. 9, 39, 419). Diese 'Blindheit' - im Sinne des Johanneischen Determinismus - rührt von der Allgemeinheit der Sünde her, die das 'Nicht-ErkennenKönnen' nach sich zieht. Rudoff Bultmann deutet den Glauben als das Eingeständnis des bisherigen Verweilens in der Blindheit. Die Entscheidung des Glaubens oder Unglaubens versteht Bultmann als ein ontisches Problem; in dieser Entscheidung konstituiert sich das Sein des Menschen. 358

Stets aufs neue rekurriert Bïezina auf den Gedanken, daß im eschatologischen Plan des "Höchsten" auch die Finsternis und der Schmerz ihren Sinn haben. Die Erfahrung der Finsternis scheint notwendig zu sein, "daß die Seelen die Kraft zur Empfängnis des höheren Lichtes gewännen" (Noci! / Nächtel, V. 20; "aby duše nabyly sily pro prijeti vyššino světla"). In dieser Vorstellung bekundet sich die Wirkung der (Leibnizschen) Theodizee. Die Theodizee versucht, die Güte und Allmacht Gottes gegenüber der Existenz des Bösen zu rechtfertigen, wenn Leibniz die Weltordnung als eine solche der Vorsehung begreift, in der die Gerechtigkeit des "Höchsten" die Naturgesetze den ethischen Gesetzen unterordnet. Entscheidend für das theo-logisch-eschatologische Modell von Vètry od pólü ist die oben zitierte verheißungsvolle Aussage: "A píece bude naposled světlo" ("Und dennoch wird am Ende Licht sein"). Mit dem von Bỉezina postulierten Willen zur Ethik und "Verantwortung" ("odpovědnost"), hängt auch die Forderung der 'Reinheit', man könnte sagen der inneren 'Lichthaftigkeit', zusammen.

357 Priroda. I. Hudbou hrály ukryté prameny a den mưj k ní zpival svou piseñ / na březích melancholických. / Smutek dávného żiti, z nẻhoż jsem vyšel, dechl mi z vưni, / a z hovoru stromủ a z téżkého zvonéni hmyzu nad vodami, I a celá staleti lez̉ela mezi mou rukou, jeż trhala květy, a jimi, I mezi mým zrakem a tajemným svétem. I jeż tisici tázavých pohledú v duši mou nẻmý se dival. /I II. Oblaky setměly západni slunce. A duse má ptala se větru: / Jsou to oblaky pricházejíci nebo odcházejić? I Odmlcely se vétry. v posluśná zrcadla se zhladily vody, I a hvẻzdy, jak ohnẻ hasnouci $v$ studených vodách svíticich mởi, / v̛̉ely a sumèly nade mnou, neviditelné: / Svétlo umirá jenom príchodem ještě větşího světla. / ještè většího, většího světla". (Natur. I. Es tönten melodisch die verborgenen Quellen und mein Tag sang sein Lied zu dieser Musik I an den melancholischen Gestaden. I Die Trauer einstigen Lebens, aus dem ich hervorging, entstieg allen Düften / und dem Flüstern der Băume und dem schweren Gelăut der Insekten über den Wassern. I und ganze Jahrhunderte lagen zwischen innen und meiner blumenpflückenden Hand. I zwischen meinen Augen und der Welt voll Geheimnis, / die mit tausend fragenden Blicken stumm meine Seele durchforschte. // II. Gewölk verdunkette die westliche Sonne. Und meine Seele befragte die Winde: / Sind dies nahende oder fliehende Wolken? / Verstummten die Winde, zu gehorsamen Spiegeln glătteten sich die Wasser, / und die Sterne, wie Brănde in den kalten Wogen strahlender Meere verlöschend, / erbrausten und rauschten über mir, unsichtbar: / Es schwindet das Licht nur beim Nahen größeren Lichtes, / eines noch größeren, größeren Lichtes" Ubers. v. O. Pick.) Die Natur erscheint hier als Sphäre des Geschaffenen, als Schöpfung des "Höchsten" im schicksalstrăchtigen Schwung aus den Hănden des "Sảemanns" (Piseñ a slunci, zemi, vodách ... I Das Lied von der Sonne, Erde, den Wassem .... V. 47; "osudné zdviżeni ruky Rozsévajica"), d. $h$. als Sphäre des Lebens aber auch des Todes, des Lichtes wie auch der Finsternis, die aber - als widergöttliche Māchte - am Ende immer vom siegreichen Licht Leben besiegt werden. Vgl. auch: $\%$... I nejhlubšim hlasem je vítala zemé, / i vidẻli ji v barvách, které se neméni smrti, transparent věcného ohné. / od obzoru $k$ obzoru nad nimi letéto hosana světla / a hlubiny kvêtủ $k$ nim vášnivẻ vykrikly vưni" (Dlouho stáli... I Lange standen sie.... III. Str.: $\%$... mit der tiefsten Stimme hieß sie die Erde willkommen, I in Farben sahn sie jene stehn, die im Tode sich nicht wandeln, ein Transparent des ewigen Feuers. I und über innen von Umkreis zu Umkreis spannte die Flügel des Lichtes Hosannah / und die Tiefe der Blüten schrie innen den leidenschaftlichen Duft entgegen". Übers. v. F. Werfel.) In diesem Sinne antworten die rauschenden aber unsichtbaren Sterne dem in seiner Ungewißheit fragenden dichterischen Ich: "Svẻtlo umirá jenom prỉchodem ješté většino světla, / ješté většino, většino světla" (Přiroda / Natur, II, 6-7; "Es schwindet das Licht nur beim Nahen größeren Lichtes, / eines noch größeren, größeren Lichtes"). Es ist kein Zufall, daß es die Sterne sind, die diese tröstende Gewißheit kundmachen: Ein Stern kündigt das Kommen des Enösers an (in den Hieroglyphica [Basel 1518) des Horapollon symbolisient der Sternhimmel Gott als das endgültige Fatum) und das Sternenlicht symbolisient (u. a.) das unsichtbar "innere Licht" des Menschen, angezündet "aus dem heiligen Geist" als das Licht der Vernunft und der Weiseheit.

358 R. Bultmann. .Untersuchungen zum Johannesevangelium“, in: R. Bultmann, Exegetica. Autsátze zur Erforschüng des Neuen Testaments, hrsg. v. Erich Dinkler, Tübingen 1967, S. 124197 (insb. S. 174ff.). 
Mit der Lichtsymbolik geht in Vëtry od pollu die des Fevers einher. Das Feuer spendet Licht, das wiederum das offenbare Leben ist. Im Unterschied zur frostigen Kälte der von der "schwarzen Sonne" oder vom kalten Mondschein beleuchteten - oder verbrannten (noch) metadekadenten Welt (Svitáni na západẻ),359 wird in Vëtry od pólü das Modell einer solaren, vom $\lambda$ óyos erleuchteten Welt konstituiert. Feuer, Glut (bzw. Glühen), Extase, Verklärung - dies alles sind I i chth afte Gegebenheiten. "Feuer"/Geist ("ohen") und "Glut" ("Zár") ermöglichen in Vètry od póiu die vollkommene Extase durch das Niederreißen der Schranken des leibhaften Selbst mit dem Ziel der totalen Spiritualisierung, die sich wiederum als pures Licht manifestiert. Das 'Glühen' vollendet sich in der Ver-Klärung:

"Chtivé jsem dýchal tuưj zár a celá má bytost se zmẻnila v żizeñ! /.../ Dech tvêho poledního zráni vali se blankyty tisicileti! /... / Tkani mých myšlenek vybẻl mi v labuti Cistotu plátna a supiny vosku / bilými učinh, neż do forem naleju svice! Chci plakati svêtlem!" (Poledni zráni I Mittäglich Reifen, V. 8. 45-46: "Gierig sog ich deine Glut und mein Wesen ward ganz ein einziges Dürsten! I... Odem deines Mittag-Reifens wallt unter dem Himmelsgewölbe der Äonen! /... / Bleiche zur Schwanenweiße des Linnens meiner Gedanken Webe und die Schuppen des Wachses / mach weiß, eh ich die Kerzen gieße in Formen! Licht will ich weinen!". Übers. v. F. Werfel).

Daher wird das Feuer als befreiendes Element apostrophiert; das Leben, das zugleich Licht ist, muß sich frei verströmen, nur damit ist es das Lichthafte. Der substantielle Leib wandelt sich - angezündet vom ('heiligen') Feuer, das in VP ein $k$ a th a rtis ches Element symbolisiert - in lodernde Flamme, d. h. er wird in den Zustand der Selbsttranszendenz versetzt. Das substanzielle Feuer, das in den Zustand der puren Selbsttranszendenz versetzen kann, ist die Liebe (oder der Zorn Gottes):

"Tajemstvi onné! Osvobozujić! / Záría symbole Všudyprítomného! / Hrdé dechnuti sily! Objetí zmènẻné v svétlo!" (Píseñ o slunci, zemi, vodách a tajemstvi ohnè / Das Lied von der Sonne. Erde, den Wassern und vom Geheimnis des Feuers, V. 54-57; "Geheimnis des Feuers! Erlösendes! Des Allgegenwärtigen strahlendes Sinnbild! / Herrischer Atem der Kraft! / Umarmung gewandeft zu Licht!").

Mit der L i c h t / Logos-Symbolik koinzidiert in Větry od pólü die Symbolik des Windes, des Hauchens, der spiratio activa, die die Willensakte des "Vaters", des Brezinaschen "Höchsten" (Poledni zrání / Mittäglich Reifen) versinnbildlichen. Der "Höchste" ist ein drohender und zugleich beschützender "Vater" und "Herrscher". Seine Stimme "erdröhnt durchs Zeitengewölb / in gefährlichen Lichtgewittern" (Vládnouci... / Herrscher..., V. 7-8; "Hlase, jeż zazníváš klenbami vékủ, / nebezpeźnými bouiemi světla") und seine Liebe "regnet wie brennender Schwefel nieder in die Gärten der irdischen Liebel" (Modlitba za nepiátele / Gebet für die Feinde, V. 21; "Ty, jehoż láska padá jako hořicí síra v zahrady pozemské lásky!"). Sein Odem kommt vom eisigen Nordpol, er kann wie ein Sturm "die Welten aus den Wurzeln reißen" (Boure / Der Sturm, IV, 2; "jež světy vyraci"), zugleich

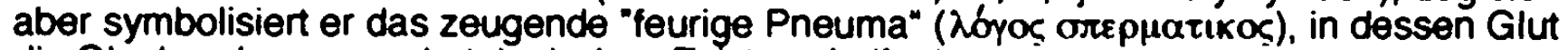
die Glaubenden zur eschatologischen Existenz 'reifen':

"Dech tvého poledniho zráni vali se blankyty tisícileti!" (Poledni zránil Mittåglich Reifen, V. 8; "Hauch deines Mittag-Reifens wallt unter ewiger Wölbung!"). "Dech Vẻněho táhne pod nebesy vašeho srpna a rijina / v den slavnosti klasú a zahrad a vinic a duši" (Láska / Liebe, V. 16-17; "Der Hauch des Ewigen zieht unter den Himmeln eures Augusts und eures Oktobers, I am Tag des

359 -O duše má, odkud on prišel? I ... / Na kollk rưžovych úsmévú dechl svưj podzemni chlad? (Legenda tajemné viny I Die Legende der geheimnisvollen Schuld, III, 1, 4; "O Seele, woher kam Dieser? I.../ Wieviel rosenatmendes Lăcheln hat je sein Grabhauch vereist?). $\%$... vy. jimż krev vyhrnula se z pórù ve vỷsich ztrnulých odvěkỳm mrazem" (Vadar̃ snù I Die Herrscher der Tráume. II, $3 ; " \%$. ihr, denen das Blut in den von ewigem Frost erstarten Hơhen herausstrơmte".). Aż sedneś za mứj stúl, cekaná, Nepozvaná, / se zraky tajemstvi, se slovy némými, / s bohatstvím neznámým, milostná, obávaná, I s dotknutím ledovým, s polibky vếnými" (AZ̉ sedneš za mưj stül.. I Wenn du an meinen Tisch dich setzt.... (IV, 1-4;"Wenn du an meinen Tisch dich setzt, du Erwartete, du Ungerufene. / mit Blicken voll Geheimnis, mit stummen Worten, / mit unbekanntem Reichtum, du Liebliche, Gefürchtete, I mit eisiger Berührung, ewigen Küssen"). $\%$. I Cerné slunce smrti tam plálo /.../I/ na kuěty naši lásky a touhy se prissálo zsinalou žizni, /.../ ledovým ohném je ztrávilo /.... // Bohatstvi nescetných pozemských zrakủ padala spálená v hlubiny dálek' (Víézná pisen I Das siegreiche Lied, II, 3; III, 1, 3; V, $1 ; "$ "... / Die schwarze Sonne des Todes loderte dort I... // Auf die Blüten unserer Liebe und Sehnsucht saugte sie sich mit fahlem Durst, /... / mit eisigem Fever verzehrte sie /.../. "/ Die Reichtümer unzähliger irdischer Blicke fielen verbrannt in die Tiefen der Fernen'). 
Festes der Ähren und Gărten, des Weinbergs und der Seelen"). "Opojeni vふ̌ech budoucich snủ, jeż rozkvetou $v$ hotícich duhách / novými slunci na oblacich tvého dechu nesmrtelného! I.../ bledé jiskieni barev, jež prýstélo z ledových kvêtú mých oken, / roztálo smyté tuým ohnivým dechem a v nádhele zahrad tvých zrakem jsem şlel" (Kde jsem uż shysel?... / Wo denn vernahm ich schon?.... V. 19-20; 25-26; "Trunkenheit allen küntt'gen Getrăums, das erblüht im Brande des Bogens, / den die neue Sonn' auf's Gewölke deines unsterblichen Atems baut. I.../ bleiches Farbengeglimmer der eisigen Blumenkristalle meiner Fenster, / schmol $z$ in deinem feurigen Hauch und mein Auge verging in dem Prunk deiner Gärten". Übers. v. F. Werfel.)

Die Wind Symbolik konnotiert Transparenz und Diaphanie des "geheimnisvollen Wehens", des spirituellen "Lächelns" usw., die den gesamten Zyklus durctwirken. Auch in seiner Ambivalenz, nämlich als die 'höchste Gefahr' und der 'größte Schutz' zugleich, bedeutet der Odem die wunderbare (sittliche) Kraft, die den Menschen erfüfft und die Hoffnung auf die eschatologische Existenz erschließt, die wiederum die Glaubenden ("vëh"c") von den Ängsten, die diese 'Gefahr' mit sich bringt, befreit:

\%.../ tisice smrt́ budete potkávat najednou v tisici cestách bez báznè- (Láska / Liebe, V. 72; $\%$... tausend Toden werdet ihr begegnen plotzlich auf tausend furchtlosen Wegen"). "Do vétrù touhy, jez staleti proudi , / 2 nešetnych duß́, z krvavjch noci našeho pólu / k rovníku tvému strhni má kî́dla! // V extasi lásky chai zpívati bratrským dušim, / Że neni bolesti vêtšich, I nežli jsou żracená vitézstvi jejich, / Ze neni radosti většich, I nežli je opojeni / zraku věcnosti sesileného!" (Vládnoucí ...I Herrscher..., V. 17-20; 29-34; "In die Winde der Sehnsucht, die durch die Jahmunderte sich werten, / aus unzăhligen Seelen hervor, von der Blutnacht unseres Pols her / zu deiner Mittagsgleiche / reiß fort meine Flügel! // In Extasen der Lebe will ich verbrüderten Seelen singen: / Keine großeren Schmerzen sind / als eure vertorenen Siege, / keine großeren Freuden / als die Verzückung des Auges, / das schauender taucht aus ewigem Bad!". Übers. v. F. Werfel.)

Eine unumgängliche Bedingung für die Erneverung des $L i c h$ ts, d. h. für die Wiedergeburt des BewuBtseins aus dem Dunkel, stelt der ascensus-Kampf der Seele dar: ${ }^{360}$ "a jejich úsmèv, magický, poručil slunci: / Zastav se nade dnem nasím a nezacházej, I až dozraje úroda setby a piseñ díkủ zapejem na bojišti!" (Stastní / Die Glücklichen, V. 23-25; "und ihr magisches Lächeln, der Sonne befahl es: / Steh still über unserem Tag und gehe nicht unter bis die Ernte der Saat reift und wir auf dem Schlachtfeld anstimmen ein Danklied!"). ${ }^{361}$ Die für den dekadenten Symbolismus signifikante Dramaturgie der Selbstaufopferung des Dichter-Priesters auf dem Altar der Kunst (Uméni I Die Kunst) und das genauso symptomatische 'nichtende' Zusammensinken auf den Grund des Nicht-Seins, werden im theo-logischeschatologischen Modell von Vêtry od pólú vollkommen zur Dynamik des ascensus umkodiert:

"At omyji oúi své, nemocné soumrakem, I na vyssitvich hor" (Vládnouci / Herrscher, V. 14-15; -Daß ich das Auge bade, das zwielichtkranke, / auf deiner Berge Scheitel /... $/$ ). $\%$.../ a stoupánim $k$ visi opilé srdce pélo svou piseñ / o slunci a zemi, vodách a tajemstvi ohné" (Pisen o stunci, zemi.

360 In der Phase des dekadenten Symbolismus und im gnostisch-eschatologischen Modell von Svitáni na západé ist es die Erkenntnis, die das eigentliche Telos des Daseins darstellt. In Tajemné dálky (Modlitba vederni I Das Abendgeben) wird vor allem die Erkenntnis der immanenten Welt, des Universums mit seinen "kosmischen Gesetzen" postuliert. In der Phase des eschatologischen Symbolismus verschiebt sich der Schwerpunkt zunăchst auf die Erkenntnis des Transzendenten und der Geheimnisse der (göttlichen) Schöpfung (Ranni modlitba). In Vëtry od poti geht es offensichtlich um die Erkenntnis der kathartischen Wirklichkeit Gottes und des göttlichen Willens, die im Glauben begründet liegen. Von der Gnosis scheint sich der Schwerpunkt auf den Glauben (Pistis / xioucs: Bratrstvi verficich / Die Bruderschaft der Glaubenden, Poledni záni / Mittăglich Reiten) und aư die Liebe (Agape / ùjúrm: Láska / Liebe. Dlouho stáli ... / Still standen sie lange .... Kdyż z lásky tvé... / Wenn aus deiner Liebe...) zu verschieben. Hierzu kommt die dritte prinzipielle Bestimmung der (christlichen) Existenz, die Hoffnung (Elpis / Ėrís), deren Symbolik das Gedicht Královna nadéji (Die Kónigin der Hoffnungen) entfaltet.

361 Als hochinteressant muß im Zusammenhang mit der 'Anbetung' des sol rex durch die "Glücklichen" (= Theurgen) in Gedicht Stastri ("Zastav se nade dnem nasim a nezacházej", V. 24; "Stehe über unserem Tage still und gehe nicht unter") die beinahe identische Anbetungsformel (als Anrede an den Licht- und Fever-Gott) der sog. Mithrasliturgie betrachtet werden, die M. P. Nilsson in seiner Monographie Geschichte der griechischen Retigion II, 1950, S. 7091., zitient.: \%... bleibe du - verlaß mich nicht. Vgl. auch: Hans Jonas, Gnosis und spastantiker Geist, Teil 2,1. Gottingen 1954, S. 56. Anm. 3. 
vodách a tajemstvi ohnè / Lied von der Sonne, Erde, den Wassern und vom Geheimnis des Feuers, V. 4-5; "und trunken wie's aufstieg zur Höhe das Herz sang sein Lied / von Sonne, Erde. von Wasser und dem Geheimnis des Feuers"). "A bolest tvá tvưrči / až k posledním končinám vesmiru zalká /... / oblouky plamenných vin / do výši tisicú mil; / a pohnutými atmostérami / ţ̉esou všemi světy tvých duši" (Když z lásky tvé... I Wenn aus deiner Liebe..., V. 6, 13-15; "Und deiner Schöptung Schmerz / stöhnt bis an die letzten Einöden des Alls /.../ Bogen von Flammenwogen / tausend Meilen hoch; / [und] in erschütterten Sphären / beben die Welten all deiner Seelen". Übers. v. F. Werfel.)

Auch in Vẻtry od polui gehört die Erfahrung der Finsternis zu dem acsensus-Kampf, mit anderen Worten, der Weg der Sublimation scheint nicht ohne die "Reise in die Tiefen der Nacht" möglich zu sein: "Noci samotárü, jichž duše zapaluji svá uhaslá světla o hvězơy / a sestupuji s nimi do hlubin, kde polibky maji silnou chut smrti a ticha!" (Noci! / Nächte!, V. 15-16: "Nächte der Sonderlinge, die das tote Licht ihrer Seelen an Sternen entzünden, I und mit ihnen steigen zur Tiefe, wo die Küsse den starken Geschmack des Todes und der Stille bereiten!". Ubers. V. F. Werfel.) In Láska (Die Liebe) heißt es: "nebot zríceninami procházi duše na cestách k vyššímu světlu" (V. 10; "denn durch Ruinen wandelt die Seele den Weg zum höheren Licht auf"). Den descensus des dichterischen Ich in das Reich des Todes thematisiert auch das Gedicht Mèsto (Die Stadt):

"V soumraku neznámého svétla uzłel jsem mẻsto. A slunce, / zbledlé a zbavené záre, viselo nad nim /.../. stíny, jeż vystouply z hrobü, bloudily uprostied davú /.../ spojovali ruce neznámých, I $\checkmark$ polibky milencú padal jich úsmév" (Mésto / Die Stadt, V. 1-2; 8, 10; "In Dämmerung fremdesten Lichts sah ich die Stadt. Eine Sonne, / Ohne Feuer, verblichen, hing über ihr /.../Schatten, die dem Grab entstiegen, schweiften inmitten der Menge /.../ sie trauten die Hände von Fremden, / sie betauten mit inrem Lächeln welk der Liebenden Küsse". Übers. v. F. Werfel.)

Nach dem descensus-Erlebnis, das mit dem Überschreiten der Schwelle der Angst koinzidiert, kann der 'Lichtweg' der Seele eingeschlagen werden: "tisice smrti budete potkávat najednou $v$ tisici cestách bez báznè / a uzríte zảstupy nesćísiných životư vcházeti v jediný Żivot" (Láska / Die Liebe, V. 73-74; "tausend Toden müßt ihr begegnen plötzlich auch tausend furchtlosen Wegen, / dann seht ihr unzähliger Leben Schar eingehn in ein Einziges Leben"). Es ist, wie es scheint, die Hingabe an die Grundbestimmungen / Charismata der eschatologischen Existenz, Glaube - Hoffnung - Liebe, die dem dichterischen Ich die Gewißheit der eschatologischen Zukunft gibt. Den wunderbaren, überweltlichen, geheimnisvollen, dem menschlichen Verständnis verborgenen Charakter des eschatologischen Geschehens, das vom menschlichen Handeln und Wollen völlig unabhängig ist, bringt Brezina im vorletzten Gedicht des Zyklus, in Letni slunovrat (Sommersonnenwende), zum Ausdruck:

-Mdlé ruce zajatých, $v$ radosti zovižené zatłásly mrižii, I nejhlubši vítr zdvih nadèje, letnice zemé a duchü se bliži. I... / Hle cestou $v$ obili skrytou, $v$ tajemném zachvěni celého kraje, / żnec nevidęn kráci, však po klasech lesk jeho ocele hraje" (Letni slunovrat / Sommersonnenwende, V. 7-8; "Erhoben in Freude rütteln matte Hănde Gefangener an Gittern, / Tiefenwind autwirbelt Hoffnung. Pfingsten der Erde und Geister naht in Gewittern. I... I Sieh, auf ăhrenbeflutetem Pfad in der Landschaft geheimem Erdbeben / ungesenn schreitet der Schnitter, doch über den Ähren Reflexe der Stahlklinge schweben". Übers. v. P. Eisner). ${ }^{362}$

362 Vgl. auch: "So ist die Gottesherrschaft, wie wenn einer Samen aufs Land wirtt. Er schlăft und steht auf im Wechsel von Nacht und Tag, und der Same sprießt und geht in die Höhe, er weißt nicht wie. Von selbst trägt die Erde Frucht, erst Halm, dann Áhre, dann reifen Weizen in der Âhre. Wenn die Frucht so gestattet, so sendet er die Schnitter, denn die Emte ist da". (Mark. 4, 2629). 
„I to. co písete o zbołnosti. podpisuji svou touhou: chci býti zbołným.

Poezie, ktera vêri v transcendentni smysl života, snad ani jinou býti

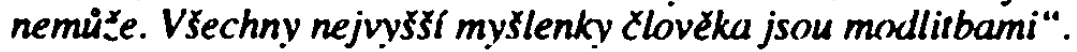

„Auch das, was sie über Frömmigkeit schreiben, unterzeichne ich mit meiner Sehnsucht: ich will fromm sein. Die Poesie, die an den trans:endenten Sinn des Lebens glaubt, kann offensichtlich keine andere ein. Alle höchsten Gedanken des Menschen sind Gebete".

Or. Brezina an Sig. Bouska (20. VII. 1896)

Es erhebt sich die Frage, was mit der Gestalt der gnostisierenden "Starken" (Vino silnych / Der Wein der Starken) im Prozeß des "mystischen Reifens" ("mystické zráni") geschehen ist? In Vètry od pólù treten die "Starken" ("Silni") unter einem neuen, signifikanten Namen auf: "svatu" (die "Heiligen"). Die Heiligkeit als persönliche Qualität kormmt in Větry od pólü keineswegs unvermittelt vor. In der Korrespondenz aus der Abfassungszeit dieses Zyklus (Sommer 1896 - Sommer 1897) verwendet Biezina oft Lexeme "svaty" ("heilig"), "zbožny", ("fromm"), "Cisty" ("rein"), "modlitba" ("Gebet") u. a.363 Einen wichtigen Impuls gab dem Dichter zwifelsohne die Rezeption des Werkes von Ernest Hello (1828-1885), eines religiösen Schriftstellers, der in den siebziger Jahren des 19. Jahrhunderts als Vertreter einer im christlichen Glauben wurzelnden Humanität den Kult des "Heiligen" aktualisierte (Physiognomies des Saints, 1875). ${ }^{364}$ Indes ist mit der bloßen Feststellung der Rezeption, die man nicht überschătzen kann, noch nichts Spezifisches besagt. Zur Semantik der Heiligkeit und des "heiligen Willens" ("svatá vưle") gelangte Bïezina, im Hinblick auf die Entwicklungsdynamik seines Werkes, durchaus organisch. Solche Wortmotive wie "modlitba" ("Gebet"). "oltár" ("Altar"), "knèz" ("Priester") u. a., kommen bereits in den Gedichten aus der Phase des dekadenten Symbolismus vor. Im System des eschatologischen Symbolismus erlangen sie jedoch eine neue Bedeutung:

"UCelem života, jak mu rozumime my, věrici, je svatost. By̆ti svatým, znamená dojíti na prảh poznáni. I...I Koncentraci vưle stávaly se silnými a divotvornými duše svatých". ("Der Zweck des Lebens, wie wir, Glaubenden, inn verstehen, ist die Heiligkeit. Ein Heiliger zu sein, das bedeutet an die Schwelle der Erkenntnis zu gelangen. /.../ Durch die Willenskonzentration wurden die Seelen der Heiligen stark und wundertatig. ") 365

363 An Anna Pammrová schretbt Bíezına (Sommer 1896): "Vrcholem żivota na zemi je mi proto Svétec, v nẻmỉ nesmrtelná đást jeho bytosti dominuje, rozlévajici záhłevné svẻtto, tajemným vlivem zasahujíci osoby, věci a sily. U nẻho rozpètí lásky stává se żivotem". (Dopisy Otokara Błeziny Anné Pammrové z let 1889 1905. Praha 1931. S. 115ft.; "Den Hōhepunit des Lebens auf Erden stellt deshalb der Heilige für mich dar, in dem der unsterbliche Teil seiner Persónlichkeit dominiert, der das wärmende Licht ergießt, [und] mit geheimnisvollem Einfluß die Personen, Dinge und Kräfte erfaßt. Bei inm wird die Spannweite der Liebe zum Leben").

$364 \mathrm{Vgl}$. den Brief (vom 8. II. 1897) an S. Bouska, in dem sich Błezina für den Hinweis auf ein Buch von Hello bedankt und dessen Rezeption erwähnt. (Vlidné setkáni. Vzájemná korespondence Otokara Bỉeziny a Sigismunda Bousky. Olomouc 1996, S. 95). Lobend schreibt Błezina über Hello auch in einigen Briefen (März-April 1897) an A. Pammrová. Er nennt inn (Brief vom 1.-2. 3. 1897) "Nietzsche viry" ("Nietzsche des Glaubes"). Dopisy Otokara Breziny Anné Pammrové $z$ let 1889-1905, Praha 1931, S. 161. Diese Charakteristik deutet auf die alimähliche Substitution der an Nietsches "Ubermenschen" alludierenden Bezeichnung der "Starken" durch die der "Heiligen" bzw. "Reinen" hin. Der Vertraute Błezinas, der Soziologie-Professor Emanuel Chalupný, macht die Freundschaft mit dem Benediktiner Bouška für Bîezinas (vermeintliche) Hinwendung zur kirchlichen Dogmatik verantwortlich. Chalupný benutzt sogar das Wort "Verirrung". Erklärungen dieser Art wären natürlich zu einfach. Bouška war vielmehr ein 'Vermittler', der die Richtung der geistigen Entwicklung Bǐezinas erkannte.

365 O. Błezina, Dopisy O. B. Annè Pammrové z let 1889-1905, Praha 1931, S. 165. 
O. Králík irrt allerdings, wenn er meint, Bỉezina dächte dabei an die wahren und konkreten Heiligen, nicht an Symbole. 366 Der Dichter bestätigt selbst, daß er gerade die symbolische Auffassung der "Heiligkeit" im Sinne hat, wenn er in bezug auf den Kult der Heiligen (bei E. Hello) an Anna Pammrová (1897) schreibt: "Jeho dílo má sice vyslovenou tendenci katolickou, on považuje za fakta, v cem my vidime symboly". ("Sein Werk hat zwar eine ausgesprochen katholische Tendenz, er hält für Fakten, was wir als Symbole betrachten"). Man sollte nicht übersehen, daß der "Heilıge" für Bïezina in erster Linie ein Theurg367 ist (signifikanterweise verwendet er in diesem Zusammenhang das Adjektiv "divotvorny" / "wundertätig"), der nach der Festigung der göttlichen Einheit streben muß. Daher wird auch in diesem Zyklus, und vor allem in inm, dem Akt der 'Vereinigung' eine enorme Wichtigkeit zugesprochen.

"I trhali jsme svá opojeni, jak zrna na jediném mystickém hroznu, / jež dotknutím pukala výtryskem jednoho vina: / jablka jednoho stromu, jeż rozłíznuta společnou, naši, krvi se zardi, polibky jediné noci, v nichž duše zpivaji o smrti a budoucich žitích, v jediné rozpláni retủ, na véky nemocných rozkosi jednoho blesku" (Bratrstvi vëricich / Die Bruderschaft der Glaubenden, letzte Str.: "Und so pflückten wir unsere Berauschung, wie Beeren auf einer einzigen mystischen Weintraube / die sprangen bei der Berührung auf im Ausbruch eines einzigen Weines: / die Äpfel eines einzigen Baumes, die zerschnitten von unserem gemeinsamen Blut erröten, die Küsse einer einzigen Nacht, in der Seelen singen von Tod und zukünttigen Leben, in einer einzigen Entfachung der Lippen, die auf ewig erkrankten von der Wonne des einzigen Blitzes").

Der dominanteste Wesenszug der "Heiligen" scheint die Willenskonzentration zu sein: "neb vưle svatých je květem, jenż roste za magického žehnáni hvězođ" (Královna nadëji / Die Könlgin der Hoffnungen, V. 52; "Denn der Wille der Heiligen ist eine Blüte, die in der magischen Segnung der Sterne wächst"). Es ist einerseits der omnipotente "heilige Wille"

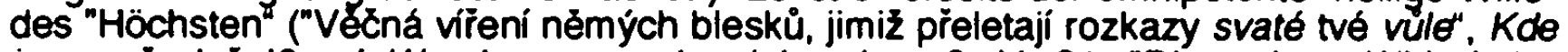
jsem uż slył̌el?... I Wo denn vernahm ich schon ?...V. 21; "Die ewigen Wirbel der stummen Blitze, auf denen die Befehle deines heiligen Willens fittichen"), andererseits der Wille der "Heiligen", kraft dessen sie auch die chthonisch-triebhafte Liebe überwinden können: "Vưle dominujicí, vítézná a jasné oči nepotrhané vášní. Vrcholem Života na zemi je mi proto Svêtec /.../. U nẻho rozpẻtí lásky stává se životem“. (An Anna Pammrová. Sommer 1896; "Der dominierende, siegreiche Wille und klare, von der Leidenschaft nicht getrübte Blicke. I.../ Den Gipfel des Lebens stelt daher der Heilige für mich dar /.../. Bei ihm wird die Spannweite der Liebe zum Leben"). 368

Der " heilige Wille" ("svatá vưle") des "Ewigen" findet im eschatologischen Symbolismus Biezinas seinen Reflex im schöpferischen Willen des Menschen:

"Byla tvá vủle, o Véčný! Pokornè léto tvé zpivám!" (Poledni zráni, V. 41; "Dein Wille war es, 0 Ewiger! Demütig singe ich deinen Sommer!"). "Když z lásky tvé vyšlehnou svètelné proudy tué vile, I slavné a těžké. jak tisicu životủ żivot /... I. A my všchni, nesmrtelni tvou vuili, I bolesti svoji I tvé bolesti sdilime slávu! / A naše radost, dar príliš těžký, I jenž z dẻtských rukou nám dosuo bezvládné padá, / je slabosti naši / sesiáblỳ odraz / vítézstvi tuýchr (Kdyż z lásky tvé... V. 1-2, 27-34: "Wenn aus deiner Liebe aufflammen die Lichtströme Deines Willens, / feierlich und sctiwer, wie Leben von tausend Leben" I... I "Und wir alle, unsterblich durch deinen Willen, / durch unseren Schmerz / nehmen wir teil an der Glorie deines Schmerzes! / Und unsere Freude, die zu schwere Gabe, / die unseren kindlichen Hănden noch immer machtlos entfăllt, / ist unserer Schwăche / ein abgeschwăchtes Abbild / deiner Triumphe?').

366 O. Králik, Otokar Březina, Praha 1948, S. 141.

367 Die Gestalt des "Theurgen" in der Lyrik des russischen Symbolismus untersucht Aage A. Hansen-Löve (Der russische Symbolismus. Diabolische und mythopoetische Paradigmatik, Bd. II, Lebenssymbolik, Wien 1984 [Typoskript], S. 1217) im Zusammenhang mit dem mythopoetischen "Žiznětvorčestvo" ("Lebes-Schöpfung"). In der symbolistischen 'Theurgie' bildet der Dichter eine Einheit mit Gott, indem er in und mit ihm verschmilzt. In der 'theurgischen' Kunst, tritt der Theurg als 'Gottmensch' auf. Das ist eine wichtige Verschiebung im Vergleich mit der Auffassung des Dichters im dekadenten Symbolismus, in dem er selbst zum 'Gott' in seiner Schein-Wett ertoben wird. Die "Heiligen" erscheinen als geistige 'Ahnen' des "Einzigen Menschen, des Erlösten" (Silenci / Wahnbetórte, $\mathrm{X}, 1 ; \%$ / sliti vsech milionú v Jediného Clovẻka vykoupeného"), aus dem letzten vollendeten Zyklus Ruce (Hände, 1901; vitalistisch-eschatologisches Modell), in dem die Kunst mit dem Leben vertließen soll.

368 Vgl. O. Bìezina, Dopisy Annẻ Pammrové z let 1889 1905, Prana 1931, S. 115tf. 
Doch ohne Absage an den sexus kann man die maximale Willenskonzentration nicht erreichen: "Jen ten, kdo potlacil pohlavi, mủže bỳt Magem, despoticky viádnoucim vưli" ("Nur derjenige, der die Geschlechtlichkeit überwunden hat, kann zum Magier werden, der über den Willen despotisch herrscht"). schreibt Bïezina an Anna Pammrová. ${ }^{369}$ Der Akt der Sublimation geschieht durch das Gebet: "Šilili jsme Ślenstvim lásky, jež byla modlitbou k Nejvyššimu" (Bratrstvi vërícich / Die Bruderschaft der Glaubenden, II, 2; "in Wahnsinn der Liebe rasten wir da, und dies war unser Gebet zum Höchsten"). In Vẻtry od pólü fungiert das Gebet auch als Medium der Verklärung des irdischen Lebens zum transzendenten Leben einerseits und des Lebens zum Kunstwerk andererseits: "Podobni Silným, když vyšli v den smrti s modlitbou na rtech /... / a modlitbou svoji jediným úderem křidel dostihli vonných snủ zemë* (Stastni / Die Glücklichen, V. 22, 29; "Ahnlich den Starken, wenn sie am Tag des Todes mit einem Gebet auf den Lippen aufbrachen /... / und mit einem einzigen Flügelschlag eures Gebets erreichtet ihr die duftenden Träume der Erde*). Hier tritt der 'genetische' Zusammenhang zwischen der mythogenen Gestalt der "Starken" (Vino silnych / Der Wein der Starken) und jener der "Heiligen" explizit zutage. Die Stärke (im Sinne von virtus) der "Starken" ("Silni") gründet in ihren wunderwirkenden pneumatischen Fähigkeiten, die ihnen die Kraft zur derartig souveränen Absage an die immanente Welt verleihen; sie erschließen innen auch die visionäre Schau. Die Stärke der "Heiligen" manifestiert sich dagegen auch in der Fähigkeit, durch das Licht der (Gottesund Bruder-)Liebe an die rechte Erkenntnis zu gelangen und diese - als Botschaft der Liebe - den "Gefangenen der Erde" ("zajatci zemè") zu verkündigen:

"I rozsîti se pohled vás jako cas plný svètla a obejme zemi, I v úsmévu vašem tisice úsmévú zasviti z tisice duši" (Láska / Liebe, V. 71-72; "Und weiten wird sich ever Blick wie die Zeit voll von Licht und er wird die Erde umarmen, / in eurem Lächeln wird tausend Lächein aus tausend Seelen aufleuchten"). "V extasi lásky chà zpivati bratrským duším /.../, Vádnouci.../Herrscher...,V. 29; "In Extase der Liebe will ich verbrüderten Seelen singen I... $/$ ).

Diese charismatische Eigenschaft besitzen die "Reinen" ("Ćisti"), die eigentlich den irdischen Pol der "Heiligkeit" repräsentieren. 370 Die "Reinheit" ("Cistota") konnotiert in VP das geistige Licht, mit dessen Hilfe man den "Durst des Blutes" ("żizeñ krve", St'astni, V. 3; Laska, V. 6), d. h. das Chthonisch-Triebhafte, sublimieren kann. Die "Reinheit" bedeutet die Katharsis der Seele, ohne die die Verklärung des Lebens kaum möglich wäre. Die Semantik der "Reinheit" der theurgischen Gestalten, der "Reinen" ("C̈isto"), organisiert die Sinnstruktur von zwei Gedichten des Zyklus: Stastni (Die Glücklichen) und Diouho stali ... (Still standen sie ...). Beide Gedichte thematisieren - in der Art 'mythischer Handlung' - die peregrinatio der theurgischen Schöpfer, der säkularisierten "Heiligen" ("Svati"), die hier als "Cisti" oder "Stastni" apostrophiert werden. Das Ziel ist die Fleischwerdung des Logos bzw. der (Symbol-)Sprache. Die Handlung von Dlouho stáli ... konzentriert sich auf die Peripetien der peregrinatio, während das Gedicht Stastni das Erreichen des angestrebten Ziels zum Thema hat. Die Theurgen in Dlouho stáli... charakterisiert der "schöpferische Schmerz" ("tvir Zi bolest"), der aus dem Zustand des Nicht-Gehen-Könnens resultient. Die symptomatischen 'Begleiterscheinungen' (1, 1-4) dieses Zustandes sind: "ml'ceni" ("Schweigen"), "závrat" ("Taumel"). "tragické snèni" ("tragisches Träumen") oder "mdloba" ("Ohnmacht"). Der "schöpferische Schmerz" scheint in der ambivalenten Natur der Theurgen verankert zu sein: " $Z$ dvou mystických oken jednoho dne, oken protiležicich, I

369 Br̉ezina paraphrasiert die Maxime des Autors von La décadence latine. Joséphin Péladan (1859-1918). Péladan, eine der skurrilsten Figuren des französischen Fin de siècle, bezeichnete sich selbst als "Magier"; die "Magie"war für inn der Ausdruck der Überlegenheit des Geistes über die Materie. Um Vollkommenheit zu erreichen, muß der 'Magier' im absoluten ('sexuellen') Asketismus leben. Péladan ist über alle Maßen von der Gestalt des Androgynen fasziniert, der die "Einheit" der polare n ('geschlechtlichen') Gegensătze symbolisiert: "Uranfängliches Geschlecht, endzeitliches Geschlecht, losgelöst von der Liebe, losgelöst von der Form, Geschlecht, welches das Geschlecht leugnet. Geschlecht der Ewigkeit! Heil dir, Androgyn!" (Roman L'Androgyne, 1891). Das (paradoxe) Verhältnis der komplementären Polarităt, kann als eine der Leitideen des theo-logisch-eschatologischen Modells von Větry od pólü (P o /a r winde) betrachtet werden.

370 Im Sinne des Partizipierenlassens an der ewigen Liebe. Vgl. hierzu J. Galot, Der Geist der Liebe. Mainz 1960, S. 34. "Der tiefste Wille in der Liebe läßt einen danach streben, mit dem geliebten Wesen ein Jenseits seiner selbst zu bilden, in dem man, sich verschwendend, untergeht und sich aư höhere Weise wiederfindet - seiner selbst zwar entäußert, aber gewissermaßen ein 'Wir' geworden, das nur noch aus Liebe besteht". 
trásly se hvězdy do jejich vigilii" (1, 3-4; "Aus zwei mystischen Nächten eines Tages wie aus zueinander gewendeten Fenstern, / zitterten Sterne in ihre Vigilien"). Rein somatischmateriell bleiben sie (noch) mit der immanenten Welt verbunden, geistig haben sie sich von ihr bereits losgelöst. Dieser Ambivallenz entspricht in Dlouho stáli... sowohl die Heimkehr ("A když se vrátili" I "Und als sie heimkehrten", III, 1) als auch der neue Aufbruch ("A když odešli" / "Und als sie fortgingen", Vill, 1) der Theurgen. Das schmerzvolle "gefährliche Schweigen" ("nebezpečná mičeni") erleben auch die "Glücklichen" (Stastni). Sie befinden sich irgendwo in der Zone des chthonischen Dämmers ("v hlubinách lesü" I "in den Tiefen der Wälder, V, 1), in einem finsteren chthonischen Labyrinth. Sie stehen zwischen Himmel und Erde ("Mezi námi a hvézdami táhnou oblaka zemę", V. 5; "Zwischen uns und den Sternen zieht das Gewölk der Erde"), in einer Zwischen-Zone, in der offensichtlich auch die Theurgen aus Dlouho stáli ... lange standen. Wie sie, betrachten auch die "Glücklichen" die "bebenden Sterne" als Orientierungspunkte (Stastni, V. 5,7; Dlouho stáli ..., I, 4; II, 1). Zu den 'Wundertaten' der Theurgen aus Dlouho stáli... gehört die Aufhebung der doppelten "mystischen Nacht eines Tages" $(1,3)$ durch ihre Entschlossenheit sich der Objektivität der irdischen Existenz zu 'öffnen'. In der fünften und sechsten Strophe (Dlouho stáli...) wird das Ziel der Rückkehr der Theurgen spezifiziert: die Spiritualisierung der irdischen Liebe (V. Str.) und des (dichterischen) Wortes (VI. Str.). Innen ist es möglich, in die Sphäre der Immanenz zurückzukehren, ohne die destruktive Macht des Todes fürchten zu müssen: "Pohřební zvony znëly v jejich blízkosti" ("Totenglocken läuteten in ihrer Nähe", IV, 1). Die theurgische Synthese der beiden entgegengesetzten Sphären bedeutet den eigentlichen Sieg der "Glücklichen", den sie für ihre lebenden sowie dahingegangenen "Brüder" erringen (V. 30). Das Medium des geistigen Kampfes der Theurgen ist das Gebet, mit dem sie der Unsterblichkeit entgegenschreiten ("Podobni Silným, když vyšli v den smrti s modlitbou na rtech", V. 21; "Ähnlich den Starken, wenn sie am Tag des Todes mit dem Gebet auf den Lippen hinausgingen"), um mit seiner Kraft die Synthese der beiden Welten vollbringen zu können: "a modlitbou svojí jediným úderem kridel dostihli vonných snù zeme" (V. 29: "mit einem Flügelschlag eures Gebets habt ihr erreicht den Traumduft der Erde"). Der Licht-Weg der "Glücklichen" korreliert mit der Himmels-Route der Sonne bzw. mit dem Gang der Himmelskörper: "kñdla bytostí vyšsich údery svými dávala rytmus jejich krokủm, I a jejich úsmév, magický, poručil slunci: / Zastav se nade dnes nasím a nezacházej I...l. I zastavilo se slunce nade dnem jejich" (V. 22-24, 26; "der Fittich höherer Wesen spannte den Rhythmus ihrer Schritte / und ihr magisches Lächeln befahl der Sonne: / Stehe über unserem Tage still und gehe nicht unter /.../. Still stand die Sonne über inrem Tag"). Die "Glücklichen" siegen durch die Zaubermacht des Gebets (V. 29) über die chthonische Tiefe; durch diesen Sieg scheinen sie die Position der "glücklichen" Licht-Träger, die das solare Licht für Tausende erkämpfen, einzunehmen. Das Ziel der Theurgen (Dlouho stáli...) ist also die Spiritualisierung der "irdischen Liebe" ("Novým pisnim učili pozemskou lásku", V, 1; "Neue Lieder lehrten sie der irdischen Liebe"), die - so wie das Opus der "Glücklichen" - von einem 'Licht-Erlebnis' begleitet wird. Die Spiritualisierung des (dichterischen) Wortes soll durch die Musik erreicht werden, die als das einzige Medium imstande zu sein scheint, das 'Unsagbare', das 'Flüstern der Seele', auszudrücken: "V jejich slovech se chvělo nadšeni letniho dne, kdyż paprskú hudbou provázi nẻmou práci zrajicich hlubin" (VI, 4-5; "In ihren Worten bebte des Sommertags Jauchzen, wenn er mit Strahlenmusiken begleitet die stumme Mühe der reifenden Tiefen"). Auch die 'Mission' der Theurgen in Dlouho stáli... mündet in das Erlösungswerk: Das spiritualisierte Wort 'ernährt' die "Namenlosen" ("Bezejmenni"), die in den chthonischen Tiefen arbeiten, die wiederum durch das spirituelle Wort "fruchtbar" gemacht werden ("zrajicich hlubin" I "reifende[n] Tiefen", VI, 5). Auffallend ist hier die Beziehung der Theurgen zum Prozeß des Reifens: "aż dozraje úroda setby a píseñ díkủ zapéjem na bojisti" (Stastni, V. 25; "bis gereift ist die Ernte unserer Saat und das Danklied sich erhebt auf dem Schlachtfeld"). "A vše, co v duši soumracich kvetlo, těžkými klasy se doteklo zemè. A sny, jako ženci poslušni rozkazu jejich, I klidili požennáni zrni a pisni“ (Dlouho stáli... VI, 3-4; "Und alles, was in der Dämmerung der Seelen reifte, streifte nun mit schweren Ähren die Erde. Und die Träume, wie Schnitter, gehorsam ihren Befehlen, / ernteten den Segen der Körner und Lieder"). Die Theurgen in Dlouho stáli... befinden sich jedoch in einem Noch-Nicht-Zustand; sie überwinden zwar das "hundertjährige tragische Träumen" $(1,2)$, sie sind aber verpflichtet, nach der Vollbringung ihrer Aufgabe auf Erden, die Grenze zum Jenseits (erneut) - über die Grenze der Immanenz hinweg - zu überschreiten. Daher thematisiert die abschließende Strophe von Dlouho stáli... den 
Aufbruch der theurgischen Dichter; durch das Erlebnis des Schmerzes (VII, 1) werden sie daran erinnert, daß ihr 'Erlösungswerk' zukünftig fortgesetzt werden muß: "neznámá města všech Cekajícich $/ . . / \mathrm{V}$ miČeni věkủ se pred nimi zrcadlily", VII, 3-4; "die unbekannten Städte aller Wartenden /.../ spiegelten sich vor innen im Schweigen der Zeiten"). Dieses Schicksal teilen sie mit den "Glücklichen" (Stastni): "ze zahrad neviditelných, jeż čkaji vašeho dila" (V. 30; "aus unsichtbaren Gärten, an deren Wachstum als Reis die unzähligen Toten gepfropft sind, eures Werkes zu harren"; übers. v. F. Werfel). Zum SchluB der beiden Gedichte wird noch einmal das Medium des spirituellen Kampfes ins Gedächtnis zurückgerufen: das Gebet. "A kdyż odešli, byl odchod jejich bratrím jako ticho, $v$ nëmż dozněla modlitba" (Dlouho stáli..., VIII, 1; "Und als sie fortgingen, da war ihr Fortgehen den Brüdern wie Stille, in der ein Gebet verschwebt"). "I... I a modlitbou svoji jediným úderem křidel dostihli vonných snú zemè" (Stastni, V. 29; "mit einem Flügelschlag eures Gebets habt ihr erreicht den Traumduft der Erde").

In der Hierarchie der mythogenen Schöpfer-Gestalten stehen die "Heiligen" zweifelsohne höher als die "Starken" (Svitáni na západẻ), die die Entweltlichung und die individualistische unio mystica als das höchste Ziel anstreben, während die "Heiligen", indem sie am Leiden des "Höchsten" partizipieren, auch der Herrlichkeit seiner Liebe, die innen die wahre Gnosis des "göttlichen Willens" offenbart, teilhaftig sind:

"A bolest tvá tvưrči / až $k$ posledním končinám vesmiru zalká /.../. Nebot' i ty, o Věcný a Trikráte Svatý, I v propastech svěho nitra, / kde tisice vesmirú mrtvých a budoucich dr̂imá, / chováš svủj sen / a k němu se bližiš úzkosti lásky / tajemstvím věkư". ("Und Schmerz Deines Schaffens / stöhnt an die letzten Grenzen des Alls /.../ Denn auch Du, o Ewiger und Dreifach Heiliger, / in den Schluchten Deines Innern, / wo unzăhlig verwest und zukünttige Welten schlummern, / wiegst Deinen Traum / durch das Wunder der Zeiten beugst Du dich über inn / mit dem Augenblick der Liebe", V. 6-7, 21-26).

Man versuchte Bïezinas Auffassung des Willens im Kode des Solipsismus zu interpretieren und das Postulat "Jsem absolutni Vüle" ("Ich bin der absolute Wille") von Ladislav Klíma auf das Werk Brezinas zu applizieren. 371 Solche Deutungen und Vorstellungen von der poetischen und gedanklichen Eigenart Bïezinas lyrischen Werkes sind grundsätzlich verfe hlt. Selbst in Poledni zráni (Mittäglich Reifen), wo die Semantik der "Stärke" am deuttichsten auf die Thesen Nietzsches zu alludieren scheint (allerdings nur auf den ersten Blick), betont das lyrische Ich: "Byla tvá Vủle, o Vě̉ný! Pokomé léto tvé zpivám!" "Dein Wille war es, o Ewiger! Demütig singe ich Deinen Sommer!", V. 41). Man muß in diesem Kontext mit allem Nachdruck erneut daran erinnern, daß der Wille bei Bïezina eng mit dem Glaubensakt und Gebet (als Ausdruck eschatologischer Existenz) verbunden ist, in welchem dem Glaubenden die Verbundenheit sowie die Distanz zum "Höchsten" geoffenbart wird. 372 Darüber hinaus bedeutet der Akt des Willens (und Wollens) bei Brezina das Verantwortlichsein, das durchaus in die Zukunft gerichtet ist. Denn in der Auffassung Brezinas ist das Wandeln des Menschen im "sichtbaren" wie auch "unsichtbaren" kóopos, in der (Heils-)Geschichte, stets zukunftsorientient. 373

371 Vgl. Jaroslav Kabeš, „Filosof vüle a jeho myslitelské dilo", in: Stavitel chrámu. Památnik básnika a myslitele Otokara Błeziny, hrsg. von Emanuel Chalupnỳ u. a., Praha 1941. S. 92-144 (insb. S. 112-113, Brezina a Klima). Signifikanterweise kommt in der Phase des dekadenten Symbolismus (Tajemné dálky / Geheimnisvolle Femen) das Lexem "vulle" (der Wille) nicht vor.

372 Diese Intention kommt in einigen Gedichten des letzten vollendeten Zyklus Ruce (Hãnde, 1901), in dem die Frequenzkurve des Lexems "vủle" ("Wille") - im Zusammenhang mit dem Subjekt des "Hochsten" - ihren Kulminationspunkt erreicht, deuttich zur Geltung (Chvime se nad moci vüle / Wir beben vor der Macht des Willens. Mista harmonie a smíreni / Die Orte der Harmonie und Versönnung u. a.): "A neznajice již bolesti jiných než nejtajemnéjši všech ztrát / na prahu vnitřnich tvých svétú blizkosti tvoji se bát -" (Mista harmonie a smíreni, VIII, 1-2; "Und wissend nicht mehr von anderen Schmerzen als dem des geheimnisvollsten aller Verluste / auf der Schwelle deiner inneren Welten sich fürchten vor deiner Năhe -").

373 Biezinas "unerschütterliches Vertrauen in die Zukunft" erfaßt sehr schön Urs Heftrich zum Schluß seiner Arbeit (Otokar Błezina, Heidelberg 1993, S. 335-337). Błezina lehnt resolut die Rousseauschen Spekulationen über die vermeintlich paradiesische Frühzeit des Menschen ab und betont die Verantwortung gegenüber der Zukunft (sowie der Vergangenheit), auf der die Einheit der Geschichte fußt. "Den eschatologischen Prozeß, auch wenn er gigantische Zeiträume in Anspruch nimmt /...l, vermag nichts aufzuhalten, da verborgen hinter inm die Vorsehung wirkt. I.../ Der Mensch vertügt als erkennendes Wesen über das Privileg, daß er den .Text, dessen 
Es ist die Aufgabe der "Heiligen" / Theurgen, die zu ihrem Ziel - zur Erkenntnis des göttlichen Heilsplans durch das Charisma der Agape - durch die "enge Pforte" schreiten, ihren irdischen Mitbrüdern (Dlouho stáli... / Still standen sie lange..., Noci! / Nächte!, Láska / Liebe) die ethische Forderung, das Platonsche Agathon, ins Gedächtnis zurückzurufen und ihnen den Weg zum "höheren Licht" ("vyšši svêtlo"), zu neuen, höheren Formen des geistigen Seins, zu weisen:

"Novým pisnirn učili pozemskou lásku, úsměvy novému kouzlu, / večery jinému hovoru duši a zardẻni jeji v rozkoši tr̉ásti se bázni: I v skr̉iženi zrakủ, jež do dálek sviti, v polibcich vonnỷch prístimi rủžemi, / Ciši svou podati do noci k prípitku nenarozených" (Dlouho stáli... / Lange standen sie..., V, 1-4; "Neue Lieder lehrten sie der irdischen Liebe, neuen Zauber dem Lächeln, / den Abenden andere Gespräche der Seelen und ihre Rōte lehrten sie in der Wonne furchtsam zu zittern: / im Kreuzen der Blicke, welche in die Femen leuchten, in duftenden Küssen zukünftiger Rosen, / ihren Becher in die Nacht zum Zutrunk der Ungeborenen zu erheben". Übers. v. F. Wertel).

\subsection{Grundbestimmungen der eschatologischen Existenz: Glaube - Hoffnung - Liebe}

„Nun aber bleiben Glaube, Hoffnung. Liebe. diese drei, aber die Liebe ist die größte unter ihnen."

\section{Korinther 12,13}

Um den relevantesten Unterschied zwischen der Axiologie des gnostischeschatologischen (Svitáni na západê) und der des theo-logisch-eschatologischen Modells (Vêtry od polư) Bïezinas eschatologischen Symbolismus zu erfassen, muß man von der unterschiedlichen Auffassung des Begriffs der ww̃ous (Gnosis) ausgehen. Im gnostischeschatologischen Modell (SZ) bezieht sich rwāots auf die Erkenntnis der kosmischen Gesetze, der Geheimnisse der Schöpfung und vor allem auf die Befreiung von der 'niederen' Welt durch erlösende S e I b s t-Erkenntnis. Im theo-logisch-eschatologischen Modell (VP) koinzidiert der Begriff der ww̃os in erster Linie mit der ex i s t e n ti e ll en Erkenntnis des Heilsplans und des Willens des "Höchsten" im Lichte der drei grundsätzlichen Bestimmungen der eschatologischen Existenz. Das Geistige, das Pneumatische, manifestiert sich hier - ăhnlich wie in der paulinischen und johanneischen Christologie - als Kraft und Wille, d. h. als die Tat Gottes. Die "Kraft" bzw. "Stärke" ist in Vëtry od pólü offensichtlich als dynamis (des Geistes) zu verstehen; die übliche Interpretation der "Kraft" als Reflex des Nietzscheanischen Übermensch-Kultes greift auf jeden Fall zu kurz. Die in Svitáni na západẻ und in Vêtry od polú vielfach variierte Formel 'in der Schwäche liegt die Kraft', rekurriert unverkennbar auf die apostolische Sendung: "Und er hat zu mir gesagt: Laß dir an meiner Gnade genügen; denn meine Kraft ist in den Schwachen mächtig. Darum will ich mich am allerliebsten rühmen meiner Schwachheit, damit die Kraft Christi bei mir wohne" $(2$. Kor. 12, 9). Die Starken in Vètry od pólü sind

Entzifferung zugleich sein Ende sein wird, wenn sich die Zeiten entüllen“ (.text, jehoż rozluštěni bude zároveñ ukončenim, až se naplní věky" [Essay Rozhodujić okamžiky / Entscheidende Augenblicke aus der Essay-Sammlung Hudba pramenú / Musik der Quellen, 1903; Anm. J.V.J). einsehen und aufgrund dieser Kenntnis den Fortgang des Geschehens bewußt unterstützen kann I...." (U. Heftrich, ibid. S. 336). Vgl. dazu auch folgendes Zitat aus Heideggers Sein und Zeit (Tübingen 1927, S. 386): "Das eigentliche Geschehen der Existenz entspringt aus der Zukunft des Daseins". Und auf S. 395: "Auch die historische Entschließung zeitigt sich aus der Zukunft". Ähnlich definiert auch R. Bultmann in seiner glänzenden Darlegung . Christlicher Glaube und Geschichte" (in: Ders., Geschichte und Eschatologie, Tübingen 1958, S. 164ff.) das geschichtliche Sein als Sein aus der Zukunft. In der Entscheidung des Glaubens und der Verantwortung vor der Zukunft entscheidet sich der Mensch zugleich $/ . . . /$ für ein neues Verständnis all meines verantwortlichen Tuns, - nicht so als ob [inm] der Glaube die je vom geschichtlichen Augenblick geforderten Entscheidungen abnehmen würde, sondern so, daß alle [seine] Entscheidungen, all [sein] verantworttiches Tun von der Liebe getragen ist". (Vgl. ibid. S. 181). 
stark in ihrem Glauben und ihrer Liebe, die, als Gaben des Geistes, zu der wahren rvõorı̣ führen.

Die Trias "Glaube" - "Hoffnung" - "Liebe", die eine unzertrennbare zueinander korrelierende Einheit bildet, kann als semantische, sinnzentrierende Konstante des in Vétry od polü konstituierten Welt-Modells betrachtet werden. Im Falle von den drei Schlüsselgedichten des Zyklus, Královna nadëji (Die Königin der Hoffnungen), Poledni zráni (Mittäglich Reifen) und Láska (Liebe), kann man direkt von einem 'eschatologischen Triptychon sprechen. Auf Bïezinas schöpferische Auseinandersetzung mit der johanneischen und paulinischen Theologie deuten zahlreiche intertextuelle Rekurrenzen sowohl auf die Paulus-Briefe als auch auf das Johannes-Evangelium hin. Der Rekurs auf die paulinische (und johanneische) Theologie hat in Vëtry od pölư seine Logik, denn es ist gerade die Theologie von Paulus und Johannes, in der das Substrat des gnostischen Mythos (und seine Begrifflichkeit) in modifizierter Form wirksam ist. Vor allem das "größte" aller drei Charismata, die Liebe (¿yórm), die als wunderbare Geistesgabe den (in der Hoffnung) Glaubenden und Liebenden die wahre existentielle Erkenntnis öffnet, hat im semantischen Arrangement von Větry od pollu einen zentralen Ort. Die Überwindung der erotischen Liebe (= "lákáni do tmy" / "Lockrufe in die Dunkelheit"), die Br̈ezina postuliert, 374 eröffnet neue Perspektiven der s p i r i t u e 1 l e n " "reinen Liebe":

"Noci, v nichż proudy mystické lásky dušemi vanou od svéta $k$ světu / a ze zrakủ zári podmaňujić hloubkou budoucich svẻtel!" (Noci! / Nächte!, V. 3-4; "Nächte, in denen die Ströme der mystischen Liebe wehen durch die Seelen von Welten zu Welten / und aus den Blicken strahlen mit der bannenden Tiefe zukünftiger Lichter!"). "Zraky naše ji pily z bratrských zrakủ a pohledưm bratrú ji dávaly piti" (Bratrství věricich / Die Bruderschaft der Glaubenden, II, 4-5; "Unsere Blicke tranken sie aus Bruderblicken und gaben sie Bruderblicken zu trinken").

Bei näherem Zusehen stellt man fest, daß hinter der "mystischen" bzw. "reinen" Liebe sich das Charisma der Agape verbirgt; das Gedicht Láska (Liebe) ist, wie noch zu zeigen sein wird, ein glănzender Beweis hiertür. Die Liebe ("láska") manifestiert sich (in VP) - im Zusammenhang mit dem Glauben (rious), der in ihr wirksam ist (Bratrstvi vérícich / Die Bruderschaft der Glaubenden) - als eschatologisches Phänomen. Die Liebe (óyরurm) kann auch deshalb als eschatologisches Phänomen bezeichnet werden, weil sie die erste Frucht des Geistes ist. ("Die Frucht aber des Geistes ist Liebe 1... "; Galater 5, 22). Der Glaubende gehört durch seinen Glauben der Sphäre des Geistes an. Das Leben "im Fleisch" ist das 'uneigentliche Leben'. Dieses pneumatologische Verstehen der Liebe entspricht, wie schon erwähnt, der Intention der Spiritualisierung und Theo-logisierung des Welt-Modells in Vètry od pólü. In Mučenici (Die Märtyrer) unterscheidet Bíezina die profane (erotische) Liebe ("láska"), die Sünde ("hrǐch") und die spirituelle Liebe ("Láska", groß geschrieben). Sich der finsteren, licht(-geist-)tötenden Macht der Begierde und Sünde hinzugeben, bedeutet sein Subjekt-Sein zu verlieren. Dadurch büßt der Mensch als wollendes Ich - seinen Willen zum Leben und sein Selbst ein, um das es inm gehen soll. 375 Die Sünde ist zwar schon immer da, die Veranlagung zu ihr liegt im menschlichen Ich; der Mensch darf die Selbstüberwindung zum Willen nicht aufgeben, da das göttliche Gebot, wie R. Bultmann betont, dem Menschen als ein "du sollst" (nicht) begegnet. Diese Problematik begreift Biezına (vor allem in V'stry od polü) als existentielle Problematik. Signifikanterweise bezahlen die "Märtyrer der Sünde" ("mucenici hřchu") ihre Verfallenheit der Sünde - besser: dem ominösen Sich-verblenden-lassen von der Sünde, das wiederum

374 O. Biezina, .Dva listy", in: Wiener Slawistischer Almanach, 4, 1979, 210. Vgl. auch den Passus aus Błezinas Brief (vom 23. X. 1897) an F. Bauer: "Velcí prożivaji všechny boửe lásky boửemi vlastni své duše /.../. Jdou żivotem teskni oním tesknem, které nabývá vznešenosti $z$

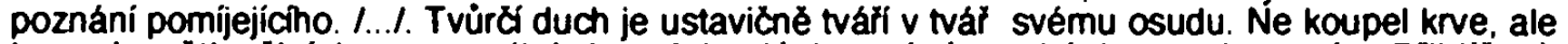
koupel světla Ciní ho nezranitelným. Jeho láska stává se Láskou, tajemstvím Pł̉ibliženi, rozechvěnim z omamujici blizkosti pravdy". (O. Bł̉ezina, Dopisy Frantisku Baverovi, Praha 1929, S. 212-213; "Die Großen erleben alle Stürme der Liebe durch die Stürme der eigenen Seele I... Sie schreiten durch das Leben, wehmütig durch die Wehmut, die ihre Erhabenheit aus der Erkenntnis des Vergănglichen gewinnt. I.../ Der schöferische Geist steht ununterbrochen von Angesicht zu Angesicht seinem Schickksal. Nicht das Bad des Blutes, sondern das Bad des Lichtes macht ihn unverwundbar. Seine Liebe wird zur LIEBE, zum Geheimnis der Annäherung. zur Erregung von der berauschenden Năhe der Wahrheit").

375 Vgl. dazu die Darlegung von Rudolf Bultmann, .Das Problem der Ethik bei Paulus*, in: Exegetica, hrsg. von Erich Dinkler, Tübingen 1967, S. 36-54). 
die Erkenntnis der wahren Liebe ("Láska") unmöglich macht - mit dem Verlust des Selbst, mit dem Entleeren des Seins und mit der quälenden Apophatik:

-Mußenici hřchu: Záhadni, kteř sami sebe hledali mamé / a na smèr cesty své k sobé ptali se vlastniho smichu ironického. / Tvári svých poznati chtěli skJonéni k zrcadlu krve / a v slzách żeny

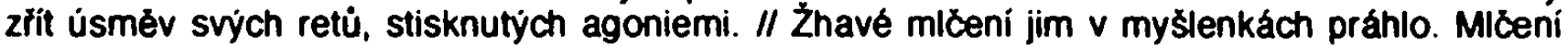
hrobu a casu, / jak hnévivé echo radosti jejich. Miceni prisah a tiže / na rtech umirajicich. A kdyż Láska vyšla o slavnostech svétla, by líbala duše, stín viny padi jim na tvá̉ a zménil je v neviditelné" (Mučenici I Märtyrer, Str. VIII-IX). ${ }^{376}$

\subsubsection{Die Hoffnung auf die 'Enthüllung' der eschatologischen Zukunft: Královna naději (Die Königin der Hoffnungen)}

„Nun aber, liebe Brüder, wenn ich zu euch käme

und redete in Zungen, was würde ich euch nützen, wenn

ich nicht mit euch redete in Worten der Offenbarung oder

der Erkenninis oder der Prophetie oder der Lehre? /...J

Wer also in Zungen redet, der bete, daß er's auch auslegen

könne“.

1. Kor. 14,$6 ; 13$

\section{Královna nadějí}

Obrazy odpovídala jsem bolesti svêtla a obdivem véxnému Mistru.

Dech Casu jsem zatajila $v$ sobê, když hudbou mi mluvila krása.

Tisíci hlasú se tázaly formy a bratrské dư̌e živých a mrtvých

a vłem jsem odpovídala.

5 Slunci, jež spočinutí zraků mých v dálce rozválo vichtici žhavého plání. nocím. když roztesknily se písnémi płedvěkých noci a zajatých duši. i snủm. když uraženy jásotem polibků od lože milencủ prchly. a Cekajíce, až lítost jim otevł̌e dvéte, bloudily v zahradách vủní. Unavila jsem se množstvím pohledủ. které jsem vyslala $k$ slavnostem hvězd

10 a které pro nesmírnou dálku se už nevráti ke mně na této zemi.

Odpovídala jsem výkfikủm. jež nad hlavami spících národủ letí, modlitby Velkých. oblaky věčň̌ho slunce. jež od věkủ do věkủ houstnou a táhnou nad osením duší a nesou vláhu budoucím neznámým květưm a západủm purpurné záłe. Větry dávaly dech svưj mému odpovídání a vlály mým šatem jak kł́dly

15 a pološera kroužila nebeskými vưněmi nad mými nápoji z pozemských zdrojú.

$K d y z ̇$ jsem se sklonila $k$ věcím. svưj vlastni obraz jsem $v$ neš̌etných reflexech złela, podobna svíci, jež uprostłed do úhlứ složených zrcadel zažihá lustry tisíceramen a v klamných hlubinách magických perspektiv tisíckrát najednou hasne.

Paprsky, které jsem sama vysílala,odrázely se do mne s palzivou trýzní

20 a omdlivala jsem vdechnutím dechu, který jsem sama vydechovala.

Poznala jsem nevémou upłímnost barev. záhadné Sepoty stíní

i క̌ilený smích měsíxního světla płi náhlém procitnutí v úzkostech.

376 "Mărtyrer der Sünde: Die rätselhaften, weiche sich selber vergebens suchten, und nach dem Weg zu sich selbst den eigenen ironischen Schatten fragten, / eigenes Anttitz wollten sie erkennen, zu dem Spiegel des Blutes geneigt / und in den Trănen des Weibes das Lăcheln der eigenen Lippen erblicken, von Agonien zusammengepreßt. // Glühendes Schweigen brannte in ihren Gedanken. Das Sctiweigen der Gräber und der Zeit, / wie zorniges Echo ihrer Freude. Das Schweigen der Schwüre und der Schwere / auf den Lippen der Sterbenden. Und als die Liebe am Fest des Lichtes herauskam, I die Seelen zu küssen, da fiel auf ihr Antlitz ein Schatten der Schuld und machte sie unsichtbar". 
Mé nuce chytaly stłely neviditelné, jež letěly do srdce tvêho, a tušení smrti jsem sytila nejsladX́imi plody tvých zahrad.

25 Ttpytem motylího letu se nesla má slova, bez bázné sedala na plameny, a když, étemá, odpoxívala na kvêtech, ani jimi nezahoupala. Odpovídala jsem bolestem zápasícího svêtla v záhadném pohledu zvif́at i v namáhavém rozpuku poupat na krystalných kełích, rostoucích z kołenủ hmoty, i bolestem, které mi pricházely naproti cestami rủzí

30 a v Zízni mne cekaly u pramenú vod a v poledním Záru pod stíny stromú Naucila jsem se fexím vł̌ech naději a každé jsem v jeji fexi odpovídala: těm, které mluvily šilenstvím věsteb zmámeny parami země - svou písní. a modlitbami svými těm, které nemluví pozemskou fex̌i.

Má snění zmírala v závratích Żivota, jenž oddechem staletí rytmicky stoupá a klesá.

35 a v krvavých soumracích dohơivajících a tvołících se sluncí, ve vưních zemí, jež płed věky zchladly, a těch, které žhavé tekají květú, boư̌emi éternych mơ̌i jsem jásala výkłiky osvobození.

VŁak procitlá, odpovídala jsem pokomé hlubokým radostem země, když ke mně se bázlivĕ tulily, oxi odvracejice.

40 abych neviděla slzí, jež kanou jim z osinexni mého pł̌lì̌ jasného světla.

A když unavená tolikerými odpověđơmi jsem smutná sklonila hlavu. těsila jsem té v podobenst vích.

Stíny jsem házela na tvưj mystický plamen, aby krví ti v soumracích jasněji záril. $v$ boứení vichri jsi uslyšel údery světla a let zemè. jak prostorem vîfí.

45 Ukázala jsem ti, že za noci propadají se dna pozemských moł́ a 2 hlubin že tłpytí se obrazy světủ, drobne jen slabým tvým zrakủm. Hudbu fíjnovych paprskủ podložila jsem textem májovych písní. a v korunách opadávajících stromú jásali ptáci, ktetí se vrátí.

A když zesmutněla tvá láska, płinášela jsem ti pozdravení zápasících

50 a vichłicí Casu, jež zdvihá oblaky prachu na cestách budoucích dư̌í, zanásela jsem $k$ tobé chorály svatých, ktě̌i budou rozkazovati odpovídáním (neb vuile svatých je květem, jenž roste za magického Žehnání hvězd, a mystický, otvírá poklady ukryté staletí v hlubinách skla).

Tak mluvila ke mnex má duše a tváł jí letěla vzpomínka na posvátnou chvili.

55 až sat zemè spadne jí z étemých údủ a zazvoní paprsky płelomenými a až płed otcovským pohledem Nejvyక̌šiho, zardžlá vonnou krví své nesmrtelnosti, bude pro věky odpovídati.

$\checkmark$ zárení pohledu jejîho videl jsem do hlubin tisíciletím a $v$ hlasu jejím bylo zpívání světel, jež odpoxívaji v proston, neviditelná.

60 vyslaná $z$ posledních sluncí a koupaná ledovou lázní, když omdlela dálkou. Nejhlubł́ myšlenky vêcí ji radostné pozdravovaly. i nazval jsem ji v opojení té chvile královnou nadějí.

\section{Die Königin der Hoffnungen}

Mit Bildem antwortete ich dem Leide des Lichtes und mit Erstaunen dem ewigen Meister. Den Atem der Zeit, wie hielt ich ihn an, als mit Musiken die Schönheit mir zusprach. Das Stimmentausend der Formen, die Bmderseelen der Lebenden und Toten, sie stellten und allen, allen stand ich da Antwor. mir zugewendet die Frage.

5 Der Sonne, die meinen ruhenden Femblick zerpeitschte mit ihren lodemden Flammenstürmen, den Nächten, die von Liedern der Vornacht und eingekerkerten Seelen bang sind, den Träumen auch, die hinweggekränkt vom Jauchzen der Küsse, das Lager der Liebenden

sie, die in Gärten der Düfte irren, wartend bis Reue wieder öffnet das Pförtchen. flohen, $O$ wie müde bin ich von meinen unzähligen Blicken, entsendet zum Feste der Sterne. 
10 die aus allzu maßloser Ferne nicht heimkehren mehr, nicht mir noch der Erde.

Ja! Antwort gab ich den Schreien, die in den Gebeten der Großen zu Häupten der schlafenden

Vöker flattem,

Gebete, Wolken der ewigen Sonne, verdichtet von Äon zu Äon, ihr zieht uiber die Saaten der

und bringt eure Feuchte den unbekannt künftigen Blüten, den späteren Untergängen von

Seelen,

Meiner Antwort liehen Winde den Odem und wehten mein Kleid mit Flügelhauch auf

15 und die Halbdunkel kreisten mit himmlischen Duften über dem Trunk aus irdischen Brunnen.

Und als ich mich neigte hinab zu den Dingen, da sah ich in tausend Reflexen mein Bildnis.

Denn die Kerze - inmitten sich winkelnder Spiegel - entzündet viel tausendarmige Lüster, und in der Trug-Tiefe der magischen Perspektive löscht sie sich selber tausendmal aus.

Strahlen, entsandt aus mir selbst, sie stürzten sich wieder in mich, geschunden,verbrannt!

20 Ich selber, wie sank ich zusammen, da den eigenen Atem ich sog!

Ich erkannte der Farben trügrischen Gradsinn, das rätselvolle Getuschel der Schatten, und auch das irre Gelächter des Mondlichts, wenn man plötzlich in Ängsten des Albdrucks

aufwacht.

Meine Hand fing den unsichtbar jagenden Pfeil auf, der in das Ziel deines Herzens schwirrte, und ich stillte den Hunger der Todesahnung mit den süßesten Fruchten aus deinen Gärten.

25 Der Glast des Schmetterlinsflugs trug mein Wort, das furchtlos sich niedersenkte auf Flammen, und als es ätherisch ausruhte auf Blüten, da kamen nicht einmal ins Schwanken die Blüten. Antwort gab ich dem Schmerz des ringenden Lichts im unverständlichen Blick der Tiere. Antwort ihm in dem krampthaften Platzen der Knospen, die auf kristallenen Sträuchen den Wurzeln des Stoffes entsprießen!

Antwort dem Schmerz, der entgegen mir kam auf den Wegen der Rosen;

30 er harte dürstend meiner am Quell und in Mittagsglut unterm Schatten der Bäume.

Aller Hoffnungen Sprache lemte ich aus, in jeder Sprache ihnen Antwort zu geben:

Mit meinem Liede den Hoffnungen, die vom Erddampf betäubt, Orakel sagen im Wahnsinn, und mit meinen Gebeten den andern, die irdische Sprache nicht sprechen.

Mein Traum erstarb im Taumel des Lebens, das steigt und das sinkt im Atemmythmus seiner

35 und im blutigen Zwielicht ausbrennender und sich bildender Sonnensysteme.

Epochen,

Es starb in den Duften längst schon vereister Erden und solcher, die glühend der Bluten noch

Ach! In den Sturm ätherischer Meere jauchzte ich hin in den Schrei der Erlösung.

warten!

Aber erwacht gab ich demútig Antwort den armen, armen Freuden der Erde,

als sie sich furchtsam schmiegten an mich, zur Seite wandten die Augen.

$40 \mathrm{daB}$ ich die Tränen rollen nicht sehe, die mein allzu blendendes Leuchten lockt.

Und als ich matt von den vielen Antworten abwärts neigte das Haupt,

da gab ich dir Trost noch im Gleichnis.

Schatten warf ich auf deine mystische Flamme, daß sie im Blut der Dämmerung dir heller

erglänze.

in der Wut der Wetter vernahmst du die Schläge des Lichts, den Flug dieser Erde wie sie durch

45 Ich lehrte dich, daß in den Nächten der Grund der irdischen Meere einstürzt den Raum rollt.

und in der Tiefe es aufblitzt von Welten, nur Splitter und Nichts für dein schwächliches Auge

Der Musik von herbstlichen Strahlen gab ich zum Text die Lieder des Maien.

und in der Krone der laublosen Bäume jauchzten die Vögel, die wiederkehren.

Und als deine Liebe so traurig und schwer ward, da grüBte ich dich von den Kämpfenden, Allen!

50 Auf der Windsbraut der Zeit, die Staubwolken scheucht von den Straßen der künftigen Seelen. trug ich dir her die Choräle der Heiligen, die in der Antwort einst werden befehlen (denn der Wille der Heiligen ist eine Blüte! Sie wächst in der magischen Segnung der Steme, und öffnet mystisch den alten Schatz, der sich in den Tiefen des Berges birgt).

So sprach meine Seele zu mir und es flog ihr über die Wangen ein Wissen der heiligen Weile,

55 wenn das Erdkleid sinkt von den Gliedem, von den ätherischen ihr, wenns erklingt in gebrochenen Strahlen, 
wenn vorm Vaterauge des Höchsten, im duftigen Blut ihrer Unsterblichkeit, für ewig

antworten wird.

Im Strahl ihres Blicks durchsah ich tief das Jahrtausend,

in ihrer Stimme war der Gesang der Lichte, der unsichtbaren Schläfer im Ra

60 die ausgesandt von den letzten Sonnen gebadet wurden in eisigen Bädern, als sie wankten

von Wandermüh

Dem tiefen Gedanken der Dinge scholl freudig ihr Grußwort entgegen,

ich aber in der Verzückung dieser Stunde, ich gab der Hehren den Namen: Du

Königin aller Hoffnung!

Deutsch von Franz Werfel.

In den bisherigen Interpretationen 377 dieses als Ansprache der Anima an das dichterische Ich arrangierten Gedichts, wurden - im Hinblick auf seine Subtextsemantik zwei sinnkonstitutive Referenzsignale verkannt, die zur Dechiffrierung des Textes führen Es ist die im Titel enthaltene, auf die christologische Bedeutung rekurrierende "nadẻje"

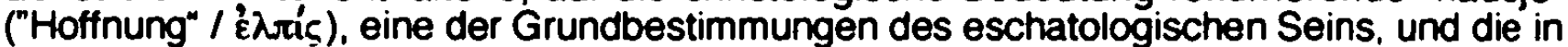
der Semantik des 'Antwortens' aktualisierte Bedeutung der paulinischen hermēneia (1. Kor. 12 und 14), die auf die 'Entkleidung' (Apo-kalypsis) der transzendenten Seinsweise hinstrebt.

In Královna nadéji spricht die Anima den Dichter an, der zugleich als Deuter (hermēneutes) ihrer Rede auftritt: "Tak mluvila ke mnè má duše /... (V. 54; "So sprach meine Seele zu mir /...." "i nazval jsem ji v opojeni té chvíle královnou nadeji" (V. 62: "und ich nannte sie in der Verzückung dieser Stunde Königin der Hoffnungen"). Das dichterische Ich wird implizit in der 2. Pers. Sing. angesprochen, wobei die Referenz des "Du" erst in der oben zitierten Verszeile (54) zum Ausdruck kommt. Das "Du" wird erst im Zusammenhang mit der 'Schutz-' und 'Trost'-Funktion der Anima (V. 23-24, 42) explizit erwähnt (im Prolog und in der ersten Sujetsequenz stellt die Anima, in der ersten Pers. Sing., ihre Aufgaben und ihr Wirken vor): "Mé ruce chytaly strelely neviditeiné, jeż letěly do srdce tvého / a tušeni smrti jsem sytila nejsladśimi plody tyých zahrad" (V. 23-24; "Meine Hände fingen die unsichtbaren Pfeile auf, die in dein Herz schwirten / und den Hunger der Todesahnung stillte ich mit den süßesten Früchten aus deinen Gärten"). Und: "Y.../ tëšila jsem tě v podobenstvich" (V. 42; ".../ ich tröstete dich in Gleichnissen"). In der dritten Sujetsequenz wird das dichterische Ich (als apostrophiertes "Du") zum einzigen Adressaten der Rede der Anima; ihr Wirken bezieht sich hier konsequent auf das "Du", das in der letzten Sujetsequenz (V. 54-62) selbst das Wort ergreift.

Der Gedichttext, den ein vierzeiliger Prolog einleitet, wird von vier Sujetsequenzen gebildet. Die abschließende Sequenz (V. 54-62) wird der Rede des dichterischen Ich eingeräumt, das die "Antworten" ("odpovëdi") der Anima deutend resümiert. Die Sujetsequenzen I (V. 5-18), II (V. 19-42) und III (V. 43-53) sind als 'Monologe' der Seele strukturiert, die signifikanterweise von jeweils einem substantivischen Licht-Motiv (als Attribut der Seele) eingeleitet werden: "Slunce" ("Sonne". V 5), "Paprsky" ("Strahlen", V 19), "Stuny ("Schatten", V. 43). Die Licht-(Strahlen-) und Odem-Motive bilden in Královna nadeji eigene semantische Isotopie; das Licht erhellt und durchleuchtet die in den Dingen verborgenen $\mathrm{H}$ of f $\mathrm{n}$ u $\mathrm{ng}$ e $\mathrm{n}$ auf die eschatologische Zukunft, es ist (als pw̃s) deren 'Mediator' I Offenbarer. Ihre Sendung, das antwortende Deuten der Hoffnungen. spezifiziert die Anima gleich in der ersten Verszeile: "Obrazy odpovidala jsem bolesti svètla I...I. " (V. 1, 27; "Mit Bildern antwortete ich dem Schmerz des Lichtes I... Anima antwortet in "Bildern" ("obrazy": dieses Motiv entspricht hier - in der

377 S. Bouška, .Výklad "Královny nadẻji “", in: O. Błezina, Básnické spisy, hrsg. v. M. Hýsek, Praha 1933, S. 263-265. Vgl. auch: O. Králik, Otokar Blezina, Praha 1948, S. 132t. oder J. Adam [M. Cervenka], "Prchavé symboly snéni", in: O. Bíezina, Nevlastni déti zemé [Anthologie], Praha 1988. S. 203f:: "Ovక̌em jeden z nejtypictéjšich symbolù je symbol duše, nejvyraznéji rozvedený v Královnè nadéji. Duše - a to vlastni duše básnického subjektu - má funkci básnikova společníka. respektive spolećnice; souvisi s motivem samoty a bolesti, básnik s ni vede nescetné hovory". (Ibid., S. 203; .Allerdings ist eines der typischsten Symbole [in Biezinas Werk. Anm. J.V.] das Symbol der Seele, am prägnantesten in Königin der Hoffnungen entfaltet. Die Seele - und zwar die Seele des dichterischen Subjekts - hat die Funktion des Gesellschaftlers des Dichters, respective der Gesellschaftlerin; sie hängt mit dem Motiv der Einsamkeit und des Schmerzes zusammen, der Dichter führt unzählige Gesprăche mit ihr"). 
mythopoetischen Dichtung Biezinas schlechthin - einem Bild-Korrelat und vice versa): Die "(Ab-)Bilder" der Phänomene und Dinge des mundus sensibilis werden gleichsam 'symbolisiert' und in religiös konnotierten Symbol-Bildern sukzessiv (weiter-)entfaltet. Kennzeichnenderweise werden die "Bilder" ("Obrazy") in der abschließenden Sujetsequenz im "väterlichen Blick des Höchsten" (V. 56. "otcovský pohled Nejvyšsiho"). fokussiert. Letzten Endes streben alle Bilder-Symbole die Synthese in/mit der göttlichen Einheit an. Noch expliziter wird die Hauptaufgabe der Anima in der wohl zentralen Aussage des Textes zum Ausdruck gebracht: "Naučila jsem se rex̌ím všech nadēji a každẻ jsem v jeji rézi odpovidala" (V. 31; "Aller Hoffnungen Sprache lernte ich aus, in jeder Sprache innen Antwort zu geben“).

Es erhebt sich zunächst die grundlegende Frage, was das antwortende Deuten der Anima überhaupt bedeutet? 378 Es bezieht sich in erster Linie auf ihre Fähigkeit, die Hoffnung auf die eschatologische Vollendung in allen Dingen aufzudecken und in ihnen das 'Offen-sein' für die eschatologische Zukunft zu erschließen, indem sie den in innen verborgenen göttlichen Funken enthüllt. Die Anima "lernte die Sprache aller Hoffnungen aus, um ihnen in jeder Sprache Antwort zu geben“, $d$. h. sie lernte nicht nur die zutiefst verborgenen Gedanken-Hoffnungen auf die eschatologische Zukunft in jedem Ding zu entdecken, sie lernte sie auch zu verstehen und zu deuten bzw. sie luzid und transparent zu machen. Daher sagt das dichterische Ich im letzten Zweizeiler pointierend: "Nejhlubsi myşlenky věci ji radostné pozdravovaly / i nazval jsem ji $v$ opojení té chvile královnou nadeji" (V. 61-62; "Die tiefsten Gedanken der Dinge grüßten sie freudig / und ich gab ihr in der Verzückung jener Weile den Namen Königin der Hoffnungen").

Diese Fähigkeit ist mit einer besonderen Gabe verbunden, die in diesem Kontext und im Hinblick auf die paulinische Mystik (1. Kor. 12 und 14) mit der Gabe der hermēneia zu korrespondieren scheint. Die Anima vermag auch der extatischen Glossolalie die Gestalt der 'bekannten Sprache' zu geben, sie in einem quasi hermeneutischen Vorgang allen Wesen und Erscheinungen der natura naturata verstehbar zu machen, d. $h$. die Wirkung des Spiritus Creatoris in verständliche Sprache zu übersetzen: "/... / tèm, které mluvily Śilenstvím věšteb zmámeny parami zemé - svou pisni / a modlitbami svými tẻm, které nemluvi pozemskou reci" (V. 32-33; "I... mit meinem Liede [antwortete ich] den Hoffnungen, die vom Erddampf betäubt, Orakel sagen im Wahnsinn / und mit meinen Gebeten den andern, die irdische Sprache nicht sprechen").

Bevor die Funktion der hermēneia näher erörtert wird, soll nun die Sujetbewegung in den einzelnen Sequenzen spezifiziert werden. Im Prolog (V. 1-4) wird das Hauptthema angedeutet: "Tisici hlasú se tázaly formy a bratrské duse zivých a mrtvych a vsem jsem odpovidala" (V. 3-4; "Das Stimmentausend der Formen, die Bruderseelen der Lebenden und Toten, sie stellten mir zugewendet die Frage, I und allen, allen stand ich da Antwort"). Das (gläubige) Sein bedeutet die Bewegung zwischen "nicht mehr" und "noch nicht"; der Glaubende lebt in der Hoffnung auf das, was er erhalten wird, auf das Zukünftige. Die Hoffnung in Králowna nadéji' bezieht sich auch auf die Hoffnung auf die 'Entkleidung' (Befreiung) aus dem irdischen Leib und auf die Herrlichkeit des Jenseits (V. 55-57). Das hermeneutische Wirken der Anima bezieht sich sowohl auf die geomorphe ("formy" I "Formen") wie auch auf die biomorphe ("duse zivych a mitvych" / die Bruderseelen der Lebendigen und Toten") Sphäre; die Hoffnung soll in allen Dingen entdeckt und geoffenbart werden, der Unterschied liegt nur im Modus des Antwortens/Deutens.

378 In seiner Kritik der praktischen Vernunft (Hamburg 1967, S. 155) stell Kant die Frage: .Was dart ich hoffen?" Bei Kant bilden die "Eroffnung" und die "Enwartung" (der Fortsetzung des Daseins) das philosophische Áquivalent der (religiósen) Hoffnung. Diese Auffassung (in der intention der "praktisctien Vernuntt" bzw. aus der Perspektive der Religion der Vernunft) hat schon sehr nahe zur kerygmatischen Hoffnung, vor allem im Aspekt der ('theoretischen') Erwartung einer Ordnung. in der wir "unser Dasein fortsetzen kơnnen"; d. h. das ewige Leben als Realisierung des "höchsten Gutes". Laut P. Ricoeur ist der Begriff des "absoluten Gutes" der einzige philosophische Begriff, der dem Reich Gottes im Sinne der Evangelien nahekommt. Paul Ricoeur, .Die Freiheit im Licht der Hoffnung", in: Hermeneutik und Strukturalismus, München 1973. S. 222. In seinem Brief (v. 15. XI. 1896) an A. Pammrová schreibet Bíezina: \%... / má mystika vycházi $z$ výsledkú exaktnich véd modernich a divala se dlouho do pyšnych perspektiv skoly Kantovy" (O. Błezina. Dopisy Annè Pammrové z let 1889-1905, Praha 1931, S. 147; \%... meine Mystik geht von den Resultaten modemer Wissenschaften aus und sie schaute lange in die stolzen idealistischen Perspektiven der Kant-Schule ein".) 
In der ersten Sujetsequenz (V. 5-18) steht die Bezıehung der Anima zur Sphäre des Lichtes, des Göttichen, im Vordergrund . Das "Licht" als Attribut des "Ewigen" indiziert die Äquivalenzrelation "vë̌̉ný Mistr" ("ewiger Meister", V. 1) - "věčné slunce" ("ewige Sonne", V. 12, als das göttliche, männliche, geistige Prinzip). 379 Überdies läßt sich hier kaum die hochrelevante Beziehung der Licht-Symbolik zur Dunkelheit übersehen: "noc" ("Nacht", V. 6). "pološra" ("Halbdunkel", V. 15) oder die oxymorale Metapher "západy purpurné záre" ("Untergänge von strahlendem Purpur", V. 13). Diese oxymorale bzw. oxymoral-paradoxe Motivik läßt mehrere Deutungen zu, die die Enthüllung-Symbolik antizipieren: Das Licht erscheint als enthüllende Macht, die das Verborgene sichtbar werden läßt. Das Licht ist das vorausgesetzte Medium der in der Dunkelheit der Nacht, im Schatten 380 - oder im Halbdunkel - verhüllten Erkenntnis der in jedem Ding verborgenen Hoffnung (auf die eschatologische Zukunft). ${ }^{381}$ Und schließlich das Licht als Spiegelreflex: "Kdyż jsem se sklonila k vẻcím, svưj vlastni obraz jsem v nesčetných reflexech zřela" (V, 16). ${ }^{382}$ Die Anima spiegelt sich in den realen Dingen der diesseitigen Welt: "der Kerze ähnlich, die inmitten sich winkelnder Spiegel, / viel tausendarmige Lüster entzündet / und in der TrugTiefe der magischen Perspektive löscht sie sich selber tausendmal aus" (V. 17-18; "podobna svici, jeż uprostred do úhlú složených zrcadel zažíhá lustry tisice ramen / a v klamných hlubinách magických perspektiv tisickrát najednou hasne"). Diese Vorstellung geht offensichtlich auf die Spiegelsemantik des dekadenten Symbolismus (Tajemné dálky Y Geheimnisvolle Fernen) zurück, in dem die Natur-Welt als fahler Reflex der intelligiblen Welt bloßgelegt wird (vgl. Kap. 2.2.1 Vézeñ / Der Gefangene). Die Natur-Welt erscheint als Produkt eigener Einbildungskraft, als ein Spiegelkabinett, in dem das Ich nur sich selbst erblickt. In Královna nadeji verschiebt sich die Bedeutung der Spiegelbild-Metapher: Die Anima sieht ihre eigenen unzähligen Reflexe in den Dingen (der Erde), zu denen sie sich hinabneigt. Sie ("der Kerze ähnlich", V. 17; d. h. als "Verklärungsleib") sieht die Reflexe des Lichts auch in den Dingen der dinglichen Welt, $d . h$. auch das (göttliche) Licht, dessen Reflex die Anima selbst ist, das verborgen in den Dingen liegt, wartet auf seine OffenbarWerdung. Ihre Kompetenz die Lichtreflexe in den Dingen zu sehen gründet darin, daß sie ihre Energie ("nápoje" I "Trunk", V. 15) auch - neben den "himmlischen Düften" ("nebeské vưnè zdrojü", V. 15).

Die Anima "antwortete den Schreien, die über den Häupten der schlafenden Völker flattern, die Gebete der Großen, / Wolken der ewigen Sonne, die sich von Äon zu Äon verdichten und über die Saaten der Seele ziehen" (V. 11-12; "Odpovidala jsem výkriküm, jeż nad hlavami spicich národư leti, modlitby Velkých, / oblaky vẻćného slunce, jeż od

379 Vgl. dazu: C. G. Jung, Psychologie und Alchemie, Gesammette Werke. Bd. 12. Freiburg im Breisgau 1972, S. 394 . "Die Sonne ist das Bild Gottes, das Herz ist das Abbild der Sonne im Menschen. Riplaeus ist der Ansicht, man müsse das Feuer aus dem Chaos ausziehen und sichtbar machen. Dieses Feuer ist der Heilige Geist, welcher Vater und Sohn eint. I.../ Dieses Feuer hat Gott in die Erde geschaffen, gleichwie das Fegefeuer der Hölle. In diesem Feuer glühe Gott selber in göttlicher Liebe"

380 Für Hrabanus Maurus ist Christus als der im Schatten Verhüllte zugleich der Enthüllende.

381 In seinem Aufsatz .Licht als Metapher der Wahmeit. Im Vorfeld der philosophischen Begriffsbildung" (in: Studium generale, 10, 1957, S. 432-447) verweist Hans Blumenberg darauf, daß̉: 'Die kosmische 'Lichtflut' ist die Voraussetzung für den Begriff der Offenbarung, die eine Wiederkehr des Lichtes als eschatologisches Ereignis ankündigt" (S. 435). Als Metaphern der 'Lichtflut' erscheinen in der ersten Sujetsequenz "vichr̂ice żhavého pláni" ("lodernde Flammenstürme", V. 5), "Oblaky vẻchého slunce, jeż I.../ táhnou" ("die Woklen der ewigen Sonne. die I.../ ziehen", V. 12), "purpumé zále" ("strahlender Purpur, V. 13).

382 Ein interessantes Motiv, das die Spiegel-Bild-Symbolik in Láska (Liebe, V. 39, vgl. Kap.4.3.3) antizipiert In den orphisch-neoplatonischen Lehren ( $z$. B. in Plotins Aeneaden) existieren Vorstellungen von Begegnungen zwischen Geist und Vision: Nach dieser Vorstellung irren Intelligenzen im Universum, die ihre Seelen auf die Erde projizieren, wo sie reflektiert werden. "Und die menschlichen Seelen? Sie sehen ihre Bilder wie im Spiegel Dionysos, und aus der Hōhe stürzen sie auf sie herab". Vgl. Jurgis Baltrušaitis, Der Spiegel. Entdeckungen, Tãuschungen, Phantasien, Giessen 1986, S. 72. In Královna nadèji (und in Láska) aber bezieht sich die Spiegel-Symbolik möglicherweise einerseits auf die 'Spiegelung' (bzw. Projektion) des Ich-Bewußtseins, andererseits auf den Gegensatz der diesseitigen und der zukünttigen Welt. In der Zukunft wird die eschatologische 'Schau' unmittelbar "von Angesicht zu Angesicht" sein. In der diesseitigen Welt kann sie nur als ein Rätsel wahrgenommen werden. 
věkư do věkủ houstnou a táhnou nad osením duši"). In dieser zentralen Aussage der ersten Sujetsequenz figuriert die Anima als 'Trösterin', weil sie den "schlafenden Völkern" bzw. den "Schreien", 383 die über ihren Häupten flattern, antwortet; $d$. h. sie vermittelt den "Schlafenden" die kerygmatische Hoffnung auf die Auferweckung, wenn die Reife- und Erntezeit angebrochen ist ("nad osením duši" / "über die Saat der Seelen", V. 12). Die "Wolken" konnotieren in diesem Zusammenhang das Wirken (die Gegenwart) des "Ewigen" ("oblaky vežného slunce", V. 12) bzw. die Gegenwart des göttlichen Wortes. Die "Wolken" koinzidieren - im Sinne der für die Mystik signifikanten coincidentia oppositorum - mit "Gebeten der Großen" ("modlitby Velkých", V. 11; das Gebet als Reden mit Gott). Daß die Anima (als "Königin der Hoffnungen") kraft des göttlichen Odems "antwortet". kommt in ihrer Aussage "Vétry dávaly dech svujj mému odpovidání a vály mým łatem jak krídly" (V. 14; "Meiner Antwort liehen Winde den Odem und wehten mein Kleid mit Flügelhauch auf") zum Ausdruck.

Die Ausgangsposition für die Konfrontation der Anima mit dem sensorisch wahrnehmbaren, realen Wesen der Natur in der zweiten Sujetsequenz (V. 19-42), bildet die Isotopie der Strahlen ("Paprsky", V. 19). O. Králík spricht treffend von der "Hypertrophie der Seele". 384 Die Seele muß den Schmerz, die Ohnmacht, die Angst und den Wahnsinn, die ihre Perspektiven verdüstern, ertragen: "Paprsky, které jsem sama yssilala, odrázély se do mne s palcivou trýzní / a omdlivala jsem vdechnutím dechu, který jsem sama vydechovala" (V.19-20). Die lebenspendenden (solaren) Strahlen metamorphieren in lebenschwächende Strahlen des lunaren Lichts: "Poznala jsem nevërnou upiímnost barev, záhadné sepoty stínủ, / i sílený smích mẻsičního svẻtla prii náhlém procitnutí v úzkostech" (V. 21-22). Im lunaren Licht verwandelt sich die Realităt in Irrealität und Sinnestäuschung ("nevêrnou uprímnost barev", V. 21), die Sprache in phantomhaftes Schattenflüstern ("záhadné sepoty stínu", V. 21), der ruhige Schlaf (V. 11) in beklemmendes Erwachen ("procitnutí v úzkostech", v. 22). Diese Metamorphosen werden als "Vorahnungen des Todes" bloßgelegt: "tuśeni smrti jsem sytila nejsladšimi plody tvých zahrad" (V. 24). Die "Vorahnungen des Todes" 'sättigte' die Königin der Hoffnungen mit den vollkommensten "Früchten" ("plody") der schöpferischen Potenz des dichterischen Ich, das hier (V. 23-24) zum ersten Male - als angesprochenes "Du" erscheint. Die Anima tritt (V. 23-24) hier als seine 'Beschützerin' aưf, die die Todespfeile auffängt: "Mé ruce chytaly stỉely neviditelné, jeż letěly do sroce tvého" (V. 23). Metapoetisch konnotiert ist auch der folgende Zweizeiler (V. 25-26: "Tippytem motylího letu se nesla má slova, bez bázné sedala na plameny" (V. 25). Die "Worte" ("slova") / "Früchte" ("plody") aus den "Gärten" des Dichters, senken sich "ohne Furcht" ("bez báznè", V. 24) auf die Flammen nieder. Diese Metapher läßt sich als Reinheit oder sogar Unsterblichkeit 385 des (dichterischen) Wortes bzw. Gedankens interpretieren. Der Nachdruck liegt auf der Adverbialsbestimmung "bez báznè" ("ohne Furcht", V 24), denn die Existenz in der "Hoffnung" (und im Glauben) auf das eschatologische Dasein bedeutet das Befreit-sein von der Angst. 386 Aber die Aufgabe der Anima ist das Ringen um die

383 Vgl. hierzu: "Aber der Geist selbst vertritt uns mit unaussprechlichen Seutzern. Er aber, der die Herzen enforscht, er weiß, was des Geistes Sinn sei (Rom. 8, 27). Vgl. auch den Zweizeiler aus dem Gedicht Noci! (Nächte!): "Noci svatých, bdicích na modlitbách díkú za úrodu, jiż celou rozdali bratríim; / pésinou polni se vrátili, chudi, neviděni pro výsi vastnich svých klasu". ("Nảchte der Heil'gen: Sie wachten in Dankgebeten für Emten, zur Gănze verteilt an die Brüder; / auf dem Feldrain kehrten sie heim, arm und verborgen, im Hochstand der eigenen Ähren". Übers. v. F. Werfel).

384 Oldỉich Králík, Otokar Błezina. Praha 1948, S. 132.

$385 \mathrm{~J} . \mathrm{J}$. Bachofen. Die Unsterblichkeitslehre der orphischen Theologie auf den Grabdenkmálern des Altertums, Stuttgart-Basel 1958, S. 167f. Auf den römischen Grabdenkmălern erscheint die Schmetterling-Darstellung als Sinnbild der Unsterblichkeit der Seele und der Verwandlung. Als Attribut der Psyche wird der Schmetterling auf den römischen Grabdenkmălern oft zusammen mit seinen 'Verfolgern', mit der lauernden Eidechse, mit dem Voget und mit der brennenden Fackel dargestellt. Der Untergang der fieischlichen Behausung ist die Bedingung für durchaus geistiges Daseins. Vgl. auch den Zweizeiler aus dem Gedicht Letni słunovrat (Sommersonnenwende, VP): "Naklon̉ se k rưzím! At úsmév, motýl vyšsíno jara, 2 nich sleti. I vyplasen dotknutím svétla z tvých zrakú, a na ty usedne ti!" (V. 3-4, 9-10; "Neig dich zu Rosen! Mag Lächeln, höheren Lenzes Falter, auffliegen, / gescheucht von Berühnung des Lichtes in deinem Aug, auf deinen Lippen sich wiegen!" Ubers. v. P. Eisner).

$386 \mathrm{Vgl}$. R. Bultmann, Theologie des Neven Testaments, Tübingen 1968, S. $321 \mathrm{f}$. 
'Enthüllung' des (göttlichen) Lichtes, um die Offenbar-Werdung der Hoffnung auf die eschatologische Zukunft in je de m Ding, auch in der tierisch-materiellen Welt, in der Bio- als auch in der Geosphäre; auch hier gibt es Streben nach der eschatologischen Vollendung: "Odpovidala jsem bolestem zápasíciho svêtla v záhadném pohledu zvifat / i v namáhavém rozpuku poupat na krystalných kerich, rostoucích z kořenú hmoty $/$...l. Naučila jsem se rečim všech nadẻji a každé jsem v jeji ré̉i odpovidala" (V. 27-28, 31; "Antwort gab ich dem Schmerz des ringenden Lichtes im unverständlichen Blick der Tiere. I Antwort ihm in dem krampfhaften Platzen der Knospen, die auf kristallenen Sträuchen und Wurzeln des Stoffes entsprießen!"). Das Ringen um Offenbar-Werdung ('Deutung') zieht den Schmerz nach sich (V. 1, 27-28). Im ganzen Kosmos existient die Hoffnung auf die eschatologische Vollendung, die die Anima in ihrer Traumvision sieht: "Má snèní zmirala /...I, I v krvavých soumracich dohorívajicich a tvoricich se slunci, / ve vünich zemí, jež pred věky zchlady a tẻch, které žhavé cekaji květú, / bouremi eterných morí jsem jásala výkriky osvobozeni. / V̧̉ak procitlá /... $/$ (V. 34-38; "Mein Traum erstarb /.../ im blutigen Zwielicht ausbrennender und sich bildender Sonnensysteme, $I$ in den Düften längst schon vereister Erden und solcher, die glühend der Blüten noch warten! / In den Sturm ätherischer Meere jauchzte ich hin in den Schrei der Erlösung. ( Aber enwacht /.../). Die auf ihre Reife - und Erntezeit wartende "Saat der Seelen" ("oseni duš", V. 12) hat ihre Parallele in der Vorstellung der auf ihre "Blütezeit" wartenden "Blüten" der künftigen Erden (V. 36)

Nach der Offenbar-Werdung und Enthüllung des verborgenen Lichts der Hoffnung in der Bio- und Geosphäre des xoouos, sieht die Anima inre (hermeneutische) Aufgabe in der Enthüllung des Lichtes der Hoffnung für das dichterische Ich - der thematische Mittelpunkt der dritten Sujetsequenz (V. 43-53) - , an das sie sich explizit wendet: "Stíny jsem házela na tvüj mystický plamen, aby krví ti v soumracich jasnēji záriil" (V. 43; "Schatten wart ich auf deine mystische Flamme, daß sie im Blut der Dämmerung dir heller erglänze"). In dieser Sequenz kommt die deutende, klärende, er-leuchtende Funktion der Anima am deutlichsten zur Geltung. Damit geht auch die hohe Frequenz der Licht-Motive einher: "mystický plamen" ("mystische Flamme", V. 43), "údery světla" ("Schläge des Lichtes", V. 44). "z hlubin se trpyti obrazy světu" ("aus der Tiefe erstrahlen die Bilder der Welten", V. 45), "magické Žehnani hvězd" ("magischer Segen der Sterne", V. 52). Erneut tritt hier die Anima als 'Trösterin' auf. Sie läßt den Dichter hören/sehen ("jsi uslyšel"), daß auch im tobenden, die "Welten aus den Wurzeln" (Bouře / Der Sturm, IV, 2) ausreißenden Sturm / Odem des strengen "Höchsten" ("bourení vichru", V. 44) das Licht strömt ("üdery světla"). Die Anima läßt den Dichter das Licht der Hoffnung (auf die transzendente Seinsweise) in den für die menschlichen Blicke undurchdringlichen Tiefen sehen (V. 4546), sie erbaut das dichterische Ich in seiner Trübsal mit den Grüßen der um das (gleiche) Licht Ringenden 387 (V. 49) und läßt inn die "Choräle der Heiligen" hören (V. 51-53). Die "Heiligen" disponieren bereits über die wunderbare Fähigkeit, die in den Tiefen "verborgenen Schätze" ("poklady ukryté v hlubinách skal", V. 53), d. h. das (göttliche) Licht der (eschatologischen) Hoffnung, kraft des Willens zu sehen (V. 52-53; "neb vile svatých je kvêtem, jenż roste za magického żehnání hvězd, / a mystický, otvírá poklady ukryté staleti v hlubinách skal") ${ }^{388}$ Es sınd offensıchtlich diejenıgen, die ihre Seele (bereits) "weiß

387 - Ukázala jsem ti, že za noci propadaji se dna pozemskỷch mori / a z hlubin že tĩpyti se obrazy svêtú, drobné jen slabým tvým zrakúm" (V. 45-46: "Ich zeigte dir, daß in der Nacht der Grund der irdischen Meere einstürzt / und aus den Tiefen Bilder von Welten erglänzen, winzig nur deinen schwăchlichen Augen"). Dazu gehōrt auch der "Kampf" ("zápas"): "Odpovidala jsem bolestem zápasicicho svétla" (V. 27), "pozdraveni zápasicich" (V. 49). Was hier gemeint ist, wird später, wenn auch unter einem anderen semantischen Kode, prägnant im Essay Smysl boje (Der Sinn des Kampfes, 1906) formuliert: "A s bolestným instinktem, jenż vyżaduje tajemný zákon zráni

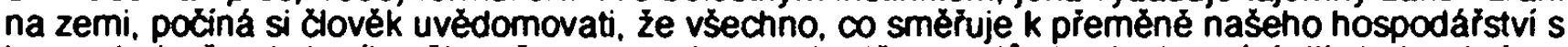
hmotnými vẻcmi, $k$ sile, cistotè, jemnosti a svobodé smyslü, je duchovni úsili, boj o krásu. postedni, do nedozirnè budoucnosti ukazujici boj na zemi. /.../ Co je viditelno tvùrčimu duchu, je viditeino jen $v$ světte. jeż se rine $z$ vyššíno života $v$ kosmu. I ... / dálka płestává být dálkou; utrpeni. Která si uvédomujeme svou všudypritomnosti na zemi, mẻni se v prírodni silu pracujici o prememẻè všeho żivota"

388 Diese "Heiligen" charakterisiert Brezina in einem Brief (vom Sommer 1896) an Anna Pammrová: "Vrcholem żivota na zemi je mi proto svẻtec, v nẻmż nesmrtelná cást jeho bytosti dominuje, rozlěvajici záhr̉evnẻ svêtlo, tajemným vlivem zasahujici osoby, vêci a síly. U něho rozpéti lásky stává se żivotem. I.../ Rozsvíti nadpozemskou nádheru a poznáni vưle bude dáno jen 
und strahlend" gemacht haben, die "mit ihrer Hilfe in allen Kämpfen, 389 die Dunkelheit besiegt haben, die sich in uns aus allen Nächten ansammelt". 350 Daher vergeistigt die Anima (als "Königin der Hoffnungen") auch die erotische Liebe (das 'Erotische' ist hier im Sinne des platonischen 'Eros' gemeint) 391 an ihrer Stelle erscheinen "Reue" ("lítost", V. 7 8), "Hoffnung" ("naděje"). "Erkenntnis", 392 und "Liebe zum Höchsten" (Bratrstvi vërícich / Die Bruderschaft der Glaubenden) inmitten einer eschatologischen Gemeinde. Das Wirken der Anima in der dritten Sujetsequenz kann man nun als die 'Vorbereitung' und 'Führung' (durch das 'Deuten', die 'Offenbar-Werdung', 'Enthüllung' usw.) auf / zur jener Fähigkeit, über die die "Heiligen" (V. 52) bereits disponieren und die auch dem dichterischen Ich in der abschliessenden vierten Sujetsequenz zuteil wird: " $V$ záreni pohledu jejího uvidẻl jsem do hlubin tisiciletím" (V. 58; "Im Strahlen ihres Blicks durchsah ich die Tiefen der Jahrtausende").

In der vierten Sujetsequenz ergreift das dichterische ich das Wort (V. 54-62): "Tak mluvila ke mné má duše l...r (V. 54; "So sprach meine Seele zu mir l... $\mu$ ). Warum kommt hier das dichterische Ich überhaupt zur Sprache? Fassen wir vorerst die Sujetbewegung und die kommunikative Funktion der einzelnen Sujetsequenzen zusammen. Im Prolog ( $V$. 1-4) spezifiziert die Anima ihre Funktion und inr Wirken als "Antworten" ("v\$em jsem odpovidala", V. 4). In der ersten Sujetsequenz (V. 5-18) spezifiziert sie ihre Beziehung zum Licht / Odem, sie erweist ihre 'Fundierung' als die (künftige) "Königin der Hoffnungen"

vyvoleným, staletimi ve skrytých pochodech tvirǩch pripravovaných". (O. Błrezina, Dopisy A. Pammrové z let 1899-1905. Praha 1931, S. 115f. "Den Hơhepunkt des Lebens auf Erden stellt für mich der Heilige dar, in dem der unsterbliche Teil seiner Persönlichkeit dominiert, der das wărmende Licht ergießt [und] mit geheimnisvollem Einfluß Personen, Dinge und Krăfte erfaßt. Bei inm realisiert sich das Leben in der Spannweite der Liebe. I.../ Die überirdische Herrlichkeit und die Erkenntnis des Willens in verborgenen, ganze Jahrhunderte vorbereiteten schøpferischen Prozessen zu entfalten, wird nur den Auserwăhiten zuteil").

389 Die herméneia (und Prophetie) bedeutet auch Erbauung und Tröstung: "Wer aber prophetisch redet, der redet den Menschen zur Erbauung und zur Ermahnung und zur Tröstung" (1. Kor. 14,3).

390 "Svou duši učinit zárici a bílou, osvobodit v ni vše, co ceká na osvobozeni, zvítězit jeji pomoci ve všech zápasech s tmou, která se v nás hromadi ze vふ̌ech noci, jimiž jsme prošli, a ze všech světel, která v nás zhasła, to je pruni a nejdúležitéjši naše práce". Vgl. O. Błezina, "Dva dopisy [A. Pammrovẻ], in: Wiener Slawistischer Almanach, 4, 1979, S. 211.

391 Die 'Metamorphosen des Weibes' im russischen Symbolismus untersucht eingehend A. A. Hansen-Löve, .Sophia-Anima", in: Der nussische Symbolismus. Diabolische und mythopoetische Paradigmatik, Bd. II. Lebenssymbolik, Wien 1984 [Typoskript], S. 542ff. Die Gefahren der erotischen Leidenschaft thematisiert das Gedicht Mucenici (Die Mấrtyrer), das in Vétry od pólü der Královna nadeji folgt. Eine Art Replik auf die spiritualisiente (erotiscte) Liebe der weiblichen Anima (Královma nadẻji) stellt im Zyklus das Gedicht Kde jsem uż słysel ...? (Wo denn vernahm ich schon...?) dar, in dem die Vater-Sohn-Liebe thematisiert wird.

392 Im Kunst-Schőnen, dessen Wesen die Liebe ist, sieht Błezina die gleiche Quelle der Erkenntnis, wie in exakten Wissenschaften: "Extase oteviela nové perspektivy poznáni. Déjiny lidskẻ duše jsou dêjinami jejich snu" ("Die Extase eróftnete neue Perspektiven der Erkenntnis. Die Geschichte der menschlichen Seele in diesem Leben ist die Geschichte ihrer Trăume"), schreibt Błezina im Essay Tajemné v uméni (Das Geheimnisvolle in der Kunst, Januar 1897). Diese Träume soltten jedoch nicht vom irdischien Leben präparient werden: "Má snéni zmirala v závratich żivota, jenż oddechem staletí rytmicky stoupá a klesa" ( Královna nadéji, V. 34). "Nebot' podstatou uméni je láska, která uçi mluviti nẻma ústa a dodává smẻlosti pr̉ilis nesmélým. Jako láska i umèni miluje zemi. I nejspirituelnějši umẻni uznává vdẻcné, że do jejiho svẻtla opiralo svá kłídla, neż mohlo vzletnouti $k$ výsi, $k d e$ vznási se rychlosti extatických pohledu. Zemé zủstane vżdy błehem, $k$ némuż se vraci ze svých vyjprav" (Tajemné v umèni / Geheimnisvolle in der Kunst; "Denn das Wesen der Kunst ist die Liebe, und die Liebe lehrt den stummen Mund sprechen und flöt dem Allzuschüchternen Mut ein. Wie die Liebe, so liebt auch die Kunst die Erde. Auch die geistige Kunst erkennt dankbar, daß sie ihre Fittiche ins Erdenlicht stemmte, bevor sie in Hōhen aufflog, wo sie mit der Schnelligkeit extatischer Blicke kreist. Die Erde wird immer das Ufer bleiben, zu dem sie von ihren Fahrten zurückkehrt". Übers. v. E. Saudek). "Vふak, procitlá, odpovidala jsem pokorné ubohým radostem zemé, / kdyż ke mnẻ se bázlivé tulily, ởi odvracejíce, / abych nevidẻla słzi, jeż kanou jim z osinẻni płriliš jasného svêtla" (Králowna nadéji, V. 38-42; "Aber erwacht gab ich demütig Antwort den armen Freuden der Erde, I als sie sich furchtsam schmiegten an mich, zur Seite wandten die Augen, / daß ich die Trănen rollen nicht sehe, die mein allzu blendendes Leuchten lockt'). 
zu wirken, d. $h$. das (göttlichen) Licht der Hoffnung auf die eschatologische Zukunft für die "Wartenden" (in der ersten Sujetsequenz die "schlafenden Völker") zu enthüllen. In der zweiten Sujetsequenz (V. 19-42) ist ihre Hauptaufgabe (neben der Funktion als 'Trösterin'. V. 23-26) die Enthüllung der Hoffnung auf die eschatologische Vollendung in jedem Ding der tierisch(-vegetativ-)materiellen Welt, $d$. $h$. in der Bio- und Geosphäre des kóouos zu 'erleuchten'. In der dritten Sujetsequenz beziehen sich alle ihre Funktionen auf das dichterische Ich mit dem Ziel, ihm das verborgene Licht der Hoffnung in den "Tiefen" zu offenbaren, inm das Charisma der Hoffnung (żrís), das "was er hoffen kann", zu vermitteln.

In der abschließenden vierten Sujetsequenz ergreift das dichterische Ich das Wort, um - wie es scheint - die Aufgabe und Funktion der Anima selbst zu d e u te n. Er tritt nun selbst als Deuter der Deutung der antwortenden Anima auf, um inr Wirken zu erfassen: "Tak mluvila ke mnẻ má duše a tvári ji letêla vzpomínka na posvátnou chvíli, /.../ až píed otcovským pohledem Nejvyšsiho, zardẻlá vonnou krvi svẻ nesmrtelnosti, / bude pro věky odpovidat" (V. 54, 56: "So sprach meine Seele zu mir und es flog ihr über die Wangen ein Wissen der heiligen Weile, I...I wenn sie vorm Vaterauge des Höchsten, im duftigen Blut ihrer Unsterblichkeit, / für ewig antworten wird"). Dadurch tritt auch der Aspekt des SichBewußt-Werdens, der Ver-Antwortung des lyrischen Ich (seiner Anima) gegenüber dem "Höchsten" (V. 56-57) - und seinen Mitbrüdern - klar zutage. In diesem Nexus offenbart sich aber auch die metap o e ti s che Bedeutung der hermēneia in bezug auf die Wirkung des dichterischen Wortes. Der Dichter (als poeta vates) tritt selbst als hermēneutes auf, er selbst besitzt die Gabe, die Wirkung des göttlichen Geistes in prophetisches Wort zu übersetzen, sie seinen Mitbrüdern zu vermitteln. Diese Intention kommt bereits im Prolog-Gedicht Vládnouci... (Herrscher...) - weniger verschlüsselt als in Králouna nadejii - zum Ausdruck:

"Hlase, jenž zazniváš klenbami vẻkủ, / nebezpečnými boửemi světla, / tmy vodopády, / ve vsudypíitomném mlčeni smrti, jež pokrývá zemi, / bezvětrỉi tvého žhavého pásma rovníkového, / a každému kroku / dává ozvěnu v nekonecnosti! /... IV extasi lásky chci zpivati bratrským dušim, I že neni bolesti většich, / nežli jsou ztracená vítězstvi jejich, / Že neni radostí většich, / nežli je opojeni / zraku věčností sesileného!" (Vládnouá... / Herrscher..., V. 7-13, 29-34; "Stimme, du, die erdröhnst durchs Zeitengewölb, I in gefăhrlichen Lichtgewittern. I in Wassertällen des Dunkels, I in Todesschweigens Allgegenwart, das die Erde zudeckt (Windstille deines glühenden ÄquatorReviers) / und jedem Schritt / Echo leiht im Unendlichen! /... In Ekstasen der Liebe will ich verbrüderten Seelen singen: / Keine größeren Schmerzen sind / als eure verlorenen Siege. / keine größeren Freuden / als die Verzückung des Auges, / das schauender taucht aus ewigem Bad!" Übers. v. F. Werfel). 393

Es ist die Hoffnung ("nadēje") auf die Auferstehung, auf die von der Zukunft erwarteten apo-kalyptischen Eschatologie, auf das "Freisein" für die Zukunft; es ist die Hoffnung auf die eschatologische Vollendung schlechthin:

- Tak mluvila ke mnè má duše a tvári ji letèla vzporninka na posvátnou chvili, / až sat zemé spadne ji s etherných údú a zazvoni paprsky pỉelomenými / a až pied otcovským pohledem Nejvyšsino, zardẻlá vonnou krvi své nesmrtelnosti , I bude pro vẻky odpovidati. I V zá̉eni pohledu jejíno vidèl jsem do hlubin tisiciletim /... (V. 54-58; "So sprach meine Seele zu mir, es flog ihr über die Wangen ein Wissen der heiligen Weile, / wenn das Erdkleid sinkt von den Gliedern, von den atherischen ihr, wenns erklingt in gebrochenen Strahlen, / wenn vorm Vaterauge des Höchsten. errötet vom duftigen Blut ihrer Unsterblichkeit, / für ewig antworten wird. I Im Strahl ihres Blicks durchsah ich tief die Jahrtausende I... $r$ ).

Die Hoffnung auf die Enthüllung (Apo-kalypsis) der transzendenten Seinsweise, auf das Offen-Sein für die Zukunft (antizipient durch das Motiv des Tür-Öfnens, V. 8), ist die kryptierte Botschaft der Královna nadeji. Die Vorstellungen von der Nacktheit der Seele und der Befreiung vom "Erdkleid" ("Sat zeme", V. 55) lassen sich, wie R. Bultmann nachweist, sowohl auf den platonischen Jenseitsmythos (die Seele erscheint nackt vor dem Richter in der Unterwelt) als auch auf die gnostische Tradition (die Hoffnung auf die Befreiung aus dem irdischen Leib) zurückführen. 394 Die Hoffnung auf die Auferstehung.

393 Daß das Epilog-Gedicht Kdyż z lásky tvé... (Wenn aus deiner Liebe ...) eine direkte Replik (sowohl form- als auch inhaltsästhetisch) auf das Prolog-Gedicht Vládnouci ... (Herrscher...) darstellt, ist offensichtlich.

394 Vgl. Rudolf Bultmann, „Exegetische Probleme des zweiten Korintherbriefes", in: Ders., Exegetica, hrsg. v. Erich Dinkier, Tübingen 1967, S. 298-322. Die gnostische Tradition lehnt die 
auf die eschatologische Vollendung und eschatologische Zukunft, deren 'Vermittlerin' die Anima ist, findet ihren Ausdruck im Enthusiasmus des abchließenden Zweizeilers: "Nejhlubši myšlenky vẻci ji radostnè pozdravovaly / i nazval jsem ji v opojeni té chvile královnou nadeji" (V. 61-62; "Den tiefsten Gedanken der Dinge scholl freudig ihr Grußwort entgegen / ich aber in der Verzückung dieser Stunde, ich gab der Hehren ihren Namen: Du Königin aller Hoffnung!").

\subsubsection{Das 'Reifen' zur (Glaubens-)Stärke und zur Erfahnung des "heiligen Willens": Pole dni zráni (Mittäglich Reifen)}

"Seid stark in dem Herrn und in der Macht seiner Stäke. /..J

Vor allen Dingen aber ergreift den Schild des Glaubens. mit dem ihr auslöschen könnt alle feurigen Pfeile des Bösen, und nehmt den Helm des Heils und das Schwert des Geistes. welches ist das Wort Gottes".

Paulus an die Epheser, 6, 10; 16-17

\section{Polední zrání}

Nejvyšxí! Oťce nezrozeného! Płijmi hymnus zpívajícîho o polednách!

Od věkư, nehnuté, sálá tvê mystické slunce do vłení míz a zpěnexní síly, stoupáním krví,ohnivými vưněmi snú a nadéjí, jež bloudí nad oseními, dech tvého poledního zrání valí se blankyty tisíciletí!

5 Myšlenky národi̊ omdlévají v smrtelných mdlobách pod jeho vedrem a bolesti, jež tisíci neviditelných plamenủ se protáhly těly všech mrtvých, zavanutím jeho mystických větri dnem nasím vyšlehly v poźár.

Dech tvêho poledního zrání valí se blankyty tisíciletí!

Bohatstvím jiskłících forem odívá věxné sny země o květech.

10 v̉ak ohnisko jeho skrývá se zrakưm: slunce. jež setmělo vlastní svou záł́́

a nad královstvími ve výsi drži oblaky s blesky płichystanými.

Slyšíte údery dvanácté hodiny dne, v nęmż každá vtełina probihá věky?

Dech tvého poledního zrání valí se blankyty tisíciletr!

Hoffnung auf die Auferweckung des Leibes, der mit dem Tod definitiv vernichtet werden soll, $a b$, obzwar die Verwendung der Termini "Haus" oder "Gewand" die gnostische Spur indiziert, woraut R. Bultmann ausorücklich verweist. Gegen diese Anschauung wendet Paulus ein: "Und es gibt himmlische Körper und irdische Körper I...F (1. Kor. 15,40). "Es wird gesăt ein natürlicher Leib und wird auferstehen ein geistlicher Leib. Gibt es einen natürlichen Leib, so gibt es_auch einen geistlichen Leib" (1. Kor. 15, 44). Der Enthüllung des 'irdischen Gewandes' folgt die Überkleidung mit dem 'Himmelsleib'. In diesem Punkt knūpft Błezina - unabhăngig von seinem Rekurs auf das gnostisch-mythische Substrat - zweifelsohne an die paulinische Theologie, an, was sich mit einigen Zitaten untermeuern lăßt. Besonders charakteristisch ist das Motiv der "Überkleidung" (durch die Engel) oder das des "Büßerkleides", das vor allem im Gedichtzyklus Stavitelé chrámu (Baumeister am Tempel, 1899) und in Ruce (Hănde, 1901) vorkommt. Dabei gilt auch tür Bỉezina als selbstverstāndlich, daß der Auferstehungsleib kein 'materieller' (d. h. 'fleischlicher'), sondern ein

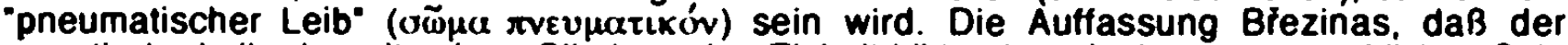
somatische Leib, der mit seinen Gliedern eine Einheit bildet, konstitutiv zum menschlichen Sein gehört (der Mensch ist Leib / (xĩ) $\mu(\alpha)$, kommt auch in seinen Essays aus den Jahren 1896-1897 deutlich zur Geltung. Zur Apokalyptik im russischen Symbolismus vgl. die Studie von Aage A. Hansen-Lơve. .Apokalyptik und Adventismus im russischen Symbolismus der Jahrhundertwende:, in: Russische Literatur an der Wende vom 19. zum 20. Jahrhundert, hrsg. v. R. G. Grübel, Amsterdam-Atlanta 1993, S. 231-325 (zur Symbolik der 'Enthüllung', S. 262-265). 
Rozkoši sálá mocnými pohledy panen, jež volají k životu snění nezrozeného,

15 a smutkem lilií, urěených $k$ smrti, vưnexmi hýrí na chvících se ładrech

a $v$ objetích nechává šilenstvím jásati bolesti budoucích žití.

Dech tvého poledního zráni valí se blankyty tisíciletí!

Pokolení táhnou za pokoleními v jeho vítězné hudbẽ jak pochody vojsk.

Snění odvěké noci zanásí $v$ odpoxinutí pozemských nocí

20 a vủni zralého ovoce ukrývá, tajemnè, v bêlostná sevłení kvêtủ.

Krev płremožených, jež stłíká pod sekerou silných, syđ̌i praskotem jeho mystických žni

a bilými vedry v ném uzrává nejprudši jedová štáva pro uštknutí hadů.

Vłení jeho odívá zvukem písně hlasu nesmrtelného, jenž hovơ̌i $v$ dušich,

a bázni vక̌ech płepadených گelestí větvemi v nexmých pralesích nepoznaného

25 a zrychluje poutníkí kroky pod jich klenbami, nad nimiž vlní se slunce.

Výkł̧iky úzkosti dusí se $v$ jeho zvonícím tichu, v němž jásot vítězů dł́ímá,

a na vlnách jeho nesou se hymny velikých mrtvých, mamé zpívané před staletími

aby $v$ Case svém vydaly vủně jak lípy, jež kvetou.

když ostatni stromy již nemají kvêtú.

$30 \mathrm{~V}$ plamenech jeho krácejí svatí, radostnex ubledlí jeho mystickou lázní.

a zraky jejich, oslepeny jeho poledním plápolem, plax́i rozkoši jiného svêtla.

Jak těžce lehlo tvé zrání v mou dữi, 6 Vex̌nnỵ! Má snění rozdechlo chorobnou zárí a vůně, $v$ nichž tłese se poledni umdlení, zdvihlo mi nad krajinami.

Chtivê jsem dýchal tvưj zár a celá má bytost se změnila v žizeñ!

35 V̌̌ak nejdrobnějłí byly mé klasy v úrodé chudých; jen sírové kvě̀y na vypráhlých mezích mne, melancholické, vítaly obrazem slunce. V slavnostech zátící oblohy chvěl jsem se bázní soumrakủ neviditelných a hlubiny duše mé zvonily rezonancemi bleskủ jež spaly ve vífícím vzduchu. Nárazy krupobití, táhnoucích za obzorem, płehlušily mi radostné praskání klasů

40 a zarmoucen ztrátou neznámých úrod jsem neslyšel jásání okolojdoucích. Byla tvá vưle, $\sigma$ Vex̃ny! Pokomè léto tvé zpivám! Žhavým svým deštěm. v němž vzkvetla a zvadla staletá setba mých otců, dư̌i mou zaplav! $V$ tropickém slunci tvém i kapradí vyrưstá $v$ stromy a na stvoly kvêtů sedají zázračné plameny $v$ zahradách země a snění.

45 Tkani mých myšlenek vybẻl mi v labutí Cistotu plátna a Šupiny vosku bílými ux̌in,, než do forem naleju svíce! Chci plakati světlem!

Spal touhy mých jiter a nocí a popel jejich obrał svým vichrem proti mé tváfi: chci jíti $v$ dusive hołkosti jeho a zaalmem svým $v$ tisíci dušch tê vítat!

Blesk, který zabijí znamenaného, ślastnému ukáže cesty a dálky.

50 úpal, v němž vadne nemocné kvítí, na zlaté dráty zesilí płénienná stébla, oslepi zraky uvyklé Seru, však zraky mocných pł̌ipraví na svítání bleskû. Hudba noxnich tvých vichrí a moł́, jež slabého v úzkostech probouzí do tmy, $\checkmark$ žhavý sen silných padá jak chladivá rosa sţíhmým ohlasem svítání jitł̌ních.

Do výse vedou tvé cesty, $v$ závrati umdlených. vłak vítézi stoupají v tanci

55 a do údolí házejí pisně v prưvodu bouti, jež pod nimi v hlubinách vî́í: v̧ak nad nimi věxná nádhera svêtla se leje sirokým obzorem dálek.

Až uzrálé do hlubin zapadnou svéty a noci a soumraky denní, pod požehnáním pohledu ivého pohne se v hlubinách nová, posvátná setba a hlahol tvých poledních zvonú pozdraví modlitba nesmrtelných.

\section{Mittäglich Reifen}

Höchster! Vater des Ungeborenen! Nimm hin den Hymnus des Sängers am Mittag!

Unregsam, von ewig her, loht deine mystische Sonne ins Sieden der Säfte, ins

ins Steigen des Blutes, ins feurigen Duften des Traums und der Hoffnung.

Kochen der Kräfte, die über den Saaten schweifen, 
Hauch deines Mittag-Reifens wallt unter ewiger Wölbung!

5 Die Gedanken der Völker sinken zu tödlicher Ohnmacht in seiner Hitze dahin, und die Schmerzen, die in tausend unsichtbaren Flammen die Leiber durchzwängten der Toten, blies dein mystischer Wind zu Bränder unseres Tags auf.

Hauch deines Mittag-Reifens wallt unter ewiger Wölbung!

Mit funkelnder Formen Fulle umhängt er den ewigen Traum der Erde: die Blüten.

10 Aber sein Glutherd birgt sich den Blicken: Sie, - die Sonne, zerfinstemd im eigenen Brand, die über den Gipfeln der Königreiche Wolken ballt mit vorbereiteten Blitzen!

Hört ihr die zwölfte Stunde des Tages, die mit jeder Sekunde durch die Ewigkeit läuft?

Hauch deines Mittag-Reifens wallt unter ewiger Wölbung!

Er glühet in Lust aus allmächtigem Blick der Jungfrau'n, die den Traum des Ungeborenen locken ins Leben,

15 und in todgeweihter Lilien Trauer schwärmt er in Düfen über den schaudemden Bristen, und heißt aufjauchzen in der Umarmung, voll Wahnsinn, die Leiden der künftigen Leben.

Hauch deines Mittag-Reifens wallt unter ewiger Wölbung!

Geschlecht um Geschlecht zieht dahin in seiner groben Siegermusik wie stampfender Marsch

Träume der Umacht trägt er herab in die Ruhe der irdischen Nächte, der Heere!

20 und birgt des reifenden Obstes Duft heimlich in weiß sich schließende Blüten.

Das Blut der Niedergetretenen, das unter der Axt der Starken springt, kocht

und in der Weißglut reift es zum Giftsud des Schlangen-Bisses.

im Prasseln seiner mystischen Emten.

Sein Wirbel umkleidet mit Schall das Lied der unsterblichen Stimme, die raunt in den Seelen, wispert mit Furcht der Angefall'nen, seit eh un je, im Geäst der Forste des Unerforschten.

25 und beschleunigt die Schritte der Pilger in diesem Gewölbe, dariber die Sonne wogt.

Schreie der Angst ersticken in seiner aufläutenden Stille, - dort schlummert das Jauchzen

Der groben Toten vorzeiten vergeblich gesungene Hymnen treiben auf dieser Flut.

der Sieger. -

zu ihrer Zeit zu entsenden den Duft, wie Linden, die dann blühn,

wenn keine Blüte mehr hängt an allen anderen Bäumen.

30 Durch seine Flammen schreiten die Heil'gen, freudig verbleichend im mystischen Bade, und ihre Blicke, geblendet vom Mittag, tränen in Wonne des anderen Lichts.

Wie schwer legt sich dein Reifen auf meine Seele, o Ewiger! Es haucht meinen Traum

Dufte. zitternd in Mittag-Ermattung, erhob es mir uber die Lande.

zu kränklichem Schein auf,

Gierig sog ich die Glut, ganz ward mein Wesen ein einziges Dursten!

35 Aber am dürtigsten war meine Garbe inmitten der Emte der Armen: nur schwefelfarbene

schwermütig mich am dürren Rain mit dem Sinnbild der Sonne.

Blüten grubten

An Festen der strahlenden Himmel würgte mich Angst unsichtbaren Gewölkes,

es hallten die Tiefen der Seel" mir von Resonanzen der Blitze, die ungezuickt im Gewirbel

der Luifte noch schliefen.

Des Hagelschlags Sturzflut, hinter den Horizonten trommelnd, uibertäubte das freudige Knistern

40 und den Verlust unbekannten Emten betraurend, hörte ich nicht der Wanderer Jauchzen.

der Ähren.

Dein Wille war es, o Ewiger! Ich sing deinen Sommer in Demut! Mit deinem glühenden Regen, darinnen blühte und welkt' die uralte Saat meiner Väter, überschwemm' meine Seele!

In deiner tropischen Sonne wächst Farnkraut baumhoch und auf die Stengel der Blüten lassen sich magische Flammen nieder in Gärten der Erd' und des Traumes.

45 Bleiche zur Schwanenweiße des Linnens meiner Gedanken Webe! Mach weiß mir die Schuppen

eh ich die Kerzen gieße in Formen! Licht will ich weinen!

des Wachses,

Verbrenne die Sucht meiner Morgen und Nächte! Es treibe dein Sturm mir ihre Asch' 
Schreiten will ich in ihren erstickenden Bitterkeiten, mit meinem Psalm in tausend Seelen

Blitz, der den Gezeichneten tötet. dem Glücklichen weißt er Wege und Weiten, dich grißend!

50 Glut, die kränkliche Blüten dörrt, zu goldenen Drähten steift sie die Halme des Weizens.

Sie blendet im Zwielicht hausende Augen, aber die Augen der Mächt'gen lehrt sie ertragen das Tagen der Blitze.

Musik deiner nächtlichen Stürme und Meere, die den Schwachen angstvoll ins Dunkel schreckt, fällt auf den glühenden Traum des Starken wie kühliger Tau im silbernen Echo auflichtenden Morgens.

Zur Höhe führet dein Weg! Wenn Schwindel die Schwachen zurückwirft, erklimmen im Tanze die Sieger den Gipfel, 55 und werfen Lieder ins Tal, zum Baß der Gewitter, die unten die Tiefen durchtoben.

Aber ihnen zu Häupten das ewige Prangen des Lichts überbreitet den weiten

Gesichtskreis der Fernen.

Bis reif in die Tiefen sinken die Welten und Nächte und das Gewölke des Tages, dann in deinem segnenden Blick regt sich im Abgrund das neue, heilige Saatgut, und das Geläut deiner Glocken am Mittag lädt zum Gebet uns, die Unsterblichen, ein.

Deutsch von Franz Werfel.

Die in der Bỉezina-Forschung allgemein verbreitete These, das Gedicht Poledni zráni sei ein Reflex Nietzsches extremen Individualismus, 395 seines "Übermensch"-Kultes, reicht nicht, um den Hintersinn dieses Gedichts adäquat zu interpretieren. Denn die Stärke der "Starken" ("silni") von Poledni zráni bedeutet, wie noch zu zeigen sein wird, die Stärke der "Glaubenden" ("vêríci") und nicht die der Übermenschen. Dem Gedicht liegen zwei auto-intertextuelle Sub-Texte zugrunde: Ranni modlitba (Das Morgengebet) und Vino silnych (Der Wein der Starken). Die (auto)intertextuelle Leistung dieses Gedichts besteht in der Herstellung eines Plexus von Rekurrenzen, durch dessen Gewebe die beiden Schlüsseltexte, Ranni modlitba und Vino silnych, neu (überdeterminiert) 'lesbar' gemacht werden. Diese Überdeterminierung bedeutet sowohl die Radikalisierung der Position des omnipotenten "Höchsten", der in Ranni modlitba die anima mundi und die unerlöste Natur vergeistigt. als auch die Umwertung der (altruistischen und auto-soteriologischen) Position des dichterischen Ich, die es in Ranni modliba (III.-IV. Sujetsequenz) einnimmt. Die Überdeterminierung vollzieht sich in Poledni zráni auf der Grundlage der hellenistischchristlichen Tradition von "Stirb und werde", die bereits am soteriologischen Geschehen in Ranni modlitbaund in Vino silnych mitwirkt, als Theo-logisierung des dichterischen Schaffens und Lebens unter ríotıs (Glaube). Durch das Charısma der ríouıs erfăhrt der (im Glauben) "Starke" die Erkenntnis (rvüoı̣) des eschatologischen Geschehens. Es ist aber nicht (mehr) die Stärke der gnostisierenden Pneumatiker (Vino silnych / Der Wein der Starken), sondern die Stärke, die sich in der an riouı gebundenen Enfahrung des "heiligen Willens" explizient.

Der Gedichttext besteht aus zwei Teilen. Der erste, vom dichterischen Ich als "Hymnus" (V. 1) spezifizierte Teil, wird von vier kleineren Sujetsequenzen gebildet. Im zweiten Teil (V. 32-59), der als Bittgesang arrangiert ist, werden zwei Sujetsequenzen konstituiert. Der ersten, als 'Beichte' vor der Majestät des "Höchsten" inszenierten Sequenz (V. 32-40), folgt (in der Logik der religiösen Rede) ein Bittgebet bzw. Bittgesang: "Pokornè lèto tué zpivám!" (V. 41-48; "Ich singe deinen Sommer in Demut!"). Beide Teile verknüptt auf der thematischen Ebene der Prozeß des Reifens. Im ersten Teil (V. 2-30) wird dieser Prozeß als Reifen der Erde, der vegetativen und geomorphen Natur und des menschlichen Geschlechts, also phyloge neti s ch (überindividuell) gestaltet, wăhrend im zweiten Teil (V. 32-59) dieser Prozeß als Reifen des schöplerischen

395 O. Kálík, Otokar Błezina, Praha 1948, S. 137. M. Cervenka, .Modlitba za nepłátele*, in: Ders., Styl a vyznam, Praha 1991, S. 17. U. Heftrich, Otokat Brezina, Heidelberg 1993, S. 330 f. $^{\circ}$ 
Individuums, der Gestalt der "Starken" zu ihrer Heiligkeit durch den Glauben - d. h. ontogenetisch-gestaltet und semantisiert wird. Derartige Zweiteilung - 1. Weltkosmos, 2. das eigene Ich des dichterischen Subjekts - scheint im eschatologischen Symbolismus ein weit verbreitetes Aufbauprinzip zu sein (vgl. Ranni modlitba / Das Morgengebet oder Královna nadëji / Die Königin der Hoffnungen). Das (leibliche) Ich des dichterischen Subjekts erscheint hier als mikrokosmisches Analogon des kóopos, eine Vorstellung, die auf die griechische Antike zurückgeht. Der Gedanke von der Verwandschaft zwischen menschlichem Körper und Kosmos, daß der kóouos eine lebendige Einheit bildet, war schon lange vor Plato bekannt. In der Kosmologie der griechischen Antike wird der kóofoos als der "von der göttlichen Seele einheitlich regierte und durchwaltete Leib", I.../ als "sichtbar gewordener Gott", begriffen. 396 Diese Vorstellung ist bekanntlich nicht ohne Einfluß auf die neutestamentliche (vor allem paulinische) Theologie bzw. Anthropologie geblieben. In der Allegorese des Glaubens von Origines hăngen alle Glaubenswahrheiten untereinander zusammen, sie bilden ein "Ganzes", in dem alles Einzeine übereinstimmt. 397 In seiner gestalthaften Totalität besitzt der Leib eine universelle Geltung. Die Wirklichkeit der Welt, der Mensch und die Schrift koexistieren in inm in einer Synthese.

Die Einteilung der Rederollen in Poledni zráni: Wăhrend im ersten Teil das dichterische Subjekt, der "Singende" ("zpivajici". V. 1), im Hintergrund die Geschichte des Reifens der natura naturata und des menschlichen Geschlechtes ("Pokolení táhnou za pokoleními", V. 18; "Geschlecht um Geschlecht zieht dahin") ${ }^{398}$ "singt", ändert sich in V.

396 Vgl. hierzu die materialreiche Darlegung von E. Schweizer, "ow̄ $\mu \alpha$ ", in: Theologisches Wörterbuch zum Neuen Testament, 7, 1964, S. 1024-1091; für die griechische Antike bes. S. 1024-1042. Zur Platonschen Auffassung vgl. den Abschnitt "Von Plato bis Aristoteles", S. 1028f.

397 Vgl. R. Gögler, Die Theologie des biblischen Wortes bei Origines, Düsseldort 1963, S. 77.

398 "Od věkú, nehnuté, sálá tvé mystické slunce /.../ stoupáním krvi, ohnivými vưnémi snù a nadëji, jeż bloudi nad osenimi I..... Myšlenky národú I..... (Poledni zráni, V. 2-3, 5; "Unregsam, von ewig her, loht deine mystische Sonne $/ . . . /$ ins Steigen des Blutes, ins feurigen Düften des Traums und der Hoffnung, / die über den Saat schweifen I.../. Die Gedanken der Völker I... $/$.) Diese Verssequenz stelit eine autointertextuelle Replik auf eine Verssequenz in Králorna nadejif (Die Königin der Hoffnungen) dar: "Odpovidala jsem výkłikủm, jeż nad hlavami spicich národú letí. modlitby Velkých, I oblaky vécného slunce, jeż od vẻkủ do vẻkú houstnou a táhnou nad osenim dusi I...F. (V. 11-12; "Antwort gab ich den Schreien, die in den Gebeten der Großen zu Hăupten der schlafenden Völker flattern, / Wolken der ewigen Sonne, die verdichtet von Äon zu Äon über die Saaten der Seelen ziehen I....). Die "schlafenden Vöker . "Gedanken der Volker"; "von ewig her - "von Áon zu Áon": "Düfte des Traums" - "Saat der Seelen": die Analogien und Parallelen zwischen den beiden Verssequenzen sind unverkennbar. Worauf mogen sie sich beziehen? Denken (bzw. Gedanken) - Traum/Schlaf - Völker (bzw. Menschen) und Saat (der Seeten - "oseni" dusi ${ }^{*}$ ) sind die Schüßelmotive der beiden Sequenzen. Versucht man sie miteinander zu kombinieren, gewinnt man folgende Derivate, die zur eventuellen Dechiffrierung der Aussage der zitierten Sequenzen führen kơnnen: Im Traum-Denken machen die VökerMenschen ihre Entwicklungsgeschichte (ergo ihre Kuttur-Geschichte) bzw. inr Seelen-Leben ("osení dusi" / "Saat der Seelen") durch. Das heißt: In der (Volker-)Psychologie scheint die Ontogenese der Phylogense zu entsprecten. Der Zustand des Denkens im Traum (ăhnlich wie im Seelen-Leben des Kindes) scheint also mit der Wiederholung der Prăhistorie zu koinzidieren. So faßt Otto Rank (im Anschluß an Freud) den Mythus als Massen traum des Volkes (O. Rank, Der Künstler. Ansätze zu einer Sexuaipsychologie, Leipzig -Wien 1907, S. 36) auf. Zur ăhnlichen Feststellung kommt auch Karl Abraham in seiner Schrift Traum und Mythus (Leipzig-Wien 1909, S. 36): "D e r Mythus ist ein Stück überwundenen infantilen seelenlebens des Volkes. Er enthalt (in verschleierter Form) die Kindheitswünche des Volkes". Und auf Seite 71: "Das Volk verarbeitet in vorhistorischer Zeit seine Wünsche zu Phantasiegebilden, die als Mythen in das historische Zeitalter hinüberreichen. Ebenso schafft das Individuum in seiner vorhistorischen Periode " aus seinen Wünschen Phantasiegebilde, die in den Trăumen der shistorischen $\propto$ Zeit persistieren. So ist der Mythus ein erhalten gebliebenes stúck aus dem infantilen Seelenleben des Volkes und der Traum der Mythus des Individu um s ". (Sperrungen von $K$. Abraham). Es ist durchaus vorstellbar, daB es unter anderem die Nietzsctie-Rezeption war, durch die Brezina auf diesen Gedanken aufmerksam gemacht wurde. In Menschliches, Allzumenschliches schreibt Nietzsche: "Im Traume übt sich dieses uratte Stück Menschtum in uns fort, denn es ist die Grundlage, auf der die höhere Vernunft sich entwickelte und in jedem Menschen sich noch entwickelt: Der Traum bringt uns in ferne Zustānde der menschlichen Kultur wieder zurūck und gibt ein Mittel in die Hand, sie besser zu 
32 der Redemodus frappant. Das dichterische Ich tritt mit seiner 'Schuldbekenntnis', mit seiner 'Beichte' an den "Höchsten", in den Vordergrund: "Jak těžce lehlo tvé zráni v mou duši, o Věčny!" (V. 32; "Wie schwer legte sich dein Reifen auf meine Seele, o Ewiger!"). Aber ab V. 49 ändert sich die kommunikative Situation noch einmal: Das Ich wird ein Teil der (eschatologischen) Gemeinde der Glaubenden (bzw. der Glaubensstarken), die den Schwachen gegenübergestellt wird: "/../ chci jíti $v$ dusivé hořkosti /.../ a Zalmem svým $v$ tisici dušich tè vitat!" ("/.../ schreiten will ich $/ \ldots /$ in erstickenden Bitterkeiten und mit meinem Psalm in tausend Seelen dich grüßen!", V. 48). Damit korrespondiert auch die auffallende Verschiebung im Redemodus. Die dominante Stimme des redenden Ich scheint (ab V. 49) mit der kollektiven Stimme der Gemeinde der Glaubensstarken, die sich der wunderbaren Fähigkeit des Glaubens - als Gabe ( $\chi \alpha ́ \rho ı \sigma \mu \alpha)$ des "Höchsten" - bewußt ist. zu verschmelzen.

Die nahezu ätherische Transparenz der diaphanen Medien von Královna naději (Die Königin der Hoffnungen) kontrastiert in Poledni zráni mit der Motivik des grellen, blendenden, ja härtenden Sonnenlichts. Der kleine Kreis der Auserkorenen (der Pneumatiken), der von mystischer "Liebe wahnsinnig gewordenen" Glaubenden, die der Glaube stärkt und zu einer "Bruderschaft" vereinigt (Bratrstvi věrícich I Die Bruderschaft der Glaubenden), soll sich - und das dichterische Subjekt als 'Mitglied' dieser eschatologischen Gemeinschaft mit ihr - einer noch höheren Form des eschatologischen 'Reifens' unterziehen. Die Semantik der mythogenen Schöpfer-Gestalt, der "Starken" (von Vino silných), wird in Poledni zráni expressiv zugespitzt, allerdings unter einem anderen Kode. Die "Starken" (Poledni zráni) 'reifen' in der Glut des (spirituellen) "mittäglichen Reifens" - durch die Macht des "heiligen Willens" und des (Auferstehungs-)Glaubens - zur Gestalt der "Heiligen" ("svati"). Das eschatologische Transzendieren der Seele (Královna nadëji / Die Königin der Hoffnungen) wird in Poledni zráni durch die Entflammung. Verzückung und Härtung des naturhaft-materiellen Leibes komplettiert, d. h. die soteriologische Orientierung des eschatologischen Symbolismus (das gnostischeschatologische Modell von SZ) wird in Poledni zráni durch eine anthropologische 399 ergänzt.

verstehen. Das Traumdenken wird uns jetzt so leicht, weil wir in ungeheuren Entwicklungsstrecken der Menschheit gerade auf diese Form des phantastischen und wohlfeilen Erklärens aus dem ersten beliebigen Einfalle heraus so gut eingedrillt worden sind"

399 Es ist die paulinische Theologie, deren Anthropologie sich in erster Linie aut die Beziehung des Menschen zu Gott konzentrient. Das, worum es hier geht, ist - wie betont - die Frage, wie Gott für die Verantwortung des Menschen und sein Heil bedeutsam ist. Demnach ist, laut R. Bultmann. die paulinische Theologie zugleich Anthropologie. Es ist geradezu symptomatisch, daß der Begriff des Leibes ("télo"), des fleischlichen Leibes, "in seinen Schmerzen und Krankheiten und seinem Reifen, I.../Schöpfer und ironischer Verwüster der Illusionen, der Körper-Geist, der tiefer sieht, als unser Verstand I... ("ve svých bolestech, chorobách a ve svém zráni /.../, tvưrce a ironický plenitel iluzí, têlo-duch, vidouci dále neż nás rozum /...r. Essay Př́tomnost / Gegenwart, 1908), bereits in dieser Schaffensphase immer mehr an der Bedeutung gewinnt. Mit "Körper" ("télo") ist freilich die ganze Persönlichkeit, das Fundament des menschlichen Seins, gemeint, ein Aspekt, der für die paulinische Anthropologie kennzeichnend ist. Vgl. Rudolf Bultmann. .Römer 7 und die Anthropologie des Paulus", in: Ders., Exegetica, Tübingen 1967, S. 198-209. in Vêtry od pólú wird der Korper nicht mehr als 'Kerker' der in ihm gefangenen Seele betrachtet, wie es noch in einigen Gedichten von Svítáni na západè der Fall war. Auch der körperliche Leib muß hier auf Erden am Reifen zu einer höheren Seinsweise, am Kampf für die eschatologische Zukuntt, teilnehmen. Denn durch den 'körperlichen Leib' hat der Mensch, wie Bultmann in seiner Darlegung betont, ein Verhältnis zu sich selbst (er kann sich selbst als Subjekt des Erleidens erfahren). Das Verhältnis des somatischen Ich zum wollenden Ich ermöglicht dem Menschen sich einerseits von sich selbst bzw. von den fremden Mächten, die inn zu beherrschen versuchen könnten, zu distanzieren. andererseits sich frei für ein bestimmtes Verhalten zu entscheiden. Darüber hinaus scheint (auch) das somatische Sein die Bedingung für die Auferstehung zu sein. Das Motiv des (körperlichen) Schmerz-Ertragens für das zukünttige und höhere Sein, begleitet von der signifikanten 'Symptomatologie' der blutigen Wunden und Narben, kommt in VP nicht nur in Poledni zráni (Mittáglich Reifen: "Krev płemożených, jeż striká pod sekerou silných /... / "Das Blut der Besiegten, das unter der Axt der Starken springt $/ . \ldots \%$ ). sondern auch im bekannten, oft zitierten Gedicht Modlitba za neprátele (Gebet für die Feinde) und in Kdyż z lásky tvé... (Wenn aus deiner Liebe...) vor: "a semeni z rukou krvácejicich dávás vykvésti lilijemi. I... I A bolestné výkřiky naše zvoniti budou jednou jak včely I...l. Učiñ rány naše sladké a nezmenšujici pođ̌et żivych, ale zvêtśujici!" (Modlitba za neprátele / Gebet für die Feinde, V. 29, 32, 46; "und den Samen aus blutenden Händen läßt du als Lilie aufblühn. I.../ Und unsere Schmerzensschreie werden dann 
In der ersten Verszeile wird das Gedicht als "Hymnus" spezifiziert: 400 Die Allusion auf Ranni modlitba bekundet sich bereits in der Invokation "Nejvyšsi! Otče nezrozeného! Prijmi hymnus zpivajiciho o polednách!" (V. 1). Die Invokation des "Höchsten" wird als exklamatorischer Vers-Refrain viermal wiederholt (V. 4, 8, 13, 17): "Dech tvého poledního zráni valí se blankyty tisicilet́!" ("Hauch deines Mittag-Reifens wallt unter ewiger Wölbung"; das Substantiv "Nejvyššl" wird durch das Possesivpronomen "tvého" I "deiner" ersetzt). Die Funktion dieser vierfachen Wiederholung ist folgende: einerseits leitet sie jeweils eine andere thematische Einheit ein, andererseits bildet der zitierte Vers-Refrein eine quasi übergeordnete kompositorische Konstante, die die vier thematisch verschiedenen Handlungsebenen vereinigt: I (V. 2-7), I (V. 8-12), III (V. 13-16), IV (V. 17-31). Schließlich soll durch diese Wiederholung auch die Omnipotenz, die zeugende Kraft des Spiritus creatoris, stets aufs neue hervorgehoben werden.

Die maskulin-patriarchalische Autorität des "Höchsten" wird durch die Apostrophe "Otce nezrozeného!" ("Vater des Ungeborenen!", V. 1) betont. In Ranni modlitba (Das Morgengebet) wartet "das wilde Verlangen des Ungeborenen" ("divoká Żádost nezrozeného", V. 10), von der zeugenden Kraft des "Höchsten" befruchtet zu werden. Nach dem "Morgengebet" singt nun das lyrische Ich einen "Mittagshymnus": "Prijmi hymnus zpivajićiho o polednách!" (V. 1). Es tritt in der Gestalt eines "Singenden" ("hymnus zpivajicího") auf, die er auch in der letzten Sujetsequenz von Ranni modlitba einnimmt: "Zpivati budu tvé dẻjiny I..." ("Deine Geschichte will ich singen I... $/$, V. 68). Der hymnische Gesang des "mittäglichen Reifens" an den "Höchsten" wird in Polední zráni nicht nur als Fortsetzung bzw. Realisierung des "Gesangs" aus Ranni modlitba, sondern gleichzeitig und vor allem als eine gewiße Korrektur des in Ranni modlitba postulierten (altruistischen und auto-soteriologischen) Geschehens arrangiert, das in Poledni zráni offensichtlich als gescheitert angesehen wird:

"VSak nejdrobnējši byly mé klasy v úrodẻ chudých /.../ / Nárazy krupobití, táhnoucich za obzorem. płehlušily mi radostné praskáni klasủ, / a zarmoucen ztrátou nezámých úrod jsem neslyšel jásáni okolojdoucích" (V. 35, 39-40; "Des Hagelschlags Sturzflut, hinter den Horizonten trommelnd, übertäubte das freudige Knistern der Ähren, / und den Verlust unbekannten Ernten betrauernd, hörte ich nicht der Wanderer Jauchzen"). Vgl. dazu Ranni modlitba I Das Morgengebet: "Úroda setby jež Łeká pod sněhem casu na dobu staletých táni, / a královská úroda zmi nezasetého" (V. 25-26. "Ernte der Saat, die unter dem Schnee der Zeit auf die Schmelze der Jahrhunderte wartet,/ und die kőnigliche Ernte ungesăten Saatguts"); "Dej požehnáni mým zrakủm, když utkvi na bujném obilí štastných, /.../ Hlasu mému dej hudbu lahodnou żencum jak zvoněni o polednách" (V. 34, 36, "Gib Segen meinen Blicken, wenn sie verweilen auf üppiger Saat der Beglückten, I.../ Gib meiner Stimme Musik, die wohlklingt den Schnittern, wie Läuten zu Mittag"): "Dej. aby mé kroky vzbudily z umdleni radostné cekáni bratti, I a na mủj pozdrav aby vlídnẻ odpovẻdéli pospichajici!" (V. 38-39, "Gib, daß meine Schritte erwecken aus Ohnmacht das freudige Harren der Brüder. / und daß meinen Gruß die Eilenden gütig erwidern!").

Die 'therapeutische' Wirkung des dichterischen Wortes im Rahmen des soteriologischen Geschehens, um die in Ranni modlitba (III. Sujetsequenz) gebeten wird, erfordet jetzt eine andere Haltung der eschatologischen Gemeinde, der "Bruderschaft der Glaubenden". Es ist der Gehorsam des Glaubens. Daher metamorphiert der stolze, ja hochmütige Gesang des gnostisierenden (Auto-)Sotērs in Ranni modlitba ("s hlavou pyšnè vzad sklonénou zpivati budu", V. 67; "mit hochmütig zurückgebeugtem Haupt werde ich singen") zum gehorsam-demütigen Gesang: "Byla tvá vưle, o věnný Pokorné léto tvé zpivám!" (Poledni zráni, V. 41; "Dein Wille war es, o Ewiger! Ich singe deinen Sommer in Demut!"). Doch der Gesang in Ranni modlitba hat auch seinen demütig-reuigen 'Teil', der Unterschied gründet darin, daß in Ranni modlitba die demütige Haltung des stolzen AutoSotērs eigentlich zukunftsorientiert ist, worauf auch das grammatische Futur hindeutet: "zpivati budu" (V. 68; "singen werde ich"). Auch der reuevolle ("litost má" I "meine Reue", V. 43) Bittgesang des dichterischen Ich in der dritten Sujetsequenz von Ranni modlitbá charakterisiert eine konsequent optative Form, aber die optio wird in quasi irrealen Konsekutivsätzen zum Ausdruck gebracht: "Dej, aby mé kroky I..." (V. 38; "Gib, daß meine Schritte"), "Dej, aby mé myslenky I...", (V. 55; "Gib, daß meine Gedanken /...").

einmal wie Bienen läuten /.../. Gib, daß unsere Hiebe süß sind, gib daß sie die Zahl der Lebenden nicht vermindern, sondern vermehren!" ).

400 Zur Gattungspoetik der religiösen Sprache bei Biezina: vgl. Kap. 3. 
Dieser optativ-konsekutive und zukunftsorientierte Redemodus scheint in Ranni moditba zu implizieren, daß ein Rezidiv des Stolzes eines gnostisierenden Pneumatikers, eınes "Starken", immer noch möglich ist. Das dichterische Ich fühlt sich offensichtlich noch nicht im Besitz der 'wahren' (Glaubens-)Stärke. Obwohl der 'Wille zur Demut' in Ranni modlitba schon sehr ausgeprägt ist, bleibt er hier (nur) ein Postulat, integriert in eine glänzende Vision (V. 85) eines grandiosen soteriologischen Geschehens. Diese Deutung der Demut in Ranni modlitba macht erst der Vergleich mit der Demut-Semantik in Poledni zráni plausibel. Es läßt sich nun sagen, daß̉ die Demut in Ranni modlitba deshalb nur ein Postulat bleibt, weil sie offensichtlich (noch) nicht auf dem Charisma des stärkenden Glaubens (und des Willens zur ethischen Reinheit) bauen kann. Es ist das Charisma des Glaubens, das die Stärke und Kraft schenkt, nicht die gnostische Erkenntnis. Daher kann sich das dichterische Ich erst in Poledni zráni seines 'Willens zur Demut' (und zum Gehorsam) sicher sein. Dieser Intention entspricht auch die grammatische Form: an die Stelle des Futurs tritt die indikative Präsensform. Erst in Polední zráni kann das dichterische Ich voller Entschlossenheit aufrufen: "Pokomé léto tvé zpivám!" ("Ich singe deinen Sommer in Demut!". V. 41). Die optio wird in Poledni zráni nicht in Konsekutivsätzen, sondern in einfachen Aufforderungssätzen artikuliert: "Tkani mých myšlenek vybėl /.../ a špiny vosku bilými učin I... / (V. 44; "Bleiche zur Schwanenweiße des Linnens meiner Gedanken Webe I...I mach weiß mir die Schuppen des Wachses I.... ${ }^{\mu}$ ). "Spal touhy mých jiter a noci $/ . . . "$ (V. 47: "Verbrenne die Sehnsüchte meiner Morgen und Nächte I... ). Erst in Poledni zráni ist sich das dichterische Ich seiner Kraft sicher, erst jetzt hat es die innere Gewißheit, daß es sich der (Sonnen-)Glut des mittäglichen Reifens (zu Glaubensstärke) furchtlos stellen kann.

Mit dem postulierten "mittäglichen Reifen" geht die Intensivierung (und Extensivierung) aller im Text thematisierten Handlungen einher: Das "mystische Lächeln" und die befruchtende eiaculatio des Logos spermatikos (Ranni modlitba) hyperthrophieren zum Ansturm des wallenden und glühenden Odems, zur erschöpfenden und versengenden Gluthitze: "Myšlenky národủ omdlévaji v smrtelných mdlobách pod jeho vedrem" (V. 5; "Die Gedanken der Völker sinken zu tödlicher Onnmacht in seiner Hitze dahin"). Die kollektive Ernte "aller sichtbaren und unsichtbaren Diener" wird zu "mystischer Ernte", in der die "Schwachen" besiegt und die "Starken" noch gestärkt werden: "Krev píemožených, jeż stríká pod sekerou silných, syči praskotem jeho mystických żni" (V. 21: "Das Blut der Niedergetretenen, das unter der Axt der Starken springt, kocht im Prasseln seiner mystischen Ernten"). Zur auffallenden Extensivierung kommt es auch auf der räumlichzeitlichen Ebene: "blankyty tisicilet" (V. 4, 8, 13, 17): "Slyšite údery dvanácté hodiny dne. v nẻmż każdá veerina probihá vẻky?" (V. 12): "Snẻni oovéké noci" (V. 19), "pied stalebimi" (V. 27); "vẻčná nádhera svếtla" (V. 56); "Do vỷse vedou I... (V. 54); "v hiubinách virì I.../" (V. 57) usw. Als das höchste Ziel wird in Poledni zráni weder das (auto-) soteriologische Geschehen, noch die zur unio mystica führende Gnosis (Ranni modlitba), sondern die Spiritualisierung a ller Lebensprozesse postuliert. Signifikanterweise wird hier der mystisch-erotische "durchbohrende Blick" ("prokláni pohledu tvého", Ranni modlitba, V. 85) durch den sakralen "segnenden Blick" ("pod pożehnáním pohiedu tvého". Poledni zrani, V. 58) und die hermetische (bzw. gnostische) "königliche Saat" (Ranni modlitba, V. 26) durch die qualitativ höhere ("neue"), christologisch motivierte "heilige Saat" ("nová, posvátná setba". Poledni zráni, V. 58) substituiert. Die Polarität "(Modlitba) vecerni" ("Abendgebet") - Ranni (modlitba", "Morgengebet") verliert in Poledni zráni ihre Relevanz. Nicht die Randpunkte, sondern der Mittelpunkt ("poledni" I "mittäglich"), der Fokus ("věcné ohnisko zrání", Ranni modlitba / Das Morgengebet, V.49; "der ewige Brennpunkt des Reifens"; "ohnisko jeho skrývá se zrakủm", Poledni zráni, V. 10; "sein Brennpunkt birgt sich den Blicken") wird jetzt zur postulierten Ordnungsmacht; $d$. $h$. weder das "Abendgebet" noch das "Morgengebet", sondern "das Gebet der Unsterblichen" ("modlitba nesmrtelnýcht', Poledni zráni I Das Mittäglich Reifen, V. 59). Die in der bisherigen BíezinaLiteratur übliche Interpretation der "Starken" (V. 20) bzw. der "Sieger" (V. 54) als "Übermenschen" bedarf unbedingt einer Korrektur. Man muß die "Starken" von Poledni zráni im Vergleich mit der Gestalt der "Starken" von Vino silných und mit der des "stolzen" (Auto-)Sotērs von Ranni modlitba betrachten. Wie bereits dargelegt, korreliert die "Stärke" in diesen Gedichten mit der Gnosis. Die "Stärke" der gnostisierenden "Starken" (Vino silnych), die kraft ihrer pneumatischen Begabung stark sind und über die in der 'Trunkenheit' verweilenden "Schwachen" triumphieren, gewinnt nicht nur in Poledni zráni. sondern im gesamten Zyklus, eine neue Qualität, eine neue Dimension. Es ist die "Kraft" (bzw. "Stärke") die Wortverkündigung des "Höchsten" zu hören und zu verstehen, d. h. der 
Glaube an das Wort, um den es sich hier handelt: "Dech tvého poledního zráni valí se blankyty tisicileti ! /.../ Vỉeni jeho odívá zvukem pisné hlasu nesmrtelného, jenž hovoři v dušich" (V. 17, 23; "Hauch deines Mittag-Reifens wallt unter ewiger Wölbung! /.../ Sein Wirbel umkleidet mit Schall das Lied der unsterblichen Stimme, die raunt in den Seelen"). Die befruchtende Potenz des göttlichen Odems (als Log.os spermatikos) wird in folgendem Vers noch prägnanter zum Ausdruck gebracht: "Žhavým svým deštèm, I v nęmż zkvetta a svadla staletá setba mých otcú, duši mou zaplav!" ( $V$. 41-42; "Mit deinem glühenden Regen, I darinnen blühte und welkt' die uralte Saat meiner Väter, überschwemm' meine Seele!"').

Im folgenden sollen die vier Sujetsequenzen des ersten Teils von Poledni zráni spezifiziert und eingehender untersucht werden. I (V. 2-7): das Reifen in Schmerzen der Sonnenglut; (V. 8-12): das Reifen in Schmerzen der Zeit(lichkeit); III (V. 13-16): das Reifen in Schmerzen des Eros; IV (V. 17-31); das Reifen in Schmerzen des Glaubens. Der weitaus größere Umfang der letzgenannten Einheit ergibt sich daraus, daß hier das Ha u p t th e m a, der Glaube, entfaltet wird. Der Glaube als Charisma des Geistes, des göttlichen Odems ("Dech tvěho poledního zráni /... $\mu$ / "Hauch deines Mittag-Reifens /... ${ }^{\prime}$. V. 8, 13, 17), erscheint hier als "Kraft" ("sila"; nicht als "Stärke" der gnostisierenden' Pneumatiker!) und "Gewißheit", die in der Überzeugung (hervorgehoben durch die vierfache Wiederholung des Refrains) von der Allmacht des "Höchsten" gründet. Diese Gewißheit prägt auch den Redemodus des Gedichts (vor allem in V. 41-48), der Entschlossenheit und Willenskraft ausdrückt: "Chci plakati svëtlem!" (V. 46; "Licht will ich weinen!"). Es ist auch die Gewißheit, daß der verborgene, fe $\mathrm{r} n \mathrm{e}$, solare Fokus (sol rex), der "unregsam von ewig her loht" (V. 2; "Od věkủ /.../ sálá") und "im eigenen Glanz zerfinstert" (V. 10; "slunce, jež setmëlo vlastni svou zári"), doch der $n$ a h e "Höchste" ist. der - so R. Bultmann - "Gott der V a te r heißt, dessen Kinder also die Menschen sind".401 Es ist eine christologische Auffassung der ríouts; signifikanterweise apostrophiert Bïezina den "Höchsten" auch "Oť́e nezrozeného!" (V. 1; "Vater des Ungeborenen!"). Die Voraussetzungen für den wahren Glauben sind (im christologischen Sinne): Gehorsam, Erfassung der sittlichen Pflichten und Verantwortung. Die von Brezina in einem Brief (vom 4. VII. 1897) an Anna Pammrová artikulierte Forderung - "P r v ní povin ností

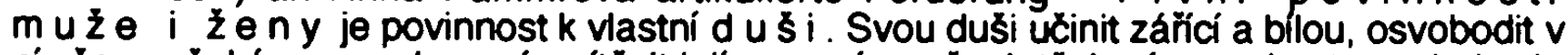
ni vsee, co ceká na osvobozeni, zvítezzit jeji pomoci ve všech téch zápasech s tmou /... / to je prvni a nejdưležitějł̧i naše práce. I...l. A všechno ostatni pǐenechat Vưli, která naši vúli objímá jako mohutná ruka svirajíci drobnou ručku ditěte" 402 - heißt in Poledni zráni: "Byla tva vưle, o Vě̉ný! I...l. Tkani mých myšlenek vybèl mi v labutí Cistotu plátna /...l. Chci plakati svêtlem!" (V. 44-45; "Dein Wille war es, o Ewiger! /.../ Bleiche zur Schwanenweiße des Linnens meiner Gedanken Webe I... I. Licht will ich weinen!"). Daß "Liebe" ("láska") bei Bïezina auch "Pflicht" ("povinnost") bedeutet, wird in der Analyse des Gedicht Láska (Liebe) dargelegt.

In allen vier Einheiten des ersten Teils spielt auch das Traum- (bzw. Trăumen-)Motiv eine wichtige Rolle. In der ersten Sujetsequenz evoziert die expressive Lexik - "viení míz a zpënēni sily" ("Sieden der Săfte und Aứschăumen der Krăfte", V. 2). "valí se" ("[sie] wallt". V. 4) usw. - die Dynamik des Reifens, die auch "Trăume" erfảßt ("ohnivými vunèmi snú" i "mit feurigen Düften des Traums", V. 3) und eine Art 'korrektiver' Replik auf die 'dekadente' Passiviät des Traum-Zustandes (Tajemné dálky / Geheimnisvolle Fernen) darstellt. Die Feuerbrunst der "mystischen Sonne" konnotient die Kraft ("zpęnęni sily", V. 2; "Aufschäumen der Kräfte") des "Höchsten". Die chaotischen "betrunkenen Düfte" (Rann' modlitba, V. 14) transmutieren zu "feurigen Düften des Traumes und der Hoffnungen" ("Ohnivými vưnémi snu a nadëji", V. 3) und der lähmende, den Körper durchdringende Schmerz, den die "Herrscher der Träume" als Folge ihrer Abkapselung in der fiktionalen

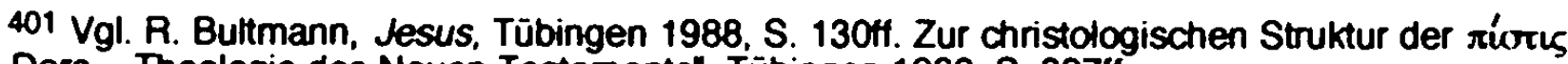
vgl. Ders., . Theologie des Neuen Testaments", Tübingen 1968, S. 327ff.

402 -Die erste Pflicht von $M$ ann und Frau ist die Pflicht gegenüber der eigenen $S$ e e l $\mathrm{e}$. Die Seele strahlend und weiß zu machen, in inr all das zu befreien, was auf die Befreiung wartet, mit ihrer Hilfe in allen Kämpfen mit der Finsternis zu siegen /.../ das ist unsere allererste und wichtigste Arbeit. $/ . . /$. Und alles andere dem Willen zu überlassen, der unseren Willen umarmt, so wie die mächtige Hand das zierliche Hāndchen des Kindes umklammert". Vgl. O. Březina, "Dva listy", in: Wiener Slawistischer Almanach, 4, 1979, S. 211. Sperrungen von Brezina. 
Schein-Welt des Kunst-Schönen erleiden müssen, zum wiederbelebenden und transformierenden "Brand": "a bolesti jeż tisici neviditelných plamenů se protáhly těly všech mrtvých, / zavanutim jeho mystických větrủ đnem našim vyšlehly v požár" (V. 6-7; "und die Schmerzen, die in tausend unsichtbaren Flammen die Leiber durchzwängten der Toten, / blies dein mystischer Wind zu Bränden unseres Tages auf"). Das Motiv der Sonnenglut scheint hier der intensivsten Form der Körper-Metamorphose zu entsprechen.

Ähnlich wird in der zweiten Sequenz das Traum-Motiv ("vě̉né sny zemè", V. 9) in das Kraftfeld des maskulin-göttlichen (solaren) "Brennpunktes" ("ohnisko", V. 10) einbezogen und dadurch dynamisiert. Auch das "Träumen der Erde" bedeutet hier einen dynamischen Prozeß, denn das 'Reifen' der Erde, der vegetativen und der geomorphen Natur, ist das Substantielle der Phylogenese, daher offenbart es sich in großer Formen-Mannigfaltigkeit: "Bohatstvi jiskrícich forem odivá vẻčné sny zemé o květech, / avšak ohnisko jeho skrývá se zrakưm: slunce, jež setmělo vlastni svou zárin" (V. 9-10; "Mit funkelnder Formen Fülle umhängt er den ewigen Traum der Erde: die Blüten. / Aber sein Glutherd birgt sich den Blicken: Sie, - die Sonne, zerfinsternd im eigenen Brand"). "Sonne, zerfinsternd im eigenen Brand": Licht qua Licht ist Dunkelheit, es macht aber alles offenbar, was in seine Sphäre fällt. 403 Doch diese Vorstellung muß in diesem Kontext vor allem als Metapher des 'verborgenen', fernen und dennoch nahen Gottes (Deus absconditus in maiestate), im Sinne der Lutherschen "theologia gloriae", d. h. als Spur der herrlichen Selbsterweise der göttlichen Majestät gedeutet werden. ${ }^{404}$ in der letzten Verszeile der zweiten Sequenz (V. 12) wird das mystische Reifen in der Zeit explizit thematisiert: "Slyšite údery dvanácté hodiny dne, v némž každá vterina probihá věky?". Das (aư den ersten Blick an Nietzsche anklingende) "Schlagen der zwölften Stunde des Tages" verheißt das kommende "ewige Tag" ( $v$ němž každá vterina probíhá věky" / "in dem jede Sekunde durch die Ewigkeit läutt, V. 12). An diesem Tag des Endgerichts verliert man das Leben nicht, wenn man es im Bekenntnis zum "Ewigen" einsetzt. Diese Verheißung wird in der letzten Verszeile des Textes zum Ausdruck gebracht: "a hlahol twých polednich zvonú pozdravi modlitba nosmrtelných" (V. 59; "und das Geläut deiner Glocken am Mittag lädt zum Gebet uns, die Unsterblichen, ein").

In der dritten Sujetsequenz (V. 13-16) wird der "Traum" als "snèni nezrozeného" ("das Träumen des Ungeborenen"), d. h. als ein wonniger Zustand, der mit "bolesti budoucich žit" ("Schmerzen der zukünfigen Leben", V. 16) korreliert, semantisiert.405 Die "mächtigen Blicke der Jungfrauen" (V. 19) erlangen inre Macht durch den Odem des "Höchsten". Hier wird die mystische und patriarchalische Zeugung 'von oben' aus Ranni modlitba (Das Morgengebet) perpetuiert: "a zdravè vtáhnuti dechu /.../ / pod jiskrivivim pohledem dne, v némż svít divoká zádost nezrozeného" (V. 8, 10; "das Gesunde Einziehen des Atems /.../I unter dem funkelnden Blicke des Tages, in dem das wilde Verlangen des Ungeborenen leuchtet"). Durch den Refrain "Dech tvého poledniho zráni vali se blankyty tisícileti" (V. 13) soll - gerade im Zusammenhang mit "Lust" / "rozkos" (V. 14) - hervorgehoben werden, daß das Pneuma die wundewirkende göttliche Lebens-Kraft sei. Die Metapher der "Trauer

403 Zur Symbolik der "gottlichen Finsternis" in der mythologischen Gnosis, vgl. die Darlegung zur Licht/Finsternis-Symbolik in Kap. 3.2.2 (Vino silnych / Der Wein der Starken). Wie schon in Králorna nadéji , handelt es sich auch hier (V. 10) um eine Art oxymoral-paradoxer Rede. In diesem Sinne ist auch die Antithese zwischen der Unbeweglichkeit der Sonne und ihrer oynamis ("vali se" /"sie wallt, V. 8, 13, 17) zu verstehen.

404 In der Tradition der Lutherschen Hermeneutik ist die Verborgenheit Gottes im Glauben an den Menschgewordenen erkennbar. Der Deus absconditus ist also im Christusglauben offenbar:

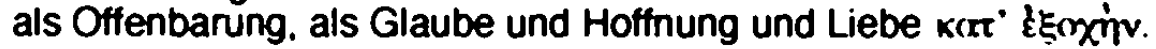

405 Diesem Verssegment (V. 14-16) liegt offensichtlich die christianisierte Tradition von "Stirt und werde" zugrunde. Vgl.: "So auch ihr, haltet dafür, daß ihr der Sünde gestorben seid und lebt Gott in Christus Jesus. I So laßt nun die Sünde nicht herrschen in eurem sterblichen Leibe, und leistet seinen Begierden keinen Gehorsam". (Römer 6, 11-12). Die Motive der "Jungfrăulichkeit", "Reinheit" (die "Lilien") etc. sind hier durchaus religiōs, christologisch zu deuten. Gerade um diese 'Reinheit' (auch im erotisch-sexuellen Sinne) bittet das dichterische Ich (Poledni zráni, V. 45-49) den "Ewigen". U. Heftrich interpretiert das Verssegment 14-16 sowie die Attribute der "Reinheit" und "Stärke", m. E. zu Unrecht, als Reflex der Lehre Nietzsches, im Sinne der "Kennzeichnung der rechten Einstellung zur Sexualităt, ja des richtigen Lebens überhaupt" (U. Heftrich, Otokar Br̈ezina, Heidelberg 1993, S. 313). Sehr richtig hingegen ist Heftrichs Schlußfolgerung, daß die Thematisierung der Liebe bei Brezina schließlich stets auf "Perpetuierung der Schuld und des Leidens" (vgl. ibid. S. 313) ziele. 
todgeweihter Lilien" ("smutkem lilii, urZených k smrti“, V. 15) verweist auf die Vergänglichkeit des Nur-Menschlichen und Irdischen. In der Sphäre der Immanenz reift letzten Endes alles zum Tode noch ehe es geboren wird; das "Ungeborene" wird noch vor der Geburt nicht nur dem künftigen Leiden für das Im-Fleisch-Sein, sondern auch dem Untergang geweiht, der aber wiederum den Keim des zuküftigen Lebens in sich trägt. Daher findet das Motiv der "todgeweinten Lilien" (V. 15) seine Replik im Motiv des "Wahnsinns der Schmerzen des künftıgen Lebens" ("a v objetích nechává Śilenstvím jásati bolesti budoucich Zit", V. 16) und im Motiv der "weißen Umarmung der Blüten": "a vưni zralého ovoce ukrývá, tajemnè, v bẻlostná sevǐeni kvẻtü" (V. 20).

Wie schon erwähnt, aktualisiert Bỉezina in Poledni zráni auch die Symbolik von "Stirb und werde". Doch es gibt einen Unterschied zwischen der antiken und der christlichen Auffassung von "Stirb und werde". In der antiken Tradition wächst das Leben aus dem Tod heraus. Die Stoikern begriffen den Tod als ein 'rechtzeitiges Aufhören' und dadurch auch als Rettung aller edien Eigenschaften und Werte, sei es Patriotismus, Edelmut. Hochsinn, Zuverlässigkeit usw. Das Hängen am Leben bedeutete Versklavung an die materiellen Dinge, der Tod dagegen die ethische Unabhängigkeit von Materie.406 In der christlichen Tradition wäre die Positivierung des 'rechtzeitigen Aufhörens' vőllig undenkbar; auch das Prinzip des organischen Wachstums wird in ihr außer Kraft gesetzt. Der Tod wächst organisch wie eine Frucht aus dem fleischlichen Leben heraus. 407 Das ewige Leben, das "Stirb und werde", hängt in der christlichen Tradition von der Begehung der Taufe und vom Leben im Glauben ab. Der Tod, der eigentlich schon Gegenwart ist, ist das paradoxe (per-vertierte) Telos des vergeblichen Strebens des Menschen nach dem Leben; ein Gedanke, der in den letzten Gedichten Bỉezinas mit gewaltiger Expressivität zum Ausdruck gebracht wird. 408

Die ewige Beständigkeit von Aufbau und Vernichtung. Tod und Wiedergeburt usw., prägt die Semantik des Traumes in der vierten Sujetsequenz: "Snéni ootvěké noci zanási v odpocinut pozemských noc" (V. 19; "Träume[n] der Urnacht trägt er herab in die Ruhe der irdischen Nächte"). Das "Träumen" ("snẻni") der "Umach" wird in das Refugium der tellurischen Nacht integriert; das Nicht-Sein des 'Ewig-Sich-Selber-Zestörens' der Welt wird durch das Prinzip des ewigen Fortbestehens neutralisiert. Die schwarze "Umacht" birgt doch in der "weißen Umarmung der Blüten" (V. 20) die "reifen Früchte" (ibid.) des zukünftigen Lebens. Die Saat des Reifens, in dem die "Großen" reifen, soll das Kommen der "Heiligen" vorbereiten. Das Reifen zur höheren Form des geistigen Seins im Leiden und Kampf des Glaubens ${ }^{409}$ ("Krev píemožených, jež stríká pod sekerou silných, syč́ praskotem jeho mystických zni", V. 21), das in der Ankunft der "Heiligen" kulminiet,

406 Vgl. H. Braun, „Das 'Stirb und werde' in der Antike und im Neuen Tetsament”, in: Ders., Gesammelte Studien zum Neuen Testament und seiner Umwelt, Tübingen 1962, S: 136ff.

$407 \mathrm{Vgl}$.: "Wer auf sein Fleisch săt, der wird von dern Fleisch das Verderben ernten; wer aber auf den $\mathrm{G}$ e i $\mathrm{t}$ săt, der wird von dem Geist das ewige Leben emten". (Galater 6, 8).

408 "Ći ruka strašná nás trná jak plevel ze záhonủ / jediným stisknutím po všech pevninách zemè ze stỉedu miliónủ?" (Zalm odcházejicich pokoleni / Der Psalm der dahingehenden Generationen. 1903; "Wessen furchtbare Hand reißt uns wie Unkraut aus den Beeten I mit einem Druck über alle Kontinente der Erde aus der Mitte der Millionen?").

409 So, wie das Leben des Glaubenden ein ununterbrochener Kampf ist, bedeutet der Glaube den S i e $g$ über die versucherische Welt (vgl. 1. Joh. 1, 5-10) und über die Macht der Finsternis (Eph. 6, 10-20). Dieser Sieg verspricht den Übergang in die eschatologische Existenz. Im ảhnlichen Sinne ist auch das Gitt-Motiv ("a bilỳmi vedry v nẻm uzrává nejprutši jedová štáva pro uštknuti hadü", V. 22; "und in der Weißglut reitt in inm der stárkste Giftsud des Schlangen-Bisses") zu deuten, nămlich als Remedium gegen die Versuchung des Nicht-Glauben-Könnens. Das "Gift" reift in der Feuerglut des mittäglichen Reifens: "Dieses Feuer, das wie "Gift" brennen kann, ist eine gewaltige "Medizin", die einzig rechte, für eine (moralisch) kranke Seele". (H. Silberer, Probleme der Mystik und ihrer Symbolik, Darmstadt 1961, S. 100). Wer das Gift "der Finsternis" übersteht, dem kann es nicht mehr schaden, mit anderen Worten, wer in seinem Glauben stark ist, der kann der Versuchung, dem 'Ruf der Welt', nicht (mehr) erliegen. In der Intention der oxymoralparadoxen Rede: das Gift birgt das Gegengitt (das heilende Gift') in sich. Vgl. folgende Antührung aus den sog. „Oden Salomos" nach: $\mathrm{H}$. Jonas, Gnosis und spastantiker Geist, Teil 1,2, Gottingen 1964, S. 328: "4. Die göttliche Hilfe: „Der Vater der Wahrheit erinnerte mich meiner"; "Der durch mich den siebenköpfigen Drachen sctilug /... / Du warest mit mir und halfest mir, / allerorten umgab mich dein Name. I Deine Rechte hat sein schlimmes Gift vernichtet, I deine Hand den Glăubigen den Weg geebnet. 
erscheint als die sinnzentrierende Intention der vierten Sujetsequenz (V. 17-31). Das transformierende Prinzip des Reifens zur höheren Form der geistigen Existenz artikuliert sich vor allem in der Weiterentfaltung der Licht(-Sonne)-Feuer-Symbolik: "V plamenech jeho kráceji svatí, radostnè ubledli jeho mystickou lázní, / a zraky jejich, oslepeny jeho polednim plápolem, pláci rozkoši jiného svètla", V. 30-31: "Durch seine Flammen schreiten die Heil'gen, freudig verbleichend im mystischen Bade. / und ihre Blicke, geblendet vom Mittag, tränen in Wonne des anderen Lichts"). Die "Starken", die den unerbittlichen Kampf überstanden haben, blendet die "mystische Sonne" (V. 2) zur scheinbar paradoxen Schau. zur Vision des zukünftigen Lebens. ${ }^{410}$ Die Symbolik des "mystischen Bades" (V. 30) läßt sich als (Wieder-)Geburt durch die göttliche Kraft, die die "Starken" erleuchtet (vergottet) und unsterblich macht, deuten. ${ }^{411}$ Die Blendung der "Heiligen" durch splendor solis (V. 31 , als Zeichen der göttlichen Epiphanie) ist eine Reinterpretation der Schlußszene aus Ranni modlitba (Das Morgengebet): "a zrak své pýchy nastavi pokornè prokláni pohledu tvého I a v syčcím vytrysku krve osleplý zárir" (V. 85-86; "und den Blick seines Stolzes demütig hinhaltend deinem durchbohrenden Schauen / im zischenden Blutstrahl geblendet vom Glanze"). Während jedoch die (ersehnte) "Blendung" des dichterischen Ich in Ranni modlitba als Vollendung der gnostischen Erkenntnis semantisiert ist, erfolgt der Blendung in Poledni zráni die Auferstehung und Verklärung des natürlichen Leibes in einen geistigen nicht nur auf ein einziges Individuum bezogen, sondern auf die ganze "Bruderschaft der Glaubenden", die im (Auferstehungs-)Glauben leben. Daher setzt der "Singende", der (Auto-)Sotér, von Poledni zráni im zweiten Teil des Textes, in dem er sein eigenes Ich zum Gegenstand der Aussage macht, seinen hymnischen Gesang gerade an jener Stelle fort, wo er in Ranni modlitba aufgehört hat: nach der kollektiven Blendung der

410 Die Symbolik der Blendung, der Augen-Schließung, geht eigentlich auf eine mystische Vorstellung zurück. Der Mystiker muß das Augen-Licht für die diesseitige Welt verlieren, um das Licht der jenseitigen Welt zu sehen. Wie der Gnosis-Forscher Richard Reitzenstein in seinem legendären Buch treffend bemerkt, ist das Licht synonym mit Pneuma, das wiederum im Hellenismus als Bezeichnung für die supranaturale Gotteskraft verwendet wurde. (R. Reitzenstein, Die hellenistischen Mysterienreligionen. 1927, S. 292f.) Plotin beschreibt die extatische Lichtschau als Weg zur höchsten Erkenntnis, der über die Stufen des abstrahierenden Denkens, über Reinigung. Tugend, Läuterung und Wandeln im geistigen Reich führt. (Plotin, Enneaden, VI 7, 36). Auch hier kann erneut an die Semantik der für Brezinas eschatologischen Symbolismus charakteristischen oxymoral-paradoxen Rede der Positivierung des Negativen erinnert werden. Die Blendung birgt das positive Gegenteil in sich: das 'höhere Sehen'

411 Vgl.: H. Silberer, Probleme der Mystik und ihrer Symbolik. Darmstadt, 1961, S. 71 ff Silberer verweist auch auf die Symbolik des Bade(n)s (bzw. Waschens) im Zusammenhang mit alchemistischen Vorstellungen, in denen sich diese Prozedur (u. a.) auf die Gewinnung des Steines der Weisen bezieht. Noch interessanter scheint - im Hinblick auf die Interpretation von Poledni zráni - folgende Anführung zu sein. "Zu den Tätigkeiten der Zerlegung der Materie, welche der Zusammensetzung oder dem Wiederaufbau vorangehen, gehört nebst der $\mathrm{W}$ a s c $\mathrm{h}$ u $\mathrm{ng}$ (Sperrung von J. V.) und Zerreibung auch die Putrefaktion oder Fäulung. Ohne diese ist kein fruchtbringendes Werk möglich. Ich habe schon früher erwähnt, daß man sich dachte, daß Sperma müsse faulen, um zu befruchten." (ibid. S. 81). An dieser Stelle rekurriert der Autor offensichtlich auf die "Stirb und werde"-Tradition: "Wahrlich, wahrlich, ich sage euch: Wenn das Weizenkorn nicht in die Erde fält und erstirbt, bleibt es allein; wenn es aber erstirbt, bringt es viel Frucht". (Johannes 12,24): "So auch die Auferstehung der Toten. Es wird gesät verweslich und wird auferstehen unverweslich. / Es wird gesăt in Niedrigkeit und wird auferstehen in Herrlichkeit. Es wird gesät in Armseligkeit und wird auferstehen in Kraft. / Es wird gesät ein natürlicher Leib und wird auferstehen ein geistlicher Leib" (1. Korinther 15, 42-44). In seiner Untersuchung zur "Stirb und werde"-Tradition verweist Herbert Braun auf die Tatsache, daß die Verwendung des Topos vom sterbenden und auferstehenden Saatkorn für die Auferstehung der Toten kein christliches Spezifikum ist, sondern in ähnlichen Formulierungen bereits in antiken Texten, namentlich bei Plutarch, thematisiert wird $(\mathrm{H}$. Braun, vgl. a. a. O.. S. 136-158). Die Wiedergeburt (bzw. Auferstehung)-Symbolik des "Bades" dokumentiert in zahlreichen Variationen der antike Mythos (Osiris, Dionysos, Pelops u. a.). In diesen Mythen geht es um die Zusammenfügung des zerstückelten Körpers, dessen Teile in einen Kessel geworten und in ihm 'gebadet' und zusammengefügt wurden, wodurch der Tote nach diesem 'Verjüngungsbad' auferstand. Diese Symbolik ließe sich natürlich auch weiter austühren, man denke Z. B. an die Bedeutung des Lebens- und Todes-Wassers in Märchen usw. 
"Starken" zur visionären Schau in Demut. 412 Die mystische Erkenntnis (pvẅors), die dem dichterischen Ich in Ranni modlitba das höchste Ziel bedeutet, reicht in Poledni zráni nicht mehr. Wie die "Heiligen", die "in Wonne des anderen Lichts weinen" ("pláci rozkošr jiného svêtla", V. 31), will nun auch das dichterische Ich "plakati svêtlem!" ("Licht will ich weinen!", V. 46). Die Symbolik der Licht-Schau in der abschließenden Sujetsequenz antizipiert die Bedeutung der Feuer-Licht-Symbolik für das "mittägliche Reifen" zur Heiligkeit und Unsterblichkeit des dichterischen Ich im zweiten Teil (V. 32-59) von Poledni zráni.

Die Handlung konzentriert sich nun auf das dichterische Ich in der Gestalt des "Singenden", der sich nach seiner 'Beichte' mit einem Bittgesang demütig413 an den "Höchsten" wendet: "Byla tvá vile, o Vẻcný! Pokornè lẻto tué zpivám!" (V. 41). Der Prozeß des Reifens (sowohl als Phylogenese wie auch als Ontogenese des Dichter-Schöpfers) kann nur durch den "Willen" des "Ewigen" geschehen; durch inn wird auch das Licht zu einer blendenden supranaturalen Kraft potenziert, die die im Glauben Starken stärkt, verklärt, erleuchtet und die im Glauben Schwachen für die göttliche Epiphanie blind macht: "Blesk, který zabiji znamenaného, štastnému ukáže cesty a dálky, I úpal, v nẻmż vadne nemocné kviti, na zlaté dráty sesili pšeničná stébla, / oslepi zraky uvyklé šeru, však zraky mocných pripravi na svitání bleskứ (V. 49-51; "Blitz, der den Gezeichneten tötet. dem Glücklichen weist er Wege und Weiten, / Glut, die kränkliche Blüten dörrt, zu goldenen Drähten steift sie die Halme des Weizens. I Sie blendet im Zwielicht hausende Augen, aber die Augen der Mächt'gen lehrt sie ertragen das Tagen der Blitze").

Die 'Beichte' des dichterischen Ich enthält zugleich eine 'Erklärung' des Mißerfolgs (V. 35-40) seiner auto-soteriologischen Ambitionen in Ranni modlitba. Resultiert dieser Mißerfolg nicht aus dem Rezidiv der (meta-)dekadenten Position in Ranni modlitba (Das Morgengebet, SZ), in dem doch die neue, eschatologische Axiologie schon auf einem sicheren Fundament zu fußen schien? Der optativ-konsekutive, zukunftsorientierte (durch gramm. Futur) Redemodus (Ranni modlitba, III.-IV. Sujetsequenz) scheint dieses Rezidiv zu 'denunzieren'. In Ranni modlitba will auch das dichterische Ich - signifikanterweise als "einer der Ärm st e n " ("I já, jeden z nejchudŠích", V. 27) - an der Ernte des "Höchsten" teilnehmen: "I já /.../ vycházím poslušen na hlas tvého zvonu na zdẻdẻnou líchu /... I (V. 27: "Auch ich /.../ komme gehorsam dem Klang deiner Glocke auf die Erbscholle /... $\mu$ ). In Poledni zráni aber 'beichtet' das dichterische Ich: "Však nejdrobnéjši byly mé klasy v úrodẻ chudých; jen sírové kvẻty / na vypráhlých mezích mne, melancholické, vítaly obrazem slunce. I V slavnostech záricí oblohy chvél jsem se bázní soumraku neviditelných" (V. 35-37; "Aber am dürttigsten war meine Garbe inmitten der Ernte der Armen: nur schwefelfarbene Blüten grüßten / schwermütig mich am dürren Rain mit dem Sinnbild der Sonne. I Am Festen der strahlenden Himmel würgte mich Angst unsichtbaren Gewölks"). Die "Schwefelblüten", "Schwermut", "Beklommenheit", "unsichtbares Gewölk" (V. 35-37) sind doch die bekannten Symptome der dekadenen Existenz. Die postulierte extatische Vereinigung mit der Majestät des "Höchsten" (V. 34; "Chtive jsem dýchal tvưj żár a celá má bytost se zménila v żizeñ!") durch die Gnosis (Ranni modlitba) reicht offensichtlich nicht. um die Finsternis, "die sich in uns aus allen Nächten, durch die wir gingen, ansammelt" ("která se v nás hromadí ze vふ̌ech noci, jimiź jsme prošli"), ${ }^{414} \mathrm{ZU}$ besiegen. Man muß, um in den blendenden Sonnenglanz schauen zu können, die transzendierende Glut des Mittag-Reifens über sich ohne A n g s t ergehen lassen, man muß wie die "Starken", die ihre Heiligkeit bereits erlangt haben, durch die Flammen der "weißen Gluthitzen" ("bilymi vedry", V. 22) schreiten: "V plamenech jeho krácejí svatí. radostné ubledlí jeho mystickou lázni" ( $V$. 30). Daher wendet sich in der folgenden Sujetsequenz ( $V$. 41-48) das dichterische ich mit einem demütigen Bittgesang an den "Höchsten". Diese Haltung des dichterischen Ich führt konsequenterweise auch zur Änderung des Redemodus. Der bis dahin vorherrschende Indikativ wird durch den Optativ abgelöst, $d$. $h$. das lyrische Ich tritt nun als 'Bittsteller' auf (V. 41-48), der den "Ewigen" um

$412 \%$ /... a zrak své pýchy nastavi pokomè I... (Ranni modlitba / Das Morgengebet, vorletzte Verszeile; $\%$... und den Blick seines Stolzes demütig hinhalten /... $/$ ); "Pokomé léto tvé zpivám!" (Poledni zráni / Mittäglich Reifen, V. 41; "Ich singe deinen Sommer in Demut").

413 Die Liebe, als Lebensäußerung des Glaubens fordert auch die Demut ("Die Liebe ist langmütig und freundlich $/ . . /$ sie blăht sich nicht auf $/ . . . /(1$. Kor. 13,4).

414 Vgl. O. Biezina, .Dva Dopisy", in: Wiener Slawistischer Almanach, 4, 1979, S. 211. 
das lyrische Ich tritt nun als 'Bittsteller' auf (V. 41-48), der den "Ewigen" um die Verklärung seines irdisch-materiellen Leibes durch das symbolische Verbrennen bittet, wodurch die Voraussetzung für die höhere, geistige Existenz ${ }^{415}$ in der jíouıç erfüllt wird. Den Akt der Verklärung (zur Reinheit und Heiligkeit) symbolisiert - nebst der "Bleichung" des Linnens (V. 45) - die "Kerze": "Tkani mých myšlenek vybẻl mi v labuti cistotu plátna a supiny vosku / bilými učiň, neż do forem naleju svice! Chci plakati světem!", V. 45-46; "Bleiche zur Schwanenweiße des Linnens meiner Gedanken Webe! Mach weiß mir die Schuppen des Wachses, / eh ich die Kerzen gieße in Formen! Licht will ich weinen!"). Die Kerze, das Symbol des Lebens, konnotiert in Poledni zráni, wie schon in Královna nadẻji (Die Königin der Hoffnungen, $v$. 16), nicht nur die absolute, 'verzehrende' (d. $h$. ohne Restbestände) weiße Reinheit, sondern auch die Lichtextase, eine Art Selbstoffenbarung: "Chci plakati světlem!" (V. 46; "Licht will ich weinen!"). Zu der Licht-Isotopie von Poledni zráni gehört auch die "Schwanenweiße" (V. 45; "labuti cistota"), ein uraltes, sowohl der antiken als auch der christlichen Tradition bekanntes Licht-Symbol. Der Schwan als Christussymbol impliziert (in diesem Kontext) den "Schwanengesang", anknüpfend an den letzten Ruf Christi am Kreuz. In diesem Sinne läßt das Motiv des "weißen Linnens" ("Cistota plátna", V. 45) die Konnotation als Bahrtuch (in das der Leib Christi eingehüllt wurde) und das der Kerze als Totenkerze zu. Die Metapher des "Gedanken-Webens" ("Tkani mých myšlenek", V. 45) kann offensichtlich als metapoetische Allusion gelesen werden.

Nach der demütigen Unterwerfung unter den Willen des "Schöpfers" - "Byla tvá vưle, o Věčny! /... / Spal touhy mých jiter" "Dein Wille war es, o Ewiger! /.../ Verbrenne die Sehnsüchte meiner Morgen und Nächte") - erbittet das dichterische Ich eine neue Befruchtung (und Saat) seiner nach der mystischen eiaculatio des "Höchsten" dürstenden Anima: "Žhavým svým deštěm, v nẻmż zkvetla a svadla staletá setba mých otcú, duši mou zaplav" (V. 41-42; "Mit deinem glühenden Regen, darinnen blühte und welkt' die uralte Saat meiner Väter, überschwemm' meine Seele!'”. Nach der vollbrachten grandiosen

415 Der Auferstehungsgedanke, die Korrelation von Leben und Tod, die in Neuem Testament vor allem das Gleichnis von Saat und Reifen zum Ausdruck bringt, rührt von der "Stirt und werde"Tradition her. Der Topos von Aussat. Reifen und Ernte spielt, wie schon dargelegt, in Ranni modlitba (Das Morgengebet. SZ) eine konstitutive Rolle. In Poledni zráni wird er erneut aufgegriffen und neu akzentuiert. Es scheint, daß die $\pi u$ rıç in Poledni zráni nicht nur als Auferstehung selber, sondem auch als das Aufkommen des "neuen, heiligen Saatguts" ("nová. posvátná setba*, V. 58) im Vordergrund steht. Das Sterben ist notwendig für die neue Existenz, für das Fruchtbringen; auf den Weg Jesu bezogen: Jesus muß sterben, damit er Nachfolger, Glaubende findet. ( $H$. Braun. "Das "Stirb und werde" in der Antike und in Neuem Testament", in: a.a. O.). In Vétry od pólú scheint der "Stirb und werde-"Topos eine ekklesiologisch Konnotation zu haben. Eine elitäre Geimeinschaft der 'wissenden' Pneumatiker wird bereits in Vino silných (Der Wein der Starken. SZ) kreiert. Die Symbolik der in Vino silnych kreierten Gemeinschaft stammt aber noch aus dem gnostischen Anschauungskreis. In Vëtry od pólú heißı diese Geimenschaft beınahe programmatisch Bratrstvi véricich (Die Bruderschaft der Glaubenden). Es ist keın Zufall. daß gerade dieses Gedicht (Bratrstvi vëricich) das wesentlıch komplizierteres, vielschichtıgeres und bedeutungsmäßig schwierigeres Poledni zráni im Gedichtzyklus Vêtry od pólú quasi einleitet. In Bratrstvi vericich geht es um die Einheit durch die Glaubensentscheidung in der Gemeinde der eschatologisch Existierenden, um die Einheit des Glaubens in und mit $\mathrm{lhm}$. Daher spielt in Bratrstvi véricich der Topos des "Lebensbaumes" (bzw. "Weinstockes") eine konstitutive Rolle: "Sny naše spojily se v jediné snéni a šumẻly tisici stromú jednoho hvozdu, /.../. I trhali jsme svá opojeni . jak zrna na jediném mystickém hroznu, / jež dotknutim pukala vỳtryskem jednoho vina: I jablka jednoho stromu, jeż rozríznuta společnou. naši, krvi se zardi l... (Bratrstvi vérícich / Die Bruderschaft der Glaubenden. III, 1. IV, 1-3: -All unser Träumen ging da in einen Traum ein und rauschte in tausend Bäumen des einzigen Hochwalds $/ . .$. . So pflückten wir unser Entzücken, die Beeren einer einzigen mystischen Traube: / sie sprangen bei der Berührung auf in des Weines Ausbruch. I Äpfel eines Baums, zerschnitten, errötend von unserem gemeinsamen Blute I... $F$. Ubers. v. F. Werfel). Diese "Bruderschaft der Glaubenden" ist offenkundig als eine (ekklesiologische) vom Walten des Geistes geleitete Gemeinde der Charismatiker konstituiert, die sich von der ('Mysterien'-)Gemeinde der (gnostisierenden) "Starken" unterscheidet. Der. (hellenistisch-) neutestamentliche "Stirb und werde"-Topos konnotiert in Poledni zráni offensichtlich das Leben im Glauben (durch das Sterben mit Christus). Vgl. "So auch inr, haltet dafür, daß ihr der Sünde gestorben seid und lebt Gott in Christus Jesus". (Römer, 6, 11). "Also seid auch ihr, meine Brüder, dem Gesetz getötet durch den Leib Christi, so daß inr einem andern angehört, nämlich dem, der von den Toten auferweckt ist, damit wir Gott F r u c h t b r in ge n* (Rổmer, 7, 4. Sperrung vom Vert.). 
Wiedergeburt zur Heiligkeit (durch die Glaubens-Stärke) wird die brennende spermatische Flut (jetzt nicht mehr als wallender Odem des Mittag-Reifens, sondern als "Musik deiner nächtichen Stürme und Meere", V. 52; "Hudba nočních tvých vichrü a morï", konnotiert) den "Starken" I "Heiligen" zum kühlenden Labsal: "v žhavý sen silných padá jak chladivá rosa stř́brných ohlasem svitáni jitr̄nich" (V. 53; "[sie] fällt auf den glühenden Traum des Starken wie kühliger Tau im silbernen Echo auflichtenden Morgens“). Der Wille des "Höchsten", der sich im verzehrenden Licht der mystischen Flammen ("zazračné plameny", V. 44) offenbart, vermag auch die Sphäre des Tellurischen mit der des schöpferischen "Träumens" ("v zahradách zemé a snént", V. 44; "in den Gärten der Erde und des Traumes") zu vereinigen.

Ab V. 48 tritt das dichterische Ich in den Hintergrund und wird ein Teil - ein 'Glied' des (eschatologischen) Gemeinde/Leibes der Glaubens-Starken. ${ }^{416}$ Seine Stimme verschmilzt mit der kollektiven Stimme der "Bruderschaft der Glaubenden", die die Eigenschaften und Werte ihrer Stärke in einem (kontrastiven) Vergleich artikuliert - es sind quasi Reformulierungen der gleichen Syptome der dekadenten Existenz (V. 49-53), die das 'beichtende' dichterische Ich erwähnt (V. 37-40) - und die wunderbare, siegreiche ("vítězi" I "Sieger", V. 54) Kraft des Charismas des Glaubens zum Ausdruck bringt. Die Frucht ihres Glaubens ist die Gewißheit der eschatologischen Existenz:

"Do vỷse vedou tvé cesty, v závrati umdlených, však vítézi stoupaji v tanci / a do údoli házeji pisnè v prưvodu bourîi, jenž pod nimi v hlubinách vî̛́: / však nad nimi věčná nádhera svếtla se lije Širokym obzorem dálek. // Aż uzrálé do hlubin zapadnou světy a noci a soumraky denní, / pod požehnánim pohledu tvého pohne se v hlubinách nová, posvátná setba / a hlahol tvỷch polednich zvonủ pozdraví modlitba nesmrtelných" (V. 54-59; "Zur Hōhe führet dein Weg! Wenn Schwindel die Schwachen zurückwift, erklimmen im Tanze die Sieger den Gipfel, / und werfen Lieder ins Tal, zum Baß der Gewitter, die unten die Tiefen durchtoben. / Aber ihnen zu Häupten das ewige Prangen des Lichtes überbreitet den weiten Gesichtskreis der Fernen. // Bis reif in die Tiefen sinken die Welten und Nächte und das Gewölke des Tages, / dann in deinem segnenden Blick regt sich im Abgrund das neue, heilige Saatgut, / und das Geläut deiner Glocken am Mittag lädt zum Gebet uns, die Unsterblichen, ein").

\title{
4.3.3 Gnosis der Agape - Erkenntnis des soteriologischen Plans durch das Charisma der Liebe: Láska (Liebe)
}

\begin{abstract}
„Die Erkenninis bläht auf: aber die Liebe baut auf. Wenn jemand meins, er habe etwas erkannt, der hat noch nicht erkannt, wie man erkennen soll. / Wenn aber jemand Golt liebt, der ist von ihm erkannt".
\end{abstract}

1. Korinther 8, 1-3

\author{
"All is beauty \\ And knowing this is, love, and love is duty." \\ Robert Browning
}

\section{Láska}

Záre dalekých jiter se zrcadlí v úsmèvech mlěení vašch płed odpovědí a myšlenky vaše jsou jako płezrálé klasy samy se otevírající.

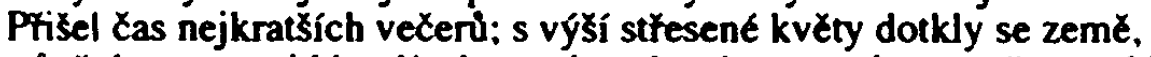
vưnè dne nocemi bloudí a konstelace letní vystouply na vašem nebi

5 a i v nejroztržitějứ pohledy vaše chytá se padání hvězd.

Smích a výkłiky žiznivé krve už nestací vaši zbohatlé duši,

416 Vgl. hierzu: -Denn wie der Leib einer ist und doch viele Glieder hat, alle Glieder des Leibes aber, obwohl sie viele sind, doch ein Leib sind: so auch Christus. I.../ Ihr aber seid der Leib Christi und jeder von euch ein Glied". (1. Kor. 12, 12; 27). 
Šlenstvi její cítí se silným phijati bolesti věků a mluviti feči, v níz láska má hluboká poznání smrti, agonie extatické úsměvy milujícîho a rozkoß̌ je sesutí světů

(nebơ złríceninami procházi duše na cestách $k$ vyšsímu světllu a bolest je výxitkou odloučeného).

Hle, bratłí! Vaše láska se plní jak stromovi jižní: plody má uprostłed kvêtú. a dech její roven je vêtru vł̌ech zahrad, ethemá kytice tisícú vủní. Mlhy zdvihly se k výsi: $k$ posledním přistím světưm se rozšî́il obzor,

15 a v extasi vaši zazvonil vesmír jak hudba płi hostině nesx̌íslných. Ale neubývá úrody vaši: dech Vex̌ného táhne pod nebesy vašeho srpna a ȟijna $v$ den slavnosti klasù a zahrad a vinic a duší. a žeñ vaše je podobna úrodě světla: do płíchodu nešetných nocí Zali z ni národové a nezmenšili ji $v$ tisíciletích -

V nové sîle život jste pocítili a tepot vašeho srdce vrací vám dálky jak bouri.

Nebol nekonečno vక̌ech cest kłízí se $v$ duši milujicího a v hlase lásky mrtvi se ptaji, kdy nastane hodina vysvobození.

25 a nezrození jim odpovídají bolestí její.

V klidu jejím je nepokoj oxekávání a v úsměvech jejích vzpomínky slunce. jež zapadlo nad nivami zemé a vyšlo na nebi neviditelném a vzpomínky slunce na ohnivá v̛̉ení, než pruní světy se odtrhly v dálku. A v blesknutí jejího zraku fełavi tajemná đára, přitomnost nepoznaného. jež protíná vidmo mlhovin nejvzdálenějš́ch. $\mathbf{z}$ nichž dosud hvězdy se neutvơ̌ily.

Braţ̌́! Vał̌e láska se plní jak stromovi jižni: plody má uprostłed kvêtư a dech její roven sepotu soumrakú v mésíci jarniho tání.

Tušeni jejímu dáno je spatłiti duše $v$ prvotním svêtle

35 a pozdravit bolest. když vrací se $z$ tajemstvi věcí zbohatlá cestami svými a silná rozpextím kf̌idel svých v Rythmu.

Z požáru dotknutí jejîho vzbouzí se vêtry, jež zmítají slehlými atmosférami a hudbou ukrytou $v$ plamenech provázejí jásot paprskủ osvobozených. Bez bázné pohliźí láska v zrcadla nocí, jež ztravuji płizraky barev. však hlubiny svoje dokơ̌án otevrou světlu. a vtełiny její éíány nejsou padáním krujpèjí z oblakú tohoto času. jenž sluně̌ní hodiny její pokrývá vrženým stínem a slabé sesmutněl nejistotami: cestami hodin kráxí $v$ nich stínem stoupání druhého slunce a měri den vašich duši.

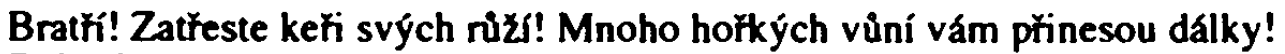
Bolesti neznámé těm. ktełí nemilovali, blíži se k samotám vašim.

Bolesti touhy, jež staletí topí se $\mathbf{v}$ krvi a tisíce rukou pozvedá $\mathbf{k}$ nebi! Bolesti lásky, jež zemfrela polibky a té. která zhłełila v ozekávání!

50 Bolesti nešetných úsměvủ odvátých vichricí pohledu neprátelského! Bolesti báznè, aby Nepłítel nepłišel k hostinẻ vaší, neviditelný, zavolán slabostí ukryté myšlenky vaši. a neotrávil vám víno dłív než jste ho podali bratłím: (neb láska, jež ztratila jediné vítězství, tisíckrát byla poražena

55 a hodující, jenž opustil komnatu svétel, zraky má zmatené vzpomínkami, a noc jeho je temnèjši vకech noci a plna nebezpečenství).

Bojte se stínù, jež padaji do vašeho světa $z$ vyhaslých płedvěkých svêtư a bolestí viny, jež plíži se podsvêtím nenarozených.

Bolesti, které vystouply z hrobủ a $z$ krve a $z$ płílił jasného svêtla 
60 a z úsměvů krásy a z odchodu dłíve než užríte spox̌inout jitro na loži riži a rosy ustlaném staletími!

V prîvodu stínù vychází duše stoupajícího: však stíny bojí se výyí a zemdlí na strmych cestách a zraky milujicích se jasní; jediná pýcha závrati nezná, bojte se pýchy, o braťrí!

65 Odměnou vaši budou chvile, kdy užríte zemi světlem své lásky:

Pozdrav vám vykł̧iknou krajiny v květu, nejhlubł̌i mlěeni daji vám lesy, a zrající léta, jež vábí svou písni podzim do polí a zahrad,

feknou vám tajemství vêxné své žízné po nových jarech.

I bude poznání vaše jak potkání noci a dne, které má za svědky tisíce hvězd,

a za kridly vašich odletlých hodin zvlní se brázdy etherné vůně.

I rozł́íti se pohled vás jako čas plný světla a obejme zemi,

a $v$ úsměvu vašem tisíce úsměvủ zasvítí $z$ tisíce duší,

tisíce smrí budete potkávat najednou $v$ tisíci cestách bez báznè

a užíte zástupy neš́íslných Zivotư vcházeti v jediný żivot.

\section{Liebe}

Frühschein künftiger Morgen spiegelt im Lächeln eures Schweigens vor aller Antwort, eure Gedanken gleichen den Ähren, die überreif selbst sich erschließen.

Zeit der kürzesten Abende kam. Von Wipfeln geschüttelt, sanken die Blüten zur Erde.

Tagduft irrt durch die Nacht. Schon stieg euren Himmel hinan die Konstellation des Sommers.

Und noch in euren zerstreutesten Blick verfangen sich fallende Sterne.

Gelächter durstigen Bluts und Schrei genügt nicht mehr der reicheren Seele.

Es fuhlt ihr mächtiger Wahn die Kraft, die Schmerzen der Zeiten zu tragen,

zu sprechen die Sprache, darin die Liebe die Tiefen des Todes erkennt.

und Agonie nur ekstatisches Lächeln des Liebenden ist und Lust sind zerstürzende Welten.

10 (Denn durch Ruinen wandelt die Seele den Weg zum höheren Licht auf und Schmerz ist Vorwurf vereinzelten Seins.)

Seht meine Brider! Eure Liebe belädt sich wie Bäume des Südens. Früchte trägt sie inmitten von Blüten.

Aller Gärten Wind ist ihr Odem, ein ätherischer Strauß unzähliger Dufte.

Nebel stiegen empor. Zu letzten zu künftigen Welten anwuchs der Gesichtskreis.

15 In euren Lichtschlaf läuteı das All wie Musik vom Mahle unzähliger Gäste.

Aber nicht nimmt eure Emte ab. Des Ewigen Hauch zieht unter den Himmeln eures Augusts und

am Tag des Festes der Ähren und Gärten, des Weinbergs, der Seelen - ...

eures Oktobers, und eure Saat ist ähnlich der Ernte des Lichtes:

Bis zum Anbruch unendlicher Nächte schnitten die Völker,

20 doch sie ward weniger nicht in Äonen der Jahre -...

In neuer Kraft habt ihr das Leben empfunden!

Und euer Herzschlag kehrt aus der Ferne wie Sturm euch zurück!

Denn aller Wege Unendlichkeit kreuzt in der Seele des Liebenden sich, und in der Stimme der Liebe fragen die Toten: Wann schlägt die Erlösungsstunde?

25 Und mit dem Schmerz der Liebe geben die Ungeborenen Antwort.

In ihrer Ruh ist Unruh des Wartens, in ihrem Lächeln der Rest jener Sonne. die unterging den Gefilden der Erde und aufging am unsichtbaren Gewölbe. und Erinnerung der Sonne im feurigen Wirbel, ehe die Urwelt sich losriß zum Wandel.

Im Blitz ihres Blicks aufgrellt die geheime Gerade, in der die Allgegenwart des Unbekannten 30 und die das Spektrum durchfährt des äußersten Stemschaums. erscheint 
aus dem noch kein Stern sich gebar.

Brijder! Eure Liebe belädt sich wie Bäume des Südens; trägt Früchte inmitten von Blüten, dem Gelispel der Dämmerungen gleicht ihr Atem im Monat der Frühjahrsschmelze.

Vergönnt ihrer Ahnung ist es, zu sehen die Seelen im Urlicht,

35 zu begrußen den Schmerz. wenn er heimkehn aus dem Geheimnis der Dinge.

beladen von Fahrten und stark vom Schwung seiner Flügel im Rhythmus.

Aus dem Brand ihrer Berïhrung erwachen die Winde, aufschleudernd die schlaff gelagerte

die mit Musik, verborgen in Flammen, das Jauchzen begleiten der befreiten Strahlen.

Luftschicht.

Ohne Furcht blickt die Liebe in die Spiegel der Nacht, die das Wahnbild der Farben verzehren.

40 doch ihre Tiefen angelweit öffnen dem Licht. - . -

und ihre Sekunden. sie sind nicht gezählt durch Tropfenfall aus Wolken der heiligen Zeit,

die ihre Sonnenuhr mit ausgeworfenem Schatten deckt.

und die Schwachen mit Trauer der Ungewißheit bestiurzt:

auf den Straßen der Stunden schreitet sie vor mit dem Schatten der aufsteigenden zweiten Sonne

45 und mißt den Tag eurer Seelen.

Briider! Schültelt den Strauch eurer Rosen! Viel bittern Duft trägt die Ferne euch her!

Und Schmerzen, jenen verschlossen, die niemals geliebt, sie treten in eure Einsamkeit.

Schmerz der Sehnsucht, die ewig im Blut sich ertränkt und tausend Hände zum Himmel

Schmerz der Liebe, die hinstarb im Kuß und jener, die sündig wurden im Warten!

hinanreckt!

50 Schmerz unzähligen Lächelns, von Windsbraut des feindlichen Blickes verweh!!

Schmerz der Furcht, daß der unsichtbare Feind nicht trete zum Gastmahl.

leise von der Schwachheil eures verdeckten Gedankens gerufen,

damit er den Wein euch vergifte, eh ihr ihn hinreicht den Brüdern.

(Die Liebe, verliert sie nur einen Sieg, tausendmal ist sie in Staub geschleudert.

55 und der Zecher, der den Saal der Lichter verließ, verwimt von Erinnerung sind seine Blicke. und finstrer ist seine Nacht und voll von Gefahren.)

Fürchtet die Schatten, die fallen in euer Licht aus verloschen vorweltlichen Welten und fürchtet Schmerzen der Schuld, die durch die Unterwelt der Ungeborenen schleichen.

Schmerzen, gestiegen aus Grab, aus Blut und aus allzuseligem Lichte.

60 aus Lächeln der Schönheit. aus dem Abschied, eh ihr noch sahet den Morgen sich neigen auf das Bette der Rosen, des Taus, das die ewigen Zeiten bereiten!

Aus dem Zug der Schatten tritt die Seele des Steigenden vor, denn die Schatten fürchten die

und schrumpfen muid auf abschüssigem Grat, wo die Blicke der Liebenden leuchien.

Doch nur Hoffan allein kennt den Schwindel nicht! Drum hütet euch vor der Hoffart, ihr

Brider!

65 Es wird euer Lohn der Augenblick sein, da ihr erblickt durchs Licht die Erde:

Aufjauchzt euch im Gruße der blühende Hag. ihr tiefstes Schweigen schenken euch Wälder. und reifende Sommer, die mit Liedem den Herbst in Felder und in Gärten locken, verraten euch ihres ewigen Durstes Geheimnis nach eurem Frihling.

Und eure Erkenntnis wird sein wie Begegnung von Nacht und Tag. als Zeugen wandeln ihr

70 und hinter den Flügeln eurer entflatternden Stunden wogen Furchen ätherischen Dufts auf.

Seht! Es weitet sich euer Blick wie die Zeit voll von Licht. und umarmt die Erde.

In eurem Lächeln leuchtet es auf von tausend I ächeln aus tausend Seelen. tausend Toden müßt ihr begegnen plötzlich auf tausend furchtlosen Wegen. dann seht ihr unzähliger Leben Schar eingehn in ein Einziges I eben.

Deutsch von Franz Werfel. 
Das Mittäglich Reifen mündet in die Verheißung des ewigen Lebens im Glauben (V. 57-59), der die Bedingung für die Hoffnung auf das Aufgehen des "neuen, heiligen Saatguts" und das "Fruchtbringen" darstellt. Aber erst in der Liebe, in der sich die Kraft der wahren Erkenntnis offenbart, bewährt der Glaube seinen Sieg.

Der Prozeß des Reifens zur eschatologischen Zukunft kulminiert in Láska in der Erfahrung der höchsten aller drei Geistesgaben, in der Erfahrung der Gottes- und BruderLiebe, die die (im Glauben) "Starken" in ihrem geistigen Kampf errungen haben. Die einzige Gefahr, die dieses Charisma überschattet, ist der auf den Irrweg führende und von der pneumatischen Begabung (der Gnostiker) herrührende Hochmut. Denn die rechte Gnosis schließt die Agape ein. Dabei beruht ihre Größe gleichermaßen auf inrem ethischen Imperativ.

Das Gedicht besteht aus drei größeren Sujetsequenzen, denen auch drei verschiedene Redemodi entsprechen. I: $V$. 1 - 45; 'Bestandaufnahme' des im eschatologischen Prozeß bereits Erreichten, dem entspricht der i n d i k a t i ve Modus. II: V. 46-64; Warnung vor den Gefahren und der Ermattung; dem entspricht die Form des

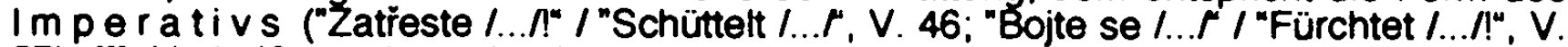
57). III: Verheißung des zukünftigen Lebens, der eschatologischen Existenz, wenn man sich an die zwei Ermahnungen hält und den Gefahren nicht unterliegt; dem entspricht das grammatische Futur: "Odměnou vaši budou chvile I... ${ }^{\prime}$ (V. 65; "Es wird euer Lohn der Augenblick sein /... ${ }^{\mu}$ ).

An welcher Gattung der religiösen Rede orientiert sich Br̈ezina in Láska ? In Poledni zráni wird die Poetik des Gebets und des Psalmes aktualisiert; in Láska greift Bỉezina, ähnlich wie in Vino silných (Der Wein der Starken, SZ), auf die Poetik der Predigt zurück. Das dichterische Ich 'deutet' bzw. reflektiert das, was im Prozeß des Reifens zur Glaubensstärke bereits erreicht wurde, es ermahnt und appelliert darauf, den lauernden Gefahren nicht zu unterliegen und es verheißt den "Brüdern" auch den "Lohn" ("odmèna"). Wie ist die Prăferenz der Predigt in diesem Gedicht zu deuten? Meines Erachtens entspricht sie dem für die semantische Axiologie des theo-logisch-eschatologischen Modells hochrelevanten christologischen - im engeren Sinne paulinischen - Verständnis der Liebe als G e b o t, als die eigentliche christliche Forderung, die Jesus gebracht und seinen Jungern g e p re digt hat. Den Höhepunkt der Liebesforderung stellt die Feindesliebe (s. die Bergpredigt Jesu, Matth. 5, 43-48) dar, die das Gedicht Modlitba za neprátele (Das Gebet für die Feinde, VP) zum Hauptthema hat.

Das höchste Charisma, ja den Höchstwert jener Dreiergruppierung der christlichen Existenzbestimmung, wird bereits durch den Gedichttitel Láska (Liebo) akzentuiert. Dem Erlangen dieses Höchstwertes entspricht auf der thematischen Ebene die Vollendung des Reifen-Prozesses:417 "a myšlenky vaše jsou jako piezrálé klasy samy se otevírajíci" (V. 2 ; "eure Gedanken gleichen den Ähren, die überreif selbst sich erschließen"); "Hle, bratr̂i! Vaše láska se pini jak stromovi jižni: plody má uprostiéed květư" (V. 12; "Seht meine Brüder! Eure Liebe belädt sich wie Bäume des Südens. Früchte trägt sie inmitten von Blüten"): "a žeñ vaše je podobna úrodě světla" (V. 18; "und eure Saat ist ähnlich der Ernte des Lichtes"). Es ist die Symbolik der "überreifen Ähren" (V. 2), des Fruchtragens (V. 12), der "bereicherten Seele" ("zbohatlé dusi", V. 7) und der Metamorphose der Sonnenglut des "mittäglichen Reifens" zur spätsommerlichen (V. 16) und wärmenden Lichtflut, die den Zustand der Vollendung konnotiert. Diese zauberhafte Lichtflut, das wohltuende Lichtbad des (ewigen) Lebens, das die "Sieger" / "Heiligen" im vorletzten Dreizeiler von Poledni zráni (Mittäglich Reifen) voraussehen ("vふaak nad nimi věcná nádhera svètla leje se Sirokým obzorem dálek": V. 56 "über innen das ewige Prangen des Lichts überbreitet den weiten Gesichtskreis der Fernen"), erleben die "Brüder" in Láska als "heilige" ("posvátná")

417 Diesem Prozeß entspricht auch der Redemodus: Das Gedicht Královna nadejji (Die Königin der Hoffnungen) ist als monologische Ansprache der Anima an das lyrische Ich aufgebaut; in Poledni zráni hingegen wendet sich das lyrische Ich mit seinen Bitten an den "Hochsten", wobei die "Starken" bzw. "Heiligen" auch schon mit einbezogen werden (daher 3. Pers. Pi.). Die Entwicklung von der individuelle n Hoffnung zum kollektiven Glauben in der Gemeinde, die Tendenz zum 'Sich-Offnen' der Gemeinde der Glaubenden, zur Sakralisierung des kollektiven Lebens, vollzieht sich dann in Liebe (Láska), wo das lyrische Ich - in der Beziehung 'Ich' - 'Ihr' - unmittelbar die "Bruderschaft" der Glaubenden (und der Liebenden) anspricht: "Hle, bratrĭ! Vaše láska se plni jak stromovi jižni" (V. 12; "Seht meine Brüder! Eure Liebe belädt sich wie Bäume des Südens“). 
"Ernte des Lichtes": "MIhy zdvihly se k výsi: k poslednim, přištim světưm se rozširiil obzor, I... I a Żeñ vaše je podobna úrode svẽtla" (V. 14, 18; "Nebel stiegen empor: Zu letzten, zu künttigen Welten anwuchs der Gesichtskreis, /.../ und eure Saat ist ähnlich der Ernte des Lichtes"). Die "Ernte" ("Zeñ") des spirituellen Reifens als Erlebnis der Liebe, ja des "Liebeswahns" ("Silenstvi", V. 7), der der Erleuchtung gleicht (V. 18), macht die Seele der Liebenden stark für den Empfang des Schmerzes: "Ślenstvi jeji cíti se silným prijiati bolesti věkưl a mluviti reči, v níż láska má hluboká poznání smri“ (V. 7-8). Diese Aussage signalisiert das dialektische Verhältnis von Liebe und Leiden, von Liebe und Erkenntnis. Das Leiden hat in Láska (V. 48-64) eine konstitutive Funktion:418 ( $\mathrm{r}$ e c h t e ) "Erkenntnis" ("poznáni") steht in Láska mit "Liebe" im Verhältnis der wechselseitigen Implikation, $d$. $h$. Liebe - Erkenntnis / Erkenntnis - Liebe. Schmerz und Untergang werden als unausweichliche Topoi des ascensus der Seele zum "höheren Licht" ("vyšši světlo") akzeptiert und "Trennung" ("rozděleni") erneut als Ursache des Schmerzes denunziert: ("nebot zríceninami procházi duše na cestách k vyššimu světlu / a bolest je výcitkou odloučeného"; V. 10-11). ${ }^{419}$

Eine der Höchstleistungen der Liebe ${ }^{420}$ gründet in ihrer Aufbaufunktion, hier allerdings nicht nur im Sinne der Auferbauung der Gemeinde der Glaubenden (Bratrstvi vëricich), sondern auch im Sinne der Überwindung der Verhältnislosigkeit zwischen Mensch und Mensch, d. $h$. als Aufbau des Christenmenschen, dem die Líebe/Agape dient. Die Ernte der 'Liebesextase' (V. 7, 14) der Theurgen wird in Laska421 an die Mitbrüder gleichsam verteilt: "Ale neubývá úrody vasi /.../ a Zeen vaše je podobna úrodẻ svétla: / do príchodu nes¿etných nocí Zali $z$ ni národové a nezmenšili ji v tisíciletich - -" (V. 16, 18-20; "Aber nicht nimmt eure Ernte ab. I... / Bis zum Anbruch unendlicher Nächte schnitten die Völker, I doch sie ward weniger nicht in Äonen der Jahre"). Die Saat der Dichter/Theurgen ist ähnlich der "Ernte des Lichtes" (V. 18). Darin offenbart sich die hohe ethische und zugleich soteriologische Funktion des Dichters: "denn in der Stimme der Liebe fragen die Toten: Wann schlägt die Erlösungsstunde?" (V. 24; "nebot' v hlase lásky mrtvi se ptaji, kdy nastane hodina vysvobozeni"). Der Sturm / Odem des "Höchsten" (Královna nadëji I Königin der Hoffnungen, V. 5, 15, 37), sein "durch Jahrtausende wallender Gluthauch" (Poledni zrání I Mittäglich Reifen, V. 8, 13, 17), wird in Láska zum milden, spätsommerlichen "Odem der Liebe" gleichsam kultiviert (V. 12-13). Die "Brüder" ("bratrï") agieren als Lichtträger, als Vermittler der göttlichen Liebe, die auf sie ausgestrahlt wird: "dech lásky" (V. 12-13; "Odem der Liebe"); "dech Věčného táhne pod nebesy vašeho srpna a îjna" (V. 16; "Des Ewigen Hauch zieht unter den Himmeln eures Augusts und

418 Möglicherweise auch als Allusion auf die Passion Christi.

419 Die "Trennung" ("odlouceni") kann hier sowohl gnostisch (als Trennung der Lichtgestalt von ihrer himmlischen Lichtheimat durch die dămonischen Măchte), als auch christologisch (als Verletzung der Einheit der Gemeinde, der "Bruderschaft der Glaubenden"), gedeutet werden.

420 Bíezina nennt das Gedicht Láska "Hymnus o nejvyšši lásce, jednu z poslednich, jak myslim silnéjక̌ich komposici I... F. (An Anna Pammrová. März 1897; "Der Hymnus von der hóctisten Liebe, eine der letzten, wie ich denke, stärkeren Kompositionen /... ). Daß die Formulierung "nejvyšsi láska" ("hōchste Liebe") dem 13. Kap. des ersten Korintherbriefes entstammt, das doch als "Hohe Lied der Liebe" bezeichnet wird, dürte außer jeden Zweifel stehen. Vgl. auch 1. Kor. 13, 13: "...$/$ aber die Liebe ist die größte unter innen". Dieses hochrelevante intertextuelle Indiz entging bisher allen Bł̈ezina-Interpreten.

421 Unter "Liebe" ist hier offenkundig die Gottes- und die Bruderliebe zu verstehen (vgl. auch: "šilili jsme šilenstvim lásky, jeż byla modlitbou k Nejvyšsimu", Bratrstvi věricich / Die Bruderschaft der Glaubenden, 11, 2; "im Wahnsinn der Liebe rasten wir da, und dies war unser Gebet zum Höchsten"). In Láska koinzidiert die "Liebe" mit Agape, nicht etwa mit Eros oder Philia. Das Motiv der Verteilung eigener Emte an die Mitbrüder als die Tat der Bruderliebe, kommt übrigens in Noci! (Nächte!) prägnant zum Ausdruck: "Noci svatých, bdicich na modlitbách dikủ za úrodu, jiż celou rozdali brattím" (V. 13: "Năchte der Heiligen: Sie wachten in Dankgebeten für Ernten, zur Gänze verteilt an die Brüder". Übers. v. F. Werfet). Gerade die Symbolik des Baumes, des Fruchttragens, der Blüten usw. in Láska (Liebe) indiziert sowohl die Einheit von Glaube und Liebe (vgl. dazu Joh. $15,1-17)$ als auch die Verpflichtung zum Lieben, die aus dem Empfang der Liebe resultiert. Zu den Agape-Gedichten zăhlt in VP (neben Láska / Liebe, Vládnouci.../ Herrscher..., Kdyż z lásky tvé... I Wenn aus deiner Liebe..., Noci! / Nächte!) auch das bekannte Gedicht Modlitba za neprátele (Das Gebet für die Feinde), das M. Cervenka (.Modlitba za neprátele", in: Ders., Styl a v'żam. Praha 1991, S. 11-31) scharfsinnig interpretiert. 
eures Oktobers").422 Die Liebe zählt zu den Frü ch te n des Geistes (vgl. Gal. 5, 22) und der Geist (Pneuma) ist grundlegend für die Orientierung des Menschen im Raum der Liebe (des "Höchsten"), wo er seine Existenz finden soll. Es ist die unerschöpfliche "Ernte des Lichtes" (V. 19-20), die die Erhelltheit des Daseins, die Erleuchtung der Existenz und zugleich die Liebe, Wahrheit, Leben und Freiheit, die miteinender korrelieren und sich gegenseitig erläutern, bedeutet. Das Motiv des "Gastmahls unzähliger Gäste" ("hostina nescisIných", V. 15), der Höhepunkt des 'Fruchttragens' der Liebe, läßt sich in bezug auf die Bedeutung von Agape als 'Liebesmahl' deuten: "Bolesti bázné, aby Nepritel neprísel k hostinè vaši, neviditelný, / zavolán slabostí ukryté myšlenky vaši, l.../ (neb láska, jeż ztratila jedinè vítězstvi, tisíckrát byla poražena)" (V. 51-52, 54; "Schmerz der Furcht, daß der unsichtbare Feind nicht trete zum Gastmahl, / leise von der Schwachheit eures verdeckten Gedankens gerufen, I.../ (die Liebe, verliert sie nur einen Sieg, tausendmal ist sie in Staub geschleudert)").

Die Semantik der Liebe wird in Láska vor allem von der Vorstellung des Sich-bewußtwerdens der eschatologischen Existenz ${ }^{423}$ in der Er-Füllung (V. 12, 32) des Liebesgebotes geprägt. 424 In diesem Sinne, als Allusion auf die neue eschatologische Existenz. in der sich der Heilsplan des "Höchsten" realisiert und in der "die Schätze der Erkenntnis" liegen, 425 kann auch die Symbolik der neuen Lebenskraft ("V nové síle żivot jste pocítili", 21) interpretiert werden: "Nebot nekonečno všech cest se kńží v duši milujicino / a v hlase lásky mrtvi se ptaji, kdy nastane hodina vysvobozeni, / a nenarození jim odpovidaji bolestí jeji. I V klidu jejím je nepokoj očekáváni /.../. A v blesknutí jejího zraku reeiaví tajemná cára, prítomnost nepoznaného I... ${ }^{\mu}(\mathrm{V} .23-26,29)$. Doch auch der Schmerz gehört zum Erlebnis der Liebe ("Tušeni jejímu bude dáno spatriti duše v prvotnim světte la pozdravit bolest, kdyż vraci se z tajemství vẻci / zbohatlá cestami svými a silná rozpétím krídel svých v Rythmu"; V. 34-36; "Vergönnt ihrer Ahnung ist es, zu sehen die Seelen im Urlicht, / und begrüßen den Schmerz, wenn er heimkehrt aus dem Geheimnis der Dinge, / beladen von Fahrten und stark vom Schwung seiner Flügel im Rhythmus"). Der "Schmerz" ("bolest") wirkt - im Hinblick auf die neuen Möglichkeiten des Lebens - als Kraft (dynamis) und als konstitutives Element des Heilsplans. ${ }^{426}$ Dieser Gedanke spielt auch in Modlitba za neprátele (Das Gebet für die Feinde) eine wichtige Rolle:

"A bolestné výkriky naše zvoniti budou jednou jak væely /.../. I A v tichu bolesti své at' słyšime suméti $v$ duši mystické prameny světla, I nebot' bolest a svẻtlo jsou formami jediné vibrace tajemstvi tvého. l.../ a tváre rozpálené odvẻkou vinou at ochladi rosa nového stinu. I v nẻmž i my duß̌e svých nepłátel proniknem jednou v lítosti lásky, / kterou jsme zapǐeli s plácem /... . (V. 32; 47-48; 50-51; "Und unsere Schmerzensschreie werden einmal läuten wie Bienen /.../. / Gib, daß

$422 \mathrm{Vgl}$. in diesem Kontext die Bedeutung der Erleuchtung bei Platon, d. $\mathrm{h}$. als Erleuchtung durch und vor allem $f$ ü $r$ die Gemeinschaft. J. Stenzel, .Der Begriff der Erleuchtung bei Platon”, in: Die Antike 2, 1926, S. 256.

423 Wie R. Bultmann darlegt, kann Agape auch dadurch als eschatologisches Phänomen betrachtet werden, weil sie die erste Frucht $(G$ al. 5,22$)$ des Geistes (Pneuma) ist und weil sie die in Pistis und in Elpis erschlossenen Moglichkeiten in der konkreten Existenz realisiert. R. Bultmann, Theologie des Neuen Testaments, Tübingen 1953, S. 340.

424 Vgl. dazu: "Wir wissen, daß wir aus dem Tod in das Leben gekommen sind, denn wir lieben die Brüder. Wer $n$ i c h t lie b $t$, der bleibt im Tod". (1. Joh. 3, 14)

425 .../ damit ihre Herzen gestärkt und zusammengefügt werden in der Liebe und zu allem Reichtum an Gewißheit und Verstāndnis, zu erkennen das Geheimnis Gottes, das Christus ist, / in welchem verborgen liegen alle Schätze der Weisheit und der Erkenntnis" (Kolosser, 2, 2-3). Vgl.: "A v blesknutí jejịno zraku reiavi tajemná cára, pî́tomnost nepoznaného" (Láska / Liebe, V. 29; "Im Blitz ihres Blicks aufgreltt die geheime Gerade, die Allgegenwart des Unbekannten").

426 Vgl. dazu: "Sind wir aber Kinder, so sind wir auch Erben, nämlich Gottes Erben und Miterben Christi, wenn wir denn mit inm leiden, damit wir auch mit zur Herrlichkeit erhoben werden". (Römer, 8, 17) Es ist nicht von ungefähr, daß diese Schmerz-Auffassung noch einmal im Epilog-Gedicht des gesamten Zyklus in Erinnerung des Rezipienten zurückgerufen wird: "A my všichni, nesmrtelni tvou vưli, / bolesti svoji / tvé bolesti sdilíme slávu! / A naše radost, dar príliš tẻżký, / jenž z dẻtských rukou nám dosud bezvládnẻ padá, / je slabosti naši / sesláblý odraz / vítězstvi tvých!" (Kdyź z lásky tvé... / Wenn aus deiner Liebe..., V. 27-34; "Und wir alle, unsterblich durch Deinen Willen, / mit unserer Qual / teilnehmend am Heil Deines eigenen Leids, / wie ist doch Freude zu schwere Gabe für uns, / die der kindlich unfassenden Hand noch immer entfiel: / Ach in unser Schwäche / ist sie verwelkend ein Abbild / Deines hohen Triumphs!" Übers. v. F. Werfel). Vgl. auch das Prolog-Gedicht Vládnouci ... (Herrscher...). 
wir in der Stille unseres Schmerzes hören durch unsere Seele springen die mystischen Quellen des Lichts, / denn Schmerz und Licht sind Formen der einen, der gleichen Schwingung deines Geheimnisses nur. I... / gib, daß auf unsere von der Erbschuld entbrennenden Wangen der Tauwind des neuen Schattens kühlend sich senke, I in welchem auch wir einst die Seelen der Feinde durchdringen in reuiger Liebe, die wir leugneten einst in Tränen /... ${ }^{\prime}$ ).

Rühren die "schleichenden Schmerzen", die jenen (noch) "unbekannt sind, die niemals geliebt haben" ("Bolesti neznámè těm, kteri nemllovali, bliží se k samotám vašim", V. 47; "Und Schmerzen, jenen unbekannt, die niemals geliebt haben, sie schleichen sich in eure Einsamkeit") nicht vom leidvollen "Leugnen" der Liebe ("/.../ lásky, kterou jsme zapieli /... $r$. Modlitba za neprátele / Das Gebet für die Feinde, V. 51) und von der Angst ("kdyż tvárè nám zsinaly bázni" I "als vor Angst unsere Wangen erblichen", ibid., V. 2) her? Auch dieser "Schmerz" ("Bolesti báznè $/ . . . \mu$ / "Schmerzen der Angst $I . . . \mu, V$. 51) wird in den Leidenskatalog aufgenommen (V. 48-64). Bevor man das Augenmerk auf inn lenkt, soll noch die aufbauende, ja wunderwirkende Bedeutung des Schmerzes kurz erörtert werden.

Dazu gehört vor allem das änigmatische Motiv der Spiegelschau: "Bez bázné pohliżi láska v zrcadla noci, jež ztravuji prízraky barev, / však hlubiny svoje dokorán otevrou světlu, / a vteřiny jeji cítány nejsou padáním krúpẻji z oblakú tohoto casu" (V. 39-41; "Ohne Furcht blickt die Liebe in die Spiegel der Nacht, die das Wahnbild der Farben verzehren, I doch ihre Tiefen angelweit öffnen dem Licht, .- / und ihre Sekunden, die sind nicht gezähit durch Tropfenfall aus Wolken dieser Zeit"). Auch die 'Spiegelschau' der Liebe (V. 39) scheint auf die paulinische Theologie zu rekurrieren. Im Spiegel (man denke an die Spiegelschau in 1. Kor. 13, 12!) der Nacht, de facto auf seinem Grund, sieht die Liebe das Licht 427 der zukünftigen eschatologischen Existenz; in der Zukunft wird die jetzt noch im Dunkel der Nacht verhüllte eschatologische Sicht direkt und klar. Der nächtliche Dämmer birgt sein positives Gegenteil in sich: das Licht des (ewigen) Tages. Es ist die gleiche oxymoral-paradoxe Vorstellung vom "Tagen im Westen" ("Svítáni na západẻ"), die Brezina in der zitierten Verssequenz von Láska wiederaufnimmt. Daher blickt die Liebe "Ohne Furcht" ("bez báznè", V. 39) in den Spiegel, weil die "Starken" (die "Glaubenden"). die weder das Leben noch der Tod von der Agape trennen kann, die Gewißheit der eschatologischen Existenz haben.428 Nur die (im Glauben) "Schwachen", die die Gewißheit der eschatologischen Existenz nicht haben (bzw. nicht haben können), werden mit "Trauer der Ungewißheit bestürzt" (V. 43; "a slabé sesmutněl nejistotami"). Die $L$ i e be ist es auch, die es vermag, den Menschen von seiner Gebundenheit an die Bedingungen der Zeittichkeit zu befreien, nicht die extatischen Grenzerlebnisse, die in Modlitba vecerni und teilweise auch in Ranni modlitba als Bedingung einer solchen Befreiung postuliert werden, weil die "höchste Liebe" dem ominösen Momentanismus der tellurischen Zeit ("a veriny jeji Zítány nejsou padáním krưpẻji z oblakú tohoto casu". V. 41). dessen Schrecken das lyrische Ich in der dekadenten (und metadekadenten) Phase erlebt, nicht unterliegt: "Mé vteriny tekou jak prosakujici krüpẻje teskného mženi / dnem mým do zahrad mé smrti“, Vteriny / Sekunden, II, 1-2, SZ; "Meine Sekunden fließen wie durchsickernde Tropfen des wehmütigen Nieselregens / durch meinen Tag in die Gärten meines Todes")

$A B$ V. 46 ändert sich der Redemodus: Der reflektierend-indikative Redemodus wird durch einen appellativ-ermahnenden Ton der Predigt verdrängt. Hier entwickelt Br̈ezina in der für den Predigt-Stil charakteristischen Form von Enumerationen (eingeleitet jeweils durch die Anapher "Bolesti I..." / "Schmerzen I...") eine Hierarchie, eine 'Symptomatologie' des Schmerzes (V. 48-64), der die Siege der "Brüder" in Gefahr bringen kann. Es ist der Schmerz des im "Fleisch-und-Blut-Seins" (V. 48), der Schmerz der zur Sünde verführenden 'fleischlichen' Liebe (V. 49) oder der Schmerz der Angst vor der Ungewißheit, die die Glaubens-Schwäche nach sich zieht (V. 51-52; vgl. V. 43). Deshalb werden die "Brüder" vor der Gefahr der atavistischen Mächte, die sich als Erinnerungen an die 'paradiesische', frühzeitliche Vergangenheit des

427 Denn der Ur-Zustand der Seele ist das Licht ("Tušeni jejímu dáno je spatrîti duše v prvotnim světle", V. 34; "Vergönnt inrer Ahnung ist es, zu sehen die Seelen im Urlicht") und zum Licht kehrt sie wieder zurück. Hier schwingt deutlich die Vorstellung der gnostischen Pneumatologie mit, die ja, wie R. Bultmann nachweist (Theologie des Neuen Testaments. Tübingen 1953, S. 151ff.), auch in der Theologie des Paulus wirkt.

428 Vgl. dazu: Römer, 8, 38. 
Menschengeschlechts maskieren, (V. 55-58) gewarnt. ${ }^{429}$ Sie werden aber auch vor dem "allzugrellen Licht" (V. 59) ${ }^{430}$ und vor allem vor dem Hochmut gewarnt (V. 64). Die "Liebenden" sind kraft ihrer Liebe ("a zraky milujicich se jasni" V. 63; "und die Blicke der Liebenden leuchten") imstande, die "Schatten" all der Leiden, Angste und Schulden hinter sich zu lassen und den ascensus zu vollenden ("však stíny boji se výši / a zemdli na strmých cestách", V. 62-62; "denn die Schatten fürchten die Höhe / und schrumpfen müd auf abschüssigem Grat"). Die Bedingung dafür ist allerdings die Furcht vor dem Hochmut:431 "jediná pýcha závrati nezná, bojte se pýchy, o bratří!" ("nur der Hochmut allein kennt den Schwindel nicht! Drum hütet euch vor dem Hochmut, ihr Brüder!"). Es ist die Aufforderung zum Ergreifen der offenstehenden Möglichkeit der (Gottes-)Erkenntnis, doch nicht durch den Hochmut der Gnosis (Ranni modlitba), sondern durch die Liebe, durch die Gnosis der Agape.

In diese Vorstellung mündet das glänzende Finale des Gedichts (V. 65-73), wo es noch einmal zur Änderung des Redemodus kommt; die appellativen Imperative (V. 46-64) werden durch die grammatische Futur-Form der eschatologischen Verheißungen ersetzt: "Odménou vaší budou chvile, kơy uzríte zemi světlem svẻ lásky: I... I a zrajici léta /.../ reknou vám tajemstvi věčné své žiznẻ po nových jarech. / bude poznání vaše jak potkáni noci a dne, které má za svědky tisice hvězd" (V. 65. 67, 68-69; " Es wird ever Lohn der Augenblick sein, da inr erblickt durch das Licht euerer Liebe die Erde: /.../ und reifende Sommer /.../ verraten euch ihres ewigen Durstes Geheimnis nach eurem Frühling. / Und eure Erkenntnis wird sein wie Begegnung von Nacht und Tag, als Zeugen wandeln inr tausend Sterne").

Die Erkenntnis (Gnosis) wird in Vëtry od polư kraft des Glaubens (Pistis) und der Liebe (Agape) erreicht; es handelt sich jedoch nicht um die Erkenntnis der immanenten Welt, die in Modlitba vecerni (Das Abendgebet) durch die Erforschung der kosmischen Gesetze erlangt werden soll, oder um die Erkenntnis der Geheimnisse der Schöpfung durch die unio mystica (Ranni modlitba / Das Morgengebet), sondern um die Erkenntnis des Willens des "Höchsten" und seines Heilsplans im Hinblick auf die eschatologische Existenz. Es ist also eine existe n ti e ll e Erkenntnis, die - als Gabe des Geistes - licht(-geist)erfüllt und allumfassend zugleich ist: "I bude poznáni vaše jak potkáni noci a dne, které má za svědky tisice hvëzd I...I. I rozširíi se pohled váš jako cas piný světla a obejme zemi“ (V. 68 , 70; "Und eure Erkenntnis wird sein wie Begegnung von Nacht und Tag, als Zeugen wandeln ihr tausend Sterne /.../. Es weitet sich euer Blick wie die Zeit voll von Licht, und

429 Dieses Leiden ist in Láska nicht unbedingt als Ursünde der Voreltern, sondern als die sich in jeder Gegenwart wiederholende Ursünde des Abfalls von der Möglichkeit der Erkenntnis des "Höchsten" und seines Heilsplans zu verstehen.

430 Meines Erachtens bezieht sich diese Warnung auf die Gefahr des Entrückt-Seins durch die extatische Lichtschau (vgl. die Schlußsequenz von Ranni modlitba / Das Morgengebet, SZ). Der Mensch hat Verantwortung vor der (eschatologischen) Zukunft, die allerdings an die Verantwortung für das he ils ges chichlliche Erbe festgebunden ist: "Bolesti $/ . . / \mathrm{z}$ odchodu drive než uztrite spocinout jitro / na loži ustlaném staletimi!" (V. 60-61: "Schmerzen /.../ aus dem Abschied, eh ihr doch sahet den Morgen sich neigen / auf das Bette der Rosen, des Taus, das die Jahrtausende bereiten!")

$431 \mathrm{Vgl} . " \%$... má hrdost, zamlklá za dne, k moji pisni se vráti /.../ a tẻm. kteri poslechnou, s hlavou pyšné vzad sklonénou / zpivati budu" (Ranni modlitba / Das Morgengebet, v. 65-66; "i.../ "mein Stolz, verschwiegen bei Tag, wird wiederkehren zu meinem Liede /.../ und denen, die horchen werden, will ich hochmütig zurückgebeugten Hauptes singen"). Auch wenn das lyrische Ich im letzten Zweizeiler von Ranni modlitba "den Blick seines Hochmuts" ("zrak své pychy") "de mütig" ("pokornē") dem durchbohrenden Blick des "Höchsten" hinhält, verzichtet es keineswegs auf seinen stolzen, aristokratischen Individualismus, der in Vino silnych (Der Wein der Starken) zum Bewußtsein des elitären Auserkoren-Seins (kraft der Gnosis) gleichsam hypertrophiert. In Láska geht es nicht mehr um die (gnostiche) unio mystica des lyrischen Ich mit dem "höchsten" Sotēr bzw. um den Übergang zum eschatologischen Sein einer Geimenschaft der Ausnahmepersönlichkeiten, der Pneumatiker, sondern um die eschatologische Existenz der "Glaubenden", um die Vollendung des eschatologischen Seins der "Scharen unzähliger Leben" ("zástupy nesčisiných životü", V. 73). In der hellenistischen Tradition resultiert der Hochmut aus der Gnosis und der pneumatischen Begabung. Diesen stolzen Pneumatikern gilt die Kritik des hl. Paulus im zweiten Korintherbrief. Der "Glaubende" muß vor jenem hochmütigen Herabblicken auf andere gewarnt werden: $" / . . /$ du aber stehst fest durch den Glauben. Sei nicht stolz, sondern fürchte dich!" (Römer 11, 20). "I../ bojte se pýchy, o bratrïi" (Láska / Liebe, V. 64; "/../ fürchtet euch vor dem Hochmut, o ihr Brüder!"). 
umarmt die Erde"). Da die "Glaubenden" in ihrem Glauben und ihrer Gottes- und BruderLiebe stark sind, vermögen sie durch das "Licht der Liebe" ("světlem lásky") die Vollendung des eschatologischen Seins "ohne Angst" ("bez bázné", V. 73) vorauszusehen, so wie auch die Liebe 432 selbst "ohne Angst" ("bez bázné", V. 39) das im Dunkel verborgene zukünttige Sein erblickt: "tisice smrti budete potkávati najednou v tisici cestách bez bảznẻ / a užríte zástupy nesčisiných životủ vcházeti v jediný život" (V. 73-74; "tausend Toden werdet ihr begegnen plötzlich ohne Angst auf tausend Wegen / dann seht ihr unzähliger Leben Schar eingehn in ein Enziges Leben"). Der "Sieg" ("vitězstvi") der Theurgen, d. $h$. die Erkenntnis durch die Teilhabe an der Agape, wird úbrigens gleich im ersten Vers antizipiert: "Záre dalekých jiter se zrcadli v úsměvech mlčeni vašich pỉed odpovědi" (V. 1; "Frühschein künftiger Morgen spiegelt im Lächeln eures Schweigens vor aller Antwort"), und: "in eurem Lächeln leuchtet es auf von tausend Lächeln aus tausend Seelen" (V. 72; "v úsměvu vašem tisice úsmévio zasvít' z tisice duši"). Es ist gerade diese Erkenntnis, die das dichterische Ich quasi antizipatorisch im Prolog-Gedicht des Zyklus seinen Mitbrüdern verkündigen will:

"V extasi lásky chci zpivati bratrským dušim, / že neni bolesti většich, / nežli jsou ztracená vitězství jejich, / że neni radosti většich, / nežli je opojeni / zraku věčnosti sesileněho!" (Vládnouci... / Herrscher.., V. 29-34; "In Ekstasen der Liebe will ich verbrüderten Seelen singen: / Keine größeren Schmerzen sind / als eure verlorenen Siege, / keine größeren Freuden / als die Verzückung des Auges, / das schauender taucht aus ewigem Bad!" Übers. v. F. Werfel.)

Zusammenfassung: Die Botschaft der Agape, die als wunderbare Geistesgabe den Glaubenden und Liebenden die existentielle Erkenntnis eröffnet, schließt den dritten Gedichtzyklus Vètry od pólü ab. Die Resultate der Untersuchung zu der in Vètry od polü konstituierten poetischen Welt zeigen, daß die Theo-logisierung (und Spiritualisierung) des Weltbildes von VP, zu dem Biezina von der gnostischen Mythologie einiger Gedichte des zweiten Zyklus Svitáni na západè gelangte, offenkundig auf seine schópferische Auseinandersetzung mit der paulinischen Theologie zurückzưühren ist, worauf auch die zahlreichen intertextuellen Rekurrenzen auf die Paulus-Briefe hinzudeuten scheinen. Br̈ezinas Rekurs auf die $\mathrm{p}$ a u li $\mathrm{n}$ i s c h e Theologie und Mystik hat $m$. E. seine Logik, denn es ist gerade die paulinische Theologie, in der der gnostische Mythos und seine Begrifflichkeit wirksam sind. Doch die gnostische Entweltlichung des Menschen, die in der Gnosis postulierte Freiheit zum Heraustreten des Menschen aus seiner wirklichen Existenz, reflektiert Bïezina in den Schlüsselgedichten von VP als einen circulus vitiosus. Der sinnstiftende Gedanke des Gedichts Láska, daß die rechte Erkenntnis ihre vollendete Realisierung nicht in der Gnosis, sondern in der Agape findet, scheint für die Hinwendung Bïezinas zur paulinischen Theologie symptomatisch zu sein. Die Existenz des Menschen in seiner steten Beziehung zur Autorität des Bïezinaschen "Höchsten" steht im Mittelpunkt der paulinischen Theologie; darin bekundet sich deutlich ihre anthropologische und soteriologische Dimension. ${ }^{433}$

432 Vgl. ".../ láska má hluboká poznáni smrti" (V. 8; \%.../ die Liebe die tiefen Erkenntnisse des Todes enthülite).

$433 \mathrm{Vgl}$. hierzu die eingehende Darlegung der paulinischen Theologie von Rudolf Bultmann, Theologie des Neven Testaments, Tübigen 1953, S. 183ff. Laut Bultmann wird die paulinische Theologie, ausgehend nur von den zweifelsohne echten Paulus-Briefen (Röm., 1.-2. Kor., Gal., Phil., 1. Th., Phm.), sachgemäß als "die Lehre vom Menschen" am besten entwickelt. In diesem Sinne kann die paulinschen Theologie zugleich als Anthropologie betrachtet werden. 


\title{
5. ESCHATOLOGISCHER SYMBOLISMUS III \\ Kosmogonisch-eschatologisches Modell \\ Gedichtzyklus Stavitelé chrámu (Baumeister am Tempel) 1899 \\ Eschatologische Existenz in Gnade (xdpıs) \\ Pluralisierung und Remythisierung der poetischen Welt
}

„Život je mnohotvärný, nesčislné jsou květy a hvězdy: nesčislné

zpuisoby existenci. Nesmíme uni s vửe ani s neprátelstvím pohlï̌ti

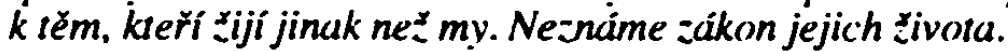

Nevíme, co v ném predcházelo, ani co v nèm hude následovati".

\begin{abstract}
"Das Leben ist vielgestaltig. es gibt unzählige Blüten und Sterne: unzählige Formen der Existenz. Wir dürfen weder von oben herab. noch mit Feindschaft jene ansehen, die anders leben als wir.

Wir kennen das Gesetz ihres Leben.s nicht. Wir wissen nicht, was in ihm voraus ging und was in ihm folgen wird"
\end{abstract}

Otokar Brezina an Anna Pammrová (19. XI. 1898)

"Das Fieber der Arbeit" und "völlige Erschöpfung" 434 begleiteten die Entstehung und die Herausgabe des vierten Gedichtzyklus Stavitelé chrámu (Baumeister am Tempel), ${ }^{435}$ dessen - im Vergleich mit Vẻtry od pólu- auffallende thematische Vielfalt, vor allem aber dessen Rückgriff auf die bildhaft-konkrete Mytho-Logik des dekadenten Symbolismus (Tajemné dálky) und seine semantische Strategien, jeden Br̈ezina-Interpreten vor die prinzipielle Frage stellen muß: Wie ist dieser 'Rückfall', dieser 'Bruch' in der schöpferischen Entwicklung Bíezinas zu deuten? Die Änderüng der in Svitáni na západẻ eingeschlagenen Richtung liegt, wie es scheint, in Bïezinas Überzeugung begründet, daß es nicht nur e in en zur postulierten Herstellung der Einheit und zum Eschaton führenden Weg gibt, sei es der Weg der Gnosis (SZ) oder der des positiven Glaubens (VP), sondern daß es "ungezählte", "tausende Wege" gibt, die zur enwarteten Vollendung der Lebens- und Kunst-Schöpfung führen. Alle Wege münden am Ende der Zeiten in die eschatologische Einheit. Im Titelgedicht Stavitelé chrámu heißt es:

".../ cestami nesčetných svètü, ústicich v jediném svëtè. I.../ V plnosti nesčisIných forem cítili prvotni napéti tvého tvưrčiho dechu." (V. 30, 74-75; "auf Wegen zahlloser Welten, mündend in einer Welt. I.../ In der Fülle zahlloser Formen / fühlten sie die Urspannung deines schöpferischen Odems"). In einem anderen, in den Zyklus nicht aufgenommenen Gedicht Pro zraky lásky... (Für die Blicke der Liehe..., 1899) heißt es: "Pro zraky lásky tisice jest otevỉeno cest" (I, 1; "Für die Blicke der Liebe stehen tausende Wege offen"). "Tu svaté tvé vzpominky v dusi mi prolétla zvěst, I nádhera mới tvych, tajemstvi noci tvých, sláva tvých cest (Doupata hadú / Die Schlangenhóhlen, IV, 1-2; "Da ging deiner heiligen Erinnerung Botschaft in mich ein, / deiner Meere Pracht, deiner Năchte Geheimnis, deiner Wege herrlicher Schein").

Zum Eschaton führen jetzt "ungezählte Wege", die "in eine einzige Welt" münden (Stavitelé chrámu, V. 30; "ústicich v jediném svêtè"), so wie "Millionen von Seelen" von einem "einzigen Rhythmus" ("jednoho rytmu") des "göttlichen Wortes" ("božského Slova"; Se smrti hovori spici.. I Mit dem Tode Reden die Schläfer..., V. 152) erfaßt oder mit dem Wein aus einer "einzigen verborgenen Quelle" (Proroci I Die Propheten, V. 84-85; "z jednoho pramene /.../ ukrytého") berauscht werden sollen. Alle zum eschatologischen Ereignis führenden Wege und diversen Lebensformen, alle kreativen Prozesse werden auf einen einzigen Punkt fokussiert. Diese neue Dimension Biezinas eschatologischen Symbolismus, die man als Prozeß der Pluralisierung, der Diversifikation, bezeichnen

$434 \%$ /... rozehrán horečkou činnosti, bohużel ale na všech stranách tak vyðerpán /... $/$. Bíezina an A. Pammrová (Brief v. 12. XI, 1898), in: O. Bỉezina, Dopisy Anné Pammrové z let 1889-1905, Praha 1931, S. 190.

435 Der Zyklus Stavitelé chrámu erschien im Mai 1899, d. h. erst zwanzig Monate nach Větry od pólù (Polanwinde). 
kann, zieht auch andere neue Aspekte nach sich, die nun - in erster Annäherung - erörtert werden sollen. Die Pluralisierung (der eschatologischen Existenz) bedeutet zugleich:

1) die Betonung der aktiven schöpferischen Teilnahme des Menschen an k o smogonische n Prozessen, d. h. an der Restituierung der kosmischen Einheit;

2) die Verzeitlichung aller kreativen Prozesse, des ganzen Weltgeschehens, um das gesamte Walten in der Lebenswelt und die Vollendung der Schöpfung zu beschleunigen und die auf die Schönheit gerichtete "Synthese aller Synthesen" ("syntézu všech syntéz" $z^{436}$ vorzubereiten. Diese Synthese, d. $h$. die Vollendung der Kunst- und Lebensschöpfung als eschatologisches Ereignis, symbolisiert die Erbauung des Tempels ${ }^{437}$ ("chrám"), das Schlüsselmotiv des gesamten Zyklus:

"Pozdravujeme jaro! Hie, dni se strídaji s noci / jak okna anděly malovaná s kresbami symbolickými, / v nesmirno sklenutá k ethemým obloukủm chrámu tvěho, / kde všechny plameny lustrú svých rozżal jsi o Vzkr̉išeni. // Pozdravujeme jaro! Vitáme netrpélivost duši! Tr̉eseni kriidel sesileny̆ch! Odvahu zraku zjasnělého! / Nekonečnosti cekaji na nás, jiná slavnéjši jara, / věčnosti hỉmici pisně, vysvobozeni!" (Pozdravujeme jaro!; Str. VII-VIII; "Wir grüßen den Frühling! Sieh, es wechseln Tage und Năchte / wie Fenster, von Engeln mit symbolischen Zeichnungen bemalt, I unendlich gewölbt zu deines Tempels ätherischen Wolken, / wo alle Flammen deiner Lüster du zur Auferstehung entfachst. // Wir grüßen den Frühling! Ungeduld der Seelen, willkommen! / Beben erstarkter Schwingen! Mut des helleren Blicks! / Unendlichkeiten erwarten uns, andere festlichere Lenze, / in Ewigkeit donnernde Lieder, - Entösung!", Übers. v. O. Pick).

Mit der Verzeitlichung der schöpferischen Prozesse koinzidiert auch die für das kosmogonisch-eschatologische Modell von Stavitelé chrámu hochrelevante adventistische Symbolik der (ungeduldigen) Endzeiterwartung. Zusammen mit den Grundbestimmungen der eschatologischen Existenz (Hoffnung - Glaube - Liebe) wird nun auch der KunstSchöpfung, der kreativen Arbeit, an der alle teilnehmen sollen, eine dominante Position im eschatologischen Prozeß zuerkannt.

Die Teilhabe des Menschen an den in Vẻtry od polü thematisierten, auf das eschatologische Sein gerichteten Prozessen des orga $\mathrm{n}$ i s $\mathrm{ch}$ e $\mathrm{n}$ Wachsens und Reifens für die spirituelle "Ernte" ("Žen"), besteht vor allem im p a s s i v e n "In-FlammenStehen', d. $h$. in einem inneren, seelischen Prozeß des 'Reifens' zur Glaubensstärke (vgl. Kap. 4.2 und Kap. 4.3.2). In Stavitelé chrámu werden die organischen Prozesse des Wachsens und Reifens in die kreativen Prozesse des Kunst-Schaffens, der Hervorbringung der anorganischen, artifiziellen Kunst-Werke, integriert. Durch die aktive und kreative Tätigkeit der schöpferischen Menschen, der artifices, erlangt auch das 'Inder-Zeit-Sein' eine schöpferische Dimension. Diesen Gedanken bringt Biezina auch in seinen Essays aus der Abfassungszeit von Stavitelé chrámu klar zum Ausdruck: "Vime jen, že v této vážnosti, provázejíci velké uméni, vyjádiena je spojitost umélecké práce s ostatni praci človéka na zemi. l.../ Nebot' i práce hmotná má svưj cíl ve véčnosti“. 438 Die

436 Vzájemnè dopisy Otokara Breziny a F. X. Saldy, hrsg. E. Chalupný. Praha 1939. S. 7. Wie $U$. Heftrich in seiner Brezina-Arbeit feststellt, gründet Bíezinas Glaube an die Kraft der Kunstschöpfung, deren Ziel es ist "die Welt ihrem eschatologischen Ziel naherzubringen", in der (im Prinzip neoplatonischen) Prämisse, die natürliche Welt habe an der des Geistes wesenhaft teil. In der Schatfensphase des eschatologischen Symbolismus wird die Kunst nicht nur als Ertüllung bzw. Vollendung der Schöpfung, sondern auch als "Bejahung des bestehenden Lebens". als "Schutz" gegen die Macht des Thanatos gleichsam 'inthronisiert' (U. Heftrich, Otokar Bïezina, Heidelberg 1993. S. 270ff.).

437 Signifikanterweise bedeutet der Tempel (bzw. die Kathedrale) auch kultur- und kunsthistorisch die monumentale Synthese aller Künste. Diese Symbolik untersucht ausführlich Hans Sedlmayr in seiner großangelegten Monographie Die Entstehung der Kathedrale (1950)

$438 \mathrm{Vgl}$. O. Bïezina, „Zasvěceni żivota“ („Die Weihung des Lebens"), in: Ders., Eseje, Olomouc 1996, S. 46. "Wir wissen nur, daß in dieser Würde, welche die große Kunst begleitet, die Verbundenheit der künstlerischen Arbeit mit der übrigen Arbeit des Menschen auf Erden ihren Ausdruck findet. I.../ Denn auch die materielle Arbeit hat ihr Ziel in der Ewigkeit". U. Heftrich macht auf die symptomatische Tatsache aufmerksam, daß nach dem zweiten Gedichtzyklus Svitáni na západé (Tagen im Westen, 1896) das Lexem "uméni" ("Kunst") vollständig aus dem Vokabular Biezinas verschwindet. Heftrich beruft sich auf die Untersuchung P. Holmans in seinem Frequenzwörterbuch des Iyrischen Werkes von Otokar Br̈ezina. Bd. II. Köln-Weimar-Wien 1993. Sehr genau sieht Urs Heftrich (Otokar Brezina, Heidelberg 1993, S. 267) darin die Tendenz, die Sphäre der Kunst "konsequent über den gesamten Bereich menschlicher Tätigkeit" auszudehnen, wodurch die Kunst aus ihrem herkömlichen Bereich gelöst wird. 
Tendenz zur Integration der organischen Prozesse in die schöpferische, artistische Tätigkeit der irdischen artifices tritt besonders prägnant in Nade vsemi ohni a vodami.. (Über allen Fevern und Wassern...) zutage. Der Titel dieses Gedichts erinnert an Das Lied von der Sonne, Erde, den Wassern und dem Geheimnis des Feuers (Piseñ o slunci, zemi, vodách a tajemstvi ohnè.... VP). In diesem Text wird das eschatologische Geschehen vor der Kulisse der monumentalen organischen Prozesse der (spiritualisierten) Geo- und Bıogenese thematisıert. In Nade všemi ohni a vodamı... (Über allen Feuern und Wassern...) wird das Organisch-Naturhafte in das SchöpferischArtifizielle, in die Sphäre der Ku n s t - S c h ö p f u n g. integriert. 439 Den Fluchtpunkt der beiden Sphären bildet das Transzendente, das Eschaton, die Ewigkeit:

"Nade všemi ohni a vodami, / vegetacemi, / mezi tajemstvim zemẻ a světủ. /.../ krouži naděje naše / ve véčném jaru. /... / a ty, kterè maji kł̉idla nejzárivivejjši, / hnizdo své stavi / pod rimsami

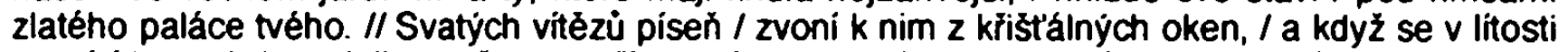
navrátí k zemi, / tu v jejich zpěvu / jiskrii se jeji ohlas. / Pĩ stavbẻ chrámu / v tesáni mramoru, / do kladiv hovoru / zniti je slyšime / z modra" (V. 1-3, 6-7, 23-34; "Über allen Feuern und Wassern, I Vegetationen, / zwischen der Erd' und der Welten Geheimnis, /... / kreisen unsere Hoffnungen / im ewigen Frühling. /.../ und die mit den allerstrahlendsten Schwingen / bauen ihr Nest sich / unterm Gesims deines goldnen Palastes. // Aus kristallnen Fenstern ertönt / das Lied heiliger Sieger zu innen, / und kehren voll Wehmut zur Erde sie wieder, / so funkelt ihr Echo / in ihrem Gesange. I Beim Baue des Tempels, I Behauen des Marmors. Zwiesprach der Hämmer, I hören wir sie klingen / aus dem Blauen". Übers. v. O. Pick.)

Im Gegensatz zu der Position des passiven 'In-der-(Sonnen-)Glut-Stehens', die das theo-logisch-eschatologische Modell (VP) kennzeichnet, wird in Stavitelé chrámu die aktive Teilhabe des Menschen an der Herstellung der kosmischen Einheit und an der Vollendung der Kunst- und Lebensschöpfung postuliert. Es ist eine der wichtigsten Aufgaben der "Baumeister", die Mitbrüder für den Tempelbau zu gewinnen: "K milionüm trpicich bratři bylo posláni jejich / jako k najmutí dẻlnikủ k stavbè (Stavitelè chrámu / Baumeister am Tempel, V. 86-87; "Zu Millionen leidender Brüder kam ihre Sendung / wie Dingung von Arbeitern zum Bau“). Im adventistischen Gedicht Hvězd hasnou tisice ... (Erióschen tausende Sterne...) steigert sich die aktive schöpferische Teilhabe am Prozeß der Vollendung der Schöpfung zur direkten Erzwingung des eschatologischen Geschehens: "Retézem magickým zlé sily spoutáme. / A donutóme zem, by rozkvetla, jak ještě nekvetla, I a mezi rủzemi vstřic pujdem nesmrtelnosti“ (VII, 2-4; "Wir binden die bösen Kräfte mit magischer Kette an. I Und zwingen die Erde zu blühen, wie sie noch niemals geblüht, / und schreiten durch Rosen der Unsterblichkeit zu“. Übers. v. O. Pick).

In diesem Postulat, das sich im Hinblick auf die in Větry od poliu vertretene Position eines demütigen Glaubenden (Poledni zráni I Mittäglich Reifen) beinahe als eine Anmaßung liest, schwingt bereits die Vorstellung mit, daß die Vollendung der Schöpfung und die Herstellung der kosmischen Einheit sich nur im Menschen und durch den Menschen im Prozeß der 'Vermenschlichung' der Lebenswelt vollzieht. Dieser um 1900 als Religionsphilosophie des Gottmenschentums ${ }^{440}$ aktuelle Gedankengang ${ }^{41}$ fußt auf der Symbolik der Fleischwerdung des "ewigen" ("věcný") Logos. Der hópoc trat in die Entwicklungsgeschichte der Menschenwelt ganz konkret und geschichtlich ein, indem er

439 In einem späteren Essay Prítomnost (Die Gegenwart) heißt es "Stejné úžasné je dnes jako pied věky uměni vod a slunce, modelujić zemi l... F. (O. Bfezina, .Pfítomnost", in: Ders., Eseje, Olomouc 1996, S. 82; "Genauso erstaunlich ist heute wie vor Ewigkeit die Kunst der Wassern und der Sonne. die die Erde modellieren $/ . . . \%$ ).

440 Zweifelsohne auch unter dem Einfluß jener großen Entdeckungen in den Naturwissenschaften, in der Technik und Medizin der damaligen Zeit, die Brezina in seiner Korrespondez erwähnt und von denen er offensichtlich beeindruckt war (M. Curie-Sklodowskas Entdeckung der Radioaktivität im Uran, Max Plancks atomare Quantenphysik usw.). Von dem wissenschaftlich-technischen Fortschrittsglauben des 19. Jahrhunderts rührt auch die - mit der Gnosis gemeinsame - Selbstvergöttlichung des Menschen her.

441 In ihrem Buch Úlomky hovorú Otokara Březiny (Die Fragmente der Gespräche von O. B.) überliefert Br̈ezinas Kollegin, die Lehrerin Emilie Lakomá: "Pro mne je Ježís .synem božim". ("Für mich ist Jesus der "Sohn Gottes"). An einer anderen Stelle: "Ze Krista jmenuji Bohem, $v$ tom neni ničeho protismysıného. Múžeme ho docela dobrie uznati za Boha, nebot' to, co lidstvu dal, je dilem Boha". ("Daß Christus Gott genannt wird, darin ist nichts widersinniges. Wir können inn durchaus als Gott anerkennen, denn das, was er der Menschheit gab, ist das Werk Gottes"). Zit. Emilie Lakomá, Ulomky hovorú Otokara Bỉeziny, Brno 1992, S. 15, 133. 
als Mensch geboren wurde und indem er - in der Menschenwelt (kóouos) - auf dem Kreuz starb und auferstand. Aus dieser Perspektive erscheint die Geschichte des kóouos als Parusie, ${ }^{442} \mathrm{~d}$. $h$. als heils- und endgeschichtliche Wiederkunft Christi. Dieser Prozeß hat einen einzigen Sinn: die Offenbarung Gottes. Ihren tiefsten Charakter symbolisiert der Advent. 443

Hier drängt sich die wichtige - mit dem Begriff der Lebens- und Kunst-Schöpfung bereits aufgeworfene - Frage auf: Inwiefern rekurriert Bíezina in Stavitelé chrámu auf die Semantik des Kunst-Schönen aus der Schaffensphase des dekadenten Symbolismus (TD)? Im dekadenten Symbolismus der Geheimnisvollen Fernen bedeutet die KunstSchöpfung in erster Linie den konsequent selbstzweckhaften 'Dienst' am Kult der Kunst im Zustand des autistischen Eingemauertseins in der Scheinwelt des Kunst-Schönen. In Stavitelé chrámu fungiert die Kunst-Schöpfung als Korrelat des schöpferischen Lebens, der auf ein Telos gerichteten kreativen Tätigkeit an einem gemeinsamen Kunst-Werk. Die Ästhetisierung aller Daseinsformen im dekadenten Symbolismus wird in Stavitelé chrámu (kosmogonisch-eschatologisches Model) im Sinne einer Existentialisierung und Objektivierung aller Formen der Kunst-Schöpfung umgewertet. D. h. die Kunst-Schöpfung wird eschatologisiert und unter die Herrschaft des einigenden Lebens-Triebes gestellt. Das Ästhetische und Kunst-Schöne, die Mannigfaltigkeit der (artifiziellen) Kunstformen bilden nicht mehr einen autonomen Wert 'an sich', sondern ein Korrelat der mannigfaltigen L e b e n s formen:444 "Denn in der Kunst kündigen sich Lebensformen an, die noch

442 Z. B. im Werk des Anthropologen, Paläontologen und Philosophen Teilhard de Chardin (1881-1955), der die Geschichte des Kosmos als Prozeß der Christifikation, der "Christogenese", begreift (vgl. z. B. seinen Essay Le Christique, Paris 1955). Für Teilhard hat die Geschichte neben der kosmisch-menschlichen Dimension auch die übernaturliche, göttliche Dimension, die in Jesu fokussiert ist, der im Sinne der johanneischen Theologie Alfa und Omega der erschaffenen Welt ist. Die Geschichte des Kosmos und des Menschen ist nach Teilhard keine statische, teilnahmslose Kulisse der Heilsgeschichte; die Kosmogenese und die Noogenese (Entwicklung der Sphäre des Geistes) tragen bereits das Vorbild der Christogenese in sich, sie seien von Anfang an in Christo Jesu integriert, den Teilhard sogar "Evolutor" nennt. Die Endphase der Geschichte der Menschenwelt charakterisient Teihard als eine ideale Gemeinschaft der Menschen, die gemeinsam nach dem absoluten Ideal der Liebe und der Brüderschaft streben. Teilhard steltt sich das als eine organische Synthese im Akt der "Super-hominisierung". als eine organische "Über-Einheit" vor. In dieser Situation wird die Menschheit imstande sein, den empirischen Rahmen von Raum und Zeit zu durchbrecten und zum "Ultrazentrum" der absoluten Einheit und Freiheit zugleich vorzudringen. Diese Evolution können nicht einmal die katastrophischen Bedingungen, der Angst und Schmerz, die sich nicht tilgen lassen, umstürzen.

443 Die in Stavitelè chrámu sehr ausgeprägte adventistische Symbolik wird in einem selbständigen Kapitel (5.2) eingehend erörtert

444 Die Tendenz zur Objektivierung der Kunst-Schöpfung, die Ablehnung des dekadenten "L'art pour l'art'-Ästhetismus und schließlich auch die Idee des 'Gottmenschentums' kơnnten bei Bỉezina durch seine Rezeption der Werke zur Ästhetik und Religionsphilosophie von Vladimir Solov'ev (1853-1900) vorbereitet worden sein, die er um 1899-1900 kennengelernt haben dürtte. Briezina enwähnt Solov'ev in einem Brief (vom 6. I. 1900) an Anna Pammrová (O. Bíezina. Dopisy Annè Pammrové 1889-1905, Praha 1931, S. 200). Nach 1900 enwähnt Bỉezina Solov'ev auch in seiner Korrespondenz mit Em. Chalupný. Er nennt inn "Genius und tiefster russischer Denker" ("Solovjev byl génius a nejhlubsi myslitel rusky"; in: E. Chalupný. Dopisy a výroky Otokara Breziny. Praha 1931, S. 204). Die 'wahre' Kunst dient nach Solov'ev dem "Guten und Wahren"; diesem Ideal dient der poeta vates, der Dichter-Prophet. Kennzeichnenderweise spielt die metaphorische Gestalt des Dichter-Propheten im kosmogonisch-eschatologischen Welt-Modell von Stavitelé chrámu eine wichtige Rolle (vgl. das Gedicht Proroci / Die Propheten, Kap .5.2.2). Die wunderbare Gabe der "Propheten" bringt Brezina auch in einem Brief (vom 8. II. 1899) an Pammrová zum Ausdruck: "Jaká vznešená jednoduchost v slovech prorokú, jaká sladká jemnost v jejich prostých symbolech I...l. V tom je sila jejich zraku: $v$ záreni světla, $v$ strídáni jar, v letu ptákú, $v$ zráni klasu nalézti tajemná spojenı, unikajici tisicum a osvětlujici záhady našeho vlastniho żivota!" (O. Bỉezina. Dopisy Annẻ Pammrovè 1899-1905, Praha 1931, S. 194-195; "Welch erhabene Einfachheit in den Worten der Propheten, welch süße Feinheit in ihren schlichten Symbolen /... Darinnen liegt die Kraft ihres Blickes: im Strahlen des Lichtes, im Wechsel der Lenze, im Flug der Vögel, im Reifen der Ähren geheimnisvolle Verbindungen zu entdecken, die den Tausenden entgehen und die die Rätsel unseres eigenen Lebens beleuchten!"). Auf Bïezinas Rezeption der Werke von Solov'ev macht auch U. Heftrich aufmerksam (Otokar Bïezina, Heidelberg 1993. S. 265) 
körperlos sind". ("Nebot" v uměni ohlašuji se tvary żivota posud nevtělené"). ${ }^{445}$ Und weiter: die Kunst-Schöpfung wird als "Bewegung des Stroms" ("pohyt proudu") mit dem Ziel der "Fortführung des Schöpfungswerkes" ("pokračováni tvurčiho díla") begriffen. 446 Diese "Fortführung" soll in eine "geistige Vereinigung" oder "Vereinigung der Geister I...I, die sich nach Erlösung sehnen" ("duchově spojeni"; "spojeni duchú /.../ toužicich po vysvobozeni"). einmünden. 447

Warum postuliert Bíezına in Stavitelé chrámu dıe 'Rehabilitierung' und Umwertung des ästhetistischen Konzeptes des Kunst-Schönen und der Kunst-Schöpfung? Man muß sich nun fragen, inwieweit die in Vẻtry od pólư und zum Teil schon in Svitání na západè postulierte produktive Auseinandersetzung mit der dekadenten Vergangenheit, d. $h$. ihre Integration in das axiologische System des eschatologischen Symbolismus, erfolgreich war? Kann man überhaupt von einer Integration sprechen? Vielmehr scheint es, daß der in Svitáni na západẻ und in Vẽtry od pólü (hier durch die Strategie der Theo-logisierung der poetischen Welt) vorgenommene In te g r a ti o n sversuch in eine irreführende Strategie der Verdrängung der dekadenten Schatten-Welt des Un(ter)bewußten, Chthonisch-Thanatophilen und Lunaren ausartete. Einige Schatten- Residuen der dekadenten Welt blieben offensichtlich un-integriert bzw. sie wurden als Schatten der Trauer, der frostigen Einsamkeit und des Todes aus den Kassematten des Un(ter)bewußten herausgelockt und kehren nun als furchteinflößende Revenanten und Schatten-Wesen zurück: sie saugen sich mit vampirhaften, erstickenden Küssen an die Schlafenden ein (Vigilie I, V. 14), sie fesseln das dichterische Ich "mit böser Suggestion der Giftschlangen" (Doupata hadü / Die Schlangenhöhlen, III, 3), sie schweben wie "Todesfalter über allen Friedhöfen" umher (Zas ve vidéni prorockém... / Wieder in einer prophetischen Vision... III, 2) oder sie pirschen sich um Mitternacht aus ihren tellurischen Waldeinöden heran (Zèmè vitězú I Das Land der Sieger, V. 2):

"/.../ reflex preses celý hvězdnatý zenit se šîiil /.../, gigantské pohybujici se stiny promitaly se na nẻm, / jak obraz tajemného zápasu kolem věcných ohnư゙ (Stavitelé chrámu / Baumeister am Tempel, V. 68, 70-71; \%.../ Abglanz sich dehnte über den bestimten Zenit /.../, drauf projizierten gigantisch sich bewegliche Schatten / ein Bild geheimnisvollen Kampfes um die ewigen Feuer"). - ... I a zmatená slova šeptaná ze snú, / dušená polibky stinù" (Vigilie I / Vigilie I, 13-14; "/.../ und die wirren Worte, im Traume geflüstert, / gedămpft von Küssen der Schatten"). "Sem nikdo z żivých nezbloudi. Jen vzkřišen zraky mými / vstal smutek těchto mist a kroky bázni ztlumenými, / by bratr̂i neviditelných ze spánku nevyrušil, / mi vyšel naproti. (Jich oddech rytmický jsem tušil, I jak $v$ tvár mi zavál, leđovỳ, a v svétel żhavém vẻení / se jini chytal jehlami na vegetace snéni" (Smutek hmoty / Die Trauer des Stoffes, V. 1-6; "Kein Lebender gerät hierher. Mein Blick nur ließ erstehen / die Trauer dieser Stätten hier und angstgedämptten Schrittes gehen, / daß nicht die unsichtbare Schar der Brüder schon erwacht, / entgegen mir. (Ihr Atemgehen fühlt rhythmisch sich, das schwache. / mein Antlitz streifend eisigkalt, und in den Lichterkronen / verting sich Reif mit Nadeln in des Traumes Vegetationen.)"). $\%$.../ motyli s smrti znamením se vznásí na všech hr̉bitovect" (Zas ve vidèni prorockém / Wieder in einer prophetischen Vision, III, 2; "die Falter mit Todeszeichen steigen von jedem Friedhof auf"). "I../ vưli mi spoutali hadi svou sugesci zlou" (Doupata hadú / Die Schlangenhöhlen. III. 3: \%.../ sie banden meinen Willen mit ihrer bösen

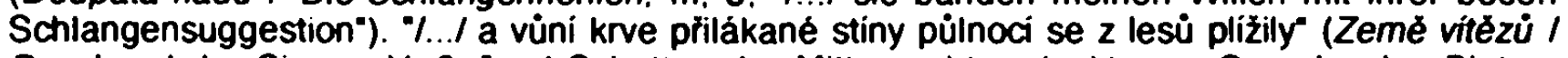
Das Land der Sieger, V. 2: "und Schatten der Mitternacht, gelockt vom Geruche des Blutes, schlichen aus den Wäldern heran". Übers. v. O. Pick).

Auch über den Pneumatikern / "Starken" schweben diese ominöse Schatten als drohende Gefahr der fröstelnden Vereinsamung. Bleibt etwa ein Teil der Welt immer noch unter der Herrschaft des Thanatos? Die vermeintliche 'Lösung', nämlich die Verdrängung

445 Vgl. O. Bł̌ezina, „Zasvěceni žitota* (Die Weihung des Lebens), in: O. Bł̉ezina, Eseje. Olomouc 1996. S. 43. In diesem Essay hebt Biezina die Verwandtschaft von Kunst und Wissenschaft hervor; beide stellen einzelne Formen der menschlichen Betätigung dar: " $V$ těchto mistech neni vnitinniho rozdilu mezi jednotlivými formami lidského úsili. Mistri vẻdy jsou zde právẽ tak uméla jako géniové cinu a srdce, dobyvatelé a svétci, a všichni nesčisıni, kteri pracuji s nimi o společném dile spojeni duchú. Všechny vede krása". ("An diesen Orten gibt es keinen innertichen Unterschied zwischen den einzelnen Formen menschlicher Betătigung. Meister der Wissenschaft sind da ebenso Künstler wie die Genien der Tat und des Herzens, Eroberer und Heilige und alle die Ungezählten, die mit innen am gemeinsamen Werke der Einheit der Geister arbeiten. Alle führt Schönheit an I... . U. Übers. v. E. Saudek).

$446 \mathrm{Vgl}$. ibid. S. $42-43$

$447 \mathrm{Vgl}$. ibid., S. 43-44. 
des Thanatos, war offensichtlich eine falsche Lösung, ein Irrweg. Die Schatten der dekadenten Vergangenheit müssen nun konsequent re-integriert werden. Man kann sogar die Hypothese aufstellen, daß die $\mathrm{g}$ e s a $\mathrm{m}$ te nachdekadente schöpferische Entwicklung Biezinas eine permanente Konfrontation und Auseinandersetzug mit der Schaffensphase des dekadenten Symbolismus bedeutet. Auch diese wiederholten Integrationsversuche können als eine bestimmte Form der Pluralisierung der Existenzformen begriffen werden. Unter diesem Aspekt betrachtet, läßt sich der Gedichtzyklus Stavitelé chrámu als erneuter Integrationsversuch deuten: die Verdrängung wird als eine falsche Strategie annuliert, die Schatten der dekadenten (Unter-)Welt ins Bewußtsein zurückgeholt und neu integriert. Auf welche Weise erfolgt nun diese Integration? Durch die Eingliederung in den Gesamtplan der Kunst- und Lebensschöpfung, in den Prozeß der Eschatologisierung. Auch die dekadenten Lebensformen und Lebenswege, zu denen auch Schmerz und Leid, Einsamkeit und Vernichtung gehören, sollen e sch a to logisiert - man könnte sagen prozessualisiert - werden. In jenem Prozeß, der zur Vollendung der Schöpfung und zur Erschließung der eschatologischen Zukunft führt, erhalten auch die 'dekadenten' Lebenshaltungen ihren konkreten Sinn. Auch das 'Schattenhafte', Unvollkommene, Dissonante, Irrationale, Irreale, Alogische usw., gehört nun in der Lebenswelt, die man nicht als ein statisches Gebilde, sondern als Werden betrachten muß, notwending zum Aufstieg. Auch die Dekadenz (im breitesten Sinne) bildet einen strukturellen Zug der (prozessualen) Kunst- und Lebenschöpfung: als deren Antriebsprinzip und als Faktor der Vergeistigung.

An dieser Stelle soll hervorgehoben werden, daß der descensus in die Unterwelt der Dekadenz und die Integration der 'Schatten' (der dekadenten Vergangenheit) nicht nur im ersten nachdekadenten Zyklus Svitáni na západẻ, sondern a u ch in Větry od pólü als eine notwendige Voraussetzung des künftigen (schöpferischen) ascensus angesehen wird. Nicht von ungefähr erreicht das Substantiv "stin" ("Schatten"), so wie die semantisch konträren Substantiva "světlo" I "Licht" - "noc" I "Nacht", seine absolute Frequenz gerade in Větry od pólü. Diese Konstellation - der "Schatten" ("stin") zwischen "Licht" und "Dunkel" - scheint mit der triadischen Symbolik (die Dreieinigkeit, Hoffnung-Glaube-Liebe; corpusanima-spiritus) von VP zu koinzidieren. Doch was geschieht in Stavitelé chrámu? Das Neue und Signifikante des in SCh konstituierten kosmogonisch-eschatologischen Modells ist seine - durch die (im Vergleich zu SZ und VP) hohe Frequenz des Substativs "tělo" ("Körper") indizierte - Semantik des Somatischen. Die in den Texten kodierte descensus -Erfahrung und die Re-Integration der dekadenten Schatten-Welt scheinen in SCh auch für die Assimilation des Körperhaft-Materiellen - als eine der Voraussetzungen für den schöpferischen ascensus - ihre Bedeutung zu haben. Erst, wenn der Mensch sozusagen körperhaft wird, kann man von der Wiederherstellung der Ganzheit sprechen. bie Akzentuierung des Körperhaften ist in Stavitelè chrámu nicht zu verkennen, eines der Gedichte des Zyklus heißt explizit Tẻlo (Der Körper), und in der Präsenz des "Körpers" in SCh bekundet sich auch die Affinität zu der hypetrophierten Material- und ArtefaktÄsthetik der in Tajemné dálky konstituierten Kunst-Welt. Signifikanterweise erreicht das Substantiv "tẻlo" seine absolute Frequenz gerade im dekadenten Symbolismus der Geheimnisvollen Fernen. In $O$ silo extasi a snú... (O Kraft der Extasen und Träume...) wird der Körper des dichterischen Ich zum "unreinen Leuchter", in dem sein "Gedanke" wie eine "Wachskerze" fahl leuchtet, verdinglicht: "myšlenka má je voskovici svẻtla molěho, I jež v těla svicnu nečistěm se ţesouc leskne“ (II, 3 - 4, X, 3-4). In Uměni (Die Kunst; s u. Kap. 2.3.1) wird der Mädchenkörper zu einer Alabasterstatue denaturiert: "blaho divčich těl, kđe v ñader lita tvar / spi vuné v alabastru“ (IX, 3-4). In Snad potom... (Vielleicht dann...; s. U. Kap. 2.1.2) spricht das dichterische Ich vom "duftenden und bebenden Schnee der Körper" ("têl vonný a chvici se snih", VI, 2). Im Gegensatz zu der StoffÄsthetik von TD wird im kosmogonisch-eschatologischen Welt-Modell das Stoffliche primär als das Organisch-Stoffliche, als materielle Natur, prima materia, gedacht. Man denke an das Bild der webenden Erd-Mutter in der Schlußsequenz des Gedichts Smutek hmoty (Die Trauer des Stoffes). Das Organisch-Stoffliche des in SCh konstituierten WeltModells koinzidiert mit dem Tellurisch-Vegetabilischen, (passiv) Erzeugenden, Formbaren, Inneren usw. (Jsem jako strom v květu / Ich bin wie ein Baum in Blüte; Svêt rostlin / Die Pflanzenwelt; Zem? / Erde?; Doupata hadü / Die Schlangenhöhlen). Das Anorganischbzw. Artifiziell-Materielle ist im Schlüsselmotiv des gesamten Zyklus kodiert: im TempelBau. Die Erbauung des Te mpels bedeutet zugleich die Erhebung des Stoffes und seine Vergeistigung: "A nejvyšši rozkoš: dáti lahodné formé / rozkvẻsti tajemstvím tíze a větrư a svêtla“ (Svèt rostlin I Die Pflanzenwelt, V. 4-5; "Und höchste Wonne: erblühen zu 
lassen die liebliche Form / im Geheimnis der Schwere und Winde und des Lichts". In Stavitelé chrámu wird freilich ein höheres Ziel als 'nur' die Danaturierung der materiellen Natur zum kunstvollen Artefakt und ihre Vervollkommnung durch das Kunst-Schöne angestrebt. Hier geht es nicht mehr darum, das Gestalthafte, Formbare, Körperhafte oder Stoffliche zu denaturieren oder zu artifizialisieren, sondern darum, die Materie des ganzen коoнos zu kultivieren, und mehr noch!, sie zu eschatologisieren, in den eschatologischen Plan zu integrieren. In diesem Aspekt kann man das kosmogonisch-eschatologische Modell von Stavitelé chrámu als Brezinas e i n d e u ti g e Antwort auf die L'art-pour-l'artÄsthetik von Tajemné dálky verstehen. Im kosmogonísch-eschatologischen Modell von SCh wird der "Körper" nicht nur als gleichwertiger 'Partner' der "Seele" betrachtet (Tèlo I Der Körper), sondern der "Körper", in dem man enthalten ist, wird als die notwendige Voraussetzung für die Teilhabe an schöpferischen Prozessen in der Sphäre der Lebenswelt (kooros) angesehen. Die "Schwere des Kosmos", dieses In - de r ( Lebens-) Welt-Sein, das sich primär als so ma tischer Schmerz manifestiert. kann der Mensch in erster Linie durch seine eigene Leibhaftigkeit erfahren, selbst wenn unter diesem Schmerz schließlich und vor allem die ewige und unsterbliche Seele leidet. Doch ohne dieses Leiden scheint die eschatologische Zukunft nicht denkbar zu sein. Es handelt sich um eine der Leitideen des großen Gedichts Se smrti hovoř spici ... (Mit dem Tode reden die Schläfer...), in dem der "Körper" - wie in keinem anderen Gedicht Bïezinas - zum Designat dieses Erlebnisses wird. Es ist kein Zufall, daß dem Gedicht Se smrti hovori spici... das Gedicht Tẻlo (Der Körper) vorausgeht: "A poslednim tajemstvim těla je bolest, tiże kosmu, citẻná duši /.../. Co znamená polibkủ šepot v této tragické hudbẻ, jež hrimá / z

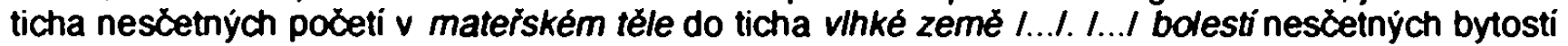
żijem. I Krev naše, zdá se, že vyprýštila z tajemné rány Všeho / a vtekla do našeho téla a kỉecovitým pulsem $v$ ném vî̉i. I... I Zmatené davy bratři zmučenỳch żitím / vali se všemi cestami myšlenky naši $z$ vẻkủ do věkủ. I... / Ticho... jako nad mrtvými těly I nad námi v modlitbách keð̌ely duß̌e I... I (Se smrti hovori spici..., V. 71, 79-80, 106-108, 110-111, 130-131; "Und des Körpers letztes Geheimnis ist der Schmerz, des Kosmos Gewicht, von der Seele erfühlt. I.../Was bedeutet das Flüstern der Küsse in dieser tragischen Musik, die donnert / aus der Stille unzähliger Empfängnisse im Mutterleib in die Stille der feuchten Erde /.../. I.../ wir leben vom Schmerze unzähliger Wesen. I Unser Blut, scheint es, entströmt einer geheimnisvollen Wunde des Alls / und ist geflossen in unseren Körper und wirbelt darin mit krampfhaftem Pulse. I.../ Aufgelöste Massen unserer vom Leben gepeinigten Brüder / wälzen sich über alle Wege unseres Gedankens von einem Zeitalter ins andere. I Stille ... Wie über toten Körpern / knieten über uns in Gebeten die Seelen I...... Übers. v. O. Pick.)

Die Eschatologisierung der dekadenten, 'Schatten-Welt' vollzieht sich in Stavitelé chrámu durch das Charisma der $\mathrm{G} n$ a de ( $\chi \alpha \dot{\rho}, \varsigma)$. Die Gnade ist das vereinigende Prinzip des kosmogonisch-eschatologischen Welt-Modells, das sowohl die Gnosis (rvẅotc) als auch den Glauben ( $\pi$ íorıc) und die Liebe (\&yárm) zu integrieren scheint. Nicht von ungefähr betont Br̉ezina zur Abfassungszeit des Zyklus Stavitelë chrámu die Notwendigkeit des Schmerzes für die Erfahrung der Gnade ("milost"). In einem Brief (vom 12. XI. 1898) an A. Pammrová schreibt er

-Ovsem ovládnout bolest a potlačit ji v celém lidstuu nebude a nesmi být nikomu dáno; bolest souvisi s tajemstvimi viny a znovuzrozeni, pr̉ináśi nová osvětleni života a v zlato, tajemnou permutaci, proménuje nižsi útvary snu; je viditelnỳm znamenim Milosti, odvracejici duše od nebezpečny̆ch cest a zjemñujici sily pro cistši a vyšsi povinnosti. Mnoho z toho nejvonnejjšho. nejdražšiho, v nejzárivějši jiskỉeni rozkvettého, co má żivot, dẻkujeme trpicim. Míti dosti sily snášeti vlastni bolest a - co je ještě vyšši - bolest těch, které milujeme! Prijimouti vděčnè každou pomoc bratři, již rozumem dovedeme Žádati. Uvědomiti si Všudyprítomnost a Jednotu. I... I Nic nechtiti. abychom všechno zastoużili" ${ }^{448}$

448 Vgl. O. Bǐezina, Dopisy Annè Pammrově 1889-1905, Praha 1931, S. 190 (Brief vom 12. XI. 1898): "Aber den Schmerz zu beherrschen, ihn in der gesamten Menschiheit zu verdrängen, das wird und dart keinem gegeben werden; der Schmerz hängt mit dem Geheimnis der Schuld und der Wiedergeburt zusammen, er bringt neue Beleuchtung des Lebens und durch eine geheimnisvolle Permutation verwandelt er die niedereren Gebilden des Traumes zu Gold; er ist ein sichtbares Zeichen der Gnade, indem er die Seelen vor den gefährlichen Wegen hütet und die Kräfte für reinere und höhere Pflichten noch feiner macht. Für vieles von dem Düftesten, Kostbarsten, ins strahlendste Funkeln Aufgeblühten, was das Leben innehat, danken wir den Leidenden. Genug Kraft zu haben, um den eigenen Schmerz und - was noch höher steht - den Schmerz derjenigen zu ertragen, die wir lieben! Dankbar jede Hiffe der Brüder anzunehmen, die wir durch die Vernunft 
Und im Brief vom 8. II. 1899: "A pak zase /.../ moderni cetba filosofická a mé viastni práce s tou kletbou věcnè touhy po nejvyššim a s presvédženim, že zde ničeho nelze bez milosti, která priicházi, tajemná, aby v několika vitěznỷch okamžicich ukázala duši krásu světa a odcházejic, v jediné gesto shmula všechny vủnè". 449

Die Gnade wird zum obersten Prinzip der Kunst- und Lebensschöpfung und darüber hinaus gibt sie - durch ihren Charakter - die Möglichkeit, auch die 'Irrwege' der

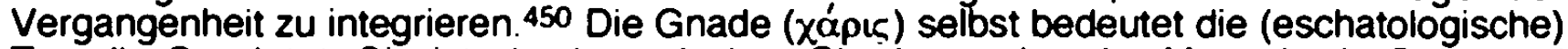
Tat, die Gnadetat. Sie ist ein dynamisches Charisma, das der Mensch als Gabe und

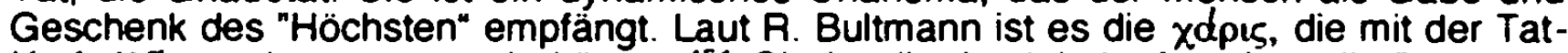
Kraft ( $\delta \tilde{u} v \alpha \mu \iota \varsigma)$ synonym sein könnte. 451 Sie ist die Antriebskraft , ohne die "man hier nichts erreichen kann" ("Že zde ničho nelze bez milosti“; s. o.). Die Bedeutung der Gnade als der eschatologischen Tat des "Höchsten" thematisiert das Gedicht Milost (Gnade); es sind die Künstler-Schöpfer bzw. die Schöpfer-Menschen (artifices; "na rtech vyvolených tvých" / "auf den Lippen deiner Auserkorenen", IV, 3; "tvé pévce" I "deine Sänger", VI, 1), die "in deiner Ufer Glut, Gefangene von Sternen und Träumen, I an deiner Welt erkrankt. im Lebensfrost klagen" (II, 1-2; "v žáru biehư tvých, zajatci hvězod a snú. I nemocni světem ivým, v zimnici žiti upęji" ${ }^{\prime \prime}$ und die hier die Gnade als eine einmalige Tat erfahren:

¿Z obloukủ triumfálných nejvyšsiho azuru / po sesti práce dnech v mystickou sálá nedèli; / a nejchudši tvě odivá v šat královského purpuru, / jenż, bratǐim zemẻ neviditeinỳ, je viděn andély". $(I$. 1-4; "Aus Ruhmesbögen des höchsten Azurs / strahlt nach sechs Arbeitstagen sie in mystischen Sonntag ein; / und schlägt um die Allerärmsten $\mathbf{4 5 2}$ ein Kleid des königlichen Purpurs, / das, Erdenbrüdern unsichtbar, die Engel sehn allein").

Das Charisma der Gnade komplettiert in Stavitelé chrámu die Grundbestimmungen der eschatologischen Existenz, den Glauben und die Liebe, die im theo-logischeschatologischen Modell von VP einen zentralen semantischen Ort haben. ${ }^{253}$ Der dynamische Charakter der Gnade, die postulierte Dynamisierung (der schöpferischen Prozesse), die auch in der Gnosis als 'Bewegung' der/zur Erkenntnis eine wichtige Rolle spielt, und schließlich auch die Auseinandersetzung mit der Kunst-Schöpfung-Mythik des dekadenten Symbolismus, alle diese Aspekte könnten den Eindruck erwecken, daß Biezina in Stavitelé chrámu auf das gnostische Denkgut zurückgreift. Das in Stavitelé chrámu konstituierte pluralistische Welt-Modell mit seinem Postulat der Synthese der Kunst- und Lebensschöpfung in der Sphäre der Lebenswelt, steht allerdings in einem krassen Gegensatz zu dem gnostischen Dualismus zwischen Mensch und Welt und zu der gnostischen Negation der Lebenswelt als einer anmaßenden, die verhängnisvolle Entfremdung des Menschen verursachenden "Fälschung". Während die gnostische Selbsterlösung des Menschen die Überwindung und endliche Auflösung des kosmischen Systems einschließt, ist das Ziel des eschatologischen Symbolismus die Vollendung der Schöpfung, die Herstellung der kosmischen Einheit und das eschatologische Ereignis. Es ist ein Prozeß der schöpferischen Bewegung, die in der Sphäre der Lebenswelt beginnt und deren Nenner die Sehnsucht nach der eschatologischen Vollendung ist. An die Stelle der stolzen gnostischen Selbsterlösung, die noch in Svitáni na západé einen integralen

verlangen können. Sich der Allgegenwärtigkeit und der Einheit bewußt zu werden. I.../ Nichts wollen, um sich alles zu verdienen:.

$449 \mathrm{Vgl}$. ibid. S. 193. "Und dann wieder /.../ moderne philosophische Lektüre und meine eigene Arbeit mit dem Fluch der ewigen Sehnsucht nach dem Hōchsten und mit der Überzeugung. daß man nichts ohne Gnade erreichen kann, die kommt, die Geheimnisvolle, um in einigen siegreichen Augenblicken der Seele die Schönheit der Welt zu offenbaren, und um beim Weggehen in eine einzige Geste alle Düfte zusammenzubündeln".

$450 \mathrm{Vgl}$. "Als Mitarbeiter aber ermahnen wir euch, daß inr die Gnade Gottes nicht vergeblich empfangt" (2. Kor. 6, 1). "Aber durch Gottes Gnade bin ich, was ich bin" (1. Kor. 15, 10).

$451 \mathrm{Vgl}$. R. Bultmann, Theologie des Neuen Testaments, Tübingen 1968, S. $287 \mathrm{ff}$.

$452 \mathrm{Vgl}$. hierzu: "Und er hat zu mir gesagt: Laß dir an meiner Gnade genūgen; denn meine Kraft ist in den Schwachen mächtig. Darum will ich mich am allerliebsten rühmen meiner Schwachheit, damit die Kraft Christi bei mir wohne" (2. Kor. 12, 9).

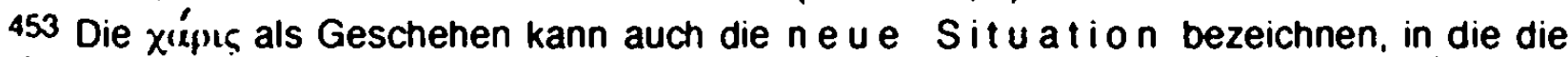
Glaubenden versetzt worden sind; sie 'markiert' den Herrschaftsbereich der göttlichen Tat. Als

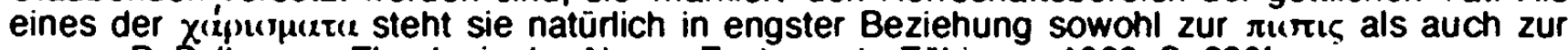
r үrevt. R. Bultmann, Theologie des Neuen Testaments, Tübingen 1968, S. 290 f. 
Bestandteil des soteriologischen Plans bildet, tritt in Stavitelé chrámu die Hingabe an die Gnade ("milost") des "Höchsten".

Die oben erwähnte Idee des Gottmenschentums kommt in Stavitelé chrámu nicht unvermittelt vor. Sie schwingt bereits in Vẻtry od pólư im Gedanken der Inkarnierung des Logos mit, der der Bewirker der Vollendung der Einheit der göttlichen und menschlichen Natur ist. Die Medien dieses Einheitsstrebens sind die Hoffnung, der Glaube und vor allem die Liebe, die zugleich - als zauberhafte "Ernte des Lichts" ("úroda světla", Láska / Liebe, VP, V. 18) - die Vollendung des "Reifen"-("zráni")-Prozesses (zur eschatologischen Existenz) bedeutet: $" / . . . / v$ úsmévu vašem tisice úsmẻvủ zasvití z tisice duši, / tisice smrti budete potkávat najednou v tisíci cestách bez báznẻ / a uzrỉte zástupy nesčisiných żivotů vcházeti v jediný żivot" (ibid., V. 71-73; "in eurem Lächeln leuchtet es aú von tausend Lächeln aus tausend Seelen, / tausend Toden werdet ihr begegnen plötzlich ohne Furcht auf tausend Wegen / und dann seht ihr unzähliger Leben Schar eingehen in ein einziges Leben").

Der Versuch einer (neven) erfolgreichen Integration der dekadenten 'Schatten-Welt' in das System des eschatologischen Symbolismus geht mit der R e $m$ y th i s i e ru ng des in Stavitelé chrámu konstituierten kosmogonisch-eschatologischen Welt-Modells einher. Nicht nur die ästhetistische Kunst-Schöplung wird in Stavitelé chrámu remythisiert und positiviert, auch die für den dekadenten Symbolismus signifikante lunare Nacht- und Hypnos-Welt soll offensichtlich positiviert und eschatologisient werden:

"Jak stráže tvé bodime / na mistech nebezpečenstvi; / pried námi hranice svaté tvé noci, / za námi královstvi spicich" (Vigilie I, V. 1-4; "Wie deine Wachen harren wir / an den Stätten der Gefahr; I vor uns die Grenzen deiner heiligen Nacht, I hinter uns das Königreich der Schlafenden"). "Ach, spáti ještè tisicileti! At krouži svèty / kolem propasti ohnẻ a padaji uzrálá zrna na klasech konstelaci / v černou pủdu etheru tvého, z záhyby tvého klina, I nekonečnem rozprostieného!" (Se smrti hovori spici / Mit dem Tode reden die Schläfer, V. 33-36: "Ach, Jahrtausende noch zu schlafen! Mögen die Welten nur / kreisen um feurige Abgründe, und gereifte Körner aus den Ähren der Konstellationen fallen / in deines Äthers schwarzen Grund, in deines Schoßes Gefälte, I des durch die Unendlichkeit sich breitenden!"). At' sladce drimou bratr̈i mi v svatebnich ložich naději / a ztroskotani na brezich at dřimou ještě sladžeji: / noc se svěm sněni uslyši, jak šeptá v reeči neznámé, / Že mile každou minutu do mơe světla padáme" (Zas ve vidèni prorockém... I Wieder in einer prophetischen Vision... letzte Strophe; "Mögen meine Brüder süß im Hochzeitsbett der Hoffnungen schlummem / und süßer noch die am Strand Gescheiterten: I sie vernehmen, wie die Nacht im Traum in unbekannter Sprache flüstert. I daß wir jede Minute viele Meilen in ein Meer von Licht fallen").

Der in Tajemné dálky thanatophil konnotierte Schlaf/Traum-Zustand als ein lustbetontes und gleichzeitig furchteinflößendes Hinabsinken des isolierten Ich in die bodenlose Tiefe, in das kalte, finstere Reich des Thanatos und der beklemmenden Leere, wird in Stavitelé chrámu zum wonnigen, verheißungsvollen Schlummer "im Hochzeitsbett der Hoffnungen" (Zas ve vidëni prorockém... I Wieder in einer prophetischen Vision.... IV, 1) auf die zukünftige eschatologische Existenz umkodient. Es ist nicht der "letzte, ewige Schlaf", aus dem es kein Erwachen mehr gibt (Modlitba vecerni / Das Abendgebet, VII, 8. TD; "sen vẻčny., posledni, z něhoż se nevzbudim"), sondern nur eine quasi 'Überbrückungszeit' vor der Auferweckung zum eschatologischen Sein. Die Strategie der Positivierung, ja sogar der 'Christifizierung' der aus dem theo-logisch-eschatologischen Welt-Modell (VP) verdrängten dekadenten 'Schatten', tritt geradezu demonstrativ gleich im Prolog-Gedicht Zpẻv staletími bloudici... (Ein Gesang, der durch die Jahrhunderte irrt...) in einem intertextuellen Bezug auf das Gleichnis des Gangs Christi auf den Meereswogen (Matt. 14, 25-27) zutage:454 "krok Mistrủv Zasu po vinách a sestup svatých vidẻni $\digamma_{\text {po }}$ schodech zárí mẻsičnich a bílých bleskủv odění" (III, 3-4; "auf Zeitwogen des Meisters Schritt, kam der Gesichte Heiligkeit / auf Mondscheintreppen, angetan mit weißer Blitze Panzerkleid". Übers. v. O. Pick). In diesem Sinne wird auch die "wehklagende Nacht" ("za nařikajicich noci", Vünè zahrad mé duß̌e... I Der Duft meiner Gärten Seele, V. 32, TD) zur "heiligen Nacht" ("svatá noc", Vigilie I, V. 3), durchdrungen von der "strahlenden Wonne" ("a světlá rozkoš, do noci", Zpěv staletimi bloudici / Ein Gesang, der durch die Jahrhunderte irnt, IV, 3), umkodiert. Die finstere Nachtwelt wird von einem "Lichtmeer"

454 -Aber in der vierten Nachtwache kam Jesus zu innen und ging auf dem See. I Und als ihn die Jünger sahen auf dem See gehen, erschraken sie und riefen: És ist ein Gespenst! und schrien vor Furcht. / Aber sogleich redete Jesus mit innen und sprach: Seid getrost, ich bin's; fürchtet euch nicht!" (Matt. 14. 25-27). 
überflutet ("magii měsice / se neprístupné moỉe světla pohnulo a z bỉehủ vylilo / a zemi zplavilo jedním prílivem" (Zemẻ vitězú / Das Land der Sieger, V. 6-8; "des Mondes Magie I ließ das unzugängliche Lichtmeer sich rühren und entrinnen dem Strand, I überschwemmend die Erde mit riesiger Flut"). Signifikant ist auch die Umkodierung und Eschatologisierung der "Nachtmeerfahrt"-Symbolik, d. h. des Eintauchens in das Reich des Hades, in die dunkle chthonische Wasser-Tiefe des Un(ter)bewußten (Motiv $z$ Beethovena / Ein Motiv aus Beethoven, TD); die vom Meer (d. h. vom Mutterschoß, von der Sphäre des Unbewußten) verschlungene Sonne (als maskulines Prinzip des Bewußten und der Bewußtseinsintegration, des Luziden und der Teleologie), erstrahlt - als Sinnbild der Wiedergeburt 'aus der mütterlichen Wassertiefe' - am Meeresgrund. Die lunare "Nachtmeerfahrt" (Motiv z Beethovena) wird zur solaren 455 Himmelfahrt umkodiert:

"/... / a všemi výšemi jak záliv mớe $z$ nedohledna / se vini jedna żeń! Snú skvouci lơ'stva ethemá / se na ni v dálce ztráceji a v zlatém pisku ze dna. I pod vesly zvireném, zár slunci hởi nádherná!" (Apotheosa klasú / Die Apotheose der Ähren, VI, 1-4; $\%$... und unabsehbar wogt. gleich einem Meeressunde. / Emte auf allen Höhn! Der Träume Ätherflotte voller Pracht / verliert sich fern auf ihr, im goldnen Sand am Grunde, / den Ruder aufgewühit, strahlt Sonne stolz entfacht!"). "Jak prủhledný byl cas a k oslepnuti vzplál! Jak den, v němż všechna slunce vesmiru by vyšla najednou / svým světtem dálkou nezeslabeným a zahởela nad zemi!" (Zemé vítézú / Das Land der Sieger, V. 38-39; "Wie durchsichtig war die Zeit und grell zum Erblinden! Wie ein Tag, da alle Sonnen des Alls erstrahlen auf einmal / mit ihrem durch Ferne ungeschwächten Lichte, entbrannt überm Erdball!". Übers. v. O. Pick.)

Es ist nicht mehr das hypnotisierende, in den Kunst-Tod ver-führende 456 Gefunkel der in der Wassertiefe changierenden, opalisierenden Edelsteine, sonden die blendende Sonne des zukünftigen Lebens, die auch unter den schwarzen Wogen auf dem Meeresgrund verheißungsvoll brennt, wie im adventistischen Gedicht Kdyż nebe vase okna ozár̆... (Füllt eure Fenster Himmelsglanz...):

"... / početi svétla, jenż se v hloubce vékú tvơ̌i, / a k nèmuž jara minulá s kỡisti svoji odplula / prüplavy żhoucich západú, pł̉es cerné viny morij; / pł̌es cerné viny mơ̈i, / kde louky na dnè, zkvetté hvězdami, v carovném tichu hới". (9-14; "\%... Aufdämmern einer Welt, aus alten Tiefen an das Licht gezogen, / wohin der Vorzeit Frühlinge mit ihrer Beute durch Kanäle / glühend Hingangs sind gezogen, auf schwarzen Meereswogen, / auf schwarzen Meereswogen, / wo auf dem Grund in zauberhafter Stille sternbeblühte Wiesen wogen"). $\% /$ a světlá rozkoš, do noci, jeż z vin mu stoupala, I jak kdyby dnem se rozlila a vłechny svẻty koupala" (Zpév staletími bloudici... I Ein Gesang, der durch die Jahrhunderte irrt..., IV. 3-4: " .../ und lichte Lust floß in die Nacht, aus Klangwogen genaht. I ward wie durch hellen Tag ein Strom und aller Welten Bad". Übers. v. $O$. Pick.)

Interessanterweise wird in Stavitelé chrámu auch die Symbolik des WeiblichAnimischen remythisiert: ein neuer Aspekt des kosmogonisch-eschatologischen Modells. Während im theo-logisch-eschatologischen Welt-Modell das patriarchalisch-maskuline. zeugende Prinzip des Logos spermatikos dominiert und das nur schwach vertretene Weiblich-Animische spiritualisiert (Královna nadéji / Die Königin der Hoffnungen), tritt in Stavitelé chrámu das weibliche Prinzip wesentlich ausgeprägter, o $\mathrm{h}$ in seinem asthetisch-femininen (Stavitelé chrámu / Baumeister am Tempel, V. 49-51), 457 rekreativen und wiedegebärenden Aspekt zutage. Nicht (nur) als translunare Lichtgestalt, als "Königin der Hoffnungen", sondern und vor allem als 'Erdgöttin', die "die tiefste Stimme

455 Signifikanterweise erreicht das Lexem "slunce" ("Sonne") gerade in Stavitelë chrámu und in Vètry od pólú die höchste Frequenz; in Tajemné dálky hingegen die niedrigste.

456 "Pojo", dej tónủ svých jsem nalil v lampy krystal, / z kamenủ sviticich jsem sklenul kryptu tvou / a z květú zázračných jsem mékký polśsár schystal, / kde $v$ rasy vủni mdlých dás hlavu zemdlenou" (Motiv z Beethovena / Ein Motiv aus Beethoven, X, 1-4. TD; "Komm, mit dem Öle meiner Töne füllte ich der Lampe Kristall, / aus strahlendem Gestein wölbte ich deine Krypta / und aus Zauberblumen bereitete ich ein weiches Kissen vor / auf das du in Falten matten Duftes dein müdes Haupt hineinlehnst").

457 -Snili /.../ O żenách zāhadných, zemdlených tiži krásy, / jeż volaji milence pisnẻmi

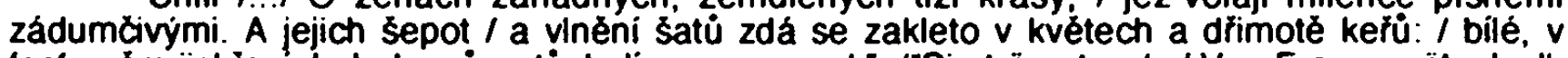
fosforném jiskỉeni drahokamú a rtú, hali se v soumrak". ("Sie träumten /.../ Von Frauen, rätselvoll, matt in der Last inrer Schönheit, / die mit Liedern der Schwermut die Geliebten rufen. Und inr Flüstern / und Wogen der Kleider scheint verzaubert in den Blumen und im Schlummer der Sträucher: / sie hüllen sich weiß, im Phosphorgefunkel der Lippen und Edelsteine, in das Dämmern"). 
des Stoffes" kennt (Jsem jako strom v květu... I Ich bin wie ein Baum in Blüte..., V. 28), ${ }^{458}$ oder als (personifizierte) re-generative Natur in ihrer Materialität (Smutek hmoty / Die Traver des Stoffes). Das metamorphierte 'Weib' (meistens als tellurisches Prinzip der 'Erd-Mutter' oder als 'Hüterin' des Geheimnisses) erscheint hier in seiner re-generativen wie auch in seiner destruktiven Gestalt (Jsem jako strom v květu / Ich bin wie ein Baum in Blüte):

\%.../ v korridorech světla jsem prosţela vủně pro kroky milencủ svych / a všechna tajemstvi noci jsem hodila do klína žen. // Vß̌ak żárlivá nechci, kdyż za noci drímu, umdlená objetim jar, I bys toužil po etherné kráse mých sester, jež vábi tè k hrám. I.../ Pro ty je żántivá krutost mé lásky, I umdleni hrobovỷ mir. / hloubka mých zrakú, z nichž sálá / osudných souhvězdi vir, / vteřin mých ciše kde věcnosti světlo / do krve zlomeno piá, / a polibkủ závrat', / sladká a zlá". (Jsem jako strom $\checkmark$ květu.../ Ich bin wie ein Baum in Blüte..., V. 3-6, 9-16; "/../ in den Korrldoren des Lichts habe ich Düfte gebreitet für meiner Liebhaber Schritte / und alle Geheimnisse der Nacht warf ich in den Schoß der Frauen hinein. // Doch eifersüchtig, will ich nicht, wenn ich nachts, matt von der Lenze Umarmung, schlummere, / daß du meine ätherischen Schwestern begehrst, die dich locken zum Spiel. I .. / Für sie ist die Grausamkeit meiner Liebe, Ermattens Grabesnacht, / meiner Blicke Tiefe, aus der / der Strudel verhängnisvoller Sternbilder lodert, / Kelch meiner Sekunden, wo der Ewigkeit Licht / ins Blut eingetaucht brennt, / und der Küsse Taumel / süß und böse").

An Stelle der transzendenten "Königin der Hoffnungen" tritt in Stavitelé chrámu die chthonische "Sklavin des Ewigen. Fürstin des Wahns" ("Otrokynẻ Věčného, Sílenstvi kněžna": Jsem jako strom v květu... I Ich bin wie ein Baum in Blüte, V. 28). In Smutek hmoty (Die Trauer des Stoffes) wird die Erd-Mutter mit der webenden Vestalin assoziiert, in deren Gestalt J. J. Bachofen die Personifikation der webenden Natur- (bzw. Erd-) Mutter erkennt, deren Tätigkeit im Grunde eine unendliche Mühewaltung, ein ewiger Kreislauf von Geburt und Tod ist, denn was sie tags wirkt, trennt sie nachts wieder auf: 459

\%.../ kde světel vlákna hedbávná pro svatebni šat żiti, / zem sprádá cemýma a svráskalýma rukama a níti / svưj oheñ zvolna hasnouci, Vestálka zádumčivá. Zpěv sester mrtvých preded věky. jejż doprovodem zpivá, / bez echa letí véčnosti a v jeho rythmu tiži, I zrcadle magickém, se zjevy privolaných duchü zhliži" (Smutek hmoty / Die Trauer des Stoffes, V. 13-18; "wo für des Lebens Hochzeitskleid mit schwarzen Runzelhänden / die Erde Licht wie Fasern spinnt und entfacht, I schwermütige Vestalin, ihr Feuer, das langsam wieder erlischt. I Das Lied seit ewig toter Schwestern, das sie im Chore singt, / fliegt ohne Echo durch die Ewigkeit und in seines Rhythmus Schwere, / sehen sich wie im magischen Spiegel die angelockten Geisterheere").

Die konsequente Integration und Eschatologisierung der dekadenten 'Schatten' in den schöpferisch-eschatologischen Prozeß scheint nun dem dichterischen Ich die Gewißheit zu geben, daß auch die Finsternis und die Schatten der dekadenten Vergangenheit von dem fleischgewordenen Logos/Lichtleben durchstrahlt und diaphanisiert werden, da auch sie zum Schöpfungsplan des "Höchsten" gehören und auch ihnen, "wenn sich die Zeiten erfüllen" ("až se naplni věky"), das Charisma der Gnade zuteil wird. Man hat keinen Grund mehr, an dem siegreichen und nahenden eschatologischen Geschehen zu zweifeln, man braucht sich nicht mehr und vor nichts zu fürchten. Das ist, wie es scheint, der Sinn der Allusion auf das Gleichnis von dem Gang Christi auf den Meereswogen

458 Der Dichter (als artifex) soll die Zauberkraft des Weiblichen sowohl in seiner kreativen als auch in seiner destruktiven Gestalt erleben, denn diese Erfahrung scheint die unerläßliche Voraussetzung für die Offenbarung des "tiefsten Geheimnisses der Erde" zu sein. Die erotisierte untere Anima in Jsem jako strom v květu...(Ich bin wie ein Baum in Blüte...) gibt signifikanterweise inre Schätze gerade den Asketen: "tisice let jsem skládala bohatstvi svá jak královský dar, / a těm, kteri dovedou ničeho neżádat, celý ho dám" (V. 7-8; "Jahrtausende türmte ich meine Schätze wie ein Königsgeschenk, / und denen, die nichts zu fordern verstehen, gebe ich es ganz"

$459 \mathrm{Vgl}$. Johann J. Bachofen, Versuch über die Gräbersymbolik der Alten, Gesammette Werke, Bd. 4, Basel 1954, S. 360-362: "Das Flechten des Seils ist eine symbolische Handlung. welche nicht selten wiederkehrt und mit dem Spinnen und Weben der großen Naturmütter auf einer und derselben Anschauungsweise beruht. So finden wir Aphrodite webend, so Penelope, so Circe, so Maria Proserpina, so die tres anus textrices der Unterwelt, welche ohne autzublicken inr Werk verrichten; spinnend die Parzen /.../. Von der Gottheit geht das Weben auf ihre Priesterinnen über. I.../ Unter dem Bilde des Spinnens und Webens ist die Tätigkeit der bildenden, formenden Naturkraft dargestellt. I.../Vollendet treten die Organismen alle aus dem Schoße der Erde hervor Von der Mutter haben sie das kunstreiche Gewebe des Leibes, das jene mit unerreichbarer Meisterschaft im dunklen Schoße des Stoffes bereitet" 
(Matt. 14, 25-27) im Prolog-Gedicht Zpěv staletími bloudici... (Ein Gesang, der durch die Jahrhunderte irrt...), nämlich die ermutigende, gegen die Kleingläubigkeit gerichtete Aufforderung: "Fürchtet euch nicht!" (Matt. 14, 27). Von dieser Intention läß̈t sich auch das semantisch relevante Konstruktionsprinzip des kosmogonisch-eschatologischen Modells von Stavitelé chrámu herleiten; der Akzent liegt nicht mehr auf dem Prinzip der U n i tä $t$. das die oxymoral-paradoxe Semantik des gnostisch-eschatologischen (SZ) und theologisch-eschatologischen Modells (VP) bestimmt, sondern auf dem negativen Parallelismus, auf der Koexistenz der mannigfaltigen, konträren Wegen (Lebensformen), die von der P I u r a li tä t der eschatologischen Existenz und von der Zuversicht herrühren, daß unter den "schwarzen Meereswogen" der lichterfüllte, strahlende Grund liegt.

Resümierend läßt sich sagen, daß die - im Vergleich mit dem theo-logischeschatologischen (und rationalisierten) Welt-Modell (VP) - größere Konkretheit des kosmogonisch-eschatologischen Welt-Modells (SCh) und die in der Forschung oft konstatierte 460 Zufuhr der neuen Lebensempirie der modernen Zivilisation mit der Remythisierung des in Stavitelé chrámu konstituierten Welt-Modells koinzidieren. In dem Sinne, daß die Welt der modernen Zivilisation hier (u. a.) durch die Synthese mit dem mythisierten Welt-Modell des dekadenten Symbolismus konsequent remythisiert und archaisiert wird. Die Realien der modernen Welt und des Lebens -

"Snili o rozkosich nejistoty a hry, rozcileni tržišt'. I o zmatku tisice jazykủ, pokřikem plnicich duši jak prístavištè" (Stavitelé chrámu / Baumeister am Tempel, V. 40-41; "Sie trăumten von der Lust des Spiels und der Unsicherheit, der Erregung auf Märkten, / von tausender Zungen Verwirrung. mit Geschrei die Seele wie einen Hafen füllend"). "Huð̌eni davu na staveništich tajemných staveb, / jichż lešeni, pokrytá cernè, jsou trísnéna krvi / popravištę!" (Proroci / Die Propheten. V. 53-55; "Heulen der Menge auf Bauplätzen geheimnisvoller Bauten, / deren Gerüste, schwarz verhüllet, mit Blut bespritzt sind. / Hinricttungsstătten!"). "/../ a mésta v kletbẻ usinajici se tměla ze hiubin / a věze jejich kathedrál a klášterú a hvézdáren / a vézeni" (Zemé vítézú / Das Land der Sieger, V. 1113: \%.../ und Städte erdunkelten Tiefen, entschlafend im Fluch, / und die Türme ihrer Kathedralen und Klöster und Sternwarten und Gefängnisse") -

werden der konkret-bildhaften Logik des mythogen-archaischen Denkens unterworten. Die zivilisatorische Moderne wird in Stavitelé chrámu durch ihre Integration in ein mythogenes Weltbild archaisiert und erst diese Mythisierung/Archaisierung trägt zu der größeren Konkretheit bei. Es scheint, daß diese Konkretheit sich vor allem in der schöpferischen Aktivität, in der Teilhabe an konkreten (wie z. B. der Tempelbau) schöpferischen Prozessen der Kunst- und Lebensschöpfung manifestiert, die zur Wiederherstellung der kosmischen Einheit führen und in das eschatologische Geschehen einmünden sollen.

460 Zum Beispiel von O. Králik, Otokar Biezina, Praha 1948, S. 340. Vgl. auch: M. Cervenka, .Błezinovské úvahy, in: Ders., Symboly, pisné a myty. Praha 1966, S. 50 ff. An dieser Stelle soll noch einmal hervorgehoben werden, daß die für Stavitelé chrámu charakteristische Konkretheit sich absolut nicht allein aus dem von Králik behaupteten "Einsturz der Mauer des symbolistischen Ästhetizismus" Błezinas und aus der Aufgeschlossenheit des Dichters gegenüber der "Welt der modernen Arbeit, Technik und Wissenschaft" (O. Krălik, a.a.O., S. 340) ableiten lāßt. Diese "Aufgeschlossenheit" für die moderne Wissenschaft wurde bereits im Zusammenhang mit der Rationalisierung des Mythischen in Vétry od pólü (Kap. 4.1) erwähnt. In VP thematisien Błrezina Erscheinungen oder verwendet Begriffe, die doch der Anno $1897 \mathrm{~m}$ o de r n e n Astrophysik. Optik. Dynamik und anderen Bereichen der Naturwissenschaft entstammen und die der Bildlichkeit dieser Gedichte (in VP) den Eindruck der Abstraktheit verleihen. In Stavitelé chrámu wird das der Bildlichkeit Brezinas zugrundeliegende mythogene Substrat seines 'rationalen' Gewandes wieder entkleldet, wodurch die bildhaft-konkrete Mytho-Logik erneut stark zur Geltung kommt. Die Konsquenz dieser Re-Mythisierung ist gerade - u.a. - die oben konstatierte A r cha is i e r ung der zivilisatorischen Moderne! 


\title{
5.1 Vita activa: Symbolik der schöpferischen Prozesse
}

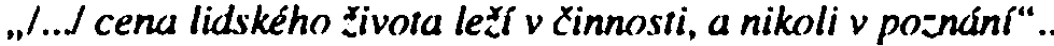 \\ "/.../ der Wert des menschlichen Lebens liegt in der Tätigkeit und nicht in der Erkenninis". \\ O. Bfezina: „Fragmenty” („Fragmente”)
}

Mit dem Prozeß der Pluralisierung der eschatologischen Existenz gehen die schöpferischen Prozesse (im "Werden") einher. Man kann durchaus von der Dominanz der Dynamik des Kreativen, Aktiven und Performativen im kosmogonischeschatologischen Modell von Stavitelé chrámu sprechen. In diesem Zusammenhang drängt sich die Frage auf: Wodurch zeichnen sich die (mythogenen) "Baumeister" aus? Sie figurieren als schöpferische Menschen (artifices), die jener besonderen Gabe

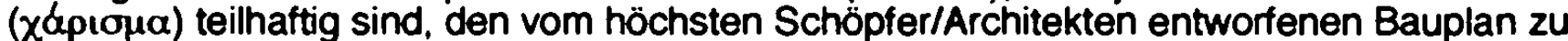
erkennen, die verschiedenen, wörtlich "zahllosen" ("nescisinę") schöpferischen 'Schritte', d. $\mathrm{h}$. die mannigfachen Kunst- und Lebensformen, zu koordinieren und auf das postulierte Ziel, auf die Vollendung der Schöpfung hin zu fokussieren:

"Mezi nimi šli stavitelé tvého chrámu. Ti jedini ze všech / poznávali se znameními. Jako slib jinỷch nebes a zemè viděli hrưzu a nádheru vẻci. $V$ plnosti nesčisinỷch forem cítili prvotni napěti tvého tvủrč́ho dechu" (Stavitelé chrámu / Baumeister am Tempel, V. 72-75; "Zwischen ihnen schritten die Baumeister deines Tempels. Sie allein unter allen / erkannten einander durch Zeichen. Wie anderer Himmel und Erden Verheißung / sahn sie die Pracht und das Grauen der Dinge. In der Fülle zahlloser Formen / fühtten sie die Urspannung deines schöpferischen Odems").

Signifikanterweise wird nicht nur die Vielfalt der Kunst- und Lebensformen, sondern auch deren völlig verschiedenartige, konträre Beschaffenheit explizit hervorgehoben: "Jako slib jiných nebes a zemé" ("Wie anderer Himmel und Erden Verheißung". Stavitelé chrámu / Baumeister am Tempel, V. 73). Die "Baumeister" sind imstande, in den Realien der Lebenswelt sowohl das Grauen ("hruzu") als auch die Herrlichkeit "nádheru", ibid., V. 74) zu sehen. Alle Formen, die herrlichen wie die grauenvollen, sind jetzt gleichberechtigt, sie alle gehören zum Bauplan des "Höchsten", sie alle münden "in eine einzige Welt" ("ústící v jediném světee", ibid., V. 30), in einen einzigen Fokus. Der schöpferische Prozeß, der zur (eschatologischen) Vollendung des Tempelbaus führen soll, setzt die a k ti ve . schöpferische Teilhabe des Menschen am kosmogonisch-eschatologischen Geschehen voraus. Nicht (nur) die passive Kontemplation und Anbetung des "Höchsten" (theolatreia), 461 sondern sein aktives Wirken (theourgia), $d$. $h$. das parallele Zusammenwirken des "höchsten Schöpfers" und seiner "(Mit-)Arbeiter" führt in der Sphäre der Menschenwelt (коo $\mu$ os) zur Vollendung der Schöpfung. Das Ziel dieses Prozesses ist die Harmonisierung aller schöpferischen Akte zu einem 'Gesamtkunstwerk'. Es ist nicht von ungefähr, daß diese harmonische Ganzheit das Bild der zauberhaften Glasblasen "der Erde Azure umfassend, I regenbogenhaft spielend und blau, Kuppel ätherischer Paläste des Glücks", im Titelgedicht Stavitelé chrámu (V. 64-65) symbolisiert.462 Der

461 Signifikanterweise kommen die in Vètry od pollu (Polarwinde) sehr frequentierten Invokationen des "Höchsten" ("Vládnouci! / "Herrscher!", "O Vẻcný!" / "O Ewiger!": "Otce!" I "Vater!": "Otvirajici!" I "Offnender!"; "Vsudypřitomný!" / "Allgegenwärtiger!"; "o Véčný a Třikráte Svaty" / "o Ewiger und Dreimal Heiliger") in Stavitelé chrámu nicht vor. Der "Höchste" figuriert hier uicht als apostrophiertes "Du", sondern als Derjenige, von dem geredet wird ("O tobé mluvi a o tvé slávẽ", Proroci / Die Propheten, V. 23; "Von dir reden sie und von deinem Ruhm"). Er erscheint inmitten seiner "Arbeiter" ("délníci") als 'Architekt' des Bauplans, als creator macrocosmi. Die "Baumeister" ("stavitelé") fühlen geradezu physisch in den von ihm geschaffenen Formen seinen "schöpferischen Odem" (Stavitelé chrámu / Baumeister am Tempel, V. 75).

462 In seiner hochinteressanten Studie Symbolism of the Sphere. A contribution to the history of eartier Greek philosophy (Leiden 1977, S. 30ff.) interpretiert der Archäologe und Kunsthistoriker Otto J. Brendel die Kugel (oyatpa) als Harmonie, als die reinste erdenkliche Schönheit des Gesamtweltgebäudes. Derartige Schönheit des Weltgebäudes schildert Plato in Timaios. Brendet macht ebenfalls auf die Koinzidenz der sphärischen Eigenschaft des Himmelsganzen mit den mythischen Vorstellung von der Kugelgestalt Gottes aufmerksam. In der christlichen Mystik (hl. Benedikt, Cusanus, Mechthild von Magdeburg) wird die Vorstellung von Gott als einer feurigen 
Rückgriff auf die Kunst-Schöpfung-Mythik des dekadenten Symbolismus (TD) ist hier nicht zu verkennen; als autointertextuelles Signal läßt dieses Bild seine Folie durchschimmern. Es ist das Gedicht Vëzeñ (Der Gefangene), in dem das Motiv der Glasbläserei semantisiert wid: "Nad výhni duše své do skelné hmoty vrouci / jsem smáčel píst'alu a vydechl tè tvarem" (V, 3-4; "Über der Glut meiner Seele in die siedende Glasmasse I tauchte ich die Pfeife und blies dich zur Form aus"). In Vëzeñ geht es um die ästhetistische Hervorbringung einer autonomen Kunstwelt durch den (demiurgischen) Kunst-Schöpfer, während in Stavitelé chrámu sich um die theurgische Schöpfung handelt: Die Glasblasen in Stavitelè chrámu sind kein 'Produkt' der Blaspfeife des $\mathrm{K}$ ü n s $\mathrm{tl}$ e $\mathrm{r}$ Demiurgen, sondern die Schöpfung des 'Fachtens' des gö ttl i che n Odems: "dmychaly vẻtry do výhni pod obzorem" (V. 62; "fachten Winde die Essen unterm Horizont")

Die theolatreia in Stavitelé chrámu bedeutet den "Höchsten" in den Realien und durch die Realien der Lebenswelt zu suchen, sich aktiv dem im Gang befindlichen Schöpfungsakt hinzugeben, um die mannigfaltigen, zahllosen (Lebens-)Formen zur Vollendung zu bringen. Dabei werden auch die niederen, finsteren Formen in diesen Prozeß mit einbezogen. Sogar die transzendente Welt, "hundert unsichtbare Hände" ("Sta rukou neviditelných", Vitáme jaro! / Wir grüßen den Frühling!), partizipiert an diesem Werk:

-Pozdravujeme jaro tvé práce! Sta rukou neviditelných / pracuje s námi. /.../ / Hlasy hmyzu, jak cvakot tajemnỷch hodin, / zni z pole jetelověho /.../. // Pozdravujeme jaro, jeż volá tisice jar! Slyšite odpovẻơ jejich, / jak ze všech světủ se tǔese, vesmir, jenż o svých nadejjich zpivá? / Zlaté petrklice jiskr̆ se v azurných lukách /...l. // Pozdravujeme jaro! Hle, dni se střidaji s noci / jak okna andély malovaná s kresbami symbolickými, I v nesmimo sklenutá k etherným obloukủm chrámu tvého, I kde všechny plameny lustrù svých rozžal jsi o Vzkñ̌̌eni." (II, 1-3; IV, 1-2; Vil, 1-4; "Wir grüßen den Frühling deines Werkes! Hundert Hände, unsichtbare / schaffen mit uns. /.../ / Insektenstimmen, wie Schlag geheimnisvollen Uhren, tönen vom Kleefeld herüber /.../. // Wir grüßen den Frühling. der tausend Frühlinge anruft! Hört inr ihre Antwort, / durchdröhnend das Weltall, das von seinen Hoffnungen singt? / Azurne Wiesen, mit Himmelsschlüsseln beglitzert /.../. // Wir grüßen den Frühling! Sieh, es wechseln Tage und Nächte / wie Fenster, von Engeln mit symbolischen Zeichnungen bemalt, / unendlich gewölbt zu deines Tempels ätherischen Wolken, / wo alle Flammen deiner Lüster du zur Auferstehung entfacht." Übers. v. O. Pick.)

Das Postulat der vita activa - in der Symbiose mit dem Schmerz als Antriebsfaktor stellt Biezina auch in seiner Korrespondenz (1898-1899) und in den Essays klar in den Vordergrund: "Nedovedu chápati żivơ bez bolesti. Povażuji každou radost, která nebyla bolesti zaplacena, za nedovolenou /.../. Bez krásy. Celý problěm spocivá v poznáni spravedinosti. Trpěti

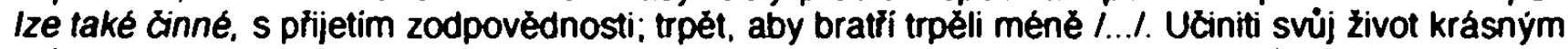
krásou ideje. cinu, odvahy mènici bolest ve vitězstvi /.../ jaká básen̆! Podałi se mi kdy dáti ji nesmrtelnou formu? 463 Es erhebt sich die Frage, was die rekurrenten Lexeme des 'schöpferischen Schaffens' ("Činnost" / "Aktivität"; "Čin" / "Tat"; "stavba" bzw. "stavět" / "Bau" / "er-bauen"; "Arbeit" / "práce": "rozkoš práce" / "Lust der Schaffens" sowie zahlreiche, das Kunst-Handwerk bezeichnende Lexeme), die in Stavitelé chrámu eine eigene semantische Isotopie bilden. im kosmogonisch-eschatologischen Modell konnotieren. Man kann, so scheint es, vom $D$ y $n$ a $m$ is $m$ u s des $L$ e be n s sprechen. d. h. vom Leben und der Vollständigkeit seiner Entfaltung. Dieser Dynamismus entspringt der Sehnsucht: "das eigene Leben schön zu machen durch die Schönheit der Idee, der Tat, der Kühnheit, die den Schmerz in Sieg verwandelt /..." ("u c i i n i ti svưj život krásným krásou ideje, činu, odvahy věníci bolest ve vitezzstvi /... $\%$ ). Das Ganze, die Einheit des Lebens, scheint aber nur dann realisierbar zu sein, wenn man auch das Mannigfaltige, Viele, Verschiedene in die Lebens-Bewegung und in die schöpferische Entwicklung integriert. Der gemeinsame Nenner ist die Sehnsucht nach der Vollendung.

Kugel überliefert. In Stavitelé chrámu handelt es sich um Glaskugel, was auf die leichte Zerbrechlichkeit dieser Harmonie deuten könnte.

463 Vgl. O. Biezina, Dopisy Annè Pammrové 1889-1905, Praha 1931, Brief v. 10. II. 1898, S. 181. "Ich kann das Leben ohne Schmerz nicht begreifen. Jede Freude, die nicht mit dem Schmerz bezahlt wurde, halte ich für unerlaubt $1 . . .1$. Ohne Schönheit. Das ganze Problem liegt in der Erkenntnis der Gerechtigkeit. Man kann auch aktiv leiden, mit der Übernahme der Verantwortung: leiden, damit die Brüder weniger leiden I.../. Das Leben schön zu machen durch die Schönheit der Idee, der Tat, der Kühnheit, die den Schmerz in Sieg verwandelt /.../ welch ein Gedicht! Wird es mir jemals gelingen inm eine unsterbliche form zu verleihen?". Sperrungen vom Vert. 
nach der Erkenntnis der "Schönheit der Welt" ("krásy svéta") und: der Wahrheit. 464 Bïezina spricht von "strahlender Fülle der Wahrheit" ("zárící p I n o s t pravdy") und später sogar von der "Polyphonie der Wahrheiten" ("polyfonie pravd"). 465 Für das Erschauen der ewigen, absoluten Wahrheit braucht der Mensch die Zeit, in der er sie stufenweise und in einem Prozeß enthüllt, so daß er eigentlich mit immer mehr Wahrheit (mit einer "Polyphonie der Wahrheiten") rechnen muß; er ist immer zum a k ti ve n Tun aufgefordert und er soll nie zu früh von ewigen Wesenheiten sprechen, die es wohi gibt, die er aber vielleicht nicht hat.

Diese Auffassung des aktiven (schöpferischen) Tuns weist überraschende Analogien zu der Auffassung des aktiven Handelns, der "Action", von Maurice Blondel (1861-1949) auf, die er in seiner großangelegten Arbeit L'Action (1893), die ihrerzeit viel Aufsehen erregte, darlegt. Nach Blondel ist das menschliche Subjekt im Universum verwurzelt. Der Mensch hat ein einziges Streben zum Licht. Dies realisiert sich zunächst von der Natur zum Leben, von da zum Geist und von hier zu Gott. Das Universum ist kein statisches Phänomen, es hat seine Geschichte, in der das Sein zu sich selbst kommt. Blondel spricht von einem Aufstieg in der Sphäre des kosmischen, dann des psychischen und schließlich des geistigen Seins. Das Ziel dieses Aufstiegs ist die Vollendung. Dem in den neunziger Jahren aktuellen 'Nihilismus' stellt Blondel die Philosophie des in der christlichen Weltanschauung gründenden a $\mathrm{k}$ ti ve $\mathrm{n} \mathrm{H}$ a n d e In s entgegen. Eine wichtige Rolle spielen dabei die Lehren der Offenbarung, die Blondel der modernen Zeit wieder nahe bringen will. Ein Vorhaben, das an einen anderen (älteren) Zeitgenossen Blondels und Br̈ezinas, an Vladimir Solov'ev, intensiv denken läßt. Für Blondel bewegt sich der Mensch in Raum und Zeit immer schon zur Ewigkeit, so wie die menschliche Gemeinschaft ihren wahren Sinn in der Gemeinschaft der Heiligen hat. Dabei scheint die aktive Teilhabe des Menschen notwendig zu sein; nämlich bei der Heimholung der Welt zu Gott. In diesem Prozeß kommt dem Menschen nicht nur die "noetische", sondern auch die "pneumatische" Aufgabe zu, d. h. die Synthese der auf die finale Einheit zielenden Teile. Nach Blondel ist das Noetische ("pensée noétique"), das als Bindeorgan zwischen Geist und Natur fungiert, auf die Ganzheit ausgerichtet, das Pneumatische ("pensée pneumatique") hingegen, das stets etwas Neues in die Welt einführt, die geprägten Formen und die Vielfalt, Verschiedenheit usw. konstituiert. 466 Von besonderer Relevanz scheint zu sein, daß Blondel - wie auch Biezina - die Bedeutung des Leidens, des Schmerzes und des Todes für die 'Einübung' in das wesentliche, aktive Handeln des Menschen hervorhebt. Blondel betrachtet das Leid als "ein Mittel der Formung" ("un moyen de formation") des menschlichen Selbst. Nimmt der Mensch das Leid und den Schmerz in diesem Sinn aut sich, dann wird das Leid "zum Signum und Objekt der großherzigen und selbstlosen Liebe" ("la marque et l'objet méme de l'amour généreux et détaché"), durch die "im

464 U. Heftrich (Otokar Biezina, Heidelberg 1993, S. 206) spricht von Biezinas "Willen zU absoluter Wahrheit", der in der Zuversicht des Dichters gründet, "es gebe eine letzte Wahrheit, die sich dem Menschen im Lauf der Geschichte schrittweise enthülle". Später noch (nach 1910) gelangte Blezina zu der Überzeugung, die Wahrheit sei "polyphon" (U. Heftrich, ibid., S. 203). "Jak płevésti tento orchestr pravd na jedinou, lidskou leci zachytitelnou formuli. Nevidime. Ze i géniovi dáno jest po celý Zivot zníti jen jednim tónem I... $P$ (O. Błezina, .Fragmenty", in: O. Błezina., Eseje. Olomouc 1996, S. 192; "Wie kann man dieses Orchester von Wahrheiten auf eine einzige. menschlicher Sprache faßbare Formel bringen? Sehen wir denn nicht, daß auch dern Genie während seines ganzen Lebens vergönnt ist, nur in einem Ton zu klingen?"). Es wird wohl die große Aufgabe der Zukunft sein, diese Polyphonie der StimmenWahrheiten zum Orchester zu versammeln und dadurch die eine Wahmeit zu retten

465 Nämlich im Zusammenhang mit Felicien Rops und "allen Künstlern seines Geschlechts" i"všichni umëlci jeho rodu"): "Zcela jasnè citim, że neobsáhli zárici plnost pravdy". ("Ich fühle ganz klar, daß sie die strahlende Fülle der Wahrheit nicht erfaßt haben"; O. Bïezina, Dopisy Anné Pammrové 1889-1905. Praha 1931. Brief vom 16. XI. 1898, S. 191. Im Brief vom 14. IX. 1898 schreibt Bỉezina: "Co dovede ostatnẻ lidská duše vyššino v tom tajemném svêtè kolem nás, nežli vytvołit pohádku o začátku a konci, které na kráse nic neubude, stane-li se pri tom snad - pravdou? Co jest pravda?" ("Was vermag übrigens die menschliche Seele höheres in dieser geheimnisvollen Welt um uns herum, als ein Märchen von Antang und Ende zu erschaffen, das nichts an seiner Schönheit verliert, wenn es dabei vielleicht - Wahrheit wird? Was ist Wahmeit?").

466 Vgl. hierzu: Peter Henrici, .Blondels 'Action' im Lichte der klassischen Philosophie", in: Theologie und Philosophie, 64, 1989, S. 161-178. Vgl. auch: Ulrich Hommes, .Das Sprechen von Gott. Zum ontologischen Argument in Blondels Philosophie der Aktion", in: Analecta Anselmiana, 4. 1975, S. 309-316. 
Menschen ein neues und mehr als menschliches Leben entsteht" ("placer l'action parfaite dans la passion douloureusse. /.../ c'est ce triomphe de la volonté qui /.../ engendre dans l'homme une vie nouvelle et plus qu'humaine"). In der Sprache Biezinas: "Trpęti lze také č i n n è s s prijetím zodpovèdnosti; trpèt, aby bratrí trpéli méné I...." (An A. Pammrová. 10. II. 1898; "Man kann auch aktiv leiden, mit der Annahme der Verantwortung; leiden, damit die Brüder weniger leiden". Sperrung vom Verf.) Im Brief vom 12. XI. 1898: "I../ bolest souvisi s tajemstvim viny a znovuzrození, pïinási nová osvětleni żivota a v zlato. tajemnou permutaci, promĕhuje nižši útvary snu; je viditelným znamením Milosti /... $/$. ("I.../ der Schmerz hängt mit dem Geheimnis der Schuld und der Wiedergeburt zusammen, er bringt eine neue Beleuchtung des Lebens und durch eine geheimnisvolle Permutation verwandelt er niedere Gebilden des Traumes zum Gold; er ist ein sichtbares Zeichen der Gnade $(. . . \mu$ ). Das Leiden begreift Blondel als "Wirkung und gleichsam Akt der Liebe" ("l'effet et comme l'acte méme de l'amour"). Die Annahme des Leides ermöglicht auch ein neues Verständnis des Todes. Im Leid antizipiert der Mensch gewissermaßen den Tod: "die Tat schle chth in " ("l'acte par excellence") ${ }^{467}$ Die 'Mortifikation' ist der Weg. auf dem der Mensch zum Leben kommt, nach dem er sich sehnt. Das totale Sichübersteigen im Tod bedeutet die Antwort des Menschen auf den Anruf des Absoluten. Die "Löcher" des Daseins werden als einzige Möglichkeit betrachtet, dem wahren. höheren Leben Platz zu verschaffen. -

Bei Bỉezina heißt es: "Nejistoty odmlčuji se, nebot poznávaji, že existuje absolutni pravda a všechny myšlenky jako kvẻty, vonné sladké, jedovatẻ i léčivé że rostou na cesté vedouç $k$ ni. Že je mravni zákon a że je clovéku urCeno vyjasniti si staletými bolestmi jeho tajemstvi. Že každé hluboké poznáni života házi světla na mystické soumraky smrti. I.../ Jen někdy, v okamżicich zapomenutí na sebe, kdy naše rozpjatá ramena měla dosti sily objati tisice bratrí, zaléhá k nám jejich vưnẻ jako halucinace a omamuje nás tak, že ji považujeme za poselstvi jiného světa. Bázen̉ smrti je svědectvim, že jsme nedovedli poznati krásy života" (Perspektivy / Perspektiven, Essay. 1898). 468

Ähnlich im Essay Dilo smrti (Das Werk des Todes, nach 1900):

"Miliony lidi umiraji, aniž okusili pravé chuti smrti, jako umiraji, aniž poznali lásku a skrytou nádheru světa, jejž opouštěji. I.../ heroism začiná teprve tam, kde duch voli smrt pozemskou vědomè, s plným, mocným, osıñujicim vẻdẻnim jeji ceny, aby ji sloužil dílu života. /... / Bázen̉ płed smrti ukazuje. že nemáme pravé souvislosti s kosmickým duchovým životem a že jsme jako žoldnéri, kter̂́ neznaji. prő̌ maji státi na svém mistě $v$ ohni boje. takže je nutno udržovati je na bojišti hrüzou". ${ }^{469}$

Von dieser Auffassung des Leides und des Todes als eines Wegbereiters der immerwährenden Fülle, des Lebens und der Wiedergeburt, führt der Weg zur Symbolik der eschatologischen Endzeiterwartung, die in einem hohen Maße an der Konstituierung des kosmogonisch-eschatologischen Welt-Modells partizipiert und die in einem

467 Alle zitierten Stellen aus Blondels .L'Action" stammen aus der Ausgabe: $M$. Blondel, L'Action. Essai d'une critique de la vie el d'une science de la pratique. Paris 1950. S. 380-382. Deutsche Ausgabe: M. Blondel, Die Aktion. Versuch elner Kritik des Lebens und einer Wissenschatt der Praktik, übers. v. Robert Scherer, Freiburg i. Br. - München 1965.

$468 \mathrm{Vgl}$. O. Biezina. Eseje, Olomouc 1996. S. 29. "Zagende Unsicherheit versinkt in Schweigen, da sie erkennt, daß eine absolute Wahrheit existiert und das alle Gedanken wie Blüten, duftige, süße, giftige, wie heilende, auf dem zu ihr führenden Wege wachsen. Daß es ein Sittengesetz gibt und daß es des Menschen Bestimmung ist, durch jahrhundertelangen Schmerz sein Geheimnis sich zu erschließen. Daß jede tiefere Erkenntnis des Lebens Lichtstreifen wirtt auf das mystische Nachtgewölke des Todes. I... N Nur manchmal, in Augenblicken, da wir uns selbst vergessen, flüchtet, wenn unsere offenen Arme Kraft genug besaßen, um Tausende von Brüdern zu umarmen, ihr Duft wie Halluzination zu uns und betäubt uns $s 0$, daß wir ihn für eine Botschaft fremder Welt ansehen. Todesfurcht ist immer ein Zeugnis dafür, daß wir nicht imstande waren, die Schönheit des Lebens zu erkennen". Übers. v. E. Saudek und F. Werfel.

469 Vgl. O. Blezina, Eseje. Olomouc 1996, S. 89-90, 96. "Millionen von Menschen sterben, ohne den wahren Geschmack des Todes zu kosten, so wie sie sterben, onne die Liebe und die verborgene Herrlichkeit der Welt, die sie verlassen, zu erkennen. I.../ der Heroismus beginnt erst dort, wo der Geist den irdischen Tod bewußt, mit vollem, mächtigem, blendendem Wissen seines Preises wählt, um damit dem Werk des Lebens zu dienen. I.../ Todesfurcht zeigt, daß wir den Zusammenhang mit dem kosmischen geistigen Leben nicht haben und daß wir wie die Söldner sind, die nicht wissen, warum sie auf ihrem Platz im Feuer des Kampfes stehen sollen, so daß es nötig ist sie auf dem Schlachtfeld durch das Grauen zu halten". 
selbständigen Kapitel eigehender dargelegt wird. Im folgenden soll die Symbolik des Tempel-Baus beleuchtet werden.

Das eschatologische Vollendung-Motiv par excellence ist das Titelmotiv des TempelBaus, das man in diesem Kontext sowohl in bezug auf die hellenistische (Philon von Alexandrien) als auch auf die neutestamentliche Tradition interpretieren kann. Es ist eine in ikonographischen Gleichungen - semantisch variable Größe (als Aut-Bau. Tempel- oder Turm-Bau usw.), die kosmologische, gnostische, anthropologische ${ }^{4} \%$ oder neutestamenttiche (im Sinne von Oikodomé / Aufbau) Konnotationen aufweist.471 In der neutestamentlichen Tradition kommt die Symbolik des Bauens in einer dialektischen Beziehung mit der des endzeittichen Zerstörens vor, das die Propheten verkünden. Wie noch zu zeigen sein wird, greift Bïezina in einigen adventistischen Gedichten des Zyklus (Hvëzd hasnou tisice... I Erlöschen tausende Sterne..., Proroci / Die Propheten u. a.) auch auf diese Bedeutung zurück. Die Vorstellung von den (irdischen bzw. 'mikrokosmischen') "Baumeistern" koinzidiert mit der Vorstellung vom "Höchsten" als dem 'Architekten' des xóouos. Gott als 'Architekt' ist ein Urbild technischer Herkunft, das in der Bibel in mannigfaltigen Variationen vorkommt. 472 in dieser Vorstellung kommen sowohl der Schöplungsgedanke als auch die Endzeiterwartung zusammen. In der Reich-GottesErwartung erscheint der "Höchste" als der Baumeister des himmlischen Jerusalems, das vom Himmel herabsteigt (Offenbarung Johannis, 21, 10-12). Im Prinzip macht Br̈ezina nichts anderes, als daß er die a r ch a i s ch-m y th i sche (biblische) Vorstellung Gottes als des Werkmeisters, Töpfers oder Baumeisters re-aktualisiert. Das gilt auch für den Gedanken der aktiven, schöpferischen Mitarbeit des Menschen am Plan des creator macrocosmi, der sich bereits im Neuen Testament findet. $473 \mathrm{Im}$ Gedicht Huzzd hasnou tisice... (Ertöschen tausende Sterne...) steigert sich der Gedanke vom Menschen als dem Mitarbeiter des "Höchsten" bis zur Vorstellung einer (spektakulären) säkularisierten Utopie der Menschheitszukunft: "Retézem magickým zlé sily spoutáme. / A donutíme zem, by rozkvetla, jak jestě nekvetla, I až mezi rǔ̉emi vstríc pưjdem nesmrtelnosti" (VII, 2-4; "Wir binden die bösen Kräfte mit magischer Kette an. / Und zwingen die Erde zu blühen, wie sie noch niemals geblüht, / und schreiten durch Rosen der Unsterblichkeit zu"). Doch andererseits kann auch diese kühne Vorstellung als Reaktualisierung des alttestamentlichen Schöpfungsberichtes begriffen werden. 474 Im Hinblick auf die Semantik der kreativen Arbeit symbolisiert der Tempel-Bau in Stavitelé chrámu jene aktive Teilhabe des Menschen an der Vollendung der Schöpfung und an der Wiederherstellung der kosmischen Einheit. Der Mensch soll nun die Mitverantwortung für das Gelingen des Tempel-Baus übernehmen, er soll seinen Beitrag leisten und selbst schöpferisch tätig werden. Nur dadurch kann er zum freien Mit-Arbeiter des "Höchsten" werden. Dabei betont Blezina mit allem Nachdruck auch in seiner Korrespondenz und in seinen Essays die Notwendigkeit der Synthese der Kunst- und Lebensschöpfung; die Kunstschöpfung ist der Weg zum (künftigen) "gesteigerten", geistigen Leben: "Ale prảce, již vykonává umêní, je touż praci, $k$ niż smểuje veškerý żivot zemé. Je to pokracováni tvưrciho díla, které položilo hvězody jako základni kameny svè stavby a obraznost jako most mezi světy

470 Vgl. dazu: "Er aber redete von dem Tempel seines Leibes" (Joh. 2, 21). Diese metaphorische Bedeutung kommt offensichtlich aus der gnostischen Tradition, in der "Bau", "Palast" oder "Haus" als anthropologische Termini für den menschlichen Körper verwendet werden. Der Tod bedeutet den Zusammenbruch des irdischen Hauses und das Ablegen des körperlichen Gewandes, um den himmlischen, pneumatischen (soma pneumatikon) zu empfangen. Vgl. Philipp Vielhauer, Oikodome. Aufsätze zum Neuen Testament, München 1979. S. 100ff. Im johanneischen Sinne bezieht sich diese Symbolik bekanntlich auf den Tod und die Auferweckung, deren doch die Glaubenden teilhaftig werden, denn die Glaubenden sind mit Christus zu einem 'Leib' ( $(\tilde{\omega} \tilde{\omega} \mu \alpha)$ verbunden.

471 Ein aufschlußreiches Ergebnis könnte in diesem Zusammenhang eine komparative Untersuchung zur Sakralbau-Symbolik des lyrisch-epischen Zyklus Karolinská epopeja (Karolinische Epopōe, 1896) von Julius Zeyer ans Tageslicht bringen.

472 Vgl. z. B.: "/.../ die Stadt, deren Baumeister und Schöpter Gott ist" (Hebr. 11, 10).

473 "Wir sind Gottes Mitarbeiter; inr seid Gottes Ackerwerk und Gottes Bau. I.../ Ich nach Gottes Gnade, die mir gegeben ist, habe den Grund gelegt als ein weiser Baumeister; ein anderer baut darauf." (1. Kor. 3, 9-10)

474 "Und Gott segnete sie und sprach zu innen: Seid fruchtbar und mehret euch und füllet die Erde und machet sie euch untertart". (Gen. 1, 28) 
viditelnými a neviditelnými. Nemủže tedy bỷti uměni proti životu. /... / Nebot umèni jako żivot jest vláda nad chaosem I... ${ }^{\mu} .475$ Auch Blondel begreift das Kunst-Schöne als Ferment des geistigen Lebens. Die Kunst habe eine metaphysische Funktion und sei ausgerichtet auf ein höheres, transzendentes Ziel. Bliebe es bei "l'art pour l'art", verfehle die Kunst inr inneres Gesetz. ${ }^{476}$

\subsection{1 'Risiken', 'Pflichten' und 'Privilegien' der Kunst- und Lebens-Schöpfung Stavitelé chrámu (Baumeister am Tempel)}

.Snili o /..J závrarich boje. / signálech jizdy. sladkosti

nehezpecenstvi /...J. Snili o rojkošich nejisioty a hry /...J".

"Sie träumsen vom /... Taumel des Kampfes, I von Fahrtsignalen.

Süße der Gefahr I..J. Sie träumten von der Lust der Unsicherheit

und des Spiels /..."."

Stavitelé chrámu

"Und ich sah keinen Tempel darin: denn der Herr.

der allmächrige Gotr, ist ihr Tempel/.../".

Offenbarung Johannis. 21,22

\section{Stavitelé chrámu}

Viděli jsme zástupy nesčisiné. Ponurou majestátnosti věcí

kráceli smutni. Cizí byly si duše, jak by každá z jiného světa

po tajemném ztroskotání zachránila se na zem.

I snily o svých ztrátách.

5 O samotách uprostłed magických lesủ, nad nimiž slunce podobno ptáku zlatými kfídly nekonex́nými brázdilo ether; celým vesmírem letěla jeho píseñ o slávě života harmonického

o zázracích tvưrčiho jitra $v$ zahradách země a podmołských nížin.

$\checkmark$ modrých preriích vzduchu a vody:

10 v oceány se sklánělo v Žíni a pijic rozvlnilo je boułí.

$v$ jeskyné ametystové pod ledovci západủ do hnizda horských rưži క̌lo spáti

a jeho sen viditelný. hra tisícủ bratrských sluncí.

tancicích $v$ rytmech hudby melancholické. vznásel se nekonečnostmi

zárící láskou. Noc dávala hovotit kvêtừm o jejich lexxivé síle

IS a opojení. jež drímá v hroznech a máku. Znali jemná slova.

jež jako rozhozené zmí lákají ptáky. A zvî́ata lesni.

která neokusila krve. je př́tulnĕ navštěvovala.

Snili o městech, jež vládnou nad zeměmi. O rozkoši práce.

475 Vgl. O. Bł̌ezina, "Zasvěceni života”, in: Eseje. Olomouc 1996. S. 43. (Die Weihung des Lebens): "Aber die Arbeit, die die Kunst leistet, ist die gleiche Abeit, dahin das Gesamtleben der Erde gerichtet ist: Forttührung des Schöptungswerkes, das Sterne als Grundsteine zu seinem Bau gelegt und die Einbildungskraft als Brücke geschlagen zwischen sichtbaren und unsichtbaren Welten. Es kann daher keine Kunst geben, die gegen das Leben gerichtet wäre. /.../ Denn Kunst ist wie Leben, die Herrschaft des Gesetzes über das Chaos /... . Übers. v. E. Saudek.

$476 \mathrm{Vgl}$. M. Blondel, La Pensée II. La responsabilité de la pensée et la possibilité de son achèvement, Paris [2. Aufl.] 1954, S. 128tt. Deutsche Ausgabe: M. Blondel, Das Denken II. Die Verantwortung des benkens und die Móglichkeit seiner Vollendung. Freiburg i. Breisgau-München 1956. 
slavnostním zvonění kladiv, zkroceni ohně, závratích boje.

20 signálech jízdy, sladkosti nebezpecenství, hrdosti dávajícich. smělosti ruky, jež házi tajemné sítex nad národy.

a o slovech. jež jako smolné věnce padají na mèsta neprátelská.

O pýse orlư na horách osamexlých, jejichž vífící křidla

rychlostí letu zdají se nehybné ztuhlá jak z kovu

25 a stači zrakuim protínajícím soumrax̌ný vesmír jak hvězdy.

O rozkoši zniðení, triumfální jízdě cyklonủ nad rovinami,

požárech lesủ, ledových vichficích pólù, o démonickém výsméchu živlù.

které $v$ ţinéení płetrhaných łetězủ blesky vybijeji se $v$ chaos.

O tragické Žízni hledajících, honbě, která tajemstvi stîhá

30 cestami nesčetných světư, ústících $v$ jediném světê. zmateně probíhá tisíciletími, čîná na předvěkých pohrebištích

a jako na skoby řěravé ješté, dokuté právě posledním úderem kladiv, na slunce věsí svá tenata neviditelná a lovecké sítě spouští v plamenná mơ̌e, která je tráví

35 jak pavuěiny. A odsouzená hledati věxně mate se mlCeními, která si kolem ní odpovídají $v$ magických dotknutích rukou, $v$ agónii mux̌ených zvî́at, $v$ pozetí zakrytém blesky, $v$ şilenstvi ztrhaných zrakú i v pýse zahrabávající do země stopy, jimiž jsi krácel.

40 Snili o rozkošich nejistoty a hry, rozčileni tržišl, o zmatku tisíce jazykú, pokrikem plnících duši jak pȟistavistě. kam ze vłech mołí se vracejí lodé a kde orgie bázní. nadžji, krve a hłíchu přehlusuji hukot mołí

a pozdravnou sţ̌elbu a orchestry prijízdějicich.

45 A vexer o sladkosti hudby táhnoucí nábłežími jak étemá mlha, do níz se stápí tisíce svêtel, nad rekami, jež jako žily studené záfe zdají se prýstit z mèsíce. O Żenách záhadných. zemdlených tízí své krásy. jež volají milence písnémi zádumx̌ivými. A jejichž šepot

50 a vlnexní కatů zdá se zakleto $v$ kvêtech a dłímotex kełu: bilé. $v$ fosforném jiskłeni drahokamů a rtủ. hali se $v$ soumrak. jak by jich ruce. s pohyby hadú uspávaných kouzlem. házely zmí magické vứné $v$ srdce zapálená jejich zraky a v omamném koưti $k$ odpovédi vyvolávaly duše mrtvých.

55 Ale nejposlednější ze všech (jak jsme zakvileli láskou!), milióny vyděděných, mravenci, ktê̌i vyhmuli se z lomú. otroci, kteři plíźi se żitím jak sady zapovězenými. táhli kolem nás mlð̌ky. Umdlená jejich duše neměla snů. Jen $v$ jiskłení oxi phi úderu rány neozekávané

60 viděli nad sebou klenutí nebes, zxemalé soumrakem věkủ jako strop ponuré dílny začazené prací tisíciletou: dmychaly větry do výhni pod obzorem. $v$ gehennu rudého záru. kde celé pralesy vyvrácené zdály se praskat vln ohnivou tízí. a jako bubliny vyfouklé ze skla, blankyty země objímající.

65 hrajicí duhou a modrem, kopule éterných palácủ stěstí. okna na vrcholu klenby pro svétlo $z$ výsese, se tavily v páfe a kroužily pẽnou po hladinách varu płipraveného. jehož reflex płes celý hvězdnatý zenit se šífil

70 gigantské pohybujíci se stíny promítaly se na ném jak obraz tajemného zápasu kolem věxných ohñủ. 
Mezi nimi sli stavitelé tvého chrámu. Ti jediní ze všech poznávali se znameními. Jako slib jiných nebes a zemé

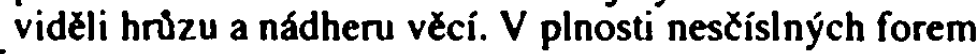

75 cítili prvotní napètí tvého tvưrčino dechu. jež jako Eliášovo světlo ze vక̌ech nejvyšsích linií krásy se jiskři nad krajinami oblaky vékủ zatízenými a ranami blesků ochromí žxernalou ruku odvážlivého. Vykoupením tajemné viny byla jim bolest a práce.

80 Jistotou cesty vniťni radost, nepohnutá. bilá a silná jak slunce. jež. ţ̌eba neviditelné uprostřed boư̌e a noci, dle věčného zákona vládne zemí. Vítězů matku a sestru ve květu tisícileti. na rtech zarděni jitłni, vítali Ženu a souhvězdí letni Orel, Labứ, Delfín a Lyra

85 vstávala v zári do jejich nocí. po dni, který se dloužil. $\mathrm{K}$ milionům trpících bratři bylo posláni jejich jako k najmutí dělniků k stavbè. Ale aby žhavější byla slova najímajicích a ruce odměnujicích horkostí touhy. tvá spravedlnost, silná a vládnoucí smrí.

90 rtům jejich odñala vzpominku na vక̌echnu sladkost země.

\section{Baumeister am Tempel}

Wir sahen zahllose Scharen. Durch der Dinge düstere Majestät schritten sie traurig. Fremd waren die Seelen einander, als hätte sich jede, geheimnisvoll gescheitert, auf die Erde gerettet aus einer anderen Welt. Und sie träumten von ihren Verlusten.

5 Von Einöden inmitten magischer Wälder, darüber die Sonne gleich einem Vogel mit unendlichen Goldflügeln den Äther durchfurchte; durchs Weltall dahin flog ihr Lied von der Hehre harmonischen Lebens. von des Schöpfungsmorgens Wundem in irdischen Gärten und unterseeischen Gefilden. in den blauen Prärien der Luft und des Wassers:

10 tauchte dürstend in Ozeane und trank. da wogten sie stürmisch, ging schlafen in Amethysthöhlen unter Gletscherwolken des Untergangs in Bergrosennestem. und ihr sichtbarer Traum. Spiel tausender Brudersonnen. tanzend zu Rhythmen melancholischer Musik, zog durch Unendlichkeiten glühend vor Liebe. Nacht ließ die Blumen flüstem von ihrer Heilkraft

15 und vom Rausche, schlummernd in Trauben und Mohn. Sie wußten suße Worte. die wie gestreute Kömer die Vögel anlocken. Und die Tiere des Waldes. die kein Blut noch verkostet, besuchten sie traulich. Sie träumten von Städten, die die Länder beherrschen. Von der Lust der Arbeit. von der Hämmer festlichem Iäuten. Bezähmung des Feuers, vom Taumel des Kampfes

20 von Fahrtsignalen. Süße der Gefahr, vom Stolze der Gebenden. Kühnheit der Hände, die geheimnisvolle Netze über die Völker werfen. und von Worten, die wie Pechkränze fallen auf die feindlichen Städte. Vom Stolze der Adler auf einsamen Höhen, deren wirbelnde Schwingen vom eiligen Fluge erstarm wie metallisch erscheinen

25 und den Blicken genügen, die das dämmemde All wie Sterne durchstoßen. Von der Lust der Zerstörung. Triumphfahrt der Zyklone über den Ebenen. Waldbränden, eisigen Polarsturmen und der Elemente dämonischem Hohne. die wie Blitze im Rasseln zerrissener Ketten zum Chaos sich wandeln.

Von der Suchenden tragischem Durste, von der Jagd nach dem Geheimnis,

30 auf Wegen zahlloser Welten, mundend in einer Welt, verwirnt durch Jahrtausende rasend. lauernd auf Gräbern der Vorzeit. 
und wie an noch gluhende, eben vom letzten Hammerschlag geschmiedete Haken. ihr unsichtbares Garn an die Sonnen hängend

und die Jagdnetze tauchend in feurige Meere, die sie verzehren

35 wie Spinnweben. Und verurteilt, ewig zu suchen. wird ratlos die Jagd durch das vielfache Schweigen, das rings um sie laut wird, in magischen Händedruicken, in der Agonie gefolterter Tiere. in blitzverhängter Empfängnis, im Wahnsinn gebrochener Augen und im Stolze, in die Erde vergrabend die Spuren von Deinen Schritten.

40 Sie träumten von der Lust des Spiels und der Unsicherheit, der Erregung auf Märkten, von tausender Zungen Verwimung, mit Geschrei die Seele wie einen Landungsplatz füllend, wohin aus allen Meeren Schiffe kehren und wo Orgien von Angst,

Hoffnung, Blut und Sünde das Tosen des Meeres übertönen. und die Salutschüsse und die Orchester der Nahenden.

45 Und abends von der süßen Musik an Uferstraßen wie Nebel aus Äther, darin tausend Lichter ertrinken. uber Flüssen, die wie Adem kühlen Schimmers vom Monde sich rinnen scheinen. Von Frauen, rätselvoll, matt in der Last ihrer Schönheit, die mit Liedern der Schwermut die Geliebten rufen. Und ihr Flüstern

50 und Wogen der Kleider scheint verzaubert in den Blumen und im Schlummer der Sträucher. sie hüllen sich weiß, im Phosphorgefunkel der Lippen und Edelgesteine, in das Dämmern, wie wenn ihre Hände, wie hypnotisch eingeschläferte Schlangen sich regend, Körner magischen Dufts würfen in die Herzen, von ihren Blicken entzündet, und im betäubenden Rauche die Seelen der Toten aufriefen zur Antwort.

55 Doch die letzten von allen (wie stöhnten wir auf vor Liebe!)

Millionen Enterbte. Ameisen, aus Steinbrüchen quellend, Sklaven, die durchs Leben wie durch verbotene Gärten schleichen. zogen still uns voriber. Nicht hatte Träume ihre ermattete Seele.

Nur im Funkeln der Augen beim unerwarteten Schlage

60 sahn sie ob sich die Wölbung der Himmel, geschwärzt von der Zeiten Gewölk, wie düsterer Werkstatt Diele, verrußt durch tausendjährige Arbeit: fachten Winde die Essen unterm Horizont, Gehenna glühender Röte. wo ganze Urwälder, gefallt, in Feuerwogen zu prasseln schienen, und wie Blasen aus Glas. der Erde Azure umfassend.

65 regenbogenhaft spielend und blau, Kuppel ätherischer Paläste des Gliucks, Fenster am Gipfel der Wölbung für Lichtglanz von oben, schmolzen im Dampfe

bekreisten schäumend die Glätten bereiteten Sudes, dessen Abglanz sich dehnte über den bestimten Zenit und im RuB der Wolken sich fing, wie Goldsand, mit Blut verpicht:

70 drauf projizierten gigantisch sich bewegliche Schatten, ein Bild geheimnisvollen Kampfes um die ewigen Feuer.

Zwischen ihnen schritten die Baumeister deines Tempels. Sie allein unter allen erkannten einander durch Zeichen. Wie andrer Himmel und Erden Verheißung sahn sie die Pracht und das Grauen der Dinge. In der Fülle zahlloser Formen

75 fühlten sie die Urspannung deines schöpferischen Odems. der wie das Licht des Elias aus allen höchsten Linien der Schönheit erfunkelt über Landschaften, belastet von der Zeiten Gewölk, und mit Blitzschlägen lähmt die verkohlte Hand des Verwegnen. Erlösung von geheimnisvoller Schuld waren ihnen Arbeit und Schmerz.

80 Wegsicherheit die innere Freude, reglos, weiB und stark wie die Sonne, die. wenngleich unsichtbar in Nacht und Gewitter. nach ewigem Gesetz herrscht ob der Erde. Die Mutter und Schwester der Sieger in der Jahrtausende Blüte. Morgenrot auf den Lippen, sie grüßten das Weib, und das Sommergestirn Adler, Schwan, Delphin und Lyra

85 stieg glänzend auf in ihre Nacht, nach einem sich verlängernden Tage. 
Zu Millionen leidender Brider kam ihre Sendung wie Dingung von Arbeitem zum Bau. Doch auf daß glühender würden

der Dingenden Worte und die Hände der mit der Wäme der Sehnsucht Entlohnenden. 90

nahm deine Gerechtigkeit, stark und dem Tode gebietend,

0 ihren Lippen das Erinnern an alle Süße der Erde.

Deutsch von O. Pick.

Die vita activa als ein vielgestaltiger Prozeß der Kunst- und Lebensschöpfung gelangt zu ihrer Vollendung in der Symbolik der Tempelerbauung. Durch diese 'schöpferische Tat' par excellence erlangen alle Lebenserscheinungen und Prozesse, die zur Pluralität der Existenz gehören, d. $h$. auch die dissonanten, ein positives Telos. Die Symbolik des (endzeitlichen) Zerstörens (Proroci I Die Propheten, Hvëzd hasnou tisice... I Erlöschen tausende Sterne...) und des $\mathrm{Ne}$ ubaus eines Tempels, die ihren Ursprung in apokalyptischen Weissagungen ${ }^{477}$ hat, deutet in diesem Kontext auf die Tendenz hin, allen Lebenserscheinungen einen 'höheren' (bzw. 'universellen') Gesamtsinn zu verleihen. Der Tempel (bzw. die Kathedrale) stellt nicht nur das mit den Mitteln a Il e r Künste erschaffene Abbild des Himmels (das "himmlische Jerusalem"), den Weltenbau, dar, sondern er repräsentiert die Synthese a ll e r Künste, auch aller ursprünglich sakral gebundenen Kunst-Schöpfungen. 478 Darüber hinaus symbolisiert der Tempel(-Bau) auch die Durchgeistigung a 1 l e r Lebens-Schöpfungen auf Erden.

Der Prolog (V. 1-4) entfaltet eine Massenszene: "Viděli jsme zástupy nesčislné" (V. 1: "Wir sahen zahllose Scharen"). Diese einander fremden Seelen-Scharen ("Cizi byly si duše", V. 2) sind "Schiffbrüchige" aus einer anderen Welt" (V. 3; "Z jiněho světa"), als hätten sie sich "auf die Erde gerettet" (V. 3). Das Motiv des "geheimnisvollen Schiffbruchs" ("tajemné ztroskotáni", V. 3) kommt auch in Proroci (Die Propheten, V. 52, 65-66; s. u. Kap. 5.2.2) und in Zemè vitézú (Das Land der Sieger, V. 46) vor, wo es den Anfang der Schöpfung des kooros markiert; 479 in dem Sinne, daß diese Menschenwelt - und inre

477 Vgl. Mk. 13, 2; 14, 58; Mt. 26, 61; Joh. 2, 21.

478 A. A. Hansen-Löve macht in seinem Aufsatz .Zur Typologie des Erhabenen in der russischen Moderne" (in: Poetica, Bd. 23, 1991, S. 190f.) auf die Symbolik des A r chitekton is Ch-Erhabenen (im AnschluB an Schopenhaver) in der Lyrik und in den theoretischen Schriften $O$. Mandel'stams aufmerksam. Mandel'štam bezieht sich $U$. a. auf $N$. Gogol', für den die gotische Kathedrale "den Gipfel der Baukunst, der niemehr erreicht wurde". (ibid. S. 191) bedeutete, und auf die Revalorisierung der Gotik in der Romantik. Auch R. Lachmann ("Vergangenheit als Aufschub: Die Kulturosophie der Akmeisten", in: R. Lachmann, Gedăchtnis und Literatur, Frankfurt a. Main 1990, S. 368) verweist auf die Vorstellung Osip Mandel'stams, der die "Text-Architektur" mit der gotischen Kathedrale identifizierte (man denke an Mandel'stams Gedicht Notre-Dame aus seinem ersten Gedichtband Kamen' / Der Stein. 1913). In der Dichtung der Akmeisten wird die Architektur zum "Text-Denkmal" der Kultur. Die Erkenntnis. daß gerade die $g$ o t i s $c$ h e Kathedrale den Höhepunkt der europäischen Kunst darstellt, datiert sich übrigens seit der Romantik. Es waren - in der Kunstgeschichtsschreibung - vor allem die Arbeiten des Archäologen und Kunsthistorikers Franz Kugler (Handbuch der Kunstgeschichte. Stuttgart 1841-1842; Geschichte der Baukunst, Berlin 1855), die zu dieser Erkenntnis in einem sehr wesentlichen MaB beitrugen. Die kosmische Symbolik der gotischen Kathedralen untersucht Hans Sedlmayr in seiner Monographie Die Entstehung der Kathedrale, Freiburg i. Breisgau 1993.

479 Explizit in Zemé vítézú (Das Land der Sieger "Hie, věkủ pohnutim, v nẻmż jednou světy potápély se / $v$ hlubiny svẻta tohoto, jak trosky fregat obtiżených bohatstvim. / kđyż skvouci vyjely z tajemných pristavì, / a bourî, které slove stvởenim, se ztroskotávaly" (V. 43-46; "Sieh, in der Regung der Zeiten, in welcher voreinst Welten ertranken / in den Tiefen dieser Welt, wie Wracks von Fregatten mit kostbarer Fracht, / die prāchtig entsegelt geheimnisvoller Bucht. I und in dem Sturme Schifforuch erlitten, der Schöpfung genannt ist"). Noch expliziter kommt dieser Gedanke im Essay Skryté déjiny (Verborgene Geschichte) zum Ausdruck: "Dẻjiny zraku! Pruni procitáni ducha zatiżeného jestee temnotou noci, z niż vyšel, úżas trosečnika probuzeného privalem slunce. jenż pohliži na ostrov zachránéni svého, priliš sláb, aby si mohl vzpomenouti na tajemné své ztroskotáni a spoluplavce své cesty ve véchosti“ 10 . Bỉezina, .Skryté déjiny”, in: O. Biezina, Eseje. hrsg. v. Petr Holman, Olomouc 1996. S. 106; "Die Geschichte des Augenlichtes! Das erste Erwachen des Geistes, auf dem noch das Dunkel der Nacht lastet, aus dem es herausgetreten ist. das Erstaunen des von der Sonnenflut auferweckten Schiffbrüchigen, der die insel seiner Rettung 
Geschichte - aus (der Geschichte) einer "unsichtbaren" (transzendenten) Welt, die einen "Schiffbruch" erlitten hat, erwächst, um am Ende der Zeiten wieder in eine unsichtbare Welt überzugehen. Der "Schiffbruch" der nicht 'sichtbaren' Welt scheint also die Entstehung einer neuen ('sichtbaren'/phänomenalen) Welt gleichsam zu initiieren. Mit dieser Vorstellung, die mythisch-mystischen Ursprungs ist, betritt Biezina erneut das Feld gnostisch-kabbalistischer Überlieferung. Die Erde wird im Prolog (V. 1-4) als ein Zufluchtsort konkretisiert. Die Seelen "träumen von ihren Verlusten" ("I snily o svých ztrátách", V. 4). ${ }^{480}$

Nun entfaltet Brezina eine erstaunlich mannigfaltige wie auch komplizierte Typologie der Lebensformen, deren Vielfalt den im Text thematisierten (individuellen; "Cizi byly si duše, jak by každá /.../" / "Fremd waren die Seelen einander, als hätte sich jede [einzelne] I... ${ }^{\prime}$. V. 2) Traum-Visionen entspricht. Die "Verlusten" ("ztráta"), von denen die Seelen träumen, beziehen sich auf die (verlorene) vorzeitliche ldylle, in der alle Dissonanzen zu einem wohlklingenden Akkord und Einklang, zu einem Lied "von der Hehre harmonischen Lebens" ("o slávě života harmonickẻho", V. 7) 'komponiert' waren. Dieser Vorstellung liegt offensichtilch das Wissen vom Urgesetz des Universums, das das Tongesetz ist, zugrunde. 'Belebte' und 'unbelebte' Substanzen in ihren zahllosen Erscheinungsformen sind Klang-Phänomene. Das Gesetz aller schöpferischen Prozesse, das Sein der Dinge, ist im (Ur-)Phänomen 'Ton' fixiert. In Se smrt' hovorí spíci... (Mit dem Tode reden die Schläfer...) wird die (vorzeitliche) Idylle als ein Traum-Zustand des wonnigen Unbewußten dargestellt, in das die "Schläfer" von der "Wonne des ewigen Rh y th m us " gewiegt wurden:

"Dni naše nejsladši byly jak dusný sen štastných z jiného světa, / 2 něhoż procitnou bledi a s chvěnim / po celă léta si ho pripomínaji ... // Tisícileti ¿ekali jsme ve tmè tajemstvi tvêho / ukolébáni lahodou vêčněho rytmu $v$ drimotu nenarozených / jak stalo se, że světlo této zemé vniklo aż $v$ hloubku odvěkẻ noci / a otevielo nám ođ̃ pro słzy a slunce? // Ach, spáti ješté tisícileti!" (V. 26-33; "Unsere süßesten Tage glichen dem lastendem Traum der Glücklichen anderer Welten, / aus dem sie blaß und mit Zittern erwachen / und Jahre hindurch sich seiner erinnern ... I/ Jahrtausende lang harten wir in deines Geheimnisses Dunkel, / von der Anmut des ewigen Rhythmus in den Schlummer der Ungeborenen gewiegt: / wie kam's, daß das Licht dieser Erde bis in die Tiefen der ewigen Nacht drang / und die Augen uns auftat für Trănen und Sonne? // Ach, Jahrhunderte noch zu schlaten!").

Doch die postulierte kreative Teilhabe des Menschen an der Kunst- und LebensSchöpfung (am Tempel-Bau) fordert jenen "geheimnisvollen Schiffbruch", das Erwachen aus dem wonnigen Traum, selbst wenn dieses Erwachen die Risiken der Existenz nach sich zieht. An dieser Stelle soll zunächst die Vision der (vorzeitlichen) Idylle näher betrachtet werden. Es ist die (orphisch-apollinische) Sphäre der Harmonie, des SonnenLichts, der Kreativität, des (hörbaren) Logos und der musica divina als Manifestation der Übernatur dessen, der alle Seinsordnungen geschaffen hat: "celým vesmírem letěla jeho píseñ o slávẻ života harmonického, I o zázracích tvưrčho jitra" (V. 6-7: "durchs Weltall dahin flog ihr Lied von der Hehre harmonischen Lebens, / von des Schöpfungsmorgens Wundern"): "hra tisicủ bratrských slunci, / tancicich v rytmech hudby melancholicke" (V. 12-13: "und ihr sichtbarer Traum, Spiel tausender Brudersonnen, / tanzend zu Rhythmen melancholischer Musik"): "Znali jemná slova, / jež jako rozhozené zrni lákaji ptáky" (V. 15-

beschaut, allzu schwach, um sich seines geheimnisvollen Schiffbruches und der Mitschwimmer seiner Fahrt in der Ewigkeit entsinnen zu können!").

480 Vgl. dazu das Motiv des Verlustes im Prolog-Gedicht VIádnouci... (Herrscher...) von Vêtry od pólu (Passatwinde): "V extasi lásky chci zpivati bratrskỳm dušim, / że neni bolesti většich, I nežli jsou ztracená vitêzstvi jejich" (V. 29-31; "In Ekstasen der Liebe will ich verbrüderten Seelen singen: Keine größeren Schmerzen sind / als eure verlorenen Siege"). Eine ăhnliche Konnotation weist das 'Verlust'-Motiv auch in Láska (Liebe, VP, V. 54; Kap. 4.3.3) auf. In diesen Gedichten geht es um den (drohenden) Verlust der Erkenntnis, des Vertrauens und der Sicherheit der eschatologischen Existenz; eine Erkenntnis, zu der man durch die Hingabe an die drei Charismata - Hoffnung - Glaube - Liebe - gelangt. In Stavitedé chrámu bezieht sich der Verlust offensichtlich auf den Zustand vor dem "geheimnisvollen Schiffbruch", d. h. auf den Zustand vor der Schöpfung. Die "Rettung" in die irdische Existenz nennt Biezina "schmerzvoller Traum des irdischen Lebens" ("bolestný sen pozemskẻho żivota", zit. nach: M. Cervenka, .Błezinùv výklad Svitáni na západè", in: Ders., Styl a vyznam, Praha 1991, S. 32). Es scheint, daß das Träumen der Seelen nach der Schöpfung (nach dem "Schiffbruch") sowohl 'retrospektiv' (vor allem in der ersten Sequenz, V. 517) als auch 'prospektiv' (die zukünftige irdische Existenz betreffend) orientiert ist. 
16: "Sie wußten suße Worte, I die wie gestreute Körner die Vögel anlocken"). ${ }^{481}$ Die Korrelation "slova" ("Wörter") - "zrni" ("Körner", im Sinne von Logos spermatikos) indiziert die solar-apollinische Sphäre (vgl. das Gedicht Apotheosa Klasú / Apotheose der Ähren). Der letzte Vers dieser Sujetsequenz konkretisiert das Modell einer (orphisch-)idyllischen, harmonisch komponierten (nach den Tönen "seines Liedes" / "jeho piseñ", V. 7) NaturWelt des goldenen Zeitalters: "A zvirata lesni, / která neokusila krve, je prítulnè navštěvovala" (V. 16-17; "Und die Tiere des Waldes, / die kein Blut noch verkostet, besuchten sie traulich"). Aber dieses solare Reich der Harmonie und der transzendenten Liebe (V. 14) ist für die "Millionen Enterbten" ("miliony vydëdëných", V. 56) - infolge eines "geheimnisvollen Fluchs"- für ewig verloren: "Celý ráj štěstí, ztracený věky. / leži zaviený mezi námi. Jen nejčistši snèni, letici v ether, I dovede pohlednout z výse do jeho zárících sadü" (Se smrti hovorii spici.../Mit dem Tode reden die Schläfer ..., V. 60-62; "Des Glücks für ewig verlorenes Eden, / verschlossen liegt es zwischen uns da. Nur der reinste, zum Äther aufsteigende Traum / vermag von oben in seine strahlenden Gärten zu blicken"). Es wird die Aufgabe und das Ziel der "Baumeister" sein, diese harmonisch aufgebaute kosmische Idylle in der Sphäre der Menschenwelt im/als Tempel-Bau zu restituieren.

Das Gegenmodell zu diesem harmonischen locus amoenus, zu dieser "himmlischen Stadt" ("nebeskẻ mẻsto", Télo / Der Körper, SCh, V. 19), 482 stellt die in der zweiten Sequenz (V. 18-22) konstituierte irdische Stadt(-Welt) dar: "Snili o mèstech, jež vládnou nad zemémi" (V. 18; "Sie träumten von Städten, die die Länder beherrschen"). Diese Stadt(-Welt) charakterisiert sowohl "die Lust des Schaffens" (V. 18; "rozkoš práce") als auch - paradoxerweise - "die Lust der Zerstörung" ("rozkoš zniceni", V. 24) und "die Lust der Unsicherheit und des Spiels" (V. 40; "rozkos nejistoty a hry"). 483 Das harmonische (Sonnestrahlen-)Lied wird in der Sphäre der Menschenwelt zum "festlichen Läuten der Hämmer" ("slavnostnim zvonẻni kladiv", V. 19). Die "Stadt" im gleichnamigen Gedicht (Město) aus dem Zyklus Vẻtry od pólư ), die in der Sphäre der Einsamkeit, Isolation und Fremdheit situiert ist, bewohnen die Schatten der Revenanten, die sich unter die Lebenden mischen: "a stiny, jež vystouply z hrobú, bloudily uprostr̈ed davü" (V. 8; "und die Schatten, die aus den Gräbern emporstiegen, streiften mitten der Massen herum"). Welche Attribute weist die "Stadt" innerhalb des kosmogonisch-eschatologischen WeltModells auf? Es ist der kämpferische "Taumel" (V. 19), das "Feuer", die aufregende Gefahr und das Chaos als Ursprung aller vitalen Prozesse und als (notwendige) Voraussetzung für die Erneuerung des Welten-Baus. In Hvězd hasnou tisice... (Erlöschen tausende Sterne...) kommt dieser Gedanke explizit zum Ausdruck: "Co ze sopečných Cerných kamenú Gehenny podzemskě jsme stavẻli, / at padne do ssutin! / ... / Z bélostných slunci touži stavéti jak z mramoru $/ . .$. " (IV, 1-2, V, 3; "Es sinke, was wir türmten aus der Gehenna schwarzem Vulkanblock, / in Schutthaufen nieder! /... Mit weißen Sonnen wie mit Marmor wollen sie baun $/ . . . \%$ ). Doch in der urbanen Welt erlangt das "schöpferische Wort" (V. 7-8) eine andere Bedeutung. Diese geradezu aggressiv schöpferische dymamis läßt die "feinen Worte" (V. 15; "jemná slova") der harmonisch-idyllischen Natur-Welt in "glühende" Worte, "die wie Pechkränze fallen auf die feindlichen Städte" (V. 22; "jeż jako smolnẻ vẻnce padaji na města nepřatelská"). $d$. $h$ in kataklysmatische und gleichzeitig 'transformıerende' Worte transmutieren, die die "feindlıchen" (V. 22; "mèsta neprátelská") aus den "s ch w a r z e n ", gehennalischen Steinen erbauten - "Städte" zerstören, um sie "mit we ißen Sonnen wie mit Marmor" (Hvězo hasnou tisice...) neu erbauen zu können. ${ }^{484}$ Auch diese Polarität von Zerstörung und Neuerschaffung gehört zur Pluralität

481 In dieser Sphāre ist auch das Dionysische (als desintegrierende Berauschung) prāsent, allerdings nur potentiell: "/.../ opojeni, jeż dřmá v hroznech a máku" (V. $15 ; \%$. I der Rausch. schlummernd in Trauben und Mohn").

482 In Se smrti hovori spici... (Mit dem Tode reden die Schläfer...) auch "věcuén mésto" (V. 116: "ewige Stadt")

483 Diese scheinbar paradoxe Parallelitāt ist offensichtlich auf die schon erwāhnte wechselseitige Beziehung von "Bauen" und "Zerstören" zurückzuführen. Diese Vorstellung läßt sich mit zahlireichen alt- (Jer. 24, 6; 31, 28; Ez. 36, 36; Ps. 28, 5 u. a.) und neutestamentlichen (Mk. 13, 1f: Mk. 14, 58; Mt. 26, 61; Joh. 2, 19 u. a.) Zitaten belegen. Die "Bauenden" der irdischen Städte sind die "Sklaven" ("otroci") aus den Steinbrüchen der Gehenna (V. 57, 62).

484 Die Metapher der glühenden FunkenWorten, die die "Schlafenden" versengen $(=$ sie erwecken/rufen zur Entscheidung; man erkennt hier die christliche Re-Aktualisierung des gnostischen 'Weckrufes' wieder), ist daher positiv konnotiert. Vgl. auch: "oblaky jisker pokryly 
des (heils-geschichtlichen) Seins des Menschen, zu den Risiken seiner Existenz, so wie der Hochmut der aristokratischen Künstler-Schöpfer, deren Personifikation der "Adler" ist, von denen die Seelen der Schiffbrüchigen in der dritten Sujetsequenz (V. 23-25) träumen, das Risiko des ominösen Nicht-Erkennen-Könnens der Botschaft (des "Höchsten") nach sich zieht: "[Snili] O pýše orlư na horách osamẻlých, jejichż vírici krídla / rychlostí letu zoaji se nehybné ztuhlá jak z kovu / a stači zrakưm protinajicím soumračný vesmír jak hvẻzờ". I... I. ".../ v šilenstvi strhaných zrakú i v pỷse / zahrabávajici do zemé stopy, jimiż sı krácel" (V. 23-25, 38-39). Auch der Glaube ist stets mit einem gewissen Risiko verbunden (man denke an die "Wette Pascals"), wer sich aber gegen die Offenbarung verschließt, wer im Hochmut "die Spuren seiner Schritte in die Erde vergräbt" (V. 39), der verurteilt sich selbst zum ewigen Irrsal im tellurischen Labyrinth und zur Qual des "tragischen Durstes", in SCh das Symptom des Nicht-HörenNestehen-Könnes der kerygmatischen Botschaft: "[Snili] $O$ tragickě zízni hledajícich, honbè, která tajemstvi stihá", V. 29; "[Sie träumten] Von der Suchenden tragischem Durste, von der Jagd nach dem Geheimnis"). Die Geheimnisse der Schöpfung bleiben für jeden verborgen ("v počtí zakrytèm I... $r$, V. 38; "), der nur mit den Möglichkeiten des Natürlichen (bzw. Rationalen) rechnet. Der Versuch, die vom "Höchsten" verborgene geschöpfliche Wirklichkeit durch die hochmütige Expansion in die noch nicht vollendete Schöpfung 485 des göttlichen xóouos zu ergründen, rächt sich mit tragischem Fluch des ewigen Suchens: "A odsouzená hledati vểnè $I \ldots /$ " $(V$. 35; "Und verurteilt ewig zu suchen (... $\mu^{\mu}$ ). Das Privileg der Erfahrung der schöpferischen Potenz des creator macrocosmi in ihrer grandiosen Mannigfaltigkeit, "in der Fülle zahlloser Formen" ("V plnosti nesčislných forem cítili prvotni napét tvẻho tvưrcího dechu", V. 74), widerfährt erst den Baumeistern des Tempels.

Die Vision einer Groß-Stadt(-Welt) der zivilisatorischen Moderne, die die Sphäre der "Unsicherheit und des Spiels" repräsentiert, wird in der vierten Sequenz (V. 40-54) als die Stadt "Babel" (als Antipol zur "himmlischen Stad") konkretisiert, in der das schöpferische Wort zum chaotischen, unverständlichen Reden, zu einem Wirrwarr "tausender von Sprachen" verschmilzt: "Snili /.../ o zmatku tisice jazykú, pokrikem plnícich duši jak prístaviště" (V. 40-41). Diese Stadt-Welt ist zugleich das Territorium des Triebhaften, ("kde orgie bázni, nadẻji, krve a hříchu /..., V. 42-43; "wo Orgien von Angst, / Hoffnung, Blut und Sünde $(. . . \digamma$ ), d. $\mathrm{h}$. die dionysisch-tellurische Sphäre, in der signifikanterweise die "naděje" ("Hoffnung") nicht fehlt. Es ist aber auch die Nacht-Welt ("A vecer o sladkosti hudby táhnouci nábieźími / jak etherná mlha do níz se stápi tišice svêtel" (V. 45-46; "Und abends von der süßen Musik an Uferstraßen / wie Nebel aus Äther, darin tausend Lichter ertrinken") des Animisch-Weiblichen, des 'Mondweibes', des Ästhetischen, Kalten und Lunaren ("nad rekami, jež jako żily studené záre zdaji se prýštit / z mésíce". V. 46-47; "Flüssen, die wie Adern kühlen Schimmers / vom Monde sich rinnen scheinen"), des Anorganisch-Kristallinen und Artifiziellen ("ve fosforněm jiskřeni drahokamü", V. 51 ; "im Phosphorgefunkel der Lippen und Edelgesteine"), ja die Welt des Hypnotischen und des Kultes. Das solare Licht der 'oberen' Welt wird durch die kalte und künstliche urbane Beleuchtung "tausender Lichter" (V. 46; "tisice svêtel"), die hier mit dem lunaren Schein korrelieren, ersetzt Dieser Transformation entspricht auch die Verwandlung des lauten Sprechens in eine Flüstersprache, die wiederum mit dem Rascheln des anorganischen Stoffes (nicht zuletzt durch die onomatopoische Alliteration sepot - satü) koinzidiert: "A jejich sepot a vnéni šatú zdá se zakleto v květech a drímotè keriü (V. 49 50: "Und inr Flüstern / und Wogen der Kleider scheint verzaubert in den Blumen und im Schlummer der Sträuche"). Während die demiurgische Stadt(-Welt) die unablässige, fieberhafte und verwirte "ewige Suche" charakterisiert, zeichnet sich die weiblichanimische, urbane Welt durch eine hypnoseähnliche Passivität des Trübsinns, der Onnmacht und der Narkose; es ist die Welt der modernen Circe, Herodias oder Persephone, die die "Fürsten der Erde" ("knízata zemè") mit melancholischen Liedern anlocken, sie mit "magischen Düften" betören und die Geister der Toten aus der

\footnotetext{
ostrovy duši a zrnim svatého ohné pálily spici" (Se smrti hovơ̌i spici.../ Mit dem Tode reden die Schläfer... V. 145; "Wolken von Funken bedeckten die Inseln der Seelen und sengten mit Körnern des heiligen Feuers die Schläfer").

485 "... / a jako na skoby leeravé ještee, dokuté právě posledním úderem kladiv, I na slunce véši svá tenata neviditelná, / a lovecké síté spoušti $v$ plamenná mơe, která je trávi / jak pavučny" (Stavitelé chrámu / Baumeister am Tempel, V. 32-35; \%... und wie an noch glühende, eben vom letzten Hammerschlag geschmiedete Haken, / ihr unsichtbares Gam an die Sonnen hăngend I und die Jagnetze tauchend in feurige Meere, die sie verzehren / wie Spinnweben").
} 


\section{8}

chthonischen Unterwelt der Stadt heraufbeschwören: "O Żenách záhadných, zemdlených tỉzi své krásy, jež volaji milence pisnẻmi zádumčivými" (V. 48-49; "[Sie träumten] Von Frauen, rätselvoll, matt in der Last ihrer Schönheit, / die mit Liedern der Schwermut die Geliebten rufen"). Die (moderne) Stadt-Frau erscheint schließlich als eine 'Schlangenhexe', die mit ihrem Blick die Herzen in Brand setzt und für das SexuellTriebhafte entfacht: "jak by jich ruce, $486 \mathrm{~s}$ pohyby hadi uspávaných kouzlem, / házely zrni magické vưnè v sroce zapálená jejich zraky" (V. 52-53; "wie wenn ihre Hände, wie hypnotisch eingeschläferte Schlangen sich regend, / Körner magischen Dufts würfen in die Herzen, von ihren Blicken entzünde"').

Die Reihe der "zahllosen Scharen" schließen in der sechsten Sequenz (V. 55-71) die "letzten von allen" ("nejposlednějši ze všech", V, 55) ab, die "schweigend vorüberziehen" ("táhli kolem nás mlčky", V. 58). Wer sind diese "enterbten Sklaven", deren "ermüdeten Seelen" keine Träume hatten ("Umdlená duše jejich nemèla snü", V. 58)? Sie schreiten zusammen mit den "Baumeistern" ("Mezi nimi šli stavitelé tvěho chrámu", V. 72; "Zwischen innen schritten die Baumeister deines Tempels"). Diese Konstellation deutet auf eine gegenüber den "Träumenden" privilegierte Position der "Sklaven" hin. Dazu kann offensichtlich nur die (leidvolle) aktive schöpferische Mit-Arbeit am Tempel-Bau berechtigen. Daraus resultiert, daß auch die "Baumeister" eigentlich ein Teil der 'Sklavenschar' sind. Der wohl einzige wesentliche Unterschied gründet darin, daß die "Baumeister" in der Lage sind, den (Schöpfungs-)Plan des "Höchsten", seinen Sinn, zu erkennen und nach inm auch den Tempel-Bau zu leiten, ihn zu organisieren ("Ti jedini ze všech poznávali se znamenimi. Jako slib jiných nebes a zemé vidẻli hrủzu a nádheru vèci", V. 72-74; "Sie allein unter allen erkannter einander durch Zeichen. Wie anderer Himmel und Erden Verheißung sahn sie die Pracht und das Grauen der Dinge“). Die (rationale) Erkenntnis durch das (aktive) Sehen ("vidëli") wird im Text dem (imaginativen, passiven) "Träumen" ("snili", V. 4) gegenübergestellt. Die "Sklaven" erkennen n u r im Akt des Leidens, das von der aktiven Mit-Arbeit untrennbar zu sein scheint, ja das Leiden ist die Triebfeder des aktiven Handelns der "Bauenden": "Jen v jiskieni oći pri úderu rány neocekávané, / vidéli nad sebou klenuti nebes, žernalé soumrakem věkú" (V. 59-60; "Nur im Funkeln der Augen beim unerwarteten Schlage / sahn sie ob sich die Wölbung der Himmel, geschwärzt von der Zeiten Gewölk“). Das aktive Tun und das Leiderlebnis - als "Mittel der Formung" ("un moyen de formation"; Blondel) - potenzieren sich gegenseitig. Implizieren das luzide für das (rationale) Erkennen ("vidět" / "sehen") notwendige Bewußtsein und die Enfahrung des Handelnmüssens, in der der Sinn des menschlichen Daseins liegt (Blondel), nicht wechselseitig einander? Bezieht sich Brezina gerade in diesem Punkt nicht kritisch auf die Position des passiven 'Gefesselt-Seins' ("Mảm v duši lítost spoutaněho v lożi“, Litost I Die Wehmut, TD, V. 1; "Die Wehmut des ans Lager Gefesselten weilt in meiner Seele") oder des 'Eingemauert-Seins' (Vězeñ I Ber Gefangene, TD) der von der "entkräftenden Ferne" ermüdeten Seele im Reich des KunstTraumes und des Kunst-Todes des dekadenten Symbolismus? Geht es in Stavitelé chrámu nicht darum auch trotz dieser 'traumlosen Ermüdung' der Seele ("Umdlená jejich

486 In Stavitelé chrámu wird eine ternäre" "Hand"-Symbolik entfaltet: es sind die "kühnen Hände" (d. h. die s c h ö p f e r i s c he Hand; "smélosti ruky, jeż házi tajemné sitě nad národy". V. 21; "Kühnheit der Hände, die geheimnisvolle Netze über die Vöłker werte"*), während die "Jagdnetze" ("lovecké sité"), in die die "verwegenen" Hände der "ewig Suchenden" (V. 29-35) die Geheimnisse der Schöpfung zu 'fangen' suchen. wie Spinnweben von 'feurigen Meeren" verzehrt werden (V. 34-35). Es ist die demiurgische "Hand des Verwegenen" ("ruka odváżlivého", V. 78), die die Schöpfung des "Höchsten" pervertieren will und die mit seinen Blitzschlägen gelähmt wird. Und schließlich die "Schlangen-Hände" der Frauen (V. 52). Zur Lebenspolyphonie und Pluralität der Lebenserscheinungen gehören sowohl die "schöpferischen" und die "entlohnenden" Hănde ("ruce odménujicich", V. 88) als auch die demiurgischen, "verwegenen" Hände oder die "Schlangen-Hānde" des Weibes. Man denke an die Plastik Rodins Main du diable (Die Hand des Teufels): Eine linke Hand (sinistra, wobei 'sinister' sowohl links als auch unheilkündend, verhängnisvoll bedeutet), das erste Verhängnis, aus der sich eine Frauengestalt erhebt. das zweite Verhängnis. Es war gerade das Werk A. Rodins, das in ungemein innovativer Weise zur Reaktualisierung der Handsymbolik in der Kunst der Jahrhundertwende (La Main de Dieu / Die Hand Gottes, auch La Création / Die Schópfung genannt, 1896) beitrug, auch im Zusammenhang mit der Symbolik der Kathedrale. So heißt auch seine berühmte Plastik (1908): zwei rectite, emporgerichtete Hände, deren Finger sich gewölbehaft zu berühren scheinen. Daß übrigens der Bildhauer Rodin auch ein kongenialer Kenner des Phänomens der Kathedrale war, beweist sein Buch Cathédrales de France (erst 1914). 
duše neměla snư V. 58) die (im dekadenten Symbolismus) zerstreuten schöpferischen Kräfte in einer 'Aktion', im Tempel-Bau zu konzentrieren, d. $h$. (unter anderem) das Seinkönnen des Menschen im Tun zu verwirklichen? Signifikanterweise erfahren die Baumeister die Gnade der "Erlösung von geheimnisvoller Schuld" gerade als "Schmerz und Arbeit" (V. 79; "Vykoupením tajemnè viny byla jim bolest a prăce"). In Fragmenten (Fragmenty, zehner Jahre) formuliert Bïezina diesen Gedanken wie folgt: "/.../ cena lidskẻho żivota leži v Čnnostı, a nikoli v poznáni. Poznáni naše je jenom o smysl vice v orientaci dëlnika." ("I.../ der Wert des menschlichen Lebens liegt im Tun und nicht in der Erkenntnis. Unsere Erkenntnis ist nur um einen Sinn mehr in der Orientierung des Arbeiters"). 487 Die "Sklaven" sehen/erkennen nur in einem besonderen Augenblick der Erleuchtung: "Nur im Funkeln der Augen beim unerwarteten Schlage / sahn sie /... ${ }^{\mu}$ (V. 59-60; "Jen v jiskieni ođ́ prii úderu rány neocekávané / vidéli /... $/$ ). Dadurch unterscheiden sie sich von den Baumeistern, denen eine besondere und 'höhere' Gabe zuteil wird: "In der Fülle zahlloser Formen / fühlten sie die Urspannung deines schöpferischen Odems, / der wie das Licht des Elias aus allen Linien der Schönheit erfunkelr" (V. 74-76; "V plnosti nesčísiných forem / citili prvotni napétí tvého tvirčiho dechu, / jež jako Eliášovo svêtlo ze vక̌ech nejvyššich linii krasy se jiskñ"m $)$. Was sehen also die "Sklaven" ob sich? "/.../ die Wölbung der Himmel, geschwärzt von der Zeiten Gewölk, / wie düsterer Werkstatt Diele, verrußt durch tausendjährige Arbeit" (V. 60-62; "I../ klenutí nebes, zCernalé soumrakem vékú / jako strop ponuré dílny zacazené praci tisíciletou“), die finstere gehennalische Schöpfungsstätte, $d$. h. den noch nicht vollendeten Tempel-Bau. Auch sein gehennaähnlicher, in der tellurisch-chthonischen Sphäre situierter Teil, wo (noch) mühevoll gearbeitet wird, gehört zum ganzen grandiosen Tempel des "Höchsten". Auch die 'niedere' "tausendjährige Arbeit" tragt zur postulierten Vollendung der Schöpfung bei, auch durch sie wird (noch nicht, aber bald) der Schlußstein in das Gewölbe des Tempels eingesetzt. Mit anderen Worten: Auch die düstere, "durch tausendjährige Arbeit verrußte" Sphäre wird eschatologisiert (und positiviert), denn alle Schöpfungsformen- und Wege sollen am Ende der Zeiten in eine "einzige Welt" (V. 30) einmünden und im Punkt "Omega" fokussiert werden. Der "höchste Schöpfer" scheint mit den "Sklaven" zu schaffen: die vertikale Achse 'oben'-'unten' büßt in diesem Prozeß ihre Relevanz zugunsten der horizontalen Achse ein. Der "schöpferische Odem" des "Höchsten" facht "die Essen unterm Horizont" ("dmychaly větry do výnni pod obzorem /.../, jehož reflex se pỉes celý hvẻzdnatý zenit síril", V. 62, 68); er selbst ent-facht und inspiriert alle Kreationen am Tempel-Bau. Das sozusagen sichtbare Artefakt der schweren "Feuerwogen" seines Odems, dessen Ur-Spannung die "Baumeister" spüren (V. 75), sind die zauberhaften "Blasen aus Glas" (ein Pendant zu der Glaskugel des Kunst-Schöpfers in Vëzen / Der Gefangene, TD), "der Erde Azure umfassend, I regenbogenhaft spielend und blau, Kuppel ätherischer Paläste des Glücks" (V. 64-66; "bubliny vyfouklè ze skla, blankyty zemę objimajici, / hrajici duhou a modrem, kopule éterných palácú stèsti").

Der "Höchste" selbst scheint nun durch seinen schöpferischen Odem, in dessen "Dampp" die 'Erwartungsorte' der eschatologischen Vollendung, die " $F$ e n s te r am Gipfel der Wölbung" (V. 66), schmelzen, die Kunst-Schöpfung zu ent-fachen, sie voranzutreiben und zu dynamisieren. Diese theurgische Kunst-Schöpfung integriert und eschatologisiert auch die in der autonomen Kunst-Welt isolierte demiurgische Kunst-Schöpfung des autistischen artifex (Vězeñ / Der Gefangene). Diese muß nicht meht verdrängt werden, denn alle schöpferischen Prozesse, die zur Vollendung des Tempel-Baus führen, inspiriert die "Ur-Spannung" des schöpferischen Odems des creator macrocosmi. Das Resultat stellen die verheißungsvollen "Paläste des Glücks" dar, derren Glanz auf die Herrlichkeit der himmlischen "Stadt Jerusalem" aus der Offenbarung Johannis erinnert: "/.../ die hatte die Herrlichkeit Gottes; / ihr Licht war gleich dem alleredelsten / Stein, einem Jaspis, klar wie Kristall; I...I. Und ihr Mauerwerk war aus Jaspis und die Stadt aus reinem Gold, gleich reinem Glas" (Offenbarung, 21, 11, 18).

Im Unterschied zu den "Sklaven" sehen/erkennen die eingeweihten "Baumeister", daß die Hervorbringung des Kunst-Schönen, das 'alte' Ideal der ästhetischen Existenz (TD), eschatologisiert und zum integralen Bestandteil der kreativen Arbeit am Tempel-Bau gemacht wird. Sie sehen/erkennen, daß das Kunst-Schöne als theurgische Schöpfung

$487 \mathrm{Vgl.} \mathrm{O.} \mathrm{Bỉezina,} \mathrm{.Fragmenty”,} \mathrm{in:} \mathrm{O.} \mathrm{Bỉezina,} \mathrm{Eseje,} \mathrm{Olomouc} \mathrm{1996,} \mathrm{S.} 189$. Kursivsetzungen von Bỉezina. 
"wie das Licht des Elias488 aus allen höchsten Linien der Schönheit erfunkelt" (V. 76: "jako Eliášovo svêtlo ze vše ch nejvyšších li nii krás y se jiskîi"). Diese artifizielle Schönheit offenbart sich - so wie die "Urspannung des schöpferischen Odems" - nicht nur in "zahllosen Formen" (V. 75), sondern auch in allen Realien/"Dingen" ("véci") des geschaffenen roouos (als Lebens- und Menschenwelt); im Schöpfungswerk des creator macrocosmi offenbart sich sowohl das "Grauen" als auch die "Herrlichkeit der Dinge", die die "Baumeister" zu sehen vermögen (V. 74-75).

Die in dieser Sujetsequenz dargestellten schöpferischen Akte/Prozesse des TempelBaus erscheinen (V. 68-71) als ein großartiges Projektionsbild, "dessen Abglanz sich dehnte über den bestirnten Zenit / und im Ruß der Wolken sich fing, wie Goldsand, mit Blut verklebt / darauf projizierten gigantisch sich bewegliche Schatten, / ein Bild geheimnisvollen Kampfes um die ewigen Feuer" (V. 68-71; "jehoż reflex pres celý hvězdnatý obzor se śíril / a v sazích mrakú se chytal, jak zlatý písek slepený krvi / gigantské pohybujicí se stíny promítaly se na nèm, / jak obraz tajemněho zápasu kolem vécnych ohnüu'). 489 Das Reflex-Bild dieser kreativen Prozesse, die einen unzertrennlichen

488 Die Symbolik des "Elia-Lichtes" ("svêtlo Eliášovo") deutet im Zusammenhang mit dem Motiv des Tempels auf das nahende eschatologische Geschehen hin. Das Kommen Elias antizipiert das Kommen des Erlösers. Im mittelalterlichen Chiliasmus (Joachim von Fiore) erscheint Elia als Vorläufer des Mesias. Als 'Bekämpfer' der Feinde, die die Schōpfung des "Höchsten" pervertieren wollen, entrückt Elia im Feuerglanz gen Himmel. Das Licht seines Feuerwagens symbolisiert das erste Aufleuchten der Feuertaufe, die sich im Evangetium aetemum auf alle Gläubigen ergießen wird. Signifikanterweise kommt das Elia-Motiv im Zusammenhang mit der Semiotik ger Kunst-Schöpfung bereits im Prolog-Gedicht des ersten Gedichtzyklus tajemné dálky vor: "Ó silo extasí a snú, z niž uméni / plá barev vẻjî́em a v tónech burácí! / I... I ó moci vítézná, jeż v inspiraci pláś, I jak v oltár kamennỳ se ohè s nebe slival, / kdyż obèt krvavou nañ kladl Eliás" (O silo extasi a snú... I Kraft der Extasen und Träume..., I, 1-2, 6-8; "O Kraft der Extasen und Träume, aus der die Kunst in einem Farbenfăcher glüht und in Tönen braust! /... / O siegreiche Macht, die du in der Inspiration glühst, / wie auf einen steinernen Altar floß das Feuer vom Himmel hernieder / als Elia das Blutopfer auf inn legte!"). Die Wiederaufnahme der Elia-Symbolik ist in Stavitelé chrámu nicht zufällig. Das Kommen des Propheten Elia wird als Vorzeichen der Epiphanie des Erlösers am Ende der Zeiten, das Feuer vom Himmel, das aut sein Opfer herabkam, als Anzeichen der feurigen Herabkuntt des HI. Geistes (an Pfingsten) gedeutet. Das Elia-Motiv in $O$ silo extasi a snú... (O Kraft der Extasen und Tráume...) verweist darauf, daß der 'Kunst-Priester', der im Tempel der Kunst (Uměni / Die Kunst. TD) seine Messe zelebriert und sich der Kunst aufopfert, von der Kunst auch seine Erlösung und Befreiung erwarten kann. In Stavitelé chrámu hingegen wird die "höchste Schónheit' als 'Produkt' des sctiöpferischen Odems von spiritus creator indiziert (V. 76); das heißt nicht die Kunst als sacrum, sondern die sakralisierte, e s ch a to log is i e r te Kunst-Schöpfung, die in der im Glauben und in der allumfas senden Gnade gegebenen Vertiefung des Daseins gründet (vgl. die Formulierungen: "bubliny vyfouklé ze skla, blankyty zemé objimajict, V. 64: "Blasen aus Glas, die Erde Azure umfassend", oder "jehoż reflex płes celý hvězdnaty obzor se sił̌il", V. 68: "dessen Abglanz sich dehnte über den ganzen bestirnten Zenit'). Das Kunst-Werk als ein 'Produkt' des schopferischen Aktes, wird zum Ausdruck. zum Resultat der Korrelation der menschlichen Seele mit dem - in der Sprache Bł̉ezinas - "höchisten Schöpfer. Daher rührt auch Bł̌ezinas Vorstellung. daß die von der Entwicklungsdynamik der kunst-geschichtlichen Epochen völlig unabhängigen genialen Kunstwerke untereinander als Kunstwerke des "gleichen Stils", des gleichechen geistigen 'Weges' jenseits von Raum und Zeit, verwandt sind. Ihre Schöpfer nennt Błezina "svati" (die Heiligen). Interessanterweise wurde diese Kunstauffassung ein wenig später in den Schriften zur Kunstgeschichte des sechs Jahre jüngeren Landsmannes von Błezina, Max Dvơák (1874-1921). unter seiner berühmt gewordenen Parolle "Kunstgeschichte als Geistesgeschichte" auf unvergleichlich inspirative und in der damaligen Zeit (zwischen 1910-1920) produktive Weise aktualisiert

489 Interessant scheint die Symbolik der kühnen Metapher "zlatý pisek slepený krvi" (V. 69; "Goldsand, mit Blut verklebt") im Zusammenhang mit der "Wölbung der Himmel, geschwärzt von der Zeiten Gewölk (V. 60; "klenuti nebes, žernalé soumrakem věkü") zu sein. Im alchemistischen Mysterium der Vereinigung symbolisiert die Schwărze (nirgedo) den als Melancholie empfundenen Anfangszustand der materia prima, die sich zur Weiße (albedo; SilberMondzustand der Materie) sublimiert, um schließlich bis zur Röte (rubedo) aufzusteigen, die den Gold- und Sonnezustand der Materie bedeutet. C. G. Jung, Psychologie und Alchemie, Psychologische Abhandlungen, Bd. 5. Zürich 1944. S. 316-318. Vgl. auch A. Jeremias, Das alte Testament im Licht des alten Orient. Leipzig 1930, S. 54. Der Autor verweist auf die rabbinische Legende, nach der der aus "adamah" ("rote Erde") geschaffene Adam in drei Farben weiß-rot-schwarz, denen eine besondere Heilsbedeutung zugeschrieben wurde, gegliedert wurde. 
Teil der dramatischen Geschichte des Menschengeschlechts darstellen ("gigantské pohybujíci se stíny promítaly se na ném, / jak obraz tajemného zápasu kolem vêčných ohnú", V. 70-71: "darauf projizierten gigantisch sich bewegliche Schatten, / ein Bild geheimnisvollen Kampfes um die ewigen Feuer"), signalisiert zugleich die Umkodierung und Eschatologisierung der dekadenten Spiegel(ung)-Symbolik (TD). Im Gegensatz zu der autistischen, autokommunikativen Kunst-Welt als Projektion der Einbildungskraft des isolierten Kunst-Schöpfers, spiegeln sich die theurgischen kreativen Prozesse - in der Sphăre der Menschen- und Lebenswelt - in mannigfaltigen Formen und in allen "Dingen" (V. 74) des geschaffenen koopos wider. Und alle "Dinge" ("vëci") reflektieren - sowohl in inrem "Grauen" als auch in ihrer "Herrlichkeit" - die "glühenden Berührungen des Ewigen" ("Žhavá dotknutí Vẻéného"; Essay Zástupové / Die Brǘder, Essay, 1899).490 in Apoteosa klasú (Apotheose der Ähren) werden die Motive des organischen Reifens in die nun eschatologisierte Sphäre des artifiziell-anorganischen, lunar-metallischen Kunst-Schönen integriert:

"A pülnoc, nèmá extasi, když bloudi nad zemémi, / lich vašich jiskłeni se do blankytủ navraci, I

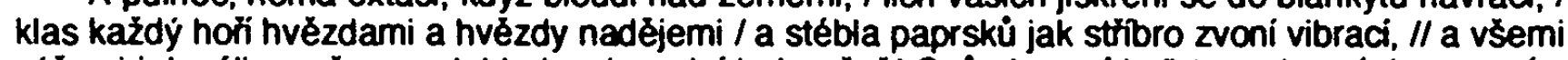
výsemi jak záliv mớe $z$ nedohledna / se vini jedna żeñ! Snú skvouci loơstva etherná / se na ni v dálœe ztráceji a v zlatém pisku ze dna, I pod vesly zvî̉eném, zár̉ slunce hởi nádherná!" (Str. V.-VI; "Wenn Mitternacht, ekstatisch stumm, hoch ob den Lảndern zieht, / und eurer Felder Glanz sich auf ins Freie schwingt, / flammt sternhaft jeder Halm, Hoffnung in Sternen glühet, / die Strahlen zittern so, daß es wie Silberläuten klingt, /I und unabsehbar wogt, gleich einem Meeressunde, I Ernte auf allen Höhn! Der Trăume Ätherflotte voller Pracht / verliert sich fern auf ihr, im goldnen Sand am Grunde, I der Ruder aufgewühlt, strahit Sonne stolz entfacht!". Übers. v. O. Pick).

Der Habitus der "Baumeister" scheint jener der männlich-apollinischen 'Lichtgestalten' zu sein, deren "Wegweiser" die "innere Freude $1 . \ldots /$, weiß und stark wie die Sonne" ist. ${ }^{491}$ Es sind gerade das "Glück" ("ráj štésti" / "das Eden des Glücks"; Se smrt' hovori spicí..., V. $60)$ und die "Freude" ("radost"), die der harmonisch komponierten solaren ldylle (Stavitelé chrámu, V. 5-17) obwalten und deren Herrschaft auf Erden wieder restituiert werden soll: $\because$ /... radost, nepohnutá, bílá a silná jak slunce, / jeż tréba neviditelné uprostíed boữe a noci, / dle vécného zákona vládne zemi" (V. 80-82; "Wegsicherheit die innere Freude, reglos, weiß und stark wie die Sonne, / die, wenngleich unsichtbar in Nacht und Gewitter, I nach ewigem Gesetz herrscht ob der Erde"). Zu den apollinischen Wesenszügen der "Tempel-Baumeister" gehört auch die ent-sexualisierte, asketische Beziehung zum Weiblichen; die Frau heißen sie in der Gestalt der (spiritualisierten) "reinen Schwester" und "Mutter", die den Antipol zu der unerlösten 'Schlangenhexe' der nächtlich-lunaren Stadt(-Welt) darstellen (V. 52-54), willkommen: "Vítézủ matku a sestru I... / vítali Żenu" (8283; "Die Mutter und Schwester der Sieger / in der Jahrtausende Blüte. Morgenrot auf den Lippen, sie grüßten das Weib"). Den Weg der "Baumeister" beleuchten die apollinischen 'Wappentiere'-Sommergestirne "Orel, Labut, Delfín a Lyra" (V. 84; "Adler, Schwan. Delphin und Lyra").492

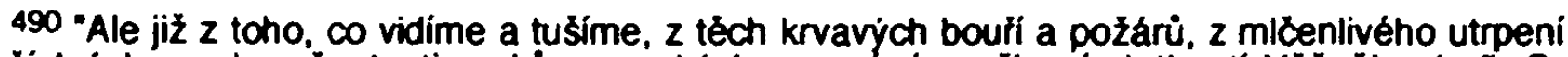
nesčisiných a $z$ horečnatosti zrakú prorockých, poznaváme zhavá dotknutí věcněho $/ . . . r$. $O$. Błezina, Zástupové, in: O. Błezina.. Eseje, Olomouc 1996, S. 39. ("Aber aus dem schon, was wir sehen und ahnen, aus den blutigen Stürmen und Bränden, aus dem schweigsamen Leiden Unzāhliger und auş dem Fieberblick der Propheten nehmen wir die glühenden Berührungen des Ewigen wahr I... $r$. Úbers. v. E. Saudek).

491 Das Adjektiv "vnittrni" ("innere[r]") könnte auch dem Substantiv "cesta" ("Weg") zugeordnet werden. Die Symbolik des "inneren Weges" ist in der gnostischen und frühchristlictien Heilspraxis verbreitet. Es ist der (eschatologische) 'Licht-Weg' (als ascensus) der Seele, den diese nach dem Tode beschreitet. Vgl. H. Jonas: Gnosis und spătantiker Geist, Teil 2, 1, Von der Mythologie zur mytischen Philosophie, Göttingen 1954, S. 126f.). Sowohl das "Glück" (bzw. die "Freude") als auch die "Verinnerlichung" zählen zu den Merkmalen des Apollinischen.

492 Kennzeichnenderweise handelt es sich auch um Christussymbole: das Symbol des (sterbenden) Schwans alludiert auf den letzten Ruf Christi am Kreuz. Der Delphin figuriert in der christlichen Ikonologie oft als Begleiter eines Schiffes (der Kirche. des Lebensschiffes der Verstorbenen), auch als Hinweis auf das tragende Geleit in die Ewigkeit. Interessant ist die Delphin-Darstellung bei der Berufungsszene der Jünger Petrus und Andreas durch Christus auf einem Mosaik in S. Apollinare Nuovo in Ravenna. Die Lyra (bzw. Harfe) ist nicht nur das Attribut Apollons (und des Gottmenschen Orpheus), sondern auch des Königs David, der in der christlichen Mythologie als Ahnherr Christi gilt und dessen Sieg über Goliath als Vorausbild des 
Das Ziel ihrer Sendung ist klar formuliert: "K milionům trpicich bratrii bylo posláni jejich / jako najmutí dělníkú k stavbe" (V. 86-87; "Zu Millionen leidender Brüder kam inre Sendung I wie Dingung von Arbeitern zum Bau"). Diese soteriologische Sednung ist jedoch gleichzeitig auch eine ethische. Die Bedeutung vom '(Auf-)Bauen' bleibt in Stavitelé chrámu nicht nur mit dem Tempel-Bau verbunden; der Tempel-Bau symbolisiert a u $\mathrm{ch}$ den 'Auf-Bau' der Beziehung zum Nächsten, zu den "leidenden Brüdern", durch das Charisma der Liebe. Dieses ethische (und gleichzeitig soteriologische) Handeln 'baut auf'. Die (Bruder-)Liebe scheint eine der Bedingungen für die Vollendung des Tempel-Baus zu sein; die "Brüder" sollen für den "Tempel-Bau" gewonnen werden 493 Daher ermahnen die vates mit ihrem Aufschrei beim Anblick der "letzten von allen", der "Millionen Enterbten". an die Liebe: "Ale nejposlednèjši ze všech (jak jsme zakvileli láskou!)" (V. 55; "Doch die letzten von allen (wie stöhnten wir auf vor Liebe!"). Es geht doch auch darum, das in der ersten Sujetsequenz thematisierte, harmonisch komponierte solare "Eden des Glücks" $\mathrm{Zu}$ restituieren. Nicht von ungefähr wird diese verlorene kosmische Idylle auch als ein "sichtbarer Traum /.../ glühend vor Liebe" ("a jeho sen viditelný /.../ vznášel se nekonečnostmi / zárici láskou", V. 12-14) charakterisiert. Die Entlohnung der "Arbeiter" ("dẻlnici", 87) ist die "Wärme der Sehnsucht" ("horkostí touhy", V. 88), das vehiculum der Vollendung des "Tempel-Baus", der künftige "erhabene Wahnsinn der Heroismen" ("vznešené silenstvi heroismü", Pozdravujeme jaro! / Wir grüssen den Frühling!, III, 4): "Ale aby Żhavẻjši byla slova najímajicich a ruce odměnujicich horkosti touhy, I tvá spravedlnost, silná a vádnouci smrti, rtúm jejich odñala vzpominku na všechnu sladkost zemè" (V. 87: "Doch aư daß glühender würden / der Dingenden Worte und die Hände der mit der Wärme der Sehnsucht Entlohnenden, / nahm deine Gerechtigkeit , stark und dem Tode gebietend, / ihren Lippen das Erinnern an alle Süße der Erde"). Diese Freiheit von der "Süße der Erde", die die wahre Zukunft, die Sicherheit des zukünftigen Lebens ist. heißt aber nicht die Freiheit von der Geschichtlichkeit der menschlichen Existenz, die im schöpferischen Tun des Menschen, in seiner unmittelbaren Partizipation an der (Heils-) Geschichte und Kultur, wie sie der "Tempel-Bau" symbolisiert, nicht nur festgehalten bleibt, sondern von den künftigen "Bauenden" auch fortgesetzt wird. 494 Die Vision der Vollendung des "Tempel-Baus" wird signifikanterweise im Epilog-Gedicht von SCh konkretisiert:

"Pozdravujeme jaro! Hie, dni se střidaji s noci / jak okna andély malovaná s kresbami symbolickými, / v nesmirno sklenutá k ethemým obloukủm chrámu tvého, / kde všechny piameny

Sieges Christi über das Haupt der widergöttlichen Măchte, ixıtıviǔ, gedeutet wird. Darüber hinaus verweist C. G. Jung auf die alchemistische Bedeutung von Adler und Schwan als Symbole des sublimierten Spiritus. Vgl. C.G. Jung. Psychologie und Alchemie, Psychologische Abhandlungen, Bd. 5, Zürich 1944, S. 316. És läßt sich nicht übersehen, daß̉ der "Adler" der "Baumeister" ein quasi Gegensymbol zu dem "Adler" als Wappentier der hochmütigen und autistischen Künstler-Schöpfer (V. 23) darstellt.

$493 \mathrm{Vgl}$. "Wir aber, die wir stark sind, sollen das Unvermogen der Schwachen tragen und nicht Gefallen an uns selber haben. I Jeder von uns lebe so, daß er seinem Năchsten gefalle zum Guten und zur Erbauung" (Röm 15, 1-2).

494 Einer der Hauptgedanken des essayistischen Werks von Bỉezina: "Veškerá minulost, stále pritomná, ơhaluje se nám każdým poznánim, jeż nám płripravuji kameny, vody, tvorstva. světy nad námi, jako by tajemná ruka obracela pơed námi lisły knihy, v niż zaznamenány jsou veškeré budouci i minule déjiny naše, a dávala nám cisti vżdy znova prvni jejich stránky, abychom porozuméli čteni následujicimu. Ćteme a zastavujeme se pojednou $v$ úzase, $v$ némż óhlasuje se pro każdého z nás druhé zrozeni naše na zemi: nânlé osinéní jistoty, że duch nás vystupuje z iáadu vẻci pozemských a stoji zapjat v łádu svẻta vyšsino" (Mir / Der Friede, in: O. Błezina. Eseje, Olomouc 1996, S. 155; "Die gesamte, stets gegenwärtige Vergangenheit enthüllt sich vor uns mit jeder neuen Erkenntnis, die uns die Steine, Gewässer, Geschöpfe, die Welten über uns bereiten, als wendete eine geheimnisvolle Hand die Blätter eines Buches vor uns um, in dem unsere gesamte zukünttige und vergangene Geschichte aufgezeichnet ist, und uns stets aufs neue inre ersten Seiten lesen ließe, damit wir die felgende Lekture verstehen. Wir lesen und plötzlich halten wir inne voller Erstaunen, in dem sich, für jeden von uns, unsere Wiedergeburt auf Erden ankündigt: die plötzliche Erleuchtung der Gewißheit, daß unser Geist aus der Ordnung der irdischen Dinge heraustritt und in die Ordnung einer höheren Welt eingegliedert dasteht"). "Pro vznešeného dẻınika i smrt je dilem. Roznási semeno jeho żné. Zasazuje posledni kámen do klenby, která płetrvá vẻky" (Fragmenty / Fragmente, ibid. S. 178; "Für einen noblen Arbeiter ist auch der Tod ein Werk. Er verbreitet den Samen seiner Ernte. Er setzt den Schlußstein in das Gewölbe ein, das die Zeiten überdauert".) 
lustrù svých rozžal jsi o Vzkř̉̌seni. // Pozdravujeme jaro! Vitáme netrpélivost duši! / Tr̉eseni krídel sesilených! Odvahu zraku zjasnélého! / Nekonečnosti ¿ekaji na nás, jiná slavnějši jara, / věčnosti hỉmici pisně, vysvobozeni!" (Str. VII-VIII; "Wir grüßen den Frühling! Sieh, es wechseln Tage und Nächte / wie Fenster, von Engeln mit symbolischen Zeichnungen bemalt. / unendlich gewölbt zu deines Tempels ätherischen Wolken, / wo alle Flammen deiner Lüster 495 du zur Auferstehung entfacht. // Wir grüßen den Frühling! Ungeduld der Seelen, willkommen! / Beben erstarkter Schwingen! Mut des helleren Blicks! / Unendlichkeiten erwarten uns, andre festlichere Lenze, / in Ewigkeit donnernde Lieder, - Erlösung!". Übers. v. O. Pick).

\title{
5.2 Symbolik der Endzeiterwartung
}

\begin{abstract}
„Die Erwartung (der parousia), die bange, gemeinsame und tätige Erwartung eines Weltendes, das heißt eines Ausweges für die Welt, ist die christliche Aufgabe im höchsten Sinne und vielleicht jener Zug an unserer Religion, der sie am deutlichsten von anderen Religionen unterscheidet. /..J Um jeden Preis müssen wir in uns selbst die Sehnsucht und die Hoffnung auf die große Ankunfi erneuern".
\end{abstract}

Pierre Teilhard de Chardin: „Le Milieu Divin“ (1957)

Mit der Symbolik der Kunst- und Lebensschöpfung. mit der Dominanz des Werdens bei der Thematisierung der auf die Vollendung der Schöpfung ausgerichteten eschatologischen Prozesse, geht die Symbolik der Endzeiterwartung - begleitet von den charakteristischen Motiven des Wartens, Harrens, der Ungeduld, des (Zeit-)Fließens, der Wellen usw. - einher. Die Lebens- und Menschenwelt als Schöpfung ist ein zeitliches Phănomen. Darin gründet das dynamische Element des (christlichen) Zeitbewußtseins, daß die Erfüllung 'vorwärts' auf ihre Vollendung hinstrebt. Die zur Verfügung stehende begrenzte Zeit, versteht man als Aufgabe schöpferisch zu wirken, $d$. $\mathrm{h}$. sich an der Vollendung der Schöpfung aktiv zu beteiligen. Durch dieses Bewußtsein gewinnt die Zeit eine völlig neue Dimension. 496 In einem Brief (vom 2. XII. 1897) an Anna Pammrová sieht Bíezina den Zweck des Geistes ("úcel ducha") "rozmnožit a stupȟovat żivot na zemi k urychleni osudu vẻci, aby se naplnila Pisma. (Ovß̌emže vývoj života jde svým odvěkým vinènim, v mystickém vlivu casu $/ . . . /$.). 497 Im weiteren soll die Semantik der Zeit-Bewegung im kosmogonisch-eschatologischen Welt-Modell năher spezifiziert werden.

495 Auch das Bild der im 'Tempel" leuchtenden monumentalen "Lüster alludiert aut die oben enwähnte Vision der Himmlischen Stadt Jerusalem und es läßt an die großartigen Lichtkronen der ottonischen und frühromanischen Dome (z. B. die Kathedrale von Bayeux) denken, die als Abbild des Himmlischen Jerusalems konstruiert wurden, was ihre Inschriften auch bekunden. Diese "coronae", wie sie genannt wurden, waren riesige metallene Reifen, an einer Kette von der Wölbung tief aus der Himmet-Wölbung des Tempels herabhăngend, meistens mit kleinen Türmen besetzt, die als Tore mit kleinen Figuren gebildet sein können. Der obere Rand war mit zahlreichen Kerzen (etwa 100) besteckt, um den Lichtglanz, die Lichtvision der Himmlischen Stadt zu suggerieren. Symbolische Bedeutung haben auch die Teile des Geständes, das den Reifen hălt: als völlig sicher gilt die Symbolik der großen Hauptkugel, die die strahlende Sonne, den himmlischen sol rex, versinnbildlicht. Vgl. H. Sedlmayr, Die Entstehung der Kathedrale, Freiburg i. Breisgau 1993. S. 125ff. Zu diesem Thema existient eine aufschluBreiche Dissertation von Adelheid Kitt. Der frühromanische Kronleuchter und seine Symbolik, Wien 1944.

496 Vgl.: "Wir müssen die Werke dessen wirken, der mich gesandt hat, solange es Tag ist; es kommt die Nacht, da niemand wirken kann" (Joh. 9, 4).

497 O. Bł̌ezina, .Dva dopisy“ [Anně Pammrové], in: Wiener Slawistischer Almanach, 4, 1979, S. 212. \%.../ das Leben auf Erden zu vervielfältigen und zu steigern, wegen der Beschleunigung des Schicksals der Dinge, damit die Schrift erfült werde. (Gewiß, die Entwicklung des Lebens geht in seinem ewigen Wellen, unter dem mystischen Einfluß der Zeit /.../.). (Kursivsetzung von Biezina). 


\section{Das "Tropfen", "Durchsickern", "Fließen" und "Pulsieren" der Zeit}

Der Begriff "urychleni" ("Beschleunigung"), den Bïezina im zitierten Brief verwendet, scheint die Zeit-Auffassung - in bezug auf die Symbolik der Endzeiterwartung - in der Schaffensphase von Stavitelé chrámu prägnant zu charakterisieren. Es ist geradezu symptomatisch, daß alle in den Gedichten dieses Zyklus thematisierten Prozesse "beschleunigt", unter die Herrschaft "des mystischen Ein-Flusses der Zeit" gestellt und dadurch verzeitlicht werden. Auch dies bedeutet eine wichtige Innovation im Vergleich mit der Zeit-Auffassung sowohl im dekadenten Symbolimus als auch im gnostischeschatologischen (SZ) und im theo-logisch-eschatologischen (VP) Modell des eschatologischen Symbolismus.

Im dekadenten Symbolismus (TD) wird die Zeit(lichkeit) des xóouos aufgehoben. Besonders deutlich tritt diese Zeit-Auffassung in Podzimni veðer (Der Herbstabend) zutage: "Do prázdna vtéká Cas /..." ("Ins Leere fließt die Zeit /... . V. 1). In Tajemné dálky liegt für Bïezina nicht nur die Erkenntnis, sondern auch das (transzendente) Ich und die Kunst-Schöpfung jenseits von Raum und Zeit. Die Zeitlichkeit erweist sich als eine annihilierende Gewalt: Die "Zeit fließt ins Leere", "ergießt sich im Regenschauer toten Laubs" (Cas lije se... I Zeit ergießt sich..., I, 1; "Čas lije se prškou mrtvého listi") oder "atmet im müden Rhythmus der Stunden" (Vonné soumraky I Wohlduttende Dämmerungen, VI, 3-4; "Cas tajemný /.../ / dýchal hodin rytmem umdleným"). ${ }^{998}$ Die Zeit selbst partizipiert an den Annihilierung- und Desontologisierung-Prozessen; es ist Máchas "wilde Wut der Zeit" ("divoký Zasu vztek"), ${ }^{499}$ die dem dichterischen Ich alles hinwegrafft, verwüstet, zersetzt, zernagt und nekrotisiert - seine Mutter (Moje matka / Meine Muter). seine Jugend (Mrtvé mládi I Tote Jugend), seine Freundschaft (Prátelstvi duši i Freundschaft der Seelen) oder seine Sehnsüchte (Agonie touhy / Agonie der Sehnsucht)-, es aber dadurch zugleich (im Sinne der für TD signifikanten oxymoral-paradoxen Semantik) wertvoll und kostbar macht. 500 Diese Zeit-Auffassung modelliert zum Teil auch das gnostisch-eschatologische Welt-Bild von Svitáni na západé. Auch hier "welkt die Zeit dahin" (Tys nešla / Du kamst nicht, II, 3; "Cas vadl") oder die "Sekunden fließen wie durchsickernde Tropfen des wehmütigen Nieselregens / /... / in die Gärten meines Todes" (Vteriny / Sekunden, II, 1-2; "Mé vteřiny tekou jak prosakujić krủpëje teskného mženi / /.../ do zahrad mé smrti“). Es kommen aber zwei neue Aspekte hinzu: Es ist der ominöse Momentanismus des (bangen) Augenblickes, in dem sich dem dichterischen Ich die Wirklichkeit oder nur eine Vision, phantomähnliche Erscheinung, ein Geheimnis usw. Offenbart, die das dichterische Ich wie die Schläge der "Uhr der Großen Nacht, die in die Dunkelheit schlagen" (Žeh bilý svètla... I Die weiße Glut des Lichtes...,VI, 1, TD; "a naslouchám hodinám Veliké Noci, bijicim tmou*), an die Vergänglichkeit des der Zeit unterworfenen Daseins erinnern (vgl. die oben zitierte Verszeile aus dem Gedicht Vteriny: "Znám chvile úzkosti" (Pró̉ odvracís se, slabá? I Warum wendest du dich ab, o

498 Zur Zeitproblematik in Tajemné dálky und in Svitáni na západẻ vgl die aufschlußreiche Darlegung von Urs Heftrich, Otokar Brezina, Heidelberg 1993, S. $70 \mathrm{H}$.

499 Die bekannte Metapher aus der lyrisch-epischen Erzählung Máj (Der Mai, 1836) von Karel Hynek Mácha (1810-1836).

500 Kongenial hat diese Intention vier Jahrzehnte später (1933) der surrealistische Maler und Dichter Jindrich Styrský (1899-1942) in seinem Essay Kraj markýze de Sade (Das Land des Marquis de Sade) ertaßt: "Déjiny nejsou neż podivuhooná ukázka, jak pravda mizi v case. Proto jsou jména básnikủ vżdy spjata s ruinami a se stiny. Vふ̌e, co opusti básnik, zešedivi a obráti se v troud a popel. A radosti básnikủ jest pozorováni, jak nicota rozleptává formy kdysi krásné, jak prázdnota se rozprostirá v srdcich kdysi svěżich, jak vše okolo nich zraje k smrti, jak se vše ríti do minula, zatimco jejich srdcim je odepreno dobrodinni stámuti. Skutečné: básníkưm nepatrí dnešek ani ziț̉ek, básnikúm patrí cas". $/ .1$ "Bylo by neodpustitelným vandalismem, kdyby se casu brala jeho potrava". (Jindrich Styrskỳ. ZZivot markỳze de Sade", Praha 1995, S. 42, 52: "Die Geschichte ist nichts weiter als ein bemerkenswertes Beispiel für das Versctiwinden der Wahrheit in der Zeit. Deshalb sind die Namen der Dichter immer mit Ruinen und Schatten verknūpft. All das, was der Dichter verläßt, ergraut und verwandelt sich in Moder und Asche. Es ist die Freude der Dichter zu beobachten, wie die Nichtigkeit die einst schönen Formen zersetzt, wie sich die Leere in den einst frischen Herzen ausbreitet, wie alles um sie zum Tode reitt, wie sich alles in die Vergangenheit stürzt, während ihren Herzen die Wohltat des Altems verweigert wird. In der Tat: Den Dichtern gehört weder das Heute noch das Morgen, den Dichtern gehört die Zeit". I... "Es wäre ein unverzeihlicher Vandalismus, die Zeit ihrer Nahrung zu berauben".) 
Schwache?, I, 1; "Ich kenne die Augenblicke der Bangigkeit"). "Jas hodin mých budoucich ozáril chvili tu v snech" (Legenda tajemné viny / Legende der geheimnisvollen Schuld, I, 1; "Der Glanz meiner zukünftigen Stunden bestrahlte jenen Augenblick im Träumen"). Der andere neue Aspekt der Zeit-Auffassung in Svitáni na západé hängt mit dem Substantiv "dẻjiny" ("Geschichte") zusammen (Ranni modlitba / Das Morgengebet, V. 68), das ein anderes Zeit-Verständnis signalisiert, das im dritten (VP) und im vierten (SCh) Gedichtzyklus voll zur Geltung kommt. Es ist das Verständnis der Zeit als Heilszeit', als 'Heilsgeschichte', 501 der Zeit, die keineswegs "ins Leere fließt", sodern aut ein ganz konkretes Ziel ausgerichtet ist: aut die Vollendung der Schöpfung und das Eschaton.

Die Zeit-Auffassung in Vêtry od polù (Polarwinde; theo-logisch-eschatologisches Modell) kennzeichnet die Haltung des eher passiven '(Er-)Wartens' nach der Formel: die Zeit ist noch nicht (aber bald) da, der Prozeß des Reifens ist noch nicht abgeschlossen und die Erntezeit noch nicht angebrochen, man muß noch unter der Sonnenglut des "mittäglichen Reifens" (zur eschatologischen Existenz; Poledni zráni / Mittäglich Reifen) oder in "Schmerzen wie im Qualm des eigenen Feuers" (Dlouho stáli... I Lange standen sie..., V. 1; "Dlouho stáli $v$ bolestech jako $v$ dýmu vlastního ohnè") stehen, sich noch gedulden (die "Königin der Hoffnungen" hielt "den Hauch der Zeit an" I "Dech Casu jsem zatajila v sobe", V. 2), aber die Zeit wird kommen und sich erfüllen, man kann es bereits (voraus-)sehen:

"/... J jejich jitra ¿ekala denniho světla, /.../ / a hvězdy na prichod druhého casu" (Mučenici / Mărtyrer, XII, 1,$3 ; \%$.../ inre Morgen harten des tagenden Lichts, /.../ / und die Sterne harrten der Zeit, der zweiten, die kommt"). "I../ hymny velikych mrtvých, marné zpivané pỉed staletími, / aby v Case svém vydaly vủnè- (Poledni zráni / Mittáglich Reifen, V. 27-28; \%.../ der Großen Toten vorzeiten vergeblich gesungene Hymnen, / damit sie zu ihrer Zeit die Düfte entsenden"). "I.../ vsak viny, jež házís, v tisici kruzích se vini az̉ $k$ bł̉ehủm / nového çasu. I.../ Vítězni ve vás zapaluji své pochodnè pro soumraky prístíno Casu" (Piseñ o slunci, zemi, vodách a tajemstvi ohnè I Das Lied von der Sonne, der Erde, den Wassern und dem Geheimnis des Feuers, V. 32-33, 65; " .../ doch die Wellen, welche du wirfst, schlagen in tausend Kreisen bis an die Ufer / anderer Zeit. I.../ Die Sieger entzünden in euch ihre Fackeln für die Dämmerung künftiger Zeiten").

Erst in Láska (Liebe), einem der letzten Gedichte des Zyklus, in dem sich der Prozeß des 'Reifens' im Akt der Erfahrung der Liebe, dieses höchsten Charismas der eschatologischen Existenz vollzieht, bricht die ersehnte "Ernte-Zeit" an: "Priisel Cas nejkrațích vecerư; s výś stỉesené květy dotkly se zemé" (V. 3; "Zeit kürzester Abende kam; von Wipfeln geschüttelt, berührten die Blüten die Erde"). Erst die Zeit, die sich nach der Liebe (áórm) mißt, kann die destruktive Macht der Zeitlichkeit und der Vergänglichkeit überwinden: "Bez bázné pohliźl láska v zrcadla nocí /.../ a vêriny její

501 In Bỉezinas Verständnis der Heilsgeschichte bekundet sich auch der Einfluß der alttestamentlichen Apokalyptik bzw. der Einfluß des apokalyptischen Geschichtsbildes, das stets vom $\tau \varepsilon \lambda d s$ ausgeht. Daß für die christliche (genauso wie für die jüdische) Heilsgeschichte - für die christliche Geschichtsphilosophie kat' exochẽn - die Verbindung von Geschichte und Mythos charakteristisch ist, wurde schon früher mehrfach nachgewiesen (in den Arbeiten von A. $v$. Hamack, W. Bousset oder in den Untersuchungen der Bultmann-Schule). Es läßt sich sagen, daß in der Błezinaschen Konzeption der Geschichte, die von der Ges ch ichtlichke it des menschlichen $\mathrm{Se}$ in s herrührt, die schöpferische Potenz, die Kreativität des Menschen und seine Geschichtlichkeit einander wechselseitig implizieren. Die "Freiheit gegenüber eigener Geschichte", von der Mircea Eliade in seiner Abhandlung Le Mythe de l'éternel retour (Paris 1969) spricht, wäre für Bł̌ezina offenkundig absolut undenkbar. Im Gegenteil! In Błezinas gesamten CEuvre lăßt sich keine Spur von jenem Phänomen finden, das Éliade kritisch "Angst vor der Geschichte" nennt. Die Vorstellung des Dichters, daß die Geschichte der Lebenswelt und die Teilhabe des (schöpferischen, d. $h$. ge schichtlichen) Menschen am schöpferischen Prozeß in einer höheren, geistigen Welt fortgesetzt wird, bildet das Hauptthema seines essayistischen Werkes, das in der Buchform erst vierzig Jahre nach Biezinas Tode unter dem Titel Skryté déjiny (Verborgene Geschichte, erste Fassungen zwischen 1905-1908) erschienen ist: "Nevime, ktera cást našeho vidẻni sahá již mimo hranice této zemé. Tušime jen, Ze skryté déjiny naše, jsou cásti vyššího systému dẻjin, jež rozvijeji se v kosmu. /... / chvěni našeho ducha a jeho rưst v pozemské práci odpovidá rưstu vyšsich duchovnich svêtư. s nimiž nás svét je spojen". (.Skryté déjiny" / Verborgene Geschichte", O. Błezina, Eseje, Olomouc 1996, S. 113; "Wir wissen nicht, welcher Teil unserer Visionen bereits jenseits dieser Erde liegt. Wir ahnen nur, daß unsere verborgene Geschichte ein Teil des höheren Geschichtssystems ist, das sich im Kosmos entfaltet. I... I das Beben unseres Geistes und sein Wachstum in der irdischen Arbeit entsprechen dem Wachstum der höheren geistigen Welten, mit denen unsere Welt verbunden ist"). 
Citány nejsou padáním krủpezji z oblakủ tohoto casu" (V. 39, 41: "Ohne Furcht blickt die Liebe in die Spiegel der Nacht /.../ und ihre Sekunden sind nicht gezählt durch Tropfenfall aus Wolken des Erdenwallens"). Hier wendet sich Bỉezina in einer autointertextuellen Allusion gegen die nihilistische Zeit-Auffassung in seinem metadekadenten Gedicht Vteriny (Sekunden, SZ): "Mé vteǐiny tekou jak prosakujici krưpẻje teskného mženi / dnem mým do zahrad mé smrti" (II, 1-2; "Meine Sekunden fließen wie durchsickende Tropfen wehmütigen Nieselregens / durch meinen Tag in die Gärten meines Todes“). Erst das Charisma der Liebe verwandelt die alles umfassenden Blicke der Liebenden "in die Zeit voll von Licht": "I rozśiri se pohled vás jak cas piný světla a obejme zemi" (V. 71; "Es weitet sich euer Blick wie die Zeit voll von Licht und umarmt die Erde"). Die ZeitAuffassung in Láska nimmt die Zeit-Semantik in Stavitelé chrámu vorweg.

Mit der Dynamik der schöpferischen Prozesse in Stavitelé chrámu geht Hand in Hand die extreme Dynamisierung der Zeit, als ob - im Sinne der postulierten "Beschleunigung des Schicksals der Dinge" ("urychlení osudu vèci") - alle Prozesse tatsächlich beschleunigt werden sollten. Man braucht nicht mehr zu warten, die Endzeit naht, die Erfüllung bricht heran: "tep srdci, zrychlen Bliženim, se v rytmech tủásl /...// krok Mistrưv času po vinách a sestup svatých vidéni" (Zpév staletími bloudici.../ Ein Gesang, der durch die Jahrhunderte irrt... III, 2-3; "durch das Nahen wuchs der Herzschlag an und zitterte im Rhythmus I.../ I auf Zeitwogen des Meisters Schritt und das Kommen heiliger Visionen“"). Die Zeit-Dynamik der nahenden Erfüllung wird nun mit Fluß, mit Meereswogen und sogar mit Wasserfall assoziiert, es ist aber keineswegs ein ruhiges, monotones Fließen "ins Leere", wie in Tajemné dálky (Podzimni vecer I Der Herbstabend, V,1), sondern ein rasender. schäumender Strom (Vigilie II, V. 29-30), eine gewaltige Flut des Lichtmeeres ("magii mésice se neprístupné moře svètla pohnulo a z brehủ vylilo / a zemi zaplavilo jedním prílivem", Zemé vitézu் / Das Land der Sieger, V. 6-8; "/... / des mondes Magie / ließ das unzugängliche Lichtmeer sich rühren und entrinnen dem Strand, / überschwemmend die Erde mit riesiger Flut") oder ein "mystischer Wasserfall" ("Pozdravujeme jaro, vodopád mystické reky, I.../ jak mezi skalami k moři se vali svétlem zatopenému"; Pozdravujeme jaro! / Wir grüssen den Frühling!, VI, 1, 4; "Wir grüßen den Frühling. Wasserfall des mystischen Flusses, I.../ wie zwischen Felsen zum lichtüberflutenen Meere sich wälz" ). Die semantische Isotopie der Zeit bilden auch Lexeme der Lichtgeschwindigkeit, die die Dynamisierung und Beschleunigung der auf die Vollendung ausgerichteten eschatologischen Prozesse konnotieren:

"Motýlüm vzňala se v plameny krídla / rychlosti letu!" (Vigilie II, 17-18; "Die Flügel der Schmetterlinge entflammten / durch die Geschwindigkeit des Fluges!"). "Pr̈́lis pomalu krouži jim zemè, príliš pomalu vstávaji jitra /... I. I Letěti pỉeji si tisicileti, rychlosti svétla letěti věky" (Proroci / Die Propheten, 74, 77; "Zu langsam kreist ihnen die Erde, zu langsam kommen die Morgen I.../. Sie wünschen sich durch die Jahrtausende zu fliegen, mit der Lichtgeschwindigkeit durch die Zeiten zu fliegen").

In Se smrti hovori spici (Mit dem Tode reden die Schläfer) entfaltet Bïezina eine großartige Metapher des rasenden Zeit-Wagens des "Höchsten":

- Cas vỷsemi letêl, v boư̌i slávy a smrti, s mystickým spiezenim hvēzd / kł̌ižovatkami nekoneçnosti. Vüz tnumfálni Nejvyśsiho, / provázen svètełnou vichrici vitézicich. I.../ Kam leti tato jizda? Kde se zastavi jednou? / Vifila kola, / v bilých plamenech žhavèly tajemnè osy jak slunce, I oblaky jisker pokryly ostrovy duši a zmim svatěho ohnẻ pálily spica". (V. 133-135, 142-145; "Die Zeit durchflog die Höhen im Sturm des Ruhms und des Todes mit dem mystischen Gespann der Sterne / über die Kreuzwege der Unendlichkeit, der Triumphwagen des Höchsten, I vom leuchtenden Sturmwind der Sieger geleitet. I.../Wohin fliegt diese Fahrt? Wo hält sie einst inne? I Die Rảder wirbelten, / die Sonnen glühten die geheimnisvollen Achsen in weißen Flammen, I Wolken von Funken bedeckten die Inseln der Seelen und sengten mit Körnern des heiligen Feuers die Schläfer").

ע. Symbolik der 'prophetischen Zeichensprache' - Topoi der Endzeiterwartung: "Fenster" ("okno"), "Grenze" ("hranice"), "Ufer" ("breh")

Der Versuch einer produktiven Integration der dekadenten 'Schatten-Welt' in das System des eschatologischen Symbolismus schlägt sich auch in der Tendenz zur Eschatologisierung und Positivierung der dekadenten, nihilistischen Apokalyptik (Podzimni vecer / Der Herbstabend, Snad potom... I Vielleicht dann..., TD) nieder. Das Ziel ist nicht mehr der 'Sturz' in die unendliche, grenzenlose Leere, in den "ewigen Schlaf", die Entrücktheit in ein 'NIchts', das autistische 'Eingemauert-Sein' in der Schatten-Welt der 
eigenen Einbildungskraft, sondern die Vollendung der Schöpfung, des "Tempel-Baus" und der (Ur-)Einheit. Die Botschaft des nahenden Eschatons verkünden die Propheten (Proroci), die als "Boten" ("Vyslanci") des "himmlischen Königreiches", vor allem jedoch als "Künder" des Wortes ("O tobe mluví a o tvé slávé", ibid. V. 23; "Von dir reden sie und von deiner Hehre") kommen. Zu ihren Wesenszügen gehört die "Allwissenheit" (Proroci / Die Propheten, V. 19) und die mantische Fähigkeit das 'Unsichtbare' zu sehen, das 'Unhörbare' zu hören und das 'Unsagbare' zu vermitteln. Die "Propheten" veriügen auch über die divinatorische Fähigkeit, das Unbekannte und Geheimnisvolle, das nahende Licht, die Epiphanie, den Inhalt des "Ewigen Wortes" usw., zu verstehen. Ihre Kommunikation besteht mehr oder weniger aus mantischer bzw. indexikalischer Ze i c h e n sprache:502

"Hlas jejich, stržený vichrici casu, za nimi vane, / sladký jak vưné za nesoucim rưże, hơký jak pochodni dým; / a nejtajnějłi myšlenky viastni, zalekli vševědoucnosti, I nad sebou slyši v

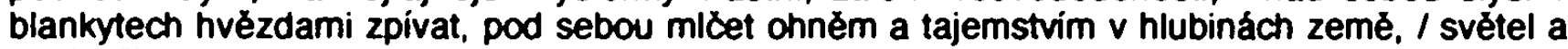
noci stridavy chor!" (Proroci / Die Propheten, V. 17-22; "Ihre Stimme, vom Sturmwind der Zeit erfaßt, weht innen nach, / süß wie der Duft hinter Einem mit Rosen, bitter wie Fackelrauch; / und die eigenen heimlichsten Gedanken, von Altwissenheit erschreckt, / hören sie über sich mit den Sternen hoch singen, / unter sich schweigen mit Feuer und Geheimnis in den Tiefen der Erde, I der Lichter und Nächte wechselnder Chor!").

Die nahende Endzeit tut sich den 'Wartenden' auch im Zustand des (visionären) 'Hörens' oder 'Schauens' kund. Diese Symbolik wird in Zas ve vidéní prorockém... (Wieder in prophetischer Vision...) konkretisiert: "Zas ve vidẻni prorockém noc septá slova neznámá, / Sum stromú, tisíc jazykư je opakuje nad náma. // I.. I noc ve svém snêní uslyš́, jak septá v reči neznámé, / Że mile każdou minutu do mởe svẻta padáme" (I, 1-2, IV, 3-4; "Wieder flüstert, seherhaft entrückt, uns Worte unbekannt die Nacht, / schon haben die Baumsprachen sie die rauschenden vertausendfacht. // I... vernehmt, wie euch in ihrem Traum die Nacht in unbekannter Sprache zuflüstert, / daß wir jede Minute viel Meilen in ein Meer von Licht fallen"). Bei der ungeduldigen Erwartung ("Tu jejich radost vykijikne silná a Żhavá a netrpélivá", Proroci / Die Propheten, V. 69-70; "Da schreit ihre Freude stark auf und von Gluten und Ungeduld voll!") des eschatologischen Geschehens "im Brand der Gnade" ("v Źáru milosti", V. 1; Když nebe vaše okna ozárí... I Füllt eure Fenster Himmelsglanz...) spielt auch das "Fenster" ("okno"), einer der signifikanten Topoi der Erwartung und Verwandlung - in Verbindung mit dem Motiv des "Himmelsglanzes" -, eine sinnkonstitutive Rolle. Der "Himmelsglanz" erscheint als Botschaft des nahenden Heilsgeschehens, das hinter dem Fenster erstrahlt und 'wartet' :503

502 Die Symbolik der indexikalischen Sprache und die des apophatischen Diskurses im russischen Symbolismus untersucht eingehend Aage A. Hansen-Löve ( $A$ Apokalyptik und Adventismus im russischen Symbolismus der Jahrhundertwende", in: Russische Literatur an der Wende vom 19. zum 20. Jahmundert. Amsterdam/Atlanta 1993, S. 250ff.). Laut der Hauptthese des Autors bildet der apokalyptische Diskurs der Moderne eine ursprünglich religióse (bzw. mystische, hermetisch-gnostische usw.), nun zur Kultur gewordene, assthetisierte Botschaft, wobei in der Moderne der 90er Jahre eine Sonderform der sog. 'negativen Theologie' des 'Unsagbaren', des referenzlosen Sprechens und Verweisens das Fundament ihres (antiapokalyptischen) Diskurses wird. Das negieren des Gegenstandes der theologischen (mystischen, gnostischen, hermetischen) Rede ist ein in der spătantiken bzw. in der hellenistisch-christlichen Tradition (Dionysius Areopagita. Philo von Alexandrien u. a.) bekanntes Phănomen, das spăter vor allem in der manieristisch-barocken Poetik aktualisiert wurde (in der tschechischen Barockdichtung bei Fridrich/Bedřich Bridel). Das Göttliche und Absolute sollte nicht verbalisiert werden. Dieser Tradition der Apophatik scheint übrigens auch Błezinas euphemistisches Benennungsverfahren bei der Bezeichnung des Absoluten, des Göttlichen ("Höchster", "Ewiger". "Allgegenwărtiger". "Dreimal Heiliger". "Vater des Ungeborenen" u. a.), zu entspringen. Im apokalyptischen Diskurs' spielt, laut Aage A. Hansen-Löve, die mantische Făhigkeit eine konstitutive Rolle (Lesen von Himmelszeichen, Orakeln usw.): das Sprachliche erscheint als das Primäre, die Gabe der 'Enthüllung' ('apokalyptein') hingegen als das Sekundäre.

503 Zur Symbolik der Erwartungshaltungen im russischen Symbolismus, vgl. A. A. HansenLöve, a.a.O., S. 261ff. In Kdyż nebe vaše okna ozáfi... (Fült eure Fenster Himmelsglanz...) vergiBt der Erwachte ("procitiy") plötzlich im Augenblick des Erwachens, d. h. im Augenblick der Gnade ("a v Záru milosti", V. 1; "in der Gnade Brand") den "schmerzvollen Traum des irdischen Daseins" ("bolestný sen pozemského żivota"). Das "Erwachen" zum eschatologischen Sein bedeutet das sofortige Vergessen des schmerzvollen irdischen "Lebenstraumes": "Je radost jako pisen̉ ztracená ze żiti vyšsího, / zpivaná v opojeni mystickêho vina, / jak úsmẻv na záríci tváni spicho, jimž náhle 
"Když nebe vaše okna ozáii a v żáru milosti / kdyż na výsluni plody zcervenaly, trhejte a jezte. I a svalou radost slavné vitejte, poselstvi vẻcnosti, I a k slovủm jejim záhadným ve jménu bratrí odpovêzte" (V. 1-4; "Wenn eure Fenster Himmelsglanz fühlt und in der Gnade Brand / wenn auf der Sonnenseite die Früchte rot warden, pflūckt sie und ißt, I und festlich grüßt die heilige Freude. die Botschaft der Ewigkeit, I und auf ihre rätselhaften Worte gebt Antwort im Brüder Namen").

Einen anderen Topos der Erwartung stellt die "Grenze" ("hranice") dar, die die Relevanz der horizontalen Achse 'hier-dort' für das in Stavitelé chrámu konstituierte WeltModell markiert, während die vertikale Achse 'unten-oben' ihr Primat verliert: "pred námi hranice svaté tvé noci, / za námi královstvi spicich" (Vigilie I, V. 3-4; "vor uns die Grenze deiner heiligen Nacht, hinter uns das Königreich der Schläfer"). Auch der Topos des "Ufers" ("bǐeh") indiziert das erwartete und ersehnte 'Dort":

"At' sladce drímou bratưi mi v svatebnich ložich nadẻji / a ztroskotani na brezich at drímou ještè sladCeji" (Zas ve vidèni prorockém / Wieder in prophetischer Vision, IV, 1-2; "Mögen doch meine Brüder im Hochzeitsbett der Hoffnungen süß schlummern, / und süßer noch die am Strandufer Gescheiterten"). "Ale ticho u skalnich pramenú vládne a u bỉehủ budoucích zemi" (Svě́t rostiin I Die Welt der Pflanzen, V. 17; "Doch Stille waltet an den Felsquellen und Utern künftiger Länder").

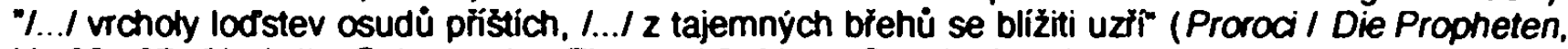
V. 65,$67 ; \%$. I die Spitzen der Flotten künftiger Geschicke, I.../ herannahen sehn sie von geheimnisvollen Küsten"). "Těm, Ktểi v žáru bỉehủ tvých, zajatci hvězd a snú, I nemocni světem tvým, v zimnici żití úpěji" (Milost / Gnade, II, 1-2; "Sie, die in deiner Ufer Glut, von Stern und Traum gebannt. I an deiner Wett erkrankt, im Lebensfrost wehkdagen").

\section{Katastrophische Symbolik der Endzeitenwartung}

In Hvèzd hasnou tisice... (Erlöschen tausende Sterne...) werden die endzeitlichen Ereignisse als eine katastrophisch-apokalytische, von einem "apokalyptischen Kollektiv 504 vorangetriebene Umwälzung, die in eine säkuläre Utopie eínmündet. dargestellt:

Den bliži se a my jsme nepripraveni! / Vzbouřeni šili v našich ulicích! /.../ // Co ze sopečných Cerných kamenư Gehenny podzemské jsme stavéli, / at padne do ssutin!

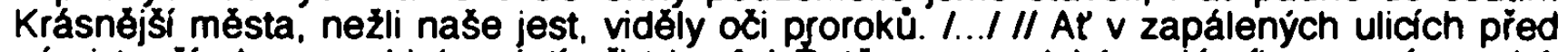
námi tancí plameny / jak zajaţ prii triumfu! Retézem magickým zlé síly spoutáme. / A donutíme zem, by rozkvetla, jak ješté nekvetla, I a mezi rủžemi vstric pújdem nesmrtelnosti". (II, 1-2, IV, 1-3; VII, 1-4; "Es nahet der Tag und wir sind nicht bereit! I Aufruhr durchtobt unsere Straßen! /.../ // Es sinke, was wir bauten aus der Gehenna schwarzem Vulkanblock, I in Schutthaufen nieder! Schönere Städte, als die unsrige ist. I sah der Blick der Propheten. I.../ // Mag vor uns in den versengten Gassen tanzen der Brand / wie Gefangene beim Triumph! Wir binden die bösen Krätte mit magischer Kette an. I Und zwingen die Erde zu blühen, wie sie noch niemals geblüht, I und schreiten durch Rosen der Unsterblichkeit zu". Übers. v. O. Pick).

Auch der Weg des radikalen 'Umbaus', der ebenfalls einen für den ascensus notwendigen strukturellen Zug der schöpferischen Prozesse bildet, mündet schließlich wie a 1 le Wege - "in eine einzige Welt" "usticích v jedıném svête"., Stavitelé chrámu I Baumeister am Tempel, V. 30), in einen einzigen Punkt. Sie alle werden durch der "Gesetze Einheir verbunden und sie "kreisen und fliegen und wehn, / in deinen heiligen Willen" ("spojené jednotou zákonú tvých /... / kroužit a letét a hrát, / do svaté tvé vưle". Vigilie III, V. 24, 26), so wie alle, "Millionen Seelen", von der "Flamme eines eizigen Rhythmus" erfaßt (Se smrti hovori spici... I Mit dem Tode reden die Schläfer... . V. 151152; "až zachváti všechny, I miliony duši, v plamenech jednoho rytmu!") und mit dem Wein, der "aus einer einzigen Quelle sprudelt", berauscht werden (Proroci I Die Propheten, V. 82, 84; "Vß̧echny duse rozjarit vínem, /.../ které z jednoho pramene prýsti"). Der eschatologische Prozeß des Aufstieges und der Vollendung (der Schöpfung)

procitlý na sen svüj zapominá" (V. 5-8; "Freude ist wie ein Lied, entglitten höherem Leben, / im Rausch mystischen Weins gesungen, I wie Lächeln auf strahlendem Antlitz des Schlāfers, wenn jählings er erwacht, seinen traum vergißt').

504 Diese Formulierung verwendet A. A. Hansen-Löve (ibid., S. 273ff.) in bezug auf die rituelle Funktion der apokalyptischen Symbole bei der Inszenierung eines "adventistisctien Dramas". In den (links-)utopistischen Konzepten des russischen Symbolismus nach 1900 solte der Kunsttext von der Apokalypse "verschlungen" und die Kunstschöpfung zur kunstreligiösen Pertormanz transformiert werden. 
konvergiert zu dem "höchsten Zusammenklang", zum Empłang der Gnade: "Tu z oteviených prostorủ tvé slávy zpivá chor, / bolesti souzvuk nejvyšši, všech stínủ skrytý jas, I všech životủ a smrti objeti a sladký rozhovor / a z bouře zápasu, jenž věky hỉmi, mystický hodokvas" (Milost / Gnade, letzte Strophe; "Da aus erschloßnen Räumen weit singt deines Ruhmes Chor, I der Schmerzen höchster Vollakkord, aller Schatten verborg'ner Jubelstrahl, / aller Leben und Tode Umarmung und süßer Zwiesprach / und aus dem Kampfsturm, donnernd durch die Zeit, mystisches Feiermahl"). So fallen Ziel des Kosmos und Ziel der Heilsgeschichte zusammen. Der Endpunkt dieses Prozesses ist "Omega“, 505 Ziel und Heimkehr der Menschheit.

\subsubsection{Erwartung des 'ewigen Morgens' - An der (Zeit-)Grenze zwischen Vorahnung und Erfüllung: Vigilie I-III (Vigilien I-III)}

\begin{abstract}
"Himmel und Erde werden vergehen: meine Worte aber werden nicht vergehen. I.../ Seht euch vor, wachet! denn ihr wißt nicht, wann die Zeit da ist. I.../ Was ich aber euch sage, das sage ich allen. Wachet!"
\end{abstract}

Markus, 13, $31 f$.

\section{Vigilie}

I

Jak stráže tvé bdíme

na mistech nebezpezenství;

płed námi hranice svaté tvé noci,

za námi království spících.

Těžký dech bratưi nám do tvátí šlehá. rož̌haven tisíci sluncí,

jež sálaji před jejich zraky

ve snéni uzavłemými,

pro nás už neviditelná.

10 A gesta jejich nesčetných rukou. umdlených $k$ smrti pracemi snění. jež mamé se hledají ve tmě.

a zmatená slova šeptaná ze snư. dušená polibky stinů.

spojuji naše duše $\checkmark$ nový smysl

\section{Viglien}

\section{I}

Wir, deine Wachen, sind wach

an den Stätten der Gefahr;

vor uns die Grenzen deiner heiligen Nacht, hinter uns das Königreich der Schläfer.

Der Brider schwerer Atem schlägt uns ins Antitz. von tausend Sonnen entfacht.

die vor ihren im Träumen

geschloßnen Blicken erlodem,

für uns schon unsichtbar.

Und die Gesten ihrer zahllosen Hände.

die todmatt von der Arbeit des Traumes sind.

die im Dunkel vergeblich sich suchen,

und die wirren Worte, im Traume geflüstert.

gedämpft von Küssen der Schatten,

vereinen unsere Seelen

zu neuem Sinn.

505 Von Pierre Teilhard de Chardin aktualisierte johanneische Bezeichnung des menschgewordenen Christus. Nach Teilhard führen alle Entwicklungslinien zum Punkt Omega, $d$. $\mathrm{h}$. der Allerlösung unweigerlich entgegen. Er ist der kosmische Brennpunkt, auf den hin alle geistigen Energien der Menschheit zusammen strömen. Die Triebkraft, die diese zusammenstrebende Bewegung bewirkt, ist die Liebe (Agape). Seine Erreichung bedeutet die volle Harmonie einer einheitlichen Menschheit. Die Schópfung ist von Gott, vom Punkt Alfa. ausgegangen. Qualitativ kulminiert sie im Menschen und sie vollendet sich durch die Heimführung der Denkwesen zu ihm. In dieser Endphase steht der Christus-Omega. Er ist Kraftzentrum, auf das hin die Teilhardsche Noosphäre (die Sphäre des Geistes) konvergient. Aus der KosmoGenese erfolgt die Bio-Genese, aus ihr die Noo-Genese und aus dieser das höchste Ziel: die Christo-Genese. Christus, als Kosmokrator, ist der Fokus des Universums und der wirkliche Vollender aller schöpferischen Prozesse. Vgl. Pierre Teilhard de Chardin, Le Milieu Divin, Paris 1957, S. $80 \mathrm{ff}$. 
Hvèzda za hvězdou hasne. za svêtem svêty, vtefiny mrtvé

na orloji věkú.

A ti, kteři $z$ braţ̌i se probudili, sedají vedle nás. ubledlí ještě tajemstvím spánku. $k$ vigiliím.

A płece, tolikrát, slabí, záviděli jsme spícím!

Zár našich zraků spálil nám rasy. kdyz jsme je płivfeli mdlobou.

Všechna světla,

30 jež do rukou vtiskli nám odcházející, vyhasla $v$ nasich lampách a my jesté bdíme.

Jen mołe svétélkující, plameny modré. nad poklady skrytými v hlubinách zemé.

35 chvêjí se క̌achtami noci, homické kahany

z výšin svêttla sestouplých

dêlníkù-stínù.

A tušení našeho jitra $v$ dálce!

40 Ve tmách symboly věcí, mỉenlivé.

Slyšte! Paprsků píseñ. sluchová halucinace. zahłmění zvonư neviditelných do bděni vysileného,

zaznívá $k$ našim duším płes celou hloubku zemé!

Odvrácená polokoule našeho svêta tam koupe se v slunci priśtitho rána!

10 Kvetouci zahrady ostrovú jižnich tam pluji uprostfed moři!

Neznámi ptáci $v$ oblacích jisker a písní

snesli se nad lesy palem!

Světlem jak tízí zlatého vína

15 se płevrhly kalichy kvêtů. až rozlité voní $z$ trávy!

Motýlưm vž̉ala se $v$ plameny křidla rychlostí letu!

Ale zde noc, otevłená věkům,

20 a zraky otevłeně noci

a bolest bránící zavłít je $v$ snèní

a oklamat žízeñ retũ

polibky stínú ...

Z chvile zas tê̌zce vyruistá chvile,
Sterne um Steme verlöschen.

Welten um Welten,

tote Sekunden

an der Uhr der Zeiten.

Und die Brider, welche erwacht sind,

setzen sich neben uns.

noch bleich von des Schlafes Geheimnis.

zu Vigilien.

Und doch, wie oft, wir Schwachen,

neideten wir die Schläfer!

Unsere Wimpern verbrannten im Glutblick. als wir sie mude halb schlossen.

Alle Lichter.

die uns die Schwindenden in die Hand driickten.

erloschen in unseren Lampen

und noch sind wir wach.

Nur das phosphoreszierende Meer, blaue Plammen

iber ruhenden Schätzen im Erdinnern.

durchzittem die Schätze der Nacht.

Bergmannslämpchen

aus den Höhen des Lichts herabgestiegner

Arbeiter-Schatten.

Und Ahnung unseres Morgens im Weiten!

Im Dunkel Symbole der Dinge.

die schweigsamen.

\section{II}

Höret! Das Lied der Strahlen,

Gehörshalluzination, unsichtbarer Glocken Gedonner in das Wachen des Entkräfteten,

tönt her an unsere Seelen

über die Tiefe der Erde!

Dort badet die abgewandte Halbkugel

unserer Welt in der Sonne

künftigen Morgens!

Blühende Gärten südlicher Inseln. dort schwimmen sie mitten im Meere!

Fremde Vögel in Wolken von Funken und Liedem

ließen sich nieder auf Palmenwälder!

Licht gleich der Schwere goldenen Weines

kippte die Kelche der Blumen,

daB sie verschüttet dem Grase entduften!

Die Fügel der Falter wurden zu Fammen im eiligen Fluge!

Hier aber Nacht, den Zeiten erschlossen,

Blicke, der Nacht geöffnet.

Schmerz wehrend im Traum sie zu schließen und den Durst der Lippen zu täuschen mit Küssen der Schatten ...

Schwer entsteigt eine Weile der anderm. wie Abgrund dem Abgrund. 
již $v$ podzemnich sklepenich horstva vápencového staletí klenou:

ztracená łeka, se světla šícená do tmy.

vrází tam, zpęněná, v tisíce slují a hledá a volá žhavého milence svého, slunce!

Celý svět kvilících zvuků. jak bázeñ kleneb se sesouvajících, hrímá ohlasem jejîho pláce. marné: zapadlo slunce, zapadlo v studených lesích, die Sonne ging unter, ging unter in Wäldem voll stalaktitových ... Stalaktitenwäldem ...

den in unterirdischer Wölbung des Kalksteingebirges Jahrhunderte wölben: ein verlorener FluB, aus Licht ins Dunkel geschleudert, stürzt dort, verschäumend, in tausend Höhlen und sucht und ruft seine heiße Geliebte, die Sonne!

Die ganze Welt klagender Töne, wie Angst stürzender Felswölbungen, erdröhnt von ihrem Weinen umsonst:

Kühle,
III

\section{Ó Moci Vě̌ného Slova!}

Vysvobozujicí!

Soumraky v sladkost rozpouštějící druhým světlem!

5 Modlitbè nové nás nauc $v$ bolestech naSich nad sněním bratř́!

Modlitbé úzkosti smrti a krve utišující. úzkosti lásky a vzristu sesilující,

10 ovládající bytosti neviditené. od lož́ brattri zaklínající upíry snění!

$A$ až promènî́s v jediný požár okamžiky naše.

15 slehni svým vichrem $\checkmark$ jejich jiskłicí chaos: do čtył tajemných pólư je rozvěj a v hlubinách noci na sta mil od sebe nechej je záriti.

20 jak v blankytu Cemém systémy hvězd.

a závratný prostor vesmín tvého pronikat vroucností světla spojené jednotou zákonù tvých,

25 hasnout a znova se nítit. kroužit a letêt a hrát. do svaté tvě vưle po věky!

\section{III}

O Macht des Ewigen Wortes!

Erlösungsreiche!

Dämmerungen in Süße zerlaßend

durch das andere Licht!

Lehr' uns ein neues Gebet

in unsem Schmerzen

uber dem Träumen der Brider!

Gebet, stillend die Ängste des Todes und des Blutes. stärkend die Ängste der Lieb' und des Wachstums, unsichtbare Wesen beherrschend, bannend vom Lager der Brider des Traumes Vampire! Und bis du unsere Augenblicke in einen Brand verwandelst. dann la $B$ deinen Sturmwind peitschen ihr funkelndes Chaos: zu den vier geheimnisvollen Polen verweh sie und $\mathrm{I}_{\mathrm{a} B}$ in den Tiefen der Nacht durch hundert Meilen getrennt sie erstrahlen, wie im schwarzen Azur die Stemensysteme. und deines Weltalls abgrindigen Raum mit heißem Lichte durchdringen. durch deiner Gesetze Einheit verbunden. löschen und wieder entlodem. kreisen und fliegen und wehn. in deinen heiligen Willen auf ewig! 
Die im Adventismus des kosmogonisch-eschatologischen Welt-Modells dominierende 'Erwartungshaltung' des (schmerzvollen) "Wachens" spielt - wie schon der Titel andeutet eine hervorragende Rolle in Vigilie I-III.506 Das Hauptsujet dieses Gedichts bildet also das Warten auf das Kommen des ewigen "Morgens", des Heilsgeschehens, in der Z e i tspanne zwischen "Vor-Ahnung" ("tušeni", Vigilie I, 39) und der erwarteten (und erbitteten) Erfüllung (Vigilie III).

Das Gedicht besteht aus drei mehr der weniger selbständigen Sujetsequenzen (I-III). wobei die erste und die zweite als quasi Monologe der "Wachenden" aufgefaßt werden können. Die dritte Sequenz ist als 'Gebet' strukturiert, mit dem sich die vigiles an den "Höchsten" wenden. Die erste Sequenz (Vigilie I) thematisiert das adventistische Warten (Wachen) auf den Aufbruch des (ewigen) "Morgens" ("jitra") an der Grenze zwischen 'Nacht' und 'Tag' 'hier' und 'dort'. In Vigilie II wird das Thema der verrinnenden Zeit der Weltgeschichte, die 'Suche' des Zeit-Flusses nach seinem heilsgeschichtlichen Telos, ja nach dem Eschaton, in den Vordergrund gerückt. Das Hauptthema von Vigilie III ist die Erfüllung und Vollendung der Zeit: Die vigiles wenden sich an die "Macht des Ewigen

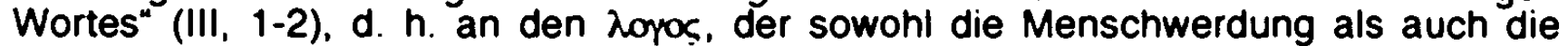
Vollendung/Erlösung vorbereitet, mit ihrer Bitte um das Kommen der "n e u e n * Zeit, der Heilszeit, aư die sie warten: "Modlitbé nové nás nauč", III, 5; "Lehr' uns ein neues Gebet"). Der Nachdruck liegt hier auf dem Adjektiv "neu", das auch in Vigilie I vorkommt: "spojuji naše duše / V nový smysI" (I, V. 15-16; "[sie] vereinen unsere Seelen / zu neuem Sinn"). Während die dritte Sequenz sich, wie noch zu zeigen sein wird, auf die erste bezieht, die die erwähnte Zeitproblematik als (visionäres) $S \mathrm{ch}$ a u e $\mathrm{n}$ der kommenden Heilszeit entfaltet, bleibt die zweite Sequenz im Textganzen quasi 'isoliert', was jedoch eine konkrete Funktion in der Sinnstruktur des Gedichts hat: Der rasende, nach seinem Telos suchende 'Zeit-Fluß', das sinnzentrierende Motiv von Vigile II, 'fließt' sozusagen zwischen den beiden Polen von Vigilie I und Vigilie III: zwischen 'Nacht' und 'Tag', 'hier' (Diesseits) 'dort', (Jenseits), 'Zeitlichkeit' - 'Zeitlosigkeit', 'Erwartung' - 'Erfüllung'

Den Sinn des Wach-Seins der vigiles, der "Wachen" des "Höchsten", ("ak stráže tvé bdime", 1, 1: "Wir, deine Wachen"), erklärt der als Motto zitierte Versett aus dem MarkusEvangelium $(13,31)$ : "/../ wachet! denn ihr wißt nicht, wann die Zeit da ist". Die vigiles befinden sich in einem Grenzbereich ("před námi hranice /.../ za námi", I, 3-4; "vor uns [prospektiv] die Grenzen /.../ hinter uns [retrospektiv] /... ${ }^{\prime}$ ), "an den Stätten der Gefahr" ("na mistech nebezpecenstvi", I, 2).507 Die prospektive Orientierung scheint sich auf die Bedeutung von vigilia(-ae) als Vortag des höchsten Festes und als Nachtgebet zu beziehen: "A ti, kterí $z$ bratri se probudili, / sedaji vedle nás, / ubledli jesté tajemstvím spánku, / k vigiliím" ( I, 21-24; "Und die Brüder, welche erwacht sind, / setzen sich neben uns, / noch bleich von des Schlafes Geheimnis, / zu Vigilier"'). Während die "Schlafenden" (V. 4: "spici") das Nahen der Endzeit, der Erfüllung, nicht voraussehen können, richten die wachenden Brüder, die an der "Grenze" zwischen der "heiligen N a c ht" $(1,3)$ und dem "Königreich der Schläfer ("království spicích", I, 4), zwischen einem sakralen und einem profanen Raum wachen, ihren (visionären) Blick in die "Ferne" ("dálka"; I, 39), d. h. auf das nahende Eschaton hin. Daher sehen die vigiles - da sie sich im Zustand der

506 Das Gedicht Vigilie I-III stellt sowohl formal (verssemantisch) als auch inhaltlich ein bemerkenswertes Experiment dar. Das Neue tritt bereits auf der syntagmatischen und mythmischmetrischen Ebene zutage. Im Vergleich mit dem für Bỉezina charakteristischen langen vers libre (mit deutlichen Allusionen auf den klassischen Hexameter), zeichnet sich dieses Gedicht durch eine innovative verssemantische und versrhythmische Struktur aus. An Stelle der langen Verszeilen, von denen jede ein 'Mikro-Sujet' entfaltet, bestehen die drei Teile von Vigilie aus kurzen, höchstens vierzehnsilbigen Verszeilen. Wie $M$. Cervenka betont ( $Z$ vecerni skoly versologie II, Praha 1991, S. 62), rufen die radikalen Eingriffe in die Intonationsstruktur des Verses nahezu physische Eindrücke von heftigen wirbelnden Bewegungen, Blitzzuckungen (ăhnlich wie in Nade vsemi ohni a vodami... I Über allen Feuern und Wassem... ) usw. hervor. In Vigilie soll dieser in einem gewissen Sinne extreme Verstypus den ebenso extremen Zustand, in dem die vigiles verharren, evozieren.

507 Die (mystische) Triplizităt, auf der die in Vigilie konstituierte semantische Welt fußt, wird explizit durch die Gliederung des Textes in drei Teile (I-III) markiert. Hinzu kommen die drei Bedeutungen von vigil-es/vigilia-e (die Wachen, der Vorabend vor einem großen religiösen Fest, das Nachtgebet; auch in der Bedeutung von vigilia - das Wachen, meton. 'Nachtwache') und schließlich auch die Grenz-Position der "Wachenden" zwichen zwei entgegengesetzten Sphăren, zwichen 'hier' und 'dort'. 
visionären Entrückung befinden - die "tausend Sonnen", die vor den geschlossenen Blicken der "Schlafenden" erlodern, nicht mehr (V. 9; "pro nás už neviditelná"; "für uns schon unsichtbar"). Sie (ihre Seelen) sind auch imstande, die "wirren Worte" der "Schlafenden" zu einem "neuen Sinn" zu vereinen: "a zmatená slova septaná ze snů, I...I spojuji naše duše / v nový smysl" (V. 13, 15-16). Alles erlangt einen "neuen Sinn" erst sub specie aeternitatis, erst vom Standpunkt des Endziels der Geschichte aus bekommt auch die (geschichtliche) Zeit, deren Bewegung von dem hic-et-nunc-Standpunkt aus völlig zielund sinnlos erscheint, ihr Telos. Bas Nahen der Endzeit indiziert das Motiv des 'Dahinschwindens' der irdischen, diesseitigen Zeit(lichkeit), das das Verlöschen der Sterne symbolisiert: "Hvězda za hiězzou hasne, / za světem svĕty, / vteriny mrtvé / na orloji věkü" ("Sterne umd Sterne verlöschen, / Welten um Welten, / tote Sekunden / an der Uhr der Zeiten", I, 17-20).

Im Schlafzustand wird das aktive Tun, der von der "Arbeit des Träumens" ermattenen Hände zu unsicheren Gesten, 508 zum vergeblichen Suchen in der Dunkelheit: "A gesta jejich nesčetných rukou, / umdlených k smrti pracemi sněni, / jeż marné se hledaji ve tmè" (V. 10-12). Dieses Bild verweist auf den für die Sinnkonstitution des Titelgedichtes Stavitelé chrámu hochrelevanten Unterschied zwischen den "Schlafenden" $r$ Träumenden" und denen, deren "Seelen keine Träume hatten" ("jejich duše neméla snu"), d. $h$. den am "Tempel-Bau" partizipierenden und dadurch privilegierten "Arbeitern". Die Gestalt der wachenden und tätigen "Arbeiter" kommt auch in Vigilie I vor: "s výsin světta sestouplých dẻlníkú-stínü" (V. 37-38). Sowohl die "Baumeister" als auch die vigiles stehen "im Dienste" des "Höchsten", die einen als seine "Wachen" ("Jak stráże tvé", Vigilie I, 1; "Wir deine Wachen"), die anderen als "Baumeister" seines Tempels ("Mezi nimi šli stavitelé tvého chrámu". Stavitelé chrámu / Baumeister am Tempel, V. 72; "Zwischen innen schritten die Baumeister deines Tempels"), und beide Gestalten verfügen über ein besonderes Charisma: während die "Baumeister" in der Lage sind, das 'Projekt' des creator macrocosmi, seinen eschatologischen Plan, zu erkennen, sind die vigiles in der Lage, das Nahen des Eschatons, das Kommen der Heilszeit vorauszusehen, da sie die (besondere) Kraft haben zu wachen ("a my ještè bdíme", V. 32; "und wir sind noch wach"). Ein anderes gemeinsames Merkmal des aktiven Tuns ist das Schmerzerlebnis, das sowohl das kreative Schaffen der "Baumeister" wie auch das Wach-Sein und das Warten der vigiles begleitet. Es ist die quälende Ermüdung und die brennende Luzidität (des visionären Schauenş), die die vigoles ertragen müssen: "A prece, tolikrát, slabi, / závidéli jsme spicím! / Zár našich zrakú spálil nám rasy, / koyż jsme je privỉeli mdlobou" (1, 25-28; "Und doch, wie oft, wir Schwachen, I neideten wir die Schläfer! / Unsere Wimpern vertrannten im Glutblick, / als wir sie müde halb schlossen"). Hier drängt sich die Frage auf, warum das (quälende) "Wachen" $/$ Warten" bei Biezina als a ktives Tun betrachtet wird? Abgesehen von der oben erwähnten Ähnlichkeit zwischen den vigiles und den "Baumeistern", scheint der aktive Charakter dieses Zustandes in drei Aspekten zu gründen. Es ist der adventistische Aspekt, das sehn-süchtige "Erwarten" der parousia, des Eschatons, der Vollendung der Schöpfung, die aber schon hic et nunc eine aktive Teilhabe Aller erfordert; der existentielle Aspekt, das Warten auf das wahre, vollendete Leben, und der altruistische Aspekt, das aktive "Wachen" "Leiden" für die "Erdenbrüder". In der Korrespondenz aus der Abfassungszeit von SCh geht Biezina immer wieder auf diese zwei Aspekte des aktiven "Wachens" ein: "Býti bdicim mezi spícími, ano, ale modliti

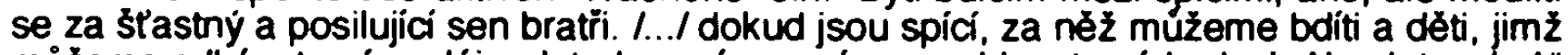
mưžeme odkázat své nadéje, dotud nemáme práva zrychlovat své kroky k Absolutnu $/ . . . I^{. "}$

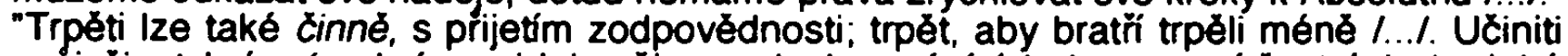
svúj Život krásným krásou ideje, Činu, odvahy ménici bolest ve vítézstvi /... I - jaká báseñ!" 509

508 "Kdo pł̉ed námi krácel / a vył̉ezal znameni do kủry stromủ pralesa tvého, / jimž nerozumime? l.../Prođ̌ slova prorokủ zni jako halucince / $\mathrm{k}$ našemu sluchu?" (Se smrti hovori spici .. Mit dem Tode reden die Schläfer..., V. 38-42; "Wer wanderte vor uns / und schnitt Zeichen in die Rinden der Bäume deines Urwaldes hinein, / die wir nicht verstehen? /... / Warum tönen der Propheten Worte wie Halluzinationen / an unser Gehör?").

509 O. Biezina, Dopisy A. Pammrové z let 1889-1905, Praha 1931, Briefe v. 23.1. 1898 und v. 10.Il. 1898: "Ein Wachender unter den Schlafenden zu sein, ja, aber für den glücklichen und stärkenden Traum der Brüder zu beten! /.../ solange es Schlafende gibt, für die wir wachen können und Kinder, den wir unsere Hoffnungen vermachen können, haben wir kein Recht unsere Schritte zum Absoluten zu beschleunigen I... $F$. (S. 178). "Leiden kann man auch aktiv, mit der Úbernahme 
Was aber charakterisiert das Tun der "Arbeiter-Schatten" in Vigilie I? Es ist der (positivierte) descensus aus den "Höhen des Lichts" ("z výsin světla", V. 37) zu den "ruhenden Schätzen im Erdinnern" ("poklady skrytými v hlubinách zemè", V. 34). 510 Die in den Tiefen verborgenen "Schätze" sind offensichtlich die göttlichen Lichtfunken und die "im Erdinnern" verborgenen Hoffnungen auf die eschatologische Zukunft, die in Královna nadéji (Königin der Hoffnungen; theo-logisch-eschatologisches Modell) der "Wille der Heiligen" ("vüle svatych", V. 52) ent-hüllt ("otvirá poklady ukryté staletí v hlubinách skal" (V. 53; "öffnet die Schäzte, Jahrhunderte lang in den Tiefen der Felsen verborgen"). Die "Arbeiter-Schatten" haben eine ähnliche Funktion: Die "Schätze" mit ihren Bergmannslampen ("hornické kahany", I, 36) sichtbar zu machen, sie zu ent-hüllen. Damit koinzidiert auch die Positivierung des lunaren Lichtes (s. o. Kap. 5), das hier nicht (mehr) die trostlose Leere, die entkräftende und "geheimnisvolle Ferne" der eisigen Nacht-Welt unheilvoll beleuchtet, sondern änigmatische 'Licht-Zeichen' ausstrahlt, die zu jenen "Schätzen" führen (können): "Jen mớe svétélkujici, plameny modré, / nad poklady I... $\mu$ (I, 33-34; "Nur das phosphoreszierende Meer, blaue Flammen, / über ruhenden Schätzen I... $\left.\mu^{\prime}\right)$. Die gleiche appellative Funktion hat auch die verheißungsvolle Fluoreszenz in Zemè vitězú (Das Land der Sieger): "A když se pievalily viny světelně, / hle, květem modrých plamenú zem po nich horela" (V. 13-14; "Und der leuchtenden Wellen Ebbe, / siehe, ließ der Erde blaue Flammen entblühn“.). Die vigiles ahnen schon das Nahen des neuen "Morgens" in der Ferne, während die "Symbole der Dinge" - die adventistischen Dinge Zeichen? - (noch) im Dunkeln schweigen (1, 39-41).

Signifikanterweise leitet die zweite Sujetsequenz (Vigilie II) die Aufforderung "Slyšte! Paprskú pisen" ("Höret! Das Lied der Strahlen", II, 1) ein, d. h. die Aufforderung zum luziden 'Schauen'. Diese appellative, alle Sinne ("Lied der Strahlen') 'aktivierende' Funktion hat natürlich auch das " unsichtbare Gedonner der Glocken / in das Wachen des Entkräfteten" (II, 3-4; "zahřměni zvonú neviditelných / do boẻni vysileněho"). Was soll wahrgenommen werden? Die Schau des "künttigen Morgens" ("prištúho rána", II, 9), einer Licht-und (Sonnen-)Welt, jenes zukünttigen "Landes der Sieger" (Zemé vitézu', SCCh), in dem das Heilswerk in Erfüllung gehen wird. Es ist die apollinische Welts11 des Logos/Abyoc, der Saiten/Strahlen-Musik (II, V. 1) und der solaren Energie: "Odvrácená polokoule našeho světa / tam koupe se v slunci / prỉstího rána! I... / Světtem jak tiżi zlatého vina / se prevurhly kalichy kvêtü" (II, V. 7-9, 14-15; "Dort badet die abgewandte Halbkugel / unserer Welt in der Sonne / künttigen Morgens! ${ }^{m}$ /... / Licht gleich der Schwere goldenen Weines / kippte die Kelche der Blumen“). Die höchste Luzidität, eines der Attribute der solaren Lichtwelt, offenbart sich auch in der 'Entflammung' und im 'Brennen' des Logos als Manifestation der solaren Energie: "Motýlúm vzhala se v plameny krídla / rychlosti letu!" (II, V. 17-18; "Die Flügel der Schmetterlinge wurden zu Flammen / durch die Geschwindigkeit des Fluges!"). 512 Das Motiv der "Geschwindigkeit" deutet hier (u. a.) auf

der Verantwortung: leiden, damit die Brüder weniger leiden $/ . . /$. Unser Leben durch die Herrlichkeit der Idee, der Tat, der Kühnheit, die den Schmerz in Sieg verwandelt /.../, schöner zu machen - welch ein Gedicht!". (S. 181).

510 Wie Aage A. Hansen-Love darlegt (.Apokalyptik und Adventismus im russischen Symbolismus der Jahmundertwende", in: R. G. Grübel (Hrsg.). Russische Literatur an der Wende vom 19. zum 20. Jahrhundert, Amsterdam-Atlanta 1993, S. 261), ist in der Apokalyptik des (russischen) Symbolismus jede Bewegung mit Entwicklung, Entfaltung usw. gleichbedeutend. In der Intention der dionysischen Erlösungslehre bildet der descensus (als Dissoziation, Aufiösung oder 'Erdwerdung' des Menschen) die Voraussetzung der Erlosung. Ein makrokosmisches Analogon dieses Prozesses stellt die Dissoziation des Ur-Einen im Akt der Schöpfung. bei der auch der katastrophische Aspekt eine Rolle spielt. Der descensus (als Verzeitlichung des Ewigen) korrespondiert mit dem ascensus (als Verewigung des Zeitlichen).

511 Zur mythisch-religiōsen bzw. alchemistischen Symbolik der Sol vgl. die ausführliche Darstellung von C. G. Jung, Mysterium coniunctionis, erster Teil, Zürich1955, S. 100-120.

512 Die "Schmetterling-Wort"-Metapher (offensichtlich als Ausdruck der Gebundenheit des Logos an das Pneumatische, Geistige, Mentale) kommt in Královna nadéji (Die Königin der Hoffnungen, VP) vor: "Tỉpytem motyliho letu se nesla má słova, bez bázné sedala na plameny" (V. 25: "Der Glast des Schmetterlingsflugs trug mein Wort, das furchtios sich niedersenkte auf Flammen"). Das Motiv des brennenden logos spermatikos erscheint bereits in Ranni modlitba (Das Morgengebet, SZ) und in Poledni zráni (Mittäglich Reifen; VP). In SCh wird das "Ewige Wort" - als das vertieißende Wort des Lebens, des Sieges über den Tod, das die "Schlafenden" erweckt, zum "glühenden Korn", zu lodernden, blendenden "Funken": "oblaky jisker pokryly ostrovy duši a zmim svatého ohnẻ pálily spici" (Se smrti hovorí spici.../ Mit dem Tode reden die Schläfer..., V. 
die postulierte "Beschleunigung" ("urychleni") des Kommens der Heilszeit und der Vollendung hin. Doch die vigiles befinden sich (noch) 'hier', in der diesseitigen Sphäre, ("Ale zde noc otevǐená vékủm, I a zraky otevĩené noci", II, 19-20; "Hier aber Nacht, den Zeiten erschlossen, I Blicke, der Nacht geöffnet"), in der ihre Wachsamkeit der Probe unterzogen wird, dem Zustand des Träumens ("snëni", II, 21) nicht zu verfallen, sondern sich dagegen erfolgreich zu wehren:513 "oklamat žizeñ retú / polibky stínů..." (II, 22-23; "den Durst der Lippen zu täuschen i mit Küssen der Schatten..."). Es ist erneut der "Schmerz" ("bolest"), der innen dabei hilft ("a bolest bránici zavirít je v sněni", II. 21; "Schmerz wehrend im Traum sie zu schließen").

Die Zeitproblematik wird in der nächsten Textsequenz (II, 24-38) im Bild der verrinnenden geschichtlichen Zeit wiederaufgenommen (II, 24-38). Hier geht es nicht um das 'Verlöschen' der Zeit ( Vigilie I: "Hvězda za hvězdou hasne, / za světem svĕty, I vteřiny mrtvé", I. 17-19; "Sterne um Sterne verlöschen, / Welten um Welten, / tote Sekunden"). das die visionäre Schau der nahenden Endzeit antizipiert, sonden - im Gegenteil - um das "schwere Entsteigen einer Weile der anderen" ("jak z propasti propast". II, 25; "wie Abgrund dem Abgrund"), um die 'Dilatation' der Zeit der Weltgeschichte mit ihren Ablagerungen und "Abgründen" ("v podzemnich sklepenich horstva vápencového" (II, 27 28; "in unterirdischer Wölbung / des Kalksteingebirges"). In der geschichtlichen Zeit entsteigt eine Weile der andreren, alle zusammen ein gewaltiger Zeit-Fluß, der sich in einem endlosen, dunklen Abgrund ("ztracená reka, se světla sñcená do tmy", II, 29; "ein verlorener Fluß, aus Licht ins Dunkel geschleudert") verliert, wo er herumirrt und vergeblich nach dem 'ewig lodernden' solaren Fokus, nach dem Telos, sucht: "vraží tam, zpẻnẻná, v tisice sluji / a hledá a volá žhavého milence svého, / slunce!" (V. 30-32; "stürzt dort, verschäumend, in tausend Höhlen / und sucht und ruft seine heiße Geliebte, / die Sonne!"). In der geschichtlichen Zeit verliert sich das Telos in der Tiefe der Urzeit: "zapadlo slunce, zapadlo v studených lesích, stalaktitových ..." (II, 37-38; "die Sonne ging unter, ging unter in Wäldern voll Kühle, / Stalaktitenwälder ..."). Das Bild des "aus Licht ins Dunkel geschleuderten" und dort verzweifelt und vergeblich nach dem Telos suchenden (geschichtlichen) Zeit-Flusses scheint lediglich eine andere Erscheinungsweise des gleichen "tragischen Durstes 514 der Suchenden" zu sein: "tragická żizeñ hledajicich" (Stavitelé chrámu / Baumeister am Tempel, V. 29); "Vßechno je piné żíznè. A suché rty

145: "Wolken von Funken bedeckten die Inseln der Seelen und sengten mit Körnern des heiligen Feuers die Schläfer"). R. Bultmann verweist auf die Tradition der kosmologischen Mythologie, aus der die Bedeutung des $\Lambda$ f́rox stammt und die namentlich Philon von Alexandrien, bei dem $\Lambda$ ífycs. eine Parallele zu Sofia bildet, beeinflußt hat. Dabei hat der $\Lambda$ óyos (bei Philon) nicht nur die kosmologische, sondern auch die soteriologische Funktion. In dieser Tradition erkennt $R$. Bultmann den Ursprung des johanneischen Aíprx. Vgl. dazu: R. Bultmann, Theologie des Neven Testaments, Tübingen 1953, S. 411

513 Genau das meint auch die Mahnung der apokalyptischen Rede in Mk. 13, 31-37: "Gebet acht, wachet! / Denn inr wißt nicht, wann die Frist da ist" $(13,33)$. Nicht im Schlummern oder im Trăumen verläuft die Existenz in der $\pi$ (irus (als Voraussetzung der eschatotogischen Existenz). sondern im Zustand der nahezu peinigenden Luzidität und der nüchternen Anstrengung des Wach-Seins. Im Neuen Testament wird das Wachen oft vom Beten begleitet; dabei wird der Ekstasis eine durchaus positive Bedeutung zugewiesen. Wach-Sein und Ekstase sind im Urchristentum keine Gegensătze, sondern sie gelten schon als Vorzeichen des eschatologischen Geschehens. (Vgl. hierzu den hervorragenden Kommentar von Emst Lohmeyer, Das Evangelium des Markus [17. Aufl.], Göttingen 1967, S. 279ff.). Die Invokation der eriösungsreichen "Macht des Ewigen Wortes" (Vigilie III, 1; "O Moci Véćného Slova") muß, m. E., als intertextuelle Allusion auf die oben erwähnte Mk.-Stelle gelesen werden: "Meine Worte werden nicht vergehen" (MK. 13, 31). Damit wird explizit gesagt, daß es weder die Taten Christi, noch sein Leiden und Tod sind, die die in Vig. III, 1 adorierte eschatologische Macht tragen, sondern Seine "Worte". In dem "ewigen Wort" ist alles zusammengefaßt, "weil Er es spricht: Er ist der Vollender, weil Er der Lehrer dieser nicht vergehenden Worte ist, Er ist der Lehrer, weil Er der Vollender ist" (E. Lohmeyer, ibid., S. 282).

514 Vgl. die Parabel vom Brunnen und Lebenswasser (Joh, 4, 14ff.): "/.../ wer aber von dem Wasser trinken wird, das ich ihm gebe, der wird in Ewigkeit nicht dürsten, sondern das Wasser, das ich inm geben werde, das wird in ihm eine Quelle des Wassers werden, das in das ewige Leben quillt". Wo das Wort Jesu ertönt, bricht die Herrschaft der Finsternis und des Todes, in dem die Welt liegt, zusammen, weil er das Lebenswasser bringt. In Vigilie II scheint der johanneische Dualismus ('Licht'-'Finsternis', 'Leben'-'Tod', 'Wahrheit' ' 'Wirklichkeit' - 'Lüge' $r$ 'lllusion' usw.) in einem myth(olog)ischen Gewand (in der Polarisierung des apollinischen und dionysischen Prinzips) zu erscheinen. 
stále nás hledaji ve tmách /... ${ }^{\mu}$ (Se smrti hovori spici... I Mit dem Tode reden die Schläfer..., V. 91; "Alles ist voll Durst. Und es suchen uns ständig die trockenen Lippen im Dunkel").

Man könnte auch folgende Allegorese vorschlagen: Das 'Untertauchen' der Sonne bedeutet (abgesehen von der möglichen psychologischen Bedeutung) nicht nur das Verlorengehen des Telos, sondern auch das Verlorengehen des Lichtes im Sinne der Einbuße des "Wort-Sinnes" (des johanneischen "Wort-Licht-Leben(s)" der Welt). Inhalt und Sinn des "Wortes" lassen sich nicht mehr dechiffrieren, man kann sie nur noch als leeren "Widerhall" vernehmen ("hrímá ohlasem jejího pláce , I marnë", II, 35-36; "erdröhnt als Wiederhall ihres Weinens, vergeblich"). Es sind die vigiles des "Höchsten", die wachen müssen, um aus dem "Lied" des "Licht-Heeres" das "göttliche Wort" auffangen und "in die Scharen hineinsingen" zu können. 515 Erst im Aufbruch des "neuen Morgens" ("nového jitra"), den die vigeles ahnen und erwarten, $d$. $h$. nach der Vollendung der (geschichtlichen) Zeit sub specie aeternitatis, wird das Telos offensichtlich wieder sichtbar.

Daher wenden sich die vigiles in der dritten Sequenz (Vigilie III) an die "Macht des Ewigen Wortes" ("O Moci Vécného Slova", III, 1) mit der Bitte, die von ihnen bereits 'geahnte' ("tušeni" / "Ahnung", Vigilie I, 39) und erwartete Vollendung zu 'beschleunigen' und zu realisieren. Im Unterschied zu Vigilie I und Vigilie II zeichnet sich die dritte Sujetsequenz durch eine einheitliche Komposition aus. Sie ist fest vom Schlüssellexem der ganzen Sequenz umklammert: "Věčnost" ("Ewigkeit"; "O Moci Věčného Slova", III, 1; "O Macht des Ewigen Wortes") und "po vêky! (letzte Zeile; "auf ewig!"). Die Idee der eschatologischen Vollendung, die das Lexem "Vécnost" ("Ewigkeit") konnotiert, bildet den semantischen Nukleus nicht nur der dritten Sujetsequenz, sondern des ganzen Textes. Die dritte Sequenz ist als ein Gebet, eigentlich als eine Art Meta-Gebet, in dem um das Erlernen eines "neuen Gebets" gebeten wird, strukturiert. Das "andere Licht" (III, 4) - als Korrelat zum "Ewigen Wort" (III, 1: "Věčného Slova") -, das Bỉezina auch "vếtši světtlo" ("größeres Licht"; Pr̈roda / Die Natur, VP) nennt und das den widergöttlichen Dämmer siegreich durchdringt (III, 3), bedeutet in diesem Zusammenhang nicht etwa das Tageslicht, sondern vor allem das Licht des nahenden "neuen Morgens". Das "Wort" ist als Licht wirksam. Die vigiles erbitten ein "neues Gebet" ("Modlitbè nové nás nauč", III, V. 5), das die Kraft einer magischen Zauberformel besitzen würde, mit der sie die widergöttlichen Mächte der Fînsternis (die "würgenden Schatten" I, V. 14; die "Vampire des Träumens", III, V. 12 sowie die "bytosti neviditelné" I "unsichtbare Wesen", III, V. 10). die die Schlafenden bedrohen, bezwingen könnten: "Modlitbé úzkosti smrti a krve utišujić, I úzkosti lásky a krve sesilujici, / ovládajíci bytosti neviditelné, / od loži bratri zaklínajici / upiry sněni" (III, 8-12; "Gebet, stillend die Ängste der Lieb' und des Wachstums, I unsichtbare Wesen beherrschend,/ bannend vom Lager der Brüder / des Traumes Vampire!"). 516 Die andere Bitte, die in diesem Gebet in einer einzigen Satzperiode (III, V. 13-28) geäußert wird, betrifft die Vollendung und Erfüllung der Zeit der Geschichte ("A aż proméniś v jediný poźár / okamžiky naše", III, V. 13; "Und bis du unsere Augenblicke / in einen Brand verwandelst"), die nun "durch der Gesetze Einheit", durch den $\lambda$ ófoc, verbunden werden sollen. 517 Alle in der geschichtlichen Zeit unaufhaltsam

515 -Vzrủstala svêtelná vojska od věku $k$ vẻku jak piseñ. / již pruni zachytil z božského Slova / a mezi zástupy zapêl" (Se smrti hovori spici..., V. 146-148).

516 Die magisch-bannende Potenz des "Wortes" thematisiert in SCh das Gedicht Doupata hadü (Die Schlangenhōhlen): "Tu svaté tvé vzporninky duši mi prolétia zvěst, I nádhera mơ̌i tvỳch, tajemstvi noci tvých, sláva tvých cest: / blankyt jak brana se otevỉel, od jihu letẻlo tisice ptákư; / tvé magické jméno jsem vyslovil - a v úsmévu hvézd, / koberec pro sny. pr̉ede mnou ležely záhony rủż a maku" (IV, 1-4; "Da ging deiner heiligen Erinnerung Botschaft in mich ein, / deiner Meere Pracht, deiner Nắchte Geheimnis, deiner Wege herrlicher Schein: / das Blau stand auf wie ein Tor. von Süd her kamen tausend Vögel geflogen; / deinen magischen Namen sprach ich - und in der Steme lächelndem Schein, / ein Traumteppich, lagen vor mir die Beete von Rosen und Mohn in flammenden Wogen". Übers. v. O. Pick).

517 Der o. zitierte Vers "spojené jednotou zákonủ tvých" (III, V. 24; "durch deiner Gesetze Einheit verbunden") kann hier $m$. E. durchaus im apostolischen Sinne verstanden werden, vor allem in bezug auf seine existentielle Dimension, die es in der paulinischen Theologie aufweist und die R. Bultmann (Theologie des Neuen Testaments, Tübingen 1953, S. 260ft.) sehr prägnant enfaßt. Er betont einerseits den heilsgeschichtlichen Sinn des Gesetzes, andererseits die Einheitlichkeit des göttlichen Willens, die zugleich die "Einheitlichkeit des menschlichen Seins auf dem Wege von der Situation unter dem Gesetz zur Situation unter der xápıç" (ibid. S. 265) 
dahinschwindenden Sekunden ("vteřiny mrtvé / na orloji věkü", I, 19-20), alle "Weilen" ("chvile"), die "schwer eine der anderen entsteigen" (II, 24), um im Unwiederbringlichen des endlos tiefen Abgrundes der unerfüllten (diesseitigen) Zeit zu verschwinden und von ihrer finsteren Schlund verschlungen zu werden, alle 'dissoziierten', isolierten "Augenblicke" ("okamžiky naše", III, 14) sollen nun vereinigt und in einem "enzigen Brand" - in der Brandstätte des formenden schöpferischen Odems - verschmolzen werden. Doch damit ist der Akt der Erfüllung und der Vollendung offensichtlich noch nıcht zu Ende. Die

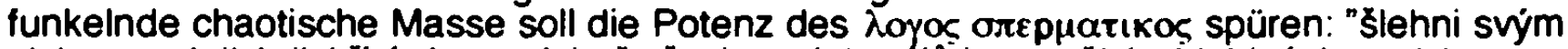
vichrem $v$ jejich jiskřici chaos; / do čtyí tajemných polư je rozvěj / $v$ hllubinách noci / na sta mil od sebe nechej je zárit" (III, 16-19; "dann laß deinen Sturmwind / peitschen ihr funkelndes Chaos; / zu den vier geheimnisvollen Polen verweh sie / und laß in den Tiefen der Nacht / durch hundert Meilen getrennt sie erstrahlen"). Interessanterweise sollen die erfültten "Augenblicke" in der "Tiefe der Nacht" (III, 18) und "durch hundert Meilen getrennt" (III, 19) erstrahlen. Die (zukunftsorientierte) Symbolik der "vier geheimnisvollen Pole" (III, 17; "Ctyr̈ tajemných pólü") ist hier offensichtlich auch auf die adventistisch-apokalyptische Rede im Markus-Evangelium zurückzuführen: "Und dann wird Er die Engel senden / und wird herführen die Erwählten / aus den vier Winden, vom Ende der Erde bis zum Ende des Himmels" (Mk. 13, 27). Engel werden die "aus den vier Winden" ("zu den vier geheimnisvollen Polen", III, 15, 17) 'Zerstreuten' herbeiholen, wenn "die Zeit da ist". Mit solcher Hinaufführung und Vereinigung der 'Zersteuten' in den "heiligen Willen" (III, 27; "do svaté tvé vưle") durch "deiner Gesetze Einheit" ("spojené jednotou zákonù tvých". III, 24), wird die Vollendung geschehen. 518 Das Entscheidende ist, daß im erwarteten Erreichen des Ziels, des Punktes "Omega", des Eschatons, alle

bedeutet. Der Sinn des Gesetzes ist es zum "Hōchsten" als Schöpfer zu führen, der das (ewige) Leben spendet. Als solcher offenbart sich der "Höchste" im Heilsgeschehen der Gnade ( $\chi$ apus). In Vigilie III tritt die Einheittichkeit des "heiligen Willens" (III, V. 27) klar zutage: Die "Entflammung", die die vigiles erbitten, scheint im Grunde nichts anderes zu sein als das Verlangen nach der Dematerialisierung der leiblichen Gegenwart für die absolute Spiritualisierung in der Ewigkeit: "AZZ promẻnís v jediny požár / okamżiky naše", (III, V. 13-14: "Und bis du unsere Augenblicke I in einen Brand verwandelst") /... "na sta mil od sebe nechej je zárit", (III, V. 19; "durch hundert Meilen getrennt laß sie erstrahlen") /... "pronikat vroucnosti svétla, i spojené jednotou zákonú tvých, / hasnout a znova se nítit, / kroužit a letêt a hrát, / do svaté tvé vúle / po věky!" (Ili, V. 23-28; "llaß sie] mit heißem Lichte durchdringen, / durch deiner Gesetze Einheit verbunden, I löschen und wieder erlodern, / kreisen und fliegen und wehn, / in deinen heiligen Willen / auf ewig!"). Vgl. hierzu: "Denn das Gesetz des Geistes, der lebendig macht in Jesus Christus, hat dich frei gemacht von dem Gesetz der Sünde und des Todes. I.../ damit die Gerechtigkeit, vom Gesetz gefordert, in uns ertültt würde, die wir nun nicht nach dem Fleisch leben, sondern nach dem Geist" (Römer, 8, 2, 4). In Vino silných (Der Wein der Starken, SZ) erwarten die gnostisierenden Pneumatiker die Errettung. d. h. die Befreiung "von den Gesetzen der Erde* (hinsichtlich der Substanz des Menschen als einer Naturgrundlage), durch eine magisch-mysteriōse Kraft (eine Vorstellung gnostischen Ursprungs): "Tajemny proud zavie se kruhem kol naseho stolu. / vymkne nás ze zákonú zemé: (V. 6.7: "Geheimnisvoll schließt ein Strom seinen Kreislauf um unser Tischrund, I hebt uns aus den Gesetzen der Erde-). Noch deutticher kommt das in der dritten Sujetsequenz von Vigilie postulierte Verlangen nach der Spiritualisierung der leiblichen Gegenwart in Milost (Gnade) zum Ausdruck. Die creatores microcosmi leiden unter dieser leiblichen Gegenwart im "Schüttelfrost des Lebens" (II, 2; "v zimnici żiti"); sie sind für die "irdischen Brüder" die "Allerärmsten" der Erde, die aber die Gnade des "Höchisten" (nach deren Verklärung) mit einem königlichen Gewand - als 'In-Signum' der Hehre der schöpferischen/künstlerischen Heiligkeit - umhülit: "a nejchudśi tvé odivá v sat královského purpuru. / jenż braţ̌ím zemé neviditelnỳ, je vidẻn andẻly. I... / zem jako v zakletí / kdyż mizi vẻtrem odvátá pred zraky vžnatými / a brány noci sklenuté před tisici se rozleti, / pobitẻ hr̉eby souhvězdi, jak znamenimi svatými" (Milost / Gnade, I, 3-4, VII, 1-4; "schlägt um die Allerärmsten dein purpurn ein königliches Kleid, I das, Erdenbrüdem unsichtbar, die Engel sehn allein. /.../ Erd' wie in Zauberbann / schwindet vor Blicken, wetche lohn, entführt vom Winde weit, / Tore der Nächte sind gewölbt vor Tausenden jäh aufgetan, / besät mit Sternen-Nägeln wie mit Zeichen ihrer Heiligkeit". Ubers. v. O. Pick.)

518 Doch erst in Zemé vitézú (Das Land der Sieger): "Neb v téchto chvilích duše ładily se podle svétel svých, / vojsk nesmrtelných pł̌ehlidka pł̉ed zrakem Vsudyprítomných, / a každá myšlenka se stala setkánim všect nekonečnosti" (V. 35-37; "Denn in diesen Augenblicken reihten sich die Seelen nach ihren Lichtern, I der unsterblichen Heerscharen Musterung vor des Allgegenwärtigen Blick, I und jeder Gedanke ward aller Unendlichkeiten Begegnung". Übers. v. $O$. Pick). 
Augenblicke in diesem Punkt vereinigt werden. Der ganze kóouos ("závratný prostor vesmiru tvého", III, 22; "deines Weltalls abgründiger Raum") ist nichts anderes als "cerná pưda etheru tvého, I... I záhyby tvého klína, I nekonečnem rozprostieného!" (Se smrti hovori spici... I Mit dem Tode reden die Schläfer..., 35-36; "deines Äthers schwarzer Grund, I.../ deines Schoßes Gefälte, / des durch die Unendlichkeit sich breitenden!"). Im Akt der Vollendung werden auch Zweifel, Angst, und Bangigkeit durch ihre 'Integration' in den "s ch w a rze n Grund des Äthers" des "Ewigen" gleichsam annuliert. Auch hier kommt die aus dem Gedicht Láska (Liebe, VP) schon bekannte Formel "bez báznè" ("furchtlos") zur Geltung: "Bez báznẻ pohliži láska v zrcadia noci /.../. / /.../ tisice smrti budete potkávat najednou v tisíci cestách bez bázne" (V. 41, 73; "Furchtios schaut die Liebe in die Spiegel der Nacht /.../ / /.../ tausend Toden werdet inr begegnen plötzlich auf tausend furchtlosen Wegen"). In diesem Sinne läßt sich auch die oxymorale Metapher "schwarzer Azur" (III, 20; "v blankytu Cerném") deuten, nämlich als Positivierung des Negativen. Die Schwärze der Ur-Nacht verhüllt nur den strahlenden Azur, der im Kommen des "neuen Morgens", wenn "die Zeit da ist", triumphieren wird. Auch diese Schwärze wird mit der Wärme des "ewigen" Lichtes im Akt der Vollendung durchdrungen ("pronikat vroucnosti svętla", III, 23; "mit heißem Lichte durchdringen"). Die erwartete Vollendung der Zeit, der zeitlosen Ewigkeit, die Herstellung der Einheit aller "Sekunden" (Vigilie I) und "Augenblicke" (Vigilie in bildet die Pointe des gesamten Textes, sein 'letztes Wort": "hasnout a znova se nitit, / kroužit a letét a hrát, / do svaté tvé vưle / po vẻky?" (III, 25-28; "löschen und wieder entlodern, / kreisen und fliegen und wehn, / in deinen heiligen Willen / auf ewig!"). Das ist der Sieg der vigiles, die "das Wachen dieser Weile ertrugen" ("kteri snesli bodéni té chvile", Zemé vítézu I Das Land der Sieger, V. 30), der sich allerdings erst in Zemé vitezzu als bereits gekommene Gegenwart vollzieht. Dieser offenbart sich zunächst als der Sieg des "Lichtes" (der Weit) über die Finsternis, als blendende Erhelltheit des zeitlichen Seins bis zur Transparenz, die den Anbruch der Heilszeit signalisiet: "/... kơyż náhle nad horami východu se vzh̆alo světlo tajemné, / jak vysilené zemè halucinace /.... I Jak prúhledný byl cas a $k$ oslepnuti vzplál! Jak den, $v$ nẻmż všechna slunce vesmíru by vyšla najednou / svým svétlem dálkou neseslabeným a zahorela nad zemi! (Zemé vitézü, V. 38-39; "I... als plötzlich über östlichen Höhen ein geheimnisvoller Morgen aufstieg. I wie eine Halluzination der entkräfteten Erde /.../. / Wie durchsichtig war die Zeit und grell zum Eblinden! Wie ein Tag. I da alle Sonnen des Alls mit ihrem durch Ferne ungeschwächten Lichte, entbrannt überm Erdball!"). In diesem Sieg bekundet sich das "Ewige Wort" so, wie es am Anfang war: als "Licht der Welt". In der Erhelltheit des zeitlichen Seins durch das Nahen der Heilszeit wird auch der Inhalt des "Wortes", seine Botschaft, (wieder) hörbar und sichtbar:

"A v slavnost pủlnoci tvüj prostor chvël se jemným jiskỉenim. / jak vojska andẻlủ by letéla jim v ozálených oblacich / od svêta k světu nesouce tvá poselstvi. I a odlesk jejich pancî̉ủ ze svêtel stríbrných se zemi zrcadlil, I až nesčisıni spici z téžkých snù se probouzeli s úsmèvem" (Země vítezu / Das Land der Sieger, V. 52-56; "Und im Feste der Mitternacht bebte in seinem Gefunkel dein Raum, I als durchschwirten inn Heere von Engeln in Strahlengewolk. deine Botschaft tragend von Welt zu Welt, I und auf der Erde spiegelte sich der Abglanz ihrer Panzer aus silbemem Licht, I bis zahllose Schläfer mit Lăcheln aus schweren Trăumen enwacht”. Übers. v. $O$. Pick.) 


\subsubsection{Katastrophische Eschatologie: endzeitliche Vollendung als 'Aufschub' Proroci (Die Propheten)}

\section{Proroci}

Do měst, jichž vě̌e a paláce zachví se jednou zemét̛́esením, až oblaky neznámých tvani zakvilí hněven, raněné blesky vlastních svých hlubin, a oheň, jenž v tisíci ukrytých doupatech snil o své slávě. až pohne se $k$ pomstê po vêky uvězznèného, a v̧̌emi jazyky tvými vzkłhikne tvé jméno, a známou tvárí, již ukazovalo věkưm, proméní slunce: płicházejí, nepovłimnutí, vyslanci tvoji, dobyvatelé království tvého.

10 Uprostred hudby a tančících dívek a písní naslouchaji tvému svatému dechu, jež smrtelným zhasíná světla, však požráy svêtư do běla rozdmychává; v němž kvêty se nepohnou ani, když v jejich hlubinách viffi,

v̌̌ak staleté skály drtí jak drobty vonného chleba, pro jemné rty života Cekajícího.

Hlas jejich, stržený vichficí Casu, za nimi vane. sladký jak vưné za nesoucím ruže, hơkyý jak pochodní dým; a nejtajnějši myšlenky vlastni, zaleklí vševědoucností, nad sebou slyši v blankytech hvězdami zpívat, pod sebou mlદet ohněm a tajemstvím v hlubinách země. svêtel a nocí sţ̌idavý chor!

O tobè mluví a o tvé slávê. o kJetbê, jež leží na bratrství duší

25 a rozdělila feč stavitelů; a jejich láska ze staletí do staletí nad zemí bloudí jak léto ze sídel, kam vểnè kolmo narấís slunce. Ovoce nové vydává stromoví zemè. stípené rouby jejich tajemnych zahrad;

ale naděje jejich, schopné tak vysokých letů a písní, stavěji hnízda svá nizko płi samé zemi, jak slavíci!

A když se płiblízí chvîle uržení jejich, svět mrtvý zatmí jim slunce; jako finutí rány ze srdce milujícího

35 v krev se jim proméní světı; a pł̌ed jejich zrakem rozloží krajiny staletí pristích, zárící novými konstelacemi. Miliony se płred nimi pohnou tvým dechem, jak vlny věxného mờe, jež v širokých zátokách zalévá zemi

40 a mění pevniny její $v$ tisíciletích.

Po sněhu, jímž tajemství Casu pokrývá ozim tvé setby, bosi, jak vyhnanci, pưjdou, a mył̌lenky jejich, neszetný zástup. $v$ tisíci łlépèjích zakrvácejí pri každěm kroku!

45 V útěku prchati budou płes hớici mèsta budoucich věků. jako po ohnivém koberci, prostłeném na schody svaté tvé vy̌še! A každá myšlenka jejich. 
která se v soucitu obrátí nazpèt. poznáním utuhne $v$ kámen! -

50 A nové a nové oblaky staletí préd nimi zahřmi:

Blesky, jež metají sinavou bledost do tváfí žencù!

Osudná sráženi odvážných korábư v mlze!

HuČeni davu na stavenił̌ích tajemných staveb, jichž lešeni. pokrytá cemex, jsou t̛̛ísnèna krvi.

55 popravištex!

O písně vášni, jež slyši z plamenů stoupat!

Pohledy trpících płristích, magická dotknutí jejich!

Polibky otvírající nové věcnosti světla a smutku!

60 houpá se zemex! Trpici věky, staletí umirajici.

nesmrtelné,

tîzi v̌̌ech souhvězdí nesoucí,

slávu svou poznávající!

\section{A když konex̌ně v stišení slavném}

65 vrcholy lodstev osudủ płístích.

jež vypluly pri stvołení tohoto svêta,

$z$ tajemných błehư se blíziti uzf̌i,

vesla zakrytá ješté vydutím hladiny $v$ dálku:

Tu jejich radost vykł̧ikne silná a žhavá

a netrpexlivá! A oni, kteł̌i nepoznali, co rozkoš, rozkoši procitnou $\mathbf{z}$ vidění svêho,

a bolest, jedině hodná jich sîly, sevłe jim duši:

bolest Casu prodlévajícího.

Płíliš pomalu krouź́ jim zemè, płiliš pomalu vstávají jitra,

75 a pȟilis dlouho poledne odpoxívají ve stínech stromú. mezi Żenci.

Letéti płeji si tisíciletí, rychlostí svêtla letêti věky, míti tisice srdcí, aby krví svou Zivila extasi jejich

a zarděnim podobným východu slunce

\section{a polárni záti a poźáru svêtư}

tváł jejich lásky!

V̌echny duše rozjałit vínem, ktere jim dalo tak slavnou

bolest a opojeni

a které z jednoho pramene prysti

85 ukrytého.

a do celého vesmín voni ze šlastné zemè.

jen $\mathbf{k}$ jejím dětem po celá staletí ještě

nadarmo!

\section{Die Propheten}

In die Städte, deren Türme und Paläste einmal ein Erdbeben zerritteln wird, die bis Wolken von unbekannten Formen aufstöhnen vor Zorn, von den Blitzen der eigenen Tiefen verwundert. und das Feuer, das in tausend verborgenen Höhlen von seinem Ruhme geträumt sich rührt, zu rächen den für Jahrhunderte Eingekerkerten. und mit all seinen Stimmen aufschreit deinen Namen. und die Sonne ihr Antlitz, wie's den Zeiten vertraut war, verändert: kommen sie, unbemerkt, deine Gesandten, die deines Königreichs Eroberer sind. 
10 Umringt von Musik und tanzenden Mädchen und Liedem

lauschen sie deinem heiligen Odem,

der den Sterblichen auslöscht die Lichter, doch die Brände der Welten

zu WeiBglut entfachet;

in welchem die Blumen regungslos bleiben, wenn er dahinbraust in ihren Tiefen,

der aber uralte Felsen zerschmettert wie Brocken duftendes Brotes

für die zarten Lippen des harrenden Lebens.

Ihre Stimme, vom Sturmwind der Zeiten erfaßt, weht ihnen nach,

süB wie der Duft hinter Einem mit Rosen, bitter wie Fackel rauch;

und die eigenen heimlichsten Gedanken, von Allwissenheit erschreckt,

20 hören sie uber sich mit den Stemen hoch singen.

unter sich schweigen mit Feuer und Geheimnis in den Tiefen der Erde,

der Lichter und Nächte wechselnder Chor!

Sie reden von dir und von deinem Ruhme,

vom Fluch, der auf der Seelen Bruderschaft liegt

25

und die Sprache der Bauenden gespaltet hat; und es int ihre Liebe

uber den Ländem von Jahrhundert zu Jahrhundert

wie der Sommer aus Siedlungen, wohin Sonne ewig steil fält.

Neues Obst gedeiht auf den Bäumen der Erde.

gepfropfte Ableger aus ihren geheimnisvollen Gärten;

doch ihre Hoffnungen, fähig so hoher Fluge und Lieder,

baun ihre Nester ganz tief nah der Erde

wie Nachtigallen!

Und nahet die ihnen bestimmte Stunde, so verdunkelt

eine tote Welt ihnen die Sonne; und wie ein Blutstrom aus liebenden Herzen

verwandelt das Licht sich ihnen zu Blut; und vor ihrem Blicke

breitet es Landschaften künftiger Zeiten,

strahlend in neuen Konstellationen.

Dein Hauch treibt Millionen vor ihnen her wie Wellen

des ewigen Meeres, das in breiten Buchten die Erde umspult

und durch Jahrtausende ihr Festland verwandelt.

Durch Schnee, mit dem der Zeiten Geheimnis die von dir gesäte Wintersaat decket,

barfuB wie Vertriebene gehn sie einher, und ihrer Gedanken zahllose Schar

blutet in tausenden Fußstapfen

bei jeglichem Schritte!

45 Fuchtend werden sie eilen über brennende Städte künftiger Zeiten.

wie auf feurigem Teppich, gedeckt auf den Stufen

deiner heiligen Hoheit! Und ihr jeder Gedanke.

der sich in Mitleid wendet zurick.

wird im Erkennen zum Stein erstarren! -

Und immer neue hundertjährige Wolken erdonnern vor ihnen:

Blitze, todfahl bestreichend das Antlitz der Schnitter!

Schwerer Zusammenprall kühner Schiffe im Nebel!

Heulen der Menge auf Bauplätzen geheimnisvoller Bauten.

deren Geriste, schwarz verhuillet, mit Blut bespritzt sind.

Hinrichtungsstätten!

O Lieder der Leidenschaft, entsteigend den Flammen!

Blicke künftig Leidender, Magie ihrer Beruhrung!

Kusse, neue Ewigkeit Lichts und der Trauer erschließend!

Wahnsinn einer einzigen Seele, auf deren lodernden Wogen

die Erde schaukelt! Einer Seele, jahrhundertlang duldend, durch Jahrtausende sterbend,

und nicht sterben könnend.

tragend die Schwere jedwedes Sternbilds,

dic eigene ruhmliche Sendung erkennend! 
Und wenn sie endlich in festlicher Stille

die Spitzen der Flotten künftiger Geschicke,

welche aussegelten, als entstand diese Welt.

herannahen sehn von trübfernen Küsten,

die Ruder verdeckt noch von der Wölbung der Fläche im Weiten:

Da schreit ihre Freude stark auf von Gluten

70 und Ungeduld voll! Und sie, die, was Wollust, nimmer erkannten.

erwachen durch Wollust aus ihrer Vision,

und Schmerz, einzig wert ihrer Kraft, preßt zusamm' ihre Seelen:

der Schmerz der saumseligen Zeit.

Zu langsam kreist ihnen die Erde, zu langsam kommen die Morgen,

und allzu lang weilen die Mittage in den Schatten der Bäume

unter den Schnittern.

Sie wünschen sich durch die Jahrtausende mit des Lichtes Eile zu fliegen,

tausend Herzen zu haben, um mit ihrem Blut ihre Ekstasen zu speisen

und mit einer Röte gleich dem Anfang der Sonne

80 und dem Polarlicht und dem Brande der Welten

das Antlitz ihrer Liebe!

Alle Seelen mit Wein aufzuheitern, der ihnen so festlichen

Schmerz bot und Räusche

und der aus einer verborgenen Quelle

emporschiebt.

durchduftend das Weltall aus der glücklichen Erde,

nur ihren Kindern noch für Jahrhunderte

vergebens!

Deutsch von O. Pick.

Den katastrophischen Aspekt der Eschatologie entfaltet das Gedicht Proroci. Das Kommen der "Propheten" antizipiert die kataklysmatischen Umwälzungen der Endzeit; das geweissagte apokalyptische Drama spielt sich auf dem Territorium der urbanen Welt ab: "Do mèst, jichź vẻze a paláce zachvi se jednou / zemétỉesením, aż oblaky neznámých

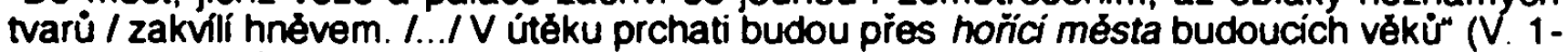
3, 45: "In die Stäotte, deren Türme und Paläste einmal ein Erdbeben / zerrütteln wird, die bis Wolken von unbekannten Formen / aufstöhnen vor Zorn. /.../ Flüchtend werden sie eilen über brennende Städte künftiger Zeiten"). Die "Propheten" kommen am Vorabend der Apokalypse als "Gesandten" des "Höchsten" ("Wyslanci tvoji"), als "Eroberer" seines Königreichs ("dobyvatelé královstvi tvého", V. 9) und als Verkünder des ^ópoc ("O tobé mluvi a o tué slávé", V. 23; "Sie reden von dier und von deinem Ruhme"). Das Ziel ihrer Sendung ist die soteriologische Allbeseelung in der Art eines kollektiven Rauschzustandes: "vsechny duse rozjalit" (V. 82; "Alle Seelen aufzuheitern"). Diese Ereignisse markieren den Übergang vom Harren (der vigiles) auf die endzeitliche Vollendung, zur aktiven Akzeleration ihrer Verwirklichung. Die "Propheten" weissagen die Zerstorung des Tempels (Jer. 26, 6. 18) und seinen Wiederaufbau; das Niederreißen wird auch in diesem Gedicht (und in Hvẻzd hasnou tisice... / Erlöschen tausende Sterne...) durch den Gegensatz, das Erbauen, komplementiert. 519 Nach der biblischen Tradition nehmen die Propheten das Werk der Oikodomantés, der "Erbaver", vorweg.

519 Vgl. 2. B. Mk. 13, 1f. Die Zerstörung des Tempels koinzidiert in diesem Kontext mit dem eschatologischen Geschehen. Wie P. Vielhauer (Oikodome. Aufsätze zum Neuen Testament, München 1979, S. 59ff.) nachweist, spiegelt sich in dieser Symbolik (Mk. 13, 1; 14, 58) die Tradition der jüdischen apokalyptischen Weissagungen wider. Die Fever-Symbolik, die in Proroci eine wichtige Rolle spielt, bedeutet sowohl das Feuer des Welt-Brandes (ignis gehennalis; "poźáry svêtü, V. 13), als auch das (apollinische) lebenspendende, solar-himmlische Feuer (ignis coelis): "a známou tvárí, jiż ukazovalo věkủm, proméni slunce. I... / a jejich láska / ze staletí do staletí nad zemi bloudi / jak léto ze sidel, kam vếnè naráži slunce" (V. 7, 25-27; "und die Sonne ihr Antlitz, wie's den Zeiten vertraut war, verändert. I.../ es irnt ihre Liebe / über den Ländern von Jahrhundert zu Jahrhundert / wie der Sommer aus Siedlungen, wohin Sonne ewig steil fällt"). Der zitierte 
Das Gedicht besteht aus sieben Sujetsequenzen, die sich weiter - thematisch - in zwei Teile gliedern: I-III Sequenz (V. 1-32), IV-VI Sequenz (V. 33-68). Bis auf die erste Sequenz (V. 1-9), in der das Kommen der Propheten als gegenwärtiges Geschehen thematisiert wird, überwiegen im ersten Teil die präsentischen Formen. Im zweiten Teil, dessen Sujet das Sein und das Handeln der Propheten als zukünftiges Geschehen thematisiert, überwiegen die futuristischen Formen: "staleti prístích" ("künftige[e] Jahrhunderte", V. 36), "puijdou", ("sie werden eilen"), "budou" ("sie werden [sein]"), "budoucich věkư" ("künftige[r] Zeiten" (V. 45), "nové a nové" ("neue und neue", V. 50), "pohledy trpicich pnístích" ""Blicke künftig Leidender"), "nové vècnosti" ("neue[r] Ewigkeit", V. 58). Der erste Teil thematisiert die in V. 1-7 geweissagten endzeitlichen Ereignisse, ohne jedoch den Endzeitzustand zu erreichen. In der letzten VII. Sequenz (V. 69-88) kulminiert die "Sendung" ("posláni") der "Propheten" in einer visionären Verzückung, deren Extatik durch die extrem kurze, auf Exklamationen (V. 70, 81, 83, 88) reduzierte Variante des vers libre (ähnlich wie in Vigilie III) evoziet werden soll. Eine andere wichtige Distinktion gründet darin, daß im ersten Teil (V. 10-32) vonwiegend die visionären und mantischen Fähigkeiten der "Propheten" zur Geltung kommen - "naslouchaji" ("sie lauschen", V. 11), "slysí" ("sie hören", V. 20), "mluvi" ("sie reden", V. 24), während im zweiten Teil das Wirken der "Propheten" vielmehr als 'existentielle Aktion", als Seinsbewegung, die sich auf die Prüfungen und Leiden der Endzeit konzentriert, dargestellt wird.

Die Voraussetzung der postulierten Verkündung der kerygmatischen Botschaft in der Art einer kollektiven Extase ist der Emplang - das 'Hören' - des erlösenden Wortes: "naslouchaji tvému svatému dechu, / jenż smrtelným zhasiná světla, však požáry svẻtư do bèla rozdmychává" (V. 11-13; "[sie] lauschen deinem heiligen Odem, / der den Sterblichen auslöscht die Lichter, doch die Brände der Welten / zu Weißglut entfachet"). Die Gabe des 'Hören-Könnens' des "heiligen Odems" ("svatý dech", V. 11), 520 dessen Botschaft, wie es scheint, "für die zarten Lippen des harrenden Lebens" ("pro jemné thy Života Cekajićno", V. 16), d. h. für den zukünttigen, erlösten und deshalb nicht-mehr-sterblichen, g e i s t i $g$ e $n$ Menschen521 bestimmt ist, offenbart sich als die "Allwissenheit" der "Prophteten": "zaleklí vక̌evẻdoucnosti" (V. 19; "von der Allwissenheit erschreckt"). Dieses wichtige Indiz erlaubt also die "Propheten" nicht nur als Gesandten ("vyslanci", V. 8) des Logos, sondern auch

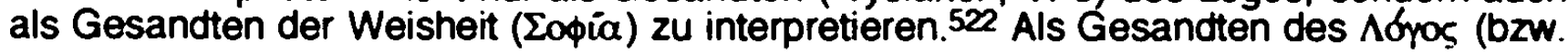

siebente Vers alludiert auf die Transfiguration Christi (Luk. 9,29), die die Sendung der Boten vorwegnimmt (Luk. 9,52 ff.).

$520 \mathrm{Im}$ anthropologisch-theologischen System Philos von Alexandrien wird gerade dem Erlebnis des "Einhauchens" eine wichtige Funktion zugewiesen: "Dreierlei muß vorhanden sein: der Einhauchende, der Empfänger, das Eingehauchte. Der einhauchende ist Gott, der Empfănger der Nus, das Eingehauchte aber das Pneuma. Was entsteht nun hieraus? Eine Vereinigung

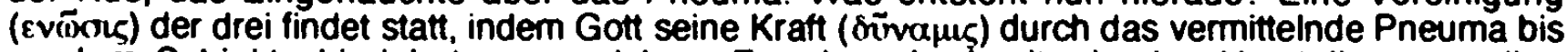
zu dem Subjekte hindehnt - zu welchem Zwecke, als damit wir eine Vorstellung von inm empfangen? Denn wie konnte die Seele Gott erkennen, wenn nicht Gott selbst sie mit seinem Pneuma entüllt und berührt hătte nach ihrem Vermógen?". H. Jonas, Gnosis und spătantiker Geist, Teil 2.1. Von der Mythologie zur mystischen Philosophie, Göttingen 1954, [Zit.] S. 110.

521 Dieser Gegensatz wird im Text explizit genannt; es ist der "alte Mensch", der "Sterbliche", der den Máchten der Finsternis und des Todes verfallen ist und deshalb eine (bloß) hyletisch: physische Signifikanz aufweist: "naslouchaji tvému svatému dechu, / jenż smrtelným zhasiná svêtla $I . .$. , staleté skály drtí jak drobty vonného chleba* (V. 11-12, 15).

522 Vgl. hierzu: " /../ darum: siehe, ich sende zu euch Propheten und Weise und Schriftgelehrte; und von innen werdet ihr einige /.../ verfolgen von einer Stadt 24 andern" (Matt. 23, 34). Die Bedeutung dieses Versettes aktualisiert Bfezina in den Metaphern faszinierender Kühnheit: "Po sněhu, jimż tajemstvi casu pokrývá ozim tvé setby, / bosi, jak vyhnanci pưjdou, a

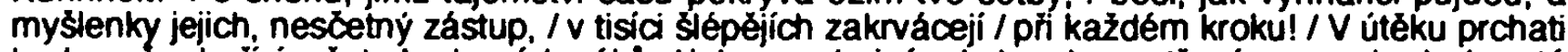
budou pres hớci mésta budoucich vékú, / jako po ohnivém koberci, prostieneném na schody / svaté tvé výse!" (Proroci / Die Propheten, V. 41-47; "Durch Schnee, mit dem der Zeiten Geheimnis die von dir gesāte Wintersaat decket, / barfuß wie Vertriebene gehn sie einher, und ihrer Gedanken zahlloser Schar / blutet in tausenden Fußstapien / bei jeglichem Schritte! / Flüchtend werden sie eilen über brennende Städte künftiger Zeiten, / wie auf feurigem Teppich, gedeckt auf den Stufen / deiner heiligen Hoheit!"). R. Bultmann (,Der religionsgeschichtliche Hintergrund des Prologs zum Johannes-Evangelium", in: Exegetica, hrsg. v. E. Dinkder, Tübingen 1967, $\$$. 10-26) deutet den 0. zitierten Matthäus-Versett in dem Sinne, daß die $\Sigma o$ cíx - als immanente Kraft der Erkenntnis - ihre "Boten" nicht nur einmal am Anfang der Geschichte, sondern in den einzelnen Generationen 


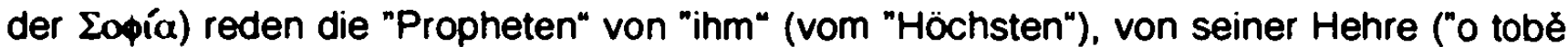
mluvi a o tvé slávè", V. 23) und von jenem Fluch, der auf den Seelen lastet ("a o kletbè. jež leži na bratrstvi đuši", V. 24) und der "die Sprache der Bauenden gespaltet hat" ("a rozdélila rè stavitelü", $\dot{V}$. 25). ${ }^{233}$ Denn die "Propheten" sind nicht nur Zeugen einer Transfiguration ("a známou tvár̆, již ukazovalo věkủm, proméní slunce", V. 7: "und die Sonne inr Antlitz, wie's den Zeiten vertraut war, veränder"'), sondern sie sind auch mit jener wunderbaren Fähigkeit begabt, dem "heiligen Odem" lauschen und seine Botschaft

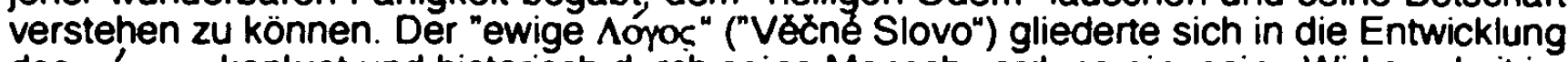
des kóouoc konkret und historisch durch seine Menschwerdung ein; seine Wirksamkeit im historischen Prozeß geht vor allem auf die Reinigung und Läuterung der Menschenwelt, die zum Ort der Geburt Christi wurde. Die ganze Geschichte des kóouos erscheint als Kommen Christi. Inr Ziel und Sinn ist die Offenbarung des "Höchsten", wie sie der Advent symbolisiert.

Die kosmische Potenz und die wirkende Erkenntniskraft des $\Lambda$ бooc tritt mit besonderer Intensität zutage, "wenn der Augenblick ihrer Bestimmung naher" (V. 33); die Aufgabe der "Propheten" ist die Verkündung des soteriologischen Plans beim Nahen der Endzeit: "A kđyż se približi chvile urČeni jejich, svět mrtvý zatmi jim slunce" (V. 33; "Und nahet die innen bestimmte Stunde, so verdunkelt / eine tote Welt innen die Sonne"). In diesem Augenblick "verwandelt sich innen das Licht zu Blut" (V. 35; "v krev se jim promèni světto“), d. h. das "Wort-Licht", dessen Träger und Verkünder die "Propheten" sind, wird sich"

sendet, um ihre Botschaft zu verkūnden (vgl. ibid., S. 23). Die Propheten personifizieren die Weisheit, die aus ihrer Verborgenheit stets aufs neue auf die Erde herabkommt. Die Botschaft dieser 'Lichtträger' (der $\Sigma(x \phi u ́ x)$ wird jedoch verkannt; das ist das Los der "Šilenci" ("Wahnbetörte") im gleichnamigen Gedicht aus dem letzten vollendeten Zyklus Ruce (Hände, 1901). Im JohannesEvangelium figuriert $\wedge$ ryos als "kombinierte Gestalt" der Schopfungs- und Offenbarungsgottheit (vgl. R. Bultmann, ibid. S. 31). Wichtig ist in diesem Zusammenhang die Auffassung von der Verkörperung dieser Offenbarungsgottheit in ihrem Gesandten (Johannes).

523 Die Symbolik der "Sprache der Bauenden" ("łeč stavitelü", V. 25) mag hier auf den ersten Blick rätselhaft erscheinen. Von den "Bauleuten" spricht Evangelist Markus (im Anschluß an Psalm 118, 22.23: "Habt ihr nicht dieses Schriftwort gelesen: "Der Stein, den die Bauleute verworten haben, der ist zum Eckstein geworden": Mk 12, 10). Die Bauleute (d. h. die Gelehrten; vgl. Mk 8. 31. LK 9. 22) haben den vor "Höchsten" erwăhiten Jesus verworfen. Ich schlage folgende Interpretation vor: In Proroci (V. 24) ist erneut die Rede von dem bereits gedeuteten "Fluch" ("kletba"; primăr als Folge des Abfallens von der in jeder Gegenwart offenstehenden Möglichkeit der Erkenntnis des soteriologischen Plans des "Höchsten"), der "auf der Seelen Bruderschaft" ("bratrstvi") liegt. Dieses Lexem "bratrstvi" impliziert die Vorstellung einer Gemeinde (man denke freilich an die Bratrstvi verricich / Die Bruderschaft der Glaubenden. VP), die aufgebaut werden soll. Es handelt sich offensichtlich um eine echatologische Gemeinde der Endzeit: signifikanterweise folgt diesem Verssegment in Proroci das Bild der (göttlichen) "Pflanzung" (V. 28-29). Der "Fluch" ("kletba") teilte allerdings die "Sprache der Bauenden" (V. 25). Das impliziert die Vorstellung von jenem Bau, der dem zukünftigen Bau des himmlischen "Tempels", desen "Baumeister erst in der Zukunft kommen sollen, voranging. Es ist der Bau, der in Hvêzo hasnou tisice... (Erlóschen tausende Sterne...) thematisiert wird: "Co ze sopečnych cernỳch kamenú Gehenny podzemské jsme stavěli, / at padne do ssutin! Krásnèjši mẻsta, nežli naše jest, / vidẻly zraky prorokủ $/ . . . / Z$ bélostných slunci touži stavěti jak $z$ mramoru a vierinu své radosti / ve vécnost nad né rozklenout jak nebesa!" (IV. 1-3; V. 3-4: "Es sinke, was wir türmten aus der Gehenna schwarzem Vulkanblock, / in Schutthaufen nieder! Schönere Stäotte, als die unsrige ist, / sah der Blick der Propheten. I.../ Mit weißen Sonnen wie mit Marmor wollen sie baun und die Sekunde ihrer Freude $/$ in Ewigkeit wölben darob als himmlischen Raum! Übers. v. O. Pick). Es ist nicht von ungefăhr, daß das Gedicht Hvézd hasnou tisice ... als eine 'Weiterentfaltung' des Sujets von Proroci erscheint. O. Králík charakterisiert (Otokar B̈rezina, Praha 1948, S. 137) das Gedicht Poledni zráni (Mittäglich Reifen) als "dobrodružný film s metafysickým happyendem" ("abenteuerlicher Film mit einem metaphysischen Happy-End"). Diese Charakteristik scheint aber eher den (für Błezina sicherlich verblüffenden) Enthusiasmus der Schlußstrophe von Hvëzd hasnow tisice... (Erlöschen tausende Steme...) zu treffen. Man müßte allerdings von einem s oteriologis chen "Happy-End" sprecten: "At" v zapálených ulicich pred námi tanči plameny / jak zajati pỉi triumfu! Retẻzem magickým zlé sily spoutáme. I A donutime zem, by rozkvetta, jak jeșé nekvetla, / a mezi rủżemi vstric pujjem nesmrtelnosti" (letzte Strophe: "Mag vor uns in den versengten Gassen tanzen der Brand / wie Gefangene beim Triumph! Wir binden die bösen Kräfte mit magischer Kette an. / Und zwingen die Erợe zu blühen, wie sie noch niemals geblüht, / und schreiten durch Rosen der Unsterblichkeit zu". Ubers. v. O. Pick). 
transsubstantituieren, es wird zu Blut.524 Die Kraft des wirkenden "Wortes" ("Odems"; "tvy'm dechem", V. 38; "mit deinem Hauch"), das die "Propheten" verkünden, wird im folgenden Verssegment spezifiziert: "Miliony se pled nim pohnou tvým dechem, jak viny věcného mởe, jeź v širokých zátokách zalévá zemi / a mení pevniny její v tisíciletích“ (V. 38-40; "Dein Hauch treibt Millionen vor innen her wie Wellen / des ewigen Meeres, das in breiten Buchten die Erde umspült / und durch Jahrtausende ihr Festland verwandelt"). Aber die Gabe der "Propheten", die "Worte", die "nicht von dieser Welt" sind, zu verstehen, 525 zieht erneut das Leiden und Verfolgung (der Endzeit) nach sich. Die "Propheten" werden zu Vertriebenen: "bosi, jak vyhnanci püjdou" (V. 42; "barfuß wie Vertriebene gehn sie einher"): "V útěku prchati budou" (V. 45; "Flüchtend werden sie eilen"). Die Freiheit von der 'alten Welt', die das "Wort-Licht" nicht erkannt hat und deshalb in der Blindheit verharrt, bedeutet eine konsequente Trennung von ihr, die jeden 'Rückblick' ausschließt: "A každá myšlenka jejich, / která se v soucitu obrátí nazpét. / poznáním utuhne v kámen!-" (V. 47-49; "Und ihr jeder Gedanke, / der sich im Mitleid wendet zurück, / wird im Erkennen zum Stein erstarren! -").526 Die "Versteinerung" deutet in diesem semantischen Kontext auf die apokalyptischen Ereignisse vor dem Kommen des Menschensohnes: "Denn wie der Blitz aufblitzt und leuchtet von einem Ende des Himmels bis zum andern, so wird der Menschensohn an seinem Tag sein* (Luk. 17, 24). Diese Ereignisse werden im unmittelbar folgenden Verssegment (50-52) thematisiert: "A nové a nové oblaky staletí pỉed nimi zahřmi: / Blesky. jež metaji sinavou bledost do tvăi žencư! I Osudná sráżeni odvážných korábư v mlzel" (V. 50-52; "Und immer neue und neue Wolken der Jahrhunderte erdonnern vor ihnen: / Blitze, todfahl bestreichend das Antlitz der Schnitter! / Schwerer Zusammenprall kühner Schiffe im Nebel!"). 527 Die Aussage des alttestamenttichen Versettes: "Im Anfang schuf Gott Himmel und Erde" (Gen. 1. 1) korreliert mit jenem danach formulierten Beginn des Joh. Ev 1, 1: "Im Anfang war das Wort". Die "Propheten" - als poetae vates - besitzen wunderbare Fähigkeiten durch die "Jahrtausende zu sehen". 528 So sehen die "Propheten" auch die (zukünftige) Erbauung

524 Die Symbolik dieses Bildes alludiert offensichtlich auf das Geschehen der Menschwerdung. Man kann stark annehmen, daß hier die Symbolik des Lanzenstichs und des der Wunde entströmenden Blutes aktualisiert wird; vgl. auch den unmittelbar vorangehenden Vers: "jako finutí rány ze srdce milujiciho" (V. 34; "wie ein Blutstrom aus liebendem Herzen"). Vgl. auch: "Krev naše, zdá se, że vyprýstila z tajemnè rány V̌̉eho / a vtekla do našeho tẻla a kỉecovitým pulsem v nèm vifíi" (Se smrti hovorí spicí.. / Mit dem Tode reden die Sctiláfer.... V. 107-108; "Unser Blut, scheint es, entströmt einer geheimnisvolien Wunde des Alls / und ist geflossen in unseren Köper und wirbelt darin mit krampfhaftem Pulse").

$525 \mathrm{Vgl}$ : "Ich habe ihnen dein Wort gegeben, und die Welt hat sie gehaBt; denn sie sind nicht von der Welt, wie auch ich nicht von der Welt bin" (Joh. 17, 14).

526 Wie ist die Symbolik der "Erstarrung des Gedankens" zu deuten? ("A každá myšlenka jejich, / která se v soucitu obráti nazpêt. I poznánim utuhne v kámen!". V. 47-49; "Und ihr jeder Gedanke, / der sich in Mitleid wendet zurück, / wird im Erkennen zum Stein erstarren!") Läßt etwa die Erkenntnis der (immer noch) in der Finstemis und Bosheit verharrenden Wett den Gedanken der Propheten zum Stein verwandeln, sie unfruchtbar werden? Man solite sich nicht nach dem umwenden, "was hinter ihm ist" (Luk. 17, 31), d. h. jetzt ist der Augenblick der Entscheidung da, jetzt gilt nur entweder (die profane Weft und ihre Güter) - oder (die Gottesherrschaft): "Keiner, der die Hand auf den Pflug legt und rückwärts schaut, taugt für die Gottesherrschaft!" (Luk 9, 62). Diese Symbolik bezieht sich auf den apokalyptischen Katakjysmus der Endzeit, der dem Kommen des "Tages des Menschensohnes" vorausgeht. (Luk. 17, 22 ff.)

527 Vgl. auch die Symbolik des Schiffbruchs und ihre Bedeutung in Země vítezzu (Das Land der Sieger): “Hile, vẻkủ pohnutim, v nẻmż jednou světy potápẻly se / v hlubiny svêta tohoto, jak trosky fregat obtižených bohatstvim, / kdyż skvouci vyjely $z$ tajemných prístaví, / a boứi, která slove stvởením, se ztroskotávaly - (V. "Sieh, in der Regung der Zeiten, in welcher voreinst Welten ertranken / in den Tiefen dieser Welt, wie Wracks von Fregatten mit kostbarer Fracht, / die prächtig entsegelt geheimnisvoller Bucht, / und in dem Sturme Schifftbruch erlitten, der Schöpfung genannt ist $-")$.

528 Diese Intention kommt in Zem? (Erde?) explizit zum Ausdruck: "Sta bratrii łeklo: Známe tajemstvi jeho. I mrtvi v něm vstávaji ze sna, Živi v nẻm zmiraji snem; / milenci łekli: Přilišnou zárí oslepi zraky / a cas jako vưné neznámých kvētú každého usmrtí v nẻm; / a ti, kteri dovedli vidéti tisicileti, / s úsmévem ptaji se: Zem?" (II. Str.; "Hundert Brüder sprachen: Wir kennen sein Geheimnis, / in ihm stehn Tote vorn Traum auf, Lebende schwinden im Traume dahin; / Liebende sprachen: Die Blicke erblinden vor maßlosem Glanz / und wie Duft fremder Blumen tötet die Zeit 
"geheimnisvoller Bauten* (V. 53) samt neuen Opfern ("jejich lešeni, pokrytá cernè, I jsou tn̂ssněna krvi, / popravištę!", V. 53-55; "deren Gerüste, schwarz verhüllet, mit Blut bespritzt sind, / Hinrichtungsstätten!"). sowie die "Blicke künftig Leidender" ("Pohledy trpicich prístích", V. 57) und die "Küsse, neue Ewigkeit Lichts und der Trauer erschließend" ("Polibky otvírajici nové věćnosti světla a smutku", V. 58) voraus. Die Semantik des Leidens ist in diesem Zusammenhang offensichtlich auf die Idee der Theodizee zurückzưühren. Der erwarteten, von den "Propheten" verkündeten Vollendung und der Herstellung der Einheit wird noch viel Übel vorangehen; man denke an das dreifache Übel der Leibnizschen Theodizee: das malum metaphysicum, das in der Unvollkommenheit aller Kreatur besteht, das malum physicum, das im Leiden besteht und den Menschen am meisten weh tut und das malum morale, das in der Sünde besteht. Das Übel in der Welt ist die Folge des "Fluchs, der aut der Seelen Bruderschaft liegt" (V. 24); ein Thema, das die semantische und kompositorische Konstante im Gedicht Se smrti hovori spici ... (Mit dem Tode reden die Schläfer...) bildet:

'Nikdo nad nás tajemstvim casu se nebližil chudši k smrti: / nebot' i bolest zrá staletimi k své dokonalosti /.../. I.../ nẻkdo neviditelný zatižil p̛̣iliš váhu osudủ našich / a aby srovnána byla, měli jsme jenom závażi słzi. I.../ Víme, że všechno zasáhla kletba. I... I a západ, jenž v staletich dávných se klenul jak brána věčného mésta, / 2 niž andẻlé pǐes cerné propasti smrti spouštěji zárici padaci mosty / a $z$ hlubin bilého svêtla zaznivá hosana blažených duchủ, I obloha nad bolesti zemè sklenutá $z$ nehybné věcnosti štéstí. I kletbou se změnil: / virem krve je slunce

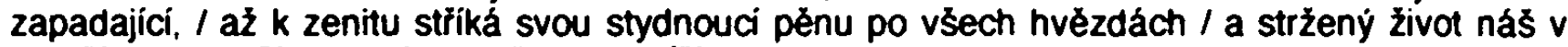
menšich a mensich kruzich $k$ nèmu se bliži, / by $v$ jeho hloubce se potopil do tmy" (V. 15-16, 20. 21, 100, 116-124; "Niemand ärmer denn wir kam nahe dem Tod auf dem Rätselwege der Zeit, I denn selbst der Schmerz reift in Jahrhunderten zur Vollkornmenheit /.../. I.../ zu sehr hat ein Unsichtbarer die Wage unserer Schicksale belastet, I und sie ins Gleiche zu bringen, hatten wir nur das Gewicht unserer Trānen. I... / Wir wissen. Fluch fiel aut alles. I.../ Und der Westen, der in fermen Jahrhunderten sich wölbte wie die Pforte der ewigen Stadt, I aus der die Engel über des Todes schwarze Abgründe strahlende Fallbrücken herablassen / und wo aus Tiefen weißen Lichts das Hosianna der seligen Geister ertönt, / Firmament, über dem Schmerze der Erde gewölbt aus der reglosen Ewigkeit des Glückes, / hat durch Fluch sich verwandelt: / ein Blutwirbel ist die versinkende Sonne, / bis zum Zenit spritzt sie ihren erkaltenden Schaum nach den Sternen / und es naht inr in immer kleineren Kreisen unser mit fortgerissenes Leben, / um in ihrer Tiefe ins Dunkel zu tauchen". Übers. v. O. Pick.)

Doch auch Übel, Leid. Schmerz und Zweifel gehören zum Schöpfungsplan des "Höchsten"; auch sie zählen zu den notwendigen Faktoren der Vergeistigung und Harmonisierung, die nicht ohne eine Unzahl von Verirrungen und Sünden geschehen. Es handelt sich um einen der Grundgedanken im Prozeß der Pluralisierung der eschatologischen Existenz. Der Aufstieg zum eschatologischen Sein, das Fokussieren aller Prozesse in einem einzigen Punkt "Omega", d. h. die "Christogenese" in der Sphäre der Menschenwelt, kann durch das Übel niemals vereitelt werden, schon deshalb nicht, weil: "Gott ist unendlich, der Dämon ist beschränkt; das Gute kann ins Unendliche wachsen, während das Böse seine Grenzen hat". (G. W Leibniz, Theodizee. Anhang. 2. Einwand)

Den "Propheten" wird die Gabe zuteil, die zukünftige Einheit der Heilsgemeinde - als Vision "einer einzigen" (erlösten) "Seele" inszeniert ("Silenstvi jediné duš" [V. 59], d. h. als Vision der zukünftigen kollektiven Erlösung, ja der glorreichen Versöhnung des Alls. die die Macht der Finsternis brechen wird - zu erleben (V. 59-63). Die nahende Endzeit wird hier signifikanterweise in der Komplementarität mit dem Anfang, mit dem Schöpfungsgeschehen, gesehen: "A kdyż konečně v stišeni slavném / vrcholy lodstev osudú pristích, I jež vypluly prii stvoieni tohoto světa, / z tajemných bỉehư se bližiti uzř̈" (V. 64-67; "Und wenn sie endlich in festlicher Stille / die Spitzen der Flotten künftiger Geschicke, / welche aussegelten als entstand diese Welt herannahen sehn von trübfernen Küsten"). Die "Propheten" erwachen durch ihren eigenen Enthusiasmus ${ }^{529}$ aus ihrer

jeden darin; / und sie, die durch die Jahrtausende sahen, / fragen: Erde? mit heiterem Sinn: Übers. v. O. Pick.)

529 Das Erlebnis von derartigem Enthusiasmus verweist hier auf die gnostische Tradition:In der hellenistischen Auffassung, insbesondere bei Philo von Alexandrien, ist das die Wirkung Gottes, die Enthusiasmus und Extase erzeugt. Interessanterweise ist die charakteristische Eigenschaft des phiionischen Propheten/Extatikers seine Askese. Er ist der Asket "des anhattenden Wahrheitsstrebens". Vgl. Hans Jonas, Gnosis und spátantiker Geist. Teil 2, 1, Von 
Vision ("rozkoši procitnou z viděni svěho", V. 71), um ihre Botschaft zu verkünden und ihre eigentliche Aufgabe zu verwirklichen: Es ist die Allbeseelung in der Art einer kollektiven Extase ("Vß̌chny duše rozjarit vínem", V. 82; "Alle Seelen mit Wein aufzuheitern"). Über die Herkunft dieses Weines kann kaum ein Zweifel bestehen: es ist der "Wein der Starken", jener gnostisierenden Pneumatiker aus dem gleichnamigen Gedicht (Vino silnych, SZ), der ihnen die "höhere Erkenntnis" erschließt. Den "Propheten" (als einstig gnostisierenden "Starken") gab er einen "so hehren Schmerz und Berauschung" ("ktere jim dalo tak slavnou bolest a opojeni", $V$ 83). Durch die Vermittlung bzw. Übertragung dieser Erkenntnis, die die Erkenntnis des "Höchsten" und seines 'Plans' bedeutet, wäre das eschatologische Geschehen vollendet. Deshalb leiden die "Propheten" unter dem Verzug ("bolest Casu prodlëvajićno", V. 73; "der Schmerz der saumseligen Zeit"), da sie das Nahen der Heilszeit voraussehen, worauf auch der Rückgriff auf die "Schnitter" I "Zenci"-Parabel (V. 76) hindeutet.530 Aus diesem Noch-Nicht-Zustand rührt die adventistische Ungeduld der "Propheten" her, die die Beschleunigung des eschatologischen Geschehens (u. a. durch die Entfachung der Herzen) anstreben: "Tu jejich radost vykriikne silná a žhavá / a netrpẻlivá! I... / Príliš pomalu krouži jim zemẻ, príliš pomalu vstávaji jitra. I a príliš dlouho poledne odpocivaji ve stínech tromú, I mezi ženci. I Letěti píeji si tisíciletí, rychlostí světla letēti věky, I míti tisice sroci, aby krví svou Zivila extasi jejich" (V. 74-78: "Da schreit ihre Freude stark auf von Gluten / und Ungeduld voll! I... I Zu langsam kreist innen die Erde, zu lagsam kommen die Morgen, / und allzu lang weilen die Mittage in den Schatten / unter den Schnittern. / Sie wünschen sich durch die Jahrtausende mit des Lichtes Eile zu fliegen, / tausend Herzen zu haben, und mit inrem Blut ihre Ekstasen zu speisen". ${ }^{531}$ Die "saumselige Zeit" wird zum quälenden Antriebsprinzip der Dynamisierung der erwarteten Vollendung. Doch die "Kinder der Erde" (V. 87) sind noch nicht imstande, dieses Opfer, die "Hehre" des Weines" (V. 82-83), zu erkennen; deshalb verzögert sich auch der Allbeseelung-Versuch der "Propheten". deshalb muß die erwartete Vollendung aufgeschoben werden: "jen $k$ jejím détem po celá staletí jesté / nadarmo!" (V. 87-88; "Nur ihren Kindern noch für Jahrhunderte / vergebens!").

Zusammenfas sung: Als eine neve, die semantische Welt des Gedichtzyklus Stavitelé chrámu modellierende Intention kann die Pluralisierung der Wege zur eschatologischen Existenz betrachtet werden. Das bedeutet auch die Intensivierung der aktiven (schöpferischen) Teilnahme des Menschen an kosmogonischen Prozessen, $d . h$. an der Restituierung der Ur-Einheit und der Vollendung der Kunst- und LebensSchöpfung, die die Partizipation am "Tempel-Bau" symbolisiert. Dabei spielen die Verzeitlichung der kreativen Prozesse, ja des ganzen - in SCh konstituierten kosmogonisch-eschatologischen Wett-Modells einerseits, und die adventistische Symbolik der Endzeiterwartung andererseits, eine sinnkonstitutive, sinnzentrierende Rolle. Mit dem Postulat der aktiven Teilhabe an kreativen Prozessen geht auch die Tendenz zur Positivierung und Objektivierung des (ursprünglich) ästhetistisch-dekadenten Ideals der Kunst-Schőpfung einher. Das Kunst-Schöne in seinen mannigfaltigen Formen wird nicht

der Mythologie zur mystischen Philosophie, Gottingen 1954, S. 111ft. Diese Feststellung wirtt ein interessantes Licht auch auf Biezinasche "Propheten"-Gestalt, die doch deutliche Symptome des Asketismus autweist: "A oni, kteři nepoznali $c 0$ rozkos" (V. 70; "Und sie, die was Wollust, nimmer erkannten"). Nicht zu vergessen ist auch die Tatsache, daß es in SCh gerade die Asketen sind, denen letzten Endes die "Reichtümer" der 'Erd-Mutter' zuteil werden: "tisice let jsem skládala bohatstvi svá jak královský dar, / a tẻm, kteři dovedou ničeho neżádat, celý ho dám" (Jsem jako strom v kvẻtu.../Ich bin wie ein Baum in Blüte..., V. 7-8; "in Jahrtausenden hảuft' ich Schătze, ein Königsgeschenk, I und jenen, die nichts zu fordern verstehen, geb' ich es ganz"). Wie dieser Rückgriff aut die gnostisch-hellenistische Tradition in Proroci zu deuten ist, dazu s. u.

530 -Priliš pomalu kroużi jim zemè. prỉilš pomalu vstávaji jitra, / a príliš diouho poledne odpotivaji ve stinech stromú. / mezi żenci" (V. 74-76). Das, was im gnostisch (Modlitba vedemi / Das Abendgebet; Ranni modlitba / Das Morgengeben)- pistologischen (Poledni zráni / Mittäglich Reifen) Drama errungen wurde, reicht offensichtlich nicht mehr (oder noch nicht); alle vitalen Prozesse müssen jetzt intensiviert werden, denn: "Wenn aber die Frucht reif ist, dann sendet er die Schnitter; denn die Emte ist da!" (Mk 4, 29).

531 In diesem Kontext möglicherweise auch als Allusion auf das Symbol des Christus/Pelikan, der sein Blut und seinen Leib den Kindern opfert, um sie zu ernähren; $d$. $h$. auch als Symbol des vergossenen, in Wein inkarnierten Blutes Christi, das aus "einer einzigen verborgenen Quelle" (aus der Wunde Christi) emporschießt: "a která z jednoho pramene prýsti / ukrytého" (V. 84-85). Zum Motiv der "Wunde" ("rána") vgl. auch V. 34-35. 
mehr als ein autonomer Wert 'an sich', sondern als Korrelat der diversen Lebensformen begriffen. Der Rekurs Bíezinas auf die 'L'art-pour-l'art'-Ästhetik der "Geheimnisvollen Fernen", die in Stavitelé chrámu in ein prinzipiell anderes axiologisches System integriert wird, bedeutet einen neuen Versuch des Dichters, seine im Zyklus Vêtry od pólü (Polarwinde) offensichtlich blOß verdrängte dekadente Vergangenheit neu - und erfolgreich - zu integrieren. Es scheint, daß̊ die gesamte nachdekadente schöpferische Entwicklung Biezinas, die Schaffensphase des e s $\mathrm{ch}$ a $t$ o $\mathrm{l}$ o g i s $\mathrm{ch}$ e $\mathrm{n}$ Symbolismus. als permanente A u se in a ndersetzung mit dem dekadenten Symbolismus (TD) strukturiert ist. In Stavitelé chrámu versucht Bỉezina die dekadenten Lebensformen in den Gesamtplan der Kunst- und Lebensschöpfung einzugliedern und dadurch zu eschatologisieren. Das Medium der Eschatologisierung in SCh ist das dynamische Charisma der Gnade ( $\chi \alpha$ pls ) als das vereinigende, integrierende und zugleich oberste Prinzip der Kunst- und Lebensschöpfung. Durch diese Strategie wird das rationalisierte, theo-logisch-eschatologische Welt-Modell (VP) konsequent remythisiert. Daraus resultiert, daß auch das in Stavitelé chrámu entworfene 'Projekt' der zivilisatorischen Moderne durch seine Integration in das mythogene Welt-Bild archaisiert und dem bildhaft-konkreten Denken unterworfen wird. 
6. ESCHATOLOGISCHER SYBOLISMUS IV

Vitalistisch-eschatologisches Modell

Gedichtzyklus Ruce (Hände) 1901

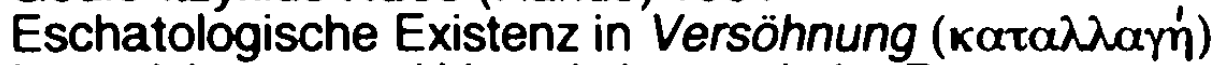

Intensivierung und Vergeistigung vitaler Prozesse

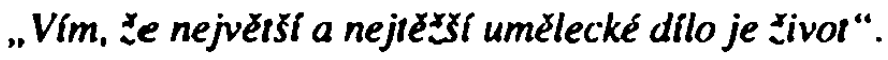

„Ich weiß, daß die größte und schwerste Kunst das Leben selbst ist.

O. Błezina an Fr. Bauer (26. VII. 1901)

Der letzte vollendete Gedichtzyklus Ruce (Hände) erschien im August 1901, zwei Jahre nach der Herausgabe von Stavitelé chrámu. Was hat sich in Ruce, im Vergleich mit dem in Stavitelé chrámu konstituierten kosmogonisch-eschatologischen Modell, prinzipiell geändert? Es läßt sich sagen, daß auch in diesem Zyklus die Symbolik der vita activa, der schöpferischen Tätigkeit, weiterentfaltet und in einem gewissen Sinne sogar 'radikalisiert' wird. Auf das schöpferische Tun des Menschen verweist das für Bỉezina verblüffend somatisch-konkrete Titelmotiv "Hände" ("ruce"), das in dreizehn von zwanzig Gedichten semantisiert wird. Die Semantik der schöpferischen Prozesse (SCh) - man denke nur an die Dominanz des Visuell-Kognitiven im Titelgedicht Stavitelé chrámu ( Vidèli jsme zástupy nesčísı̀ne", V. 1; "Wir sahen zahllose Scharen"; "poznávali se znamenimi", V. 7; "sie erkannten einander durch Zeichen" usw.) wird in Ruce durch die Semantik des $\mathrm{H}$ aptis ch-Somatischen (mit signifikanten Merkmalen der physischen Arbeit: "Pot setřeli jsme se svých čel"; Bolest človéka / Schmerz des Menschen, 11, 1; "Den Schweiß trockneten wir von unseren Stirnen" ) komplementiert. Die Dominanz des Haptisch-Somatischen in Ruce bedeutet einen weiteren Schritt auf dem Wege zur Vollendung der Schöpfung und zur Herstellung der eschatologischen Einheit. Diese Entwicklung führt von den kosmogonisch/kreativen (Stavitelé chrámu) zu den vitalen Prozessen (Ruce) mit dem Ziel der maximalen Intensivierung des Erden lebens und des Erreichens des Eschatons in der Heilstat der universalen "Versöhnung" ("smifreni"). Auch das schwere i r d i s c h e Schaffen in den "Steinbrüchen" ("v lomech") und "in den Goldwäschen des siegreichen Eroberers" ("na ryžovištich vádce vitézného"; Bolest Člověka / Schmerz des Menschen, I, 4, III, 3), oder die (re-)generativen, elementaren Prozese der Erde (Zpivaly vody / Es sangen die Wässer, Zpivaly hořć hvëzody / Es sangen die brennenden Sterne, Dithyramb světu / Dithyrambus der Welten). führen im vitalistisch-eschatologischen Welt-Modell zur Vollendung der Schöpfung und zur Allbeseelung; auch diese Prozesse bereiten das Kommen des "Einzigen erlösten Menschen" (Silenci / Wahnbetörte, $X, 1)$ vor. Geradezu programmatisch kommt diese Intention im oft zitierten Gedicht Kolozpeev srdci (Rundgesang der Herzen) zum Ausdruck; das Erdenleben wird hier trotz aller schmerzvollen Eftahrungen und Niederlagen durch den Refrain "sladko je žiti!" ("süß ist's zu leben!") emphatisch, ja extatisch bejaht:

-Pro vichrice, płevraty, boułe! Paroxysmy lásky a vule! / Války duchủ! /... / Pro silnou rozkos rozdrcen býti jak vina, / pohybem bratrského oceánu majestátního /.../ sladko je zíti!" (V. 69-70, 110-111, 118; "Wegen der Stürme, Umwälzungen, Unwetter! Paroxysmen der Liebe, des Willens! I Kămpte der Geister! /... I Wegen der Lust, die eignet der Starken, zermalmt zu werden, gleich einer Welle, / im Wogen des majestätischen brüdertichen Ozeans /.../süß ist das Leben!").

Als Antriebsfaktor der vitalen Prozesse wird in Ruce die (dionysische) Rauschextase in enger Verbindung mit Leiden - postuliert. Mit der Sendung "Alle Seelen mit dem Wein zu berauschen" ("Vß̌echny duß̌e rozjařit vínem", Poroci, V. 82, SCh) kommen die "Propheten" im gleichnamigen Gedicht, doch die kollektive, endzeitliche Allbeseelung geht im Rahmen des kosmogonisch-eschatologischen Welt-Modells nicht in Erfüllung. In Ruce soll der Versuch sozusagen noch einmal wiederholt werden, diesmal aber mit gewaltiger Intensität eines dionysischen, an der Vernichtung grenzenden, rauschähnlichen Durchbrechens der Schranken des leibhaften Selbst. In Kolozpěv srdci (Rundgesang der Herzen) wird sogar die Ich-Auflösung im "Ozean" der kollektiven, "brüderlichen Menge" bejaht: "Pro silnou rozkoš rozdrcen býti jak vina, / pohybem oceánu majestátniho ?.../ 
sladko je Žiti!" (V. 110-111, 118; "Wegen der Lust, die eignet der Starken, zermalmt zu werden, gleich einer Welle, / im Wogen des majestätischen brüderlichen Ozeans /.../ süß ist das Leben!"). Die Remythisierung und Positivierung der dekadent-ästhetistischen Kunst-Schöpfung (TD) innerhalb des kosmogonisch-eschatologischen Modells (SCh), wird in Ruce durch die Remythisierung und Eschatologisierung der dekadenten und todbringenden Kunst-Extase ergänzt. Der grundsätzliche Unterschied zwischen der 'Thanatos'-Semantik von TD und der extatischen Selbstvernichtung im vitalistischeschatologischen Modell resultiert daraus, daß die rauschhafte Desintegration des leibhaften Selbst (in Ruce ) nicht (mehr) zur absoluten Erkenntnis der kosmischen Gesetze (Modlitba vecerni I Das Abendgebet, TD) oder zu dem offenbarenden 'Sturz' in den Kunst-Tod (Motiv z Beethovena / Ein Motiv aus Beethoven, Umèni / Die Kunst u. a.), den das autistische, dem Ideal des absolut autonomen Kunst-Schönen 'unheilbar' verfallene dichterische Ich heraufbeschwört, führen s o II, sondern zur Beschleunigung des eschatogischen Geschehens am Ende der Zeiten, das als $k$ o 1 l e $k t i$ v e r Rausch erlebt wird. Ein anderer hochrelevanter Unterschied gründet darin, daß der dekadente Kunst-Tod bei Breina stets als 'zentripetal' gedacht wird: als 'Versinken' in den "Sarg der Träume wie in Zinn" (Uméni I Die Kunst) oder in eine "Krypta aus strahlendem Gestein", die in den finsteren Meerestiefen ruht (Motiv z Beethovena / Ein Motiv aus Beethoven), als 'Eingemauert-Sein' in den "feuchten Katakomben" einer Schattenwelt ( Vẻzeñ / Der Gafangene) oder als 'Begraben-Sein' in den Armen des Kunst-Todes, wie "in einem kalten, lebendigen Grab" (Tichá bolest / Der stille Schmerz); $d$. h. das leibhafte Selbst wird in die autonome Welt des Kunst-Schönen integriert, 'eingeschlossen' und dadurch quasi 'artifizialisiet'. Innerhalb des vitalistisch-eschatologischen Modelis (R) wird der autodestruktive, todbringende Rausch als 'zetrifugal', $d$. $h$. nicht als Ich-integration, sondern als Ich-Auflösung gedacht; als totales Hervorbrechen aus sich, unter anderem auf Grund des fortbestehenden inneren Erregungsübermaßes, dessen signifikante Erscheinungsmodi der rauschfafte Tanz und die Glut-Extase (im Feuer-Brand) sínd:

"I.../ proud vonný. İełavici hvězdami jader, vino sumici světlem, / vystrikne na rty nesčisiných! Vedra krve a touhy! / Cišemi rajských zapomenuti jsou srdce! Fermenty Żtí a smrti / zdvihly se na dnè a v jejich parách myšlenky šlii! Tance kol ohñú! Květy jež rozkoše boulîi se lámou!" (Vedra I Gluthitzen, V. 33-37; " \%.../ duftender Strom, rotglühend von Stemen der Kerne. Wein, schäumend vor Leuchten, / hinspritzt auf die Lippen Unzähliger! / Gluthitzen des Bluts und des Verlangens! / Becher paradiesischen Gedankens sind die Herzen! Fermente Lebens und Todes / hoben sich aut dem Grunde, und in ihren Dämpten rasen die Gedanken! Tänze um Feuer! Blüten, die brechen im Sturme der Wollust!" ). "Każdou vter̂inu, vždy na svêm mistě / v mystickém tanci světủ / kroužime kosmem /... / Do tvári našich, jež v extasi hởi, / chladivě věky nám vanou / a schvácené štěstim letu svého, / zárenim bolestné rozkoše vysilené. I.. I klesáme, mystické tanećnice / a v krvi své. jako pohr̉bené v rủžch, / umiráme" (Zpivaly horiç hvězdy / Es sangen die brennenden Steme, V. 1-3. 11-19; "Jede Sekunde. Stets treu unserem Posten / im mystischen Tanz der Welten / kreisen wir im Kosmos. I.../ Auf unsere Wangen, extatisch erglühend. / kühlende Zeiten uns wehen / und ermattet vorn Glück unseres Fluges, I vom Glanze schmer zlicher Wonne entkräftet. I. . I sinken wir, mystische Tãnzerinnen. / und in unserem Blute, wie in Rosen begraben, / sterben wir) "A naše vlastni bytost záhadná! Na hranici své Zalmy péjici / v sarlatnem plástı plamenú! /... / A rozjałená jako v šlenstvi / tisicim smrti v ironické tahy pohliži, / 2 všech cernych rukou prijimá ciš halucinaci / a ve pripitku extatickém żivotu / a slunci. smifeni a nadéjim, / až ke dnu v temné rozkoši ji dopiji" (Stráż nad mrtvými I Totenwache, V. 48-53; "Und unser eignes rätselhaftes Wesen! Am Scheiterhaufen seine Psalmen singend / im scharlach'nen Mantel der Flammen! /../ Und freudetrunken, wie in Wahnsinslust, / dem Tode tausendfach blickt es ins ironische Gesicht, / aus allen schwarzen Hănden nimmt den Becher der Halluzinationen / und zutrinkend extatisch jedem Lebenstrieb, I der Sonne. Harmonie und Hoffnungen. I bis an den Grund in düst'rer Wollust trinkt".übers. v. E. Saudek.)

In dionysische "Lust am Vernichten"532 mündet auch das Gedicht Silenci (Wahnbetörte) ein:

532 Nach Urs Heftrich (Otokar Brezina, Heidelberg 1993, S. 256ft.) rekurriert Biezina in diesen Gedichten erneut auf Nietzsche. Heftrich zitiert dazu einen Passus aus der Fröhlichen Wissenschaft: "Das Verlangen nach Zerstörung. Wechsel, Werden kann der Ausdruck der übervollen, zukunftsschwangeren Kraft sein (mein terminus ist dafür, wie man weiss, das Wort 'dionysisch')". Zit. nach U. Heftrich, S. 258. Es handelt sich aber um einen durchaus spiritualisierten Nietzsche: sein Biologismus, sein Postulat der geradezu 'nackten' physischen Macht, seine Mitleidskritik, seine strikte Ablehnung der christlicten Grundwerte u. a., das alles 
"A tehdy, pr̉ed našimi zraky uzavǐenými, nový kosmos se mihl: / jako sloup rudý vedla nás k nẻmu slunci všech dráha mléçná; / a z lẻavého poháru touhy, kde snéni zdroj magický vyseh, I Žiznivi věcnè, posledni vino jsme pili na našich tlačené lisech, I nesmrtelnosti nápoj, zničeni tvarù. zmámeni nekonećna" (XIV, 1-5; "Und damals, vor unseren geschlossenen Augen zog blitzschnell vorüber dein neuer Kosmos: / gleich der brennenden Säule führte zu inm und die Milchstraße aller Sonnen; / und aus den glühenden Becher der Sehnsucht, wo des Träumens magischer Bronnen versiegt war, / ewigen Durstes, tranken wir den letzten Wein, in unseren Keltern gepreßt, / den Trank der Unsterblichkeit, der Vernichtung der Formen, der Unendlichkeit Rausch". Ubers. v. E. Saudek.)

Auch im vitalistisch-eschatologischen Welt-Modell wird dem Tod ein fester Platz eingeräumt; die leidenschaftliche Bejahung des Lebens geht mit der Rechtfertigung des Todes einher. Es ist aber nicht mehr die thanatophile Todessehnsucht, der "ewige, letzte Traum", aus dem es kein Erwachchen mehr gibt und nach dem es das dichterische Ich im "Abendgebet" verlangt (Modlitba večerni, TD, letzte Verszeile; "sen věčný, posledni, z něhož se nevzbudim"). Signifikanterweise gießt der "mystische Herbst" im Gedicht Cas (Die Zeit) aus "dem Becher der Strahlen, I.../ Trauer und Träumen, / aller Weine berauschendsten Wein" ("I.../ a v paprskü cỉ̉e nalěvá mystický podzim smutek a snëni, I nejopojnejš̉i z opojných vín", II, 5-6). Diese Verszeile enthält eine autointertextuelle Referenz, die man als eine Replik auf das dekadente, thanatophil konnotierte 'Herbst' Motiv in Apostrofa podzimni (Herbstapostrophe, TD) lesen kann, in dem der blendende Glast der zum Kunst-Werk denaturierten und artizialisierten Herbst-Natur den Tod ergießt:

-Dny jasné podzimni, v nichž zári azur Cistý / a z vêtvi bronzových se níti rudé listy, I jeż sváty ostrým vanem podzimniho dechu / se skvi jak varáženy ze zlatého plechu! / Svuii rozestrete lesk a plajte v chladný f́jen / svou záži karminưv a minii a sien / a rożévejte smit, jež proudem deště kane / vám z tropytných paprskü, jak z Ciše vytepané / ze studeného kovu!" ( Apostrofa podzimni, II, 1-9; "Helle Oktobertage, die vom reinen Azur strahlen / und an Bronzeästen flammt der dunkeiroten Blätter Brand, I die, vom scharfen Herbsthauch verweht, / blinken wie aus Goldblech gestanzt! Breitet euren Glast und flammt in den kühlen Oktober / in der Lohe von Karmesin.Sienna und Mennige / und laßt den Tod ergießen, der als Regen aus euren Strahlen / wie aus einem Becher rinnt / kalten, getriebenen Metalls!").

Den "Trank der Vernichtung der Formen", der zugleich der "Trank der Unsterblichkeit" und der "Unendlichkeit Rausctr" ist ("nesmrtelnosti nápoj, zničení tvarú, zmámení nekonecna"), trinken auch die "Wahnbetörten" aus dem gleichnamigen (s. o.) Gedicht. Den Tod begreift Bïezina als "zkušební kámen života" ("Prüfstein des Lebens"). 533 Das Phänomen des (Ab-)Sterbenes ist ein integraler Bestandteil des organischen und dynamischen koouos und aller vitalen Prozesse: "Záríá zrození i hasnutí / milionủ slunci / do tmy věkủ se tứst i..." (Dithyramb svêtú I Dithyrambus der Welten, V. 1-3; "Strahlendes Werden und Erlöschen / Millionen von Sonnen / in die Nacht der Ewigkeit splittert /... $/$ ). Das Bewußtsein, daß der Tod unzertrennlich zum "schmerzvollen" Érdenleben gehört, wird gleich im Prolog-Gedicht Chvile slávy... (Augenblicke der Hehre...) zum Ausdruck gebracht:

"Vidél jsem také zem bolestnou jak byla od věkủ. l.../ zem jednu z nejchudšich mezi svými sestrami ve vesmiru / na mơi ticha ostrov, jenż mimo smrt nepoznal miru. // V oblacich casu jsem blesky ž̌el jak apokalypsy ohnivé pismeny, / césarủv pokyn otrokủm, krvi jak rủžemi kvetouci areny, I zrak muže, pýchu a vưli zemé, tvrdý bojem, zlomený vitézstvími" (Chvile slávy...I Augenblicke der Hehre..., VI, 34, VII, 1-2; 'Doch sah ich die Erde schmerzvoll auch, wie sie war seit Ewigkeit, /.../Erde, eine der ärmsten unter ihren Schwestern im Weltall, / im Meere der Stille ein Eiland, daß außer im Tode nie Frieden gefunden. // In den Wolken der Zeiten sah ich Blitze. wie Apokalypse feurigen Zeichen, / Wink der Cäsaren den Sklaven, Arenen, die Bluttau wie Rosen spein, I des Mannes Blick, den Stolz und Willen der Erde, hart vom Kampfe, gebroctien von Siegen").

wäre für Błezina undenkabar. Signifikanterweise wirtt Bł̌ezina nach 1896 der Philosophie Nietzsches immer ofter Plattheit vor. Vgl. die aufschlußreiche Darstellung dieser Problematik bei U. Heftrich (ibid., S. 167ff.). In der Vorstellung von der idealen Einstellung zum Tod als dern stimulus des schöpterischen Tuns kommt Bïezina nicht nur Nietzsche (U. Heftrich, ibid. S. 307), sondern auch der Gedankenwelt von Maurice Blondel, mit dessen 'action' - für Blondei ein Inbegriff menschlichen Daseins - die Błezinasche Auffasung des schöpferischen Tuns in erstaunlicher Weise koinzidiert. Blondel begreift auch den Tod als "Tat schlechthin" ("lacte par excellence"). Zur Biezinas Auffassung des Todes, vgl. Kap. 5.1.

533 O. Błezina, .Fragmenty", in: O. Błezina, Eseje, Olomouc 1996, S. 176. 
Auch das ununterbrochene "Werden und Erlöschen" (Dithyrambus svẻtü / Dithyramb der Welten) gehört zum dionysischen Prinzip der Reversibilität im Verhältnis von Schöpfung und Untergang. Leben und Tod, Rausch und Schmerz usw. In das vitalistischeschatologische Welt-Modell integrien Biezina auch die "zorngeballten, müden Hände der Brüder" (Chvile slávy I Augenblicke der Hehre, VIII, 2-3; "bratî́ svých ruce zemdlené, I hnévem seviené"), die "arbeitsgebrochenen" Hände (Jarni noc / Frühlingsnacht, I, 7; "zlomeny pracf") oder die Hände "blau von Frost der Aonen und im Flug der Erde über Abgründen zitternd" (Ruce / Hände, V. 50; "zmodralé mrazem věkú, a v letu zemè, nad propastmi vrávorajica"). Denn, wenn die Zeit "da ist", im Akt der Vollendung der Schöpfung. werden sich alle Hände in eine "magische Kette Ungezählter" einfügen (Ruce / Hände, V. 60); Millionen von Händen werden "zu einer geistigen, riesigen Hand erstarren, die die Erde umklammert" (Zpivaly vocty / Es sangen die Wässer, V. 39; "vǐení milionú rukou I tuhne $v$ jedinou duchovou ruku gigantickou, zem objimajic ${ }^{\prime \prime}$ ).

In Ruce wird also - noch energischer als in Stavitelé chrámu - die Integration a II e r Phänomene und a Il e r Formen der Lebensschöpfung postuliert. Der Schlüsselbegriff dieses Prozesses und das Konstruktionsprinzip des vitalistisch-eschatologischen Modells ist das "Zusammenfließen" ("sliti") "aller Millionen zu einem Einzigen erlösten Menschen / dem Steuermann geistigen Landes" (Silenci / Wahnbetörte, X, 1-2; "siití všech milionú v Jediného Clovéka vykoupeného, / kormidelníka duchové zeméc). Das "Zusammenfließen" wird auch als Bedingung für das Erreichen des höchsten Zieles, der endzeitlichen "Versöhnung", postuliert. Zu diesem Plan der kosmischen 'Totalintegration' gehört auch das "Zusammenfließen" der individuellen Stimme zu einem kollektiven, dionysischen534 "Dithyrambus" a ller Welten (Dithyramb svêtú / Dithyrambus der Welten), zum "Rundgesang" ("kolozpěv") a ll e r "Herzen". Es ist nicht mehr das harmonische "Lied der Strahlen" ("paprskú pisen", Vigilie II, 1, SCh) oder das "aus den Kristallfenstern" des Tempels läutende kunstvolle Lied "der heiligen Sieger" (Nade všemi ohni a vodami... I Über allen Fevern und Wassern, SCh, V. 26-27; "Svatých vitězú piseñ / zvoni k nim z křisttálných oken"), sondern der "brennende", den ganzen xóouos durchdringende und alles integrierende Chorgesang der Himmelskörper (Zpivaly h o ri ci huẻzơy / Es sangen die brennenden Sterne) und Naturelemente (Zpivaly vody I Es sangen die Wassern), zusammen mit dem gewaltigen "Rundgesang der Herzen" ("Kolozpěv srdci") aller Erowesen:

"Slyšite tajemné suméni krve? Vỉeni ve zrajicim kvasu / omamujicim? Horečnỳ hlahol v temnu úlü? / Bolestná zazněni srdci, ladēných věky jak struny pro souznēni hvězdná? I.../ Pro vỷk ̛̌ik srdce osamélěho / když zajásá v úzkosti svoji jako pták zbloudilý, / jenż nalezl bratrské množstvi zpivajici, / sladko je żíti!" (V. 11-14, 93-96: "Hört ihr das raunende Rauschen des Blutes? Das Kochen reifender Gährung. / Betāubend? Fieberhaft Brausen im Dunkel der Stöcke? I Schmerzhaft Ertönen der Herzen, gestimmt von Āonen, wie Saiten, I Zum Einklang der Sterne? I... / Wegen des Aufschreis des einsamen Herzens / wenn es aufjauchzt aus seiner Angst wie ein verimter Vogel, / der gefunden die brüdertiche singende Menge, / süß ist das Leben!").

Die Synthese aller Chorgesänge stellt der donnernde, rauschhafte und versöhnende "Dithyrambus der Welten" dar:

534 In der Kunst des Symbolismus repräsentiert das sehr ausgeprägte 'dionysische' Prinzip (als mythologisches Prinzip) den rauschhaft-extatischen, un(ter)bewußten Aspekt der KunstSchöpfung. Der in tausend Gestalten auftretende Dionysos figuriert als Sinnbild ständiger Metamorphose und Hypostase. Sein fortwährendes Fließen und Verwandeln determiniert die Kunst-Schópfung als performative Prozessualităt. Aage A. Hansen-Löve spricht von der "dionysischer Theatralisierung aller vitalen Prozesse". (.Dionysos und 'Svirel'. (Der "untere Ertóser)", in: A.A. Hansen-Lōve, Der russische Symbolismus, Bd. II. Wien 1984, Typoskript, S. 490). Das dionysische Prinzip ist immer mit dem Erd-Kult, mit der natura naturans verbunden, mit dem Ziel der Vereinigung und Verschmelzung ("sliti") der Gegensātze; das Individuelle verschmilzt zum Kollektiven, die vereinzelte Stimme zum gewaltigen Chor der "Ungezählten" ("nescislnẏch"). Der apollinisch-harmonischen Strukturiertheit und 'Architektonik' (der "Tempel-Bau") steht in der dionysischen Kunst-Schöpfung mit ihrem performativen Charakter, die rauschhafte Gestik einer "Theatralisierung" entgegen. Die dionysische Erlösung ist die Erōsung "von unten" als Selbsterlösung Gottes durch Menschwerdung. Der sich aufopfernde Dionysos(-Christus) erleidet in der Unterwelt physische Qualen, bevor er nach seiner zweiten Wiedergeburt (im Fleisch zum Menschensohn) aus dem Schoß der 'Erd-Mutter' als der "untere Erlöser zurückkehrt. Vgl. M. Frank, Der kommende Gott. Vorlesungen über die neue Mythologie I, Frankfurt am Main 1982, S. 308ff. Damit geht Hand in Hand die Rehabilitierung und Verteidigung des Körperlichen und Erotisch-Schöpferischen. 
"Ukolébavka milionủ / celým vesmirem otłásajici, / v jejimż rytmickém taktu / houpou se bolestné zemè, / kolébky duchü" (V. 57-61: "Wiegenlied von Millionen / das ganze Weltall erschütternd, $/$ in dessen rhythmischen Takte / schaukeln schmerzvolle Erden, / Wiegen der Geister")

Mit der Dynamisierung der vitalen Prozesse korreliert die auffallende, durch das Titelmotiv "ruce" ("Hände") antizipierte Intensivierung, ja sogar Hypertrophie des Haptischen und Emotionalen, dem im vitalistisch-eschatologischen Modell das Symbol des "Herzens" ("srdce") - als Topos der emotinalen Erkenntnis - zugeordent wird. In Ruce verschiebt sich der Swerpunkt, wie es scheint, vom Visuell-Rationellen, Konstruierten. Strukturierten und Artifiziellen der kosmogonisch-eschatologischen Kunst- und Lebensschöpfung auf das Emotional-Emphatische, Rhythmisch-Kreisende'535 (bzw. Pulsierende) des in Ruce konstituierten vitalistisch-eschatologischen Welt-Modells. Der Nachdruck liegt nun nicht sosehr auf dem Sehen / Verstehen, auf dem Kognitiven, sondern vor allem auf dem Empfinden / Er-Leben, auf dem Intuitiven. Das "Herz" ist nicht nur das Organ der emotionalen Erkenntnis, sondern auch der Sympathie und der alivereinigenden Liebe. Man denke an Pascals Postulat der "Logik des Herzens" ("logique du coeur") und der "Ordnung des Herzens" ("ordre du coeur"), das im 20 . Jahmundert von Max Scheler aktualisiert wurde. Auch das Herz, das Gefühl, der Instinkt führen zur wirklichen Erkenntnis, nur die Operationsbasis ist eine andere: das Ich in seiner Totalität als erkennender, fühlender Geist. Die von der Liebe gesteuerte, der inneren "Ordnung des Herzens" entsprechende Handlung des Menschen bedeutet die Teilhabe an der (Schelerschen) "Urperson", die Gott ist. 536

"Císemi rajskych zapomenuti jsou srdce!" (Vedra / Gluthitzen, V. 35; "Becher paradiesischen Sicherinnerns sind Herzen!"). "Tep srdci, vesel údery..." (Tichý oceán / Der stille Ozean. I. 2; "Schläge der Herzen, Schläge der Ruder ..."). "A ze vsech błehú kosmu nepláce / šlenstvi rukou marně rozpjatých, / tep srdci oddělených nekonečnostmi?" (Stráż nad mrtvými / Totenwache, V. 32; "Und weint nicht aus allen Küsten des Kosmos / der Wahnsinn der Hānde, die vergeblich sich recken, / der Puls der Herzen getrennt durch Unendlichkeiten?"). "Srdce naše tam zkvétá jak jaro, hnizdo všech skrivanủ tvých" (Mista harmonie a smî́eni / Orte der Harmonie und der Versöhnung. V, 1: "Unser Herz blüht dort wie der Lenz, ein Nest aller deiner Lerchen" Übers. v. E. Saudek.)

Um die Einsamkeit der isolierten, ins frostige Dunkel eingetauchten Herzen zu durchbrechen - "/.../ hudbu milionú srdci uslyšel jsem, / milionù srdá, jak hvězdy od sebe vzdálených, odcizených: / po sobẻ tajemnẻ toužicich a v mrazivé soumraky pohřžených"

535 Im Zusammenhang mit dem kosmogonisch-eschatologischen Modell (Stavitelé chrámu) kann man von der linearen Bewegungssemantik sprechen. Die Bewegung führt meistens auf der horizontalen Achse von (diesseitigem) "hier" - zu (jenseitigem) "dort" (Vigilie I, 3-4); "Od královstvi I...I v královstvi" (Zemé vítézú I Das Land der Sieger, 8-9; "Von Königreich I... I zu Königreich"). Als der charakteristische Bewegungstypus erscheint in SCh das Dehnen ("jehoz reflex /.../ se sifil", Stavitelé chrámu / Baumeister am Tempel, V. 68; "dessen Abglanz sich dehnte"), das Nahen ("Blizeni", Zpêv staletimi bloudía I Ein Gesang, der durch die Jahrhunderte irrt, III, 2), die 'Dilatation' (der Zeit; vgl. das Gedicht Vigilie) usw. Die Bewegung auf der vertikalen Achse kennzeichnet das Emporsteigen bzw. Fallen, wie Z. B. in Zas ve viděni prorockém... (Wieder in einer prophetischen Vision ...), oder in Nade všemi onni a vodami... (Über allen Feuem und Wassem...). Der signifikante Bewegungstypus im vitalistisch-eschatologischen Modell (R) ist das Kreisen ("krouženi") des rauschhaften Tanzes: "Tance kol ohnú!" (Vedra / Gluthitzen, V. 36; "Tänze ums Feuer!"). "Każdou vterinu /... / / v mystickém tanci světú / krouzíme kosmem" (Zpivaly hớia hvězdy / Es sangen die brennenden Steme, V. 1-3; "Jede Sekunde /... / I im mystischen Tanz der Welten / kreisen wir im Kosmos"). "A v'sechna slunce, / krouža kolem věcného slunce" (Dithyramb svẻtú / Dithyrambus der Welten, V. 45; "Und alle Sonnen, / kreisend um die ewige Sonne"). "Dokud srdce hłmíti budou /.../. I na kroužici kouli zemé kolébat se tanec jar" (Vécée znova / Stets aufs Neue, III, 1-2; "Solang' Herzen donnern werden I.../, I und auf der kreisenden Erdenkugel wiegen sich der Lenze Tanz'), der Gedichttitel Ko lo zpév srdci ( $R$ u n d gesang der Herzen) usw.

536 Vgl. B. Pascal, Pensées IV (CEuvres de Blaise Pascal, ed. Léon Brunschvicg, Paris 1904 [Nachdruck, Vaduz 1966], S. 201-203): "Le coeur a ses raisons, que la raison ne connait point; ou le sait en mille choses". (277; "Das Herz hat seine Gründe, die die Vernunft nicht kennt, das erfărt man in tausend Făllen:). "Nous connaissons la vérité, non seulement par la raison, mais encore par le coeur 1.... (282; "Wir erkennen die Wahtheit nicht nur durch die Vernunft, sondern durch das Herz l... . ). Das "Wertfühlen" des Herzens behandelt Max Scheler in seiner bahnbrechenden "Phănomenologie der Sympathiegefühle" (1913). Für Pascal wie für Scheler beruhen sogar die obersten Prinzipien der Logik in einer Wertordnung des Herzens. 


\section{4}

(Chvile slávy ... I Augenblicke der Hehre ..., IX, 2-4; "/... ich hört' Musik Millionen von Herzen, / Millionen von Herzen, wie Sterne getrennt von einander, einander entfremdet, I geheimnisvoll nach einander sich sehnend, in frostige Dảmmerung eingetaucht") - und ihre grandiose kollektive Integration in das "ewige Herz" ("Srdce vécné") zu vollziehen, müssen alle Herzen entfacht, in Brand gesetzt werden:537

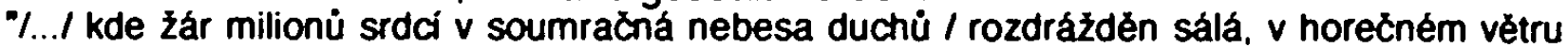
slasti a smrti" (Ruce / Hände, V. 10-11; "I../ und dort, wo die Glut Millionen von Herzen in die dāmmernden Himmel der Geister / aufgestachelt emportreibt in sengender Windsbraut der Lust und des Todes"). " .../ a ve svém srdci oheň vక̌ech srdc" (Silenci / Wahnbetörte, VII, $5 ; \%$.../ und in unserem Herzen das Feuer aller Herzen"). "A naše słzy, dẻst věchỳ, do srdci živoucich kanou, Iv krùpẻjich ohné tam pálí, vzlykotem lásky tam zni" (Cas / Die Zeit, letzte Strophe, 5-6; "Und unsere Tränen, ein ewiger Regen, fallen in lebendige Herzen, / in Topfen des Feuers brennen sie dort, im Schluchzen der Liebe verklingen sie dort". Übers. v. E. Saudek.)

In Stavitelé chrámu ist die Vollendung der Schöpfung als Erbauung des Tempels, als Hervorbringung eines Kunst-Werkes (auch im Sinne der Verschmelzung von Kunst- und Lebensschöpfung) konnotiert. In Ruce hingegen zielt die Dynamisierung aller v i t a I e n Prozesse auf die 'Entstehung' des "geistigen M e n s c h e n". der "einzig in Millionen der Brüder, die waren, sind und sein werden, I Überwinder der Räume, der Herr verborgener Mächte, / verändert die Erde vom Pol zum Pol nach deinem Heiligen Willen" (Kolozpév srdc' I Rundgesang der Herzen, V. 121-123; "jenž jediný v milionech bratîi, co budou a byli, nad prostorem vítéz, / proméni zemi od polu $k$ polu dle svaté tvé vúle"). Die Schöpfung - unter dem Gesetz der Integration und der Kollektivierung - vollendet sich in Ruce im Kommen des "geistigen", "kosmischen Menschen", in der Vergeistigung des bios (in der Art einer kollektiven Menschwerdung) und im unabwendbaren Aufstieg zur Noosphăre, die Bïezina "duchová zemè" ("geistiges Land") oder "vesmír duchư" ("Kosmos der Geister") nennt. Der "duchový Člověk" (bei Brezina oft mit Versal geschrieben) erinnert an den (eschatologisierten) Ubermenschen; es ist aber nicht der "Übermensch" Nietzsches, gegen den sich Brezinas Kritik wendet, 538 sondern das Resultat und Symbol einer neuen Synthese, in der sich die Freiheit und die individuelle Persönlichkeit aller Menschen in ihrer ganzen Mannigfalt und in ihrem Reichtum "nach dem Heiligen Willen" entfalten wird. Den Höhepunkt stellen der "erlöste" ("vykoupeny") "duchový Clověk" ("geistiger Mensch") und "duchová zeme" ("geistiges Land") dar, d. h. die Sublimierung und Spiritualisierung des (bloß) Vitalen von der idealen, nämlich der "versöhnten" ("smif̌ený) Welt her. Der Geist / Odem steuert die Lebenswelt zu einem idealen Ende. Solange aber dieser Prozeß noch im 'Gang' ist, stehen Licht und Dunkel in einem tragischen Kampf.

Durch welches Charisma vollzieht sich in Ruce die Eschatologisierung der vitalen Prozesse? Was ist deren vereinigendes und integrierendes Prinzip? In Stavitelé chrámu war es das Charisma der "Gnade", das oberste Prinzip der Kunst- und Lebensschöpfung.

537 Die Entfachung des Herzens gehort zum Repertoir der dionysischen Extatik (im Unterschied zur apollinischen Erleuchtung). Sie ist eines der Symptome der Ich-Auflósung, die sich in der Wiedergeburt durch das extatische "ZusammenflieBen" ("sliti") aller Herzen in "einem einzigen Herzen" vollendet. Der vitalisierende "Herzbrand" stelt einen der Aspekte der dionysischen Selbstaufopferung / Selbstvertorennung dar. Vgl. A. A. Hansen-Löve, Zur Typologie des Erhabenen in der russischen Moderne", in: Poetica, 23, 1991, S. $193 f$.

538 In seinem Essay-Fragment Sen o nadčlověku (Der Traum vom Übermenschen, in: $O$. Bľezina, Eseje, Olomouc 1996, S. 169) schreibt Bł̌ezina: "Mluvivá se o velikosti osamélỳch lidí: vyrostl sen o nadZ̋ovẻku, jenż jako osamélỳ orei sidli v ledových koncinách ducha. Ale je to vše mamé; tento ứték $z$ družiny pracujicich lidi je nejvyšši mukou tvưrziho ducha. Každý żivot, ktery se odchýli od zákona lásky. je stihán bolestí. Celý vyvoj lidi, všechna umẻni, všechny vẻdy maji jedinỳ smysl: vyjiti z této osamélosti a vytvơit spojeni mezi lidskými dušemi, spojeni aż do hlubin. které jsou đnesnimu Clověku závratné a jichž se hrozi" ("Man spricht von der Größe des Menschen gesprochen; es wuchs der Traum vom Übermenscten empor, der wie ein einsamer Adler in den eisigen Regionen des Geistes siedelt. Aber all das ist eitel; diese Flucht aus der Gemeinschaft der arbeitenden Menschen ist die größte Qual für den schopferischen Geist. Jedes Leben, das vom Gesetz der Liebe abweicht, wird mit Schmerz bestraft. Die gesamte Entwicklung der Menschheit, alle Künste, alle Wissenschaften haben nur einen einzigen Sinn: aus dieser Einsamkeit harauszutreten und eine Verbindung zwischen den menschlichen Seelen zu schaffen, eine Verbindung, die in solche Tiefen geht, die für den heutigen Menschen schwindelerregend sind und vor denen es inm graust"). 
das auch die Integration der 'Schatten' der dekadenten Vergangenheit in das Wertsystem des eschatologischen Symbolismus ermöglichte. In Ruce ist wohl das erwartete und

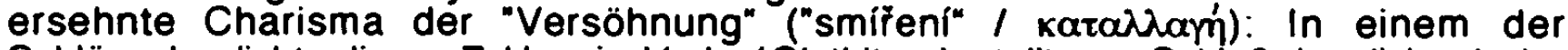
Schlüsselgedichte dieses Zyklus, in Vedra (Gluthitzen), stellt zum Schluß das dichterische Ich die Frage: "Ach, $z$ bolestné promény véci nad Gehennami poznati slávu tvé vưle /...I. Ale snesla by zem toto celé bohatstvi s míre ni tvého?" (V. 46, 49; "Ach, aus der schmerzlichen Wandlung der Dinge über den Gehennen den Glanz deines Willens zu erkennen /.../. Aber ertrüge die Erde den ganzen Reichtum deiner V e r s ö h n u n g ?"). Als eine Art Antwort auf diese Frage kann das Epilog-Gedicht Cas (Die Zeit) gelesen werden: "Zdrceni nesmirností tvé slávy, cekáme stále, teskni a tisí, / na sladké usmáni s mi í e n i tvêho, skonđeni dní, /.../ zlomeni mystické vazby, o d p u s té ni " (VI, 1-2, 4; "Zermalmt von der Unendlichkeit deines Ruhmes, warten wir immer bang und ergeben, i aufs süße Lächeln deiner Versöhnung. der Tage Vollendung. I.../ Sprengen der mystischen Fesseln, deine Vergebung ". Übers. v. E. Saudek.) Die erwartete Versöhnung am Ende der Zeiten wird aber hinausgeschoben. Der Dichter - stellvertretend für die gesamte Menschheit und hinter dem kollektiven "wir" versteckt - verharrt im Zustand des endlosen Wartens.539 Er trinkt zwar "dem Leben, der Sonne, Versöhnung und Hoffnung" extatisch zu ("ve pripitku extatickêm životu / a slunci, smífení a nadejím" (Stráż nad mrtvými / Totenwache, V. 51-52), in einer visionären 'Schau' sieht er sogar die "Orte der Harmonie und der Versöhnung" (Mista harmonie a smî́eni; gleichnamiges Gedicht), doch das letzte Wort ist das bange, stille und enttäuschte "Warten". "\%.../ zemdleni vêky Cekáme stále na tvưj tajemný pî́chod" (Cas IDie Zeit, III, 5; "I...I von Äonen ermattet, warten wir immer auf deine geheimnisvolle Ankunft"). Im Hinblick auf das erwartete Heilsgeschehen bedeutet die Versöhnung - wohl auch in diesem Kontext - die Erfahrung der Reinheit (durch die Tilgung der Sünde), die Aufhebung des Feindschąttverhältnisses und die Herstellung des Friedenszustandes, im Sinne der

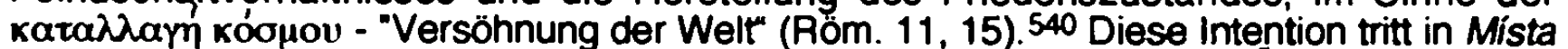
harmonie a smireni (Orte der Harmonie und der Versöhnung) und in Cisté jitro (Reiner Morgen) explizit zutage:

1.../ a naše myšlenky nejukrytějši, magickým obrazem / jak souhvězdi nejčistši noci tam viditelny jsou všem. // A neznajice jiż bolesti jiných neż nejtajemnéjši všech ztrát / na prahu vnitł̌nich tvých světủ blizkosti tvoji se bát - / dobyvatelé pokorni , za tebou jeme $k$ tvým zahradám. I a všechna proti nám vyslaná vojska pridávaji se k nám". (Mista harmonie a smir̂ení / Orte der Harmonie und der Versöhnung. IV, 3-4, VIII, 1-4; "/.../ und unsere heimlichsten Gedanken, durch magische Spiegelung. I wie Sternbilder der klarsten Nacht sind sichtbar dort allen. I... / // Und wissend nicht mehr von anderen Schmerzen als dem des geheimnisvollsten aller Verluste, / auf der Schwelle deiner inneren Welten sich fürchten vor deiner Năhe - / demütige Eroberer, dir folgend, geh'n wir zu deinen Gărten, I und alle gegen uns ziehenden Heere treten zu uns über'. Übers. v. E. Suadek). "Tíz tajemstvi svych bolestných jsme prijali jak vüli tvou, / preded rozlomenim peceti list polibený s pokorou; / a nepritel, jenž Cínaje u našich usnul bran, / jak unavený posel tvưj byl od nás uvitán" (Cisté jitro / Reiner Morgen, III, 1-4; "Unserer Rắtsel Schmerzenslast empłangen wir als deinen Willen, / einen vor dem Zerbrechen des Siegels mit Demut geküßten Briet; / und unseren Feind, der lauernd, bei unserem Tor schlief ein, / als deinen ermatteten Boten luden wir freundlich ein").

Die Versöhnung vollzieht sich als eine vom Menschen völlig unabhängige Heilstat des "Höchsten". Die Menschen können diese Heilstat nur "emplangen", daher warten sie "ergeben" ("oddane") und "von Äonen ermattet": "Zdrceni nesmirnosti tvé slávy, Cekáme stále, teskni a tišn" (Cas / Die Zeit, VI, 1: "Zermalmt von der Unendlichkeit deines Ruhmes, warten wir immer, bang und still"). Die Versöhnung vollzieht sich vor allem durch das Sühnopfer, durch die Hingabe Christi in den Tod. Sein Tod kann dabei als kosmisches Ereignis gedacht sein, wie in hellenistischen Mysterienreligionen bzw. in der Gnosis;

539 Die Symbolik des 'enttāuschten Adventismus' wird im selbständigen Kapitel ausführlicher dargelegt.

540 Vgl. R. Bultmann, Theologie des Neuen Testaments [9. Aufl.], Tübingen 1984, S. 285ft. Vgl. 2. Kor. 5, $17 \mathrm{ff}$.: "Darum: Ist jemand in Christus, so ist er eine neue Kreatur; das Alte ist vergangen, siehe, Neues ist geworden. I Aber das alles von Gott, der uns mit sich seiber versöhnt hat durch Christus und uns das Amt gegeben, das die Versöhnung predigt. I Denn Gott war in Christus und versöhnte die Welt mit sich selbst und rechnete innen ihre Sünden nicht zu und hat unter uns aufgerichtet das Wort von der Versöhnung". 


\section{6}

hierzu gehört die Selbstaufopferung des Dionysos, der als mythischer Gottmensch, als der "untere Erlöser", wiederkam. Indem Christus starb, sind alle mit inm gestorben, so wie seine Auferstehung das Auferstehen aller bedeutet. Wie R. Bultmann nachweist, sind alle diese Gedankengänge mythologischen Ursprungs. ${ }^{541}$ Es ist die Versöhnung (und Vergebung / "odpušsténi" / aфعouç) des "Höchsten", die den Menschen n e u macht. 542 In diesem Sinne ist offensichtlich auch der erwartete, 'neue', "Einzige Mensch, der Erlöste", der "Steuermann des geistigen Landes" zu deuten, von dem die "Wahnbetörten" (Silenci) träumen und dessen Ankuntt in Kolozpevv srdci (Rundgesang de Herzen) beschwört wird: "/.../ prichod jasného clovẻka tajưpného, / jenž jediný v milionech bratrí co budou a byli, I nad prostorem vitěz, / promẻni zemi od polu k polu die svaté tvé vưle" (V. 119-122; "/../ Ankuntt des strahlenden, geheimnisumwobenen Menschen, / der einzig in Millionen der Brüder, die waren, sind und sein werden, / Überwinder der Räume, / verändert die Erde von Pol zum Pol nach deinem heiligen Willen"). Noch deutlicher kommt die Vorstellung der 'Entstehung' eines neuen, "geistigen Menschen" im Gedichttext Nëdële svatodušni (Der Pfingstsonntag, 1904) zum Ausdruck:

"Vstal v milionech bratři çověk tajemnỳ, / na kouli zemè vztyčen, celo mezi hvězdami, / a srdce jeho, plamen rozžatỳ na Žáru Srdce věcného, / do kosmu duchủ svitilo. I Neděli svatodušni slavi národové na zemi" (V. 87-91; "Inmitten Millionen von Brüdern entstand der geheimnisumwobene Mensch, / emporgereckt auf der Erdkugel, die Stim zwischen Sternen, / und sein Herz, entfacht an der Glut des ewigen Herzens, / leuchtete in den Kosmos der Geister. I Pfingstsonntag feiern die Völker auf Erden").

Hier drängt sich noch die Frage auf: In welcher Gestalt erscheint der "Höchste" in Ruce? Signifikantenweise tritt er in den Gedichten dieses Zyklus nicht mehr als abstrakter. 'theo-logisienter' "Dreimal Heiliger" ("Triikráte Svaty"; Kodyż z lásky tvé... I Wenn aus deiner Liebe..., VP) oder als "Öffnender" ("Otvirajic"; Kde jsem uż slysel... ? I Wo denn vernahm ich schon?..., VP) auf, sondern als konsequent mythisierter, 'bildhaft-konkreter' (man möchte fast sagen säkularisierter) "Vogelsteller der Seelen" ("ptáčník duši"; Vedra I Gluthitzen, V. 44), "mystischer Gärtner" ("mystický zahradnik"; Kolozpěv srdci I Rundgesang der Herzen, V. 10) oder als "Strenger" ("Prísny"; Chvime se nad moci vile I Wir beben vor der Macht des Willens, V, 1). Derartige 'Verkleidungen' sind charakteristisch für den dionysischen "unbekannten Gott", der - als einfacher Mann verkleidet - aus der chthonischen Sphäre wiederkehrt. So, wie dem dionysischen "unerkannten Gott" ein Teil seines eigenen Selbst unbekannt bleibt, 543 so kennzeichnet auch den (dionysischen) sich opfernden Dichter die rätselhafte 'Unwissenheit' um sein "eigenes Wesen": "A naše vlastni bytost záhadná! / Na hranici svê Żalmy péjicí / v sarlatném plášti plamenú!" (Stráz nad mrtyými / Totenwache, 38-40; "Und unser eignes rätselhaftes Wesen! Am Scheiterhaufen seine Psalmen singend / im schrlach'nen Mantel der Flammen!"). Der "Einzige Mensch, der Erlöste", der "geheimnisvolle Mensch", der 'unbekannte' Gott(-Mensch), das "Zusammenfließen", die (rauschähnliche) 'Umwissenheit' um sich selbst: alle diese Vorstellungen und Motive entspringen dem gnostischen Erlösungsmythos, in dem es doch um die Erlösung des 'inneren', "geistigen Menschen" (anthropos) durch die Erkenntnis, die die Freiheit (von der diesseitigen Welt) bedeutet. geht. 544 Aber nicht die Erkenntnis, (rwëors; gnostisch-eschatologisches Modell, SZ).

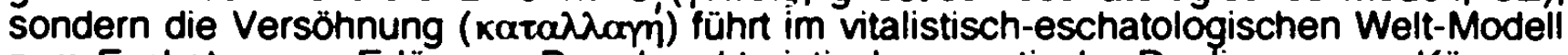
zum Eschaton, zur Erlösung. Der charakteristische gnostische Dualismus von Körper Geist, Licht - Finsternis usw. oder die konsequent akosmische Orientierung der gnostischen Lehren, die den xóoros als Zwangssystem, als Reich der Unwissenheit negieren und die die Menschneit Christi nicht anerkennen, sind im Prinzip für die Semantik des in Ruce konstituierten Welt-Modells irrelevant. Dennoch reicht hier die gnostische Eschatologie - mit ihrem Postulat der Erlösung des "geistigen Menschen" ("duchový Clovek") - der christlichen Eschatologie die Hand. Warum aber greift Biezina in Ruce aư den gnostischen Erlösungsmythos zurück? Kann man darin nicht den 'letzten'

541 R. Bultmann, a.a.O., S. $295 f$

542 Vgl. ibid., S. 25.

$543 \mathrm{Vgl}$. Aage A. Hansen-Löve, .Dionysos und "Svirel' $\alpha$ " (Der "untere Erlöser"), in: Der russische Symbolismus II. Lebenssymbolik [Typoskript], Wien 1984, S. 496.

$544 \mathrm{Vgl}$. K. Rudolph, Gnosis. Wesen und Geschichte einer spätantiken Religion, Göttingen 1994, S. 132ff. 
Schritt auf dem Wege zur Integration des $m$ y sti s ch-g n o st i s che n Denkgutes in die Werthierarchie des eschatologischen Symbolismus sehen? In Stavitelé chrámu geht es in erster Linie um die Integration der 'Schatten' der dekadenten Vergangenheit und der L'art-pour-l'art-Ästhetik (TD). In Ruce soll offensichtlich der 'Rest', $d$. $h$. das in Vëtry oo pollu (Polarwinde) verdrängte Substrat des (hermetisch-)gnostischen Denkens, integriert werden. Damit wäre die Integration der dekadenten 'Schattenwelt' in das System des eschatologischen Symbolismus wohl vollbracht. Diese Intention bekundet sich nicht nur im vereinigenden Prinzip des vitalistisch-eschatologischen Modells, in der Ve r s ö h n u n g. die sich durch das Sühnopfer vollzieht, sondern auch im angestrebten "Zusammenfließen" ("sliti"), "aller Millionen zu einem Einzigen erlösten Menschen" (Silenci I Wahnbetörte, $X, 1-2$ ). Doch auch das vitalistísch-eschatologische Welt-Modell hat seine Schatten; es ist vor allem der Schmerz der enttäuschten Endzeiterwartung, der sie wirft. Diese Problematik soll im weiteren näher betrachtet werden.

\subsection{Symbolik der enttäuschten Enwartung: 'erstarrte' Zeit - 'verstummte' Erde - 'vereiste' Welt}

"Zdrceni nesmirnosti tvé slávy, cekáme stále, teskní a tişi".

"Zermalmt von der Unendlichkeit deines Ruhmes, warten wir immer bang und still".

O. Błezina: Cas (Die Zeit)

Die Verzweiflung. Ernüchterung und Skepsis als Folgen der nicht erfülten und (daher) enttăuschten Endzêttenwartung, prägen die Sujettogik einiger Schlüsselgedichte Biezinas letzten vollendeten Zyklus. Die Semantik der wehmütigen Desillusionierung, die sogar in solchen Gedichten wie Vedra (Gluthitzen) oder Hudba slepcú (Musik der Blinden) zum (kosmischen) Drama des völligen Debakels jeglicher Aspirationen auf die endzeitliche Vereinigung und Harmonisierung ausartet, scheint der in der älteren Bíezina-Literatur etablierten These von dem vermeintlich unerschütterlichen Optimismus des in Ruce konstituierten Welt-Modells zu widersprechen.

Das Nicht-Eintreten des eschatologischen Geschehens, der erwarteten Parusie, zieht einen Stillstand der schöpferischen Prozesse, eine furchteinflößende 'Thanatosis' der Zeit und eine 'Vereisung' der Welt nach sich. Das Erwarten der "Ewigkeit morgendlich Fever" ("vęnnosti jitł̌ni pozár". Silenci / Wahnbetörte, IX, 2) kippt um ins ewige, "bange" ("teskny") und "stille" ("tichy") Warten:

"mocná slova harmonická zniti budou v hlahol svẻtù, / płedvoj na výpravě duchủ v jasné stéry závrati, I a pak s kłidly rozpjatẏmi, zastavena ve svém letu, I v bouk̉ casu zavẻsena, nepohnuté Cekati" ( Vécné znova... Stets aufs Neve... VI. 1-4: "mächtige Worte, harmonische, werden ins Weltenbrausen forttönen, / Vortrab auf der Geister Heertahrt zu des Taumels hellen Sphăren, I und mit ausgespannten Flügeln, auf dem Fluge aufgehalten, / in der Zeiten Stürmen hangend, werden sie dann regungslos harren"). "Ale my cekáme oddané jako jsme ¿ekali jednou" (Cas / Die Zeit, III, 1; "Aber wir warten ergeben, so wie wir einstens gewartet").

Das paradox-absurde und ewige Warten begleiten charakteristischen Symptomen des enttäuschten Adventismus - das gefährliche Verstummen" ("nebezpečné ztisení"; Tichý oceán I Der stille Ozean, VI, 1), die "Stille des Ekels und der Ermüdung" ("z ticha hnusu a umdleni"; Silenci / Wahnbetörte, V. 3), die "Suggestion der Ohnmacht" ("Suggesci mdloby"; Bolest Cloveka / Schmerz des Menschen, 1, 1), der "Wahnsinn der Hände, die vergeblich sich recken" (Stráż nad mrtyými / Totenwache, V. 31; "Sílenstvi rukou marnè rozpjatych" usw. -, die allesamt ein ominöses Negativ der rauschhaften 'Vokalisierung' des кoopos mit seinen 'Sternen'- und 'Wässerchören', mit seinem "Dithyrambus der Welten", fundieren. Diesem sich immer aggressiver verbreitenden "gefährlichen Verstummen" wird der kollektive und gewaltige Chorgesang gegenübergestellt, um die schwach gewordene individuelle Stimme, ja die ganze Lebenswelt, die der "Wahnsinn der selbstmórderischen Nacht" (Chvime se nad moci vule... I Wir beben vor der Macht des Willens", VIII, 4; "Sílenstvi noci sebevražedné") zu umfangen droht, zu retten: "Pro vykkikik srdce osamélého I kdyż zajásá v úzkosti svoji jako pták zbloudiiý, / jenż nalezl bratrské mnożstvi zpivajici, / sladko je 
Žiti!" (Kolozpév srdć / Rundgesang der Herzen, V. 92-95; "Wegen des Aufschreis des einsamen Herzens / wenn es aufjauchzt aus seiner Angst wie ein verirter Vogel, / der gefunden die brüderlich singende Menge, / süß ist's zu leben!"). Das kosmogonisch-eschatologische "durch Welten blühende All" (Hvẻzd hasnou tisice... / Erlöschen tausende Sterne..., V, 2, SCh; "vesmir, svẻty kvetouc" ), in dessen Städten Getobe und Lärm "der Menge auf Bauplätzen geheimnisvoller Bauten" herrschen (Proroci / Die Propheten, V. 53; "Hučení davu na staveništich tajemných staveb"), droht im "gefährtichen Sweigen" des dunklen Ozeans zu versinken: "Uprostred Cerných oceánů zniceni / ostrovy micenlivé budou naše sny / a lođstva mrtvých, $v$ horká pásma plujicich, I na horizontech siných světel uzríme" (Stráż nad mrtvými / Totenwache, V. 18-21; "Inmitten schwarzer Ozeane der Vernichtung / werden unsere Träume schweigsame Eilande sein / und die Flotten der Toten, segelnd nach heißen Zonen, / werden wir am Horizont fahler Lichter erblicken").

Mit dem "gefährlichen Verstummen" geht - als 'Reaktion' auf das Ausbleiben der endzeitlichen Vollendung, die 'Erkaltung' und 'Vereisung' des Weltalls einher, das sich in einen herrlichen vor zauberhaften Eisblumen funkelnden und changierenden Wintergarten zu verwandeln scheint;545 seine "Fenster" ("okno"), als medialer Topos des Übergangs, sind zwar "offen", aber nicht (mehr) transparent und diaphan. Es leuchtet auch kein warmes, verheißungsvolles Licht dahinter, wie z. B. im adventischen Gedicht Když nebe vał̌e okna ozárí... (Fült eure Fenster Himmelsglanz..., SCh). Im Gegenteil! Die "Fenster" sind vom "frostigen Licht" ("mrazivým světlem") umflossen, mit "Eispalmen" bedeckt und opak. Sie führen nicht ins jenseitige Licht, sondern in den frostigen "nächtlichen Azur des Todes":

'Zahrady zimní vidèl jsem, haluze rozkvetlé v krišt’ály, / jak právé rozżaté lustry ješté se houpaly, duhami zahrály; / jak ledové palmy na oknech tajemstvi, mrazivým světlem ozárenè / a jako zahrady kosmu priblížené, rozjiskǐené a otevřené" (Chvile slávy... I Augenblicke der Hehre.... V, 1-4; "Wintergärten sah ich, die Zweige erblüht zu Kristall, / wie eben entzündete Lüster schaukelten sie, erspielten in lichtem Opal; / wie Eispalmen an Geheimnisses Fenstern, von frostigem Lichte getroffen / und wie Gärten des Kosmos Nähe winkend, funkensprühend und offen". Übers. v. P. Eisner.) \% I nočni blankyty smrti, / kvetouci v kosmickém mrazu hvězdnými asfodely" (Hudba slepcü / Musik der Blinden, VIII, 1-2; \%.../ des Todes nächtliche Azure / blühend im kosmischen Frost in Asfodelen der Sterne"). "\% / jak zbloudila væ̌la zvonici, / kdyż o sklo oken naráżi do zledovatělých blankytü" (Tichý oceán / Der stille Ozean, III, 3-4; "I../ wie die irrende Biene, läutend, / wenn sie ans Glas der Fenster wie an vereiste Himmelsgewölbe anstößt"). $\%$.../v extasich lásky jak tiché slunce v nesmirno zơvižená / nad zemi čistou a zárnou jak zimni zahrada diamantová" (Chvime se nad moci vuile / Wir beben vor der Macht des Willens, IV, 3-4; "/../ in Extasen der Liebe wie die stille Sonne, in die Unendlichkeit erhoben, / über der Erde, der reinen und strahlenden, wie der diamantene Garten des Winters". Übers. v. E. Saudek.) "Ó mocné ruce zárici, kam naši touhu vedete? I... I Do jakých tich, kde zazivá v žal príliš velké nádhery. I zpèv ptákú polámich nad melancholickými jezery?" (Żeny I Frauen, IV, 3-4; "O máchtige Hănde. strahlende, wohin entführt ihr unsere Sehnsucht? I.../ In welche Stillen, wo ertönt, ins Weh' der allzugroßen Herrlichkeit. / der Polarvögel Gesang über den melancholischen Seen?").

Mit der desillusionierten, depressiven Lebenshaltung der "stets Wartenden" ("Bloudíme tajemstvim zemè, ptáme se vẻci mlZenlivých / na jaro, kterẻ nepricházi, na květy, které se nerozviji", Silenci I Wahnbetörte, I, 1-2; "Durch der Erde Geheimnis irren wir, befragen schweigsame Dinge, / nach dem Frühling, der nicht herannaht, nach Blüten, die sich nicht erschließen"), 546 mit dem unheilverkündenden 'Verstummen' der Erde ("Jak všechno

545 Hier greift Bǐezina offenkundig aư die Ästhetik der kalten lunaren Welt (TD) mit inrem silbrigen Gefunkel der Edelsteine oder des glitzernden Schnees zurück. Während jedoch die 'Vereisung' der zu einer paysage intime transformierten Welt des Dichters im axiologischen System des dekadenten Symbolismus positive Bedeutung hat - námlich als stimulus des ästhetischen Genusses -, wird der 'kosmische Frost' der Weltlandschaft in Ruce zum Sinnbild der zwar herrlichen aber "schmerzvollen Erde" (Chvile slávy I Augenblicke der Hehre), in der der Mensch vor Einsamkeit, Erschöpfung und Leiden 'erfriert'. In dem Anno 1906 in Moderni revue veröffentlichten Gedicht Nepremożitelní rostem... (Unüberwindlich wachsen wir...) kommtd diese Intention besonders prägnant zum Ausdruck: " $V$ mrazu bolesti jak v̌̌ely ülu zimniho se $k$ sobẻ tiskneme, / ve všech světech miliony bytosti, / zavěšeni v třesouc se hrozen jediny" (V. 31-33; "Im Frost des Schmerzes wie die Bienen des winterlichen Stocks drücken wir uns aneinander, / in allen Wetten Millionen von Wesen, / hangend in einziger zitternder Traube").

546 Die oben zitierte Verszeile aus Silenci (Wahnbetörte, 1, 1-2) kann als eine autointertextuelle Replik auf das ungeduldig erwartete, im Epilog-Gedicht Pozdravujeme jaro! (Wir grüssen den 
tichne z téchto mist!", Tichý oceán I Der stille Ozean, VII, 1; "Wie alles doch in Still' ertrinkt von diesen Orten aus!") ist der Höhepunkt der visionären Enttäuschung offensichtlich noch nicht erreicht. Hinzu kommt das schmerzvolle 'Nicht-Verstehen-Können' und das 'NichtVerstanden-Werden'. Es ist die Unmöglichkeit die Botschaft des "Höchsten" zu lesen, sie zu verstehen, nämlich: wann die Zeit 'da ist', wann die Heilstat der Versöhnung in Erfüllung geht. Diese Botschaft pervertiert zu unverständlichen Hieroglyphen, zu warnenden aber vollkommen änigmatischen "feurigen Buchstaben", die der Mensch nicht zu dechiffrieren vermag und deren Apokalypsis vergleblich, unerreichbar bleibt:

"V oblacích casu jsem blesky ž̉el jak apokalypsy onnivé písmeny", Chvile stávy I Augenblicke der Hehre..., VII, 1; "In Wolken der Zeit sah ich Blitze wie der Apokalypse feurige Buchstaben".) - Ach, z bolestné promény véci nad Gehennami poznati slávu tué vưle / a jako pismo sdẻlení tajných za doby nebezpecenstvi, / zjasnẻné nad onnẻm tahy blankytovými, Císti ji v zárî" ( Vedra I Gluthitzen, V. 44-48; "Ach, aus der schmerzlichen Wandlung der Dinge über Gehennen die Herrlichkeit deines Willens erkennen / und wie die Schrift geheimer Kundschaft zur Zeit der Gefahren, / über dem Feuer erhellt in himmelblauen Zügen, sie im Lichte zu lesen (").

Es ist das tragische Los des 'Nicht-Verstanden-Werdens', das den visionären Gestalten, den von den 'Erdbrüdern' als "Wahnbetörte" gebrandmarkten und verlassenen vigiles widerfährt, die auch jetzt - einzig unter allen - das Nahen der "Ewigkeit morgendlich Feuer" ("vëčnosti jit̛́ni pożar", Ślenci, IX, 2) und die (zukünftige) Parusie des "Einzigen Menschen, des Erlösten" $(X, 1)$, voraussehen können:

-A ać jsme nestísinými żivoty żili, żárem všect kvêtu kvetli, I.../ / a ve svém srdci oneh vsech srdai - stáli jsme osaméli. // Za zrádce zemé vyhlásili nás tajné, kdyż jeji slávu, véčnosti jitłni požár, jsme v extasi vitali na kolenou. I..... II I... / nad każdou krajinou krásy, kam zrak náś vibojem dostih, I znameni twého panstvi suverénniho ve všech nekoneénostich" (Silenci I Wahnbetơrte, VII, 1. 4, IX, 1-2, XI, 3-4; "Und obgleich in ungezāhlten Leben wir lebten, in der Glut aller Blüten blühten, $I \ldots / /$ und in unserem Herzen das Feuer aller Herzen, - blieben wir einsam. / Heimlich hießen sie uns Verrăter der Erde, wenn wir den Ruhm ihrer Sendung. / der Ewigkeit morogendlich Feuer auf Knien in Verzückung begrüßten. I.../ // I.../Über allen Stătten der Schơnheit, wohin unsere Blicke erobernd drangen, / als Wahrzeichen deiner selbstherrlichen Macht im unendlichen Raume").

Es ist nicht zu verkennen, daß die "Wahnbetörten" das bittere Schicksal des 'NichtVerstanden-Werdens' mit den "Herrschern der Träume" 547 aus dem gleichnamigen Gedicht des Zyklus Svítáni na západẻ (Tagen im Westen) teilen. Bỉezina scheint hier (erneut) den romantischen Topos der Isolierung des Künstlers in/von der Gemeinde der 'Erdbrüder', die seine Sendung nicht versteht, zu aktualisieren, gleich in welcher Gestalt er erscheint, ob als stolzer Künstler-Schöpfer, als "Heiliger" ("svaty̆"), als visionărer poeta vates, als "Fremder" ("cizinec") oder als "ewiger Pilger", wie im Sonett des Romantikers Karel Hynek Mácha (1810-1836): "Jest pévcivv osud suêtem putovati" ("Es ist des Sängers Schicksal durch die Welt zu wandern"). Als "Fremder" und "Sänger", der für sich selbst ein

Frühling!) von Stavitelé chrámu (Baumeister am Tempen) visionierte aber unertülte Nahen des eschatologischen Geschehens gelesen werden: "Pozdravujeme jaro! Vítáme netrpělivost duši! /.../ Nekonečnosti cekaji na nás, jiná slavnéjśi jara, I vécností hỉmíci pisné, vysvobozenil", letzte Strophe: "Wir grüßen den Frühling! Heißen die Ungeduld der Seele willkommen! /.../ Denn Unendlichkeiten warten auf uns, andere, ruhmvollere Frühlinge, / Befreiungen, Lieder, in der Unendlichkeit drobnnend!"). Einen schweren 'Schock' erleidet der adventistische Enthusiasmus von Pozdravujeme jaro! (Wir grüBen den Frühling!) auch im Gedicht Chvime se pred moci vile (Wir beben vor der Macht des Willens, R). In Pozdravujeme jaro! bannt der herannahende "Frühling" der Erlösung " \%... / mit dem Blick der Schónheit die selbstmörderische Hand / und läßt die Seele trăumen vom erhabenen Wahnsinn der Heroismen" (III, 3-4; "Pohledem krásy zadrži ruku sebevrażednou I a duši dá sniti o vzneseném silenstvi heroismü). In Chvime se nad moci vüle (Wir beben vor der Macht des Willens, R) schrumpft der adventistische "erhabene Wahnsinn der Heroismen" (Pozdravujeme jaro!) zum gefăhrlichen "Wahnsinn der selbstmörderischen Mitternacht!" (VIII, 4; "Silenstvi pülnoci sebevražedné!").

547 "Poniženi vracite se v domov, $k$ vápeným br̉ehùm, jež houbovité se droí / nárazem věkủ, a kde nikdo nevêrí vašim zvéstem, syceným vúnémi jihu". (Vladari snú / Herrscher der Trăume, iX, 3-4; "Emiedrigt kehrt ihr nach Hause zurück, zu den Kalkufem, die wie Schwämme zerbrösseln I unter dem Anprall der Äonen, und wo keiner euren Botschaften glaubt, die gesăttigt sind von Düften des Südens"). 
"Rătsel" ("záhada") bleibt und vertrauensvoll,548 in die Zukunft schaut, stilisiert sich das dichterische Ich in der Schlußstrophe des Prolog-Gedichts Chvile slávy (Augenblicke der Hehre):

-Na prahu brat̛̃i usedal jsem, záhadny cizinec, podveðer, / a v dalekém šuméni vod, a v pisni

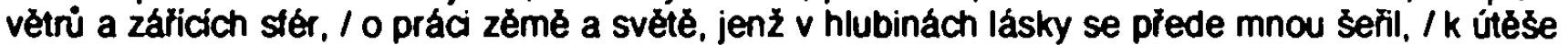
bratr̆i jsem zpival, stasten $z$ úsměvu jejich, a věril". ("Auf der Schwelle der Brüder, ein rătselhaft Fremder, saß ich am Abend / und im fernen Rauschen der Wăsser, dem Liede der Winde und Sphăren, weit strahlend, I von der Arbeit der Erde, der Welt, die in den Tiefen der Liebe tagen ich schaute, / zum Troste der Brūder ich sang, glücklich über inr Lảcheln und glaubter. Übers. v. E. Saudek.)

Das Motiv der 'Fremaheit', der 'Unerkanntheit', führt zu der bereits erwähnten dionysischen Symbolik des "unerkannten Gottes". Auch die poetae vates bleiben als Seher und Verkünder des "Kommens" des "Einzigen Menschen, des Erlösten" ("Jediného Clovẻka, vykoupeného"), von den 'Erdbrüdern' unerkannt. Damit koinzidiert eine wichtige Bedeutungsverschiebung auf der Ebene der Bewegungssemantik. Die signifikante Bewegung der verheißungsvollen, positiv konnotierten Endzeiterwartung innerhalb des kosmogonisch-eschatologischen Welt-Modells ist doch das ungeduldige "bliženi" ("Nahen"), das "Kommen" der "Propheten" im gleichnamigen Gedicht, des "Meisters" auf den Wogen der Zeit im Prolog-Gedicht usw., oder das 'Rasen' bzw. das 'Fliegen' des Wagens der Zeit (besonders prägnant in der letzten Sujetsequenz von Se smrti hovori spici...I Mit dem Tode reden die Schläfer...), die 'Hyperkinesis' schlechthin, die in den Gedichten der 'enttäuschten Endzeiterwartung' ins Gegenteil umschlägt: in 'SichEntfernen' ("vzdalováni") oder sogar "Herumirren" ("bloudéni") im "stummen Labyrinth". Dieser 'Rückfail' wird im Prolog-Gedicht Chvile slávy (Augenblicke der Hehre) antizipiert: Der Blick des Dichters sieht nicht (męhr) das 'Nahen' des "ewigen Morgens" wie der divinatorische "Glutblick" der vigiles ("Zár našich zrakü", Vigilie 1, 27), sondern ist "voll Bangigkeit in die Ferne versunken" (VI, 2; "zrak teskný zhroužený v daleku"):

- ... I żal zemè, navżdy ztracené, se slival v našich myšlenkách. I.../ noci za námi, v jichż nebezpečném ztiseni / jsme bloudivali, cizinci /.../. I Jak všechno tichne $z$ těchto mist! Po mơ̈i nẻmém veslujem, / slavici leti v dálce pł̌ed námi, nad námi výše bez hlasu ... I Však naše zraky

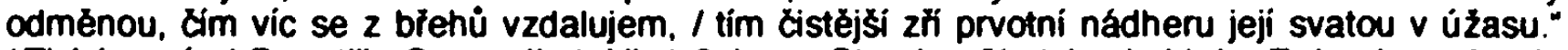
( Tichý oceán / Der stille Ozean, II, 4; VI, 1-2; letzte Strophe; "I.../ das Leid der Erde, der auf ewig verlorenen, ergoB sich in unseren Gedanken. I.../ Năchte hinter uns, in deren gefăhrlichen Schweigsamkeit / wir herumirrten. Fremdlinge /.../. / Wie Alles verstummt von diesen Orten aus! Auf stummem Meere rudem wir, I Nachtigallen fliegen in der Ferne vor uns, über uns die stumme Höhe... I Doch unsere Blicke zum Lohn dafür, je mehr wir uns jedoch vom Ufer der Erde erntfernen, / sehen reiner stets ihre ursprüngliche heilige Schönheit im Schauer"). "I.../ když jsme se bratrím nejbližsi zoáli, nejvic se vzdalovali I.... Ale ani v zálicich mihovinách světủ nejvzdálenějsich / miru jsme nepoznali" (Silenci / Wahnbetörte, VI, 2; XI, 1-2; "Wenn wir am năchsten den Brüdern schienen, entfernten wir uns am meisten I.../. Aber nicht einmal in den strahlenden Nebelgestirnen fernster Welten / fanden wir Frieden"). "A smrti poselstvi I.../ I

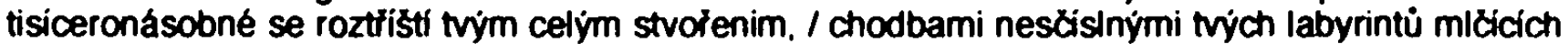
I... (Straż nad mrtvymi / Totenwache, V. 71, 79, 80; "Und des Todes Botschaft /.../ / wird sich tausendfach zersplittern durch deine gewaltige Schöpfung, I durch die unzăhligen Gănge deiner schweigenden Labyrinthe I... $r$. Übers. v. E. Saudek.)

Das endlose "Herumirren", das "Sich-Verlieren" in der erschöpfenden "Ferne", das "gefährliche Verstummen" oder das "Erlöschen der Erde* ("Uhasla zemê, ussvobozená..."; Cas I Die Zeit, V, 1) sind doch Motive, die zur Dramaturgie der Irrealisierung in der Schaffensphase des dekadenten Symbolismus (TD) gehören. Ein weiteres Indiz dafür, daß auch innerhalb des vitalistisch-eschatologischen Welt-Modells des letzten vollendeten Zyklus die (erfolgreiche) Integration der dekadenten 'Schattenwelt' angestrebt wird. Auch diese Aspekte des dekadenten Symbolismus sollen nun neugewertet und in die Werthierarchie des eschatologischen Symbolismus integriert werden. In Stavitelé chrámu war es die Strategie der Pluralisierung und der Parallelităt nach der Formel "es gibt diesen Weg, aber neben inm auch tausende andere Wege“, die zu der postulierten Integration führen können. In Ruce ist es das "Zusammenfließen" ("sliti") und die "Versöhnung" mit

548 Das im Frühjahr 1901 abgefaßte Gedicht Chvile słávy (Augenblicke der Hehre) gehört zu den späteren Gedichten des Zyklus, in denen der optimistische, das Leben trotz allen Niederlagen bejahende Tonus ertönt. 
dem Ziel der kompletten Umwertung des Negativen zum Positiven nach der Formel "Süß ist's zu leben!" ("Sladko je žitil"), weil das Leben auch Niederlagen und schmerzvolle Verluste einschließt: "Pro tajemství bolesti, smrti a znovuzrození / sladko je ź́ti! /.../ Pro vichỉice, prevraty, boure!" (Kolozpèv srdci / Rundgesang der Herzen, V. 45-46, 97: "Wegen des Geheimnisses des Schmerzes, des Todes und des Wiedererwachens / süß ist's zu leben! /... / Wegen der Stürme, Umwälzungen, Gewitter!). Geradezu extatisch wird die Intensivierung aller vitalen Prozesse, die zur kosmischen Versöhnung führen sollen, in dem vier Monate nach der Herausgabe von Ruce veröffentlichten (in Moderni revue) Gedicht V $\mathcal{S}_{\Theta}$ zachiátit... (Alles ergreifen...) postuliert:

"Vše zachvátit a v krásy vyhnat kvêt, jak miza prostoupit / v plod nechat usládnout a zduchovêt, smifit a vykoupit, / vše nezrozené z noci vyvolat, obejmout $v$ jásotu / a všechno mrtvé v novỳ Zár navrátit k životu!" (VI, 1-4; "Alles ergreifen und die Blūten zur Schōnheit erblühen lassen, wie der Saft durchdringen, I zur Frucht süß werden lassen und vergeistigen, versöhnen und erlösen, / alles Ungeborene aus der Nacht heraufbeschwören, im Jauchzen umarmen / und alles Tote zu neuer Lebensglut zurückverwandeln!").

Im folgenden soll die Symbolik der enttäuschten Endzeiterwartung und die dramatischen Konsequenzen des Nicht-Eintretens des erwarteten "ewigen Morgens", ("vëcné jitro", Vigilie I, SCh), des Eschatons, anhand von zwei paradigmatischen Gedichten - Vedra (Gluthitzen) und Hudba slepcú (Musik der Blinden) - eingehender erörtert und weiter spezifiziert werden.

\subsubsection{Entropie des (Welt- und Existenz-) Sinns statt erwarteter Vollendung: Vedra (Gluthitzen)}

„Je dunkler, je mehr lichter.

Je schwärser A.L.L.S., je weißer weißt sein Sam".

Quirinus Kuhlmann, .Kühlenpsalter" (Der 62. Kuhlpsalm)

\section{Vedra}

lluze v Záru, jak halucinace umírajících Zízní!

Zem jako płezrálá puká. Kvêty plamenư neviditelných

vyvłely, parazitní, mezi liliemi a jako błecłany do výse plápolající

płisávaji se $k$ nehybným stromưm. Sinavé blesky

5 ţ̌̉stí se v svêtle: $v$ ironickém nárazu čisi slaví svou hostinu knízata noci - -

Ale jak oblaky nazpět do mołe odnásející útěchu vláhy

nadXje naše zapadají za horizonty rozpálenými.

Jen němé vedro tvé spravedinosti sálá jak brázdy jejich letu

nad nivami a nad staveništi a nad cestami, kde bilé kameny svítí

10 jak fexišť̉ ohně a kde jak námèsíxní plíži se vojska.

Żhavý dech prace stoupá nad Žhavý dech zemé, nad vinu žhavějjí vina,

údery tepen na spáncích otrokủ svistí jak hvízdání bixủ.

smrtelně zvážněly zraky. Krutost věkủ ožívá v krvi:

nebezpex̃ná procitnutí pralesa němého $v$ żáru, když stíny se dlouží

15 v zimnixnich pałeništich tropú. A na hlavy milionu

ze hlubin slunce, trhaného krěemi bourí.

lávy sopeěné proudy, rozstłiklé v prachu oslñujícím, títí se v kataraktech.

Němé jsou nivy, ponurá města; v zakletých jeskyních dílen

na rtech zalatých utichly písně ve vł̌eten výsmex̌ñem vłení. 
$20 v$ úlisném sepotu łemenư. $v$ úpěních ohně a koví.

v zamlklých modlitbách volajících: Vysvobození! Al pochodeñ hněvu

blíz ještě k zemi se nakloní z modra a sžehne pavux̌inný květ její!

Syči ječmenné klasy płred zraky žencú płedrážděnými

jak tažení hmyzú. jež usedly na žhavá stébla.

25 v hnévivém šlehnutí jehel, v klokotném varu

nenávistném. A cekajíce na nahá téla a na rty onémlé žíní

tvrdê smêji se svedené vody, $v$ nichž jako trsy jiskł̌ících osţ̌ic.

nože pod hladinami. paprsky odraženě tresou se $z$ viru.

A večery se sady zapálenými! Posledni vegetace ohně

30 na žriceninách! Když jako mystické ovoce osudných poznání, slunce, uzrálé v západu horečném. podzimním listí k zemi padne svou tî̌j

a puká, plod zesládlý płrilił, a 2 purpumé kưry omamnou šávu. proud vonný, fełavící hvězdami jader, víno, šumici svêtlem. vysthikne na rty nesčislných! Vedra krve a touhy!

35 Cisemi rajských rozpomenuti jsou srdce! Fermenty žití a smrti zdvihly se na dně a v jejich parách myšlenky šili! Tance kol ohñủ

Květy, jež rozkoše boư̌i se lámou! Smrtelná zblednutí v úpalech snění!

Požrary pýchy! Ve zracích zajatců šilenstvi tvůrěi!

Bolestná procitání tisíce oxí z němého množstvi nedoxkavého.

40 které $v$ úżase tohoto kosmu touži se rozlíti věky!

Hvězdami zjasněné cesty království tvého! Dobyti země a nebes! - -

Ale $v$ hinčení čisí slaví svou hostinu knízata noci!

A tvoje píseñ je tichá jak reka za horami kolotající.

sladký ptáxníku duší! Od obzonu k obzonu šlehá tvůj úsměv.

45 linie bleskủ, ale ztrácí se dł́ve, než umdleni zdvihneme zraky!

Ach, $z$ bolestné promény věci nad Gehennami poznati slávu tvé vůle

a jako pismo sděleni tajných za doby nebezpečenství.

zjasněné nad ohněm tahy blankytovými, čisti ji v zá̌i!

Ale snesla by zem toto celé bohatstvi smifeni tvého?

50 Nepotopila by se, lod płetízená nákladem královských dari.

i s plavci?... Hluboké jsou noci v mésíci vedra ... A hvězdy jak zvoni ...

\section{Gluthitzen}

Illusionen in Glut, wie Halluzinationen Verdürstender!

Wie überreif birst die Erde. Blüten unsichtbarer Flammen

wallten hervor, parasitär, zwischen Lilien, und wie emporiodernder Efeu

saugen sie sich fest an reglose Bäume. Fahlblaue Blitze

5

splittem im Lichte; im ironischen Aneinanderschlagen der Becher feiem ihr Gastmahl

die Fürsten der Nacht - -

Aber wie Wolken, die zurick in das Meer den Trost ihrer Labung tragen.

sinken unsere Hoffnungen hinter glühend gewordenen Horizonten nieder.

Nur die stumme Gluthitze deiner Gerechtigkeit glüht wie Furchen ihres Fluges

über den Fluren und über den Bauplätzen und über den Wegen, wo weiß die Steine leuchten.

10 wie FluBbetten des Feuers und wo traumwandlerisch die Heere schleichen.

Der glühende Atem der Arbeit steigt über den glühenden Atem der Erde. Welle über heißere

Welle. 
die Schläge der Pulse auf Schläfen der Sklaven sausen wie Pfeifen von Peitschen, tödlich ernst wurden die Blicke. Die Grausamkeit von Äonen steht auf im Blute: das gefährliche Erwachen stummen Urwalds in Glut, wenn die Schatten sich dehnen

15 in den fiebernden Treibhäusem der Tropen. Und auf die Häupter von Millionen aus Tiefen der Sonne, die Sturmkrämpfe auseinanderreißen.

Ströme vulkanischer Lava, zerspritzt zu blendendem Staube, niedersausen in Katarakten.

Stumm sind die Fluren, düster die Städte, in den verwunschenen Höhlen der Arbeit verstummten auf zusammengepreßten Lippen die Lieder im höhnischen Sieden der Spindeln,

20 im schmeichelnden Flüstern der Riemen, im Stöhnen des Feuers und der Metalle, in wortlosen Gebeten, die rufen: Erlösung! Mag die Fackel des Zornes noch näher zur Erde sich neigen aus dem Azur und ihre Spinnwebblute versengen! Gerstenähren erzischen vor den überreizten Blicken der Schnitter, wie Insektenziuge, die sich auf glühende Halme niedergelassen.

25 im zornigen Schnellen der Nadeln, im brodelnden Sieden des Hasses. Und harrend der nackten Leiber und durstverbrannten Lippen lachen hart die verführten Wasser, in denen wie Büschel von funkelndem Riedgras, Messer unter den Wasserspiegeln, abgeprallte Strahlen hervorzittern aus den Wirbeln.

Und Abende mit entzündeten Gärten! Letzte Vegetationen des Feuers

30 auf Ruinen! Wenn wie mystische Fucht schicksalsschwerer Erkenntnis, Sonne, gereift im fiebernden Herbstlaub des Untergangs nieder zur Erde fällt vor eigener Schwere und birst, überBüs gereifte Frucht, und aus der Purpurschale betäubende Säfte, duftenden Strom, rotglühend von Sternen der Kerne, Wein, schäumend vor Leuchten, hinspritzt auf die Lippen Unzähliger! Gluthitzen des Bluts und des Verlangens!

35 Becher paradiesischen Gedenkens sind die Herzen! Fermente Lebens und Todes hoben sich auf dem Grunde, und in ihren Dämpfen rasen die Gedanken! Tänze um Feuer! Blüten, die brechen im Sturme der Wollust! Tödlich Esbleichen im Gluthauch des Traumes! Brände des Stolzes! In Blicken Gefangener das Rasen von Schöpferm! Schmerzlich Erwachen von tausenden Augen aus lautlos voll Ungeduld harrender Menge.

40 die sich sehnt, im Staunen des Kosmos sich durch die Zeiten zu gießen!

Deines Königreichs von Stemen erleuchteten Wege! Eroberung der Erde und Himmels! - -

Aber im Klirren der Becher feiem ihr Gastmahl die Fürsten der Nacht!

Und dein Lied ist still, wie der Fluß, der hinter Gebirgen nachtigallt, süßer Vogelsteller der Seelen! Von Horizont zu Horizont schlägt flammend dein Lächeln,

45 Linien von Blitzen, doch verliert er sich früher, eh wir Ermuldeten heben die Blicke.

Ach, aus der schmerzlichen Wandlung der Dinge über Gehennen die Herrlichkeit deines Willens

erkennen und wie die Schrift

geheimer Kundschaft zur Zeit der Gefahren. über dem Feuer erhellt in himmelblauen Zügen, sie im Lichte zu lesen!

Aber vermöchte diese Erde den ganzen Reichtum deiner Versöhnung zu tragen?

50 Sänke nichı unter das Schiff vor Last der fürstlichen Gabe mitsamt dem Schiffsvolk? Tief sind die Nächte in der Gluthitze Monden...

Und wie die Steme klingen ...

Deutsch von Paul Eisner. 
Die im kosmogonisch-eschatologischen Welt-Modell angestrebte Vollendung des "Temepl-Baus" als Symbol der Wiederherstellung der kosmischen (Ur-)Einheit, scheint in Vedra (Gluthitzen) dem Chaos der vor Glut "überreif berstenden Erde" "Zem jako prezrálá puká". V. 2) anheimzufallen. In diesem desintegrierenden und desontologisierenden 'Sonnenbrand'-Kollaps des xoouos werden die 'Zeichen' der (kerygmatischen) Botschaft des creator macrocosmi gelöscht; das Telos und der Sinn der Lebenswelt verlieren sich, so wie die Hoffnung auf die eschatologische Vollendung, im Unwiederbringlichen hinter den "glühend gewordenen Horizonten": "nadẻje naše zapadaji za horizonty rozpálenými" (V. 7: "unsere Hoffnungen sinken hinter glühend gewordenen Horizonten nieder"). Die in Vedra entwickelte Handlung erscheint als eine geradezu karikaturhafte Überspitzung der kosmogonisch-kreativen Prozesse von Stavitelé chrámu. An die Stelle der visionären 'Lichtgestalten', der "Tempel-Baumeister", die den Plan des 'höchsten Architekten' zu verstehen und zu realisieren wissen, treten in Vedra die düsteren "Fürsten der Nacht" ("knízata noci", V. 5), die als 'Gesandten' der widergöttlichen Mächte 549 "im ironischen Aneinanderschlagen der Becher" inr Gastmahl feiern (V. 5; "v ironickěm nárazu čiší, slavi svou hostinu knížata noci"). Auch die lebenspendenden und 'aufbauenden' Sonnenstrahlen devalvieren zu destruktiven, "parasitären Flammen" ("plameny /.../ parazitni", V. 2-3) des Erdfeuers, so wie das kosmische "Lied von der Hehre des harmonischen Lebens" " "píseñ o slávẻ Života harmonického", Stavitelé chrámu I Baumeister am Tempel, V. 7) in ominöse, lebensfremde Stummheit umkippt: "Jen nëmé vedro /...I. I Nẻmé jsou nivy /... I na tech zatatých utichly pisnè ve vieten výsmẻšném vieni“ (V. 8, 18-19; "Nur die stumme Gluthitze /.../. Stumm sind die Fluren /../ / auf zusammengepreßten Lippen verstummten die Lieder im höhnischen Sieden der Spindeln"). Bie signifikante Haltung der apollinischen "Tempel-Baumeister", der "erhabene Wahnsinn der Heroismen" ("vznesené ślenstvi heroismü", Pozdravujeme jaro! / Wir grüßen den Frühling, III, 4), pervertiert in Vedra zur animalisch-ungezügelten "Grausamkeit" der Atavismen ("Krutost věkú oživá v krvi", V. 13) und zu rauschhaften "Tänzen um Feuer" ("Tance kol ohnự!", V. 36).

Das Gedicht besteht aus einem Prolog (V. 1-5) und vier Sujetsequenzen. Im Prolog wird ein als "Halluzinationen Verdürstender" (V. 1; "halucinace umirajicich Žizni!!") indizierter, destruktiver Prozeß der verbrennenden Gluthitze, die die ganze Erde zu erfaßen scheint, thematisiert. Die Motive der ersten Sujetsequenz (V. 6-17) bilden eine semantische Isotopie der solaren Brand-Katastrophe. Die zweite Sujetsequenz (V. 18-28) entfaltet das für dieses Gedicht signifikante Merkmal der "Gluthitze": das Verstummen der Lebenswelt, inr Versinken in eine unheilvolle Apophatik, durch die sich sowohl die Naturals auch die urbane Welt in "stumme" und finstere, "verwunschene Höhlen" verwandeln: "Némé jsou nivy, ponurá mésta" (V. 18; "Stumm sind die Fluren, düster die Stäđte"). Während die ersten zwei Sujetsequenzen die katastrophischen Aspekte der "Gluthitzen" thematisieren, 'konzeptualisieren' die dritte und die vierte Sujetsequenz die Móglichkeiten der (Er-) Lösung (von) dieser Krise: in der dritten Sequenz (V.29-41) wird ein soteriologisches 'Konzept' der (dionysischen) Erlösung 'von unten' präsentiert; die Befreiung durch das Körperhaft-Materielle, durch 'Fleisch', 'Blut' und Eros im Akt der kollektiven Berauschung, inszeniert als ein extatısches, herbstliches Bacchanal. In der vierten Sujetsequenz (42-51) tauchen allerdings Zweifel an der Möglichkeit der Erkenntnis der eschatologischen Botschaft und der Enfahrung der Versöhnung auf. Auf der wortsemantischen Ebene wird diese Skepsis durch die Partikel "Ale"... ("Aber...", V, 42. 49) noch verstärkt.

Im Hinblick auf die Kommunikationssituation charakterisiert Vedra (bis V. 43) der indikative, vorwiegend präsentische Redemodus, der (vor allem im Prolog und in den

549 Die Benennung "knižata" ("Fürsten") bezieht sich in der christlichen (im engeren Sinne neutestamentlichen) Mythologie auf die 'Repräsentanten' der widergöttlichen Mächte (auch als Verkörperung des (rotruās). Im Sinne der Eschatologie wird die Situation des Menschen in der Lebenswelt als ein Versklavtsein unter den dämonischen Māchten begriffen. Vgl. R. Bultmann. Theologie des Neven Testaments, Tübingen 1968. S. 258t. Demnach sind die "Fürsten der Nacht" die "Fürsten" des Chaos", in dem das "Licht(-Logos) der Welt" sich aufzulösen droht. Die Motive der "Finsternis", der "Nacht", der "Stummneit" usw. deuten in diesem Kontext u. a. auf die Unmöglichkeit des Menschen den wahren Sinn seiner eigenen Existenz und den Inhalt der 'Botschaft' (des Welt-Schöpfers) zu verstehen. Den "Fürsten der Nacht" stellt Bïezina die "Fürsten des Kosmos" ("knižata kosmu"; Kolozpèv srdci / Rundgesang der Herzen, V. 128) entgegen, die als Enöser erwartet werden. 
ersten zwei Sujetsequenzen) den Eindruck eines unpersönlichen 'Protokolls' der beobachteten Katastrophe hervorruft. Eine Ausnahme sind die Verse 7-8, in denen das kollektive "Wir" zur Sprache kommt: "nadéje naše zapadaií za horizonty rozpálenými. I Jen nẻmé vedro tvé spravedinosti sálá $/ \ldots \mu$ / "unsere Hoffnungen sinken hinter glühend gewordenen Horizonten nieder. I Nur die stumme Gluthitze deiner Gerechtigkeit loht /... $/$ ). In der dritten Sequenz wird der nahezu schroffe indikative Ton durch eine Anzahl von Exklamationen in kurzen Ausrufesätzen dramatisiert und 'emotionalisiert', um die heftige innere Bewegung, die Atmosphäre des rauschhaften Bacchanals und die Sehnsucht nach dem Eintreten der ungeduldig erwarteten Vollendung zum Ausdruck zu bringen. Erst in der letzten Sequenz (42-51) wird der unpersönliche Ton eines quasi 'Protokolls', dessen Ende die resümierende Wiederholung der identischen 'Mitteilung' aus dem Prolog markiert ("v ironickém nárazu Ciši slavi svou hostinu knižata nocil", V. $5+42$; "im ironischen Aneinanderschlagen der Behcher feiern ihr Gastmal die Fürsten der Nacht!"), durch die unmittelbare Ansprache des "Höchsten" ("A troje píseñ je tichá I... F. V. 43; "Und dein Lied ist still /... $)^{\prime}$ ) und durch den stark emotional besetzten, optativen Redemodus substituiert: "Ach, z bolestné promény vécí nad Gehennami poznati slávu tvé vủle I..." (V. 46; "Ach, aus schmerzlichen Wandlungen der Dinge über Gehennen die Herrlichkeit deines Willens erkennen /... $r$ ).

In keinem anderen Gedicht von Br̈ezina kommen die Phänomene des Zerfalls, der Desintegration und des totalen Durchbrechens der Leibhaftigkeit des Materiellen, mit solcher Intensität und Dramatik zum Ausdruck, wie in Vedra. Die lebenspendende und stărkende Sonnenglut von Poledni zráni (Mittáglich Reifen, VP) transmutiert hier zu Katarakten der glühender Lava, die die ganze Erde überfluten, verbrennen und austrocknen: "A na hlavy milionú / ze hlubón slunce, trhaného křẻemi bourî́, / lávy sopezné proudy, rozstriklé v prachu oslñujicím, híti se v kataraktech" (V. 15; "Und auf die Häupter von Millionen / aus Tiefen der Sonne, die Sturmkrämpfe auseinanderreißen, I Ströme vulkanischer Lava, zerspritzt zu blendendem Staube, niedersausen in Katarakten"). Hier macht sich die für das vitalistisch-eschatologische Modell signifikante Tendenz zur 'dionysischen' Kontamination von entgegengesetzten Erscheinungen bemerkbar. 550 In Vedra werden einzelne Motive untereinander kombiniert, 'montiert', kontaminiert oder ineinander integriert. Diese Strategie manifestiert sich am deutlichsten in der Integration von Motiven des Feuers und der Glut ("iezišsté onne" / "Flußbetten des Fevers", V. 10, u. a.) in das 'semantische Feld' des Abends und der (kühlen) Nacht. Die Kontamination heterogener Erscheinungen soll unter anderem die Dramatik des Zerfalls und des Kollapses der kosmischen Ordnung im chaotischen Wirrwarr potenzieren. Der Aspekt des Verwirrenden, Flüchtig-Trügerischen, Unklaren, Heteronomen oder Transfigurativen gehört im Text zu der Isotopie der "Illusion" und der "Halluzination" (Illuse v Záru, jak hallucinace umírajících żízn" I "Illusionen in Glut, wie Halluzinationen Verdürstender!"), deren Lexeme die Devalvierung der prophetischen Vision des nahenden "ewigen Morgens" (Vigilie I, V. 39; SCh) zu einer trügerischen, pathischen Fatamorgana markieren. Die "Illusion", "Halluzination" und die "unsichtoaren Flammen" ("plameny neviditelné", V. 2) signalisieren die Herabminderung der divinatorischen Gabe, des prophetischien Schauens und der (ausbleibenden) Erlösung, nach der sich die "Sklaven" der Erde sehnen: "Zhavý dech práce stoupá nad żhav'́ dech zemè, nad vinu žhavêjjí

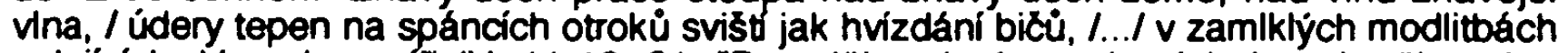
volajicich: Vysvobozeni?" (V. 11-12, 21; "Der glühende Atem der Arbeit steigt über den glühenden Atem der Erde. Welle über heißere Welle, / die Schläge der Pulse auf Schläfen der Sklaven sausen wie Pfeifen von Peitschen, $I . . . /$ in wortlosen Gebeten, die rufen: Erlosung!")

Die paradoxe Situation des Nichteintretens der in Stavitelé chrámu erwarteten, "in Ewigkeit donnernden Lieder" der nahenden Erlösung ("Nekonečnosti Cekají na nás, jiná slavnejsí jara, věcnosti hímíci pisnę, vysvobozeni!", Pozdravujeme jaro! / Wir grüßen den Frühling!, VIII, 3-4; "Unendlichkeiten enwarten uns, andere festlichere Lenze, / in Ewigkeit donnemde Lieder, - Erösung!"), artet in unheilvolles Verstummen ("némá", "onémí") des

550 Eine der signifikanten Eigenschaften des Dionysos schlechthin. Liebe und Tod, Tod und Auferstehung, Morgen- und Abenddāmmerung, Zerstückelung (Zerreißung) und Vereinigung usw. fallen in die Kompetenz dieses alles ewig verwandelnden, transformierenden, umformenden und vielgestaltigen Gottes. Vgl. J. J. Bachofen, Das Mutterrecht, Gesammelte Werke, Bd. 3. StuttgartBasel 1957, S. 585tt. 
gesamten Erdenlebens und in totalen Stillstand jeglichen Handelns aus: "Jen némé vedro" (V. 8; "Nur die stumme Gluthizte"). "procitnutí pralesa némého" (V. 14; "gefährliches Erwachen stummen Urwaldes"). "Némé jsou nivy" (V. 18; "stumm sind die Fluren"), "utichly pisne" (V. 19; "verstummten die Lieder"), "v zamlklych modlitbách" (V. 21; "in verstummten Gebeten"), "rty onèmlé žizni" (V. 26: "durstverstummte Lippen"), "z némého množstvi nedockavého" (V. 39; "stumm voll Ungeduld harrende Menge"). 551 Das Verbale pervertiert zum Non-Verbalen, Unsagbaren, Apophatischen, zum unheilverkündenden wie absurden "höhnischen Sieden der Spindeln" ("ve vieten výsměšném vïeni", V. 19), zum "schmeichelnden Flüstern der Riemen" ("v úlisném sepotu remenü", V. 20), zum "Zischen der Gerstenähren" ("Syči ječmenné klasy", V. 23), zum "zornigen Śchnellen der Nadeln" ("v hněvivém šlehnuti jehel", V. 25), zum "brodelnden Sieden des Hasses" ("v klokotném varu nenávistném", V. 25-26) oder zum "harten Lachen" der "verführten Wassern" ("tvrdẻ smëjí se svedené vody". V. 27). Es sind, wie es scheint, nicht nur Symptome einer ontologischen Krise der Welt, die das "Wort" und das "Licht" nicht erkannt hat, sondern auch Symptome des enttäuschten Nichteintretens der erwarteten Vollendung der Schöpfung.

Während die Stadt-Welt sich in der "Gluthitze" in düstere und "verwunschene Höhlen der Arbeit" ("v zakletých jeskynich dílen", V. 18) voll von "schmeichelnden Flüstern" ("v úlisném گepotu", V. 20) und "Stöhnen des Feuers" ("V úpěnich ohně", V. 20) verwandelt, metamorphiert die 'Sprache' der Natur zum boshaft-höhnischen "Sieden" zum bedrohlichen und haßefüllten "Zischen" usw. Selbst das 'apollinische' Motiv der "Ähren" (Apotheosa klasú / Apotheose der Ähren, SCh) ist in Vedra negativ konnotiert: "Syči jecmenné klasy pỉed zraky żencủ pỉedráżdẻnými“ (V. 23; "Gerstenähren erzischen von den überreizten Blicken der Schnitter"). Der "andachtshelle Blick" ("a zrakú zbožnosti", Apotheose klasí I Apotheose der Ahren, V. 1) der "Schnitter" ("Zenci"), wird zum" "überreizten Blick" ("pred zraky Żencu predráždèmymi", V. 23). Auch die Natur-Welt stellt in Vedra dem Menschen hinterlistig nach: Mit der unheilvollen Metamorphose der Sonnenstrahlen (V. 16) zu glühenden, das Erdenleben versengenden Lavaströmen, geht die Metamorphose der unter dem Wasserspiegel "abgeprallten Lichtstrahlen" ("paprsky odražené", V. 28) zum "Büschel von funkelndem Riedgras" ("trsy jiskrícich ostřic", V. 27) und in folgendem Vers zu "Messern" ("nože", V. 28) einher, die auf "nackte Körper" ("nahá têla", V. 26) lauem.

Als eine mögliche (Er-)Lösung (von) dieser Krise wird in der dritten Sujetsequenz (V. 29-41) ein rauschähnliches herbstliches Bacchanal inszeniert. Die in der ersten und der zweiten Sujetsequenz thematisierten destruktiven Prozesse, scheinen hier ihren Endpunkt erreicht zu haben. Die Erde taucht in den Brand des abendlichen Sonnenuntergangs: "A večery se sady zapálenými! Posledni vegetace ohné / na zícenináchr (V. 29-30; "Und Abende mit entzündeten Gärten! Letzte Vegetationen des Feuers auf Ruinen!). Die Vision des zerstörerischen Kataklysmus transformiert nun zum berauschenden Bacchanal der untergehenden Sonne, die mit einer "übersüß gereiften Frucht" assoziiert wird: "Když jako mystické ovoce osudných poznání, slunce, uzrálé v západu horénném, podzimním listí $k$ zemi padne svou tízi / a puká, plod sesládlý príliš /... $/$ (V. 30-32). Die Metapher der "berstenden Sonne" ("slunce /.../ puká, plod sesládlý prilis", V. 30, 32; "Sonne /.../ birst. übersüß gereifte Frucht") variiert die Metapher der "überreif berstenden Erde" aus dem Prolog ("Zem jak piezrála puká", V. 2; "Wie überreif birst die Erde"). Doch das Chaos, die destruktive Zentrifugalität ("sopečné proudy, rozstriklé v prachu osınujicim", V. 17; "Ströme vulkanischer Lava, zerspritzt zu blendendem Staube") der "berstenden Erde“. dieser gesamtkosmische Katastrophismus erlangt in dem hier entworfenen '(Er-)LösungKonzept" eine positive Konnotation als "wohlduftender Strom" ("proud vonny", V. 33) des "berauschenden Saftes" ("omamnou St'ávu", V. 32), der auf die Lippen der Menschen hinspritzt: "Vystřikne na rty nesčislných" (V. 34). Es ist das 'Konzept' der (dionysischen) Erlösung von 'unten', durch die Extatik, durch die Befreiung des Körpers und der Leidenschaften ("Vedra krve a touhy!", V. 34; "Gluthitzen des Blutes und des

551 Unsäglichkeit, Hinauszögem, Maskierung usw. gehören zu den signifikanten Merkmalen der Destruktion der positiven Apokalyptik in der Spätphase des russischen Symbolismus. Auch der Glaube artet zum Wahnsinn aus, so wie der Glaubende zum 'Wahnsinnigen' devalviert wird. Vgl. A. A. Hansen-Löve. Apokalyptik und Adventismus im russischen Symbolismus der Jahmunderten", in: Russische Literatur an der Wende vom 19. zum 20. Jahrhundert, hrsg. v. R. G. Grübel, Amsterdam-Atlanta 1993, S. 311ft. Man denke an Birezinas Gedicht Silenci (Wahnbetörte), in dem diese Umwertung eine sinnkonstitutive Rolle spielt. 
Verlangens!") und duch die Entfachung des Organs der Empfindung und der Liebe: "Ćisemi rajských rozpomenutí jsou sroce!" (V. 35; "Becher paradiesischen Gedenkens sind die Herzen!). Aber der "berauschende Saft" sol den "Ungezählten" offensichtlich nicht nur die Extase, sondern auch die Beseelung und Vergeistigung bringen; es ist nicht der "Begierden schwarze Wein" aus Motiv z Beethovena ("Cerné vino tuh", VIII, 4, TD), sondern ein Wein, "schäumend vor Leuchter" ("Sumici svétlem", V. 33). Es ist allerdings fraglich, ob allein der (dionysische) Rausch, die "Brände des Stoizes" ("Pozány pýchy!", V. 38), die in extremis gesteigerte Traum-Imaginativität und Kreativität ("v úpalech snéni $/ . . . /$

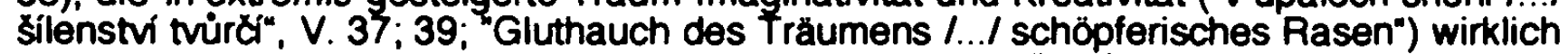
zu der postulierten Dechiffrierung der "Kundschaft" ("sdëleni") des "Höchsten" führen können. Die (Er-)Lösung bleibt vorerst mit dem "schmerzvollen Erwachen" ("bolestná procitáni", V. 39) verbunden: "Bolestná procitání tisice ož z némého mnoźství nedockavéno, / které v úžase tohoto kosmu touž se rozlíti vêky!" (V. 39-40; "Schmerzlich Erwachen von tausend Augen aus lautlos voll Ungeduld harrender Menge, / die sich sehnt, im Staunen des Kosmos sich durch die Zeiten zu gießen!").

Wie ist aber das Motiv der "schicksalschweren Erkenntnis" ("osudných poznáni", V. 30) zu interpretieren? Es bezieht sich offensichtlich auf das Motiv der fallenden, wie "übersüß gereifte Frucht" berstenden Sonne (V. 31-32). Es sind die katastrophischen Ereignisse, die die Geheimnisse erschließen. In der letzten Sujetsequenz (V. 46) wird die Sehnsucht nach der Entschleierung des "hehren Willens" des "Hochsten", d. h. nach der Erkenntnis seines eschatologischen Plans, durch die "schmerzliche Wandlung" der Realia explizit zum Ausdruck gebracht: "Ach, z bolestné promẻny vécl nad Gehennami poznati slávu tvé vüle I... ( V. 46; "Ach, aus der schmerzlichen Wandlung der Dinge über Gehennen die Herrlichkeit deines Willens zu erkennen"). Gleichzeitig wird aber die Frage aufgeworfen, ob diese Erkenntnis ("poznáni") nicht den totalen Untergang des kbouos hebeiführen würde: "Nepotopila by se lod' pretízená nákladem královských darú, / i s piavci?" (V. 50 51: "Sănke nicht unter das Schiff vor Last der fürstlichen Gaben / mitsamt dem Schiffswolk?).

Das Motiv der "Erhellung" ("zjasněni, V. 41) scheint eine positive Wende im Drama der "Gluthitzen" zu antizipieren. Die tragische Gespaltenheit, der (erneut) zum Chaos pervertierte Kosmos, soll durch die "Versöhnung" (in diesem Kontext auch im Sinne der Versöhnung des Makrokosmos mit dem Mikrokosmos) zu seiner (Ur-)Einheit restituiert und zusammengefügt werden: "Dobytí zemé a nebes!-" (V. 41; "Eroberung der Erde und Himmels?'). Wăhrend die Sonne hier als die Quelle der destruktiven "Gluthitze" semantisiert wird, fungieren die "Sterne", die im lichten "Wein" schäumen ("proud vonný, réravía huézdami jader, víno sumía suétemt, V. 33), als Wegweiser im Königreich des "höchsten Schöpfers": "Hvêzdami zjasnêné cesty královstvi tvého!" (V. 41; "Deines Königreichs von Sternen erleuchtete Wege!").

In der letzten Sujetsequenz (V. 42-51) wird auch der indikative Redemodus durch den optativen ersetzt. Diese Änderung der Kommunikationssituation signalisiert die Ansprache des "Höchsten" ("sladký ptácníku dứi!", V. 44; "süßer Vogelsteller der Seelen!") durch die kollektive Stimme, die zum ersten Male in V. 7 zur Sprache kommt. Die Wiedernolung der Verszeile "Ale v rinceni Ciś slavi svou hostinu knizata noci!" (V. 5, 42; "Aber im Klirren der Becher feiern ihr Gastmahl die Fürsten der Nacht!"), soll daran erinnern, daß der in Vedra modellierte xóouos (immer noch) unter der Herrschaft der "Fürsten der Nacht" steht. Die Partikel "Ale..." ("Aber...") verstärkt noch den Zweifel an der visionären Erscheinung; sie deutet darauf hin, daß die "Zeit noch nicht da ist". Daher wird dem "Klirren der Becher ("řinceni Cíś", V. 42) das "stille Ljeo" des "süßen Vogelstellers" entgegengesetzt: "A tvoje piseñ je tichá I.../ sladký ptácníku duši!" (V. 43-44). Sein "Lied" ist (zu) "leise", seine "Zeichen" (zu) veschlüsselt, sein "Lächeln" ist zwar (auf dem Horizont) allumfassend ("Od obzoru k obzoru Slehá tvujj usmévv. V. 44; "Von Horizont zu Horizont schlăgt flammend dein Lächeln") aber dennoch "unsichtbar'; es verliert sich noch bevor man es erblicken kann. Seine Botschaft bzw. "Kundschaft" ("sdęleni") offenbart sich als "linie bleskü" ("Linien von Blitzen", V. 45), die (als Symbol der Theophanie) an dieser Stelle als Opposition zu den négativ konnotierten "fahlblauen Blitzen" ("sinavé blesky", V. 4; das Attribut der "Fürsten der Nacht") fungieren.

Die Sehnsucht der "voll Ungeduld harrenden Menge" (V. 39) nach der Erkenntnis des "Willens" des "Höchsten" und nach der Entschleierung seiner "geheimen Kundschaft" - der endzeitlichen Vollendung und Versöhnung - kommt zum Schluß dieser Sequenz explizit zum Ausdruck: "Ach, z bolestné proméný véci nad Gehennami poznati slávu tvé vile / a jako pismo sdẻleni tajných za doby nebezbecenstvi, I zjasnéné nad ohněm tahy 
blankytovými, Cisti ji v zárị" (V. 46-48). Doch die Möglichkeit der postulierten Entschleierung - symbolisiert durch die Motive der "Hellwerdung" bzw, der "Erleuchtung" ("zjasnèny" / "erhell", "záre" I "Glanz" und "blankytovy" I "himmelblau", V. 48) - der "geheimen Kundschaft" ("sdẻleni tajných", V. 47) und der Erreichung der erwarteten -Versöhnung" ("smíreni“), 552 wird im letzten Verssegment (V. 49-51) in Frage gestellt. Würde die Wiederherstellung der kosmischen Harmonie durch das Charisma der Versöhnung, die Apokalypsis der "geheimen Kundschaft" nicht eine totale Entropie des Sinns der Lebens-Welt-Existenz nach sich ziehen?: "Ale snesla by zem tato celé bohatstvi smiŕeni tvého? I Nepotopila by se lođ píetižená nákladem královských darú, / i s plavci? ..." (V. 49-50; "Aber vermöchte diese Erde den ganzen Reichtum deiner Versöhnung zu tragen? / Sänke nicht unter das Schiff vor Last der fürsterlichen Gaben / mitsamt dem Schiffvolk?"). Diese Fragen bleiben offen, so wie die Hoffnung auf das höchste Ziel - die (eschatologische) "Versöhnung" - in diesem Gedicht offen bleibt. "Hluboké jsou noci v mésici vedra... A hvězdy jak zvoni ...", V. 51; "Tief sind die Nächte im Monat der Gluthitze...". Und die Sterne, wie sie erklingen..."). Die ganze Szenerie der "Gluthitzen" taucht schließlich - wie eine oneiroide Halluzination mit phantastischen Akusionen - in die Tiefe der kühlen und alles umhüllenden Nacht. Als einzige 'Antwort' erklingt nur der Chor der Sterne.

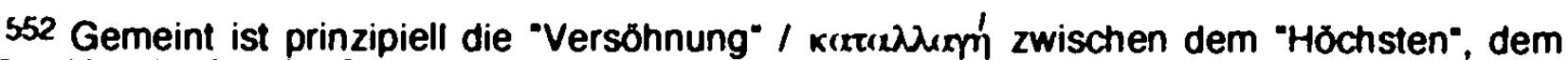
"süßen Vogelsteller der Seelen" (V. 44) und den Menschen, um die es nicht nur in Vedra, sondern in Ruce überhaupt geht. Diese "Versöhnung", ein Akt der Gerechtigkeit des "Höchsten", bedeutet die Herstellung des Friedenszustandes, nach dem es die "voll Ungeduld lautlos harrende Menge" ("nèmého mnożstvi nedočkavého", V. 39) vertangt, denn: "Jen némé vedro tvé spravedinosti sálá I.... (V. 8; "Nur die stumme Glut deiner Gerechtigkeit loht /... $\%$ ). Der Inhalt der "geheimen Kundschaft" ("sdéleni tajných", V. 47), die zur "Herrtichkeit des Willens" des "Höchsten" gehört, ist offensichtlich die "Kunde" - in der Sprache Błezinas - von der bereits vollzogenen Versōhnung. Das objektive Feindschaftsverhältnis schaffen die Sünden ("Krutost věkú oživă v krvi", V. 13; "Die Grausamkeit der Äonen steht auf im Blutt"), die beseitigt werden müssen. Vgl. hierzu R. Bultunann, Theologie des Neuen Testaments, Tübingen 1968, S. 285ff. Die Erfahrung des "Geheimnisses" der Versöhnung thematisiert das Gedicht Mista harmonie a smiřeni (Orte der Harmonie und der Versöhnung): "I pricházime konečnẻ do kr̉ištálných sini tvÿch tich, / (słtasten, kdo do nich vesel. stastnéjši, kdo nenajde návratu $z$ nich) / A celé tajemstvi svêta bolestného a nádherného / pred námi chvi se tam ve svétle tvého úsmévu düvěrného" (III, 1-4; "Und wir gelangen endlich in die kristallenen Hallen deiner Stillen. I (Glücklich, wer sie betreten, glücklicher wer nicht gefunden den Rückweg aus ihnen) / und das ganze Geheimnis der schönen und schmerzvollen Erde / zittert vor uns dort im Lichte deines vertraulichen Lächelns". Ubers. v. E. Saudek.) Doch im letzten Gedicht des Zyklus, in Cas (Die Zeih), wird die erwartete Versöhnung wieder hinausgeschoben: "Zdrceni nesmirnosti tvé słávy, cekáme stále, teskni a tiši, I na sladké usmáni smireni tvého, skonceni dni" (VI, 1-2; "Zermalmt von der Unendlichkeit deines Ruhmes, warten wir immer, bang und still, I auts süße Lácheln deiner Versōhnung, der Tage Vollendung"). 


\subsubsection{Das Scheitern des kosmischen Vereinigungs- und Harmonisierungsversuchs durch die Liebe und das Licht des Herzens: Hudba slepcú (Musik der Blinden)}

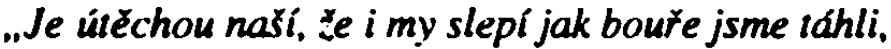
¿eho jsme nechtěli, stane se, čeho jsme chtěli nedosáhli? “

"Ist unser Trost, daß auch wir Blinden zogen wie Gewitter herauf. was wir nicht wollten, wird geschehen, was wir wollten, erreichten wir nicht?"

„Žalm odcházejících pokolení“ („Der Psalm der dahingehenden Generationen“, 1903)

\section{Hudba slepců}

I. Jdou naše duše $v$ tisíciletích exilem zemè. slepci osleplí mystickou vinou narození. ke svým vášnivým, kvilícím, hýfícím houslím, 6 srdce. $v$ horečné improvizaci nakloněni.

11. Svêtelná nádhera kosmu, ztracená vyhaslým zrakưm, vífí k nim z tónư, změněná na hudbu tajemstvími. a Živé housle jejich, jak plameny $v$ kJubko sehnané větrem. svíjeji se pod éterných prstů dotyky šilenými.

III. Ke komu kvilí tvá píseñ. 6 srdce, jak úzkosti výkłik $v$ hớcím vězení, žhavými pruty zamłízeném?

Jak mamé busící touha po procitnutí na horkém loži, vłemi atmosférami výsí zatízeném?

IV. Zahrady gigantských kvêtư voní z tvých tơnư. triumfálný let duchủ $v$ nich slyšime ze vక̌ech nebes se t̛̉ast. $v$ boứ vక̌ech blesků $v$ nich pracující slunce svým pluhem vichfici jisker rozhmuje $\mathbf{z}$ azumých brázd.

V. V̧̌echna mołe $v$ nich kypí, do vara zpěněná tisíci vesel, prostori కera. jež letem neznámých kłídel se zachvívají. a vlny Casu. jež plácí jak vody čistého zdroje. kde ruce bratrovražedné svá krvavá znamení umývají.

VI. Hołce, jak kełe ztracených zahrad, $v$ nich do věkư dýchají żeny, $v$ temnotách ťhavého vêtru polibky ztłásajíce. mésíxní záfe $v$ nich $k$ rozkoł̌i zvoní jak stưibraé kruhy nad bílými kotníky zajaté tanex́nice.

VII. Vక̌echny písně slité $v$ nich vî́í, jak věky je zpívali bratł̌í. knižata, proroci, Śilenci, světci a zavraždění. disonance všech životủ mrtvých, zoufalství svatého boje. i budoucích jiter, $v$ krvi se Se ̌̌icích, kuropění;

VIII. ohnivé propasti zemé, nox̌ní blankyty smrti, kvetoucí v kosmickém mrazu hvězdnými asfodely. a všechno, co myšlenku hrůzou a závratí jímá a Ceho osleplé pohledy nevidẻly.

IX. Jdou naše duše $v$ tisíciletích exilem zemé. slepci osleplí mystickou vinou narození. 
v hudbẽ tvých vášnivých, kvilících, hýfících houslí, $\delta$ srdce. marně hledají utišení.

X. A když konex̉ně kosmu nejvyłşi souzvuk milostí objaly $v$ nekoneênost rozpjaté intervaly: proud slzí a krve $z$ osleplých oxí spálil jim tváre a všechny struny tvých housli, 6 srdce, se potrhaly.

\section{Musik der Blinden}

1. Auf die Erde verbannt, tasten sich vorwärts unsere Seelen,

Blinde, erblindet durch mystische Schuld der Geburt, durch die Zeiten, zu deiner zehrenden, klagenden, jauchzenden Geige, o Herz, improvisierend geneigt, im Fieber der Saiten.

II. Leuchtende Schönheit des Kosmos, verloren erloschenen Augen, wirbelt ihnen aus Tönen, in musikgewordenem Zauber. und seine lebende Geige, wie in Knäuel geballte Flammen im Winde, winden sich unter wahnsinnigen Beruhrungen ätherischer Finger.

III. Wem gilt dein klagendes Lied, o Herz, der ängstliche Aufschrei im brennenden Gefangnis, vergittert mit glühenden Stäben? Wie vergeblich pochendes Sehnen dem Traum zu entrinnen auf heißem Lager, im Alpdruck unendlicher Welten.

IV. Gärten gigantischer Blüten entströmen in Düften den Tönen, aus allen Himmeln saust uns entgegen der Geister Triumphflug. In aller Blitze Getümmel die Sonne mit feuriger Pflugschar scheucht aufwühlend die Windsbraut der Funken aus azumem Feld.

V. Aller Meere wallendes Sieden brandet darin an schaumichten Rudem, Zwielicht der Räume, die beben im Fluge unheimlich wehender Flügel, Wogen der Zeiten, die weinen, wie Wässer krystall reiner Bronnen, Wo brudermordende Hände wuschen die blutigen Male.

VI. Bitter, wie Sträucher verlorener Gärten atmen dort Frauen ins Antlitz der Zeiten, auf nächtigen Pfaden glühenden Windes, Küsse verstreuend, Schimmer des Mondes läutet zur Lust, wie silberne Schellen oberhalb weißer Knöchel der tanzenden Sklavin.

VII. Alle Sänge brausen darin zusammengeflossen, die Brider sangen seit Urzeit. Fürsten. Propheten. Wahnbetörte. Heilige. Verstoßene. Mißklang verklungener Leben, Verzweiflung im heiligen Kampfe. auch künftiger Morgen schüchternes Dämmem, blutrotes Glüh’n.

VIII. Feurige Schlünde der Erde, des Todes nächtige Femen, blühend im kosmischen Frost, in Asfodelen der Sterne, und alles, was den Gedanken erfüllt mit Entsetzen und Grauen und was die erblindeten Augen nicht geseh'n.

IX. Auf die Erde verbannt, tasten sich vorwärts unsere Seelen, Blinde. erblindet durch mystische Schuld der Geburt, durch die Zeiten, in deiner klagenden, zehrenden, jauchzenden Geige, o Herz. vergeblich suchen sie Frieden.

$X$. Und als sie endlich des Kosmos ureigenen Einklang

durch Gnade erfaßten, die endlosen Intervalle, trotz gähnenden Klüften: Ein Strom von Tränen und Blut, aus geblendeten Augen, sengte die Wangen und alle Saiten an deiner Geige, o Herz, zerbarsten, verklangen.

Deutsch von E. Saudek. 
Das Gedicht Hudba slepcu் (Musik der Blinden) scheint an Vedra (Gluthitzen) - wie schon die Reihenfolge innerhalb des Zyklus signalisiert - anzuknüpfen, denn auch in Hudba slepcü wird das Thema der Restitution der kosmischen Einheit und Harmonie weiterentfaltet. Dieses Ziel soll allerdings in Hudba slepcú nicht durch die Allbeseelung in einer kollektiven Extase, sondern durch die Empathie des Herzens, durch die alles vereinigende Liebe, erreicht werden.

Das Gedicht Hudba slepcu hat also die Harmonisierung der Welt durch die Musik (des Herzens) der "Blinden" ("slepci") zum Thema. Die "Blindheit" (der Herzens- bzw. Seelen a ugen - oculi animae, oculi cordis) wird in der ersten Strophe als Folge der Urschuld konnotiert ("oslepli mystickou vinou narozeni", I, 2), die sich hier möglicherweise auch als Folge des unheilvollen Verharrens in der 'Finsternis' (des 'Scheins' und des Todes im johanneischen Sinne) interpretieren läßt, das bereits in Vládnouci...I Herrscher...) 553 aus dem Gedichtzyklus Vètry od polü (Polanwinde) thematisiert wird. Während in den Gedichten des gnostisch-eschatologischen Modells (SZ) die unio durch das Charisma der Erkenntnis (rvöors) erreicht werden soll, wird in Hudba slepcú die Vereinigung und Harmonisierung der Menschenwelt durch das "Herz", das Organ der (inneren) Bewegtheit durch Gefühle (Liebe, Schmerz usw.) postuliert. In Huctba slepcú verschiebt sich der Schwerpunkt vom Visuell-Kognitiven, das im kosmogonischeschatologischen Modell (SCh) eine dominante Position einnimmt, auf das Emotionale bzw. Vital-Psychische, auf die Pascalsche "Ordnung des Herzens".

Die Urschuld 554 als Ursache der "Blindheit" von oculi cordis - "Jdou naše duše v tisićletich exilem zemê, / slepci oslepli mystickou vinou narozenf' (I, 1-2; "Auf die Erde verbannt, tasten sich vorwärts unsere Seelen, / Blinde, erblindet durch mystische Schuld der Geburt, durch die Zeiten") - kommt auch im Essay Skryté défin (Vertorgene Geschichte) explizit zum Ausdruck: "Dotknutí, jimiž duch jako slepec poznává misto zajet' svého, rodné tahy ve tvári zemè $/ . . . \%$. ("Die Berührungen, mit denen der Geist wie ein Blinder den Ort seiner Gefangenschaft erkennt, die Gesichtszüge der Erde $/$... $/$ ). Die Erde ist der Zufluchtsort, das exsilium der Seele nach dem "geheimnisvollen Schiffbruch" namens "Schőpfung": "Cizi byly si duše, jak by každá z jîného světa / po tajemném ztroskotání zachránila se na zem“. (Stavitelé chrámu / Baumeister am Tempel, V. 2-3; "Fremd waren die Seelen einander, als hätte sich jede, / geheimnisvoll geschattct, aif dic Erde gerettet aus einer anderen Welt').

Im Hinblick auf die formalen Aspekte fällt auf, daß Biezina in Hudba slepcù erneut auf die strophische Gliederung zurückgreift. Das Gedicht besteht aus zehn im daktylisch konturierten vers libéré ("uvolněný vers") 555 abgefaßten Strophen. Die in Huoba slepcú arrangierte Kommunikationssituation erinnert - neben dem musikalischen Titelmotiv - an die kommunikative Struktur von Motiv z Beethovena (Ein Motiv aus Beethoven, TD). Im Vergleich mit Motiv $z$ Beethovena findet in Hudba slepcú eine Inversion im Verhältnis zwischen Sprecher und Angesprochenem statt. Während in Motiv z Beethovena die Stimme der Musik die 'Sprecherin' ist, die ihre Lockrufe zu einer Nachtmeerfahrt in das untermeerische Reich des Kunst-Todes, in das Jenseits dieser Welt, an das angesprochene "Du" adressient ("Pojd ...", III, 3; "Komm ..."), fungient in Hudba slepcu die Musik (und inr Instrument, die "Geige des Herzens", I, 3) als "Adressatin", die von der Seele des kollektiven "Wir", angesprochen wird. Ein wichtiger Aspekt soll nicht überseherl werden: Dem kollektiven Plural ("my" / "wir") der "auf die Erde verbannten" Seelen (1, 1)

553 -At omyji ởi své, nemocné soumrakem, / na vỷši tvỷch hor, z jichž temen se vali / prameny šumia pisnèmi nesmrtelnými!" (Vládnoua'... I Herrscher ..., 14-16; "Möge ich doch meine Augen baden, die zwielichtkranken, / auf deiner Berge Scheitel, wo niederstürzt / der Quellen Autruhr in unsterblichen Liedern!")

554 Bereits in Vẻtry od pólü und in Stavitelé chrámu (Se smrti hovơi spici... I Mit dem Tode reden die Schläfer..., V. 125) wird das ominöse Verharren in der Finsternis, das die Erkenntnis "sich selbst" und damit auch des "Höchsten" und seines eschatologischen Plans unmöglich macht, als "Ur-Schuld" semantisiert. Darauf scheint die Symbolik der Seelenaugen hinzudeuten. Bei Platon schaut oculus animae die Idee, in der christlichen Mythik wird mit inm der Kontakt mit Gott hergestellt. Bei J. Scheffler Z. B. heiBt es: "Die Seele, welche Gott das Herz treffen will, / Seh nur mit einem Aug', dem rechten, auf das Ziel" (Cherubinischer Wandersmann, V. 336). Auch in der ('verchristlichten') Gnosis spielt diese Symbolik eine wichtige Rolle. Philo von Alexandrien bezeichnet die Gottesschau mit Seelenaugen als Hohepunkt menschlichen Erlebens. Vgl. dazu: Gudrun Schleusener-Eichnolz, Das Auge im Mittelatter, Bd. 1. München 1985, S. $1040 \mathrm{ff}$.

555 Vgl. M. Cenvenka, „Bł̌ezinưv verš", in: Ceská literatura, 13, 1965, S. 143 (Fußnote 47). 
steht hier das Singular des angesprochenen Herzens gegenüber: "Ke komu kvili tvá piseň, $\delta$ srdce" (III, 1; "Wem gilt dein klagendes Lied, 0 Her $z^{\prime \prime}$ ). Daraus resultiert, daß das kollektive "Wir" offensichtlich ein gemeinsames Herz besitzt.

Hinzu kommen auch andere wichtige Bedeutungsverschiebungen. In Motiv z Beethovena wird der hypnotische (Todes-)Schlaf, in den der intendierte Leser durch die Suggestion der 'Musik-Sprache' eingeschläfert werden soll, als eine unumgängliche Bedingung für das Betreten des magischen Kunst-Reiches beschwört: "/... jak noci narkosou dech unaven se úżi? /.../ a z květư zázračných jsem mëkký polštáĭ schystal, I kde $v$ ỉasy víni mdlých dás hlavu zemdlenou".(V, $1, x, 3-4 ; \% /$ wie sich der Atem engt, betäubt von der Narkose der Nacht? /.../ aus Zauberblumen bereitete ich ein weiches Kissen, / aut das du in Falten matten Dufts dein müdes Haupt hineinlehnst"). In Hudba slepcu wird das Gegenteil angestrebt. Das Herz - als Organ der (Menschen-)Liebe, der Zuneigung und Sympathie - sehnt sich nach dem Erwachen aus dem Schlaf, der eine gewisse Form der Dissoziation und Isolation (von den Herzen der "Brüder") bedeutet. Das "lebendig zugemauerte" (Vézeñ / Der Gefangene, TD, VII, 4), "eingekerkerte" Lied des Herzens (III, 2) sehnt sich nach der Befreiung aus diesem Gefängnis: "Ke komu kvilí tvá piseñ, $\delta$ srdce, jak úzkosti, výkriik /.../, jak marnẻ bušcí touha po procitnuti / na horkém loži, všemi atmosferami výsi zatí̌eném?" (III, 1, 3-4; "Wem gilt dein klagendes Lied, 0 Herz, der ängstliche Aufschrei, / im brennenden Gefängnis, /.../, / wie vergeblich pochendes Sehnen dem Traume zu entrinnen / auf heißem Lager, im Alpdruck unendlicher Welten?"). Das Lied des einsamen Herzens, das alle, auch disharmonische Lieder dissonanter Töne "aller toten Leben" integrieren will ("vsechny pisnẻ slité v nich vir̂́ I...I, dissonance všech żivotú mrtvých $/ . . . \%$. VII, 1, 3), soll zu jenem harmonisierenden, vereinigenden "Rundgesang" aller Herzen intensiviert werden; ein Postulat, das sich in Hudba slepcu (noch) als unrealisierbar erweist. Die Voraussetzungen für seine Verwirklichung werden erst in Kolozpév srdci (Rundgesang der Herzen) gegeben: "Ke komu kvili tvá piseñ, ó srdce, jak úzkosti vikrik I... ${ }^{\prime}$ (Hudba slepcu / Musik der Blinden, III. 1: "Wem gilt dein klagendes Lied, o Herz, der ängstliche Aufschrei I... ${ }^{\prime}$ ). - "Pro výkrik sroce osamélěho / koyż zajásá v úzkosti svoji jako pták zbloudilý, / jenž nalezl bratrské množstvi zpivajici, / sladko je žitil" (Kolozpěv srdci / Rundgesang der Herzen, V.; "Wegen des Aufschreis des einsamen Herzens / wenn es aufjauchzt aus seiner Angst wie ein verirter Vogel, / der gefunden die brüderliche singende Menge, / süß ist's zu leben!").

Die Tendenz zur Rettung des einsamen 'Herzens-Liedes' durch seine in Kolozpèv srdci (Rundgesang der Herzen) vollzogene Integration in einen kollektive n Chorgesang, bekundet sich bereits in Hudba slepcu, worauf die auffallend große Anzahl der pluralischen Terme hindeutet - "ze vsech nebes" (IV, 2; "aus allen Himmeln") "vsech bleskü" (IV, 3; "aller Blitze",) "Vß̌cchna more" (V, 1; "Alle Meere"). "Vß̌chny pisné" (VII, 1; "Alle Lieder"), "všechny struny" ( $X, 4$, "alle Saiten") usw. -, die wiederum die Pluralităt und Vielfalt der Phänomene der Menschenwelt, im Gegensatz zur Singularität und EinzigArtigkeit der fiktionalen und selbstgenügsamen Kunst-Welt des dekadenten Symbolmus, indizieren

Das Musikinstrument der "Blinden" ist die "Geige des Herzens" ("v hudbè tvých vášnivych, kvilicich, hýticich housll, 6 srdce", IX, 3; "in der Musik deiner leidenschaftlichen, klagenden, schwelgenden Geige, o du Herz"). Es ist die Musik des cor ardens ("a zivé housle jejich, jak plameny v klubko sehnané větrem", II, 3; "und seine lebende Geige, wie ein Knäuel gebalite Flammen im Winde"); damit koinzidieren die zahlreichen Lexeme des Brennes, der Flammen, des Glühens, der Funken usw., die hier dem "kosmischen Frost" ("v kosmickěm mrazu", VIII, 2) gegenübergestellt werden: "v horícím vězeni, Zhavými pruty zamíižovaném?" (III, 2; "im brennenden Kerker, vergittert mit glühenden Stäben"). "Zhavého vêtru" (VI, 2; "[des] glühenden Windes"). "Ohnivé propasti zemé" (VIII, 1; "Feurige Schlünde der Erde") usw. Das (feurige) Entfachen des Herzens fungient auch als' Aktivierung des Organs des e m o t $\mathrm{i}$ o $\mathrm{n}$ a 1 motivierten Trachtens, Wollens und natürlich der Liebe. Die Geige ist ein ('apollinisches', 'orphisches') 556 Saiteninstrument, das jedoch

556 Vgl. Aage A. Hansen-Lōve, .Apollon und wira . (Die mānnliche "Lichtgestalta)", in: A.A. Hansen-Löve, Der russische Symbolismus, Bd. II, Lebenssymbolik [Typoskript], Wien 1984, S. 478ff. Die 'apollinischen' Saiteninstrumente (als Analogon zu den Sonnen-bzw. Lichtstrahien) symbolisieren die Harmonie (der 'Sphărenmusik') und Vollkommenheit der "komponierten' kosmischen Ordnung. Interessanterweise tritt Apollon auch als "Psychopompos" auf (SO Z. B. in der Dichtung Vjaceslav Ivanovs), der vom "Herzen" des Dichters sowohl "ästhetisch-künstlerische als auch ethische 'Reinheit' verlangt' (ibid., S. 482). 
in der Schlußstrophe zerstört wird. Die apollinischen Licht- bzw. Sonnenstrahlen, der männlich-solaren Logos usw., werden durch das "klagende, ängstliche Lied" (III, 1), durch die Tränen und das Blut ("proud slzi a knve", $X, Z$ ), verdrängt. Zu der Tragödie der "Blinden" in der Menschenwelt gehört auch die bittere Entfremdung der Geschlechter: - Horce, jak keře ztracených zahrad, $v$ nich do vêkủ dýchaji żeny, I v temnotách žnavého vêtru polibky strásajice" 557 (VI, 1-2). Aber die Menschenwelt ist zugleich die Sphäre der Verfallenheit an den Tod, ja sogar an den (Bruder-)Mordwillen: "a viny Casu, jeź pláć jak vody Eistého zdroje, / kde ruce bratrovrażedné svá krvavá znameni umývaji" (V, 3-4; "Woge der Zeiten, die weinen, wie Wăsser krystallreiner Bronnen, / wo brudermordende Hände wuschen die blutigen Male").

Doch auch dem Klagelied der "Blinden" wird eine in te gri e re n de, in Kolozperv srda' (Rundgesang der Herzen) noch intensivierte, Funktion zuerkannt: "Vß̇echny pisné slité v nich virí, jak věky jej zpivali bratî́, / kniżata, proroci, šilenci, svêttci a zavržení, / dissonance všech żivotú mrtvých, zoufalství svatēho boje, I i budoucích jiter, v krvi se కerícich kuropẻni" (VII, 1-4; "Alle Sänge brausen darin zusammengeflossen, die Brüder sangen seit Urzeit, I Fürsten, Propheten, Wahnbetörte. Heilige, Verstoßene, I Mißklang toter Leben, Verzweiflung im heiligen Kampfe, / auch künftiger Morgen schüchternes Dämmern, blutrotes Glüh' $n^{\prime \prime}$ ). In dieser Strophe kündigt sich bereits das im vitalistischeschatologischen Welt- Modell postulietre "Zusammentließen" ("slita") von Gegensätzen (als 'dionysische' Eigenschaft) und die Komplementarität des ('Apollinisch'-)Geistigen und ('Dionysisch'-) Vitalen an, mit dem Ziel der universalen "Versóhnung" ("smî́eni"). Die "Blinden", stellvertretend für die gesamte M e n s $\mathrm{h} \mathrm{h}$ eit, vereinigen in ihrem Lied die Lieder inrer Vorgänger (das Autozitat: "kniżata, proroci, śílenci, svẻetci a zavrženi", VII, 2; "Fürsten, Propheten, Wahnbetörte, Heilige, Verstoßene"). Das Postulat der Vereinigung von "Leben" ("zivot") und "Tod" ("smrt") bzw. die Integration des Todes (d. h. des "Fremden") ins Leben (in das "Eigene") und vice versa, kommt explizit in der oxymoralen Konstruktion "životü mrtwych" (VII, 3; "der toten Leben") 558 zum Ausdruck: "Vsechny pisné slité v nich virî $/ . . . /$ dissonance všech żivotú mrtyých $/ . . .1$ i budoucich jiter $v$ knvi se Serících/... $/$ (VII, 1-4). Die Vereinigung von Leben und Tod spielt nicht nur im dionysischen, sondern auch im orphischen Mythos eine dominante Rolle (der Tod als "ewige Verbindung"). 559 Die Tendenz zur Verschmelzung von Gegensätzen tritt auch in der Infrastruktur des Gedichts in der Komplementarität von "oben" ("Svêtelná nádhera kosmu" / "Läuchtende Herrlichkeit des Kosmos", II, 1) und "unten" ("Ohnivé propasti zemë, [vs.] nočni blankyty smrti, / kvetouci v kosmickem mrazu I... . VIII, 1-2; "Feverige Schlünde der Erde, [vs.] des Todes năchtige Azure, / blühend im kosmischen Frost I... r) $^{2}$ zutage.

557 Vgl. hierzu den bekannten Passus aus Se smitf hovoff spici...(Mit dem Tode reden die Schilafer..., SCh). "Noc tisiciletí odhala bratrskou Cistotu pohledum našim / a rozklenula se mezi

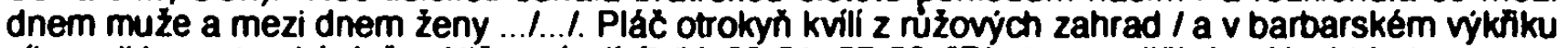
síly umlkla sesterská duše, / tišse zpivajid" (V. 50-51, 57-59; "Die tausendjährige Nacht hat unseren Blicken die brüderliche Reinheit gebracht / und sich gewölbt zwischen dem Tage des Mannes und des Weibes /...l. Aus Rosengärten klagt der Sklavinnen Weinen / und im barbarischen Aufschrei der Kraft ist die Schwesterseele verstummt, / die leise singende". Úbers. v. O. Pick.) Auf das Gedicht Se smrti hovori spici... verweist schließlich auch das Motiv der "tragischen Musik": "Co znamená polibkủ sepot v této tragické hudbé, jež hřmál... $\%, v .79 ;$ " Was bedeutet das Flüstem der Küsse in dieser tragischen Musik, die tost /...F. Übers. v. O. Pick.)

558 Vgl. auch das Motiv der "kūnttigen Morgen", die im "Blut der Dāmmenung" untergehen (VII, 4; "i budoucich jiter v krvi se sericich, kuropéni").

559 Wie Dionysos versinnbildlicht auch Orpheus den "leidenden Gottmenschen". Mit Dionysos teilt er das gleiche Schicksal; auch er wurde - von wütenden Bacchantinnen- bei lebendigem Leib in Stücke zerrissen. Vgl. auch die Sonette an Orpheus von Rilke, in denen gerade die Vereinigung von Leben und Tod die sinnkonstitutive Intention des ganzen Zyklus bildet. In seinem Mutterrecht betrachtet J. J. Bachofen die Auffassung von der "Identität von Leben und Mutterrecht' als einen dominanten Aspekt der Mysterien: "Der Tod selbst ist Vorbedingung für das Leben, und dieses Iost sich wieder in jenem auf. I...I In keinem Zeitpunkte, in keinem tellurischen Organismus ist Leben ohne Tod zu denken. Was dieser wegnimmt, ersetzt jenes, und nur wo altes verschwindet. kann wieder Neues entstehen". (J. J. Bachofen, Das Mutterrecht. Eine Untersuchung über die Gynaikokratie der atten Welt nach ihrer religiosen und rechttichen Natur, hrsg. v. H.-J. Heinrichs, FrankfurtMain 1975, S. 67 f. 
Wie ist aber in Hudba slepcu் das Schlüsselmotiv der "Blindheit",560 (bzw. der Finsternis) zu deuten? An dieser Stelle soll zunächst der gnostische Erlösungsmythos erwähnt werden, dessen Spuren, wie schon dargelegt, im vitalistisch-eschatologischen Welt-Modell nicht fehlen. Der vom "Vater" gesandte präexistente Gottessohn kommt als "Licht", "Wahrheit" und "Leben", um die Befreiung den in der "Blindheit" verharrenden "Gefangenen" zu bringen; es geht also um die Befreiung der präexistenten Lichtfunken aus der Gefangenschaft der dämonischen Mächte. ${ }^{561}$ In der neutestamentlichen Tradition wird diese Symbolik ('verchristticht') weiterentfaltet. Das Wesen des Kosmos ist die Finsternis (" nočni blankyty smrti, / kvetouci v kosmickém mrazu hvězdnými asfodely". VIII, 1-2; "des Todes nächtige Azure, / blühend im kosmischen Frost in Asfodelen der Sterne") 562 und die Menschen sind "Blinde", ohne es zu wissen (vgl. Joh. 9, 39-41; 1. Joh. 2. 11), ohne diese Finsternis zu erkennen ("a ceho osleplé pohledy nevidëly". Vill, 4; "und was die erblindeten Augen nicht sahen "). In Vládnouci... (Herrscher..., VP) oder in Poledni zráni (Mittäglich Reifen, VP, theo-logisch-eschatologisches Modell) kennt das dichterische Ich ein 'Remedium' gegen diese 'Blindheit'

560 In der christlichen Ikonologie kommt das 'Blindheit' am häufigsten in bezug auf die Blindenheilung, ferner in bezug auf die Erleuchtung (Illuminatio), Taufe, Wiederherstellung des Lichts oder auf den himmlischen Aufstieg vor. Vgl. G. Heinz-Mohr, Lexikon der Symbole. Bilder und Zeichen der christlichen Kunst, 1988. S. 53. Eine wichtige Position nimmt die Blendungsmetaphorik ein, vor allem im Zusammenhang mit der Lichtmetaphysik, so z. B. in Dantes Divina Comedia, wo ebenfalls die Parabel von den Blinden thematisiert wird. Zu der allegorischen Bedeutung der Blindheit äußert sich Dante auch in seiner Korrespondenz (vgl. Lettere di Dante, Monti 1921. S. 337. § 7.) Die allegorische Bedeutung der 'Blindheit' als Allusion auf Matthăus 15,14 (ein Blinder, der einen anderen Blinden fühnt) ist spātestens seit dem 13. Jahrhundert ein beliebtes Exemplum der 'umgestülpten Welt'. Vgl. dazu auch E. R. Curtius, Europăische Literatur und lateinisches Mittelalter, Bern 1948. S. 103. Das 'Sich-Führen-Lassen' von einem Blinden verweist auf ein anderes im Mittelalter und in der Neuzeit verbreitetes Exemplum, nämlich das der imprudentia (Torheit). Zu den allegorisch-moralisierenden Bedeutungen treten die symbolischen hinzu: Die 'Blindheit' als 'Irrweg', auf dem sich die (im religiósen Sinne) 'Irrenden' bewegen und in den Abgrund der Ketzerei fallen, das 'Verblendet' Werden von der Begierde und Versuchung usw. Die Lehre von der Unkenntnis des Menschen über sein Schicksal und von seiner hotfnungsiosen seelischen Blindheit wurde vor allem im Calvinismus entwickelt. Es scheint in vieler Hinsicht kennzeichnend zu sein, daß die 'Blindheit' eine paradigmatische Funktion sehr oft in der Literatur und bildenden Kunst der sekundären Stilbzw. Kunstperioden (nach dem Model der diactronen Semiotik von I. P. Smirnov: Manierismus und Barock, Romantik, Symbolismus) erlangt. Sowohl in der Kunst des Manierismus/Barock als auch in der des Symbolismus und später des Surrealismus ist die klare Grenze zwischen Realităt und Illusion, Sein und Schein, Traum und Wirklichkeit fließend geworden. Für die Künstler des Manierismus und Barock war die ăußere, sensorisch wahrnehmbare Realitắt einschließlich der gewöhnlichen Erkenntnismőglichkeiten genauso unbefriedigend wie für die Symbolisten und die Surrealisten vier Jahrhunderte später. Die Äquivalenzrelation 'Auge' (äußeres-rationales-Sehen) 'Herz' (inneres-emotionales-Sehen, Organ der Liebe) sowie die Blendungsmetaphorik, die auch in den Sonetten von Shakespeare und Michelangelo eine wichtige Rolle spielt, werden im Symbolismus und Surrealismus als 'inneres Sehen', im Sinne der Umwertung der kognitiven Funktion des Auges durch seine Destruktion (das 'blinde Sehen'), aktualisiert. Bei den Surrealisten bedeutet die 'Blendung' die symbolische Veränderung des Sehens als Ausdruck der 'Traumrevolte' des modernen Ich. Die sensorische Wahrnehmung sollte durch die Imagination ersetzt werden. Vgl. U. M. Schneede, "Das Blinde Sehen - Zur Ikonographie des Surrealismus", in: Max Ernst, hrsg. v. Werner Spies, München 1991. S. 351-356. In der Literatur und bildenden Kunst des Symbolismus wird allerdings auch die christologiche bzw. eschatologische oder mystische Bedeutung der Blindheit aktualisiert (Baudelaire, Maeterlinck, Mallarmé u. a.). A. A. Hansen-Löve verweist auf die Korrelation zwischen 'Taubheit' und 'Blindheit' der "staubigen Alltagswelt" (bei Brjusov, Bal'mont $u$. a.), die als Symptome der negativen Seite der Sprachlosigkeit semantisiert werden. Vgl. Aage A. Hansen-Lōve, Der russische Symbolismus. Band I, Diabolischer Symbolismus, Wien 1989, S. 198-199, 260.

$561 \mathrm{Vgl}$. H. Jonas, Gnosis und spätantiker Geist, Góttingen 1964, S. 118-119, 414-415. Im gnostischen Mythos koinzidiert die 'Blindheit' mit 'Schlaf'. 'Trunkenheit' oder 'Vergessen', die die fatalen 'Lockungen' der "lärmenden" Welt bedeuten.

562 Das Motiv der Asfodelen im Zusammenhang mit dem kalten Sternenhimmel ist offensichtlich eine intertextuelle Allusion auf das gleiche Motiv in Maeterlincks Les Aveugles (1893): "Une très ancienne forêt septentrionale, d'aspect étemel sous un ciel profondément étoilé. I...I Une touffe de longs asphodèles maladiff I.... 
"At' omyji oủi své, nemocné soumrakem, I na výši tvjch hor, z jichž temen se vali / prameny

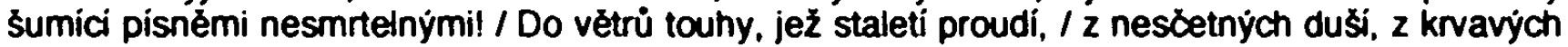
noci našeho pólu / k rovniku tvému, / strhni má kł̌dla!" (Vládnouci, V. 14-20; "Möge ich doch meine Augen baden, die zwielichtkranken, / auf deiner Berge Scheitel, wo niederstürzt / der Quellen Aufruhr in unsterblichen Liedern! / In die Winde der Sehnsucht, die durch die Jahrhunderte strömen, I aus unzăhligen Seelen hervor, von der Blutnacht unseres Pols her, I zu deiner Mittagsgleiche / reiß fort meine Flügel!". Übers. v. F. Wertel.)

In Hudba slepcú geschieht aber nichts derartiges. Die "Blinden" versuchen die verlorene kosmische Harmonie und die "mystische Schuld", die das Erlöschen des Augenlichts verursachte, durch die Macht der Empathie, der Leidenschaft des "brennenden Herzens" und durch das Licht der oculi cordis, d. $h$. durch Gefühle und Gemütserregungen, die ihren Sitz im Herz haben, vergeblich zu 'kompensieren' und zu harmonisieren: "v hudbè tvých vášnivých, kvilicich, hÿĭicich housli, 6 srdce, I marnè hledaji utiseni" (IX, 3-4; "in deiner klagenden, zehrenden, jauchzenden Geige, o Herz, / vergeblich suchen sie Frieden"). Der Versuch scheitert - paradoxerweise - im Augenblick "des höchsten Einklangs": "A když konečné kosmu nejvyక̌sí souzvuk, / milostí objaly v nekonečnost rozpjaté intervaly: / proud slzi a krve z osleplých oú spálil jim tváłe / a vङechny struny twých housli, $\delta$ srdce, se potrhaly" ( $X, 1-4 ;$ " Und als sie endlich des Kosmos ureigenen Einklang / begnadet erfaßten, die endlosen Intervalle, trotz gähnenden Klüften, / ein Strom von Tränen und Blut, aus geblendeten Augen, sengte innen die Wangen / und alle Saiten an deiner Geige, o Herz, zerbarsten, verklangen “).

In seiner Monographie interpretiert $O$. Králík diese äußerst expressive Pointe als ein wiederholtes Erblinden, das ihm "in gewisser Hinsicht unlogisch" vorkommt. $563 \mathrm{Er}$ übersieht jedoch volikommen, daß die in der Schlußstrophe thematisierte Erblindung sich gerade $\mathrm{n}$ icht auf die Augen als Organ der Sinneswahrnehmung (sensus exterior), sondern auf die oculi cordis, die A ugen de s Herzen s, 564 bezieht: "proud slzí a krve 2 osleplých oli spálii jim tváre", $X, 3$; "ein Strom von Tränen und Blut aus geblendeten Augen sengte ihnen die Wangen"). Die Vereinigung und Harmonisierung gelingt den "Blinden" nicht einmal durch die Empathie, durch die Entfachung des Herzens und der Liebe; sie gelingt nicht einmal durch das Charisma der "Gnade" ("milost", X, 2). Im Akt des Erreichens des ersehnten Ziels kann das Herz die extreme Spannung nicht mehr ertragen: die Saiten seiner "Geige" zerbersten und seine Augen erblinden. Daher muß ein anderes, noch mächtigeres Charisma - die "Versöhnung" - angestrebt und das "einsame Herz" in den gewaltigen, kollektiven "Rundgesang" aller Herzen intergrient werden:

"Slyšite tajemné suméni krve? I.../ Bolestná zaznēni sroć, laděných véky jak stuny / pro souznéni hvẻzoná? I Zakvileni strun philiš napjatých, płetrżených? / A všemi svéty letid onnivy ton I dosażeného souzvuku serafického? / /... / Pro výkđ̌ik srdce osamélého / kdyż zajásá v úzkosti svoji jako pták zabloudily. I jenż nalezl bratrské množstvi zpivajici, I sładko je źtit! (Kolozpév srda' I Rundgesang der Herzen. V. 11, 13-17, 94-97; "Hort itr das geheimnisvolle Rauschen des Blutes? I.../ Leidvolles Ertónen der Herzen, gestimmt in Äonen wie Saiten / zum Einklang der Sterne? Aufseufzen allzu gespannter, gezerter Saiten? / Und durch alle Welten sausenden feurigen Ton / des erreichten seraphischen Einklangs? / I../ Für den Autschrei des vereinsamten Herzens I wenn es aufjauchzt aus seiner Angst wie ein verirrter Vogel, I der gefunden die brüdertiche singende Menge, I süß ist's zu leben!")

563 Vgl. O. Králik, Otokar Błezina, Praha 1948, S. 331. Králík (ibid. S. 313-315) interpretiert Hudba stepcui nur ansatzweise. Die Spezifika, die intendierte Bedeutung und die Position dieses Textes im Gedichtzyklus Ruce bleiben unberucksichtigt. U. Heftrich (Otokar Bł̈ezina, Heidelberg 1993. S. 192, 290-291) erwähnt das Gedicht an zwei Stellen; seine Deutung des 'Blindheit' als "Vertiaftet-Sein" in der Illusion und als Ausdruck der Urschuld (in bezug auf den Anfangsvers (I, 1 , $(X, 1)$ ist sehr aufschluBreich.

564 Die Symbolik der 'Blindheit' der Herzensaugen, ein bereits in der Antike verwendete und im Mittelalter zum Topos gewordene Motiv, weist mehrere Bedeutungen auf. In der alttestamentlichen Tradition (z. B.) bezieht sich die Blindheit der oculorum cordis auf die Blindheit der Einsicht des jüdischen Volkes in Gottes Wirken. Augustinus betrachtet diese Art der Blindheit als Ursache für die Sünde, die die Liebe zur Welt (d. $h$. zur Finsternis; man denke an die gnostische Bedeutung der Blindheit) zeugt. Erst durch die Vergebung der Sünde kann das Herz wieder erleuchtet werden (bei Johannes von Ford durch das "große Licht" der sapientia, worunter er offensichttich Gott versteht). Vgl. Gudrun Schleusener-Eichtiolz, Das Auge im Mittelaiter, Bd. 1. München 1985, S. 1019ff. 


\subsection{Komplementarität des ('Dionysisch'-) Vitalen und ('Apollinisch'-) Geistigen}

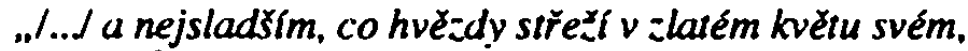
jak úl svůj včela loupe đná svou obohatit :em“.

„I... I mit dem Süßesten, was die Sterne in ihrer goldenen Blüte hüten. die Erde bereichern wie die räuberische Biene ihren Stock“.

O. Błezina: Vłe zachvátit... (Alles ergreifen....,1901)

Das schmerzvoll gescheiterte 'Projekt' der universalen Harmonisienung der Lebenswelt und ihrer Dissonanzen, durch die Empathie des Herzens, versucht Brezina durch die 'dionysische' Intensivierung und Dynamisierung aller vitalen Prozesse zu retten. Alles, was in der ontologischen Krise der "Gluthitzen" der zerstörerischen Desintegration und Dissoziation durch das Zerbersten, Zersplittern, Zerreißen, Verglühen usw. anheimfiel, muß reintegriert, neu zusammengefügt und 'geformt' werden. Daß in diesem Prozeß der Integration und Versöhnung gerade dem dionysischen Prinzip die sinnkonstitutive Funktion zuerkannt wird, hängt mit der mythischen Bedeutung des Dionysos zusammen, dessen (polymorphe) Gestalt die ständige Metamorphose und die Fähigkeit die Polaritäten und Gegensätze zu vereinigen und zu versöhnen - den Makrokosmos mit dem Mikrokosmos und dadurch auch jegliche Widersprüche des Lebens und der Schöpfung symbolisiert. 565 Doch das Dionysische scheint bei Biezina stets auch das Apollinische zu tangieren; das Rauschhaft-Extatische wird durch das Maßvoll-Harmonische und Geistige komplementiert. Diese Komplementarităt scheint der von J. J. Bachofen verwendete Terminus "dionysische Orphik" prägnant zu charakterisieren. 566 Damit koinzidiert die für das vitalistisch-eschatologische Welt-Modell hochrelevante Symbolik der "Kette" und des "Kreise(n)s“:567 der Inbegriff dionysischer Prozessualität und Kontinuität, das Ganzheit-

565 Die 'synthetisierende' Fähigkeit des Dionysos, das Zerstückelte und Gevierteilte wieder zu vereinigen, ist auf sein eigenes Schicksal zurückzuführen. Laut des Mythos wurde der kleine Dionysos auf Befehl der Hera von den Titanen zerstückelt und in einem Kessel gekocht. Seine Körperteile wurden von seiner Großmutter, der Erdgöttin Rhea, wieder zusammengestelt und durch diese 'Synthese' ist Dionysos auferstanden. Vgl. dazu: R. Ranke-Graves, Griechische Mythologie. Quellen und Deutung. Bd. I. Reibneck bei Hamburg 1965, S. 91 ff.

566 J.J. Bachofen, Die Unsterblichkeitslehre der orphischen Theologie, Gesammelte Werke, Bd. 7, Basel-Stuttgart 1958, S. $96 f f$.

567 Das Motiv der "Kette" (des "Kreises") kommt hier keineswegs unvermittelt vor. In Motiv Z Beethovena (Ein Motiv aus Beethoven, TD) heißt es: "stín. Jetéz krokú tvých ti rozlomil a shal" (VII, 2: "den Schatten, deiner Schritte Kette, nahm er und brach"); oder in Modlitba vecerni (Das Abendgebet, VI, 3): "sil živých věčný kruh" ("der Lebenskrăfte ewiger Kreis"). In Vino silných (Der Wein der Starken, SZ) hat der "Kreis" eine magisch-schützende Funktion: "Tajemný proud zavie se kruhem kol našeho stolu, / vymkne nás ze zákonú země a život a smrt bude našemu sněni odpovidati. I.../V Čarovném knuhu, velkém jak obzor, se uzavł̌em úzkostem noci“ (V. 6-7, 13: "Geheimnisvoll schließt ein Strom seinen Kreislauf um unser Tischrund, / hebt uns aus den Gesetzen der Erde, und Leben und Tod werden Antwort stehn unserem Träumen. I.../ In einem Zauberkreis, groß wie der Horizont, wollen wir uns den Ängsten der Nacht verschließen"). Während diese magische Bedeutung des "Kreises", die die gnostisierenden Pneumatiker zugleich als 'Magier', 'Zauberer' ("v Carovněm kruhu" / "im Zauberkreis") oder als eine Art "Bruderschaft" der Hūter des Heiligen Grals in einer Tafelrunde ("kol našeho stolu" / "um unser Tischrund") erscheinen läBt, wird das "Kreis" $/$ Kette"-Motiv in Ruce gleichsam 'entindividualisiert'. Im Titetgedicht Ruce sollen "unzählige Hände" eine einzige "Kette" bilden, nicht nur die Eingeweihten und Auserwählten. Der "Z a u b e r kreis" wird zum "É r d kreis" ("na kroužici kouli zemé", Věčnè znova / Stets aufs Neue, III, 2; "aut der kreisenden Erdenkuget"), zu einer einzigen "Kette", die den Erdball umschließt. Der endzeittichen Ver-Einigung und Versöhnung sollen nun a II e - "Fürsten der Erde und Sklaven, blutig gegeißelt" (Silena / Wahnbetơte, IV, 1; "Knižata zemé i otroci do krve ubičcovani") - teilhaftig werden. Laut Bachofen (a.a.O., S. 63-69) verweist das Motiv der Scheibe, des Reifes, des Rades, der Kette usw. nicht nur auf die kosmisch-mystische Symbolik der Vollkommenheit der Kreisform (des Universums), sondern auch auf die Symbolik der 
Symbol par excellence. Auch die fünf im Zyklus nacheinanderfolgenden Gedichte - Ruce (Hände), Zpivaly vody (Es sangen die Wässer). Zpivaly horíci hvězdy (Es sangen die brennenden Sterne), Kolozpév srdcl (Rundgesang der Herzen) und Dithyramb svètü (Dithyrambus der Welten) -, die als eine kleine 'Pentalogie' konzipiert sind, verknüpft und vereinigt symbolisch das Motiv der "Kette". Diese Intention kommt im letzten Zweizeiler des ersten Gedichts der 'Pentalogie', in Ruce (Hände), 568 antizipatorisch zum Ausdruck: "uslyseli jsme kolozpęv vod, hvězd a srdci a mezi slokami jeho, / v intervalech kadence melancholické, dithyramb svẻtů za sebou následujícich" (V. 70-71; "wir hörten den Rundgesang der Wässer, Sterne und Herzen und in seinen Strophen, $/$ in Intervallen, melancholische Kadenzen, den Dithyrambus der Welten, die einander folgen").

Im Prozess der Re-Integration müssen auch die vom (Lebens-)Kampf (Chvile slávy I Augenblicke der Hehre, VIII, 3-4) oder von der schweren Arbeit "gebrochenen" (Jarni noc I Frühlingsnacht, I, 6-7) und schwachgewordenen, "zitternden Hände" der Erd-Brüder (Bolest Clovéka I Schmerz des Menschen, I, 3) in eine "magische Kette ungezählter Hände“ (Ruce / Hände, V. 60) eingefügt werden. Das Resultat der Re-Integration des "zersplitterten Ringens Millionen von Händen" ("roztr̂ístèné vỉeni milionú rukou", Zpivaly vody / Es sangen die Wăsser, V. 38) stellt die "enzige geistige, gigantische Hand, die die Erde umklammert" ("v jedinou duchovou ruku gigantickou, zem objímajíci", ibid., V. 39) dar, d. h. die finale Vergeistigung aller vitalen Prozesse im Akt des "Zusammenfließens" ("slita") von (Erd-)Leben und Geist, unter dem Aspekt der Stärkung eines g e i s ti g e n Lebensinhaltes. Das Sinnbild dieser Synthese, in der das postuliente "Zusammenfließen" des Geistigen mit dem Haptisch-Körperlichen klar zutage tritt, heißt "duchová ruka" ("geistige Hand"; Zpivaly vody / Es sangen die Wässer, V. 39). Signifikanterweise wird die "Kette ungezählter Hănde" von "Hănden höherer Wesen" erfaßt; ein Gestus, der wohl die Vollendung der Vergeistigung des ganzen koopos indiziert: "citíme, jak jetézz nás, zachycen rukama bytostí wyšsich, / v nový jetéz se zapiná do vsech prostorú hvézdných / a objimá svêty" (Ruce / Hănde, 65-66; "wir fühlen, wie unsere Kette, effaßt von Hănden höherer Wesen, I in eine neue Kette sich fügt in alle sternbesäeten Räume / und umklammert die Welten"). Die Vorstellung einer allumfassenden Vergeistigung der Lebenswelt ("von unten", durch das Haptisch-Somatische) nimmt auch in anderen Gedichten des Zyklus eine dominante Position ein:

" $V$ sepjetí modlitby úderem blesku / jak pisek ztavené ruce płemoženého! /.../ Zethemélé jak světto a k ovoci mystických stromú / prodlużujić se celým vesmirem do nekonečnal" (Ruce I Hănde, V. 53-54, 58-59; "Im Håndefalten der Andacht, vom Schlage des Blitzes, / leuchtende, vom Glutenschimmer überfließende Hănde des Überwundenen! /... I Ätherisch gewordene wie das Licht, und zum Obste mystischer Băume hin, / sich verlăngernde, durch des Kosmos Bereich bis

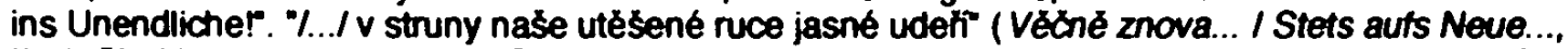
II. $4 ; " \% /$ in unsere stummen Saiten schlagen lichte Hănde ein"). "Vsak jejich ruce duchové $k$ hvězdám se rozepjaly, I miliony duši na zemi a ve všech světech objaly" (Jarni noc I Frühlingsnacht, II, 1: "Doch ihre geistigen Hănde breiteten sich aus empor zu den Sternen, I Millionen von Seelen der Erde umarmten sie und aller Wetten". Übers. v. E. Saudek.)

Wie es scheint, kann die erwartete und postulierte "Vergeistigung" ("zduchovêni"), die Bïezina nun in einem Atemzug mit der "Versöhnung" ("smífeni") nennt - "zduchovêt, smírit a vykoupit!" ("vergeistigen, versöhnen und erlösen!") -, nur dann erfolgreich sein, wenn sie auch alles Vitale bzw. Vital-Stoffliche, in seiner Mannigfaltigkeit (und Widersprüchlichkeit) in ihr Konzept - nach der Formel "A ll e s ergreifen!" - integriert. Auf die Komplementarität von Körper/(Erd-)Leben und Geist, wie sie in der Kontamination "duchová ruka" ("geistige Hano") zutage tritt, deutet auf der Ebene des myth(olog)ischen Denkens in Ruce auch der

Unsterblichkeit und der Wiedergeburt. Nicht zu vergessen ist auch Blezinas Auffassung seines dichterischen Gesamtwerks als einer "Kette" von fünf vollendeten Gedichtzyklen, die - laut Błezina - eine "abgeschlossene Ganzheit bilden. Vgl. E. Chalupný, Dopisy a viroky Otokara Breziny, Prana 1931, S. 112.

568 Im Titelgedicht Ruce strukturiert das Motiv der "Kette" (magický letěz rukou nesčisıných". V. 60; "magische Kette ungezăhiter Hảnde") den syntaktischen Aư⿱ au des gesamten Textes. Im Unterschied zu den meisten Langgedichten Biezinas (2. B. Ranni modlitba I Das Morgengebet, Poledni zuani / Mittáglich Reifen, Stavitelé chrámu / Baumeister am Tempel, Vedra / Gluthitzen u. a., besteht das Titelgedicht Ruce, abgesehen von dem Prolog-Zweizeiler, aus einer "Kette" von zweiundvierzig Versen. Die zehn in diesem Gedicht enttalteten Adverbialbestimmungen symbolisieren die Mannigfaltigkeit der vitalen Prozesse, die auch völlig u n te r s c h i e d li c he Lebens- und Schópfungsbereiche mit einbeziehen. 
'Duett-Gesang' der Wässer (Zpivaly vody I Es sangen die Wässer) und der brennenden Sterne (Zpivaly hořci hvëzdy I Es sangen die brennenden Sterne) hin. Das "Wasser" als tellurisches, 'dionysisches' Element, das der "Mutter-Erde" entquillt, wird mit dem 'apollinischen' Element, dem Sternen-Fever kontaminiert, das eine "obere" Analogie des solaren Gottes zu den "feuchten Augen" des tellurischen Gottes bildet. 569 Die Synthese vollzieht sich im "Rundgesang" aller Herzen (Kolozpẻv srdci), im "Dithyrambus" aller Welten (Dithyramb svêtü). Ein faszinierendes Bild der Komplementarität, ja der Durchdringung der "unteren" Erdhaft-Weiblichen ('dionysischen') generatio mit der "oberen" Solar-Männlichen ('apollinischen') creatio im Akt der Lebens-Schöpfung, wird im Titelgedicht Ruce entfaltet:

a Żena, zblediá năhle płi zavolání svého skrytého jména, agoniemi / jako po stupnich, kluzkých krvi, sestupuje $k$ zakletým pramenủm žití, / v úpẻni věkủ do kruhu hnaných, v żárlivé vłeni bytosti neviditelných, / a s výkrikem hrủzy zpèt letí, siná, a bolestnými plameny rukou / k prsủm tiskne svou kớist: život, kvilíci v potkáni tohoto slunce" (V. 39-43; "und das Weib, plötzlich erbleichend beim Aufruf seines verborgenen Namens, in Agonien, / wie auf Stufen, schlüpfrig vom Blute, zu den verwunschenen Quellen des Lebens herabsteigt, I in das Heulen der im Kreise getriebenen Jahrtausende, ins eifersüchtige Ringen unsichtbarer Wesen, / und mit dem Aufschrei des Schreckens zurückwankt, bleich, und mit schmerzhaften Flammen der Hände / drückt an die Brust ihre Beute: ein Leben klagend bei dieser Sonne Begegnung". Übers. v. E. Saudek.)

Das und erwartete "Zusammenfließen" von Leben und Geist, kann man, wie bereits angedeutet, als 'Fortsetzung' und Intensivierung der in Stavitelé chrámu thematisierten kosmogonischen Prozesse begreifen, die im schöpferischen Akt des "Tempel-Baus" kulminieren und die beinahe ausschließlich auf den Dynamismus des geistigen Lebens orientiert sind. In Ruce verschiebt sich der Sctwerpunkt auf die vitalen Prozesse, die nicht in der Hervorbringung eines (artefiziellen) Kunst-Werkes ("Tempel" / "chrám"), sondern im Kommen des neyen, geistigen "Menschen" kulminieren sollen, dessen Ankunft die "Wahnbetörten" ("Silenci") voraussehen. Aber das (Erd-)Leben, das an sich 'formlos" ist, muß etwas Bleibendes, die Form, den geistigen Gehalt, erlangen. Das Wollen, dem Leben eine geistige Form zu geben, kommt besonders prägnant im Motiv der den (Lebens)Lehm knetenden "geistigen Hand" ("duchová ruka") zu Geltung:

"A hle! Pied pohledem jejich roztî́stèné vłeni milionủ rukou / tuhne v jedinou duchovou ruku gigantickou, zem objímajici, I jež v słavném a tragickém gestu sochałe, / hnẻtouciho kouli své posłušné hlíny / pỉeménuje tajemstvi vẻci dle nádhery viděni svého, / v mucivé kỉeči tvưrči / vždy nespokojená" (Zpivaly vody / Es sangen die Wăsser, V. 38-44; "Und siehe! Vor ihren Blicken das zersplitterte Ringen Millionen von Händen / erstart zu einer geistigen, gigantischen Hand, die die Erde umklamment, / die mit der erhabenen tragischen Geste des Bildners, welcher knetet den Klumpen seines gehorsamen Lehms, / das Geheimnis der Dinge verändert, I nach der Herrlichkeit seines Hellseh'ns / im qualvolien Krampte des Schaffens, I immer unzufrieden". Übers. v. E. Saudek.)

Ähnlich auch in Dithyramb sừtu (Dithyrambus der Welten): "Zárici zrozeni i hasnuti I milionú slund / do tmy vêkú se tłłśt / diouhými nychlými blesky, / jak zrcadlení svêtla / na cepeli nože štèpujicího, płi každém horečnem pohybu ruky / mistra" (V. 1-8; "Strahlendes Werden und Erlöschen / Millionen von Sonnen / in die Nacht der Ewigkeit splittert / in langen, schnellen Blitzen, / wie Aufspiegeln des Lichtes / auf der Klinge des Messers des Pforpfenden ( bei jeder fieberhaften Bewegung der Hand / des Meisters"). In diesem Gedicht, das auch das letzte "Glied" jener "Pentalogie-Kette" bildet, wird die Symbolik der erwarteten Versöhnung von Geist und (Erd-)Leben, vom kreativen (apollinischen) und regenerativen (dionysischen) Prinzip, als ein sukzessiver, von der Schöpfung in der Geound Biosphäre der Lebenswelt bis zum Aufstieg zum "geistigen Kosmos" ("duševni kosmos") führender Prozeß dargestellt.

569 Vgl. dazu die Darlegung von Aage A. Hansen-Löve, .Dionysos und „Svirel' ' . (Der .untere Erlöser"), in: A.A. Hansen-Löve, Der russische Symbolismus, Bd. II, Die Lebenssymbolik [Typoskript], Wien 1984, S. 496 .) Das Wasser, als dionysisches Element, die "Tränen" im "feuchten Auge" des "unteren Erlösers", charakterisieren die "Unbewußtheit des dionysischen Blickes", während die "Sterne" des "solaren Auges" von Apollon die leuchtende, strahlende Luziditắ indizieren (ibid., S. 496). Zur Komplementarität (und Distinktion) von 'Dionysisch' 'Apollinisch' vgl. auch: J.J. Bachofen Die Unsterblichkeitslehre der orphischen Theologie, Gesammelte Werke, Bd. 7, Basel-Stuttgart 1958, S. 96ft. 


\subsection{1 "Zusammenfließen" des Erdhaft-Vitalen und des Geistigen im kollektiven Chorgesang: Dith y ramb s vètü (Dithyrambus der Welten)}

\section{Dithyramb světů}

Zárící zrozeni i hasnuti miliónů sluncí do tmy věkủ se tớî́ti dlouhými rychlými blesky

5 jak zrcadlení světla na Cepeli nože štěpujícího při každém horečném pohybu ruky mistra.

\section{Dithyrambus der Welten}

\author{
Strahlendes Werden und Erlöschen \\ Millionen von Sonnen \\ In die Nacht der Ewigkeit splittert \\ In langen, schnellen Blitzen, \\ Wie Aufspiegeln des Lichtes \\ Auf der Klinge des Messers des Pforpfenden \\ Bei jeder fieberhaften Bewegung der Hand \\ Des Meisters.
}

Svéty za sebou následující v tajemství Casu! Welten, folgend einander im Geheimnis der Zeiten!

10 Gigantská jara věnného tropu!

Koberce mystických stupnù!

Údery krve omlazující!

Znova a znova se navracející,

vždy duchovéji burácející

15 vich hice vášní!

Okł̌idlená semena letící tisíciletí,

Jahrtausende.

klíxivá i uprostfed ohnex!

Rozkoši ruky polouvłené, zasévající!

Striknutí Žhavého zmi płres propasti kosmu,

20 Mléñé dráhy!

Blankyty nesxetných zemi svítící

na błezích teky extatické. jako pomněnky jamí

jež letí v rozpjatou náruč

mołe tvého!

25 Klokotná vífeni s arktických výsí roztrîstěné ledy s sebou unásející. krystalná lodstva mrtvých světủ!

Golfickě proudy lásky!

30 Svaté żnę Slova!

Z pramene každého zrna

veletok klasú!

Nad každým místem, kam padlo.

i nejukrytějším.

35 tisíce cervenců v ohni!

Dusevní kosmy!

Plující zahrady, šlící ptactvem.

zemé snění!

Žhavými nižemi sršící protuberance

40 tvůréích sluncí!

Světy zapalující,
Gigantische Lenze der Ewigen Tropen!

Teppiche mystischer Stufen!

Pulsschläge des Blutes, verjüngende!

Stets aufs neue zurickkehrende,

Stets geistiger tosende

Stürme der Leidenschaften!

Beflügelte Samenkörner, durchfliegend

Keimend auch inmitten des Feuers!

Wonne der halbgeschlossenen Hand des Säenden!

Spritzen glühender Körner ubber schluchten des

Kosmos!

Milchstraßen!

Himmelsgewölbe unzähliger Erden, leuchtend wie VergiBmeinnichte des Lenzes

Auf Ufern des extatischen Flusses,

Der fliegt in die offenen Arme

Deines Meeres!

Sprudelnd Wirbeln aus arktischen Höhen,

Zersplitterte Eise entfuhrend,

Krystallene Flotten

Toter Welten!

Golfische Ströme der Liebe!

Heilige Emten des Wortes!

Aus der Quelle jeglichen Kornes

Ströme von Ähren.

In jeder Stelle, wo's hinfiel,

Auch an verborgenster,

Tausend Juli im Feuer!

Geistige Welten!

Segelnde Gärten, vögeldurchjauchzt.

Welten des Träumens!

Gluhende Rosen versprühend Protuberanzen

Schöpferischer Sonnen!

Welten entzündend, 
světy zhasínajíci

viry spravedlnosti!

A všechna slunce,

45 kroužící kolem věxného slunce neviditelného.

zárícîho hrobu cekajicího, tajemstvi nového kosmu skrývajícîho,

50) mlěenlivého!

Na rtech. jež láskou se třesou jak vonným větrem silným a oživujícím. pres oceány

55 zní vaše piseñ, 6 paní, novorozencủm.

Ukolébavka miliónů celým vesmírem otłásající, v jejímž rytmickém taktu

${ }^{60}$ houpou se bolestné zemè. kolébky duchů.
Welten verlöschend

Der Gerechtigkeit Wirbel.

Und alle Sonnen,

Kreisend um die ewige Sonne,

Die unsichtbare,

Um das strahlende, wartende Grab,

Das verbirgt das Geheimnis

Des neuen Kosmos.

Das schweigsame.

Auf Lippen, die beben vor Liebe

Wie im duftigen Winde,

Dem starken, belebenden,

Über die Meere

Tönt euer Lied, o Herrin.

Den Neugeborenen.

Wiegenlied von Millionen

Das ganze Weltall erschiutternd,

In dessen rhythmischen Takte

Schaukeln schmerzvolle Erden,

Wiegen der Geister.

Deutsch von E. Saudek.

Mit der rauschhaften Extatik des dionysischen Gesangs in einem kollektiven "Dithyrambus der Welten" koinzidiert der indikative und 'unpersönliche' Redemodus des Gedichts. Auf der verssemantischen Ebene kennzeichnen diesen "Dithyrambus" emphatische, vorwiegend (bis auf eine Ausnahme) nur fünfsilbige Exklamationen in kurzen, asyndetisch verbundenen Satzsegmenten, die die starke emotionale Spannung und Intensität ("vichrice vášni!", V. 15; "Stürme der Leidenschaften!"), zugleich aber auch die Unmittelbarkeit der dithyrambischen 'Performance' potenzieren. Signifikant ist auch die hohe Frequenz der Partizipien und Verbalsubstantiva. Das Spezifikum des Dithyrambus als eines kultischen Fest- und Chorgesangs wird durch das daktylotrochäisch rhythmisierte Unisono akzentuiert, mit dem die Stimme des lyrischen Ich verschmilzt. Hinzu kommt auch die auffallende und für das dionysische Prinzip charakteristische 'EsDominanz'. Daher rührt die Reduktion der Sujetbewegung auf ein 'Wechselspiel' von Einund Ausblendungen der einzelnen Sequenzen (bzw. Exklamationen) oder 'Aufnahmen' (ähnlich wie im Film: "Světy zapalujić, / světy zhasinajić", V. 41-42: "Welten entzündend, I Welten verlöschend") der im Gedicht thematisierten Prozesse. Diese Intention kommt gleich in der ersten Textsequenz klar zum Ausdruck: "Zárici zrozeni i hasnuti / milionu் sluna / do tmy věkú se trístí / dlouhými rychlými blesky / jak zrcadleni světla" (V. 1-5; "Strahlendes Werden und Erlöschen / Millionen von Sonnen / in die Nacht der Ewigkeit splittert / in langen, schnellen Blitzen, / wie Aufspiegeln des Lichtes").

Das lyrische Ich tritt 'anonym' - in das kollektive Über-Bewußtsein integriert - als einer der "ungezählten" Singenden des. Dithyrambus auf. Sein Thema ist die Integration und Synthese des (Erdhaft-)Vitalen ("Údery krve omlazujici", V. 12; "Pulsschläge des Blutes, verjüngende!") und Geistigen ("Dusevni kosmy!", V. 36; "Geistige Kosmen!"), der Gegensätze schlechthin ("vżdy duchovneji burácejici / vichřice vášn" V. 14-15; "stets geistiger tosende / Stürme der Leldenschaften!"). mit dem Ziel der Vergeistigung des Vitalen und des Aufstieges zum "geistigen Kosmos" ("Duševni kosmy!", V. 36; "Geistige Kosmen!": "kolěbky duchü", V. 61; "Wiegen der Geister"). Dabei durchdringen sich gegenseitig im "sprudelnden Wirbel" ("Klokotná vírení", V. 25), in der Dynamik des extatischen "Kreisens" ("a v'̌echna slunce, / kroužić kolém věcného slunce", V. 44-45; "Und alle Sonnen, / kreisend um die ewige Sonne") und im "rhythmischen Takt" ("v rytmickém taktu", V. 59) die Bio- und Geosphäre mit der Sphäre des "Geistigen Kosmos". Das dynamische "Zusammenfließen" bekundet sich auch in der Korrelierbarkeit oder 
Reversibilität des Verhältnisses zwischen der (apollinischen) "Sonne" ("Slunce"; V. 44-45), den "Samenkörnern" ("semena", V. 16) oder dem "Logos" ("Slovo", V. 30, im Sinne von

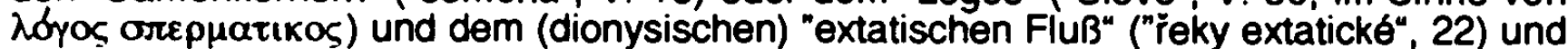
den (re-generiereden) "Golfischen Strömen der Liebe" ("Golfické proudy lásky", V. 29). Die für das dionysische Prinzip charakteristische "dynamische Gegenläufigkeit" 570 jene Fähigkeit das Ambivalente und Desintegrierte stets aufs neue zu re-integrieren, die heterogenen Phänomene zu kontaminieren, findet in Dithyramb svëtú ihren prägnanten Ausdruck: Der licht- und lebenspendende sol rex ("slunce") wird (auch) als "strahlender, wartender Grab" apostrophiert (V. 47) und die "schmerzvollen Erden" ("bolestné zemè", V. 60) schaukeln in einem und demselben "rhythmischen Takt" wie die kosmischen "Wiegen der Geister" ("kolébky duchü“, V. 61). Zu dieser Text-Strategie gehört auch die Anthropomorphisierung der thematisierten, tellurisch/vitalen und kosmisch/geistigen Prozesse - wie z. B. die Personifikation der Erde, der anima mundi: "pres oceány / zni vaše piseň, o pant" (VIII, 5; "über die Meere / tönt euer Lied, o Herrirt") -, wăhrend das menschliche Subjekt, "ein kurzes Fest in den gewaltigen Zeitdauern universaler Lebensentwicklung", 571 sich völlig anonym in diesen Prozessen de facto 'auflöst', mit innen 'restlos' verschmilzt.

Jede der neun Textsequenzen entfaltet jeweils einen anderen dynamischen Prozeß des komlementären "Werdens und Erlöschens": "Záricá zrozeni i hasnutí I milionů slunca" (V. 1-2). In der ersten Textsequenz (V. 1-8) wird die creatio des Sonnensystems als fieberhafte, zeitlose Schöpfung des creator macrocosmi, d. $h$. als maskuline, patriarchalische Ur-Zeugung von "oben" dargestellt: "pǐi každém horečném pohybu ruky' mistra"; I, 7-8; "Bei jeder fieberhaften Bewegung der Hand / des Meisters"). Der maskuline (apollinische), kon-zentrierte Schöpfungsakt ist als "schnelles Aufblitzen" ("rychlými blesky", V. 4) "aư der Klinge des Messers des Pforpfenden", 572 (V. 6; "na cepeli nože štěpujicího") konnotiert. Auf die Tendenz zur Kontamination und Vereinigung der Gegensätze verweist auch das Motiv der schnellen, blitzartigen Zuckungen (V. 4) als Metapher des permanenten "Werdens und Erlöschens" (I, 1; "zrození i hasnuti"), das durch die hyperbolische Metaphorik, die das Zeitlose und Maßlose der gewaltigen universalen Lebensschöpfung und Lebensentwicklung im xdouos markiert, ergänzt wird (das Adjektiv "věcný" I "ewig", II, 2; VII, 2; "Gigantská jara" I "Gigantische Lenze", II, 2; "semena letící tisicilet" I "Samenkörner, durchfliegend Jahrtausende", III, 1, "tisice cervencư" I" tausend Juli", V, 6; "veletok klasu்!" I" Ströme von Ähren!", V, 3; "Úkolébavka milionư" / "Wiegenlied von Millionen", IX, 1).

Die (dionysische) Fruchtbarkeit der unermüdlich ("gigantská jara" / "gigantische Lenze", V. 10) gebärenden Erde ("Údery krve omlazujici! / Vždy znova a znova se

570 Aage A. Hansen-Löve (a.a.O., S. 498ff.) spricht vom mythologischen Prinzip der "Enantiodromie" (Gegenlăufigkeit), die die dionysische Vereinigung der Gegensătze kennzeichnet ("Sieg im Scheitern". "Auferstehung im Abstieg" usw.). Die kosmogonische creatio, die ein Analogon zum menschlichen opus darstellt, muß durch die tellurische generatio komplettient werden, um die Vollendung zu erreichen.

571 Max Scheter, Philosophische Weltanschauung, 1929, S. 103.

572 In der Intention des vitalistisch-eschatologischen Modells wird hier die creatio des "Höchsten", des "Meisters" ("mistr", V. 8), mit der Tätigkeit des (sekulăren) "Pforpfenden" ("Stěpujićn'o") identifiziert. Es ist ein anderer 'Beiname' des genauso sekulären "mystischen Gärtners" aus Kolozpév srdá (Rundgesang des Herzen, V. 10). És lăßt sich kaum übersehen, daß dies eine Tătigkeit ist, die vielmehr dem dionysischen, auf die vital-organischen Prozesse orientierten Prinzip entspricht. Kennzeichnenderweise ist die Domăne des "mystischen Gărtners" nicht der 'artifizielle' Tempel, sondern der schlechterdings dionysische "zauberhatte Garten der Metamorphosen" (Kolozpév srdci I Rundgesang der Herzen, V. 9: "v kouzelných zahradách metamorfos"). Im vitalistich-eschatologischen Welt-Modell tritt der "Höchste" nicht mehr in der Gestałt des "höchsten" artifex auf, dessen Kunst-Schőpfung die "Blasen aus Glas, der Erde Azure umfassend, / regenbogenhaft spielend und blau, Kuppel ätherischer Paläste des Glücks" (Stavitelé chrámu / Baumeister am Tempel, V. 64-65; "bubliny, vylouklé ze skia, blankyty zemé objimajici, I hrajici duchou a modrem, kopule eterných palacu stesti" darstellen) sind, sondern in der 'Verkleidung' eines einfactien "Gărtners", "Pforpfenden" oder "Vogelstellers" ("ptácník", Vedra I Gluthitzen, V. 44). Doch bereits in Ranni modlitba (Das Morgengebet; gnostisch-eschatologisches Modell, SZ) wird der "Höchste" als "Majitel roli a stád" (V. 17: "Besitzer der Fluren und Herde") apostrophiert. Ein weiteres Indiz für Bỉezinas Rückgriff auf die konkrete, gnostisch-mythologische Bildlichkeit. 
navracejici I....,$V$. 12-13; "Pulsschläge des Blutes, verjüngende! / Stets aufs neue zurückkehrende /..." ) mit ihren "Stürmen der Leidenschaften" ("vichřice vášni", V. 15), wird durch die (apollinische) solare eiaculatio (zugleich wohl auch als solare Emanation) 'befruchtet' und komplementiert. Die maskuline creatio "von oben" vollzieht sich als

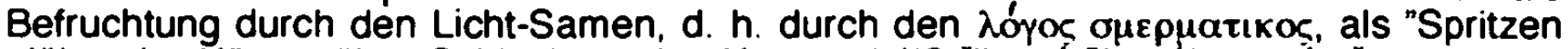
glühender Körner über Schluchten des Kosmos" ("Strỉiknutí Žhavéhp zrní přes propasti kosmu“, V.19), den die "säende Hand" - eine andere 'Geste' der "schöpferischen Hand des Meisters" (V. 7-8) - ausstreut ("Rozkoši ruky, polouvĩené, zasévajíc", V. 18). 573

Die Symbolik des lebenspendenden Wassers, das (als dionysisches 574 Element) der "Erd-Mutter" entstammt und das 'Strömen' des Lebens bedeutet, wird in der vierten Textsequenz (V. 21-29) aktualisiert. Auch hier kommt die Tendenz zur Integration und Versöhnung deutlich zur Geltung. Der "extatische Fluß" ("reka extatická", V. 22; im Tchechischen ein Femininum) stürzt sich "in die offenen Arme" des Ozeans ("jeż letí v rozpjatou náruč / mởe tvého", V. 23-24). Eine Art Synthese stellen die "Golfischen Ströme der Liebe" (IV. 9; "Golfické proudy lásky!") dar, die - als Metapher der im ruhigen, permanenten Fließen begriffenen Welt - nicht nur den "extatischen Fluß ${ }^{n}$ (V. 22), sondern auch die "kristallenen Flotten / toter Welten" (V. 27-28; "krystalná lodstva / mrtvých světü") integrieren, um sie, die "zersplitterten Eise" aus "arktischen Höhen" (V. 25-26) in ihrer 'vitalisierenden' Wärme ("Golfische Ströme", 29) der Liebe (wie im "[Frucht-] Wasser" der Mutter-Erde) zu re-generieren.

Diese (tellurisch-)vitalen Prozesse in der Sphäre der Lebenswelt gehen den 'mentalen' Prozessen in der Sphäre des Geistes, des "geistigen kóouoc" ("Dušsevni kosmy!", V. 36), unmittelbar voraus. Sie erscheinen als Voraussetzung für die Fortsetzung dieser Prozesse in der ('geahnten') idealen Sphäre der Werte, der Wahrheiten und der Gerechtigkeit ("viry spravedlnosti!", V. 43; "Wirbel der Gerechtigkeit!"), kurzum in der Sphäre des Geistes. Das Motiv der apollinischen Zeugung "von oben" mit dem Licht-Samen und den "glühenden Körnern" ("Sriknut́ žhavého zrni"; III, 2V. 16-19), wird in der fünften Textsequenz (V. 30) im Motiv der "heiligen Ernten des Wortes" (V, 1) und im Motiv der "Ströme von Ähren" (V. 32; "veletok klasü") weiter entfaltet. Das Resultat dieser Zeugung durch die eiaculatio der "glühenden Körner" (V. 19) stellen die "Svaté Żně Slova!" (V. 30; "Heilige Ernten des Wortes ${ }^{u}$ ) dar. Es ist nicht zu übersehen, daß in der ersten Textsequenz die Schöpfung des "Meisters" direkt als manuales Gestalten und Formen der kosmischen Ur-Masse semantisiert wird ("prii každém horénném pohybu ruky / mistra"; V. 7-8), während in der fünften Textsequenz das 'Handwerkliche' durch das Verbale (bzw. Mentale), durch das "heilige Wort", substituiert wird. Das Modell des "geistigen Kosmos" ist als solarer Komos "schöpferischer Sonnen" (V. 40; "tvürčich slunci") und zugleich als "Land des Träumens"

573 Psychologisch interpretient, stellt hier die maskulin-apollinische "Hand" ("ruka" / membrum) ein Analogon zu membrum virilis, das den Licht-Samen in die vaginalen "Schluchten" ("propasti", V. 19) des Kosmos eiakuliert ("Striknuti żhavého zmi pres propasti kosmu, / Mléčné dráhy!", V. 1920: "Spritzen glühender Körner über Schluchten des Kosmos! / Milchstraßen!"). Aus der Samenflüssigkeit der "Milchstraße" ("Mléčná dráha", V. 20) entsteht das neue Leben. Vgl. das Motiv des mystischen eiaculatio in Ranni modlitba (Das Morgengebet, SZ; Kap. 3.1.2). Diese Symbolik wurde auch in der tschechischen bildenden Kunst der zehner Jahre intensiv reflektiert, nicht zuletzt unter dem Einfluß der Lebensphilosophie von Henri Bergson, dessen L'évolution créatrice im Jahre 1907 erschien, und der deutschen Lebensphilosophie, vor allem von Hans Driesch. Man denke vor allem an die Bilder des Malers Frantisek (Frank) Kupka: Die Entstehung des Lebens (1900-1903). Der kosmische Frühling (1911-1920), Die Sctöptung (1911-1920), Die Amorpha (1912), "Die Farbige" (1919) u. a. Eines der Schlüsselmotive Kupkas abstrakten, bildnerisch-visualen Kosmogonien der zehner Jahre, stellt die (sexualisierte) kosmische 'Befruchtung' dar.

$574 \mathrm{Vgl}$. J.J. Bachofen, Die Unsterblichkeitslehre der orphischen Theologie, Gesammelte Werke, siebenter Band, Basel-Stuttgart 1958, S. $96 \mathrm{ff}$. Bachofen betont die Bipolarität des Dionysos, seinen 'Dialogismus', die starke Affinität zwischen inm und allem Weiblichen sowie seine Fähigkeit zur Trennung und Wiedertherstellung. Die dionysische Religion, die im Tellurischen (und Lunaren) verankert ist, hăngt mit dem Prinzip der Matemität eng zusammen. Die Superiorität der Weiblichkeit zählt zu den charakteristischsten Merkmalen des Dionysos. Laut Bachofen ist Dionysos vor allem der Frauen-Gott (vgl. dazu: J. J. Bachofen, Das Mutterrecht, Gesammelte Werke, dritter Band, $\S \S 109-111$, S. 585 ff.) und die dionysische 'Allbeseelung' bezeichnet er als "das Bekenntnis der Demokratie". Vgl. dazu auch: Manfred Frank, Der kommende Gott. Vorlesungen über die Neue Mythologie, FrankfurtM., 1982, S. 17 ff.. M. Frank verweist auf die Beziehung des Dionysos zum orgiastischen Kult der Erdmutter Demeter (S. 19). 
("země snění", VI, 3) und "schwimmender Garten" (V. 37; "Plujici zahrady") konnotiert. Das "Garten"-Motiv, integriert in den "geistigen Kosmos", scheint nicht nur auf den "Garten Eden", sondern auch auf die postulierte Vereinigung des (erdhaft-)Vitalen mit dem Geistigen hinzudeuten. Signifikanterweise sind diese "Gärten" ("zahrady") "vogeldurchjauchzt" (V. 37; "Śílić ptactvem"). Während die "Vögel" (V. 37) die Sphäre des Geistes (als dessen Symbol) indizieren, verweist das Partizip "silici" (wörtlich "vom Wahnsinn rasend") auf die Intensităt der Prozesse im "geistigen Kosmos". Den 'Intensitätsgrad' der (erdhaft- bzw. triebhaft-)vitalen Prozesse markieren die "Stürme der Leidenschaften" (V. 15; "vichrice váśni"), den der geistigen Prozesse hingegen die "Wirbel der Gerechtigkeit" (V. "viry spravedlnosti"). Auch im "geistigen Kosmos" herrscht ein permanentes "Werden und Erlóschen" ("zrození a hasnutü", V. 1): "Svéty zapalujíć I svèty zhasinajić" (V. 41-42; "Welten entzündend, / Welten vertöschend"). Doch auch in dieser Sphäre ist der Prozeß der Vergeistigung offensichtlich noch nicht vollendet. 575 Das Geheimnis des "n e u e n Kosmos" (V. 48), jenes ersehnten "geistigen Landes" ("duchová zemè", Ślienci I Wahnbetörte, $x, 2)$, dessen "Stevermann" ("kormidelník", ibid.), der "Einzige Mensch, der Erlöste" ("Jediný Clovę́k vykoupeny" (Silenci / Wahnbetörte, $\dot{X}, 1$ ), ungeduldig enwartet wird, bleibt auch weiterhin geheimnisumwoben, unbekannt und im "unsichtbaren, strahlenden und wartenden Grab" der "ewigen Sonne" (V. 44-50), d. $h$. in der Majestät des "Höchsten" verborgen, von ihr verhehlt. Das Motiv der "unsichtbaren Sonne" evoziert das Bild der verborgenen "Sonne, zerfinsternd im eigenen Brand" aus dem Gedicht Poledni zráni (Mittäglich Reifen, VP): "však ohnisko jeho skrývá se zrakưm: slunce, jeż setmëlo vlastní svou zárí" (V. 10; "aber sein Glutherd birgt sich den Blicken: Sie, die Sonne, zerfinsternd im eigenen Brand"). Auch in Dithyramb svëtú scheint die "unsichtbare, ewige Sonne" den menschlichen Blicken 'verborgenen', fernen und dennoch nahen Gott (und sein Reich) als Deus absconditus in maiestate zu konnotieren. Diese Verborgenheit des "Höchsten" ist jedoch sowohl in der der paulinischen als auch in der Lutherschen Theologie im Glauben an den Menschgewordenen (des "Einzigen Menschen, des Erlösten") ${ }^{576}$ erkennbar. Aber seine Ankunft liegt noch im Dunkeln verborgen und die "ewige Sonne" schweigt: "tajemství nového kosmu I skrývajíćiho / ml¿̌enlivěho" (V. 48-50; "das Geheimnis des neuen Kosmos / verbergend, / schweigsam!"). Doch eine Hoffnung gibt es: die "Neugeborenen" (V. 56; "novorozenci"), den "über Ozeane" (V. 54; "pies oceány") das "Lied der Herrin", der anima mundi, der Erd-Mutter (als tellurische Entsprechung der Regina coell) tönt, gestärkt und belebt vom Odem des "Höchsten" (auch als Metapher seiner spirituellen Liebe): "Na rtech, jeż láskou se tíesou / jak vonným vestrem / silným a oživujićm, / pỉes oceány / zni vaše píseñ, 6 paní, / novorozencủm" (V. 55-56: "Auf Lippen, die beben vor Liebe / wie im duftigen Winde, / dem starken, belebenden, / über die Ozeane / tönt euer Lied, o Herrin, I den Neugeborenen"). Einer von innen könnte doch auch der "Einzige Mensch, der Erlöste", der zukünftige Erlöser sein. Da aber seine Ankunft noch in undurchdringlicher Finsternis liegt, wird die ganze Lebenswelt $(\kappa \delta \sigma \mu \propto s)$ von diesem "Wiegenlied der Millionen" (als spiritualisierte Version des extatischen "Dithyrambus"), das verheißungsvoll das "ganze Weltall erschüttert" (V. 58; "celým vesmirem otrásajić"), 'getröstet'. In seinem "rhythmischen Takt" schaukeln die

575 Diesen Gedanken formuliert Bł̌ezina auch spăter, explizit in seinen Fragmenten: "Ale marný je ưtèk, i neviditelný svêt je ve varu a boji. Neni strašnejjứno klamu nad sebevrażdu" $(O$. Blezina, .Fragmenty", in: O. Biezina, Eseje, Olomouc 1996, S. 176; "Doch die Flucht ist vergeblich, auch die unsichtbare Welt befindet sich im Wirbel und Kampf. Es gibt keine schrectlichere Täuschung als den Selbstmord").

576 Diese Formulierung erinnert an den gnostischen Gedanken vom "erlōsten Erlöser". Diesen Terminus technicus führte Richard Reitzenstein in die Gnosisforschung ein. Er verstand darunter, daß ein Lichtwesen (Sohn Gottes oder der anthropos / "Clověk") in die Finsternis gerăt, dor' gefangengehalten wird und erst nach der Hinterlassung eines Teils seines Wesens wieder zurückkehren kann. Um den Rest seines Wesens zu er-lösen, muß der in die transzendente Sphăre gelangte 'Teil' noch einmal als "Erloser" in die Unterwelt hinabsteigen und dadurch seine uranfăngliche Ganżheit restituieren. In Nag-Hammadi-Texten oder in den sog. "Oden Salomos", lassen sich zahlreiche Stellen finden, die einen engen Zusammenhang zwischen Christus als "Salvator" ("Erlöser") und als "Salvandus" ("zu Erlösender") bestätigen: "Auch er (Christus) selbst, der Sohn, der zu einem Ort der Erlösung für das All gesetzt wurde, hat die Erlösung selbst auch benōtigt, indem er Mensch geworden war ... . (K. Ruddph, Die Gnosis. Wesen und Geschichte einer spätantiken Religion, Göttingen 1994, S. 141f.) 
(noch nicht erlösten) "schmerzvollen Erden" (V. 60; "bolestné zemè"), die "Wiegen577 der Geister" (V. 61, "kolébky duchü"). Es ist der harmonische und verheißungsvolle Schlaf, nach dem sich auch die "Schläfer" ( "Spici") in Se smrti hovori spici... (Mit dem Tode reden die Schläfer..., SCh) sehnen:

-Tisicileti cekali jsme ve tmè tajemstvi tvého / ukolébáni lahodou vécného rytmu v drímotu nenarozených /.../. / Ach, spáti ještè tisicileti! At' krouži světy / kolem propasti onné a padaji uzrálá zrna na klasech konstelaci / v črnou pủdu etheru tvého, $v$ záhyby tvého klina, nekonečnem rozprostłeněho!" (V. 30-31, 34-37; "Jahrtausende lang harten wir in deines Geheimnisses Dunkel, I von der Anmut des ewigen Rhythmus in den Schlummer der Ungeborenen gewiegt /.../. I Ach, Jahrtausende noch zu Schlafen! Mögen die Welten nur / kreisen um feurige Abgründe, und gereifte Körner aus den Āhren der Konstellationen fallen / in deines Äthers schwarzen Grund, in deines Schoßes Gefālte, / des durch die Unendlichkeit sich breitenden!". Übers. v. O. Pick.)

Solange der "Einzige Mensch, der Erlöste", nicht kommt, müssen die "Millionen" (V. 57) auf die ersehnte Versöhnung ("smíreni") "bange und still" warten. Das ist auch das letzte, pessimistisch-melancholische Wort des Epilog-Gedichts Cas (Die Zeit): "/.../ Cekáme stále, teskni a tiši, / na sladké usmáni smił̌eni tvẻho, skončeni dni, / zchladnuti snèni rož̌haveného, 578 na času zjasněni vỷsi, / zlomeni mystické vazby, odpuštèni, / a naše sizy, dẻšt' věcnỳ, do srdci živoucich kanou, / v krupeejich ohnẻ a touny tam páli, vzlykotem lásky tam zni". (VI. 1-6; "wir warten immer, bang und still, I aufs süße Lächeln deiner Versöhnung, der Tage Vollendung. I Verkühlen des glühenden Träumens, der Zeiten höhere Erhellung, I Sprengen der mystischen Fesseln, deine Vergebung, / und unsere Tränen, ein ewiger Regen, fallen in lebendige Herzen, / in Tropfen des Feuers und Sehnsucht brennen sie dort, im Schluchzen der Liebe verklingen sie dort". Übers. v. E. Saudek.)

Zusammenfassung: Das Hauptthema der gesamten nachdekadenten schöpferischen Entwicklung von Otokar Bïezina, die Vereinigung, Vollendung und Erfüllung der (irdischen) Zeit und das Erreichen des Eschatons, wird im letzten vollendeten Gedichtzyklus Ruce im Kode der Intensivierung aller vitalen Prozesse entfaltet. Die visuell-kognitive Dimension der im kosmogonisch-eschatologischen WeltModell (Stavitelé chrámu / Baumeister am Tempel) dargesteltten schöpferischen Prozesse wird in Ruce (Hănde) um die vital-haptische und emotionale Dimension bereichert. Als Antriebsfaktor der vitalen Prozesse wird in Ruce der 'dionysische', zur endzeitlichen Allbeseelung führende Rausch postuliert. Am Ende sollen alle vitalen Prozesse in einen gewaltigen "Dithyrambus der Welten" einmünden und in einen "Rundgesang" a II e r Herzen integriert werden. Die Integration, das "Zusammenfließen" ("sliti") "aller Millionen zu einem Einzigen Menschen, dem Erlösten" (Sílenci / Wahnbetörte), kann auch als das Konstruktionsprinzip des vitalistisch-eschatologischen Modells begriffen werden. Diese Integration, die auch die Auflösung des Individuums und der Individualität in einem kollektiven "Meer der Ungezählten" mit einbezieht, erscheint als Voraussetzung für das

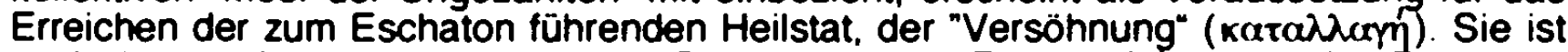
auch das vereinigende, integrierende Charisma der in Ruce entfalteten vitalen Prozesse. Das Postulat des "Zusammenfließens" zu einem "Einzigen Menschen" deutet auf die Reaktualisierung und Remythisierung des gnostischen Substrats hin, in dem die Vorstellung vom anthropos (als "Erlöser") eine dominante Rolle spielt. Die Forderung des "Zusammenfließens" resultiert $u$. a. aus der Enttäuschung vom Nichteintreten der in Stavitelé chrámu ungeduldig erwarteten endzeitlichen Vollendung der Schöpfung. In einigen Gedichten des letzten Zyklus Ruce scheint die vitale Prozessualität in inr unheilvolles Gegenteil umzuschlagen: in ominöse Erstarrung, in ontologische Krise, in Chaos und Zerfall. Daher müssen alle "schwachgewordenen", "vom Kampf gebrochenen" Hände in eine "magische Kette, die Welten umklammert" (Titelgedicht Ruce), eingefügt werden. Doch diese gewaltige Entfesselung aller vitalen Prozesse enweist sich letzten Endes nur als 'Vorstufe' auf dem Wege zur universalen Ve r g e i s ti g u ng der ganzen Lebenswelt (koouos), zur Synthese von Leben und Geist.

577 Es handelt sich offensichtlich um eine intertextuelle Allusion auf die berühmte Apostrophe der "Mutter-Erde" aus Máchas Poem Máj(Der Mai, 1836): "Ach v zemi krásnou, zemi milovanou, I kolébku mou i hrob múj, matku mou" ("Zur schönen Erde. der geliebten Erde. I meine Wiege. meine Mutter und mein Grab").

578 Der "geistige Kosmos" heißt in Dithyramb světư auch "země sněni! / Žhavými rủžemi sršici protuberance" (V. 38-39; "Welten des Träumens! / Glühende Rosen versprühende Protuberanzen"). 
7. LETZTE GEDICHTE (1901-1907)

Auflösung der poetischen Welt: Von der Pluralität

zur in sich geschlossenen Auto-Intertextualität - Das Verstummen

"Ale ł̇ivot nezưstává stát, dlữno /... j jít dál.

Mlěeni - je dalsím krokem ....".

"Aber das Leben bleibt nicht stehen, man muß/... weiter gehen.

Das Schweigen - ist der nächste Schritt...".

Gisa Picková-Saudková

Hovory s Otokarem Błezinou (Gespräche mit O. Błezina, 1929)

"Nur in der Sprache des Dichters erscheint manchmal noch

das wirkliche, mit dem Schweigen zusammenhängende Wort".

Max Picard: Die Welt des Schweigens (1948)

Nach der Herausgabe des Gedichtzyklus Ruce (Hände, 1901) verfaßte Bïezina nur noch fünfzehn Gedichte, 579 von denen dreizehn im Zeitraum vom Dezember 1901 bis April 1907 in Moderni revue580 veröffentlicht wurden. Im Jahre 1907 verstummte Bíezina als Lyriker vollständig, ein Jahr später verstummte er - allerdings nur für die Óffentlichkeit auch als Essayist.

Thematisch und motivsemantisch knüpfen die letzten Gedichte an die Paradigmatik des vitalistisch-eschatologischen Modells an. Es ist, neben der Isotopie des ("dürstenden", "gefesselten", "zermürbten", "zitternden", "sehenden" usw.) "Herzens", das hier zur Metonymie der Personen wird, vor allem die Symbolik der "schmerzvollen Erde", die in diesen Gedichten weiterentfaltet wird. Es kommen aber auch neve Bildfelder hinzu, die die poetische Welt dieser Texte modellieren: die Symbolik der "unsichtbaren Welt" und die 'Privatisierung' und 'Biographisierung' des (eigenen) symbolistischen Kosmos. Im Hinblick auf die Psycho-Logik der schöpferischen Entwicklung Bïezinas, könnte man in diesem Zusammenhang von einem Rückzug des $\mathrm{Kün} \mathrm{s}$ tl e r-Menschen Otokar Bíezina und einer Rück(-bzw. Heim-)kehr des 'p r i va te n', 'de-mythisierten' Menschen Václav Jebavý (Bïezinas bürgerlicher Name) sprechen.

Die Symbolik der "schmerzvollen Erde" ("zem bolestná) zeichnet sich durch krąsse Ambivalenz aus. Mit der ('natürtichen') Pracht der Erde 581 ("A prece jak krásná!", Zalm

579 Einige Br̈ezina-Forscher halten diese dreizehn Gedichte für einen abgeschlossenen Zyklus, der angeblich "Zeme" ("Erde") heißen sollte. Diese These vertritt vor allem Otakar Fiala (.Mlceni Otokara Bíeziny v zrcadle korespondence a hovoru I-lil", in: Listy filotogické, 66, 1939, S. 43-60, 235-251; vgl. auch Fialas Arbeit: "Studie $z$ novorišského obdobi Otokara Breziny" in: Rozpravy Ceskoslovenské akademie vẻd, Rada spolecenských vẻd, 79, Heft 9. Praha 1969). Dagegen spricht die Tatsache, daß Br̉ezina die letzten Gedichte nie zu einem, für sein dichterisches CEuvre doch so charakteristischen Zyklus komponierte; sie erschienen erst postum (abgesehen von der exklusiven, handgeschriebenen Ausgabe aus dem Jahre 1926 in 24 Exemplaren nur für den engsten Freundeskreis) in der Gesamtausgabe seines Werkes (Bd. I, 1933). Fialas Hypothese relativiert auch die Entdeckung von zwei Gedichten $(1906,1907)$ im Nachlaß des Dichters, die erst vier Jahrzehnte nach seinem Tode veröffentlicht wurden. Diese Gedichte werfen ein interessantes Licht auf Br̈ezinas 'rätselhaftes' Verstummen.

580 Eine einzige Ausnahme stellt das Gedicht Pisen̉ o věcném młádi (Das Lied von der ewigen Jugend) dar, das in der Revue Srdce I, Nr. 7, Mărz 1902 abgedruckt wurde.

581 Nach Petr Holmans Frequenzwörterbuch des lyrischen Werkes von O. Br̈ezina (KölnWeimar-Wien 1993) zählt das Lexem "zemé" ("Erde") zu den frequentiertesten Lexemen der letzten Gedichte. Im Hinblick auf ihre Verssemantik kann man von einem Rückgriff auf die 'alten' versformen des dekadenten Symbolismus (TD) sprechen. Wie M. Cervenka nachweist, wird in den letzten Gedichten der "gelockerte Vers" (vers liberé) wiederaufgenommen, der Z. B. im Langgedicht Nepremozitelni rostem... I (Unüberwindlich wachsen wir...) deutlich auf den klassischen Blankvers (Cervenka erwăhnt in diesem Zusammenhang Miltons Paradise lost) alludiert. Kennzeichnend ist auch die Aktualisierung der traditionellen strophischen Variante der 
odcházejicich pokoleni / Der Psalm der dahingehenden Generationen, V. 70; "Und dennoch ist sie so wunderschön!") kontrastiert, trotz der beinahe verzweifelt leidenschaftlichen Bejahung des Erdenlebens im Refrain dieses Gedichts ("Ach, neodejít vy trikráte Sttastni!", V. 86; "Ach, nicht fortzugehen, ihr dreimal Glücklichen!"), ihre rohe Materialität, stumpfe Rücksichtslosigkeit, Grausamkeit, und "Eifersucht auf den Geist": "Ale ona je záhadná, némá, żárlivá k duchu a krutá" (V. 64: "Doch geheimnisumwoben ist sie, stumm, auf den Geist eifersüchtig und grausam"). Daher scheint es unmöglich zu sein, die Erde als Sphäre der zukünttigen, höheren Existenz der erlösten Menschheit zu betrachten, denn auf ihr lastet der geheimnisvolle Fluch: "Nesli jsme vinu dávného kosmu? A v osudu desky / psány snad byly dẻjiny naše /..." (V. 47-48; ibid.; "Trugen wir die Schuld eines längst vergangenen Kosmos? Und auf die Tafeln / wurde vielleicht unsere Geschichte geschrieben $\left(. . .{ }^{\prime}\right)$. Die großen Hoffnungen, die das dichterische Ich in Ruce (vgl. Kap. 6.2 und 6.2.1) auf die Vergeistigung des Erdenlebens und der vitalen Prozesse setzt (Ruce, Dithyramb svëtü, Kolozpèv srda), werden in den letzten Gedichten immer deutlicher von peinigender Skepsis paralysiert, die sich schließlich zur deprimierenden Gewißheit über die Unrealisierbarkeit des Jenseitigen in der diesseitigen Welt entwickelt:

"Chudá byla zemẻ otcủ mých a tvých. A vešli v ni, / oči zastīené, jak posiové do mẻsta obleženého / a vyšli, oči zastīenē, a cestou $k$ smrti celou pỉešli ji. /... / V mrazu bolesti jak včely úlu zimniho se $k$ sobẻ tiskneme. / ve všech světech miliony bytosti, / zavěšeni v tresouci se hrozen jediný. I... I. Jako dobyvatele jsme vojska mrtvých vyslali, / aby pripravovali nám cestu ve svêtech neviditelných" (Nepremožitelni rostem... / Unüberwindlich wachsen wir..., 17-19, 31-33, 36-37; "Arm war die Erde dein und meiner Väter. Und sie gingen ein in sie, / die Augen vernangen, wie Boten in belagerte Stadt, I und kamen hervor, die Augen verhangen, und unterwegs zum Tod. schritten sie ganz hinweg über sie. I.../ Im Frost des Schmerzes wie die Bienen winterlichen Bienenstocks drücken wir uns aneinander, / in allen Welten Millionen von Wesen, / hangend in einziger zittemder Traube. I.../ Als Eroberer haben wir die Heere der Toten ausgesandt, I daß sie uns den Weg in unsichtbaren Welten vorbereiten". Übers. v. P. Eisner.)

Selbst der enthusiastische "Rundgesang der Herzen" (Kolozpëv srdci, R) schrumpft in den letzten Gedichten zum "schmerzvollen" Pulsschlag der Herzen, die "zermürbt und aufgewühlt der Pflug der Schmerzen hat!" (Gigantské stiny / Gigantische Schatten, I, 4; "srdci zdrcených a obrácených pluhem bolesti"). Damit geht eines der Hauptmerkmale dieser Gedichte einher: die Resignation, die in einen 'depressiven' Diskurs ausartet:

"Je útěchou naši, že i my slepi jak boửe jsme táhli, / ¿eho jsme nechtéli stane se, čeho jsme chtěli nedosáhli? I.. I se zemi jako s bolestnou matkou po slavnosti jsme osaméli /.../. V závisti hledime v údolí kvẻtú, kudy jsme bloudili v bolu, I na cemé mucirny dilen, gehenny výhni, pohỉebištè svých dolü, I na svá mẻsta nedostavěná, popluži opuštěná, / pole, z pralesủ od otcú vymýcená, západu krvi potopená ..." (Żalm odcházejicích pokoleni III I Der Psalm der dahingehenden Generationen III. V. 7-10; "Ist es unser Trost, daß auch wir. Blinden, zogen wie ein Gewitter herauf, I was wir nicht wollten wird passieren, was wir wollten, erreichten wir nicht? /.../ mit der Erde, wie mit der Schmerzensmutter, vereinsamten wir nach dem Fest /.../. Neidisch schauen wir in das Blütental. wo wir im Schmerz umherirten, / in schwarze Folterkammer der Werkstätte, in die Gehennen voller Esse, auf die Grăberfelder unserer Bergwerke, I auf unsere unvollendeten Stădte. verlassenen Landgüter, / Felder, aus Urwäldern von unseren Vätern gerodet, im Blut des Sonnenuntergangs versunken..."). "Kłižovatkou všech světủ je zem, vichřice zemi hr̉mi nedohlednem, bolesti duši je domov náš hlubši neż kosmos, tisickrát vyšši snem" ( Na zemi rưže nepiestávaji hởet / Auf der Erde Rosen hören nimmer auf zu brennen. IV, 1-2: "Wegkreuzung aller Welten ist Erde. Sturmwind der Erden donnert durch unabsehbaren Raum, I und den Schmerz der Seelen ist unsere Heimat tiefer als der Kosmos, tausendmal schöner um unseren Traum".)

Die "schmerzvolle Erde", die zwar auch in den letzten Gedichten den Schauplatz mannigfaltiger Lebenserscheinungen- und Prozesse darstellt, erscheint nun wie von einer unheimlichen "unsichtbaren Welt" umgeben. Die "unsichtbare Welt", ein

Gedichte (meist in vierzeilig atternierenden, gereimten Strophen) mit regelmāßigem Reim, ferner der Rückgriff auf der Poetik des Liedes (Piseñ o věčném mládi / Das Lied von der ewigen Jugend, Zpivala / Sie sang. Na zemi rúze neprestávaji hớet / Auf der Erde Rosen hören nimmer auf zu brennen. Tisice srdci pélo v srdci tvém I Tausende Herzen sangen in Deinem Herzen) und die Wiederaufnahme der in Tajemné dálky vorherrschenden Singular-Form, die den Redemodus einiger Gedichte prägt (Cižzba / Der Vogelfang. Tisice srdci pẻlo v srdci tvém). Vgl. M. Cervenka, $Z$ vecerni skoly versologie II. Praha 1991, S. 67-69. 
'Negativ' der "Erde" ("zemë"), ist ein Teil eines höheren "Geisterkosmos" ("vesmír duchü"), in dem die "verborgene [Heils-]Geschichte" ("skryté dëjiny") des menschlichen Geschlechts fortgesetzt wird. Das Motiv der "geistigen Kosmen" ("duševni kosmy", Dithyramb svêtú I Dithyrambus der Welten, V. 36) kommt bereits im Zyklus Ruce vor. In den letzten Gedichten aber verwandelt sich der "g e istige Kosmos" in einen "G e i s te r kosmos" ("vesmir duchü"; Na zemi rüže... / Auf der Érde Rosen..., III, 1). Der 'vergeistigte' Kosmos pervertiert zum Kosmos der Geister, Phantome, Spukwesen und gespenstigen "gigantischen Schatten" ("gigantské stiny"). Es sind offensichtlich nicht die "höheren Wesen" ("bytosti vyšsil"; Ruce 9 Hände, V. 65), die die "magische Händenkette Ungezählter" ("magický retéz rukou nescisiných", V. 60) auffangen und emporheben. sondern furchterregende "Heere der Toten" ("vojska mitvych"; Nepremožitelni rostem... I Unüberwindlich wachsen wir.., V. 36), "Phantome der Mitternacht" ("fantomy púlnocni", ibid., V. 60), unsichtbare "Verlorene" ("Ztraceni", gleichnamiges Gedicht) oder "gigantische Schatten" ("gigantské stíny").

"Gigantskẻ stiny, jdete národy a zrni svaté vzpoury metáte /.../ a klasy vitězstvi, jež požati má kdysi plémé tajemné /.../ vy, mrtvi, svỷmi prsty ješté drtit budete/.../. Vふ̌ak vaše duše pluji smrti tmou jak mnożstvim obsazené lodẻ válečnén (Gigantské stíny / Gigantische Schatten, I, 3, V, 2-3. VI, 1: "Schatten gigantisch, schreitend völkerhin, ihr schleudert heiliger Empörung Korn /... / und Siegesähren, die einst schneiden soll geheimnisvoll Geschlecht, / werdet ihr Toten noch mit euren Fingern malmen I...l. Doch eure Seelen segein durch des Todes Dunkel, Kriegsschiffen dicht bemannten gleich:. Übers. v. O. Pick). "Jako dobyvatele jsme vojska mrtvých vyslali, / aby pripravovali nám cestu ve světech neviditelných" (Nepremožitelní rostem... I Unüberwindlich wachsen wir..., V. 36-37; "Als Eroberer haben wir die Heere der Toten ausgesandt, I daß sie uns den Weg in unsichtbaren Welten vorbereiten"). "Do Žáru léta našeho ze zahrad smrti dýse mráz, I... I a mnozi kteři už mrtvi jsou, joou ještě jak živi vedle nás" (Ztraceni / Verlorenen, I, 2; "In die Glut unseres Sommers haucht Frost aus den Gărten des Todes, / und viele, die bereits tot sind, schreiten wie lebendig neben uns").

Die signifikanten Toponyme der "unsichtbaren Welt", des "Geisterkosmos" ("kosmos duchü", heißen "verwunschene Katakomben" ("katakomby zakleté"; Hlubiny bolesti / Die Tiefen des Schmerzes, IV, 2), "Nester der Geister im schwarzen Forst der Urnach" ("Hnizda duchú v Cerném hvozdu pranoci"; Nedèle svatodušni / Der Pfingstsonntag, V. 98), "Landschaften der Hoffnungslosigkeit" ("krajiny beznadēji"; Na zemi rủze... / Aữ der Erde Rosen..., III, 1) oder "unsichtbarer Eichenwald" ("neviditelná doubrava", Ztraceni IVerlorene, V, 1). Die ganze Lebenswelt scheint sich zu de-materialisieren, sich gleichsam aufzulösen oder 'verflüchtigen', de-semiotisieren, ihre Evidenz und ontologische 'Festigkeit' zu verlieren. Die "unsichtbare Welt" ("neviditelný svët") ist offensichtlich nicht identisch mit der "anderen Welt" ("jiný svět", Modlitba vecerni / Das Abendgebet, TD) aus der Schaffensphase des dekadenten Symbolismus. Der wesentlichste Unterschied gründet darin, daß der Sinn der "unsichtbaren Welt" genauso verborgen, unverständlich, unsichtbar' oder unvorstellbar bleibt. Nicht von ungefähr heißt die metaphorische Gestalt der letzten Gedichte "ztraceni" ("Verlorene"). Die Toten mischen sich unter die Lebenden, es scheint überhaupt unsicher zu sein, ob die Lebenden noch lebendig oder bereits nur phantomhafte Schattenwesen sind, als müßten jetzt sogar Phantome und Revenanten mithelfen, den Raum gegen die Expansion des "geheimnisvollen Grauens" ("tajemná hrüza", Ztraceni / Verlorene, II, 4) auszufüllen:

"Proti vưli svẻ nám slouži úzkost démonú, fantomy pủlnočni, / tragičti stavitelé silenstvi" (Nepremožitelni rostem... / Unüberwindlich wachsen wir..., V. 60-61; "Gegen ihren Willen dient uns die Beklommenheit der Dämonen. Phantome der Mitternacht, / die tragischen Baumeister des Irrsinns"). "Jak dlouho jsme słi? Ci jsme zemreli a tisickrát se znovu zrodili? Byl każdý krok nás jako płechod $z$ véku do vẻku?" (Nedẻle svatodušni / Der Pfingstsonntag, V. 71-73; "Wie lange gingen wir? Oder starben wir hin und wurden tausendmal wiedergeboren? War jeder unser Schritt wie ein Übergang von einem Zeitalter in das andere? $) ; " / . . /$ do jejich duši piá / skrytého Żiti druhého halucinace zlá" (Ztracení / Verlorene, III, 3-4. " $/ . . /$ in ihren Seelen lodert / des verborgenen anderen Lebens böse Halluzination").

Mit der Dematerialisierung und Desontologisierung der phänomenalen Welt korreliert ihre 'Stimmlosigkeit', 'Apophatik, Unhörbarkeit' und inr ominöses Schweigen:

"/.../ do noci micenlivých hvézd /... (Zpivala / Sie sang, I, 7; "in verschwiegener Sterne Nacht). "Cizi je tvá łeč a mlŁ̌eni jak bojišté / leži mezi rodem tvým a mým" (Nepremožitelni rostem .../ Unüberwindlich wachsen wir..., V. 11-12; "Fremd ist deine Sprache und Schweigen wie ein Schlachtfeld / liegt zwischen mein und deinem Geschlecht"). "Hluboko pod námi jsou zemské zahrady a všechny utichly" (Nedẻle svatodušni / Der Pfingstsonntag. "Tief unter uns liegen die 
irdischen Gärten und alle sind still geworden"). "Jak padáni sněhu jest jejich mičeni a zraky teskné jsou, / zrcadla ledu utuhlá nad mrtvou hladinou bezhlesou" (Ztracení / Verlorene, II, 1-2; "Wie der Schneefall ist ihr Schweigen und Blicke voller Wehmut; / Spiegel aus Eis, erstart über der toten, stimmlosen Wasserfläche"). "Sla životem tvỳm smrt a mlčenimi vládla" (Tisice srdci.../ Tausende Herzen ..., I, 1; "Schritt der Tod durch dein Leben und herrschte durch das Schweigen").

Auch die divinatorischen Visionen bzw. Auditionen der "Propheten", der "Wachenden" (vigiles) oder der "Baumeister" pervertieren zu Halluzinationen und Akusionen, zu "verborgenen Bildern" (Hlubiny bolesti / Die Tiefen des Schmerzes, V, 1; "Je skryt nám obraz vảs"), zum "Flüstern wie im Traum" (Zpivala / Sie sang, II, 4; "§epot ze snèni"), zum "Schauen ins Unsichtbare" (Zalm... I Der Psalm..., V. 23; "zraky, jež patfily v neviditelné") usw. Und das prophetische, visionäre "Schauen" des "ewigen Morgens", des kommenden "neuen Menschen", schlägt um ins (profane) "S t a u n e n " ("úzas"):

$\%$ /... / rány / za stěnou kamennou v úzase bolestném jsme slycchali" (Hlubiny bolesti I Die Tiefen des Schmerzes, III, 4; \%.../ Schläge / hinter einer Steinwand vernahmen wir im schmerzvollen Staunen"). ".../ a svati, v závrati úžasu svého /... (Na zemi nuże... I Auf der Erde Rosen ..., V, 3; $" / . . /$ und Heilige, im Taumel ihres Staunens /... $r$ ). "Miliony zrakú, rozeviených úżasem, $v$ tajemstvi zemẽ hledime" (Nepremožitelni rostem... / Unüberwindlich wachsen wir..., V. 72; "Mit Millionen von Blicken, die weitaufgetan sind vor Staunen, sehen wir in das Geheimnis der Erde"). "Jak rozsevači użasli jdem celou zemi Čověka" (Neděle svatodušni / Der Pfingstsonntag. V. 75; "Wie erstaunten Sämänner schreiten wir durch die ganze Menschenerde").

Aber trotz der Skepsis, Depressivität und Hoffnungslosigkeit ("Krajiny beznaději“, $\mathrm{Na}$ zemi rủže... I Auf der Erde Rosen..., III, 1; "Landstriche von Hoffnungslosigkeiten") hört das dichterische Ich nicht auf, an die Macht des entfachten Herzens - cor ardens - zu glauben. Das Herz wird nun zum 'Fokus' der Bewegtheit und des Strebens des wollenden Ich, zum Organ der e m o ti o n e l l e n Erkenntnis; es scheint sogar, daß die in Hudba slepcú (Musik der Blinden, R) erblindeten oculi cordis kraft der Liebe wieder sehen: "Hluboká je noc, však milujíci vidí srdcem svým" (Nepiemoźitelni rostem ...' Unüberwindlich wachsen wir..., letzte Verszeile; "Tief ist die Nacht, doch der Liebende sieht mit dem Herzen sein“). Bis auf eine einzige Ausnahme (Ztraceni / Verlorene) wird in jedem der letzten fünfzehn Gedichte das "Herz" ("srdce") apostrophiert. In Nẻdéle svatodušni (Der Pfingstsonntag) heißt es:

"A tepot srdce našeho zem celou prostoupil /.../. Vstal v milionech bratfí Clověk tajemný, I na kouli zemé vztyčen, celo mezi hvézdami, / a srdce jeho, plamen rozżatý na żáru Srdce věčného, I do kosmu duchủ svitilo". (V. 62, 87-90; "Und der Pulsschlag unseres Herzens durchdrang die ganze Erde /.../. Inmitten von Millionen erstand der geheimnisvolle Mensch, / emporgereckt auf der Erdkugel, / die Stirn zwischen Sternen, / und sein Herz, eine Flamme entfacht an der Glut des ewigen Herzens, 582 / leuchtete in den Kosmos der Geister"). Eine symbolische Botschaft scheint auch der vielsagende Titel des letzten veröffentlichten Gedichts Tisice srdci pẻlo v srdci tvém (Tausede Herzen sangen in Deinem Herzen, 1907) zu 'kryptieren'. Das Herz ist die Sphäre des Innern, des fortdauernden Lebens; in bezug auf die ambivalente Semantik der letzten Gedichte wird es aber auch zum Topos des Schmerzes und der Verzweiflung. der Liebe und des Erkennens:583

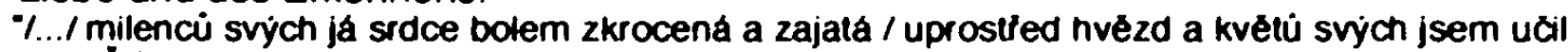
zpivati" (Cižba / Der Vogelfang, V, 3-4; "meiner Liebenden Herzen, vom Schmerz gezähmt und gefesselt / lehrte ich inmitten meiner Sterne und Blüten singen"). "/.../ srdci zdrcených a obrácených pluhem bolesti!" (Gigantské stiny / Gigantische Schatten, I, 4; "/../ Herzen, die zermürbt und aufgewühlt der Pflug der Schmerzen hat!"). "Na zemi rủze nepíestávaji hơet, pod zemi prameny hrát, / v milencủ srdce ze slunce jiskry se ţ̉ast /... I ( Na zemi ruže... I Aư der Erde Rosen.... V. 1-2; "Auf der Erde Rosen hören nimmer auf zu brennen, Quellen zu spielen im

582 Vgl. hierzu: "Denn Gott, der sprach: Licht soll aus der Finsternis hervorleuchten, der hat einen hellen Schein in unsere Herzen gegeben, daß durch uns entstünde die Erleuchtung zur Erkenntnis der Herrlichkeit Gottes in dem Angesicht Jesu Christi" (2. Korinther 4, 6). Vgl. auch Röm 5, 5.

583 An dieser Stelle erinnere ich noch einmal an Pascals "Vernuntt des Herzens": "Le coeur a ses raisons, que la raison ne connait point; ou le sait en mille choses" [277). ("Das Herz hat seine Grūnde, die die Vernunft nicht kennt, das erfährt man in tausend Fällen"). "C'est le coeur qui sent Dieu, et non la raison; voilà $œ$ que c'est que la foi: Dieu sensible au cœur, non à la raison" [278]. ("Es ist das Herz, das Gott spürt, und nicht die Vernunft. Das ist der Glaube: Gott spürbar im Herzen und nicht in der Vernunft'). Vgl. B. Pascal, Pensées IV, hrsg. Léon Brunschvicg, Paris 1904. Nachdruck, Vaduz-Lichtenstein 1966. 
Erdengrund, / in die Herzen der Liebenden Sonnentunken zu zittern /... $/$ ). "A srdce dychtivê jak vir na mơ̌i světla rozkroužit, / všech srdci tepot, stržený, v hloub jeho rytmu pohroužit" (VŠe zachvátut... Alles ergreifen..., V, 1-2; "Und das dürstende Herz wie einen Strudel auf dem Meere des Lichtes zum Kreisen zu bringen, I den hingerissenen Pulsschlag aller Herzen in die Tiefe seines Rhythmus zu tauchen").

Die Idee der Vergeistigung und "Befreiung Aller" sowie das 'Projekt' der angestrebten Vereinigung der Menschheit zu einer höheren Existenz "durch machtvolle Erdenschau und durch die Einsicht in die Wirklichkeit" ("mocným viděním zemè a skutečnosti I... $r$. Zasvěceni Żivota / Die Weihe durchs Leben; Essay, 1902) gibt Bïezina nicht auf; er thematisiert und 'konzeptualisiert' sie auch nach seinem Verstummen als Dichter, in der fiktionalen Erzählkunst: im Essay, in der Korrespondenz und in den Gesprächen.

Mit der Tendenz zur Auflösung der eigenen (mytho-)poetischen Welt geht Hand in Hand die Tendenz zur 'Privatisierung' des (mytho-)poetischen Symbol-Kosmos; hinter seinen Symbolen verbergen sich jetzt auch konkrete 'Lebensfakten' (Zpivala / Sie sang, Za v'echno diky ... I Danke für alles...). Die Gedichte Zpivala, Tisíce srdci pélo v sroci tvém (Tausende Herzen sangen in deinem Herzen) und Zalm odcházejicich pokoleni III (Der Psalm der dahingehenden Generationen III) entstanden unter dem schmerzvollen Eindruck des frühzeitigen Dahinscheidens eines Freundes von Brezina:584 "Cí ruka

584 Gemeint ist Dr. Karel Kłivy (1866-1902), der Arzt in Nová Řiše (Neureisch), wo Błezina die Jahre 1888-1901 verbrachte. Die Kontakte waren so eng, daß Biezina fast zur Familie Krivýs gehörte, die inn auch materiell unterstūtzte. Kłivý starb jedoch im Oktober 1902 an Typhus. Sein Tod war ein schwerer Schock für Błezina: “A na konec zprávu, která vlastné zni v celém tomto

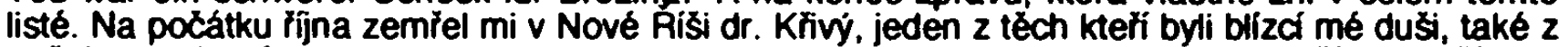
našeho duchového rodu, a jeho odchodem stala se samota kolem mne jesté tišsí a hlubšs" (O. Bỉezina an Anna Pammrová, Dezember 1902, in: Dopisy O. B. Anné Pammrová I, Praha 1931, S. 207: "Und zum Schluß noch eine Nachricht, die eigentfich in diesem ganzen Brief tönt. Anfangs Oktober erstarb in Nová Ríse Dr. Kłrivý, einer von denen, die meiner Seele sehr nahe standen. auch einer aus unserem geistigen Geschlecht, und durch sein Dahingehen ist die Einsamkeit um mich herum noch stiller und tiefer geworden"). Diese konkrete Tragödie bildet, laut O. Fiala, den 'Subtext' der oben erwăhnten Gedichte. Otakar Fiala, .Studie 2 novorišského obdobi Otokara Błeziny", in: Rozpravy Ceskostovenské akademie vêd, łada spolecenských véd, Jhg. 79, Heft 9 , Praha 1969. Fiala untersucht textologisch vor allem das Gedicht Zpivala (Sie sang) und seine Varianten und interpretiert es auch ausführtich und einfallsreich. Fialas Untersuchung zeigt, wie die letzten Gedichte von Indizien auf ganz konkrete Situationen und Ereignisse aus Brezinas Leben durchsetzt sind. AufschluBreich ist seine Hervorhebung der sinnkonstitutiven Rolle der intertextuellen Referenzen im Bedeutungsaufbau von Zpivala auf Máchas Poem Máj (1836). Es ist die Substitution der sensoralen Eindrücke durch die akustischen (II. Strophe und der zweite Gesang von Máj), die das Fließen der (absoluten) Zeit symbolisieren; in Máj durch das Fallen der Tropfen aus dem Kerkergewolbe, in Zpivala durch die Schlăge des Herzens, in denen die Axthiebe widerhallen: "Ozvěnou krokủ ztracených jsou mého srdce údery, I v horečném spéchu nárazy dł̉evorubcovy sekery / a mezi ptáky znêmlými, $v$ kłidel úzkostném sevelu / dohìméni dávných výstỉelú nad nehybnými jezery" (Zplvala / Sie sang, II, 5-8; "Die Schläge meines Herzens sind ein Widerhall verlorner Schritte, / die Hiebe einer Fällaxt, wenn sie fiebrig niedergehn, / im angstertültten Flügelwwispern, in verstummter Vögel Mitte: / der Nachhall femer Schưsse über unbewegten Seen". Übers. v. Uwe Grüning). Femer ist es auch die Konstellation der handelnden Subjekte. Sowohl im ersten Máj-Gesang als auch in der ersten Strophe von Zpivala 'verwickeln' sich zwei Menschen in eine Liebestragödie mit todlichem Ausgang, der die Liebenden für immer in dieser Welt - trennt. Zum Schluß der beiden Texte tauchit noch ein drittes Subjekt auf, das lyrische Ich, das durch seine Empathie des Schmerzes diese Tragödie quasi miterlebt. Der wichtigste Unterschied gründet darin, daß Zpívala als ein Monolog der vereinsamten Heldin strukturiert ist. Die von Fiala festgestellten Divergenzen, kann man (im AnschluB an A. A. HansenLōve, Der russische Symbolismus, Bd. II, Lebenssymbolik, Wien 1984 [Typoskript], S. 764 ff.) als Simultaneitāt von Symbol und Gegensymbol. Wert und Gegenwert usw., spezifizieren. Es handelt sich um ein charakteristisches Merkmal der letzten Gedichte von Biezina. In Zpivala sind das die Polarităten von Leben und Tod, Tod $x$ (ewiges) Leben, Liebes-Glück $\times$ Schmerz der Trennung $x$ Verheißung künftigen Wiedersehens' usw.: "smich dívek sladký jest, zemdlené srdce touži spát 1.... U nohou mistru Źáci sedéli; jich odpovédi soucitné / pro bolest moji ani slova nemély (III, 4, 7. 8: "Süß ist das Mådchenlachen, doch das müde Herz sehnt sich nach dem Schlaf /.../. Und die mitfühlenden Antworten der Schüler, um des Meisters Fuß geeint, / fanden kein Wort doch für mein Leid"). Laut A. A. Hansen-Löve dient diese symbolistische Ambivalenz der Rettung des myth(opoet)ischen Symbolkosmos, indem jedem "positiven", "abstrakten" usw. Symbol ein "niederes", konkretes Gegensymbol zugeordnet wird (in Zpivala z. B. das "Lachen" des naiven Lebensoptimismus + die mittühlende aber gleichzeitig schweigede philosophische Distanz). Im 
strašná nás trhá jak plevel ze záhonů / jediným stisknutim po všech pevninách zemę ze stredu milionü" (Zalm...III, V. 1-2; "Wessen furchtbare Hand reißt uns wie Unkraut aus den Beeten / mit einem Druck über alle Kontinente der Erde aus der Mitte von Millionen?"). Im aus der literarischen Hinterlassenschaft Biezinas herausgegebenen (1970) Gedicht Za v'sechno diky (Danke für alles..., 1906), 585 tritt die Tendenz zur 'Privatisierung', ja sogar 'Biographisierung' der poetischen Welt bereits deutlich zutage. Das große Thema der eschatologischen Existenz schrumpft hier zum 'profanen' Thema der (unerfüllten) alltäglichen Existenz in der Form einer (auto-)biographischen 'Rekapitulation' Der Traum von "erhabenem Wahnsinn der Heroismen" ("vznešené śilenství heroismü", Vitáme jaro! I Wir grüßen den Frühling!, SCh, III, 4) kippt um in Enttäuschung, Depression und Resignation:

"Za všechno diky, Tajupıný: / Za bolest našeho dětstvi, za sladký smich a rozkoš /.../. Polibky

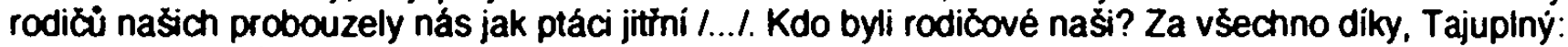
I.../ Było sladké učiti se jazyku bratrí. /.../ Nikdo od nás neodešel prílišs smuten. / Nikdy jsme neodmitli bázlivy úsmèv šeptajici o usmifieni. I... I láska $\mathrm{k}$ nám prišla - pozdè. I Jak Żalovati? I Posledni dar dal jsi bolesti naši - ml¿̌eni svoje. / V̌̌echny hlasy pohr̉bilo: /.../ i hlas pochybnosti za noci, / kdyż jako zuby v šileném smichu / jiskï se hvězdy / a nicota zdá se jedinou pravdou / ve

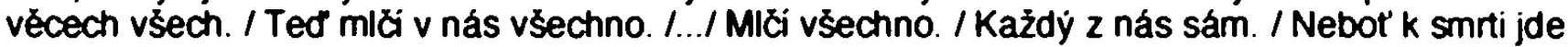
każdý sám I... . (V. 5-6, 21, 26-27, 42, 45-46, 49-53, 57-61, 69-71: "Danke für alles, Geheimnisvoller: / Für das Leid unserer Kindheit, für das süße Lachen und die Wonne /.../. Die Küsse unserer Ettern weckten uns wie die Vögel der Morgendämmerung I... . Wer waren unsere Ettern? / Danke für alles, Geheimnisvoller: /... / Süß war es die Sprachen der Brüder zu lernen. I.../ Niemand ging allzu traurig weg von uns. / Niemals lehnten wir ängsttiches Lächeln ab. das um Versöhnung flüsterte. I.../ Auch die Liebe kam zu uns - zu spät. / Wie könnte man klagen? / Die letzte Gabe gabst du unserem Leid - dein Schweigen. / Alle Stimmen begrub es: /.../ auch die Stimme des Zweifels in der Nacht, / wenn die Sterne, wie Zähne im irrsinnigen Lachen funken I und die Nichtigkeit die einzige Wahrheit / in allen Dingen zu sein scheint. / Jetzt schweigt alles in uns. I.../ Alles schweigt. / Jeder von uns allein. / Denn zum Tode geht jeder allein /... $/$ ).

Das Verstummen des Dichters, das zahlreiche Spekulationen auslöste, scheint in diesem Gedicht bereits 'vorprogrammiert' zu sein. Die These, daß das 'rätselhafte' Verstummen zur Bỉezinas Autostilisierung gehörte, klingt zwar plausibel, 586 zur Erklärung

Endeffekt führt diese relativierende Ambivalenz zu einer "Dynamisierung permanenter De- und Revaluierung, De-und Resymbolisierung" (A. A. Mansen-LOve, ibid. S. 766). Natürtich wird diese Simultaneitât in den Gedichten Błezinas nicht so radikal realisiert. wie in den Gedichten der Postsymbolisten der zehner Jahre (Gellner, Toman. Houdek, Srámek), die die Grenze zwischen 'hohem' und 'niederem' Stil absichtlich und konsequent annulieren.

585 Auf die Frage, warum Bỉezina die letzten zwei Gedichte - Za všechno diky... (Danke für alles...) und Návrat (Die Heimkehn) - in die blbliophile Ausgabe seiner letzten Gedichttexte (1926) nicht aufgenommen hatte, werde ich noch eingehen. Lange Zeit hielt man Tisice srdci pello v srdci tuém (Tausene Herzen sangen in deinem Herzen) für Bỉezinas letztes Gedicht. Seine eingehende Interpretation präsentiert O. Králík in: Otokar Brezina, Praha 1948, S. 435-443. Die oben erwähnte Simultaneitát von Symbol und Gegensymbol. Welt und Gegenwett. Wert und Gegenwert usw. durchdringt auch Tisice srdci... . O. Králik verweist in diesem Zusammenhang auf "parataktisches Zusammenfügen von Vorstellungen, die sich gegenseitig nahezu ausschließen" ("parataktické slučováni piedstav, které se témér vylučuji", ibid. S. 440)

586 O. Králik, Otokar Biezina, Praha 1948. S. 441ff. Zu dieser Erklärung hat in hohem Maße Biezina selbst beigetragen, indem er in seiner Korrespondez aus dieser Zeit (1903-1907) und in den Gesprächen mit seinen Freunden betonte, Gott habe inm ein Zeichen gegeben, er solle rechtzeitig verstummen und sein Werk nicht zermalmen (Emilie Lakomá, Úlomky hovorú Otokara Bíeziny, Brno 1992, S. 405). E. Chalupný (Dopisy a výroky Otokara Bíeziny. Praha 1931, S. 116) sieht die Ursache seines Verstummens in der Mißgunst der Kritik, die 1903 Birezinas Essays Hudba pramenú (Musik der Quellen, 1903) ablehnte. Die bisher plausibelste Erklärung liefert M. Cervenka (Z vecerni školy versologie II. Praha 1991, S. 69; vgl. auch, M. Cervenka. Slovnik básnickych knih, [Stichwort: Ruce]. hrsg. v. M. C. et al. Praha 1990, S. 253), der eine enge, ja untrennbare Verbindung der Poetik von Biezina mit der Werthierarchie des Symbolismus in seiner Kulminationsphase (in der tschechischen Literatur um 1900) betont. Die Integration neuer Motive der alltäglichen Realität, die das lyrische Werk $K$. Tomans, VI. Houdeks, F. Śrámeks oder F. Gellners kennzeichnet, und die zur radikalen Umorientierung zu neuen Versformen und Themen führen müßte, wäre, laut M. Cervenka, für Bïezina offensichttich undenkbar. Nach 1908 feilte Bỉezina unermüdlich an seinen Essays, deren Veröffentlichung er damals, wie die Korrespondenz beweist, nicht für ausgeschlossen hiett. Einer von diesen Essays, Stavba ve výsi (Bau in der 
der wahren Ursache von Bïezinas Vestummen greift sie allerdings zu kurz. Die in den letzten Gedichten auffallende 'Multiplikation' von auto-intertextuellen Referenzen, die eigentlich (nur noch) als quasi autoreferentielle und sich wiederholende (Auto-)Zitate fungieren,587 verrät die Tendenz zur 'Reduktion' dieser letzten Gedichte auf 'geschlossene' Texte, in denen die auto-intertextuellen Referenzen wie in einem circulus vitiosus kreisen.

Ein Beispiel einer extrem gesteigerten, in sich geschlossenen Auto-intertextualität stellt das letzte - ebenfalls aus der Hinterlassenschaft herausgegebene - Gedicht Návrat (Heimkehr, 1907) dar.

\subsection{Eine Heimkehr-Idylle als 'post-modemer' (Auto-)Zitat-Text ? Návrat (Heimkehr)}

"Die Lust der Fremde ging uns aus, zum Vater wollen wir nach Haus ..."

\section{Novalis}

„Kam se zachránit? Do ráje mého dëtství. Do krajin mé détské Arkadie. Mé dětství je má vlast. Mé sny jsou má vlast. Z oblak padá tam Cerný sníh".
„Wohin kann man sich retten? In das Paradies meiner Kindheit. In die Landschaften meines kindlichen Arkadiens. Meine
Kindheit ist mein Vaterland. Meine Träume sind mein Vaterland. Dort fallt schwarzer Schnee vom Firmument".

\section{Jindrich Styrsky (1940)}

\section{Návrat}

Známe hlubiny lesní, kam pít chodí lanè

$v$ májových nocích, když małinky vủně se lije.

sladce mdlá,

5

prameny tajné, jež skrývají kapradin zeleně dlaně.

v oblaku bilém když luna

jak lampa $z$ opálu plá.

jezera uprostłed lesũ a v mýtinách zátiši slunná.

kde jako znamení polibkủ dávných

Höhe; spăter im Zyklus Skryté dejiiny / Verborgene Geschichte), hat dreizehn Versionen, die insgesamt 710 hangeschriebene Seiten umfaßen.

587 Mit dieser Tendenz koinzidiert auch die 'Rückkehr' zur 'Musikalităt' des Verses, die Aktualisierung der Euphonie (M. Cervenka, .Błezinúv verš, in: Ceská literatura, 13, 1965, S. 142ff.). Die intendierte Wirkung dieser 'Musikalităt' bedeutet die Nivellierung der Bedeutungskonfrontationen zugunsten des euphonischen Effektes, des grammatischen Parallelismus usw.: "Vesmiry duchủ! Souznëni tragických tich a svëtel! Krajiny beznadëji, / kde hvêzdy se do jezer nezaskveji a ani jara se nezasmęji!" (Na zemi rủze / Auf der Erde Rosen..., III, 1-2; "Weltalle der Geister! Zusammenklingen tragischer Stillen und Lichter! Landstriche von Hoftnungstosigkeiten. I wo Sterne in Seen nicht erschimmern und nicht einmal die Lenze zum Lãcheln sich breiten!". Über. v. P. Eisner). Die Erklărung M. Cervenkas ("Omezeni kontaktu s realitou, která si $v$ tẻchto básních Bł̌ezina kladi, jsou tak pronikavá, že pokračváni mohio být jen opakovánim, a proto se stalo nemožným". / "Die Einschränkungen des Kontaktes mit der Realităt, die Brezina sich in diesen Gedichten auferlegte, sind derartig gravierend, daß die Fortsetzung nur zur Wiederholung führen konnte und deshalb unmöglich wurde') trifft den Kem des Problems. $M$. Cervenka, .Blezinovské úvahy", in: Ders., Symboly, pisné a mýty, Praha 1966, S. 60. Im abschließenden Kapitel zur Psychologik Brezinas schöpferischer Entwicklung versuche ich nachzuweisen, daß die von $M$. Cervenka konstatierte gravierende Einschrānkung des Kontaktes mit der (Lebens-)Realität, die sich Blezina "auferlegte", evident psychologischen Ursprungs war und in schweren seelischen Konfilikten des Dichters gründete. 
každě misto jahody nejsladß̌i má.

10 Známe azurná nebesa nad vinohrady, pě̉inky v jiskřících klasech. mlýny u pèjícich vod, topolù dvojstup jak tajemných poutníkủ rady. ptaxí hnizda v stł̧ibmých lesích, vonících do samol ...

Koho jsme $z$ bratťi potkali,

15 po dávněm znameni rodněm jsme poznali. $\checkmark$ úsměvu détí matek panenskou krásu. praotcủ staletý rod.

Na známá místa zraky se vracely. $\checkmark$ štěstí se zavłely jak pod horkými pocely.

$20 v$ tepotu srdce nám hłrimalo tisíce srdcí.

a kroků svých ohlas ze hlubin věků jsme slyšeli.

Známé jsou linie dalekých hor, modrá bratrská mèsta. známé je vక̌echno, Zeho se zraky a myšlenky tkly:

$v$ šechno je cesta, $k$ domovu jediná cesta.

25 tisíckrát jsme tady záhadni. mlxíci. neznámí şli.

Ze zemé do zemé bloudili, lovcové pravěku.

u ohñů sedali, zraky ztracené $v$ daleku,

hlasy svých mistrơ po věky slýchali, v pokoře ztišeni.

$v$ předvěkých nocich mlěení, v slavnostním jiskł̌eni hvězd.

30 s osvobozenými zapêli, s přemoženými úpěli, se staviteli města a chrámy a řî́se jsme stavěli,

s objevitelů lodstvy do nových zemí slavili vjezd.

\section{Heimkehr}

Wir kennen die Tiefen des Waldes, wohin die Rehen zu trinken gehen in Mainächten, wenn des Waldmeisters Duft sich ergießt. süßlich fahl, geheime Quellen, die des Farns grüne Handflächen bergen.

wenn die Luna in weißer Wolke.

wie eine Opallampe lodert.

Seen inmitten von Wäldern und sonnige Schlupfwinkel in den Ijchtungen. wo wie ein Zeichen längst vergangener Küsse

jeder Ort die süßesten Erdbeeren birgt.

10 Wir kennen das azurblaue Firmament über den Weinbergen.

Pfade in funkelnden Ähren. Mühlen an singenden Gewässem,

Pappelalleen wie geheimnisvoller Wanderer Reihen,

Vogelnester in silbemen Wäldern, die in Einöden duften ...

Wem von den Brudem wir begegneten.

15 den erkannten wir nach uralten leiblichen Malen. im Lächeln der Kinder lerkannten wirl die jungfräuliche Schönheit der Mütter. die jahhundertelange Generation der Urväter.

Auf bekannte Orte kehrten die Blicke zuruck. im Glück schlossen sie sich wie mit heißen Küssen bedeckt.

20 im Pulsschlag unseres Herzens tosten tausende Herzen, aus der Tiefe der Zeiten hörten wir das Echo unserer Schritte.

Bekannt sind die Linien der femen Berge, blaue Bruderstädte. bekannt ist alles. was die Blicke und Gedanken berührten: alles ist der Weg, der einzige Heimweg.

25 tausendmal gingen wir geheimnisvoll, schweigsam, unbekannt auf ihm.

Von Lande zu Lande zogen wir umher, wie der Vorzeit Jäger. zu Feuem saßen wir uns, die Blicke in die Ferne schweifend. 
die Stimmen unserer Meister hörten wir jahrhundertelang, in Demut verstummt. im Schweigen der vorzeitlichen Nächte, im feierlichen Gefunkel der Sterne,

30 mit Befreiten sangen wir, mit Besiegten klagten wir,

mit Baumeistem bauten wir Städte und Tempel und Reiche,

mit Flotten der Entdecker feierten wir Einzug in neue Länder.

In Bïezinas Werk nimmt Návrat (1907) 588 eine besondere Position ein. Die Eigenart dieses in der bisherigen Bỉezina-Forschung völlig außer acht gelassenen Gedichts gründet in der Intention, die 'hohe' myth(opoet)ische Welt der fünf vollendeten Gedichtzyklen durch die Reflexion aus einer scheinbar naiv-kindlichen Perspektive zu verfremden. Diese 'naivistische' Folie schließt eine psychopoetische ein, so wie der Titel, der auf das gleichnamige Gedicht aus dem ersten Zyklus fajemné dálky (Geheimnisvolle Fernen) verweist, 589 die autointertextuelle aufruft (dazu gehört, wie noch zu zeigen sein wird, auch die Assoziierung der fremden Textfolien). Biezinas letzter Gedichttext gewinnt seine hohe semantische Organisation durch eine 'Schichtung' verschiedener Sinnfolien, die einander gegenseitig zu überschreiten scheinen.

In welcher Weise 'dialogisiert' Návrat (1907) mit seinem gleichnamigen 'Auto-Intertext' (1894)? Das Gedicht Návat (1894) hat die Rückkehr der Seele des dichterischen Ich aus den "blühenden Gărten", d. h. aus dem Reich der 'Mutter'(-Imago), 590 das mit der Sphäre des Kunst-Schönen und des ästhetischen Genusses koinzidiert, in die Einsamkeit der immanenten Welt, in die "ewige Finsternis" ("Do věcného sera", VI, 3) der alltäglichen Lebensrealität, zum Thema. 591 Das Reich des Kunst-Schönen, des Unbewußten, der (Erd-)Mutter gleicht in Návrat (1894) einem Jungbrunnen ("Znám rozkoł téch kvetoucích zahrad /...I. I/ i zapovézený pivab tẻch lázni, kde v ströbrnou páru / jsi vystoupla zmladlá a vonná I...F. III, 3, IV, 3-4; "Ich kenne die Wonne jener blühenden Gärten /...I. II auch die untersagte Anmut der Bader, aus denen du in den silbernen Dampf / verjüngt und wohlduftend ausstiegst /... ${ }^{\prime}$ ). Die Anima (des Dichters) muß diesen "Garten" betreten und in den 'Verjüngungsbad' eintauchen, um das 'Gold der Poesie' ("znám tavená zlata", IV, 1; "ich kenne das Schmelzgold $/ . . . r$ ) zu finden und die 'ewige Jugend' zu erlangen. Danach kehrt sie in die 'graue' Oberweit zurück: "A ty jsi se vrátila! Do vénéno sera, / kde úsmév tvijj lepý / ti uhasne v tvári I... N NI, 3-4; "Und du kehrtest zurück! In ewigen Dămmer, wo dein anmutiges Lächeln / dir aư den Wangen erlischt /... $/$ ).592 Aber wohin führt die Rückkehr in Návat (1907)?

588 Als Biezinas letztes Gedicht identifizierte Návrat sein Herausgeber Otakar Fiala (Otokar Błezina: Návat, [Okresni knihovna] Prostéjov 1968. Zwei Jahre spăter wurde Návrat in der Błezina-Monographie von Josef Zka (Otokar Blezina, Praha 1970, S. 254-255) wiederabgedruckt. Bedauerlicherweise konnte Návrat erst vierzig Jahre nach dem Tode Błezinas verófentlicht werden. In die bisher letzte Gesamtausgabe (O. Błezina, Básnické spisy, hrsg. v. Błetistav Storek, Praha, 1975) wurde Návrat auch nicht aufgenommen. Diese miBgưnstigen Umstănde problematisier(t)en freilich seine Rezeption.

589 Dies ist gewiB kein Zufall, da Błezina bekanntlich bei der Titelwahl mit grobter Sorgfalt vorging.

590 Der "Garten" stellt eines der Symbole des Mutterarchetypus dar. Vgl. C.G. Jung. Die Archetypen und das kollektive Unbemusste, Gesammelte Werke, Bd. 9/1, Oiten-Freiburg i. Br. 1976, S. 96. Der Schatten der (toten) Mutter, der den Lebensweg des Dichter 'überschattet' ("tvým stínem oviván". Moje matka / Meine Mutter, IX, 4, TD; "umweht von deinem Schattert"), tührt' ihn auch in das Reich des Kunst-Schönen (vgl. Moje matka, VI, 1-4) ein.

591 "Má dusé se vrátila z kvetoucich zahrad /... Znám rozkos tẹch ketoucich zahrad /.... . (I. 1. III, 3; "Meine Seele kehrte aus blühenden Gărten zurück I.../. Ich kenne die Wonne jener biūhenden Gărten $/ . . . \digamma$ ).

592 In den mythopoetischen Vorstellungen muß der Dichter-Demiurg in die Unterwelt, in das Hades-Reich, $d$. $h$. in die düstere Tiefe des UnbewuBten, hinabsteigen, wo er das Wasser des Lebens findet. Im ănigmatischen Sonett El Desdichado von G. de Nerval sagt das dichterische Ich: "Et j'ai deux fois vainqueur traversé l'Achéron: / Modulant tour à tour sur la lyre d'Orphée" (Les Chimères, 1854; "). Der Dichter bewegt sich als 'Vermittler' zwischen Extremen und Polaritäten wie Zukunft und Vergangenheit, Leben und Tod usw. Das ist auch der Grund, warum viele Dichter "das dámonische und todliche Prinzip des poetischen Schaffens so bewuBt erleben und warum sie zur Vernichtung und Selbstopferung streben". Vladimir N. Toporov, "Die Ursprūnge der indoeuropăischen Poetik, in: Poetica, Bd. 13, 1981, S. 222 . 
Man kann die Antwort andeuten, wenn man den Titel "Návrat" nicht als "Rückkehr", sonden als "Heimkehr" übersetzt. Es ist die Heimkehr in die Welt der Erinnerungen, in das vertraute Arkadien der (frühesten) Kindheit, in das Reich der 'Mutter', in jenen Zaubergarten, aus dem die Anima des Dichters in Návrat (1894) in die trostlose Oberwelt zurückkehrt und wo die "Heimatgefühle und die Hoffnungen alles Werdenden" schlummern. 593 An Stelle des mystisch-mythischen Bades, in das die Anima in Návrat (1894) eintaucht, erscheint in Návrat (1907) ein Waldbrunnen. Die erste Sujetsequenz (insbesondere V. 1-4) liest sich wie eine stellenweise wörtliche Paraphrase des bekannten K in de r gedichts Lesni studánka (Der Waldbrunnen, 1894) von Josef Václav Sládek:594

(Bỉezina) "Známe hlubiny lesni, kam pít chodi laně, v májových nocich, kdyż mariinky vưnẻ se lije, /.../ prameny tajně, jaž skrývaji kapradin zelené dlaně" (V. 1, 4; "Wir kennen die Tiefen des Waldes, wohin die Rehen zu trinken gehen, in Mainächten, wenn des Waldmeisters Duft sich ergießt, /.../geheime Quellen, die des Fams grüne Handflächen bergen").

(Sládek) "Znám kr̉išt’álovou studánku, / kde nejhlubšije les, / tam roste tmavé kapradi / a vủkol rudý vǐes. // Tam ptáci, lanẻ chodi pít / pod javorový kmen, / ti ptáci za dne bilého, / ty lanè v noci jen" (I.-II. Str.; "Ich kenne einen kristallklaren Brunnen, / tief, tief im Wald vertraut, / dort wächst der dunkle Adlerfarn / und ringsumher das dunkelrote Heidekraut, / Die Vögel, Rehen gehen dort zu trinken, / vom Ahorn überdacht, / die Vögel am hellichten Tag, / die Rehen nur bei Nachr". Übers. v. U. Grüning.)

Die Paraphrase des Kindergedichts von Sládek läßt die Semantik der Heimkehr in den idyllischen, glücklichen, vertrauten, sicheren, vor der (feindlichen) Außenwelt abgeschirmten Raum der Kindheit, wo das dichterische Ich alles wiedererkennt, wo inm alles wohlbekannt vorkommt, noch klarer in den Vordergrund treten: "Na známá místa

593 C.G. Jung, Heros und Mutterarchetyp, Grundwerk, Bd. 8, Otten-Freiburg i Br. 1991, S. 146.

594 J.V. Sládek (1845-1912) gehörte in den siebziger Jahren zu den führenden Autoren, ja zu den Sprectiern der literarischen Gruppierung Ruchovci (Eigenname nach der Revue Ruch) an, die eine eminente Rolle in der Nationalbewegung der siebziger Jahre spielte. Spăter (um 1877) übernahm Sládek die Redaktion einer anderen bedeutenden Revue Lumir, um die sich die sog. "Lumirovci" ("Lumiristen") gruppierten (unter innen vor allem die Parnassisten Jaroslav Vrchlický und Julius Zeyer), deren Schlagworte nun "světovost" ("Weltläufigkeit") und "kosmopolitism" ("Kosmopolitismus"), als Reaktion auf das von der "Ruch"-Generation vertretene "Volkstum" oder "Tschechentum", lauteten. Was Sládek mit dieser Gruppe verband, war in erster Linie die Suche nach neuen Möglichkeiten und Formen der Dichtersprache. Es war - neben Vrchlicky - gerade Sládek, der Błezinas symbolistische Gedichte wegen ihrer angeblichen "Unverständlichkeit" verurteilte und sogar parodierte. In Lumír, v. 10. VI. 1893, wies Sládek die symbolistische Dichtung (namentlich die von Bïezina) als "Gitt" und "Unkraut" zurück. Wie ist Bỉezinas Rekurs auf Sládek zu deuten? Zu den signifikanten Merkmalen der Kindergedichte von Sládek $(1889,1894)$ zählen deren "wirkungsvolle Schlichtheit" (M. JankoviČ) und Melodizität. Bïezina selbst versuchte sein Verstummen als Ausdruck des Strebens nach der 'Befreiung' seiner Wortkunst aus dem Bann der mittlerweile etwas konventionalisierten Symbol(ismus)sprache zu erklăren: „Basné ty nevyhovuji takẻ již dneśnimu mému stanovisku. Opustil jsem volný verš a vrátil jsem se k pevnému rytmu". (E. Chalupný. Dopisy a vyroky Otokara Breziny. Praha 1931, S.112; "Diese Gedichte entsprectien nicht mehr meinem heutigen Standpunkt. Ich habe den freien Vers verlassen und bin zum regelmäßigen Rhythmus zurückgekehrt"). Im ähnlichen Sinne äußerte sich Bỉezina auch gegenüber Jakub Deml: "Kdybych já psal jestě verše, ty by musely bỳt pedantsky pravidelné. jednoduché, prostinké jako lidová pisen". (J. Deml, Mé svédectvi o Otokaru Březinovi, Praha 1931. S. 228; "Wenn ich noch Verse schreiben würde, müßten diese pedantisch regelmăßig, einfach. schlicht sein wie ein Volkslied"). Es ist aber offensichttich nicht nur die raffiniert schlichte, ziselierte Versstruktur Sládek Kindergedichte, die Bł̌ezina zum 'Dialog' mit diesem Dichter motivieren könnte; $m$. E. ist das vor allem der Chronotop der idyllischen "Heimkehr, der in den späteren elegischen Gedichten Sládeks eine sinnkonstitutive Funktion aufweist. Vgi. Z. B. das Motiv des vereinsamten Wanderers in Sládeks Gedicht To všechno už jen bylo (Dies alles ist schon vorbei; aus der Gedichtsammlung Za soumraku, 1907): "Od známých milých tvári / jou, poutnik, nevím kam, / tak mnozi šli mi dî́ve, / ju jako oni sám. // Jen jesté pohled zpátky / s tím trpce nẻmým rtem; / a kdoź mi ruku stiskli, / všem dik a sbohem všem!" (II.-III. Str.) Vgl. dazu die abschließende Verssequenz aus Bł̌ezinas Za všechno díky...(Danke für alles...):" MIĺi všechno. I Každý z nás sám. Nobot' k smrti / jde každý sám a marne jsou słzy milovaných zrakú, I marné ruce chladnouci tisknete / horkými tty, I odchazejici je sám, sám ... / Za všechno diky!". Vgl. auch das Motiv der "Heimkehr" in Sládeks $V$ náruć bożi (In die Arme Gottes): "Z oteckých paži, z otcova domu / byli jsme navżdy posláni v svêt; - / kdo by se obával vrátit se zpét? / Po trapné pouti navżdy zas domủ, I nikdy, už nikdy v tu chiadnou dál! I V náruči boži kdo by se bál?" (II.-III. Str.; aus: Za soumraku. 1907) 
zraky se vracely, I v štésti se zaviely jak pod horkými pocely" (V. 18-19; "Aứ bekannte Orte kehrten die Blicke zurück, / im Glück schlossen sie sich wie mit heißen Küssen bedeckt"). 595 Das erste Lexem von Návrat (1907) heißt "známe" ("wir kennen"). Der Akt des Wiedererkennens ist das signifikante Merkmal der Heimkehr- und Erinnerungsidylle schlechthin, die in der tschechischen Literatur eine lange Tradition hat 596 Die frappante Allusion auf das Kindergedicht von Sládek deutet an, daß die in Návrat (1907) modellierte Heimkehridylle durch das Prisma einer quasi 'kindlichen' Optik reflektiert wird. Die Welt (en miniature) von Návrat (1907) stellt einen locus amoenus dar, dem eine (noch) ungetrübte Harmonie obwaltet. Auf einen abgeschirmten, eingegrenzten 597 locus amoenus-Topos deuten einige Landschaftsmotive hin: "verborgene Quellen" (V. 4), "schattige Bäume" (V. 12), aber auch "sonnige Lichtungen" (V. 7), reife, "funkelnde Áhren" (V. 11), "süße Erdboeren" (V. 9), stille, ruhige "Waldeinöden" (V. 13), "Vogelnester" (V. 13) usw. Gerade die abgeschirmten "sonnigen Schluptwinkel in den Lichtungen" ("v mýtinách zátiši slunná". V. 7) erscheinen als ein geradezu paradigmatisches Äquivalent des pastoralen locus amoenus. 598 Es ist eine Welt, die die Atavismen und Triebe nicht kennt; die Welt der 'reinen' Kinder, in deren Lächeln sich die "jungfräuliche Schönheit der Mütter" offenbart ("po dávném znamení rodném jsme poznali / v úsmèvu détí matek panenskou krásu", V. 15-16). Ein anderes Merkmal ist die Vereinigung von Natur und Kunst. Die Natur wird anthropomorphisiert oder vice versa zu einem artifiziellen Kunst-Werk denaturiert. Die Denaturierung der (organischen) Natur durch die Kunst gehört zu den dominanten Paradigmen des dekadenten Symbolismus (Tajemné dáky, Kap. 2.2): Die Farnblätter (Návrat, 1907) werden zu "grünen Handflăchen" ("kapradin zelené dlanè", V. 4) anthropomorphisiert, 599 die "Pappelalleen" erscheinen wie "geheimnisvoller Wanderer Reihen" ("tajemných poutníkú rady", V. 12) und die "Mühlen" stehen an "singenden Gewăssern" (V. 11; "u pejjicich vod"). Und umgekehrt wird die Luna zur artifiziellen "lodernden Opallampe" ("v oblaku bilem kdyż luna / jak lampa z opálu plá", V. 5-6) denaturiert. Als denaturiert erscheinen auch die "funkelnden Ähren" (V. 11; "v jiskricich klasech") und die "silbernen Wälder" (V. 13; "v str̈brnych lesich"). Hier greift Bíezina auf sein eigenes poetologisches Verfahren des dekadenten Symbolismus zurück: auf dem Weg in die heimatliche loylle 'verwendet' und reflektiert er dieses Verfahren noch einmal ("Známe... " I "wir kennen..."). Nur die ganze Betrachtungsweise scheint jetzt wesentlich 'einfacher' zu sein. Das dichterische Ich apperzipient die Phănomene des mundus sensibilis 'mit Hilfe' von 'naiven' Assoziationen: der Mond ist eine "Opallampe", die Pappelallee eine "Doppelreihe geheimnisvoller Wanderer" usw. Die Vereinigung von Natürlichem und Artifiziellem bzw. das Streben nach der Abschwächung oder sogar Tilgung des Spannungsverhătnisses zwischen diesen beiden Bereichen, deutet aut einen wichtigen Aspekt des idyllischen Diskurses hin. 600 Darüber hinaus scheinen die Motive

595 Im semantischen Arrangement der beiden Návrat-Gedichte (1894, 1907) spielt das Verb "znám" / "ich kenne" (bzw. "známe" / "wir kennen") eine wichtige Rolle. In der ersten Pers. Sing. oder PI. kornmt dieses Verb im gesamten lyriscten Werk von Blezina außerst selten vor. Die Návrat-Gedichte stellen eine Ausnahme dar. Laut P. Holman (Frequenzwörterbuch des tyrischen Werkes von Otokar Bíezina. Bd. II, Kön-Weimar-Wien 1993) taucht das Verb "znám" (1. Pers. Sing.) - außer in Návrat (1895) - nur in Proc odvraciśs se, o slabá? (Warum wendest du dich ab, 0 Schwache?, I, 1 SZ) und in Jsem jako strom v kvêtu (Ich bin wie ein Baum in Blüte, V. 28, SCh: hier im Monolog der Erde) auf. Die Form "známe" (1. Pers. PI.; "wir kennen") kommt in Zem? (Erde?, II, 1. SCh; hier in der direkten Rede der "Liebenden"), in Neplemożitelni rostem... (Unüberwindlich wachsen wir..., V. 44) und in Návrat $(1907$, V. 1, 10) vor.

596 M. Sedmidubský, .Die Gestaltung des Idyllischen in der tschechischen Avantgarde: J. Wolkers Svaty kopodek. Typoskript, München 1992, S. 1-40. In tschechischer Sprache in: Ceská literatura, 43, 1995, S. 192-214.

597 R. Böschenstein-Schăfer, kylle, Stuttgart 1977, S. 8 .

598 M. Sedmidubský, Vytváleni idyly v ceské avantgardè. Jir̂́ Wolker: Svatý Kopecek, in: Ceská literatura, 43, 1995, S. 208.

599 Laut R. Bóschenstein-Schăfer (kylle, Stuttgart 1977, S. 101f.) gehơrt auch der Anthropomorphismus zu den charakteristischen Merkmalen der loylle (meistens als Ersatz für die vertorene Mythologie; so Z. B. in der Dichtung Hebels).

600 In seinem Modell des Idyllischen geht $M$. Sedmidubský davon aus, daß die Bedeutungsintention der idyllischen Fiktion, deren Kompetenz in der Lósung von bestimmten lebensweftlichen Problemen begründet liegt, hauptsăchlich darin besteht, .den allgemeinen 
der leuchtenden Luna (V. 5-6) und der sonnigen Lichtungen (V. 7) - ebenfalls 'naiv' wahrgenommen - auch die Vereinigung von iunarer und solarer Welt (coniunctio Solis et Lunae), d. $h$. die Vereinigung vom mănnlichen und weiblichen Prinzip, ein anderes großes Thema nicht nur in der Alchemie, sondern auch in der Kunst des Symbolismus, zu indizieren. Und schließlich manifestiert sich der in Návrat konstituierte idyllische Raum als eine Kontamination von zwei Idyllenkonzepten: der Kindheits- und der Todesidylle. Hier ruft die 'naivistische' (den Eindruck einer kindlich-naiven Betrachtungsweise suggerierende) - und zugleich myth(opoet)ische - Folie die psych(opoet)ische auf. Aus dieser Perspektive bedeutet die "Heimkehr" das "Hinabsteigen zu den Müttern" (Goethe). im Augenblick des "Glücks", in dem sich die Augen schließen, bekundet sich das wonnige

kulturmodellierenden Gegensatz von Kultur und Natur aufzubrechen, fiktionale Weltmodelle zu entwerfen, in denen die beiden gegensătzlichen semantischen Kategorien in ein Konjunktionsverhältnis, in einen Gleichgewichtszustand gebracht sind. I.../ Ihr pragmatisches Hauptanliegen scheint /.../ darin zu bestehen, Probleme zu reflektieren, die sich in der realen Lebenswelt aus dem ungelösten Verhältnis von Kultur und Natur ergeben, imaginäre Welten hervorzubringen, in denen die in der realen Lebenswelt bestehenden Spannungen, Widersprüche und Konflikte im Verhältnis von Kultur und Natur einer modellhaften Problemlösung zugeführt werden". M. Sedmidubsky், „Das Idyllische im Spannungsfeld zwischen Kultur und Natur: Božena Nẻmcovás "Babickka", in: Zur Poetik und Rezeption von B. Nẻmcovás .Babicka", hrsg. v. A. Guski, Berlin 1991, S. 27-79 (Zitat S. 32). Diese These scheint auch für die Semantik der Heimkehridylle in Návrat (1907) von großer Relevanz zu sein. Die Modellierung des idyllischen Raumes in "Návrat" drückt überaus deutlich Bỉezinas Streben nach der Lōsung der lebensweltlichen Probleme aus, die ihn offensichtlich auf seinem schöpferischen (Lebens-) Weg im zunehmenden Maße hindernd befielen. Die "lebensweltlichen Probleme" heißen bei Bfezina Furcht vor der Anpassungsleistung und vor dem (realen) Leben. In Návrat wird dieser Versuch - wie bereits oben erwähnt - absichtlich aus der 'kindlich-naiven' Perspektive gewagt. Es ist zu einem die Anthropomorphisierung des Antifiziellen, die 'Integration' der Kultur- und Kunstsphäre in die der Natur und vice versa (im Sinne der Denaturierung der ledendigen' Natur durch die Kunst), zu anderem - psychologisch gesehen - der Versuch, die Spannung zwischen seiner eigenen inneren 'Narur' (zwischen dem instinktiven Ich) und der Lebenswelt (dem kollektiven Unbewußten) zu Iösen, sie zu harmonisieren (wohl auch im Sinne der Vereinigung archetypischer Gestalten). Damit geht Hand in Hand jene für die schöpferichen Künstlerpersönlichkeiten signifikante Dissonanz zwischen dem 'natürlichen' Menschen und seiner extremen biologischen Variante: dem KünstlerSchöpfer. Gemeint ist das konfliktbeladene Verhältnis zwischen dem Menschlichen auf der einen Seite und dem Künstlerischen auf der anderen. Die Kunst selbst, das Kunstwollen, wird der Künstlerpersönlichkeit zum Trieb, der sie erfaßt und zum instrument, zum 'Opfer' einer 'fremden' Bestimmung macht. Die 'fremde Bestimmung' ist dieser Trieb (man denke nur an Bíezinas Gedicht Slysim v duši / Ich höre in der Seele, SZZ). "Das in letzter Linie in inm Wollende ist nich er, der persönliche Mensch, sondern das Kunstwerk. I.../ Daher rührt es, daß das persönliche Lebensschicksal so vieler Künstler so überaus unbefriedigend, ja tragisch ist, nicht etwa aus dunkler Fügung. sondern aus Minderwertigkeit oder ungenügender Anpassungstähigkeit ihrer menschlichen Persönlichkeit. Es gibt selten einen schöpferischen Menschen, der den göttlichen Funken des großen Könnens nïcht teuer bezahlen muß Das Stärkste in inm, eben sein Schöpferisches, wird das meiste an Energie an sich reißen $/ . . . /$ Im Gegenteil wird das Menschliche zugunsten des Schópferischen oft dermaßen entblutet, daß es nur noch auf einem primitiven oder sonstwie erniedrigten Niveau leben kann". C.G. Jung. .Psychotogie und Dictitung", in: Über das Phänomen des Geistes in Kunst und Wissenschatt. Gesammelte Werke, Bd. 15. Otten-Freiburg i. Br. 1990, S. 114ff. (Sperrungen vom Verf.). In den Gedichten Błezinas aus dem ersten Zyklus Tajemné dálky (1892-1895) werden die Metamorphosen des persönlichen Menschen zum Kunst-Werk, das totale Verfließen in der Kunst, ja selbst der Kunst-Tod geradezu extatisch bejaht (Modlitba večemi I Das Abendgebet. Vèzeñ I Der Gefangene. Uměni I Die Kunst u. a.). Im letzten vollendeten Zyklus Ruce (1901) wird hingegen ungeduldig und sehnsuchtsvoll das Kommen des "M e n s c he n " ("Clověk"), des "geistigen Menschen", enwartet, (Kolozpèv srdci / Rundgesang der Herzen; Silenci / Wahnbetörte. R). Und in den letzten Gedichten kehrt der "persönliche Mensch" zurück (Za vsechno díky...) Danke für alles...; Návrat I Die Heimkehn und versinkt ins Schweigen. Aus dieser Perspektive betrachtet drückt die Heimkehridytle von Návat die Sehnsucht des Dichters aus, zum "Brunnen" ("studánka"), zu den "geheimen Quellen" ("prameny tajné"), d. h. zum 'Ursprung', in das Reich der 'Mutter' - als 'Kind' - zurückzukehren, um die peinigende, ja entkräftende Spannung zwischen dem Menschlichen ('Natürlichen') und dem Schöpferischen (bzw. Künstlerischen) zu harmonisieren. Daher rührt wohl einerseits auch die für die Welt der Idylle symptomatische Tendenz zur Anthropomorphisierung und andererseits zur quasi 'natürlichen' Artifizialisierung der lebendigen Natur. Natur-Welt und Kunst-Welt erscheinen in diesem idyllischen Raum als eine 'natürliche', sich gegenseitig ergänzende Einheit, ganz im Sinne der Idyllensernantik. 
Gefühl des befreienden 'Heraustretens' aus dem circulus vitiosus, der das 'Leben' heißt, ja das beglückende Gefühl des 'Sich-vom-Ufer-der-Erde-Entfernens': "Na známá mista zraky se vracely. I v stëst' se zavre/y jak pod horkými pocely" (V. 18-19; "Auf bekannte Orte kehrten die Blicke zurück, / im Glück schlossen sie sich wie mit heißen Küssen bedeckt"). Was vernimmt das dichterische Ich in diesem Zustand des "unermeßlichen" Glücks? "I...I $v$ tepotu srdce nám hrímalo tisice srdá, / krokủ svých ohlas ze hlubin vêkü jsme słyseli" (V. 20-21; "Im Pulsschlag unseres Herzens tosten tausende Herzen / aus der Tiefe der Zeiten vernahmen wir das Echo unserer Schritte"). Dieses Textsegment evoziert einerseits den Titel des letzten (gedruckten) Gedichts Tisice srdci pëlo v srdci tvém (Tausende Herzen sangen in deinem Herzen), andererseits das Motiv der in der Tiefe verhallenden Schritte aus dem Gedicht Ztraceni (Vertorene): "I.../ kdyż zamyšleni naslouchaji z hlubin samot svých / /.../ Ohlasu krokü vzdálených" (Ztraceni, VII, 3-4, "/../ wenn sie gedankenverloren aus der Tiefe ihrer Einsamkeit l.../ / dem Echo entfernter Schritte lauschen"). Beide Gedichte (Tisice srdć... und Ztraceny) sind 'thanatoide' Gedichte, die einen quasi 'prae'mortalen (Tisice srdci pẻlo v srdci tvém) und einen quasi 'post'-mortalen Zustand (Ztraceni) thematisieren. Die "Verlorenen" sind die Schatten der Toten; das 'heimkehrende' Ich vernimmt - als eine Art akustischer Nekrangelie - das Echo seiner eigenen Schritte (bereits) aus der "unsichtbaren Weit". Die einzigen, die vor den Toten I "Verlorenen" keine Angst haben, sind - signifikantenweise - die Kinder ("Hoffnungen alles Werdenden"):601 "A jenom déti, které zemé dosud neznaji, / bázlivé v pootvěer se pritulí $k$ nim potaji" (Ztraceni, VII, 1-2; "Und nur die Kinder, die die Erde noch nicht kennen, I schmiegen sich, ăngstlich am Abend, heimlich an sie"). Die Gewesenen und nun Vertorenen der Erde, die Toten und die zukünttigen Kinder der Erde ("de̋ti, které země dosud neznaji", VII, 1; "Kinder, denen die Erde noch unbekannt ist"), das vergangene und das zukünttige Leben, bilden in Návrat eine Symbiose. Das Ende führt zurück zum Anfang; das "Kind" als Anfangs- und Endwesen, als Symbol des vorbewußten und des nachbewußten Wesens des Menschen, deutet auf diese Intention hin. Laut der Interpretation von Bachtin, stellt das Kindmotiv eine sublimierende Transformienung des Zeugungsaktes dar, der das Moment der Wiedergeburt reprăsentiert. Darin manifestient sich einer der Hauptaspekte des semantischen Mechanismus des idyllischen Chronotops, nämlich die Überwindung der grundlegenden Dualismen der menschlichen Existenz, vor allem die Überwindung der Ur-Opposition zwischen Leben und Tod. 602 Noch expliziter wird das Ziel der 'Heimkehr' im vorletzten Gedicht Blezinas Za vsechno diky... (Danke für alles..., 1906) artikuliert:

-Polibky rodici nás probouzely jak ptáci jitłni / a v každém znovazrození byly rty nase / vonné jako ny dét, I sladké od ovoce zapomenutí, jeź jako jahody zraje / v zahradách płed narozením. I... I Teơ mič v nás všechno /.../, všechno je tajuplné a zraje / k štèsti / k nesmimému štèsti, které nemá słova v jazyce lidském; / nebot' díté bolesti je Clověk / a nástroj bolesti je jazyk lidský. // Mil̆ vsechno. I Każdy $z$ nás sám. Nebot' k smrti jde każdý sám I... I (V. 21-25, 61, 65-71; "Die Küsse der Eltem weckten uns wie die Vŏgel der Morgendämmerung / und in jeder Wiedergeburt waren unsere Lippen / duftig wie die Kinderlippen, / süß vom Obst des Vergessens, das wie Erdbeeren / in den Gărten vor der Geburt reift. - I.../ Jetzt schweigt alles in uns $/ . . /$, alles ist geheimnisvoll und reift / zum Glück / zum unermeBlichen Glück, tür das es kein Wort in der menschlichen Sprache gibt; / denn das Kind des Schmerzes ist der Mensch / und das Werkzeug des Schmerzes die Sprache des Menschen. / Alles schweigt. I Jeder von uns ist allein. Denn zum Tode schreitet jeder allein $($... $r$ ).

Wie in Za všechno diky (V. 21-25) erscheinen auch in Návat - als eines der signifikanten Indizien des in diesen Gedichten modellierten idyllischen (Garten-)Raumes die "Erdbeeren" ("jahody"): "I... / v mýtinách zátiši slunná, / kde jako znamení polibkư dávných / każdé misto jahody nejsladśi má" (Návrat / Hoimkehr, V. 7-9; "/.../ und sonnige Schluptwinkel in den Lichtungen, / wo wie ein Zeichen der lăngst vergangenen Küsse / jeder Ort die süßesten Erobeeren birgt'). 603 Auch in Biezinas 'Heimkehr'-Gedichten 146.

601 C.G. Jung, Heros und Mutterarchetyp, Grundwerk, Bd. 8, Otten-Freiburg i. Br. 1991, S.

602 M.M. Bachtin, Literatur und Kameval, Frankfurt am M. 1990, S. 28ff. Vgl. auch die Interpretation dieses Motivs von $M$. Sedmidubský in seiner Analyse des Textes von Wolker (.Vytuáleni idyly v Ceskẻ avantgardë", in: Ceská literatura, 43, 1995, S. 209ff.

$603 \mathrm{Vgl}$. das Motiv der Küsse in Návrat (1894): "/.../ kde bledost tvȳch tvári / (o vynucené polibky dní!) na rủze se mêni" (III, 3-4; “.../ wo die Blăße deiner Wangen / (oh erzwungene Küsse 
fungiert die Erd beere als topische Frucht der ewigen Wiederkehr. Wegen inrer Zugehörigkeit zu der Familie der Rosen gehört sie den Pflanzen der Liebesgöttin Aphrodite an. Die Süßigkeit der Erdbeere, ihr betörender Duft, ihre Kugelform, übersăt mit unzähligen Samenkörnern, macht sie in ihrem satten Rot zum Sinnbild der irdischen Lust. Man denke nur an die erotisch-mythologische Ikonographie der Erdbeere im Obsthain des "Paradieses auf Erden“ von Hieronymus Bosch. Auch im idyllischen Raum des in diesem Kontext schon erwähnten 'Epos' der tschechischen Literatur, in Božena Němcovás "Babicka" (1855), wird das Motiv der Erdbeeren (im fünften Kapitel) gerade vor dem Hintergrund des Dualismus zwischen Leben (repräsentiert durch das Kindmotiv) und Tod funktionalisiert. 604

der Tage!) sich in Rosen verwandelt"). Die Metaphorik dieses Bildes erörtert J. Mukał̌ovský (.Básnická sémantika", Praha 1995, S. 66-67).

604 .Kněżna se usmála; vidouc stát na lavici košicek jahod, ptala se, kde je déti nasbiraly. Babicka hned pobidla Barunku ł̌kouc: „Jdi, děvečko, podej milostivé knẻżnè. Jsou ¿erstvé, dẻti je po cestě nasbiraly, snad prijdou milostivé pani $k$ chuti. Kdyż jsem mladá byla, také jsem to ovoce ráda jídala, ale co mi dẻcko umỉelo, nevzala jsem żádnou do úst." A prož? ptala se kněżna, berouc od Barunky kośícek s jahodami. To je tak mezi námi, milostivá pani, jak umíe matce díté, neji do svatého Jana Krttitele ani tł̉ešnẻ ani jahody. To prý chodi Panna Maria po nebi a rozdává to ovoce têm malým dítkám. Kterého dítête matka ale zdrženlivá nebyla a od toho ovoce jedla, tomu łekne Panna Maria: 'Vidís, holátko, na tebe se máio dostalo, matka ti to snédla". B. Nẻmcová, Babicka. Obrazy venkovského Żvota, Praha 1961, S. 45. (.Die Fürstin lächelte; und als sie ein Körbchen mit Erdbeeren auf der Bank sah, fragte sie, wo die Kinder die Beeren gepflückt hätten. Großmutter sagte sogleich zu Barunka: «Geh, Mädel, und biet' der Frau Fürstin die Beeren an. Sie sind ganz frisch, die Kinder haben sie auf dem Weg hierher gepflückt, vielleicht kommen sie der gnädigen Frau gerade recht? Als ich jung war, aß ich Beeren sehr gerne, aber seit mir ein Kind gestorben ist, habe ich keine Erdbeere mehr angerührt. \& \&nd warum nicht? \& fragte die Fürstin und nahm das Körbchen, das ihr Barunka entgegenhielt. $\propto$ Das ist bei uns so üblich, gnădige Frau: wenn einer Mutter ein Kind wegstirbt, soll sie bis zum nächsten Johannistag keine Erdbeeren und keine Kirschen anrūhren. An diesem Tag nămlich - so heißt es - geht die Jungfrau Maria im Himmel umher und verteilt Obst unter die Kinder. Wo sich aber die Mutter eines der Kinder nichts versagt hat, spricht die Jungfrau: <Siehst du, Kindlein, für dich ist nichts übriggeblieben, deine Mutter hat dir alles aufgegessen.> B. Němcová. Die GroBmutter, übers. von Hanna und Peter Demetz, Zürich 1959, S. 79-80). Unmittelbar vor dieser Begegnung mit der Fürstin erzählt die GroBmutter den Kindern eine Geschichte von einem Wunder, das sich im benachbarten Wald .pł̌ed dávnými Casy („vor langer Zeit') einem kleinen Mädchen ereignete. Die Erzählung der Großmutter mündet in die tröstliche Feststellung des ewigen Wechsels von Leben und Tod ein: . Ale dẻvéátko uż dávno dávnicko umielo, a pan Turynský umiet i pani Tunnská /.. / a zámek na Turyni je zbởen." A kam prisły ovce a pec? ptal se Vilim. Inu, pes posel, staré ovce zkapaly. mladé vyrostly a mély zase beránky. A tak to na torn světé chodi, milé déti, jeden zajde, druhý prijide." (Ibid., S. 44-45; "Aber das Mágdlein ist jetzt schon lange, lange tơ, und der Herr von Thüren und seine Frau Gemahlin /... / und das Thürener Schloß liegt in Trümmern... Und was ist mit den Schafen und mit dem Schäferhund geschehen?» fragte Wilhelm. oNun, der Hund ist auch gestorben, die alten Schafe auch, aber die jungen sind aufgewactsen und haben wieder junge Lämmlein geboren, und so geht's auf der Welt, liebe Kinder, das eine geht und das andere kommt. B.N., Die GroBmutter, ibid., S. 77). Auch im ldyllisctien Raum ist der Tod ins Leben eingeschlossen und bestimmt - wie die Geburt - seine ewige Bewegung. Im Idyllischen Raum von .Babicka" wird das Phänomen des Todes den Kindern von der GroBmutter aus einer 'kindlich. naiven' Perspektive besanftigend 'nähergebracht' Auch im Raum der Idylle gibt es den Tod (der Tod Viktorkas und zum Schluß auch der der Großmutter), doch auch umgekehrt kann es selbst im Raum des Todes die Idylle geben. Diese Intention kommt im nactisinnlichen Monolog der Großmutter über der im Sarg liegenden, vom Blitz getơteten, wahnsinnigen und verwildeten Viktorka zum Ausdruck (17. Kap.): .Babicka zatocila rủženec okolo ztuhlých rukou zemfelé, divala se ji dlouho do tváre. To nebyla již tvál divoká! Cerné žhavé oći byly zavłeny, svit jejich uhasl. Cemý zcuchanỳ vlas ležel scesán a kolem cela co mramor chladného vinul se cervený vẻneček. jako páska lásky /...l. "Co té asi bolèo, ty ubohé srdce? Co ti udẻlali?" povidala si babicka tichým hlasem. .No, už ti nikdo nenachradi, cos utrpèla; kdo je vinen, Bủh ho bude soudit, tys ve svẻtle a $\checkmark$ pokoji." (Ibid., S. 183-184. Kursiv vom Verf..: "Großmutter wand den Rosenkranz um Viktorkas kalte Hände und blickte die Tote Lange an. Inr Antlitz zeigte keine Spur von Wildheit mehr. Die schwarzen, feurigen Augen waren geschlossen, ihr Glanz war dahin. Man hatte ihr das schwarze, zerzauste Haar gekämmt, um die marmorkühle Stim wand sie der Blumenkranz wie ein Band der Liebe. I... / «Was hast du gelitten, du armes Herz, was haben sie dir angetan?» sagte Großmutter leise. aNun, niemand kann gutmachen, was du gelitten hast; wer an dir schuldig geworden, den wird Gott richten, du aber ruhst in Licht und Frieden.» B.N., Die GroBmutter, S. 393). Und 
Wie realisiert sich in Návrat das Aufeinandertreffen der Auto-Zitate? Und welche Sinnintention markiert diese Strategie? Die Zitat-Montage (V. 22-32) ${ }^{605}$ aus eigenen Gedichten ist so arrangiert, als ob im Augenblick des Erreichens eines 'Endzustandes' der Erkenntnis ("známé je všechno", V. 23; "alles ist bekannt") vor den Blicken des dichterischen Ich, vor dem Organ seiner rationalen Erkenntnis ("zraky" I "Blicke" "myšlenky" I "Gedanken", V. 23), die wichtigsten 'Bilder' seines 'Lebens-Textes' (wie im Film) vorüberzögen. Dieses 'Wiedererleben' (und 'Wiedererkennen') des eigenen 'LebensTextes' erfolgt im Medium der Erinnerung und daher wird es im Präteritum (ab. V. 14 bis V. 32) wiedergegeben. Kennzeichnenderweise kommen bis zur vierzehnten Verszeile keine Verba der Bewegung (bis auf eine Ausnahme in V. 1) und des aktiven (bzw. kreativen) Tuns vor, dafür aber ab der vierzehnten Verszeile: "jsme potkali" (wir begegneten", V. 14), "jsme Sli" ("wir gingen", V. 25); "bloudili" ("wir irrten herum", V. 26); "zapéli" ("wir sangen", V. 30); "stavěli" ("wir bauten", V. 31); "slavili" ("wir feierten", V. 32). Das Aufeinandertreffen der Zitate aus eigenem dichterischen Gesamtwerk scheint in diesem letzten, retrospektiv ("Návrat": "Heimkehr", "Rückkehr") konnotierten Text als eine Art imaginativer Mnemotechnik zu fungieren. Die Ästhetik der ars memoriae entwirft hier (aut der auto-intertextuellen Folie des Textes) einen auto-intertextuellen 'Gedächtnisraum', in den der Dichter zurückkehrt, um eigene Texte (noch einmal) 'durchqueren' zu können: "na známá mista zraky se vracely" (V. 18; "Aư bekannte Orte kehrten die Blicke zurück"). Der letzte Text manifestiert sich nun (auch) als Versammlung von (Auto-)Intertexten.

Der psychische Zustand (der darunterliegenden Sinnfolie), in dem die 'Erinnerungen' die dominanten Ereignisse des Lebens 'kinematographisch' vor dem inneren Auge des Erlebenden beinahe zusammenhanglos auftauchen und geradezu 'rasend' bewegen lassen, ist symptomatisch für spezifische Erlebnisformen im Augenblick des nahenden Todes, des emotionalen Schocks oder des 'Einsteigens' in psych(ot)ische Ausnahmezustände. Dieses "panoramatische Sehen" der 'Bilder' bzw. 'Szenen' aus dem eigenen 'Lebens-Text' ist (V. 18-32) als eine Art ('literarisierter') Ekmnesie inszeniert, $d . h$. als Übertragung des ganzen seelischen Lebens des erlebenden Subjektes in einen früheren Abschnitt seiner Existenz. Es ist ein (bereits) depersonalisiertes Wiedererleben

schließlich wird die Vorstellung der 'Heimkehr' in die Todesidylle - als der letzte Satz des gesamten Textes - durch den wehmütigen Seufzer der Fürstin, die aus dem Schloßfenster den Begräbniszug mit der verstorbenen Großmutter mit ihren Blicken begleitet, gleichsam 'bestătigt': - Jak dlouho bylo prúvod vidẻt, tak dlouho smutnỳ zrak jeji ho provázel, aż pak záctonu spustic a hluboce si vzdechnouc zaseptala: .Stastná to Zena? - (Ibid., S. 198; "Solange der Begräbniszug zu sehen war, blickte sie inm traurig nach. Dann ließ sie die Vorhänge zurūckgleiten, seufzte tief und flüsterte: «Die Glückliche!»; B.N., Die Großmutter, S. 424).

605 Hier einige Beispiele: Návrat (V. 13): "/.../ ptađi hnizda v stríbrných lesich, vonicich do samot" ("Vogelnester in silbernen Wăldern, die in Einoden duften"). - Motiv z Beethovena (TD, II.

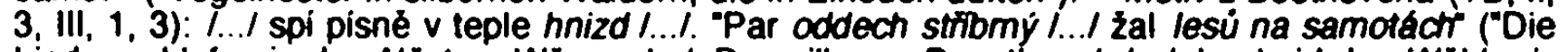
Lieder schlafen in der Năstem Wărme /.... . Der silbeme Dunsthauch I.../ das Leid der Wăber in den Einsamkeiten"). - Návrat (V.15): “.../ po dávném znameni rodném jsme poznali /... $/($ ".../ den erkannten wir nach uralten leiblichen Maten"). - Stavitelé chrámu / Baumeister am Tempel (SCh. V. 72-73): "Ti jedini ze všech / poznávali se znamenimi." ("Sie allein unter allen / erkannten einander durch Zeicherr"). - Návrat (V. 19): ".../ v štèsti se zavłely jak pod horkými pocely" ("im Glück schlossen sie sich wie mit heißen Küssen bedeckt). - Zpivala / Sie sang (letzte Gedichte, III, 6): $\%$.../ pod novych slunci pocely" ("unter neuen Küssen der Sonnen"). - Naurat (V. 20): \%... v tepotu sroci nám hrimalo tisice srda" ("im Pulsschlag unseres Herzens tobten tausende Herzer"). - "Tisice srdci pélo v srdç tvém" (Gedichttitel: "Tausende Herzen sangen in deinem Herzen"). Návat (V. 21): \%.../ krokú svých ohlas ze hlubin vékú jsme slyšeli" ("/../ aus der Tiefe der Zeiten hörten wir das Echo unserer Schritte"). - Ztraceni / Verlorene (VII, 3-4): “.../ kdyż zamyšleni naslouchaji z hlubin samot svych / /.../ ohlasu krokü vzdálených" ("wenn sie gedankenverioren aus den Tiefen ihrer Einsamkeit / I... / dem Echo ihrer femen Schritte lauschen"). - Návrat (V. 26): "Ze zemé do zemé bloudili" ("Von Lande zu Lande zogen wir umher). - Silenci / Wahnbetörte (I. 1): "Bloudime tajemstvím zemé" ("Durch der Erde Geheimnis irren wir). - Návrat (V. 27): \%... zraky ztracené v daleku" (".../ die Blicke in die Feme schweifend"). - Chvile stávy... I Augenblicke der Hehre... (VI, 2): "...I zrak teskný zhroużený v daleku ("der Blick in die Ferne versunken, voll Bangigkeit) usw. Aus dieser Perspektive erscheint Navrat (1907) als ein 'post-modemer' AutoZitat-Text, der auf seine Authentizităt und 'Originalităt' ostentativ verzichtet, denn "alles ist schon bekannt" ("známé je všechno", v. 23), "alles ist bereits gesagt worden" (zumindest in der Sprache der imaginativen Wort-Kunst), die Ausdrucksmöglichkeiten scheinen erschöptt zu sein, der Text wird zu einem in sich 'geschlossenen, (bloß) enumerativen und tautologischen Auto-Intertext. 
des eigenen Leben; das Ich betrachtet sich selbst als eine fremde Person, die ihr eigenes Leben wie 'auf der Bühne' vorführt. Aus solcher befremdlich distanzierten Perspektive (in der 2. Pers. Sing.) betrachtet das dichterische Ich sein eigenes Leben im 'Abschiedsgedicht' Tisice srdci pèlo v srdci tvém (Tausende Herzen sangen in deinem Herzen). Diese Betrachtungsweise der (realen) Lebenswelt entspricht genau dem Postulat des Dichters, das er in seiner Korrespondenz aus der Abfassungszeit von Návrat (1907) formuliert: "A filosofický chlad, s nímż hledíme na vastni minulost jako na vzrušujici román cizi bytosti, se dostavi". ("Und die philosophische Kälte, mit der wir unsere eigene Vergangenheit wie einen aufregenden Roman eines fremden Wesens betrachten, tritt ein").606

M. Cervenkas Erklärung des abrupten Verstummens des Dichters 607 als Folge seiner extremen Einschränkung des Kontaktes mit der Realität, 608 stimmt - objektiv gesehen durchaus. Die Alternative einer 'Neuwertung' der symbolistischen Poetik von 'unten' war für Bïezina offensichtlich unannehmbar. 609 Doch die Ursache dieser "Einschränkung" ist eine psychologische. In Wirklichkeit war es Bïezinas Zurückweichen vor der Anpassungsleistung, das sich nach 1901 nur noch vertiefte und schließlich zur Lähmung seiner schópferischen Energie führte: "Ich bin oft zum Tode erschöpft" ("/... bývám k smrti znaven"), schreibt Biezina 1905 an seinen Freund, den Bildhauer F. Bilek. Aus der Korrespondenz des Dichters nach 1901 geht eindeutig hervor, wie sehr er auch unter der großen Last, die inm als Dichter aufgebürdet wurde, gelitten hatte. 586 In den letzten Gedichten scheint der Dichter-Schöpfer aus dem Zustand der 'participation mystique', aus der Zitadelle seines Kunst-Werkes herauszutreten, um als "persönlicher Mensch" zu sich selbst heimzukehren. In Za vsechno diky... (Danke für alles...) wird diese 'Reinkarnation' vom 'schöpferischen' (im höheren Sinne "kollektiven Menschen") zum 'persönlichen Menschen' als ein Akt des symbolischen Wiedererlebens der einzelnen 'Lebensstufen' thematisiert. Am Ende dieses Prozesses steht "das Kind des Schmerzes", der "Me n s ch" ("ditě̉ bolesti je Clověk", V. 67), vor dem Leser:

"Za všechno díky I.../. Za bolest našeho d è t s $\mathrm{t} v \mathrm{i}$, I.../ nebot' rust je rozkoš i bolest. I... I Żhavé je slunce našeho $\mathrm{m}$ u ż s $t \mathrm{v}$ i - I pochopili jsem a nereptali. I... I. Za vsechno diky, Tajuplný. I... I Za horečné hodiny dila, extasi tvorby, kdy duše rozpominá se na svou knižeci slávu, / bezesné noci nad roztopeným varem, ktery se má líti ve vécnou formu /.../. Posledni dar dal jsi bolesti naši mlßeni svoje. I.../ nebot díté bolesti je ć l o v è k * (V. 5-6,10-12, 27, 35-38, 51-52, 67; "Danke für alles /.../. Für den Schmerz unserer $\mathrm{Kin} d \mathrm{~h}$ e it. I.../ denn das Wachsen bedeutet Wonne und Schmerz. I.../ Glühend ist die Sonne unserer Măn $\mathrm{nlich} \mathrm{ke} \mathrm{it} \mathrm{-} \mathrm{/} \mathrm{wir} \mathrm{haben} \mathrm{verstanden} \mathrm{und}$ nicht gemurnt. I.../ Danke für alles, Geheimnisvoller. I.../ Für die fieberhaften Stunden des Werkens, für die Extase des Schaffens, wenn die Seele sich ihrer fürstlichen Hehre entsinnt, / für die schlaffosen Năchte über dem glühenden Sud, das in die ewige Form gegossen werden soll. I.../ Die letzte Gabe gabst du unserem Schmerz - dein Schweigen. I.../ denn das Kind des Schmerzes ist der Me $\mathrm{n} \mathrm{s} \mathrm{ch}^{\text {- }}$. Sperrungen vom Vert.)

Die 'Heimkehr' zu sich selbst, die Herstellung der psychischen Einheit der Persönlichkeit, mußte Biezina teuer bezahlen: "Der Schöpfer in inm starb langsam bei vollem Bewußtsein" 610 Es ist kein Zufall, daß Biezina (nach 1907) in seiner Korrespondenz und in seinen Gesprăchen mit zahlreichen Besuchern gerade das Allgemein-Menschliche im Wirken des Dichters unermüdlich betonte:611

606 O. Bł̌ezina, Listy O.B. Annè Pammrové [1905-1929], Żơárec 1933, Brief v. 4.II. 1906.

607 M. Cervenka, .Błezinovské úvahy", in: Ders., Symboly, pisné a mýty, Praha 1966, S. 60.

608 Vor Otakar Fiala (Herausgeber der Essays von Biezinas) solte der Dichter um 1910 gesagt haben. "alle" Möglichkeiten seines "dichterischen Stils" seien erschöpft. Vgl. O. Fiala, .Ml¿eni Otokara Br̈eziny", in: Listy filotogické, 66, 1939, S. 46.

609 Im Gegensatz zu einigen anderen bedeutenden Autoren der Generation der neunziger Jahre (Neumann. Antonín Sova), die in den zehner Jahren - zumindest zeitweilig (Sova) derartige 'Neuwertung' anstrebten und realisierten.

586 O. Fiala. .Miceni Otokara Bíeziny v zrcadle korespondence a hovoru", in: Listy filologické, 66,1939, S.43ff.

610 .Tvưrce v nẻm umiral prì pinẻm vèdomi /.. $\%$ : eine treffliche Charakteristik von 0 . Králik (Otokar Brezina, Praha 1948, S: 442).

611 Zur imaginativen Wort-Kunst kehrte Blezina (nach 1907) nie wieder zurück und er veröffentlichte auch keine einzige n e u e Zeile mehr. Für die literarische Öffentlichkeit war 
„Tvớicimu Člověku neni tł̌eba, aby psal mnoho knih; stači jen ž́ti mocně až do hlubin věčnosti a smrti viastni svưj život, v pravý cas rici pravé slovo a kdyż je toho t̛̉eba, míti odvahu k miceni". („Der schöpferische Mensch hat es nicht nötig, viele Bücher zu schreiben; es reicht nur, wenn er bis in die Tiefen der Ewigkeit und des Todes sein eigenes Leben gewaltig lebt, zur richtigen Zeit das richtige Wort sagt, und wenn es nötig ist, den Mut zum Schweigen hat"). ${ }^{612}$ "Clověk nepúsobi jen proneseným slovem, dílem. Ćlovék pł̌edevším a nejvice pủsobí príkladem svého života I... $\digamma$. ("Der Mensch wirkt nicht nur durch das vorgetragene Wort, durch sein Werk. Der Mensch wirkt vor allem und am meisten durch das Beispiel seines Lebens $/ . . . \Gamma$ ).613

Das 'Wiedererleben' der dominanten 'Sequenzen' des eigenen 'Lebens-Textes' in Návrat (V. 18-32) signalisiert in der Tat das Heraustreten des Dichters aus seinem (schöpferischen) Leben, das Nahen des symbolischen Todes von Bïezina als DichterSchöpfer. Das Ziel seiner 'Heimkehr', die Vereinigung und Versöhnung der Gegensätze und Ur-Oppositionen, scheint erreicht zu sein, "alles ist schon bekannt" ("známé je všechno", v. 23), "alles ist bereits gesagt worden". Die 'Heimkehr' in die glückliche Welt der Kindheit bedeutet den Abstieg in die Tiefe, zu "geheimen Quellen" ("prameny tajne", V. 3). zum "Brunnen" des Lebens, zur "Mutter". Kennzeichnenderweise heißt das erste Substantiv des Textes "hlubiny" ("Tiefen", V. 1). Der Dichter kehrt in jene Sphäre zurück, aus der inn das Gesetz der rollenden Zeit vertrieben hat. Er steigt aus dem rasenden "Wagen der Zeit" - "Tak z Casu, vitęz, ystoupil's jak z vozu válecného / ze stiedu bratr̆ svých u cíe $v$ jemné únavê /.../. / A do soumraku svého za námi odjíżéjícími hledél's laskavê..." (Tisice sroci pélo v sroci tvém I Tausene Herzen sangen in deinem Herzen, VII, 1-4)614 - und versinkt in die Tiefe der Introversion. Diese gefährlichen "Tiefen des Schmerzes" ("Hlubiny bolesti", gleichnamiges Gedicht) sind aber zugleich die "Tiefen" der Heilung, wo der 'Schatz' der psychischen Ganzheit liegt und wo alle abgespalteten Teile der Persönlichkeit vereinigt werden können. Der Preis dafür ist der Rückzug, Stillstand, der den in Návrat modellierten (V. 1-13) idyllischen Raum durch die Ábsenz der Bewegungsverba, charakterisiert, und das Schweigen. 615

"Upadăm v mičeni jako lidé, ktefí védi, że jim neize fíci vsecchno" (O. Błezina an A. Pammrová, 11. X. 1903; "Ich versinke ins Schweigen wie Menschen, die wissen, daB es nicht in ihrer Macht steht alles zu sagen").

The rest is silence.

Biezina als Dichter so gut wie tot'. Im Jahre 1913 erfolgte dann die Herausgabe des gesamten lyrischen Werkes. Sein Vestummen als lyrischer Dichter versuchte Biezina durch die "Synthese aus heterogenen Diskursgattungen" (Aage A. Hansen-Love, Der russische Symbolismus, Bd. II, Lebenssymbolik [Habilitationsschritt; Typoskript]. Wien 1984, S. 766) zu kompensieren. Das Resultat stellen Brezinas Essays dar, an deren unzăhligen Versionen er bis zu seinem Tode arbeitete. In der Bíezina-Literatur verwendet man auch die Bezeichnung "básnická próza" ("dichterische Prosa": Cervenka. 1990, S. 253; Holman, 1996). Einen anderen Synthese-Versuch stellen schließlich auch Błezinas Gesprăche und seine Korrespondenz dar.

612 O. Bł̌ezina. Listy O. B. Annẻ Parnmrové [1905-1929], Žơárec 1933, S. 119.

613 G. Picková-Saudková, Hovory s Otokarem Bł̌ezinou, Praha 1929, S. 169).

614 "So stiegst du, der Sieger, aus der Zeit, wie aus einem Kriegswagen, / aus der Mitte deiner Brüder am Ziel in sanfter Müdigkeit /...I. / Und bis zu deiner Dámmerung schautetst du, uns Fortfahrenden, liebenswürdig nach ...".

615 In seinem Aufsatz "Miceni Otokara Błeziny v zrcadle korespondence a dopisu I-III" (in: Listy filologické, 66, 1939, 'S. 43-60, 235-251) dokumentient O. Fiala anhand von zahireichen Zitaten aus der Korrespondenz von Błezina, wie hartnăckig sich der Dichter bis zu seinem Tode (1929) weigerte, die (nach 1903 abgefaßten) Essays zu verơffentlichen. 


\section{AUSBLICK: PSYCHOLOGIK DER SCHÖPFERISCHEN ENTWICKLUNG VON OTOKAR BREZINA - VERSUCH EINER REINTERPRETATION}

„Es giht selien einen schöpferischen Menschen, der den gö̈lichen Funken des großen Könnens nicht teuer he:ahlen muß. I... der schöpferische Mensch /ist/ ein Rätsel, dessen Lïsung man zwar auf vielerlei Weise, aber immer vergebens versuchen wird."

C. G. Jung, Psychologie und Dichtung (1930)

„Clověk, který umëlecky tvoři uneh umëleckv ciní.

v pravém smìslu slova neni c̆lověkem normálním".

„Ein Mensch, der sich künstlerisch hetätigt oder künstlerisch fühl, ist im wahren Sinne des Wortes kein normaler Mensch".

Ot. Brezina an Fr. Bauer (3. IV. 1892)

Am Ende meiner Rekonstruktion der Symbolparadigmen des lyrischen Werkes von Otokar Bïezina angelangt, möchte ich in diesem abschließenden Kapitel noch den Versuch einer Rekonstruktion der P sychologik Biezinas schöpferischer Entwicklung wagen. Dabei geht es vor allem darum, den archetypischen Hintergrund der Brezinaschen Symbolwelt mit Hiffe der Psychologik und der Religionspsychologie C. G. Jungs aufzuzeigen und zu erklären. Die Heranziehung der Jungschen Archetypologie, die als Paradigma einer Psychopoetik der Symbolbildungen betrachtet werden kann, liegt darin begründet, daß diese dem religiös-mythologischen Denken der Symbolisten wohl am nächsten kommt. Diese 'Nähe', oder sogar Analogie, erklärt sich, wie Aage A. Hansen-Löve betont, einerseits durch die Rezeption identischer mythologischer, gnostisch-hermetischer, mystischer oder religionsphilosophischer Texte (bei Bïezina positiv nachweisbar), andererseits "durch eine für die Moderne charakteristische epistemologische Konvergenz der religiösen, ästhetischen und psychologischen Prämissen".616 Eine außerordentlich wichtige Rolle spielt dabei auch jene für die symbolistische Moderne der Jahrhundertwende charakteristische Tendez zur Ästhetisierung und Aktualisierung des Religiösen (sowie Hermetisch-Gnostischen, Mystisch-Mythischen usw.). Dazu gehört auch das besondere Interesse der Künstler der Moderne für außergewöhnliche, $d$. h. okkulte, mystisch-erotische, irrationale oder psychopathologische (auch sexualpathologische) 617 Phänomene. Es ist C. G. Jung, der in seinen Arbeiten aus den zehner Jahren618 nachweist, daß auch die individuellsten psychischen Phantasiebildungen der subjektiven Geistestätigkeit, die aus dem Unbewußten ins Bewußtsein expandieren, keinesweg 'eınzıgartıg' sind, sondern verblüffend unverkennbare Analogien $z u$ anderen, vor allem $\mathrm{m} y$ th o logis $\mathrm{ch}$ e $\mathrm{n}$ Bildungen bieten. Jung wendet sich gegen Kausalismus und Reduktionismus der

616 A.A. Hansen-Löve, .Zur Mythopoetik des russischen Symbolismus", in: Mythos in der slawischen Modeme, Wiener Slawistischer Almanach, Sonderband 20, hrsg. v.. W. Schmid, Wien 1987, S. 70.

617 Aus der Korrespondenz Biezinas erfahren wir, daß er z. B. Kraftt-Ebings bekannte Psychopathia sexualis, Weiningers Geschlecht und Charakter, die Schriften Freuds, Bleulers und anderen Psychiatern gut kannte.

618 Gemeint ist vor allem die umfangreiche Studie .Wandlungen und Symbole der Libido",Teil I. in: Jahrbuch für psychoanalytische und psychopathologische Forschungen, 3, 1911, S. 120-227, Teil II., ibid., Bd. 4. 1912, S. 162-464. (Wiederabdruck in: Gasammelte Werke, Bd. 5, OltenFreiburg i. Breisgau 1973), die nach ihrer Veröffentlichung auf vieffache Mißverständnisse (seitens der Freudschen Schule) gestoßen ist, da Jung hier eine neue Definition des Libidobegriffes aufstellt. Im Gegensatz zu der rein biologisch-medizinischen (und sexuellen) Bedeutung der Libido, faßt Jung sie energetisch auf, nämlich als Ausdruck für wirksame psychologische Werte (nicht unähnlich dem Bergsonschen .élan vital"). 
Freudschen Psycho a n a I y s e, die das Unbekannte und Komplizierte, den enormen Reichtum an phantastischen Symbolbildungen, auf die bekannte, einfachere und allgemeinmenschliche Grundlage zurückführt. Jung bietet seine eigene, synthetische und konstruktive Methode an. Er begreift die Seele als ein Werdendes, das nur synthetisch und konstruktiv erfaßt werden kann. Im einem ähnlichen Sinne betrachtet er auch die Hauptwerte eines Kunstwerks: nicht in seiner kausalen Entwicklung, sondern in seinem "lebendigen", auf das Zukünftige orientierten Wirken. Da die konstruktive Methode Komplizierteres und Höheres elaboriert, scheint sie daher auch mehr spekulativ zu sein, als die auf das Einfache reduzierende, kausal-analytische Methode.

In der vorliegenden Arbeit wird die These vertreten, daß das Streben nach der Herstellung der eschatologischen Einheit, das Brezinas gesamte nachdekadente Entwicklung kennzeichnet, zugleich auch als das Streben nach der Herstellung der p s y ch i s c h e n Einheit durch die - im Sinne der Jungschen Psychologik - erfolgreiche und produktive Integration des "Schattens" der dekadenten Vergangenheit in das axiologische System des eschatologischen Symbolismus erscheint. Doch es ist nicht nur der "Schatten" ("stín") der dekadenten Vergangenheit, dessen Integration der Dichter anstrebt. Bereits im ersten Gedichtzyklus Tajemné dálky ist das vor allem der "Schatten" des Unbewußten, repräsentiert durch die Mutter-Imago, die das Leben des Dichters über s ch a tte t, verhüllt und in ihren Bannkreis zieht. In einem der ersten Gedichte Bíezinas, Moje matka (Meine Mutter), wird diese Beziehung, dieses geheime. schicksalhafte "Komplott" zwischen Mutter und Sohn, explizit thematisiert:

"A pủlnoc zelenă kdyż svíti nočním tiším, / ty z hrobu povstáváš a se mnou lože sdilíš; / v svém dechu známý rytmus tvého dechu slyšim / a vinou mého hiasu oživená kviliš. I.../ A jako tvoje kdys i moje cesta smutná; / bez vưnẻ den je múj, bez barev, květủ jasu; / plod żiti suchý jen, jenž jako popel chutná, I tyým stínem oviván se stromu trhám Casu" (Str. VII, IX; "Und wenn die grüne Mitternacht in die năchttiche Stille leuchtet, / da erhebst du dich aus dem Grab und teilst mit mir das Lager; / in meinem Atem höre ich den bekannten Rhythmus deines Atems / und belebt von der Welle meiner Stimme klagst $d u$. /... / Und so, wie einstens $d u$, muß ich jetzt traurig schreiten, / mein Tag ist ohne Duft, farblos, kein Blühn, kein Glanz; / des Daseins trockene Frucht, die wie nach Asche schmeckt, / umweht von deinem Schatten, pflück' ich vom Baum der Zeiten").

Die archetypische Einheit - die Vereinigung mit der weiblichen Anima (mit der Mutter) auf dem nächtlichen Lager (vgl. auch das Gedicht Den výočni / Der Gedenktag) - scheint nicht nur latent erotisch motiviert zu sein; diese Einheit ist auch für die schópferische Potenz des Dichters von immenser Bedeutung. Es ist offensichtlich ein gewisses feminines Element im Dichter, das den Zugang zum Reichtum der Gefưhle, zur faszinierenden Sphäre des Schöpferischen schlechthin, erschließt.619 Aus einer Äußerung Bỉezinas geht deutlich hervor, daß er sich dieses psychologischen Hintergrundes des dichterischen Schaffens, seiner eigenen Beziehung zur Anima, zur subjektiven Imago des Weiblichen, sehr wohl bewußt war: "V básniku je néco mateỉského, aby mohl tvoriti. Proto básník není ani pravý muž". ("Im Dichter ist etwas Mütterliches, damit er schaffen kann. Daher ist ein Dichter kein echter Mann“).620 In diesem Sinne betont C. G. Jung in seinem Aufsatz "Psychologie und Dichtung" (1930): "Die Psychologie des Schöpferischen ist eigentlich weibliche Psychologie, denn das schöpferische Werk wächst aus unbewußten Tiefen empor, recht eigentlich aus dem Reiche der Mütter" 621 Für die Psychopoetik Bïezinas lyrischen Werkes ist diese Feststellung von größter Relevanz. Wie schon gesagt, dominiert in der Schaffensphase des dekadenten Symbolismus das Prinzip der D i s o zia tion unter der Herrschaft des Destruktionstriebes und des Tha $\mathrm{n}$ a to $\mathrm{s}$.

619 -Tvé krve vychladlé jsem bilým kvétem, / jenž vláhou zrakủ tvých se rozpučel a vzrưstal I.../. V mých żilách zahrivá se teplo tvého těla, / tvých zrakủ tmavý lesk se do mých ở płetil, / Žeh víry mystický, jimż duše tvá se ctivẻla, I v mé duši v oheñ žhavý a krvavý se vtélil". (Moje matka I Meine Mutter, VI, 1-2, VIII, 1-4; "Deines erkatteten Blutes fahle Blüte bin ich, / die deiner Blicke Nässe aufsprießen und wachsen ließ /.../. In meinen Adern quillt die Wärme deines Körpers, I deiner Blicke dunkler Glanz erstrahlt in meinen Augen, / des Glaubens mystische Glut, in der deine Seele bebte, I inkarnierte in meiner Seele in sengender und blutroter Flamme").

620 Diese Äußerung (aus dem Jahre 1906) überliefert eine Kollegin von Bỉezina, die Lehrerin Emilie Lakomá in ihrem Buch Ulomky hovorú Otokara Bieziny, Brno 1992, S. 14.

621 C.G. Jung. .Psychologie und Dichtung", in: C.G.Jung., Über das Phänomen des Geistes in Kunst und Wissenschaft, Gesammelte Werke, Bd. 15, S. 118. 
Die These, daß der Dichter bereits in Tajemné dálky die Einheit mit der (toten) MutterImago anstrebte, steht keinesfalls im Widerspruch zu dem in vorliegender Arbeit prăsentierten Erklärungskonzept Bỉezinas dekadenten Symbolismus. Die Mutter figuriert in Biezinas CEuvre in ambivalenten archetypischen Gestalten: sie ist die lebenspendende 'Initiatorin', die dem Dichter durch ihre "mystische Glut des Glaubens" (Moje matka, VIII, 3; "Zeh viry mystickÿ") das Reich des Kunst-Schönen erschließt; als solche 'Initiatorin' wird die Mutter im zitierten Gedicht Moje matka apostrophiert.622 Zugleich aber symbolisiert sie - als negativer Aspekt des Mutterkomplexes623 - auch den anderen Pol des Daseins: den

622 Es ist kein Zufall, daß Moje matka die Position des zweiten Gedichts im Zyklus (hinter dem Prolog-Gedicht) einnimmt. Das zweite Gedicht stellt in jedem der fünf Gedichtzyklen den Knotenpunkt, bzw. einen der Knotenpunkte im semantischen Plexus des ganzen Zyklus dar.

623 Wie es scheint kann tatsächlich von einem Mutterkomplex bei Biezina die Rede sein. Seine Anamnese läßt sich aus einem Brief (vom 12. V. 1897, in: Dopisy O. Błeziny A. Pammrovë. Praha 1931, S. 167-168) an Anna Pammrová rekonstruieren: \%.../ kdyż vzpomenu si na svou matku, tak nèkdy vpodvečer, v němž si kladu úcet ze svěho života: Co mne poutalo $\mathrm{k}$ té żenẻ /...I kterou jsem vidél tolikrát bledou a uštvanou potácet se ze dne do dne, štíhlou a hubenou $/ . . . /$. Nikdy jsem ji plnẻ nerozuměl, jejím očim żhavỹm, v nichż drỉmala nábożenská extase, jejímu hlasu sonornimu, $v$ němž chvěla se zvláštni inteligence citová s bohatstvim modulaci pro nesčisinẻ odstíny myšlenky, ironie, trpkosti, hnẻvu, préedrážděni, nesmélosti, teskna /... . A přece cim dále do sebe pronikám, tím vice citim jeji blizkost $/ . .$. . Se stisknutẏmi ity, s profilem zjemněným utrpenim. s rezignaci, která nikdy nepoznala naděje a která nevédéla o tom, $\infty$ múże být $v$ źivotẻ svẻtla a vášnẻ a boưri a lásky a slávy, kreslila mi svưj żivot /.../ všechno potopené v melancholický soumrak, jimż krácela oddané. s nenávisti $k$ rozkošim a $k$ tělu /.../. Teprv dnes, po letech, kdyź vidím ji pied sebou zidealizovanou dálkou, dovedu oceniti jeji zvláśtni duši, píedrá̃dẻnou v poslednich letech a tvrdẻ stisknutou, jako $\mathrm{k}$ tajemnému pokáni vyslanou do tohoto żivota, $v$ nẻmż jsem ji vidal a snad i miloval, ale ne tak. jak dovede milovat ten, kdo po soumracich bloudéni uvidi konecnè jasnè. A píece co by bylo mé smutné mládi bez ni, jeż byla celou jeho poesii? Neni mi možno jíti osm, devět let nazpẻt, aby najednou nebyla vedle mne, bledá a mičenlivá ... N e b y la jeji duse moji sestrou?" (Gespernt von J. V.: "I.../ wenn ich an meine Mutter zurückdenke, so manchmal gegen Abend, an dem ich mir Rechenschaft über mein Leben ablege: Was verband mich mit dieser Frau $/ . . . /$, die ich so oft bleich und gehetzt sah, sich von einem Tag auf den anderen abzumühen, schlank und schmăchtig $/ . . . /$. Ich verstand sie nie so ganz, ihre glühenden Augen, in denen religiöse Extase schlummerte, ihre Sonorstimme, in der eine eigenartige Gefühlsintelligenz mit einem Modulationsreichtum an unzähligen Schattierungen des Gedankens, der Ironie, der Bitterkeit, des Zorns, der Überempfindlichkeit, der Schüchternheit, der Wehmut vibrierte /.../. Und dennoch, je tiefer ich ins mein Innere vordringe, desto intensiver spüre ich ihre Nähe I.../. Mit zusammengepreßten Lippen, mit ihrem vom Leiden feingeformten Profil, mit Resignation, die keine Hoffnung kannte und die nichts davon wußte, wieviel Licht und Leidenschaft und Stürme und Liebe und Hehre es im Leben geben kann, zeichnete sie vor mir ihr Leben /.../ das alles in melancholische Dämmerung getaucht, durch die sie ergeben und mit $H a ß$ gegen Lust und Leib schritt I...I. Erst heute, wenn ich sie nach Jahren durch die Ferne idealisient vor mir sehe, weiß ich ihre eigenartige, in den letzten Jahren überreizte und hart gepreßte Seele zu schäłzen, als ob sie zu irgendeiner geheimnisvollen Buße in dieses Leben ausgesandt worden ware, in dem ich sie sah und vielleicht auch liebte, doch nicht so, wie derienige lieben kann, der nach Dämmerungen seines Irrsais endlich klar sieht. Doch was wäre meine traurige Jugend ohne sie. die ihre ganze Poesie war? Es ist mir nicht möglich acht, neun Jahre zurückzugehen, daß sie aut einmal nicht neben mir stünde, bleich und schweigsam ... War denn ihre Seele nicht meine Schwe ster?" Zu dem Aspekt der Identifikation mit der Anima (der Mutter) tritt noch ein anderer hinzu: die Idealisierung des Mutterbildes. Wie Jung betont, hat das Mutterbild für den Mann einen "ausgesprochen symbolischen Charakter" und darin gründet wohl auch die Neigung des Mannes die Mutter zu idealisieren. In dieser Idealisierung sieht Jung einen "geheimen Apotropäismus": "Man idealisient, wo eine Furcht gebannt werden soll. Das Gefürchtete ist das Unbewußte und dessen magischer Einflu B". (C.G. Jung. .Die psychologischen Aspekte des Mutterarchetypus", in: Ders.. Die Archetypen und das kollektive Unbewusste, Gesammelte Werke. Bd. 9/1, Otten-Freiburg i. Br. 1976, S. 119.) Der ambivalente Charakter der magischen Autorität des Weiblichen, die geradezu verblüffende Gegensătzlichkeit der Eigenschaften der (Mutter-) Anima, tritt in einer Reihe von Bỉezinas Gedichten sehr deutlich zutage. Besonders eindrucksvoll wird die Ambivalenz des Weiblichen (des Mutterarchetypus) in Aż sedneš za múj stül... (Wenn du an meinen Tisch dich setzt...) aus dem zweiten Gedichtzyklus Svitáni na zapadë (Tagen im Westen, 1896) thematisiert: "Aż sedneš za múj stùl, cekaná. Nepozvaná, / se zraky tajemstvi, se slovy nẻmými. / s bohatstvim neznámým, milostná obávaná. / s dotknutím ledovým, s polibky vécnỳmi" (IV. 1-4; "Wenn du an meinen Tisch dich setzt, du Erwartete. Ungerufene, I mit Blicken des Geheimnisses, mit stummen Worten, / mit unbekanntem Reichtum, I du Liebliche. 
Tod, 624 den Kunst-Tod, in dessen magischen Bannkreis der Dichter/Sohn hineingezogen wird. Die D i s s o z i a ti o $n$ von der irdischen Welt, die das Überschreiten der Grenze zur Sphäre des Unbewußten und des Thanatos bedeutet die Verwirklichung der ästhetischen Existenz und die Vereinigung mit der Anima; dies alles wird auf das KunstSchöne - auf die technë poiētikë - projiziert. 625 Der 'Sturz' in den Kunst-Tod scheint der Garant für die postulierte ästhetische Existenz zu sein. Das Bild der Anima, das "der Mutter in den Augen des Sohnes übermenschlichen Glanz verlieh",626 inkarniert in der Schaffensphase des dekadenten Symbolismus (auch) in der Gestalt der personifizierten Dichtkunst/Geliebten, wie im Gedicht Tichá boiest (Der stille Schmerz), in dessen ersten Strophe eine beinah identische Situation wie in Moje matka inszeniert wird: "Po cerném koberci, jejž k mému loži stínem / v šat vonný kašmiru Noc tkala kyprou vinou, / ty's prì̌̌la. Milá má, a nalila's mi vinem / svých retủ hởkou čiši plnou. / Mé tẻlo projala's jak bledá záre divem, / v mých nervech hởelas jak umiráni pocit, / a pohr̉ben v loktech tvých, jak v chladném hrobẻ żvém, I pod tiži polibkủ jsem unavený procit' (I. Str.). 627 Mit der Anima will sich das dichterische Ich in der autonomen und isolierten Kunst-Welt (des Zyklus Tajemné dálky) 'verschanzen'. 628 Sie ist die (verjüngte Mutter-)Geliebte, die "tote Jugend", die Dichtkunst, das KunstSchöne selbst; im weiteren Sinne die "feuchte Katakombe" ("vihká katakomba"; Vèzeñ I Der Gefangene, VII, 2), das "Gewölbe" ("klenba", Tichá bolest / Der leise Schmez, V, 5; Vězeñ / Der Gefangene, VII,3), d. h. jede Hohlform, aber auch die Wassertiefe (z. B. in Motiv z Beethovena / Ein Motiv aus Beethoven), der "Zinnsarg" ("rakev z cínu". Uméní I Die Kunst, IX, 2), das Liebeslager, das zugleich das Sterbebett bzw. das Grab darstellt (Moje matka I Meine Mutter, VII, 2; Den výročni / Der Gedenktag, VII, 5), die Revenantin (Moje matka, Str. VII), der Tod usw. 629 Der Dichter wird zum Medium, durch das die Mutter(-Imago) spricht: "a vinou mého hlasu oživená kvílís" (Meine Mutter, VII, 4; "und

Gefürchtete, / mit eisiger Berührung, mit ewigen Küssen"). In der Gestalt der Revenantin, der "Lieblichen"-"Gefürchteten", erkennt man die Imago der toten Mutter aus dem Gedicht Moje matka (Meine Mutter), die sich aus ihrem Grab erhebt und mit dem Dichter/Sohn das Lager teilt.

624 Bỉezina wuchs als Einzelkind auf, seine zwei Geschwister starben im frühen Kindesalter. Dazu Bỉezina in einem Brief an A. Pammrová: "/.../ když vzpomenu na svou matku $/ .$. / štîhlou a hubenou, znið̌enou nemoci, již zaplatila život mého mladšiho bratra, zeḿ̛elého $v$ dètstvi?" (Brief vom 12. 5. 1897; $\%$... wenn ich an meine Mutter zurückdenke $/ \ldots$. , die ich so oft schlank und schmächtig, von der Krankheit vernichtet sah, mit der sie das Leben meines jüngeren Bruders bezahtte, der im Kindesalter starb?"). Auch hier liegt offensichtlich der Ursprung der in Tajemné dálky thematisierten Ambivalenz der Mutterimago, ihrer starken Affinität zur Sphăre des Thanatos (als archetypisches Bild der 'Mutter', die nicht nur das Leben, sondern auch den Tod 'gebiert'). Pavel Fraenkl schreibt in seiner Br̉ezina-Monographie: "/.../ stigma smrti Ipělo /.../ na básnikovẻ rodové minulosti svou osudnou stopou". (Otokar Bł̌ezina. Mládi a plerod - Genese dila, Praha 1937. S. 154: \%... das Stigma des Todes haftete mit seiner schicksalhaften Spur am Stammbaum des Dichters." )

$625 \mathrm{Im}$ oben zitierten Brief an A. Pammrová (v. 12. V. 1897) schreibt Bỉezina ausdrücklich: "A płece $\infty$ by bylo mé smutné mládi bez ni, jeż byla celou jeho poesii?" "Doch was wäre meine traurige Jugend ohne sie (ohne Mutter; J.V.], die ihre ganze Poesie war?").

626 C.G. Jung. Die Archetypen und das kollektive Unbewusste, Bd. 9/1, Olten-Freiburg i. Br. 1976, s. 84.

627 -Auf schwarzem Teppich, den zu meinem Lager / die Nacht mit Schatten wie ein wohlduftendes Cashemirekleid mit weicher Wolle webte, / kamst du, meine Geliebte, und schenktest mir mit dem Wein deiner Lippen / einen bitteren Pokal ein. / Meinen Körper durchdrangst du mit einem Wunder wie ein fahler Strahl, / wie des Sterbens Gefühl lodertest du in meinen Nerven. / und in deinen Armen begraben, wie in einem kalten lebendigen Grab, / wachte ich unter der Küsse Last ermattet auf" (Tichá bolest / Der leise Schmerz, I. Str.).

628 Vgl. hierzu C. G. Jung: $\%$.../ die Mutter [ist] alt und jung, Demeter und Persephoneia, und Sohn ist Gatte und schlafender Säugling in einem; ein Zustand unbeschreiblicher Enfültheit, mit dem die Unvollkommenheiten des wirklichen Lebens, die Anstrengungen und Mühen der Anpassung und das Leiden der vielfachen Enttäuschung an der Wirklichkeit natürlich nicht von ferne konkurieren können". Die Syzygie: Anima und Animus", in: Aion. Beiträge zur Symbolik des Selbst, Gesammelte Werke, Bd. 9/2, Otten-Freiburg i. Br. 1976, s. 20-31.

629 Der toten Mutter sind in TD noch zwei Gedichtte gewidmet: Den vyrocni (Der Gedenktag) und Znameni duše (Das Zeichen der Seele), deren Semantik in einem anderen Kontext erörtent wird (Vgl. Kap. 2.1.1). 
belebt von der Welle meiner Stimme klagst du").630 In dem von der Mutter-Revenantin überschatteten Reich des Kunst-Schönen herrschen Kälte und ästhetizistische Vollkommenheit (der artefiziellen Kunstgegenstände), ganz im Sinne des (thanatophil orientierten) ästhetisierten Masochismus bzw. oder des masochistischen Ästhetismus (vgl. Kap. 2.3.1). Noch im Gedichtzyklus Stavitelé chrámu (Baumeister am Tempel, 1899) wird im Gedicht Smutek hmoty (Die Traver des Stoffes) die Mutter-Imago in ihrer numinosen Autorität in die archetypische Gestalt der webenden Erdmutter, der schwermütigen Vestalin projiziert.631 Der Mutter(-Imago) bleibt der Dichter/Sohn - im psychologischen Sinne - tatsächlich treu: "V královstvi Zeny jsem se setkal jedinẻ se svou matkou a s Vaši duši." ("Im Königreich der Frau bin ich nur meiner Mutter und Ihrer Seele begegnet"). ${ }^{632}$

630 Noch in einem Brief vom 3. VI. 1905 schreibt Bíezina an A. Pammrová: "Povidala mi jednou: Chtéla jsem mit díté ... Mèla ho ... Bude ono mít kdy sily, aby łeklo, co ona zamlčla?" (Dopisy O. Bíeziny A. Pammrové z let 1889-1905, Praha 1931, S. 217; "Einmal sagte sie [die Mutter; J.V.] zu mir: Ich wollte ein Kind ... Sie hatte es... Wird es jemals die Kraft haben, um zu sagen, was sie verschwiegen hatte?".

631 'Żal stromú resignovanỳ, v mou duši z hloubky vydech' / o smutku hmoty hovoril a lethargických klidech, / kde světel vlákna hedvábná pro svatebni šat żiti / zem spłádá cernýma svráskalỳma rukama a níti / svujj oheñ zvolna hasnouca, Vestálka zádumčivá". (Smutek hmoty I Die Trauer des Stoffes, V. 11-15; "Der Bäume resigniertes Leid stieg auf in meine Seele, / sprach von des Stoffes Trauer ihr, von lethargischer Stille. I wo für des Lebens Hochzeitskleid mit schwarzen Runzelhänden / die Erde Licht wie Fasern spinnt und facht zu neuen Bränden, / schwermütige Vestalin, Glut, die langsam wieder zündet". Übers. v. O. Pick.) Das (Gedä̀chtnis-)Bild der spinnenden Mutter erscheint auch in der Korrespondenz des Dichters. Im Brief vom 12. V. 1897 an Anna Pamrová schreibt Bł̌ezina: "A płece Cím dále do sebe pronikám, tím vice ćitim jeji blizkost a mám v sobẻ soumraky naplnẻnẻ jejim hlasem, kdyż jsme sedávali spolu za zimnich veðerủ, u malẻ lampičky, svitici cervenẻ v pološeru svẻtnice; dlouhá pásma konopi jiskrïla se reflexem svétta, svítly jeji ruce a ona ke mné mluvivala, predouc ..." (S. 168; "Und dennoch, je tiefer ich ins mein innere vordringe, desto mehr spüre ich ihre [d.h. der Mutter; Anm. vom Verf.] Nähe und in mir liegen Dämmerungen, erfültt mit ihrer Stimme, als wir an Winterabenden bei einer kleinen Lampe, die im Halbdunkel der Stube rötlich leuchtete, zusammensassen; die langen Hanfsträhnen funkelten im Lichtreflex, ihre Hände leuchteten und sie sprach zu mir spinnend ..."). Im Spinnen. Weben, (Seil-) Flechten usw. erkennt J. J. Bachofen symbolische Handlungen der großen Naturmütter in bezug auf die tellurische Schōpfung. Der Erdzeugung und Geburt wird das Auflösen und Formnehmen entgegengesetzt. Die webende, spinnende und lebengebende Erdmutter erweist sich zugleich auch als die .große Moira, die in das Gewebe jedes irdischen Daseins den Todesfaden mit einflicht”. J.J. Bachofen, Versuch über die Gräbersymbolik der Alten, Gesammelte Werke, Bd. 4. Basel 1954, S. 359-369.

632 Dopisy O. Bỉeziny Annè Pammrové z let 1889-1905, Praha 1931, S. 151. Brief v. 15.XI. 1896. In seinem bakannten Lehrbuch der Konstitutionspsychologie Körperbau und Charakter (1921) stellt Ernst Kretschmer eine für viele Schizothymiker charakteristische "überstarke gefühlsmäBige Fixierung an die Mutter" fest. Als eine der häufigsten Charaktereigenschaften dieses Konstitutions- und Temperamenttypus nennt Kretschmer auch die bei Biezina sehr stark ausgeprăgte. geradezu hypertrophiente Schüchternheit. "Sie kann bei innen so hohe Grade erreichen, daß sie die Gewinnung eines selbst heftig begehrten Sexualzieles schlechterdings verhindert". Das psychische Liebesbedüntnis .behălt dann eine der frühen Pubertătszeit ähnliche Form bei; es wirkt sich rein auf dem Phantasieweg in inneren Träumereien. Gedanken- oder Wahngebäuden, sehr häufig $z$. B. als Fernliebe zu $k$ aum gesehenen Personen aus". Kretschmer spricht in diesem Zusammenhang vor signifikanter Klutt bzw. Spaltung bei Schizothymikern: .Hier Ich, meine ethische Persönlichkeit. dort der Sexualtrieb als etwas Feindliches, als ein beständig störender Fremdkörper. So daß dann der aufs schärtste zugespitzte moralische Kampf zwischen den beiden nie vereinten Instanzen geradezu zum dauernden Lebensinhalt werden kann*. E. Kretschmer, Körperbau und Charakter [21. U. 22. Aufl.]. Berlin 1955, S. 132-133. Bł̌ezinas Gedichte (insbesondere aus Tajemnè dálky) und seine Korrespondenz enthalten zahlreiche implizite oder explizite Hinweise auf die von Kretschmer dargestellte charakteristisch schizothyme Einstellung zum Liebesleben. Man denke nur an Br̈ezinas platonische Liebe zu seinen Mitschülern Alois Cermák und František Bauer während der Gymnasialzeit ("Má láska k Cermákovi se Vám tedy libila? Proð̉ pišete, że skončila tak prosaicky?", Dopisy O. Bỉeziny Annẻ Pammrově, Praha 1931. Brief. v. 25.XI. 1896, S. 151; "Meine Liebe zu Cermák hat Innen also gefallen. Warum schreiben Sie dann, daß sie ein prosaisches Ende nahm?"). In dieser Hinsicht scheint auch Březinas geistige Freundschaft mit Anna Pammrová symptomatisch zu sein: Bł́ezina lernte Pammrová im Herbst 1887 kennen; seit 1889 korrespondierten sie vier J a h r z e h n te lang (1889-1929) intensiv miteinander. Während dieser Zeit ist Bł̌ezina seiner Freundin lediglich dreimal $(1925,1927,1928)$ persönlich 
Wie es scheint, vermochte sich Bïezina von der Animafaszination der Mutter, selbst wenn dieses Faszinosum inm - bzw. seiner schöpferischen Energie - letzten Endes zum Verhängnis wurde, nie 'restlos' zu befreien.633 In der Phase des eschatologischen Symbolismus werden aber neben dem Mutterarchetypus auch andere Archetypen 'aktiviert'. Der Weg zur Herstellung der psychischen Einheit, dessen erste 'Stufe' in der Phase des dekadenten Symbolismus die Einheit mit der (Mutter-)Anima in der autonomen Kunst-Welt darstellt, wird in der Phase des eschatologischen Symbolismus fortgesetzt. wobei die einzelnen Modelle, die zur Herstellung der eschatologischen Einheit führen, mit den Modellen der Herstellung der psychischen Einheit korrelieren. Diese Entwicklung kulminiert im letzten vollendeten Gedichtzyklus Ruce (Hände, 1901) und in den letzten Gedichten (1901-1907) in der Manifestation des Kindarchetypus, der die (psychische) Einheit des Menschen kat exochēn symbolisiert.

Im ersten $\mathrm{n}$ a ch de $\mathrm{k}$ a de $\mathrm{n}$ te $\mathrm{n}$ Zyklus Svitáni na západè (Tagen im Westen, 1896; gnostisch-eschatologisches Modell) macht sich die Tendenz bemerkbar, die paradoxe Einheit (paradox, weil ihre Bedingungen die Dissoziation und Isolation sind), die die psychische Sinnfolie des dekadenten Symbolismus (TD) charakterisiert, zu

begegnet. Aư die Problematik der sog. 'Timidität' in der Persönlichkeitsstruktur Brezinas gehen J. Bartos, .O typu lidi timidních. Príspěvek k psychologii Ot. Breziny", in: Filosofie 2, 1929, S. 289 297, und auch P. Fraenkl in seiner Monographie ein: Otokar Březina. Mládi a prerod-Geneze dila, Praha 1937, S. 25, 50f. Nicht ohne Interesse ist in diesem Kontext die Feststellung von Wolfgang Kretschmer (in: Vorwort zur 26. Aufl. von Korperbau und Charakter, Berlin-Heidelberg-New York 1977): "Denkwürdig und kaum zufällig ist die wenig bekannte Tatsache, daß die verbreiteten und dauenaftesten Temperaments- und Charakterlehren, die von Jung und Kretschmer, im gleichen Jahr 1921 unabhängig voneinander veröffentlicht wurden. Sie überschneiden sich sachlich und ergänzen sich durch die verschiedene Blickrichtung aufs beste".

633 Im wirklich en Leben aber sehnte sich Br̈ezina nach der Künstlerexistenz in einer schöpferischen Gemeinschaft mit seinem Jugendfreund und Kommilitonen aus dem Realgymnasium, mit František Bauer. In seinen langen Briefen versucht er immer wieder seinen Freund für das gemeinsame Leben für die Kunst zu gewinnen. " $/ . . /$ znám Tebe lépe neż sama sebe a myslím na Tebe při każdé nové stránce, kterou písi /... / nic vic bych si neprál, neż żíti $s$ Tebou jeden dva trị roky, a vidèl bys, co bych z Tebe udélal! Snad je domýšlivost i $v$ tèchto slovech, ale domýšlivosti, kterou diktuje láska, milerádo odpouśsti płáátelstvi. I... I A pamatuješ, jak leżivali jsme spolu pod jednou prikrývkou krčice se $k$ sobé a hovởice blouznivẽ o vši té slávé, která nas jednou ozárí? A vše to, co tehdy ohřivalo naši duši, mělo by prijíti na zmar? Vše to mělo by sežehnuto býti mrazem a nerozkvésti vic? Prikryto býti tmou a nezapláti barvou? Vše by mělo býti pouhým snem miadistvěho studenta, který zahởel jako sțelná bavina pro první ideál a ztrnul jako stalaktit na chladném vzduchu skutecněho Żivota?". O. Bł̌ezina, Dopisy O.B. Frantisku Bauerovi, Praha 1929, S. 117 (Brief vom 30. IV. 1890; $\%$. I Dich kenne ich besser als mich selbst und an Dich denke ich bei jeder neuen Seite, die ich schreibe /.../ ich würde mir nichts anderes wünchen, als mit Dir nur ein, zwei, drei Jahre zusammenzuleben und Du würdest sehen, was ich aus Dir machen würde! Es liegt vielleicht Einbildung in diesen Worten, aber der Einbildung, die die Liebe diktiert, verzeiht die Freundschaft herzlich gern. I.../ Und erinnerst Du Dich, wie wir aneinandergedrückt unter einer Decke lagen und schwärmerisch von all dem Ruhm, der über uns einmal erstrahlen sollte, redeten? Und all das, was damals unsere Seele wärmte, sollte zugrunde gehen? All das sollte vom Frost vesengt werden und nie wieder aufblühen? Vom Dămmer zugedeckt werden und nie in Farbenpracht auflodem? All das soltte nur ein bloßer Traum eines jungen Studenten sein, der für das erste Ideal wie die Schießbaumwolle aufflammte und wie ein Stalaktit in kalter Luft des wirklichen Lebens erstarte?"). Und in seinem Brief vom I. XII. 1892 (ibid., S. 177) schreibt Bỉezina: "Co bych za to dal, kdybych mohl žiti v tvém ovzduši, najíti v Tobè onoho prítele studentských našich let, kdy spávajice na jedné posteli, umírali jsme rozkośi prí vzpominkách na naši budouci slávu". "Was würde ich dafür geben, wenn ich in Deiner Atmosphäre leben, in Dir den alten Freund unserer Studienjahre finden könnte, als wir, in einem Bett schlafend, bei der Erinnerung an unseren künftigen Ruhm vor Lust starben"). Sction in der Schule schwärtme Bỉezina für einen Mitschüler: "Imenoval se Cermák. Știhlý, sličnè rostlý brunet, $s$ podivnou nuanci $v$ hiase, kterou jsem -zbožnonoval, se zvláštni nedbalosti $v$ prízvuku, nenapodobitelnou. I.../ Podle Hálkových písni psával jsem pro nèj verše s naivnim smutkem. Vymýšlel jsem rozmluvy s nim, $v$ duchu podávali jsme si ruce, chodivali jsme dlouhými kaśtanovými alejemi mého snu I... (Dopisy O. Br̈eziny A. Pammrové z let 1889-1905, Praha 1931; Brief vom 30. IX. 1896; "Er hieß Cermák. Ein schlanker, anmutig gewachsener Brünetter, mit einer sonderbaren Nuance in der Stimme, die ich vergötterte, mit einer eigenartigen, unnachahmlichen Lässigkeit in der Tonart. /... In der Manier von Háleks Liedern verfaßte ich für inn Verse von naiver Wehmut. Ich erdichtete mir Gäspräche mit ihm, in der Phantasie gaben wir uns Hände, spazierten durch die langen Kastanienalleen meines Traumes /... $r$.) 
'vervollkommnen'. Es scheint, als ob der Dichter diese 'Sonderform' der psychischen Einheit als die nicht ideale, noch nicht vollendete 'durchschauen' würde. Daraus resultient einerseits eine gewisse 'Lockerung' der Bindung an die weibliche Anima, an den Mutterarchetypus, andererseits der damit zusammenhängende Versuch die "Schatten" der dekadenten Vergangenheit in das semantische System des e s c h a to l o g i s c he $n$ Symbolismus zu (re)integrieren. Damit geht Hand in Hand die Verdrängung bzw. Unterbindung des thanatophilen Pols der Anima-Fixierung, des Finsteren, Ominösen, Verborgenen, Vergiftenden usw., und die Stärkung und Exponierung des erotischen Pol: des Produktiven, Vitalen, Wachstum-, Fruchtbarkeit- und Lebenspendenden usw. Vor allem jedoch wird die paradoxe, vom bannenden Einfluß der Mutterimago überschattete Einheit mit der Anima durch die Orientierung auf das Bild des - in der Sprache Bïezinas "Höchsten" ("Nejvyšši"), auf die imago Dei, komplementient und 'korrigient'. Diese Orientierung führt im dritten Gedichtzyklus Vêtry od pólü (Polarwinde, 1897; theo-logischeschatologisches Modell) zur Manifestation des Vaterarchetypus, insbesondere im Logos spermatikos-Bild (als befruchtendes Pneuma).

Die wahre imago Dei, die Christus ist, 634 symbolisiert nach Jung den Archetypus des Selbst und stellt "eine Ganzheit göttlicher oder himmlischer Art dar, einen verklärten Menschen, einen Gottessohn "sine macula pecati», der von der Sünde nicht befleckt ist". 635 Christus bedeutet das vollkommene Gottesbild, daher wird er auch "König" genannt. Seine "Braut" ist die menschliche Seele. Durch den Sündenfall wurde das Gottesbild im Menschen nicht gänzlich zerstört, sondern nur verdorben und durch die göttliche Gnade wird es wieder hergestellt. Diesen 'Integrationsversuch' symbolisiert die Höllenfahrt ("descensus ad inferos") der Seele Christi. Die Problematik der Wiederherstellung des ursprünglichen Zustandes, des Archetypus der Ganzheit, ist jedoch auf der psychischen Bühne mit dem Problem des Bösen (des Antichristen als 'Gegenspieler' Christi) verbunden. In der Jungschen Psychologik entspricht der Antichrist dem Schatten des Selbst, dem dunklen, verhülten, chthonischen und verdrängten Pol der menschlichen Totalität. Und Licht und Schatten bilden im Selbst wiederum eine paradoxe Einheit. 636 Ein wichtiger Aspekt der gnostichen Lehre ist die Auseinandersetzung mit dem Problem des Bösen. Wie die spätantiken Gnostiker lehren, habe "Christus seinen Schatten von sich abgeschnitten". Nach Jung läßt sich dieses abgeschnittene SchattenGegenstück unschwer als die Gestalt des Antichristen, der als böser 'schattenhafter' Geist der Christi Fußstapfen folgt, interpretieren.637 Diese Symbolik spielt in Svitáni na západè eine semantisch konstitutive Rolle: der "Schatten von Jemand" ("Stín Nëkoho", Legenda tajemné viny / Die Legende der geheimnisvollen Schuld), d. h. des 'bösen' Gottes, findet sein Analogon im Schatten des Selbst (Jung spricht von einer "Kreuzigung des Ich", die eine Differenzierung des Ich-Bewußtseins zwischen unvereinbare Gegensätze bedeutet):

'VŠak marně jsem krácel, kde v závratnỳch rytmech se t̛̉ás' / zpẻv Żiti. Stín Nékoho, jenż za

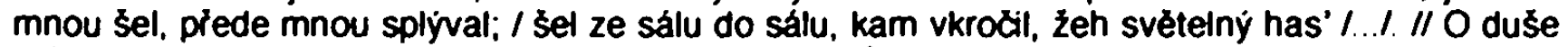
má. odkuđ on prišel? A kolik staleti snad / mých piedkủ dušemi procházel, neż došel aż ke mnẻ? I $\mathrm{Na}$ kolik svatebnich stolü jak ubrus koberec rekvii klad? I Na kolik rủżových úsmévu் dechl svùj podzemni chlad? I A v kolika lampách plamenem soli a líhu sesinal temnę?-638

Eines der im gnostisch-eschatologischen Modell von Svitáni na západé gesetzten Hauptziele ist die (erfolgreiche) Integration der "Dunkelheit" in das "Licht" und umgekehrt die coniunctio von "Licht" und "Finsternis". Das Resultat heißt in SZ "zárici tma"

634 "Augustinus unterscheidet zwischen der imago Dei, welche Cristus ist, und jener imago, die dem Menschen als ein Mittel, oder eine Möglichkeit, die Gottebenbildlichkeit zu erlangen, eingepflanzt ist". C.G. Jung. .Cristus, ein Symbol des Selbst", in: Aion. Beitrāge zur Symbolik des Selbst, Gesammelte Werke, Bd. 9/2, Otten-Freiburg i. Br. 1976, S. 48.

635 Ibid., S. 47.

636 Ibid., S. 52

637 Ibid., S. 51.

638 "Doch schritt ich umsonst, wo in taumelnden Rhythmen voll Überschwang / das Leben vibrierte. Der Schatten von Jemand, der hinter mir herging, floß vor meinen Schritten; / er ging von Saal zu Saal, und wo er eintrat, der Lichtstrom versank /.../. / O Seele, woher kam Dieser? Und wieviel Jahrhunderte kreist / er durch meiner Ahnen Seelen, eh zu mir seine Schatten kamen? I Auf wieviel Hochzeitstischen hat schon als Matte sein Requiemteppich gegleißt? / Wieviel rosenatmendes Lächeln hat je sein Grabhauch vereist? / Und in wieviel Lampen ward fahl er in Salzes und Brenngeistes Flamen?" Übers. v. P. Eisner. 
("strahlende Dunkelheit", Vino silných I Der Wein der Starken, V. 46) als Sinnbild der unio mit dem "Höchsten":

"Barvami neviditelného vidma mé obrazy se vzejmou, hýrici slávou, I stíny jejich budou položeny osłñujicim zárenim pozemských svểet, / však jejich svêtla tvỷm stínem" (Ranni modlitba I Das Morgengebet, V. 78-80; "In Farben unsichtbaren Spektrums entzünden sich meine Bilder, schwelgend in Hehre; / ihre Schatten werden gelegt sein durch das blendende Strahlen der irdischen Lichter; I doch ihre Lichter durch deinen Schatten"). "At rostou Cerné vegetace stínu $z$ kởenú stromú, zalitých krví! /... / A zastavi-li se duše má na dlouné pouti svých otcủ staletími, / až v cerném zrcadle zmaru uvidim tvár svou změnénou formami nového žití, I pozdravem zulibám stiny a piseň zazpivám żivým, / i poutnikủm budoucim, kteři se odvaži țhati kvíti v údoli smrti" (Mythus duše I. Mythus der Seele, V. 43, 50-53; "Mögen doch schwarze Vegetationen der Schatten aus den Baumwurzeln wachsen, den vom Blut übergossenen! I.../ Und wenn meine Seele auf dem langen Weg meiner Väter durch die Jahrhunderte einhält, wenn ich im schwarzen Spiegel der Vernichtung mein Antlitz erblicke, verwandelt von den Formen neuen Lebens, / küsse ich grüßend die Schatten und singe ein Lied den Lebendigen / und den künftigen Pilgern, die es wagen, die Blüten im Tal des Todes zu pflücken"). "Stíny slożi se nám jak péra v kłídlech, posetá hvézdami, smějici se dálkám" (Víno silných / Der Wein der Starken, V. 25; "Schatten legen sich uns zusammen wie Federn in Flügeln, besät mit Stemen, spottend der Weiten").

Den Akt der Vereinigung mit der imago Dei und das Erreichen der psychischen Einheit des in Gegensätze gespalteten Ich-Bewußtseins thematisiert die Schluß-Sequenz des wohl zentralen Gedichtes von Svitáni na západé, Ranni modlitba (Das Morgengebet). Die als "Traum" apostrophierte Seele des dichterischen Ich nimmt die Gestalt eines majestätischen Adlers639 an, der in seinen "glühenden Krallen" die (unerlöste) anima mundi ("zem"), die miterlöst werden soll, trägt. Er durchdringt die Finsternis und läßt sich zu den Füßen des Höchsten nieder:

"I pozdvihne se sen mưj s křidly ozáǐenými reflexy věčného jitra / a jako gigantský fantom orla zem ponese $v$ Žhavých svých spárech, I na dvẻ strany rozhme ¿emé oblaky nocí a lehne $k$ tvým nohám" (Ranni modlitba / Das Morgengebet, V. 82-84; "Und erheben wird sich mein Traum mit Flügeln, die auffangen die Reflexe ewigen Morgens, / und wird wie das gigantische Phantom eines Adlers die Erde in seinen weißglühenden Fängen hintragen; / wird zu beiden Seiten das schwarze Gewölke der Nacht auseinandertreiten und nieder sich lassen zu deinen Füssen").

Der Seelenaufstieg kulminiert in der extatischen Vision einer erotisch-mystischen Vereinigung; as dichterische Ich läßt sich - indem es sich mit der Anima identifiziert - in der w e iblich e n Position640 (analog zu jener der anima mund) von der Majestät des

639 Das Bild der "beflügelten Seele" ist eine antike Vorstellung (Platon u. a.); in der Lehre von Basilides (2. Jahrhundert) hat die Seele die "Flügel des Adlers" um das Schwere emporzuheben und die Lichtregion zu erreichen. C.G. Jung. Aion. Beiträge zur Symbolik des Selbst, Gesammelte Werke, Bd. 9/2, Olten-Freiburg i. Br. 1976, S. 74.

640 In der oben zitierten Schlußsequenz von Ranni modlitba stellt sich das dichterische Ich gegen den "Hochsten" ("Nejvyšsi") ausgesprochen feminin ein. In der weiblichen Position tritt das dichterische Ich auch in einem der Schlüsselgedichte des dritten Zyklus Vêtry od pólü, in Poledni záni (Mittäglich Reifen; Kap. 4.3.2), auf. Meines Erachtens manifestiert sich darin sowohl die (unbewußte) Wirkung der weiblichen Anima auf die Psychik Błezinas bzw. das Oszillieren zwischen dem weiblichen und dem männlichen Pol seiner Persönlichkeit, als auch das (in diesem Gedicht) ambivalente Verhältnis des Dichters zum "Hochsten". In Ranni modlitba oszilliert dieses Verhältnis zwischen mănnlicher Tatkraft und männlichem Stolz und zwischen weiblicher Hingabe und Demut. Diese Form der von Biezina thematisierten femininen Einstellung genen die Majestät Gottes weist geradezu verblüffende Analogien zu den Phantasien des ehemaligen Senatspräsidenten Daniel Paul Schreben, die S. Freud in seiner bekannten "Schreber-Analyse“ (1910-1911) interpretiert: .Psychoanalytische Bemerkungen über einen autobiographisch beschriebenen Fall von Paranoia (Dementia paranoides)", in: S. Freud, Studienausgabe, Bd. VII, Frankfurt am Main 1978, S. 135-203. Im Jahre 1884 traten bei Schreber Symptome einer psychischen Störung hervor, deren Verlauf er in seinen autobiographischen Denkwürdigkeiten eines Nervenkranken (1903) schildert. Schrebers Erkrankung diagnostiziert Freud als eine Paranoia mit einem von Schreber vertretenen charakteristisctien Wahnsystem besonderer Art. Es handelt sich um Wahnideen religiös-mystischer Art, in denen der Patient "Wundererscheinungen" sah, direkt mit Gott verkehrte, "heilige" Musik" hörte usw. Der erste Keim und man könnte sagen auch der Kern - Schrebers Wahnbildung ist die 'Verwandlung' in ein weibliches Wesen, in das "Weib Gottes". Vor seiner Erkrankung tendierte Schreber zum sexuellen Asketismus und zweifelte an die Existenz Gottes; durch die Krankheitsveränderung war er ein mystischer Gottesgläubiger, dem Sexualgenießen zugeneigt. Doch seine 'Wollustempfindung' war 
"Höchsten" durchdringen: 641 "a zrak své pýchy nastavi pokornè proklání pohledu tvého / v sycicim výtrysku krve osleplý zárí" (V. 85-86; "und [wird] den Blick seines Stolzes demütig hinhalten deinem durchbohrenden Schauen / im zischenden Blutstrahl geblendet vom Glanze“). ${ }^{642}$ Doch es ist nicht nur der Akt der mystisch-erotischen Vereinigung mit dem "Höchsten", der in Svitáni na západè die neue Orientierung auf dem Wege zur Herstellung der (psychischen) Einheit signalisiert. Es ist auch eines der charakteristischsten Symbole der Einheit, das bereits in den Gedichten von SZ vorkommt: der Kreis. Von diesem Symbol leiten sich andere Symbole der Einheit her: Rad, Stadt, Kirche, Gefäß, Garten u.a. Diese wiederum leiten über zum Inhalt, d. h. zu den Bewohnern der Stadt oder zu dem Wasser, dem Wein usw. 643 Signifikanterweise spielen diese Symbole eine eminente, sinnkonstitutive Rolle im Epilog-Gedicht Vino silných (Der Wein der Starken):

"Tajemný proưd uzavie se kruhem kol našeho stolu, / vymkne nás ze zákonù zemè, a żivot a smrt bude našemu sněni odpovidati. I...I V carovném kruhu,velkém jak obzor, se uzavieme úzkostem noci. I.../ Bratrí. z ruky do ruky podávejme vino silných ve své dús" (V. 7-8. 13; "Geheimnisvoll schließt ein Strom seinen Kreistauf um unser Tischrund, / hebt uns aus den Gesetzen der Erde, und Leben und Tod werden Antwort stehn unserem Träumen. I.../ In einem

von einem äußerst ungewöhnlichen Charakter, der in der weiblichen Einstellung Schrebers gegen Gott begründet liegt. Nach seiner "Verwandlung zum Weib" empfand Schreber sich selbst als "Gottes Weib" mit dem Eindruck, "daß sein Körper mit weiblichen Brüsten und weiblichem Geschlechtsteil ausgestattet sei. I.../ Es war nicht mehr männliche Sexualfreiheit, sondern weibliches Sexualgefühl /...r. (Ibid.. S. 159). In der weiblichen Gestalt fühlte sich Schreber in der Lage zu sein, den Same Gottes (die "Str a h I en Gottes") zu empfangen. Die Bedeutung der Schreber-Analyse ist mit den Erklärungen zur Paranoia keineswegs erschöpft. Sie gilt als eine der ersten metapsychologischen Schriften Freuds, die sich mit den mythologischen Aspekten und dadurch auch mit bestimmten archetypischen Unorstellungen auseinandersetzt. In bezug auf die von Błezina konkretisierte Vorstellung der femininen Einstellung gegen die patriarchalische Majestät des "Höchsten" scheint die Schreber-Analyse äuBerst aufschluBreich zu sein. Von besonderem Interesse ist in diesem Zusammenhang nicht nur die Vorstellung der durchdringenden, befruchtenden "Str a hle n" Gottes, sondern vor allem die Einstellung Schrebers zu Gott als Vater, dessen sublimiertes Symbol die $S$ o $n$ n e ist. Schreber identifiziert die Sonne mit Gott, daher rührt auch die Vorstellung der machtvollen "Strahlen". Freud reduziert die Deutung dieser Wahnldeen (deren 'Held' eigentlich der behandelnde Arzt Schrebers war) mehr oder weniger auf das infantile Verhältnis des Kranken zu seinem Vater. Die höchst eigentümlichen Symbolbirdungen dieser Wahnideen. die deutliche Analogien zu mythologischen Symbolbildungen aufweisen, werden nicht interpretiert. Nur in seinem kurzen Nachtrag zu der Schreber-Analyse (ibid.. S. 201-203) geht Freud auf das Verhältnis Schrebers zum Vater- und Gott-Symbol ein: es ist die Sonne. Die Sonne offenbart sich Schreber als belebtes, sprechendes Wesen. Schreber sehnt sich danach, ruhig in die Sonne zu sehen, und davon "nur in sehr bescheidenem Maße" geblendet zu werden. Diese archetypische Vorstellung, ungeblendet in die Sonne zu schauen, gründet sich auf einem mythologischen Fundament. Nach den alten Naturforschern war dieses Vorrecht allein den Adlern, als Bewohnern der höchsten Luftschicht, vergönnt. "Und wenn Schreber sich rühmt, daß er ungestraft und ungeblendet in die Sonne schauen kann. hat er den mythologischen Ausdruck für seine Kindesbeziehung zur Sonne wiedergefunden, hat uns von neuem bestătigt, wenn wir seine Sonne als ein Symbol des Vaters auffassen". (Ibid., S. 202). Das dichterische Ich im Epilog von Bỉezinas "Morgengebet" (Ranni modlitba) läBt sich in der weiblichen Position von splendor solis b le n de n (symbolisch entmannen. soweit man hier die Blendung als Aufopferung der eigenen Männlichkeit intrepretieren kann). Ich bin absichtlich in die Einzelheiten des Schreber-Falles eingetreten, um auf die Parallelität der beiden hochinteressanten archetypischen und im kollektiven Unbewußten gründenden Bildungen hinzuweisen. Der "zischende Blutstrahl" (V. 86; "v syčicim vytrysku krve") kann in diesem Kontext durchaus als Euphemismus für Spermastrahl (Ejakulation) gedeutet werden. In Träumen, Phantasien usw. symbolisiert das Blut häufig das Sperma, woraư bereits Wilhelm Stekel in seinen zahireichen Analysen hingewiesen hat.

641 Die Vorstellung der festen und harten Substanz des Sonnenstrahls war - als "Sonnenp e $\mathrm{n}$ i s" - bereits in der Antike als Libidosymbol bekannt. Dieser Strahl/ "Sonnenpenis" dringt tief in die Erde ein und 'befruchtet' sie (kommt ganz explizit in Ranni modlitba / Das Morgengebet. V. 11-16, zum Ausdruck). C.G. Jung verweist auf die Bedeutung des griechischen

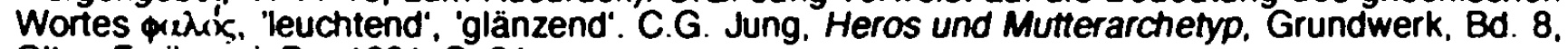
Otten-Freiburg i. Br., 1991, S. 64.

$642 \mathrm{Vgl}$. die eingehende Interpretation von Ranni modlitba, Kap. 3.1.2.

643 C.G. Jung, Aion. Beiträge zur Symbolik des Selbst, Gesammelte Werke, Bd. 9/2, OltenFreidurg i. Br. 1976, S. 240 f. 
Zauberkreis, grOß wie der Horizont, wollen wir uns den Āngsten der Nacht verschließen. I.../ Brüder, von Hand zu Hand reichet den Wein der Starken in eurem Becher').

Die schmerzvolle Katabasis in die Unterwelt der Dekadenz (und in die Sphäre des Unbewußten), wie sie z. B. das Gedicht Vitezzná pisen (Das siegreiche Lied) thematisiert, stellt eine der Bedingungen (auch) für die Bewußtwerdung des (eigenen) "Schattens" dar. Nach C. G. Jung wird der "Schatten" durch die Bewußtwerdung und Erkenntnis, durch die Berührung der archaischen Psyche mit dem Bewußtsein, dem Ich integriert, wodurch sich auch eine "Annäherung an die Ganzheit vollzieht". Die wesentliche Frage, die aus der Konfrontation mit dem "Schatten" resultient, heißt: "Wie kann der Mensch mit seinem Schatten leben?"644 Diese Frage scheint auch für Bïezina von großem Belang zu sein. Sein eigenes Leben empfindet er nur als 'Produkt' einer Fremdbestimmung ( Slysim v duši I Ich höre in der Seele; Mè dédictvi položil's... ( Mein Erbe legtest du ...). Das Omen einer "geheimnisvollen Schuld" (Legenda tajemné viny), einer "geheimen Sünde" (Vladari snù I Die Herrscher der Träume, $X, 1)$, lastet auf ihm. In Svitáni na západé versucht Bỉezina das Problem, "wie man mit eigenem Schatten leben kann", durch die Integration des Ich in den Kreis der Gleichgesinnten, der "Brüder" ("Bratrĭ"), 645 und durch das Streben nach der zur unio mit dem "Höchsten" führenden Erkenntnis zu lösen.

Im dritten Gedichtzyklus Větry od pólù (Polanwinde, 1897) scheint die Suche nach der Herstellung der psychischen Einheit eng mit dem "Vater" / Logos-Begriff verbunden zu sein. Mit dieser Entwicklung geht die Tendenz zur Rationalisierung des Mythischen und zur Theo-logisierung des poetischen Weltbildes einher. Die Vorstellung der Vereinigung der Anima (des Passiv-Weiblichen des dichterischen Ich) mit dem (zeugenden) "Höchsten" in der oben zitierten Verssequenz von Ranni modlitba (Das Morgengebet). wird in Vestry od pollu in einem gewissen Sinne radikalisiert und in den Zusammenhang sexualisierter Symbolik einbezogen. Dem postulierten Ziel, der coniunctio der Anima (des dichterischen ich) mit dem "Vater des Ungeborenen" ("Oť̌e nezrozeněho", Poledni zrání I Mittäglich Reifen, V. 1), gehen die 'Entblößung' (apokalypsis) der Anima646 "vorm Vaterauge des Höchsten" ("pred otcovským pohledem Nejvyssího", Králouna nadeji / Die Königin der Hoffnungen, V. 56) und der Akt "höherer Begattung"647 voraus, begleitet vom Verlangen nach der "Überschwemmung" der "dürstenden" Anima mit dem "glühenden Regen", mit dem Fluß des befruchtenden Samens des "Höchsten": "Chtivě jsem dýchal tvüj Žár a celá má bytost se zménila v žizen̉! /.../ Byla tvá vưle, 6 Věčný! Pokorně léto tvé zpivám! Žnavým svým deštèm/... / duši mou zaplav!" (Poledni zráni / Mittăglich Reifen, V. 34, 41-42; "Gierig sog ich die Glut, ganz ward mein Wesen ein einziges Dürsten! /... / Dein Wille war es, o Ewiger! Ich sing deinen Sommer in Demut! Mit deinem glühenden Regen /.../ überschwemm' meine Seele!"). Die "Früchte" der coniunctio, nämlich die angestrebte Einheit im mystischen Hierosgamos, scheint sich im Gedicht Láska (Liebe) zu vollziehen: "Hle bratr̂̆! Vaše láska se plni jak stromovi jižni: plody má uprostied květú" (V. 12, 32: "Seht meine Brüder! Eure Liebe belädt sich wie Băume des Südens. Früchte trăgt sie inmitten von Blüten”.). Die Trias der Gedichte, die den semantischen Nukleus von Vètry od pólü bildet (Královma nadeji / Die Königin der Hoffnungen, Poledni zráni / Mittäglich Reifen und Láska / Liebe), koinzidiert

644 C.G. Jung. .Die Psychologie der Übertragung", in: Ders., Praxis der Psychotherapie, Gesammette Werke, Bd. 16, Otten-Freiburg i. Br. 1991, S. 239-240.

645 Die Apostrophe "Bratri!" ("Ihr Brüder!") kommt zum ersten Mal in Svitáni na západě vor. Ebenso das Pronomen "my" I "wir" (bzw. "nás" / "unser), hinter dem sich das dichterische Ich verbirgt und durch den 'kollektiven' Mund der 'Brüder' spricht. Die Suche dieses 'Brüderkreises' nach der "Nähe brüderlicher Menge" ("blizkost bratrského množstvi", Vitézná píseñ I Das siegreiche Lied, V, 3), gewann an Intensität, nachdem Bfezina seine Hoffnungen auf eine schōplerische Zusammenarbeit mit seinem Jugendfreund František Baue definitiv (auf Grund eines Briefes, in dem F. Bauer Bł̌ezina über seine Heiratspläne informiert) aufgeben mußte. Vgl. hierzu die Analyse des Gedichts Vladañ snú / Die Herrscher der Trăume (Kap. 3.1.1).

646 -Tak mluvila ke mně má duše a tváîi ji letěla vzpominka na posvátnou chvili, / až sat zemẻ spadne jí z éterných údủ /...// a aż pǐed otcovskỷm pohledem Nejvyššino, zardẻlá vonnou krví své nesmrteinosti I...F. (Královna nadeji / Die Königin der Hoffnungen, V. 54-57; "So sprach meine Seele zu mir und es flog ihr über die Wangen ein Wissen der heiligen Weile, I wenn das Erdkleid sinkt von den Gliedern, von den ätherisctien ihr /...// und wenn vorm Vaterauge des Höchsten. errotert vom duttigen Blut ihrer Unsterblichkeit /... $r$ ).

647 J. W. v. Goethe, .Selige Sehnsucht", in: West-Ostlicher Divan. "Nicht mehr bleibst du umfangen / In der Finsternis Beschattung, I Und dich reißt neu Verlangen / Auf zu hŏherer Begattung". 
mit der (christologischen) Trias der Charismata "Hoffnung" - "Glaube" - "Liebe". Doch diese Trias ruft, wie es scheint, noch eine andere $t r i$ a dische $E$ in h e it auf: die von corpus, anima und spiritus. 648 Die Trias dieser Gedichte bildet einen Kreis, der sich kennzeichnenderweise im dritten Gedicht Láska (Liebe; die "Liebe" I "Agape" ist doch das höchste und vollkommenste aller drei Charismata) zusammenschließt: "I rozsinin se pohled vás jako cas plný světla a obejme zemi, /.../ tisice smrti budete potkávat najednou v tisici cestách bez báznè / a uzríte zástupy nesčislných životư vcházeti v jediný živơt. (Láska, V. 71, 73-74; "Und es weitet sich euer Blick wie die Zeit voll von Licht, und umarmt die Erde, I... I tausend Toden müßt inr begegnen plötzlich auf tausend furchtlosen Wegen, I dann seht ihr unzähliger Leben Schar eingehen in ein Einziges Leben"). Es ist daher kein Zufall, daß die Dreiheit auch im Epilog-Gedicht Když z lásky tvé ... (Wenn aus deiner Liebe ..., VP) adoriert wird: "Nebot' i ty, o Věčný a Trikráte Svaty" (V. 21; "Denn auch du, o Ewiger und Dreifach Heiliger")

Die Ablehnung der körperlichen Liebe, die Bïezina zur Abfassungszeit dieser Gedichte als "lákáni do tmy" ("Verlockungen ins Dunkel") 'diffamiert', 649 findet ihre Kompensation in der Erzeugung sexualisierter Symbolik (durch das Unbewußte), die am deutlichsten wohl in Poledni zrani (Mittäglich Reifen) zur Sprache kommt. Die angestrebte (psychische) Einheit, die Fähigkeit "mit sich selber zu leben", $d$. h. (auch) mit der dunklen Seite der Psyche, mit eigenem "Schatten", verlangt "eine Reihe von christlichen Tugenden, die man in diesem Fall bei sich selber anwenden muß, nämlich Geduld, Liebe, Glaube, Hoffnung und Demut". 650 Verrät Biezinas Postulat der "geistigen Lust" ("duchovní rozkos"), seine Sehnsucht, die "Seele" (die 'dunkle' Anima) "strahlend und weiß zu machen" ("duši učinit zárici a bílou"), 651 sich der geschlechtlichen Liebe zu entsagen, 652 nicht seine Unsicherheit über den Erfolg der "Schatten"-Integration? Rühren die bangen Ermahnungen und Warnungen vor der paralysierenden, destruierenden Macht des "Schattens", die der Dichter in Láska (Liebe) an seine "Mitbrüder" adressiert, nicht von den Bedenken her, daß die vermeintliche "Schatten"-Integration in Wirklichkeit nur eine Verdrängung ist?: "Bojte se stínủ, jež padaji do vašeho světa z vyhaslých prèuvěkých světư /...I. / V prùvodu stínú vycházi duse stoupajicino; však stíny boji se výsi /.../ (V. 57. 62; "Fürchtet die Schatten, die fallen in euer Licht aus verloschnen urzeitlichen Welten I...I. I Aus dem Zug der Schatten tritt die Seele des Steigenden vor, denn die Schatten fürchten die Höhe /...F). Die "Schatten" aus "verloschnen urzeitlichen Welten", das Dunkel der Urzeit, die finstere, furchteinflößende Sphäre des Unbewußten, aus der sich das Bewußtsein herausentwickelt hat, von deren "Schatten" jedoch das Bewußtsein des Menschen offensichtlich noch nicht frei ist, überschatten' das luzide Ich. Diese dunkle Sphäre des Unbewußten ist mit dem chthonischen Reich der (Erd-)Mutter verbunden, 653

$648 \mathrm{Vgl}$. hierzu auch die Aurora consurgens I. Cap. 9: $\%$ /../ qualis pater talis filius, talis et Spiritus Sanctus et hi tres unum sunt, corpus, spiritus et anima, quia ornnis perfectio in numero ternario consistit, hoc est mensura. numero et pondere*. (.Wie der Vater, so der Sohn und sn auch der Heilige Geist, und diese drei sind Eines. Körper, Geist und Seele, da alle Vollkommenheit in der Dreizahl besteht, das heißt in Maß. Zahl und Gewicht"). Zit. nach C.G. Jung. .Psychologie der Ubertragung", in: C.G. Jung. Praxis der Psychothrapie, Gesammelte Werke, Bd. 16. OltenFreiburg i. Br. 1991, S. 242.

649 O. Brezina an A. Pammrová (2. XII. 1897). „Dva listy”, in: Wiener Slawistischer Almanach, 4, 1979. S. 212.

650 C.G. Jung. „Psychologie der Übertragung”, in: a.a.O., S. 301.

651 O. Biezina. „Dva listy”, in: Wiener Slawistischer Almanach, 4, 1979, S. 211

652 "Jen ten, kdo /.../ potlačil pohlavi, mủže být Magem, despoticky vládnouci vưli". ("Nur derjenige, der /.../ die Geschlechtlichkeit verdrăngt, kann zum Magier werden, der über den Willen despotisch herrscht"). O. Bïezina, Dopisy O. B. Anné Pammrové z let 1889-1905. Praha 1931. Brief vom Mai 1896.

653 Die 'Anamnese' Bỉezinas, die Problematik seiner Beziehung zur Sphăre des Weiblichen. beleuchten zwei erst unlängst entdeckte Briefe (vom 4.VII. 1897, d. h. zwei Monate vor der Herausgabe von VP; und vom 2.XII. 1897) an Anna Pammrová, die jahrzentelang als verschollen galten. In seiner Br̈ezina-Monografie bedauert $O$. Králik den Verlust des ersten Briefes, denn: "Kdybychom méli tento nezvẻstný list, dozvẻdẻli bychom se z ného o erotickém dramatu Br̉ezinové vice I...r. (O. Králik, Otokar Bïezina, Praha 1948, S. 200; "Wenn wir diesen vermißten Brief hätten, würden wir aus ihm mehr über das erotische Drama Bïezinas ertahren $/ . . . \digamma$ ). Für das Verständnis der komplizierten Persōnlichkeit des Dichters ist sein Inhalt vom großen 
während die luzide Sphäre des Bewußten mit dem männlichen, dem triadischen Prinzip koinzidiert. 654 Bekundet etwa das Streben nach der coniunctio mit dem "Vater", nach der 'Befruchtung' von seinem logos spermatikos (Poledni zráni / Mittäglich Reifen), die die Erhebung in die Sphäre der 'totalen' Luzidität, in die Regionen des "höheren Bewußtseins" (des Geistes) 'garantieren' würde, 655 nicht die Sehnsucht nach der Befreiung vom

Qsychologischen Wert. "Za světem muže, ozałován tajemným, nepristupným sluncem, leži svět Zeny: vsecchao, $\infty$ v mužovẻ myšlence kvete vonného a silného, vzrostlo v paprsich tohoto svẻta. I tenkrát, kdyż nepoznal ženu, a snad nejsilnēji tenkrát, i tenkrát, kdyż ji nenáviděi (nebot nenávist vzniká $\mathbf{z}$ lásky $\mathbf{k}$ dokonalejšimu). Historie lidstva je historii těch tứ hercu: muže, ženy a prírody.l...l Tragédie každěho vyšsiho mużskěho života je zaviněna ženou. Tou dẻmonickou moci, ktera z ni sálá, a která pł̌evraci všechny sny, všechny naděje a bázné, tvởi ze světla tmu, ze tmy světlo. dává zapomenout na słávu, čni lhostejnou pravdu, rozviłuje nejspodnéjši slehlá ložiska bytosti anebo u bytosti ješté vyšsich házi do duševního kvasu ferment nemoźné, nadpłrirozené krásy, věcnè żiznẻ, rozpěti rukou po stínu. Tragédie i tenkrát, když se v životě muže žena neobjevi. Klamala byste se, kdybyste chtěla vidět $v$ muži pouze żiznivou žádostivost; ale i ta je těžkou kapltolou $v$ životé muže a mnoho hlubokých vêci bylo o ni napsáno od poćátečni kapitoly Platónovy Republiky až $k$ Schopenhauerovi a -- $k$ církevnim otcúm. l.../ Ale vždy budou bytosti predestinované $k$ osamélosti i ve svém snu /.../. Je-li kdo neschopen vyšśimu muži dnes rozumét, je to - až na ojedinělě vyjimky - dnešni žena. I... I. Im Breif vom 2.XII. schreibt Bł̌ezina: "\%... a nespocivá velikost muže ve vúli? I... / A polibky zeslabuji vưli; pro tajemství ženy a lásky zapominá muż na tajemstvi poznáni, płestává bỳt ideovẻ tvứćim a dobyvatelem, viádcem pohybu. I...I Nejvyšsi a nejčistš́ sen muže je pozdravit v ženě svěho bratra. I.../L' amitié d' une femme? Znali uż svati otcové jeho nebezpeć: Żena bojuje vždy magickými prostł̌edky a vítézi vżdy (Casto ani neví, že chce, tajemná sama sobẻ). I.../ ale muži transcendentnich snah siuši jedinẻ askese". (O. Błezina, „Dva listy, in: Wiener Slawistischer Almanach, 4, 1979, S. 208-209, 214: . Hinter der Welt des Mannes liegt, beleuchtet von geheimnisvoller und unzugănglicher Sonne, die Welt der Frau; alles Duftige und Starke, was im Gedanken des Mannes blüht, wuchs in den Strahlen dieser Welt. Auch dann, wenn inm die Frau unbekannt blieb, und am stärksten vielleicht gerade dann, selbst dann, wenn er sie haßte (weil der Haß aus Liebe zu Vollkommenerem entsteht). Die Geschichte der Menschheit ist die Geschichte dieser drei Schauspieler: des Mannes, des Weibes und der Natur. Die Tragödie jedes höheren mănnlichen Lebens wird durch die Frau verursacht. Durch jene dămonische Macht, die sie ausstrahlt und die alle Trăume, alle Hoffnungen und Ängste umwühlt, die aus Licht das Dunkel und aus dem Dunkel das Licht macht, die den Ruhm vergessen lăßt, die Wahrheit gleichgültig macht, die tiefsten gesenkten Lager des Wesens autwirbeft - oder bei den noch hoheren Wesen das Ferment der unmöglichen, übernatürlichen Schönheit, des ewigen Durstes, der Ausstreckung der Arme nach dem Schatten in die geistige Gărung wirft. Eine Tragōdie ist es auch dann, wenn die Frau im Leben des Mannes nicht erscheint. Sie würden sich tăuschen, wenn Sie nur die brünstige Begierde im Manne sảhen; aber auch diese bedeutet ein schweres Kapitel im Leben des Mannes, und es wurden viele tiefsinnige Sachen darüber geschrieben vom Anfangskapitel von Platons .Staat" bis hin zu Schopenhauer und - den Kirchenvătern. I... Doch es wird immer Wesen geben, die auch in ihrem traum zur Einsamkeit prădestiniert sind $/ . .$. . Wenn heute jemand unfăhig ist, den hơheren Mann zu verstehen, dann ist das - bis auf vereinzelte Ausnahmen - die heutige Frau. $I . . \digamma$. Im Brief vom 2.XII. 1897: $\%$.../ und liegt die Große des Mannes nicht in seinem Willen? I.../ Und die Küsse schwăchen den Willen ab; wegen des Geheimnisses der Frau und der Liebe vergißt der Mann das Geheimnis der Erkenntnis, er hört auf, ideell kreativ und der Eroberer, der Herrscher der Bewegung zu sein. I...I Der höchste und reinste Traum des Mannes ist es in der Frau seinen Bruder zu begrüBen. I.../ L'amitié d'une femme? Schon die Kirchenvăter kannten ihre Gefahr: Die Frau kămpft immer mit magischen Mittein und sie siegt auch immer, wenn sie will (oft weiß sie überhaupt nicht, geheimnisvoll für sich selbst, daß̉ sie will). I.../ aber dem Manne mit transzendenten Ambitionen steht einzig und allein die Askese."

654 C.G. Jung. Die Archetypen und das kollektive Unbewusste, Gesammelte Werke, Bd. 9/1, Olten-Freiburg i. Br. 1976, S. 260f.: Man könnte daher die Dreiheit direkt als «Männlichkeit» übersetzen, welche in der altăgyptischen Drei-Einigkeit von Gott-Kamutef-Pharao noch eindrücklicher ist".

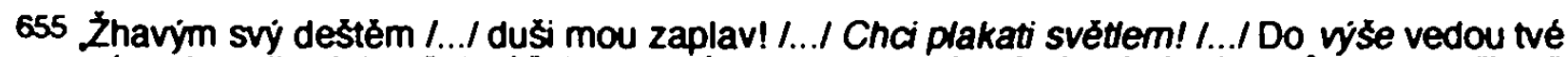
cesty, v závrati umdlených, však vitézi stoupaji v tanci / a do údoli házeji pisné v prưvodu bour̂i, jež pod nimi v hlubinách vî̛i: / však nad nimi vẻcuá nádhera svẻta se leje sirokým obzorem dálek. (Poledni zráni I Mittáglich Reifen, V. 41-42, 46, 54-56; "Mit deinem glühenden Regen I...' überschwem' meine Seele! I... / Licht will ich weinen! I.../ Zur Hohe führet dein Weg! Wenn Schwindel den Schwachen zurückwirt, erklimmen im Tanze die Sieger den Gipfel, / und werfen Lieder ins Tal, zum Baß der Gewitter, die unten die Tiefen durchtoben. I Aber innen zu Hâupten das ewige Prangen des Lichts überbreitet den weiten Gesichts kreis der Fernen"). 
chthonischen (anim[al]ischen) Dunkel des Unbewußten? Die 'Erklärung' einer geradezu bedingungslosen Hingabe an die Autorität des " $\mathrm{V}$ a te r s", an den "Dreifach Heiligen", die der Dichter noch einmal im Epilog-Gedicht Kdyż z lásky tvẻ... (Wenn aus deiner Liebe...) zum Ausdruck bringt. scheint diese These zu unterstützen:

"A my všichni, nesmrtelni tvou vưli, / bolesti svoji / tvé bolesti sdilime slávu! / A naše Radost. dar príliš tẹžký, / jenż z dètských rukou nám dosud bezvládnẻ padá. / je slabosti naši / sesláblý odraz / vitèzstvi tvých!" (V. 27-34; "Und wir alle, unsterblich durch deinen Willen, / durch unseren Schmerz / nehmen wir Teil an der Glorie deines Schmerzes! / Und unsere Freude, die zu schwere Gabe, / die unseren kindlichen Händen noch immer machtlos entfällt, / ist unserer Schwäche / ein abgeschwächtes Abbild / deiner Triumphe!").

Die Adoration (Poledni zráni) der wunderwirkenden Macht des "Vaters" ist ein deutliches Indiz auf die enge Affinität gewisser religiöser Vorstellungen zu der 'magischen' Bedeutung der Vaterimago.656 Diese enorm interessanten Vorstellungen scheinen - vom psychologischen Standpunkt her betrachtet - im wesentlichen auf der Tätigkeit des Unbewußten zu beruhen. Vielsagend ist bereits das sinnkonstitutive Motiv zahlreicher Gedichte Biezinas eschatologischen Symbolismus: der (glühend-)zeugende "Hauch" ("Dech") des Vatergottes: "Dech tvého poledniho zráni valí se blankyty tisicileti!" (V. 4, 8, 13, 17; "Hauch deines Mittag-Reifens wallt unter ewiger Wölbung!"). Die Aufblähung durch den befruchtenden Windhauch ("Chtivě jsem dýchal twưj žár a celá má bytost se změnila v žizeñ!", V. 34; "Gierig sog ich die Glut. ganz ward mein Wesen ein einziges Dürsten!") ist eine uralte mythogene Vorstellung. Anaxagoras entwickelt in seinem fragmentarischen naturphilosophischen Werk (Uber die Natur I Peri Physeōs) die kosmologische Theorie vom formenden Ordnungsprinzip (nous / voú's). das als eine besonders feine und reine, mit selbständiger und lebendiger Potenz begabte Art von Sperma charakterisiert wird. In seiner Kosmologie läßt Anaxagoras den Kosmos durch eine Art Wirbelwind aus dem Chaos entstehen. Man denke auch an die Beseelung des Adam durch das $\pi v \varepsilon \tilde{r}_{\mu \alpha}$. Die Einatmung des glühenden göttlichen Odems kann quälen, ja vernichten, doch das, was vernichtet, kann zugleich stärken; auch in diesem Falle handelt es sich um einen antiken, mythisch-mystischen Gedanken, der in Poledni zráni explizit zur Geltung kommt (V. 49-53):

"úpal, v němž vadne nemocné kviti, na zlaté dráty sesfli pšeničná stébla. / oslepi zraky uvykłé ふ̌eru, však zraky mocných pripravi na svitáni bleskủ./ Hudba nơ̌nich tvých vichrù a mởi. jež slabého $v$ úzkostech probouzi do tmy. I v žhavý sen silných padá jak chladivá rosa stríbrným ohiasem svitáni jiţ̉nich". ("Glut, die krănkliche Blüten dörnt, zu goldenen Drähten steift sie die Halme des Weizens. I sie blendet im Zwielicht hausende Augen, aber die Augen der Mächt'gen lehrt sie ertragen das Tagen der Blitze. / Musik deiner nächtlichen Stürme und Meere, die den Schwachen angstvoll ins Dunkel schreckt. I făltt auf den glühenden Traum der Starken wie kühliger Tau im silbernen Echo auflichtenden Morgens".) 657

Es stellt sich nun die Frage, warum das dichterische Ich nach dieser 'quälenden Stärkung' so verlangt? Durch das Eintreten der magisch wirksamen Persönlichkeit in den eigenen Körper ( $\begin{aligned} & 2 \\ & B\end{aligned}$ durch das Einatmen des "glühenden Odems" des Vatergottes; in Poledni zráni auch als "mystická lázeñ" / "mystisches Bad". V. 30), ist der von Gott erfüllte Myste nicht mehr er selber, sondern er ist selbst ein gottahnliches bzw. theurgisches Wesen geworden, wie die "Starken" I "Heiligen" von Poledni zráni: "V plamenech jeho kráčeji svatí, radostnẻ ubledli jeho mystickou lázni l...l. Zhavým svým deštẻm, v nẻmż vzkvetta a zvadla staletá setba mých otcü, duši mou zaplav! I... / Chci plakati svéttem!" (V. 30, 41-42. 46; "Durch seine Flammen schreiten die Heiligen, freudig verbleichend im mystischen Bade I... Mit deinem glühenden Regen, darinnen blühte und welkte die uralte Saat meiner Väter, überschwemm' meine Seele! Licht will ich weinen!" [Hinweis auf die Pneumanatur des Eintretenden]). 658 Die Flamme. Sonne, Hitze, das Feuer, Licht usw.

656 Offensichtlich als regressive Wiederbelebung des Vaterbildes.

657 Ich bin nicht der Ansicht, daß diese Vorstellung, die Bỉezina in der oben zitierten Textsequenz von Poledni zráni aktualisient, bloß auf seine Nietzsche-Rezeption zurückzuführen ist. Wenn Urs Heftrich glaubt, daß die These Nietzsches "Was mich nicht umbringt, macht mich stärker" (Götzen-Dämmerung), "ihre genaue poetische Entsprechung in Poledni zráni findet" (Otokar Birezina, Heidelberg 1993, S. 330), so scheint mir diese Annahme nicht ganz berechtigt zu sein (s. meine obige Analyse von Poledni zráni, Kap. 4.3.2).

658 Die oben zitierte Verssequenz kann wie ein Hinweis auf die Vorstellung von der Präexistenz des dichterischen Ich im "Vater" gelesen werden; es handelt sich um eine gangbare 
sind, wie C. G. Jung nachweist, nicht nur Attribute der Gottheit, sondern auch Libidobilder. 659 Durch das Einatmen des "glühenden" Pneumas des V a ter gottes, um das das dichterische Ich in Demut bittet ("Pokorné léto tvé zpivám!, V. 41; "Ich síng deinen Sommer in Demut!"), soll das dichterische Ich die wundersame "Kraft" erlangen. Gemeint ist allerdings nicht die übermenschliche "Stärke" (im Sinne Nietzsches), sondern die ù l a u b e n s stärke im Sinne der neutestamentlichen (paulinischen) Theologie. Indiziert das Verlangen des Dichters nach der (Glaubens-)Stärke - als Gabe des "V a te r $s$ " seine (unbewußte) Sehnsucht die verhängnisvolle Gabe der "Mutter" zu kompensieren? In Moje matka (Meine Mutter, TD) heißt es: "Tvé mrtvé krve vychladlé jsem bledým kvètem, / jenż vláhou zrakủ tvých se rozpucel a vzrustal: / chut trpkou Żivota svýmulibalas mi retem / a trojím dédictvím mi smutek $v$ dusi zústal" (VI, 1-4; "Deines toten erkalteten Blutes fahle Blüte bin ich, I die deiner Blicke Nässe aufsprießen und wachsen ließ: I des Lebens herben Geschmack küßtest du mir mit deinen Lippen ein / und als dein Erbe blieb der Gram mir in der Seele"). Ein Teil dieses mütterlichen Erbes ist auch "die brutale Wollust aus dem unreinen Kelch meines Blutes" (Návrat / Die Rückkehr, TD, VIII, 4: "brutální rozkoš z nečisté cíše mé krve"). Was geschieht jedoch mit den fahlen, "krănklichen Blüten" in Poledni zráni ?: "V tropickém slunci tuém i kapradi vyrústá v stromy a na stvoly kvétú sedaji zázračé plameny l...l. I... I úpal, v némż vadne nemocné kvít, na zlaté dráty sesili psenenićná stébla I... ${ }^{\prime}(\mathrm{V}$. 43-44, 50; "In deiner tropischen Sonne wáchst auch Farnkraut baumhoch und auf die Stengel der Blüten lassen sich magische Flammen nieder I...I. I...। Glưt, die krănkliche Blüten dört, zu goldenen Drähten (Feuer/Glut und Gold gelten in den mythischen Vorstellungen als wesentlich ähnlich]steift sie die Halme des Weizens /...F). Signifikant ist auch die Symbolik des befruchtenden văterlichen Blickes ${ }^{600}$ im Vergleich zu dem feuchten, kalten, 'thanatoiden' Blick (Pohled smrti / Der Blick des Todes, TD) der (Erd-)Mutter: "vláhou zrakú tvých" (Moje matka, VI, 2; "deiner Blicke Năssen). "\%... pod pożehnáním pohledu tvého pohne se v hlubinách nová, posvátná setba" (Poledni zráni, V. 58; "in deinem segnenden Blick regt sich im Abgrund das neue, heilige Saatgut"). Bemerkenswert ist auch die Symbolik des "Gift"-Motivs. In Znameni duße (Das Zeichen der Seele, TD) spricht das dichterische Ich - im Zusammenhang mit dem Lächeln seiner (toten) Mutter - von der "vergiftenden Süße des Kusses" ("jak otráven sladkostf polibku", III. 4). In der oben zitierten Strophe aus dem Gedicht Moje matka (Meine Mutter) sagt das dichterische Ich: "des Lebens herben Gram küBtest du mir mit deinen Lippen ein" (VI. 3; "chut trpkou Żivota svým víbalas mi retem"). In der Axiologie des dekadenten Symbolimus konnotiert das "Gift"-Motiv das Abtöten der Lebenskraft, den (Kunst-)Tod und descensus in das chthonische Reich (der Erd-Mutter; "feuchte Katakomben" / "vihkých katakomb": Vézeñ / Der Gefangene, VII, 2; usw.) oder in die düstere (Wasser-)Tiefe des Unbewußten (Motiv z Beethovena). In Poledni zráni (VP; theo-logisch-eschatologisches Modell) hingegen "reift" der "heftigste Giftsaft des Schlangen-Bisses" ("nejprudśi jedová stáva pro ustknuti hadu", V. 22) in der "Weißglut" der "mystischen Sonne" des "Höchsten" und in seinem glühenden Hauch zum Lebens-[und Liebes]Trank. In den mythischen Vorstellungen symbolisient das "Gift" (bzw. die "Vergiftung") häufig einen "Liebestrank".

Christliche Anschauung, die vor allem im Johannesevangelium $(10,30 ; 14,9 ; 16,28$ u. a.) eine wichtige Rolle spielt. Vgl. C.G. Jung. . Wandlungen und Symbole der Libido. Beiträge zur Entwicklungsgeschichte des Denkens., erster Teil, in: Jahrbuch für psychoanalytische und psychopathologische Forschungen, Bd. 3, 1911, S. 199ff.

659 ibid., S. 200. "Da, psychologisch verstanden, die Gottheit nichts anderes ist, als ein projizierter Vorstellungskomplex, der je nach der Religiosität des einzelnen gefühlsbetont ist, so ist der Gott mithin als Reprăsentant einer gewissen Energie-(Libido-)Summe zu betrachten, die darum projiziert (.metaphysisch") erscheint, weil sie vom UnbewuBten aus wirkt, indem sie dorthin verdrăngt ist $/ \ldots /$. Wie ich früher (Bedeutung des Vaters) wahrscheinlich machte, zehrt der religiose Trieb die inzestuöse Libido der infantilen Vorzeit auf. In den uns vorliegenden hauptsăchlichen Religionsformen scheint zum mindesten das Formgebende die Vaterübertragung, in alteren Religionen scheint es auch die Mutterübertragung zu sein, welche die Attribute der Gottheit formt. I... Nirgends fehlt das Intantile, das den religiosen Phantasien oft nur $z u$ sehr anhaftet und von Zeit zu Zeit wieder măchtig hervortricht'. A.a.O., S. 177.

$660 \mathrm{Vgl}$. auch das Motiv des maskulin durchbohrenden und befruchtenden "Blicks" des "Höchsten" in der Schlußsequenz von Ranni modlitba (Das Morgengebet, SZ, V. 85). Die Assoziation der Sehkraft (der Augen im engeren Sinne) mit der sexuellen Potenz ist bekannt, daher wird dem 'Glanz' der Augen, den 'Strahlen' des Blicks usw. eine magisch-bannende und befruchtende Funktion zugeschrieben. 
Hochinteressant ist in diesem Kontext das Schlangen-Motiv. Die "Schlange" ("had") kommt in Biezinas Gedichten nur selten vor und zwar in VP. in SCh und einmal in R (insgesamt nur sechsmal). In Stavitelé chrámu symbolisiert die "Schlange" ganz evident die chthonisch-weibliche Sphäre (vgl. das Gedicht Doupata hadu I Die Schlangen $h o ̈ h l e n ; s$. unten). Im Titelgedicht Stavitelé chrámu konnotieren die Frauenhände die "Schlangen" ("Snili /.../ O Éenách záhadných /.../ jak by jich ruce s pohyby hadú /... $/$. V. 48, 52; "Sie träumten /.../Von Frauen, rätselvoll, I.../ wie wenn ihre Hände, wie hypnotisch eingeschläferte Schlangen sich regend $/ . . \%$ ). Als Attribut des "müterlichen" Wasser-Reiches fungiert das "Schlangen"-Motiv auch im letzten vollendeten Zyklus Ruce (Hände, 1901) im Gedicht mit dem signifikanten Titel Zpivaly vody (Es sangen die Wässen: "Jak oći hadü fascinujici leskly jsme se zrádnými víry", V. 22: "Wie der Schlangen faszinierende Augen glänzten wir über verräterischen Strudein" ). In Vëtry od polú fungiert das "Schlangen"-Motiv als deutliches Libidobild in bezug auf die $V$ a te $r$ Imago. Das "Schlangen"-Motiv kommt lediglich in zwei Gedichten des Zyklus vor: in Poledni zráni (Mittäglich Reifen) und im Epilog-Gedicht Kdyż z lásky tvé... (Wenn aus deiner Liebe...). In Poledni zráni reift der "Giftsaft" des "S c h l a n g e n-Bisses" in der "Weißglut" der Sonne und des zeugenden Hauches des "Vaters des Ungebore ne n! " (V. 1; "Otče nezrozeného!").

"Od vẻkú. nehnuté, sálá tvé mystické slunce do vieni miz a zpẻnẻni sily. I stoupánim krvi. ohnivými vủnèmi snủ a nadèji. jeż bloudi nad osenimi, I dech tvého poledniho zráni vali se blankyty tisicileti!" (V. 2-4; Unregsam, vom ewig her, toht deine mystische Sonne ins Sieden der Säfte, ins Kochen der Kräfte, I ins Steigen des Blutes, ins feurigen Düften des Traums und der Hoffnung, die über den Saat schweifen, I Hauch deines Mittag-Reifens wallt unter ewiger Wölbung!").

Die semantische Reihe der uralten symbolischen Libidobilder läßt sich hier unschwer rekonstruieren: Sonne, Hitze, Feuer, Hauch, Saat, Reifen, Säfte und schließlich der "Gift saft des Schlangen-Bisses" (V. 22). Die befruchtende Glut der Sonne ist ein Analogon zur befruchtenden Glut der Liebe. Eine ähnliche Analogie besteht auch zwischen dem "Sieden der Säfte" und dem "Reifen des Giftsaftes" (beides ist als Resultat der Wirkung der maskulin-befruchtenden Sonnenglut aufzufassen). Dementsprechend erscheint hier die "Schlange" als Analogon zum Phallus, der die Quelle des Lebens ist, nämlich als Phallus der Sonne, und der "Giftsaft" als Analogon zum "Liebessaft" (Euphemismus für

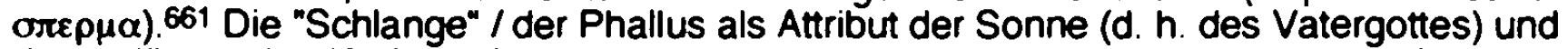
der verjüngenden Kraft der Natur, koinzidiert mit der Vorstellung von der zeugenden Kraft des Menschen; die Verehrung der männlichen Zeugungsorgane in den phallischen Kulten war mit der Anbetung der Sonne identisch. Das dichterische Ich sehnt sich nach der 'Befruchtung' seiner Seele von dieser glühenden Urpotenz des Vatergottes: "Žhavým svým dẻštẻm /.../ duší mou zaplav!". V. 41-42; "Mit deinem glühendem Regen I.../ überschwemm' meine Seele!").662 Dadurch soll das dichterische Ich auch jene wunderbare und charismatische "Stärke" erlangen. 663 Das Motiv der "feurigen Schlangen"

661 -Es ist deshalb nicht ganz unerhort. wenn die Sonnenscheibe außer mit Hănden und Füßen auch mit einem Penis begabt wird. Den Beleg für dieses Bild finden wir in einem sonderbaren Gesichte der Mithrasliturgie". C. G. Jung. .Wandlungen und Symbole der Libido", a.a.O.. S. 211

662 Hier wird offensichtlich die mythische Vorstellung von der Herabkunft des Göttentranks aktualisient. In den indogermanischen Mythen werden dem Göttertrank ("Soma" in der indischen. "Nektar" in der griechischen Mythologie) verschiedene wunderbare und geheimnisvolle Wirkungen zuerkannt. Dieser Göttertrank manifestiert sich auch als Tau und Regen, als Saft der gewaltigen Bäume oder als himmlisches Feuer (wie im Prometheusmythos). So besteht eine frappierende Analogie zwischen dem Göttertrank und dem männlichen Samen. Das crrépucu hat eine belebende und unsterblichmachende Bedeutung. Es ist ein Inbegriff der Kraft und der Zeugung. Der Göttertrank/Samentran war der Trank der Unsterblichkeit. Der Feuenaub im Prometheusmythos ist identisch mit dem Samenraub. Vgl. K. Abraham. Traum und Mythus. Eine Studie zur Völkerpsychologie. Schritten zur angewandten Seelenkunde. Heft 4. Leipzig-Wien 1909, S. 61ff. Interessant ist die indogermanische Etymologie des Namens Prometheus: pramantha (im Sanskrit der "Hervorreibende", d. $h$. [derjenige] der durch Reiben hervorbringt und zugleich der [das Feuer] Raubende) - math al's Verbalwurzel ("nehmen", "rauben") - und dazu die Klangăhnlichkeit mit dem Substantiv matha (das männliche Glied; vgl. das lateinische Substantiv mentula).

$663 / . . . /$ die inm sein leiblicher Vater offensichtlich nicht geben konnte. Als Bïezina 1868 zur Welt kam, war sein Vater (Jahrgang 1816) bereits 52 Jahre alt. Biezina erwähnt diese Tatsache in 
("rozhrabaná hnizda ohnivých hadư / zasyči sinými světly") im Epilog-Gedicht Kơyž z lásky tvé... (Wenn aus deiner Liebe..., V. 17-18, VP), steht in direkter Beziehung zur Sonne, begleitet von den anderen bekannten Libidoattributen wie "Flamme", "Glut", "Lichtströme" oder "Bögen von Feuerwellen". Kennzeichnend ist hier auch die Apostrophe des "Vatergottes": "o Věčný a Trikráte Svaty" ("o Ewiger und Dreifach Heiliger"; Kdyż z lásky ivé..., V. 21). Die Dreizahl ist symptomatisch, historisch hat sie $\mathrm{m}$ à $\mathrm{n} \mathrm{n} l \mathrm{l}$ c h $\mathrm{e}$ Bedeutung (membrum virile und zwei testes).

Der Weg zur Herstellung der psychischen Einheit, die in solchen Gedichten wie Láska (Liebe, VP) beinahe schon die Wirklichkeit zu sein schien, wird im vierten Gedichtzyklus Stavitelé chrámu (Baumeister am Tempel, 1899), von interessanten Wendungen aber auch Rückschlägen gekennzeichnet, fortgesetzt. Der Rückgriff auf das 'dekadente' ideal des Kunst-Schönen (TD) und das damit korrelierende Streben nach der nun konsequenten Integration der "Schatten", diese zwei Determinanten des kosmogonischeschatologischen Modells (SCh), werfen Reflexe auch auf die psychologische Bühne des in Stavitelè chrámu konstituierten Modells. Die unmittelbare Konsequenz dieser Entwicklung ist auch die 'Rückkehr' der weiblichen Anima in der ambivalenten Gestalt der Erd-Mutter (Jsem jako strom $v$ kvétu... I lch bin wie ein Baum in Blüte...). deren mythisches Gewand das Phantom der toten Mutter (Smutek hmoty / Die Traver des Stoffes) umhülit. Das bedeutet die erneute Auseinandersetzung mit dem Mutterarchetypus, mit der 'Schattenseite' der eigenen Persőnlichkeit, mit dem Unbewußten. Eine andere Konsequenz ist die Kreierung der 'konkreten' Heros-Gestalten, die als Hypostase der abstrakten, spirituellen Gestalten - der "Starken", "Reinen" oder der "Heiligen" - in SCh figurieren. Die Bedeutung dieser Heldenprojektion auf 'konkrete', ja menschliche Erscheinungen, spiegelt sich in der Tatsache wider, daß der Name dieser Gestalt, der (nahezu sekulären) " $\mathrm{B}$ a u $\mathrm{m}$ e i s ter am Tempel", zum Titel des ganzen Zykius wurde. Die andere Heroengestalt repräsentieren die "Propheten" ("Proroci").

Wie bereits enwähnt, wird der in Vètry od pólư vorgenommene Integrationsversuch in Stavitelé chrámu als eine irreführende Strategie der "Verdrängung" der "Schatten" (des Unbewußten) zurückgewiesen. Die Aufgabe, vor der der Dichter-Schöpfer in Stavitelé chrámu steht, ist eine neue Projektion der (verdrängten) "Schatten" ins Bewußtsein und ihre konsequente Integration durch die Eingliederung in den Gesamtplan des Lebens- und der Kunstschöpfung. Benn ohne Anerkennung und ohne Integration der "Schatten", der "Nachtseite" seelischer Natur, d. h. auch des Unvollkommenen und Dissonanten, kann die psychische Einheit nicht erreicht werden. Daher muß sich das dichterische Ich, seine Seele, auf eine symbolische Reise (peregrinatio) begeben:

"Dalekou cestu jsem konal, neznámý navštívil svêt, I nescetné duše jsem objal, z nescetných zrakú tvá tajemstvi Cet', I a unaven milostí vrátil se do svych ukrytých sadü" (Doupata hadú / Die Schlangenhohlen, II, 1-3; "Ich tat weiten Weg, hatte die Welt, die fremde, bereist, / zahllose Seelen umfaßt, in tausend Blicken erkannt deinen innersten Geist, / um, müde der Gnade, in meine heimlichen Gărten wieder zu gelangen"). "Řekni mi, duse má (z daleka jsi se vrátila), I koho jsi na zemi potkala, vidéla, ztratila? ( Têto / Der Kơrper; I, 1-2; "Sage mir, Seele (die fernher du kehrtest), I wenn du auf Erden trafst, sahst und entbehrtest?).

Das Gedicht Doupata hadu (Die Schlangenhohlen) ist in mehrfacher Hinsicht bemerkenswert. Das "Schlangen"-Motiv bedeutet in diesem Zusammenhang die Gefahr, die die Konfrontation mit dem (regressiven) Libido nach sich zieht. Doch freilich nicht nur das. Das Gedicht heißt "Die Schlangenhöhlert". In diesem Gedicht figuriert die Schlange (u. a.) als Symbol des Todes und der (wohl unbewußten) Angst vor der "Höhle", vor dem "(Todes-)Schoß" der Erd-Mutter. 664 In den mythischen Vorstellungen muß der Held (als

\footnotetext{
seiner Korrespondenz und in seinen Gesprăchen: "Otec byl za mého dètstvi už stár. Mèl bilé vlasy, které mu dẻlaly daleko po kraji reklamu". ("In meiner Kindheit war mein Vater schion alt. Er hatte weiße Haare, die inm weit und breit im Landkreis Reklame machten"). O. Chalupný, Dopisy a výroky Otokara Br̈eziny. Praha 1931. In einem Brief (v. 28. III. 1890), kurz nach dem Tod der Eltern, schreibt Błezina an Anna Pammrová: "Mnohdy $v$ okamżicich ünavy a nudy nebyl jsem vdęcen za to, ze jejich zásluhou koluje $v$ mých żilách ta zkažená lidská krev". ("Manchmal in Augenblicken der Müdigkeit oder der Langeweile war ich innen [den Eltem; Anm vom Verf.] nicht dankbar, daB in meinen Adern das verdorbene menschliche Blut kreist".) in diesem Zusammenhang erwähnt Błezina. daß er ein schwächliches und krānkliches Kind war.

664 In den mythischen Vorstellungen des griechischen Seetenkultes erscheinen die Seelen der Verstorbenen, den chthonischen Göttern gleich, als Schlangen, als Bewohner des Reiches der
} 
Personifizierung des unbewußten Selbst) aus der dunklen Mutterleibshöhle des Unbewußten 665 den von der Erd-Mutter neidisch bewachten Schatz, das Geheimnis des Lebens, d. h. das "Zentrum" der psychischen Ganzheit, herausholen. Die Konfrontation mit der bannenden, ominösen und vergiftenden "Schlangensuggestion" kann auch den Versuch bedeuten, sich aus dem Bann des Mutterkomplexes zu befreien. 666 Nicht von ungefähr taucht das Motiv des vergiftenden und dennoch betörenden Kusses der Anima (der toten Mutter) im ersten Zyklus Tajemné dálky (Geheimnisvolle Fernen) auf: "Nikdy

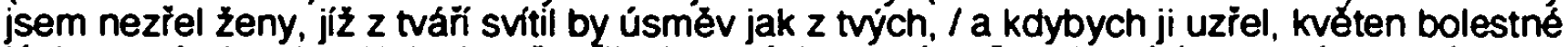
lásky v má okna by dých, / z nẻj prijal bych úzkost tvé duše, bloudíci v neznámou dál, / jak otráven sladkosti polibku, jejž bych se utrhnout bál" 667 Den bekannten Gegensatz zur chthonischen "Schlange" stellt in Doupata hadú der "Vogel" dar, Symbol des Geistes, ja des Animus und des Bewußten: "v blankytủ etherná loubi se slétlo tisice tajemných ptákủ $/ . . . /$. I...I blankyt jak brána se otevielel, od jihu letélo tisice ptákü" (I, 2, IV, 3; "tausend geheimnisvolle Vögel kamen im Aether des Blaus herniedergeflogen /.../. I... das Blau stand aut wie ein Tor, von Süd her kamen tausend Vögel geflogen"). Das Gegensatzpaar "Schlange" und "Vogel" symbolisiert den "Kreis der Zeit" und der ewigen Wiederkunft. Vor der "bosen Schlangensuggestion". vor dem Ertrinken in der Tiefe des Unbewußten, rettet sich das dichterische Ich durch das Aussprechen des "magischen Namens" (des "Höchsten"): "Tu svaté tvé vzpominky $v$ duši mi prolétla zvẻst, I nádhera morii tvých, tajemstvi noci tvých, sláva tvých cest: / blankyt jak brána se otevǐel, oo jihu letélo tisice ptákủ; / tvé magické jméno jsem vyslovil - a v úsmévu hvèzd, / koberec pro sny, pỉede mnou ležely záhony rưżi a máku“ (IV, 1 5). 668 Es handelt sich offensichtlich um den Akt der Bewußtwerdung, die einen Teil des göttlichen Lebensprozesses bildet: "Tu svaté tvé vzpominky v duši mi prolétla zvěst" (IV, 1; "Da ging deiner Heiligen Erinnerung Botschaft in mich ein"). Das ist aber gewiß nicht der einzige 'Gewinn'. Das Ziel dieses Vorgangs ist die Integration des Unbewußten ins Bewußtsein. Auf die coniunctio dieser Art deutet bereits das erwähnte Gegensatzpaar "Vogel" und "Schlange" hin. Aber die wichtigste Verwandlung wird in der letzten Verszeile (IV, 5) vollbracht. Während das Ich in der ersten Strophe (lediglich) die "Mohnbeete" ("záhony máku", I, 4) in seinen "heimlichen Gärten" (in diesem Gedicht das Sinnbild der Sphäre des Bewußten als Gegensatz zu den "Schlangenhöhlert") sieht, erscheinen in der letzten Strophe, nach der vollzogenen integrierenden Bewußtwerdung, auch die "Beete von Rosen u n d Mohn": "prede mnou ležely záhony rửi a máku" (IV. 5; "vor mir lagen die Beete von Rosen und Mohn"). Die "Rose" ist ein doppelsinniges Symbol. Als allegoria Mariae (man denke auch an die rosa mystica in Dantes Paradiso) symbolisiert sie verschiedene Tugenden. Als die Blume der Venus bedeutet sie die irdische Liebe, den weiblichen (bzw. mütterlichen) Schoß, ja sogar die "Wollust der Welt" (voluptas mundi). Die vierstrahlige Anordnung der Rose indiziert die Quadratur des Zirkels, die Gegensätze

Todesmutter. Vgl. E. Rohde, Psyche. Seelenkult und Unsterblichkeitsglaube der Griechen, Bd. I. Freiburg i. Br.-Leipzig 1890. S. 244

665 /... / a všechny mé záhony kvétủ se zménily v doupata hadủ. // Pỉed kroky mýmı se vztýcili. otravné prameny syçici tmou. I na stvolech zmitanych vichíici hlubin, nestvirné hlavy jim kvetty; / v tẻlo mé vrústali, vúli mi spoutali hadi svou suggesci zlou, / a v zraky mé $z$ nehybných oči svých stríkali sinými svétly". (Doupata hadú / Die Schlangenhöhlen, II, 4; III, 1-4; "und all meine Blumenbeete wurde zu Höhlen von Schlangen. / Reckten vor mir sich, gittige Quellen, zischend im Dunkel voll Hohn, I den Stengeln, gefegt vom Sturme der Tiefen, entblühten unfórmige Häupter an den Spitzen, / sie wuchsen in mich, banden meinen Willen mit ihrer bósen Schlangensuggestion, / und ließen blaue Lichter aus reglosen Augen in meine Blicke spritzen". Übers. v. O. Pick.) $220 \mathrm{ft}$

666 C.G. Jung. Heros und Mutterarchetyp, Grundwerk, Bd. 8. Otten-Freiburg i. Br. 1991, S.

667 Das Gedicht Znameni duše (Das Zeichen der Seele; letzte Strophe): "Noch nie sah ich eine Frau, I der aus den Wangen ein Lächeln leuchten würde wie aus den deinigen, / und wenn ich sie sähe. / würde der Mai der schmerzvollen Liebe in meine Fenster hauchen. / von inm würde ich die Angst deiner Seele empfangen, die in der unbekannten Ferne umherirrt, / wie von der Süße eines Kusses vergiftet, den zu pflücken ich mich fürchten würde".

668 Doupata hadu (Die Schlangenhöhlen, IV, 1-5: 'Da ging deiner heiligen Erinnerung Botschaft in mich ein, / deiner Meere Pracht, deiner Nächte Geheimnis, deiner Weege herrlicher Schein: / das Blau stand auf wie ein Tor, von Süd kamen tausend Vögel geflogen; / deinen magischen Namen sprach ich - und in der Sterne lächelndem Schein, / ein Traumteppich, lagen vor mir die Beete von Rosen und Mohn in flammenden Wogen". Übers. v. O. Pick). 
in ihrer Ve r e i n i g u n g 669 Ähnlich wie das Rad, der Kreis oder das Gefăß symbolisiert auch die Rose die transzendente Einhe it

Das ist auch das Ziel der Heroen dieses Gedichtzyklus, der "Baumeister": die Vereinigung der Gegensätze. Der Habitus der "Baumeister" weist charakteristische Helden-Attribute auf. Es ist vor allem die starke Affinităt zur Sonne und zum solaren Mythos: "souhvêzdi letni Orel, Labut, Delfín a Lyra / vstávala v zárii do jejich noci, po dni, který se dloużi" (Stavitelé chrámu, V. 84-85; "das Sommergestirn Adler, Schwan, Delphin und Lyra / stieg glänzend auf in ihre Nacht, nach einem sich verlängendem Tage"). "Adler" und "Schwan"670 sind Sonnenvögel par excellence und überdies (wie der Delphin, das heraldische Tier des Sonnengottes Apollon) bekannte Attribute des Christus, der als menschliche Erscheinung selbst ein Heros und sündenloser Gottmensch ist. Die Sonnenvögel symbolisieren das erneute Aufgehen der Sonne, ergo das Gelangen der Helden ans Tageslicht (d. h. die Wiedergeburt). Außerdem ist die "innere Freude" der Baumeister "weiß und stark wie die Sonne" ("bilá a silná jak slunce", V. 80). Die "Baumeister" sind imstande sowohl das "Gravert als auch die "Pracht der Dinge" ("videli hrúzu a nádheru věci*. V. 76) zu sehen/erkennen, weil sie mehr als die bloße Menschlichkeit besitzen. Es gibt keine Ganzheit, keine Vollständigkeit (keine Vollendung des Tempelbaus), ohne notwendige Komplementarität von Licht und Schatten ("Grauen und Pracht"). Einer der charakteristischsten Wesenszüge des Heldentypus der "Baumeister" ist deren Askese ("Vykoupenim tajemné viny byla jim bolest a práce", V. 79; "Erlösung von geheimnisvoller Schuld waren ihnen Schmerz und Arbeit"). Als psychologisches Phänomen bedeutet die Askese die Introversion und Introspektion, als positiven Aspekt des Eingehens in das Unbewußte. Die Introspektion als Resultat der asketischen Einstellung671 gegenüber der Welt, bedeutet eine unerläßliche Bedingung der Vereinigung der bewußten Inhalte mit den unbewußten, $d$. $h$. einen der wichtigsten Abschnitte im komplizierten Prozeß der Selbsterkenntnis.672 Diese psychische Einheit vom Bewußten und Unbewußten, die den Fokus der Gesamtpersönlichkeit bildet und die als "schwer erreichbare Kostbarkeit" im Schoß der Erd-Mutter, in der Tiefe des Unbewußten liegt, in die man sich durch die Introversion und Askese versetzen kann, wird von ihr streng bewacht. Es sind gerade die A sketen, die diesen "Reichtum" zurückgewinnen können. In ihrem Monolog Jsem jako strom v kvëtu (Ich bin wie ein Baum in Blüte...) spricht die Erd-Mutter: "tisice let jsem skládala bohatství svá jak královský dar, I a tẻm, kterí dovedou niceho neżádat, celỳ ho dám" (V. 7-8; "in Jahrtausenden häuft' ich Schätze wie ein Königsgeschenk, / und jenen, die nichts zu fordern verstehn, geb' ich es gan

Das Streben nach der Versöhnung, nach dem Erreichen der psychischen Einheit, kulminiert in der vitalistischen Phase des eschatologischen Symbolismus, im letzten

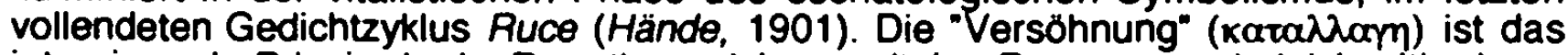
integrierende Prinzip der in Ruce thematisierten vitalen Prozesse und gleichzeitig deren erwartetes, höchstes Ziel. Die "Versöhnung" hat auch eine hochrelevante psychologische Bedeutung, nämlich als "Versöhnung" mit dem Unbewußten (als einem Teil der Persönlichkeit), mit der weiblichen/mütterlichen Anima, ja als (integrierende) "Versóhnung" mit sich selbst, die in Ruce und in den letzten Gedichten zur Heimkehr in die vertraute Welt der Kindheit und zum Kindarchetypus führt. Daraus erklärt sich auch der auf den ersten Blick 'rätselhafte' Umstand, daß die zwei allerletzten Gedichte Bł̉ezinas

669 C.G. Jung. Die Archetypen und das kollektive Unbewusste, Gesammelte Werke. Bd. 9/1, Olten-Freiburg i. Br. 1976, S. 383ff.

670 C.G. Jung (Symbol und Libido, Grundwerk, Bd. 7, Olten-Freiburg i. Br. 1991, S. 168f.) macht auf die etymologische Bedeutung von "Schwan" aufmerksam. Im "singenden Schwan" ist das S on $n$ e $n$ symbol des vom Wasser auffliegenden Vogels erhatten. Laut Jung stammt "Schwan", wie die Sonne und die Töne, von der Wurzel "sven".

671 In einem Brief an A. Pammrová (vom 2. XII. 1897) schreibt Błezina ausdrūcklich: "Pak by pro pravou velikost muže byla jen jedna cesta: askese. I.../ muži transcendentnich snah slußsi jediné askese. A Żenẻ také. (O. Błezina, .Dva listy", in: Wiener Slawistischer Almanach, 4, 1979. S. 214: "Dann găbe es für die geistige Grỏße des Mannes nur einen einzigen Weg: die Áskese. I...I dem Manne der transzendenten Ambitionen steht einzig und allein die Askese. Und der Frau auch"). 270fi.

672 C.G. Jung. Mysterium coniunctionis, Gesammelte Werke, Bd. 14/2, Olten-Freiburg i. Br. S. 
diese symbolische "Heimkehr", wie das letzte Gedicht auch (Návrat, 1907) heißt. thematisieren:

"Pủl cesty za námi a snad - kdo vi? - I jsme bliže domovu svému, / nežli tuši naše srdce. Dủvěmý stal se pohled všech vẻci a poznáváme każdý strom a každý kámen své cesty / a vzduch voni jak zahrada otcovského domu. I.../ Polibky rodiču našich probouzely nás jako ptáci jitȟni / a v każdém znovuzrozeni byly naše tty / vonné jako tty déti, / sladké od ovoce zapomenuti, jeż jako jahody zraje / v zahradách pied narozenim. I Kdo byli rodičcóé naši?" (Za všechno diky I Danke für alles, V. 1-4, 21-26; "Der halbe Weg liegt hinter uns und vielleicht - wer weiß? - / sind wir unserer Heimat näher, / eh unser Herz es ahnt. Vertraut ist der Blick aller Dinge geworden und wir erkennen jeden Baum und jeden Stein auf unserem Weg / und die Luft duftet wie der Garten des väterlichen Hauses. I...I Die Küsse unserer Eltern weckten uns wie die Vögel der Morgendảmmerung / und in jeder Wiedergeburt waren unsere Lippen / wohlduftend wie die Kinderlippen, / süß von den Früchten des Vergessens, das wie die Erdbeeren reift / in den Gărten vor der Geburt. / Wer waren unsere Eltern?").

Auf die Herstellung der (psychischen) Einheit deutet die in Ruce mannigfaltig variierte Symbolik des Kreise(n)s, des Runden, der Kette usw. hin, die allesamt als Inbegriffe der Vereinigung und der Komplementarität par excellence fungieren. Im Titelgedicht Ruce werden die schwachgewordenen Hände der 'Erdenbrüder' in eine 'magische Kette ungezählter Hände" eingefügt (V. 60; "magický retězz rukou nesčisiných"). Die Synthese, die alles umfassende Vereinigung, vollzieht sich im "Rundgesang" aller Herzen (Kolozpév srda), im "Dithyrambus" aller Welten (Dithyramb svẻtü; vgl. hierzu Kap. 6.2.1). Diese Symbole der Einheit haben in Ruce ihre Parallele in der Symbolik des "Kindes". Das Kindmotiv, das in den vorangehenden Gedichtzyklen kaum eine Rolle spielt und als Lexem nicht einmal vorkommt, gewinnt in Ruce wesentlich an Bedeutung. In den letzten fünfzehn vom Dichter nicht mehr zu einem Zyklus komponierten Gedichten weist das Kindmotiv eine geradezu sinnkonstitutive Funktion auf.

In der Psychologie des Einzelnen antizipiert das Kindmotiv (ähnlich wie das des Kreises, des Runden, der Kugel u. a.) die Synthese der bewußten und der unbewußten Persönlichkeitselemente, ja die Synthese des Selbst. Der Kindarchetypus repräsentiert nicht nur den Vergangenheitszustand, sondern auch den Zukunftscharakter und die Komplementarität von Anfang und Ende. Der Hermaphroditismus des Kindes symbolisiert die Vereinigung der stärksten Gegensätze aus; das kleine, ausgelieferte und verlassene Kind ist zugleich der göttlich-mächtige Kindgott und das unüberwindliche Heldenkind. 673 Und es ist gerade die Symbolik des "Heldenkindes" und des "Kindgottes", die an der Konstituierung des mythopoetischen Welt-Modells von Ruce in hohem Maße partizipiert. In Bolest Clovéka (Der Schmerz des Menschen) erscheinen die Künstler-Menschen als 'Heldenkinder': "Pot setieli jsem se svých Cel, se smrti hovorili I.../ a jako déti hlavu svou $v$ klín mateisky jsme položili" (II, 1,3; "Den Schweiß trockneten wir von den Stirnen, besprachen uns mit dem Tode /.../ und wie Kinder in den Schoß der Mutter, legten wir inr unser Haupt"). In diesem Gedicht wird auch die Problematik des Wiedererlebens der Beziehung zur mütterlichen Anima erneut aufgegriffen, die psychologisch eine seelische Gefahr für den erwachsenen Mann bedeuten kann. Noch deutlicher tritt die verhăngnisvolle Bezıehung zur Mutter-Imago in der Symbolik des ausgesetzten "Stiefkindes" im Gedicht Silenci (Wahnbetörte) zutage. Die Botschaft - das Nahen der "Ewigkeit morgendlich Feuer" (IX, 2; "věčnosti jitřní požár") - der als "Wahnbetörte" gebrandmarkten visionären Gestalten, der Künstler-Helden, bleibt (im 'realen Leben') den 'Erd-Brüdern' unverständlich: "Nevlastni dẻti tvoje, ó zemé, byli jsme bolesti mlékem / jako na prsou svedených matek svých odkojeni" (II, 1-2; "Deine Stiefkinder, Erde, wurden wir mit der Milch des Schmerzes / wie aư Brüsten unserer verführten Mütter gestill"'). Die einzigen, die die Botschaft der verlassenen "Stiefkinder der Erd-Mutter verstehen können. sind: "nur Tote und aus kommenden Zeiten nahende Brüder" (Ślenci / Wahnbetörte, VIII. 1-2: "Jen mrtvi a $z$ věkú přštich se bližici bratrï ${ }^{u}$ ). Was bedeutet in diesem semantischen Kontext die 'Verlassenheit', die 'Aussetzung' des Kindes? In der Psychologie des Individuums indiziert diese Symbolik die Konfrontation mit einem unbekannten Inhalt; sie signalisiert stets eine quälende Konfliktsituation. ${ }^{674}$ Im Extremfall kann diese

673 C.G. Jung. .Zur Psychologie des Kindarchetypus", in: Die Archetypen und das kollektive Unbewusste, Gesammelte Werke, Bd. 9/1, Otten-Freiburg i. Br. 1976, S. 165-195.

674 Ibid., S. 181-184. "Ein bedeutender, aber unerkannnter Inhalt hat immer eine geheime faszinierende Wirkung auf das BewuBtsein. Die neue Gestalt ist eine werdende Ganzheit. 
Konfliktsituation sogar zur Lähmung der Energie und des Lebensdrangs führen. Nicht von ungefähr scheint der mit dem second sight der "Wahnbetörten" gesehene und erwartete "Einzige Mensch, der Erlöste" ("Jediného Clověka vykoupeného", $X, 1), 675$ die Attribute

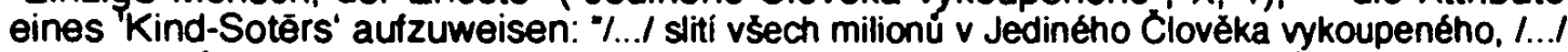

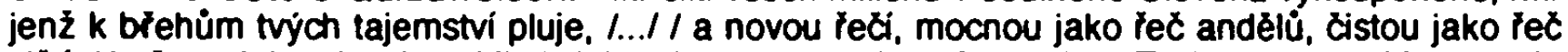

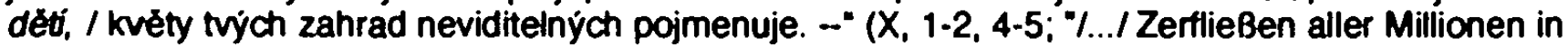
den Einzigen Menschen, den Erlösten, / der zu den Küsten deiner Geheimnisse steuert /.../ /, und mit neuer Sprache, mảchtig wie Sprache der Engel, rein wie die Sprache der Kinder, I deiner verborgenen Gărten Blüten benennt*). Das Ziel des Helden-Kindes ist die Dunkelheitsbesiegung, d. h. der erhoffte Sieg des Bewußtseins über das Unbewußte. Zugleich aber repräsentiert das "Kind" den vorbewußten Zustand des Menschen, es ist die "Geburt des Unbewußten" aus dem Schoß der lebenden Natur, eine Lebensmacht, die zur Herstellung der Einheit führt und die es vermag auch die 'Abgründe' der Natur zu integrieren. Das "Kino" ist die Personifizierung des Drangs zur Selbstverwirklichung. ${ }^{676}$ Als Anfangs- und Endwesen symbolisiert das Kind das vorbewußte wie das nachbewußte Wesen des Menschen, $d$. $h$. den frühesten und gleichzeitig den quasi 'postmortalen' Zustand, Leben und Tod in inren Komplementarität: das Ende führt erneut zum Anfang, der Tod erneut zum Leben, symbolisiert durch das Bild des "ewigen Kindes":

"Z domu svých mrtvých jsme vyšli (vime, jak bratưi jej zvou), / lehci a radostni jdeme jak dếj symbolickou zahradou tvou. / Není už minulosti - płítomnosti jsou všechny nekonečnosti / a svět kolem nás jako pri stvớeni je mlád" (Piseñ o věcném mládi I Das Lied von der ewigen Jugend, IV, 1-4: "Aus dem Hause unserer Toten gingen wir heraus (wir wissen, wie die Brüder es nennen). I leicht und frohlich gehen wir wie Kinder durch deinen symbolischen Garten. I Die Vergangenheit gibt es nicht mehr - alle Unendlichkeiten sind jetzt die Gegenwart / und die Welt um uns herum ist jung wie bei ihrer Erschaffung"). "Do žáru léta našeho se zahrad smrti dýše mráz, I a mnozí ktełí uż mutvi jsou, joou jeșté jak żvi vedle nás /... I. I A jenom déti, které zemè dosud neznaji, / bázlivé v podvecer se płitulí $k$ nim potaji, / kdyż zamyłleni nasłouchaji z hlubin samot svých / voláni bratrí ztracených, ohlasu kokú vzdálených ..." (Ztraceni / Die Vertorenen, I, 1-2, VII, 1-4; "In die Glut unseres Sommers haucht der Frost aus den Garten des Todes, I und viele, die bereits tot sind, schreiten wie lebendig neben uns /...I. I Und nur die Kinder, denen die Erde noch unbekannt ist, I schmiegen sich, die Angstlichen, am Abend heimlich an sie, / wenn sie gedankenverloren aus den Tiefen ihrer Einsamkeiten / dem Rufen verlorener Brüder, dem Echo entfernter Schritte lauschen

..."). "Horké dni padaly na naši cestu, I.../ každý żivot v mlceni smrti. / Polibky rodicu probouzely nás jako ptáci jitł́ni / a v każdém znovuzrozeni byly tty naše / vonné jako tty déti l.... / vahradách pied narozenim." (Za všechno diky I Danke für alles, 18-25; "Heiße Tage fielen aư uneseren Weg. I...I jedes Leben in das Schweigen des Todes. I Die Küsse der Eltern weckten uns wie die Vógel der Morgendämmerung / und in jeder Wiedergeburt waren unsere Lippen / wohlduftend wie die Kinderlippen I.../ in den Gărten vor der Geburt").

Nun erklärt sich auch, warum die zwei letzten Gedichte die Heimkehr in die Welt des vertrauten kindlichen Arkadiens inszenieren, warum das allerletzte Gedicht Návrat (Heimkehr, 1907) gleich in der ersten Verszeile ein bekanntes K in d e r gedicht von J. V. Sládek (1845-1912) paraphrasiert (vgl. hierzu Kap. 7.1). Diese Heimkehridylle bedeutet in der Tat die 'Rückkehr' zu sich selbt, die 'Versohnung' mit sich selbst und die Herstellung

wenigstens insofern, als sie an *Gănze « das durch Gegensătze zerrissene Bewußtsein übertrifth und dieses daher an Vollständigkeit überragt. Daher kommt auch allen øvereinigenden Symbolen Ertösungsbedeutung zu. Aus dieser Situation entsteht das $\star$ Kind $\alpha$ als ein symbolischer Inhalt, erkennbar vom Hintergrund (der Mutter) getöst, respektive isoliert /...l. Darum nimmt sich die Natur, die Instinktwelt selber, des $*$ Kindes $\propto$ an: es wird von Tieren ernăhrt oder geschützt'. In Błezinas Żalm odcházejicich pokoleni (Der Psalm der dahingehenden Generationen, V. 64-65: letzte Gedichte) heißt es: "I.../ se zemi jako s bolestnou matkou po slavnosti jsme osaméli, /.../I pocthopiti jsme toužili pod úsmévem jejim tajemný smutek její. II Ale ona je zánadná, némá, Źárlivá $k$ duchu a krutá. I V pouta jimá své déti a sama v mystické fetézy kosmu je vkutá". ("I... / mit der Erde wie mit der Schmerzensmutter vereinsamten wir nach dem Fest $/ . . . /$ / wir sehnten uns danach, die geheimnisvolle Trauer unter ihrem Lảchein zu verstehen. / Aber sie ist rătselhaft, stumm, eifersüchtig auf den Geist und grausam. I In Fesseln legt sie ihre Kinder und sie selbst ist in mystische Fessein des Kosmos eingekettet').

675 Zu der gnostischen und der christlichen Bedeutung des "Einzigen Menschen" ("Jediného Clovéka") vgl. Kap. 6.

676 C.G. Jung. Zur Psychologie des Kindarchetypus", in: Die Archetypen und das kollektive Unbewusste, Gesammelte Werke, Bd. 9/1, Otten-Freiburg i. Br. 1976, S. $184 f$. 
der Einheit: "známé je všechno, ¿eho se zraky a myšlenky tkly: / všechno je cesta, $k$ domovu jediná cesta, / tisickrát jsme tady záhadni neznámi, mlCici šli (Návrat / Heimkehr, V. 23-25; "/... bekannt ist alles, was die Blicke und Gedanken berührten: I alles ist der Weg, der einzige Heimweg, tausendmal gingen wir geheimnisvoll, schweigsam, unbekannt auf ihm").

Doch mit welchem Opfer wird diese Einheit erkauft? Was bedeutet psychologisch die 'Heimkehr' in die Welt der Kindheit, in die Verborgenheit des (Erd-)Mutterschosses und die 'Versöhnung' mit sich selbst? Nach Jung drücken diese Psychologeme die Angst vor Welt und Menschen, ja die reale Panik vor dem Leben aus. Das am "Geist seiner Zeit" leidende dichterische Ich677 (seine Libido) sinkt in die Tiefe, in einen extremen Introversionszustand, in die 'dunkle' Sphäre der Erinnerungen der (frühesten) Kindheit, in der es den Ersatz für die 'Oberwelt' findet. Das dichterische Ich sinkt - zum Teil aus Entschluß, zum Teil aus Erschöpfung - in die Tiefe des Unbewußten, es zieht sich vor der Anpassungsleistung zurück und kehrt zu der Lebensquelle, d. h. zu der 'Mutter' zurück, von der es sich einst zu trennen suchte. Der Anfang Bïezinas schöpferischer Entwicklung. die Phase der "Geheimnisvollen Fernen", überschattet die Mutter-Imago. In den ersten Gedichtzyklus nahm Bỉezina das Gedicht Návrat (Rückkehr) aư: "Má duše se vrátila z kvetoucich zahrad a méla / dech noci tủpytnỳ na nádhere údư. I.../ / O prớ jsi se vrátila? V krajiny spálenou tiži /...I. I A ty jsi se vrátila! Do věčného Łera, kde úsmév tvưj lepý / ti uhasne v tvári /...F (I, 1-2, V, 1, VI, 3-4; "Meine Seele kehrte zurück aus blühenden Gärten / und glitzender Hauch der Nacht lag auf der Pracht ihrer Glieder. I.../ / O, warum kehrtest du zurück? In die Landschaften, verbrannt von der Last /.../. / Und du kehrtest zurūck! In ewige Finsternis, wo dein anmutiges Lächeln / dir auf den Wangen erlischt /... $/$ ). Die "Rückkehr" der Anima aus den blühenden Zaubergärten bedeutet die "Rückkehr" aus dem Jungbrunnen, 678 aus jenem paradiesischen (unbewußten) Zustand in die trostlose Obenwelt.679 Es ist kein Zufall, daß Bíezinas "Heimkehr" in seinem letzten Gedicht (Návrat, 1907) in die vertrauten "Gärten" (eines der charakeristischen Symbole des Mutterarchetypus), 680 in die "Heimat", zurück "zur Mutter", führt: "vక̌echno je cesta, k domovu jediná cesta" (V. 24; "alles ist der Weg, der einzige Heimweg"). "Púl cesty za námi a snad - kdo vi? - / jsme bliže domovu svému, neżli tuši naše srdce". (Za všechno diky I Danke für alles, V. 1-3; "Der halbe Weg ist hinter uns und vielleicht - wer weiß? - / sind wir näher unserer Heimat, eh unser Herz es ahnt").

Die "Heimkehr" in die Zaubergärten der inneren Welt aus Angst vor Leben bedeutet für die Oberwelt so gut wie tot $\mathrm{zu}$ sein. Sie führt konsequenterweise $\mathrm{zu}$ schweren Depressionen, zur Lähmung der Lebensenergie, zur Flucht vor dem Kampf mit den schwierigen Aufgaben des Lebens, zur Erschöpfung. Resignation und schließlich zu Selbstmordgedanken. Dem Dichter gelang es, die psychische Einheit herzustellen und den "Schatten" - den dunklen Teil seiner Persönlichkeit - zu integrieren, aber die ganze Oberwelt verwandelte sich vor seinem inneren Blick in ein erhabend schauriges Spiel der .Gigantischen Schatten" (Gigantské stiny, gleichnamiges Gedicht, 1902). Das unheilvolle Heraustreten über die Grenzen der realen Lebenswelt hinaus thematisiert das Gedicht mit dem vielsagenden Titel Tichý oceán (Der stille Ozean, R):

677 -Těm. Kteli v žáru błehủ tvých, zajatci hvězd a snù. / nemocni suètem mým. v zimnici zitf úpéji" (Milost' / Gnade, II, 1-2, SCh; "Sie, die in deiner Ufer Glut, von Stern und fraum gebannt, I an deiner Wett erkrankt, im Lebenstrost fiebernd klagen").

678 'O Zári a Sereni bytosti mé! Ty paprsku věçnẻho chvẻní / Znám rozkoš těch kvetoucich zahrad /...// i zapovézený pủvab tèch lázni, kde v stüibrnou páru / jsi vystoupila zmladlá a vonná. jak z pèny rủžových mýdel". (Návrat / Rückkehr, III, 1-3, IV, 3-4; "O Glanz und Dämmer meines Wesens! Du Strahl des ewigen Bebens! / Ich kenne die Wonne jener blühenden Gärten /.../ auch die untersagte Anmut jener Bäder, aus denen du in silbernen Dampf /verjüngt und wohlduftend, wie aus Schaum der Rosaseifen ausstiegst".).

679 Die Bedeutung dieser "Rückkehr" konkretisiert Bỉezina in einem Brief an A. Pammrová: "I po těch okamżicich vysoké a cisté rozkoše, kterou vám podá uméní, dostavi se trapný okamžik návratu v żivot, okamżik, kdy naše duše, utržená na chvili od našeho já /.../ vraci se nazpét $\mathrm{k}$ nám, bere na sebe tẻzké brímé našich všednich starosti, banálností a komické mizérie żivotni". (O. Bł́ezina, Dopisy Anné Pammrové z let 1889-1905, Praha 1931. S. 91; "Auch nach den Augenblicken hoher und reiner Wonne, die Ihnen die Kunst vermittelt, tritt der peinliche Augenblick der Rückkehr ins Leben ein, der Augenblick, da unsere Seele, für kurze Weile von unserem Ich losgerissen /.../ zu uns zurückkehrt und die schwere Last unserer alttäglichen Sorgen, Banalitäten und der kornischen Lebensmisere auf sich nimmt').

680 C.G. Jung. Die Archetypen und das kollektive Unbewusste, Gesammelte Werke, Bd. 9/1, Otten-Freiburg i. Br. 1976, S. 96. 
\%.../ Żal zemè, navždy ztracené, se slivai v nasich myšlenkách. /.../ / Jak všechno tichne z těchto mist! Po mơi némém veslujem, / slavici leț v dálce pł̉eo námi, nad námi vỷše bez hlesu .... I Vsak naše zraky odměnou, Cím vic se z b̌̌ehü zemẻ vzdalujem, / tím Cistějši zř́ prvotni nádheru jeji svatou v úžasu". (II, 4, VII, 1-4; I.../ das Leid der Erde, der auf ewig veriorenen, ergoß sich in unseren Gedanken. I.../ / Wie Alles verstummt von diesen Orten aus! Auf stummem Meere rudern vir, I Nachtigallen fliegen in der Feme, über uns die stumme Hôhe... I Doch unsere Blicke zum Lohn dafür, je mehr wir uns doch vom Ufer der Erde entfernen, I sehen reiner stets ihre ursprūngliche heilige Schónheit im Schauer.' Übers. v. E. Saudek).

In den letzten Gedichten scheint die Lebenswelt in die Nacht der "gefăhrlichen Stille" ("nebezpécné ztišeni". Tichý oceán, VI, 1) zu versinken, die das dichterische lch wie eine furchteinflößende, ominöse Aura umgibt, wie im letzten gedruckten Gedicht Tisice srdci pëlo v srdci tvém (Tausende Herzen sangen in deinem Herzen, 1907). Hier betrachtet das dichterische Ich sein eigenes Leben, wie mit 'fremden' Augen, aus einer völlig distanzierten, entfremdeten Perspektive (in der 2. Pers. Sing.): "Sla Životem tvým smrt a mlŽenimi viádla /.../. I Svujj żivot rủsti cítil jsi, tvè ticho ménilo se, / nad cestou tvoji nesmírným se rozklenulo dnem" (Tisice srda... / Tausende Herzen ..., I, 1, IV, 1-2; "Der Tod schritt durch dein Leben und herrschte durch das Schweigen I.... I Du fühltest wie dein Leben wächst, deine Stille wandelte sich, / über deinem Wege wölbte sie sich wie ein unermeßlicher Tag"). In seinen Erinnerungen an Bïezina schreibt Emanuel Chalupný, spăter habe der Dichter ihm gegenüber erwăhnt, bei der Abfassung dieses Gedichtes dăchte er ernsthaft daran, aus dem Leben freiwillig zu scheiden. Bỉezinas Depressionen verraten auch seine Briefe aus dieser Zeit: "Ještě nẻkolik silnẻjšich dechnutí z mrazivého prostoru mezi svẻty jako letošni zimy a zemé je mitvá hvězda, kroužíá tichem I... $F$. ("Noch ein etwas kräftigeres Hauchen aus dem frostigen Raum zwischen den Welten wie im diesjăhrigen Winter und die Erde wird zum toten Stern, der durch die Stille kreist $/ . . . F)$. $\$ 1$ Das aus dem Nachlaß herausgegebene Gedicht des damals neununddreißigjăhrigen Dichters, Za vsechno diky... (Danke für alles..., 1907), liest sich in der Tat wie ein 'Abschiedsgedicht': "MIČi všechno. / Każdý z nás sám. Nebot k smrti / joe každý sám a mamé jsou slzy milovaných zrakú, I marné ruce chladnouci tisknete / horkými tty - odcházejici je sám, sám ... / Za všechno díky!" (V. 69-75; "Jetzt schweigt alles. I Jeder von uns ist allein. Denn zum Tode / schreitet jeder allein und vergeblich sind die Trănen der geliebten Blicke, / vergeblich preßt ihr heiße Lippen / auf erkaltende Hănde - / der Fortgehende ist allein, allein ... / Danke für alles!").

C. G. Jung interpretiert die lăhmende $L e$ b e n s a n g s t 682 als Sehnsucht dem Druck der Außenwelt - dieser Quelle der Selbstmordgedanken - zu entkommen. In Wirklichkeit ist es die Todes a ng st eines "instinktiven, unbewußten Menschen, der durch das anhaltende Zurückweichen vor der Wirklichkeit vom Leben ausgeschlossen ist" 683 Als eine symptomatische 'Dublette-Erscheinung', ăhnlich wie Todesangst und Todessehnsucht, betrachtet die Lebens- und Todesangst auch E. Wexberg:

"Die $L$ e be n s a ng s t und die T ode s a ng st. Die Lebensangst, die sich unter anderm darin auswirkt, dass so gut, wie jede Neurose früher oder spăter in Selbstmordgedanken, Selbstmordversuche oder Selbstmord ausläutt, drückt unmittelbar das Gefühl der Unzulänglichkeit gegenüber den Forderungen des Lebens aus... Lebensangst und Todesangst heben gemeinsame Nenner: den neurotischen Individualismus und den neurotischen Pessimismus ... Das Finale ist in beiden Fällen, und für den Neurotiker überhaupt, $S \mathrm{t}$ ill s $\mathrm{t}$ a n d und R ũ $\mathrm{c}$ K z u g :.684

In diesen psychologischen Aspekten, in der Lebensangst Biezinas, in seinem Zurückweichen vor der Anpassungsleistung - allesamt Folgen seiner 'unheilbaren', schicksalhaften Fixierung an die bannende, das Unbewußte reprăsentierende und beherrschende Mutter-Imago - , liegt $m$. E. die Ursache für sein abruptes und 'geheimnisvolles' Verstummen, über das in der bisherigen Bỉezina-Literatur viel gerătselt

681 Ibid. (Brief vom 4. II. 1907).

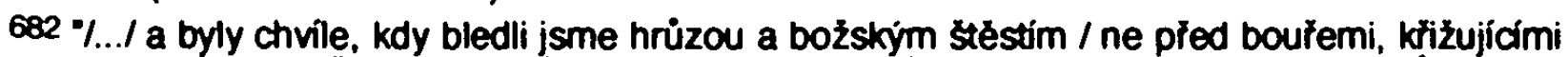
se blesky, smrt, / ale płed tajemstvim vastniho żvota suêho. / jako téżce nemocný s hrúzou vidi svou tvai I v zrcadle I... I ( $Z a$ vsechno díky I Danke für alles, v. 13-17; $\%$... und es gab Augenblicke, da wir vor Entsetzen und göttlichem Glück erbleichten / nicht vor Gewittern, vor zuckenden Blitzen, vor Tod, I sondern vor Geheimnis unseres eigenen Lebens, I wie ein Schwerkanker, der mit Graven sein Antlitz / im Spiegel sient /... $/$ ). 153.

683 C.G. Jung, Heros und Mutterarchetyp, Grundwerk, Bd. 8, Otten-Freiburg i. Br. 1991, S.

684 E. Wexberg, Individualpsychologie, Leipzig 1928, S. 207. 


\section{4}

wurde. 685 Biezina erlangte die schöpferische und die psychische Einheit, seine fünf vollendeten Gedichtzyklen stellen eine solche, mit "einzigartiger Konsequenz und Vollkommenheit realisierte" 686 Einheit dar, aber er bezahlte dafür mit der Lähmung der Lebenskraft, der schöpferischen Energie. Der Dichter, "vom Leben und Tod genesen" ("od żití a smrti uzdraven(ij"), 687 "überlebte seinen Tod, es erwartete inn jedoch eine phantomhafte Existenz, verkeilt zwischen Wahnsinn und Selbstmord /... / Jahre eines mehr als zwanzigjährigen Kampfes um das Gleichgewicht, des Ringens nach Atem, nach erlösendem Wort $1 . . . r .688$

"Clovêk nepúsobi jen pronesenym slovem, dilem. Clovék prédevsim a nejvice púsobi

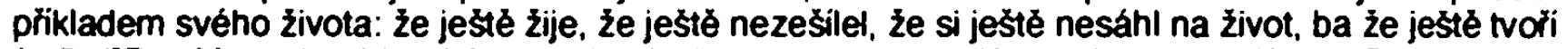
I...F. ("Der Mensch wirkt nicht nur durch das vorgetragene Wort. durch das Werk. Der Mensch wirkt vor allem und am meisten durch das Beispiel seines Lebens; daß er noch lebt, daß er noch nicht wahnsinnig geworden ist, daß er sich das Leben noch nicht genommen hat, ja daß er sogar noch schafft (... $/$ ). 689

685 Zu einer plausiblen 'poetologischen' Erklärung (Konventionalisierung der symbolistischen Wortkunst nach 1900) seines Verstummens hat Blezina selbst (absichtlich) beigetragen: "Básné ty nevyhovuji také jiż dneśnimu mému stanovisku. Opustil jsem volnỳ verś a vrátil se $k$ pevnẻmu rytmu". (E. Chalupný, Dopisy a viroky Otokara Breziny. Praha 1931, S. 112; "Diese Inach 1901 verfaßten; Anm. J.V.] Gedichte entsprechen nicht mehr meinem heutigen Standpunkt. Ich habe den freien Vers verlassen und bin zum regelmāßigen Rhythmus zurūckgekehrt"). Diese Erklärung versucht im Prinzip die tieferen, subjektiven und zum Teil wohl auch unbewußten oder irrationalen psychologischen Ursachen zu objektivieren und zu rationalisieren. S. 51.

686 M. Cervenka, „Bỉezinovské úvahy", in: M. Cervenka. Symboly, pisnẻ a mÿty, Praha 1966,

$687 \mathrm{Na}$ zemi rủže neprestávaji hơet (Auf der Erde Rosen hören nimmer auf zu brennen, V. 3).

688 "Básnik płežil svou smrt, ale cekala ho prizzračná existence, zakliněná právě mezi silenství a sebevrażdu. I... /. Roky vice neż dvacetiletého boje o rovnováhu, lapáni po dechu a osvobozujicim slovè I...F. O. Králik, Otokar Biezina. Logika jeho dila, Praha 1948, S. 442.

689 Zit. nach: G. Picková-Saudková. Hovory s Otokarem Bíezinou (Gesprāche mit Otokar Brezina), Praha 1929, S. 169. 


\section{LITERATURVERZEICHNIS}

\section{OTOKAR BÁEZINA - WERKE}

1933 Básnickě spisy. Red. Miloslav Hýsek. V úpravě Frantiska Bilka, [Česká akademie vẻd a umèni], Praha.

1933 Prosa. Réed. Miloslav Hýsek. V úpravě Františka Bilka, [Ceská akademie véd a uměni]. Prana.

Prvotiny. Red. M. Hýsek. V úpravě Františka Bîka, [Ceská akademie vẻd a umèni], Praha.

Eseje. Red. Petr Holman, Olomouc.

IN DEUTSCHER ÜBERTRAGUNG

1908 Hảnde. Gedichte. (Orig. Ruce). Deutsch von Dr. Emil Saudek. Mit Buchschmuck von Frantisek Bilek, Wien.

1913 Hymnen. Deutsch von Otto Pick, [Ed. Der jüngste Tag, Bd. 12] Leipzig.

1917 Tschechische Anthologie. Vrchlický-Sova-Błezina. Deutsch von Paul Eisner, (InselVerlag] Leipzig.

1920 Baumeister am Tempel. (Orig. Stavitelé chrámu). Deutsch von Otto Pick, München.

1920 Winde von Mittag nach Mittemacht. (Orig. Větry od pólú). Deutsch von Franz Werfel und Emil Saudek, München.

1923 Musik der Quellen. (Orig. Hudba pramenủ). Deutsch von Dr. Emil Saudek unter Mitwirkung von Franz Wertel, München.

\section{BRIEFE}

1929 Dopisy Otokara Bieziny I. Frantisku Bauerovi. Red. M. Hýsek, Praha.

Dopisy Otokara Bieziny II. Emanuel Chalupný, Praha.

Dopisy Otokara Bỉeziny Anné Pammrové z let 1889 až 1905. Red. Em. Chalupný, Praha.

Dopisy Otokara Błeziny Frantisku Bilkovi. Red. V. Necas, Praha.

Listy Otokara Błeziny Annè Pammrové [1905-1929]. Red. Jan Amos Verner, Žoárec.

Hledáni a jistota. Vzajemná korespondence Otokara Bł̉eziny s Otakarem Theerem,

hrsg. J. Kabes, Praha.

1969 .Hovory básníkủ. Poesie pro věky urđená. Vzájemná korespondence Otokara Błeziny

a Miloše Martena", hrsg. V. Kuchał", in: Vlastivedný véstník moravský, 21, 1969, Nr. 2-3,

S. 140-150.

1979 "Ova listy (Anně Pammrové), hrsg. v. Petr Holman, in: Wiener Slawistischer Almanach, Bd. 4. 1979, S. 205-223.

1989 Vzájemná korespondence Otokara Błeziny a Sigismunda Boušsy, hrsg. v. M. Cervenka, P. Holman, in: Literámi archiv. Sbomík Památniku národnino pisemnictvi v Praze, 23,

1990 Dopisy F. X. Saldy Otokan Błezinovi, hrsg. v. P. Holman, in: Zprávy Spolku Ceskych bibliofilu. 1990, Nr. 3/4, S. 78-87.

\section{SONSTIGE LTERATUR}

APOKALYPSE. Weltuntergangsvisionen in der Literatur des 20. Jahrhunderts, hrsg. v. G.E. Grimm et all. Frankturt am Main 1986.

Auriednizelk, 0 .

1891 Zpivajici labutè, Tumov.

Bachofen, J. J.

1954 Versuch über die Gräbersymbolik der Alten, Gesammelte Werke, Bd. 4, Basel.

1958 Die Unsterblichkeitstehre der orphischen Theologie, Gesammelte Werke, Bd. 7, BaselStuttgart.

1975 Das Mutterrecht, hrsg. v. H.-J. Heinrichs, Frankturt am Main.

Bachtin, $M$.

1979 Die Ästhetik des Wortes, hrsg. v. R. Grübel, Frankfurt am Main.

Bahr, $\mathrm{H}$.

1920 .Otokar Bỉezina", in: Neues Wiener Joumal, 25. 6. 1920.

Balthaser, H. U. v.

1960 Verbum caro. Skizzen zur Theologie I, Einsiedeln.

1962 Hernlichkeit. Eine theologische Ästhetik, 2. Band, Făcher und Stile, Einsiedeln. 
1974 Pneuma und Institution. Skizzen zur Theologie IV. Einsiedeln.

Baltrucaitls, Jurgis

1984 Imaginäre Realitäten. Fiktion und Illusion als produktive Kraft. Köln.

1986 Der Spiegel. Entdeckungen, Täuschungen, Phantasien, Gießen.

Barth, K.

1932 Die kirchliche Dogmatik, IV/4, Zollikon-Zürich.

Bartos, J.

1929 O typu lidi timidnich. Prispévek k psychologii Ot. Bỉeziny", in: Filosofie 2, 1929, S. 289. 297.

Baudelaire, Ch.

1968 CFuvres complètes, hrsg. v. M. A. Rutf, Paris.

1973 Correspondance I-II, hrsg. v. Claude Pichois, Paris.

Baver, R. (Hirsg.)

1977 Fin de siècle. Zur Literatur und Kunst der Jahrhundertwende. Frankturt am Main.

Beil, U. J.

1988 Die Wiederkehr des Absoluten. Studien zur Symbolik des Kristallinen

Bianchi, U. und Metallischen in der deutschen Literatur der Jahrhundertwende. Frankfurt am Main.

1975 "Gesichtspunkte zur Erforschung der Ursprūnge der Gnosis", in: Gnosis

Blondel, $M$. und Gnostizismus, hrsg. v. K. Rudolph, Darmstadt, S. 707-748.

1950 L'Action. Essai d'une critique de la vie et d'une pratique [1893]. Paris.

Blumenberg, $\mathrm{H}$.

1957 .Licht als Metapher der Wahrheit. Im Vorfeld der philosophischenBegriffsbildung".

1979 in: Studium generale, 10. S. 432-447.

1979 Arbeit am Mythos, Frankturt am Main.

1981 Die Lesbarkeit der Welt, Frankfurt am Main.

Böschenstein-Schäfer, R.

1977 Idylle, [2. Aufl.] Stuttgart.

Bohrer, K. H.(Hrsg.)

1983 Mythos und Moderne. Begriff und Bild einer Rekonstruktion, hrsg. v. K. H. Bohrer,

Bouska, $S$. Frankfurt a. Main.

1896 .Otokar Biezina", in: Nový život, 1, [2. Halbjahr] S. 2-7, 38-42, $50-55$.

1903 "Básnik mystik. Glosy k dilu Otokara Bỉeziny" in: Novy żivot, 8, Nr. 3. S. 88-90;

Bousset, $W$ Nr. 4. S. 104-105; Nr. 5, S. 156-157; Nr. 10, S. 306-310, Nr. 11-12, S. 353-358.

1973 Hauptprobleme der Gnosis [1907], Göttingen [Nachdruck].

Braun. $\mathrm{H}$.

1962 "Stirb und werde $\mu$ in der Antike und im Neuen Testament", in: Ders., Studien

Bräuninger, $F$. zum Neuen Testament und seiner Umwelt, Tübingen.

1926 Untersuchungen zu den Schritten des Hermes Trismegistos. [Phil. Diss.] Berlin.

Brendet. O.J.

1977 Symbolism of the Sphere. A contribution to the history of earlier Greek

Bultmann, $R$ philosophy, Leiden.

1941 Das Evangelium des Johannes, Göttingen.

1952 .Das Problem der Hermeneutik" [1950], in: Ders., Glaube und Verstehen II, Tübingen, S.

1953 Theologie des Neuen Testaments, Tübingen.

1958 Geschichte und Eschatologie, Tübingen.

1962

1967

Das Urchristentum im Rahmen der antiken Religionen [Nachdruck], Hamburg.

1967 Die Geschichte der synoptischen Tradition, [7. Aufl.], Gơttingen.

Exegetica. Aưsätze zur Erforschung des Neuen Testaments, hrsg. v. Erich Dinkler, Tübingen.

1980 Glauben und Verstehen I. [1. Ausgabe 1933]Tübingen.

1988 Neues Testament und Mythologie. Das Problem der Entmythologisierung

der neutestamentlichen Verkündung. Nachdruck der 1941 erschienenen Fassung. hrsg. v. E. Jüngel, München.

$1995 \mathrm{~J}$ ežis Kristus a mytologie, [Orig. Jesus Christ and Mythology], Praha.

Caillois, R.

1988 Der Mensch und das Heilige, München.

Campbell.J.

1978 Der Heros in tausend Gestatten [1949]. Frankfurt am Main.

Cerny. V. 
1991 Stavitel chrámu, in: Ders., Tvorba a osobnost II, Praha, S. 484-490.

Cervenka, $M$.

1965 Błezinüv verš, in: Ceská literatura, 13, Nr. 2, S. 113-146.

1966 Błezinovské ưvahy, in: Ders.. Symboly, pisné a myty, Praha, S. 30-64.

1968 Osud v zrcadle dopisu. Kronika Bł̌ezinova života a tvorby, in: O. Brezina,

1969 Temezpeć sklizné. Praha, S. 113-149.

Tajemné dălky, Svitáni na západé, Vếtry ơ pólú Stavitelé chrámu,

Ruce, in: Slovnik básnických knih, hrsg. von M. Cervenka et al., Praha, S. 316-318,

$311-314,358-360,301-303,250-253$.

1991 Błezinùv výklad Svítáni na západè, in: Ders., Styl a význam, Praha, S. 32-46.

1991 Modlitba za nepłátele, in: Ders. Styl a vyznam, Praha, S. 11-31.

$1991 Z$ vecerni \$koly versologie II. Sèmantika a funkce versovych útvaru: versologicky

Crova privodce tvorbou generace 90. let, Praha.

Chalupy. E.

básnická moderna. Poezie z konce 19. století (kommentierte Anthologie), hrsg. v. B. Svozil, Praha 1987.

1929 Památce Bł̌ezinovē", in: Národni osvobozeni, 6. VII., Nr. 184. S. 5-6.

Crome, $P$.

1970 Symbol und Unzulänglichkeit der Sprache. Jamblichos, Plotin, Porphyrios, Proklos, München.

Curtius, E. R.

1967 Europāische Literatur und lateinisches Mittelalter [1948], Bem.

Deleure, $G$.

1980 Sacher-Masoch und der Masochismus", in: L. v. Sacher-Masoch, Venus in Pelz,

1989 Frankfurt am Main, S. 163-281.

Delfoaum. B.

1964 Teilhard de Chardin und das Evolutionsproblem, München.

Delevoy, R. L.

1979 Der Symbolismus in Wort und Bild, Gent.

De Man, P.

1988 Allegorien des Lesens, Frankfurt am Main.

Dem., J.

1928 .Básnik viry", in: Tvar, 2, S. 241-254.

1931 Mé svédectvi o Otokaru Biezinovi, Praha.

Derrida, J.

1985 Von einem neuerdings erhobenen apokalyptischen Ton in der Philosophie. No

Dithey, $W$.

Apocalypse, not now, Graz-Wien.

1973 Gesammelte Schriften, Bd. VII, Der Aufbau der geschichtlichen Welt

Dlowhy. $\stackrel{H}{H}$. in den Geisteswissenschaften, Stuttgart-Göttingen 1973.

1903 Moderni mystik, in: Hlidka, 20, Nr. 1, S. 6-11; Nr. 2, S. 115-118; Nr. 3, S. 197-200;

Nr. 4, S. 269-273; Nr. 5, S. 345-349.

Döring-Smimova, I. R. - Smimov, I. P.

1980 "Poéticeskij avantgard" s tocki zrenia évoljucii chudožestvennych sistem", in: Russian Literature, Vill, 403-468.

1980a "Realizm: diachroißeskij podchod", in: Russian Literature, VIII, S. 1-39.

Dórmie, H.

1969 Spătantike Symbolik und Allegorese", in: Frühmittelatterliche Studien, 3, S. 1-12.

Durych, $j$.

1928 .Svatost uměni", in: Akord, 1, 1928, S. 226-227.

1929 a "Ferdinand Peroutka a Otokar Błezina", In: Akord, 2, 1929, S. $129-131$.

1929 b "Odpovéd E. Chalupnému", in: Akord, 2, 1929, S. 229-237.

1931 "Otokar Biezina", Praha.

Dvorík, Max

1991 Studien zur Kunstgeschichte, Leipzig.

Dvoriti. Milos

1928/29 .Pohyt v dile Otokara Błeziny", in: Host, 1, S. 7-13.

1935 O skladbé Błezinovych metator, in: Listy pro uméni a kritiku, 3, S. 387-393.

1943 Vùle v dile Otokara Błeziny, in: Akord, 11, 1943/44, S. 98-111.

1943 Zvuk a slovo aneb drama dnessni lyriky, in: Akord, 11, S. 13-24. Wiederabdruck in:

Ders., Nékolik znameni Casu. Pét literámich studii, Otomouc-Třebíc-Bmo, S. 7-21.

1969 Apotheosa klasu. [Gedichtinterpretation] in: Rocenka okresnino archivu v Blansku, 4, S. 
85-89.

1993 Mir Otokara Bỉeziny. Komentár k básnickému odkazu Bỉezinovu, in: Ders., Nékolik znameni Casu. Pẻt literárních studii, Olomouc-Tíebíc-Bmo, S. 129-151.

Ebeling, G.

1958 .Jesus und der Glaube", in: Zeitschrift für Theologie und Kirche.

1965 "Wort Gottes und Hermeneutik", in: Die neue Hermeneutik, hrsg. v. J. M. Robinson

Eilert, $\mathrm{H}$ u. J.B. Cobb, Zürich-Stuttgart, S. 109-146.

1977 .Die Vorliebe für kostbar-erlesene Materialien und ihre Funktion in der Lyrik des Fin de siècle", in: Fin de siécle. Zu Literatur und Kunst der Jahrhundertwende, hrsg. v.

Eisler, $R$ R. Bauer et al., Frankfurt am Main, S. 421-440.

1925 .Orphisch-dionysische Mysteriengedanken in der christlichen Antike", in: Vorträge der

Eliade, $M$. Bibliothek Warburg. hrsg. v. Fritz Saxl, Bd. II, Vorträge 1922-1923, Leipzig.

1993 Mýtus o věčném návratu. Archetypy opakováni [Orig. Le Mythe

Fiala, 0 . de l'éternel retour. Archétypes et répétitions, Paris 1949], Praha.

1939 Mičeni Otokara Březiny v zrcadle korespondence a hovorù I-III, in: Listy filologickẻ. 66. S. 43-60, 235-251.

1941 Doba jaromérická, in: Stavitel chrámu. Památnik básníka a myslitele Otokara Bỉeziny, hrsg. Em. Chalupný et al., Praha, S. 61-76.

1969 Studie z novớiśského obdobi Otokara Bỉeziny, in: Rozpravy Ceskoslovenské akademie věd, Rada spoleð̌nských věd, 79, Heft 9, Praha.

Fillipec, $\mathrm{J}$.

1969 .K jazyku a stylu Otokara Breziny", in: Naše R̉eč, 52, S. 1-22.

Fischer, $\vec{F}$. W.

1977 Geheimlehren und moderne Kunst". Zur hermetischen Kunstauffassung von Baudelaire bis Malewitsch", in: Fin de siècle. Zu Literatur und Kunst der Jahrhundertwende, hrsg. v.

Fischer, $O$.

R. Bauer et al., Frankfurt am Main, S. 344-377.

1929 .Březinùv rým", in: Ders., Duše a slovo, Praha, S. 219-239.

Fiaker, A.

1979 Symbolism or Modernism in Slavic Literatures, in: Russian Literature, VII, S. 329-348.

Flogl, $M$.

1975 .Brezinùv boj se smrti", in: Křest’anská revue, Nr. 1-2, S. 25-29.

1979 "Protiklad života a smrti v dile Otokara Bíeziny", in: Ceská literatura, 27, S. 66-71

Forstner, D

1967 Die Welt der Symbole, Innsbruck-Wien-München.

Fraenki, $P$

1928/29 .Básnický typ Otokara Bỉeziny”, in: Rozpravy Aventina, 4, Nr. 1, S. 3, 5, Nr. 2, S. 16-17, Nr. 3, S. 26-27, Nr. 4, 38-39.

1936 "Biezinova "Modlitba ve¿ernice", in: Listy pro uméni a kritiku. 4, S. 87-93, 119-126.

1937 Otokar Bỉezina. Mládi a přerod. Genese díla. Praha.

Franzosische Symbolisten. Franz. Deutsch, ausgewāhlt, übertragen und hrsg. v.

Frazer, J. G.

H. Hindenterger. [2. Autl.] Heidelberg. 1969

1994 Zlatá ratolest. Magie, mýty, nábożenstvi [The Golden Bough, 1890; tschech. Ausgabe],

Fromm, $E$ Praha.

1964 The Heart of Man, New York.

Freud, S.

1980 "Jenseits des Lustprinzips" [1920], in: Studienausgabe, Band. III, Psychologie des Unbewußten, Frankfurt a. Main, S. 213-272.

1980 .Das Unbehagen in der Kultur" [1930], in: Studienausgabe, Band IX, Fragen der

Frick, K. R. H.

Gesellschaft, Ursprünge der Religion, Frankfurt a. Main, S. 193-270.

1973 Die Erleuchteten. Gnostisch-theosophische und alchemistisch-rosenkreuzerische

Früchtel, U. Geheimnisgesellschaften .... Bd. 1, Bd 2, Licht und Finsternis.

1968 Die kosmologischen Vorstellungen bei Philo von Alexandrien. Ein Beitrag zur Geschichte der Genesisexegese. Arbeiten zur Lit. und Gesch. des hellenistischen Judentums, Bd. 2,

Fucik, $B$. Leiden.

1928 "Metafora", in: Tvar, 2, Nr. 7-8, S. 257-267

1992 "Od zemè k hvèzđám", in: Ders., Ctrnáctero zastaveni, Praha. 
Gadamer, H.-G.

1972 Wahrheit und Methode. Grundzüge einer philosophischen Hermeneutik, Tübingen.

Galot, J.

1960 Der Geist der Liebe, Mainz 1960.

GEDACHTNISKUNST. Raum-Bild-Schrift. Studien zur Mnemotechnik, hrsg. v. A.

Haverkamp U. R. Lachmann, Frankfurt am Main 1991.

Genette, G.

1982 Palimpsestes. La littérature au second degré, Paris 1982.

1993 Palimpseste. Die Literatur auf zweiter Stufe, Frankturt a. M. 1993.

GNosis und Gnogtizismus, hrsg. v. K. Rudolph, Darmstaft 1975.

Golosovker, Ja. E.

1987 Logika Mifa, Moskva 1987.

Grivel, Ch.

1982 .Serien textueller Perzeption. Eine Skizze", in: Dialog der Texte. Hamburger Kolloquium Gsteiger, $M$. zur Intertextualităt, Wiener slawistischer Almanach [Sonderband 11], 1982, S. 53-83.

1971 Franzosischer Symbolismus in der deutschen Literatur der

Günther, $H$. Jahrhundertwende 1869-1914, Bern 1971.

1993 Zeit der Geschichte. Welterfahrung und Zeitkategorien in der Geschichtsphilosophie, Gunkel, $H$.

1930 .Mythus und Mythologie. Im A(Iten) T(estament)", in: Die Religion in Geschichte

Habiina, R. und Gegenwart, 4, S. 381-390.

1935 Biezina a Nietzsche. Essaye, Otomouc.

Haenchen, E.

1952 Gab es eine vorchristliche Gnosis?", in: Zeitschrift für Theologie und Kirche, 49. S. 316-349.

Hákova, A.

1982 .Czech Symbolist Poetry", in: A. Balkian (hrsg.). The Symbolist

Movement in the Literature of European Languages, Budapest 1982, S. 617-625.

Hansen-Love, A. A.

1980 Semantik der Evolution und Evolution der Semantik. Ein Forschungsbericht zu I. P. Smimovs Modell einer diachronen Semiotik", in: Wiener Slawistischer Almanach, 6, S. 131-189.

1982 .Die .Realisierung" und "Entfattung" semiotischer Figuren zu Texten", in: Wiener

Slawistischer Almanach, 10, S. 179-252.

1984 Der Russische Symbolismus. Diabolische und Mythopoetische Paradigmatik, Bd. II, Lebenssymbolik, Habilitationsschrift [Typoskript], Wien.

1987 Zur Mythopoetik des russischen Symbolismus", in: Wiener slawistischer Almanach,

1988 Sonderband 20, Mythos in der slawischen Moderne, hrsg. v. Wolf Schmid. S. 61-103.

1988 Zwischen Natur- und Kunstmythos. Zur Mythopoesie des russischen

Symbolismus zu Beginn des Jahrhunderts', in: Festschrift für H. Kunstmann

1989 ber Russische Symbolismus. System und Entfaltung der poetischen Motive, Bd. I. Diabolischer Symbolismus.

1989 Der Weg und/als Ziel. Zur Symbolik der Bewegung im russischen Symbolismus", in: Wiener Slawistischer Almanach, 23, S. 151-174.

1991 Zur Typologie des Emabenen in der russischen Modeme", in: Poetica, Bd. 23, S. $166-216$.

1992 Zur psychopoetischen Typologie der russischen Moderne", in: Pychopoetik, Wiener slawistischer Almanach, Sonderband 31, Wien, S. 195-288.

1993 Apokalyptik und Adventismus im russischen Symbolismus der Jahrhundertwende*. in: Russische Literatur an der Wende vom 19. zum 20. Jahmundert, hrg. v. R. G. Grübel, Amsterdam-Attanta, S. 231-325.

1993 Zur Periodisierung der russischen Moderne. Die «Dritte Avantgarde s", in: Wiener Slawistischer Almanach, 32, S. 207-264.

Hamack, A. v.

1931 Lehrbuch der Dogmengeschichte I [1886], Tübingen.

1964 Das Wesen des Christentums [1900], München-Hamburg.

Haved, $R$.

1949 "Biezina a Schopenhauer, in: Listy filologické, 73, S. 100-108.

Hefirich, U.

1993 Otokar Biezina. Zur Rezeption Schopenhauers und Nietzsches im tschechischen Symbolismus, Heidelberg. 
Heidegger, $M$

1977 Sein und Zeit [1927], Tübingen.

Heinz-Mohr, G.

1988 Lexikon der Symbole. Bilder und Zeichen der christlichen Kunst.

Hello, E.

1950 Mensch und Mysterium. Heidelberg.

1959 Heiligengestalten, Frankfurt am Main.

Henrici, P

1989 "Blondels 'Action' im Lichte der klassischen Philosophie”, in: Theologie und Philosophie, Hermand, j. 64, S. 161-178.

1972 Der Schein des schōnen Lebens. Studien zur Jahrhundertwende, Frankfurt am Main.

Hinterhäuser, $H$.

1977 Fin de siècle. Gestalten und Mythen, München.

Hlavacek, $K$.

1958 Básnè. Prana.

Höllerer, $W$.

1966 Theorie der modernen Lyrik. Dokumente zur Poetik I, Hamburg.

Hocke, G. R.

1987 Die Welt als Labyrinth. Manierismus in der europäischen Kunst und

Hofmann, $W$. Literatur. Durchges. und erweiterte Ausgabe, hrsg. v. Grützbacher, Reinbek b. Hamburg.

1970 Von der Nachahmung zur Erfindung der Wirklichkeit. Die schöpferische Befreiung

Hoftimann, C. der Kunst 1890-1917, Köln.

1908/09 .Otokar Biezina", in: Das literarische Echo, 11, Nr. 15. S. 1058-1061.

Hofstätter, H. H.

1965 Symbolismus in der Kunst der Jahrhundertwende, Köln.

Holman, P.

1993 Frequenzwörterbuch zum lyrischen Werk von Otokar Br̈ezina H-II, Köln-Weimar-Wien.

Holthusen. $J$.

1957 Studien zur Āsthetik und Poetik des russischen Symbolismus, Göttingen.

Hommes, U.

1975 Das Sprechen von Gott. Zum ontologischen Argument in Blondels Philosophie

Houdek, VI. der Aktion" in: Analecta Anselmiana, 4, S. 309-316.

1899 Vykvetly bliny, Praha.

1901 V pavućnáct nervú. Básnè, Praha.

Hrabák. J.

1975 "Doslov", in: O. Březina, Básnické spisy, Praha, S. 237-245.

Ingold, F.P.

1981 .Kunsttext und Lebenstext. Thesen und Beispiele zum Verhältnis zwischen Kunst-Werk Jakobson, $R$. und Alltags-Wirklichkeit im russischen Modernismus", in: Die Welt der Slawen, S. 37-61.

1972 .Novejšaja russkaja poézija. Nabrosok pervyj. Viktor Chlebnikov", in: Texte der russischen Formalisten, Band II, Texte zur Theorie des Verses und der poetischen Sprache, hrsg. v. W.-D. Stempet, Münctien, S. 18-135.

1975 Poetik, Frankturt am Main.

Jankcek. A.

1935 Zrození básnika Otokara Bł̌eziny", in: Casopis Národního Musea. 109, lodd. duchovēdnỳ],1935, S. 242-293.

1936 .Otokar Bỉezina a F. X. Salda', in: Casopis Matice Moravské, 60, 1936, S. 500-513

Janśckové., J.

1988 Román mezi modernami. Studie z historické poetiky. Praha 1988

Jankovic, $M$.

1970 "Perspektivy sémantického gesta", in: K interpretaci uméleckého literámino dila, Praha 1970, S. 7-28.

1992 "Ješté jednou k pojmu "sémantické gesto ", in: Ceská literatura, 40, S. 158-163.

Jaspers, K. - Bultunann, R.

1981 Die Frage der Entmythologisierung [Serie Piper 207], München

JauB, H. R.

1982 Aिsthetische Erfahrung und literarische Hermeneutik, Frankturt am Main.

Jensen, P.A.

1993 Zum Problem der primăren und sekundären Stile", in: Periodisierung und Evolution, hrsg. v. W. Koschmal (Wiener slawistischer Almanach, 32), Wien, S. 9-20. 
Jones, $\mathrm{H}$.

1954 Gnosis und spảtantiker Geist. Von der Mythologie zur mystischen Philosophie,

1964 Teil 2,1, Gottingen.

1964 Gnosis und spătantiker Geist. Die mythologische Gnosis [1934], Teil 1,2,Göttingen.

1975 .Typologische und historische Abgrenzung des Phảnomens der

i977 Gnosis", in: Gnosis und Gnostizismus, hrsg. v. K. Rudolph, Damstadt, S. 626-645.

Jung, C. G. Im Kampf um die Möglichkeit des Glaubens`, in: O. Kaiser (Hrsg.). Gedenken an Rudolf Buttmann, Tübingen, S. 41-70.

$1955^{\prime}$ Mysterium coniunctionis. Untersuchung über die Trennung und

1963 Zusammensetzung der seelischen Gegensătze in der Alchemie, Erster Teil, Zürich.

1967 Zur Psychologie westlicher und östicher Religionen, Gesammelte Werke, Bd. 11, Zürich.

1967 Die Dynamik des UnbewuBten. Gesammelte Werke, Bd. 8, Zürich.

1976 Die Erösungsvostellungen in der Alchemie.

1976 Die Archetypen und das kollektive Unbewusste, Gesammette Werke, Bd. 9/1, OttenFreiburg i. Br.

1978 Studien über alchemistische Vorstellungen, Gesammelte Werke, Bd. 13, Freiburg i. Br. 1991 Heros und Mutterarchetyp, Grundwerk, Bd. 8, Otten-Freiburg I. Br.

Kabes, J.

1941 "Filosof vưle a jeho myslitelské dilo", in: Stavitel chrámu. Památnik Kaemptert, $M$.

básnika a myslitele Otokara Błeziny, Praha, S. 91-114.

1974 "Lexikologie der reigiōsen Sprache", in: Sprachwissen für Theologen, hrsg. v. H. Fischer, Hamburg, S. 62-81.

Kromann, E.

1964 Zum Thema der urchristlichen Apokalyptik", in: Ders., Exegetische Versuche und Besinnungen II, Gottingen, S. 105-131.

Kerterex, J.

1903 "Otokar Błezina", in: Ders., impressionisté a ironikové. Dokumenty k psychologii literámi

1995 generace let devadesátých. Studie kritické, Praha, S. 47-58.

Kentemyi, K. Basné z konce stolet.. Zazdèná okna [1894], Sodoma [1895], Kniha aristokratická [1896], Sexus necans [1897], Praha.

Die griechisch-orientalische Romanliteratur in religionsgeschichtlicher Beleuchtung. Tübingen.

KERYGma und Logos. Beitrag zu den geistesgeschichttichen Beziehungen zwischen Antike und Christentum. Festschrift für Cart Andersen zum 70. Geburtstag, hrsg. v. A.M. Ritter, Gottingen 1979.

KEFrGm und Mythos, hrsg. v. H.W. Bartsch, Bd. 1, Hamburg 1948, Bd. 2, ebd. 1952.

Knoll, J.H. - Schoeps, J.H. (Hrsg.)

1984 Von kommenden Zeiten. Geschichtsprophetien im 19. und 20. Jahmundert, Stuttgart-

Koppen, E. Bonn 1984.

1973 Dekadenter Wagnerismus. Studien zur europăischen Literatur des Fin de siècle, Berlin New York.

Kritik. $O$.

1929 .F.X.Sada jako kritik Otokara Bieziny, in: Tvar, 3, S. 257-270, 385-394.

1948 Otokar Biezina 1892-1907. Logika jetio dila, Praha.

1948 .Ot. Błezina a indické mysteni", in: Stovo a stovesnost, 10, Nr. 2, S. 114-119.

Kretachmer, E.

1955 Kớperbau und Charakter [21 u. 22. Aufl.], Bertin.

Kubicak, J.

1971 Otokar Błezina. Soupis literatury o jeho životé a dile, Bmo.

1989 Dílo Otokara Bieziny v Casopisech a stornicich 1886-1929. Knižni dilo O. Błeziny, Kubinovd, $M$. dodatky. Soupis o żvoté a dile O. Błeziny, dodatky, Bmo.

1996 Prostory víry a transcendence. Kostel, chrám a boži muka v novodobé ceské literatưre". Kudinte. j. in: Ceská literatura, S. 17-48.

1982 Ceská dekadence. Príspęvek k hledáni jejího typu", in: Sbomik praci filosofické fakulty brnènské university, D 29, S. 65-75.

Kümmol, W. G.

1964 .Die Naherwartung in der Verkūndigung Jesu", in: Zeit und Geschichte, hrsg. v.

Krapil, J.

E. Dinkler, Tübingen, S. 31-46. 
1890 Rưžový ker. Básné, Praha.

Lachmann, R. (Hrsg.)

1982 Dialogizităt, hrsg. v. R. Lachmann, München.

1990 Gedăchtnis und Literatur. Intertextualităt in der russischen Moderne, Frankturt am Main.

1994 .Acumen-Tradition und Stilistik des Oxymorons bei Daniel Naborowski (Exkurs)", in: R. Lachmann. Die Zerstörung der schönen Rede. Rhetorische Tradition und Konzepte des Poetischen, München, S. 135-147.

Lakomá, E.

1992 Úlomky hovori Otokara Bł̉eziny, Bmo.

Lehnert, $\mathrm{H}$.

1966 Struktur und Sprachmagie. Zur Methode der Lyrikinterpretation, Stuttgart.

Leisegang. $\mathrm{H}$.

1985 Die Gnosis [1924], Stuttgart.

Leany. V.

1945 Básnicky zápas Otokara Breziny, Praha 1945.

Levi-Strouss, C.

$1967 / 75$.Die Struktur der Mythen", in: Strukturale Anthropologie I, Frankfurt am Main, S. 226-254.

LEXIKON Ceské Itheratury. Osobnosti, dila, instituce, Bd. 1, A-G, hrsg. VI. Forst et al., Praha 1985, Stichwort .Otokar Br̈ezina", S. 316-320.

Lohmeyer, E.

1967 Das Evangelium des Markus [17. Aufl.], Göttingen.

Losev, A.

1994 Die Dialektik des Mythos, Hamburg.

Lotman. Jurij $M$.

1973 .O dvuch modeljach komunikacii v sisteme kultury", in: Semeiotike. .Trudy po znakovym sistemam", 6, Tartu, S. 227-243.

1973.0 mifologiðeskom kode sjužetnych tekstov, in: Sbornik statej po vtoriönym

modelirujustim sistemam, Tartu, S. 86-90.

1974 Aufsātze zur Theorie und Methodologie der Literatur und Kultur, hrsg. v. K.

Eimermacher, Kronberg/Ts.

1989 Die Struktur literarischer Texte, München.

Lotman, J. M. - Minc, Z. G.

1981 Literatura i mifologija*, in: Semeiotike, Trudy po znakovym sistemam, 13, Tartu, S. 35-55.

Lotman, J. M. - Uspenskif, B. A.

1971 .O semioticeskom mechanizme kultury," in: Trudy po znakovym sistemam, 5, Tartu.

Mallarme, $S$. S. $144-166$

1992 Sămtliche Dichtungen. Zweisprachige Ausgabe, München.

Maletinskij. M. E.

1976 Poetika Mifa, Moskva 1976.

Marten, $M$.

1903 Otokar Błezina. Essay. Praha.

1916 .Otokar Błezina", in: Akkord. Mácha, Zeyer, Błezina, Prana, S. 83-133

Mayer-Gross. W.

1924 Selbstschilderungen der Venwirttheit. Die oneiroide Enebnistorm. Berlin

Med, J.

1985 .Symbolismus - dekadence:. (Ze studie k pripravovaným Déjinám ceské literatury), in: Ceská literatura, 33, S. 119-126.

1988 .K zrodu Ceské moderny, in: Slavia, 15, S. 15-21.

1989 .K interpretaci symbolismu u Otokara Breziny", in: Slavia, 58, S. 79-81.

1995 "Otokar Brezina - skica k portétu", in: Ders., Spisovatelé ve stinu. Studie k ceské literatuie. Praha, S. 17-41.

Morhaut. L.

1994 Cesty stylizace. (Stylizace, "okraj" a mystifikace v ceské literatule prelomu

Minc. Z. G. devatenáctého a dvacátého stoleti). Praha.

1974 .Ponjatie teksta i simvolistskaja estetika", in: Materialy vsesojuznogo simpoziuma po vtoricnym modetinujusctim sistemam, 1 (5). Tartu, S. 134-141.

1980 Blok i russkoj simvolizm", in: Literatumoe nasledstvo, 92/1, Moskva, S. 98-172.

Minkomiki, $H$.

1991 Vermutungen über den Turm zu Babel [2. Auff.], Freren.

MODERNi revue 1894-1925, hrsg. v. L. Merhaut und O. M. Urban, Praha 1995.

Mojsisch, B.

1983 Meister Eckhart: Analogie, Univozităt und Einheit, Hamburg, S. 6-18.

Mukarovasky, J. 
1948 Kapitoly z leské poetiky, Bd. 2, Praha.

1966 Studie $z$ estetiky. Praha.

1971 Cestami poetiky a estetiky. Prana.

1995 Básnická sémantika. Univerzitni préednásky Praha - Bratislava, Praha.

Nietzsche, F.

Die Geburt der Tragödie ... .Sămtiche Werke, Kritische

Studienausgabe, hrsg. v. G. Colli, M. Montinari, München, Berlin,

New York 1980.

Also sprach Zarathustra. Sämtliche Werke, 1980.

Nilseon, M.P.

Ecoe homo. Sămtliche Werke, 1980.

1961 Geschichte der griechischen Religion II, München.

Nov'tk. A.

1928 Krajinárský živel v poesii Otokara Błeziny", in: Ders., Nosiđi pochodni, Praha,

S. 226-236.

1995 .Národní význam Otokara Bíeziny [1923], in: Ders., Ceská literatura a národni tradice.

Nyesa, Gregor v. Bmo, S. 159-172.

1963 Der Autstieg Moses, Freiburg i. Breisgau.

Panmutz, R.

1931 Erinnerung an Otokar Błezina", in: Slavische Rundschau, 3, 1931, Nr. 3, S. 153-162.

Panofsky. E.

1980 Die neoplatonische Bewegung in Florenz und Oberitalien", in: Ders., Studien zur

Paccal, B. İkonologie, Köln.

1966 Pensées IV. Cuures de Blaise Pascal. Ed. Léon Brunschvicg. [Nachdruck der Ausgabe

Pexat, $Z$. aus dem Jahre 1904], Vaduz (Lichtenstein).

1988 Peská moderna", in: Slavia, 57, 1988, S. 6-14.

1988 Die Welt des Schweigens [1948], München.

Pick, 0.

1918 Otokar Błezina", in: Die Aktion, 8, Nr. 27-28, S. 358-359.

Pickovt-Saudkovt. G.

1929 Hovory s Otokarem Biezinou, Praha 1929.

Platon

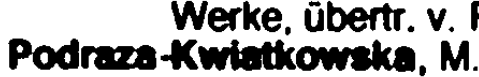

1975 Symbolizm i symbolika w poezji Mitodej Polski. Krakow.

Poenicke, k.

1989 Eine Geschichte der Angst? Appropriationen des Emabenen in der englischen Ásthetik des 18. Jahthunderts", in: Das Emabene. Zwischen Grenzerfahrung und Großenwahn,

Pokormy. P. hrsg. v. Ch. Pries, Weinheim, S. 75-90.

1962 Epheserbrief und gnostische Mysterien", in: Zeitschrift für die Neutestamentliche Wissenschaft, 53, S. 160-194.

1968 Poxátky gnose. Praha.

1969 .Gnosis als Weltreligion und als Hăresie", in: Numen, 16, S. 51-62. 1973 Der soziale Hintergrund der Gnosis", in: Gnosis und Neves Testament.

Pran, M.

1988 Liebe, Tod und Teufet. Die schwarze Romantik [1930], München.

PRAMENY ceské moderni kutury I-II, Praha 1988.

PROUDY ceské umélecké tvorby 19. stoleti: Sen a ideál. Praha 1990.

Pustygina, A. S.

1975 K izubeniu évoljucii russkogo simvolizma, in: Tezisy I. vsesojuznoj (III) konferencii, Tartu, S. 143-147.

Pynowt, $R$.

1988 "The Decadent Nation: The Politics of Arnost Procházka an Jifí Karásek ze Lvovic", in: L. Péter, R. B. Pynsent (Hrsg.). Intellectuals and the Future in the Habsburg Monarchy 1890-1914, New York, S. 63-91

1988

Pytin. R. .K morfologii Ceské dekadence", in: Ceská literatura, 36, S. 168-181.

1984 .Nové rysy literatury na prelomu stoleti. (Úvaha o koncepci déjin Ceské literatury 1890 1918)" in: Ceská literatura, 32, S. 203-215.

1988 Na preiomu stoleti. Soubor stati k vyvojovému rytumu literatury let devadesátych. Prana. 
Ratt, T.

1994 Die Sprache der Materialien. Einleitung zu einer Ikonologie der Werkstoffe, [Deutscher Kunstverlag].

Ranke-Graves, R. v.

1985 Griechische Mythologie. Quellen und Deutung I-II, Reinbek bei Hamburg.

Rasch, W.

1986 Die literarische Décadence um 1900, München.

Reitzenstein, R.

1904 Poimandres. Studien zur griechisch-ăgyptischen und frühchristlichen Literatur, Leipzig.

1956 Die hellenistischen Mystenenreligionen, (Nachdruck der Aufl. aus dern Jahre 1928]

Ricoeur, P. Darmstadt 1956.

1969 Die Interpretation. Ein Versuch über Freud, Frankfurt a. M.

1973 Hermeneutik und Strukturalismus (Konflikt der Interpretationen 1), München.

1974 Stellung und Funktion der Metapher in der biblischen Sprache", in:

P. Ricoeur - E. Jüngel (Hrsg.), Metapher. Zur Hermeneutik religióser Sprache, München.

1984 Poetik und Symbolik", in: Die Mitte der Welt. Aufsätze zu Mircea Eliade, Frankfurt am Main. S. 11-34.

1993 Zivot, pravda symbol, (Aufsatzsammlung in tschech. Übers.), Praha.

Rinner, $F$.

1989 Modellbildungen im Symbolismus. [Habilitationsschrift] Heidelbeg.

Rudolph, K.

1994 Die Gnosis, Gortingen.

Salda, F. X.

1929 Probtérmy błezzinovské", in: Saldùv zápisnik 1 (1928/1929), S. 233-238, wiederabg., in: Ders., Z obdobi Zápisniku. Bd. 2, Praha, S. 149-151.

1937 .Synthetism v novém umeni [1892], in: Ders., Boje o zițek, Praha, S. 11-54.

1937 Vyvoj a integrace v poesii Otokara Bieziny" [1913], in: Ders., Duse a dílo. Podobizny a medaillony. Praha, S. 201-233, dt. Ubers.Ausschnitt in: Prager Presse, 9. IX. 1928 [Beilage Dichtung und Welt]

1950 Vêtry od Pólü" in: Ders., Kritické projevy 3. 1896-1897 [Soubor dila F. X. Saldy, Bd. 12], Prana, S. 433-438.

1957 Národni podobenstvi tvorby Błeziny, in: Kritické projevy, 10, 1917-1918, Praha,

1963 Otokar Brezina, myslitel a básnik, in: Kritické projevy, 13, Prana, S. 342-347.

Sanger, $j$.

1978 Aspekte dekadenter Sensibilităt, Frankturt am Main.

Schamschula, $W$.

1996 .Otokar Biezina", in: Ders., Geschichte der tschechischen Literatur. Bd. II, Von der

Scholer, $M$. Romantik bis zum Ersten Weltkrieg. [Bohlau-Verlag], Köln-Weimar-Wien.

1970 Liebe und Erkenntnis, München.

Schever, $\mathrm{H}$.

1977 Zur Christus-Figur in der Literatur um 1900", in: Fin de siecle. Zu Literatur und Kunst der Jahmundertwende, hrsg. v. R. Bauer et al., Frankturt am Main, S. 378-402.

Schirmacher, $W$.

1984 Natur, Geschichte, Utopie: Philosophie als Zettkritik im 19. und 20. Jahmundert, in: Von kornmenden Zeiten. Geschichtsprophetien im 19. und 20. Jahrhundert, hrsg. v. J.H. Knoll U. J.H. Schoeps, Stuttgart-Bonn, S. 10-26.

Schloiermacher, F. D. E.

1974 Hermeneutik [1829]. Nach den Handschriften neu hrsg. und eingel. v. H. Kimmerle, Heidelberg.

Schlousener-Elchiolz, $\mathbf{G}$.

1895 Das Auge im Mittelatter, Bd. I-II, München.

SCHLIER, $\mathrm{H}$.

1975 Gnosis", in: Gnosis und Gnostizismus, hrsg. v. K. Rudolph, Darmstadt, S. 495-509.

Schinid, Herta

1982 .Die 'semantische Geste' als Schlüsselbegriff des Prager literaturwissenschaftlichen Strukturalismus", in: Schwerpunkte der Literaturwissenschaft, hrsg. v. E. Ibsch, Bd. 15. Amsterdam 1982, S. 208-259.

1992 'Tiff́ázový model' ceskétio literámèvédného strukturalismu", in: Ćeská literatura. 39. S. 193-219.

Schmid, H. H. (Hrsg.)

1988 Mythos und Rationalităt [Sammelband v. Wiener Theologenkongreß,1987], Gütersion. Schmithais. $W$.

1973 .Die gnostischen Elemente im Neuen Testament als hermeneutisches Problem", 
in: Gnosis und Neues Testament. Studien aus reiigionswissenschatt und Theologie. hrsg. v. K.-W. Troger, Berlin 1973.

Schmoll, J. A. gen. Eisemwerth

1977 Zur Christus-Darstellung um 1900', in: Fin de siźcle. Zu Literatur und Kunst der Jahmundertwende, hrsg. v. R. Bauer et al., Frankfurt am Main. S. 403-419.

Schneede, U. M.

1991 Das blinde Senen - Zur Ikonographie des Surrealismus", in: Max Emst, hrsg. v. W. Spies, München 1991.

\section{Schopenhaver, A}

1977 Die Welt als Wille und Vorstellung. Bd. I-II, Historisch-kritische Ausgabe von Arthur Hübscher, Zürich 1977.

Sedimayr, $H$.

1993 Die Entstehung der Kathedrale [1950], Freiburg-Basel-Wien.

\section{Sedmidubaky. M.}

1981 Asthetische Funktion, semantische Geste und der Wirklichkeitsbezug des ásthetischen Zeichens", in: Zeichenkonstitution. Akten des 2. Semiotischen Kolloquiums, Regensburg 1978, hrsg. v. Annemarie Lange-Seidl, Bd. I, Berlin-New York, S. 267-272.

1988 Die Struktur der tschechischen Lyrik zu Beginn des 20. Jahrhunderts, [Slawische Beitràge, Bd. 234] München.

1991 Das ldyllische im Spannungsfeld zwischen Kultur und Natur: Bożena Némcovás "Babicka", in: Zur Poetik und Rezeption von Božena Némcovás .Babicka", hrsg. v. A. Guski, Berlin. S. 27-79.

1995 .Vytváłeni idyly v ceské avantgardè. Jiłr Wolker: Svatý kopecek (Die Gestaltung des idyllischen in der tschechischen Avantgarde: J. Wolkers Svatý Kopecek), in: Ceská literatura, 43, S. 192-214.

SLOWNIK básnických knih. Dila Ceské poezie od obrozeni do roku 1945, hrsg. v. M. Cervenka u.

Simme, $\mathbf{G}$.

$$
\text { a., Praha } 1990 .
$$

1963 Rembrandtstudien, Darmstadt.

1990 Schopenhauer und Nietzsche, Hamburg.

Sledek, J. V.

1907 Spisy básnické I-II, Praha.

1989 Tiché hovory [Lyrik-Anthologie], hrsg. v. J. Janácková, Praha.

Smimov, I. P.

1977 Chudožestvennyj smysl i évoljucija poetißeskich sistem, Moskva.

Sova, A.

1922/30 Sebrané spisy. Praha.

Splt, H.-J.

1972 Die Metaphorik des geistigen Schriftsinns. Ein Beitrag zur allegorischen Bibelauslegung

Stala, M. des ersten christlichen Jahrhunderts, München.

1980 .Od czamego stonca do ciemnego swiecidta", in: Teksty, 6, S. 105-121.

stansk, j.

1918 .Otokar Biezina. Studie literámé historická, in: Ders., [u. Jarosłav Durych] Otokar Biezina. Plerov.

STAVITEl chrámu. Památnik básnika a myslitele Otokara Błeziny, hrsg. Em. Chalupný.

Staked, $W$ V. Charvát, Praha 1941.

1911 Die Sprache des Traumes, Wiesbaden.

1912 Die Trăume der Dichter, Wiesbaden.

Stenred, J.

1926 .Der Begriff der Enleuchtung bei Platon', in: Die Antike, 2, S. 235-257.

Strioditor, J.

1966 Transparenz und Vertremdung. Zur Theorie des poetischen Bildes in der russischen Modeme, in: Immanente Asthetik, Lyrik als Paradigma der Moderne. Poetik und

Svodl, B. Hermeneutik, München, S. 263-296.

1979 V krajinách poezie. Realismus, impressionismus, dekadence, symbolismus.

Básnické vyojové tendence z konce 19. století, Praha.

Simedenborg, E.

1949 Ausgewăhtte religiőse Schriften, Marburg/Lahn.

Szondi, $P$.

1975 Eintührung in die literarische Hermeneutik, hrsg. v. Jean Bollack u. Helen Stierlin,

Taegor, A.

Frankturt a. Main.

1987 Die Kunst Medusa zu töten. Zum Bild der Frau in der Literatur der Jahmundertwende, 
Taubes, J.

\section{Bielefeld.}

1971 .Der dogmatische Mythos der Gnosis", in: Terror und Spiel. Probleme der Mythenrezeption, [Poetik und Hermeneutik] hrsg. v. M. Fuhrman, München,

Taxovt, E. S. $145-156$.

1986 .Otokar Błezina: Ruce", in: M. Zeman u. a. (hrsg.), Rozumét literature 1 Interpretace základnich dél ceské literatury, Praha, S. 172-182.

Teilhard, Chardin de

1957 Le Milieu Divin, Paris.

1963 Der göttliche Bereich, Olten.

Thereaja von Jesus

Såmtliche Schriften der hl. Theresia von Jesus, Bd. I, München.

Tiedemann-Bartels, O. A.

1971 .Versuch über das artistische Gedicht". Baudelaire, Mallarmé, George, München. Timm, $\mathrm{H}$.

1986 „Die Botschaft hört ich wohl... Dichter-Theologie nach der Aufklănung”, in: Was aber bleibt, stiften die Dichter? Zur Dichter-Theologie der Goethe-Zeit. hrsg. v. H. Timm u. a.. München, S. 1936.

Tolnay, Ch. de

1953 Michelangelo, Bd. III, The Medici chapet, Princenton.

Toporov, V. N.

1981 Die Ursprünge der indoeuropäischen Poetik", in: Poetica, 13, S. 189-251.

Tröger, K.W.

1973 "Die hermetische Gnosis", in: Gnosis und Neues Testament, hrsg. K.-W. Tröger, Bertin, S. 97-119.

Tschtrewstki, D.

1961 "Umkehrung der dichterischen Metaphern", in: Die Welt der Slaven, 6, S. 337-354.

1972 Zu Máchas Weltanschauung", in: Ders., Kleinere Schriften II, Bohemica, München,

Ulonska, $H$. S. 240-286.

1986 Zeit und Ewigkeit. Von der Zeittichkeit der Zeit”, in: Zeit(t)räume. Perspektiven der Zeiterfahrung in Literatur, Theologie und Kunstgeschichte, hrsg.

Veasely. A. v. W. C.-W. Clasen U. G. Lehnert-Rodiek, Reinbach-Merzbach.

1928 Otokar Biezina. Osobnost a dilo, Brno.

Vielhaver, $P$.

1979 Oikodome. Aufsätze zum Neuen Testament, hrsg. v. Günter Klein, München.

Vodikka, $F$.

1933 Brezina a Baudelaire", in: Casopis Národnino Musea, 197 [odd. duchovédný]. S. 86-104.

1969 Struktura vivoje. Praha.

Vondung, $K$.

1988 Die Apokalypse in Deutschland, München.

Wertourg. A. M.

1992 Ausgewähtte Schriften und Würdigungen, hrsg. v. Dieter Wuttke, Baden-Baden.

1993 Bildersammlung zur Geschichte von Sternglaube und Sternkunde im Hamburger Weder, $\mathrm{H}$. Planetarium, hrsg. v. U. Fleckner u. a., Hamburg.

1983 .Die Gabe der hermēneia (1. Kor. 12 und 14)", in: Wirkungen hermeneutischer

Werner, R Theologie, hrsg. v. H. F. Geißer u. W- Mostert, Zürich, S. 9-112.

1993 Mnemosyne. Ein Sturmlauf an die Grenze", in: Bildersammlung zur Geschichte von Sternglaube und Sternkunde im Hamburger Planetarium, hrsg. v. U. Fleckner et al., Wexberg, E. Hamburg. S. 363-377.

1969 individualpsychologie, [3. Auft.] Darmstadt.

Whyte. I. B. (Hrsg.)

1985 The Crystal Chain Letters. Architectual Fantasies by Bruno Taut and His Circle, Massachusetts.

Whitehoad, A.

1953 Science and the modem World [1927, Nactidruck], Cambridge.

1958 Religion in the Making. Cambridge.

1980 Prozeß und Realităt [1929, Process and Reality], Frankturt am Main.

Wilson, $E$.

1973 Axels Schloß. Studien zu literarischen Einbildungskraft 1870-1930, München.

Winczer, $P$. 
1974 Poetika bésnickych smerov, Bratislava.

Winkier, $W$.

1949 Psychologie der modernen Kunst, Tübingen.

WAKUMGEN HERMENEUTSCHER THEOLOGE. Eine Zürcher Festgabe zum 70. Geburtstag Gerhard Ebelings, hrsg. v. H. F Geißer U. W. Mostert, Zürich 1983.

Wuthenow, R. R.

1978 Muse, Maske, Meduse. Europajscher Ásthetizismus, Frankturt a. M. 1978

Zarek. J.

1980 Eseistyka Otokara Błeziny, Wroctaw 1980.

Zelinaky, $H$.

1984 .Richard Wagners .Kunstwerk der Zukunft und seine ldee der Vemichtung", in: Von kommenden Zeiten. Geschichtsprophetien im 19. und 20. Jahmundert, hrsg.

Zever, J. v. J.H.Knoll U. J.H.Schoeps, Stuttgart-Bonn, S. 84-106.

1988 Troje paméti Vita Choráze", in: Ders., Epické zpévy, Praha,

Zleilinatu, Th.

1905 Hermes und die Hermetik I: Das hermetische Corpus", in: Archiv für

1906 .ll. Der Ursprung der Hermetik, in: Archiv für Religionswissenschaft, 9, S. 25-60.

Zika, J.

1970 Otokar Brezina, Prana

Zming. S.

1909 .Otokar Blezina", in: Osterreichische Rundschau, 19, Hen 6, S. 444-450.

1915 .Otokar Błezina", in: Osterreichischer Almanach aut das Jahr 1916, Leipzig. S. 36-46. 


\section{SLAVISTISCHE BEITRÄGE}

Herausgegeben von Peter Rehder

1995-1998

323. Tchouboukov-Pianca, Florence: Die Konzeptualisierung der Graphomanie in der russischsprachigen postmodernen Literatur. 1995. 140 S. 34.- DM. (3-87690-594-X)

324. Lehfeldt, Werner: Einführung in die Sprachwissenschaft für Slavisten. 1995. 2. verb. und erg. Aufl. 1996. 182 S. 30.- DM. (3-87690-606-7) (Studienhilfen. 3.)

325. Bonola, Anna: Osip Mandel'stams „Egipetskaja marka“. Eine Rekonstruktion der Motivsemantik. 1995. 286 S. 46.- DM. (3-87690-607-5)

326. Бирих, Александр: Метонимия в современном русском языхе. (Семантический и грамматический аспекты). 1995. II, 191 S. 40.- DM. (3-87690-608-3)

327. Schuster, Rudolf: Synonymität im Text. Eine Untersuchung an russischen Textbeispielen. 1995. 232 S. 44.- DM. (3-87690-609-1)

328. Miszewski, Brigitta: New-Age-Diskurs in der polnischen Literaturwissenschaft, Literaturkritik und Lyrik der 70er und 80er Jahre. Rekonstruktion eines Weltbildes. 1995. 236 S. 44.- DM. (3-87690-611-3)

329. Pülsch, Anja: Emigration als literarisches Verfahren bei Zinovij Zinik. 1995. 202 S. 40.- DM. (3-87690-612-1)

330. Богатырев, Конставтин К.: Акцентуация северолехитских говоров с исторнческой точки зрения. 1995. VI, 169 S. 40.- DM. (3-87690-613-X)

331. Mielke, Tomas M.: Der homosexuelle Wortschatz im Russischen. Einvernehmliche und Lagersexualität zwischen Männern. 1995. 139 S. 32.- DM. (3-87690-621-0)

332. Slavistische Linguistik 1994. Referate des XX. Konstanzer Slavistischen Arbeitstreffens, Zürich 20.-22.9.1994. Herausgegeben von Daniel Weiss. 1995. II, 393 S. 52.- DM. (3-87690622-9)

333. Meyer, Holt: Romantische Orientierung. Wandermodelle der romantischen Bewegung (Rußland): Kjuchel'beker - Puskin - Vel'tman. 1995. 542 S. 58.- DM. (3-87690-623-7)

334. Schmaus, Alois: Lehrbuch der serbischen Sprache. Band II. Vollständig neu bearbeitet von Vera Bojić. 1996. 252 S. 36.- DM. (3-87690-624-5) (Studienhilfen. 4.)

335. Lauersdorf, Mark Richard: The question of 'Cultural Language' and interdialectal norm in 16th century Slovakia. A phonological analysis of 16 th century Slovak administrative-legal texts. 1996. 267 S. 44.- DM. (3-87690-640-7)

336. Huelmann, Magdalene: Die litauischen und lettischen Arbeitslieder. Ein Vergleich. 1996.318 S. 48.- DM. (3-87690-641-5)

337. Drews, Peter: Deutsch-slavische Literaturbeziehungen im 18. Jahrhundert. 1996. 430 S. $52 .-$ DM. (3-87690-642-3)

338. Mendoza, Imke: Zur Koordination im Russischen: $u, a$ und $\partial a$ als pragmatische Konnektoren. 1996. 248 S. 44.- DM. (3-87690-648-2)

339. Eggers, Martin: Das Errbistum des Method. Lage. Wirkung und Nachlehen der kyrillomethodianischen Mission. 1996. 185 S. 40.- DM. (3-87690-649-0)

340. Maurice, Florence: Der modale Infinitiv in der modernen russischen Standardsprache. 1996. 337 S. 48.- DM. (3-87690-650-4)

341. Willich, Heide: Lev. L. Kobylinskij-Ëllis: Vom Symbolismus zur ars sacra. Eine Studie über Leben und Werk. 1996. 299 S. 48.- DM. (3-87690-651-2)

342. Slavistische Linguistik 1995. Referate des XXI. Konstanzer Slavistischen Arbeitstreffens, Mainz 26.-29.9.1995. Herausgegeben von Wolfgang Girke. 1996. II, 456 S. 56.- DM. (387690-662-8)

343. Федор Сологуб: Собрание сочинений. Том второй: Рассказы (1909-1921). Составитель Ульрих ШІтельтнер. 1997. VIII, 434 S. 54.- DM. (3-87690-663-6)

344. Evans-Romaine, Karen: Boris Pasternak and the tradition of German romanticism. 1997. 329 S. 48.- DM. (3-87690-664-4)

345. Kluge, Robert: Der sowjetische Traum vom Fliegen. Analyseversuch eines gesellschaftlichen Phänomens. 1997. II, 246 S. 44.- DM. (3-87690-665-2)

346. Oppermann, Hans u.a.: Частное неофициальное письмо и тексты-рассуждения. Persönlicher Briefwechsel und Erörterungen auf Russisch. Ein Lehr- und Übungsheft für Fortgeschrittene. 1997. 123 S. 20.- DM. (3-87690-666-0) (Studienhilfen. 5.) 
347. Sippl, Carmen: Reisetexte der russischen Moderne. Andrej Belyj und Osip Mandel'stam im Kaukausus. 1997. 283 S. 46.- DM. (3-87690-667-9)

348. Birnbaum, Henrik, Jos Schaeken: Das altkirchenslavische Wort. Bildung - Bedeutung - Herleitung. Altkirchenslavische Studien I. 1997. 190 S. 36.- DM. (3-87690-668-7)

349. Israeli, Alina: Semantics and pragmatics of the "reflexive" verbs in Russian. 1997. 226 S. 42.DM. (3-87690-669-5)

350. Ylli, Xhelal: Das slavische Lehngut im Albanischen. 1. Teil: Lehnwörter. 1997. 344 S. $48 .-$ DM. (3-87690-670-9)

351. Frei, Bohumil Jił̌: Tschechisch gründlich und systematisch. Ein Lehrbuch. Band I. 1997. 360 S. 36.- DM. (3-87690-671-7) (Studienhilfen. 6.)

352. Semjatova, Bärbel: Sologubs Schopenhauerrezeption und ihre Bedeutung für die Motivgestaltung in seinen Erzählungen. 1997. 451 S. 54.- DM. (3-87690-672-5)

353. Зализняк, Анна А., Алексей Д. Шмелев: Лекции по русской аспектологии. 1997. 151 S. 26.- DM. (3-87690-673-3) (Studienhilfen. 7.)

354. Slavistische Linguistik 1996. Referate des XXII. Konstanzer Slavistischen Arbeitstreffens, Potsdam 17.-20.9.1996. Herausgegeben von Peter Kosta und Elke Mann. 1997. 368 S. 50.DM. (3-87690-691-1)

355. Wolf, Markus: Freimaurertum bei Puskin. Einführung in die russische Freimaurerei und ihre Bedeutung für Puskkins literarisches Werk. 1998. 115, LXXIII S. 36.- DM. (3-87690-692-X)

356. Bohnet, Christine: Der metafiktionale Roman. Untersuchungen zur Prosa Konstantin Vaginovs. 1998. 293 S. 46.- DM. (3-87690-693-8)

357. Baumgarten, Caroline: Die spätklassizistische russische Komödie zwischen 1805 und 1822. Studien zu Sachovskoj, Zagoskin, Chmel'nickij und Griboedov. 1998. XVIII, 322 S. 52.DM. (3-87690-695-4)

358. Fenner, Ingrid: Zur Poetik des Lyrikers Konstantin M. Fofanov. 1998. XII, 232 S. 44.- DM. (3-87690-696-2)

359. Fischer, Christine: Musik und Dichtung. Das musikalische Element in der Lyrik Pasternaks. 1998. 358 S. 52.- DM. (3-87690-697-0)

360. Huber, Katja: „Aelita“ - als morgen gestern heute war. Die Zukunftsmodellierung in Jakov Protazanovs Film. 1998. 129 S. 26.- DM. (3-87690-698-2)

361. Lindseth, Martina: Null-subject properties of Slavic languages. With special reference to Russian, Czech and Sorbian. 1998. VIII, 207 S. 42.- DM. (3-87690-699-7)

362. Маляр, Т.Н., О. Н. Селиверстова: Пространственно-дистанционные предлоги и наречия в русском и английском языках. 1998. 345 S. 48.- DM. (3-87690-708-X)

363. Seitz, Elisabeth: Primus Truber - Schöpfer der slovenischen Schriftsprache? Versuch einer Antwort unter besonderer Berücksichtigung seines Satzbaus. 1998. 300 S. 46.- DM. (387690-709-8)

364. Шмигер, Роланд: Нестрамски говор. Допринос јужнословенској дијалектологији. 1998. 492 S. 60.- DM. (3-87690-710-1)

365. Demijanow, Assinja: Eine semantische Analyse der Perfektivierungspräfigienung im Russischen. Fallstudie pere-. 1998. x 193 S. 36.- DM. (3-87690-711-X)

366. Hubenschmid, Markus: Text und Handlungsrepräsentation. Ein Analysemodell politischer Reden am Beispiel V.1. Lenins. 1998. X, 244 S. 44.- DM. (3-887690-712-8)

367. Tichomirova, Elena (Hrsg.): Russische zeitgenössische Schriftsteller in Deutschland. Ein Nachschlagewerk. Unter Mitwirkung von Ute Scholz. 1998. 190 S. 36.- DM. (3-87690-7136)

368. Zink, Andrea: Andrej Belyjs Rezeption der Philosophie Kants, Nietzsches und der Neukantianer. 1998. 387 S. 50.- DM. (3-87690-714-4)

369. Korom, Marija: Kroatisch für die Mittelstufe. Lese- und Übungstexte. 1998. IV, 216 S. 34.DM. (3-87690-715-2) (Studienhilfen. 8.)

370. Trunte, Nikolaos H.: САавє́нскї̆ ю́зы்ъ. Ein praktisches Lehrbuch des Kirchenslavischen in 30 Lektionen. Zugleich eine Einführung in die slavische Philologie. Band 2: Mittel- und Neukirchenslavisch. 1998. XXX, 520 S. 56.- DM. (3-87690-716-0) (Studienhilfen. 9.)

Verlag Otto Sagner - D-80328 München

e-mail: postmaster@kubon-sagner.de 


\section{WISSENSCHAFTLICHE LITERATUR AUS OST - UND SÜDOSTEUROPA}

\section{BÜCHER}

Literatur- und Sprachwissenschaft

ost- und südosteuropäische Geschichte Humaniora

Neuerscheinungsdienst

Sortiment

Antiquariat

\section{ZEITSCHRIFTEN UND ZEITUNGEN}

Abonnements

Besorgung rückliegender Jahrgänge

Zeitschriftenantiquariat

\section{VERLAG OTTO SAGNER}

Wissenschaftliche Arbeiten zur Slavistik und zur ost- und südosteuropäischen Geschichte und Geistesgeschichte

\section{KUBON \& SAGNER}

Buchexport Import $\mathrm{GmbH}$

D-80328 München

Telefon: (089) 54 218-0 - Telefax: (089) $54218-218$

cmail: postmasicr@kubon-sagner.de 